\title{
Poetry, Bible and Theology from Late Antiquity to the Middle Ages
}




\section{Millennium-Studien}

zu Kultur und Geschichte

des ersten Jahrtausends $\mathbf{n}$. Chr.

\section{Millennium Studies}

in the culture and history

of the first millennium C.E.

Herausgegeben von/Edited by

Wolfram Brandes, Alexander Demandt,

Peter von Möllendorff, Dennis Pausch,

Rene Pfeilschifter, Karla Pollmann

\section{Volume 86}




\section{Poetry, Bible and Theology from Late Antiquity to the Middle Ages}

Edited by

Michele Cutino

DE GRUYTER 
Diese Publikation wurde im Rahmen des Fördervorhabens 16TOA021 - Reihentransformation für die Altertumswissenschaften („Millennium-Studien“) mit Mitteln des Bundesministeriums für Bildung und Forschung im Open Access bereitgestellt. Das Fördervorhaben wird in Kooperation mit dem DFG-geförderten Fachinformationsdienst Altertumswissenschaften - Propylaeum an der Bayerischen Staatsbibliothek durchgeführt.

\section{(cc) BY-NC-ND}

Dieses Werk ist lizenziert unter der Creative Commons Attribution-NonCommercial-NoDerivatives 4.0 International Lizenz. Weitere Informationen finden Sie unter http://creativecommons.org/licenses/by-nc-nd/4.0/.

Die Bedingungen der Creative-Commons-Lizenz gelten nur für Originalmaterial. Die Wiederverwendung von Material aus anderen Quellen (gekennzeichnet mit Quellenangabe) wie z.B. Schaubilder, Abbildungen, Fotos und Textauszüge erfordert ggf. weitere Nutzungsgenehmigungen durch den jeweiligen Rechteinhaber.

ISBN 978-3-11-068719-4

e-ISBN (PDF) 978-3-11-068722-4

e-ISBN (EPUB) 978-3-11-068733-0

ISSN 1862-1139

\section{Library of Congress Control Number: 2020932189}

\section{Bibliographic information published by the Deutsche Nationalbibliothek}

The Deutsche Nationalbibliothek lists this publication in the Deutsche Nationalbibliografie; detailed bibliographic data are available from the Internet at http://dnb.dnb.de.

(C) 2020 Walter de Gruyter GmbH, Berlin/Boston

Printing and binding: $\mathrm{CPI}$ books $\mathrm{GmbH}$, Leck

www.degruyter.com 


\section{Introduction}

This volume contains the proceedings of the International Symposium "Poetry, Bible and Theology from Late Antiquity to the Middle Ages" organized on 25-27 January 2018 in Strasbourg by ERCAM, "Research Team on Ancient and Medieval Christianity”, belonging to UR 4377 of Catholic Theology and Religious Sciences of Strasbourg, in collaboration with several French institutions (IEA, "Institut d'Études Augustiniennes “-LEM, "Laboratoire d'études sur les monothéismes “-UMR 8584; École Nationale des Chartres; THAT Association, "Texts for the History of Late Antiquity"; CARRA EA 3094- University of Strasbourg) and international Institutions (Facultad de Literatura Cristiana y Clásica "San Justino" (FLCC) of Madrid; Universidad Complutense de Madrid). This conference was attended by the greatest specialists in late ancient and medieval poetry, involving a total of 33 papers, divided into three full days.

All methodological questions concerning Christian poetry-i. e. Christian, Greek and Latin, ancient and medieval, poetic texts, in classical metres - with biblical and theological content, were approached from a diachronic perspective which made it possible to evaluate the doctrinal significance and the role that these compositions play even in the development of Christian theological ideas and biblical exegesis. From a chronological point of view, we have taken into account the period from Late Antiquity to the Middle Ages, with particular attention to the adaptation of classical poetic modules to the rewriting of the Bible in all its forms by Greek and Latin poets of Late Antiquity, and to the new forms of biblical poetry promoted in the West, from the Carolingian Renaissance to the 12th-13th centuries, when the Charters legitimized the use of poetry in the theological debate, and to the later polemics between scholastic theologians (such as Giovanni Dominici and Jean Gerson) and Christian "humanist" poets. Indeed, it can be noted that the use of poetic genres by Greek and Latin-speaking Christians begins much later (especially from the end of the 3rd century / beginning of the 4th century) than the birth of Christian literary production in prose, which accompanies the very birth of this religion. This "delay" reveals a real difficulty for Christian culture: the creation of a code adapted to the expression of biblical contents, central in this religion, through the cultural tools of Greek and Latin literary production in verse. This difficulty is often reflected in declarations of radical incompatibility between the two areas of reflection of Sacred Scripture and poetry, which is the instrument of expression privileged by profane culture (just think of certain statements hostile to poetry by important authors, such as Jerome or Augustine, who will have a follow-up to the Middle Ages, as M. Zink Poésie et conversion au Moyen Âge, Paris 2003. has clearly shown). On the other hand, poetry is at the origin of attempts to integrate the style of biblical poetic texts, psalms, and classical literary forms (this is the path followed, for example, by the type of Responsorial Psalm, which will not be very successful. The solution that ultimately prevails over the others gives rise, using a remarkable expression of Herzog, to the third 
cycle of poems of Western literature, which flanks the Homeric and Carolingian-Arthurian cycles: the cycle of biblical poetry in classical meters. This is a literary field of vital importance, which, after having encountered prejudices from a certain classicising perspective, especially from the middle of the 20th century, has been established in the panorama of critical studies because of its chronological cross-cutting. Indeed, the "canons" of biblical poetry developed in Late Antiquity will dominate medieval schools and even those of the humanist era, finding also a favourable ground in the culture of the Reformation and Counter-Reformation, to enter definitively into crisis with the cultural renewal of the Enlightenment. This has also been established thanks to the interaction that the field has promoted between emerging cultures, biblical-Christian and Germanic, and Greek-Latin civilization in its expressive forms.

The symposium highlighted the socio-cultural importance of this transposition of scriptural content into poetic forms: in fact, according to various modalities and purposes, and in relation to different recipients and reference environments, this transposition aims, first of all, at the "vulgarization" of the biblical interpretation and theological speculation in favor of the rudes, i.e. people who are foreign to catechetical schools or to the ecclesiastical careers, but who belong to the cultured/educated elites of their time, through the expressive instrument privileged by them, that is, the production in verse. This is the reason why Christian literature in verse is of great interest in the in-depth evaluation even of the phenomenon of the Christianization of the ruling classes, especially from the fourth/fifth century. A literary genre such as the 'epic' or the 'biblical paraphrase' clearly shows the value of this cultural operation: the transposition principally into hexameters of the books of the Old Testament (mention the paraphrases of Genesis by Cyprian the Gaul, Claudius Marius Victorius and Avitus) or of the New Testament (such as the Evangeliorum libri of Juvencus, the Carmen Paschale of Sedulius, the Paraphrase of the John's Gospel of Nonnos of Panopolis and the Historia apostolorum of Arator) is not reduced to a simple rhetorical exercise or a literary reading. As M. Roberts (Biblical Epic and Rhetorical Paraphrase in Late Antiquity, Liverpool 1985) and D. Nodes (Doctrine and Exegesis in Biblical Latin Poetry, Leeds 1993) have clearly shown, from different perspectives. J. Nodes, such transpositions into verse offer readers a re-reading of the biblical hypotext, an "update" of Scripture in relation to the requirements and expectations of the reference environment. So, this production associates scriptural interpretations and doctrinal commentaries with paraphrasing in verse, so that for this genre, we can also speak of a true biblical exegesis in verse, which is often accompanied by very precise theological objectives.

The study of Christian biblical poetry, therefore, requires a global and organic scientific approach, that is, an approach not limited to examining the formal questions related to the transposition into scriptural content, but also to showing how poetic form and exegetical-theological content support each other. On the other hand, there is a need for reflection on the very legitimacy of calling Christian poets true theologians. This is an issue that challenges even our notion of theology. Indeed, from 
the essay Gloria. Pour une esthétique théologique (ed. 1962) by the theologian Hans Urs von Balthasar, a new attempt was made to recover, within the theology, the aesthetic dimension of theology, underlining how symbolic and metaphorical language can be a very effective instrument of theological language. This is an aspect that medieval theologians were already very familiar with: thus, since Carolingian times, Jean Scot Erigène (PL 122, 146 B-C) has brought the theology of poetry (theologia veluti quaedam poetria) closer together through this particular use of language for teaching purposes.

By publishing these proceedings, we are convinced that the contributions they contain will make it possible to provide a good framework for these issues and to bring new clarification to them.

Michele Cutino 



\section{Contents}

\section{Part I: The Greek-Latin Biblical Epic in Late Antiquity}

Michael Roberts

Narrative and Exegesis in Sedulius' Carmen paschale - 3

Michele Cutino

Fictions poétiques et vérités bibliques dans les réécritures vétéro et néotestamentaires en vers

Questions méthodologiques -13

Nicole Hecquet-Noti

L'auteur et son public

Les différentes lectures de l'épopée biblique selon Avit de Vienne — 27

Sylvie Labarre

La réécriture des récits bibliques de guérison chez les poètes latins $\mathrm{du}_{\mathrm{IV}}^{\mathrm{e}}$ au $\mathrm{VI}^{\mathrm{e}}$ siècle -41

Luciana Furbetta

Avit de Vienne et Dracontius en rapport

'Chanter' et 'expliquer' la Bible entre formation scolaire et création poétique — $\mathbf{5 7}$

Bruno Bureau

L'autorité apostolique à travers les discours de l'Historia Apostolica

d'Arator -75

Franca Ela Consolino

Severus (of Malaga?) and Narrative Construction

The Healing of Bartimaeus (VIII.119-153) — 89

Renaud Lestrade

Usage des sources poétiques classiques et perspectives "théologiques" dans l'Heptateuchos de Cyprien le Gaulois ( $V^{\mathrm{e}}$ s.) -105

Donato De Gianni

Four Variations on the Theme

"The Withered Fig Tree" (Mt 21.17-22; Mc 11.12-14. 20-25) in Juvencus,

Sedulius, Avitus of Vienne and Severus of Malaga(?) - 127 
Filip Doroszewski

Dieu rejeté, Dieu triomphant

Réception des Bacchantes d'Euripide dans la Paraphrase de l'Évangile de

Saint Jean de Nonnos de Panopolis — 151

Arianna Rotondo

Salut et prophéties messianiques dans le septième chant de la Paraphrase de Nonnos -161

Salvatore Costanza

Voices, Hearing and Acoustic Epiphany in Nonnus' Paraphrase of St. John's Gospel — 175

\section{Part II: Biblical Poetry and Theological Aims in other Poetic Genres between Late Antiquity and the Middle Ages}

Gianfranco Agosti

La poésie biblique grecque en Égypte au IV siècle

Enjeux littéraires et théologiques — 191

Anna Lefteratou

Deux chemins d'apprentissage

Le didactisme dans les Centons homériques -203

Rachele Ricceri

Two Metrical Rewritings of the Greek Psalms

Pseudo-Apollinaris of Laodicea and Manuel Philes — 223

Jesús F. Polo

Descent and Ascent in the 8th Hymn of Synesius of Cirene - 237

Miguel Herrero de Jáuregui

Gregory of Nazianzus' Hymn to Parthenie (II.1.2.1-214)

Christianizing Greek Theogonies — 259

Juliette Prudhomme

Les personnages bibliques, héros d'une épopée grecque chrétienne dans la poésie de Grégoire de Nazianze — 273

Danuta Shanzer

Grave Matters: Love, Death, Resurrection, and Reception in the De laudibus Domini — 289 
Gabriella Aragione, Agnès Molinier Arbo

Un diner sur l'herbe

Proba et le pouvoir évocateur de la poésie — 309

Manuel José Crespo Losada

Biblical hypotexts in Prudentius' Contra Symmachum

Case study of C. Symm. II.95-96-321

Patricio De Navascués

$\boldsymbol{O}$ crucifer bone lucisator (Prudence, cath. 3.1)

Doctrine ancienne en termes nouveaux - 337

Alice Leflaëc

Figures bibliques et idéal familial de la consécration à Dieu

Le protreptique de l'Ad Cytherium (Carm. 24) de Paulin de Nole — 349

Christophe Guignard

Poétique des listes apostoliques

Les premières énumérations d'apôtres dans la poésie latine chrétienne $\left(\mathrm{V}^{\mathrm{e}}-\mathrm{VI}^{\mathrm{e}}\right.$ siècle) -363

\section{Part III: The Versification of the Bible in the Latin West in the Middle Age}

Vincent Zarini

La réception en Afrique, au $\mathrm{VI}^{\mathrm{e}}$ siècle, du motif apocalyptique de la fin du monde à travers le poème de Verecundus de Junca et l'anonyme «À Flavius

Felix» 393

Céline Urlacher-Becht

La doctrine dans les hymnes de la liturgie wisigothique

Entre tradition patristique et réécriture biblique -403

Pascale Bourgain

La dramatisation de l'histoire biblique dans la poésie carolingienne - 425

François Ploton-Nicollet

Entre satire de l'Église et parodie biblique

L’Apocalypse de Golias — 437 
XII

Kurt Smolak

Die Bibeldichtung Aurora des Petrus Riga (P.R.)

Beobachtungen zu Stil und Poetik — 451

Francesco Stella

Théologie de la poésie entre Scolastique et Humanisme

Le statut de la poésie biblique - 473

Daniel Nodes

Voice of the Muse, Word of the Church

The Parable of the Rich Man and Lazarus in Late Medieval Latin

Poetry -495

Isabelle Fabre

Post vestigia gregum

La poétique de l'image dans le commentaire Super Cantica Canticorum de Jean Gerson (1429) - $\mathbf{5 1 1}$

Isabel Iribarren

Bible, poésie et doctrine dans la Josephina de Jean Gerson - 525

Abstracts -539

Index of Ancient and Medieval Authors - 553

Index of Biblical Texts -567 
Part I: The Greek-Latin Biblical Epic in Late Antiquity 



\section{Narrative and Exegesis in Sedulius' Carmen paschale}

Sedulius' Carmen paschale, dated to the second quarter of the fifth century, is the second of three New Testament biblical epics that survive in their entirety from late antiquity. The poems are spaced roughly a century apart and each poet clearly knew the work of his predecessor or predecessors. ${ }^{1}$ In Sedulius' case Juvencus' Evangeliorum libri quattuor (hereafter ELQ) provided some form of precedent for his undertaking, though the later poem is very different in its free handling of the biblical original and in the incorporation of exegetical material into the narrative. These two aspects of the Carmen have been the subject of an important recent book by Daniel Deerberg that significantly advances the study of the poem. ${ }^{2}$ In my paper I should like to suggest a slightly different way of thinking about the relation between narrative and exegesis in the poem from that adopted by Deerberg.

Fundamental to his approach is a distinction between horizontal reworking of a text, which involves variation in length-abbreviation and amplification-and the introduction of edifying elements sanctioned by the biblical original, and vertical reworking, introducing elements absent from the original. ${ }^{3}$ Juvencus, with rare exceptions, confines himself, in Deerberg's account, to the horizontal level of the narrative. ${ }^{4}$ Overt exegesis is almost entirely absent from Juvencus' poem. In this respect, the contrast could scarcely be more pronounced with the Carmen paschale, which contains multiple exegetic and homiletic elements that, in Deerberg's analysis, belong to the vertical level of the text.

To provide a different perspective on this issue-broadly speaking the relationship between narrative and exegesis-I should like to cite a passage from the second book of Cicero's De Oratore, in which Marcus Antonius is discussing historiography (II.15.62-63):

Nam quis nescit primam esse historiae legem, ne quid falsi dicere audeat? Deinde ne quid veri non audeat? ... Haec scilicet fundamenta nota sunt omnibus, ipsa autem exaedificatio posita est in rebus et verbis: rerum ratio ordinem temporum desiderat, regionum descriptionem; vult etiam, quoniam in rebus magnis memoriaque dignis consilia primum, deinde acta, postea eventus exspectentur, et de consiliis significari quid scriptor probet et in rebus gestis declarari non solum quid actum aut dictum sit, sed etiam quo modo, et cum de eventu dicatur, ut causae explicentur omnes vel casus vel sapientiae vel temeritatis hominumque ipsorum non solum res gestae, sed etiam, qui fama ac nomine excellant, de cuiusque vita atque natura.

1 Springer (1988) 62-63.

2 Deerberg (2011).

3 Deerberg (2011) 333-335.

4 Deerberg (2011) 347. Confusingly, though, he earlier (334) seems to describe such "erbauliches Relief," using Herzog's term, as vertical in nature. 


\begin{abstract}
"Everyone, of course, knows that the first law of historiography is not daring to say anything false, and the second is not refraining from saying anything true... These foundations are, of course, recognized by everyone, but the actual superstructure consists of content and style. It is the nature of content, on the one hand, that it requires a chronological order of events and topographical descriptions; and also, since in the treatment of important and memorable achievements the reader expects intentions, the events themselves, and consequences, that it needs the writer to indicate what intentions he approves of, to reveal not only what was said and done but also in what manner, and, when speaking of consequences, to explain all the reasons, whether they result from chance, intelligence, or impetuousness, and also to give not only the achievements of any famous protagonist but also his life and character".
\end{abstract}

The translation I provide is adapted from that of A.J. Woodman, in an important article on this passage, published in 1988, that I follow in my analysis. ${ }^{5}$ Shortly before this passage Antonius had criticized early Roman annalists, whose bare, unornamented record of events left much to be desired in his judgment. Woodman's interpretation of Cicero stresses the basic distinction between the foundations (fundamen$t a$ ) of a historiographical text and its superstructure (exaedificatio). Early annalists confined themselves to the fundamenta, an unadorned account of the simple facts, or what they took to be the simple facts. But for Antonius the real quality of a historian lay in his construction of a superstructure upon those bare facts, in which he would recount not just what was done (acta), but for what purpose (consilia), and with what outcome (eventus), and include an evaluation of the purposes for an action and the reasons (causae) for its outcome. The requirements largely coincide with those for a narration in oratory: the Rhetorica ad Herennium recommends enumerating "the reasons for purposes" (consiliorum rationes, I.9.16), and Cicero himself, in the Partitiones oratoriae requires the inclusion of "the cause of every deed and outcome" (cuiusque facti et eventi causa, 9.32). Underlying Antonius' discussion is the belief that the art of historiography consists in the elaboration of a "hard core" (as Woodman calls it) of factual information. That elaboration, a matter of inventio in rhetorical terms, may involve an account of actions (a battle narrative, for instance) or a description of a scene (Quintilian gives instructions for how to treat the sack of a city [VIII.3.67-70]), but also takes in accounts and discussions of purposes and motives, the outcomes of events and the reasons for those outcomes. All these constitute parts of an artistically composed narrative.

This notion of a simple factual narrative serving as a foundation (fundamentum) on which to build ([ex]aedificare) some more sophisticated superstructure finds echoes in Christian homiletic and exegesis. Augustine speaks of the scriptures narrating actions (quae gesta sunt), which serve as a foundation (fundamentum), a factual base without which to propose further spiritual interpretation is like "trying to build on air" (quasi in aere quaeratis aedificare, Serm. 2.7, CCL 41: 14.170-74; cf. Serm. 8.2, CCL 41:80.53-81.1). The architectural language, of foundations and structures raised on those foundations, corresponds to that in Cicero's treatise. The specific reference

5 Woodman (1988) 78-94. 
in the Augustine passage is to the sacrifice of Isaac, included among the "mysteries of the Holy Scriptures" (sacramenta divinarum scripturarum), in Augustine's language. He insists that recognition of the literal, historical sense of the event is a precondition for exposition of its spiritual meaning. Jerome uses similar language, talking of "laying the foundations of history" (historiae fundamenta iaciamus, In Abdiam 2/4, CCL 76:357.170-72), before moving on to "raising up lofty towers and roof tops" (excelsas turres et tectorum culmina subrigamus) on those foundations. It is worth noting that in the same passage of his Sermo Augustine uses the word aedifico in the more familiar Christian sense of providing moral and spiritual improvement; expounding the mysteries of scripture "edifies those who have fallen away" (aedificant lapsos). Textual and spiritual edification seem here to coincide.

Be that as it may, for my purposes it is sufficient that Augustine and Jerome show familiarity with the view of historical narrative outlined in Cicero's text. But how does this relate to Sedulius? Most clearly in his treatment of the events of the biblical text. By a process of abbreviatio this is reduced to a bare narrative thread, what Deerberg calls "a "narrative core", ${ }^{6}$ echoing Woodman's language. In the terms Antonius uses in the De oratore this is the foundation on which we can expect an elaborate superstructure to be built. From the rhetorical point of view this core constitutes the basic subject of the text. Everything else is elaboration that builds on, but does not alter the basic meaning. It was this I had in mind when in my book on the biblical epic I said that stylistic embellishments "did not alter the sense of the base text". ${ }^{7}$ At the time I was concerned to show that even biblical poems that elaborate extensively on the biblical original can still be said to preserve the sense of the original, a key feature of the paraphrase. Whatever one thinks of the paraphrase theory in relation to biblical epic, I still believe my characterization of rhetorical theory was correct. Indeed, if Woodman is to be followed, not only stylistic embellishment (elocutio), but even invention of new content (res) does not necessarily affect the basic meaning. Of course, for a modern reader even a small change-the addition of an adjective or replacement of a name by a title-changes the sense-it is an act of interpretation, however small-scale-but this is not the view transmitted by the study of rhetoric. It is important to emphasize, further, that it is not just the factual core that constitutes the narrative, but foundation and superstructure, actions and explanations of those actions, together.

Deerberg helpfully enumerates some of the devices Juvencus employs to amplify the biblical original: ${ }^{8}$ substitution of title for proper name (the trope antonomasia), appositional phrases, and relative clauses, to which might be added participial phrases, as well as periphrases and various kinds of synonymic amplification, most prominently the figure called interpretatio in the Rhetorica ad Herennium

\footnotetext{
6 Deerberg (2011) 396; cf. 406.

7 Roberts (1985) 162.

8 Deerberg (2011) 342.
} 
(IV.28.38) and theme and variation in Virgilian scholarship, by which a single action is described in a succession of syntactically parallel clauses, to examine that action from different perspectives. These techniques all retain the narrative structure of the text: in Juvencus they characteristically serve to intensify the biblical original as an expression of Christian devotion; to explore the psychological motives of the actors in the text; and to enhance the text's affective impact on the reader. In the ELQ amplification of this sort does not incorporate exegetical detail. Sedulius uses the same stylistic devices, but often with exegetical content, for instance, in his account of the Samaritan woman at the well, from John's gospel. Here are the first lines:

\footnotetext{
Praeteriensque viae Dominus loca Samaritanae

humanam flagrante sitim collegerat aestu,

fonsque perennis aquae, modicum desiderat undam

ut biberet qua corpus erat. (CP IV.222-25)

"As he made his way through the region of Samaria, the Lord experienced thirst in the burning heat and, though himself a spring of eternal water, requested a little water to drink, inasmuch as he was a body".
}

The passage shows a number of simple paraphrastic amplification strategies, the adjective humanam, the appositional phrase fonsque perennis aquae, and the relative clause qua corpus erat. As far as the syntactic structure of the sentence is concerned, there is nothing that would not be at home in Juvencus' poem. But in every case the expansion serves an exegetical point. The emphasis on the coexistence of the human and divine in Christ and the expansion on those two natures is characteristic of Sedulius' anti-Nestorian stance. ${ }^{9}$ The adjective humanam clarifies how Christ is able to feel thirst: that is, in his human nature; the substitution of the periphrasis sitim collegerat for a part of the verb sitio opens up the syntactical space for the inclusion of the adjective. The same exegetical point is pursued further in the relative clause qua corpus erat, an implicit response to the question of how, if Jesus is divine, he can be subject to human appetites. A similar issue is raised by Jesus' tears at the tomb of Lazarus, when Sedulius employs a parenthetical relative clause to explain that he wept only in that part of him that was mortal (IV.277-78; cf. III.87-88).

In all three expansions in the woman at the well story, despite their exegetical content, Sedulius nevertheless maintains the posture of a narrator giving an account of events. Rhetorical precepts for the construction of the narration expect something more than a recounting of a succession of actions. They require description of purposes or motives (consilia) and the reasons for those purposes and motives and not just the recording of actions and their outcomes but the reasons for those actions and outcomes. Sedulius' amplification of the woman at the well story conforms to these requirements, which necessarily demand a form of exegesis of the actual events, or, in Cicero's terms, a superstructure erected on the bare factual foundation.

9 Springer (1988) 39-44; Green (2006) 239-44. 
In the $C P$, when such expansions deal with causes, motives, and purposes, they often take the form of participial phrases, or causal or purpose clauses. For instance, Jesus' motive for the healing of a blind man by anointing his eyes with moist clay is described with a participial phrase, "not enduring that the features of his own creation should be considered imperfect" (imperfecta diu proprii non passus haberi / membra operis, IV.255-56). ${ }^{10}$ In the episode in which Peter cuts off the ear of a servant of the High Priest, Jesus restores the ear "in order that, being merciful, he be in no way deficient in mercy" (ne qua pius a pietate vacaret, V.71), a purpose clause, and bids Peter sheathe his sword "because he had come to give his life for all, not take life from anyone” (quia venerat / ipse ponere pro cunctis animam, non tollere cuiquam, V.77-78), a causal clause.

In these cases the motives and purposes are attributed to Jesus as an actor in the narrative. At other times, though, the cause or purpose of an action transcends the immediate level of events and reflects a divine plan that goes beyond normal understanding of motivation. So the wise men present their gifts to the child Jesus "in order that their (i.e., the gifts') appearance may proclaim Christ" (ipsae etiam ut possint species ostendere Christum, II.94), in that gold is appropriate to a king, frankincense to God, and myrrh to a tomb. The same higher purpose is evident in the details of the crucifixion: Jesus is clothed in a scarlet robe "so that its entire bloodlike appearance should present the image of death" (species ut cuncta cruenta / mortis imago foret, V.166-67); he has a crown of thorns on his head "because he in his goodness had taken on himself all the thorns of our wickedness" (quoniam spineta benignus / omnia nostrorum susceperat ille malorum, V.168-69); and he is given wine mixed with gall "because he was soon to taste the bitterness of death, which he was about to flout with the resumption of flesh" (quippe necem parvo degustaturus amaram / tempore, quam reduci contemnere carne pararet, V.180-81). The purpose and causal clauses meet the requirement that a properly composed narrative should include the intentions (consilia) that prompt actions and the reasons for the actions and their results. The narrative differs from the kind that Cicero has in mind because the purpose derives from a higher ordering principle of which the actors themselves are unaware. The practice has more in common with Augustine's requirement in the De catechizandis rudibus (6.10) that in narrating individual events and actions the reasons and rationale (causae rationesque) for them be given. The passage is cited by Deerberg (2011). ${ }^{11}$ The language, as Deerberg notes, corresponds with that for the rhetorical narratio, which also called for causae rationesque, though the context suggests that Augustine has in mind the higher level of explanation that informs specific actions and events with their full meaning. In supplying just such explanatory details, Sedulius is conforming with Augustine's precepts. Deerberg too recognizes that the introduction of such material is consistent with the theory of the rhetorical

10 For this passage see Stella (2001) 50-51.

11 Deerberg (2011) 441; cf. 465. 
narratio. He speaks of a specifically Christian narratio, employing exegesis to highlight the spiritual meaning of events and their place in the history of salvation, but does not distinguish between the motivation of individual agents and the higher supra-personal order that action and events conform to.

For Deerberg the crucial advance in Sedulius' poem, which sets him apart from his predecessor Juvencus, is the introduction of exegetic material, what he calls the vertical axis of elaboration. While recognizing Sedulius' innovative use of Christian exegesis, at least by comparison with Juvencus, my own emphasis is on the poet's continuing identity as narrator. I argue that despite the presence of exegetical material, the manner in which it is typically introduced is quite consistent with the identity of narrator. But it is important to recognize that generalizing about Sedulius' poem is quite hazardous. Part of its appeal is the variety of its constituent books. Two books, 3 and 4, are devoted to miracles, as normally understood, the announced subject of Sedulius' poem: quattuor ... mirabilium divinorum libellos, Ep. Ad Mac. 1 (12.4-5); (cur) clara salutiferi taceam miracula Christi? (CP. I.26). Sedulius' reference to four books implies that he includes book 2 and 5 in his account of mirabilia. ${ }^{12}$ But the content of these books is rather different, being biographical in nature, describing Jesus' early life and in the last book his arrest, trial, and crucifixion, and subsequent appearances to the apostles rather than his wonder-working activities. Book 1 is different, accurately characterized by Springer as prefatory and programmatic, made up of a variety of constituent parts, including an enumeration of Old Testament miracles, introduced as a demonstration of nature's subordination to divine commands. ${ }^{13}$

The Opus paschale, Sedulius' prose rewriting of his biblical poem, confirms to some extent this impression of the structure of the Carmen, but also introduces some qualifications. It is striking that the miracle stories of books 3 and 4 stick very closely to the verse original. On the other hand, books two and five are treated very differently from those books and from each other. Book 2 on multiple occasions incorporates verbatim quotations, sometimes lengthy, from the Gospel narrative. This is extremely rare elsewhere in the $O P$, though exact quotation of proof texts cited from elsewhere in the Bible is more common, especially in book 5. It is perhaps significant that on the three other occasions where the biblical text is quoted verbatim the reference is to advancing the Christian mission, in Christ's address to the disciples $(O P$ III.14; $243.6-10$ = Matthew 10.7-8), his commission to 72 other disciples $(O P$ IV.14; 264.10 - 17; Luke 10.3 and 19-20), and to the apostles after the resurrection (OP V.37; 302.2-7 = Matthew 28.18-19). Book 1 of the poem ends with references to the four evangelists and the twelve disciples and it is plausible that in his own small way Sedulius sees himself as contributing to their mission of spreading the word. ${ }^{14}$

12 The citation of the evangelists at the end of book 1 (355-60) supports the argument that the four books he refers to in the letter to Macedonius are those dealing with material from the Gospels. 13 Springer (1988) 98.

14 Springer (1988) 53. 
Book 5 stands apart from the other books, both in the $C P$ and $O P$, primarily in its distinctive subject matter. The events surrounding Christ's crucifixion and resurrection carry a special charge for the Christian poet. This is reflected in the frequency of the poet's insertion of his own response to the events narrated, expressed by the figures of apostrophe, exclamation, and rhetorical question. By my somewhat inexact calculation these occupy about five times as much space in book 5 as in book 3 or book 4. (The equivalent calculation yields a somewhat lower figure in the case of book 2-book 5 has about $31 / 2$ times more such passages-because of the poet's animated treatment of Herod.) The evidence of the $O P$ reinforces the sense that Sedulius varies his compositional practice to suit his subject matter. It is hard to account for the different treatment of biblical quotations in book 2 from the other books. Did Sedulius later just abandon a practice that he found wasn't working? Or is he aiming for a kind of documentary authenticity? Whatever the case, book 5 , though also to some degree biographical, is quite different in nature. In both poem and prose it is distinguished by the poet's personal involvement in the narrative, expressed in the more emotional figures of thought. By comparison with books 3 and 4 it is also richer in exegetical detail, the kind characterized by Deerberg as vertical amplification. It provides a high intensity destination which the journey of the preceding books has been leading up to. There follows a coda in a much lower key (the emotional figures of thought are absent) describing Jesus' post-resurrection appearances to the apostles (V.365-421), and including the apostles' mission and implicitly the institution of the church with Peter as pastor (V.411-21). It is presumably no accident that Sedulius refers to the missions of the evangelists, disciples, or apostles at the end of books 1 (355-363) and 5 and in the middle of books $3(158-75)$ and $4(150-62)$. The end of book 5 even echoes the language of book 1: in the earlier book the evangelists (i.e, their Gospels, I take it) are "dispersed over the whole world" (latum sparguntur in orbem, I.360); in the last book Jesus instructs the apostles that "the nations from all regions where the wide world extends should receive a mission" (finibus e cunctis, latus qua tenditur orbis, V.420).

So far I have argued that typically when exegetical amplifications are introduced in the Carmen paschale, the poet still maintains a narratorial voice. But this is not to deny that there are some passages where that voice is abandoned, most clearly in the exposition of the Lord's Prayer that ends book 2 (231-300). Once again the Opus paschale provides a useful yardstick. Since it follows closely the $C P$, the $O P$ too normally adopts a narrative voice. But there are many occasions on which that approach is replaced by that of a teacher expounding a text, introduced by expressions like "the language of the Gospels/prophet/ divine reading / holy scriptures declare(s)." The passages cluster in book 5, which introduces a number of proof texts absent from the Carmen. Interpretations are introduced by id est (II.4; 199.17) or hoc est (V.10; 281.19) or the wording of the Gospels is praised as "well chosen" (conveniens, conven- 
ienter) ${ }^{15}$ or "apt and appropriate" (II.14; 216.9-10). It is especially striking that the $O P$ uses the first-person plural on a number of occasions to enlist its readers in the process of interpretation, most often with the verb audiamus, "let us listen to." This is the language of instruction rather than the language of exhortation, the function served by the first-person plural in the Carmen (or, perhaps better, the language of exhortation serving instructional purposes). ${ }^{16}$ A further expository practice found in the $O P$ is to pose a question, or report it in indirect form, and then proceed to answer it (II.8; 206.3, III.6; 236.6-7, V.17; 286.19-20). The practice occurs only once in the Carmen, of the three gifts of the magi, "why the three gifts?" (cur tria dona tamen, 2.97), a passage that already received exegesis in Juvencus' biblical poem.

In large part Sedulius avoids such overt didactic procedures in the $C P$. But there is certainly a large grey area where it is a judgment call whether or not he abandons the role of narrator for that of teacher. Consider this passage, describing the descent of the Holy Spirit in the form of a dove onto Christ at his baptism by John.

\footnotetext{
Confestim patuere poli, sanctusque columbae spiritus in specie Christum vestivit honore mansuetumque docet multumque incedere mitem per volucrem quae felle caret. (CP II.168-171)
}

"Immediately the heavens lay open and the Holy Spirit in the appearance of a dove clothed Christ in glory and teaches with a bird that lacks gall that his deportment is very mild and gentle".

Quod autem Spiritus Dei super eum in specie columbae descendit, ostenditur quanta sit eius bonitas, mansuetudo, simplicitas per volucrem fellis amaritudinem non habentem. (OP II.13; 213.17-20)

"As to the fact, however, that the spirit of God descended on him in the appearance of a dove, it is shown by a bird that is without the bitterness of gall how great is his goodness, mildness, and simplicity”.

Both passages clearly contain exegetical material on the significance of the dove. But in the Carmen the lines devoted to the dove's descent are syntactically parallel, joined by parataxis; the sentence structure does not distinguish event from interpretation. In the Opus a subordinate clause introduced by quod conveys the factual information, which the main clause then expounds. The use of a quod clause in this

15 II.7 (203.18), III.7 (237.10), IV.5 (258.13), V.17 (287.10), V.19 (290.19), V.21 (291.12) see CP V.257.

16 OP II.4 (200.19-20: audiamus vocem Pauli), III.14 (244.11: Paulum audiamus), V.22 (291.22-23: audiamus ... Iohannes evangelista quid referat); cf. V.8 (279.8-9: debemus ... dinoscere) and V.17. (287.5-6: spiritaliter illud sentiamus impletum). In the Carmen paschale (omitting book 1 and the Lord's Prayer) the first-person plural occurs at II.104-106, II.155, III.287, III.327, IV.122-123, IV.264-265, IV.268, V.100 - 103, V.169, V.290, V.292-293. IV.263-264, cognoscite cuncti / mystica quid doceant animos miracula nostros, of the healing of a blind man at the pool of Siloam, is closest to the usage in the OP. For the use of the first person in biblical epic see Hecquet-Noti (2009) 197-215; for OP V.22 see Mori (2013) 56, n.107. 
way is at home in commentaries; Sedulius uses it in the $O P$ in his account of the crucifixion, of Jesus' red cloak (V.12; 284.19) and of the title King of the Jews (V.17; $287.8-9)$. Such language, I suggest, begins to reduce event to text; it has something of the quality of a lemma. In this case I would be inclined to say that the $C P$ text retains the narrative voice, while the $O P$ does not, but I can well imagine that others might point to the present tense of the verb docet and its sense to argue that the narrative voice is abandoned here in the $C P$ too.

In the end, my reading of the $C P$ does not contradict Deerberg's but complements it. He emphasizes as a crucial distinction the introduction of exegesis into the text, I the abandonment of the narrative voice. Neither distinction, I suspect, is entirely clear cut. The passage just cited describing Jesus' baptism illustrates the uncertain boundary between narrative and instruction. In addition, as I have argued, retaining the narrative voice does not exclude exegesis; there is a large area where commentary and narrative coincide. I would disagree, though, with Deerberg's rejection of the description of the poem as epic. ${ }^{17}$ The presence of a large narrative element and the concern to retain, in however rudimentary a form, some chronological sequencewhat Cicero calls ordo temporum-support that characterization of the poem. Echoing Müller's judgment on the first biblical poet, in a recent commentary on Juvencus' account of the crucifixion and resurrection of Christ, ${ }^{18}$ I see Sedulius' poem too as consistent with the historical development of the epic genre. Indeed I cannot escape the conclusion of a continuity between the three main biblical poets of Latin late antiquity. Even Arator, whose Historia apostolica incorporates such a large element of exegesis, clearly aspires to continuity with Sedulius (see Schwind 1990). ${ }^{19}$ His poem begins where the earlier poet left off, with the Ascension, and shows close familiarity with the Carmen paschale. Readers would approach it with expectations, including generic expectations, shaped by their familiarity with Sedulius' poem, although the relation between the voices of narrator and instructor is certainly different in the two poems. I would like to think that in Sedulius' case his popularity derives at least in part from his unusual ability to strike a balance between the two.

\section{Bibliography}

Deerberg (2011): Daniel Deerberg, Der Sturz des Judas: Kommentar (5,1-163) und Studien zur poetischen Erbauung bei Sedulius, Orbis antiquus 43, Münster.

Green (2006): Roger P.H. Green, Latin Epics of the New Testament: Juvencus, Sedulius, Arator, Oxford.

Hecquet-Noti (2009): Nicole Hecquet-Noti, “Entre exégese et épopée: Présence auctoriale dans Juvencus, Sedulius et Avit de Vienne” in: Henriette Harich-Schwarzbauer and Petra Schierl

17 Deerberg (2011) 466-69.

18 Müller (2016) 373; cf. Green (2006) 143.

19 See Schwind (1990) 161-79. 
(eds.), Lateinische Poesie der Spätantike, Internationale Tagung in Castelen bei Augst, 11.13. Oktober 2007, Basel, 197-215.

Mori (2013): Roberto Mori, Sedulio, tra prosa e poesia: L'Opus Paschale e il Carmen Paschale di Sedulio, Padua.

Müller (2016): Michael Müller, Tod und Auferstehung Jesu Christi bei Iuvencus (IV 570-812):

Untersuchungen zu Dichtkunst, Theologie und Zweck der Evangeliorium Libri Quattuor,

Palingenesia 105, Stuttgart.

Roberts (1985): Michael Roberts, Biblical Epic and Rhetorical Paraphrase in Late Antiquity, Arca

16, Liverpool.

Schwind (1990): Johannes Schwind, Arator-Studien, Hypomnemata 94, Göttingen.

Springer (1988): Carl P.E. Springer, The Gospel as Epic in Late Antiquity: The Paschale Carmen of

Sedulius, Vigiliae Christianae Suppl. 2, Leiden.

Stella (2001): Francesco Stella, Poesia e teologia: L'occidente latino tra IV e VIII secolo, Milan.

Woodman (1988): A.J. Woodman, Rhetoric in Classical Historiography: Four Studies, London. 
Michele Cutino

\section{Fictions poétiques et vérités bibliques dans les réécritures vétéro et néotestamentaires en vers}

\section{Questions méthodologiques}

En commençant cette contribution à ce colloque, qui, je l'espère, sera riche de discussions et fécond en résultats, il me semble nécessaire d'éclaircir la perspective précise de ma contribution dédiée aux questions méthodologiques concernant le rapport entre fictions poétiques et vérités bibliques dans les paraphrases vétéro et néotestamentaires. Si l'on devait s'en tenir aux déclarations programmatiques de ces poètes, il n'y aurait rien à approfondir. En effet, si l'on considère les affirmations explicites de ces auteurs, il va de soi qu'ils soulignent comment l'horizon de leur inspiration est la vérité historique de la Bible: ces poèmes sont véritables, comme l'affirme Arator dans l'épitre-préambule de son Historia Apostolica adressée à Virgile $^{1}$, parce qu'ils suivent l'hypotexte biblique, ici les Actes des Apôtres de Luc, qui est histoire. Et il va également de soi que cette vérité historique est constamment opposée dans ces déclarations aux fictions poétiques de la poésie païenne: tout le monde sait bien comment, tout au début de leurs poèmes sur l'évangile, Juvencus dans ses Evangeliorum libri ${ }^{2}$ et Sedulius dans son Paschale Carmen ${ }^{3}$, soulignent que les Christi vitalia gesta pour Juvencus, et les clara salutiferi miracula Christi pour Sedulius, sont d'autant plus dignes d'être célébrés en vers que, comme l'observe Juvencus, des poèmes comme ceux d'Homère et de Virgile ont connu une réputation durable, alors qu'ils entremêlent de mensonges la geste des hommes anciens, ou que, comme le fait remarquer Sedulius, les poètes gentils font un étalage grandiloquent de leurs fictions ${ }^{4}$. Sans parler de la prise de position nette sur cette question, au moins sur le plan théorique, de la part du poète vétérotestamentaire Avit, qui, dans la lettre/dédicace de ses livres De spiritalis historiae gestis à Apollinaire ${ }^{5}$, in-

1 Arat. ad Vigil. 19-20 : Versibus ergo canam quos Lucas rettulit Actus, / historiamque sequens carmina vera loquar.

2 Iuvenc. praef. 15-18: quae veterum gestis hominum mendacia nectunt, nobis certa fides aeterna in saecula laudis inmortale decus tribuet meritumque rependet. Nam mihi carmen erit Christi vitalia gesta.

3 Sedul. Pasch. carm. I.17-18; 23; 26 : Cum sua gentiles studeant figmenta poetae / grandisonis pompare modis ... cur ego ... clara salutiferi taceam miracula Christi?

4 Pour les rapports entre la préface des Evangeliorum libri de Juvencus et celle du Carmen Paschale de Sedulius je renvoie à la contribution de Costanza (1985) 253-286.

5 Avit. epist. ad Apol. : Quamquam quilibet acer ille doctusque sit, si religionis propositae stilum non minus fidei quam metri lege servaverit, vix aptus esse poemati queat; quippe cum licentia mentiendi, 
terdit radicalement la licentia mentiendi, la permission de dire des mensonges, quand on traite d'arguments sérieux comme les matériels bibliques, alors qu'Horace dans son Art poétique ${ }^{6}$ avait accordé cette liberté aux poètes et aux peintres: et il dit expressément qu'il ne s'agit pas seulement ici des fictions du mythe, mais des mensonges poétiques en général ${ }^{7}$.

Reste également en dehors de la perspective de mon intervention l'ambiguïté avec laquelle les poètes chrétiens, en dépit de leurs déclarations poétiques éloquentes, s'approchent de l'imaginaire de la poésie profane, jugée viciée par le mensonge, aspect que Paul Augustin Deproost ${ }^{8}$ a mis bien en évidence dans sa contribution sur le rapport entre ficta et facta dans la poésie chrétienne latine. C'est une ambiguïté qui ressort de toute évidence du fait que les poètes chrétiens trouvent dans le langage de la poésie païenne, notamment dans les images de la fabula épique, des vérités cachées qui les intéressent, ainsi que les moyens expressifs privilégiés pour communiquer ces vérités, si bien qu'on peut parler, à cet égard, d'un véritable double langage.

Notre intervention porte plutôt sur une troisième perspective, plus rare, mais, je pense, très intéressante, c'est-à-dire l'insertion consciente de la fiction littéraire dans le récit biblique là où celui-ci est, de quelque façon, incomplet, ou, ce qui est encore plus radical, la substitution de la fiction poétique à l'histoire biblique qui subit, par conséquent, une ré-sémantisation profonde.

La première de ces possibilités, je l'ai mise en évidence à propos du poème Alethia composé par Claudius Marius Victorius selon toute probabilité dans le deuxième quart du $\mathrm{V}^{\text {ème }} \mathrm{s}$., dans la monographie que je lui ai consacrée en $2009^{9}$, dont je vais reprendre et approfondir quelques données. En effet, au début du deuxième livre de ce poème (vv. 1-5), nous trouvons un bref préambule de cinq vers, introduits selon des formules de récapitulation typiques des poèmes didactiques :

Hactenus arcanam seriem, primordia mundi,

ut sincera fides patuit, sine fraude cucurri,

dum dignis leto vitiis terrena carerent.

Nunc hominum mores et iam mortalia versu

ingressum fas sit veris miscere poetam.

«Jusqu'ici j’ai parcouru, sans aucun mensonge, d'après la manifestation de la foi sincère, la succession mystérieuse des événements et des origines du monde, pendant que la réalité ter-

quae pictoribus ac poetis aeque conceditur [Hor. ars 9], satis procul a causarum serietate pellenda sit. In saeculari namque versuum opere condendo tanto quis peritior appellatur, quanto elegantius, immo, ut vere dicamus, ineptius falsa texuerit. Taceo iam verba illa vel nomina, quae nobis nec in alienis quidem operibus frequentare, ne dicam in nostris conscribere licet: quae ad compendia poetarum aliud ex alio significantia plurimum valent.

6 Hor. Ars 9-10: Pictoribus atque poetis / quidlibet audendi semper fuit aequa potestas.

7 Sur ce texte voir Roberts (1980) en particulier 400-402.

8 Deproost (1998) 101-121.

9 Cutino (2009). 
restre échappait aux vices dignes de la mort. Maintenant que j’ai commencé à traiter en vers les coutumes des hommes et les réalités désormais mortelles, qu'on m'accorde de mêler l'attitude du poète à la vérité» (trad. M. Cutino)

Ce préambule constitue un important tournant de la stratégie de composition du poème, comme on peut le remarquer du fait que Victorius reprend consciemment une déclaration programmatique de Paulin de Nole dans le Natalicium $12^{10}$-nous suivons la numérotation de la nouvelle édition des poèmes de cet auteur par Fr. Dolveck (CCSL 21, 2015) - déclaration qui porte justement sur le rapport entre vérités chrétiennes et fictions poétiques. Dans ce passage, Paulin revendiquait comme point fort du lettré chrétien, le fait que, même s'il compose des poèmes, il ne recourt jamais à la fraus poetae, c'est-à-dire aux faussetés qui sont propres aux poètes païens : cette fraus, en effet, peut intéresser selon Paulin seulement les gentils, dévoués aux pratiques idolâtriques, non les chrétiens, qui, en ayant comme mesure de leur propre production poétique et artistique la foi en Jésus Christ, se fondent sur l'historicité de cette foi qui caractérise leurs récits, relatifs dans ce poème à trois miracles animaliers œuvrés par les reliques de saint Félix à Nole.

La reprise antiphrastique des affirmations pauliniennes est ultérieurement enrichie et renforcée par l'allusion à un passage de l'Art poétique d'Horace concernant la licentia mentiendi que, comme nous l'avons dit, Avit-à mon avis en référence allusivement polémique à ce qu'affirme justement Victorius et à ses modalités de narration dans ce deuxième livre ${ }^{11}$ - avait condamnée également en rapport à un passage de ce texte d'Horace : en effet, dans les vv. $149-152^{12}$ le poète classique fait l'éloge d'Homère, capable d'imaginer si bien ses mensonges, et de mêler si bien invention/fausseté et vérité/réalité qu'il confère une unité profonde à son ouvrage du début à la fin en passant par le milieu. Il est évident que l'hémistiche veris miscere poetam du v. 5 d'Alethia II est calqué sur l'hémistiche du v. 152 d'Horace sic veris falsa remiscet, avec l'importante substitution de falsa avec poeta, employé avec valeur antonomastique pour poésie, attitude des poètes. Substitution qui fait remarquer que le poète ne peut pas ne pas dire de mensonges. Et Victorius demande-fas sitjustement cette licence dans son préambule. Il y a de quoi s'étonner, parce que le bouleversement du modèle paulinien est conduit à l'intérieur d'un poème biblique, c'est-à-dire d'un genre littéraire qui est basé de façon programmatique, comme nous venons de le voir, sur la vérité historique.

Cependant, cette licence est demandée par Victorius par rapport au contenu qu'il va traiter : il s'agit des mœurs des hommes, devenus mortels, après la faute des

10 Paul. Nol. Nat. 12.28-32 : Non adficta canam, licet arte poematis utar. / Historica narrabo fide sine fraude poetae: / absit enim famulo Christi mentita profari. / Gentibus hae placeant ut falsa colentibus artes; / at nobis ars una fides et musica Christus.

11 Cutino (2009) 221-224.

12 Hor. ars 151-152 : atque ita mentitur, sic veris falsa remiscet, / primo ne medium, medio ne discrepet imum. 
protoparents Adam et Ève. C'est pourquoi ce sujet exige des formes expressives différentes par rapport à celles utilisées jusqu'ici par lui : si en effet il avait traité les primordia mundi, c'est-à-dire Gen 1-3 sine fraude, parce que dans ceux-ci s'était manifestée la foi sincère, cette fois s'étant corrompue à cause du péché originel, il y a l'exigence de modifier aussi le code stylistique. Victorius théorise, donc, la possibilité de recourir aux mensonges pour un poète-tout en sachant bien qu'il s'agit de mensonges-pour mieux illustrer la décadence de l'humanité dans la condition postlapsaire. Ça veut dire que le mensonge n'est pas autorisé dans l'absolu, mais dans le cadre d'un critère précis d'homologie entre forme et contenu. Il est important, en effet, de remarquer, à cet égard, qu'après cette ouverture programmatique le livre II du v. 6 jusqu'au v. 195 est occupé par une digression sur les modalités à travers lesquelles Adam et Eve chassés de l'Eden, se sont adaptés à la nouvelle situation caractérisée par le besoin, en découvrant par hasard le feu et les métaux : l'intertexte de cette digression est constitué, comme je l'ai souligné dans la dite monographie, par la conclusion du livre V du De rerum natura concernant la condition des hommes primitifs et leur évolution progressive. Par ailleurs, le récit de ces découvertes dans Alethia II se conclut (vv. 179-185) avec la prosopopée de Dieu même qui s'oppose au rôle du hasard et de l'expérience dans la connaissance humaine, ressortant du modèle lucrétien, en revendiquant les dons qu'il a fait providentiellement à l'homme de la connaissance innée. A la fin de cette digression, en tout cas, Victorius, en se référant très librement à Gen 4.1 «Adam s'unit à Eve, sa femme, et elle conçut et enfanta Caïn», se hâte de préciser déjà à partir du v. $195^{13}$ qu'on peut, en tout cas, s'en tenir aux limites de la vérité biblique, consistant dans le fait que le premier intérêt témoigné par Adam ayant quitté le paradis, fut justement l'amour pour sa femme et les enfants qu'elle lui donna.

Le critère donc de l'homologie et le recours à l'une des modalités narratives typiques des réécritures de la bible en vers, comme la digression/excursus, mettent, de quelque façon, en sourdine l'insertion dans la narration biblique, de l'un des thèmes pratiqués et aimés par la poésie profane, celui du progrès de l'histoire humaine à partir de sa condition primitive.

Ces cautèles, ces précautions sont tout à fait absentes dans un autre cas, cette fois concernant une paraphrase néotestamentaire, que je veux prendre en considération de plus près. Il s'agit d'un passage de la Laus Iohannis, petit poème dédié à la figure de Jean Baptiste, attribué, pour ainsi dire, jusqu'à hier à Paulin de Nole, mais non reproduit dans la dernière édition, déjà mentionnée, des poèmes de cet auteur par Fr. Dolveck, avant tout parce que dans l'intitulatio du manuscrit qui nous a transmis intégralement l'œuvre, manque l'indication de l'auteur. Sans entrer dans cette question complexe-que A.-M. Turcan-Verkerk ${ }^{14}$ a le mérite d'avoir posée et dont je suis en

13 Mar. Vict. Aleth. II.195-198 : ... Summo ergo hoc limite veri / haereat, augustis quod pulsus sedibus Adam, / nullum aliud prius officium quam coniuge dignum / egit et ignotos natis impendit amores.

14 Turcan-Verkerk (2003) en particulier 155-164. 
train de m'occuper, - le passage que je prends en considération est celui des vv. 229254 qui est articulé autour de la description des mœurs de Jean Baptiste pendant sa retraite dans le désert, dont l'intertexte biblique est Mc 1.6 et Mt $3.4^{15}$ :

Vestis erat curvi saetis conserta cameli

contra luxuriem molles duraret ut artus

arceretque graves conpucto corpore somnos.

Hunc vilis rigidos ad lumbos zona ligabat.

Praebebant victum facilem silvestria mella

pomaque et incultis enatae cautibus herbae

235 arentemque sitim decurrens unda levabat.

Quis locus hic vitiis? Aditum quem prava cupido

invenit haec inter sacrae ad penetralia mentis?

Quo peccet qui nil cupiat? Quo tendat iniqui

illecebras sensus quisquis non indiget ullo?

240 Sic primi vixere homines, mundoque recenti

hos auctor dederat ventura in saecula mores, inseruit donec sese malesuada voluptas

ac secum luxus et amorem invexit habendi.

Hinc odia, hinc lites, hinc fraus, hinc livor et irae,

245 caedes arma cruor conflictus proelia mortes,

hinc offensa dei, quam tartara saeva piabunt.

Verum ego cur nimium communes arguo culpas,

inmemor ipse mei, quem non commissa gravare, sed veniam sperare decet? Mirabimur immo

250

rectius invictum nullique imitabile prisci

exemplum saecli transgressum humana labore

semideumque virum, qui labe inmunis ab omni,

cum sua tam saevis cruciarit corpora poenis,

praescripsit quid nos vel post peccata deceret ${ }^{16}$.

«Son vêtement était tissu des poils d'un chameau courbé, pour endurcir les membres amollis contre le luxe et empêcher le sommeil lourd en piquant le corps. Il était attaché à ses hanches rigides une ceinture humble. Miel sauvage, fruits et herbes poussées sur des rochers incultes lui fournissaient une nourriture aisée, et l'eau courante étanchait sa soif ardente. Quelle place dans cette condition pour les vices ? Comment, dans ces réalités, la convoitise perverse pourrait-elle avoir accès à l'intérieur d'un esprit consacré ? En quoi pourrait pécher qui n’a aucun désir ? Où pourrait diriger les tentations d'un sentiment malveillant celui qui n’a besoin de rien ? Ainsi vécurent les premiers hommes, selon ces coutumes que le créateur avait données pour les siècles futurs au monde qui venait d'être créé, jusqu'à ce que le plaisir, mauvais conseiller, ne s’y

15 Mc 1.6 : Et erat Iohannes vestitus pilis cameli / et zona pellicia circa lumbos eius, et lucustas et mel sivestre edebat; Mt 3.4 : Ipse autem Iohannes habebat vestimentum de pilis camelorum et zonam pelliciam circa lumbos suos. Esca autem eius erat lucustae et mel silvestre. Il s'agit de l'une des intégrations - par ailleurs, très peu nombreuses -à l'intertexte fondamental de ce poème paraphrastique qui est constitué par Lc $1 ; 3 ; 7$.

16 Le texte suit l'édition critique que je vais préparer de cet ouvrage: en particulier, je fais remarquer au v. 239 la leçon illecebras que ja’i choisie à la place de in latebras de la dernière édition révisée (par M. Kamptner) de von Hartel dans CSEL 30, Vindobonae $1999^{2}$. 
insinuât et n'apportât avec lui la luxure et l'amour pour les richesses. D'où vinrent les haines, d'où les litiges, d'où la tromperie, d'où l'envie et la colère, les massacres, les armes, le sang, les conflits, les batailles, les morts, d'où l'offense envers Dieu, qui sera expiée par le Tartare cruel. Mais pourquoi est-ce que je reproche trop les fautes communes, m'oubliant moi-même, alors qu'il me convient non d'aggraver ce que j'ai commis, mais d'espérer le pardon ? Au contraire, il sera plus juste d'admirer cet exemple du temps passé invaincu et inimitable, qui a dépassé par ses efforts les possibilités humaines, et cet homme demi-dieu, qui, exempt de toute tache, ayant crucifié son corps à travers des supplices si cruels, nous a prescrit ce qu'il convient de faire même après les péchés». (trad. M. Cutino)

A propos de ce passage on a déjà remarqué - en particulier P. Flury ${ }^{17}$ et A.V. Nazzaro ${ }^{18}$ -la dette de l'auteur envers la description de Baptiste par Juvencus ${ }^{19}$ et la présence dans la description de ses mœurs des particularités appartenant au motif littéraire de l'âge d'or, notamment des Saturnia regna dont parle Virgile à plusieurs reprises dans Géorgiques II et dans Énéide VIII. En effet les vv. 229 (Vestis erat curvi saetis conserta cameli) et 232-233 évoquent sans aucun doute, surtout ce dernier v. 233, le modèle de Juvencus, tout comme il est évident que l'insertion dans ce même v. 233 de facilem à la place de tenuem (victum) de Juvencus donne lieu à une tournure propre à la caractérisation de la vie heureuse des agriculteurs, auxquels la terre fournit un aliment «facile», vie heureuse que dans le texte de Géorgiques II Virgile rapproche de la condition également bienheureuse des hommes à l'époque de Saturne, avant que la Justice quittât la terre ${ }^{20}$. Ces références méritent d'être approfondies à travers une analyse attentive du contexte dans lequel s'insère cette présentation de Baptiste, qui donne matière à d'importantes réflexions à propos de l'interaction entre vérités bibliques et faussetés poétiques. Remarquons avant tout que la particularité du manteau en poils de chameau et du pagne de peau autour des reins portés par Jean Baptiste, enregistrée fidèlement par Juvencus, dans la Laus Iohannis est amplifiée : pour l'auteur ce vêtement est conçu comme un véritable antidote contre le luxe, afin d'endurcir les membres mouillés, si bien que les reins de Baptiste sont définis au v. 232 rigides, rigidos lumbos, et afin de repousser le sommeil lourd au moyen des poils piquant son corps. C'est un élément qui renvoie sans aucun doute au milieu monastique : on le retrouve, en effet, dans la transposition en vers de la Vita Martini de Sulpice Sévère par Pauline de Périgueux à propos de la praxis de certains aristocrates qui à Marmoutier se conformaient à cette typologie exotique de vêtement, rapportée par les pèlerins d'Orient, pour mortifier leur chair dans leurs surenchères ascéti-

17 Flury (1973) 129-145. Cette étude est encore l'unique expressément consacrée à l'analyse formelle globale de la Laus.

18 Nazzaro (2003) 283-306 ; Nazzaro (2004) 19-33 ; Nazzaro (2006) 133-146 ; Nazzaro (2008) 315324.

19 Iuvenc. evang. I.323-325 : Texta camelorum fuerant velamina saetis, / et zonae pellis medium cinxere profetam / et tenuem victum praebent silvestria mella.

20 Verg. georg. II.458-460 : O fortunatos nimium, sua si bona norint, / agricolas! Quibus ipsa procul discordibus armis / fundit humo facilem victum iustissima tellus. 
ques $^{21}$. Mais la référence à l'endurcissement voulu des membres rigides nous conduit plutôt à la récupération de la condition primordiale des hommes avant que le luxe alanguît le corps à l'origine résistant et fort, comme le soulignent Lucrèce dans sa digression, déjà mentionnée, sur les hommes primitifs à la fin du $\mathrm{V}^{\mathrm{e}}$ livre de son $D e$ rerum natura ${ }^{22}$, et ensuite Prudence dans son Hamartigénie dans un passage où nous trouvons rigidos duraverat artus référé aux intentions, au projet du créateur sur l'homme avant sa corruption par le luxe $\mathrm{e}^{23}$.

Le modèle de Juvencus subit des modifications/amplifications à propos aussi de la nourriture du Baptiste qui vont dans le même sens : avant tout, il est vrai que le facilis victus de v. 233 rappelle georg. II, mais il ne faut pas également oublier le réemploi de cette tournure par Juvencus dans la paraphrase de Mt $6.24-25^{24}$, là où le Christ exhorte ses disciples, sur le modèle des oiseaux qui sont facilement alimentés par la terre, à ne pas se tourmenter avec des questions de nourriture ou de vêtement : le facilis victus évoque ici la disponibilité immédiate des dons de la nature créée par Dieu. Ensuite, dans la Laus, en dépit de l'omission par Juvencus des sauterelles dans le régime alimentaire du prophète, omission suivie par notre auteur, nous avons la mention des fruits, dans la forme coordonnée au début du v. 234 pomaque, qui rappelle un texte des Amours d'Ovide ${ }^{25}$ concernant encore la nourriture spontanée fournie par la nature dans l'âge d'or. L'image des poma/fruits, par ailleurs, étant associée dans ce vers aux herbes non cultivées, nées du terrain rocheux, n'évoque pas du tout le caractère luxuriant de la nature, propres à certaines descriptions de

21 Paul. Petr. Mart. II.141-148 : Multis vestis erat saetis contexta cameli, / quae levibus stimulis vigiles contingeret artus, / excludens tenuem compuncta carne soporem, / mollia ne fluxum nutrirent vellera corpus / lasciva et tenui vestis fluitaret amictu, / qualia praeteritae consuerat copia vitae. / Nam multos illuc prisco de sanguine claros traxerat ad talem prudens sententia vitam : pour ce rapprochement voir Weidmann (1991) 174-175. L'hypotexte de référence est Sulp. Sev. Mart. 10, 8 (plerique camelorum saetis vestiebantur: mollior ibi habitus pro crimine erat), où on parle de l'habitude d'une grand nombre de disciples de Martin dans l'anachorèse, de porter justemement des habits de poils de chameau, croyant être un crime de se vêtir plus délicatement.

22 Lucr. V.925-938: At genus humanum multo fuit illud in arvis / durius, ut decuit, tellus quod dura creasset, / et maioribus et solidis magis ossibus intus / fundatum.

23 Prud. ham. 279 ; 282-284 : Quid quod et ipse, caput muliebris corporis et rex, / ... / solvitur in luxum? Cernas mollescere cultu / heroas vetulos, opifex quibus aspera membra / finxerat et rigidos duraverat ossibus artus. Voir, à cet égard, Nazzaro (2008) 318 n. 11.

24 Iuvenc. evang. I.631-633 : Neu faciles victus aegra disquirite cura. / Nonne animam pluris facimus quam corporis escas / aut dubitat corpus quisquam praeponere vesti?

25 Ov. am. III.8.33-34: At meliora dabat curvo sine vomere fruges / pomaque et in quercu mella reperta cava, où on peut remarquer également l'association entre mel et poma. L'absence des sauterelles depend avant tout du modèle de Juvencus, mais il est clair qu'elle produit un portrait 'végétarien' de l'alimentation du Baptiste qu'on a rattaché à l'influence du modèle de l'Adversus Iovinianum de Jérôme: cf. Duval (1989) 184-187. 
l'âge d'or ${ }^{26}$, mais insiste plutôt sur la frugalité et l'essentialité de cette nourriture spontanée, comme le faisaient les textes illustrant la condition de vie des hommes primitifs, en particulier le déjà cité livre V du De rerum natura ${ }^{27}$. Mais c'est surtout le dernier élément de cette description, tout à fait gratuit par rapport à l'hypotexte biblique, qui est très intéressant : Jean Baptiste, affirme notre auteur, satisfaisait la soif en buvant l'eau courante d'un fleuve : cet élément évoque sans aucun doute l'une des conditions des hommes primitifs encore selon le modèle du De rerum natura $\mathrm{V}^{28}$.

Si l'on met ensemble ces éléments il est évident que l'auteur de la Laus à travers les allusions intertextuelles, représente Baptiste comme suivant le régime de vie des premiers hommes, et que pour lui l'essentialité, l'autarkeia de ce régime constitue le véritable âge d'or de l'humanité. Ainsi il peut conclure, à la fin de cette présentation, aux vv. 240 - 241 que les premiers hommes vécurent ainsi (sic primi vixere homines) et que Dieu avait prévu cette condition pour le temps à venir (hos auctor dederat ventura in saecula mores), deux vers qui sont encore une adaptation savante de passages de la poésie païenne concernant l'âge d'or ${ }^{29}$.

Jusqu'ici il n'y a rien d'étonnant, on reste dans le réemploi des matériels littéraires païens dans la réécriture biblique pour des finalités stylistiques, expressives. C’est la suite qui revêt un intérêt particulier pour notre sujet, c'est-à-dire la présentation de la perte de la part de l'humanité corrompue de cette condition édénique, basée sur l'autarkeia, et de ses conséquences sur le plan théologique. À cet égard, il me plait de mettre au clair le développement argumentatif à travers un schéma (Fig. 1).

La corruption de l'humanité est décrite selon un réemploi original du motif païen de la diffusion des maux dans le monde suite à la fin de l'âge d'or et à la succession d'âges progressivement inférieurs par rapport à celui d'or, jusqu'à l'âge de fer. L'originalité consiste avant tout dans le fait que ce motif se substitue complètement aux références à l'histoire biblique de cette dégradation à partir du péché des protoparents. Ce péché est sans doute évoqué par la mention du premier vice qui est à l’origine de la décadence, la malesuada voluptas du v. 242, mais il s'agit d'une évocation allusive et en tout cas à travers la médiation exégétique. En effet, l'unique intertexte biblique possible, le suasit de certaines traductions Veterae latinae, relatif

26 C'est pourquoi je ne suis pas d'accord avec ceux qui voient dans la description de cette condition une sorte de scène idyllique : cf. Nazzaro (2008) 323 n. 32 qui renvoie à Lupieri (1984) 48-49 qui fait rentrer ce paysage dans l' 'idéologie claustrale' du monachisme de Lérins.

27 Lucr. V.937-938: Quod sol atque imbres dederant, quod terra crearat, / sponte sua, satis id placabat pectora donum.

28 Lucr. V.945: At sedare sitim fluvii fontesque vocabant. Je me réfère au concept, parce que sur le plan formel, comme l'a bien remarqué Nazzaro (2008) 319 n. 15, le vers rappelle Ov. epist. 4.174 : arentem quae levet unda sitim.

29 Cf. Eleg. in Maec. 1.23-24 : Sic illi vixere quibus fuit aurea Virgo, / quae bene praecinctos postmodo pulsa fugit ; Avien. Arat. 292-294 : ... tu cum sincera priorum / vita hominum nullis ageret sub legibus aevum / aureaque innocuos servarent saecula mores. 
vv. $229-241$

Présentation orientée du récit évangélique (Mc 1.6 ; Mt 3.4)

sur la nourriture et sur le vêtement de Jean Baptiste :

celui-ci vit selon la condition de frugalité et d'essentialité

voulue par Dieu pour les premiers hommes,

véritable âge d'or de l'histoire humaine

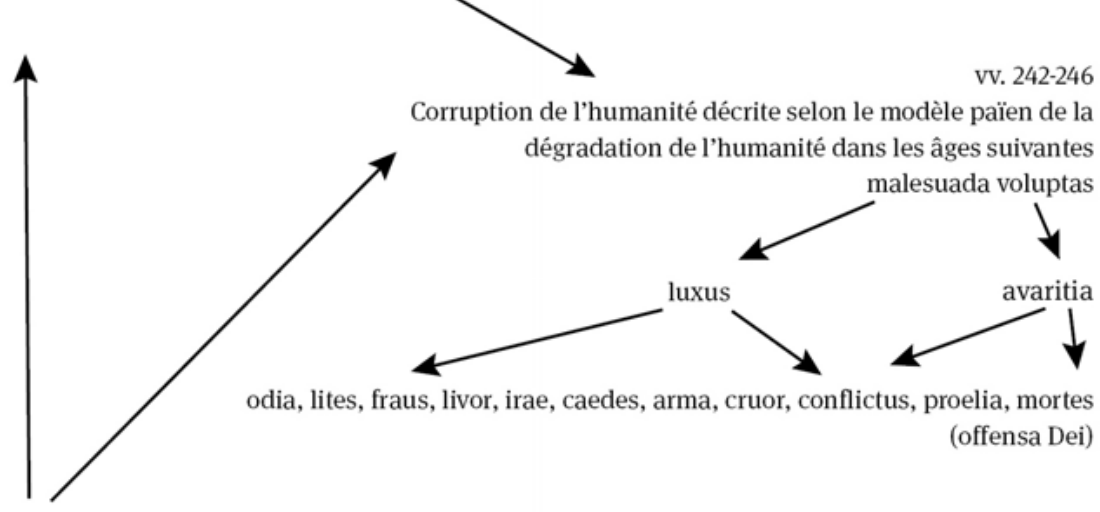

vV. $247-254$

Interprétation théologique : Jean Baptiste, étant un renouveau exceptionnel, hérö̈que, dans des temps de corruption, du modèle de la vie primitive bienheureuse, ignorant du péché, fournit un modèle actuel aux hommes : au lieu de se concentrer sur la condition pécheresse de toute l'humanité, il les exhorte à poursuivre un idéal de vie convenant même après les péchés commis.

Fig. 1

à la justification qu'Eve donne de son péché devant Dieu, en l'attribuant à la tentation du serpent/diable, est englobé dans l'adjectif poétique malesuada d'allure déjà virgilienne-la très fameuse malesuada fames du vestibule des Enfers dans l'Énéide (VI.883)- et il est associé au substantif abstrait voluptas selon l'identification du péché des protoparents avec le plaisir, origine de tous les autres maux, proposée par les exégètes chrétiens, avant tout par Ambroise ${ }^{30}$. Mais après disparaissent même des allusions possibles au canevas biblique : de la voluptas viennent des maux, le luxe et l'avidité, dont la complémentarité dans l'imaginaire classique comme causes

30 Ambr. parad. 15.73 : «Serpens» inquit «suasit» (Gen 3.13) ... Serpens enim mulierem decepit , virum mulier ad praevaricationem de veritate deduxit. Serpentis typum accepit delectatio corporalis. Mulieris symbolum sensus est nostri, vir mentis. Delectatio itaque sensum movet, sensus menti transfundit quam accepit passionem. Delectatio igitur prima est origo peccati. 
principales de la dégradation de l'humanité est topique ${ }^{31}$. Et observons que l'avidité en particulier est évoquée à travers une tournure expressive, amor habendi, appartenant à la réécriture virgilienne de la fin de l'âge d'or dans le huitième livre de l'Enéide ${ }^{32}$. De ces deux maux, ainsi, viennent tous les autres selon une liste dans les vv. 244-245 qui appartient elle-même à la topique des maux apportés à l'humanité par les âges suivant celui d'or- la référence formelle la plus proche c'est celle des Métamorphoses d'Ovide ${ }^{33}$. Le module expressif de la liste des maux a séduit les poètes chrétiens mais elle n'est jamais utilisée, comme dans notre cas, pour connoter la dégradation de l'humanité (Prudence dans l'Hamartigenia vv. 395-397 mentionne une liste de vices qui constituent le cortège de Satan, Avit dans le chant II de son De spiritalis historiae gestis, II.31-32, indique par énumération les maux que la condition eschatologique fera finalement disparaitre). On pourrait rapprocher de l'opération conduite par l'auteur de la Laus seulement un passage du Centon de Proba ${ }^{34}$ qui présente, cependant, des caractéristiques bien différentes par rapport à notre passage. Avant tout, dans la Laus cette modalité de narration est un choix, là où dans le Centon, lié à l'emploi de matériels virgiliens, son utilisation est, de quelque façon, une obligation propre à ce genre poétique. Mais ce qui est plus important, dans le centon de Proba le thème de la dégradation de l'humanité est articulé selon une progression qui suit l'intertexte biblique clairement évoqué par la poétesse : ainsi la situation des protoparents expulsés de l'Eden à cause de leur péché est connotée par la rareté de la nourriture, que la nature, auparavant prodigue des biens, leur rend disponible ; la venue du règne plus dur de Jupiter après les Saturnia regna dont parle Virgile en Georgiques I, est utilisée pour indiquer la dégradation après le premier meurtre de l'humanité, celui d'Abel par Caïn ; enfin l'ultérieure dégradation qui conduit à la punition par le déluge est caractérisée comme l'âge de fer, qui est encore pire, decolor aetas selon le modèle virgilien d'Énéide VIII. En revanche dans la Laus l'image littéraire est devenue la véritable histoire et a oblitéré complétement l'histoire biblique. Ce n'est pas dû au hasard si l'auteur parle au v. 246

31 Sall. Cat. 5.8 : corrupti mores, quos... diversa inter se mala luxuria atque avaritia vexabant. Cf. aussi Cic. fin. III.75; Liv. I, praef. 11; XXXIV.4.1; Sen. epist. 7.7; 40.5; 56.5; 69.4; 90.36; dial. XI.10, 1; Tert. nat. I.5; Prud. psych. 454-457; Aug. civ. II.19.

32 Verg. Aen. VIII.324-327 : aurea quae perhibent illo sub rege fuerunt / saecula: sic placida populos in pace regebat, / deterior donec paulatim ac decolor aetas / et belli rabies et amor successit habendi. 33 Ov. met. I.128-130 : fugere pudor verumque fidesque, / in quorum subiere locum fraudesque dolique / insidiaeque et vis et amor sceleratus habendi; Avien. Arat. 338-343: ruit haec quoque rursum / vivendi series ac successere pudendo / aurea saecla habitu. Fraus ilicet et furor ardens / adque cruentus amor chalybdis.

34 Proba Cento 276-277: tum [= Gen. 3.23] victum in silvis bacas lapidosaque corna / dant rami et vulsis pascunt radicibus herbae; 290-293 : tum [= Gen. 4.8] genitor virus serpentibus addidit atris / mellaque decussit foliis ignemque removit / praedarique lupos iussit pontumque moveri / et passim rivis currentia vina repressit; 299-302 : deterior donec (= Gen. 6.4-5) paulatim ac decolor aetas, / ferrea progenies, duris caput extulit arvis / et belli rabies et amor successit habendi. / Iustitia excedens terris vestigia fecit. 
de l'offensa Dei et de la conséquente condamnation du genre humain à cause des fautes communes (v. 247 communes ... culpas) après l'énumération de tous les maux qui ont corrompu l'humanité. Il n'y a pas un moment décisif, où, comme le témoigne la Bible, l'homme se détache de Dieu, le péché originel, mais, à travers l'itération d'hinc... hinc..., la venue de la corruption généralisée est associée à la condamnation de l'homme de la part de Dieu.

Davantage encore : cette histoire littéraire remplaçant l'histoire biblique conditionne l'interprétation théologique même de la figure de Jean Baptiste. Celui-ci, donc, représente le renouveau exceptionnel, inimitable, dans des temps caractérisés par la dégradation, du modèle de vie primitive bienheureuse, ignorant du péché (v. 252 labe immunis ab omni). Pour cela cette exceptionnalité est remarquée à travers la représentation de Jean Baptiste en tant que véritable héros des temps anciens : il est vrai qu'Ambroise dans son De Helia donne du précurseur de Jésus une caractérisation très proche de notre texte, qui sans aucun doute constitue son intertexte ${ }^{35}$, en associant ses surenchères ascétiques, capables d'aller bien au-delà des limites de la condition humaine, à une interprétation de sa qualification d'angelus en Mt, non comme messager mais comme ange ${ }^{36}$, mais l'emploi au v. 252 de semideus, qui est un terme totalement inusuel dans la poésie chrétienne pour indiquer quelqu'un qui, en tout cas , appartient à la dimension humaine, de l'adjectif invictus pour le qualifier, et du verbe transgredior qui est plus fort par rapport à supergredior utilisé par Ambroise, ainsi que la mention de son labor, ne peuvent pas ne pas évoquer cette dimension héroïque. Ce qui compte le plus, ce paradigme héroïque fournit un modèle actuel aux hommes : au lieu de se concentrer sur la condition pécheresse de l'humanité due à sa corruption, le poète, sur la base de ce modèle, attire l'attention du lecteur plutôt (mirabimus immo) sur un idéal de vie adapté à l'homme même après les péchés (vel post peccata). La caractérisation, donc, de la vie de Baptiste comme reprise héroïque de la vie primitive, avant la corruption progressive des mœurs de l'humanité, sert à faire ressortir un enseignement actuel : il est encore possible, même dans cette condition pécheresse de dégradation, bien lointaine de celle des débuts de l'humanité, de poursuivre l'idéal ascétique.

35 Ambr. Helia 3.4 : in hac virtute et spiritu Heliae venit Johannes. Denique in deserto et ille vacabat ieiuniis: «esca autem eius erant locustae et mel silvestre» (Mt 3.4). Et ideo qui vitae humanae possibilitatem continentia supergressus fuerat, non homo, sed angelus aestimatus est. De ipso legimus: «Etiam plus quam propheta. Hic est de quo scriptum: Ecce mitto angelum meum ante faciem tuam qui praeparabit viam tuam ante te» (Mt 11.9-10).

36 Cette interprétation 'orientée' du mot angelus est mise à profit dans la Laus aux vv. 317-318. 


\section{Conclusions}

On peut tirer, donc, à la fin de l'analyse de ces cas, quelques conclusions qui me semblent intéressantes et susceptibles d'approfondissements ultérieurs. Observons, avant tout, que le thème littéraire païen à propos duquel on a remarqué les affirmations programmatiques et les modalités de composition les plus originales parmi les paraphrases vétéro et néotestamentaires, est celui de la préhistoire de l'humanité, de sa condition initiale et de sa décadence ou de son progrès ultérieur. Il s'agit d'un thème qui croise nécessairement le récit biblique de la perte de la condition édénique de la part de l'homme à cause du péché originel et celui de la dégradation progressive de l'humanité, et qui pour cela est inséré par certains poètes dans le tissu de la vérité biblique.

Deuxièmement, on doit remarquer que les poètes trouvent dans ce thème, pour ainsi dire, un espace 'neutre' pour employer de façon légitime les fictions de la littérature classique en tant qu'exemplaires de cette dimension de chute et de décadence, et pour discuter les grandes questions de la littérature classique, celles du progrès ou de la corruption de l'humanité, comme le fait Victorius très probablement en rapport avec la destination didactique, voire scholastique de son Alethia, ou pour transmettre des considérations théologiques à travers des formes bien compréhensibles à un auditoire cultivé, peu à l'aise avec l'exégèse biblique : en effet, la substitution du récit biblique avec l'histoire littéraire de l'humanité primitive, favorisée par la représentation orientée de la figure de Jean Baptiste, permet à l'auteur de la Laus de valoriser aux yeux de ce public l'expérience de l'anachorèse comme restauration authentique de la dimension paradisiaque et de souligner ainsi, à travers l'exemple du Précurseur du Christ, l' 'actualité' de l'idéal ascétique, montrant celuici ce que la nature humaine peut encore accomplir même dans sa condition pécheresse.

En outre, ces éléments posent le problème fascinant du contexte dans lequel ces compositions s'insèrent. J'ai étudié ce contexte à propos de l'Alethia, je vais le faire pour la Laus. Mais il me plait ici de faire remarquer que et l'Alethia et la Laus nous ont été transmises par un seul même manuscrit, le Parisinus Latinus 7558 de l'époque carolingienne, à côté d'autres compositions, comme la correspondance en vers entre Ausone et Paulin, le poème adressé encore par Paulin à Jovius pour l'inviter à ne plus se dédier à la poésie profane, mais à se consacrer à une véritable poésie chrétienne, et un petit poème appelé Epigramma Paulini : il s'agit des compositions toutes intéressées au rapport entre littérature et en général culture classique et nouveauté chrétienne, ce qui témoigne d'un choix savant-et je dirais idéologiquement orienté- de la part de celui qui a fait ce recueil, un choix qui mérite d'être attentivement étudié. 


\section{Bibliographie}

Costanza (1985): Salvatore Costanza, «Da Giovenco a Sedulio. I proemi degli Evangeliorum libri $e$ del Carmen Paschale», in: Civiltà Classica e Cristiana 6, 253-286.

Cutino (2009): Michele Cutino, L'Alethia di Claudio Mario Vittorio: la parafrasi biblica come forma di espressione teologica, Roma.

Deproost (1998): Paul-Augustin Deprooost, «Ficta et facta : la condamnation du »mensonge des poètes« dans la poésie latine chrétienne», in: Revue des Études Augustiniennes 44, 101-121.

Duval (1989): Yves-Marie Duval, «Les premiers rapports de Paulin de Nole avec Jérôme: moine ou philosophe? Poète ou exégète?», in: Studi Tardoantichi 7, 177-216

Flury (1973): Paul Flury, «Das sechste Gedicht des Paulinus von Nola», in: Vigiliae Christianae 27, $129-145$.

Lupieri (1984): Edmondo Lupieri, «Felices sunt qui imitantur Iohannem (Hier. Hom. In lo.). La figura di S. Giovanni Battista come modello di santità », in: Augustinianum 24, 33-71.

Nazzaro (2003): Antonio Vincenzo Nazzaro, «L'annunzio dell'Angelo a Zaccaria (LC. 1, 5-25) nelle parafrasi di Giovenco (I, 1-51) e Paolino di Nola (carm. 6, 27-107)», in Centro internazionale di studi sulla poesia greca e latina in età tardoantica e medievale. Quaderni 2, 19-33.

Nazzaro (2004): Antonio Vincenzo Nazzaro, «L'annunzio dell'angelo a Maria (LC. 1, 26-38) nelle riscritture metriche di Giovenco (I, 52-79) e Paolino di Nola (carm. 6, 108-138)», in Munera amicitiae. Studi di storia e cultura sulla Tarda Antichità offerti a Salvatore Pricoco, Soveria Mannelli, 283-306.

Nazzaro (2002-2006): Antonio Vincenzo Nazzaro, «La nascita di Giovanni Battista (LC. 1, 57-80) nelle riscritture metriche di Giovenco (I, 105-132) e Paolino di Nola (carm. 6, 229-235)», in: Impegno e dialogo 15, 133-146.

Nazzaro (2006-2007): Antonio Vincenzo Nazzaro, «La veste e il cibo del Battista (Mc 1, $6=$ Mt 3, 4) nelle riscritture metriche di Giovenco (I, 323-325) e Paolino di Nola (carm. 6, 179-228)», in: Rendiconti dell'Accademia di Archeologia Lettere e Belle Arti 74, 315-324.

Roberts (1980): Michael Roberts, «The Prologue to Avitus De spiritalis historiae gestis. Christian Poetry and Poetic License», in: Traditio 36, 399-407.

Turcan-Verkerk 2003: Anne-Marie Turcan-Verkerk, Un poète latin chrétien redécouvert: Latinius Pacatus Drepanius, panégyriste de Théodose, Bruxelles.

Weidmann (1991): Clemens Weidmann, «Zu des Quellen des Paulinus von Petricordia», in: Wiener Studien 104, 169-189. 



\section{Nicole Hecquet-Noti}

\section{L'auteur et son public}

\section{Les différentes lectures de l'épopée biblique selon Avit de Vienne}

Dans une lettre adressée peu avant 507 à son cousin germain Apollinaire, fils de Sidoine, Avit de Vienne demande à ce dernier son avis sur les poèmes qu'il lui a fait parvenir. ${ }^{1}$ Il ressort de cette lettre qu'Avit se présente comme un évêque dont l'occupation principale est l'édification de la communauté catholique burgonde et qui, au milieu de ces occupationes, prend le temps de s'amuser (lusi) à écrire des libelli de Spiritalis Historiae Gestis (SHG) : il s'agit des cinq chants de l'Histoire spirituelle dont les circonstances de publication seront précisées dans le prologue du poème. Il ajoute ensuite :

Hic nunc nihil falso, nihil adsentatorie me loqui coram sinceritate uestra imprecor testem Deum : tantum me tuo iudicio delectatum, ueluti si auribus domni mei, patris tui (scil. Sidonii Apollinaris), meditata confessus, cuiuscumque laudis momentis eo censore donarer. ${ }^{2}$

Avit semble donc tenir au jugement littéraire de son cousin car il voit en lui l'ombre de son père Sidoine, le chantre admiré d'une poésie fortement marquée par la rhétorique et la préciosité. ${ }^{3}$ L'évêque viennois cherche ainsi à se placer dans la continuation de son oncle.

C'est donc en écrivain pleinement conscient des virtuosités poétiques acquises lors de sa formation rhétorique qu'il compose une épopée biblique adressée à un public partageant cette même culture. ${ }^{4}$ Ses lecteurs premiers sont, comme lui, les représentants d'une élite politico-religieuse gallo-romaine très attentive à la pratique d'une poésie respectueuse des lois métriques et rhétoriques classiques.

Toutefois, dans le prologue du $S H G$, Avit prend soin de définir plus précisément sa conception de la poésie. ${ }^{5} \mathrm{Il}$ s'éloigne alors de la rhétorique précieuse de son oncle Sidoine pour préférer une austérité stylistique plus appropriée selon lui à la transmission de la vérité chrétienne; il termine son manifeste poétique par la revendication d'une poésie qui dit la vérité en s'appuyant sur une citation de Mt 12.36 :

1 Alc. Avit., Epist 48MR (51P), 9-10. Les lettres sont citées d'après l'édition Malaspina/Reydellet de la CUF avec entre parenthèses la référence à l'édition Peiper des $M G H$.

2 «Pour l'heure, je prends Dieu à témoin qu'en présence de votre sincérité je ne dis rien faussement, rien par flatterie, sinon que je suis ravi de ton jugement comme si, ayant présenté aux oreilles de mon seigneur ton père, le fruit de mes travaux, j'étais gratifié par ce censeur de quelque louange d'importance» : traduction de Malaspina/Reydellet (2016) 117.

3 Cf. Charlet (2008) 165.

4 Alc. Avit. Prol. Carm. 6, p. 275,9-12 (Peiper).

5 Cf. Hecquet-Noti (2011) 200-207.

https://doi.org/10.1515/9783110687224-004 
Salubrius dicenti clerico non impletur pompa quam regula et tutius artis pede quam ueritatis uestigio claudicatur. Non enim est excusata perpetratione peccati libertas eloquii. Nam si pro omni uerbo otioso quod locuti fuerint homines, rationem redhibere cogentur, agnosci in promptu est illud periculosius laedere, quod tractatum atque meditatum, anteposita uiuendi legibus loquendi lege, praesumitur. ${ }^{6}$

Ainsi la poésie n'est pas uniquement l'expression d'un loisir agréable, mais avant tout la transmission sérieuse d'un message dont le poète chrétien est responsable devant Dieu et son but est d'instruire son public en le divertissant. C'est en conformité avec cette conception d'une poésie austère et subordonnée à la transmission de la vérité, que les cinq livres du $S H G$ débutent assez abruptement par une série de relatives descriptives donnant immédiatement la portée d'une catéchèse poétique visant à l'instruction du lecteur, en contaminant deux matrices poétiques classiques :

\footnotetext{
Quidquid agit uarios humana in gente labores, unde breuem carpunt mortalia tempora uitam, uel quod polluti uitiantur origine mores, quos aliena premunt priscorum facta parentum, - addatur quamquam nostra de parte reatus -, quod tamen amisso dudum peccatur honore, adscribam tibi, prime pater, qui semine mortis tollis succiduae uitalia germina proli. ${ }^{7}$
}

$\mathrm{Au}$ procédé de l'énumération didactique initiale de Verg. Georg. I.1-5, s'adjoint l'énumération critique de Juv. I.85-86 dont le vers 85 commence par la iunctura quidquid agunt homines imitée par le début du SHG. Selon un procédé caractéristique de cette poésie, l'énumération proémiale se conclut au v. 7 par l'adresse directe à Adam, adscribam tibi, qui se substitue au hinc canere incipiam de Verg. Georg. I.5, Adam étant le protagoniste principal des chants 1-3. Ici donc, point d'invocation à l'Esprit Saint pour remplacer les Muses, comme dans Juvencus (v. 25-27), ou de prière comme dans le Carmen Paschale de Sédulius (v. 23-35), mais au contraire une

6 Alc. Avit. Prol. SHG, p. 202,11-16 (Peiper) : «Mieux vaut pour un clerc poète écrire des vers sans ostentation que sans respect de la foi : il est plus satisfaisant de trébucher sur un pied que dans la voie de la vérité. En effet, commettre un péché n'est pas excusé par la liberté de l'expression. Car, si pour toute parole vaine qu'auront proférée les hommes, ils seront forcés à rendre compte, il faut alors reconnaître qu'il est tout particulièrement dangereux d'oser écrire une telle parole après réflexion et considération et de préférer la loi du langage aux lois de la vie». Ce prologue a été admirablement étudié dans Roberts (1980).

7 «Tout ce qui, dans la race humaine, engendre des tribulations variées, /d'où l'existence humaine tire une vie brève, /ou encore la souillure originelle de nos mœurs corrompues / qu'accablent les fautes de nos premiers parents, qui nous sont étrangères, / - il est vrai que notre propre culpabilité s'y ajoute -, /notre inclination à pécher du fait de la perte déjà ancienne de nos prérogatives,/ tout cela, c'est à toi que je l'imputerai, premier père, toi qui, par la semence de la mort,/ enlèves à ta postérité déchue le germe de la vie». 
amorce poétique polémique pour souligner l'importance du péché originel, et ainsi la portée du message théologique transmis dans la suite du poème.

Les passages cités d'Avit montrent que la tension esthétique entre une poésie dont le sens est trop souvent obscurci par les raffinements de son style et la nécessité de transmettre la vérité n'est pas résolue, malgré les justifications passées de Lactance et plus d'un siècle de poésie chrétienne depuis Juvencus et Sédulius. De plus, en se plaçant sous le jugement de Dieu plutôt que sous celui des hommes lettrés, Avit invite ses lecteurs à une lecture très attentive de son poème. Mon propos est ici de souligner à l'aide de deux exemples parallèles, la description du jardin d'Eden dans le chant 1 et celle du déluge dans le chant 4, que différents niveaux de lecture se croisent, chacun prenant sens par la présence d'un marqueur signifiant voulu par l'auteur pour que son public approfondisse la portée du texte proposé, tant sur le plan littéraire que sur le plan théologique.

Je laisserai de côté les différents sens exégétiques portés par l'intrusion de la voix auctoriale de l'évêque dans son poème ${ }^{8}$ pour me concentrer sur deux niveaux de lectures particuliers : je voudrai montrer comment le récit poétique est porteur d'un discours géographique implicite qui renouvelle la vision du monde transmise par les épopées classiques, et comment, sur le plan esthétique, le poète essaie de concilier la sobriété stylistique qu'il revendique avec les goûts de son public, plus habitué aux raffinements formels d'une poésie virtuose.

\section{Le jardin d'Eden : une topographie nouvelle}

Conformément aux codes poétiques, la description est utilisée par Avit comme ornement de la narration épique ; mais, dans un désir d'amplification rhétorique, il développe longuement deux descriptions antithétiques mises en miroir, le jardin d'Eden (SHG 1,188-298) et le déluge (SHG 4,435-540).

Dans le chant 1 , de mundi initio, le poète a une focalisation anthropologique et non cosmologique puisqu'il insiste avant tout sur la création des êtres humains après avoir brièvement résumé les cinq premiers jours de la création selon Gn 1,1-8. Ensuite, loin de se livrer à une simple transposition poétique de Gn 2,8-15, il déploie toute sa connaissance rhétorique ${ }^{9}$ : il lisse le texte génésiaque en effaçant le problème de la double création de l'homme (Gn 1.27 puis Gn 2.7) pour proposer une séquence simplifiée en cinq étapes développées à partir de Gn 2.7 : 1.) création d'Adam, 2.) domination donnée à Adam sur la création, 3.) création d'Ėve, 4.) union des deux êtres humains, 5.) description du paradis.

C'est après avoir créé Adam et Ėve (et non après la seule création d'Adam comme dans Gn 2.8-16), que Dieu scelle leur union en leur adressant ses commandements

8 Cf. Hecquet-Noti (2009).

9 Sur la technique de recomposition du texte biblique, cf. Roberts (1985). 
puis en leur offrant le monde en dot et le jardin d'Eden en guise de chambre nuptiale (v. 191-192). Conformément à la tradition épithalamique, le poète propose alors une description très détaillée de la demeure des nouveaux mariés. Par cette reconstruction et cette recontextualisation du texte génésiaque, Avit se présente en évêque désireux de diffuser une catéchèse et non en théologien soucieux de l'exégèse du texte biblique comme l'Augustin du De genesi ad litteram, dont l'exégèse est toutefois centrale dans le poème d'Avit.

La longue description du Paradis, inscrite dans la tradition rhétorique de l'ekphrasis topou par son initiale est locus (v. 193), est porteuse d'une lecture - construite par l'utilisation maitrisée d'une rhétorique classique - qui se développe selon trois axes principaux :

1. Tout d'abord, le paradis terrestre est l'aboutissement parfait de l'harmonieuse beauté de la création divine soulignée à maintes reprises par le poète en écho au uidit Deus quod esset bonum du premier chapitre de la Genèse. Placée à la fin du chant 1 , cette hypotypose présente toutes les caractéristiques attendues d'un locus amoenus détaillé selon les préceptes de l'euidentia rhétorique (cf. Quint. Inst. VIII.3.61-71) en symbiose avec l'évocation de la vision d'Ez 28.13 comme le montre en particulier le petit médaillon évoquant les parfums, la brise paradisiaque, les fleurs odorantes, la source cristalline et les gemmes brillant sur les rives de la source (v. 245-257). ${ }^{10}$

2. Ensuite, la beauté du lieu est la réalisation concrète de l'amour que Dieu porte à toute la création, et à l'homme en particulier, comme le souligne Aug. Gen. ad litt. I.8.14. La recontextualisation du texte génésiaque opérée par le poète souligne ainsi l'importance d'une union pure voulue par Dieu et la confiance que le créateur a en sa créature : se crée ainsi, dans l'épopée, une tension poétique entre le décor harmonieux de ce premier chant et la rupture induite ensuite par le récit de la tentation (chant 2) et la désobéissance d'Adam et Ėve (chant 3). Théologiquement, cette insistance sur le lien entre Dieu et les protoplastes s'interprète comme une affirmation de la prééminence de la grâce divine donnée aux hommes et donc implicitement comme une condamnation de la doctrine semipélagienne défendue par Faustus de Riez que combat par ailleurs Avit dans Epist. 1MR (4P). ${ }^{11}$ Elle s'inscrit parfaitement dans le propos premier du poème qui est une forme poétique de catéchèse baptismale prouvant l'importance de la médiation du Christ, ici célébré dans la geste antithétique d’Adam, et de Noé et Moïse.

3. La nécessité de la grâce divine et l'amour infini de Dieu pour sa création sont les points centraux qui expliquent la décision divine de produire un déluge pour anéantir «une race humaine pervertie....après avoir rompu le pacte qui préside à la nature...<qui> est en proie à la folie, ayant repoussé toute raison» (SHG

10 Sur les modèles classiques de cette description, cf. Labarre (2011).

11 Cf. Nodes (1993) 55-73 ; Stella (2001) 129-137. 
IV.32-34). C'est un Dieu en colère devant la déchéance humaine (SHG IV.133142) qui se voit contraint de mettre un terme à une création totalement dépravée, mais son profond amour l'amène pourtant à sauvegarder les germes de cette création initialement bonne en préservant Noé, sa famille et les couples d'animaux dans l'arche.

4. Enfin, la description propose une topographie chrétienne renouvelant la vision du monde héritée des profanes. En effet, organisée selon un plan bien structuré, elle débute par une précision topographique inconnue de la Genèse : non content de situer le paradis à l'Est (v. 193 eoo in axe), suivant en cela le texte des Veteres latinae contre celui de la Vulgate, le poète lui donne une localisation particulière, inconnue des poèmes bibliques précédents (v. 211-217) :

Ergo ubi transmissis mundi caput incipit Indis, quo perhibent terram confinia iungere caelo, lucus inaccessa cunctis mortalibus arce permanet, aeterno conclusus limite postquam decidit expulsus primaeui criminis auctor : atque reis digne felici ab sede reuulsis caelestes haec sancta capit nunc terra ministros. ${ }^{12}$

Par cette localisation précise du jardin d'Eden en continuité des contrées humaines connues, le poète donne une réalité historique au premier séjour d'Adam et Ėve ${ }^{13}$, mais également une réalité au paradis eschatologique puisque ce jardin, devenu inaccessible aux mortels depuis la chute (nunc), sera ouvert aux âmes des justes après leur mort, comme le précise le début du chant 2 (v. 1-35) pour souligner la fusion entre le paradis terrestre et le paradis spirituel. Ce faisant, le poète s'inscrit dans le courant chrétien qui, dès le milieu du siècle, s’intéresse à la géographique du jardin d'Éden et cherche à le situer en relation avec le monde humain. ${ }^{14}$

D'une part incise perhibent laisse entendre que le poète renvoie à une tradition géographique sans doute courante à son époque dans le monde occidental mais dont nous ne conservons pas de trace précise. ${ }^{15}$ On sait, en effet, qu'il existe une importane littérature géographique décrivant le monde à partir du paradis, dont témoignent, vers le milieu du $\mathrm{VI}^{\mathrm{e}}$ siècle, les textes grecs, comme L’itinéraire de l'Eden

12 «Là où commence le monde, par-delà les Indes, là où, dit-on, se rejoignent les confins de la terre et du ciel, sur une hauteur inaccessible à tous les mortels, demeure un bois sacré fermé par une limite éternelle, depuis que l'auteur du premier crime en fut chassé après sa chute ; après la juste expulsion des coupables de ce séjour bienheureux, cette terre bénie accueille maintenant les serviteurs célestes». Pour un commentaire, cf. Morisi (1996) 107-132.

13 Il suit ainsi l'exégèse proposée par Aug. Gen. ad litt. 8,1,1 même si ce dernier admet que le paradis étant maintenant inconnu de l'humanité, il ne peut être localisé précisément, tandis que Ambroise le juge indescriptible car uniquement spirituel (Parad. 1,1).

14 Cf. Alexandre (1988), Delumeau (1997) et Inglebert (2001) 73-98.

$15 \mathrm{Au} \mathrm{v.} \mathrm{111,} \mathrm{la} \mathrm{même} \mathrm{incise} \mathrm{se} \mathrm{faisait} \mathrm{écho} \mathrm{d'une} \mathrm{tradition} \mathrm{physiologique} \mathrm{aristotélicienne} \mathrm{:} \mathrm{cf.}$ Hecquet-Noti (1999) 143 n. 5. 
au pays des Romains et la Topographie chrétienne de Cosmas Indicopleustès, ou latins, comme les Descriptio et Expositio totius mundi et gentium. ${ }^{16}$

D'autre part, Avit semble reprendre ici une tradition cosmographique proposant une terre plate et non sphérique. Ce faisant, il préfère le modèle cosmographique archaïque (biblique), connu en particulier par Lact. Inst. III.24, au modèle sphérique grec présent chez tous les grands exégètes latins. ${ }^{17}$ Ce choix significatif «d'une opposition entre un savoir extérieur faux, car païen, et un savoir chrétien véritable ${ }^{18}$ est en parfaite conformité avec la revendication avitienne de la transmission d'une parole vraie.

En situant ce lucus sur une hauteur (arce), le poète distingue un espace en bas, siège du périssable, et donc du monde des hommes pécheurs, et un espace en haut, siège du paradis. Ici, en écho à Gn 3.24, seuls, des anges défendent cette terra sancta alors que, traditionnellement, un obstacle physique - muraille de feu (Isid. Orig. XIV.3.2) ou océan (Cosmas, Topogr. IV.7-8) - la sépare du monde humain. Or, dans l'évocation du déluge au chant 4, Avit apporte une précision qui laisse supposer que l'océan entourant le monde humain le sépare du jardin. En effet, le point non-retour qui fait du déluge un cataclysme cosmique, et non une terrible tempête humaine, est marqué par la fusion des eaux de l'océan primordial délimitant le monde avec les eaux terrestres (Carm. IV.461-463).

$\mathrm{Au}$ cœur du jardin, se trouve la source donnant naissance aux quatre fleuves paradisiaques énumérés dans un ordre différent de celui de Gn 2.10-14 afin de terminer la description par le Gange indien (v. 290-295). Ces fleuves sont en lien avec le monde humain puisqu'ils coulent dans différentes contrées terrestres : en suivant l'usage traditionnel, Avit identifie le Géon au Nil, donnant ainsi une source connue et réelle à ce grand fleuve, et le Physon au Gange, expliquant ainsi rationnellement la richesse de ces contrées éloignées et mythiques. ${ }^{19}$

Pour terminer sa description par un effet de Ringcomposition, le poète rappelle que l'opulence proverbiale de l'Inde trouve son origine dans la magnificence du jardin d'Eden. S'ensuit un court développement exégétique rappelant que, dans sa vie terrestre qui, depuis la chute, est un exil avant le retour à sa véritable demeure éternelle, l'homme actuel n'a qu'une infime connaissance des richesses paradisiaques qu'il pourra retrouver puisque le Gange charrie dans ses alluvions provenant du jardin d'Eden des rejets paradisiaques que nous regardons comme des richesses incomparables (v. 290.293b-294a.297-298) :

16 Cf. Rougé (1966) et Wolska-Conus (1976).

17 Cf. Inglebert (2001) 40 - 47 : la position d'Augustin sur le sujet est hésitante puisque dans Gen. ad litt. II.20 - 21, il semble accepter le modèle archaïque qu'il refuse par ailleurs.

18 Je cite Inglebert (2001) 50.

19 Cf. Agaësse/Solignac (1972) 500-501. 
Quartus Physon erit, quem possidet India Gangen.

(...) furatur opes et gurgite nostrum

ducit in exilium.(....)

excrementa trahens magnus sic ditia Ganges

hoc etiam donat mundo, quod proicit alueo. ${ }^{20}$

Ce lien fluvial entre le paradis et la terre humaine, déjà souligné par Jérôme $(E p .125,3)$ suppose d'abord un cours souterrain des fleuves pour passer sous l'Océan primordial avant d'émerger sur terre, expliquant ainsi pourquoi certaines sources sont inconnues des hommes. Cette vision est précisément celle qui est proposée par Cosmas Indicopleustès (Topogr. IV.7), comme l'illustre la carte transmise par les manuscrits. ${ }^{21}$

Par la réalité de ce paradis, historiquement perdu pour Adam et Ève, mais spirituellement toujours accessible à l'âme grâce à la médiation du $\mathrm{Christ}^{22}$, le poète suggère à son lecteur une compréhension nouvelle du monde puisque l'universalité du christianisme se substitue à la domination politique de l'imperium Romanum. Les beautés célébrées dans la laus Italiae (Verg. G. II.110-176) sont ici surpassées ${ }^{23}$ et le poème véhicule une vision géographique et cosmologique remplaçant l'antique représentation du monde transmise par l'épopée classique. ${ }^{24}$

L'harmonie immuable du paradis s'oppose à la fragilité du monde de l'humanité pécheresse qui sera anéanti dans le déluge : les contours de ce monde vicié sont marqués par l'énumération des montagnes terrestres connues dans la géographie grécoromaine (SHG IV.516-521a) $)^{25}$ qui disparaitront dans le cataclysme alors que seule émergera la cime d'une montagne nouvelle, inconnue de cette tradition, le mont Arménie (SHG IV.539) sur lequel échouera l'arche de Noé.

20 «Le quatrième <fleuve> sera le Physon qui appartient à l'Inde en tant que Gange.(...) Il dérobe les richesses et les entraîne dans son tourbillon vers cet exil qui est le nôtre (...) Ainsi, le Gange au cours imposant, emportant de riches alluvions, offre aussi au monde ce qu'il rejette de son lit».

21 Cf. Wolska-Conus (1976) t. 1, 545.

22 Cf. Daniélou (1950) 13-20.

23 Cf. Nodes (1993) 125-127.

24 Cf. Hardie (1993) 57-58.

25 Delituit tectus ponto tum piniger Othrys,/ Parnasi uertex cautem non protulit altam,/ ipsa cupressiferi latuerunt saxa Lycaei,/ subductae rupes, aequatae fluctibus, Alpes,/ omnibus exclusis totus iam denique mundus/ axis et unda fuit ("Alors l'Othys planté de pins disparut, caché par la mer ; le sommet du Parnasse ne montra plus sa haute falaise, et même les rochers du Lycaé porteur de cyprès furent dissimulés; les parois des Alpes égalées par les eaux se dérobèrent ; finalement le monde entier fut désormais ciel et eau, tout étant supprimé»). 


\section{Le jardin d’Eden : une praeteritio néoalexandrine}

La description est aussi porteuse d'une lecture métapoétique qui positionne le poète par rapport à l'usage de l'écriture poétique. Conscient des attentes esthétiques d'un public lettré, il s'éloigne parfois de l'austérité stylistique revendiquée dans son prologue pour se rapprocher de l'esthétique néoalexandrine privilégiant le spectaculaire et l'extraordinaire dans un style très travaillé comme l'illustre le petit médaillon des v. 245-257 où le lexique établit un lien entre les éléments naturels du jardin et les bijoux manufacturés pour se terminer par une sententia tout à fait en adéquation avec le Jewelled Style analysé par Roberts : uarios dant arua colores/ et naturali campos diademate pingunt. ${ }^{26}$ D'une manière plus spécifique, le vers introductif de la grande fresque paradisiaque (Est locus eoo mundi seruatus in axe) établit un dialogue particulier entre Avit et Sidoine, chantre de la préciosité néoalexandrine, ${ }^{27}$ qui donne aussi l'Inde comme patrie du Phénix (Carm. II.407-408a : Est locus Oceani, longinquis proximus Indis,/ axe sub Eoo). ${ }^{28}$

Alors qu'il avait fortement affirmé se concentrer sur une écriture sobre et austère, dans cette grande fresque, Avit montre qu'il est tout à fait capable de rivaliser esthétiquement avec les poètes néoalexandrins : je propose d'appeler cette manière de refuser un style tout en montrant, dans des moments bien particuliers et de manière tout à fait ciblée, la capacité de l'adopter, une praeteritio néoalexandrine. Je donnerai deux courts exemples de nature différente de cette pratique :

1. En évoquant les essences odorantes qui naissent dans le paradis et que, grâce aux fleuves, les hommes peuvent connaître, Avit fait une allusion au mythe du (v. 238-250), si emblématique de la poésie néoalexandrine, par une amorce polémique face à la tradition poétique classique :

\footnotetext{
Hic, quae donari mentitur fama Sabaeis, cinnama nascuntur, uiuax quae colligit ales, natali cum fine perit nidoque perusta succedens sibimet quaesita morte resurgit : nec contenta suo tantum semel ordine nasci, longa ueternosi renouatur corporis aetas incensamque leuant exordia crebra senectam. Illic desudans flagrantia balsama ramus perpetuum pingui promit de stipite fluxum. ${ }^{29}$
}

26 «Les guérets offrent des couleurs variées / et peignent les plaines d'un diadème naturel» : cf. Roberts (1989).

27 Cf. Loyen (1943).

28 Cf. Furbetta (2017a) 106-109.

29 SHG I.238-246 : «Ici naît le cinnamon, que mensongèrement la tradition attribue aux habitants de Saba. Ce sont ses branches que rassemble l'oiseau à la longue vie lorsqu'il périt d'une mort qui le fait renaître : consumé sur son nid, il se survit à lui-même et ressuscite après une mort volontaire ; non content de vivre une seule fois selon son destin naturel, son corps alangui par le grand âge se 
L'expression mentitur fama affirme certes la vérité de la parole chrétienne face aux mendacia poetarum, mais elle évoque aussi l'esthétique de la tradition poétique classique en associant les essences rares au Phénix, non nommé mais seulement défini comme uiuax ales, en écho au uiuax Phoenix de Ov. Am. II.6.54 et de Stat. Silv. III.2.114, deux poètes emblématiques du raffinement et de la préciosité néoalexandrine. En outre, dans le contexte épithalamique du passage avitien, l'allusion au Phénix entre aussi en dialogue avec l'épithalame pour Rurique et Hiberia dont Sidoine décrit la chambre nuptiale parfumée par divers essences dont le cinnamon que le Phénix offre aux nouveaux mariés (Carm. XI.125).

Ce médaillon enchâssé est ainsi plus justifié par une prétérition esthétique prouvant la virtuosité dont le poète pourrait faire preuve s'il voulait rivaliser avec la tradition profane que par la volonté de transmettre une catéchèse. En effet, même si la tradition chrétienne s'est emparée de ce mythe pour illustrer le mystère christique, ici, rien ne permet de relier le uiuax ales au Christ mort et ressuscité. ${ }^{30}$ En lisant ces vers au style et au rythme raffinés ${ }^{31}$, le public lettré ne peut manquer de faire le lien avec les évocations poétiques antérieures de l'oiseau, notamment Ovide (Met. XV.392-407) qui fait de l'oiseau l'exemple le plus extraordinaire des mirabilia présentés dans le discours cosmologique de Pythagore. ${ }^{32}$

2. La brève comparaison suivant l'évocation du Phénix a aussi une fonction métapoétique prégnante :

Hic fons perspicuo resplendens gurgite surgit :

talis in argento non fulget gratia, tantam nec crystalla dabunt nitido de frigore lucem. ${ }^{33}$

Si la transparence de l'eau est une topique des évocations de sources idylliques, la comparaison de la brillance de l'eau avec l'argent est un écho au fons argenteus dans lequel se mire Narcisse (Ov. Met. III.407), tout en filant, dans un style travaillé, ${ }^{34}$ le Jewelled Style par la comparaison entre la brillance naturelle de l'eau et celle du métal servant de miroir, et celle du cristal qui est une pierre utilisée en joaillerie (Sen. Q Nat. III.25.12).

régénère et des naissances réitérées soulagent sa vieillesse qui se termine sur un bûcher. Alors, l'arbre qui distille le baume odorant laisse échapper un flot perpétuel de parfum de sa souche grasse. 30 Cf. Clem. Rom. Ad Cor. 1.259 ; Ambr. Hex. V.23 ou Comm. Apol. 139-40.

31 On notera les deux vers spondaïques (v. 238, 250) qui encadrent le médaillon et les uersus aurei 243, 246, ce dernier souligné par l'allitération.

32 Charisius $(4,6)$ cite un poème de Laevius sur l'oiseau ; cf. ensuite, outre Ovide, Lact. Phoen., Claud. Carm. min. 27 (Phoenix).

33 SHG I.251-253 : «Ici, d'une source transparente surgit une étincelante eau : moins vif est l'éclat de l'argent, moins abondante la lumière que reflétera le cristal scintillant de l'eau glacée».

34 Variatio du vocabulaire de l'éclat, structure tactique recherchée des vers, allitération imitant le glougloutement de l'eau surgissant de la source, hyberbate remarquable. 
L'analogie de la source paradisiaque avec le cristal reprend aussi un mirabile dont l'étrangeté fait le succès poétique : les variations épigrammatiques sérielles de Claudien (Carm. min. $33-39)^{35}$ sont la preuve des possibilités poétiques que pouvait offrir cet étrange phénomène naturel qui unit des natures contraires, le liquide et le solide.

La comparaison évoque aussi les jeux épigrammatiques du Symposium duodecim sapientum (Anth. Lat. 495-638). On trouve en particulier, dans les variations de unda et speculo du cycle 3 (Anth. Lat. 519-530), le distique hexamétrique 524 montrant un lusus poétique de même nature portant sur la comparaison entre eau et miroir : ${ }^{36}$

Vnda quieta refert alto de gurgite formas

Ac ueluti speculum nitido splendore coruscat.

S’il n’y a pas de véritable intertextualité entre cette épigramme et notre passage, en revanche, le lien peut être fait à propos du style maniériste caractéristique de ces variations épigrammatiques que Friedrich rapproche justement de la poésie de Claudien et d'Ausone. Ensuite, lorsque, à la fin du chant 4 (v. 625-635), Avit décrit un autre mirabile naturel, l'arc-en-ciel, on retrouve un écho marqué avec les variations proposées dans les tristicha de arcu caeli du cycle 5 (Anth. Lat. 543-554) ${ }^{37}$ en particulier entre SHG IV.627-628 et Anth. Lat. 552.38

Ces rapprochements entre les exercices de style de l'Anthologie et les vers du $S H G$ présentant de petits tableaux descriptifs virtuoses prouvent en tout cas le choix conscient de l'évêque viennois de donner à son style les colores raffinés appréciés de son lectorat, lui-même habitué à la virtuosité de tels exercices littéraires. Le poète fait ici encore une praeteritio, puisqu'il montre, brièvement mais de manière très étudiée, qu'il est tout à fait capable d'écrire avec la virtuosité néoalexandrine que goûte son public.

La delectatio poétique étant nécessairement subordonnée à l'utilitas de la transmission de la vérité chrétienne, l'évocation de ces deux mirabilia que sont le Phénix et le cristal prend aussi sens sur le plan théologique. En prouvant la réalité de phénomènes naturels extraordinaires et unissant des natures contraires, le poète rappelle corporaliter la réalité de la beauté de la nature voulue par Dieu en opposition avec les ficta de la poésie profane, et spiritualiter que ces phénomènes sont un symbole de la double nature du Christ, affirmant par-là la vérité catholique face à l'arianisme. ${ }^{39}$ Toutefois, il me semble que cette fonction n'est pas la justification première de leur insertion dans l'hypotypose qui donne déjà au lecteur ce sens théologique, puisque toute la description est construite sur les caractéristiques

35 Cf. Laurens (2008) 1-25, Harich-Schwarzbauer (2009) 24-27.

36 Cf. Friedrich (2002) 118 pour un commentaire de ces vers.

37 Cf. Friedrich (2002) 137-157, Canellis (2013) 192-195.

38 Cf. Furbetta (2017b).

39 Cf. Nodes (1993). 
étonnantes du jardin paradisiaque qui est la permanence de phénomènes distincts selon les lois de la nature humaine.

\section{Conclusion}

La description du jardin d'Eden devrait être, selon la classification rhétorique antique, une topothesia, c'est-à-dire la description d'un lieu imaginaire, mais, sous le calame d'un évêque chrétien, elle devient topographia, ${ }^{40}$ c'est-à-dire description d'un lieu réel même s'il est maintenant inaccessible. S'il s'agit d'un paysage idyllique très stéréotypé qui reprend tous les éléments topiques du genre, le poète chrétien l'associe à la réalité du monde humain afin de lui donner une matérialité. Il participe ainsi à la transformation chrétienne de la conception du monde : par l'utilisation appropriée des techniques rhétoriques acquises, il propose à son lecteur un savoir nouveau, différent de celui hérité par la tradition classique ${ }^{41}$. Se profile ainsi une vision du monde que la chrétienté médiévale reproduira, en faisant du jardin d'Eden le point d'orientation de toute la cartographie. ${ }^{42}$

Sur le plan esthétique, cette description montre la volonté consciente et pleinement assumée du poète de recourir aux formes élevées d'ornementation rhétorique malgré son choix initial d'une sobriété revendiquée, proposant ainsi une sorte de praeteritio de l'esthétique néoalexandrine. En effet, dans ces grandes fresques que sont le jardin d'Eden au chant 1 ou le déluge au chant 4, il s'appuie non seulement sur une tradition rhétorique pleinement maitrisée, mais, de manière plus particulière, il recherche l'esthétique du spectaculaire et de l'extraordinaire qui, depuis Ovide, est emblématique d'une poésie néoalexandrine se déployant pleinement dans l'antiquité tardive non seulement dans les poèmes de Claudien ou d'Ausone, mais aussi dans ceux de Sidoine Apollinaire, oncle admiré d'Avit.

\footnotetext{
40 Sur la distinction rhétorique entre topothesia et topographia, voir Serv. Aen. I.159 : topothesia est, id est fictus secundum poeticam licentiam locus ; cf. aussi les Schemata dianoeas 11-12 (RLM 73,1-4 Halm).

41 Je reprends l'opposition proposée par Inglebert (2001) 12.

42 Il s'agit des cartes en T-O qui sont orientées en fonction de la localisation du paradis terrestres : cf. Scafi (2006).
} 


\section{Bibliographie}

Agaësse/Solignac (1972): Paul Agaësse/Aimé Solignac, La Genèse au sens littéral (VIII-XII), Bibliothèque augustinienne t. 49 , Paris.

Alexandre (1988): Monique Alexandre, «Entre ciel et terre: les premiers débats sur le site du Paradis (Gen. 2,8-15 et ses réceptions)», in: François Jouan/Bernard Deforge (eds), Peuples et pays mythiques, Paris, 187-224.

Arweiler (1999): Alexander Arweiler, Die Imitation antiker und spätantiker Literatur in der Dichtung "De spiritalis historiae gestis» des Alcimus Avitus: mit einem Kommentar zu Avit. carm. 4,429-540 und 5,526-703, Berlin.

Canellis (2013): Aline Canellis, "La nature dans le Symposium duodecim Sapientum (AL 495-638 R)", in: Florence Garambois/Daniel Vallat (eds), Le lierre et la statue. La nature et son espace littéraire dans l'épigramme gréco-latine tardive, Saint-Etienne, 181-203.

Charlet (2008): Jean-Louis Charlet, «Tendances esthétiques de la poésie latine tardive (325-470)», in: AnTard 16, 159-67.

Daniélou (1950): Jean Daniélou, Sacramentum futuri: études sur les origines de la typologie biblique, Paris.

Delumeau (1997): Jean Delumeau, Une histoire du paradis, tome 1: Le jardin des délices, Paris.

Friedrich (2002): Anne Friedrich, Das Symposium der XII sapientes. Kommentar und Verfasserfrage, Berlin/New York.

Furbetta (2017a): Luciana Furbetta, «Da Lucrezio a Sidonio Apollinare. Esempi di intertestualità nei versi di Avito di Vienne», in: Lucio Cristante/Vanni Veronesi (eds), Il Calamo della memoria VII, Trieste, 85-146.

Furbetta (2017b): Luciana Furbetta, «L'arcobaleno in Alcimo Ecdicio Avito De spiritalis historiae gestis, carm. 4,621-635», in: Koinonia 41, 545-577.

Harich-Schwarzbauer (2009): Henriette Harich-Schwarzbauer, «Prodigiosa silex. Serielle Lektüre der Carmina minora Claudians», in: Henriette Harich-Schwarzbauer/Petra Schierl (eds), Lateinische Poesie der Spätantike, Basel, 11-31.

Hardie (1993): Philip Hardie, The Epic Successors of Virgil: a Study in the Dynamics of a Tradition, Cambridge.

Hecquet-Noti (1999): Nicole Hecquet-Noti, Avit de Vienne, Histoire spirituelle: t. 1, SC 444, Paris. Hecquet-Noti (2005): Nicole Hecquet-Noti, Avit de Vienne, Histoire spirituelle: t. 2, SC 492, Paris. Hecquet-Noti (2009): Nicole Hecquet-Noti, «Entre exégèse et épopée: Présence auctoriale dans Juvencus, Sédulius et Avit de Vienne», in: Henriette Harich-Schwarzbauer/Petra Schierl (eds.), Lateinische Poesie der Spätantike, Basel, 197-215.

Hecquet-Noti (2011): Nicole Hecquet-Noti, Avit de Vienne, Éloge consolatoire de la chasteté (sur la virginité), SC 546, Paris.

Inglebert (2001): Hervé Inglebert, Interpretatio Christiana: les mutations des savoirs (cosmographie, géographie, ethnographie, histoire) dans l'Antiquité chrétienne (30-630 après J.-C.), Turnhout.

Labarre (2011): Sylvie Labarre, «Âge d'or, Orient rêvé ou Terre promise : le Paradis de Dracontius et d'Avit», in: Anne Gimbert (ed.), Le paysage ou les reliefs du texte, Paris, 9-20.

Laurens (2008): Pierre Laurens, La dernière muse latine: douze lectures poétiques, de Claudien à la génération baroque, Paris.

Loyen (1943): André Loyen, Sidoine Apollinaire et l'esprit précieux en Gaule aux derniers jours de l'Empire, Paris.

Malaspina/Reydellet (2016): Elena Malaspina et Marc Reydellet, Avit de Vienne. Lettres, Paris.

Morisi (1996): Luca Morisi, Alcimi Auiti De mundi initio. Introduzione, testo, traduzione e commento, Bologna. 
Nodes (1993): Daniel Nodes, Doctrine and Exegesis in Biblical Latin Poetry, Leeds.

Peiper (1961): Rudolf Peiper, Alcimi Ecdicii Aviti Viennensis episcopi opera quae supersunt. $M G H$ $A A$ 6,2, Berlin, réimpression de l'édition de 1883.

Roberts (1980): Michael Roberts, «The prologue to Avitus' De spiritalis historiae gestis. Christian Poetry and Poetic License», in: Traditio 36, 399-407.

Roberts (1985): Michael Roberts, Biblical Epic and Rhetorical Paraphrase in Late Antiquity, Liverpool.

Roberts (1989): Michael Roberts, The Jeweled Style. Poetry and Poetics in Late Antiquity, Ithaca, NY.

Rougé (1966): Jean Rougé, Expositio totius mundi et gentium, SC 124, Paris.

Scafi (2006): Alessandro Scafi, Mapping Paradise: a History of Heaven on Earth London.

Stella (2001): Francesco Stella, Poesia e teologia. 1, L'Occidente latino tra IV e VIII secolo Milano. Wolska-Conus (1976): Wanda Wolska-Conus, Cosmas Indicopleustès, Topographie chrétienne, 3 vol., SC 141,159,197, Paris. 



\section{La réécriture des récits bibliques de guérison chez les poètes latins $\mathrm{du} \mathrm{IV}^{\mathrm{e}}$ au $\mathrm{VI}^{\mathrm{e}}$ siècle}

L'inspiration biblique est très présente dans la poésie latine chrétienne des $\mathrm{IV}^{\mathrm{e}}-\mathrm{VI}^{\mathrm{e}}$ siècles ${ }^{1}$. Que le poète se fasse nouveau psalmiste ou qu'il puise dans les eaux du Jourdain son inspiration ${ }^{2}$, afin de promouvoir et défendre la foi, faire connaître les Écritures ou louer Dieu, les textes bibliques sont maintes fois récrits et interprétés selon des modalités et des finalités variées, à destination de lecteurs ou de milieux culturels différents.

Les Évangiles ou les Actes des Apôtres traitent d'une manière sobre les miracles opérés par le Christ ou ses disciples, car ils ont été écrits dans un contexte et à une époque où les faits prodigieux semblaient familiers, qu'ils soient attribués à des démons, des mages ou des divinités païennes ${ }^{3}$.

Quand les poètes chrétiens transposent ces récits, ce n'est plus la même discrétion qui est de mise. Ils doivent répondre aux attentes d'un public lettré séduit par les attraits de la littérature païenne. Ils assurent une médiation, afin de «vulgariser» l'interprétation scripturaire, les spéculations théologiques ou les commentaires doctrinaux au-delà des milieux ecclésiastiques ou des écoles catéchétiques. La création poétique est aussi un moyen de méditer et d'actualiser le message de l'Évangile et de rendre grâces à Dieu.

Dans une première partie, je procéderai à un inventaire des différentes formes poétiques qui traitent des miracles de guérison du Christ ou de ses disciples, en ayant soin d'éclairer le contexte qui a vu naître ces œuvres et les intentions qui ont présidé à leur composition. J'irai des formes les plus développées, comme les épopées, aux formes les plus resserrées, comme les épigrammes, de la réécriture la plus littérale à l'interprétation la plus synthétique et la plus stylisée.

Dans une deuxième partie, j'aborderai ce qui relève d'un discours exégétique dans ces réécritures poétiques, en insistant sur deux thématiques principales : la nature divine du Christ et la symbolique baptismale.

Dans une troisième partie, j'étudierai les différentes modalités de la réécriture poétique, là encore en allant des épopées bibliques aux formes les plus brèves, pour finalement me concentrer sur une forme de stylisation qui n'est pas sans rappeler les arts figurés.

1 Charlet (1985) 613-643.

2 Prud. Cath. IX.1-4; Juvencus, Euang. praef. 1-27.

3 Doré (2010) 559-579.

https://doi.org/10.1515/9783110687224-005 


\section{Diversité des formes poétiques}

Le corpus latin des réécritures de guérison relève de genres poétiques variés et d'intentions diverses.

\section{A Les épopées bibliques}

Les épopées bibliques latines ${ }^{4}$ naissent de la rencontre entre l'héritage culturel antique, dont l'Énéide est le fleuron, et les Écritures, dont le style, si l'on excepte les livres poétiques comme les Psaumes ou le livre de Job, semble bien pauvre aux yeux de ceux qui ont été formés dans les écoles des rhéteurs.

Sous le règne de Constantin, une fois établie la paix de l'Église, le prêtre espagnol Juvencus entreprend de paraphraser en hexamètres dactyliques l'Évangile en quatre livres. Il veut raconter «la geste vivifiante du Christ» (Praef. 19 : Christi uitalia gesta) et se livre à la paraphrase la plus littérale, comme l'a noté Jérôme, dans son $D e$ uiris illustribus : «traduisant les Évangiles en vers hexamètres, presque mot à $\operatorname{mot}^{5}$ ». Il suit majoritairement l'Évangile de Matthieu, dont il reprend tous les récits de miracles sans en changer l'ordre ${ }^{6}$. Toutefois il omet les deux aveugles de Jéricho, qui pourraient faire doublon avec le miracle rapporté par Mt 9.27-31, déjà traité en II.408 - 416, et ajoute la guérison du fils du fonctionnaire royal en II.328-346 tiré de Jn 4.46-54 et le démoniaque gérasénien selon Mc 5.1-17.

Dans la première moitié $d u V^{e}$ siècle, Sédulius, seul poète à embrasser l'ensemble de l'histoire sainte, Ancien et Nouveau Testament, en cinq livres, accorde une large part aux miracles, dans son Carmen paschale, spécialement dans les livres 3 et $4^{7}$. Sa composition en médaillons met en valeur la succession rapide des miracles du Christ sous forme de vignettes expressives, sans véritable commentaire, liées entre elles souvent par un simple inde ou interea. Il rapporte ainsi des miracles tirés de Matthieu, mais aussi de Luc et de Jean. Sa réécriture vise davantage la méditation spirituelle, l'interprétation morale et la contemplation du mystère pascal qu'un commentaire exégétique auquel il se livre plus largement dans son Opus Paschale, rédigé en prose.

À la fin $\mathrm{du} \mathrm{V}^{\mathrm{e}}$ siècle, quand Dracontius compose, dans l'Afrique vandale, ses Louanges de Dieu, en trois chants, sous le coup d'une incarcération dont l'issue est incertaine, c'est pour célébrer la miséricorde divine. Si la réécriture poétique de l'hexameron au chant 1 place l'œuvre dans la continuité des épopées bibliques, la composition des livres 2 et 3 est plus disparate et le ton plus varié : exposé didactique

\footnotetext{
4 Deproost (1997) 14-39.

5 Hier. uir. ill. 84 : «Iuuencus... euangelia hexametris uersibus paene ad uerbum transferens.»

6 Green (2006) 28-29.

7 Green (2006) 180-181.
} 
et louange alternent ${ }^{8}$. C'est ainsi qu'au chant 2, vers 111 à 153, après une défense du dogme trinitaire et une condamnation de l'hérésie arienne, l'exposé des miracles de Jésus et de ses disciples précède un hymne à la toute-puissance de Dieu. Le poète retient sept miracles, dont trois guérisons :1) aveugle-né, 2) paralytique, 3) Lazare, 4) hémorroïsse, 5) marche sur l'eau, 6) noces de Cana, 7) multiplication des pains et des poissons. Le récit de miracle illustre le dogme et introduit une louange.

Arator, dont Ennode, futur évêque de Pavie, a assuré la formation littéraire ${ }^{9}$, d'abord haut fonctionnaire, puis sous-diacre de l'Église romaine, offre au pape Vigile une Histoire apostolique, en deux livres, l'un centré sur Pierre, l'autre sur Paul ${ }^{10}$. Il en donne une lecture publique en quatre séances dans la basilique Saint-Pierre-auxLiens, en avril-mai 544. En un sens, il complète l'œuvre de Juvencus, mais en fait il transforme profondément l'épopée biblique en l'infléchissant vers une paraphrase exégétique qui lui vaut un immense succès au Moyen Âge. Il suit la trame des Actes des Apôtres, tout en réduisant le plus possible le texte scripturaire, afin de composer une Historia narrative assortie d'un commentaire dont la forme est tantôt celle d'un traité, tantôt celle d'un sermon. Il récrit trois épisodes de guérison : Pierre guérit un boiteux qui mendie à la porte du Temple appelée la Belle Porte (I.244-292 = Ac 3.1-11), puis un paralytique nommé Énée à Lydda (I.754-800 = Ac 9.32-35 $\left.{ }^{11}\right)$, enfin Paul guérit un boiteux à Lystres (II.156-241 = Ac 14.6-18).

\section{B La poésie apologétique et didactique}

La réécriture du miracle de guérison a aussi sa place dans la poésie didactique et apologétique. Commodien, un ancien païen converti au christianisme, au milieu du III $^{\mathrm{e}}$ siècle, présente dans son Carmen apologeticum, appelé aussi de duobus populis, en hexamètres dactyliques, un exposé de l'histoire du salut et de la doctrine chrétienne, pour convertir Juifs ou païens et instruire les croyants ${ }^{12}$. Les miracles du Christ y occupent les vers 639 à 660. On trouve successivement : la marche sur l'eau, la résurrection de Lazare, la guérison de la fille de Jaïre, chef de la synagogue (Mc 5.21-43), celle d'une portée très générale d'un sourd et d'un muet (Mt 9.32 ; Mc 7.32 ; Lc 11.14), de l'aveugle né (Jn 9.1), du paralytique depuis 38 ans (Jn 5.5), de l'hémorroïsse (Mt 9.20 ; Mc 5.25 ; Lc 8.43), la multiplication des pains et les noces de Cana (Jn 2.1).

Autour de 400, le poème didactique du poète Prudence, intitulé Apotheosis, c'est-à-dire la «divinisation » à laquelle sont appelés les chrétiens, s'abstient de tout

\footnotetext{
8 Labarre (2015) 229-242.

9 Zarini (2009).

10 Bureau-Deproost (2017). Sur la question du titre, voir p. XXIV-XXV.

11 Ac 9,34 : «Énée, Jésus Christ te guérit. Lève-toi et fais toi-même ton lit !» (Traduction Ecuménique de la Bible, désormais TOB).

12 Martin (1960) ; Salvatore (1977) ; Salvadore (2011).
} 
exposé théorique ou abstrait et préfère tirer des miracles évangéliques la preuve de la divinité du Christ, afin de réfuter ceux qui la nient ${ }^{13}$. Entre les vers 608 à 781, après une évocation de la tempête apaisée et de la marche sur l'eau, il récrit la guérison de l'aveugle-né (v. 672-703), avant de passer à la multiplication des pains et la résurrection de Lazare.

\section{La poésie lyrique et épigrammatique}

La poésie lyrique célèbre elle aussi les miracles du Christ. Dans le Cathemerinon IX, hymne narratif intitulé «hymne de toute heure», Prudence annonce : «Esclave, donne-moi ma lyre, afin que je chante en trochées pleins de foi, un poème doux et mélodieux : les actes sublimes du Christ !». Sur les trente-huit tercets de tétramètres trochaïques, un mètre à tonalité militaire, les guérisons occupent les vers 34-39 (le lépreux, puis un aveugle), 40-42 (l’hémorroïsse), 55-57 (le possédé gérasénien) et 64-69 (un sourd, un muet, un paralytique) ${ }^{14}$.

C'est un autre choix que fait Sédulius, pour son hymne $A$ solis ortus cardine, composé de 23 quatrains de dimètres iambiques, formant un acrostiche alphabétique, encore en usage dans la liturgie. Il a sélectionné et résumé des miracles des Évangiles, sans respecter leur ordre chronologique, ni suivre celui de Juvencus ou de Prudence dans le Cathemerinon IX. Les noces de Cana (v. 49-52 = Jn 2.1-11), le serviteur malade du centurion (v. 53-56 = Mt 8.5-8; Lc 7.1-10), puis la marche de Pierre sur l'eau (v. 57-60 = Mt 14.22-23) et la résurrection de Lazare (v. 61-64 = Jn 11.1-44) précédent la guérison de l'hémorroïsse (v. 65-68 = Mt 9.20-22 ; Mc 5.25-34; Lc 8.43-48) et celle du paralytique (v. 69-72 = Mt 9.1-8 ou Jn 5).

La forme de l'hymne, plus synthétique que l'épopée, se prête aux regroupements de miracles. Comme déjà Commodien (Carmen Apologeticum 649-650), Prudence (Cath. 9.69) et Sédulius (Hymne 2.69-72) opèrent une synthèse entre les deux paralytiques des Évangiles, celui de Jean (chapitre 5) et celui des trois synoptiques. Le contexte s'efface, les protagonistes perdent leurs signes distinctifs. La péricope est fortement stylisée.

Cette tendance s'accentue encore avec les épigrammes narratives qui composent le Dittochaeon de Prudence, la «double nourriture» ou le «double véhicule (de la pensée)», quarante-huit quatrains hexamétriques, consacrés en nombre égal à des péricopes de l'Ancien, puis du Nouveau Testament, comme pour constituer les légendes de peintures ou de mosaïques ${ }^{15}$. Deux strophes seulement correspondent à

13 Fabian (1988).

14 Charlet (1982) 38-39, $110-119$.

15 Charlet (1985) 636 : «Cette série d'épigrammes narratives constitue une espèce d'anthologie de la Bible (peut-être d'intention simplement didactique ?). Elle crée en tout cas une forme nouvelle de paraphrase poétique du texte sacré»; Quacquarelli (1986) 166-171, ici 168 : «una particolare parafrasi biblica a carattere popolare»; Stella (2001) 78-79 : «la tipologia epigrafica : il Dittochaeon». 
des guérisons : la strophe 33 évoque l'aveugle-né et la piscine Siloé (Jean 9), la strophe 45, le boiteux de la Belle-Porte (Ac 3).

$\mathrm{Au}$ contraire, deux autres cycles, qui pourraient avoir constitué les légendes d'une iconographie, offrent une bien plus grande place aux miracles de guérison. Ce sont d'abord les Miracula Christi du Pseudo-Claudien ${ }^{16}$ et les Tristicha de Rusticus Helpidius. Les premiers pourraient avoir été écrits à partir du milieu du $\mathrm{V}^{\mathrm{e}}$ siècle. La critique a quasi unanimement réfuté l'attribution à Claudien, mais souligné les parallèles avec Sédulius ${ }^{17}$. En neuf distiques élégiaques sont évoqués l'Annonciation et la conception du Christ, les cadeaux des Mages (Mt 2.1-12), les noces de Cana, la multiplication des pains et des poissons. Suivent alors l'aveugle-né (v. 9-10 ; Jn 9.1-41), puis la résurrection de Lazare, l'hémorroïsse (v. 15-16) et le paralytique (v. 17-18), que l'on reconnaît comme celui de Jn 5, en raison de l'indication de la durée post multos annos, puisque le texte biblique précise qu'il était infirme depuis trente-huit ans. Le poète suit l'ordre déjà observé dans l'hymne $A$ solis ortus cardine pour ces trois derniers miracles.

Le second cycle est formé de vingt-quatre Tristicha, des tercets de trois hexamètres, probablement composés dans la seconde moitié du $\mathrm{V}^{\mathrm{e}}$ siècle par Rusticus Helpidius $^{18}$. Anita Di Stefano présente les différentes identifications de l'auteur qui ont été proposées par les savants, mais laisse la question ouverte, car aucune n'est totalement convaincante. Ce cycle rappelle les vingt-et-un distiques hexamétriques De Vetere Nouoque Testamento attribués à Ambroise ${ }^{19}$. Mais l'organisation en est très différente : les seize premiers Tristiques de Rusticus Helpidius, regroupés deux à deux, selon un principe typologique, présentent huit parallèles entre des scènes de l'Ancien Testament et des scènes du Nouveau ${ }^{20}$. Viennent ensuite huit strophes purement néo-testamentaires, dont certaines évoquent des guérisons : Marthe et Marie (Lc 10.38-42), la guérison du serviteur du centurion (Mt 8.5-8), les noces de Cana (Jn 2.1-11), la femme guérie par le Christ le jour du Sabbat (Lc 13.10 -13) ou la bellemère de Pierre ${ }^{21}$ (Mt 8.14-15), l'hémorroïsse (Mt 9.20 - 22 ; Mc 5.25-34; Lc 8.43-48), la guérison du fils de la veuve (Lc 7.11-15), le salut de Zachée (Lc 19.1-16), enfin la résurrection de Lazare (Jn 11.1-44).

Les miracles retenus ne sont donc pas toujours les mêmes et leur ordre varie. Mais l'hémorroïsse, l'aveugle-né et le paralytique ont la palme et la fréquence de

16 App. 14 Charlet; Carm. min. app. 21 Hall ; Anthologie latine 879 Riese.

17 Springer (1988) 121-127.

18 Di Stefano (2013) : sur les différentes hypothèses d'identification de l'auteur, voir p. 18-33 ; Pietri (1995) : d'après elle, Rusticus Helpidius pourrait être un questeur de l'empereur à Ravenne ; Pietri (1988).

19 Lubian (2017).

20 Par exemple Ėve séduite par le serpent associée à l'Annonciation, la Tour de Babel à la Pentecôte, le sacrifice d'Abraham à la crucifixion de Jésus...

21 Di Stefano (2013) 118 : D.H. Groen (1942) p. 99 et F. Corsaro (1955) p. 150 et 161 rattachent ce tercet à la guérison de la belle-mère de Pierre (Mt 8.14-15). Mais A. Di Stefano rapproche curuarant de erat inclinata et longinqua de annis decem et octo en Lc 13.10-13. 
leurs figures se vérifie aussi dans les peintures des catacombes, sur les sarcophages ou les diptyques de la même période ${ }^{22}$.

L'importance des miracles dans les différentes formes poétiques entre les IV et $\mathrm{VI}^{\mathrm{e}}$ siècles contraste avec la sobriété et la relative discrétion des récits évangéliques. Le miracle devient alors un élément essentiel de la propagande chrétienne.

\section{Les enjeux exégétiques et théologiques des réécritures de guérison}

\section{A Le débat christologique}

Les réécritures de guérison prennent sens dans le contexte du débat christologique des $\mathrm{IV}^{\mathrm{e}}$ et $\mathrm{V}^{\mathrm{e}}$ siècles. Elles défendent et illustrent la double nature du Christ, à la fois homme et Dieu, telle qu'elle a été définie au concile de Nicée.

Sous le règne de Constantin, l'auteur anonyme des Laudes Domini insiste sur la fonction du miracle, en une louange adressée au Christ : «afin que l'origine divine (missa Deo penitus praecepta) de tes préceptes soit tout à fait manifeste, tu ôtes à la mort son empire, tu ordonnes que ceux que tu délivres de la maladie assument les fonctions de la vie dont ils désespéraient, tu rends aux aveugles la lumière du jour » (v. $112-115)^{23}$.

Dans l'Apotheosis, aux vers 672-674, dont l'intention apologétique est claire, Prudence veut persuader quiconque douterait : «Pourquoi rappellerais-je les divers faits illustres (facta inclyta) du Christ-Dieu ? En examinant de plus près leur grandeur (inspecta maiestate), toi qui ne doutes pas de sa nature humaine (haud dubitans hominem), mais nies sa divinité (negator), tu avoueras toi-même qu'ils sont l'œuvre d'un Dieu (tute ipse fatebere numen)». Cependant les termes employés ne sont pas les termes techniques du débat christologique, mais bien plutôt le vocabulaire du merveilleux et de l'éloge.

Les Miracula Christi du pseudo-Claudien, au vers 6, sont plus précis : le miracle de Cana est reconnu comme la première preuve de la nature divine du Christ : Quo primum facto se probat esse Deum. Cette formulation donne une signification plus théologique à Jn 2, 11 qui y voyait simplement : «le commencement des signes de Jésus ${ }^{24} »$.

22 Dulaey (2006) 321-327 ; Dulaey (2007a) 127-131 ; Dulaey (2007b) 83, 87, 101, 107, 125, 143, 147, 151 ; Bisconti (2000).

23 Van der Weijden (1967) ; Salzano (2001). Laudes Domini v. 112-115 : «Atque ut missa Deo penitus praecepta paterent/Imperium <tu $>$ morti adimis morboque solutos/ Desperata iubes apprendere munia uitae/ Restituisque diem caecis...»

24 In 2.11 : «Tel fut, à Cana de Galilée, le commencement des signes de Jésus. Il manifesta sa gloire, et ses disciples crurent en lui.» (TOB) 
Les poètes se font l'écho de la position doctrinale défendue par les Pères, pour qui les guérisons montrent que le Christ est «ce Fils autrefois annoncé par Dieu, et né pour le salut de tous, ce Verbe de Dieu, éternel, premier-né, accompagné de sa puissance et de son intelligence, ayant pour support son esprit», selon les mots employés par Tertullien ${ }^{25}$. Au début du livre 1 du Carmen paschale, Sédulius affirme solennellement l'égalité du Père et du Fils qui ont «semblable éclat, commune grandeur, pareille sublimité, honneur égal, même puissance» (I.14-19/30-35) ${ }^{26}$. Dans son commentaire Sur Matthieu, Hilaire de Poitiers explique justement la guérison du paralytique par la communauté de substance entre le Fils et le Père ${ }^{27}$.

La nature humaine du Christ est également affirmée. Sédulius, en III.273 ne manque pas de rappeler qu'il possède aussi un «corps d'homme ${ }^{28}$ ». Dans les vers 950 -967 de l'Apotheosis, Prudence réfute les tenants du docétisme qui prétendaient qu'il n'avait pas de corps véritable et qu'il était un fantôme, en montrant que le Fils de Dieu prouve son pouvoir sur les corps, en accomplissant des guérisons ${ }^{29}$ : «c'est le Fils de l'homme qui peut chasser les fléaux du corps», et il prend précisément alors l'exemple du paralytique.

De tous les poètes cités, c'est Arator qui pousse le plus loin le commentaire exégétique, en faisant la synthèse des tendances allégorisantes traditionnelles ${ }^{30}$. Il entend montrer que les miracles de guérison témoignent de la relation privilégiée qui unit les Apôtres au divin. Il en dégage d'abord le sens littéral, avant de passer à une exégèse symbolique ${ }^{31}$. Le boiteux, qui mendie à l'entrée du Temple, représente l'ancien Israël qui erre, regrettant l'Égypte et recherchant ses idoles, avant d'atteindre la Belle Porte qui est le Christ (I.261-292). Les guérisons accomplies par Pierre dans le livre 1 d'Arator montrent que la Nouvelle Alliance l'emporte en efficacité salvatrice sur l'ancienne Loi de Moïse ${ }^{32}$, que l'apôtre agit au nom du Christ, que l'Église catholique romaine, représentée par Pierre, est dépositaire de ce pouvoir de guérison ${ }^{33}$.

Les manifestations de la puissance divine, matière privilégiée de la poésie antique, sont un sujet fécond pour les poètes qui trouvent là l'occasion de rivaliser avec

25 Tert. Apol. 21.17, trad. Waltzing.

26 Sed. carm. I.30 - 35 (éd. Huemer) : «cui iure perenni/Arcibus aetheriis una est cum patre potestas,/Par splendor, communis apex, sociale cacumen,/Aequus honor, uirtus eadem, sine tempore regnum,/Semper principium, sceptrum iuge, gloria consors,/Maiestas similis.»

27 Hilar. Mat. VIII.8 (SC 254, p. 202, 12-13) : «Au Christ seul, il appartient de faire ce miracle en raison de sa communauté de substance avec le Père».

28 Sed. carm. III.273 : «Nec tamen humano quamuis in corpore Christum».

29 Dulaey (2006) 290 n. 15 ; Brox (1984).

30 Bureau (1997) 287-339; Bureau-Deproost (2017) LXIV-LXV.

31 Arat. Act. I.261-262 : «Stat facti manifesta fides. Sed et altera nobis /res aperit quod causa gerit»; 1,771-772 : «Eloquar hic sacrae quae sint arcana figurae / Si mihi corda mouet, cuius uox corpora reddit».

32 Arat. Act. I.797 : «la Grâce a surpassé la Loi».

33 Bureau (1997) 332. 
les païens, en leur empruntant nombre de formules poétiques propres à exprimer le merveilleux chrétien. La nature humaine du Christ les inspire incontestablement beaucoup moins.

\section{B La symbolique baptismale}

L'interprétation des guérisons en fonction d'une symbolique baptismale est très fréquente chez les poètes. Si les Pères ont plutôt interprété la guérison du paralytique de Capharnaüm (Mt 9) comme une figure de résurrection et celle de Bethesda (Jn 5) comme une figure baptismale $e^{34}$, les poètes ont souvent fusionné les deux figures, ils ont aussi parfois confondu la piscine Siloé de l'aveugle-né avec celle du paralytique et rattaché de manière générale tout élément liquide à l'eau du baptême par le jeu de l'allégorie et des images poétiques.

Prudence, dans sa réécriture de la péricope de l'aveugle-né (Jn 9.1-7), aux vers v. 672-703 de l'Apotheosis, établit un laborieux parallèle entre l'aveugle guéri par la salive de Jésus, puis par l'eau de la fontaine Siloé de Jn 9.7, qu'il confond avec la source de Bethesda, qui elle se déverse par intermittence ${ }^{35}$, et l'homme aveuglé par le péché originel guéri d'abord par le souffle sorti de la bouche de Dieu, sous la forme de l'Esprit Saint qui a fécondé la Vierge Marie, ensuite par les eaux du baptême.

La guérison de la belle-mère de Pierre, délivrée de la fièvre en Mt 8.14-15 ${ }^{36}$, est interprétée par Sédulius comme une figure baptismale en III.33-39 : «Mais, après que la main du Seigneur eut touché son corps alangui, /l'ardeur du feu s'en alla, et, s'éteignant dans tous ses tissus, /la violence de la flamme céda devant cette source d'eau discrète» (trad. Bureau). La fièvre représente le feu de l'enfer et de la damnation, dont le baptême libère le chrétien.

L'interprétation baptismale des Miracula Christi a été soigneusement discutée et nuancée par F. Lubian ${ }^{37}$. En revanche, Arator se livre de manière évidente à un commentaire baptismal de la guérison du paralytique nommé Énée à Lydda (I.754800). Il confond la piscine Siloé avec la piscine Bethesda qu'il voit comme un symbole du peuple juif, selon une interprétation d'Augustin, les cinq portiques représentant la Loi Juive ${ }^{38}$ : «après que le Christ en s'affranchissant du sabbat, l'eut poussé vers la source, la Grâce a supplanté la Loi» (v. 796-797).

34 Dulaey (2006) 326.

35 Iren. Contre les hérésies IV.19 ; Prud. Ditt. (Piscina Siloa) 130 ; Arat. Act. I.788.

36 Mt 8.14-15: «Comme Jésus entrait dans la maison de Pierre, il vit sa belle-mère couchée, et avec de la fièvre. Il lui toucha la main, et la fièvre la quitta ; elle se leva et se mit à le servir» (TOB) 37 Lubian (2016) 96.

38 Hillier (1993) 122-138. Pour la confusion, voir Dulaey (2006) 314, et l'interprétation de la piscine Bethesda par Augustin comme symbole du peuple juif (Aug. Sur Jean 17,2, BA 71, p. 76). 


\section{Une lecture allégorique}

L'interprétation allégorique qui fait correspondre à la vue recouvrée la lumière du salut est privilégiée dans les guérisons d'aveugles, par exemple chez Prudence (Cath. IX.34-36) : «Des yeux étaient désormais ensevelis sous des ténèbres éternelles, tu les enduis d'une boue salutaire et du nectar de ta bouche sacrée ; bientôt, grâce à ce remède, la lumière arrive par ces orbites qui s'ouvrent». Vue, lumière et salut sont indissociables. Quand Sédulius récrit l'épisode des deux aveugles de Mt 9.27-30 dans le Carmen Paschale en III.148-151, il fait de la lampe à huile (lucerna) une métaphore du regard qui désormais illumine leur visage. La traduction littérale donnerait : «leurs visages renouvelés rayonnèrent de leurs propres lampes ${ }^{39}$ ». En l'abbaye Saint-Victor de Marseille, le sarcophage de la Traditio legis, qui rappelle le don de la Loi à Pierre en présence de Paul et qui date du milieu du $\mathrm{V}^{\mathrm{e}}$ siècle, opère le même glissement de la guérison de l'aveugle représentée sur la grande face, à la célébration de la lumière, figurée sur le petit côté de la cuve sous la forme d'une lampe à huile suspendue entre deux rideaux qui s'entrouvrent (Fig. 1 et Fig. 2).

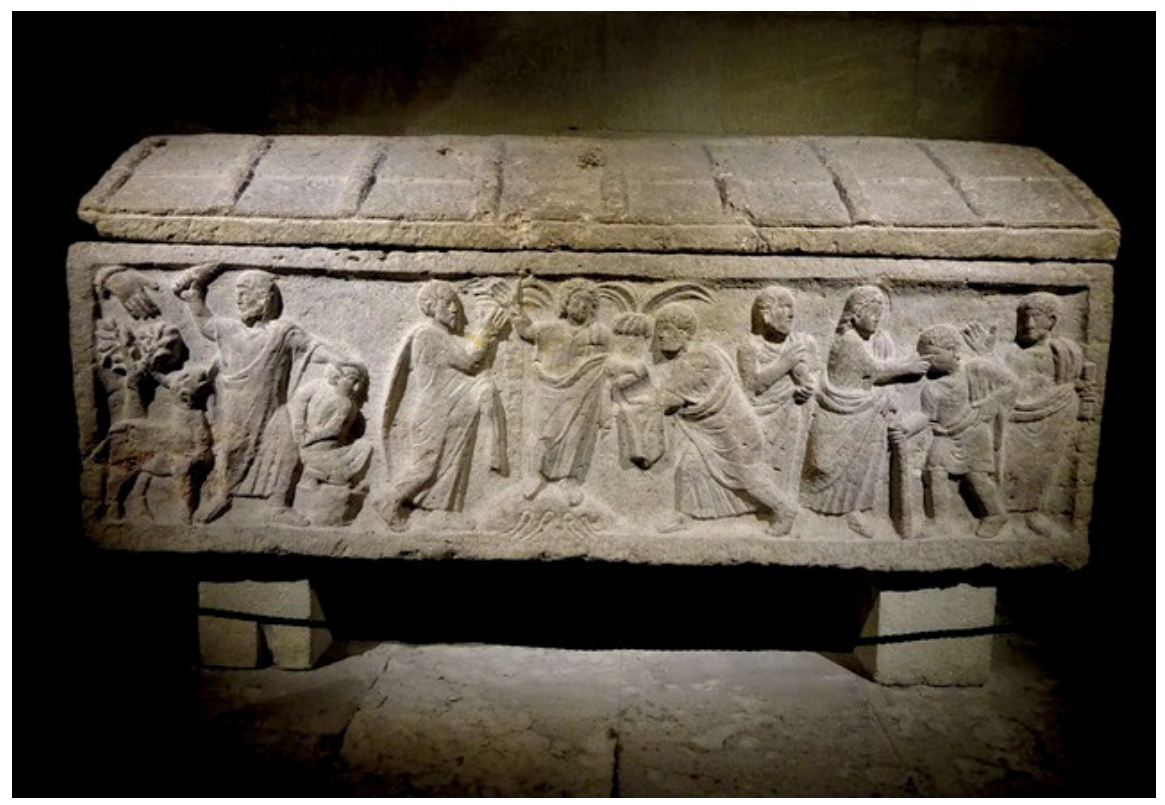

Fig. 1 : sarcophage de la Traditio legis, abbaye Saint-Victor de Marseille

39 Sed. carm. III.148-151 : «tunc caeca precantum/ Lumina defuso ceu torpens ignis oliuo/Sub Domini micuere manu, tactuque sereno/Instaurata suis radiarunt ora lucernis.». 


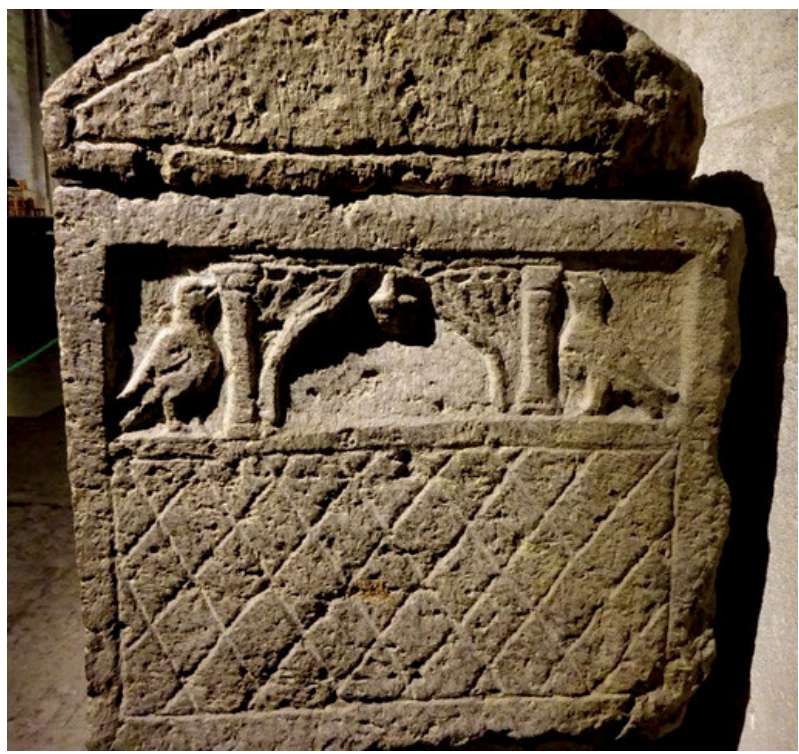

Fig. 2 : sarcophage de la Traditio legis, abbaye Saint-Victor de Marseille

La guérison est une nouvelle naissance, une figure de la résurrection. Quand Sédulius évoque le paralytique comme presque déjà mort ${ }^{40}$, l'interprétation baptismale et l'interprétation funéraire sont étroitement liées ${ }^{41}$. D'ailleurs Damase, lorsqu'il rédige son épitaphe, fonde sa foi en sa propre résurrection, sur les miracles du Christ $^{42}$ : «celui qui de ses pas foula les flots amers...au-delà de ses cendres, fera lever Damase : je le crois», selon une argumentation déjà présente dans les Constitutions apostoliques ${ }^{43}$.

Les poètes laissent donc aux exégètes les débats de spécialistes pour traduire sur le plan littéraire et esthétique les thèmes majeurs de l'initiation chrétienne.

40 Sed. carm. III.89-92 : «Ecce aderant uiuum, portantes iamque cadauer /bis bina ceruice uiri lectoque cubantem /uix hominem cui uita manens sine corpore usu /mortis imago fuit». Mortis imago est une réminiscence de Verg. Aen. II.369.

41 Dulaey (2006) 327.

42 Damas. epigr. 12 (épithaphe de Damase) éd. Ferrua, p. 112 ; Fontaine (1981) 115 ; Trout (2015) 105106 ; Charlet (1985) 615.

43 Les Constitutions apostoliques, t. 2, livres 3 à 6, introduction., texte critique, traduction et notes par Marcel Metzger, SC 329, Paris, 1986, 5,7,12 (sur la résurrection promise) : «nos raisons de croire que la résurrection aura lieu, nous les trouvons aussi dans celle du Seigneur ; car c'est lui qui a ressuscité Lazare, mort depuis quatre jours, ainsi que la fille de Jaïre et le fils de la veuve, et sur l'ordre du Père, il s'est relevé lui-même le troisième jour, lui, le gage de notre résurrection.» 


\section{Les modalités de la réécriture}

\section{A La dramatisation épique}

Je passerai rapidement sur les modalités de la réécriture épique déjà bien étudiées par Michael Roberts, Paul-Augustin Deproost, Bruno Bureau ou Roger Green ${ }^{44}$, et me contenterai de prendre quelques exemples chez Juvencus, dont j'ai peu parlé jusqu'ici, en m'appuyant sur la guérison du paralytique au livre II, vers 75-94.

La réécriture épique est centrée sur un héros, ici le Christ, et elle insiste sur le caractère merveilleux de ses actes, spécialement des guérisons qu'il opère. Juvencus multiplie les mots comme miracula, mirabile, mirari ${ }^{45}$. Il dramatise le récit, en imaginant les sentiments du Christ pris de compassion pour le malade (v. 79 miserans Iesus) et les réactions de la foule partagée entre joie et admiration. Il utilise l'expression pectora plebis que réemploiera Paulin de Nole à propos de la foule qui se détourne des cultes païens ${ }^{46}$. Mais à cet empressement des foules, il ajoute la force du paralytique guéri, ses épaules désormais solides (umeris iam fortibus):

«"Aussi, jeune homme, ayant retrouvé l'usage de ton corps, lève-toi avec vigueur et rapporte ton lit sous ton toit ". Il se leva et il ajuste son lit sur ses épaules désormais solides, et vigoureux il s'en allait au milieu du peuple admiratif. Alors la crainte et les louanges du Seigneur se répandent à travers le cœur de la foule, qui célèbre en même temps ces heureux miracles ${ }^{47}$ ».

Le Christ apparaît comme la lumière qui sauve, un héros dont la uirtus est salvatrice. La forme longue et l'intention narrative de l'épopée biblique permettent de réaliser une actualisation de la geste du Christ (ou de ses disciples), qui est propre à nourrir la vie spirituelle du chrétien.

Chez Dracontius, l'écriture épique culmine en des ekphraseis riches de sens ${ }^{48}$. Dans l'évocation de l'aveugle de naissance à qui le Christ donne la faculté de voir, en II.123-125 (=Jn 9.1-6), le poète met en valeur l'image de l'œil-joyau : «Il donne l'ordre aux yeux d'étinceler sous le front comme des joyaux (oculos gemmare micantes) et l'homme qui vivait dans les ténèbres s'étonne de voir la lumière du jour qu'il ne connaissait pas et que la nature lui avait refusée dès la naissance ${ }^{49} »$. Or cette

44 Roberts (1985) ; Green (2006) ; Deproost (2014).

45 Voir Deproost (2014) 214 n. 8 sur les emplois de miracula chez Juvencus au nombre de vingt-et-un. 46 Paul. Nol. Nat. 19 (éd. Hartel)/11 (éd. Dolveck).108.

47 Juvencus II.89-94 : «Quapropter iuuenis, firmato corporis usu/ Surge uigens stratumque tuum sub tecta referto./ Surrexit lectumque umeris iam fortibus aptat,/Per mediumque uigens populi mirantia abibat. /Tunc timor et laudes Domini per pectora plebis/Concelebrata simul miracula laeta frequentant.»

48 Labarre (2009) 47-48.

49 Drac. laud. II.123-125 : «Ipse oculos gemmare iubet sub fronte micantes/Ignotumque diem mirantur nosse tenebrae /Quem simul ex utero matris natura negarat.» ; voir aussi 1,237 (oculi gem- 
image est employée dans deux passages du chant 1, à propos de la création divine : d'abord l'onde qui devient des yeux au cinquième jour, lors de la création des poissons (I.237), puis le corps d'Adam qui prend vie (I.345 : «Tels des joyaux, les yeux brillants étincellent dans leur double orbite...»). Ainsi est suggérée la continuité entre la puissance du Père dans la Genèse et celle du Fils dans l'Évangile de Jean, lorsqu'il guérit l'aveugle de naissance. L'aveugle représente, quant à lui, l'humanité tout entière sauvée par le Verbe fait chair.

\section{B La stylisation hymnique et épigrammatique}

Dans le Cathemerinon IX, Prudence traite les miracles sous la forme de petits tableaux autonomes et varie le ton. Il place chacun sous les yeux du lecteur, sans préciser les lieux, ni les protagonistes. La guérison du lépreux est décrite en des termes presque cliniques (v. $31-33)^{50}$, celle du paralytique réduite à un vers (v. 69), mais elles s'inscrivent dans un mouvement plus vaste qui emporte tous les maux : «Toutes les maladies s'en vont, toutes les fatigues sont chassées.»

Quant aux épigrammes, même si l'on a la conviction que ni les strophes du Dittochaeon, ni les distiques des Miracula Christi, ni les Tristicha de Rusticus Helpidius ne correspondent à un cycle iconographique pré-existant, elles participent d'un programme à la fois pictural et poétique, sans qu'on puisse savoir si les représentations figurées ont été réalisées ou si elles sont restées à l'état de projet ou d'imagination. Francesco Lubian a bien analysé les enjeux de ce qu'il identifie comme le «(sous)-genre» des Tituli Historiarum entre ekphrasis, iconographie et catéchèse ${ }^{51}$.

La stylisation des péricopes, dans l'hymne comme dans l'épigramme, est justifiée par la volonté de montrer plus que de raconter, selon le principe de l'euidentia formulé par Quintilien ${ }^{52}$. Le fait que l'acteur principal, en l'occurrence le Christ, ne soit pas nommé, n'est pas justifié à mon avis par le fait qu'on le reconnaîtrait grâce à l'image ${ }^{53}$, mais par l'intention de styliser l'épisode par un geste, une attitude, une silhouette reconnaissables entre tous, celle du paralytique avec son lit sur le $\operatorname{dos}^{54}$.

mantur) ; 1,345 : «orbe micant gemino gemmantia lumina uisus» ; 3,698 : «inde duces oculi gemmato lumine uibrant».

50 Prud. Cath. IX.31-33 : «Membra morbis ulcerosa, uiscerum putrides /mando ut abluantur, inquit, fit ratum, quod iusserat ; /turgidam cutem repurgant uulnerum piamina.»

51 Lubian (2015).

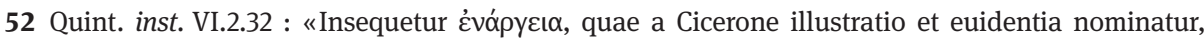
quae non tam dicere uidetur quam ostendere, et affectus non aliter quam si rebus ipsis intersimus sequentur».

53 Pietri (1995) 126 : «on doit surtout noter que dans de nombreuses scènes évoquées, l'acteur principal n'est pas nommé ( $n^{\circ} 16-20-21-24$, le Christ). Comme l'intention didactique est par ailleurs évidente, cette abstention ne se justifie que si le personnage central peut être reconnu grâce à l'image». 
Sur les fresques des catacombes, le paralytique est d'ailleurs le plus souvent seul. Le Christ en train de le guérir figure en revanche sur une fresque de la catacombe de Pierre et Marcellin et sur une autre dans le cimetière de Thrason, situé sur la Via Salaria ${ }^{55}$, ou encore sur le feuillet latéral d'un diptyque en ivoire en cinq parties conservé au Louvre (Fig. 3). La stylisation des péricopes s'observe aussi bien dans les arts figurés que dans la poésie hymnique ou épigrammatique.

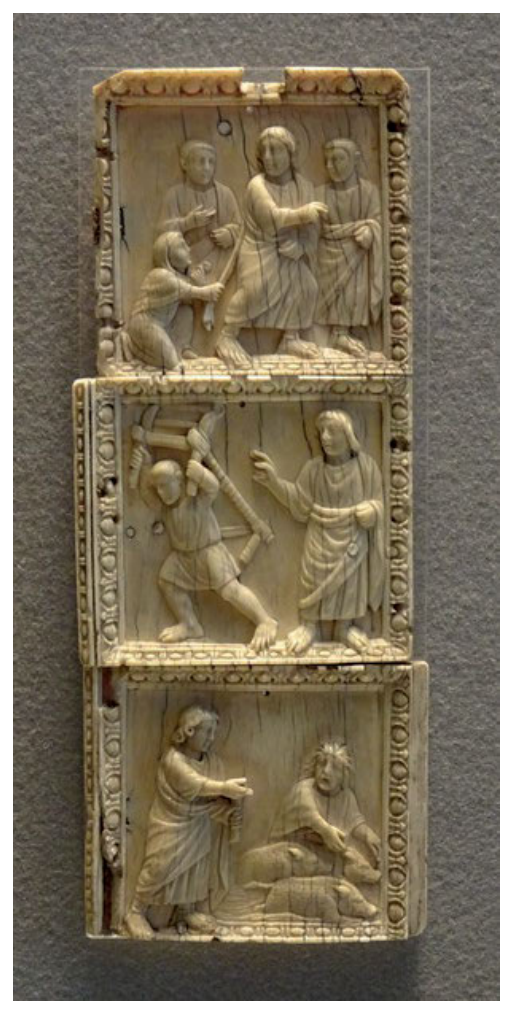

Fig. 3 : ivoire, OA 7876-7877-7878, musée du Louvre

La guérison de l'hémorroïsse est ainsi réduite à un geste furtif (furata, furtim), au simple contact avec un vêtement, au sang arrêté, afin de souligner l'efficacité du remède, chez Prudence (Cath. IX.40 - 42) : «une femme touche furtivement le bord de ton vêtement ; la guérison suit aussitôt ; son visage perd sa pâleur, et son incessant écoulement de sang s'arrête». Sédulius, quant à lui, amplifie le flux de sang jusqu'à imaginer des rivières (Hymne 65-68) : "Un vêtement touché retient/des rivières de sang brûlant,/Tandis que les larmes d'une suppliante coulent,/les flots de sang s’assèchent.». Rusticus Helpidius insiste sur la foi (Tristicha 21) : «Cette femme en

54 Prud. Cath. IX.69 : «gestat et suum per urbem laetus aeger lectulum»; Sed. hymn. II.72 : «aeger uehebat lectulum»; Ps. Claudien Miracula Christi 18 (dernier vers) : «lecti portitor ipse sui».

55 Dulaey (2006) 322. 
touchant le vêtement (du Christ) a dérobé son salut et la foi a asséché ses veines et une hémorragie honteuse : belle la foi qui a la grande force de contraindre le Tonnant». Le Ps.-Claudien résume l'épisode en une sententia (Miracula Christi 15-16) : «Une femme exsangue touche le vêtement (du Christ). Le sang s'arrête dans ses veines. La foi se fait médecine».

Nous trouvons là l'expression poétique d'une spiritualisation de la chair qui interviendra lors de la résurrection, selon Hilaire de Poitiers, dans son Commentaire sur Matthieu ${ }^{56}$. Si la divinité du Verbe s'incorpore aux réalités physiques, les poètes peuvent légitimement concentrer la signification de la péricope évangélique dans ces pieds qui marchent ${ }^{57}$, ces yeux qui voient, ce sang qui s'arrête. Si le corps est évoqué de manière précise, c'est pour rendre manifeste la toute-puissance de la divinité incarnée.

\section{Conclusion}

J'ai voulu montrer la diversité des réécritures de guérison et leur diffusion dans des genres littéraires variés d'une part, la cohérence d'un projet didactique et artistique d'autre part. Tout en restant à l'écart des débats de spécialistes, les poètes se font les médiateurs de l'enseignement biblique et de la doctrine orthodoxe pour un public de lettrés et de candidats au baptême. Ils stylisent le discours exégétique, en recourant à un langage symbolique et métaphorique. Cette stylisation se poursuivra avec la réécriture poétique des miracles accomplis par les saints, qui sont eux-mêmes une forme de réécriture des miracles de Jésus ${ }^{58}$.

\section{Bibliographie}

Bisconti (2000): Bisconti Fabrizio, Temi di iconografia paleocristiana, Città del Vaticano.

Brox (1984): Norbert Brox, «Doketismus, eine Problemanzeige», in: Zeitschrift für

Kirchengeschichte 95, 301-314.

Bureau (1997): Bruno Bureau, Lettre et sens mystique dans l'Historia apostolica d'Arator, Exégèse et épopée, Paris.

Bureau-Deproost (2017): Arator, Histoire apostolique, texte établi, traduit et commenté par Bruno Bureau et Paul-Augustin Deproost, CUF, Paris.

Charlet (1982): Jean-Louis Charlet, La création poétique dans le Cathemerinon de Prudence, Paris.

Charlet (1985): Jean-Louis Charlet, «L'inspiration et la forme bibliques dans la poésie», in: Le monde latin antique et la Bible, BTT 2, Paris, 613-643.

56 Hilar. Mat. 9,6,8-10.

57 Prud. Ditt. 183 (Porta speciosa) : «laxatos currere gressus».

58 Fort. Mart. I,487-513 : guérison d'un lépreux par un baiser donné par Martin et comparé avec l'eau du Jourdain, selon une thématique baptismale. Voir De Nie (1997) ; Rousselle (1990). 
Deproost (1997): P.-A. Deproost, «L'épopée biblique en langue latine. Essai de définition d'un genre littéraire», in: Latomus, 56, 1 (janvier-mars) 14-39.

Deproost (2014): Paul-Augustin Deproost, «Les guérisons merveilleuses dans la geste évangélique de Juvencus ou l'extravagance épique du retour à la norme», in: Paul-Augustin Deproost (éd.), Extravagances. Écarts et normes dans les textes grecs et latins, Actes du colloque de Louvain-la-Neuve (16-17 mai 2013) «Structures et pouvoirs des imaginaires», Paris, 211-233.

Di Stefano (2013): Rustico Helpidio, Tristicha, de Christi lesu beneficiis, introduzione, testo e traduzione, commento di Anita Di Stefano, coll. Studi latini 85, Napoli.

Doré (2010): Joseph Doré, La portée révélatrice des miracles de Jésus, in: Recherches de science religieuse, t. 98, 559-579.

Dulaey (2006): Martine Dulaey, «Les paralytiques des Évangiles dans l'interprétation patristique. Du texte à l'image», in: REAug 52, 287-328.

Dulaey (2007a): Martine Dulaey, «La guérison de l'hémorroïsse (Mt 9, 20-22) dans l'interprétation patristique et l'art paléochrétien", in: RechAug 35, 99-131.

Dulaey (2007b): Martine Dulaey, Symboles des Évangiles. Le Christ médecin et thaumaturge, Paris.

Fabian (1988): Claudia Fabian, Dogma und Dichtung: Untersuchungen zu Prudentius’ «Apotheosis», Frankfurt-Bern-Paris.

Fontaine (1981): Jacques Fontaine, Naissance de la poésie dans l'Occident chrétien, Paris.

Green (2006): Roger P. H. Green, Latin Epics of the New Testament. Juvencus, Sedulius, Arator, Oxford.

Hillier (1993): Richard Hillier, Arator, the Acts of the Apostles. A Baptismal Commentary, Oxford.

Labarre (2009): Sylvie Labarre, «Le projet poétique des auteurs latins d'épopées bibliques: la place des ekphraseis», in: Manifestes littéraires dans la latinité tardive, colloque international organisé par P. Galand-Hallyn et V. Zarini (Université Paris - Sorbonne, 23-24 mars 2007), Paris, 35-50.

Labarre (2015): Sylvie Labarre, «Dracontius et les 'crimes' des héros païens: historiographie, quête du salut et drames humains", in: Littérature, politique et religion en Afrique vandale, Actes du colloque international tenu à l'Université Paris Ouest (6 et 7 octobre 2014), textes réunis et édités par É. Wolff, Paris, 229-242.

Lubian (2015): Francesco Lubian, «Tituli for Illiterates ? The (Sub-)Genre of Tituli Historiarum between Ekphrasis, Iconography and Catechesis», in: P.F. Moretti et al., Culture and Literature in Latin Late Antiquity. Continuities and Discontinuities, Turnhout, 53-68.

Lubian (2017): Disticha sancti Ambrosii, Introduzione, testo criticamente riveduto, traduzione e commento, Francesco Lubian, CCLP 10, Turnhout.

Martin (1960): Commodiani Carmina, cura et studio losephi Martin, CC 128, Turnhout.

Nie (de) (1997): Giselle, Nie (de), «Iconic Alchemy: Imaging Miracles in Late Sixth-Century Gaul», in: E. A. Livingstone (éd.), Papers presented at the Twelfth International Conference on Patristic Studies held in Oxford 1995, Studia Patristica, vol. 30, Leuven, 158-166.

Quacquarelli (1986): Antonio Quacquarelli, Reazione pagana e trasformazione della cultura (fine IV sec. d. C.), Quaderni di Vetera christianorum 19, Bari.

Pietri (1988): Luce Pietri, «Pagina in pariete reserata: épigraphie et architecture religieuse», in: La Terza età dell'epigrafia, Colloque de l'Association Internationale d'Épigraphie Grecque et Latine (Borghesi 1986), Faenza, 137-157.

Pietri (1995): Luce Pietri, «Rusticus Helpidius: un poète au service d’un projet iconographique», in: Bulletin de la Société Nationale des Antiquaires de France, 116-131.

Roberts (1985): Roberts Michael, Biblical Epic and Rhetorical Paraphrase in Late Antiquity, Liverpool.

Rousselle (1990): Aline Rousselle, Croire et guérir, la foi en Gaule dans l'Antiquité tardive, Paris. 
Salzano (2001): Laudes Domini, introduzione, testo, traduzione e commento a cura di Aniello Salzano, Napoli.

Salvadore (2011): Commodiano, Carmen de duobus populis, introduzione, nota critica e commento a cura di Isabella Salvadore, Bologna.

Salvatore (1977): Commodiano, Carme apologetico, introd., testo critico, trad., commento, glossario e indici a cura di Antonio Salvatore, Torino.

Stella (2001): Francesco Stella, Poesia e teologia. L'Occidente latino tra IV e VIII secolo, Milano.

Springer (1988): Carl P. E. Springer, The Gospel as Epic in Late Antiquity. The Paschale Carmen of Sedulius, Leiden-New York.

Trout (2015): Dennis Trout, Damasus of Rome: The Epigraphic Poetry, introduction, texts, translations and commentary, Oxford Early Christian Texts, Oxford-New York.

Van der Weijden (1967): Pieter van der Weijden, Laudes Domini, tekst, vertaling en commentaar, Amsterdam.

Zarini (2009): Vincent Zarini, «Ennode et Arator: une relation pédagogique et son intérêt littéraire», in: Manifestes littéraires dans la latinité tardive, colloque international organisé par P. Galand-Hallyn et V. Zarini (Université Paris - Sorbonne, 23-24 mars 2007), Paris, $325-342$. 


\title{
Luciana Furbetta
}

\section{Avit de Vienne et Dracontius en rapport}

\author{
'Chanter' et 'expliquer' la Bible entre formation scolaire et \\ création poétique
}

Le rapport entre Avit et Dracontius s'est imposé à l'attention de la critique comme un point tourmenté dont l'implication va bien au-delà du rapprochement entre leurs deux poèmes majeurs en s'étendant au débat sur la datation et composition du de spiritalis historiae gestis (à partir d'ici indiqué : $S H G$ ). À ce sujet, par rapport à la cautèle des premiers chercheurs ${ }^{1}$ qui ont centré l'attention surtout sur l'individuation dans le vers d'Avit de reprises et d'échos ramenés au de laudibus Dei (à partir d'ici indiqué : laud.), la dernière éditrice du SHG fait de laud. et surtout de 496 un terminus post quem : «Il ressort donc du prologue qu'Avit avait déjà écrit le De gestis avant l'année 500. Plus précisément encore le poème doit avoir été rédigé dans les toutes dernières années du Vème siècle. Il semble en effet d'après certains parallèles textuels, qu'Avit ait eu connaissance du De laudibus Dei de Dracontius, publié selon toute vraisemblance après 496. La date de 496 constituerait ainsi un terminus post quem pour la rédaction du De gestis et permettrait de situer la date de sa composition

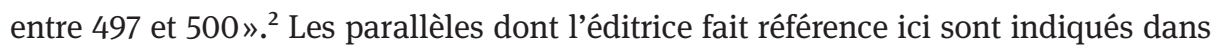
l'apparat des sources et pour la plupart coïncident avec les loci indiqués par Schippers (1945) dans le chapitre Avitus en Dracontius (p. 7-24) qui précède le commentaire au SHG I. La vérification d'une influence (ou moins) du laud. dans SHG et la mémoire poétique d'Avit passe nécessairement à travers une analyse textuelle ponctuelle ; dans l'espace qui nous est accordé ici nous nous interrogerons sur quels

\footnotetext{
1 Vollmer (1905) exclut, suivi par Romano (1959), la connaissance de la part d'Avit de laud. et estimait que les rapprochements tiennent seulement à la parenté des sujets, motifs et images communes tirées du récit biblique. Moussy-Camus (1985) 100 s'insère dans le débat avec une phrase qui reflet toute la complexité d'un rapport entre les deux textes : «En Gaule il est probable que saint Avit, l'évêque de Vienne, s'est inspiré de Dracontius dans son De spiritalis historiae gestis». Par contre une prise de position plus nette arrive avec Roberts (1985) 100 n. 158, qui estime fort improbable une imitation de la part d'Avit. De même avis Arweiler (1999) dans le commentaire de plusieurs vers de SHG IV et $\mathrm{V}$ a montré avec clarté l'absence des emprunts dérivés d'une manière univoque de Dracontius en soulignant comme la connaissance de laud. soit « umgewiss » (cf. p. 230).

2 Telle la position prise par Hecquet-Noti (1999) 33 par rapport aux seules données disponibles : le poème de Dracontius (indépendamment de la composition effective de laud. dans sa totalité) peut être divulgué et publié avec le début du royaume de Trasamond à partir de 496, pas nécessairement dans la même année (cf. Moussy-Camus (1985) 26-29). Le SHG selon le témoignage d'Avit dans le prologue avait été écrit avant la prise de Vienne en 500, mais il fut publié après dans une date comprise entre 500 et 507 (année à laquelle remonte selon la chronologie actuellement proposée par la critique l'epist. 51 Peiper = 48 Malaspina-Reydellet dans laquelle Avit fait référence à son texte en indiquant aussi le thème).
} 
sont les points sûrs de contacts entre les loci similes individués par la critique et leur poids pour la démonstration d'une connaissance de la part d'Avit. ${ }^{3}$

Nous prendrons en considération deux exemples afin d'évaluer les modalités et les fonctions de l'inclusion du laud. par rapport aux autres modèles qui font partie de la formation littéraire d'Avit et de valoriser les caractéristiques du traitement poétique des sujets communs entre les tableaux les plus caractérisés par l'interprétation exégétique du récit biblique.

La majeure partie des rapprochements envisagés par Schippers est concentrée dans SHG I dans l'ekphrasis sur le Paradis dont les v. 218-224 seraient inspirés par laud., cf. v. 222 hic ver adsiduum caeli clementia servat laud. I.185 illic floret humus semper sub vere perenni, et 199 ver ibi perpetuum communes temperat auras, v. 223 turbidus auster abest semperque sub aere sudo laud. I.190-191 flammatur radiis, quatitur nec flatibus ullis / nec coniuratis furit illic turbo procellis, v. 225 nec poscit natura loci quos non habet imbres laud. I.452 imbre ferax nullo, pluviis absentibus uber. Comme on peut constater les parallèles sont très faibles et les consonances d'ensemble plutôt reliées à la commune emprunte par ex. à Ov. met. II.101-111 (en particulier le v. 107), à Mar.Vict. aleth. I.224-236 et Sidon. carm. 2.407-411 pour SHG I.193-195, 218-222. ${ }^{4}$ Les passages d'Avit et de Dracontius sont semblables dans leur ensemble seulement en raison de l'identité du motif mis en vers en s'appuyant d'une manière indépendante sur un commun background littéraire ancré à la connaissance et l'inclusion dans le tissu poétique des auctores comme Ovide et à la formation et pratique scolaire, ainsi que à l'exploitation dans la production poétique chrétienne d'un topos, celui du locus amoenus et de l'âge d'or ${ }^{5}$, adapté pour décrire le jardin de l'Éden avec tous les procédés rhétoriques propres de l'ekphrasis. La structuration même de la péricope apparaît très différente : Dracontius introduit la description à la fin du troisième jour de la création, Avit après la création d'Adam et Ėve et sans souligner la réaction émotive et psychologique des protagonistes au contraire de Dracontius qui met bien en évidence la merveille, l'étonnement devant la beauté de l'Éden. ${ }^{6}$

3 Nous avons examiné toutes les suggestions et les loci proposés par la critique en étendant l'analyse dans une étude centrée sur : Proposte per una definizione dei rapporti tra i carmina di Avito di Vienne $e$ il de laudibus Dei di Draconzio (à paraître) ; dans cette étude émergent d'une manière détaillée les résultats de l'enquête sur le rapport (ici seulement abordé) entre les deux poèmes.

4 Pour l'analyse de l'influence d'Ovide, Marius Victor et Sidoine chez Avit : Furbetta (2017) 85-93, 106-109 pour un commentaire de SHG I : Morisi (1996). Tizzoni (2014) à propos de ces vers en reconnaissant la dépendence de modèles communes et en particulier de Sidoine Apollinaire, envisage une influence étroite de laud.

5 À ce sujet pour l'élaboration du cliché chez Prudence : Fontaine (1970), sur le traitement thématique du tableau sur l'Éden et la vie des hommes dans le Paradis chez Avit et Dracontius : Labarre (2011).

6 On peut remarquer l'absence des points de contact dans le traitement des thèmes communs exploités dans SHG I et laud. I surtout en ce qui concerne la création d'Adam et Ève dans lesquels Avit pouvait trouver chez laud. un exemple de récriture poétique plus innovatrice et moins liée à la 
Si ces vers ne permettent pas d'envisager un véritable rapport entre les deux poèmes, $S H G$ I.24-29 montre de consonances précises. Au cœur du proème, après les v. 1-13 qui font d'introduction à la matière de $S H G$, Avit abrège le récit de la création du monde avec une grande liberté par rapport au récit biblique et aux v. 24-29 rappelle la création sine germine : actutum suavi producens omnia fetu / pulchra repentino vestita est gramine tellus. / Accepere genus sine germine iussa creari / et semen voluisse fuit. Sic ubere verbi / frondescunt silvae: teneris radicibus arbor / duravit vastos parvo sub tempore ramos. Dans le v. 28 la critique envisage d'une manière concorde une reprise de laud. II.224 frondescunt silvae, spirat flos, germinat arbor, motivée par l'occurrence de la même expression : frondescunt silvae. En fait, comme noté par Hecquet-Noti (1999), le verbe est commun d'après les chrétiens, mais le syntagme ne recourt pas ailleurs. Au-delà de cette affinité à l'apparence le passage ne montre pas d'autres échos, mais si on va étendre l'analyse on dévoile sous le tissu des vers un jeu de mémoire plus profonde et l'usage du même syntagme dévient plus significatif par rapport au contexte. Le v. 224 fait partie d'une section hymnique dans laquelle Dracontius chante la puissance de Dieu en rappelant les images de la création : v. 223-236 per te fetat humus, per te, Deus, herba virescit, / frondescunt silvae, spirat flos, germinat arbor; / messis aristatas acuit per culmina fruges, / palmite gemmato post pampinus admovet uvas / et numquam caritura comis pinguescit oliva et toute la première partie du laud. II insiste sur le motif de la grandeur du Créateur. Dans laud. II.224-225 il y a une sorte d'abrégé de la création avec le topos de la floraison de la végétation en faisant l'écho à la description beaucoup plus étendue de laud. I.167-168; dans ce cadre au v. 168 : semper vestita comis frondescit oliva. Vestita est utilisé aussi par Avit à peu de distance dans le même passage rappelé ci-dessus au v. 25 mais en référence à la tellus dans une image pas loin des laud. I.257 silva comis vestita viret nidos loquaces, un vers ceci qui fait partie de la description du sixième jour de la création avec l'essor des oiseaux. La possibilité que vestita est tellus du v. 25 d'Avit soit un indice d'une mémoire des vers de Dracontius est vraisemblable du moment que le deuxième hémistiche du v. 28 teneris radicibus arbor semble reprendre laud. I.628 (cf. v. 627-628 maior et ex truncis surgit radicibus arbor / et foliis vestita viret redeuntibus annis) en recombinant dans son ensemble deux hémistiches de deux vers déplacés de Dracontius : laud. II.224 frondescunt silvae et laud. I.628 radicibus arbor, mais qui font partie de deux tableaux centrés sur le même sujet. En plus au v. 29 Avit remploie l'expression parvo sub tempore, qui montre affinité avec laud. II.364 omnibus atque suus, solus sub tempore parvo où il y a la seule occurrence sûre poétique précédente, même si variée, du syntagme. Ce vers fait partie d'une section (v. 360 -371) où Dracontius introduit le récit du déluge à travers un vibrant mépris de la désobéissance des hommes qui

paraphrase de la Genèse (surtout en comparant les vers de l'Alethia et de l'Heptateuchos les deux référents poétiques les plus proches), ou la question même de la création de la nature à laquelle Dracontius confère beaucoup de centralité - cf. Speyer (1988), (1996), (2002) - au contraire d'Avit, qui focalise l'attention sur les labores de l'homme. 
attire le châtiment de Dieu. Un thème ceci au cœur de la réflexion d'Avit, qui développe à travers ses carmina une théologie de la faute, à partir de la réalité même du péché de l'homme. La tendance d'Avit à la superposition de plusieurs tesselles en façon de mosaïque est bien évidente et toutes ces expressions peuvent être sans doute le résultat d'une élaboration personnelle sur la base d'une multiplicité des modèles, pas nécessairement une imitation contrainte de laud., mais la concentration des fragments cohérents au contexte, pertinents au niveau lexical combinés entre eux-mêmes, entremêlés à d'autres intertextes dans une péricope limitée, rend la présence d'une mémoire dracontienne vraisemblable et ancrée soit à la sensibilité poétique d'Avit, soit à sa lecture et interprétation du message biblique sous-entendu au parcours thématique spirituel développé dans le poème.

Dans ce cadre on peut s'interroger sur une influence éventuelle de laud. à un niveau plus profond, telle de faire envisager un rôle actif des vers de Dracontius dans les procédés rhétoriques et narratifs suivis par Avit dans la structuration des passages où lecture exégétique et création poétique sont combinées dans la narration et l'explication des récits bibliques. SHG III est centré sur le drame de l'esprit et de la conscience humaine au cœur du récit du châtiment et de la chute d'Adam et Ève ; aux v. 220-310 Avit introduit la parabole du riche et de Lazare et selon les suggestions de Schippers - qu'on retrouve pour la plupart dans le commentaire de Hoffmann (2005) - le texte montrerait ici des bons points de contact avec laud. III.49-79. La péricope nous permet ainsi de tester le traitement d'un sujet tiré du Nouveau Testament et une analyse parallèle ponctuelle des modalités suivies par les deux poètes.

\section{Drac. laud. III.49-80}

Nec bona praesentis hic tantum perdere vitae

50 contingit miseris, perdunt bona cuncta futura:

numquid eris pius, alme Deus, iam morte perempto

illi quippe magis qui proditur impius in se

et sibi vel cunctis solacia tota negavit? Non exempla docent damnati divitis ignes

55 pauperis et requies, qui post sua membra beatus

Abrahae portante sinu per saecla quiescit?

Divitis extincti tormenta exspectat egestas immitesque vices alterna sorte rependit. Serica quem tenuis, quem mollia lina gravabant,

60 qui solet aestivum membris sudantibus ostrum

\section{Alc.Av. SHG III.213-278}

Haud aliter vivax deceptus mole caduca

spiritus, impleto venit cum terminus aevo,

215 post obitum peccata dolet: tum quidquid iniquum

gesserit, in mentem revocat, tum paenitet omnis

errorum lapsus, semet quos iudice damnat; et si praeteritae reddatur copia vitae, sponte ferat, quoscumque dabunt mandata labores.

220 Sanctus namque refert de quodam divite Lucas, quem nimio luxu dissolvens vita fovebat. Ipse coturnatus gemmis et fulgidus auro serica bis coctis mutabat tegmina blattis.

Inde ut bacchantem suasissent tempora mensam, 
poscere, deposito confractus murice denso,

cuius et in digitis non sedit crassius aurum et licet exiguae non ferret pondera gem-

mae,

inter anhelantes tormenta ultricia flammas

65 supplicium crudele luens exaestuat ardens et tolerat poscitque rogans ardente palato

ut gelidum digito mereatur lingua liquorem, sed negat hoc immane chaos; crudele profundum

dividit inter aquas et saeva incendia mortis,

70 quae sine fine manent et stant sub perpete nexu.

Et miser hic qui dives erat non vixit egenter; vestibus indutus Tyriis processit et ostro, delicias consumpsit edax, reus inde vocatus, pauperibus miseris quod trux alimenta negabat,

75 nam sibi dives erat dapibus conviva repletus.

Si tales damnare placet sub perpete poena

qui sibi, non aliis, proprium dependere curant,

quid passurus erit qui nec sibi praestitit umquam

aut qui aliena rapit praedo temerarius audax,

80 cuius facta gemens plaudit spoliatus egenus?

\section{v. $86-90$}

Nil opus est praeferre Deo. Sententia prisca est:

«summum crede nefas animam praeferre pudori».

Si maius scelus est animam praeferre pudori,

quam sit grande nefas animam praeferre datori,

demere dum liceat quicquid dedit et cui confert?
225 currebant epulae, totus quas porrigit orbis.

Cumque peregrinus frugem misisset acervus, fervebat priscum crystallo algente Falernum.

Vivida quin etiam miscebant cinnama turi et suffita domus pingui fragrabat amomo.

230 Quod pelagus, quod terra creat, quod flumina gignunt, certatim mensis cedentibus undique lassus portabat pallens auri cum fasce minister.

Languidus ante fores pauper tunc forte iacebat

divitis obstrictis resoluto corpore membris

235 et supplex poscebat opem, non munera captans, reliquias tantum sed, si quas copia iecit, has tunc opperiens alvus ieiuna rogabat.

Sed proclamanti dives non addidit aurem nullaque languentem pietas respexit egenum,

240 nec quae completis cecidere superflua mensis, pauperis ad victum quisquam dedit. Insuper aegri

despicitur facies et putria vulneris horrent.

Cumque canes miti perlambant ulcera lingua

blandior et fesso feritas medicabilis adsit,

245 sola hominum nescit mens semper dura moveri.

Haec sed diversa penitus dum sorte geruntur, impendens obitus pariter pulsavit utrumque divite praevento, numquam qui credidit istud.

Optatam pauper longo vix tempore mortem

250 pervenit et victor morbos artusque relinquit. Ille quidem, celsa qui dudum floruit arce, fletibus ad tumulum stipato funere fertur auratoque datur conditus membra sepulchro 
et pretiosa tegunt elatum lintea marmor.

255 Spiritus abstruso sed mox demissus Averno incidit aeternas per saeva incendia poenas.

E quarum medio sublimi sede locatum haut procul (hoc certe censetur, nam procul inde, ut docet eventus) sinibus conspexit ovantem

260 Abrahae iusti mutatum in paupere vultum nec eius similem, quem dudum luce receptum, quarto forte die vix quisquam largus humandi, Ne per dispersum naturae lege cadaver, dira frequentatae contagia mitteret urbi,

265 obtectum laceris tenui velamine pannis naribus adstrictis nuda tellure locavit. Angelicis manibus tunc in sublime levatus iam dives, iam sanus erat: contraque superbi, qui congesta tenens opibus diffluxerat amplis,

270 arida sic flammis mendicant guttura guttas: «O pater, electas animas qui sede beata colligis et meritis dispensas praemia iustis, haec ego non mereor: sed saltim deprecor unum, Lazarus ut missus veniat digitoque levatum

275 adferat huc labris ardentibus inde liquorem quique refrigerio, si non extinxerit omnes, ad tempus saltim tantos vel mitiget aestus, donec fessa brevi respirent membra quiete.

D’après Avit les vers sont insérés à la fin du récit du châtiment, un tableau construit à travers des insertions du discours de Dieu au serpent (v. 66-89) et puis aux hommes (v. 66-89). À la fin de la scène Avit introduit la plainte sur le Paradis perdu (v. 195219) et termine avec une comparaison entre les tourments des hommes et la douleur de l'âme éternelle qui rend compte de sa conduite après la mort du corps. Dans ce cadre la parabole est introduite d'une manière explicite avec l'indication au v. 220 de la source : l'Évangile de Luc 16.19-31. En revanche dans le livre de Dracontius la parabole est insérée dans la première partie du chant qui s'ouvre avec un hymne de louange au Créateur dont l'épilogue est centré sur la bonté divine ; avec les v. 49-53 de transition, sans expliciter la source, le poète insère - à partir du motif de la perte des biens et de la vie future éternelle - la parabole. Cela s'inscrit ainsi dans un tableau (v. 32-75) tout consacré à démontrer la cupidité et l'avarice de l'homme qui s'éloigne de Dieu et qui attire avec sa conduite le châtiment. Le récit exemplaire et bien connu est référé d'une manière directe par l'auteur, au contraire d'Avit qui s'appuie sur l'autorité de l'Écriture (v. 220) en introduisant l'exemplum comme au début d'une sorte d'homélie (une pause exégétique) développée à partir de l'Évangile 
et visant à l'explication (en continuité avec le Nouveau Testament) des conséquences du péché, de la douleur du remord et de la nécessité du repentir en vie car la faute après la mort reste immutable. Le cœur de l'enseignement est anticipé aux v. 213219 qui font de lien entre l'image d'Adam et Ėve perdus pour l'éternité et la chaine des péchés perpétués par leur descendance. En revanche chez laud. III la parabole complète avec simplicité et cohérence l'exemplum de l'accapareur de blé (v. 32-53) afin de souligner la cupidité, l'avarice et le manque de miséricorde qu'éloigne le chrétien de l'exemple de la bonté divine. Le récit s'insère sans évidence particulière dans la série d'exempla au cœur de la narration et fait déjà partie de la démonstration de la miséricorde de Dieu en démontrant dans la réalité les effets de la vie chrétienne, seul moyen de salut. Le récit constitue en fait la réponse à la question posée aux v. 49-53 à partir de laquelle Dracontius développe la matière de son chant. À côté de ces données le traitement poétique et les modèles choisis par les deux poètes contribuent à éclairer la différente structuration, lecture et usage du même récit. Tous les deux soulignent la richesse avec une petite digression sur le luxe du protagoniste, introduite par Avit avec le v. 221 qui anticipe d'une manière indirecte l'enseignement moral. La description dans $S H G$ constitue elle même un tableau amplifié jusqu'au v. 232 où le poète introduit la figure du pauvre, par contre l'espace confié par Dracontius est très limité. La comparaison entre le riche et le pauvre, leurs différentes richesses (l'une terraine éphémère et nuisible, l'autre durable et éternelle) est à la base de toute la scène, là où Avit procède d'une manière plus descriptive par tableaux distingués auparavant sur le riche et ensuite sur le pauvre. Laud. III.57-70, comme souligné par Moussy (1988), montre des emprunts très nets surtout aux de Nabuthae historia (à partir d'ici : Nab.) d'Ambroise et à Iuv. 1.27-29 Crispinus Tyrias umero revocante lacernas / ventilet aestivum digitis sudantibus aurum / nec sufferre queat maioris pondera gemmae, ce dernier exploité à sauts aux v. 60 (avec une reprise ad verbum et peu de variation du v. 28 de Juvénal) et 63 (où la clausule est empruntée au seul précédent Iuv. 1.29). L'influence de sat. 1 est corroborée par laud. I.588 ventilat aestivo quas flatu mollior aura (où recourt dans la même position métrique, mais sans relation de contexte, la combinaison ventil* aestiv $^{*}$ présente seulement dans ses loci et chez Eug.Tol. hex. 470). Au-delà de l'exemplarité de la figure de Crispinus (étudiée en rapport à l'exploitation dans ses vers par Gnilka (1965-1966), qui relève plutôt les divergences entre les deux textes), la réminiscence de ce passage dans la mémoire poétique de Dracontius ne nous semble pas casuelle. Juvénal énumère Crispinus parmi les exemples de l'injuste et les motivations qui nourrirent la nécessité de faire de la satire (v. 81-88), surtout on retrouve d'après sat. 1 des passages en ligne avec le blâme de la funesta Pecunia (v. 113) et des vices sans fin et l'idée mutatis mutandis de la postérité du mal et de la chute qui tombe toujours plus en bas jusqu'à toucher le fond de la dégénérescence des générations futures, cf. v. 147-149 : nil erit ulterius quod nostris moribus addat / posteritas, eadem facient cupientque minores, / omne in praecipiti vitium stetit. De vers ceux-ci qui deviennent de maximes universelles à caractère moral introduites dans la partie finale de la satire et qui suivent l'image du goulu avide et de sa mort (cf. v. 
139-146), un cliché qui peut bien s’adapter à la condamnation d'un des péchés capitaux. Sans sous-évaluer cette modalité du remploi des vers de Juvénal ${ }^{7}$, l'imitation des v. 27-29 pourrait être aussi déclenchée par un souvenir plus étendu de sat. 1 qui montre dans l'ensemble une cohérence de fond avec les thèmes et les mépris sur lesquelles Dracontius insiste dans son chant. ${ }^{8}$ Les v. 63-70 sont une amplification $^{9}$ du récit de $L c$ 16.19-21 dont Dracontius tire aussi une citation presque littérale au v. 53. Dans le tissu des vers la tendance à la paraphrase glisse vers l'élaboration poétique sur la base d'une réminiscence des lectures exégétiques du récit évangélique, dans le cas spécifique influencé par des passages de l'expositio sur l'évangile de Luc d'Ambroise, cf. en particulier VIII.14-20 et V.107 Quid existis videre? hominem mollibus vestimentis indutum? non hic Domini sermo de vestibus, quamquam plerosque mollioris cura vestis effeminet, qui quasi lanae onus ferre non possint, sericas vestes tectis per terram verrunt vestigiis usuque faciunt ut amictus oneri sit. Sed tamen alia videtur hic indumenta signare et, nisi fallor, humana corpora, quibus anima nostra vestitur - un passage ce dernier à l'apparence décontextualisé, car Ambroise y explique le message de saint Jean dans Lc 7.18-28 - mais dans lequel Dracontius trouve vraisemblablement le lien thématique pour introduire la figure de l'effeminatus Crispinus dans le contexte du mépris de la mollitia du luxe et donc une suggestion d'ensemble de l'image (et l'idée du poids des vêtements) à combler avec le souvenir du modèle païen. L'influence d'Ambroise (dont le poète rappelle et combine plusieurs passages) est d'ailleurs bien plus profonde en ce qui concerne le $N a b$., un texte qui montre les caractéristiques de l'homélie $^{10}$ et que Dracontius semble suivre avec cohérence. Moussy envisage dans les v. 71-75 le souvenir de Nab. 1.1 quis enim divitum non cottidie concupiscit aliena? Quis opulentissimorum non exturbare contendit agellulo suo pauperem atque inopem auiti ruris eliminare finibus? Quis contentus est suo? Cuius non inflammet divitis animum vicina possessio? qui montre d'affinités au niveau lexical et thématique aussi avec Ambr. Off. III.3.15, 18, 19

7 Sur ce point et la modalité d'inclusion des vers de Juvénal dans les poèmes à sujet biblique on renvoie à De Gianni (2015) qui a étudié le cas spécifique de l'Heptateuchos, texte dont l'exemplarité (côté de l'Alethia de Claudius Marius Victor) pour les poèmes postérieurs à été déjà reconnue par la critique. En général sur la présence des modèles païens et la technique d'inclusion dans laud. : Stella (1985-1986), De Gaetano (2009) 241-315.

8 De vers de la même satire sont rappelés selon les loci indiqués par l'édition Moussy dans laud. II.289 quae natura negat per nos elementa petuntur sat. 1.79 si natura negat, facit indignatio versum et dans Drac. Satisf. 15 quicquid agunt homines, bona tristia prospera prava sat. I.85 quidquid agunt homines, votum, timor, ira, voluptas (tous les deux à notre avis pas sûrs, le dernier surtout du moment que le syntagme recourt dans Prud. ham. 763 quidquid agunt homines Sodomorum incendia iustis qui élabore évidemment le vers de Juvénal.

9 Le v. 64 rappelle pour la structure Auson. Mos. 339 voluit anhelatas tectoria per cava flammas sans aucune relation de contexte, la clausule du v. 65 recourt d'après Coripp. Ioh. VI.302 et la iunctura : chaos crudele est présente dans Drac. Orest. 483. Pour Vestibus indutum (v. 72) dans la même position métrique, cf. Drac. Romul. VIII.482, X.258, Orest. 305.

10 À ce sujet : Gori (1985) 18-28, Palumbo (2012) 183-207, plus en général sur l'interférence des genres et des styles chez Ambroise : Fontaine (1976). 
et que Dracontius ici amplifie en faisant de pendant à l'image déjà développée aux v. 43, 59 autour de l'idée centrale du châtiment de l'avare en soulignant la gravité de l'avidité sans limites afin de dénoncer la cupidité. Le poète semble faire l'écho au début du texte d'Ambroise et au thème portant de ses argumentations dont l'ancrage repose sur le principe : in commune omnibus, divitibus atque pauperibus, terra fundata est. ${ }^{11}$ Cet écho de Nab. 1.1-2 est cohérent dans l'ensemble avec l'image de l'accapareur sur laquelle Dracontius centre les v. 32-53 afin d'introduire le thème du malheur et du châtiment de l'homme cupide, des vers (comme montré par Moussy) inspirés eux-mêmes par Ambr. hex. III.8.35 et Off. III.6.40-41. Il n'est pas inutile de souligner que pour les v. 44-45 Arevalo (1791) avait envisagé une ressemblance avec Iuv. 14.303-304 (tantis parta malis cura maiore metuque / servantur: misera est magni custodia census) et que surtout pour les v. 43-45 (extinctam dolet esse famem, bene dives egenus. / Semper avarus inops, pauper sub divite nummo / aestuat et custos alieni thuris odorat) le référant est encore $N a b$. 2.4 (O dives, nescis quam pauper sis, quam inops tibi ipse videaris, qui te divitem dicis. Quanto plus habueris, plus requiris et quidquid adquisieris, tamen tibi adhuc indiges. Inflammatur lucro avaritia, non restinguitur) qui montre des affinités aussi avec les v. 64-70 où l'image des tourments du riche est plus étendue. Les v. 68-69 font l'écho à expos. Luc. VIII.18 où le chaos, l'abime qui attend le riche est inséré dans l'explicitation très nette de la part d'Ambroise sur la question des mérites et de la paenitentia : inter hunc igitur divitem et pauperem chaos magnum est, quia post mortem nequeunt merita mutari. Une influence du Nab. au niveau lexical est présente en plus dans laud. III.59 Nab. 1.3 sericae vestes et auro intexta velamina, quibus divitis corpus ambitur ainsi que dans les v. 59-63 Nab. 5.26 habent et gemmae pondera sua, habent et vestes sua frigora. Sudatur in gemmis, algetur in sericis: tamen pretia iuvant et quae natura aversatur commendat avaritia, où le poète transfère l'image dès femmes (auxquelles se réfère le passage d'Ambroise) à l'homme avare en reprenant dans le v. 63 le syntagme gemmae pondera, mais à travers la citation de Iuv.1.27-28. On peut en plus souligner que l'image de l'anneau et du riche infelix recourt mutatis mutandis dans Nab. 13.56. Au v. 75 le petit tableau avec la parabole termine sur l'image de la réfutation de la part du riche d'aider le pauvre, une image peu développée par Dracontius qui passe (v. 76 - 85) à tirer les files du sens des deux récits (celui du laboureur et l'accaparateur inséré aux v. 32-43 et celui du riche et de Lazare) en anticipant le noyau thématique (à savoir négliger les biens et choisir la vie éternelle car : quod spectat finem fragile est totumque caducum) explicité aux v. 86-98. Dans ce cadre encore une fois Dracontius recourt à la superposition des modèles de Juvénal et d'Ambroise : la sententia prisca insérée ad verbum et puis recombinée dans le développement du discours aux v. 86-89 est en fait tirée de Iuv. 8.83. Le choix de la maxime nous semble suivre les modalités déjà soulignées et être guidé par le même critère de sélection sur

11 Ceci répété dans off. I.28.132, hex. VI.8.52, exp.ps. 1188.22 et proche aux affirmations de Lact. inst. V.5 et à la diatribe stoïcienne, cf. Gori (1985) 132-133 n. 4. 
la base d'une consonance large avec le message de la satire de Juvénal. Cette-ci est construite autour de l'idée de la noblesse qui dérive de la virtus, de la supériorité de la bonne conduite morale au regard d'une supériorité par naissance présumée $a$ priori, contredite par les vices et la méchanceté de l'homme, des idées en ligne avec la démonstration d'Ambroise de la valeur de l'action et de la bonne conduite chrétienne opposée dans Nab. 13.54 au riche superbe pour ses origines et méprisable pour ses actions. Toutefois on peut souligner que l'usage des tesselles poétiques tirées de Juvénal ne semble pas seulement cohérent au contenu et à la lecture allégorique de la parabole, mais d'une certaine manière autorisé, légitimé par Nab., où les échos à Juvénal ont étés mis en évidence par la critique. Tandoi (1980) 94 par exemple avait souligné avec clarté les traces précises de Iuv. 11.6 dans Nab. 5.26 (un passage dont comme nous avons vu la présence dans ces vers de Dracontius est sûre) et remarqué le rôle actif de l'exemple de la courante moralisante représentée par Juvénal dans l'esprit d'Ambroise. En recombinant tous ces indices il nous semble vraisemblable que le critère et la modalité d'inclusion des modèles de cette péricope de laud. III reposent sur la relecture de la parabole du riche et de Lazare à la lumière de la réflexion et l'exégèse déployées par Ambroise non seulement dans l'expositio sur la page de l'Évangile, mais surtout sur le commentaire (le premier) du récit de Naboth, texte dans lequel Dracontius perçue une veine polémique et moralisante, qui à niveau de création poétique se traduit dans l'inclusion des citations et emprunts aux vers de Juvénal.

La centralité de l'exemple d'Ambroise (et des modèles y reliés) n'est pas seulement saisissable au niveau de construction des tableaux narratifs, mais aussi dans le développement du message au cœur de laud. III. Le lien entre la parabole et le récit de Naboth est en fait ancré à la condamnation de la richesse, au thème de l'oppression sociale ainsi que à l'insistance dans une perspective eschatologique à l'exhortation à l'exercice de la miséricorde, à la charité qui éloignent la mort éternelle (cf. e.g. Nab. 8.38 et expos. Lc. VIII.20). Dans les textes d'Ambroise se combinent ainsi lecture, explication des récits du Ancien et du Nouveau Testament sans distinction avec une lecture unitaire et l'intérêt sociopolitique, l'actualité du message y sous entendu (cf. e.g. Nab. 1.1 historia tempore vetus est, usu cottidiana). Le choix de l'hypotexte parait ainsi encore plus profonde et poussé par l'adhésion à la valeur des passages d'Ambroise, à leur ancrage historique ${ }^{12}$ dans le cadre d'une réflexion plus large sur la richesse, sa légitimité et son usage. Des thèmes où exégèse et sentiment / histoire personnelle du poète emprisonné et privé de ses biens ${ }^{13}$ se rencontrent dans l'actualisation et la démonstration de l'universalité et de la réalité du récit biblique dans la vie quotidienne de l'homme.

12 Cf. Cracco Ruggini (1976), Vasey (1982). Plus en général sur les réflexions autour de la richesse d'après Ambroise : Brown (2016) 120-147.

13 Sur le poids de l'expérience personnelle en filigrane dans les tableaux de laud. III on renvoie à l'introduction Moussy-Camus (1985). 
L'influence de la récriture ambrosienne soit de la parabole que du Nab. s'étend à un modèle poétique commun à Dracontius et Avit : Paul.Nol. carm. 31 (Hartel), où aux v. 459-498 le poète insère une péricope avec l'explication du significat de la parabole du riche dans le cadre de la consolatio pour la mort de Celsus. ${ }^{14}$ La séquence des tableaux dans la pièce de Paulin montrent de points de contact avec $S H G$ III et laud. III et les consonances lexicales - comme laud. III.57 Paul.Nol. carm. 31.490 gaudet ibi, et pleno paupere dives eget ${ }^{15}$ - sont vraisemblablement suggérées par la sélection thématique adoptée par Paulin qui aux v. 75-192 rappelle le péché d'Adam et Ėve, l'origine du mal dans leur descendance et le rachat à travers le Christ (avec une sorte d'abrégé poétique d'Ancien et Nouveau Testament), puis aux v. 193198 il y a l'exemplum du bon larron qui fait de lien avec les v. 213-220 où Paulin se réfère à la foi et à la grâce divine donnée et élargie d'une manière gratuite sans le concours de l'action humaine. Aux v. 315-322 suit la récriture d'Ez 37.1-14 et aux v. 464-474, 487-501 Paulin introduit la parabole du riche et de Lazare et un commentaire intercalé par une pause avec le mépris des ficta des païens (v. 475-486). Les v. 583-598 sont en fin plus centrés sur le passage de Lc 16.22-24. À l'exclusion de la référence topique aux ficta (qu'on retrouve dans SHG IV.3 et par allusion dans laud. III.251-260) le carm. 31 constitue un incontournable exemple dans lequel Bible, exégèse et exhortation à la vie chrétienne se combinent sous forme poétique comme expression d'une «teologia sapienziale ${ }^{16}$ qui touche les noyaux de la foi, de la grâce, de la confessio, de la paenitentia et de la résurrection. Des thèmes présents avec de formes et modalités différentes d'après Dracontius - qui au-delà de la parabole introduit aux v. 689-717 l'image de la résurrection des ossements desséchés empruntée à la lecture allégorique d'Ez 37.1-14 en se fondant sur Ambros. hex. VI.9 et les vers de Paulin ${ }^{17}$ - et d'après SHG III. Dans ce dernier surtout on retrouve la même sensibilité aux questions doctrinales, la parabole du riche, puis le récit du bon larron sur l'exemple de l'Évangile de Luc, la préfiguration de la résurrection avec le Christ et le rachat de l'homme héritier de la faute d'Adam et de sa chute.

L'importance du carm. 31 dans SHG III est témoignée en plus par de reprises plus évidentes si on compare les vers de Dracontius. La récriture poétique de la parabole est conduite par Avit avec une liberté majeure ${ }^{18}$, sans se conformer à la trace dressée par les traités d'Ambroise ou la superposition adoptée par Dracontius. Avit combine de citations plus ou moins ponctuelles de Lc 16.24-25 avec des tesselles précises tirées de Paulin. Les v. 243-245 rappellent carm. 31.470-472 stercoris et lambant ulcera nostra canes, / ut placida tristem post vitam morte solutos / mitis ad occursus

14 La présence du modèle ambrosien chez Paulin est suggérée par le v. 511 où le syntagme consors naturae dérive de Nab. 1.2. Sur le rapport entre les deux auteurs : Costanza (1976).

15 Cf. aussi e.g. Paul.Nol. carm. $31.176 \sim$ laud. I.650; v. $291 \sim$ laud. I.329 ; v. $351 \sim$ laud. III.224.

16 Cf. Nazzaro (2015). Pour une analyse du carm. 31 : Bordone (2015) 37- 45.

17 Sur ce passage : Stella (2001) 100-107, De Gaetano (2010).

18 Nous borderons l'analyse du tableau aux vers dans lesquels la critique voit un rapprochement à laud. III. Pour un commentaire ponctuel on renvoie à Hoffmann (2005). 
angelus excipiat, les v. 259-260 carm. 31.473-474 et patriarcharum sinibus deponat ovantes, / unde Gehenna procul saevit hiante chao, v. 488 pauper in Abraham, dives in igne iacet et les v. 274-276 carm. 31.495-498 inde in eum ardentem nec parva e pauperis imo / stillavit digito gutta refrigerii, / de magnis quoniam dapibus nec mica referto / esurientis in os pauperis exciderat. Le souvenir de Paulin s'étend aussi à la lettre 25bis (Hartel), adressée au compagnon d'armes de Victorius comme exhortation à la conversio, où aux par. 2-3 Paulin introduit un commentaire de la parabole dont on reconnait des consonances avec les images exploités dans le carm. 31 et reprises par Avit (cf. par. 3 itaque in ipsum mendicitate conversa nunc male dives in abundantia tormentorum suorum stipem roris exigui de mendico suo vitae opibus abundante mendicat, sed iustam vicem recipit, ne refrigeretur inopis misericordia, quem de copia sua nunquam refrigeraverat. Quid autem illud est, quod toto ardens corpore linguam tantum suam vel minimo pauperis digito aspergi rogat). À côté de ces emprunts le jeu de mosaïque d'intertextes dans les vers d'Avit est moins serré ; pour en donner seulement quelque exemple le v. 221 rappelle sans rapport de contexte Prud. ham. 942-943 ossibus extructum, corrupta quod incola luxu / heu nimium complexa fovet, pour nimio luxu cf. Verg. georg. III.135. Les v. 222-223 montrent des combinaisons lexicales utilisées par Avit dans SHG IV.386-387 serica contextoque aurum pretiosus ostro (à propos du roi de Ninive converti grâce à l'exemple de Jonas) et dans carm. VI.35-40. L'ensemble des v. 223-229 a été rapproché à Lucan. X.123124, 160 -163, 167-168 modèle aussi de Sidon. epist. II.13.7 également évoqué comme hypotexte (cf. Hecquet-Noti (1999) 288 et Hoffmann (2005) ad loc.), mais on peut voir aussi Paul.Nol. carm. 31.465 nolo mihi Tyrio modo serica murice vestis, un référant commun à laud. III.72. L'apparente similarité des vers d'Avit avec laud. III.59-63, 72 est donc bordée au traitement topique de la figure du riche et de son luxe, mais sans de points de contact univoques et l'élaboration de l'image repose sur de modèles accessibles par les deux poètes sans nécessité de médiation réciproque. Cela vaut aussi pour le v. 230 rapproché par la critique à laud. I.412 nam totum quod terra creat, quod pontus et aer (pour le syntagme quod terra creat) et rappelle SHG II.154 quod caelum, quod terra creat, quod gurgite magno, surtout les précédents : Lucr. V.937 quod sol atque imbres dederant, quod terra crearat, Sedul. carm.pasch. I.12 quidquid terra creat, quidquid ad astra volat et pour le v. 256 semblable à laud. III.69 où recourt dans le même contexte la iunctura virgilienne saeva incendia. Le vers à l'analyse montre un entrelacement qui n'a pas aucun lien avec le vers de Dracontius et combine d'empruntes à Lucr. I.111 aeternas quoniam poenas in morte timendumst et Ps.Cypr. resurr. 300 hos aeternae iubet Dominus discedere poenae ainsi que à Prud. apoth. 938-939 quid Christi in membris peccati saeva satelles / poena ageret? Quid mors hominis sine crimine posset? L'exemple de Prud. apoth. est actif aussi au v. 232 où la clausule fasce minister est modelée sur le v. 720 de Prudence ; l'auctor est le référant (cf. ham. 188) aussi pour SHG II.81-82 où recourt la même iunctura : saeva incendia. Si Dracontius procède d'une manière plus étroite en suivant surtout Ambr. expos.Lc et $N a b$. (avec les emprunts à Juvénal, un modèle qu'il retrouve d'après le Nab.) avec des réminiscences de Paul.Nol. carm. 31, par contre les vers d'Avit mon- 
trent un ancrage d'ensemble plus fort avec les vers de Paulin, dont le souvenir, comme nous avons vu, est combiné à la paraphrase de l'Évangile de Luc et aux auctores païens largement présents à la mémoire poétique de l'auteur.

Pour compléter l'analyse on peut souligner aussi l'interprétation exégétique et théologique de la parabole beaucoup plus marquées chez Avit. L'élargissement du récit, élaboré à travers une structuration par tableaux dialogiques, vise à emphatiser les tourments du riche mort, en pendant avec les tableaux précédents avec le dialogue entre Dieu et le serpent et puis Dieu et l'homme auxquels correspondent mutatis mutandis les insertions dialogiques avec la prière du riche qui demande de recevoir par Lazare de l'eau pour trouver du soulagement et la réponse qui confirme une condamnation éternelle définitive, sans possibilité de changement, car les larmes vaines ne portent aucune espoir de salut. Avit insiste et introduit une dernière prière du riche, qui désormais perdu sans pardon demande d'envoyer un message d'avertissement à ses frères qui vivent dans le péché afin qu'ils puissent se repentir et donc sauver en temps. Cette requête reste sans réponse (v. 297-310) et le poète évêque conclut avec une sorte d'actualisation en revenant à l'exemple d'Adam et à la condition de l'homme, à la réalité de la faute. Ce jeu de juxtaposition des cadres sur la trace du récit biblique aboutit à l'image finale de la désolation du riche qui admet trop tard ses fautes sans aucune possibilité de miséricorde (en parallèle avec l'image d'Adam aux v. 303-310). La parabole s'inscrit ainsi dans le noyau théologique de la prééminence de la grâce divine sur l'intentio de l'homme, un discours qui dans le cours de $S H G$ III. fait de contrepoint aux idées de Faustus de Riez ${ }^{19}$ et qu'aboutit d'une façon toute implicite dans le récit du bon larron. Ce dernier récit tiré de l'Évangile de Luc impose une réflexion sur la valeur de la paenitentia in extremis ${ }^{20}$ et sur l'intervention en perspective eschatologique de la misericordia, toute comprise dans la prière exégétique qui inclut le récit de la parabole du larron et qui introduit la préfiguration du pardon. D’implications différents essorent des vers de Dracontius, tous centrés sur les louanges, la démonstration et le témoignage de la grandeur de la bonté de Dieu et du pardon élargi à l'homme, qu'aboutirent dans l'hymne final à la résurrection et au retour de l'état édénique (en combinant ainsi la dimension de la confessio et de la prière avec celle eschatologique et explicitant les liens entre le message d'Ancien et du Nouveau Testament), mais sans entrer directement dans la question ni de l'action de la grâce divine, ni de l'intervention de la paenitentia ou dans la réflexion sur le statut de la faute. ${ }^{21}$

19 Un exemple concret est l'interprétation de la parabole de la femme qui retrouve la drachma, Avit compare la femme à Christ qui récupère le pécheur, pour Faustus dans de gratia 1.1 par contre la femme est symbole de l'homme qui retrouve à travers sa propre action la salut de l'âme ; sur Avit et Faustus cf. Nodes (1988).

20 Sur ce point et l'analyse des v. 407-425: Neri (2015).

21 Pour une synthèse sur la théologie de la faute et la perspective antipélagienne en filigrane dans SHG III : Stella (2001) 129-136, sur les implications doctrinales de SHG I-III : Nodes (1984) et plus en général sur ce point dans les deux poèmes Nodes (1993) 45-71. 
Le manque d'une influence sûre des vers de Dracontius est témoignée aussi par SHG III.334-341: posteritas nam quanta ferat dispendia rerum, / non cui vel centum linguae vel ferrea vox est, / enumerare queat, nec si, quem Mantua misit, / Maeoniusve canant diversa voce poetae. / Quis tales referat motus? Quis denique fando / evolvat totos, qui volvunt saecula, fluctus? / Arma fremunt, crebra quatitur formidine mundus, / funditur irriguus sanguis maiorque sititur. Le choix de la citation de Verg. georg. II.44; Aen. VI.626 qu'on retrouve dans laud. III.565-568 gens scelerata sumus, nil de pietate merentes, / quorum primus ego plus quam peccator habendus. / Quando fatebor enim scelerum simul omne, reatum / pectoris et carnis? non si mihi ferrea vox sit dérive d'un cliché désormais fixe dans la tradition poétique chrétienne où souvent la citation recourt pour condamner l'indicible méchanceté de l'homme. Entre les exemples poétiques Sedul. carm.pasch. I.99-100 nam centum licet ora movens vox ferrea clamet / centenosque sonos humanum pectus anhelet est un modèle commun aux deux auteurs ${ }^{22}$, mais le cliché recourt aussi en prose comme chez Hier. epist. 60.16 et epist. 77, dans cette dernière lettre ad Oceanum de morte Fabiolae, aux par. 6 la citation est introduite au milieu des louanges de la miséricorde montrée par Fabiola durant sa vie, dans lesquelles Jérôme insère un souvenir de la parabole du riche et de Lazare et du châtiment éternel qui ne touchera pas la jeune. Il nous semble utile de remarquer l'occurrence d'une allusion au par. 4 au récit de Naboth dans une péricope avec les exempla les plus célèbres pour montrer la valeur de la bonne conduite et de la pénitence. Cette lettre est un exemple significatif de l'agrégation et juxtaposition des récits bibliques et des clichés poétiques autour de noyaux théologiques dans de séquences définies, de modules littéraires fixes bien connus et exploités.

En tenant compte de toutes ces données la diversité au niveau thématique et exégétique de l'exploitation des mêmes récits et des images bibliques ainsi que le traitement poétique révèlent le manque d'une dépendance indéniable de laud. dans les vers d'Avit et plutôt la présence d'emprunts à de modèles communs fort liés à la tradition exégétique accessibles aux deux poètes d'une manière indépendante. Le bilan de cette analyse semble pencher vers l'absence au niveau textuel d'une évidence réelle dans $S H G$ de reprises ou d'inspirations tirées d'une manière univoque du laud. : les vers de Dracontius n'acquièrent aucune priorité parmi les modèles exploités par Avit et les consonances sont trop limités à des péricopes désormais topiques et largement exploités dans la tradition pour envisager un rôle du laud. dans la rédaction du $S H G$ où pour en définir la date de composition comme terminus post quem. Plutôt on pourrait réfléchir sur une autre hypothèse : à savoir qu'Avit ait eu la possibilité d'utiliser ou lire le texte de Dracontius (mais nous ne pouvons définir sous quelle forme si par extrait ou dans sa totalité) quand il a remanié et révisé son poème pour la publication définitive (après le 500, cf. supra n. 2). Avec

22 Pour l'importance des vers de Sédulius dans l'image élaborée par Dracontius aux v. 565-592 cf. Stella (2005-2006). 
beaucoup de cautèle on pourrait songer à une influence (au sens large du terme) du laud. dans une phase plus tardive au fil d'un procès de labor limae, de révision, dont on peut avoir un reflet par exemple dans $S H G$ I.24-29. ${ }^{23}$ Une présence qui dans le cas spécifique peut être bien compatible avec une opération de révision du texte car le poète condense dans peu de vers le contenu des ses carmina en reliant toute le significat littéral et spirituel de son ouvrage et puis le récit de la création d'une façon toute personnelle (qui ne trouve pas ni de référents ni de précédents précis), dans une section initiale pour son statut sensible et susceptible de remaniement et d'une 'mise à jour' avant la publication définitive. Une influence qui donc pour $S H G$ I.24-29 ne serait pas casuelle dans son évidence et concentration et bien favorisée par l'intérêt pour les thèmes abordées par Dracontius avec sensibilité et liberté poétique similaires dans la mise en vers du texte biblique, de son adaptation et une focalisation sur la dimension spirituelle de la confessio, ainsi que une perspective eschatologique développées mutatis mutandis dans le tissu des vers sur la base d'une coexistence de clichés poétiques et de lecture exégétique dont on a un exemple dans l'inclusion de la parabole du riche et de Lazare.

23 Dans ce sens peut être inclus l'autre cas de vraisemblable mais pas univoque consonance entre SHG II.98-99 laud. I.463-467, à ce sujet : Mondin (2011), étude où à côté de la démonstration de la circulation de l'image de la simplicitas d'Adam et Ève bien avant laud. est envisagée, à notre connaissance pour la première fois, la possibilité qu'Avit ait eu 'sous les yeux' laud. au moins dans une phase de révision (cf. p. 221). 


\section{Bibliographie}

Arevalo (1791): Dracontii poetae christiani seculi V carmina ex mss. Vaticanis duplo auctiora iis quae adhuc prodierunt recensente Faustino Arevalo, Romae.

Arweiler (1999): Alexander Arweiler, Die Imitation antiker und spätantiker Literatur in der Dichtung 'De spiritalis historiae gestis' des Alcimus Avitus. Mit einem Kommentar zu Avit. Carm. 4,429-540 und 5,526-703, Berlin-New York.

Bordone (2015): Fabrizio Bordone, «Povertà ed escatologia nei carmi di Paolino di Nola tra Scrittura e retorica», in: Fabio Gasti, Michele Cutino (édd.), Poesia e teologia nella produzione latina dei secoli IV-V, Pavia, 29-57.

Brown (2016): Peter Brown, À travers un trou d'aiguille. La richesse, la chute de Rome et la formation du christianisme en Occident, 350-550, (trad. par B. Bonne), Paris.

Costanza (1976): Salvatore Costanza, «l rapporti tra Ambrogio e Paolino di Nola», in: Giuseppe Lazzati (éd.), Ambrosius Episcopus. Atti del Convegno internazionale di studi ambrosiani nel XVI centenario della elevazione di sant'Ambrogio alla cattedra episcopale, Milano 2-7 dicembre 1974, vol. II, Milano, 220-232.

Cracco Ruggini (1976): Lellia Cracco Ruggini, «Ambrogio di fronte alla compagine sociale del suo tempo», in Giuseppe Lazzati (éd.), Ambrosius Episcopus. Atti del Convegno internazionale di studi ambrosiani nel XVI centenario della elevazione di sant'Ambrogio alla cattedra episcopale, Milano 2-7 dicembre 1974, vol. I, Milano, 230-265.

De Gaetano (2009): Myriam De Gaetano, Scuola e potere in Draconzio, Alessandria.

De Gaetano (2010): Myriam De Gaetano, «Echi politici nell'esegesi draconziana di Ez. 37,1-14», in: Clara Burini De Lorenzi, Myriam De Gaetano (édd.), La poesia tardoantica e medievale. IV Convegno internazionale di studi. Perugia, 15-17 novembre 2007. Atti in onore di Antonino Isola per il suo $70^{\circ}$ genetliaco, Alessandria.

De Gianni (2015): Donato De Gianni, «La presenza di Giovenale nel poema dell'Heptateuchos», in: BstudLat 45,1, 39-63.

Fontaine (1970): Jacques Fontaine, «Trois variations de Prudence sur le thème du Paradis», in: Walter Wimmel (éd), Forschungen zur Römischen Literatur. Festschrift zum 60. Geburtstag von K. Büchner, Wiesbaden, 96-115.

Fontaine (1976): Jacques Fontaine, «Prose et poésie: l'interférence des genres et des styles dans la création littéraire d’Ambroise de Milan», in: Giuseppe Lazzati (éd.), Ambrosius Episcopus. Atti del Convegno internazionale di studi ambrosiani nel XVI centenario della elevazione di sant'Ambrogio alla cattedra episcopale, Milano 2-7 dicembre 1974, vol. I, Milano, 124-170.

Furbetta (2017): Luciana Furbetta, «Da Lucrezio a Sidonio Apollinare. Esempi di intertestualità nei versi di Avito di Vienne», in: Lucio Cristante, Vanni Veronesi (éd.) Il Calamo della memoria VII, Trieste, 85-146.

Gnilka (1965-1966): Christian Gnilka, «Der Ring des Crispinus zu Juvenal und Dracontius», in: JbAC, 8-9, 177-182.

Gori (1985): Sant'Ambrogio. Opere esegetiche VI. Elia e il digiuno. Naboth. Tobia, introduzione, traduzione, note e indici di Franco Gori, Roma.

Hecquet-Noti (1999): Avit de Vienne. Histoire spirituelle, t. I, chants I-III, introduction, texte critique, traduction et notes par Nicole Hecquet-Noti, Paris.

Hoffmann (2005): Manfred Hoffmann, Alcimus Ecdicius Avitus, De spiritalis historiae gestis. Buch 3, Einleitung, Übersetzung, Kommentar, München-Leipzig.

Labarre (2011): Sylvie Labarre, «Âge d'or, Orient rêvé ou Terre promise: le Paradis de Dracontius et d’Avit», in: Anne Gimbert (éd.), Le paysage ou les reliefs du texte, Paris, 9-20. 
Mondin (2011): Luca Mondin, «Simplicitas ignava: testo e intertesto di Alc.Av. carm. 2,98-99», in: Paolo Mastandrea, Linda Spinazzé (édd.), Nuovi archivi e mezzi d'analisi per i testi poetici, Amsterdam, 217-225.

Morisi (1996): Alcimi Aviti de mundi initio. Introduzione, testo, traduzione e commento di Luca Morisi, Bologna.

Moussy-Camus (1985): Dracontius ⿷匚一urres. Tome I. Louanges de Dieu, livres I et II, texte établi, traduit et commenté par Claude Moussy et Colette Camus, Paris, CUF.

Moussy (1988): Dracontius Euvres. Tome II. Louanges de Dieu, livre III. Réparation, texte établi, traduit et commenté par Claude Moussy, Paris, CUF.

Nazzaro (2015): Antonio Vincenzo Nazzaro, «Paolino di Nola: teologo sapienziale?», in: Fabio Gasti, Michele Cutino (édd.), Poesia e teologia nella produzione latina dei secoli IV-V, Pavia, 13-28.

Neri (2015): Marino Neri, «Alcimo Avito e l'episodio del buon ladrone (spir. 3, 407-425): tra gratia Dei e paenitentia in extremis», in: Fabio Gasti, Michele Cutino (édd.), Poesia e teologia nella produzione latina dei secoli IV-V, Pavia, 133-148.

Nodes (1984): Daniel J. Nodes, «Avitus of Vienne's Spiritual History and the Semipelagian Controversy. The Doctrinal Implications of Books I-III», in: VChr XXXVIII, 185-195.

Nodes (1988): Daniel J. Nodes, «De subitanea paenitentia in Letters of Faustus of Riez and Avitus of Vienne», in: Recherches de Théologie ancienne et médiévale, LV, 30-40.

Nodes (1993): Daniel J.Nodes, Doctrine and Exegesis in Biblical Latin Poetry, Leeds.

Palumbo (2012): Stefania Palumbo, Ambrogio di Milano, De Nabuthae historia, Bari.

Roberts (1985): Michael Roberts, Biblical Epic and Rhetorical Paraphrase in Late Antiquity, Liverpool.

Romano (1959): Domenico Romano, Studi draconziani, Palermo.

Schippers (1945): Abraham Schippers, Avitus. De mundi initio, Amsterdam.

Speyer (1988): Wolfgang Speyer, «Kosmische Mächte im Bibelepos», in: Philologus, 132, $275-285$.

Speyer (1996): Wolfgang Speyer, «Die Bibeldichter Dracontius als Exeget des Sechstagewerkes Gottes», in: Georg Schöllgen, Clemens Scholten (édd.), Stimuli. Exegese und ihre Hermeneutik in Antike und Christentum. Festschrift für E. Dassmann, Münster, 464-484.

Speyer (2002): Wolfgang Speyer, «Das Leben im Garten Eden nach Dracontius», in: Jean-Michel Carrié, Rita Lizzi Testa (édd.), Humana sapit. Études d'Antiquité tardive offertes à Lellia Cracco Ruggini, Paris, 277-282.

Stella (1985-1986): Francesco Stella, «Per una teoria dell'imitazione poetica cristiana; saggio di analisi sulle Laudes Dei di Draconzio», in: Inv.Luc. 7-8, 193-224.

Stella (2001): Francesco Stella, Poesia e teologia. L'Occidente latino tra IV e VIII secolo, Milano.

Stella (2005-2006): Francesco Stella, «Imitazione interculturale e poetiche dell'alterità nell'epica biblica latina», in: Incontri triestini di filologia classica, V, 9-24.

Tandoi (1980): Vincenzo Tandoi, (recensione a) La storia di Naboth, introduzione, commento, edizione critica, traduz. a cura di Maria Grazia Mara, L'Aquila, 1975, in: A\&R, 25,1, 92-94.

Tizzoni (2014): Mark Lewis Tizzoni, Dracontius and the Wider World. Cultural and Intellectual Interconnectedness in Late FifthCentury Vandal North Africa, in: N\&N, II,1, 87-105.

Vasey (1982): Vincent R. Vasey, The Social Ideas in the Works of St. Ambrose. A Study on De Nabuthae, Roma.

Vollmer (1905): Fridericus Vollmer, Fl. Merobaudis Reliquiae. Blossii Aemilii Dracontii Carmina. Eugeni Toletani episcopi Carmina et Epistulae cum appendicula carminum spuriorum, MGH AA XIV, Berolini. 



\section{Bruno Bureau}

\section{L'autorité apostolique à travers les discours de l'Historia Apostolica d'Arator}

Parmi tous les auteurs que l'on rattache au genre de l'épopée biblique ${ }^{1}$, Arator est sans nul doute celui qui prend le plus de soin à exposer son projet et le sens qu'il va donner à sa lecture des Actes des Apôtres. Écrivant à l'évêque de Rome, Vigile, sans doute au printemps 544, au moment de lui remettre son Historia Apostolica ${ }^{2}$, il la présente en ces termes (Arat. Vig. 17-22) :

\footnotetext{
Sensibus ardor inest horum celebrare labores, quorum uoce fides obtinet orbis iter.

Versibus ergo canam quos Lucas rettulit Actus, historiamque sequens carmina uera loquar. Alternis resonabo modis quod littera pandit et res si qua mihi mystica corde datur ${ }^{3}$.
}

Si le texte de Luc est expressément nommé (Actus), le contenu du poème tel qu'il est décrit fait subir à ce matériau une double reconfiguration : le texte est envisagé sur le mode d'une forme d'épopée panégyrique (celebrare labores), mais surtout il est prévu comme un commentaire conforme à la pratique des sens multiples de l'Écriture $^{4}$. Le but de ce travail de commentaire du texte est bien d'actualiser, pour l'Église de Rome de 544, le message apostolique. On notera en effet le présent obtinet là où on attendrait obtinuit, signe que le travail d'évangélisation mené par les apôtres doit se poursuivre dans le présent et pour l'auditoire du poème lui-même qui se trouve ainsi placé dans la position des premiers auditeurs des apôtres.

Notre propos sera donc ici de montrer, à partir de quelques exemples, comment Arator dispose et recompose les discours des apôtres dans le but de construire une image de l'autorité apostolique dans l'Église conforme à la volonté de l'évêque de Rome Vigile. On se souviendra en effet que le poète écrit en un temps de controverses religieuses aiguës qui se doublent de plus de différends politiques très violents entre

1 Sur le genre lui-même voir par exemple Deproost (1997). Voir également Green (2006).

2 Sur les circonstances de cette remise, voir Arator (2017), p. xx-xxvii et 185-186. Sur les liens entre Arator et Vigile, voir Sotinel (1989).

3 Sur ce texte et en particulier sur le choix de la leçon resonabo, voir Arator (2017), p. 189-190. Voir également ibid. les antécédents de l'emploi de labores pour des héros chrétiens.

4 Le poète fait d'ailleurs lui-même une mise au point sur cette manière d'expliquer l'écriture en Arat. II.890-891 : Qui canit Ecclesiae tria dogmata saepius edit / historicum, morale sonans typicumque uolumen. On notera que cette méthode d'explication de l'Ecriture est explicitement rattachée à l'enseignement de la foi trinitaire. 
Goths et Byzantins, catholiques et ariens, monophysites, ariens et chalcédoniens ${ }^{5}$. Il est donc sans doute très important, voire crucial que le poète affirme l'autorité de Pierre et du Siège apostolique et donc la parfaite orthodoxie de celui-ci.

Pour mettre en évidence le travail considérable que le poète opère sur sa matière scripturaire, nous partirons de la place des discours dans l'économie du poème comparée à leur place dans les Actes, puis nous verrons, à partir de deux exemples, comment le poète reprend très vite la main sur son original et le recompose totalement à sa façon, avant de souligner, pour terminer, quelques points saillants de ce qu'Arator met sous le patronage de la catéchèse apostolique.

\section{La place des discours dans l'économie du poème : concentration, simplification, amplification et mise en scène épique.}

Dans son traitement des discours, Arator se livre à de très nombreuses modifications du matériau orignal des Actes qui touchent aux trois aspects fondamentaux de son projet : 1-donner un cadre épique à une geste qu'il veut représenter comme fondatrice, en peignant les apôtres comme les fondateurs de la nouvelle et parfaite cité de Rome, 2-éliminer tout ce qui pourrait détourner l'attention du lecteur de la contemplation des deux figures apostoliques de Pierre et Paul, et 3-développer certains discours pour faire apparaître clairement la dimension catéchétique de l'enseignement apostolique dans le contexte du $6^{\mathrm{e}}$ siècle.

Un bon exemple de la mise en place du cadre épique peut être donné par l'attaque des deux premiers discours de chaque apôtre. Dans les Actes, ces discours (1.16 et suiv. et 13.16 et suiv.) s'ouvrent de manière assez différente ${ }^{6}$, mais le poète n'a pas manqué de remarquer que dans l'annonce des deux discours le rédacteur des

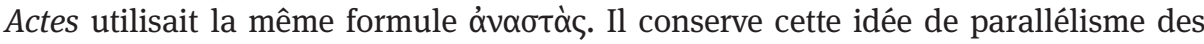
deux discours, mais la transporte sur la forme même de la parole, alors qu'il retravaille le geste de chaque apôtre pour lui donner un sens symbolique très fort.

Tout d'abord il rapproche les deux premières phrases des discours pour en faire deux facettes d'un même enseignement (Arat. I.83-84 et II. 43-44) :

...Nostis qua proditor amens

Mercedem sceleris soluit sibi;

5 Sur cette situation fort compliquée, voir Sotinel (1989) ; Sotinel (1992) ; Sotinel (2005). Voir également pour les questions théologiques Grillmeier (1993).

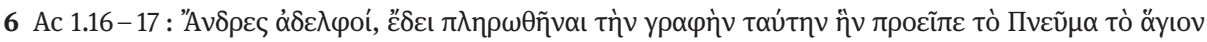

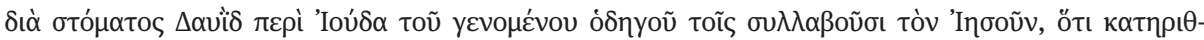

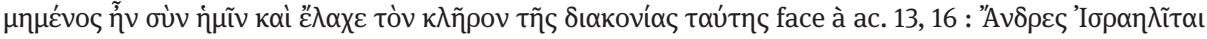

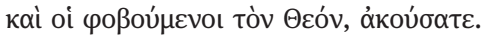


Nostis... patribus tellus Aegyptia nostris

Qua posuit feritate iugum

Ce déplacement en apparence sans importance tend clairement à souligner qu'il faut lire les paroles des deux apôtres comme strictement complémentaires, parce que leur fonction apostolique l'est également. Mais cette complémentarité est reportée à une lecture «politique» et historique de la prédication apostolique comme fondatrice de la nouvelle Rome, à travers les formules introductives qui ne doivent plus grandchose aux Actes. L'ouverture du livre 2 paraît la plus conforme à l'original ${ }^{7}$ et demeure assez sobre (Arat. II.40-42) :

Antiochi dictam de nomine uisitat urbem

Paulus et exemplo properat dare uerba cateruis

Quas synagoga tenet dextraque silentia mandans,...

mais le poète introduit une délicate référence épique à la fois par le choix du mot cateruis et par le renvoi à la figure de César dont Paul imite le geste (Lucan. I.298 ${ }^{8}$ ). $\mathrm{Au}$ contraire l'introduction du discours de Pierre donne lieu à la plus longue préparation du poème (Arat. I.69-83) :

Primus apostolico, parua de puppe uocatus, agmine Petrus erat, quo piscatore solebat Squamea turba capi. Subito de litore uisus, dum trahit, ipse trahi meruit. Piscatio Christi discipulum dignata rapit qui retia laxet humanum captura genus. Quae gesserat hamum, ad clauum est translata manus, quique aequoris imi ardebat madidas ad litora uertere praedas et spoliis implere ratem, melioribus undis nunc alia de parte leuat nec deserit artem, per latices sua lucra sequens. Cui tradidit Agnus quas passus saluauit oues, totumque per orbem hoc auget pastore gregem. Quo munere summus surgit et, insinuans diuina negotia, coram sic uenerandus ait:

Dans cet ensemble très complexe et qui rappelle les très longues introductions des discours épiques ${ }^{9}$, les derniers mots méritent toute notre attention dans la mesure où ils remotivent la figure d'Énée protecteur des siens, par un renvoi assez patent à Verg. Aen. VIII.69-71 :

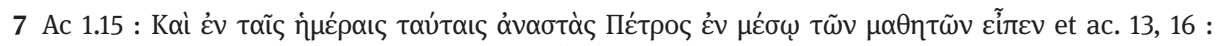

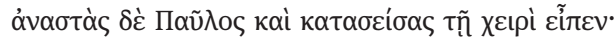

8 dextraque silentia iussit: sur le choix un peu étrange du personnage de Lucain qui n'est rien moins que sympathique, voir Bureau (1997), p. 182-183.

9 Voir par exemple Verg. Aen. XII.1-10. 
Surgit et aetherii spectans orientia solis

Lumina rite cauis undam de flumine palmis

Sustinet ac talis effundit ad aethera uoces:

«Nymphae, Laurentes nymphae, genus amnibus undest,

Tuque, o Thybri tuo genitor cum flumine sancto,

Accipite Aenean et tandem arcete periclis.

On peut donc ici parler d'un double geste fondateur d'autorité : d'un côté Pierre et Paul sont pourvus d'une forte coloration épique, et rapprochés de deux héros ouvertement dotés d'une valeur fondatrice, Énée et César, et de l'autre leur parole est présentée dès le début comme ce qui les constitue en tant que héros et assure à la fois leur lien protecteur à la communauté et l'articulation de leurs deux missions. En effet, la formule, plus ramassée pour Paul, et exempte de toute idée de primat largement affirmée pour Pierre ${ }^{10}$, prépare clairement l'image que le poète donne de l'autorité conjointe des apôtres en Arat. II.216-218 ${ }^{11}$ :

...gloria rerum

contulit ut Petro Paulum gerat ordo secundum, qui fundamentis manet architectus in illis.

Ainsi les dimensions ecclésiale, politique et théologique de l'autorité apostolique s'affirment dès le début de l'oeuvre pour culminer dans la louange finale ( Arat. II.1233-1245) :

\footnotetext{
Dignaque materies Petri Paulique coronae

Caesareas superare minas et in arce tyranni pandere iura poli, summumque in agone tribunal uincere, ne titulos paruus contingeret hostis.

Aegyptus mundi formam gerit. Inde uocari quae meruit, ducibus plebs est commissa duobus in quibus officium fraternus nexuit ortus. Idola tot Romae, mundo collecta subacto quae fuerant, tenebris obnoxia corda premebant. Liber et hic populus, quem uinxerat ante Pharao, Exuit Aegypti totidem ductoribus umbras, perque lauacra Dei, quae tunc maris egit imago, Vitae nactus iter caelestem repperit escam.
}

Cette représentation des apôtres conditionne en réalité tout le travail de recomposition du matériau scripturaire, et en particulier le choix des discours conservés ou éliminés, ainsi que la place même de la parole apostolique dans l'ensemble de l'œuvre.

10 Sur la lecture pétrinienne de l'ouverture du discours, voir Deproost (1990), p. 142-147.

11 Sur ce texte voir Deproost (1990), p. 189 et Bureau (1997), p. 129 et 293. 
En effet, de très nombreux éléments que nous jugeons, nous, fondamentaux pour la compréhension des Actes sont purement et simplement omis par Arator, ce qui le distingue par exemple du soin méticuleux que Juvencus mettait à décrire tous les épisodes de la vie de Jésus et Sédulius à décrire tous ses miracles. Cela est particulièrement vrai des discours.

Dans la partie des Actes des apôtres qui recouvre le livre 1 d'Arator, le rédacteur fait parler 23 personnages (parfois pour quelques mots) et Pierre prononce 38, $6 \%$ des paroles rapportées ; dans la seconde partie des Actes, parlent 40 personnages et Paul prononce $63 \%$ des paroles. Chez Arator, le livre 1 fait parler 5 personnages et Pierre prononce 69, $8 \%$ des paroles rapportées, tandis que le livre 2 fait parler 9 personnages et Paul prononce $84,3 \%$ des paroles ${ }^{12}$. Cette remarquable concentration sur les figures apostoliques s'accompagne évidemment de la disparition de bien d'autres locuteurs, la plus voyante étant celle d'Étienne dont le poète rapporte le martyre mais non les paroles.

On voit donc s'opérer dans cette sélection un centrage des discours sur la personne des apôtres Pierre et Paul, fût-ce au prix de l'élimination d'éléments essentiels du récit scripturaire. Mais cette tendance ne va pas sans une autre qui, derrière une apparente contradiction, confirme ce que nous venons de montrer : l'importance considérable que prennent les discours par rapport au reste du récit. Apparemment les discours sont moins importants chez Arator que dans les Actes (11,7\% du livre 1 et $23,4 \%$ du livre 2 contre $59,4 \%$ et $55,4 \%$ pour les deux parties respectives des Actes), mais cette lecture ne doit pas nous tromper car le récit chez Arator n'occupe qu'une partie très limitée de l'oeuvre, dont une bonne partie est dévolue au commentaire. Ainsi, si l'on ne prend en compte que les vers narratifs du livre 1 , soit environ 300 vers, les discours en occupent $42 \%$, ce qui se rapproche de la pratique des Actes.

On voit donc que le poète conserve à peu près la répartition entre discours et récits dans les Actes (en la réduisant un peu en éliminant des discours qu'il juge inutiles), mais que surtout il englobe l'ensemble dans un système commentatif qui recouvre environ $70 \%$ du texte et qui de ce fait constitue le poème plus comme une série d'homélies en vers que comme un récit proprement dit.

Ces tendances complexes ne sont cependant pas contradictoires, car le poète articule clairement la dimension épique, discursive et homilétique de son travail. La dimension épique lui sert à fournir un cadre à l'actualisation historico-politique du texte, ce qui fonde de manière renouvelée l'auctoritas de la parole apostolique. Le discours apparaît alors comme la pierre angulaire d'un enseignement que le poète va ensuite développer et préciser au gré de ses propres commentaires. La question de l'autorité se déplace donc légèrement pour se poser ainsi : comment le poète accrédite-t-il sa propre parole par la parole des apôtres ?

12 Pour le détail, voir Bureau (1997), p. 229-231 et Arator (2017), p. xxiv et suiv. 


\section{La manière de construire les discours en parallèle avec les discours des Actes, paraphrase exégèse et cathéchèse.}

Pour montrer le travail opéré par le poète pour «actualiser» son propos à l’Église de son temps, le discours d'adieu de Paul aux Anciens d'Asie fournit un excellent champ d'observation. Discours essentiel dans les Actes (20.18b-35), il l'est aussi dans le poème, dont il est le plus long morceau d'une seule pièce au style direct (Arat. II.831-879). On peut aborder le travail poétique sur ce discours de trois manières : la structure à la fois héritée et nouvelle que lui donne Arator, la manière dont il utilise les poètes antérieurs pour colorer son discours, et la théologie qu'il ajoute à la parole paulinienne originale.

La comparaison des deux structures montre un respect parfait par le poète de la macrostructure du discours paulinien, qui donne à penser à une stricte paraphrase de l'original. Les trois parties (rappel de la mission, évocation de la suite de la mission et recommandations finales) sont parfaitement conservées, mais le poète modifie considérablement les proportions en faveur de la partie centrale, celle qui concerne les suites de la mission. Or, si l'on observe le détail, le poète a considérablement remanié le discours en déplaçant plusieurs éléments essentiels, éliminant et ajoutant partout.

Les quatre ajouts sont évidemment les éléments-clé de la transformation, et ils relèvent clairement à la fois du rapport que le poète entretient avec la tradition poétique épique antérieure et du rapport qu'il entretient avec la tradition même de l'Église.

Le premier ajout, l'adresse solennelle, n'a rigoureusement aucun correspondant dans les Actes, mais en a plusieurs dans la tradition poétique antérieure, et, allusivement, dans la tradition paulinienne :

O delecta manus quae Christi militat armis!

O summo plebs nata Deo!

Le renvoi probable à l'univers épique passe ici par une formule chère à Silius Italicus, croisée avec un souvenir de l'éloge de Constantin par Optatien Porphyre ${ }^{13}$. Dans les deux cas, la parole apostolique se donne non comme une parole d'adieu, mais comme une exhortation au combat dans un monde romain désormais devenu chrétien et où la militia n'est plus celle du prince ou du roi terrestre mais du vrai roi du monde, le Christ. En même temps que le thème paulinien du combat spirituel se glisse, via une allusion à Paulin de Périgueux, celui de l'enfantement en Christ qui

13 Opt. 16.23-25: Omnis ab Arctois plaga finibus horrida Cauro / Pacis amat cana et comperta perennia iura, / Et tibi fida tuis semper bene militat armis, 
caractérise les saints ${ }^{14}$. Dès ce début, on observe donc comment le poète oriente la lecture du discours dans un sens qui n'est pas exclusivement, voire prioritairement celui de l'original.

Les deuxième et troisième ajouts, qui se suivent, soulignent une autre manière de repenser le texte des Actes et donc de le commenter en feignant de le paraphraser (Arat. II.839b-844) :

...Vos conuenit inde

usuram praestare piam cum uenerit Auctor, qui meriti discussor erit seruosque reposcet mensurae crementa suae. Mihi germina ferre sensibus ardor erat, quae passim credita sulcis sparsimus. At fructus tenues mala terra dolebit.

Plusieurs références évangéliques se croisent ici (Mt 25.14-30 et 13.3-23), et rattachent la parole apostolique à l'enseignement de Jésus, mais le plus intéressant n'est sans doute pas là, mais dans trois renvois de la parole apostolique à des éléments contemporains. Le premier et le plus voyant est le renvoi au poème lui-même à travers la reprise de la iunctura sensibus ardor qui se trouve aussi en Arat. Vig. 15-16 :

sensibus ardor inest horum celebrare labores,

quorum uoce fides obtinet orbis iter.

Cette reprise indique clairement que l'actualisation même de la parole de Paul se trouve dans le poème, et, par un mouvement inverse, que le poème est tout entier dépendant de la parole apostolique qui seule le justifie. Mais on peut aisément trouver un autre point de contact avec la réalité contemporaine, dans la lettre que Vigile adresse à Auxanius l'année précédant la récitation du poème, et où il parle de la charge de l'épiscopat, comme des talents confiés par Dieu aux bons serviteurs pour qu'ils les fassent fructifier (Epist. pontif. Vigil. ad Auxanium 3 [PL 69, 27]) :

superest ut Deus qui nos immeritos ineffabili misericordia honorem miserans pontificalem habere pro sua pietate concedit, donet et praemium, ut illud in nobis compleatur quod Christi Dei et Saluatoris nostri uerba testantur dicentis : «Euge serue bone et fidelis, quia in pauca fuisti fidelis supra multa te constituam "... sunt etiam quae per Dei gratiam... ad facienda bona hortentur exempla. Si enim decessoris tui illa quae a sede apostolica de fundamento petrae dominicae doctrinae bona suscipiens actibus exaequauit, imitari uolueris, et a sedis apostolicae in nullo deuiaueris constitutis.

Ainsi, la charge épiscopale et les devoirs qui s’y rattachent sont inscrits dans les mêmes termes dans la parole apostolique et dans la parole du successeur de Pierre et

14 Paul. Petric. Mart. I.232-234 : O tanto partu felix enixaque natum, / Per quem nata Deo est, unoque et mater et infans / Facta puerperio! 
les normes qu'il édicte sont comme des normes édictées par l'apôtre lui-même. Le poète marque ainsi une continuité parfaite entre l'enseignement apostolique et celui de l'évêque de Rome.

Il reste à voir, avec le dernier ajout, comment le poète utilise Paul lui-même pour compléter l'autorité du discours de son personnage de paroles non pas prononcées par lui en cette circonstance, mais qui relèvent de sa doctrine et qui donc, conformément aux canons de l'historiographie antique, pourraient lui être ici attribuées (Arat. II.871-879) :

Assuescite gazas
In lucis proferre uias operumque locare
Thesauros in sede poli; nil proderit aurum
Defossis quaesisse locis, si claudat auarus
Quod celabat humus; quod non in paupere surgit,
In tellure iacet caecoque reuoluitur antro
Obscura peccante manu; laxate supernis
Corda, precor, monitis, neque respuat ullus egeno
Tecta parare gregi, quo suscipit hospite Christum.

Tout le passage se fonde évidemment sur une lecture de $1 \mathrm{Tm}$ 6.17-19, où l'apôtre disait :

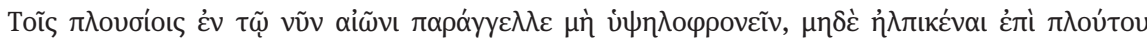

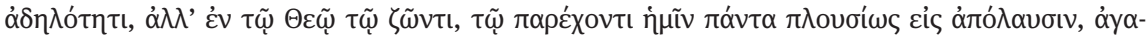

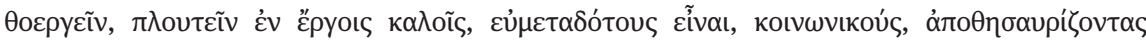

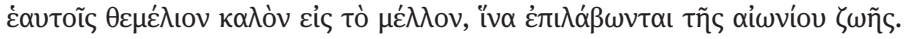

Mais il ne le fait pas exclusivement car le poète reprend l'image évangélique des trésors dans le ciel (Mt. 6.20), au point que les références évangéliques et pauliniennes se croisent sans cesse et s'interpénètrent de façon à rendre difficilement identifiable le passage de l'un à l'autre. Ce faisant, le poète associe sans cesse l'autorité apostolique et l'autorité évangélique, mais il le fait dans la lumière de la tradition de l'Église. Tout le développement est de fait en grande partie tributaire d'une homélie d'Augustin sur la fête de Pierre et Paul (Aug. serm. 296.9) :

quid recusas uapulare multis, o serue sciens uoluntatem domini tui, et faciens digna plagis? dicitur tibi - ecce una uoluntas domini tui: thesaurizate uobis thesaurum in caelo, ubi neque tinea neque aerugo neque comestura exterminat, et ubi fures non effodiunt, neque furantur. tu in terra, ille in caelo, dicens tibi: mihi da, ibi habeto thesaurum, ubi ego sum custos, mitte ante te: quid seruas? quod custodit christus, numquid tollit gothus? tu contra, prudentior scilicet et sapientior domino tuo, non nisi in terra thesaurizare uis. sed cognouisti uoluntatem domini tui, sursum te condere uoluit ille: ergo, in terra condens, paratus esto uapulare multis.

L'utilisation de l'enseignement augustinien achève ici le processus de création de l'autorité. Paul et la tradition catholique parlent de la même voix, et cette voix est en 
amont celle de l'évangile et en aval celle du siège apostolique voulu par Dieu pour conserver intact le dépôt de la vraie foi.

On comprend alors l'importance que revêtent les discours dans l'Historia Apostolica et la nécessité de leur recomposition. Ils deviennent le lieu où se manifeste de la manière la plus immédiate la continuité de la tradition évangélique et apostolique dans la foi de l'Église romaine, seule apte à énoncer la vérité de la foi dans la succession pétrinienne.

On peut donc alors observer les éléments que le poète insère sous cette autorité particulière et qu'il ajoute aux Actes pour en actualiser le propos. Ce sera le but de notre troisième et dernière partie que nous centrerons sur les discours de Pierre.

\section{Les insertions théologiques dans les discours, une catéchèse pour la Rome du $6^{\mathrm{e}}$ siècle.}

Pierre parle bien moins que Paul, mais, outre son discours d'ouverture sur lequel, faute de temps nous ne reviendrons pas, il prononce trois discours importants, quoique brefs, deux au livre 1 (devant les Anciens du Temple sur la valeur de son témoignage, Arat. I.297-301, et devant le magicien Simon, Arat. I.634-642) et un au livre 2, lorsque le poète lui fait, à la place de Jacques dans les Actes, régler la question des obligations légales auxquelles sont soumis les chrétiens (Arat. II.262273). On notera immédiatement que le poète élimine des discours extrêmement importants de Pierre, comme par exemple le discours qu'il tient au peuple après la guérison du boiteux de la Belle Porte (ac 3.12-26), celui à Corneille (ac 10.28 - 43), ou celui qu'il fait devant l'Église pour justifier le baptême des païens (ac 11, 5-17). Il faut donc évidemment expliquer pourquoi il conserve ceux-là et quelle forme d'autorité ils portent.

Le premier discours insiste clairement à la fois sur la nouveauté inouïe du message chrétien et son caractère salvateur (Arat. I.297-301 = ac 4.8-12) :

\footnotetext{
« Non hunc reticebimus » inquit

« quo remeat praestante salus qui iure creantis

infectum suppleuit opus, solidumque decorem

pars reparet quam iussa nouant. Hic membra redemptor

saucia restituit qui mortua surgere cedit ».
}

Ce discours est surtout remarquable par l'élimination de plusieurs éléments le rattachant à son contexte juif, que ce soit l'apostrophe aux Juifs, la mention de Nazaréen ou la citation de ps 117.22, pourtant très utilisé dans l'argumentation christologique $^{15}$. Mais ce qui est surtout remarquable est l'ouverture du discours non

15 Le texte original disait (ac 4.8-12) : «Chefs du peuple et anciens, nous sommes interrogés aujourd'hui pour avoir fait du bien à un infirme, et l'on nous demande comment cet homme a été 
reticebimus, qui impose la figure de Pierre, et de son successeur, comme celui qui ne peut pas ne pas annoncer la vérité de la foi, quoi qu'il doive lui en coûter. De plus, l'argumentaire de Pierre se teinte de fortes colorations pauliniennes, soulignant ainsi que d'un apôtre à l'autre la continuité doctrinale est totale. Arator introduit en effet pour évoquer le sacrifice du Christ une nette référence à Ph 3.20-21 où l'apôtre disait :

«Mais nous, nous avons notre citoyenneté dans les cieux, d'où nous attendons comme sauveur le Seigneur Jésus Christ, lui qui transformera nos pauvres corps à l'image de son corps glorieux, avec la puissance active qui le rend même capable de tout mettre sous son pouvoir».

Ainsi l'enseignement apostolique apparaît comme une doctrine unifiée et cohérente, ce qui en renforce évidemment l'autorité et le choix comme locuteur de Pierre, le disciple choisi par le Seigneur lui-même pour "affermir ses frères» impose immédiatement ces paroles comme la norme absolue de la foi.

Le deuxième discours adressé à Simon le magicien est encore plus clairement marqué par le souci de manifester la tradition de l'Église, mais cette fois dans un contexte de discipline morale (Arat. I.634-642 = ac 8.20) :

«Quisnam te, perdite,» dixit

«mouit ad ista furor, Domini quod gratia donat, ut uenale putes? Sensu hoc, non sumitur auro, nec licet ut caelum corrupta pecunia quaerat, quam terrae scrutator amat. Tibi nulla profecto hac superest in sorte quies nec ad ista uenire tu poteris, pollute dolis, qui cordis amari felle tumens aliena petis. Namque atria mentis Spiritus illa subit quae simplicitate nitescunt».

Le premier élément remarquable est évidemment que le poète supprime toute mention d'un possible pardon pour le personnage qui est réduit à sa faute ${ }^{16}$. Or cette faute elle-même est assez nettement déplacée, d'un simple désir d'argent, à la corruption même du message chrétien qui professe la gratuité du don de Dieu, puisque

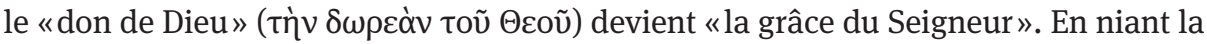

sauvé. Sachez-le donc, vous tous, ainsi que tout le peuple d'Israël : c'est par le nom de Jésus le Nazaréen, lui que vous avez crucifié mais que Dieu a ressuscité d'entre les morts, c'est par lui que cet homme se trouve là, devant vous, bien portant. Ce Jésus est la pierre méprisée de vous, les bâtisseurs, mais devenue la pierre d'angle. En nul autre que lui, il n'y a de salut, car, sous le ciel, aucun autre nom n'est donné aux hommes, qui puisse nous sauver».

16 Ce pardon possible était explicite dans l'original qui disait (ac 8.20-23) : «Périsse ton argent, et toi avec, puisque tu as estimé pouvoir acheter le don de Dieu à prix d'argent! Tu n'as aucune part, aucun droit, en ce domaine, car devant Dieu ton cœur manque de droiture. Détourne-toi donc de ce mal que tu veux faire, et prie le Seigneur : il te pardonnera peut-être cette pensée que tu as dans le cœur. Car je le vois bien : tu es plein d'aigreur amère, tu es enchaîné dans l'injustice». 
gratuité de la Grâce, Simon se condamne lui-même, et n'a plus de place pour le pardon. Ainsi la simonie ou l'amour des richesses par les clercs deviennent une faute contre la Grâce même de Dieu et donc non une faute seulement morale, mais une forme de déviance dans la foi. Ici évidemment le poète se souvient, pour faire parler le chef de l'Église, d'Aug. in psalm. 30.2.14, 21 :

non est tibi pars neque sors in hac fide; id est, non pertines ad istam gratiam, quam gratis omnes accipimus, quia pecunia te putas emere quod gratis datur. ex eo autem quod gratis datur, sors uocatur: non est tibi pars neque sors in hac fide. ista dixi, ne expauesceremus quod ait: in manibus tuis sortes meae. quae sunt enim sortes? hereditas ecclesiae.

C'est clairement cet emprunt homilétique qui opère le transfert de la réflexion morale à la réflexion ecclésiale et théologique, qui, mise dans la bouche de Pierre, prend immédiatement la valeur d'une norme intangible pour l'Église.

Le dernier discours de Pierre peut alors affirmer clairement l'autorité de l'apôtre et de son successeur dans les prescriptions légales qui constituent l'Église. Tout l'enjeu ici réside dans un double déplacement du texte original ${ }^{17}$ pour aboutir au discours de Pierre tel que le recompose le poète (Arat. II.262-273) :

\begin{abstract}
Cernitis Aeternum, saeclis memorata uetustis quae populo docili cecinerunt ore Prophetae, in nobis complesse Deum, qui maluit emptor omnibus esse salus, nullum discernere passus in pretio quo uita redit. Mihi iussit apertam gentibus hanc monstrare uiam. Quid uota morari tardarique iuuat, quidue haec aenigmata cana misceri cum luce noua ? Quos gratia purgat, ut ueniant, lex nulla uetat. Caelestis amoris materia est festina fides. Hanc Christus adoptat, hanc facit esse suam. Qua quisque merebitur uti, circumcisus adest et iure renascitur undis.
\end{abstract}

Le premier élément essentiel est extérieur à ce discours, mais fondamental pour la compréhension de l'épisode tel que le livre le poème. La décision, qui dans les Actes revient essentiellement à Jacques (ac 15.13-22), est ici le seul fait de Pierre, puisque Jacques n'apparaît même pas et que son discours n'est pas rapporté, le poète passant directement à la rédaction de la lettre pour les Églises. C'est donc Pierre, et Pierre seul, qui donne la décision et il est difficile de ne pas voir dans cette adaptation une

17 Ac 15. 7b-11: «Frères, vous savez bien comment Dieu, dans les premiers temps, a manifesté son choix parmi vous : c'est par ma bouche que les païens ont entendu la parole de l'Évangile et sont venus à la foi. Dieu, qui connaît les cœurs, leur a rendu témoignage en leur donnant l'Esprit Saint tout comme à nous ; sans faire aucune distinction entre eux et nous, il a purifié leurs cœurs par la foi. Maintenant, pourquoi donc mettez-vous Dieu à l'épreuve en plaçant sur la nuque des disciples un joug que nos pères et nous-mêmes n'avons pas eu la force de porter ? Oui, nous le croyons, c'est par la grâce du Seigneur Jésus que nous sommes sauvés, de la même manière qu’eux». 
allusion directe à l'autorité souveraine de son successeur pour toutes les questions de discipline ecclésiastique. D’ailleurs la reprise du récit est sans appel sur ce point (Arat. II.274) :

pastorem statuere sequi.

Le deuxième élément important est celui de la recomposition du plan du discours pour lui donner une structure de parole d'autorité que n'a pas l'original qui se contente de soumettre une question à la communauté. Le propos de Pierre est clairement en trois parties : l'apôtre commence par poser comme une évidence issue de l'Écriture l'appel universel au salut, puis il se pose en figure d'autorité, avant de résoudre lui-même le problème posé, en affirmant la non-nécessité de la circoncision. Or dans l'original, les deux premières parties sont imbriquées et Pierre se place en Juif qui a été choisi pour étendre le salut des Juifs aux Nations. C'est également en Juif qu'il interroge la pratique légale, avant de donner sa conviction sur la question posée. Toute la fin, très clairement normative et dogmatique dans le poème, n'existe purement et simplement pas dans l'original. On assiste donc ici, à travers une apparente fidélité à l'original, à une transposition complète du message apostolique dans le contexte de l'Église contemporaine au poète, comme si les siècles qui séparent les apôtres d'Arator étaient abolis.

La question de l'autorité apostolique apparaît donc comme le cœur du travail de recomposition que le poète fait subir aux discours des Actes des apôtres. Mais cette autorité n'est pas envisagée d'un point de vue historique (comment s'exerçait l'autorité dans les premiers temps de l'Église?), mais d'un point de vue doctrinal et disciplinaire, en lien avec l'Église de son temps. Il y a donc clairement à l'œuvre un procédé d'actualisation du texte pour le faire résonner dans le contexte politicoreligieux du $6^{\mathrm{e}}$ siècle romain.

En jouant sur les éléments épiques pour construire une figure héroïque et fondatrice des deux apôtres Pierre et Paul, le poète légitime une forme de translatio imperii de la Rome des Césars à la celle des successeurs de Pierre qui seuls gardent l'héritage de l'empire universel à travers l'universalité de l'Église.

Mais, en concentrant les discours et l'attention du public sur la figure des deux apôtres romains, Pierre et Paul, le poète fait dévier le contenu des Actes vers ce que P.A. Deproost a appelé une vision pétrinienne et romaine du texte, qui en modifie radicalement à la fois le sens et la portée théologique. C'est ce que confirme la technique de transformation des discours où Arator mélange avec virtuosité références évangéliques, pauliniennes et patristiques, pour faire tenir à ses apôtres le discours de la tradition catholique romaine, face à toute forme d'hérésie ou de contestation de l'autorité romaine.

On voit donc que le terme de paraphrase en vers ne s'applique absolument pas à ce texte qui est en réalité une construction autonome, se fondant sur les Actes des 
apôtres, mais dont le but est bien lié aux nécessités et aux combats de l'Église romaine de Vigile. Le poète qui est en réalité plus un exégète qu'un conteur parachève ainsi l'évolution du genre de l'épopée biblique, vers une forme versifiée d'homilétique.

\section{Bibliographie}

Arator (2017): Histoire apostolique, texte établi et traduit par B. Bureau \& P.-A. Deproost (trad.), Paris, France, les Belles lettres.

Bureau (1997): Bruno Bureau, Lettre et sens mystique dans l'«Historia apostolica» d'Arator: exégèse et épopée, Paris, France, Institut d'études augustiniennes.

Deproost (1990): Paul-Augustin Deproost, L'apôtre Pierre dans une épopée du Vie siècle: l'«Historia apostolica» d'Arator, Paris, France, Institut d'études augustiniennes.

Deproost (1997): Paul-Augustin Deproost, «L'épopée biblique en langue latine. Essai de définition d'un genre littéraire», Latomus 56, p. 14-39.

Green (2006): Roger P.H. Green, Latin epics of the New Testament: Juvencus, Sedulius, Arator, Oxford ; New York, Oxford University Pr.

Grillmeier (1993): Alois Grillmeier, Le Christ dans la tradition chrétienne. Tome II/2, L’Église de Constantinople au Vle siècle, Pascale-Dominique (trad.), Paris, France, les Éd. du Cerf.

Sotinel (1989): Claire Sotinel, «Arator, un poète au service de la politique du pape Vigile?», Mélanges L'École Fr. Rome Antiq., Cl, p. 805-820.

Sotinel (1992): Claire Sotinel, «Autorité pontificale et pouvoir impérial sous le règne de Justinien: le pape Vigile», in: Mélanges L'École Fr. Rome Antiq., CIV, p. 439-463.

Sotinel (2005): Claire Sotinel, «Emperors and popes in the sixth century: the western view», M.Mass, éd. Camb. Companion Age Justinian, p. 267-290. 



\title{
Severus (of Malaga?) and Narrative Construction
}

\author{
The Healing of Bartimaeus (VIII.119-153)
}

Discussing the in Evangelia libri XII is not a straightforward matter, and not simply because of the uncertain identity of the author, ${ }^{1}$ a certain Severus to whom a midninth-century catalogue of the library at Lorsch also attributes ten Eclogues and four books of Georgics, all now lost. Rather, what really makes it difficult to truly evaluate this work, which would be the last biblical epic of late antiquity, ${ }^{2}$ is the condition in which the text has reached us. We have a mere fragment of 717 hexameters that includes the end of the eighth book (228 verses), the 406 verses of the ninth book and the first 83 of the tenth. ${ }^{3}$ Added to the absence of a considerable part of the text is the fact that more than thirty percent of the surviving hexameters are shorn of either their beginning or final section.

Michele Cutino's valuable and articulate contribution has brought renewed attention to Severus's work, offering both a general introduction to the in Evangelia libri XII and a detailed analysis of its account of the resurrection of Lazarus (VIII.8-84). ${ }^{4}$ Taking up the baton from Cutino's analysis, so to speak, this enquiry focuses on the way Severus constructs his account of a miracle that appears in two of the Synoptic Gospels, and that is also treated by Sedulius. In doing so, it enables us to examine the relationships between the Severus text and both its biblical hypotexts and an alternative epic treatment of the same subject.

\section{The healing of Bartimaeus}

The object of this analysis is the passage that deals with the healing of the blind man Bartimaeus (VIII.119-153), ${ }^{5}$ which is described in the Gospels of Mark (10, 46-52)

\footnotetext{
1 We cannot be certain that the author of the in Evangelia libri XII is the same Bishop Severus of Malaga who died during the reign of the Emperor Maurice (582-602), and who authored an anti-Arian treatise mentioned in Isid. vir. inlustr. 43, 61.

2 On Latin biblical epics, I shall restrict myself to referring the reader to Herzog's classic text of 1975, Roberts' (1985) analysis and Deproost's overview (1997); on New Testament epics, such as that of Severus, see Green (2006).

3 Discovered by Bernhard Bischoff in the Stadtbibliothek in Trier (cf. Bischoff (1994) 9), the text was published by Otto Zwierlein in a critical edition with commentary that drew on the philological work of Berhard Bischoff, Willy Schetter, Reinhardt Herzog and Zwierlein himself. I have relied on this edition for the quotations in this essay.

4 Cutino (2016-2017).

5 See the commentary on this section in Bischoff (1994) 82-86.
} 
and Luke (18.35-43), as reproduced in the Appendix. ${ }^{6}$ Verse 119 (iamque propinquabant portis splendentis Jericho), which introduces the episode, follows the version in Luke: where Mark has Christ encounter the blind man as he is about to leave Jericho, Luke situates the episode as Christ is approaching the city. By following Luke on this occasion, Severus is able to introduce an excursus into a number of Old Testament episodes that took place in Jericho (119-136).

Iamque propinquabant portis splendentis Iericho
Quo primum fuerat meretrix, quę mente benigna
Sese seruauit propria cum gente relicta
Incolumis, murosque tuba cum perderet: intus
Bacchabant hostes, ipsam liquere, benignam
Experti, quam nulla ducis flexere minantis
Verba, sed egregio facto delusit iniquos.
Hanc disturbatam quondam praecepit Hiesus
Sic bustam remanere nec hanc repararier umquam
(Nomine nam luna Graeco quęrente uocatur)
Falsa deum credens uaria contagia lege
Extingui dixitque suis: “si fecerit ullus,
A supero capiet sceleris condigna”, fuitque;
Nam post effecta poenam condente creauit.
Ipsa manens lymfas habuit, quae peste necabant
Progenitos omnes, quas post purgauit Eliseus
Cum sale demonstrans Christi propiare ministros,
Qui lymfis mundi detergent crimina cuncta.

Severus first recalls the aid given by Rahab to the spies of Israel (vv. 120 -125, cf. Jos $2.1,3-5$ ), then the destruction of the city ordered by Joshua (vv. 126-132, cf. Jos 6.16-26), finding room to mention Origen's interpretation of the city's name (Jericho means 'moon' - v. 128 nomine nam luna Graeco quaerente uocatur). ${ }^{7}$ The excursus on Jericho ends with a note on the wickedness and the punishment of the city, and the purification of its waters by Elisha (2 reg 2.19-24), an act that prefigures the coming of Christ's ministers, who will wash away the sins the world by the waters of baptism (vv. 133-136).

The digression on Jericho is followed by the account of the miracle, which is of a similar length (VIII.137-153): ${ }^{8}$

6 In the Appendix, I reproduce the Vulgate text (ed. R Weber, Stuttgart 20075). In the course of my analysis, I highlight relevant differences between the Vulgate account and the variants of the Veteres Latinae.

7 Severus may have encountered this detail in Jerome's translation of Origen's Lexicon Nom. Hebr., PL 23, 1284 Jerico, odor eius, vel luna, Liber interpretationis Hebraicorum nominum CCSL 72. 137,2 Iericho odor eius sive luna and 157,6 Iericho luna sive odor eius.

818 verses in all, if we consider that v. 119 introduces both the excursus and the account of the miracle. 
Bartimias illic orbus sic prope sedebat, Timaei natus. sonitu perculsus et iste Pergentis populi coepit perquirere, quidnam Turba foret, dicuntque illi transire Hiesum.

Qui tum proclamans fatur: "iustissima Dauid Progenies, miserere, precor!” multique suadent, Vt taceat, crebroque magis clamabat at ille.

Flectitur his dominus uerbis gressumque repressit Atque uenire uirum iussit. mandata peragunt

Ex populo suadentque uiri gaudere, quod ipsum

Adfore praecepit. letus tunc ille reliquit

Vestimenta diu studens uenitque; rogatque:

"Quid tibi uis faciam?" "pande mea lumina” fatur.

Respondit: "pande! saluum te reddidit alma

Ipsa fides." qui mox dominum cum ple[be

Luminibus saluis sequitur super[umque

Cum populis, factum clarum quos [

In verses 137 and 138 (Bartimias illic orbus sic prope sedebat, / Timaei natus), Severus introduces the blind man, using the name given in Mc 10.46 (filius Timei Bartimeus), although rather than fïlius, which - followed by sonitu - would scan as a cretic, he uses nātus, that could also deemed a more elegant solution. The two evangelists have the blind man sitting at the side of the road, begging (sedebat ... mendicans). Severus limits himself to describing the man as sitting (sedebat), but only provides a vague idea of his location (illic...prope), and does not describe him as begging. In Mark, having heard (cum audisset) that Jesus of Nazareth was passing, ${ }^{9}$ the blind man begins to shout. Severus, taking his lead from Luke, gives him a more active role: Bartimaeus (et iste at the end of v. 138) hears the noise (v. 138 sonitu perculsus) of the advancing crowd and asks what is happening (Severus's coepit perquirere corresponds to the interrogabat in Luke). The description of the blind man's immediate reaction - introduced in v. 141 by qui tum, does not stray from that of the Gospels, although it does evince certain (small) formal variations: in place of the simple verb used in the Gospels, clamare, we find the compound proclamare (proclamans fatur); ${ }^{10}$ the combination of finite verb and participle in Lc 18.38 (et clamavit dicens) is mirrored in Severus's text in preference to the coordinate construction in Mark (coepit clamare et dicere), although the syntax is inverted, i.e. Severus's proclamans corresponds to the perfect clamavit in Luke, his fatur to the participle dicens. The use of the present indicative, meanwhile, instils the narrative with a greater urgency.

9 Transire Iesum might derive from Lc 18.37, or may have been suggested by a variant of Mc 10.47 found in a version of the Itala: Iesus esset qui transibat.

10 Proclamo, which the Veteres Latinae often use in invocations of God-in correspondence with the Greek ßoõv and compounds thereof (see ThLL X, 2, 1534,74-1535,8)-does not appear in any version of this episode (see Jülicher (1970²) 99 and Fischer (1989) 403 for Mark and Jülicher (1976²), 209 for Luke). 
The appeal to Christ, although repeated by the blind man in the accounts of Luke and Mark (Jesu, fili David, miserere mei), is only made once in Severus's text, with fili replaced by the stylistically more sophisticated progenies, which is qualified with iustissima ${ }^{11}$ an adjective that does not appear in the Gospel versions.

In v. 142, with his choice of multique, Severus follows Mc 10.48 (multi), rather than the more precise indications of Lc 18.39 (qui praeibant). He also attenuates the reaction of the crowd, which he expresses as suadent, a gentler term than the increpabant or corripiebant ${ }^{12}$ in Luke, or the comminabantur and its variants obiurgabant and increpabant in Mark. Describing the repetition of the blind man's calls, and their increasing intensity, he uses crebroque magis clamabat, which corresponds to the multo magis [or magis magisque] ${ }^{13}$ clamabat of the Gospels. At ille-which also features in Mark - is lent greater emphasis by its position in the clause, which is not uncommon in hexametric poetry. ${ }^{14}$

While the Gospels simply indicate that Jesus stops (stans), in v. 144 Severus also provides a reason: flectitur his dominus verbis gressumque repressit. In both the Gospel accounts, Christ orders that the blind man be brought to him, but only Mark reports the execution of this order, and the words of encouragement that the bystanders call to Bartimaeus (Mc 10.49). Severus follows Mark, but rather than the simple vocare of the Gospel, ${ }^{15}$ he uses the Ovidian pairing mandata peragere, ${ }^{16}$ and even specifies-albeit redundantly-that the order is carried out by members of the crowd following Jesus (v. 145f. mandata peragunt / ex populo). Luke moves directly into the dialogue between Christ and the blind man, while Mark first depicts Bartimaeus throwing off his cloak and rushing to Jesus. Here, Severus follows Mark, amplifying the drama by underlining the joy of the blind man (v. 147 letus) who had been so long striving (v. 148 diu studens). All the same, his reliquit vestimenta in vv. 147-148 is much less impactful than Mc 10.50, whether the proiecto (abiecto in the Afra) vestimento suo exiliens venit ad eum of the Vulgate and the Itala or the variants, ille vero [or qui] ut audivit proiecit vestimenta sua et exiliens venit. ${ }^{17}$

With venitque rogatque at the end of v. 148, a coordinate construction of suitably epic stamp, Severus sets the arrival of the blind man (venitque) and Christ's questioning (rogatque) in rapid succession, in doing so effecting a rather brusque change of

11 It is likely that this is an echo of Iuvenc. II.119: Progenies ueneranda Dei, rex inclite gentis. The iustissima of Severus, who describes Christ as iustissimus auctor in 9.94, with the adjective in the same metrical position, corresponds to Juvencus's veneranda.

12 Used in the Afra: cf. Jülicher $\left(1976^{2}\right) 209$.

13 A variant of Mc 10.48 that appears in the Itala-see Jülicher $\left(1970^{2}\right) 99$-and in some manuscripts mentioned by Fischer (1989) 407.

14 The digital archive Musisque deoque counts 30 other occurrences starting with Lucr. III.312.

15 Vocant, with the variants abierunt vocare and vocaverunt, both found in the Itala.

16 This construct is only found in Ov. Met. VII.502 (peragit mandata) and Trist. I.1.35 (peragas mandata).

17 See Fischer (1989) 412-413. 
grammatical subject. ${ }^{18}$ In v. 149 , a penthemimeral caesura separates Christ's question from the blind man's answer. The question takes the same form as it does in the Gospels: quid tibi vis faciam? (the word order is that of Luke). This is the only point in which Severus cites the Gospel text without modification, almost as though he wishes to lend Christ's intervention greater weight by reproducing his ipsissima verba. ${ }^{19}$

The answer-pande mea lumina-which is more sophisticated than the ut videam in both Mark and Luke, ${ }^{20}$ is echoed directly by the imperative pande, with which Christ addresses the blind man, 'ordering' him to see. The vocative used by the blind man in the Gospels (Domine in Luke, Rabboni in Mark) is sacrificed to achieve a more rapid exchange. In v. 149, Bartimaeus's request ends with fatur; the following verse begins with respondit, which introduces Christ's answer. Christ uses the same imperative, pande (scil. tua lumina) that the blind man had used in his request. Pande, here, has the same meaning as respice (or vide) ${ }^{21}$ in Luke (Mark, which Severus does not follow in this instance, has vade). In vv. 150 -151, the fides tua te salvum fecit of the Gospels is intensified as salvum te reddidit alma ipsa fides; ${ }^{22}$ ipsa is employed her to reinforce the nexus alma fides - although it was an especial favourite among Christian poets. ${ }^{23}$

The last three verses, which are shorn of their final sections, report the miracle and its consequences. Where both Gospel accounts use the coordinate constructions of et confestim vidit et sequebatur illum, Severus has luminibus salvis sequitur, with the ablative absolute reporting the miracle that has occurred, and the present indicative sequitur indicating the consequence - i.e. Bartimaeus becomes a follower of Christ. Lc 18.43-adding that the healed man followed, glorifying God, and that all the people, having witnessed what had happened, likewise praised God. Severus takes this ending (v. 153) and underlines it with the addition of factum clarum, a suitably epic iunctura that had been introduced into the Christian poetic tradition, in plural form, by Juvencus and adopted in the singular, as it is here, by both Paulinus of Périgueux and Arator. ${ }^{24}$ It is most likely that the final clause, now missing, lent the verse even greater impact. ${ }^{25}$

18 Another sudden change of subject occurs at 9. 251 suadet (scil. pater) / dicitque (scil. filius): Bischoff 199, 85 ad loc.

19 On the possible meanings of citations in biblical poetry, see Breau 2004. Ours is not the most meaningful example, but it is very unlikely that the use of the precise wording of the Gospel is a coincidence.

20 The construct appears, with this meaning, in Arator II.532 lumina pandit: see Bischoff (1994) 85 ad loc.

21 In the Afra, see Jülicher $\left(1976^{2}\right) 209$.

22 First appearance in Enn. scaen. $380 \mathrm{R}^{2}$ in pagan dactylic poetry, there are one occurrence of alma fides in Statius, and one in Silius Italicus.

23 Musisque deoque counts 3.

24 Iuvenc. II.242 Splendeat ut claris uirtutis gloria factis; Paul. Petr. I.71-72; 358 and 367; Arator II.1195. 
Regarding the stylistic and lexical choices made by Severus, there are a number of pertinent observations that we can add to the comments made thus far. The amque propinquabant portis at the start of v. 119 is found in Virgil, ${ }^{26}$ as is the quo primum of v. 120. The phrase mente benigna in v. 120 , which adapts a paring from Virgil, ${ }^{27}$ is found in this form in Christian poetry. ${ }^{28}$ Severus uses it again in VIII.200. The same adjective reappears three verses later (benignam, at the end of the verse), here again used to characterise Rahab's benevolent disposition towards the Jews. The construct egregio facto in v. 125 returns in the plural (facta egregia) in IX.372; the phrase fecerit ullus in v. 130 finds precedent-fecerit ulli-in Dracontius (laud. 2 , 585). With a supero in v. 131, Severus may be drawing on the a superis used more than once by Lucan as an hexameter opening, ${ }^{29}$ while the fuitque at the end of the same verse had been employed in the same metrical position in Ovid. Met. I.51 and Mart. X.63.7. Severus himself uses it again at IX.364. The sonitu perculsus in v. 138 is from Statius. ${ }^{30}$ In v. 139 Severus uses a hitherto unknown construction -a favourite of his-coepit perquirere. ${ }^{31} \mathrm{~V}$. 139 begins with the word pergentis; in the entirety of poetry, there are only two other es of the use of pergent ${ }^{*}$ to open an hexameter, one by Severus himself, the other by Juvencus, ${ }^{32}$ that Severus may well have recalled. Qui tum, which we encounter at the start of v. 141, appears five more times in all in dactylic poetry, two of these examples being in the Heptateuch Poem. ${ }^{33}$ In the blind man's appeal to Christ, rather than the miserere mei of the Gospels, Severus uses miserere precor, which he probably considered more elegant, and/or charged with greater pathos. ${ }^{34}$ In short, Severus is thoroughly entrenched in the Latin poetic tradition - both profane and Christian - and evinces a clear awareness of his own stylistic choices.

Bringing this analysis to a close, we can draw a number of conclusions. The digression on Jericho, which affords the author the opportunity to display his erudition on Old Testament matters, also reveals the character and limits of what Severus was

25 Two possible versions of the concluding clause have been proposed e.g. by the authors of the edition:credere fecit (cf. VIII.108 Lazar multos ... credere fecit) and moverat omnes: see Bischoff (1994), 86.

26 Cf. Aen. II.730 iamque propinquabam portis (Bischoff (1994), 82 ad loc.), but also iamque propinquabant, which appears in Aen. V.159; IX.371 and XI.621.

27 Aen. 1, 304 mentemque benignam: see Bischoff (1994) 83.

28 Musisque deoque counts 9 examples, starting with Mar. Victor. aleth. praef. 56.

29 Lucan. V.200; VIII.643; 847; IX.477. There is a previous example in Ovid. Pont. II.9.18 and a later one in $A L$ 761.50; cf. also Sil. III.485 a supera at the hexameter opening.

30 Theb. X.122 Nec sonitu nec uoce deae perculsus.

31 IX.96 coepit perquirere in the same position, and IX.106 perquirere coepit at the end of the hexameter.

32 With pergentes in Sev. VIII.53 and Iuvenc. II.436.

33 In exod. 173 and iud. 138 respectively.

34 Both constructs are found elsewhere in hexametric poetry: miserere precor appears on five other occasions, four of which use it in the same position as in our verse; miserere mei, meanwhile, counts seven examples, of which five mirror the positioning used by Severus. 
able to offer in terms of exegesis. He reports the 'moon' meaning of the name Jericho, taking pains to acknowledge Origen as his source (v. 128), but he does not allude to the deeper exegetic implications of this meaning. ${ }^{35}$ In a similar manner, he offers no typological interpretation of the figure of Rahab, who - in addition to being compared in the New Testament to the Patriarchs, both for her faith (Heb 11.31) and for her works (lac 2.25) - was treated, according to a widespread exegesis, as a type of the Church, who had been recruited from among the sinners and pagans. ${ }^{36}$ The only figural interpretation offered by Severus in this text is the treatment of the purification of the waters as a prefigurement of the sacrament of baptism. ${ }^{37}$ In short, Severus sets himself a decidedly didactic task - one that does not apply, for instance, to Juvencus - but proves reluctant to expand his exegesis of the events described.

In his retelling of the miracle, Severus remains true to his sources, although he is careful to follow whichever of the Gospel accounts affords him the richer and more detailed narrative of a particular instance. As such, he draws on Mark for the name of the blind man, which does not appear in Luke, but follows the latter both in his account of the timing of the miracle (as Christ was approaching Jericho, rather than on the way out, thereby enabling the author to introduce his excursus on the city), and in emphasising the involvement and reactions of the bystanders. In contrast to the two Gospels, he omits to mention Bartimaeus's 'profession' as a beggar, and where the blind man beseeches Jesus twice in the Gospels, he does so only once in our text, albeit - with the use of progenies and the addition of iustissima - in a more solemn manner.

The same miracle is described by Sedulius in carm. Pasch. IV.210-221: ${ }^{38}$

Cum residens caecus Timei filius illud

Propter iter, Dominum per quod cognouerat ire,

Vociferans crebro lumen clamore petisset

Nec populo prohibente tacens, accedere iussus

Ad Dominum palpante manu, uisumque recepit

Et nullo ducente redit. quam fortiter instat

215

Importuna fides! quidquid res dura negarit,

Sola frequens uotis oratio praestat honestis.

Vnanimum panem sic ille petebat amicum,

Qui foribus clausis per opaca silentia noctis

35 In Origen's interpretation, Jericho - with the meaning of its name - is figura mundi huius (In Jesu Nave 6.4 cf. ibid. 7.1 forma saeculi praesentis. We find an echo of this in Isid. in Jos. VII.1 f., PL 83, 374 (Jericho autem per interpretationem luna dicitur. luna vero mundi huius speciem tenet). The reasons for the mutability of the moon, represented by Jericho, are also explored: see Aug. in ps. 60.8, CCSL 39, 770, $28-31$ and 88.2.5, ibid. 1236, 32-37.

36 See Langlamet (1979) 1086-1079; this interpretation is offered first by Origen, In Jesu Nave VI.4: see Jaubert (1960) $44 \mathrm{f}$.

37 On this typological interpretation and its dissemination, see vv. 134-136 in Bischoff (1994) $84 \mathrm{f}$.

38 For a commentary on this episode, see van der Laan (1990) 137-143. 
Vocibus assiduis precibusque extorsit anhelis.

The account of the healing itself is much condensed in comparison not only to its counterpart in Luke, but also to the corresponding section of the Opus Paschale: it takes up less than six of the twelve verses, and is resolved in a single period. ${ }^{39}$ Sedulius highlights the contrast between the blind Bartimaeus who must grope his way to Christ, and the healed man who can make his way without aid (v. 213-215 accedere iussus / Ad Dominum palpante manu ${ }^{40}$, uisumque recepit / Et nullo ducente redit): as we find, in particular, in books III and IV, it is the wonder of the miracle that he is at pains to emphasise. ${ }^{41}$ Unlike Severus, Sedulius draws his account only from Luke, although he takes the Latin translation of the name Bartimaeus from Mc 10.46; like Severus, he neglects to say that he was a beggar. With the vociferans crebro clamore in v. 212 he condenses both the et clamavit dicens of Lc 18.38 and the ille autem multo magis clamabat of Lc 18.39 into a single image ${ }^{42}$ that denotes both the repetition and volume of the shouts. Unlike Luke, Sedulius does not allude to the assistance the blind man received in coming before Christ, ${ }^{43}$ an omission that heightens the drama of the scene.

The commentary that follows the account of the miracle, and exceeds it slightly in length, reveals Sedulius's concern not so much for the dynamics of the event as for the lesson that can be taken from it: that with importuna fides and frequens oratio anything can be obtained from God (v. $215 \mathrm{f}$.). In support of his interpretation, Sedulius (vv. 218-221) recalls an exemplum of a request fulfilled by virtue of its very importunitas, namely that made by the man who - with voces assiduae - convinces his friend to open the door in the middle of night and give him bread (Lc 11.5-8). ${ }^{44} \mathrm{Ul}$ timately, the miracle is retold in a manner that communicates this moral lesson.

Let us now consider the situation of the miracle in the context of the wider narrative. In Sedulius, the healing of Bartimaeus is preceded by the healing of the ten lepers (recounted in Lc 17.12-19), only one of which returns to thank Jesus and thus receives absolution form him (Lc 17.15-19). Here, Sedulius departs from the account in Luke (which continues with Jesus's declaration on the coming of the kingdom of God: 17.20 -37), drawing on the episode to proclaim Christ the true new Melchizedek. The healing of Bartimaeus follows immediately thereafter, without any indication for the reader of Christ's movements, nor of his location at the time of

39 On omissions in the poetry of Sedulius and his compression of the Gospel story, see van der Laan (1990) 137-138. For the relationship between prose and verse treatments, see Mori (2013).

40 Paul. Nol. carm. 18.349 and 20.406.

41 See Springer (2013) XXXVII.

42 See van der Laan (1990) 138.

43 Iussit adduci in Luke, and thus also in the Opus Paschale 267,13-14(ad Dominum venire iussus aliena manu perrexit): van der Laan (1990) 139.

44 On the dissemination of this interpretation of Lk 11.5-8, see van der Laan (1990) 140 ad loc. 
the miracle. In characteristic fashion, Sedulius cultivates the expressive impact of his narration ${ }^{45}$ without showing much concern for narrative continuity. In this sense, what we have is an example of his tendency to treat the Gospels as a source of exempla, which serve to illustrate different aspects of the way Christ effects the redemption of humanity. ${ }^{46}$

Severus, meanwhile, is preoccupied as always with ensuring the continuity of his narrative, not least when - as in this case - he shifts from one Gospel to another, and in particular when moving from John (which features heavily in the surviving sections of the poem) to the Synoptic Gospels and vice versa. ${ }^{47}$ Thus, after the resurrection of Lazarus (VIII.8-110) - for which he draws on John, with the miracle occurring at Bethany - he effects a smooth transition, using the adverb interea (VIII.111), to the Gospel of Luke, in which Jesus announces that he wishes to go to Jerusalem (before going on to foretell his impending death and resurrection: Lc 18.31-34). The encounter with the blind man and the miracle of his healing take place on this journey, as Christ is approaching the gates of Jericho (Lc 18.35). The introduction of the city provides an historic backdrop to the scene of the miracle, the details of which are evoked in a fluid narrative style that lends greater energy to the dialogue. ${ }^{48}$

\section{A comparison with another episode: the healing of the man blind from birth}

We can supplement this comparison between Severus and Sedulius with a brief analysis of the same authors' accounts of the miraculous restoration of another blind man's sight, namely the episode of the healing of the man born blind recounted in Jn 9. Severus IX.163-209 paraphrases the entire account; let us examine the part strictly related to the miracle (IX.163-180):

Post haec transibat Christus, subit[oque ministri

Adduxere orbum, qui numquam u[iderat

Ex partu lucem, mater quem prod[

165

Et dicunt: "doctor, filii peccat[a patrisve

45 Consider, in particular, the palpante manu, which he takes from (see above note 40), the per opaca silentia noctis, which derives from Valerius Flaccus (II.288), and the pairing vocibus adsiduis in v. 221, which is adapted from Virgil (Aen. IV.447 adsiduis ... vocibus). For a detailed analysis, see van der Laan (1990) 139 and 142-143. For an articulate summary of the expressive forms used by Sedulius and his baroque tastes, see Springer (2013) XXXIII.

46 On the use of miracles to emphasize the theme of salvation see Green (2006) $224 \mathrm{f}$.

47 On Severus's skill in preserving narrative continuity in the passage from one episode to another, see Cutino (2016-2017) 192-194.

48 It is Severus's 'flüssige Erzählungsweise' and 'lebhafte dialogische Gestaltung einzelner Szenen' that in Schetter's opinion 'weisen Severus im Rahmen der Bibeldichtung als einen Autor von Rang aus': Bischoff (1994) 7. 
Hunc talem nasci fecerunt?” [Christus ad ipsos

"Nullus peccauit, sed signat[

Confuso turbata modo complen[

Et reparare decet: capiet sub lu[mine lumen

Et cunctos doceat lingua reti[

Confundetque malos oculis fre[

Haec dicens lutum format, quod d[

Atque uolens multos homin[es

Hoc subitum clarumque nimis sple[ndensque

Ablutum misit Siloan monstr[

Qui multis populis cinctus[

Vndique currebant auidi $\operatorname{cog}[$ noscere

Qui postquam iussa lymphas [

Lumina detergit cernens et [

The incomplete verses notwithstanding, the way Severus constructs the episode is clear. ${ }^{49} \mathrm{He}$ is preoccupied with establishing narrative continuity in regard to the preceding text (v. 163 Post haec transibat Christus) and is faithful to his source save for a modification at the beginning of the account, which has the blind man brought to Christ by a third party (v. 164 adduxere orbum), whereas in John it is Christ himself who notices him.

The same miracle is narrated by Sedulius (IV.251-270) shortly after his account of the healing of Bartimaeus, the episodes only being separated by Christ's encounter with the Samaritan woman and the absolution of the adulteress. ${ }^{50}$

Inde means genitum cernit considere caecum,

Qui male praegnantis dilapsus uentre parentis

In lucem sine luce ruit. tunc sanguinis ille

Conditor humani mundique orientis origo,

Imperfecta diu proprii non passus haberi

Membra operis, natale lutum per claustra genarum

Illiniens hominem ueteri de semine supplet.

Nec uisum tamen ante capit, quam uoce iubentis

Accepta Domini Siloam uenisset ad undam

Et consanguinei tutus medicamine limi

Pura oculos fouisset aqua. mox ergo gemellae

Vultibus effulgent acies tandemque merentur

Ignotum spectare diem. cognoscite cuncti,

Mystica quid doceant animos miracula nostros.

Caeca sumus proles miserae de fetibus Euae,

Portantes longo natas errore tenebras.

Sed dignante Deo mortalem sumere formam

Tegminis humani, facta est ex uirgine nobis

49 The whole episode is commentated in Bischoff (1995) 120-127.

50 For a commentary on the passage from Sedulius see van Laan (1990) 165-175. 
Terra salutaris, quae fontibus abluta sacris

Clara renascentis reserat spiramina lucis.

Again, Sedulius's is the briefer retelling, with just thirteen verses to Severus's seventeen. The latter follows John's text closely, and includes the question posed to Christ as to the reason the man was born blind. Sedulius omits this exchange, seeking greater impact through a conceptual puzzle: in lucem sine luce ruit (v. 253, which he varies in op. pasch. IV.20: in lucem sine luce pervenit). Furthermore, in introducing the miracle, he takes the opportunity to remind the reader that Christ is the creator of the world, on a level with the Father (v. 254 Conditor humani mundique orientis origo and vv. 255-256 proprii ... membra operis). Having recounted the miracle, Severus continues to follow the narrative in John, describing the manner in which the Pharisees challenge the healed man (Jn 9.8-41). Sedulius, meanwhile, uses the six verses following the account to explain the meaning of the miracle (v. 263 cognoscite cuncti / Mystica quid doceant animos miracula nostros), ${ }^{51}$ in a manner that recalls the earlier explanation proffered by Prudentius: ${ }^{52}$ we are the descendents of Eve, blind from birth (v. 265), to whom a land of salvation has been created, deriving from the Virgin, thanks to Christ's incarnation, through the cleansing of baptism.

\section{Severus, Sedulius and the ineluctability of exegesis}

These two comparisons with Sedulius's treatments of the same episodes throw Severus's scarce propensity for reshaping the Gospel narrative for the purposes of theological or exegetic interpretation into sharp relief. All the same, in the course of his verse, Severus does not exempt himself entirely from providing explanations that he clearly believes will interest his readers. Alongside a number of excursus of a narrative character, ${ }^{53}$ the surviving portion of the poem contains four passages of exegisis. The first two consist in the figural interpretation of the purification of the waters of Jericho (VIII.133-136), which we have discussed already, and explanation of the

51 This very passage is singled out by Dermot Small (1986) 233 as 'an interesting example of Sedulius' method of extracting a spiritual significance from the literal events'. An interesting detail is that the typological interpretation here is applied to an episode from the New Testament in order that the healing of the blind man foreshadow the salvation of humanity from its spiritual blindness: see Dermot Small (1990) 199-200. On the use of amplificatio for exegetic purposes in Sedulius, see Roberts (1985) $165-171$.

52 For a comparison with Prud. Ap. 675-703, see van Laan (1990) 165-166. On the poetry of Prudentius as a precursor to Sedulius's epic verse, see Green (2006), 148-150.

53 In addition to the excursus, examined above, on Jericho (VIII.120 -136), there is the parallel between the Samaritan woman and Mary, who are compared with Jezabel and Eve (VIII.4-7) and an excursus on Herod the Great (IX.326-331) and his son Herod Antipas (IX.332-337). 
parable of the talents (VIII. 219-228). ${ }^{54}$ The third (IX.81-93) concludes the account of the healing of the paralysed man at Bethsaida (IX.40-92) - as recounted in Jn 5.2-18 - with an apostrophe directed at the reader:

Haec tamen exquirens poteris sentire priora

Et retinens facta specta, quid carpas ab illis:

$\star \star \star$

Sensus quinque puta peccataque turpia poenas,

Quis cuncti pariter foeda sub mente gemebant,

Depositum in medio, primus qui perditus esset.

Annorum numerum nomen retinere necati

Tractans inuenies, liuor quem prauus inique

Innocuum damnans mortis exordia fecit,

Vnum duo quinque triginta postea ponens.

Ex numero nomen poteris captare perempti,

Surgere quem superus indigna morte necatum

Praecepit uerum prisca signante figura.

Severus's exegesis makes reference to the topothesia with which the episode opens, ${ }^{55}$ and to the duration of the affliction, although the poet does not actually give the latter detail, no doubt assuming that the reader is familiar with the account in John where it is mentioned. As such, it appears that Severus is not concerned on this occasion with communicating every last detail of the episode, aligning himself here more closely with the approach of Sedulius. ${ }^{56}$ The apostrophe that introduces the allegorical interpretation exhorts the reader to grasp the deepest meaning of the Scriptures. The very urgency of this appeal, which is addressed to the reader in almost Dantean fashion, ${ }^{57}$ also leads us back to Sedulius. It is the only intervention of its kind among the surviving verses of the in evangelia libri, although we cannot exclude the (indeed highly likely) possibility that the roughly four fifths of the text that are lost to us contained others like it.

Severus's last exegetic digression is even more significant (IX.103-140). Elucidating the episode of the withered fig tree, ${ }^{58}$ which he interprets as Christ's warning to Judas (IX.124-136), Severus is at pains to put his own, original exegesis -incidenntally, the only one in any of the surviving verses - of which he claims true authorship in perspective (vv. 137-149):

54 On the nature of this reflection and the paraenesis that follows (8, 224-228), see Cutino 20162017, 198-199.

55 9, 40-44, which closely follows the description in Jn 5.2.

56 As demonstrated in Springer (1988) 28-48 and (2013) XXXV-XXXIX, Sedulius imagined a readership of initiates, who would not be 'novices to the faith by any means' (Springer (2013) XXXV). 57 The obvious reference is to Auerbach (1954).

58 IX, 103-140, on which see Cutino (2016-2017) 199-201. 
Diximus haec nostros sensus proferre uolentes; ast alios, quo quisque modo perquirere temptat, inueniet, gemmae quoniam sunt gesta superna, quae, quocumque modo tractantur, pulchra uidentur.

The poet states that he is providing his own interpretation, but that anyone who seeks to explore the meaning of the sacred text may derive another. After all, the gesta superna are precious jewels that retain their beauty however they are treated. It is a declaration that suggests that Severus considered exegesis as an obvious aspect of the text, whose practice is something that he, and his readers, would consider a matter of course.

Arator, perhaps unknown to Severus, ${ }^{59}$ had picked up the baton from Sedulius, liberating himself further from paraphrasis to develop the exegetic potential of epic poetry and put it at the service of biblical commentary. ${ }^{60}$ Severus, in contrast, adopts a much more paraphrastic approach, whereby he avoids modulating his narrative for the purposes of emphasising its exegetic dimension. He composes a poem that, in its very title, declares its author's adherence to the epic tradition and that of Virgil in particular. ${ }^{61}$ However, it is a work that, in contrast to Sedulius (who establishes a lively dialectic relationship with the Virgilian model), ${ }^{62}$ makes little space for theological or doctrinal considerations. ${ }^{63}$ All the same, writing after Sedulius - whose works he knew and clearly appreciated ${ }^{64}$ - Severus would not have been unaware of the exegetic bent his precursor had brought to the tradition of epic biblical verse (both Old and New Testament) and indeed he acknowledges it, albeit in measured fashion. His attitude, although timid in comparison to that of Sedulius, appears audacious when measured against Juvencus, a poet who shared Severus's enthusiasm for narration. Paradoxically, the very admission of few exegetic excursus, on the part of Severus, reluctant as he is to stray too far in his poem from the letter of the Gospels, helps us to appreciate how, with Sedulius, exegesis had become a distinctive trait of the Bibelepik tradition - one that would be inescapable for the poets that were to follow - and how, in this sense, the Carmen Paschale represents a watershed in the history of late-antique epic biblical poetry.

59 See Bischoff (1994) 23f. and notes 28 and 29.

60 On this aspect of Arator's writing, see Bureau-Deproost (2017), in particular XXVII-XLVII.

61 Even to the point that the surviving incipts follow those of the corresponding Virgilian books.

62 See, in particular, van Der Laan (1993) 142-143.

63 See Cutino (2016-2017) 212f.

64 See Bischoff (1994) 17-20 


\section{Appendix}

\section{Lc 18}

${ }^{35}$ Factum est autem cum adpropinquaret Hiericho cæcus quidam sedebat secus viam mendicans ${ }^{36}$ et cum audiret turbam prætereuntem interrogabat quid hoc esset $^{37}$ dixerunt autem ei quod Iesus Nazarenus transiret ${ }^{38}$ et clamavit dicens Iesu Fili David miserere mei ${ }^{39}$ et qui praeibant increpabant eum ut taceret ipse vero multo magis clamabat Fili David miserere mei ${ }^{40}$ stans autem Iesus jussit illum adduci ad se et cum adpropinquasset interrogavit illum ${ }^{41}$ dicens quid tibi vis faciam at ille dixit Domine ut videam ${ }^{42}$ et Iesus dixit illi respice fides tua te salvum fecit ${ }^{43}$ et confestim vidit et sequebatur illum magnificans Deum et omnis plebs ut vidit dedit laudem Deo

\section{Mc 10}

${ }^{46}$ Et veniunt Hierichum et proficiscente eo de Hiericho et discipulis eius et plurima multitudine filius Timei Bartimeus caecus sedebat iuxta viam mendicans ${ }^{47}$ qui cum audisset quia Iesus Nazarenus est coepit clamare et dicere Fili David Iesu miserere mei ${ }^{48}$ et comminabantur illi multi ut taceret at ille multo magis clamabat Fili David miserere mei $^{49}$ et stans Iesus praecepit illum vocari et vocant caecum dicentes ei animaequior esto surge vocat te ${ }^{\mathbf{5 0}}$ qui proiecto vestimento suo exiliens venit ad eum ${ }^{51}$ et respondens illi Iesus dixit quid vis tibi faciam caecus autem dixit ei rabboni ut videam ${ }^{52}$ Iesus autem ait illi vade fides tua te salvum fecit et confestim vidit et sequebatur eum in via

\section{Bibliography}

Auerbach (1954): Erich Auerbach, 'Dante's Addresses to the Reader', in: Romance Philology, 7, $268-78$.

Bischoff (1994): Severi episcopi <Malacitani?> in Evangelia libri XII. Das Trierer Fragment des

Bücher VIII-X. Unter Mitwirkung von R. Herzog erstmalig herausgegeben und kommentiert von

B. Bischoff und W. Schetter, bearbeitet von O. Zwierlein, München.

Bureau (2004): Bruno Bureau, 'Citer et/ou paraphraser chez quelques poètes bibliques latins: Juvencus, Sedulius, Arator', in: C. Darbo-Peschanski (ed.), La citation dans l'Antiquité: actes du colloque du PARSA Lyon, 6-8 novembre 2002, Grenoble, 199-219.

Bureau-Deproost (2017): Arator, Histoire Apostolique, Texte établi, traduit et commenté par B. Bureau et P.-A. Deproost, Paris.

Cutino (2016 - 2017): Michele Cutino, 'L'accomplissement de la paraphrase néotestamentaire en Occident: les In evangelia libri de Severus de Malaga', in: RET 6, Suppl. 4, 189-213.

Deproost (1997): Paul-Augustin Deproost, 'L'épopée biblique en langue latine. Essai de définition d'un genre littéraire', in: Latomus, 56, 14-39.

Dermot Small (1986): Caroline Dermot Small, 'Rhetoric and Exegesis in Sedulius' Carmen Paschale', in: C\&M 37, 223-244. 
Dermot Small (1990): Caroline Dermot Small, 'Typology in Sedulius' Carmen Paschale', in: Studia Patristica 18 /4, Kalamazoo-Leuven, 195-200.

Fischer (1989): Bonifatius Fischer, Die lateinischen Evangelien bis zum 10. Jahrhundert, II., Varianten zu Markus, 1989.

Green (2006): P.H. Green, Latin Epics of the New Testament. Juvencus, Sedulius, Arator, Oxford. Herzog (1975): Reinhart Herzog, Die Bibelepik der lateinischen Spätantike: Formgeschichte einer erbaulichen Gattung, Vol. 1, München.

Jaubert (1960): Annie Jaubert (ed.), Origène, Homélies sur Josué, Paris [SC 71].

Jülicher $\left(1970^{2}\right)$ : Adolf Jülicher, Itala. Das neue Testament in altlateinischer Überlieferung. II Marcus-Evangelium, Berlin.

Jülicher (1976²): Adolf Jülicher, Itala. Das neue Testament in altlateinischer Überlieferung. III Lucas-Evangelium, Berlin-New York.

Langlamet (1979): F. Langlamet, 'Rahab', Dictionnaire de la Bible, Suppl. 9, Paris, 1065-1092.

Mori (2013): Roberto Mori, Sedulio: tra prosa e poesia. L’Opus Paschale e il Carmen Paschale di Sedulio, Padova.

Roberts (1985): Michael Roberts, Biblical Epic and Rhetorical Paraphrase in Late Antiquity, Liverpool 1985

Springer (1988): Carl P. E. Springer, The Gospel as Epic in Late Antiquity. The Paschale Carmen of Sedulius, Leiden.

Springer (2013): Carl P.E. Springer, Sedulius, The Paschal Song and Hymns, translated with an introduction and notes by C. P. E. Springer, Atlanta.

van der Laan (1990): Paul Willem A. Th. van der Laan, Sedulius Carmen Paschale Boek 4, Oud-Beijerland.

van der Laan (1993): Paul Willem A. Th. van Der Laan, 'Imitation créative dans le Carmen Paschale de Sédulius', in: J. Den Boeft and A. Hilhorst (eds), Early Christian Poetry: a Collection of Essays. Leiden, Suppl. VChr 22, 135-166. 

Renaud Lestrade

\section{Usage des sources poétiques classiques et perspectives "théologiques» dans l'Heptateuchos de Cyprien le Gaulois ( $V^{\mathrm{e}} \mathrm{s}$. )}

L'Heptateuchos est une paraphrase en hexamètres virgiliens des sept premiers livres de l'Ancien Testament, probablement écrite au début du $\mathrm{V}^{\mathrm{e}} \mathrm{s}$. par un auteur non déterminé conventionnellement dénommé «Cyprianus Gallus», ${ }^{1}$ et que nous appellerons ici «Cyprien» par commodité d'expression.

Tous les lecteurs de ce long poème (5262 vers) ont été frappés par sa sobriété, comparé aux réécritures bibliques des $\mathrm{V}^{\mathrm{e}}-\mathrm{VI}^{\mathrm{e}}$ siècles : pas de déclaration d'intention liminaire, pas de notations exégétiques, d'arguments théologiques saillants ni même d'exhortations morales.

Les visées de l'œuvre comme le type de lecture de la matière biblique qu'elle est supposée véhiculer restent donc relativement obscures, et l'absence de tout projet explicite de la part de l'auteur du texte contraint à en chercher la ratio dans le fonctionnement interne.

À ce titre, l'étude du traitement du contenu narratif a déjà donné des éclaircissements, montrant comment le poète s'applique à éliminer les doublons et contradictions présents dans le texte biblique afin de produire un récit cohérent et rationalisé, quitte parfois à prendre la liberté d'inventer des motifs par nécessité dramatique $^{2}$; de façon complémentaire, il donc a paru intéressant d'examiner plus particulièrement la couche ornementale de cette poésie néoclassique, en analysant la nature des emprunts poétiques, ce qui semble motiver leur emploi, et le type de rapport intertextuel que les fragments importés entretiennent éventuellement avec leur contexte d'origine, comme on le ferait en somme pour étudier un centon, forme littéraire qui partage avec l'Heptateuchos, outre une intention manifeste d'«illustration» de la matière biblique, une forte dépendance à des monuments littéraires antérieurs comme une éthique d'effacement de l'auteur.

\footnotetext{
1 La tradition manuscrite directe crédite Juvencus ou un «Cyprianus» que la première édition partielle de l'Heptateuchos (les 165 premiers vers du Liber geneseos, par G. Morel, Paris 1560) identifia à saint Cyprien de Carthage ; une source indirecte crédite Tertullien. La dénomination «Cyprianus Gallus» est due à R. Peiper, pour son édition du CSEL en 1891, voir Peiper (1891) xxiv-xxix.

2 Voir Roberts (1985) 116 pour une analyse de la méthode, et Cutino (2016) 116-123, pour une étude de la réécriture du récit de la Chute.
} 
Il a donc été procédé à un relevé des emprunts au corpus classique dans la réécriture du livre de la Genèse par Cyprien, qu'on a tâché de classer en fonction de leur type d'usage dans le texte d'arrivée. ${ }^{3}$

\section{Chevilles métriques}

Le première catégorie donne à voir trois cas qui relèvent d'un "psittacisme virgilien » endémique dans la poésie latine postclassique, et dont le Centon de Proba est la manifestation la plus aigue. La forme du centon connaît une réévaluation relativement récente, qui s'appuie sur la conviction que ces œuvres sont le lieu d'un jeu intertextuel subtil qui échappait jusqu'à présent aux lecteurs. Pour valider ou infirmer cette théorie, il importe donc d'une part de déterminer dans quelle mesure le contexte d'origine des emprunts est présent à l'esprit du centoniste, et dans quelle mesure il s'attend à voir ce contexte présent à l'esprit du lecteur ; d'autre part, de montrer que les rapprochements des contextes de départ et d'arrivée produisent des convergences ou des collisions signifiantes. Ainsi l'étude récente du centon de Proba de par M. Bazil, ${ }^{4}$ qui oppose une «imitation analogique» à une «imitation contrastive», suppose l'existence de ce type de jeu érudit, et c'est l'un des objectifs de cette étude que de déterminer si ce type de lecture peut éclairer celle que nous faisons de l'Heptateuchos.

Ainsi, pour commencer par les contre-exemples, voyons d'abord des cas pour lesquels on n'a trouvé ni apport sémantique ou argumentatif, ni jeu décelable avec le contexte d'origine des emprunts ; ils portent seulement la simple valeur épidictique du verbe cadencé ; ce seraient les intertextes de degré zéro, si l'on veut.

Le premier exemple,

Ne trepidate simul licitos praecerpere fructus ${ }^{5}$

donne ainsi à voir la réminiscence d'un simple patron rythmique appelé par l'incipit fort ne trepidate ; dans les deux contextes, il s'agit de mots prononcés par un être divin, mais il est difficile de trouver une analogie entre des situations montrant d'une part Vénus au secours des Troyens dans l'Énéide, et d'autre part la mise en garde du premier couple par le Seigneur ; le verbe trepidare ne semble même pas employé dans la même acception, plutôt «s'empresser» chez Virgile et «craindre» chez Cyprien.

3 La relégation des deux autres grandes strates d'inspiration poétique de l'Heptateuchos, l'épopée flavienne et la poésie chrétienne de ses quasi contemporains Prudence ou Paulin de Nole relève de la limitation arbitraire du corpus d'étude.

4 Bazil (2009).

5 Cypr. Gall. gen. 66 pour Gn. 2.16, cf. Aen. IX.114 : Ne trepidate meas, Teucri, defendere naues. 
L'exemple suivant,

[...] libera tellus

uisa aperire procul montes ac uoluere fumum ${ }^{6}$

montre une reprise de tout un vers avec davantage d'opportunité narrative au premier abord (les deux exemples concernent une terre aperçue au loin depuis le large), mais sans qu'il y ait possibilité d'envisager un jeu intertextuel avec le contexte d'origine de l'extrait : la mise en relation de la fin de l'errance de Noé et de l'approche des Strophades infestées par les harpies dans l'Énéide ne produit, là encore, pas d'effet de sens décelable.

De même encore au vers 326,

atque memor uoti adolet dum altaria flammis ${ }^{7}$

avec la reprise du syntagme adolet dum altaria flammis : nous trouvons là un contexte d'origine qui constitue une scène très frappante visuellement (la chevelure de Lavinia prend feu pendant la célébration d'un sacrifice), et dont rien n'est applicable au contexte d'arrivée, qui présente une action de grâce de Noé après qu'il vient de toucher terre.

Nous aurions pu ici multiplier les exemples similaires, mais il paraitrait oiseux de gloser davantage ce qui apparaît comme des traces de l'aspect le plus artisanal de la composition poétique, activité parfois assimilée par les anciens au travail du charpentier ou du constructeur naval ; réduit à sa dimension technique, elle pouvait être décrite comme un processus d'assemblage d'unités métriques et narratives, qui pouvaient en cas de besoin être calées ou calfatées avec cola, des clausules et des iuncturae d'emprunt : pangere uersus, disaient Ennius et Lucrèce. ${ }^{8}$

\section{Formules épiques}

Examinons à présent les éléments qui justifiaient le classement du poème dans la catégorie aujourd'hui moins usitée d'«épopée biblique» : il s'agit d'une phraséologie, d'un répertoire de «formules», c'est-à-dire d'expressions fortement stéréotypées qui présentent souvent des traits linguistiques archaïques ou grammaticalement forcés, et qui visent à la liaison, à la pompe, et à la scansion dramatique et rythmique du texte ; ces formules interviennent principalement lors des transitions narratives et des évé-

6 gen. 316-317 pour Gn. 8.13, cf. Aen. III.205-206: quarto terra die primum se attollere tandem / uisa aperire procul montis ac uoluere fumum.

7 gen. 326 pour Gn. 8.20, cf. Aen. VII.68-70 : praeterea, castis adolet dum altaria taedis / et iuxta genitorem adstat Lauinia uirgo, / uisa - nefas - longis comprendere crinibus ignem.

8 Enn. ann. VIII.299 et Lucr. I.24-25. 
nements solennels ou sublimes ; dans l'Heptateuchos, on pourrait parler de «ponctuation épique».

Mais la conscience de cet apport très formel de l'épique dans les réécritures ne devrait pas nous amener à minorer la façon dont ces éléments verbaux tendent néanmoins à véhiculer une tonalité idéologique héroïque, à porter une vision du monde qui peut jurer plus ou moins avec le monde biblique qu'elles viennent illustrer.

\subsection{Transitions}

De manière emblématique on relève de nombreuses occurrences de l'utilisation de la transition nec minus interea qui par ailleurs, en dehors d'un emploi chez Stace et d'un autre chez Valerius Flaccus, est jusqu'à l'Heptateuchos une exclusivité virgilienne. ${ }^{9}$ Cette formule se range parmi la panoplie d'épicismes (nec mora, ilicet ut, haec ubi etc.) qui viennent substituer des expressions littéraires et métriquement conditionnées à la litanie de coordinations qui scandent le texte biblique d'origine.

\subsection{Idéalisation, et dramatisation de l'exposition des circonstants de temps et de lieu}

Dans le même ordre d'idées, on observe ainsi des procédés de dramatisation du passage $\mathrm{du}$ temps qui cherchent à incorporer l'action narrée à un grand drame cosmique :

Haec ubi disseruit, laetus paradisus in aula instruitur, primique adspectat lumina solis ${ }^{10}$

Scandebat medium iam sol flagrantior axem ${ }^{11}$

Tertia iamque die, cum sol candentior axe

fulgeret medio, totas dum contrahit umbras ${ }^{12}$

Il s'agit là d'une série d'emprunts à Virgile ou Ovide d'expressions emphatiques qui utilisent la course solaire comme jalon chronologique.

9 gen. 70, 293, 835, 1452, cf. Aen. I.633 ; VI.212 ; VII.572 ; XII.107, ainsi que georg. II.429 et III.311. 10 gen. 50-51 pour Gn. 2.8, cf. Aen. VI.255 : ecce autem primi sub lumina solis et ortus.

11 gen. 596 pour Gn. 18.1, cf. Aen. 6,536 : hac vice sermonum roseis Aurora quadrigis / iam medium aetherio cursu traiecerat axem.

12 gen. 745-746 pour Gn. 22.4, cf. Ov. ars III.723 : iamque dies medius tenues contraxerat umbras, et aussi Ov. met. III.143-144. 
Relèvent aussi de cette poétique épique la louange du sang des princes, encodée dans des locutions comme genus egregium, ${ }^{13}$ ainsi que l'idéalisation des circonstants de lieu et la dramatisation de leur présentation comme dans l'expression très marquée syntaxiquement du vers suivant,

Est locus Assyriis, gemino qui cingitur amne $\mathrm{e}^{14}$

avec est locus en tête de rubrique ; constatons en revanche que l'auteur a tenu à traduire du grec «Mésopotamie» par gemino qui cingitur amne, ce qui en l'occurrence sonne comme une glose scolaire, quand l'épopée, habituellement, n'hésite guère à faire cliqueter des noms propres chargés de leur plein potentiel d'exotisme.

Sont également fréquents les accents mis sur les grandes étapes du voyage (péripéties, arrivées et retours) avec le reprise de syntagmes comme iter inceptum celerans $^{15}$ ou gratatur reduces, ${ }^{16}$ ou encore la reprise d'un vers entier quasi à l'identique, avec en tout cas une structure rythmique et syntaxique identique :

atque ubi iam Phariae peruentum ad moenia terrae est ${ }^{17}$

\subsection{Mérismes}

Les exemples suivants présentent ce que Calvert Watkins, a nommé des mérismes, ${ }^{18}$

exigit ut dicta portent placitura parenti;

quae sint, quae fuerint, quae mox uentura ferantur ${ }^{19}$

des expressions analytiques et emphatiques de la totalité : ce premier cas, avec l'expression quae sint, quae fuerint, quae mox uentura trahantur, est célèbre, qui vient de Virgile et d'Homère, et exprime l'omniscience en termes temporels ; le suivant

13 gen. 908-909 : Illa tibi coniunx, moneo, de stirpe petatur / quae genus egregium nostro de sanguine ducit pour Gn. 28.2, cf. Aen. VII.213 ; 556.

14 gen. 904, cf. Aen. I.530 ; III.163 ; VII.563 ; Ov. pont. III.2.45 ; fast. II.491 ; IV.337 ; epist. XVI.53 ; met. II.95 ; XIV.488, etc.

15 gen. 935 pour Gn. 29.1, cf. Aen. VIII.90 : ergo iter inceptum celerant rumore secundo.

16 gen. 1350, pour Gn. 42.29, qui montre Jacob accueillant ses fils de retour d'Égypte, cf. Aen. V.40-41 : gratatur reduces et gaza laetus agresti / excipit ac fessos opibus solatur amicis.

17 gen. 1312 pour Gn. 42.5, cf. Aen. II.634 : Atque ubi iam patriae peruentum ad limina sedis.

18 Watkins (1995) $15 ; 43-47$.

19 gen. $1418-1419$ pour Gn. 45.9, cf. Verg. georg. IV.39 : nouit namque omnia uates, / quae sint, quae

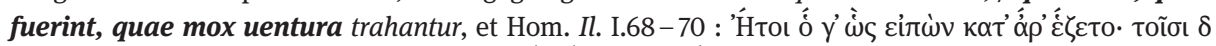

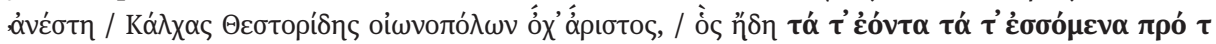
ćóvTa. 
quant à lui désigne la totalité de la vie terrestre par les différentes espèces, «les hommes, le bétail, les oiseaux et les bêtes sauvages» :

\author{
Ius delere mihi mundi peccata nocentis, \\ fluctibus aequoreis totamque inuoluere terram, \\ humanumque genum uastis mersare fluentis \\ omnigenasque simul pecudes, quae laeta per agros \\ gramina detondent, celsis dum collibus errant. \\ Serpentes nex una premat uolucresque ferasque ${ }^{20}$
}

et dans ce second cas l'emploi de cette figure du mérisme est doublée chez Cyprien par l'emploi d'un autre procédé poétique archaïque qu'il affectionne et qui est la composition «en anneau» : de mêmes termes sont ainsi redoublés, à l'ouverture et à la clôture d'un épisode dramatique ; ici, lors de la décision de détruire la Création, et une fois le fait accompli :

non uolucres leuibus suspendunt corpora pinnis, nec fera celsiiugo deuitat marmora colle ;

omnia conduntur pelago, mors omnibus una est ${ }^{21}$

\title{
2.4 Parallélismes et antithèses
}

Il y aurait davantage à dire sur le réseau de correspondance entre Cyprien et Virgile dans ce dernier cas, mais notons principalement que l'énumération des êtres vivants n'est ici pas plus une division argumentative que l'expression quae sint quae fuerint quae mox uentura n'est une expression du «triple présent» augustinien ; et si l'on énonce cette évidence, c'est pour souligner le fait que le style épique use naturellement de procédés archaïsants, dont beaucoup sont des procédés de répétition ou de balancements binaires qui constituent des ornements stylistiques sans valeur dialectique. C'est encore le cas pour les vers suivants :

ac postquam compressa fames dimotaque mensa est ${ }^{22}$

atque ubi iam saturis amor est compressus edendi ${ }^{23}$

20 gen. 243-248, cf. Verg. georg. III, 242-244: Omne adeo genus in terris hominumque ferarumque / et genus aequoreum, pecudes pictaeque uolucres, / in furias ignemque ruunt : amor omnibus idem, pour Gn. 6.7.

21 gen. 290-292 pour Gn. 7.21-23, cf. Aen. V.615-616 : [...] heu tot uada fessis et tantum superesse maris, uox omnibus una.

22 gen. 884, pour Gn. 27.25.

23 gen. 1400, pour Gn. 43.34. Pour les deux derniers vers cités, cf. Aen. I.216 : postquam exempta fames epulis mensaeque remotae, ainsi qu'Aen. VIII.84 : postquam exempta fames et amor compressus edendi. 
Si l'on considère non pas le texte de Cyprien mais l'original virgilien d'Aen. VIII.184 Fames et amor edendi semblent ici des équivalents, avec une gradation hyperbolique si l'on veut, et le cas permet de voir la façon dont un exégète lit ordinairement ce type de figure : nam iste amor edendi non edendo, sed continendo est comprimendus, dit saint Augustin en commentant incidemment ce vers dans son Contra Iulianum. ${ }^{24}$

Ainsi Augustin, avec ses réflexes dialectiques, prendra souvent une gémination pour une antithèse ou un distinguo, quand un poète comme Cyprien y verra une expression chargée que son goût peut à l'occasion lui commander d'alléger. Le problème étant, dans une perspective herméneutique, que dans le cas du livre biblique de la Genèse, il est fort possible que le texte original hébreux relève davantage de cette poétique archaïque que de l'éloquence athénienne déployée par les exégètes.

Édouard Dhorme, dans son ouvrage La poésie biblique de 1931, relevait que «les premiers chapitres de la Genèse [...] ne sont que de la prose, mais de la prose d'ordre sublime. $»^{25}$ Or cette prose usait volontiers de procédés issus de la poésie orale, le plus important en poésie hébraïque étant le parallélisme, qui consistait à «[...] diviser chaque période en deux membres, le plus souvent égaux, qui se correspondait pour le sens et pour le son. Le premier membre de la période contenait un sentiment qui, dans le second, était amplifié ou relevé par un contraste [...].» ${ }^{26}$

Enfin, il tentait d'expliquer la finalité du procédé :

L'âme est cadencée par le parallélisme, d'autant plus facilement qu'il existe au fond de nousmêmes une tendance à répéter l'idée, l'image, l'émotion, soit en elles-mêmes, soit dans leurs répliques similaires ou contrastées. ${ }^{27}$

Pour notre propos, qui concerne les interférences entre le langage et la pratique poétique d'une part, et le processus exégético-théologique d'autre part, il importe de retenir le fait que la langue poétique qui informe en partie la Genèse biblique, et en totalité notre paraphrase de Cyprien, est souvent fondée sur l'approximation, la répétition et l'analogie quand l'exégèse des Pères est principalement un processus dialectique qui se nourrit de clarté, d'antithèses et de divisions.

\section{Le commentaire moralisant}

Cette troisième catégorie présente des cas a priori plus inattendus que les ornements virgiliens déjà relevés : il s'agit d'utilisation, en commentaire du texte biblique,

24 Aug. c. Iulian. IV.771.

25 Dhorme (1931) 85.

26 Dhorme (1931) 76.

27 Dhorme (1931) 84-85. 
d'écrits à contenu satirique ou moral. ${ }^{28}$ Ce sont de plus les éléments qui se sont avérés les plus intéressants du point de vue de ce nous nommons aujourd'hui «intertextualité», c'est-à-dire qu'ils paraissent faire pleinement appel à la connaissance du contexte d'origine du fragment évoqué pour créer un phénomène polyphonique.

\subsection{Lieux communs philosophiques}

Pour débuter par des choses encore relativement convenues, notons les emprunts lucrétiens, avec d'abord le lieu commun qui euphémise la mort en l'assimilant au sommeil,

Nongentos igitur postquam complerat Adamus

ter denosque annos, sopitus morte quieuit ${ }^{29}$

sopitus morte reprenant leto sopitus ; dans l'exemple suivant, on trouve une reprise de l'utilisation péjorative de la locution delubra deum pour désigner les temples des dieux païens qui marque une convergence rationaliste ponctuelle entre le discours du chrétien et celui du païen d'obédience épicurienne :

festinat paretque deo natosque precatur,

ut delubra deum rigido formata metallo

comminuant niueoque togas sub tegmine sumant. ${ }^{30}$

\section{2 Éléments satiriques}

De manière plus étonnante relativement au contexte biblique, qui s'accommode bien d'une pincée de sagesse des nations, la réécriture de Cyprien fait régulièrement appel à des textes qui induisent un commentaire satirique de l'action narrée, comme dans le vers suivant :

soluitur in tremulos uultu crispante cachinnos ${ }^{31}$

28 Il s'agit en l'occurrence de Juvénal, Perse et Horace auquel nous ne mentionnons pas les emprunts par souci de concision, ainsi que Lucrèce, dont la présence est forte dans les hypotextes. 29 gen. 197-198 pour Gn. 5.5, cf. Lucr. III.904-905 : tu quidem ut es leto sopitus, sic eris aeui / quod super est cunctis priuatus doloribus aegris ; cf. aussi Lucr. III.1036-1038.

30 gen. 1081-1083 pour Gn. 35.2, qui voit Jacob admonester les siens, cf. Lucr. V.306-308 Denique non lapides quoque uinci cernis ab aeuo, / non altas turris ruere et putrescere saxa, / non delubra deum simulacraque fessa fatisci [...] ? cf. aussi Lucr. V.1155-1158 et VI.68-78.

31 gen. 592 pour Gn. 17,17, cf. Pers. 3.86-87 : His populus ridet, multumque torosa iuuentus / ingeminat tremulos naso crispante cachinnos. 
Cet emprunt à Perse, qui blâme dans l'original le rire idiot des sceptiques, vient ici interpréter l'incrédulité avec laquelle Abraham accueille la nouvelle de sa paternité tardive. Le fait remarquable ici est que Cyprien oppose cette lecture aux arguments autorisés : ainsi saint Paul (rom. 4, 19) juge qu'Abraham est ici admiratif et non sceptique, de même qu'Augustin. Risus Abrahae exultatio est gratulantis, non inrisio diffidentis $^{32}$ dit-il, et il semble ici que, chez l'apôtre comme chez le docteur, la théologie qui commande la louange d'Abraham guide l'exégèse d'une façon téléologique, car le texte biblique permet difficilement, pour dire le moins, de se prononcer d'une façon aussi nette.

Plus inattendue encore est l'utilisation fréquente de Juvénal, ${ }^{33}$ comme dans l'exemple suivant :

Tobelum mox Sella parit, cui fondere riuos aeris erat moris ferrumque incude subactum diuersis formare modis stridente camino ${ }^{34}$

Le texte du satiriste ici vient blâmer de manière implicite, par la reprise d'éléments presque musicaux (diuersis modis) qui connotent la vanité de l'agitation des hommes, l'impiété industrieuse de la descendance de Caïn. D’une manière analogue, dans les deux exemples suivants,

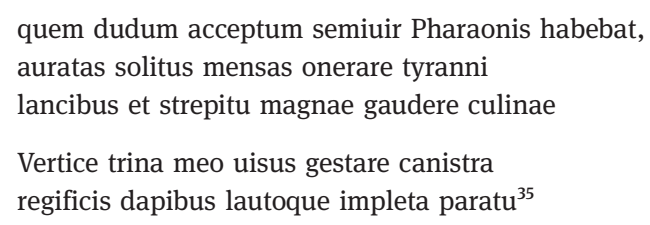

la cible implicite de l'ironie est le luxe, supposé dissolu par nature, de la cour du Pharaon où évolue Joseph, à travers la critique convenue des raffinements de la table ; ces deux accusations de cupidité et de gourmandise, ne sont, au mieux, guère explicites dans le texte biblique et comptent parmi les adjonctions remarquables au matériel biblique d'un texte qui s'en permet fort peu.

32 Aug. ciu. 16.26.2.

33 Pour les modalités et le détail des emprunts à Juvénal, voir De Gianni (2015).

34 gen. 188-190 pour Gn. 4.2, cf. Iuv. 14.116-117, où est dénoncée la façon dont l'avare accroit ses richesses : sed crescunt quocumque modo, maioraque fiunt / incude assidua, semperque ardente camino, et Iuv. 10.61-63, qui est une vitupération sur la vanité de la puissance : Iam strident ignes, iam follibus atque caminis / ardet adoratum caput et crepat ingens / Seianus [...].

35 Respectivement, gen. 1172-1174 pour Gn. 37.36 et gen. 1236-1237 pour Gn. 40.16. Les deux extraits se rapportent au même passage de la satire 14, cf. Iuv. 14.10-14 : [...] cum septimus annus / transierit puerum, nondum omni dente renato, / barbatos licet admoueas mille inde magistros, / hinc totidem, cupiet lauto cenare paratu / semper et a magna non degenerare culina, et plus loin en Iuv. 14.18-20 : An saeuire docet Rutilus, qui gaudet acerbo plagarum strepitu et nullam Sirena flagellis comparat $[\ldots]$ ? 


\subsection{Satire et intertextualité}

L'exemple suivant présente un rapport intertextuel d'autant plus convainquant qu'il dépasse la stricte correspondance formelle ; il s'agit du vers 1200, relatif au verset 39.14 de la Genèse, qui tente de caractériser la réaction de l'épouse de Putiphar lorsque Joseph refuse ses avances :

femina proclamat uiresque a crimine sumit

Iuv. VI.284-285

[...] nihil est audacius

illis deprensis : iram atque animos a crimine sumunt.

Certes, uiresque a crimine sumit trouve son modèle dans animos a crimine sumunt, mais c'est en en remontant de quelques vers dans le texte de Juvénal, en VI.268 - 271, que l'on trouve des termes qui constituent aisément une glose du comportement de l'épouse de Putiphar :

Iuv. VI.268-271

Semper habet lites alternaque iurgia lectus in quo nupta iacet ; minimum dormitur in illo.

Tum grauis illa uiro, tunc orba tigride peior, cum simulat gemitus occulti conscia facti

Le rapport intertextuel n'est pas ici rapport esthétique ou narratif, mais un rapport argumentatif.

On peut ainsi considérer que les satires 6 et 14 de Juvénal sont des intertextes de plein droit, quand la plupart des autres sources poétiques sont souvent moins et parfois plus que cela : ainsi l'Énéide en particulier n'est pas tant un intertexte qu'une matrice poétique qui opère à toutes les échelles, de l'elocutio à la vision générale du monde, mais rarement en faisant appel à un référence textuelle précise.

\subsection{La «tendance moralisante»}

Pour conclure cette rubrique, il faut dire un mot de la «tendance moralisante» de l'auteur de l'Heptateuchos, remarquée par de nombreux critiques : il abrège en effet fortement, par exemple, des chapitres entiers de la seconde partie de la Genèse, quand les réalités évoquées (le commerce, les coutumes matrimoniales, les mœurs politiques tribales, la physiologie féminine) peuvent échapper à certaines convenances ; pour autant, il ne semble pas nécessaire d'associer comme cela a été fait parfois, cette tendance à une forme d'ascétisme : pour toute une série de raisons dont la moindre n'est pas son usage sensualiste du langage, Cyprien parait moins attentif à la Loi qu'aux convenances, à une forme de decus littéraire, et sa morale nous semble ainsi moins ascétique que mondaine. 
En témoigne sa réécriture du verset 7,2 , qui voit dans la Genèse Noé sommé d'embarquer dans son arche une certaine quantité d'animaux purs, et une moindre quantité d'animaux impurs ${ }^{36}$ : dans sa paraphrase, à grex immundus est opposé pecudes mites, le «doux bétail» avec une épithète typiquement virgilienne et de valeur strictement pathétique ; sans scrupule apparent il oppose ainsi à une catégorie théologique légale un caractérisant affectif. Incidemment, cela contribue à produire une acclimatation, une interpretatio christiana de l'Ancien Testament, mais l'on peut y voir un manque d'intérêt pour la loi difficilement conciliable avec une sensibilité ascétique.

\section{La caractérisation poétique : «merveilleux» et style subjectif-empathique $^{37}$}

Voyons à présent ce qui relève de la caractérisation poétique, laquelle passe en premier lieu par les épithètes, justement, épithètes souvent topiques, qui constituent donc un fonds commun qu'il peut être difficile de rapporter à tel ou tel auteur, et qui découragent vite la recherche de sources. Cyprien se conforme en cela encore aux canons virgiliens, avec une prédilection pour la caractérisation affective et morale ; on peut grossièrement partager les nombreuses épithètes utilisées entre celles dites «de nature» (les plumes sont légères, la conjointe est fidèle, et l'araire recourbé) et celles plus directement pathétiques comme mitis Abelus ou molle pecus.

\subsection{Prodiges et merveilles}

Mais outre cette caractérisation quelque peu automatique, voyons quel type d'ornement privilégie Cyprien dans ses emprunts :

Quarta die generat solis cum lampade lunam, et stellas tremulo radiantes lumine fingit

Namque uidebatur roseum sibi cernere solem coniunctamque simul tremulo cum lumine lunam ${ }^{38}$

36 gen. 266-269 pour Gn. 7.2 : claude simul pecudes omni de germine mites / septenis paribus, immundo de grege bina / esse sines tecum [...].

37 Nous empruntons la notion de style «subjectif» ou «empathique» à Otis (1967) 41-96.

38 Respectivement, gen. 15-16 pour Gn. 1.14-17, et gen. 1141-1142 pour Gn. 37.9 (rêve d'élection de Joseph), cf. Aen. VII.8-9 : Aspirant aurae in noctem nec candida cursus / luna negat, splendet tremulo sub lumine pontus. 
En premier lieu il faut mentionner le goût pour le chatoiement lumineux ${ }^{39}$ qu'il $^{\prime}$ partage avec la poésie de l'époque, et qui, pour stéréotypé qu’il soit, n'est pas dénué d'implications affectives et même théologiques ${ }^{40}$; il peut faire preuve par ailleurs d'une relative audace, conforme néanmoins à la tendance alexandriniste tardo-antique, en usant volontiers d'images hardies à la limite de l'adynaton :

et uolucres uaria suspendunt corpora pinna

non uolucres leuibus suspendunt corpora pinnis ${ }^{41}$

Ces deux vers entrent dans un nouveau cas de construction en anneau, entre la Création et la destruction par le Déluge, cette fois : plus d'oiseaux pour suspendre leur corps à leurs plumes légères. Dans le même registre, une image pathétique,

Cumque recurrentis fulgerent septima solis

lumina, dimittit pinna plaudente uolucrem ${ }^{42}$

avec cet oiseau qui «applaudit de l'aile » (littéralement, «la plume battante»), qui, quoiqu'avec une variation syntaxique, emprunte les termes d'une scène de nature oraculaire issue de l'Iliade via l'épopée virgilienne. ${ }^{43}$

Aux vers 293-294, un emprunt inspiré assimile l'arche ballottée par les eaux du Déluge à Camille filant sur le champ de bataille à la faveur d'un simile virgilien :

Nec minus interea tumidum suspensa per aequor,

arca fluens clausum munibat pendula uatem ${ }^{44}$

$\mathrm{Au}$ vers 147, pour achever ce petit catalogue, on trouve enfin une antithèse violente pour décrire la réaction de Caïn à la préférence exprimée par le Seigneur :

quod propter gelida Cain incanduit ira ${ }^{45}$

39 Sur les modalités et les causes de cette tendance de la poésie tardo-antique, voir Roberts (1989). 40 Voir à ce sujet l'étude sur la poésie de Prudence de Gosserez (2001).

41 Respectivement gen. 20 et 290, pour Gn. 1.21 et 7.21-23, cf. Ov. met. XI.339-341 : [...] miseratus Apollo, cum se Daedalion saxo misisset ab alto, fecit auem et subitis pendentem sustulit alis.

42 gen. 306-307 pour Gn. 8.10, cf. Aen. V.513-514 : iam uacuo laetam caelo speculatus, et alis / plaudentem nigra figit sub nube columbam; cf. aussi Ov. met. 14,507.

43 Hom. Il. 23.875-881.

44 Pour Gn. 7.18, cf. Aen. VII.808-811 : illa uel intactae segetis per summa uolaret / gramina nec teneras cursu laesisset aristas, / uel mare per medium fluctu suspensa tumenti / ferret iter celeris nec tingueret aequore plantas ; cf. également Cypr. Gall. Ios. 49 (Jos. 2.10) : ut mare per medium fluctu suspensa tumenti.

45 Pour Gn. 4.5, cf. pour le verbe incandescere, qui ne connaît par ailleurs que des emplois poétiques, Verg. georg. III.478-479 : Hic quondam morbo caeli miseranda coorta est / tempestas totoque autumni incanduit aestu. 
Caïn ici « s'enflamme d'une colère glacée», et si le verbe est un vocable poétique usité par Virgile et d'autres, l'oxymore semble bien originale.

\subsection{Pathos}

Dans l'ensemble, si l'on se reporte au style biblique et à sa sécheresse en terme de caractérisation, la poésie de l'Heptateuchos nous expose à une abondance de sentimentalité, illustrée aux vers 593 et 620 par la reprise de cette image, que Virgile emprunte encore à Homère, et qui présente des personnages «roulant des pensées/ un état de fait dans leur cœur/esprit», et porte une emphase sur la vie intérieure et les perceptions affectives :

dum tacitus secum promissa ingentia uoluit

dum timet et tacito uoluit sub pectore culpam ${ }^{46}$

Dans le même ordre d'idées, Cyprien agrémente ainsi son récit biblique de mille notations empathiques : des scènes aimables, avec un vieillard qui prend le frais, magnificusque senex frigus captabat in umbra ${ }^{47}$

des vocables hypocoristiques,

sed memor eloquiis cari genitoris adhaere ${ }^{48}$

ou des tableaux plus tristes, comme aux vers 1147-1149, qui représentent Joseph en cavalier solitaire avec des termes empruntés à la lamentable histoire de Nisus et Euryale :

Ilicet excedunt iuuenes, gregibusque paternis

disquirunt laetas per florea gramina ualles ;

ad quos missus abit dumisque silentibus errat ${ }^{49}$

Sur le pôle opposé de l'aversion, le poème peut donner à voir des images horrifiques comme cette tête arrachée,

46 Respectivement gen. 593 et 620, cf. Aen. I.305 : At pius Aeneas, per noctem plurima uoluens, Aen. 4,533 : sic adeo insistit secumque ita corde uolutat ; Aen. VII.254 : et ueteris Fauni uoluit sub pectore sortem.

47 gen. 597 pour Gn. 18.1, cf. Verg. ecl. 1.51-52 : Fortunate senex! Hic inter flumina nota / et fontis sacros frigus captabis opacum.

48 gen. 903 pour Gn. 28.1, cf. pour cari genitoris Aen. I.677 ; II.560 ; VI.108.

49 Pour Gn. 37.12-14, cf. Aen. IX.393 : [...] simul et uestigia retro obseruata legit dumisque silentibus errat. 
mactandum duro testatur mox fore ferro

auulsumque caput figendum in stipite celso ${ }^{50}$

et même la reprise de la métalepse virgilienne horrendum dictu dans un songe du Pharaon:

ecce uidet spicas fecundo e germine septem, atque alias tenues et farris semine cassas (horrendum dictu !) grauidas ceu mandere fruges ${ }^{51}$

\subsection{Implications idéologiques}

La multiplication de ce type de détails porte implicitement une valorisation de la figure humaine, de la vie intérieure avec ses fluctuations émotionnelles, qui n'est là encore pas ascétique, et d'autre part crée un climat de pitié qui n'est pas de la Genèse.

Par ailleurs, les broderies bucoliques, comme d'ailleurs les amplifications épiques, suggèrent de leur côté une valorisation du monde, à rebours des tendance gnostiques qui guettent naturellement les gens cultivés qui tendent à surestimer la valeur de la connaissance : on pense ici à la jeunesse manichéenne de saint Augustin, par exemple, comme au récit de la Chute que donne Cyprien, où la théorie du péché originel en particulier est remarquablement absente, et où la tentation est comprise comme une aspiration certes illégitime mais compréhensible aux lumières de l'omniscience divine, aspiration qui n'est pas explicitement condamnée par le texte..$^{52}$

\section{Parallèles mythico-épiques}

Dans cette dernière catégorie, nous avons voulu rassembler des cas où les événements du récit biblique étaient amplifiés par des parallèles issus du fond mythicoépique gréco-romain ; ce processus d'interpénétration des imaginaires païens et bibliques ne se signale pas toujours par des correspondances formelles strictes, et relève même souvent de l'implicite.

50 gen. 1240 -1241 pour Gn. 40.19, cf. Ov. met. III.725-727 : "Adspice, mater ! ", ait. Visis ululavit Agaue / collaque iactauit mouitque per aera crinem / auulsumque caput digitis conplexa cruentis, et Aen. II.557-558, avec cette vision du cadavre du grand Priam : [...] iacet ingens litore truncus / auolsumque umeris caput et sine nomine corpus.

51 gen. 1255-1257 pour Gn. 41.5-6, cf. Aen. IV.435-454 : uidit, turicremis cum dona imponeret aris / (horrendum dictu), latices nigrescere sacros, et aussi Aen. VIII.565.

52 Voir Cutino (2016). 


\subsection{Stéréotypie dramatique}

Ainsi, il pourrait y avoir dans notre réécriture biblique une forme d'analogie intentionnelle et filée entre la figure de Caïn et celle de Turnus ; voici les éléments du dossier, avec tout d'abord la caractérisation initiale de Caïn :

ast alius curuo terram uertebat aratro $0^{53}$

Chez Virgile, le vers est une évocation posthume du "vieux Galésus», pacifique cultivateur qui tombe le premier lors de la guerre contre les Rutules, alors qu'il tente en vain de négocier la paix ; la figure associe ainsi des traits de l'un comme de l'autre des frères, la condition de Caïn et la vertu comme le destin d'Abel. Plus tard, Caïn est sur le point d'assassiner son frère,

atque ubi deprensum deserto in gramine uidit ${ }^{54}$

et Cyprien reprend alors les termes d'un reproche adressé à Turnus par l'un de ses hommes, qui est de rester dans l'inaction quand son camp est en pleine débâcle. Enfin, Caïn est condamné par le Seigneur :

nam modo quae maduit germani sanguine terra

inuiso maledicta tibi commissa negabit ${ }^{55}$

Ici est évoqué l'épisode qui voit Turnus aller au devant de sa fin, à travers l'image commune de la terre imbibée de sang. On trouve par ailleurs, de façon symétrique, deux fois l'épithète pius pour qualifier Abel dans les vers précédents, alors qu'il n'est pas si courant chez Cyprien (4 autres occurrences sur les 1500 vers du liber geneseos), ce qui renforce le réseau d'analogies. Pourtant, la comparaison ne fonctionne pas très bien, avec ses inversions et ses jeux de miroir, et on peut simplement dire sans s'avancer que la fable d'Abel et Caïn a appelé sous la plume du paraphraste des vers consacrés à Turnus ; tout cela n'a pas la belle clarté théorique d'une «imitation analogique».

53 gen. 140 pour Gn. 4.2, cf. Aen. VII.539 : [...] et terram centum uertebat aratris.

54 gen. 154 pour Gn. 4.8, cf. Aen. XII.664 : [...] Tu currum deserto in gramine uersas.

55 gen. 162-163 pour Gn. 4.11-12, cf. Aen. XII.689-692 : [...] disiecta per agmina Turnus / sic urbis ruit ad muros, ubi plurima fuso / sanguine terra madet striduntque hastilibus aurae, / significatque manu et magno simul incipit ore. 


\subsection{Motifs mythico-épiques}

Ces motifs ne sont souvent présents qu'à l'état d'harmoniques, si bien qu'il est parfois difficile de savoir si on les imagine, si l'on fait violence au texte, ou s'ils s'inscrivent dans une intention littéraire. Passons quelques exemples en revue :

Aux vers 120-121 se trouve une analogie attendue entre les conséquences agricoles de la Chute et les mythes de type Déméter-Perséphone :

Nam tibi triticeae surget pro germine messis

carduus et spinis multum paliurus acutis ${ }^{56}$

Au vers 324, on lit évocation du cheval de Troie qui l'assimile à l'Arche :

laxat claustra senex reddens noua semina terrae $e^{57}$

Laxat claustra senex pour laxat claustra Sinon : le contenu de l'Arche envoyé ensemencer la terre est donc comparé aux Grecs lancés dans le sac de Troie. C'est assez étonnant ; une fois encore, on en ferait bien une «imitation contrastive», mais on ne saurait quel sens attribuer au contraste ; peut être s'agit-il d'une analogie matérielle et visuelle entre deux massifs artefacts de bois, voire une phénomène de langage, une simple réminiscence du syntagme laxat claustra au moment de rédiger cette partie de la paraphrase.

$\mathrm{Au}$ vers 365 encore, un exemple intéressant, qui par ses sources évoque d'une part la gaieté et le dynamisme de Carthage sous le règne de Didon au livre 1 de l'Énéide, et d'autre part le cynisme cruel de Turnus tandis qu'il achève un adversaire à terre :

dumque operi instantes certatim moenia condunt ${ }^{58}$

Ces allusions viennent caractériser d'une manière prophétique et douce-amère la série de fondation de cités qui débouche sur l'épisode de Babel. Cela dit, les éléments textuels communs sont de faible ampleur ici, et il n'est pas, là encore, assuré que ce vers soit censé être lu comme une charade de ce type.

56 Pour Gn. 3.18, cf. Verg. ecl. 5.38-39 : pro molli viola, pro purpurea narcisso / carduos et spinis surgit paliurus acutis.

57 Pour Gn. 8,17-19, cf. Aen. II.252-254 : [...] fatisque deum defensus iniquis / inclusos utero Danaos et pinea furtim / laxat claustra Sinon [...].

58 Le vers fait figure d'abreuatio pour le chapitre 10 de la Genèse dans son ensemble, cf. Aen. I.503504 : talis erat Dido, talem se laeta ferebat / per medios, instans operi regnisque futuris, et Aen. XII.359-361: En agros et quam bello, Troiane, petisti, / Hesperiam metire iacens : haec praemia qui me ferro ausi temptare ferunt, sic moenia condunt. 
Le dernier exemple, en revanche, présente l'analogie, claire et filée celle-là, entre les pérégrinations de la lignée Abrahamique et celles des Troyens en Italie, avec les promesses d'imperium afférentes :

namque pater iussus terram lustrare tuendo,

flammeus e celsis quam sol utrumque recurrens

aspicit aut gemini despectant usque triones

promissam generi tanto genitore creando

cuius qui numerum gestit comprendere fatu,

stellarum citius turbas uel dicet harenae

quas pelagus dubio nonnumquam litore nudat..$^{59}$

Cette assimilation, elle, est visible un peu partout dans le liber geneseos, et c'était manifestement une similitude qui paraissait évidente à un lettré comme Cyprien.

\subsection{Religio}

Voyons enfin le vers 81 qui décrit les dénégations initiales d’Ève tentée par le serpent :

Illa negat uetitosque timet contingere ramos $^{60}$

La clausule virgilienne contingere ramos mentionnée en note n'est guère ici qu'une notation pathétique, et à l'origine une évocation pittoresque de l'âge tendre ; mais voyons à présent un extrait des Fastes :

Ov. fast. IV.747-755

Siue sacro paui, sediue sub arbore sacra, pabulaque e bustis inscia carpsit ouis ; si nemus intraui uetitum, nostrisue fugatae sunt oculis nymphae semicaperque deus ; si mea falx ramo lucum spoliauit opaco, unde data est aegrae fiscina frondis oui, da ueniam culpae [...]

En harmonie totale avec le récit de la Chute de l'Heptateuchos, ce texte nous montre dans quelle mesure, au-delà des jeux de pistes érudits, une fable comme celle de l'arbre mystique pouvait être assimilée par le romain cultivé à quelque chose de

59 gen. 463-466, pour Gn.13.14-15, cf. Aen. VII.98-101 : externi venient generi, qui sanguine nostrum / nomen in astra ferant quorumque a stirpe nepotes / omnia sub pedibus, qua Sol utrumque recurrens / aspicit Oceanum, uertique regique uidebunt. Cf. aussi Cypr. Gall. exod. 1004, pour Ex. 23,22.

60 Pour Gn. 3.2-3,3, cf. Verg. ecl. 8.39 : iam fragilis poteram ab terra contingere ramos. 
connu ; c'est là comme une définition de ce qu'un romain entendait par le mot religio, une appréhension inquiète et scrupuleuse des manifestations comme des pouvoirs latents de l'invisible.

\section{Conclusions}

\section{Composition poétique et modalités paraphrastiques}

Dans la méthode d'utilisation des sources, il n’y a pas de procédés systématiques (le même colon peut servir parfois deux buts ou situations opposés dans la réécriture), et sur un plan formel on observe une forte tendance à la réécriture des fragments sollicités plutôt qu'à la suture ; par ailleurs, pas de pratique cohérente où toutes les références seraient faites pour être identifiées, avec un beau système symétrique d'imitations contrastives et analogiques. Ce qui frappe en revanche, c'est que Cyprien semble chercher toujours dans la bible, non un éclaircissement doctrinal, mais une compréhension personnelle souvent axée sur la représentation visuelle.

Par ailleurs, ses associations d'idée et sa conception des «scènes bibliques» paraissent souvent de première main, sans qu'il s'attache jamais à invoquer telle référence philosophique ou telle exégèse autorisée ; le texte engage néanmoins un dialogue entre la bible et la culture classique, dans un processus qui relève de l'«édification» théorisée par Herzog, ${ }^{61}$ c'est-à-dire la recherche d'une intériorisation et d'une amplification du message et de la fable biblique.

\section{Caractérisation idéologique}

Il ressort de toute cette ornementation poétique néo-classique une atmosphère, des tendances à la fois religieuses et psychologiques : un anthropomorphisme divin et cosmique, la forme de relativisme que donne souvent toute culture un peu étendue, une valorisation du monde phénoménal, une valorisation aussi de la pitié qui s'exprime par ailleurs d'une façon plus théorique à travers le thème de la justice de Dieu (Il est de mon droit - Ius mihi - de détruire les péchés d'un monde mauvais, dit le Seigneur pour annoncer le déluge tout en le justifiant).

\section{Une théologie de poète}

D’un point de vue herméneutique enfin, on sent parfois poindre une attitude presque désinvolte envers le texte biblique : les exemples suivants présentent ainsi des

61 Herzog (1975) 140-145. 
clausules parenthétiques qui ressemblent à des sautes d'attention, et qui viennent poindre au moment, sans doute laborieux, du travail du poète sur la réécriture des notices généalogiques :

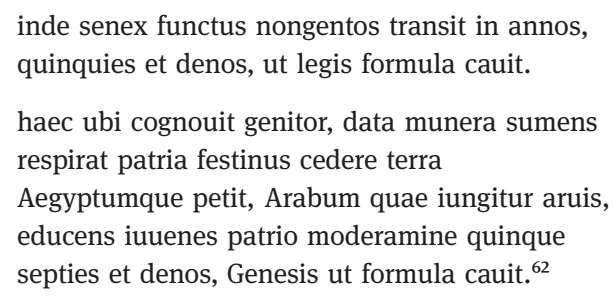

Vt legis (genesis) formula cauit : «comme le stipule la lettre de la Loi (ou de la Genèse)».

Ces phrases produisent, dans la continuité de la lecture, un effet étrange ; d'autant plus étrange que, on l'a dit, Cyprien est un auteur par ailleurs totalement invisible dans l'énonciation de l'Heptateuchos.

[...] ipsi (les Donatistes sc.) prius exegerint ut ecclesiae causa non forensibus formulis, sed magis diuinarum scripturarum testimoniis ageretur $[. . .]^{63}$

Nous portons, hors contexte, cette citation d'Augustin à l'appui de la connotation péjorative que l'on peut entendre dans le mot formula, avec son suffixe diminutif, et de fait sont opposés ici la "petite forme» de la loi humaine aux grands «témoignages» des Écritures divines.

Chez Cyprien ainsi, ce type de suspension apparente du scrupule religieux dans le rapport au texte rappelle l'attitude de saint Jérôme, qui tient en théorie pour la mystique de l'ordo uerborum, mais dans les faits, cite de manière inconstante le texte biblique et n'attache pas le même scrupule de traducteur à tous les passages de l’Écriture ; il apparaît que le christianisme des Pères a toléré une forme de nonchalance dans l'approche herméneutique, qui suppose une conception de la sacralité textuelle fondée sur une acceptation du caractère "littéraire ", c'est-à-dire partiellement arbitraire et contingent, du contenu du Livre saint.

Plus généralement, Cyprien nous apparaît comme d'une sensibilité «conciliatrice», ${ }^{64}$ (typiquement, dans sa paraphrase de Gn 1.1 il dit principio dominus caelum terramque locauit au lieu de creauit, comme pour ne pas se prononcer sur la question délicate de la préexistence de la matière) ; sensibilité conciliatrice qui est un trait marquant du stoïcisme syncrétique des intellectuels de la Rome classique, et qui prédispose à voir le nouveau comme analogue, et l'exotique comme semblable.

62 Respectivement gen. 361-362 et 1433-1437, pour Gn. 9.29 et 46.22-28.

63 Aug. Coll. Don. 3.2.51.

64 Nous empruntons le terme à Boyancé (1972) 255. 
Cette constatation d'une similitude de sensibilité intellectuelle a appelé un rapprochement avec la célèbre théorie des «trois théologies» ${ }^{65}$ de Varron, cette distinction entre une théologie civile, une théologie «fabuleuse», et une théologie naturelle dans les termes de saint Augustin ; une théologie qui vienne des juristes, des poètes ou des philosophes autrement dit.

Le texte suivant tiré du livre VI de la Cité de Dieu, est un extrait de la discussion de cette théorie par saint Augustin :

[...] cum memoratus auctor (Varron sc.) ciuilem theologian a fabulosa et naturali tertiam quandam sui generis distinguere conaretur, magis eam ex utraque temperatam quam ab utraque separatam intellegi uoluit. Ait enim ea, quae scribunt poetae, minus esse quam ut populi sequi debeant ; quae autem philosophi, plus quam ut ea uulgum scrutari expediat. "Quae sic abhorrent, inquit, ut tamen ex utroque genere ad ciuiles rationes adsumpta sint non pauca. Quare quae erunt communia cum propriis, una cum ciuilibus scribemus; e quibus maior societas debet esse nobis cum philosophis quam cum poetis ». Non ergo nulla cum poetis. Et tamen alio loco dicit de generationibus deorum magis ad poetas quam ad physicos fuisse populos inclinatos. Hic enim dixit quid fieri debeat, ibi quid fiat. Physicos dixit utilitatis causa scripsisse, poetas delectationis. Ac per hoc ea, quae a poetis conscripta populi sequi non debent, crimina sunt deorum, quae tamen delectant et populos et deos. Delectationis enim causa, sicut dicit, scribunt poetae, non utilitatis ; ea tamen scribunt, quae dii expetant, populi exhibeant. ${ }^{66}$

Nous ne nous arrêtons pas sur le détail du débat, où Varron, en bon romain, promeut la théologie civile, en tenant, en tant que lettré, à reconnaître les apports substantiels des deux autres, quand Augustin veut abattre tout l'édifice, souillé à ses yeux par les proverbiaux mensonges des poètes, dont il se méfie d'autant plus qu'il y est naturellement sensible.

Le problème que pose l'existence de cette théorie n'est donc pas, pour Augustin, sans doute, l'éventuelle prééminence de l'une des trois théologies par oppositions aux deux autres ; mais plutôt le fait qu'elle laisse entendre qu'il puisse y avoir plusieurs sources légitimes et concurrentes pour expliquer et répercuter la parole de Dieu.

Ainsi, s'il prend la peine d'attaquer la vieille division de Varron, cela semble indiquer la persistance en son temps, y compris au sein même d'un milieu scolaire contexte auquel il est probable qu'il faille rattacher Cyprien, du relativisme dénoté par cette théorie ; certains, forts de leur culture, de leur relative ignorance en théologie, et de leur habitude de la manipulation des textes, pouvaient être tentés d'approcher la Bible avec leur sensibilité propre et par suite, d'y chercher leurs propres lumières ; ce qu'Augustin, aux prises avec les conséquences politiques d'une forme de dispersion théologique, tenait probablement à prévenir.

65 Voir à ce sujet Boyancé (1972).

66 Aug. ciu. VI.6. 


\section{Bibliographie}

Bazil (2009): Martin Bazil, Centones Christiani: métamorphoses d'une forme intertextuelle dans la poésie latine chrétienne de l'Antiquité tardive, Institut d’Études Augustiniennes, Paris.

Boyancé (1972): Pierre Boyancé, "Sur la théologie de Varron » in: Id., Études sur la religion romaine, École française de Rome, Rome, 253-282.

Cutino (2016): Michele Cutino, «Per un inquadramento dell'Heptateuchos di »Cipriano Gallo «: cronologia relativa e finalità compositive ", in: "Studium in Libris », Mélanges en l'honneur de Jean-Louis Charlet, éds G. Herbert de la Portbarré-Viard \& A. Stoehr-Monjou, Collection des Études Augustiniennes, Paris, 103-123.

De Gianni (2015): Donato De Gianni, «La presenza di Giovenale nel poema dell'Heptateuchos » in: Bolletino di studi latini 45, fasc. 1, Napoli - Catania, 39-63.

Dhorme (1931): Édouard Dhorme, La poésie biblique, Paris.

Gosserez (2001): Laurence Gosserez, Poésie de lumière, une lecture de Prudence, Bibliothèque d'Études Classiques no 23, Louvain-Paris.

Herzog (1975): Reinhart Herzog, Die Bibelepik der lateinischen Spätantike: Formgeschichte einer erbaulichen Gattung, Fink, München.

Otis (1967): Brooks Otis, Vergil: A Study in Civilized Poetry, Clarendon Press, Oxford.

Peiper (1891): Cypriani Galli Poetae Heptateuchos, recensuit et commentario critico instruxit Rudolfus Peiper, CSEL 23, Vindobonae.

Roberts (1989): Michael Roberts, The Jeweled Style: Poetry and Poetics in Late Antiquity, Cornell University Press, Ithaca.

Roberts (1985): Michael Roberts, Biblical Epic and Rhetorical Paraphrase in Late Antiquity, Cairns, Liverpool.

Watkins (1995): Calvert Watkins, How to Kill a Dragon, Aspects of Indo-European Poetics, Oxford University Press, New York. 

Donato De Gianni

\title{
Four Variations on the Theme
}

\author{
"The Withered Fig Tree" (Mt 21.17-22; Mc 11.12-14. 20-25) in \\ Juvencus, Sedulius, Avitus of Vienne and Severus of Malaga(?)*
}

\section{Introduction}

Among the narratives that appear in succession in the Gospels, the episode of the barren fig tree cursed ${ }^{1}$ by the Lord has raised a wide set of different exegetic problems, both to ancient and modern critics, due to some peculiar features, which were already considered absurd by Theophylact ${ }^{2}$. Leaving aside the analogies with the parable of the fig tree in the vineyard found in Luke 13.6-9, which must be placed in a completely different context and implicates a different symbolic significance $^{3}$, the versions found in Mc 11.12-14 and Mt 21.17-22 are the only known biblical records of this miracle. In the version of Mark, the episode, which is split into two segments and frames the narrative of the cleansing of the temple (verses 15-19), closes with a parenetic speech of Christ about the power of faith and prayer, which may seem incongruous with the sequence of the events, or even cryptic, despite its internal logic and coherence. Although, in a more concise form and completely embedded in the main narrative, this dialogic addition is also found in Matthew, in the shape of an immediate back and forth between Jesus and the disciples

\footnotetext{
* All translations are mine, unless otherwise indicated.

1 The denomination commonly used to designate the episode is only deduced from the words of

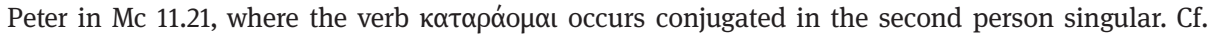
Pesch (1980 - 82) 295.

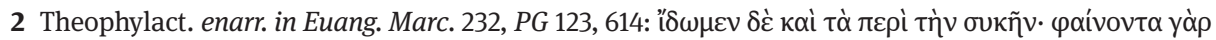

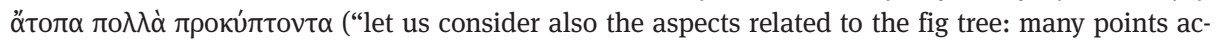
tually emerge that seem to be absurd"). Modern scholars have critically commented especially on Jesus' excessive strictness in punishing the tree and, in general, on the questions regarding the literary form of the evangelical passage, starting from the methodological approaches of the Formgeschichte and of the Redaktiongeschichte. For on of the most interesting contributions on the topic see Biguzzi (1987) 55. Original and thoroughly conducted is the recent analysis of the pericope by Grosso (2004) 121-147.

3 In the field of the scriptures, the symbolic connotations assumed by the fig tree are varied: Nathanael is identified as an Israelite through a reference to the fig tree in Ioh 1.48; elsewhere, its leaves forecast the summer (Mc 13.28); in the Old Testament tradition the fig tree is often associated with the concepts of peace and salvation (Mich 4.5; Zacch 3.10; I Macc 14.12). A broad discussion of the significance of the fig tree in classical and Christian sources, both biblical and patristic, can be found in Reichmann (1969) 640-689.
} 
about the immediate withering of the tree (verses 20 -22). The overall structure of the narrative is summarised in the following diagram:

Jesus' hunger

He approaches the tree and does not find any fruits

Because it was not the season for figs

Curses
Mc 11.12; Mt 21.18

Mc 11.13; Mt 21.19

Mc 11.13

Mc 11.14; Mt 21.19

Inserted into this common structure, which is - taking also into account that the above-mentioned parallel of Luke's narrative is based on the same plot outline deeply rooted in tradition, are grafted elements that significantly differentiate the two versions. The most obvious among these elements is certainly the passage found in Mark which generally translates as follows: "for the time of figs was not yet". This passage has been the object of botanical ${ }^{4}$ and allegorical conjectures since the time of the Church Fathers and is still the object of interpretative hypotheses of New Testament critics, who, however, tend to see in this paradoxical sentence the real expressive power of the narrative ${ }^{5}$. Thus, it is easy to understand its fruitful reception even among Christian poets, who rendered its plot in verses.

In the framework of the general debate about biblical paraphrasis that has taken place in the last 40 years ${ }^{6}$, the four most complete poetic retractationes of this New Testament passage ${ }^{7}$, realised in late antiquity by Juvencus, Sedulius, Avitus and Severus of Malaga(?) $)^{8}$, will be discussed in this paper. Similarities and differences in comparison with the narratological characteristics of the original narrative will emerge, as well as possible exegetical and theological additions, comprehensible

4 The pericope of Mark's Gospel has recently been re-examined, with new methodological approaches, by Oakman (2008) 184-186, whose interpretative proposal is originated by socio-economic premises, concerning the expropriation of farmers' lands through taxes and an accumulation of debts by the élites of the first-century Palestine, with subsequent repercussions on the agricultural production. The fig tree wood was specifically intended for sacrifices in the temple; thus, the barrenness of the fig tree would symbolically show the passage to this new agricultural and economic Palestinian system, condemned (cursed) by Jesus.

5 Some scholars have considered this aside a gloss, preceding or following the final redaction merged into the text: Hatch (1923) 6-12; Manson (1950 - 51) 271-281; Smith (1960) 326-327; some others, with grammatical stretches, have suggested to read the whole expression as an interrogative clause: Romaniuk (1975) 277-278. However, the sentence is unanimously attested by the tradition and with valid arguments defended by Grosso (2004) 123-124.

6 Among the most relevant studies are Kartschoke (1975); Herzog (1975); Kirsch (1979) 38-53; McClure (1981) 305-321; Roberts (1985); Nodes (1993); Deproost (1997) 14-39; Nazzaro (2001) 119153; Nazzaro (2006) 397-439; Dinkova-Bruun (2007) 315-342.

7 The passages from Mark and Matthew are cited according to the text of the Vetus Latina, which most probably Juvencus, too, had at hand: Jülicher (1938) 150 -151 and Jülicher (1940) 103-106. Possible comparisons with the Vulgata, which has been used by later authors, are made on the basis of the edition of Weber-Gryson $\left(2007^{5}\right)$.

8 The following critical editions have been consulted: Huemer (1891) 106-107; Huemer (1885) 94; Hecquet-Noti (2011) 168-170; Zwierlein (1994) 52-53. 
in the light of the communicative purpose and function of each poetic work. An idea of the different compositional orientations in relation to the overall structure of the works can be gleaned from the following tables:

Table 1: The Episode's Position within the Compositional Structure

\begin{tabular}{|c|c|c|}
\hline Authors & Preceding Section & Following Section \\
\hline Juvencus & $\begin{array}{l}\text { II. } 622-652: \text { entrance into Jerusalem } \sim \mathrm{Mt} \\
21.1-16 .\end{array}$ & $\begin{array}{l}\text { II. } 674-691 \text { : challenge of Jesus' au- } \\
\text { thority Mt } 21.23-27 \text {. }\end{array}$ \\
\hline Sedulius & $\begin{array}{l}\text { II. } 31-39 \text { : healing of two blind men } \sim \text { Mt } \\
\text { 20.29-34, Il. } 40-41: \text { healings in the temple } ~ \\
\text { Mt } 21.14-17 .\end{array}$ & $\begin{array}{l}\text { Il. } 57-63 \text { : healing of a mute man } \sim \text { Lc } \\
\text { 11.14-16; cf. Mt } 9.32-33 \text {. }\end{array}$ \\
\hline Avitus & $\begin{array}{l}\text { II. } 379-416 \text { : list of the biblical books suitable to } \\
\text { moral edification. }\end{array}$ & $\begin{array}{l}\text { II. } 441-502 \text { : parable of the ten virgins } \\
\text { and exegesis. }\end{array}$ \\
\hline Severus & $\begin{array}{l}\text { Il. } 40-92: \text { healing of a paralysed man at the } \\
\text { pool of Bethesda } \sim \text { loh } 5.2-18 .\end{array}$ & $\begin{array}{l}\text { II. } 143-162 \text { : Jesus' speech on the } \\
\text { power of faith } \sim \text { Mt } 21.21+\text { Lc } \\
17.7-10 \text {. }\end{array}$ \\
\hline
\end{tabular}

Table 2: Alternation of Narrative Sections and Exegetical Asides

\begin{tabular}{lrrrrr}
\hline Authors & Verses in Total & Narrative Section & $\%$ & Exegetical Aside & $\%$ \\
\hline Juvencus & 22 & 22 & 100 & 0 & 0 \\
\hline Sedulius & 15 & 10 & 66.66 & 5 & 33.33 \\
\hline Avitus & 24 & 8 & 33.33 & 16 & 66.66 \\
\hline Severus & 48 & 10 & 20.83 & 38 & 79.16 \\
\hline
\end{tabular}

\section{Spatio-Temporal Coordinates}

The retention of spatio-temporal coordinates reflects the need to guarantee that the episode is arranged as an organic narrative within the whole sequence of events ${ }^{9}$, in accordance with the classical rhetoric, which prescribes starting a narrative a per-

9 Sedulius (IV.42: talia ... post facta) and Severus (IX.93 post haec) link the narrative incipit with the previous section of the text through temporal conjunctions referring to past events, in order to obtain a coherent narrative sequence. At III.653 Juvencus prefers an opening formula that, though referring to the preceding narrative section, focuses on the words that Christ has just pronounced. It is a common device, through which the author generally links more diegetic sections, thus underlining the importance of the main character's words. In Sedul. carm. pasch. IV.43 the neuter uicina can be intended to mean either the "neighbourhood" of Bethany or the "neighbour" Bethany. 
sona or a re, and the principle of unity typical of epic poetry. Free from this compositional necessity, by contrast, is the choice of a single biblical unity expounded by Avitus, who introduces the episode by an unspecified quondam, an internal diegetic signal. Juvencus reprises the toponym Bethania (Bethaniam ... petit) and then accurately follows Matthew in referring to Jerusalem and its inhabitants (linquens cum ciuibus urbem $)^{10}$; he introduces, however, the epithet ingratam, which anticipates the possible identification of the city with the barren fig tree that has to be destroyed; this identification is suggested by the patristic sources and also on the basis of Ier 8.13. On an intertextual level, however, the possible reference to Vergil, ecl. 1.34 ingratae...urbi, which is nowhere else attested in Latin poetry, can be classified as a significant conceptual transposition: the ingratitude, which in the eclogue relates to the city dwellers, who, according to the interpretation of Servius, are guilty of scoffing the products of Tityrus and the farmers ${ }^{11}$, is transferred in the paraphrasis to Jerusalem, which refuses the salvific gifts offered by God through his Son.

On the other hand, completely free from negative implications is the epithet $D a$ vitica, which Sedulius ascribes to Jerusalem, on the basis of some Old Testament formulations ${ }^{12}$. Severus is the only one to mention the presence of the disciples, found in verse 11 of Mark's writing, which is a necessary elucidation in the narrative framework built by the poet, who, underlining the role of the disciples as the first recipients of the symbolic explanation of the prodigy, makes them a projection of the reader who is to be instructed. In the very first verse, the final clause iustissimus auctor, already found in Ov. met. XV.833 ${ }^{13}$ with reference to Augustus, represents a clear example of an ersetzende Übertragung ${ }^{14}$; in a contamination of cultural models, however, the Ovidian reminiscence blends with the traditional messianic attribute of Christ, defined as auctor already in Hbr 2.10 and 5.9. The reference to justice, another biblical divine prerogative, discloses the reason behind the supernatural deed, carried out, as the poet points out in I.136, "without injustice (sine crimine)"15.

10 This expression allows the author to condense the expression of Matthew relictis illis abiit foras extra ciuitatem. For the locution cum ciuibus urbem see Lucr. VI.590: cum ciuibus urbes and 1140: ciuibus urbem (= Verg. Aen. V.631; VIII.571; Lucan. I.592).

11 See the interpretation of Serv., ad buc. 1.34: INGRATAE VRBI quia cum alimenta ciuitatibus praestentur ex rusticorum labore, in his rustici et deridentur a ciuibus, et multa perdunt, et aduectarum rerum pretia iniqua suscipiunt.

12 Cf. II reg 5.7: arcem Sion, haec est ciuitas Dauid e III reg 2.10: in ciuitate Dauid.

13 Cf. also Ov. met. VIII.101 with reference to Minos.

14 Cf. Thraede (1960) 1034-1041; Stella (2006) 10-13.

15 Unlike Juvencus, the author of the In Euangelia amplifies with luci ... futura the temporal specification mane of Mt 21.18, varied by Sedulius (IV.44) with the poetic nexus clarescente die. The location of the tree is also significantly different in the four versions. Juvencus, consistent with the hypotext of Matthew, places it on the side of the street (1l. 654 s.: in margine ... / stratae); Sedulius, who in the prose redaction (IV.5) refers to the scriptures with haud procul a semita, in the hexametric version opts for a more poetic mediis ... in aruis (IV.45). The particulars of the location are, by contrast, completely omitted by Avitus, who with the participle uianti, echoing the coradical uia of the Gospel, alludes to the fact that the tree was placed alongside the street travelled by Christ; the same happens in 


\section{The Lord's Hunger}

In the biblical model, Jesus' search for fruits points to a physiological need of his, which is not further specified or motivated, so someone who interprets the text from a historical point of view run could into difficulties and some exegetes have been forced to give a non-literal interpretation ${ }^{16}$. Thus, it is striking that only in Severus, the only one among the four to provide a detailed theological comment on the biblical passage, is a reference to this motivation completely lacking, to the detriment also of the logical sequence of the narrated events. Behind this omission lies maybe the necessity to avoid a possible exegetical difficulty by exclusively selecting material on which a comprehensive interpretation of the scriptural text can be built, more than a form of negligence in reproducing the narrative moves of the source.

The refined periphrasis cibi pertemptans corda uoluntas of Iuvenc. III.656 offers, instead, a subtle form of interpretatio, which indirectly stresses the human nature of Christ. The abstract subject uoluntas ${ }^{17}$ seems to personify a negative and hostile force ${ }^{18}$, whose action is explained through a particularly expressive verb, in the intensive form ${ }^{19}$, which recalls the concept of temptation. While pertempto, attested only

the rendition of Severus who, noting the fact that the tree was isolated (IX.96: quae sola stabat), adds a detail that is not explicitly expressed in the model, unless one wants to understand in this sense unam of Mt 21.19, which, however, as is usual in biblical Latin, has the meaning of an article. Cf. Leumann-Hofmann-Szantyr (1972) 193.

16 On these historical and theological implications, see Bartsch (1962) 256-260.

17 While the reading uoluntas is attested in the vast majority of the manuscripts, the codices $\mathbf{T}(=\mathrm{Tu}$ ricensis C 68, saec. IX) and Bb (=Bobiensis [nunc Ambrosianus C 74], saec. IX-X) show the variant uoluptas, which would of course be much more typical and explicit with regard to the concept of desire, appetite expressed by the text. It must be stressed that in the Euangeliorum libri the term uoluptas is nowhere else attested, apart from I.418 as a minor variant and in III.333 as a conjecture of the 16th century editor Theodor Poelmann. On the other hand, there are in the whole text nine instances of uoluntas, all in the same metrical position. It cannot be excluded, however, that the authentic reading is, in fact, uoluptas and that this word, possibly perceived to be disrespectful if referring the Saviour, was later corrected by a medieval scribe into an semantically less expressive alternative.

18 According to a recurring use in Juvencus' paraphrase, which in this way tends to give substance to certain spiritual or psychological phenomena, such as the malice of the scribes and Pharisees, the Devil's tricks, etc. Thus, in this case, the use of the abstract noun fits into this series of examples and indirectly points to those negative forces that operate against Christ, hampering his actions. Hatfield (1890) 30, and Fichtner (1994) 158-167, have demonstrated how this preference for abstract nouns (which is a peculiar feature of Christian authors) must be ascribed to the canons of the poetry of late antiquity, especially of the Constantinian era.

19 While it is true that in the Euangeliorum libri these intensive and frequentative forms do not have meanings different from the corresponding simple ones, as is usual in late antique Latin, it is also true, however, that in some cases, since they are more substantial and forceful, they are more suitable to convey concepts that are particularly relevant or to underline incidents or actions that are crucial to the narrative structure. For a list of frequentatives in Juvencus, see Hatfield (1890) 34. 
here in the Euangeliorum libri ${ }^{20}$, possibly derives, in conjunction with corda, recta via from Stat. Theb. V.445f. tacitis corda aspera flammis / Lemniadum pertemptat Amor, the cognate words temptare and temptatio are largely used in the poem to indicate the action of the Devil and of the enemies of Christ. This is the case, for example, and this detail is not unimportant, of the narrative of the temptations in the desert in the first book, in which we observe the Devil proposing to the starving Lord the possibility to turn stones into bread ${ }^{21}$. This interpretation, only roughly sketched out there, finds its complete form in the later patristic commentaries, as e.g. Jerome's, in which, nonetheless, the allegorical and spiritual meaning of the hunger, which had already emerged at least as early as Origenes ${ }^{22}$, prevails.

\section{The Description of the Plant}

The biblical sources alternate the synonymic variants ficulnea and ficus (appearing alone or, in the genitive, dependent on the substantive arbor). According to his desire for uariatio, Juvencus uses a wider set of synonyms, starting from ficus (III.655) found in the model and meaningfully used only in the exordium of the narrative to define its thematic core, to arbor (III.660. 661. 668) and lignum (III.663). The choice of these two terms, and particularly of lignum, which indicates an already withered plant, seems to be anything but haphazard, if we take into account that, according to the subsequent patristic tradition, in the narrative of the Passion, the synecdoches "tree" and "wood" are equivalent to Cross. The term lignum, like its Greek equivalent

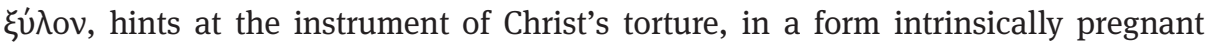
with Old and New Testament significances, e.g. the tree of the Genesis, the curse of Dt 21.23 and, indeed, the barren fig tree ${ }^{23}$. The detail of the shadow cast by the tree (1. 655 tendentem diffusa umbracula ficum) recalls, on an intertextual level, Tibullus' verbiage (II.5.97) about an old tree that shelters the farmers during the Palilia ${ }^{24}$; on an intratextual level, it recalls, with slight modifications, the expressions through which in II.115-17 cum te diffusae tegerent umbracula ficus, / ante etiam quam te uocitarent uerba Philippi, / uidit Juvencus amplified Ioh 1.48 priusquam te Philippus uo-

20 The passage of Juvencus is noted in ThlL X 1778, 48 under the rubric "c. notione afficiendi (in relation to animated beings)".

21 Cf. I.368; 374; 383; 396; see also I.599; II.476; 586; III.222; 464; IV.2.

22 Cf. Hier. in Matth. III.21.18: esuriit, uel ueritatem humanae carnis ostendens uel esuriens salutem credentium et aestuans ad incredulitatem Israhelis. This spiritual interpretation, on which also the parallel passage of Mc 11.13c (Luz [1997] 199-200 and n. 16) could have had an influence, is largely developed in Greek and Latin patristic literature; cf. Ioh. Crys. hom. 67.1 (= PG 58,634); Aug. serm. 98.3; also the anonymous author of the Opus Imperfectum in Matthaeum 844 focuses on the hunger not of food but of justice and salvation.

23 Cf. Roberts (1985) 200, and Piscitelli (2007) 129-152.

24 On the identification of the religious festival alluded in Tibullus' elegy and on the cited verse see the notes of Murgatroyd (2002) 224-225, and Maltby (2002) 459. 
caret cum esses sub ficu uidi te, where the fig tree, a symbol of Israel, points to the conversion of Nathanael.

Sedulius' description tends to focus the attention on the aesthetic of the tree, through a rich usage of adjectives and metrical-rhetorical devices. The first hemistich 46, emphasised by the alliteration frondea ficus, closes the metrical period started in the preceding verse by the formula ecce autem, which introduces the new, surprising event. The participle astans, framed between the penthemimeres and the hephthemimeres, and especially the adjective sublimis, picture the tree towering in the middle of the countryside. If astans in conjunction with syntagmata formed by in+abl. is common in epic poetry, the possible reminiscence of patristic commentaries ad loc. must not be underestimated. Jerome, e.g., in the traditional analogy between the fig tree and the synagogue, defines the plant as stantem scilicet et immobilem et non habentem euangelii pedes (in Matth. III.21.18). In this case, too, the epic dictio requires a lexical diversity that places robore, stipite and arboreis comis beside the biblical ficus and ficulnea. Of great interest is the restoration of this last term, which enters the poetic dictionary thanks to Sedulius ${ }^{25}$. It is a typically biblical word picked up then by the ecclesiastic writers, like Ambrose ${ }^{26}$ and Augustine ${ }^{27}$, mainly in negative contexts, often related to the Jews.

Avitus talks about delicate and extended fronds. The adjective diffusa (1. 418), although largely used in poetry with reference to the width of plants, might bring to mind at this precise point of the description, the text of Juvencus, recurring in the same metrical position. It also activates the intratextual identification with the luxuriant fig tree in Paradise, from whose cortex Adam cuts a strip to cover himself, which is described by the poet in III.12-15 (umbrosis propter stabat ficulnea ramis / frondentes diffusa comas, quas protenus Adam / umentem capiens raso de cortice librum / adsuit et uiridi solatur ueste ruborem). This is a simple mnemonic reuse, to be sure, but probably also a clue to a tacit parallelism between the two plants, suggested, as we will fully see in Severus, in patristic thought. The chiastic structure of 1.421 indutam tantum foliis, sed germine nudam, divided into two parts by the coincidence of the hephthemimeres and the syntactic pause, emphasises the opposition between the two antithetic characterisations, with homoeoteleuton, underlining the contrast between the luxuriant foliage and the absence of fruits. In the following depiction of the withering, Avitus stresses, with greater emphasis than his predecessors, the biblical reference to the presence of leaves only, also through a web of characterisations and a verbal accumulation aimed to reflect the meaning (1. 422 ... inane uirens ornatus inutilis ...). This may show the influence of the previous and contemporary patristic interpretation, which, in an overlapping of symbolic levels, built the allegorical comparison between Israel and the pharisaic traditions precisely on the

25 Apart from the passages of Avitus discussed below, the term is found in poetry also in Ven. Fort. carm. V.2.33; Columba hymn. I.256; Inscr. chr. Rossi II.247.10.1.

26 Iac. I.1.4: de infructuosa ficulnea dicere, hoc est malitia Iudaeorum.

27 Serm. ed. Mai 97.14: infructuosa synagogae ficulnea. Cf. ThlL VI 650, $19 \mathrm{ff}$. 
foliage. According to Hilary, the Synagogue is covered in leaves, i.e. empty words, but lacking fruits, i.e. good actions (in Matth. III.21.6 Inveniet infecundam, foliis tantummodo uestitam, id est, uerbis inanibus gloriantem, sed fructibus uacuam, operibus quippe bonis sterilem, et expectatis prouentibus nudam); similarly, Jerome insists on the empty orotundity of the Pharisees' speeches, which do not bear any truthful fruit (in Matth. III.21.19 nihil ... inuenit in ea nisi folia tantum, promissionum strepitum, traditiones Pharisaicas et iactationem legis et ornamenta uerborum absque ullis fructibus ueritatis). The terminological and conceptual coincidences might suggest a direct or indirect use of these commentaries by the poet.

Completely isolated remains the uncommon form caricem (maybe derived from a nominative carice or carix mentioned only in the Corpus glossariorum Latinorum ${ }^{28}$ used by Severus, who also uses the more common ficus at 1. 108. At VIII.157, in the episode of Zacchaeus, this word replaces the biblical sycomorus, which is found in the vast majority of the Vetus Latina manuscripts. In that case, unless a gloss read by Severus in some obscure source is conjecturable, the substitution might have been introduced for metrical reasons, with the aim of replacing the Greek calque of the model with a term more appropriate to the hexameter, the alternative and more common form of carice, namely carica, being already attested in poetic language since Ovid ${ }^{29}$. However, the problem of the choice of such a rare morphological variant remains. Apart from a possible mistake in the textual transmission, i.e. the change of caricam to caricem, which for paleographic reasons is not so unbelievable, we could take this form as a hint at the Greek cultural roots of the author, who elsewhere flaunts unusual lexemes, as is observed by Zwierlein in his prefatory words.

\section{The Curse}

The retention, in three cases out of four, of the direct speech, which draws attention to the passage in question, confirms the general tendency of the biblical epic poets to literally reproduce Christ's words or those about the relationship between Christ and God, especially in those episodes about miracles and healings ${ }^{30}$. At 1l. 659f., Juvencus specifies the recipient of the curse, but he substitutes illi of the VL with an archaic and more solemn olli, expressing the implied subject Christus with a common transitional formula in the Euangeliorum libri ${ }^{31}$. The lexical choice is effective, playing on the ambivalence of the word copia, employed here in the figurative sense of "potestas, facultas” (ThlL IV 909, $20 \mathrm{ff}$.) - which is actually attested in the poem only here

28 Gloss. III.538.49; 546.13 and Zwierlein ad loc. Noticeable is the correptio of the first syllable metri causa.

29 Cf. Ov. met. VIII.674: hic nux, hic mixta est rugosis carica palmis; fast. I.185: "Quid uult palma sibi rugosaque carica” dixi; Seren. med. 974: carica uel betis lento cum melle iugetur.

30 Cf. Roberts (1985) 138.

31 Cf. Rodríguez Hevia (1980) 255-271. 
-, yet at the same time allusively connected to the original meaning of "abundance" (in relation to the fruits), in which sense it normally occurs in the poem ${ }^{32}$. The restricted space of the second hemiepes 660 palpably works on the sense, conveying the idea of the immediateness of the drying.

In Sedulius, the recipient of the curse is the foliage, which is more than a simple synecdoche; we can observe here the author's intention to polemically emphasise how such a prosperous exterior, the implicit cause of the barrenness, will in future correspond a lack of fruits. The author is the only one to maintain the temporal annotation in sempiternum (1. 49 reliquum ... in aeuum) ${ }^{33}$, which Juvencus and Severus completely omit. Also remarkable in the Sedulian version is the insertion of ex germine vestro ("from your stock"). In the narrow sense, the expression denotes the tree's sprouts but, according to the recurring allegorical reading of the Fathers ${ }^{34}$, it also figuratively points to Israel's offspring. The abundance of descriptive details that portray the fig tree as drained of its lymph, dead and with dry branches, is an example of synonymic amplification, as noted by Roberts ${ }^{35}$; according to traditional rhetoric, this figure of speech conveys to the reader the importance of the passage, thus allowing the poet to display his stylistic abilities and refined lexical repertoire.

Frame by frame, like an Ovidian metamorphosis, Avitus describes each phase of the wilting, which gradually involves the entire plant, starting from the verdant crown, which by now has stiffened, to the roots, which have been overwhelmed by a sudden heat, to the trunk, which is dried and devoid of branches. The clause of 1. 423, adflata calore, is a borrowing from Sidon. carm. 11.126 proxima quin etiam festorum afflata calore, from the epithalamium for Ruricius and Iberia, where it indicates the heat that floods the nuptial room, whichever season it is. The Sidonian reminiscence then blends with another one, of Stat. Theb. X.674 fulminis haud citius radiis adflata cupressus, where the poet talks about a cypress hit by lightnings. A lexical similarity is found also between 1.424 ramorum tegmine and 1.26 of the pseudoCyprianic De Pascha, where the author refers to the shadow cast by the branches, in a depiction of Heaven according to the locus amoenus topos. Apart from a taste for descriptive preciosity, widespread at the time, the emphasis on the transformation exalts the grandiosity of the miracle, causing the barren beauty of the fig tree to appear more inconsistent and fragile.

Severus underlines the centrality of the curse by insisting on the notion of "word". While the "iunctura" siccauit verbo finds an immediate parallel in Eusebius

32 Cf. I.344: horreaque inplebit secreti copia farris; I.460: illos plena manet satiandos copia mensae; I.653 crastina nec uobis curetur copia rerum; II.753: incrementa sui centeno copia fetu.

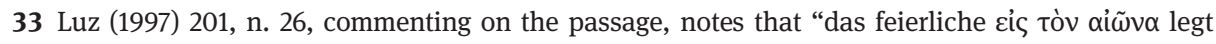
keine zeitliche Begrenzung nahe”.

34 Cf., e.g., Hilary's commentary on the passage in question (in Matth. 21,7 infidelitatis Iudaicae sterilitatem aeternae damnationis sententia consequetur).

35 Cf. Roberts (1985) 154-155. 
of Emesa ${ }^{36}$, a comparison must also be made with a passage of Commodian (instr. II.10.9-11):

... sterelis Christianos uos esse designo.

Maledicta fuit arbor sine fructu ficulna

in uerbo Domini et statim exaruit illa ${ }^{37}$.

The allusion to the parable of the barren fig tree, which complements the allusion to the parable of the chaff rewritten in the previous portion of text, clarifies in which precise sense the Pauline exhortation of Eph 6.8, evoked in 1. 5 Lex ager nobis est: qui fecerit bonum in illa, must be understood. With a metaphorical language of Cyprianic origin ${ }^{38}$, Commodian defines as "barren" those Christians who are incapable of performing charitable acts, thus proposing a spiritual explanation of the evangelical passage that is not so different from the one given by Sedulius and Avitus, despite the specificity of the relative contexts. But it is the reference ex novo to the power of the word that performs the miracle that brings into contact the text of Severus with the one of Commodius, and thus with the one of Eusebius. I find this parallel noteworthy, given that, in his recent commentary on the Instructiones, Poinsotte ${ }^{39}$ traces for the expression in uerbo Domini only a single possible formal model in Syracides 48.5. Apart from an indemonstrable interdependence between Commodian and Eusebius, whose speeches were translated into Latin between the end of the 4th and the beginning of the 5th century, or the influence of a common patristic source, the conceptual coincidence shows the strong influence wielded by the immediate effect of the curse on the Christian writers ${ }^{40}$.

\section{The Reaction of the Disciples}

Juvencus emphasises the disciples' astonishment not only over the miracle, but also over its immediate realisation, and stresses this feeling with a crescendo of psychological remarks, from mirantur to the figura etymologica stupidis ... /... stupuistis (1l. 662-663). In comparison with the Gospel, the insertion of the participle adsistens, which introduces the following answer of Christ, also appears significant; intention-

36 Cf. Euseb. Emes. serm. 11.2: interrogationem quamdam de illa fici arbore, quam dominus uerbo siccauit and the commentary of Zwierlein (1994) 110.

37 "I intend that you, Christians, are barren. The fig tree was cursed and thanks to the strength of the Lord's words immediately withered."

38 Cf. Cypr. eleem. 8; 9; 15; 22; 23.

39 Poinsotte (2009) $378-379$.

40 In the passage of Commodian the expression may refer either to the textual portion of 1.10 or to that of the following line. In any case, of crucial importance is the emphasis on the Lord's word, further emphasised by the metrical position of the syntagma in verbo Domini (with instrumental value) at the opening of the line. 
ally ambiguous, this verb alludes both to the fact that the protagonist is physically close to the disciples ${ }^{41}$ or witnesses their astonishment ${ }^{42}$, and to the fact that, with a shift in sense, he offers them assistance, instructing them by his explanatory answer $^{43}$. In a swerve from the hypotext, 'Severus' the fear more than the astonishment, transferring onto the disciples' emotions and their behaviour what elsewhere in the Gospels characterises the reaction of the crowds towards Christ's miracles (Mt 9.8 uidentes autem turbae timuerunt et glorificauerunt Deum and Lc 7.16 accepit autem omnes timor, et magnificabant Deum). This variation, which emphasises the importance of the event, acquires especially a theological and catechetical significance, thanks to the parenthesis on the omnipotence of God's word ${ }^{44}$. If, as the editors believe, the work was composed in the strong anti-Arian atmosphere that characterised the Visigothic Spain of the second half of the 6th century, the formulation carries a Christological substance, aimed to reaffirm, in an indirectly polemic way, the divine nature of Christ and his consubstantiality with the Father. The absence of this fundamental biblical aside in Sedulius and Avitus, apart from their respective poetic intentions, aims to uncouple the event from the temporal coordinates of the incident of the Gospel, with a view towards actualisation. In other words, the disciples are replaced by the recipients of the work, who are offered the subsequent interpretation with a parenetic purpose.

\section{The Vocabulary of the Miracle}

The vocabulary used to denote the miracle is indicative of the poetic purposes and the times of composition. Thus, it is not surprising to find, in the Euangeliorum libri, a term like honor (III.663 nunc ligni istius nostro stupuistis honore), which is not characterised as Christian, but culturally compatible with the feelings of the

41 Canali (2011) 183; McGill (2016) 90.

42 Galli (2012) 211.

43 On this meaning of adsisto cf. the entry by Münscher in ThlL II 901, 82ff.

44 I think that the conjecture uerbum proposed by the editor Thomas Klein (as is inferable from the critical apparatus) to fill the gap of 1.102 must be preferred to the addition regem suggested by Willy Schetter. In this specific context, in fact, the reference to the word, which must be understood metonymically here, as relating to God or to his Son, according to the New Testament definition of Ioh 1.1-3 (in principio erat Verbum, et Verbum erat apud Deum, et Deus erat Verbum. Hoc erat in principio apud Deum. Omnia per ipsum facta sunt), acquires a particular relevance and helps to emphasise the greatness of the miracle just realised only through the word pronounced by Christ, the incarnate verb. The conjecture, which would acquire greater effectiveness also on a stylistic level thanks to the polyptoton with uerbo of 11.98 and 100, seems to be supported also by a series of intratextual parallel passages noted by Zwierlein (1994) 111. Furthermore, in the text of Severus, on the basis of the aforementioned passage of John, the clause cuncta peregit has a gnomic value, through which the author intends to underline God's power over nature, an aside, which in this case, with a reference to the specific prodigy narrated, aims to recall the fact that He, who has created everything, has also got the power to regulate and dominate the natural cycle of things. 
Roman audience. The same term recurs in IV.400 pars credens sequitur tantae uirtutis honorem, but in a syntagma with uirtus, periphrastically formulating a miracle that has already happened, namely the resurrection of Lazarus. This word, which covers a wide semantic range, denotes in the Latin world, in sacral contexts, the religious devotion or the concrete demonstration of pietas towards the gods (sacrifices, libations, votive offers; cf. ThlL VI 2921, $74 \mathrm{ff} . ;$ 2924, $61 \mathrm{ff}$.). For the benefit of the audience, the miracle is represented, according to epic modes of expression, as an act of submission and deference of the natural elements, in this case the plant (ligni is here a subjective genitive) towards the superior will of the God-man. In the later compositions of Avitus (VI.425 instruimur tali legem cognoscere signo) and Severus (IX.104 quod signo fecit), the technical term signum easily finds its place, a typical lexeme of the Christian Sondersprache, where it occurs in its double meaning of "signe, préfigu-

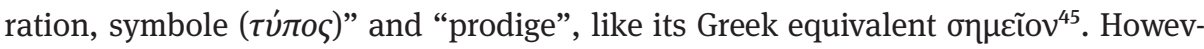
er, especially noteworthy, as a witness to the changes in times and circumstances, is the fact that in both cases, in spite of, as we will see, the difference of the contexts and of the subsequent exegetical implications, the substantive precedes a more or less ample section of commentary. The signum, in fact, being anticipation or a symbol of something else, must be explained, contextualised and interpreted.

\section{Exegesis}

The lack of an exegesis is compensated in Juvencus by a thick web of intertextual references. In the final passage about rocks and animals, in which Green sees a touch of humour ${ }^{46}$, an allusiveness can be observed that acquires its own value as an exegetical amplification. At III.671, in the sequence siluis ... saxisque ferisque, the commentators ${ }^{47}$ point out echoes of Ov. met. XI.1-2 carmine dum tali siluas animosque ferarum / Threicius uates et saxa sequentia ducit (of Orpheus) and XIV.338-40 siluas et saxa mouere / et mulcere feras et flumina longa morari / ore suo uolucresque uagas retinere solebat (of Canens). The Ovidian reminiscences, especially the one of the Thracian cantor, obtain an allusive power that has not yet been adequately stressed by critics. The poet seems to suggest, in fact, an implicit analogy between Orpheus and Christ. This analogy characterised early Christian iconography and was decoded on a typological level in the patristic witnesses, starting at least from Clemens of Alexandria, who emphasises how the real Orpheus is the Logos, able to wield his power not only over animals but over natural elements and men's hearts, too ${ }^{48}$.

45 Blaise-Chirat (1954) 759.

46 Green (2006) 86.

47 Cf. Zuliani (2005) 329; Santorelli (2011) 375-376; McGill (2016) 229.

48 Clem. Alex. protr. 1.2-5. The Christianisation of the Orpheus myth, starting especially from the analysis of passages from Clemens of Alexandria and Eusebius of Caesarea, has recently been dis- 
The text of Sedulius is established on a different level that develops a minimal interpretation of the parable in the form of a moral exegesis. With the allegorical deepening of the literal foundation, focusing on a triple botanical similitude distinguished by the usage of comparative tags (ceu, aequabitur, similis, tamquam), the poet gives to the narrative detail a theological depth, or at least a spiritual one, open, even on a poetic level, to different reading possibilities. In this case, the allegory makes use of intra-biblical references both in the comparison between the barren faith and a dry trunk, comparable with passages of Mattew ${ }^{49}$ and Luke $^{50}$, and in the comparison between the upright people and the Cedar of Lebanon, found in psalm.91(92).13, which is quoted literally in the prose version (iustus ut palma florebit et sicut cedrus, quae in Libano est, multiplicabitur). The ideological fundament of this exegetical insertion must be sought in the Opus Paschale, where, with a programmatic declaration, the interpretation of the narrative is shifted from the literal sense (ad litteram) to the allegoric-spiritual one (spiritales causae), more appropriate to the lex diuin $a^{51}$. The greater thoroughness of the prose rewriting allows greater clarity, necessary in the field of faith, which is diluted by poetic polysemy. This is further confirmation that the Opus, more complete and exhaustive on the level of content, is conceived by the author as an instrument for a better understanding of the poetic composition, which was published before ${ }^{52}$.

In Avitus a notable double exegetical level goes from the general to the particular. First, the biblical exemplum is, in fact, explained on an ethical-moral level, suitable for the parenetic-pastoral purposes of the poem. In the light of this first level, it is possible to catch the sense of the subsequent link with chastity, expressed as a similitude, otherwise not so perspicuous (11. 430-40):

cussed by Arcari (2016), 41-88. On the Orpheus myth as a Christological image in medieval Latin literature see Dronke (1998), 55-79.

49 Cf. Mt 3.10: iam enim securis ad radicem arborum posita est; omnis ergo arbor quae non facit fructum bonum exciditur et in ignem mittitur and 7,19: omnis arbor quae non facit fructum bonum exciditur et in ignem mittitur.

50 Cf. Lc 13.6 - 9: dicebat autem hanc similitudinem: arborem fici habebat quidam plantatam in uinea sua et uenit quaerens fructum in illa et non inuenit. Dixit autem ad cultorem uineae: ecce anni tres sunt ex quo uenio quaerens fructum in ficulnea hac et non inuenio; succide ergo illam ut quid etiam terram occupat. At ille respondens dixit illi: domine dimitte illam et hoc anno usque dum fodiam circa illam et mittam stercora et si quidem fecerit fructum, sin autem in futurum succides eam.

51 Cf. op. pasch. IV.5: Non tamen haec accipiamus ad litteram, licet manifesto credantur impleta, quoniam spiritalibus causis conuenit lex diuina. Quid enim materies sine sensu peccauerat? Praesertim quae fructum, sicut Marcus euangelista commemorat, incongrui ratione temporis non habebat: nisi ad instructionem Dominus nostrae utilitatis hoc ageret, qui factorum sermonumque parabolis uitale nobis iter ostendit.

52 The linguistic and rhetoric analogies and differences, as well as the ones related to content, between the poetic rendition and the prose have recently been discussed by Mori (2013), who underlines how the prose version aims to clarify the author's literary purposes. 
Sic et uirginitas sacro deuota pudori

indiget adiunctis uirtutibus et, nisi mentem

intactam seruans casto cum corpore iungat,

concumbit uitiis nec castam dicere carnem

iure potest, animus quam sic corrumpit adulter.

Ira, furor, maeror, liuor, discordia, luxus

lingua duplex, constricta manus, laxata uoluntas

moechantur cum corde hominis, tum semine turpi

fetus mortis alunt. En quo perducitur omnis,

nomine uirgineo quae se dum iactitat, intus

criminibus grauidam nescit turgescere mentem ${ }^{53}$.

What has generally been said about those who proclaim themselves Christians (1.426 Christi famulum solo sermone fatenti), namely that they must match this self-proclamation with a uiuens operatio (1.427), and that they must testify to their faith through acts of charity, is now applied specifically to the behaviour of the virgins. The under-

53 This is not the place to discuss this passage at length; it seems nonetheless necessary to highlight a few devices used by the poet to express effectively the moral teaching. In the first section, the accumulation of strongly positive adjectives, denoting the concepts of pureness and modesty, together with their respective substantives (1. 430 sacro ... pudori; $11.431 \mathrm{ff}$. mentem / intactam; 1.432 casto ... corpore; 1.433 castam ... carnem), anticipates the following contrast with the vocabulary of both the second and the last section, which focuses on the concepts of immodesty and adultery (1. 433 concumbit uitiis; 1.434 animus ... corrumpit adulter; 1.437 moechantur ... semine turpi). The vocabulary, which also through different communicative levels and different linguistic and stylistic registers conveys the antithesis between the two opposite realities that are represented, consists of verbs as concumbere, absent from Vergil and Horace, but frequent in the elegiac poets (ThIL IV 102, 18ff.), and moechari, which is chiefly used by Catullus and Martial, but also found in the Latin Bible, both in its literal and its metaphorical sense. These verbs belonging to the sexual sphere play a functional role in the formulation of a critic of the lack of spiritual purity. This highly allusive sexual lexicon culminates in the peculiar metaphor of the impure soul's pregnancy (1. 440 grauidam ... turgescere mentem), which, having fornicated with vices and sins, gives birth to deadly fetuses (1. 438 fetus mortis), that is to say bad actions. The sins that commit adultery with the hearts of human beings are listed in a long congeries at 1l. 435f., according to the traditional form of the Lasterkatalog, which is already used by the poet in carm. II.31f. (cessabit gemitus, luxus, metus, ira, uoluptas, / fraus, dolor atque dolus, maeror, discordia, liuor) with regard to the eschatological vision of the freedom from sins, and which finds immediate parallels in Prud. ham. 395-397: ira superstitio maeror discordia luctus / sanguinis atra sitis, uini sitis et sitis auri / liuor adulterium dolus obtrectatio furtum (about the Devil's army) and psych. 629f. Metus et Labor et Vis / et Scelus et placitae fidei Fraus (Operatio has just gained victory over Cupiditas); on this imitation of Prudentius, see Arweiler (1998), 48. What is missing in the previous catalogues is a reference to furor (to be understood here in the double meaning of "anger" and "uncontrolled lust", "passion", which the virgin may nourish in her soul) and the three pairs of noun+adjective, which at 1.435 follow the nominative-only list of 1.434 . On a stylistic level, the chiastic disposition of the nouns and the relating adjectives at $11.431 \mathrm{f}$. (mentem ... intactam ... casto ... corpore) and the alliterative sequence of $c$ at $11.432-434$ are noticeable. The contrast between a positive exterior and an interior dirtied by sins must recall Christ's condemnation of the formalism of the Pharisees, which is compared to whitewashed tombs, which, behind a pleasant appearance, hide the decomposition of corpses. 
lying reference to 1 Cor 7.34 (et mulier innupta et uirgo cogitat quae Domini sunt ut sit sancta et corpore et spiritu) summarises the ideal according to which true virginity combines pureness of the body with that of a soul that is kept free from sins and impure thoughts. On a literary level, the equation (leafy but barren fig tree $=$ Christians solo sermone = virgins chaste in their body but impure in their spirit) responds to the lack of epic similitudes within Avitus' work, supplying biblical-moral terms for comparison. Thus, the poet imparts to his main readers, namely his sister Fuscina and those Christians who adopted an ascetic life following the Lerinian example, those biblical passages that are connected to chastity or, as in this case, to be read with regard to chastity, applying a kind of moral exegesis for his parenetical purposes.

In comparison with a mere ten verses used for the poetic retractatio of the Gospel passage, we can count in the In Euangelia of Severus 38 verses of exegetical aside (1l. 103-140). The centrality of the exegetical component is especially demonstrated by the plurality of interpretational suggestions made by the author. Like Avitus, who, however, does not follow up with the theological implications, Severus, following the hypotext of Mark, notes the fact that Christ's search for fruits happens tempore non apto (1. 105), a parenthetical remark, which imposes on the reader the need to investigate further and go beyond the simple thaumaturgical deed. The Lord's gesture, otherwise incomprehensible, displays the divine soteriological perspective (1. 107 quo cunctos doceat clementia numina sancta). The poet proposes at this point three different interpretational readings of the evangelical passage:

a. 11. 108-118. The fig tree recalls the tree of life, under which the original parents found shelter after eating the forbidden fruit, and with the leaves of which they covered their nudity. In the context of this figural reading, the drying of the tree represents the deliverance brought by Christ, who burdens himself with men's sins, thus regenerating their hearts. This interpretation, widespread in the exegesis of the Fathers, is found, among others, also in Augustine; in serm. 122, commenting on the episode of Nathanael, the bishop of Hippo makes a comparison between the fig tree and the sin committed by Adam and Eve, identifying the tree as symbol of the $\sin ^{54}$.

b. To the first one, Severus adds a second exegetical suggestion introduced in 1.119 by ast alii credunt. According to others, in fact, in an eschatological sense, the

54 Cf. Aug. serm. 122.1: quod dictum audiuimus a Domino Iesu Christo Nathanaeli, si bene intellegamus, non ad ipsum pertinet solum. Ipse quippe Dominus Iesus sub ficu uidit omne genus humanum. Isto enim loco intellegitur per arborem fici significasse peccatum. Non ubique hoc significat, sed hoc loco, ut dixi, ea scilicet significandi congruentia, qua nostis primum hominem, quando peccauit, foliis ficulneis fuisse subtectum. His foliis enim pudenda texerunt, quando de peccato suo erubuerunt; et quae Deus illis membra, ipsi sibi pudenda fecerunt [...] Hoc autem dixi, quare? Ut per ficum intellegamus significatum esse peccatum. Quid est ergo: Cum esses sub ficu, uidi te? Cum esses sub peccato, uidi te. Et ad rem gestam quidem respiciens, recordatus est Nathanael se fuisse sub ficu, ubi non erat Christus. Also in Kontakion 54.3 of Roman the Melodist the tree of the terrestrial paradise, origin of Adam's sin, becomes the barren fig tree of the Gospel; cf. Catafygiotu Topping (1978) 22-35. 
unexpected gesture of Christ would serve as a warning of future punishment that is in store for evil people at the end of times. This argument reflects the one proposed by Isidore of Pelusium in epistle 1,51 addressed to the tribune Theopompus (PG 78,213): The anti-Arian polemist, who participated in the council of Chalcedon, but was barely known in the West (except for Facundus of Hermiane and Rusticus Deacon), had probably been read by Severus in a Latin translation of Greek chains.

c. 11. 124-136. With an implicit allusion to Judas' treason, a warning to the apostle takes place, in order to deflect him from his intentions and to redeem him. This unusual link might imply an underlying reference to the words of Juvencus, according to which Judas hangs himself from a fig tree $\mathrm{e}^{55}$. Whether this is an invention by Juvencus ${ }^{56}$ or a popular legend is hard to say; the legend may actually have arisen from the curse of the fig tree, although already in antiquity this

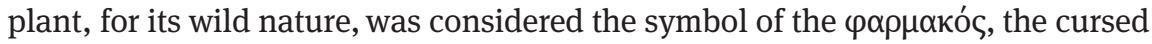
man who lives on the margins of society ${ }^{57}$. However, the possibility must not be ruled out that Severus derived the detail of the fig tree linked with suicide from Juvencus, in order to then create a link with the narrative of the cursed fig tree. The poet, anyway, clarifies in the statement of 1.137 diximus haec nostros sensus proferre uolentes that this is a completely personal interpretation, not derived directly from any other source. In support of his own interpretation, the poet then builds a complex similitude (11.128-136) in which he compares Christ to a doctor who, in order to save the life of his dying patients, sacrifices some animals to extract from them the necessary medicine. The worthy purpose, then, justifies the otherwise unintelligible action, which happens sine crimine (1.136). The refined similitude, which makes use of Greek medical sources ${ }^{58}$, which the author may have read in Latin translation, also retrieves the traditional theme of the Christus medicus, widespread in Christian literature, especially Augustine, in connection with its soteriological and Christological doctrine ${ }^{59}$. Nevertheless, on a literary level, the similitude, through which the poet enlarges and gives substance to his explanation, also matches the compositional characteristics of the epic genre.

55 Iuvenc. IV.630 - 631 exorsusque suas laqueo sibi sumere poenas / informem rapuit ficus de uertice mortem. See also Itin. Anton. Plac. rec. A 17: ibi est ficulnea in qua Iudas se suspendit cuius talea stat munita petris; on this anonymous Itinerarium Antonini Placentini, composed approximately between 560 and 570, cf. Milani (2002) $40-46$.

56 The author is however the most ancient source of this version of the death of Judas.

57 See Colombi (1997) 32, who conjectures that Juvencus followos popular legend in identifying the fig tree as the site of the suicide of Judas; Leone (2004) 92 refers vaguely to some apocryphal legends in which Judas hanged himself from a fig tree; McGill (2016) 264 quotes the Brescia Casket (ca. 394), wich features a figure, probably Judas, hanging from an oak tree.

58 See Zwierlein (1994) 116-117.

59 Cf. Hübner (1985) 324-335; Gollwitzer-Voll (2007); Weber (2013) 125-142. 
In any case, the exegetical effort of the author does not exhaust the multiple interpretative possibilities offered by the biblical text. And other interpretations will be given by other authors (11. 138-139 ast alios, quo quisque modo perquirere temptat, / inueniet). With the concluding picture, which compares the actions of Christ to precious gems, Severus not only recalls a biblical-patristic metaphor related to the Holy Scripture but also alludes to that preciosity typical of late antique artistic and literary aesthetic.

The usage of technical terminology related to the interpretational activity ("teach", "research" or "study") and the reutilisation of Lucretian expressions at 11. $137-140^{60}$ confirm the didactic character of Severus' poem. The didactic function, associated in the Gospels with Christ, is in the metaliterary play associated with the poet, who gives his readers a doctrinal and religious lesson. As Michele Cutino has poignantly pointed out in his recent work ${ }^{61}$, the final link between the gesta superna (1. 139), which are an echo of the Christi vitalia gesta (1. 19) found in the preface of Juvencus' Euangeliorum libri, and the need to interpret the actions of Christ in order to extrapolate a teaching from them symbolically marks the transition of the biblical paraphrasis from an epic-narrative modality to a fusion of epic and exegesis. With regard to Severus' readers, what is conceivable is not exclusively a scholastic purpose, a context of monastic-presbyterial education, but also a larger audience, constituted by culturally elevated classes that are pressed by the doctrinal questions that emerged from the growth in theological thinking, which took place in the Latin west at that time.

\section{Conclusions}

The poetic versions of the pericope, which reflect different literary sensitivities due to the changes in the socio-cultural contexts and the constantly new requirements of the readers, exemplify the evolution in the relationship between poetic expression and theological research and their reciprocal influence on each other. The initial phase of acquisition of the epic mode of expression having been overcome, which, due to the propagandistic need to spread the biblical text in palatable linguistic forms, imposed on Juvencus a more literal paraphrasis, the poetic approach to the scriptures that starts with Sedulius offers a new form, characterised by metaliterary interventions aimed at an intra-scriptural, allegorical or spiritual exegesis ${ }^{62}$. The biblical text, then, assumes a new context and a new function also in works that belong to literary genres different from the Bibelepos, as in the case of the De Virginitate of Avitus, or undergoes a strict exegetical analysis with additions that are no longer

60 E.g., l. 137 nostros sensus: cf. Lucr. IV.111-112: quoniam primordia tantum/ sunt infra nostros sensus; 1. 140 quocumque modo: cf. Lucr. II.774: nam quocumque modo perturbes caerula, quae sint. 61 Cutino (2016-2017) 201.

62 Cf. Stella (2001) 47. 
only narrative, but tend to convey theological messages and to explain specific doctrinal aspects.

\title{
Appendix: Texts and Translations
}

\author{
Mt 21.17-22 (VL: ed. A. Jülicher, Berlin 1938, 150-151)
}

${ }^{17}$ Et relictis illis abiit foras extra ciuitatem in Bethaniam ibique mansit. ${ }^{18}$ Mane autem transiens in ciuitatem esuriit. ${ }^{19}$ Et uidens fici arborem unam secus uiam uenit ad eam, et nihil inuenit in ea nisi folia tantum, et ait illi: "Numquam ex te fructus nascatur in sempiternum". Et arefacta est continuo ficulnea. ${ }^{20}$ Et uidentes discipuli mirati sunt dicentes: "Quomodo continuo aruit?"

${ }^{21}$ Respondens autem lesus ait: "Amen dico vobis: si habueritis fidem et non haesitaueritis, non solum de ficulnea facietis, sed et si monti huic dixeritis: tollere et mittere in mare, fiet. ${ }^{22} \mathrm{Et}$ omnia quaecumque petieritis in oratione credentes accipietis.
${ }^{17}$ And he left them and went out of the city to Bethany and stayed there. ${ }^{18}$ Early in the morning, as Jesus was returning to the city, he was hungry. ${ }^{19}$ Seeing a fig tree by the road, he went up to it but found nothing on it except leaves. Then he said to it, "Let there be no fruit from you henceforward forever!" Immediately the tree withered. ${ }^{20}$ When the disciples saw this, they marveled and said: "How did [the fig tree] wither so quickly?" 21 Jesus replied and said: "Truly I tell you, if you have faith and do not doubt, not only can you do what was done to the fig tree, but also you can say to this mountain: 'Go, throw yourself into the sea,' and it will be done. ${ }^{22}$ And whatever you ask in prayer, you will receive, if you have faith.

Mc 11.12-24 (VL: ed. A. Jülicher, Berlin 1940, 103-106)

${ }^{12}$ Et alia die cum exisset a Bethania, esuriit. ${ }^{13}$ Cumque uidisset a longe ficum habentem folia, uenit uidere, si quid esset in eam; et nihil inuenit nisi folia tantum: non erat enim tempus ficuum. ${ }^{14}$ Qui dixit ei: "Iam non amplius in aeternum quisquam fructum ex te manducet”. Et audiebant discipuli eius [...]. ${ }^{20}$ Et cum transirent mane, uiderunt arborem ficus aridam factam a radicibus. ${ }^{21}$ Et recordatus Petrus ait: "Rabbi, ecce ficus, cui maledixisti, aruit”. ${ }^{22}$ Et respondens lesus ait illis: "Si habueritis fidem Dei, ${ }^{23}$ amen dico uobis, quia quicumque dixerit huic monti: tollere et mittere in mare, et non haesitauerit in corde suo, sed crediderit futurum, fiet, quodcumque dixerit. ${ }^{24}$ Propterea dico uobis: Omnia quaecumque orantes petitis, credite quia accipietis, et euenient uobis".
${ }^{12}$ And on the morrow, when he came out from Bethany, he hungered. ${ }^{13}$ And seeing a fig tree afar off having leaves, he went to see if anything was thereon; and he found nothing but leaves; for it was not the season of figs. ${ }^{14}$ And he said to it: "No man eat fruit from you henceforward forever". And his disciples heard it [...]. ${ }^{20}$ And as they passed by in the morning, they saw the fig tree withered away from the roots. ${ }^{21}$ And Peter remembered and said to him: "Rabbi, behold, the fig tree which you cursed is withered away. ${ }^{22}$ And Jesus answering said to them: "Have faith in God. ${ }^{23}$ Verily I say to you, whoever shall say to this mountain: "Be taken up and cast into the sea", and shall not doubt in his heart, but shall believe that what he said will come to pass, it will be done for him. ${ }^{24}$ Therefore I tell you: All things whatever you pray and ask for, believ2e that you will receive them, and they will be yours. 
Juvencus, Euangeliorum libri III.653-674 (ed. I. Huemer, CSEL 24, Vindobonae 1891, 106-107)

Haec ait ingratam linquens cum ciuibus urbem Bethaniamque petit, rediensque in margine cernit stratae tendentem diffusa umbracula ficum. Illic forte cibi pertemptans corda uoluntas arboris adtrectat ramos, sed nulla facultas pomorum sterili frondis concreuerat umbrae. Olli Christus ait: "Non sit tibi fructibus umquam copia promendis." Tum protinus aruit arbor. Discipuli celerem mirantur in arbore mortem. Sed Christus stupidis adsistens talia fatur: "nunc ligni istius nostro stupuistis honore, desisse ad uires terrenos ducere sucos.

Sed ueris uerbis iterumque iterumque monebo: 665 namque fides si certa animi consistet in arce nec dubiis nutans uitiis tremebunda iacebit, arboris istius uobis substantia cedet. Nec tantum istius, sed montis celsa reuelli credentum uerbo poterunt undisque profundi cum siluis pariter saxisque ferisque recondi. Et quaecumque fides robusto pectore poscet, credentum semper digna uirtute tenebit." Haec ubi dicta dedit, templi se moenibus infert.
This said, he leaves the ingrate town and its inhabitants and goes to Bethany; returning, he glimpses on the roadside a fig tree, stretching

655 a wide sheltering shadow. There, by chance, the wish for food, seizing his heart, urges him to scour the tree's branches. But in the barren shadow of the leaves not a single fruit had grown. To the tree Christ says:"May you never have the power to produce", and the tree im-

660 mediately withered. The disciples wonder at the sudden death of the tree. Christ, coming near the astounded men, says: "Now you are astonished how this tree honored me, because it has ceased to draw sap from the soil for its nourishment. But again and again with truthful words I will exhort you: If your faith remains firm in the fortress of your soul and, trembling, does not fall, wavering in doubt and error, the essence of this tree will yield to you. And not

670 just this; if believers give the word, the mountain peaks can be torn up and cast into the depth of the sea along with woods, rocks and beasts. And what steadfast faith demands, it will always obtain due to the worthy virtue of believers". After these words, he enters the temple.

\section{Sedulius, Carmen Paschale IV.42-56 (ed. I. Huemer, CSEL 10, Vindobonae 1885, 94)}

Talia Dauiticam post facta reliquerat urbem Bethaniae uicina petens, eademque reuersus clarescente die properabat uisere tecta. Ecce autem mediis astans sublimis in aruis frondea ficus erat, cuius in robore nullum repperit esuriens lustrato stipite pomum; arboreisque comis "iam nunc ex germine uestro

nullus" ait "fructus reliquum generetur in aeuum".

Confestim uiduata suis ficulnea sucis aruit et siccis permansit mortua ramis. Omnis enim quicumque Deo nil fertile nutrit, ceu sterilis truncus lignis aequabitur ustis. At iustus palmae similis florebit amoenae, semper habens frondes et tamquam Libana cedrus multiplicandus adest et uertice sidera tanget.
After such deeds, he left the city of David and headed for neighbouring Bethany. At daybreak, heading back to Jerusalem, he was hastening to look at the buildings. But, behold, towering in the middle of a field stood a leafy fig tree: hungry, he searched the branches of the tree, but he did not find any fruit. To the tree's foliage he said: "Now, may never grow a fruit from your stock for all time". Devoid of its sap, the fig tree suddenly withered and remained

50 there, dead, with dried branches. For everyone who produces nothing fruitful for God, in fact, like a barren trunk, will be compared to wood that is burnt. But the righteous man will flourish like a luxuriant palm tree always in leaf 55 and will grow tall like a cedar of Lebanon and touch the stars with his crown. 
Alcimus Avitus, De uirginitate 417-440 (ed. N. Hecquet-Noti, Paris 2011, 168-170)

Esuriit quondam dominus, cum forte uianti conspicitur diffusa leui ficulnea fronde, nec iam maturum praedicta ex arbore fructum carpere tempus erat. Quam mox ut repperit ille 420 indutam tantum foliis, sed germine nudam, prorsus inane uirens ornatus inutilis horret, percutitur subito radix adflata calore aruit et posito ramorum tegmine truncus. Instruimur tali legem cognoscere signo: ne Christi famulum solo sermone fatenti nomine conficto uiuens operatio desit. Nam si Christicolas nosmet sanctosque putemus, adgrauat hoc etiam, ni dictum facta sequantur. Sic et uirginitas sacro deuota pudori indiget adiunctis uirtutibus et, nisi mentem intactam seruans casto cum corpore iungat, concumbit uitiis nec castam dicere carnem iure potest, animus quam sic corrumpit adulter.

Ira, furor, maeror, liuor, discordia, luxus, lingua duplex, constricta manus, laxata uoluntas moechantur cum corde hominis, tum semine turpi fetus mortis alunt. En quo perducitur omnis, nomine uirgineo quae se dum iactitat, intus criminibus grauidam nescit turgescere mentem.
One day the Lord was hungry, when, by chance, he glimpsed on his way a wide fig tree with delicate foliage, but it was not yet the time to gather ripe fruits of the tree. As soon as he noticed that the tree was covered only in leaves but devoid of seeds, the worthless ornament, uselessly flourishing, stiffens, the roots are flooded and hit by a sudden warmth,

425 the trunk, having lost the protection of the branches, dries out. From such a sign we learn the rule: The man who proclaims himself Christ's disciple only in words, after having given himself such a name, must carry out good deeds in his life. For if we consider our-

430 selves Christians and pious, it is even more unjustifiable if our deeds do not follow our words. Thus, chastity, too, devoted to holy demureness, needs other virtues to be added and, if it does not preserve a pure spirit to join it to a chaste body, it lies with the vices and

435 cannot rightfully call chaste the flesh thus corrupted by an adulterous soul. Wrath, insanity, affliction, envy, discord, lust, a duplicitous tongue, a chained hand, an uncontrolled will fornicate with men's hearts and then, with their shameful seed, feed deadly fetuses. Behold, where every woman is conducted who,

440 while boasting about her virginity, does not know that inside herself a sinful spirit is growing.

\section{Severus of Malaga (?), In Euangelia IX.93-140 (ed. B. Bischoff - W. Schetter - O. Zwierlein, München 1994, 52-53)}

Bethaniam post haec uenit iustissimus auctor discipulisque simul mansit; lucique futura pergens sic urbem coepit perquirere cibum, 95 et petiit caricem, quae sola stabat, et hic tum, cum non inuenit fructum (nec tempus erat nam), siccauit uerbo florentes arbore ramos "ex te" sic dicens "foetus non creuerit umquam!"

Quae uerbo citius demum siccata remansit. Quod cum uiderunt, pauidi coepere ministri laudare aeternum <uerbum>, quod cuncta peregit.
The righteous creator then arrived in Bethany and stayed there with the disciples; the following day, heading to the city, he began to look for food. He moved close to an isolated fig tree, and, not finding any fruit there (it was not the right time!), with his word made the branches, which flourished on the tree, wither, saying these words: "You will not grow any fruit ever again!" The tree withered even faster

100 than the words. Seeing this deed, the disciples, frightened, began to praise the eternal word, which accomplishes everything. This action, too, carried out through a miracle by the one who knows all past events, offers ex- 
Hoc quoque tractanti praebet documenta decora,

quod signo fecit, qui sciuit cuncta priora. Tempore non apto fructum perquirere coepit ostendens maius sese perficere uelle, quo cunctos doceat clementia numina sancta. Nam ficus fuit ista, prius quae stabat in horto regis iussa gerens, ne sumat primus; et illum forma repens quoniam legi succumbere fecit et foliis caelare sua iam turpia membra, haec post porrexit supero querente peremptum, nunc ideo damnata suum dimisit honorem. Quae male praestiterat fructum foliaque priora a Christo siccata docet, quod cuncta reformat 115 primitias scelerum sumens (quae fecit iniquus sic suadens homini legem calcare supernam) euoluens sceleri mortalia corda subacta. Ast alii credunt Christum siccasse, suapte ut doceat se posse feros damnare, quod illi credebant Christum solum perficere, nolle et punire malos: "hominem non perdit, eo quod

ipse deus dixit semet concedere cuncta." Atque ideo fecit: uoluit cohibere rapacem, ne se perdat amens prodens per lucra magistrum

cognoscens ipsum posse et damnare nefandos ex ipsis rebus seseque recolligat ardens.

Vt medicus, hominum custos, sanare uolutans occulta quos pestis agit, pernosse praetemptat membrorum positus, solitamque adhibere me- 130 delam

vestigat pecudum quidquid sic possidet artus ceu mortale genus, et uiscera uiua recludens porcorum morte uitam languentibus affert: debile sic Christus proprii cum cepit inopsque discipuli, uoluit damnata sub arbore firmum efficere ramosque ideo sine crimine siccat. Diximus haec nostros sensus proferre uolentes; ast alios, quo quisque modo perquirere temptat, inueniet, gemmae quoniam sunt gesta superna, quae, quocumque modo tractantur, pulchra uidentur. cellent teachings to those who investigate. He started to look for fruits at an unseasonable time, showing his will to accomplish an even

105 greater deed, with the purpose to certify in front of everyone the mercy of the holy numen. This was, in fact, the fig tree that once stood in the garden and carried the King's order that the protoplast might not take anything from it; 110 and, since a sudden figure made him yield to the law and led him to cover his limbs, by then shameful, with its leaves, it tore him down and killed him for divine complaint; therefore, it has now, damned, lost its crown. This fig tree, which in the past had carried bad fruits and

115 leaves, made barren by Christ, teaches that $\mathrm{He}$ renews everything taking the first fruits of sin (which the devil produced, thus persuading man to trample on divine law) and freeing the mortals' hearts subjugated to it. On the other

120 hand, others believe that Christ made the tree wither to teach that he could by himself damn those who are evil, because they thought that Christ wanted to perfect those who are evil and not to punish them: "He does not annihilate man, because God himself says that He for-

125 gives everything". And he did it also for this reason: He wanted to discourage the greedy so that he, mad, would not lose himself betraying his master for money and so that he, being aware that He can also punish the sacrilegious, would, terrified, give up on this purpose. Like a doctor, guardian of men, intending to heal whoever is afflicted by an internal disease, tries at first to recognize the position of the limbs and to use the usual healing method, namely investigating every animal that has similar limbs to the human ones and, opening

135 the entrails alive, gives life to his patients through the death of the pigs, in the same way Christ, when he noticed the weakness and gullibility of his disciples, wanted to strengthen them through the example of the cursed fig tree; therefore, he, without guilt, lets the branches wither. We have said such things with the intent to report our thought, but

140 whoever tries to investigate in any way will find other interpretations, because divine deeds are like gems; however they are interpreted, they will look marvelous. 


\section{Bibliographie}

Arcari (2016): Luca Arcari, "Il "canto nuovo" di Cristo, tra Davide e Orfeo (Clem., Protr. 1, 2-5; Eus., L. Const. 14, 5)", in: Gennaro Luongo (ed.), Amicorum munera. Studi in onore di Antonio V. Nazzaro, Napoli, 41-88.

Arweiler (1998): Alexander Arweiler, Die Imitation antiker und spätantiker Literatur in der Dichtung "De spiritalis historiae gestis" des Alcimus Avitus. Mit einem Kommentar zu Avit. carm. 4,429-540 und 5,526-703, Bonn 1998 ("Untersuchungen zur antiken Literatur und Geschichte" 52).

Bartsch (1962): Hans-Werner Bartsch, "Die Verfluchung" des Feigenbaums", in: Zeitschrift für die Neutestamentliche Wissenschaft und die Kunde der Älteren Kirche 53, 256-260.

Biguzzi (1987): Giancarlo Biguzzi, "Io distruggerò questo tempio". Il tempio e il giudaismo nel vangelo di Marco, Roma.

Blaise-Chirat (1954): Albert Blaise/Henri Chirat, Dictionnaire Latin-Français des auteurs chrétiens, Turnhout.

Canali (2011): Luca Canali, Aquilino Giovenco, Il poema dei Vangeli, Milano.

Catafygiotu Topping (1978): Eva Catafygiotu Topping, “On earthquakes and fires: Romano's encomium to Justinian”, in: Byzantinische Zeitschrift 71 (1), 22-35.

Colombi (1997): Emanuela Colombi, "Paene ad verbum: gli Evangeliorum libri di Giovenco tra parafrasie commento", in: Cassiodorus 3, 9-36.

Cutino (2016-2017): Michele Cutino, “L’accomplissement de la paraphrase néotestamentaire en Occident: les In evangelia libri de Severus de Malaga", in: Michele Cutino (ed.), Poésie et Bible aux $I V^{e}-V I^{e} s$. Actes de la session scientifique de l'Assemblée générale de l'Association "Textes pour l'Histoire de l'Antiquité Tardive" Paris, École Nationale des Chartes, 8 octobre 2016. Revue des Études Tardo-Antiques 6. Supplément 4, 189-213.

Deproost (1997): Paul-Augustin Deproost, "L'épopée biblique en langue latine. Essai de définition d'un genre littéraire", in: Latomus 56, 14-39.

Dinkova-Bruun (2007): Greti Dinkova-Bruun, "Biblical Versifications from Late Antiquity to the Middle of the Thirteenth Century: History or Allegory?", in Willemien Otten and Karla Pollmann (eds.), Poetry and Exegesis in Premodern Latin Christianity, Leiden, 315-342.

Dronke (1998): Peter Dronke, "La persistenza dei miti musicali greci attraverso la letteratura mediolatina”, in: Musica e Storia 6 (1), 55-79.

Fichtner (1994): Rudolf Fichtner, Taufe und Versuchung Jesu in den Evangeliorum libri quattuor des Bibeldichters Juvencus (1, 346-408), Stuttgart und Leipzig.

Galli (2012): Giovenco. I libri dei Vangeli. Introduzione, traduzione e note a cura di F. G., Roma.

Gollwitzer-Voll (2007): Woty Gollwitzer-Voll, Christus Medicus - Heilung als Mysterium. Interpretationen eines alten Christusnamens und dessen Bedeutung in der Praktischen Theologie, Paderborn.

Green (2006): Roger P.H. Green, Latin Epics of the New Testament: Juvencus, Sedulius, Arator, Oxford.

Grosso (2004): Matteo Grosso, “L'enigma del fico senza frutti. Questioni critiche e interpretative su Mc 11,12-14.20-25”, in: Quaderni del Dipartimento di Filologia, Linguistica e Tradizione Classica "Augusto Rostagni" 3, 121-147.

Hecquet-Noti (2011): Nicole Hecquet-Noti, Avit de Vienne. Eloge consolatoire de la chasteté (sur la virginité), Paris.

Hatch (1923): William H.P. Hatch, "The Cursing of the Fig Tree”, in: Journal of the Palestine Oriental Society 3, 6-12.

Hatfield (1890): James T. Hatfield, A Study of Juvencus, Bonn.

Herzog (1975): Reinhart Herzog, Die Bibelepik der lateinischen Spätantike, München. 
Hübner (1985): Jörg Hübner, “Christus medicus. Ein Symbol des Erlösungsgeschehens und ein Modell ärztlichen Handelns”, in: Kerygma und Dogma 31, 324-335.

Huemer (1891): Iohannes Huemer, Gai Vetti Aquilini luvenci Evangeliorum libri quattuor. Recensuit et commentario critico instruxit I. H., CSEL 24, Pragae-Vindobonae-Lipsiae.

Jülicher (1938): Adolf Jülicher, Itala. Das Neue Testament in altlateinischer überlieferung nach den Handschriften, I. Matthaus- Evangelium, Berlin.

Jülicher (1940): Adolf Jülicher, Itala. Das Neue Testament in altlateinischer überlieferung nach den Handschriften, II. Marcus-Evangelium, Berlin.

Kartschoke (1975): Dieter Kartschoke, Bibeldichtung. Studien zur Geschichte der epischen Bibelparaphrase von Juvencus bis Otfrid von Weißenburg, München 1975.

Kirsch (1979): Wolfgang Kirsch, "Strukturwandel im lateinischen Epos des IV-VI Jhs.", in: Philologus 123, 38-53.

Leone (2004): Massimo Leone, Religious Conversion and Identity: The Semiotic Analysis of Texts, London and New York.

Leumann-Hofmann-Szantyr (1972): Manu Leumann, Anton Szantyr and Johann Baptist Hofmann, Lateinische Grammatik. II. Lateinische Syntax und Stilistik, München.

Luz (1997): Ulrich Luz, Das Evangelium nach Matthäus, III, Zürich.

Maltby (2002): Robert Maltby, Tibullus: Elegies. Text, Introduction and Commentary, Cambridge.

Manson (1950-1951): Thomas W. Manson, “The Cleansing of the Temple", in: The Bulletin of the John Rylands Library 33, 271-281.

McClure (1981): Judith McClure, "The biblical Epic and its Audience in Late Antiquity”, in: Papers of the Liverpool Latin Seminar 3, 1981, 305-321.

McGill (2016): Scott McGill, Juvencus' Four Books of the Gospels: Evangeliorum libri quattuor. Translated and with an Introduction and Notes. Routledge later Latin poetry, London and New York.

Milani (2002): Celestina Milani, "Gli Intineraria ad loca sancta", in: Giovanni Gobber-Celestina Milani (eds.), Tipologia dei testi e tecniche espressive. Atti del convegno, Milano, 15-16 novembre 2001, Milano, 37-46.

Mori (2013): Roberto Mori, Sedulio: tra prosa e poesia. L'Opus Paschale e il Carmen Paschale, Padova.

Murgatroyd (2002): Paul Murgatroyd, Tibullus, Elegies II, Oxford.

Nazzaro (2001): Antonio V. Nazzaro, "Poesia biblica come espressione teologica: fra Tardoantico e Altomedievo", in: Francesco Stella (ed.), La scrittura infinita. Bibbia e poesia in età medievale e umanistica, Firenze, 119-153.

Nazzaro (2006): Antonio V. Nazzaro, "Riscritture metriche di testi biblici e agiografici in cerca del genere negato", in: Auctores Nostri 4, 397-439.

Nodes (1993): Daniel J. Nodes, Doctrine and Exegesis in Biblical Latin Poetry, Leeds 1993.

Oakman (2008): Douglas E. Oakman, Jesus and the Peasants, Eugene (Matrix: The Bible in Mediterranean Context).

Panagl (2007): Victoria Panagl (ed.), Sedulius. Opera Omnia. Ex Recensione Iohannis Huemer, CSEL 10, Wien.

Pesch (1980-82): Rudolf C. Pesch, Il Vangelo di Marco, vol. II, tr. it. Brescia 1980-82.

Piscitelli (2007): Teresa Piscitelli, “La croce nell'esegesi patristica del II e III secolo", in: Boris Ulianich and Ulderico Parente (eds.), La croce. Iconografia e interpretazione: secoli I-inizio XVI. Atti del convegno internazionale di studi, Napoli, 6-11 dicembre 1999, Napoli, I, $129-152$

Poinsotte (2009): Jean-Michel Poinsotte, Commodien. Instructions. Texte établi et traduit par J.-M. P., Paris.

Reichmann (1969): Viktor Reichmann, "Feige I (Ficus carica)", in: Reallexikon für Antike und Christentum 7, 640-689 
Roberts (1985): Michael Roberts, Biblical Epic and Rhetorical Paraphrase in Late Antiquity,

Liverpool.

Rodríguez Hevia (1980): Vicente Rodríguez Hevia, “Las fórmulas de transición en Juvenco”, in:

Studia philologica Salmanticensia 5, 255-271.

Romaniuk (1975): Kazimierz Romaniuk, “Car ce n'etait pas la saisons des figues ... (Mk 11 12-14

parr.)", in: Zeitschrift für die neutestamentliche Wissenschaft 66, 277-278.

Santorelli (2011): Paola Santorelli, Aquilino Giovenco, Il poema dei Vangeli, Milano.

Smith (1960): Charles W.F. Smith, "No Time For Figs (Mc 11:12-14, 20-23)", in: Journal of Biblical Literature 79, 326-327.

Stella (2001): Francesco Stella, Poesia e teologia: l'Occidente latino tra IV e VIII secolo, Milano.

Stella (2006): Francesco Stella, “Imitazione interculturale e poetiche dell'alterità nell'epica biblica latina” in: Incontri triestini di filologia classica V. Il calamo della memoria. Trieste, 9-24.

Thraede (1960): Klaus Thraede, “Epos”, in: Reallexikon für Antike und Christentum 5, 983-1042. Weber-Gryson (20075): Robert Weber and Roger Gryson, Biblia sacra Vulgata, Stuttgart $2007^{5}$. Weber (2013): Dorothea Weber, “Medicorum pueri - Zu einer Metapher bei Augustinus”, in: Zeitschrift für Antikes Christentum 17, 125-142.

Zuliani (2005): Maurizio Zuliani, Commento al III libro degli Evangeliorum libri di Giovenco. Tesi di Dottorato, Macerata.

Zwierlein (1994): Severi Episcopi (Malacitani (?) In Evangelia libri XII: Das Trierer Fragment der Bücher VII-X. Unter Mitwirkung von Reinhart Herzog erstmalig herausgegeben und kommentiert von. Bernhard Bischoff $\dagger$ und Willy Schetter $\dagger$ bearbeitet von Otto Zwierlein, München. 


\section{Filip Doroszewski}

\section{Dieu rejeté, Dieu triomphant}

\section{Réception des Bacchantes d'Euripide dans la Paraphrase de l'Évangile de Saint Jean de Nonnos de Panopolis ${ }^{1}$}

Les Bacchantes d'Euripide ont exercé une énorme influence sur la littérature antique. $^{2}$ La littérature chrétienne ne fait pas exception, surtout dans le milieu alexandrin où Philon avait déjà introduit les motifs dionysiaques dans l'exégèse biblique. ${ }^{3}$ C'est là que, au moins à partir de Clément d'Alexandrie, les Bacchantes furent réinterprétées pour exprimer les croyances chrétiennes. ${ }^{4}$ La Paraphrase de l'Évangile selon Saint Jean de Nonnos, poète épique qui a vécu au cinquième siècle de notre ère dans le milieu alexandrin, s'inscrit dans la continuité de cette tradition exégétique. ${ }^{5}$ Dans cet article, nous abordons donc la question de la réception des Bacchantes d'Euripide dans la Paraphrase de Nonnos.

Dans les Bacchantes d'Euripide, Dionysos est présenté comme un dieu qui exerce sur la vie humaine une très profonde influence. Auprès de Déméter, qui nourrit les hommes et les maintient en vie, c'est Dionysos qui est le plus important parce qu'il donne aux hommes le vin - la délivrance du chagrin et le remède unique de tous maux et douleurs. Dans une de premières scènes des Bacchantes Tirésias dit à Penthée (274-285, tr. Berguin):

«Il y a deux divinités, ô jeune homme, qui tiennent le premier rang chez les hommes. L'une est

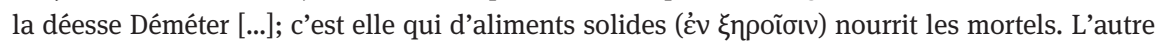

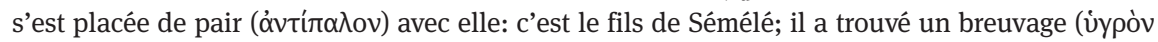
$\pi \tilde{\omega} \mu \alpha)$, le jus de la grappe, et l'a introduit parmi les mortels pour délivrer les malheureux

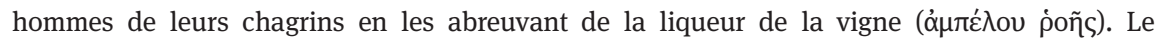

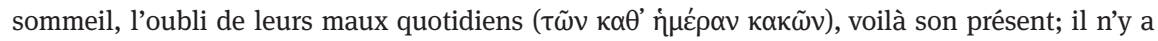
pas d'autre remède à leurs peines. Lui, qui est un dieu, s'offre en libations aux dieux: c'est donc à lui que les hommes doivent leurs biens. ${ }^{6}{ }$

1 Je tiens à exprimer ma vive reconnaissance à Michele Cutino pour m'avoir invité à publier mon article dans ce volume, et aussi pour sa patience et sa compréhension. Je voudrais aussi remercier David Lorin de sa lecture attentive du présent article et de ses suggestions.

2 Voir récemment sur ce point Friesen (2015).

3 Voir p.ex. Lewy (1929) 3-66 ; Nikiprowetzky (1977) 23 et 26; Friesen (2015) 198-205.

4 Sur la réception des Bacchantes chez Clément d'Alexandrie, voir Riedweg (1987) 150-155; Massa (2014) 161-189.

5 Sur la vie et la chronologie de Nonnos voir récemment Accorinti (2013).

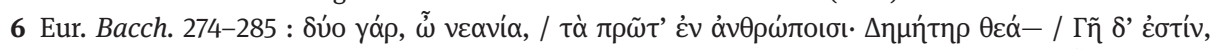

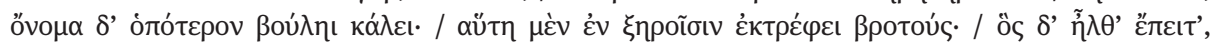

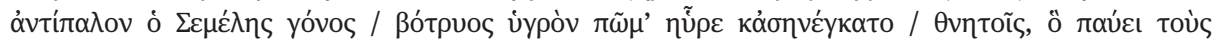

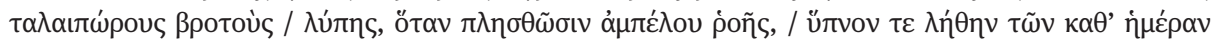

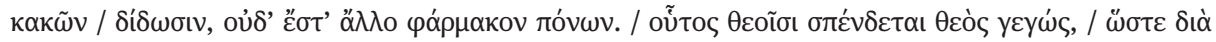

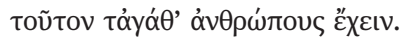


Un autre passage des Bacchantes nous apprend ouvertement que sans vin les hommes ne sont capables d'éprouver ni de l'amour ni une quelconque autre joie. ${ }^{7}$

Il n'y a aucun doute que Nonnos connaissait bien ces vers des Bacchantes. Au début du chant VII de ses Dionysiaques, poème mythologique qui raconte les légendes liées à Dionysos, Nonnos parle du monde qui vit dans un grand chagrin parce que Dionysos n'est pas encore né et, par conséquent, le vin n’a pas encore été inventé. Privés de vin, les hommes ne trouvent pas de repos après d'innombrables peines quotidiennes et rien n'est en mesure de le changer : ni le mariage, ni les joies de l'amour. Même les divertissements comme la danse ou la musique ne leur procurent pas de plaisir. Zeus promet la naissance de Dionysos qui apportera aux hommes le don du vin et dissipera leur tristesse (Dion. VII.82-88, tr. Chuvin) :

«Hier, sur un signe de ma chère Déô, la déesse des vastes champs, la terre ouverte par le fer, son

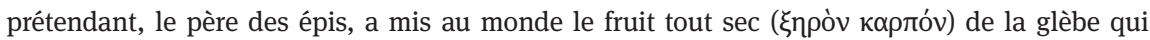
enfante les gerbes. Désormais mon fils, porteur d'un splendide présent, va planter en terre le

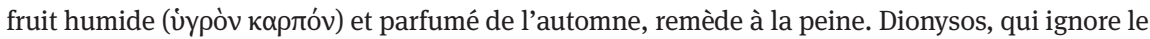

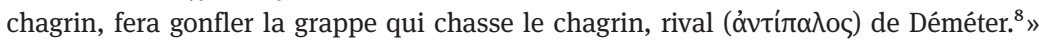

La promesse de Zeus est clairement liée aux paroles que Tirésias dit à Penthée dans les Bacchantes ${ }^{9}$ : il s'agit ici non seulement de délivrer les hommes de la tristesse et

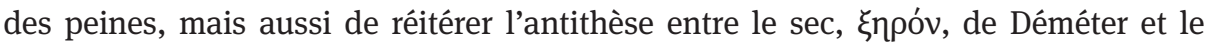
liquide, úypóv, de Dionysos. De plus, comme dans les Bacchantes, Dionysos est

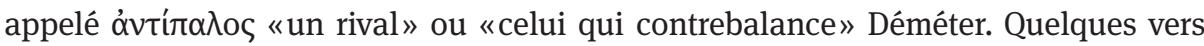
plus loin, Zeus annonce la joie qui règnera grâce à l'apparition du vin (Dion. VII.9496, tr. Chuvin) :

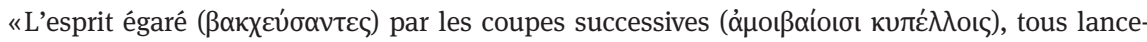

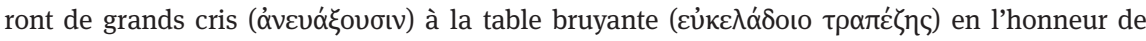
Dionysos, protecteur ( $\dot{\alpha} \lambda \varepsilon \xi \eta \tau \tilde{\eta} \rho \alpha)$ de la race humaine. ${ }^{10}{ }^{»}$

Comme nous pouvons voir, la façon dont Nonnos décrit dans le septième livre des Dionysiaques le rôle de Dionysos et du vin est inspiré par les Bacchantes d'Euripide. Nous pouvons trouver la même inspiration et un ensemble d'associations très semblables dans la Paraphrase de Nonnos. Dans le récit des noces de Cana, Nonnos fait allusion au rôle important du vin présenté dans les Bacchantes et le réinterprète

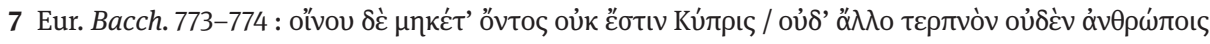
हैंт.

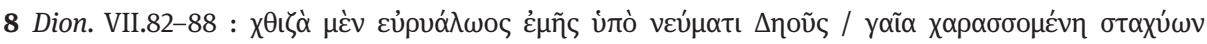

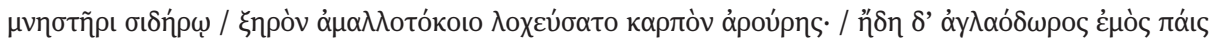

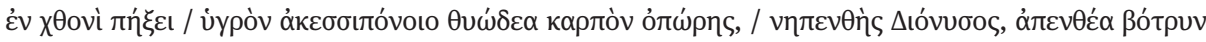

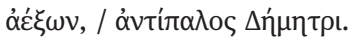

9 Chuvin (1992) ad loc.

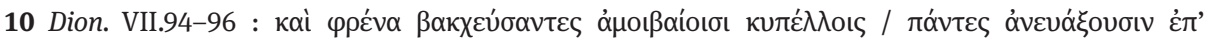

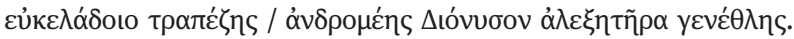


selon l'esprit chrétien pour montrer le passage de l'Ancienne Alliance vers la joie de la Nouvelle Alliance. Deux extraits du chant deux de la Paraphrase le démontrent très bien. Le premier présente le moment où le vin manquait (II.12-20, tr. de Marcellus) :

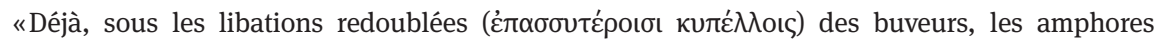
odorantes demeuraient vides de la liqueur savoureuse. Déjà, dans la salle des noces qui aime le vin pur, les échansons attristés (otuyvoí), qui servaient une table privée de Bacchos (ảßak-

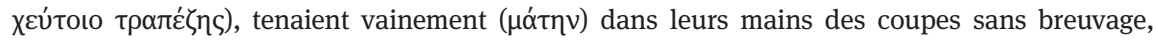
lorsque la mère assise auprès de son fils lui dénonça, bien qu'il le sût d'avance, ces boissons inachevées du repas et cette absence de vin: » Cette noce a besoin de ta parole qui écarte le mal

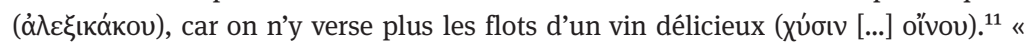

Dans cet extrait, comme dans les Bacchantes, le manque du vin s'inscrit dans une ambiance de tristesse et de vanité : les échansons sont tristes (бтuyvoí II.14), et leurs

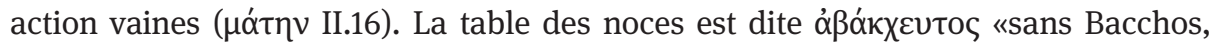
non initiée aux mystères de Bacchus» (II.15) qui renvoie à un passage précis des Bacchantes d'Euripide : lorsque Penthée demande à Dionysos le secret des orgies

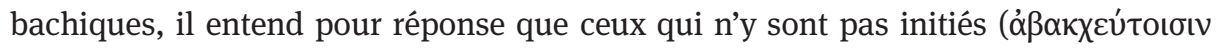
471) ne peuvent pas le savoir. ${ }^{12}$ De plus, Nonnos prend pour exemple Clément d'Alexandrie qui met la même phrase dans le bouche du Christ lui-même. ${ }^{13}$ Aussi

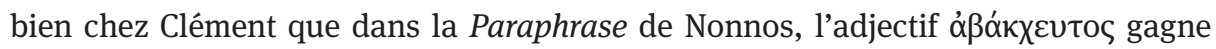
un nouveau sens. Il se réfère maintenant à une réalité qui n'a pas encore connu la vie nouvelle que le Christ donne aux hommes. Toutefois, dans l'extrait cité de la Paraphrase nous pouvons montrer aussi un parallèle avec les paroles de Tirésias à Penthée (voir plus haut Bacch. 274-285) : dans les Bacchantes, c'est le «jus de la

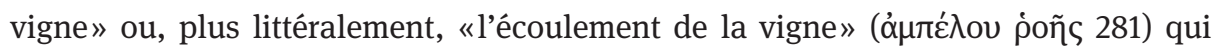

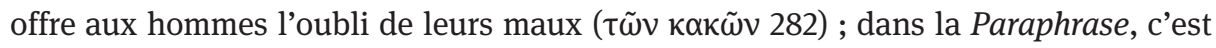

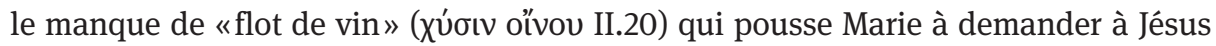
d'intervenir, lui dont la voix «détourne le mal» ( $\dot{\alpha} \lambda \varepsilon \xi \xi$ Łó́кov II.19). Il est intéressant que, un peu plus tard, lorsque Jésus ordonne aux serviteurs de porter l'eau transformée en vin à l'ordonnateur du repas, sa voix est décrite par l'adjectif oỉvwrós «de

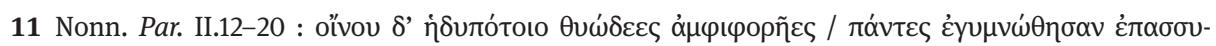

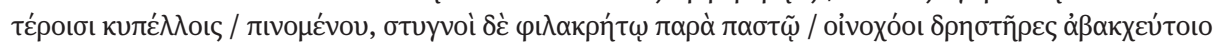

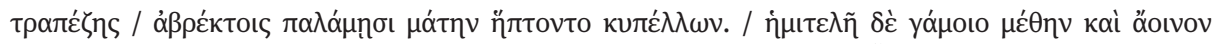

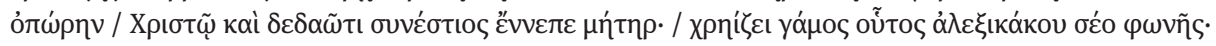

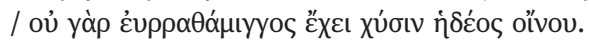

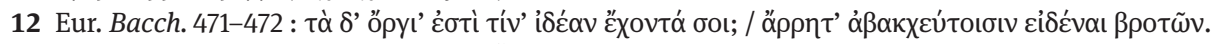

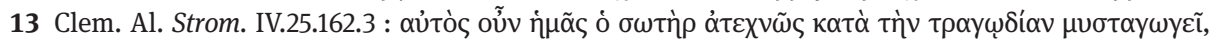

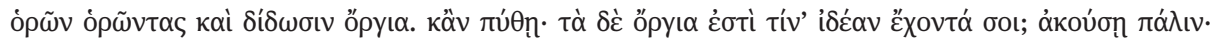

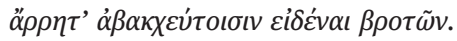


la couleur du vin» qui dans les Bacchantes d'Euripide est attribué à Dionysos luimême. ${ }^{14}$

La tristesse qui accompagnait le manque du vin devient une joie extatique quand s'accomplit le miracle de la transformation de l'eau en vin (Nonn. Par. II.3538, tr. de Marcellus) :

«Soudain s'opère le miracle. Cette eau se colore, altère sa nature, s'empourpre, change ses flots de neige en flots d'un liquide noirci ( $\alpha^{\prime} \theta$ Өолоৎ), et, à travers ces vases qui ont reçu des eaux, nage

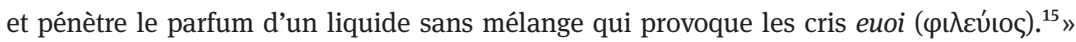

Le vin, provenant d'un miracle, répand un parfum décrit par un adjectif ultra-dio-

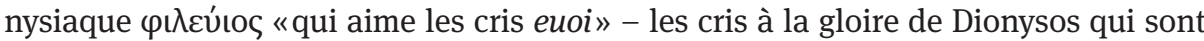
souvent évoqués dans les Bacchantes d'Euripide. ${ }^{16}$ La couleur du vin, quant à elle, est décrite comme aĩ $\theta$ o $\psi$ «éclatante», tout comme la flamme d'un flambeau, qui dans Bacch. 594 devait brûler le palais de Penthée. La table des noces qui, avant

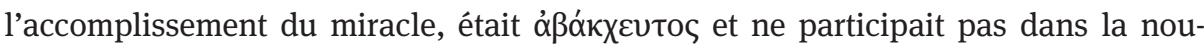
velle vie offerte par le Christ, devient maintenant pleinement dionysiaque, c'est-àdire, dans la perspective d'une réinterprétation chrétienne, unie à Dieu par le Christ. $^{17}$

Dans les Bacchantes, le culte bachique est lié à un sentiment de joie profonde et de bonheur existentiel. Celui qui pratique le culte de Dionysos, celui qui tombe en

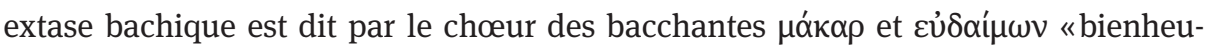
reux». ${ }^{18}$ Les deux vieillards, Cadmos et Tirésias, qui quittent la ville pour rejoindre les montagnes et y célébrer Dionysos, oublient leur âge avancé et, remplis de joie, veulent danser comme des sauvages (Eur. Bacch. 178-214). Leur joie vient du fait de suivre la divinité : dans son commentaire sur les Bacchantes Eric Dodds observe que

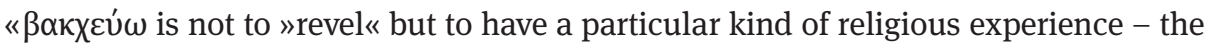

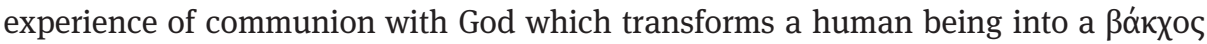

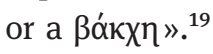

Les auteurs chrétiens de l'antiquité qui interprétaient les Bacchantes comprenaient parfaitement cette idée. C'est pourquoi Clément d'Alexandrie utilise le terme provenant des Bacchantes $\beta \alpha \kappa \chi \varepsilon u ́ \mu \alpha \tau \alpha$ «mystères de Bacchus» pour décrire la ma-

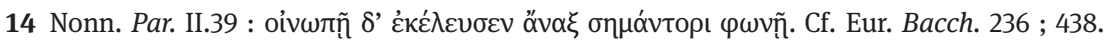

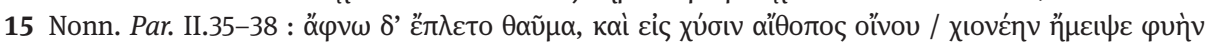

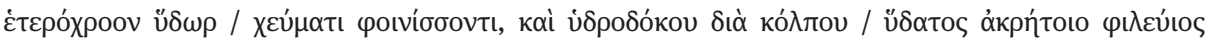

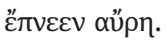

16 Eur. Bacch. 68 ; 129 ; 141b ; $151 ; 1034$.

17 Pour une discussion plus détaillée sur la terminologie dionysiaque utilisée par Nonnos dans l'épisode de Cana, voir Doroszewski (2014) 287-294 et (2016) 335-340. Voir aussi Livrea (2000) 77-92 et les commentaires ad loc., Shorrock (2011) 58-71, Cusset (2015).

18 Eur. Bacch. 73. Voir aussi Dodds (21960) ad loc.

19 Dodds (21960) XII-XIII. 
nière dont il vit lui-même la foi chrétienne..$^{20}$ On ne peut alors s'étonner que, dans la scène des noces de Cana, Nonnos a recours à un adjectif qu'avait employé Euripide,

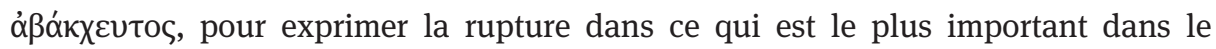
christianisme - la plénitude de l'intimité avec Dieu. La scène de Cana n'est d'ailleurs pas la seule dans la Paraphrase, où la présence du Christ, l'intermédiaire entre Dieu et les hommes, provoque parmi ses adeptes une extase dionysiaque. Par exemple, lorsque Marie, sœur de Lazare, plongée depuis un moment dans la douleur depuis la perte de son frère, apprend l'arrivée du Christ en Béthanie, elle est frappée de la folie bachique et court à la rencontre du Christ (Nonn. Par. XI.96-102, tr. de Marcellus) :

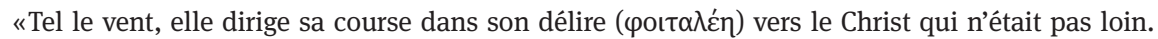
Toutes les personnes qui, dans la maison plaintive, en adoucissaient le chagrin par des paroles sympathiques, des consolations de la douleur qui veille, en voyant Marie courir si vite, en

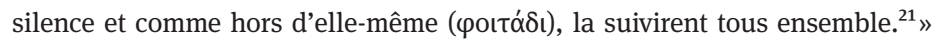

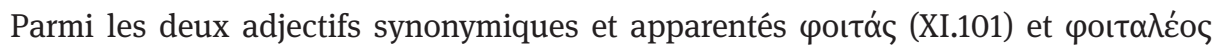
(XI.96) «insensé», qui décrivent ici le comportement de Marie, le premier apparaît dans Bacch. 165 par rapport aux bacchantes qui célèbrent Dionysos. ${ }^{22}$

Un autre extrait de la Paraphrase, où la présence du Christ provoque un enthousiasme bachique et où l'action renoue clairement avec la trame des Bacchantes se trouve dans le septième livre. À partir du début du livre et - ce qui est important d'une manière indépendante de l'Évangile de St Jean, Nonnos introduit dans sa narration le motif d'une vraie et d'une fausse sagesse. Avant l'arrivée de Jésus à Jérusalem pour la fête de Soukkot, les foules débattent sur la question s’il est

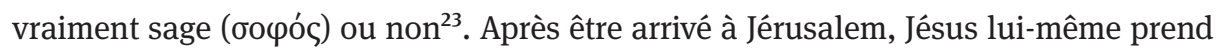
la parole à ce propos et explique qu'une vraie sagesse ( $\left.\sigma 0 \varphi i^{\prime} \alpha\right)$ consiste à accomplir les commandements de Dieu. En même temps il se présente comme celui qui le fait. ${ }^{24}$ Une foule qui se rassemble avec approbation autour de Jésus est définie par Nonnos de manière positive comme '́xर́ $\varphi \rho \omega v$ «prudent» (Nonn. Par. VII.53). Le moment culminant arrive lorsque les autorités juives, mécontentes du fait que la foule accepte

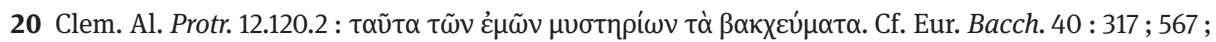
$608 ; 720 ; 724$.

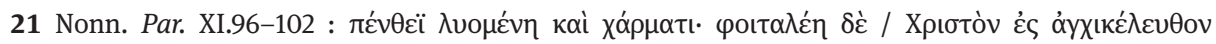

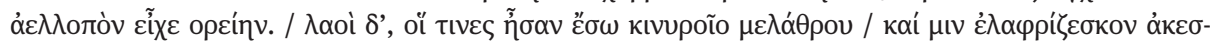

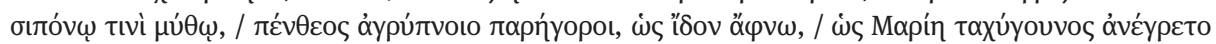

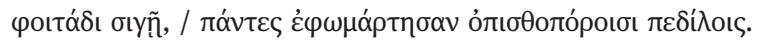

22 Sur ces deux termes, voir Spanoudakis (2014) ad loc.

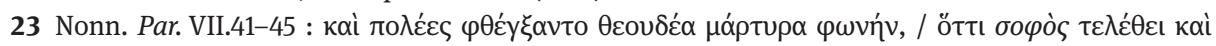

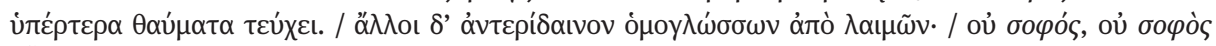

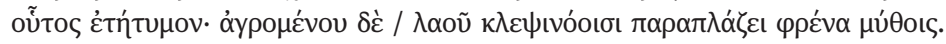

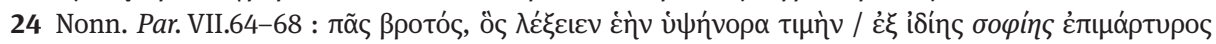

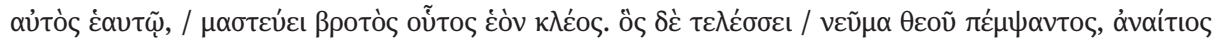

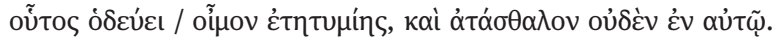


avec enthousiasme les paroles de Jésus, envoient les gardes pour qu'elles l'arrêtent. Ceux-ci reviennent les mains vides (Nonn. Par. VII.172-182, tr. de Marcellus):

«Les serviteurs intelligents ( $\pi$ ivvtoí) revinrent stupéfaits vers les prêtres ennemis de Dieu

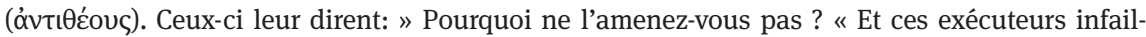

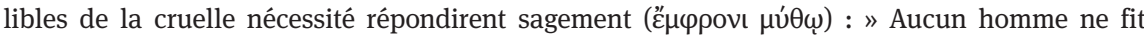

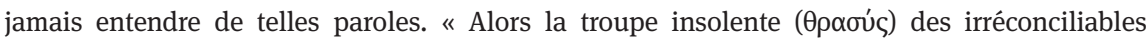

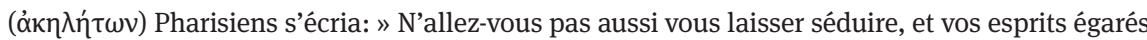
vont-ils ajouter foi à ses inventions ? Est-ce qu'aucun des chefs ou des Pharisiens éclairés (ảyxıvó $\omega v)$ a cru en lui ? C'est cette populace méchante et maudite, cet essaim de vagabonds,

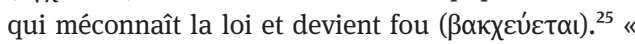

Il est aisé de noter que Nonnos poursuit ici la trame introduite auparavant de la sagesse. Les gardes sont présentés à ce propos de manière particulièrement avantageuse, car ils admettent ouvertement leur admiration devant l'enseignement de

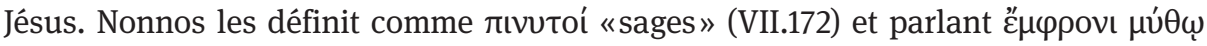
«avec des paroles raisonnables» (VII.174). Les prêtres et les pharisiens sont présentés d'une manière tout à fait opposée. Bien qu'ils se considèrent eux-mêmes comme

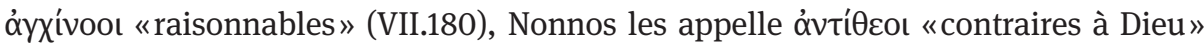

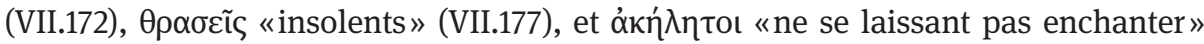
(VII.177). Cet extrait, lu dans ce contexte, inspire une tragique ironie. Les archiprêtres et les pharisiens, bien que persuadés de leur raison, rejettent en réalité la vraie sagesse, personnifiée par Jésus. Par la même raison il n'y a pas de doute que la foule, rassemblée en admiration autour de Jésus, bien qu'elle soit considérée par des pharisiens, apparemment sages, comme plongée dans une extase bachique ( $\beta \alpha$ -

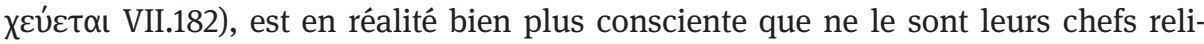

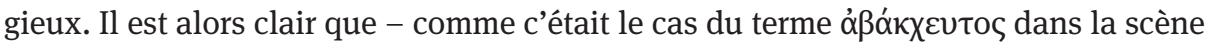

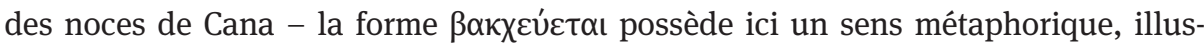
trant l'état d'esprit de ceux qui reçoivent la vérité et se rapprochent de Dieu.

Dans les Bacchantes la question de la sagesse et de la raison est constamment présente dans le contexte d'une juste attitude envers Dionysos et son culte. ${ }^{26}$ La sagesse de Tirésias et de Cadmos qui accueillent le nouveau culte avec enthousiasme est mise en valeur à plusieurs reprises. ${ }^{27}$ Les deux vieillards sont contraires à l'attitude hostile du roi Penthée vis-à-vis des rites bachiques et s'efforcent de le persuader qu'il change d'avis. Parmi leurs arguments nous constatons que les actions

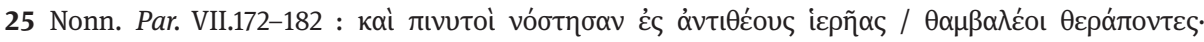

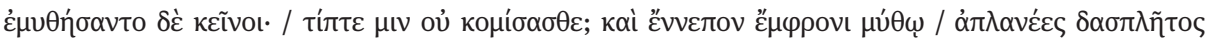

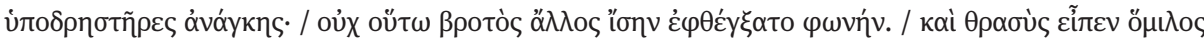

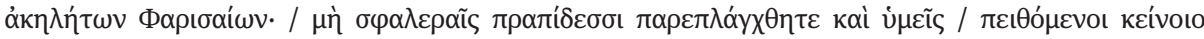

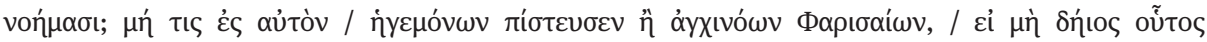

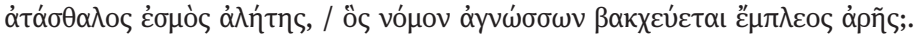

26 Dodds (21960) ad 179.

27 Eur. Bacch. 179 ; $186 ; 196 ; 200$; 329. 
du roi sont raisonnables seulement en apparence. ${ }^{28}$ Néanmoins, Penthée rejette le conseil de Tirésias de s'adonner à la folie bachique qu'il considère comme un symptôme de sottise. ${ }^{29} \mathrm{Il}$ continue sa lutte contre Dionysos, ce qu'Euripide souligne à travers l'emploi du verbe $\theta \varepsilon o \mu \alpha \chi \varepsilon \dot{\varepsilon} \omega$ «combattre contre la divinité» (Bacch. 45, cf. 325 ; 1255). Ceci mène Penthée à une confrontation immédiate avec Dionysos, où l'opposition entre vraie et fausse sagesse est de nouveau exposée de manière très forte (Bacch. 479-480 ; 482-484 ; 489-490 ; 655-656, tr. H. Berguin) :

(Pe.) Tu as pris une fois de plus un détour habile pour ne rien dire.

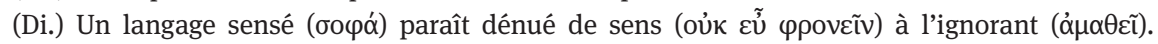
[...]

(Di.) Tous les barbares fêtent par des choeurs ses orgies.

(Pe.) Oui, ils sont beaucoup moins sensés ( $\varphi$ povoṽбı) que les Grecs.

(Di.) En cela du moins, ils le sont bien plus: leurs usages sont différents.

[...]

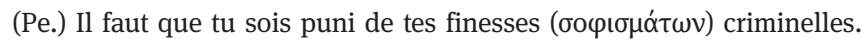

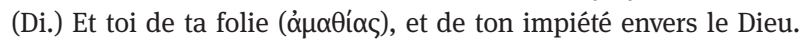

[...]

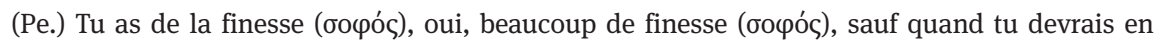
(боழóv) avoir.

(Di.) C'est surtout quand il en faut que j'ai de la finesse (бофóৎ), et naturellement. ${ }^{30}$

Le parallèle avec l'opposition entre deux manières de réfléchir, celle présente dans les Bacchantes et celle des événements que nous observons dans le septième livre de la Paraphrase, est très clair. Comme Penthée qui, parfaitement convaincu de sa propre rationalité, s'oppose de façon implacable à Dionysos, tout en ignorant les signaux qui lui proviennent de toutes parts et révèlent la fausseté de son comportement, de même les chefs religieux juifs, espérant à tort en leur raison, s'opposent à Jésus, en dépit de l'admiration que lui vouent les foules et les gardes. Dans les deux cas, les persécuteurs ne croient pas en la nature divine de leurs victimes, bien qu'ils commettent une erreur dramatique aux yeux du lecteur des deux textes. L'intertextualité entre les Bacchantes et la Paraphrase est ici d'autant plus évidente que le verbe $\theta \varepsilon \circ \mu \alpha \chi \varepsilon \dot{\varepsilon} \omega$ «combattre contre la divinité», qui s’adresse à Penthée, possède son équivalent dans une épithète attribuée aux prêtres juifs óvtí $\theta \varepsilon$ co «ennemis de Dieu». En outre, le lecteur de la Paraphrase sait que la résurrection mettra définitivement fin

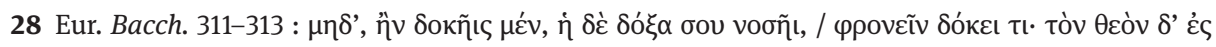

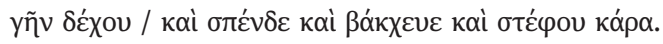

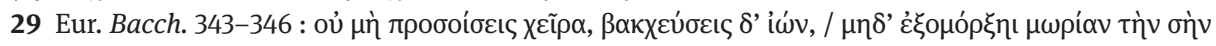

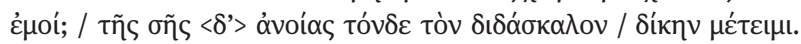

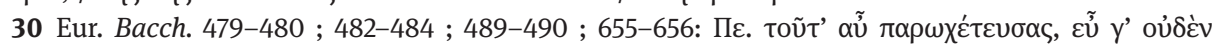

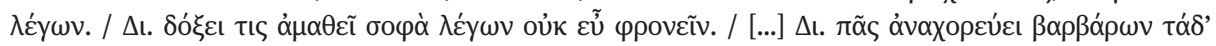

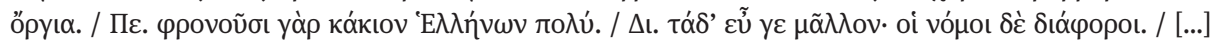

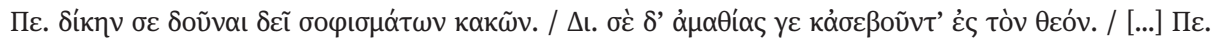

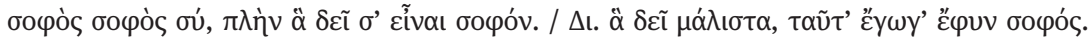


au conflit entre Jésus et les chefs religieux juifs dans le texte johannique. Aussi pouvons-nous constater que les autorités juives sont condamnées à l'échec autant que l'est Penthée.

Le même motif revient encore dans le chant XI de la Paraphrase quand, après la résurrection de Lazare, les autorités juives délibèrent sur le moyen de remédier à la popularité du Christ et d'éviter la destruction d'Israël par les Romains (Nonn. Par. XI.185-206, tr. de Marcellus).

\begin{abstract}
«Plusieurs d'entre eux [c.-à-d. ceux qui ont vu Lazare sortir de la tombe], retournant dans la cité

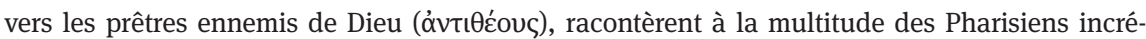

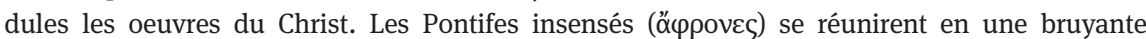
assemblée [...] et l'un dit à l'autre: » Qu'allons-nous faire? Cet homme, notre adversaire (åvtí$\pi \alpha \lambda \circ \varsigma)$, accomplit les miracles les plus grands et les plus divers «. [...] Il y avait parmi eux un homme injuste, astucieux, nommé Caïphe [...]. Celui-ci adressa aux Juifs ces paroles perfides:

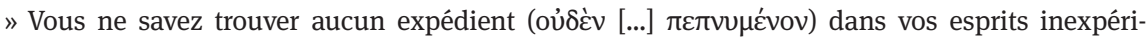
mentés, et vous ne considérez point ce qu'il y a de préférable : [...] Par la mort d'un seul homme toute la communauté sera sauvée. ${ }^{31}$ «
\end{abstract}

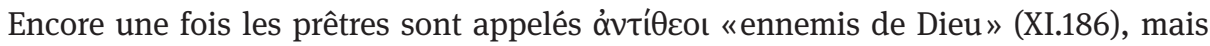
aussi ö́poves «insensés» (XI.188), bien que, d'après Caïphe lui-même, le plan

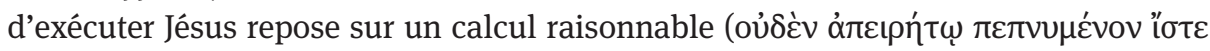
$\mu \varepsilon v o เ v \tilde{n}$ XI.202 ${ }^{32}$ ). En plus du conflit entre une vraie et une fausse raison, est dissimulée une autre référence très significative aux Bacchantes. En effet, chez Euripide,

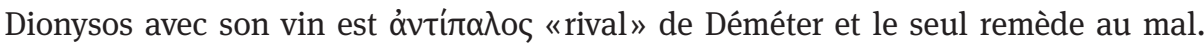
Ceci signifie que Dionysos en tant que vin devient un sacrifice offert aux dieux pour assurer aux hommes la prospérité (voir plus haut Bacch. 274-285). Tel est aussi le cas

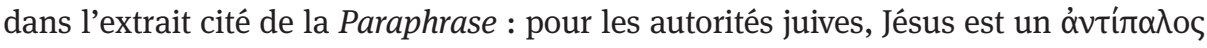
«rival» (XI.191) dont la mort remédiera au mal et sauvera l'état entier.

Pour résumer, dans les Bacchantes, Dionysos est $\Delta$ iò $\pi$ đĩৎ «fils de Zeus» (Bacch. 1) et bienfaiteur de l'humanité. Son don, le vin, est pour les hommes la délivrance du mal et une source de joie. Malgré son ultime triomphe, Dionysos se trouve d'abord face au rejet et à la persécution de la part de l'autorité terrestre qui, étant donné la nature limitée de sa raison, ne parvient pas à saisir la logique de cette divinité. En même temps, il est accueilli avec enthousiasme par ceux pour qui la volonté divine, même incomprise, est le plus important des impératifs terrestres. Dans la Paraphrase, texte pleinement exégétique, Nonnos place les événements évangéliques sur fond

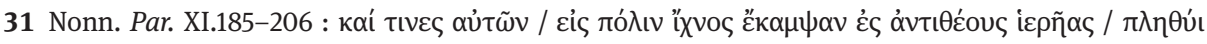

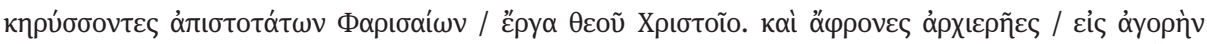

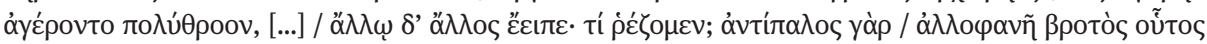

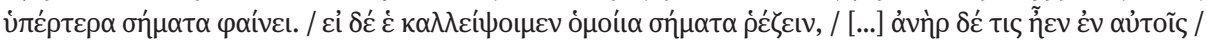

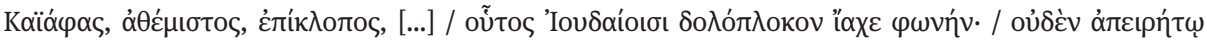

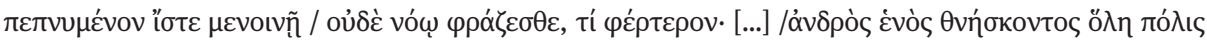

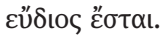

32 Voir Spanoudakis (2014) ad loc. 
d'épisodes provenant des Bacchantes pour rendre le message de l'Évangile encore plus lisible. Jésus, $\pi \alpha$ ĩ $\theta \varepsilon$ oṽ «le fils de Dieu » ${ }^{33}$, crée le vin de l'eau, accomplissement parfait de l'Ancienne Alliance. La présence du Christ inspire dans ceux qui le reçoivent un enthousiasme bachique parce que, grâce au Christ, ils peuvent vivre dans l'intimité de Dieu même. La sagesse divine de Jésus, dans la mesure où elle dépasse le raisonnement terrestre des autorités juives, est donc rejetée et persécutée. Mais chaque lecteur de la Paraphrase savait que la crucifixion est l'accomplissement du plan de Dieu est dont les Juifs n'ont pas conscience : c'est le Christ qui triomphe.

\section{Bibliographie}

Accorinti (2013): Domenico Accorinti, «Nonnos von Panopolis», in: Reallexikon fur Antike und Christentum, Band 25, 1107-1129.

Chuvin (1992): Pierre Chuvin, Nonnos de Panopolis, Les Dionysiaques, Tome III, chants VI-VIII, Paris.

Cusset (2015): Christophe Cusset, «Les Noces de Cana dans la Paraphrase de Nonnos de Panopolis: entre mystère dionysiaque et miracle chrétien», in: Jean-Marc Vercruysse (ed.), Les Noces de Cana, Arras, 71-86.

Dodds ('1960): Eric R. Dodds, Euripides' Bacchae, $2^{\text {nd }}$ edition, Oxford.

Doroszewski (2014): Filip Doroszewski, «Judaic orgies and Christ's Bacchic Deeds: Dionysiac Terminology in Nonnus' Paraphrase of St. John's Gospel», in: Konstantinos Spanoudakis (ed.), Nonnus of Panopolis in Context. Poetry and Cultural Milieu in Late Antiquity, Berlin -Boston, 287-301.

Doroszewski (2016): Filip Doroszewski, «The Mystery Terminology in Nonnus’ Paraphrase», in: Domenico Accorinti (ed.), Brill's Companion to Nonnus of Panopolis, Leiden, 327-350.

Friesen (2015): Courtney J.P. Friesen, Euripides' Bacchae and the Cultural Contestations of Greeks, Jews, Romans, and Christians, Tübingen.

Lewy (1929): Hans Lewy, Sobria ebrietas. Untersuchungen zur Geschichte der antiken Mystik, Giessen.

Livrea (2000): Enrico Livrea, Nonno di Panopoli, Parafrasi del Vangelo di S. Giovanni. Canto B, Bologna.

Massa (2014): Francesco Massa, Tra la vigna e la croce: Dioniso nei discorsi letterari e figurativi cristiani (II-IV secolo), Stuttgart.

Nikiprowetzky (1977): Valentin Nikiprowetzky, Le commentaire de l'ecriture chez Philon d'Alexandrie: son caractere et sa portee, observations philologiques, Leiden.

Riedweg (1987): Christoph Riedweg, Mysterienterminologie bei Platon, Philon und Klemens von Alexandrien, Berlin-New York.

Shorrock (2011): Robert Shorrock, The Myth of Paganism. Nonnus, Dionysus and the World of Late Antiquity, London.

Spanoudakis (2014): Konstantinos Spanoudakis, Nonnus of Panopolis, Paraphrasis of the Gospel of John XI, Oxford.

33 Nonn. Par. III.170 ; X.131 ; X.149 ; XI.182 ; XII.50 ; XII.169. 



\section{Salut et prophéties messianiques dans le septième chant de la Paraphrase de Nonnos}

Le septième chant de la Paraphrase ${ }^{\star}$ est un exemple éloquent des grandes lignes interprétatives que Nonnos de Panopolis suit dans sa relecture complète et attentive du modèle évangélique de Jean. Des thèmes de grande importance exégétiquethéologique trouvent une synthèse efficace dans le septième chapitre du Quatrième Évangile: l'opposition entre le Logos et l'humanité incrédule, illustrée par la confrontation entre sagesse et ignorance; la polémique au sujet de l'interprétation et/ou de la transgression des prescriptions de Moïse et la didaché de Jésus; l'envie et la colère des adversaires de la foi (le groupe des Juifs/Pharisiens/la foule); ${ }^{1}$ l'interprétation chrétienne de la figure du Messie et des attentes de son avènement historique.

Nous voulons parcourir la paraphrase de Jean 7 en portant notre intérêt sur les solutions exégétiques nonniennes les plus intéressantes, dans le but d'identifier certains éléments fondateurs de la structure théologique de son œuvre.

Le cadre du récit est la fête juive des Tentes² (бкпvoлcyía: 'planter la tente'), qui était une des trois célébrations qui imposaient le pèlerinage à Jérusalem. Cela se déroulait de fin septembre à début octobre en mémoire des pérégrinations d'Israël dans le désert et en remerciement pour les récoltes. Durant la fête, les israéliens demeuraient dans des tentes de broussailles montées dans les rues et sur les terrasses. Nonnos mentionne toujours cette fête en la qualifiant de différentes manières, avec des allusions aux aspects rituels qui la caractérisaient: «la fête populaire consacrées a Dieu, qui porte le nom de la fixation des Tabernacles et qu'on célèbre

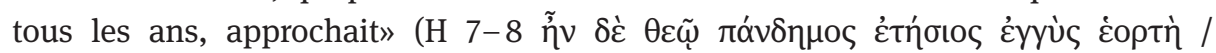

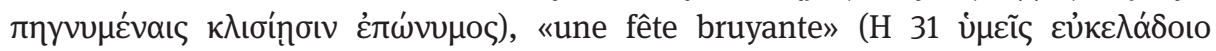

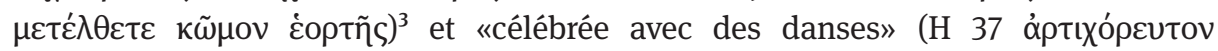
غ̇optńv). ${ }^{4}$

\footnotetext{
* Le texte de la Paraphrase est cité selon l'édition critique d'A. Scheindler, Nonni Panopolitani Paraphrasis S. Evangelii Ioannei, Leipzig, 1881; le texte de l'évangile selon Jean est reproduit selon l'édition de La Bible de Jérusalem, Paris 1998. Toutes les traductions des verses de Nonnos sont personnelles.

1 Au sujet de la représentation du group de Juifs et de Pharisiens dans la Paraphrase voir Ypsilanti/ Franco (2018) 166-183.

2 À propos de l'interprétation de Nonnos sur la fête juive de Tentes, en générale, et sur le sens de

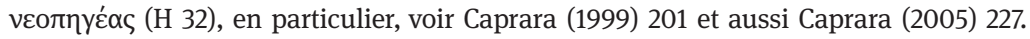

3 Doroszewski (2014) 299-300. Sur l'utilisation du vocabulaire mystique dans la Paraphrase, par exemple pour traduire le terme غ̇optń, voir Vian (1988) 408-409.

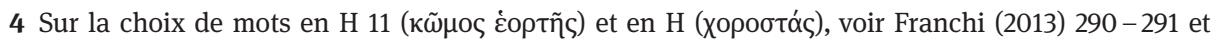
Doroszewski (2016) 345-346, qui rappelle l'emploi nonnien de caractériser les fêtes hébraïques avec 
L’évangéliste présente Jésus qui reste en Galilée en considération des menaces

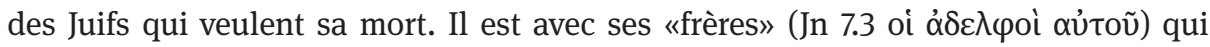
l'invitent à participer à la fête pour montrer ses dons extraordinaires. Nonnos les

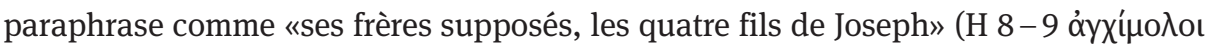

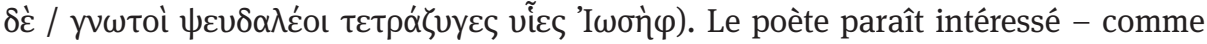
l'avait été Cyrille d'Alexandrie même (ce dernier sur la foi de Jérémie 1.6) ${ }^{5}$ à réaffirmer que les frères, dans le sens de frères de sang, étaient fils de Joseph mais pas de Marie. Il mentionne les quatre frères sur la base d'un témoignage de la tradition synoptique (Mt 13.55; Mc 6.3) qui parle de Jacques, Joseph, Simon et Judas.

Les frères de Jésus l'invitent à se joindre à la fête déjà commencée afin de démontrer qui il est et surtout «afin que, ramenant vers vous un peuple inconstant et

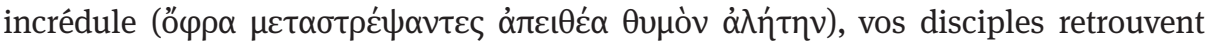

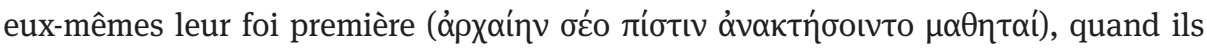

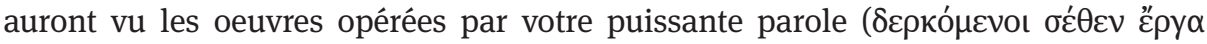

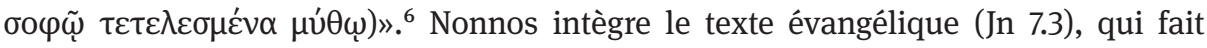
allusion à la nécessité d'une preuve concrète qui alimente le discipulat, ajoutant l'objectif de reconduire ces $\mu \alpha \theta \eta \tau \alpha i ́$ à leur foi, une foi perdue ( $\alpha \rho \alpha \alpha i ́ \eta v . . . \pi i ́ \sigma \tau ı v)$ parce qu'entre temps, leur cœur incrédule et instable avait changé ( $\mu \varepsilon \tau \alpha \sigma \tau \rho \varepsilon ́ \psi \alpha \nu \tau \varepsilon \varsigma$

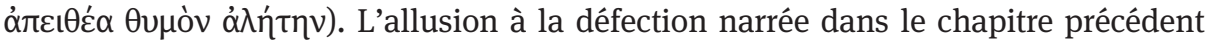
(Jn 6.6) est évidente. Il y a une certaine ironie de la part du poète, qui attribue aux frères de mauvaise foi, qui ne croyaient pas sans la preuve par les signes, une invitation adressée aux incrédules à recouvrer la foi. La considération suivante complète le tableau: l'œuvre réservée et discrète de Jésus est rendue par une image que Nonnos répète plusieurs fois dans sa Paraphrase, en référence à l'action du Christ en conformité au dessin du Père. Jésus «tisse une œuvre» ("̌pyov v́ $\varphi \alpha i ́ v \varepsilon ı)$, son œuvre, sans ostentation. ${ }^{7}$ Les frères, au lieu de cela, l'interprètent selon l'optique du monde attiré par le spectacle, comme dit Cyrille. ${ }^{8}$ D’où, dit le poète: «une œuvre

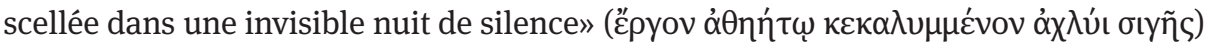

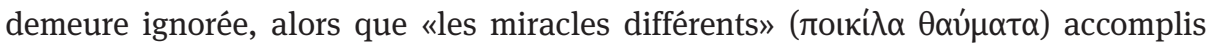

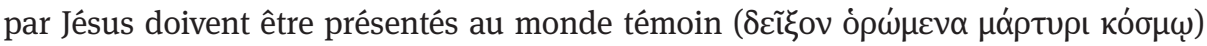
pour qu'il puisse en tirer notoriété et succès (H 19). Paraphrasant Jn 7.5 («Pas même ses frères en effet ne croyaient en lui») Nonnos insiste sur l'incrédulité de sa famille

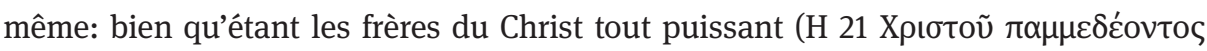

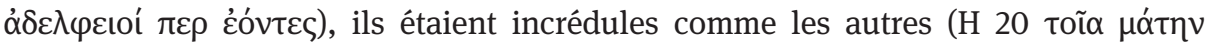

des topoi de la polémique judéo-chrétienne; à l'appui il mentionne le septième Discours contre les Juifs (7.1.2) de Jean Chrysostome (PG 48,915) et le commentaire sur Jn 7.8 de Cyrille d'Alexandrie. 5 Cyr. Al. in Io. IV.5 (PG 73,637B).

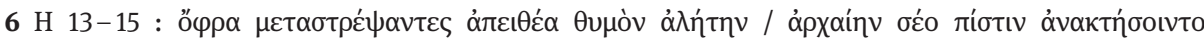

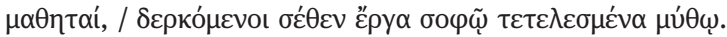

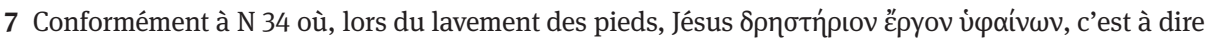
qu'il agit comme un serviteur.

8 Cyr. Al. in Io. IV.5 (PG 73,636D). 


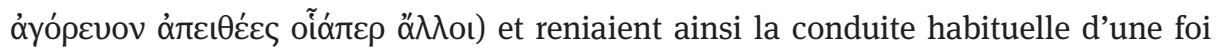

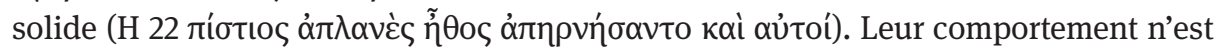
pas adapté au véritable croyant comme le démontre leur façon de considérer l'œuvre du Christ.

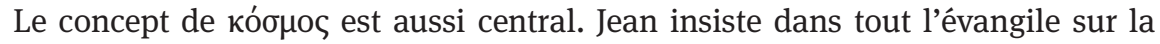

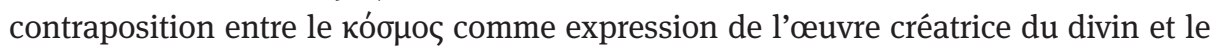

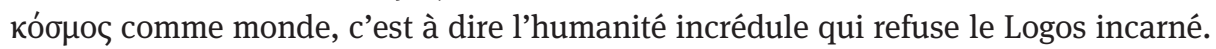
Nonnos amplifie la dualité de ce concept, surtout dans la réponse de Jésus, paraphrase de Jn 7.6-7: le monde arrogant qui prétend des signes pour croire, déteste et

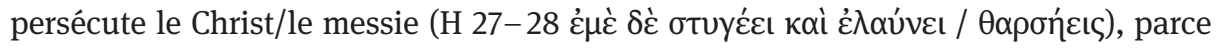

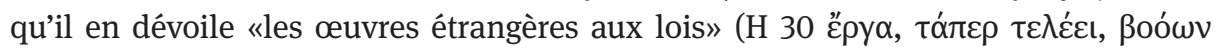
$\dot{\alpha} \lambda \lambda o ́ \tau \rho ı \alpha \theta \varepsilon \sigma \mu \tilde{\omega} \nu)$. Nonnos explique cette aversion par le moyen d'une double

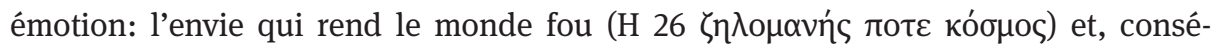

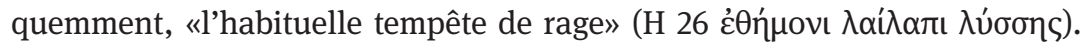

\section{Le temps messianique: le каıрós}

L'inexplicable réticence de Jésus, ${ }^{9}$ qui refuse de participer à la fête des Tentes, ${ }^{10}$ offre à l'évangéliste l'occasion d'introduire la question du kaıpós qui marque la frontière entre le temps de Dieu et celui de l'homme, mais distingue aussi l'heure reliée à la volonté du Père, du kaıpós comme moment décisif du choix du Fils face à son mandat. Ce concept détermine aussi une interprétation chrétienne de la dogmatique messianique. «Mon temps n'est pas encore arrivé; par contre, le vôtre court toujours

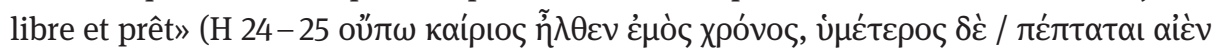
$\dot{\varepsilon} \tau о \tilde{\mu} \mu о \varsigma, ~ \varepsilon ่ \lambda \varepsilon u ́ \theta \varepsilon \rho \circ \varsigma)$, ainsi Nonnos paraphrase-t-il Jn 7.6 («Mon temps n’est pas encore venu, tandis que le vôtre est toujours prêt»), dans lequel Jésus refuse la de-

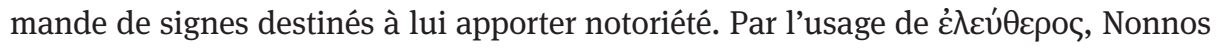
qualifie le xpóvos selon la conception humaine et synthétise en un seul adjectif ce concept de temps selon le monde. Le commentaire de Cyrille contient une réflexion sur cet aspect : d'abord il explique que Jésus, à propos du kaıpós, s'exprime dans un langage obscur et c'est voulu, parce que l'esprit des Juifs, qui sont dévorés par $\theta u \mu o ́ \varsigma$ et ópyń, ${ }^{11}$ n'était pas encore mûr pour accueillir son enseignement. ${ }^{12}$ Puis il clarifie le

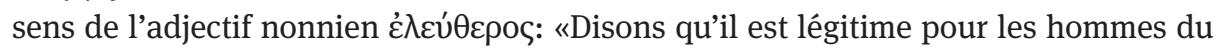
monde de faire ce qu'ils veulent, sans qu'il n'y ait de motif d'empêchement, qui les invite à un temps plus adapté, qui les exhorte à faire ou à ne pas faire, comme c'est le

9 Ce problème fait l'objet d'un traité distinct en Smith (2017).

10 Sur l'imperfection du culte juif dans la Paraphrase voir Doroszewski (2014) 300.

11 Voir Rotondo (2017a).

12 Cyr. Al. in Io. IV.5 (PG 73,637C). 
cas, précisément, du Christ; en effet, la vie des hommes du monde est libre d'anxiété et de fatigue $[. ..]{ }^{13}{ }^{13}$

Cette idée du temps et de la vie propre des hommes amants du plaisir rend la réprobation de Jésus inacceptable: cela déchaine la manifestation émotionnelle de la

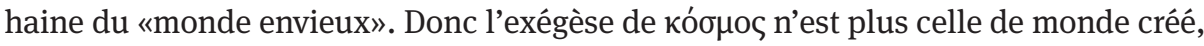
mais de ceux qui aiment les choses du monde, c'est à dire en général les incrédules et en particulier le groupe des Juifs/Pharisiens/foule, les ennemis du Christ. Nonnos explique de façon plus approfondie le contenu des remontrances de Jésus: il dénonce, ou même «hurle» (30 ßoó $\omega v$ ) que les œuvres du monde sont «étrangères aux lois» (30 $\alpha \lambda \lambda o ́ \tau \rho ı \alpha \theta \varepsilon \sigma \mu \tilde{\omega} \nu$ ). Le poète reprend ici la critique cyrillienne dans le commentaire de Jn 7.13 sur «les princes» des Juifs, préoccupés de soumettre le peuple

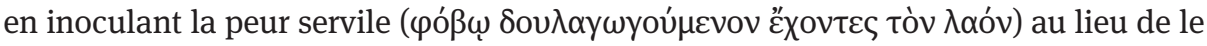
guider selon les lois divines: pour cela, ils devront pâtir des peines. ${ }^{14}$ La peur l'emporte sur la $\pi \alpha \rho \rho \eta \sigma i ́ \alpha$ - dit l'évangéliste - et Nonnos amplifie cette dimension de contrainte qui sévit sur Jérusalem, alimenté par des menaces (comme leur exclusion des synagogues dans Jn 9.22) ; il amplifie cette liberté réprimée qui serre la bouche: «Personne n'osait parler de lui avec une voix intrépide, à lèvres dénouées, tous étant

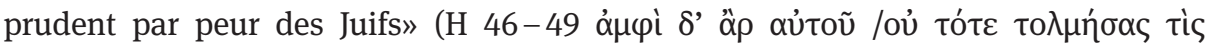

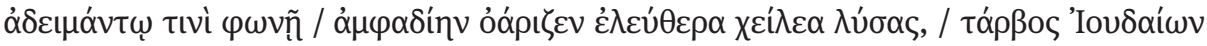
$\pi \varepsilon \varphi v \lambda \alpha y \mu \varepsilon \varepsilon^{\prime}$ oc). Pour l'évangéliste, cet aspect était important, afin d'exprimer l'hésitation de la foi en Jésus à se manifester et pour raisonner sur la situation de la communauté de son temps face à l'influence judaïque, forte en Asie Mineure. Au lieu de cela, pour notre poète, la responsabilité judaïque ou bien des autorités religieuses en général, (donc aussi celle de son temps) est centrale; celles-ci affirment leur pouvoir en recourant par prétexte à un usage dévié et faussé des Écritures.

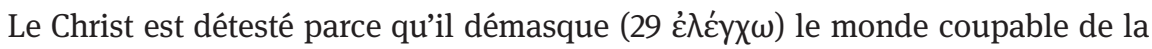
faute même dont on l'accuse - explique Nonnos - c'est à dire le respect manqué au loi divine. De cette manière, le poète anticipe l'argument de la polémique qui l'oppose à ses adversaires, indignés par sa transgression du repos sabbatique, ayant guéri un paralytique justement ce jour-là. Ils veulent donc le tuer puisqu'il a méprisé les prescriptions de Moïse. Le poète ajoute que dans cette 'chasse à l'homme', paradoxalement, les ennemis du Christ agissaient selon «une nécessitée chère» (H 38 $\varphi$ la dernière heure. ${ }^{15}$ Le paraphraste ne néglige pas la question de l'heure; au contraire, il la marque avec force, lui conférant une teneur dramatique: ${ }^{16}$ l'acmé de la

13 Cyr. Al. in Io. IV.5 (PG 73,637D).

14 Cyr. Al. in Io. IV.5 (PG 73,653B). Cyrille rappelle les mots de Jr 10,21: «C'est que les pasteurs furent stupides; ils n’ont pas cherché Yahvé. Aussi n’ont-ils point réussi et tout le troupeau a été dispersé». 15 Sur le rapport entre l'accomplissement de l'heure de Jésus et les fêtes juives, voir Daise (2007).

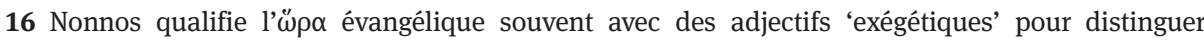
l'heure qui reste à venir de l'heure qui est déjà arrivée : voir Caprara (2005) 227-228 ( $\Delta$ 10: l'heure du culte spirituel en esprit et en vérité) et Agosti (2003) 474-475 (E 107-108: la dernière heure). 


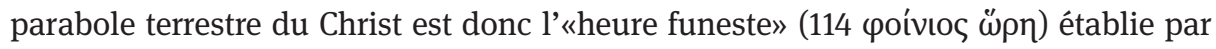
le Père et que le Christ attend; l' «heure délibérément choisie, qui apporte rapidement

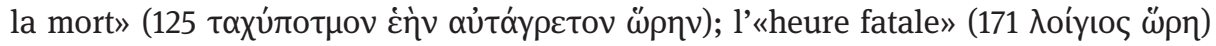
pas encore arrivée, raison pour laquelle le groupe des gardes des Pharisiens renonce à capturer Jésus.

\section{La stupeur des Juifs et la polémique sur la sagesse/ignorance de la Loi et des Écritures}

Après que tous soient partis, Jésus, se gardant de suivre ses frères, décide finalement d'aller à Jérusalem pour la fête des Tentes. L'évangéliste dit qu'il le fait en cachette (Jn 7.10), Nonnos au lieu de cela spécifie qu’il y va plus tard (36 ỏ $\psi$ É). Il rappelle ce

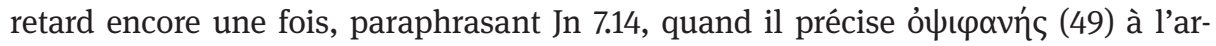
rivée de Jésus au temple à la moitié de la fête.

Il enseigne à ceux qui s'étaient assemblés pour l'écouter; sa didaché suscite stupeur. Nonnos paraphrase Jn 7.15 avec ironie : «L'essaim intelligent des Juifs se

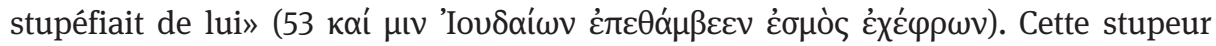

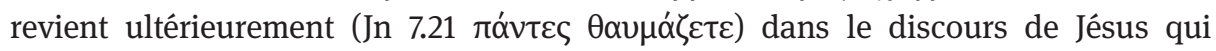
conteste à ses détracteurs l'injuste critique de ses œuvres: «J'ai accompli une seule œuvre, et par le prétexte d'une œuvre religieuse, vous tous, stupéfiés, me contestez»

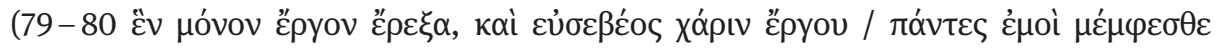
$\tau \varepsilon \theta \eta \pi$ т́тৎ). La stupeur en tant que réaction propre à l'incrédule marque toute la Paraphrase : Nonnos l'utilise pour expliquer le niveau de la foi de Nathanaël, de Nicodème, de la samaritaine après leur rencontre avec Jésus et surtout après avoir écouté ses incompréhensibles paroles. Dans la géographie émotionnelle de la $P a$ raphrase, dans la plupart des cas la stupeur est improductive, du fait qu'elle découle du désarroi. ${ }^{17}$ C'est la réaction de ceux qui ne croiront pas, restant conditionnés par les signes. C'est seulement dans de rares cas qu'elle se traduit en foi. Un cas est celui de Nathanael: pris de stupeur face aux dons prophétiques de Jésus, il se frappe le front avec sa main craintive de Dieu, dit le poète (A 198-199); ${ }^{18}$ ainsi, il en reconnaît le caractère royal et la messianité (A 200 -204). Un autre exemple de stupeur comme prémisse positive d'une intuition de foi en Christ est offert dans le chant 7 par les

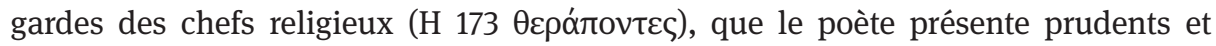

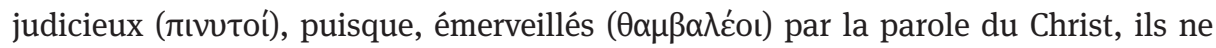
l'avaient pas capturés comme il leur avait été ordonné.

Cyrille considère la stupeur des incrédules en tant que manifestation de leur ignorance: ils auraient dû admirer Jésus pour la guérison du paralytique, accomplie le samedi ou non. Nonnos reprend cette idée, situant la dispute du Christ avec ses

17 Au sujet de la stupeur et l'envie dans la Paraphrase voir Rotondo (2018) 210 - 213.

18 Voir Rotondo (2017b) 33 ss. 
adversaires dans un climat de tension et de défi : le yoyyvouós des Juifs et des Pharisiens mais surtout du $\lambda \alpha$ ós, du peuple, de la foule sert de décor aux trames des chefs du peuple orientées à la suppression du prédicateur blasphème. À un $\lambda \alpha$ ó composé de gens du commun, qui considéraient Christ un sage du fait de ses signes

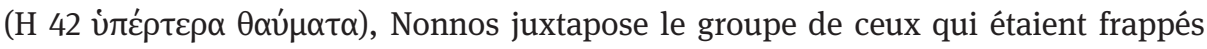
par sa connaissance des Écritures: «De quelle manière celui-ci de sa propre autorité dit la voix des Écritures? Comment a-t-il appris les Écritures, sans les avoir étudiées selon la technique parfaite? Comment se peut-il que cet ignorant connaisse les

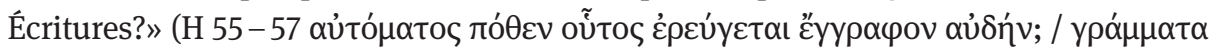

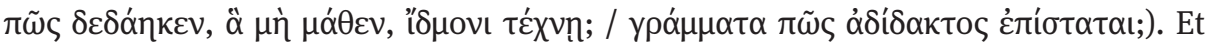

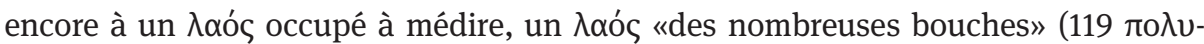

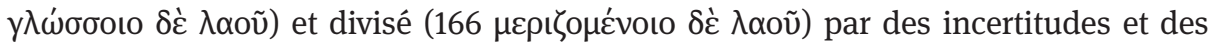

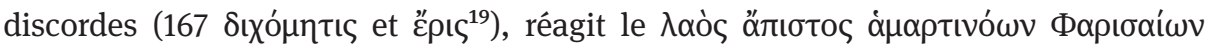
(121), le groupe des chefs, fou d'envie.

La tension qui anime tout le chant $^{20}$ s'appuie sur les concepts de sagesse et d'ignorance: selon les hommes, la sagesse vient des Écritures, à travers leur connaissance diligente; pour le Christ nonnien, la sagesse est un don divin (62 oủpavín

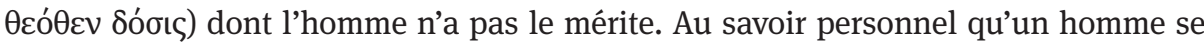

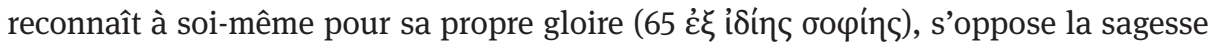
de celui qui entend faire la volonté de Dieu: «Celui-ci sans faute parcourt un chemin

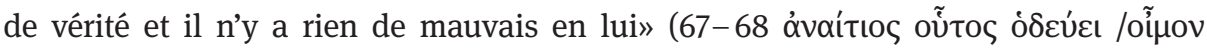

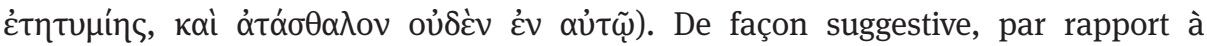

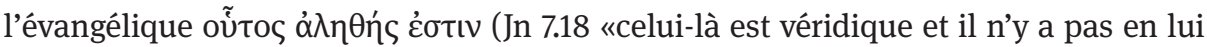

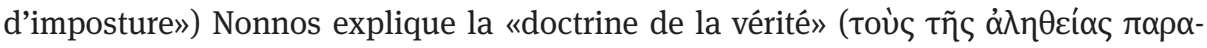

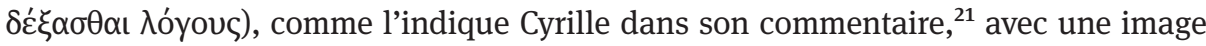
interne au texte de Jean: c'est à dire le Logos comme chemin, óoós; emprunter ce chemin signifie suivre la vérité. Pour cela Cyrille ajoute que cette doctrine de la vérité est à accepter sans alternatives d'interprétation ${ }^{22}$ et que le savoir personnel en ce qu'il a de présomptueux, origine de l'ignorance juive, consiste en une approche que l'on peut qualifier d'hérétique à la Loi. Cyrille dit dans son commentaire à Jn 7.18 que les chefs religieux ont mis de côté les préceptes de la Loi et fidèles à leur cupidité,

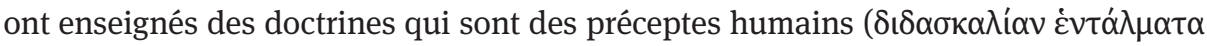

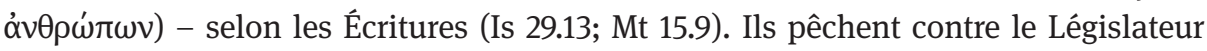
parce qu'ils ne vivent pas selon ses lois, au contraire, ils convainquent leur audience

19 Dans le verset Jn 7.43 on lit $\sigma x i ́ \sigma \mu \alpha$.

20 Nonnos souligne le sens de défi, qu'il caractérise le débat entre Jésus et ses adversaires dans ce

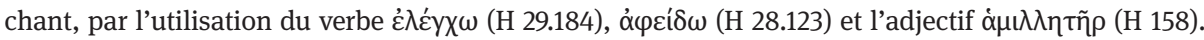
21 Cyr. Al. in Io. IV.5 (PG 73,661 A).

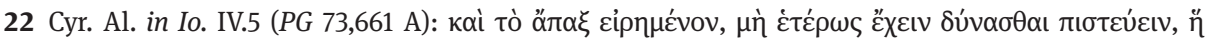

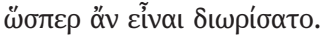


à obéir à la doctrine qui les arrange (

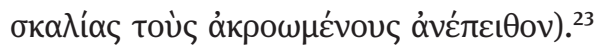

\section{La polémique sur le repos sabbatique et sur la circoncision: Moïse transgresseur ou Christ transgresseur?}

Dans la réplique de Jésus à ceux qui l'avaient accusé d'être possédé, parce qu'il avait contesté l'usage malhonnête de la loi de Moïse, instrumentalisée contre lui (72-73

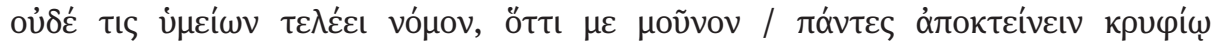

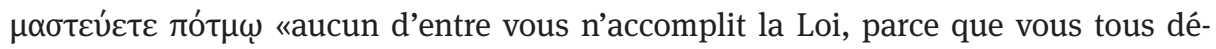
sirez me tuer, moi seul, de mort secrète»), l'évangéliste affronte ensemble l'interprétation chrétienne du repos sabbatique et de la circoncision. Jésus conteste les médisances sur sa guérison du paralytique, d'un homme tout entier (Jn 7.23 ő

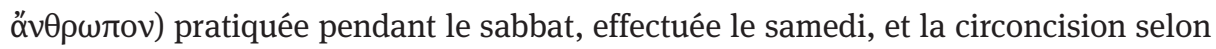
Moïse (censée "guérir» un membre particulier) pratiquée le même jour. ${ }^{24}$ Nonnos interprète ce passage difficile, suivant encore une fois la ligne exégétique de Cyrille : il recoure à l'image du fer qui circoncit, selon un usage antique, le septième jour. Selon des normes ávćyyva, illégitimes (86) attribuée à Moïse, «vous circoncisez un

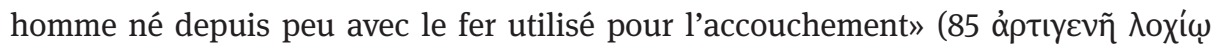

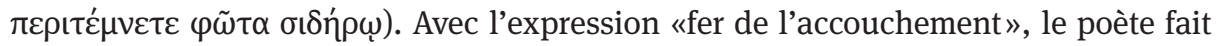
allusion à la prescription de circoncire le nouveau né le huitième jour de sa vie, dans le cas où il est né au domicile (Lv 12.3; Gn 17.9-14). Le Christ nonnien, «sans le fer

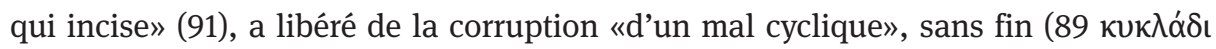

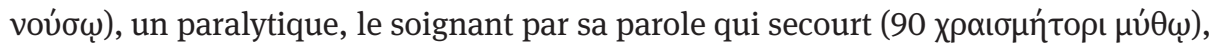

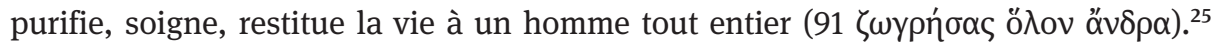
Quel serait, donc, le motif des médisances qui alimente la haine de ceux qui, «ex-

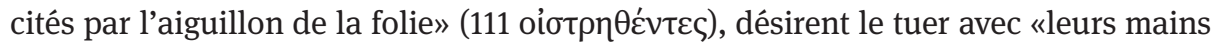

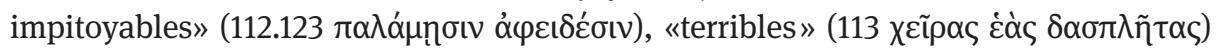

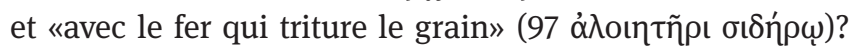

\section{Le Messie connu vs le Messie inconnu}

Nous sommes à la moitié de la semaine de festivités, lorsque les habitants de

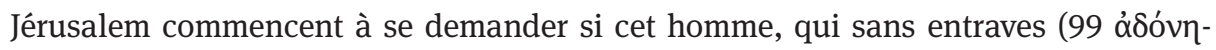

23 Cyr. Al. in Io IV.5 (PG 73,664C).

24 Voir Pancaro (2014) 127-157.

25 Voir Paul (Rm 2.26-29), qui explique, en rappelant le prophète Jérémie, que la vraie circoncision est celle du cœur. 
тoৎ) ni craintes, continuait à prêcher dans la ville, malgré que les chefs religieux voulaient sa mort, n'était pas le Christ attendu. On savait que le Messie devait être un descendant de David et naître à Bethléem, comme il est dit ultérieurement (Jn 7.42 : «l'Écriture n'a-t-elle pas dit que c'est la descendance de David et de Bethléem, le village où était David, que doit venir le Christ?»), mais la croyance populaire, c'est à dire des hommes de Jérusalem, imaginait qu'il serait apparu à l'improviste d'un lieu secret. La figure de Jésus ne correspondait à aucune des attentes d'un sauveur ni dans le contexte de son temps ni dans le temps des destinataires de l'évangéliste. De dures attaques à la messianité de Jésus ont animé les disputes entre les premiers groupes chrétiens et les groupes juifs. On connaissait en effet l'origine de Jésus, et cela contredisait la dogmatique messianique sur le Messie inconnu, mais présent sur la terre. ${ }^{26}$ La preuve des œuvres de Jésus, argument principal de la partie chrétienne, ne trouve pas de collocation dans cette conception: voir la paraphrase de Jn 7.27 «lors de la venue du Christ, personne ne saura d'où il vient : alors que lui, vous le

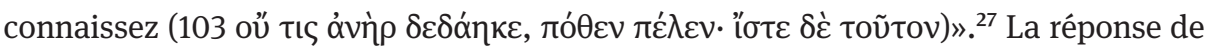
Jésus est lapidaire, mais absolument incompréhensible : il révèle qui il est, disant qu'il n'est pas venu de lui-même, mais le Père l'a envoyé. Pour autant tous le connaissent dans sa figure humaine, mais nul ne le reconnaît dans sa dimension divine. Hélas, du fait d'une lacune après le vers 107, nous manque la paraphrase de Jn 7.28.

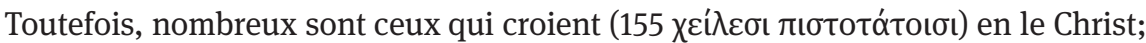

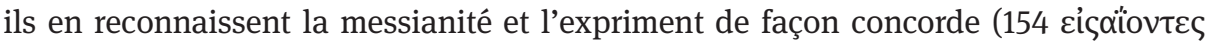

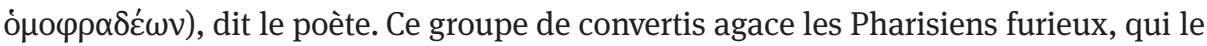
dépeignent comme «cette foule errante, présomptueuse et méchante, ignorant la loi,

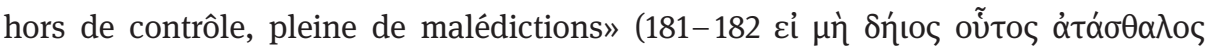

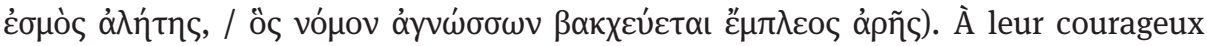
témoignage est confié le point de vue chrétien de la dogmatique messianique, que Nonnos restitue de la façon suivante: «Peut-être que Christ Seigneur et Sauveur, quand'il viendra, fera des miracles plus grands des œuvres que celui-ci a accompli

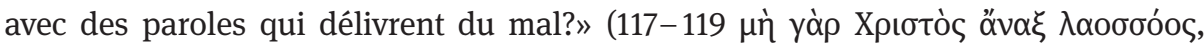

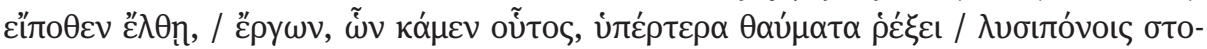

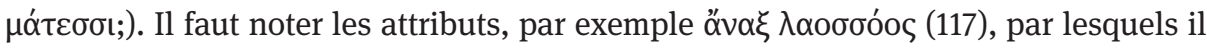
paraphrase le simple Xpıбós de Jn 7.31 et qui 'christianisent' le concept de Messie reconnaissable par les extraordinaires signes accomplis.

Suivent deux discours complexes de Jésus sur sa disparition et sur son héritage spirituel.

26 Cette conception est propre du judaïsme palestinien: voir En 48:6; 4 Esd 7:28; 13:2; 2 Bar 19:3. L'affirme Justin dans le Dialogue avec Tryphon (8.14; 49.1).

27 Sur le Messie inconnu dans l'évangile de Jean voir Casalegno (2006) 160-164. 
Discours 1. L'obscure prophétie sur la voie inaccessible (H 139) : «vous me chercherez et ne me trouverez pas ; et où je suis, vous ne pouvez pas venir» (Jn 7.34)

Jésus préannonce son éloignement: personne ne pourra le suivre. Utilisant les mots de notre poète, il parle d'un átралós, un sentier le long duquel les siens ne pourront le suivre, perçu par

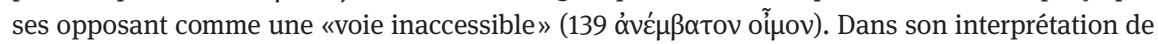
Jn 7.34 le poète souligne la recherche vaine des disciples qui ne pourront pas l'accompagner,

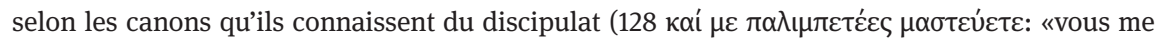
chercherez en me suivant»); le désirer sera également vain (128 $\mu$ ató $\mu \varepsilon v o เ ~ \delta \varepsilon \dot{)})$ face à l'impossibilité (129 oủ ớ́voৎ ćotì) de parcourir le même chemin. La solitude du Christ de la Paraphrase est encore plus radicale que celle du Jésus de l'évangile: l'incompréhension de l'être humain est totale. Les Juifs qui l'écoutent sont frappés par ce profond hiatus qu'il crée entre lui et eux. Nonnos le met en évidence dans leur reformulation de la parole de Jésus : «et il n'est pas

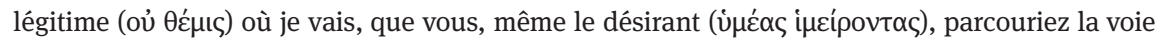
inaccessible» (138-139).

Discours 2. "Si quelqu'un a soif [...] de son sein couleront des fleuves d'eau»: l'exégèse de Jn $7.37-38$

Il s'en suit un retour sur la scène de la fête. C'est le dernier jour de la semaine, le septième: selon le rite, en ce moment conclusif, les chefs religieux tournaient sept fois autour de l'autel, versant ensuite sur le sol, à l'aide d'un entonnoir en argent, l'eau puisée à la source du Siloé, en mémoire de l'eau libérée par la roche dans le désert. Peut-être que Nonnos avait à l'esprit ce rituel, quand il décrit le temple de Jérusalem, où Jésus parlait, comme «scintillant d'argent» (104

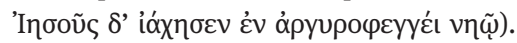

Auprès du temple, Jésus prononce des paroles incompréhensibles: «Si quelqu'un a soif, qu'il vienne à moi et qu'il boive celui qui croit en moi!» (Jn 7.37). Ainsi Nonnos : «si quelqu'un a une

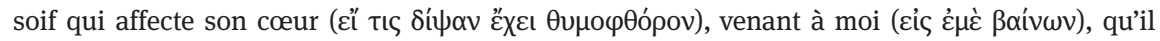

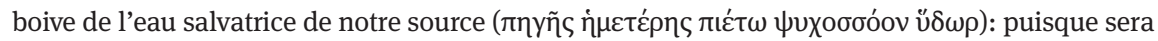

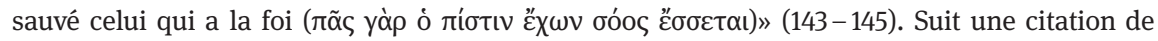
l'Écriture, certainement à l'appui de cette autorévélation. ${ }^{28}$ Jn 7.38 pose de nombreux problèmes. ${ }^{29} \mathrm{D}$ 'abord, la signification du verset peut varier considérablement selon les variantes de la ponctuation; ensuite, l'évangéliste reporte une citation qui ne correspond pas exactement à un unique et de l'Ancien Testament. Les deux variantes possibles sont générées par le signe de ponctuation et correspondent à deux hypothèses interprétatives:

(a) Si quelqu'un a soif, qu'il vienne à moi et qu'il boive!

Celui qui croit en moi (pour lui il on va de même) selon le mot de l'Écriture:

'De son sein couleront des fleuves d'eau vive'.

(b) Si quelqu'un a soif, qu'il vienne à moi et qu'il boive, celui qui croit en moi!

(Pour lui il on va de même) selon le mot de l'Écriture:

'De son sein couleront des fleuves d'eau vive'.

(a) L'une est centrée sur la figure du croyant, qui serait la source d'eau vive, hypothèse soutenue par Origène et par la tradition orientale; (b) dans l'autre, christologique, c'est Jésus qui est la source d'eau vive et c'est de son sein (voir Jn 19.34)

28 Freed (2014) 21-38.

29 Sur l'interprétation nonnienne de Jn 7.37-38 voir Franchi (2018). 
qu'il jaillira des fleuves, selon l'hypothèse de Hyppolite, Cyprien, Aphraates, Éphrem, Theodore d'Eraclée (donc l'Afrique septentrionale et la Syrie). ${ }^{30}$ Nonnos paraphrase ainsi: «Si quelqu'un a une soif qui affecte son cœur, venant à moi, qu'il boive l'eau salvatrice de notre source: ainsi sera sauvé quiconque a la foi. Comme le soutient l'antique parole de Dieu 'Toujours de son sein (ventre; grec: koı $\lambda \lambda^{\prime} \alpha$ ), des fleuves de savoir, avec un courant vif et spontané, verseront de l'intérieur l'eau divine

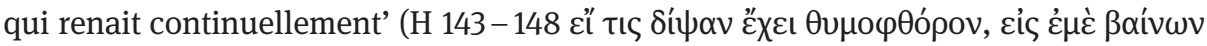

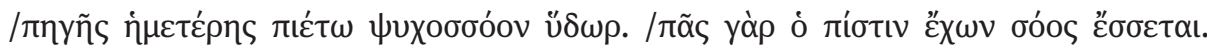

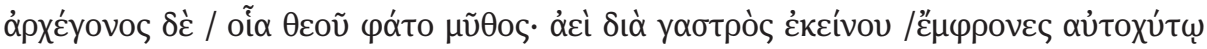

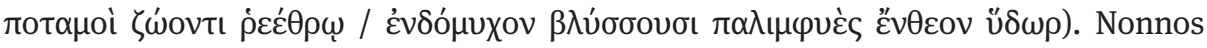
démontre de lire la première variante $(\mathrm{a})$, ou peut être, plus simplement, démontre de préférer cette interprétation. ${ }^{31}$ Qui croit se sauve. La manière selon laquelle le paraphraste insiste sur le thème du salut et donc sur le Christ sauveur est évidente: l'eau

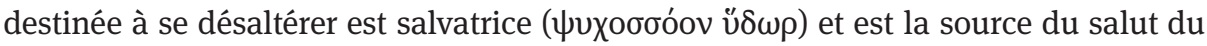

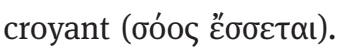

La citation de l'Écriture est reliée au sein du croyant et intégrée par des adjectifs

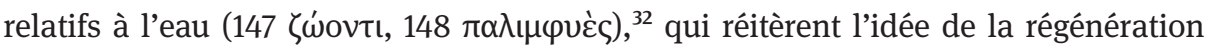
permanente et donc du salut. ${ }^{33}$ Jn 7.39 explique que la source d'eau vive est une allusion au don de l'esprit à venir: le paraphraste rappelle l'idée de la foi en Christ comme garantie du salut, présentant le don de l'esprit comme une expérience universelle «sur l'entière génération des croyants, des hommes de toutes les origines»

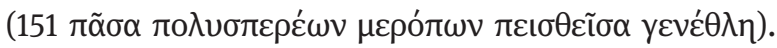

\section{Nicodème, un juste parmi les injustes}

Nicodème, appartenait au «parti opulent» des Pharisiens, ${ }^{34}$ qui avaient blâmé avec violence l'approbation que les foules crédules et ignares de la Loi avaient accordé aux paroles trompeuses de Jésus (Jn 7.45-49). Il était l'un d'entre eux, riche

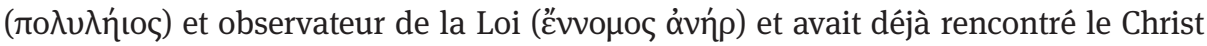

30 Rahner (1941); Schnackenburg (1977) 286-287.

31 Cutino (2009) 232 rappelle que «le lien entre la splendeur et la communication verbale» de $\Gamma$ 6 -7 se retrouve en H 146-152, où le poète interprète l'image des fleuves d'eau vive selon l'exégèse patristique (d'Origène) de Jn 7.37-39 en clé baptismale. Voir surtout l'analyse minutieuse de Franchi (2018).

32 Franchi (2018) 215: «The nonnian use of water symbolism is therefore discussed in terms of creation, vivifyng power, human life, and the manifestation of God known as theophany».

33 Voir aussi $\Delta 65-69$ avec le commentaire de Caprara (2005) 195-199.

34 Jn 19.39 démontre sa richesse grâce au mélange d'environ cent livres de myrrhe et d'aloès qu'il achète pour répandre un parfum précieux dans le tombeau de Jésus. Selon des source rabbiniques $(B$. Gittin 56a) Nicodème était fils de Gorion et un des trois plus riches patriciens; voir Flusser (2005) 135136. 
( $\Gamma 1-2) .{ }^{35}$ Nicodème, en désaccord manifeste avec son groupe d'appartenance, prend la défense de Jésus: justement en se basant sur une norme contenue dans la Loi, il soutient que l'on ne peut juger un homme sans l'avoir préalablement écouté et sans en avoir vérifié les œuvres (Jn 7.51). Nonnos insiste fortement sur la distance qui

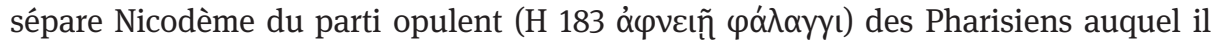

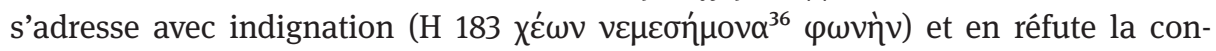

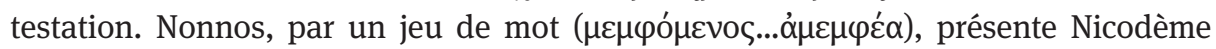

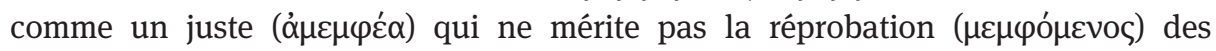

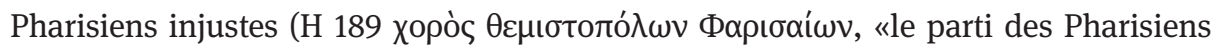
qui s’appuie sur la Loi»). Leur réplique est aux limites de l’insulte : «tu as toi aussi du sang galiléen? Restes assis et tournes les pages du Livre, cherches et tu sauras qu'un

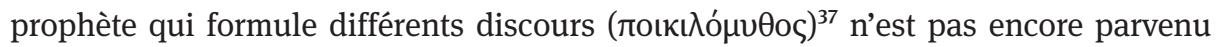

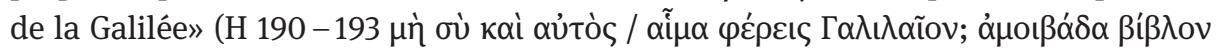

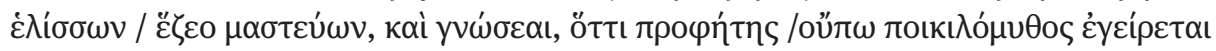

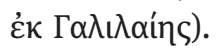

\section{Conclusions}

Dans la Paraphrase l'incrédule a deux visages : 1 . soit il est celui qui résiste à la foi en Christ, suggestionné par les miracles qui le touchent émotivement mais ne génère pas en lui une conscience ; 2. soit il est l'ennemi violent et hostile du Christ (le groupe des Juifs/Pharisiens/ foule) défenseur acharné d'une autorité fondée sur la connaissance des écritures et qui, pourtant, ne sait pas les interpréter.

Nonnos entend la foi chrétienne comme aboutissement d'un parcours difficile

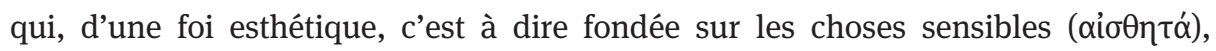
conduit à une foi noétique fondée sur la compréhension de l'œuvre divine et du message de Jésus. Il s'agit d'une connaissance qui a les caractéristiques de l'intuition et que l'on saisi d'un coup. Les vonpá sont donc les acquisitions cognitives que, selon l'interprétation de Nonnos, les initiés ont la possibilité d'obtenir de la rencontre avec le Christ durant lequel ils voient les signes et écoutent ses paroles. Toutefois, la vision et l'écoute ne sauraient être suffisantes pour arriver à la foi véritable. Selon Nonnos, croire est un acte de réception : seuls ceux qui sont disposés à le faire peuvent y arriver. Seules la réception et l'expérience de la foi comme don et choix apportent le salut au véritable chrétien, désireux d'accomplir les œuvres de

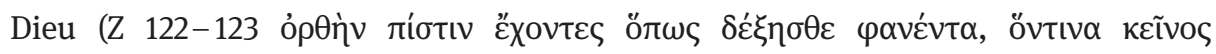

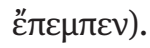

35 Sur cet épisode voir Cutino (2009).

36 Aussi à $\Lambda$ 32b, voir Spanoudakis (2014) 178, comm. ad loc. («expresses human indignation»). 37 Pour la première fois $(\Gamma$ 9) c'est Nicodème qui utilise cet adjectif pour appeler Jésus $(\dot{\rho} \alpha \beta \beta i ̀ v$

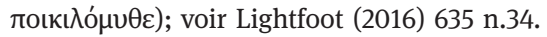




\section{Bibliographie}

Agosti (2003): Gianfranco Agosti, Nonno di Panopoli. Parafrasi del Vangelo di San Giovanni. Canto quinto. Introduzione, edizione critica, traduzione e commento, Firenze.

Caprara (1999): Mariangela Caprara, «Nonno e gli Ebrei. Note a Par. IV 88-121», in: Studi italiani di Filologia Classica $92 / 3^{\circ}$ s. 17, 195-215.

Caprara (2005): Mariangela Caprara, Nonno di Panopoli. Parafrasi del Vangelo di San Giovanni. Canto IV. Introduzione, edizione critica, traduzione e commento, Pisa.

Casalegno (2006): Alberto Casalegno, « Le opinioni degli anonimi circa l'identità messianica di Gesù nel Vangelo di Giovanni» in: Annalisa Guida e Marco Vitelli (eds.), Gesù e i messia di Israele. Il messianismo giudaico e gli inizi della cristologia, Trapani, 159-174.

Cutino (2009): Michele Cutino, "Structure de la composition et exégèse dans la Paraphrase de l'Évangile de s. Jean de Nonnos de Panopolis: Une lecture du chant IIl», in : Revue d'études augustiniennes et patristiques 55, 225-246.

Daise (2007): Michael A. Daise, Feasts in John, Tübingen.

Doroszewski (2014): Filip Doroszewski, «Judaic Orgies and Christ's Bacchic Deeds: Dionysiac Terminology in Nonnus' Paraphrase of St. John's Gospel», in: Konstantinos Spanoudakis (ed.), Nonnus of Panopolis in Context: Poetry and Cultural Milieu in Late Antiquity with a Section on Nonnus and the Modern World, Berlin/Boston, 287-301.

Doroszewski (2016): Filip Doroszewski, «The Mistery Terminology in Nonnus' Paraphrase» in: Domenico Accorinti (ed.), Brill's Companion to Nonnus of Panopolis, Leiden/Boston, $327-350$.

Flusser (2005): David Flusser, Jésus, Paris/Tel Aviv.

Franchi (2013): Roberta Franchi, Nonno di Panopoli. Parafrasi del Vangelo di San Giovanni. Canto sesto. Introduzione, edizione critica, traduzione e commento, Bologna.

Franchi (2018): «Flumina de ventre eius fluent aquae vivae. Nonnus' Paraphrase 7.143-148, John 7.37-38, and the Symbolism of Living Water», in: Herbert Bannert and Nicole Kröll (eds.), Nonnus of Panopolis in Context II: Poetry, Religion, and Society, Leiden, 195-215.

Freed (2014): Edwin d. Freed, Old Quotations in the Gospel of John, Leiden.

Ypsilanti/Franco (2018): Maria Ypsilanti and Laura Franco, «Characterization of Person and Groups of Persons in the Metabole», in: Herbert Bannert and Nicole Kröll (eds.), Nonnus of Panopolis in Context II: Poetry, Religion, and Society, Leiden, 166-183.

Lightfoot (2016): Jane L. Lightfoot, «Nonnus and Prophecy: Between 'Pagan' and 'Christian' Voices», in Domenico Accorinti (ed.), Brill's Companion to Nonnus of Panopolis, Leiden/Boston, 625-643.

Pancaro (2014): Severino Pancaro, The Law in the Fourth Gospel. The Torah and the Gospel, Moses and Jesus, Judaism and Christianity According to John, Leiden.

Rahner (1941): Hugo Rahner, «Flumina de ventre Christi. Die patristische Auslegung von Joh 7,37-38», in : Biblica 22, 269-302.

Rotondo (2017a): Arianna Rotondo, «Aggregati emozionali e dinamiche cognitive in Nonno di Panopoli», in: Sergio Botta, Marianna Ferrara e Alessandro Saggioro (eds.), La Storia delle religioni e la sfida dei pluralismi, Brescia, 359-371.

Rotondo (2017b): Arianna Rotondo, Ascoltare, vedere, credere. Itinerarium fidei nella Parafrasi di Nonno di Panopoli, Soveria Mannelli.

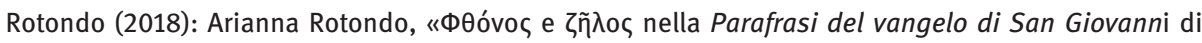
Nonno di Panopoli», in: Carmelo Crimi, Paolo Cipolla, Renata Gentile, Lisania Giordano, Arianna Rotondo, (eds.), Spazi e tempi delle emozioni. Dai primi secoli all'età bizantina, Acireale/Roma, 205-225.

Schnackenburg (1977): Rudolf Schnackenburg, Il vangelo di Giovanni, vol.2, Brescia. 
Smith (2017): Tyler Smith, «Deception in the Speech. Profile of the Johannine Jesus (John 7.1-10)», in: Journal for the Study of the New Testament 40/2, 169-191.

Spanoudakis (2014): Konstantinos Spanoudakis, Nonnus of Panopolis. Paraphrasis of the Gospel of John XI, Oxford.

Vian (1988): Francis Vian, «Les cultes païens dans les Dionysiaques de Nonnos: étude de vocabulaire», in: Revue des Études Anciennes 90/3-4, 399-410. 

Salvatore Costanza

\section{Voices, Hearing and Acoustic Epiphany in Nonnus' Paraphrase of St. John's Gospel}

At first, if we consider Nonnus' paraphrastic poem, we can state that the appearance of the Lord as a perennial theophany countermarks his epic devoted to a learned audience, which is comprised of Christians and not-Christians alike. ${ }^{1}$ Hexameter rewriting of the Fourth Gospel relates to the outstanding interactionist process between Hellenism, not to be merely likened to 'paganism' and Christianity deeply engaged with Greek paideia. ${ }^{2}$

As far as it concerns epiphanic signs, this Christian poem deals with the prophetic power of the voice of Christ as an eminent proof of his divinity revealed to his witnesses. ${ }^{3}$ The discovery of Jesus' divine presence is not restricted to visual signs, such as beauty, brightness and radiance, which are traditionally attached to divine epiphany since Homeric epics. ${ }^{4}$ These signs are likewise linked with the nearness of Jesus in Nonnus' Paraphrase. ${ }^{5}$ Beyond any doubt, Nonnian light symbolism widely develops the idea of the Saviour as the $\varphi \omega \sigma \tau \eta \dot{\rho}$, which enlightens the world by giving illumination to his disciples. ${ }^{6}$ Apart from explanations about light upon Gnostic sources, $^{7}$ the Paraphrast, here, follows Alexandrian theology, especially Cyril's teachings. ${ }^{8}$

1 On cultivated readers and/or listeneres of Nonnus' epics, see Agosti (2001) 97-99; Id. (2005); Id. (2009) 332; Whitby (2016) 216; Franchi (2016) 247.

2 On this intercultural meeting, see Dijkstra (2016) 83-84 with the status quaestionis of Nonnian studies. The use of Homeric topoi beside models drawn from Christian poetry is very common, not only in Gregory of Nazianzus and Nonnus, but also in epigraphic poems of the $4^{\text {th }}$ and $5^{\text {th }}$ centuries, see Agosti (2010) 329-330, 347-349; Id. (2016).

3 For epiphany as an arising phenomenon in the Graeco-Roman world, see Pfister (1924) 314-317, Pax (1955) 30, 109, 144; Gladigow (1990); Versnel (1987); Id. (2016) 37-43; Graf (1997), Id. (2004). On New Testament epiphany motives, see Frenschkowski (1995) 9-20; Id. (1997); Mitchell (2004) $183-187$.

4 See Pfister (1924) 316; Beierwaltes (1957) 14-23; Pax (1962) 842; Bremer (1975) 1-12; Gladigow (1990), 98-100; Graf (1997) 1151; Bierl (2004) 51; Bravo (2004) 66-67; Versnel (2011) 38; Id. (2016) 38 with nt. 50, 60 .

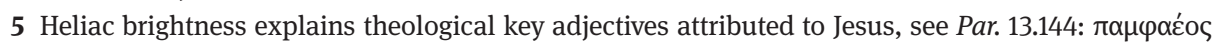
Xрıбтоĩo, with an Orphic ambience, see Greco (2004) 168 ad loc., with Homeric, Classical and postClassical parallels. Among them, similarities of Orphic poetry are very relevant, see Orph. H. $6.5 \pi \alpha \mu-$

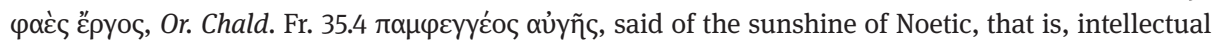
light. In Latin Poetry Iuvencus puts particular emphasis on light symbolism, see Röttger (1996) $80-91$.

6 See Filoramo (1980) 28-42; Id. (1982) 868-880; Zoroddu (1994) 231-232; Thomassen (2004) 222224.

7 For Jesus' self-identification with the Light, see Johnson (2016) 273; Sieber (2016) 314 with reference to the Logos in the Par. See Zöckler (1999) 127; Popkes (2004) 654-655; Id. (2005) 541 with nt. 83; Id. 
Christ healing the man born blind is defined as a light-bringer ( $\left.\varphi \alpha \varepsilon \sigma \varphi \rho_{\rho} \rho \varsigma\right)$ in Par. IX.28. ${ }^{9}$ Similarly, Nonnus puts great emphasis on the restoration of light at the Raising of Lazarus. This healing also establishes the identity between light and life. ${ }^{10}$ The language of sunlight in the Paraphrase is closely linked with the divine mission of Jesus as heavenly Saviour, ${ }^{11}$ as well as with the opposition between the darkness of sins and the dawn of his redemption. ${ }^{12}$

As relevant as visual aspects may be, they are, however, not the only ones involved in epiphany according to a longdating tradition. Greek religious experience also puts emphasis on acoustic signs revealing the divine presence. It often happens that the listener recognizes a superhuman voice that addresses him through a numinous message and/or an order to be promptly executed. ${ }^{13}$ Starting from Homeric epics until Neoplatonic teaching, auditory revelations are focused on instructions,

(2007) 137; Onuki (2008) 297-299, 303, 307-317 with theological relation to the Gospel of Thomas and Manichaean dualism between Light and darkness.

8 See Livrea (2000) 155, with reference to Cyril's theology in his commentary to Johannine logion

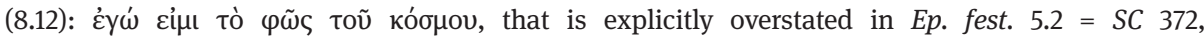
288.40 - 42. Évieux-Burns. In Alexandrinian realm, see also Clem. Alex. Strom. 1.28.178: oủk ővev

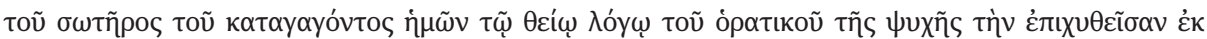

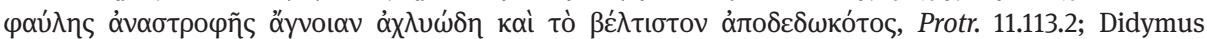
Caec. De Trin. $P G 39.728$.

9 See Johnson (2016) 273-274: Nonnus puts emphasis on material elements such as clay and water

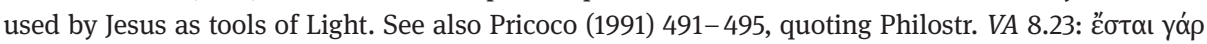

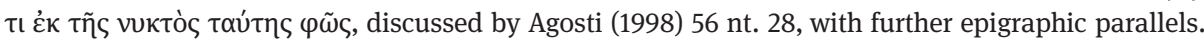
On Homeric antecedent of Odysseus who brought light into the house and the polis, see Bremer (1976) $150-160$ discussed by Birl (2004) 56, who points out the Odyssey, as "an extremely protracted performance of an epiphany of is main hero". Isillus portrays the Pagan Healer god, Asclepius, as "gleaming with golden armament" in an epigraphic hymn set up in Epidaurus, where he describes

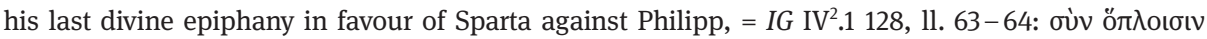

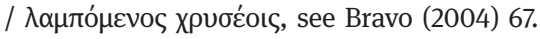

10 On the comparison between miracle reports in Par. 9 and 11, see Spanoudakis (2014) 88-90: the close association of these episodes is operative in art representations and theological contemporary debate. In Dion. 25, Dionysus heals an Indian born blind before enacting the resurrection of Tylus. 11 The healing of the blind man in Par. 9 is explained as a rebirth of a child emerging from the womb. Hence, the emphasis on the dawn as birth-panged (9.158: ноуобтóко૬) and unbeheld (9.178: $\dot{\alpha} \theta \eta \dot{\eta} \tau o \varsigma)$ underlies the idea of salvation given through revelation, which "in Nonnus' vision is both creation and illumination”, as Franchi (2016) 260 remarks; see also Spanoudakis (2014) 91; Johnson (2016) 275 on the imagery of light as a mediumistic way of access to Jesus' self-revelation.

12 See Par. 1.20 - 27a. See Platt (2009) 154; Ead. (2011) 11; Whitaker (2015) 55- 58 on Johannine model of spiritual blindness needing the illumination given by Jesus; Bennema (2014) 253-255. On Christ as Sol salutis, see Dölger (1925); Agosti (1998) 55-57; Greco (2004) 111; Spanoudakis (2014) 179 on Par. XI.34a.

13 On Wortepiphanie, see Pax (1955) 20, 35; Id. (1962) 20, 30; Dodds (1959) 140; Benz (1969) 94-97, 150, 413 - 440; Speyer (1972) 340; Id. (1991) 288; Id. (1994) 18 - 20; Id. (1995) 75-95, Id. (2007) 91; Hanson (1980) 1411; Casadio (1989) 141; Dulaey (1989) 379 (vision auditive); Frenschkowski (1995) 195, 197, 220; Weber (2000) 42. 
teachings, or prophecies. ${ }^{14}$ Notoriously, Gnostic doctrine is mostly related to heavenly voices. Marcos, a chief teacher of Valentinian School in Rome, was claiming to receive complex revelations by the voices of Pleromatic hypostases that he would have heard without seeing any superior being. This modus apparendi corresponds to usual didactic epiphany among the Gnostics. ${ }^{15}$

The lore of magic also focuses on the revelation of true names of gods unknown to the uninitiated through special acoustic sounds. Thus, the magical name Batv $\chi \omega$ $\omega \omega \chi$ that expresses the hidden name of the highest god is based upon the prolonged sound of /o:/. ${ }^{16}$ Phonetic association, alliteration (/r/, /vr/, /t/), repetition and various other sound plays are widely exploited in Graeco-Egyptian magical papyri for these purposes. ${ }^{17}$

In the Graeco-Roman world, the spoken word quickly gained the significance of a fatal voice: the god choses a human speaker as his medium in order to reveal hidden truths. Therefore, the $\kappa \lambda \eta \delta \omega \dot{v}$ as chance voice was conceived as embodying a presage of future events, the epithet $\kappa \lambda \eta \delta \omega$ vios (producing an ominous voice) is attributed to Zeus. A personified divine voice, as $\Phi \eta$ n spired a crowd of people by creating mutual feelings to everyone of them. ${ }^{18}$ Many examples of panic running through armies or assemblies because of mysteriously heard voices also come from the realm of Greek war. ${ }^{19}$ Words overheard accidentally were often interpreted as prophetic omens. The revelation was originated by single words or a complete phrase, a carelessly pronounced utterance was listened by somebody else in a wholly fortuitous and unexpected manner. The listener just simply had to link such word(s) through mental association to some plane, project, or event of particular importance for his personal destiny. ${ }^{20}$ All these omens employed the human word as an outgoing presage. Therefore, a word's divination like cledonism was closely associated to Hermes, the divine Master of the Logos. ${ }^{21}$ If the children pronounced the fateful saying without being in any relation to the listener, they were

14 See Roloff (1970) 48-49 on Homeric heroes hearing godly voice; Procl. In Crat. 36.20; Hippol. Ref. 4.28 knows of tricks drawn by manipulating divine auditions, see Dodds (1959) 366 with nt. 3. 15 Marcos' teaching is a matter of a mystical doctrine about letters and numbers learned through revealing speeches, such as Derdekeas experiences in his teaching transmitted in the Paraphrase of Sem, see Casadio (1989) 126-127, 142.

16 In PGM IV 1. 936, the magician prescribes to hold the numerical value of 3663 on a leaf of papyrus, in order to pray the mystical name of Baıv $\omega \omega \omega \chi$ quoted at 1. 1057, see Brashear (1989), 123-124.

17 On these key issues of Ancient ritual experience, see Crippa (2015) 245-249.

18 Scholia to Iliad VIII.250; Eustathios 169.27. Denominative verb $\kappa \lambda \eta \delta o v i \zeta \omega$ is found in P. Oxy. VI 886 (= PGM XXIVa) 1l. 13-15, $3^{\text {rd }}$ century $^{\mathrm{p}}$ also means 'to receive an omen'. For the Ancient idea of $\Phi \eta \dot{\mu \eta}$ linked with divination by casual words, see Pritchett (1979) 132, 134-135; Crippa (2012) 550-553. 19 For military examples of chance voices in topic moments, see passages discussed by Pritchett (1979) 133-134, 137; Lateiner (2005).

20 See Hopfner (1928) 1282-1283; Riess (1939) 373-376; Peradotto (1969) 8. As Johnston (2008) 131 puts out, "unexpected" is the key-word for this method of approaching the supernatural sphere. 21 See Peradotto (1969) 9; Johnston (2008) 100. 
regarded as the most truthful ones. ${ }^{22}$ The most famous example in Christian milieu is the tolle et lege heard by Augustine. ${ }^{23}$

All of this ascertained, acoustic revelation is worthy of further examination in this Nonniam poem. With respect to Biblical parallels, it would be a simplistic approach to overstate auditory elements in Old Testament epiphany, while to assign a major role to New Testament visual signs in accordance with typical Hellenistic and Late Antique trends. ${ }^{24}$

In fact, visual and auditory elements are intertwined in the realm of godly revelation in the Old as well as in the New Testament. ${ }^{25}$ If we analyze Old Testament reports about self-perception, the mystical narrator mostly refers to an epiphanic encounter with the divine without any distinction between seeing and hearing. For example, the prophet Isaias simultaneously describes the vision of the Lord sitting upon the throne and the hearing of his voice before receiving a commission. ${ }^{26}$ Generally said, sensorial perceptions of seeing and hearing are interlinked in biblical epiphanic accounts. Similarly, Graeco-Roman thinkers were aware that seeing and hearing are in fact interchangeable as indicators of a revelation's superhuman encounter. This link clearly appears at the descent to the Trophonios' hole at Lebadeia in Boeotia. After a frightening catabasis into the hole meant with the hope of meeting the Chthonian hero, the enquirers were compelled to record everything they saw or heard. ${ }^{27}$

As far as concerns Nonnus' epiphany reports, we remark that they are deeply engaged in acoustic effects. At first, Jesus' voice provides an auditory sign of his revelation as Messiah. Therefore, Christ's word is defined as Life-giving ( $\beta\llcorner\delta \omega \dot{\tau} \tau \omega)$ ). This is observed under a key theological perspective in Par. X.133:

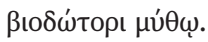

This adjective (and its alternative form $\beta ı \delta \delta \tilde{\omega} \tau \iota)$ ) is a standardized epithet used in Orphic Hymns. It has many Late Antique parallels, often with reference to traditional deities of a politheistic pantheon. In this respect, an epigraphic sentence concerning

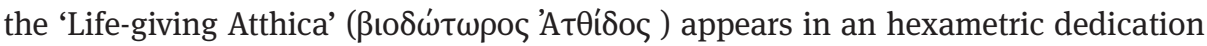

22 For children considered as ominous speakers among the Egyptians, see Plutarch., De Is. et Os. 14; Athen. 8.8; Hopfner (1928b) 1277; 1279; Peradotto (1969) 4 with n. 8; Somville (1989) 202-204; Montero (1999) 291.

23 See Aug. Conf. VIII.12.29, Dulaey (1989), 379, 384, 389, see also Benz (1969), 95; Giannarelli (1989), 234. On children as privileged medium of divine revelation, see Courcelle (1953), 194-220; Johnston (2001), 97-99.

24 See Björck (1946) 306-310; Pax (1955) 20, 110 -111; Balthasar (1968) I, 261-262.

25 See Moreira (2000) 18 with nt. 15.

26 Is 6.1-8, see Pax (1955) 110; Déonna (1965) 62; Benz (1969) 98-99, 418 on the Zusammenspiel of sensorial perceptions; Speyer (1972) 340; Agosti (2003) 378-379.

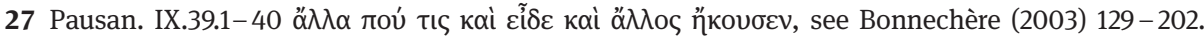


of late $4^{\text {th }}$ - early $5^{\text {th }}$ century given by the proconsul Phaedrus, in order to celebrate his restoration of Dionysos' theatre in Athens. ${ }^{28}$

Subsequently, Jesus' voice is the first way of access to salvation. It is people-sav-

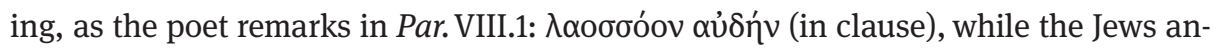

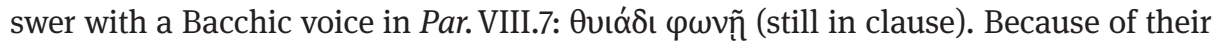
spiritual blindness, they cannot but shout nonsensical words in reply to the divinely inspired word of the Saviour. ${ }^{29}$

Superhuman force is expressly attributed to the Voice of the Lord in reply to Peter at the washing of the feet in Par. XIII.30:

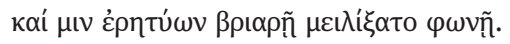

Here, the poet uses the pregnant adjective ßpıарó in order to focus on strenght of divine Jesus' utterance.

Likewise, he says for Jesus speaking to Annah in Par. XVIII.95-96:

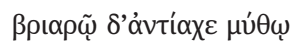

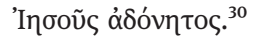

There is further evidence for epiphany as auditory revelation. Divine proximity is evidenced through Christ's liberating voice in the healing of the paralyzed man accounted in Par. V. At first, the Lord consoles the poor man through his voice that can breathe new life at v. 29:

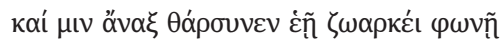

The key adjective $\zeta \omega \alpha \rho \kappa n ́ \varsigma^{31}$ probably echoes a Proclus' passage (H. 1.2) in praise of the Sunlight, where the role of Helios as creator of all things is described, as Agosti has pointedly illustrated. ${ }^{32}$

Then, the Lord suddenly healed the paralyzed man through his word releasing grief at v. 37:

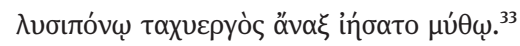

$28 I G^{I I} 5021$ discussed by Agosti (2010) 347.

29 On the theological significance of properties enounced for the Word, see Sieber (2016) 313. On the blame against Jews, see Livrea (2000) 234-235 on Par. II.58.

30 As Livrea (1989) 156 pointed out; see also Greco (2004) 95.

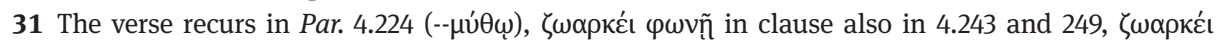
$\mu v \dot{\theta} \omega$ even in 15.32, 17.60 .

32 Proclus' locus similis was recognized by Schneider (1892) 599; see also Golega (1930) 102; Agosti (2003) 362-363 assigns chronological priority to Proclus or alternatively to a common model in Neoplatonic writings. See parallels in the Par. and Ancient Christian literature quoted ibid.

33 See Agosti (2003) 378-379 ad loc. 
In this respect, Christ is focused as a clear counterpart for Dionysos who is equally portrayed as a celestial Healer through his Bacchic voice. Nonnus describes the 'pagan' god exercising his healing power in favour of Aristeus in Dion. XVII.373:

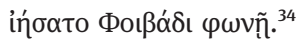

Christ in turn bestows the Resurrection of the flesh through his Word of Life in Par. V.110:

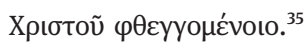

A close association of revealing through vision and hearing is experienced at the first appearance of Jesus in the poem. Two disciples near to John the Forerunner and the Lord are still unaware of the divine nature of the latter in Par. I.129b-130:

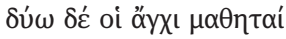

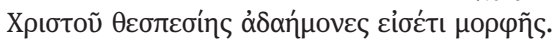

In the following, the epiphanic experience is fulfilled first through the holy word of John as the true witness, as it is remarked in I.135:

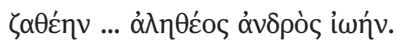

Here, John the Baptist's utterance arises to the highest witness of the divine Logos. In

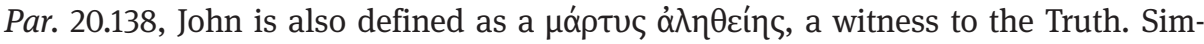

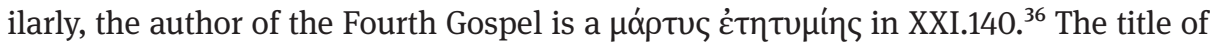
martys is, here, subsumed as a technical word for the true witness who announces the forthcoming of the Messiah after having personally experienced the meeting with him. ${ }^{37}$

Jesus himself gives the value of true witness to his prophetic words at the last supper in Par. XIII.85-89:

34 Passage quoted by Agosti (2003) 379-380 with further loci similes relating to the healing power of Dionysus, who is an evident counterpart for Christ. Both gods enact a cathartic power exercised in favour of their elected. On healing by magic lullabies in Nonnus' 'pagan' poem, see Gigli (1985) 221-223 with further parallels.

35 On Theurgic power of Christ's voice, see Agosti (2003) 140, 478 ad loc.; Rotondo (2008) 298-302. 36 Ebener (1985) 406 and Sherry (1991) 276 wrongly refer this title to Jesus. On the value of the Fourth Gospel's last chapter, see Sherri 2015.

37 Therefore, the Baptist is defined as a martys and John the Evangelist alike, see Vian (1997) 145; 150 - 154 with further examples about Nonnus' special love for this semantic family; see also Accorinti (1996) 228 on XX.138. 


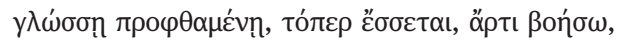

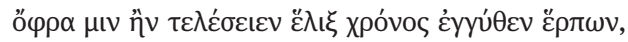

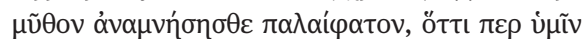

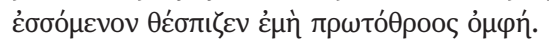

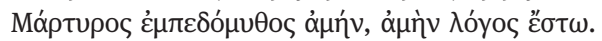

The solemn address to the apostles is built around the notion of a prophetic, arcane voice, that carries great significance and discovers hidden meanings. There is relevance in the use of words borrowed from the oracular vocabulary of divination like $\theta \varepsilon \sigma \pi i \zeta \omega$ and ỏ $\mu \varphi \eta$ at the same verse (XIII.89). All these remarks convey a superhuman value to the Christ's voice according to a theophanic dimension, the divinity of the truthful Teacher being disclosed to his listeners. ${ }^{38}$

The key idea of the true witness plays a major role in the Paraphrase. It is linked with a conceptual mode concerning the person of Christ. As the author of Apc 3.14.

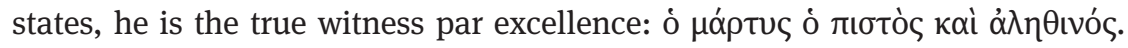

If we analyze the first meeting between the disciples of the Baptist and Jesus, sound and visual effects are intertwined, so as to allow the access to the divinity

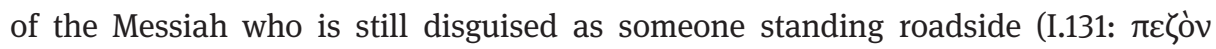
ósítnv).

In the first encounter with Jesus in Par. 1, the two disciples are finally overcome by the godly gaze of Christ, which is defined as being self-learned (I.137: $\alpha$ vito $\delta i \delta \alpha-$

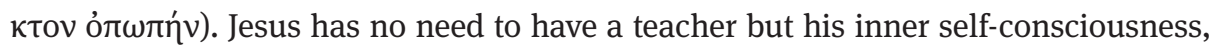
as his gnosis has nothing to do with human knowledge that can be learned. However, revelation of divine presence is accompanied by authoritative words which are intimately connected with the vocation of the apostles.

Similarly, the miracle of Jesus in Par. VI.4 is enacted through his Word, even if it has a visual form for the observers:

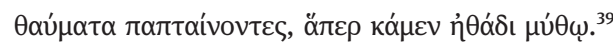

In Par. XXI, the dialogue between the Risen Lord and Peter corresponds with a postResurrection appearance accounted under an ecclesiological perspective. Specifically, Peter is asked three times: "Do thou love me?" (vv. 83-107). This triple question focuses on his three-part denial previously accounted in Par. XVIII.70-129.40 Jesus had already prophesied of Peter's denial until the cockcrows at the end of XIII.158-160: ${ }^{41}$

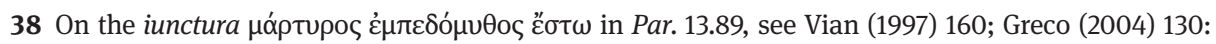
this formula was created by Nonnus for his Christian poem and later introduced in Dion.

39 On people observing the miracle performed through Jesus' usual word, see Franchi (2013) 278. 40 See Livrea (1989) 143-153, 167-173; Costanza (2014) 136-137. Generally, the first place in Apostle's catalogues of the New Testament is always reserved to Peter, as Greco (2004) 91 remarks.

41 See Greco (2004) 174-176. 


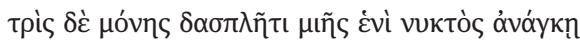

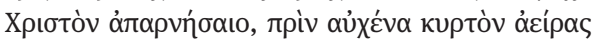

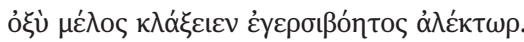

Here, the first cockcrow is to be explained as another acoustic sign relating to epiphany, because the cockerel is a clear symbol of Christ. ${ }^{42}$ Nonnus paraphrases his Vorlage with consistent embroidery. His abundant adjectival use at v. 160 is far from

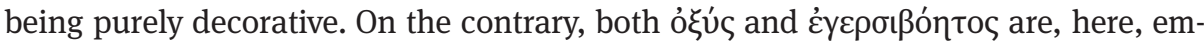
ployed on the grounds of exegetical undertones.

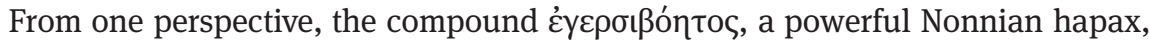
refers to a spiritual soul's awakening according to a major initiatory trend of Late Antique religion, especially in Orphic milieu..$^{43}$ In contrast, the cockcrow is described as a high song in Dion. XI.89:

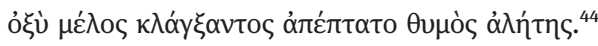

Symbolically, the image of the cockerel crowing in Par. XIII is referred to the voice of Christ himself following the exegetical explanations given by Cyril of Alexandria:

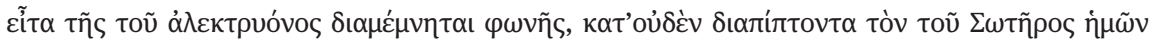

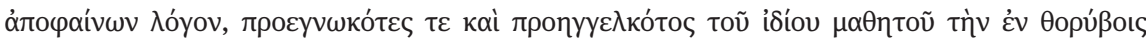

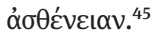

Ultimately, Peter may receive his full investiture at the head of the apostolic group and also of the herd of believers in the course of Jesus' last appearance after his Resurrection in Par. 21. Indeed, this investiture is conferred upon him just after he has duly performed his profession of faith by speaking aloud with his Teacher in a dramatic verbal contest. This contest in which Peter is involved is comparable to that of Pallene in the last song of the either Nonnian epic. Both heroes are fighting with the god and reach him after diving into water. If Pallene is engaged with a hard physical fight against Dionysos, Peter must counterbalance the divine words of his Lord. ${ }^{46}$

Finally, the Word of Christ in Nonnus' poem is not only convincing in rhetorical terms, but also revealing about God's presence to the cosmos awaiting its Redeemer. All these things considered, epiphanic issues in Par. renew a complex intertextual framework, in which auditory elements undeniably play a major role within a history

42 On Christian soteriologic idea, see Pintus (1985-86) 262-266.

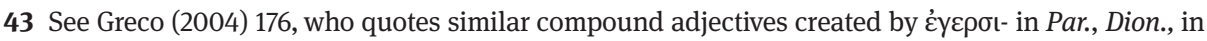
Proclus and Orphic milieu. These adjectives express the soul's awakening.

44 See Cyril 609a, as Livrea (1989) 172-173 remarks with further parallels for the cockcrow; Greco (2004) $175-176$.

45 Indeed, Nonnus does not further develop the cockerel's symbolism in Par. 18.129, in order to keep the brevity of Gospel's narrative, see Livrea (1989) 173.

46 For Pallene in Dion. 48.118-120, cf. Par. 21.41-42; see Costanza (2014), 125. 
of multiform and disguise. Beyond any doubt, the Paraphrast overlooks Biblical exegesis and Greek poetry relating to the access to the divine. At the same time, he is able to adapt his narrative concerning theophany to many settings. Nonnus carefully establishes the necessity of auditory revelation as a source of theological knowledge, not merely because it helps humans to understand the truth of Christian faith, but because it is a privileged source of discovering the mysteries of the numinous upper world.

As a follower of Greek epic tradition, the poet is conscious of the mystical power of the Word and its great fascination. He could have exercised a stronger attraction to his listeners through his hexameters with their special subtle acoustics. Since his epics were reasonably destined to public performances, the voice of the poet echoes that of the heavenly Master and it is, subsequently, put at the service of the divine Revelation by conferring to it a special power of persuasion.

\section{Bibliography}

Accorinti (1996): Domenico Accorinti (ed.), Nonno di Panopoli. Parafrasi del Vangelo di S.

Giovanni. Canto XX (Pubblicazioni Cl. Lettere e Filosofia SNS Pisa 15), Pisa.

Accorinti (2016): Domenico Accorinti (ed.), Brill's Companion to Nonnus of Panopolis, Leiden and Boston.

Addey (2014): Crystal Addey. Divination and Theurgy in Neoplatonism. Oracles of the Gods (Ashgate Studies in Philosophy \& Theology in Late Antiquity), Farnham-Burlington/VT.

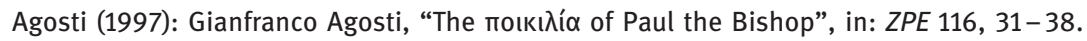

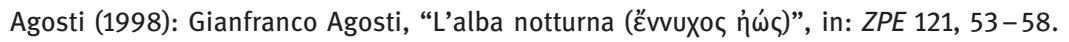

Agosti (2001): Gianfranco Agosti, “L'epica biblica nella tarda antichità greca. Autori e lettori nel IV e V secolo", in: Stella (ed.), 67-104.

Agosti (2003): Gianfranco Agosti (ed.), Nonno di Panopoli. Parafrasi del Vangelo di San Giovanni, Canto Quinto. Firenze.

Agosti (2005): Gianfranco Agosti, “Interpretazione omerica e creazione poetica nella Tarda

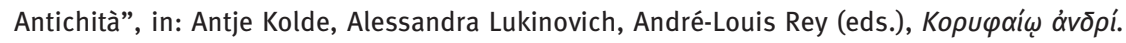
Mélanges A. Hurst, Geneva, 19-32.

Agosti (2006): Gianfranco Agosti, “La voce dei libri. Dimensioni performative dell'epica greca tardoantica”, in: Eugenio Amato, Alexandre Roduit, Martin Steinrück (eds.), Approches de la Troisième Sophistique. Hommages à Jacques Schamp, Brussel, 33-60.

Agosti (2009): Gianfranco Agosti, “Cristianizzazione della poesia greca e dialogo interculturale”, in: CrSt 31, 313-335.

Agosti (2010): Gianfranco Agosti, “Paideia” classica e fede religiosa: annotazioni sul linguaggio dei carmi epigrafici tardoantichi”, in: Cahiers du Centre Gustave Glotz 21, 329-353.

Agosti (2016): Gianfranco Agosti, “Les langues de l’épigramme épigraphique grecque : regards sur l'identité culturelle chrétienne dans l'Antiquité tardive”, in: E. Santin, L. Foschia (eds.), L'épigramme dans tous ses états: épigraphiques, littéraires, historiques, Lyon, 276-295.

Balthasar (1968): Hans Urs von Balthasar, La Gloire et la Croix: les aspects esthétiques de la Révélation, Paris.

Bannert (1978): Herbert Bannert, “Zur Vorgestalt der Götter bei Homer”, in: WS 12, 29-42.

Beierwaltes (1957): Werner Beierwaltes, Lux intelligibilis: Untersuchungen zur Lichtmetaphysik der Griechen, Munich. 
Bennema (2014²): Cornelis Bennema, Encountering Jesus. Character Studies in the Gospel of John, Minneapolis.

Benz (1969): Ernst Benz, Die Vision. Erfahrungsformen und Bilderwelt, Stuttgart.

Björck (1946): Gudmund Björck, “ővap íðعĩv. De la perception du rêve chez les anciens”, in: Eranos Jb. 44, 306-314.

Bonnechère (2003): Pierre Bonnechère, Trophonios de Lébadée. Cultes et mythes d'une cité béotienne au miroir de la mentalité antique (RGRW 150), Leiden.

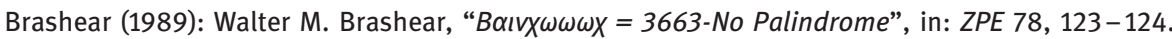

Bravo (2004): Jorge Bravo, "Heroic Epiphanies: Narratives, Visual, and Cultic Contexts", in Marinatos (ed.), 63-84.

Bremer (1975): Dieter Bremer, "Die Epiphanie des Gottes in den homerischen Hymnen und Platons Gottesbegriff”, in: ZRGG 27, 1-21.

Bremer (1976): Dieter Bremer, Licht und Dunkel in der frühgriechischen Dichtung: Interpretationen zur Vorgeschichte der Lichtmetaphysik, Bonn.

Busine (2005): Aude Busine, Paroles d'Apollon. Pratiques et traditions oraculaires dans l'Antiquité tardive (ii ${ }^{e}$-vi $i^{e}$ siècles), RGRW 156, Leiden-Boston.

Cadau (2015): Cosetta Cadau, Studies in Colluthus' Abduction of Helen. Mnem. Suppl. 380, Leiden-Boston.

Casadio (1989): Giovanni Casadio, "La visione in Marco il Mago e nella gnosi di tipo sethiano", in: Augustinianum 29, 123-146.

Clinton (2004): Kevin Clinton, “Epiphany in the Eleusinian Mysteries”, in: Marinatos (ed.), 85-109.

Costanza (2014): Salvatore Costanza, "La vestizione di S. Pietro (Nonno, Parafrasi 21, 37-48): paralleli nelle Dionisiache e significati simbolici”, in: Koinonia 38, 119-140.

Costanza (2017): Salvatore Costanza, "Le catalogue des Apôtres à la pêche miraculeuse: Nonn., par. xxı, EvPt 14.60”, in: Claude Bernard-Valette, Jérémie Delmulle, Camille Gerzaguet (eds.), Nihil veritas erubescit. Mélanges offerts à Paul Mattei par ses élèves, collegues et amis (IPM 74), Turnhout, 511-525.

Courcelle (1953): Pierre Courcelle, “L’enfant et les 'sorts bibliques”, in: Vig. Chr. 7, 194-220.

Crippa (2012): Sabina Crippa, "Entre la nature et le rite: reflexions sur le statut des signes, voix divinatoires”, in: Stella Georgoudi, Renée Koch Piettre, and Francis Schmidt (eds.), La Raison des signes. Présages, rites, destin dans les sociétés de la Méditerranée ancienne (RGRW 174), Leiden and Boston, 547-555.

Cutino (2009): Michele Cutino, "Structure de la composition et exégèse dans la Paraphrase de l'Évangile de s. Jean de Nonnos de Panopolis. Une lecture du chant III", in: RÉAP 55, $225-246$.

De Stefani (1999): Claudio De Stefani, “Nonniana”, in: Philol. 143.2, 336-343.

De Stefani (2002): Claudio De Stefani, ed. Nonno di Panopoli. Parafrasi del Vangelo di S. Giovanni Canto I (Eikasmos Studi 6), Bologna.

Dijkstra (2016): J. H. F. Dijkstra. The Religious Background of Nonnus, in: Accorinti (ed.), 75-90.

Dodds (1951): Eric R. Dodds, The Greeks and the Irrational, Berkeley-Los Angeles.

Dölger (1925): Franz Joseph Dölger, Sol Salutis, Münster.

Doroszewski (2014): Filip Doroszewski, “Judaic Orgies and Christ’s Bacchic Deeds: Dionysiac Terminology in Nonnus' Paraphrase of St. John's Gospel”, in: Spanoudakis (ed.), 287-301.

Dulaey (1989): Martine Dulaey, "Songe et prophétie dans les Confessions d'Augustin. Du rêve de Monique à la conversion au jardin de Milan", in: Augustinianum 29, 379-391.

Ebener (1985): Dietrich Ebener, Nonnos, II: Leben und Taten des Dionysios XXXIII-XLVIII. Nachdichtung des Johannesevangeliums, Berlin and Weimar.

Filoramo (1980): Giovanni Filoramo, Luce e gnosi. Saggio sull'illuminazione nello gnosticismo, Rome. 
Filoramo (1982): Giovanni Filoramo, “Phoster e Salvatore in alcuni testi gnostici”, in Ugo Bianchi and M. J. Vermaseren (eds.), La soteriologia dei culti orientali nell'impero romano, Leiden, $868-880$.

Filoramo (1989): Giovanni Filoramo, “Diventare Dio: visione e rigenerazione nello Gnosticismo”, Augustinianum 29, 81-121.

Franchi (2013): Roberta Franchi (ed.), Nonno di Panopoli, Parafrasi del Vangelo di San Giovanni. Canto sesto. Bologna.

Franchi (2016): Roberta Franchi, “Approaching the 'Spiritual Gospel': Nonnus as Interpreter of John”, in Domenico Accorinti (ed.), 240-266.

Frenschkowski (1995): Marco Frenschkowski, Offenbarung und Epiphanie. 1: Grundlagen des spätantiken und frühchristlichen Offenbarungsglaubens. WUNT, 2.79, Tübingen.

Frenschkowski (1997): Marco Frenschkowski, Offenbarung und Epiphanie. 2: Die verborgene Epiphanie in Spätantike und frühem Christentum. WUNT, 2.80, Tübingen.

Garcia (1999): Hugues Garcia, “La polymorphie du Christ. Remarques sur quelques définitions et sur des multiples enjeux", Apocrypha 10, 16-55.

Giannarelli (1989): Elena Giannarelli, “Sogni e visioni dell'infanzia nelle biografie dei Santi: fra tradizione classica e innovazione cristiana”, Aug. 29, 213-235.

Gigli (1985): Daria Gigli, Metafora e poetica in Nonno di Panopoli, Florence.

Gigli (1990): Daria Gigli, La cosmogonia di Strasburgo, Florence.

Gigli (1995): Daria Gigli, “Il pozzo di Giacobbe e Danao in Nonno”, in: Koinonia 19, 153-161.

Gladigow (1990): Burkhard Gladigow, “Epiphanie, Statuette, Kultbild, Griechische

Gottesvorstellungen im Wechsel von Kontext und Medium”, in: Visible Religion 7, 98-121.

Golega (1930): Joseph Golega, Studien über die Evangeliendichtung des Nonnos von Panopolis. Ein Beitrag zur Geschichte der Bibeldichtung im Altertum, Breslau.

Graf (1997): Fritz Graf, “Epiphanie”, in: Neue Pauly 3, 1150-52.

Graf (2004): Fritz Graf, “Trick or treat? On collective epiphanies in antiquity”, in: Marinatos (ed.), $111-130$.

Greco (2004): Claudia Greco (ed.), Nonno di Panopoli. Parafrasi del Vangelo di S. Giovanni, Canto tredicesimo, (Hellenica 12), Alessandria.

Hanson (1980): John S. Hanson, "Dreams and Visions in the Graeco-Roman World and Early Christianity", in: ANRW 2, 23, 2, 1395-1427.

Heinsdorff (2003): Cornel Heinsdorff, Christus, Nikodemus und die Samariterin bei Juvencus. Mit einem Anhang zur Lateinischen Evangelienvorlage (Untersuchungen zur antiken Literatur und Geschichte 67), Berlin-New York.

Hopfner (1928): Theodor Hopfner, “Mantike”, in: RE 14.1, 1258-87.

James (1981): A. W. James, "Night and Day in the Epic Narrative of Nonnus and Others", in: Mus. Phil. Lond. 4, 115-143.

Johnson (2016): S. F. Johnson, Nonnus' Paraphrastic Technique: A Case Study of Self-Recognition in John 9, in Accorinti (ed.), 268-288.

Johnston (2001): Sarah Iles Johnston, "Charming Children: the Use of the Child in Ancient Divination", in: Arethusa 34.1, 97-117.

Johnston (2008): Sarah Iles Johnston, Ancient Greek Divination (Blackwell Ancient Religions), Malden/Ma. and Oxford.

Junod/Kaestli (1983): Eric Junod and Jean-Daniel Kaestli (eds.), Acta Iohannis, textus alii Commentarius, Indices, CC-SA 2, Turnhout.

Koschorke (1977): Klaus Koschorke, “Eine gnostische Pfingstpredigt: Zur Auseinandersetzung zwischen gnostischem und christlichem Christentum am Beispiel der, Epistula Petri ad Philippum“ (NHC VIII, 2)”, in: ZKTh 74, 323-343.

Lateiner (2005): Donald Lateiner, "Signifying Names and Other Ominous Accidental Utterances in Classical Historiography.” in: GRBS 45.1: 35-57. 
Livrea (1989): Enrico Livrea (ed.), Nonno di Panopoli. Parafrasi del Vangelo di S. Giovanni Canto XVIII, Naples.

Livrea (2000): Enrico Livrea (ed.), Parafrasi del Vangelo di San Giovanni: Canto B, Bologna.

Marinatos (2004): Nanno Marinatos, ed. Divine Epiphany in the Ancient World = ICS 29.

Ménard (1972): Jacques E. Ménard, Transfiguration et polymorphie chez Origène, in Epektasis. Mélanges patristiques offerts au cardinal J. Daniélou, Paris, 367-372.

Mitchell (2004): Margaret M. Mitchell, "Epiphanic Evolutions in Earliest Christianity", in Marinatos (ed.), 183-204.

Moreira (2000): Isabel Moreira, Dreams, visions, and Spiritual Authority in Merovingian Gaul, New York.

Moreschini (1973): Claudio Moreschini, "Luce e purificazione nella dottrina di Gregorio Nazianzeno", in: Augustinianum 13, 535-549.

Nock (1934): Arthur Darby Nock, “A Vision of Mandulis Aion”, in: HThR 27, 53-104 = Id. 1972, I, 357-400.

Nock (1972): Arthur Darby Nock, post. Essays on Religion and the Ancient World selected and edited with an Introduction, Bibliography of Nock's writings, and Indexes by Z. Stewart, I-II, Oxford.

Onuki (2008): Takashi Onuki, “Das Logion 77 des Thomasevangeliums und der gnostische Animismus", in: Jörg Frey, Enno Edzard Popkes and J. Schröter (eds.), Das Thomasevangelium. Entstehung - Rezeption - Theologie, Berlin, 294-317.

Pax (1955): Elpidius Pax, EПIФANEIA. Ein religionsgeschichtlicher Beitrag zur biblischen Theologie (Münchener Theologische Studien, I Hist. Abt. 10), Munich.

Pax (1962): Elpidius Pax, "Epiphanie", in: RAC 5, 832-909.

Peradotto (1969): John Peradotto, “Cledonomancy in the Oresteia", in: AJPh 90, 1-21.

Pfister (1924): F. Pfister, “Epiphanie”, in: RE Suppl. 4, 277-323.

Pintus (1985-86): Giovanna Maria Pintus, “Storia di un simbolo: il gallo”, in: Sandalion 8-9, $243-267$.

van der Plas (1987): Dirk Van der Plas (ed.), Effigies Dei. Essays on the History of Religions (Suppl. Numen), Leiden.

Platt (2009): Verity Platt, "Virtual visions: Phantasia and the perception of the divine in the Life of Apollonius of Tyana”, in: E. L. Bowie and J. Elsner (eds.), Philostratus, Cambridge.

Platt (2011): Verity Platt, Facing the Gods: Epiphany and Representation in Graeco-Roman Art, Literatur and Religion. Greek culture in the Roman world, Cambridge.

Popkes (2004): Enno Edzard Popkes, "”Ich bin das Licht“ - Erwägungen zur Verhältnisbestimmung des Thomasevangeliums und der johanneischen Schriften anhand der Lichtmetaphorik”, in: Jörg Frey, Udo Schnelle, with J. Schlegel (eds.), Kontexte des Johannesevangeliums. Das vierte Evangelium in religions- und traditionsgeschichtlicher Perspektive (WUNT 175), Tübingen, 641-674.

Popkes (2005): Enno Edzard Popkes, “Die Umdeutung des Todes Jesu im koptischen Thomasevangelium”, in: Jörg Frey, Jens Schröter (eds.), Deutungen des Todes Jesu im Neuen Testament (WUNT 181), Tübingen, 513-545.

Popkes (2007): Enno Edzard Popkes, Das Menschenbild des Thomasevangeliums. Untersuchungen zu seiner religionsgeschichtlichen und chronologischen Einordnung (WUNT 206), Tübingen.

Prichett (1979): William Kendrick Pritchett, The Greek State at War, Part 3: Religion. Berkeley.

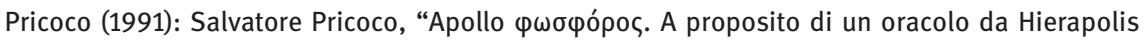
frigia", in: Studi di filologia classica in onore di Giusto Monaco, Palermo, 491-495.

Riess (1939): E. Riess, “Omen”, in: RE 18.1, 350-378.

Roloff (1970): Dietrich Roloff, Gottähnlichkeit, Vergöttlichung und Erhöhung zu seligem Leben. Untersuchung zur Herkunft der platonischen Angleichung an Gott (Untersuchung zur antiken Literatur und Geschichte 4), Berlin. 
Rotondo (2007): Arianna Rotondo, Dialogo d'amore. Figure femminili del Vangelo giovanneo (Appunti di teologia 11), Roma.

Rotondo (2008): Arianna Rotondo, “La voce ( $\varphi \omega v \eta ́)$ divina nella Parafrasi di Nonno di Panopoli”, in: Adamantius 14, 287-310.

Röttger (1996): W Röttger, Studien zur Lichtmotivik bei luvencus (JAChr. 24), Münster.

Schneider (1892): M. Schneider, "Die Hymnen des Proklos in ihrem Verhältnis zu Nonnos", in: Philol. 51, 593-601.

Sherri (2015): Brown Sherri, "What's in an Ending? John 21 and the Performative Force of an Epilogue”, in: Perspectives in Religious Studies 42, $29-42$.

Sherry (1991): L. F. Sherry, The Hexameter Paraphrase of St. John Attributed to Nonnus of Panopolis. Prolegomenon and Translation, Diss. Columbia University, New York.

Sieber (2016): Fabian Sieber, Nonnus' Christology, in: Accorinti (ed.), 308-326.

Somville (1989): Pierre Somville, "Jeux de mots et sense du sacré dans la religion grecque", in: Kernos 2, 199-211.

Spanoudakis (2014): Konstantinos Spanoudakis, ed. Nonnus of Panopolis. Paraphrasis of the Gospel of John XI. Oxford.

Spanoudakis (2016): Konstantinos Spanoudakis, Pagan Themes in the Paraphrase, in: Accorinti (ed.), 601-624.

Speyer (1972): Wolfgang Speyer, Fälschung, pseudepigraphische freie Erfindung und "echte religiöse Pseudepigraphie", in: K. von Fritz (ed.), Pseudepigrapha I. PseudopythagoricaLettres de Platon. Littérature pseudépigraphique juive. Entr. Ant. Class. 18, Genève-Vandoeuvres, 331-366.

Speyer (1991): Wolfgang Speyer, “Himmelsstimme”, in: RAC 15, 286-303.

Speyer (1994): Wolfgang Speyer, "Das Hören einer göttlichen Stimme. Zur Offenbarung und zu Heiligen Schriften im frühen Rom", in: Helmantica 45, 7-24.

Speyer (1995): Wolfgang Speyer, Religionsgeschichtliche Studien. Collectanea 15, Hildesheim, Zürich and New-York.

Speyer (2007): Wolfgang Speyer, Frühes Christentum im antiken Strahlungsfeld. Kleine Schriften III (WUNT 213), Tübingen.

Stella (2001): Francesco Stella (ed.), La scrittura infinita: Bibbia e poesia in età medievale e umanistica (Atti del convegno di Firenze 26-28 giugno 1997), Florence.

Thomassen (2004): Einar Thomassen, The Epiphany of Gnosis, in: Marinatos (ed.), 217-226.

Versnel (1987): Henk S. Versnel, What did Ancient Man see when He saw a God? Some Reflections on Greco-Roman Epiphany, in: van der Plas (ed.), 42-55.

Versnel (2011): Henk S. Versnel, Coping with the Gods. Wayward Readings in Greek Theology (RGRW 173), Leiden-Boston.

Vian (1990): Francis Vian (ed.), Nonnos de Panopolis. Les Dionysiaques, Tome IX: Chants XXV-XXIX, Paris.

Vian (1997): Francis Vian, "MAPTY乏 chez Nonnos de Panopolis: études de sémantique et de chronologie", in: RÉG 110, 143-160.

Weber (2000): Gregor Weber, Träume und Visionen in Prinzipat und Spätantike (Hist. 143), Stuttgart.

Whitaker (2015): Robin J. Whitaker, Ekphrasis, Vision, and Persuasion in the Book of Revelation (WUNT 2. 410), Tübingen, 641-674. 

Part II: Biblical Poetry and Theological Aims in other Poetic Genres between Late Antiquity and the Middle Ages 



\section{Gianfranco Agosti}

\section{La poésie biblique grecque en Égypte au IV siècle}

\section{Enjeux littéraires et théologiques}

Cette contribution porte sur un petit groupe de textes qui nous permet de jeter un coup d'œil sur les premières de la poésie biblique dans l'Orient grec, et qui, malgré leur intérêt, attend encore d'être mis en valeur dans cette perspective. Ces textes ont été transmis par un codex sur papyrus du IV $/ \mathrm{V}^{\mathrm{e}}$ siècle ap. J.-C., conservé parmi les nombreux trésors de la Collection Bodmer à Cologny-Genève, et publié en deux phases par André Hurst, Olivier Reverdin et Jean Rudhardt.

En 1984 les éditeurs ont publié ce qu'ils considéraient à l'époque comme le premier texte de notre codex, un poème d'environs 350 hexamètres qui a pour titre

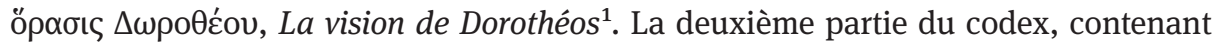
sept nouveaux poèmes chrétiens (P.Bodmer 30 - 37) n'a vu la lumière que quinze ans après, en 1999, avec une nouvelle description du manuscrit ${ }^{2}$. Comme cela est souvent le cas avec les découvertes papyrologiques, l'intérêt de la communauté scientifique s'est concentré surtout sur les aspects textuels et philologiques. La Vision a été reéditée, avec beaucoup d'amméliorations et une traduction anglaise (qui est encore aujourd'hui la plus utilisée), par A.H.M. Kessels et P.W. van der Horst, juste un an après l'editio princeps ${ }^{3}$; d'autres éditions partielles ont suivies au fil des ans ${ }^{4}$. En revanche, les nombreuses questions que ces textes soulevent sur le plan historicolittéraire et théologique n'ont pas rétenu la même attention. Il y a eu, certes, des travaux sur les techniques littéraires de la Vision, sur sa langue et sa métrique, sur son rôle dans le panorama littéraire $d u I^{\text {ème }}$ et $V^{\text {ème }}$ siècle, ainsi que sur les genres littéraires des autres textes du codex et sur la communauté qui les a produit. La

1 P. Bodmer 29-37; LDAB 1016 = TM 59994. Ed. pr.: Hurst/Reverdin/Rudhardt (1984). Voir le compte rendu de Livrea (1986).

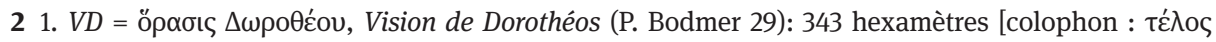

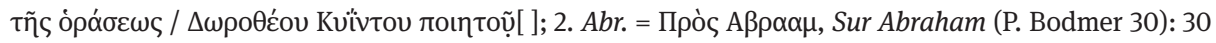

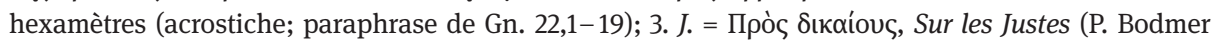
31): 164 distiques élégiaques (poème sur le mal et la théodicée ; au v. $160 \Delta \omega[\rho o ́ \theta] \varepsilon o v$ Kúvtov) ; 4.

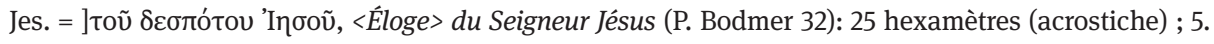

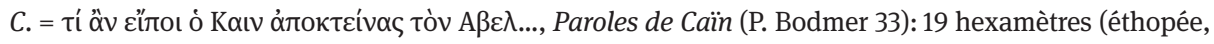

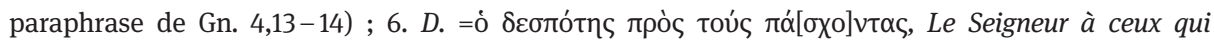

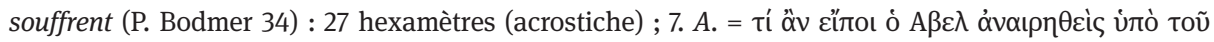
Kaıv, Paroles d'Abel (P. Bodmer 35): 69 hexamètres (éthopée, paraphrase de Ps. 101) ; 8. X. = Poème au titre mutilé (P. Bodmer 36): 75 hexamètres (paraphrase des 145-150) ; 9. Hy. = Hymne (P. Bodmer 37). 3 Kessels/Van Der Horst (1987) 313-59.

4 Livrea (1994) 175-187; Hilhorst (2002) 96-108; Livrea (2004), 39-43; Livrea (2006-2008) 27-43; Berolli (2013) 83-173. 
recherche récente sur le contexte de la bibliothèque Bodmer a contribué à nous faire mieux comprendre le milieu d'origine de ces poèmes - une conférence organisé à Rome en 2014 par Paola Buzi, Alberto Camplani et moi-même a fait le point sur le sujet ${ }^{5}$. Malgré ces efforts, nombreux problèmes littéraires et théologiques restent encore à peine abordés, surtout par rapport au thème de la présence de poésie biblique dans.

Je ferai d'abord une brève présentation du recueil. Le codex appartient à la typologie qu'on appelle 'multiple texts manuscripts', c'est-à-dire un manuscrit qui contient des textes différents mais organisés dans un ensemble cohérent. Les 24 folios du codex comprenaient $a$ ) les quatre premières visions du Pasteur d'Hermas (I-XIII ; la quatrième vision est perdue car les folios XII-XIII ont disparu), suivies $b$ ) par une série de nouveaux poèmes chrétiens (700 vers, à peu près), ouverte par la Vision de Dorothéos (d'où l'appellation de «Codex des Visions» par laquelle le codex est souvent mentionné). Le livre a été copié par six mains de formation diachronique différente, qui ont été datés entre la seconde moitié $d u I^{\text {ème }}$ et le début $d u V^{\text {ème }}$ siècle ${ }^{6}$.

Le codex - les recherches des derniers années l'ont bien montré - est l'expression poétique d'un groupe qui lisait et pratiquait la poésie classicisante en suivant l'exemple de son guide spirituel, le Dorothéos protagoniste de la Vision. En effet, l'ensemble a été conçu comme un recueil de poèmes épiques chrétiens axé sur un personnage exemplaire, un 'Ideal Type’7 (le déjà mentionné Dorothéos). Sur un plan théologique et spirituel le recueil trace une histoire du salut individuel et collectif à la fois. Après les Visions d'Hermas qui constituent le " prologue » théologique, la Vision de Dorothéos raconte l'histoire de la chute du protagoniste, de son baptême et de sa rédemption. Les autres poèmes sont une sorte de commentaire théologique et morale de la Vision: le poème Sur Abram, une éthopée acrostiche, montre avec l'exemplum d'Isaac l'acceptation du vouloir divin et la récompense pour les fidèles. Le poème Sur les Justes (le seul en distique élégiaques) offre ensuite une réflexion sur le mal, la tromperie du démon, le caractère pernicieux des richesses. S'en suivent un éloge du Christ (Jes.) et une éthopée sur Cain (C.) qui montrent le sort des pécheurs ; puis une exhortatio de Jésus à Ceux qui souffrent $(D$.$) , suivie par une éthopée d'Abel$ (A.), lamentation du Juste qui souffre. Le dernier poème lisible reprend les thèmes caritatifs déjà annoncés dans le poème sur les Justes, à savoir la sollicitude envers les veuves et les orphelins, et la renonciation aux richesses. La cohérence de l'ensemble

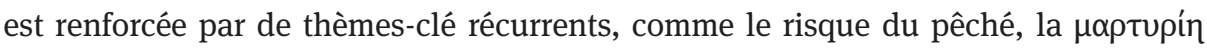
(pas un martyr réel, mais symbolique et lié plutôt à une crise personnelle ${ }^{8}$ ), la

5 Agosti/Buzi/Camplani (2015) 6-172.

6 Kasser/Cavallo/Van Haelst (1999); Crisci (2002) 115-122; Orsini (2015) 66-67.

7 Brown (2016) 88.

8 Verheyden (2011) 123-141. 


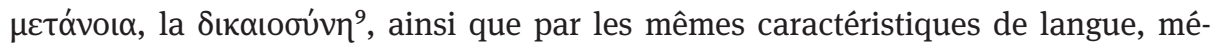
trique et rhétorique ${ }^{10}$. Si tous le poèmes remontent au même auteur (le Dorothéos protagoniste de la Vision), ou si une partie d'entre eux est due à ses disciples, c'est une question encore ouverte - personnellement, je ne vois aucune difficulté à attribuer tous les textes à la même main ${ }^{11}$. En tout cas, le codex porte des signes de lecture (corrections, variantes), qui témoignent sinon d'une revision philologique, au moins d'une attention soigneuse par ceux qui l'ont copié.

De nombreux indices font penser que les poèmes sont des produits locaux. Il est probable que le recueil de ces poèmes ait été conçu et réalisé par une des communautés de physionomie 'presque monastique' qui dans la première moitié du IV ème siècle pratiquaient l'enkrateia et le renoncement au monde, comme celle fondée par Ieraca à Leontopolis ou les philoponoi alexandrins du V vème siècle. Les idéaux de cette

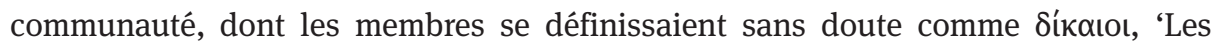
Justes', semblent être déclineés dans un passage du poème Sur les Justes (11. 111$119)^{12}$.

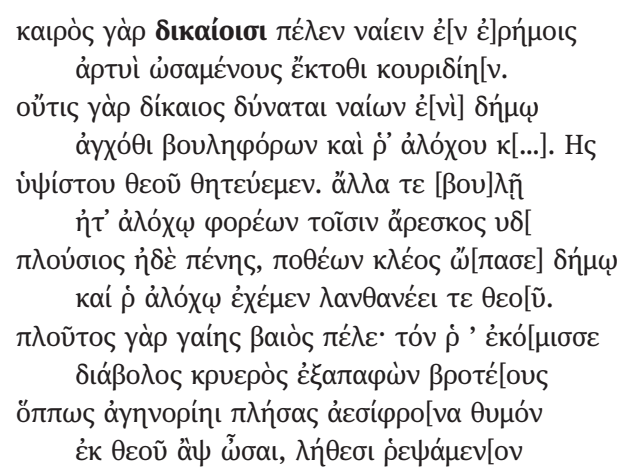

«Le moment en effet venu pour les justes de vivre parmi les solitaires, après avoir renvoyé leur épouse, en concluant avec elle un arrangement ; car aucun juste ne peux, s'il vit à côté des gens, de conseillers et d'une ... épouse, servir Dieu très haut. Pour des conseils ou pour une épouse, chargé d'autres fardeaux, il est asservi parce qu'il veut.... Qu'il soit riche ou pauvre, animé de ce désir, il donne de la gloire à son pays, à épouse il oublie Dieu. La richesse terrestre et en effet de courte durée : le diable terrible la fourni quand il trompe les mortels pour, ayant empli d'orgueil leur esprit insensé, les éloigner de Dieu, fléchissant sous l'effet de l'oubli».

9 Le repentir et la justice sont les concepts clés du Pasteur aussi. Voir Carlini (2002) 123-38 ; Camplani (2015) 108-12. Je soupçonne que les relations avec le Pasteur sont encore plus profondes qu'on l'admet d'habitude : on pourrait par exemple expliquer le poème Sur le Justes comme une sorte de 'méditation morale' sur quelques thèmes du Pasteur. J'y reviendrai dans un prochain travail. 10 Agosti (2001), et Miguélez Cavero (2012).

11 Deux sont les principales hypothèses : $a$ ) la Vision a été composé par Dorothéos et les autres poèmes par ses 'adeptes' (suiveurs ?: (Rudhardt, Gelzer) ; $b$ ) toutes les poèmes ont été composées par le même auteur (Livrea; une idée à laquelle je suis favorable).

12 Texte Livrea 2006/08 ; traduction Hurst Rudhardt 1999, adaptée. Sur ces vers voir Hurst Rudhardt (1999) 102 ; Livrea, (1996) 78 ; Agosti (2002) 84 ; Berolli (105) 140 -1 ; Agosti (2017). 
La caractéristique la plus considérable de cette communauté était, cependant, l'intérêt pour la culture classique et pour la composition poétique, comme témoignent nos poèmes et la nature même de la soit-disante 'bibliothèque Bodmer'. Cette 'bibliothèque’ est un recueil hétérogène (un peu moins de 40 rouleaux et codices), caractérisée par une chronologie limitée (entre III ${ }^{\text {ème }}$ et siècle, avec une concentration autour du IV ${ }^{\text {ème }}$ siècle) et par le mélange de langues et de culture classique et chrétienne : $40 \%$ de textes grecs (avec Homère et Ménandre, Thucydide, Achille, des diatribes cyniques), 4\% de texte latins (Cicéron, l'Alceste etc.) et 56\% de textes coptes $^{13}$, éparpillés entre Genève, Dublin (the Chester Beatty library), la Duke university, Cologne, l'abbeye de Montserrat, le Vatican et Oslo. Le lieu d'origine de cette bibliothèque n'est pas précisement connu, même si les savants sont presque tous d'accord pour indiquer le Panopolite dans la Haute Égypte (selon la dernière hypothèse avancée par Fournet, le lieu de provenance serait les environs de Dishna, une zone qui faisait partie du nome Panopolite) $)^{14}$. La date de composition des poèmes contenu dans le codex Bodmer est la première moitié ou autour de le la moitié du IV ${ }^{\text {ème }}$ siècle ${ }^{15}$.

Parmi les poèmes du codex quatre appartiennent au genre de la paraphrase de l'Ancien Testament, à savoir le poème Прòs A $\beta \rho \alpha \mu$ (paraphrase de Gn 22.1-19), les

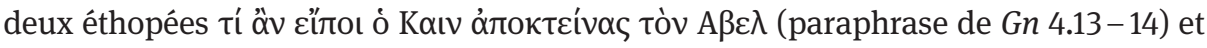

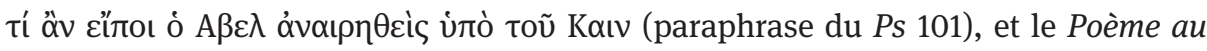
titre mutilé qui est une paraphrase des Ps 145-150.

Le poème Sur Abraham (P. Bodmer 30) est une paraphrase du récit sur le sacrifice d'Isaac, caractérisée par une structure soignée : au début, on trouve un

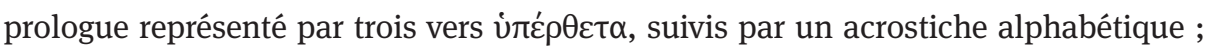
en fin, trois vers $\pi \rho o ́ \sigma \theta \varepsilon \tau \alpha$, qui contiennent la requête finale. Le poème s’inscrit dans la longue tradition exégétique et liturgique sur le sacrifice d'Isaac ${ }^{16}$, en adoptant en même temps la structure plus répandue parmi les structures rhétoriques de la poésie de l'antiquité tardive, l'éthopée. Comme d'habitude dans les éthopées tardives, la narration est caractérisée par de dialogues, ou mieux par une juxtaposition de monologues (\#̈usserungen, comme les appelait Albert Wifstrand) : il y a un discours d'Abraham à Sarah, suivi par un autre de Sarah à Isaac, et un autre encore d'Isaac (ces discours sont connus surtout dans la tradition exégétique en syriaque, mais aussi dans un sermon d'Amphilochios d'Iconium conservé par une traduction copte et dans une homélie versifiée de Romanos). Le fil rouge du poème est constitué par la joie avec laquelle les personnages acceptent leur destin. Du point de vue des rapports avec la Vorlage, ce poème montre déjà certaines caractéristiques de l'épique biblique mûre : on peut le définir à bonne raison comme une exégèse en vers de l'épisode testamentaire (et les travaux de van der Horst, Parmentier, et Hilhorst ont

13 Robinson 2011 ; Fournet (2015) 8-24 ; Buzi (2015) 47-59.

14 Fournet (2015).

15 Voir Agosti (2002) 80 ; (2001) 189.

16 Livrea (1994); Hilhorst (2002) ; Byron (2011). 
bien mis en évidence plus d'une consonance avec l'exégèse juive de l'épisode, au point qu'Hilhorst s'est même demandé si l'auteur ne venait pas d'un milieu juif - ce qu'il me semble franchement peu probable). Ici je me borne à observer que le poème vise des lecteurs familiers avec des Écritures et aussi avec de la poésie épique, capables d'apprécier les aspects d'imitation contrastive et de juxtaposition de deux systèmes culturels. Pour ne donner qu'un exemple de la façon de composer du poète,

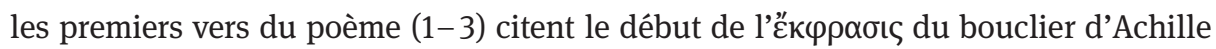
dans l'Iliade XVIII.483-484 : le poète superpose la citation homérique au début de la déclaration de foi des Actes 17.24 (qui est souvent citée dans les professions de foi des martyrs $)^{17}$.

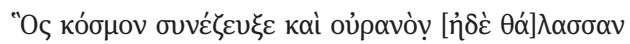

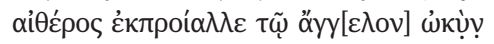

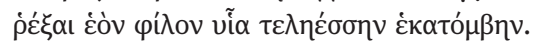

«Celui qui créa le monde, avec le ciel et la mer, envoya du haut de l'éther un ange rapide vers Abraham, avec l'ordre d'immoler son propre fils en sacrifice solennel»

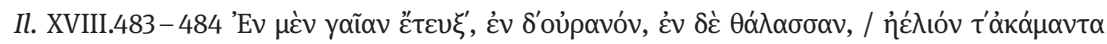

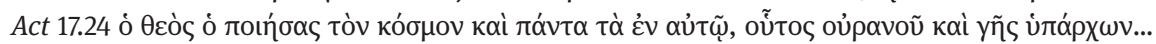

La structure de ce poème rappelle, me semble-t-il, celle d'une homélie métrique sur le sacrifice d'Isaac : en effet, dans un autre codex de la 'bibliothèque Bodmer', le codex miscellaneus de Montserrat, un texte liturgique rythmique et acrostiche (copié dans le manuscrit comme s'il était de la prose), dont le contenu et très proche à celui du notre poème, au point qu'on peut bien dire qu'il est une des ses sources principales $^{18}$. Encore une fois je ne donne qu'un exemple. La mention de la Mer Rouge

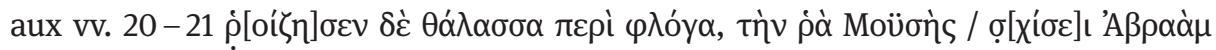

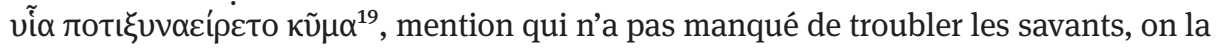

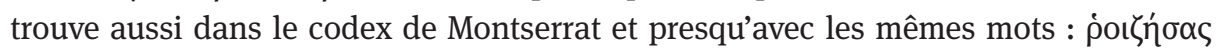

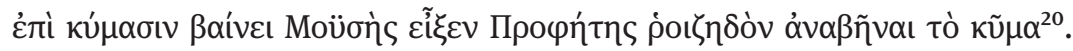

Cela nous permet de donner la juste restitution au début de la ligne 20 du poème Bodmer, et nous assure en même temps qu'il faut lire l'allusion à la Mer Rouge come une allusion au baptême, selon une interprétation courante, d'ailleurs, dans l'exégèse.

Je passe maintenant aux poèmes sur Cain et Abel, qui constituent les deux volets d'un diptyque d'éthopées (P. Bodmer 33 et 35). Le premier est une amplificatio de Gn 4.9-14, conduite selon une structure progymnasmatique qu'on retrouve identique

17 Texte et traduction: Hurst/Rudhardt 1999.

18 Agosti (2015); Camplani (2015).

19 «Et la mer gronda autour de la flamme, le mer que Moïse allait fendre un jour, et la vague prenait

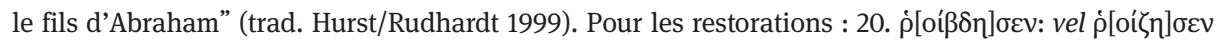
HR \| 21. $\sigma[x i ́ \sigma \varepsilon] \iota$ HR: $\sigma ̣[x i ́ \zeta \varepsilon] \underline{~ L i . ~}$

20 Roca-Puig (1999). 
(même sur le plain verbale) dans un passage des Dionysiacques de Nonnos de Panopolis (II.113-162) ${ }^{21}$. Aux lignes 17-19 il est évident que le poète interprète Caïn come l'archétype du malfaiteur, une interprétation qui se trouve déjà dans $1 \mathrm{Gv}$

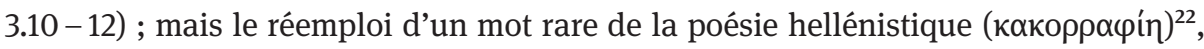
utilisé dans la langue patristique pour désigner les herétiques, transmet aussi l'idée que Caïn est le fils du diable, selon une exégèse largement répandue ${ }^{23}$.

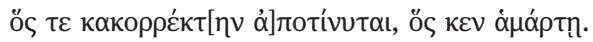

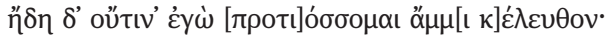

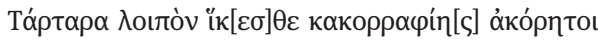

«Il châtie tout méchant qui a commis un péché. Désormais, je ne vois plus de chemin qui s’offre; allez dans le Tartare, vous qui n'êtes jamais rassasiés de méchanceté!»

Le deuxième volet du ditpyque, le poèmes Paroles d'Abel est à une autre amplifi-

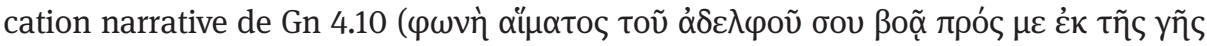

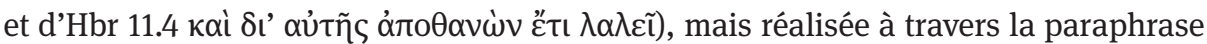
du Ps 101, qui dans la tradition exégétique est expliqué en sens christologique. Du

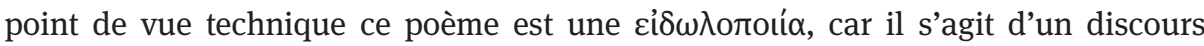
prononcé par quelqu'un qui est mort ${ }^{24}$. Mais l'intérêt historico-littéraire de ce poème réside dans la possibilité de le comparer avec la seule autre paraphrase épique grecque du Psaume qui nous a été conservé, celle du Ps.-Apollinaire ${ }^{25}$, et qui est posterieure d'un siècle peu près. Le poème Bodmer montre un penchant pour l'amplificatio et aussi une majeure liberté dans le choix des modèles classiques que la paraphrase du Ps-Apollinaire (bien que ce dernier soit un poète avec une meilleure formation grammaticale). Les techniques qui deviendront les plus communes de la poésie biblique, épicisation, agrandissements, omissions, additions, sont utilisés sans incertitudes par le poète égyptien. Il est également intéressant de remarquer que dans un passage le poète utilise deux vers qui proviennent de la Vision de Dorothéos, ce qui témoigne encore une fois de plus liens entre les textes du codex et la tendance à construire un système formulaire (même s'il faut parler de véritable citation, pour ce passage) qui les caractérise : mais le contexte est tout à fait différent et dans le passage du poème Paroles d'Abel le sens est plus proche du modèle

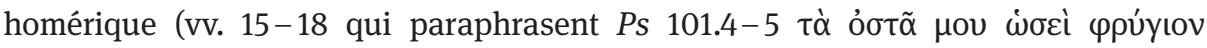

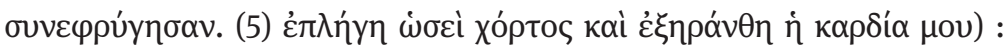

21 Agosti (2011) 278-279.

22 "Mauvais, hérétique, lapsus", cf. aussi $A .58$ et $X .17$; pour la poésie hellénistique voir Ap.

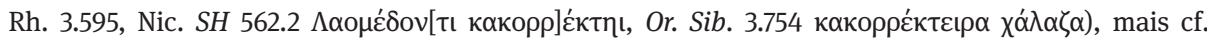

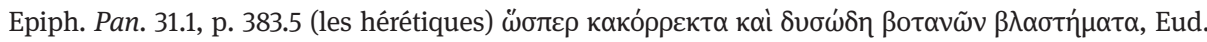

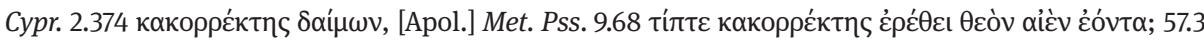

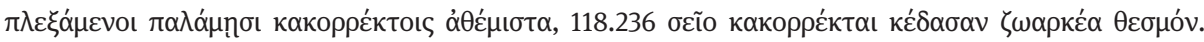

23 Voir Byron (2011) 18-20 et passim ; Grypeou/Spurling (2013) 99ss.

24 Cp. Agosti.

25 Voir pour l'instant Hurst (2002). 


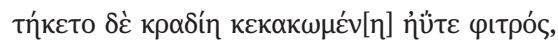

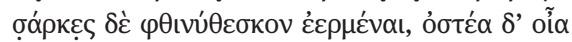

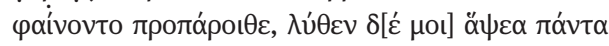

«mon coeur maltraité a fondu, rongé comme un tison, le tissu de ma chair s'est défait, mes os, dénudés, sont devenus visible, et toutes mes jointures ont cédé2 ${ }^{26} »$.

J'ai l'impression que ces poètes avaient un répertoire de stock phrases homériques qu'ils adaptaient en fonction de leurs besoins.

Enfin, le poème mutilé et dépourvu de titre (P. Bodmer 36) est la paraphrase de plusieurs passages des Psaumes 145-150, comme l'a bien montré Enrico Norelli ${ }^{27}$.

Je viens à quelques mots de conclusion. Les poèmes Bodmer, on l'a vu, revêtent une certaine importance pour l'histoire de la poésie grecque chrétienne. Ils montrent que la question centrale de cette poésie ne résidait pas dans le langage formel à adopter, car la tradition hellénique transmise par l'école donnait tous les outils pour réaliser une épique chrétienne. Il est bien connu que les chrétiens n'ont jamais sérieusement proposé un système d'éducation 'secondaire' alternatif au système traditionnel, bien que l'enseignement basé sur la $\pi \alpha ı \delta \varepsilon i ́ \alpha$ ait été parfois mis en discussion par les rigoristes. Tout au plus, on a souvent affirmé l'opportunité de se servir de la culture profane d'une façon pragmatique en se fondant sur le bon sens

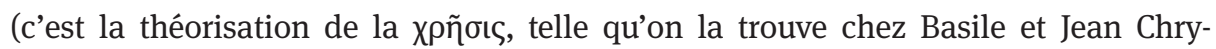
sostome par exemple), ou pour combattre les païens sur leur propre terrain. D'ici vient le rôle du sujet et l'importance de sélectionner ce qu'on peut et ce qu'on ne peut pas chanter - ce qui est la version grecque du problème de la vérité et du mensonge ${ }^{28}$. La découverte des poèmes Bodmer nous a révélé que presqu'un siècle avant les poèmes de Nonnos, du Ps. Apollinaire et d'Eudocie, et quelques années avant les légendaires (en tous les sens, je crois) effort de deux Apollinaires, père et fils, et leurs prodigieuses paraphrases pour répondre à la loi de Julien (une histoire qui sont évoquées trop souvent pour expliquer la création de la poésie grecque chrétienne ${ }^{29}$ ), il y avait en Orient des intellectuels chrétiens qui composaient de poèmes bibliques, qui à part l'extension sont analogues à ce qu'on avait commencé à faire en Occident quelques années auparavant (je pense à Juvencus, évidemment; et même au Cento de Proba, s’il faut l'attribuer à Betonia Faltitia Proba au milieu du IV ${ }^{\text {ème }}$ siècle). Faut-il donc parler d'un développement parallèle ? C'est évidemment la solution la plus probable, et je l'ai proposée moi-même dans d'autres contributions. Toutefois, aujourd'hui les récentes études sur d'autres manuscrits de la bibliothèque Bodmer pourraient nous faire envisager la possibilité d'une autre solution. En effet, le latin a son rôle dans cette collection. La Vision de Dorothéos est caractérisée par la présence

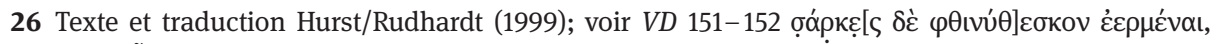

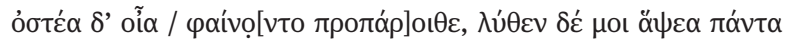

27 Norelli (2002).

28 Voir la contribution de Michele Cutino dans ce volume, 13-25.

29 Voir p.ex. Sandnes (2009) et (2011). 
d'un certain nombre de latinismes qui appartient à la langue militaire et administrative (come tiron, domestikos, praipositos etc.) ${ }^{30}$. Dans le déjà mentionné codex de Montserrat on trouve des textes latins à caractère profane et chrétien, qui attestent de l'intérêt pour la culture et l'histoire de Rome ${ }^{31}$. Voilà une description de son contenu : A: Inv. no. $128 \downarrow-149 \downarrow$, pp. 5-47 (Latin): R. Roca-Puig, Cicero. Catilinaries, Barcelona 1977

B: Inv. no. $149 \rightarrow-153 \rightarrow$, pp. $48-56$ (Latin): R. Roca-Puig, Himne a la Verge Maria, Barcelona 1965

C: Inv. no. $154 \rightarrow$, p. 57: dessin mythologique (R. Roca-Puig, «Quatre papirs inedits», in R. Roca-Puig i la ciència dels papirs, Algerri 1989,139-169)

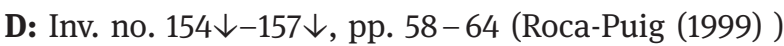

E: Inv. no. 158 -161, pp. 65 - 71 [72] (Latin): R. Roca-Puig, Alcestis. Hexametres Llatins, Barcelona 1982 [nouv. éd. G. Nocchi Macedo, Liège 2014]

F: Inv. no. 162-165, pp. 73-80 (Latin): Hadrianus (nouv. éd. T. Berg, Liège 2018).

G: Inv. no. 166-178, pp. 81-106 liste de mots et commentaire tachygraphique (Torallas Tovar/Worp (2006) )

Le même codex a aussi deux colophons où il est mentionné un certain Dorothéos comme dédicataire. Et ces colophons en latin ${ }^{32}$.

Filiciter / Dorotheo

Utere felix / Dorothee

P. Monts.Roca inv. 162-165 [MP ${ }^{3}$ 2752.1], tabula ansata :

Filiciter ... / Dorotheo

Étant donné que les deux codex appartenaient à la même bibliothèque, comme on a l'a vu, il est fort probable que ce Dorothéos soit le même que le personnage-poète de la Vision. Cela ouvre, je trouve, des perspectives intéressantes et une piste de recherche qu'il vaut la peine de suivre. Dorothéos et sa communauté ont-ils composé des paraphrases bibliques en suivant l'exemple des poètes latins ? Il faudra, évidemment, reconsidérer la question, très complexe, de la connaissance de la littérature latine de la part des poètes grecs en Égypte et de la possible circulation des modèles. En générale, dans le multiculturalisme de l'Égypte de l'antiquité tardive la connaissance de biblique latine serait loin d'être surprenante.

L'étude des poèmes Bodmer nous aide, j'en suis convaincu, à dégager un cadre en ce qui concerne les premières phases de la poésie chrétienne grecque et du développement de l'épique biblique plus nuancé et complexe. Mon impression est qu'à côté du rôle fondamental joué par l'éducation scolaire (comme nous l'a montré

30 Agosti (2015) 93-94.

31 Sur ce codex voir Gil/Torallas (2010) 19-20 ; Nocchi Macedo (2013).

32 P. Monts.Roca 1 inv. 128-149, tabula ansata; voir Crisci (2004) 131; Torallas Tovar/Worp (2006), tavv. XVII et XXIX. 
Michael Roberts), il y a aussi eu une circulation d'idées et d'expériences poétiques dans la première moitié $d u I^{\text {ème }}$ siècle, que nous ne connaissons que très imparfaitement. La convergence de la paideia classique et des Écritures, qui est un des traits caractéristiques des poèmes Bodmer et de la poésie biblique grecque, a eu une histoire plus complexe que ce que l'on pense d'habitude. Je termine avec une dernière suggestion. Dans quelques cas les poèmes Bodmer montrent la réutilisation des expressions et des formules qui sont propres à la poésie épigraphique (et même les colophons dans la tabula ansata appartiennent à cette catégorie). Or, dans les inscriptions métriques de la fin du III $^{\text {ème }}$ et de la première moitié du IV $^{\text {ème }}$ siècle la superposition des modèles classiques et chrétiens commence à être courante. Voici un exemple, très simple, mais qui a l'avantage d'être bien daté (IGLS XXI 5/1 $323=$ SEG 59.1723, Umm al-Jimāl, 344 ap. J.-C.) :

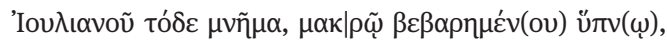

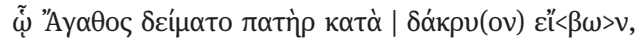

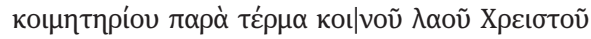

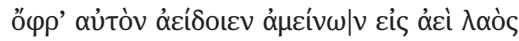

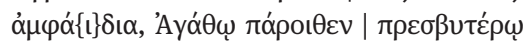

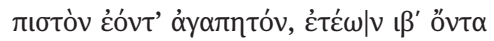

«Ce tombeau (est celui) de Ioulianos, alourdi par un long sommeil, pour qui Agathos son père, en versant des larmes, l'a construit, près de la clôture du cimetière de la communauté du peuple du Christ, pour que le meilleur peuple le célèbre pour toujours publiquement, lui qui était auparavant (le fils) fidèle (et) bien aimé d'Agathos le prêtre, et qui était âgé de douze ans, en l'an 239» (soit 344 apr. J.-C.) [trad. Bader]

Au vers $1 \beta \varepsilon \beta \alpha \rho \eta \mu \varepsilon ́ v \omega$ ürtvov (lapis, corr. Littmann) vient de l'évangile de Luc 9.32 ò

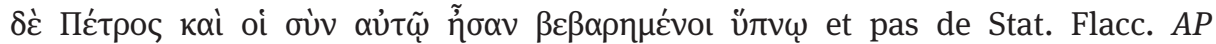

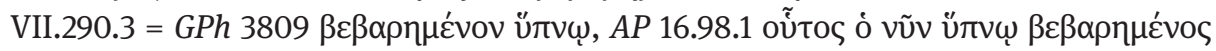

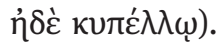

Faut-il chercher dans la "poésie de la rue» (selon l'hereuse définition de Gabriel Sanders) les traces de la préhistoire de la poésie biblique?

\section{Bibliographie}

Agosti (2001): Gianfranco Agosti, «Considerazioni preliminari sui generi letterari dei poemi del Codice Bodmer», in: Aegyptus 81, 115-147

Agosti (2002): Gianfranco Agosti, «l poemetti del codice Bodmer e il loro ruolo nella storia della poesia tardoantica», in: Hurst (2002) 73-114

Agosti (2011): Gianfranco Agosti, «Usurper, imiter, communiquer: le dialogue interculturel dans la poésie grecque chrétienne de l'Antiquité tardive», in Nicole Belayche, Jean-Daniel Dubois (eds), L'oiseau et le poisson. Cohabitations religieuses dans les mondes grec et romain, Paris, 275-299

Agosti (2015): Gianfranco Agosti, «Poesia greca nella (e della?) Biblioteca Bodmer», in: Agosti/Buzi/Camplani (2015) 86-97 
Agosti (2017): Gianfranco Agosti, «Re)constructing a Christian Community through its Poetry», in: Joseph Verheyden, Tobias Nicklas, Elisabeth Hernitscheck (eds), Shadowy Characters and Fragmentary Evidence. The Search for Early Christian Groups and Movements, WUNT, Tübingen, 233-250

Agosti/Buzi/Camplani (2015): Gianfranco Agosti, Paola Buzi, Alberto Camplani (eds.), «l Papiri Bodmer, Biblioteche, comunità di asceti e cultura letteraria in greco e copto nell'Egitto tardoantico», in: Adamantius 21, 6-172

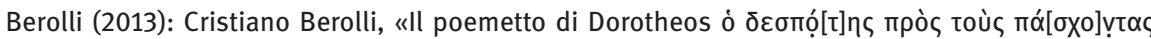
(P.Bodm XXXIV)», in: Analecta Papyrologica 25, 83-173

Brown (2016): Peter Brown, Treasure in Heaven. The Holy Poor in Early Christianity Charlottesville \& London

Buzi (2015): Paola Buzi, «Qualche riflessione sugli aspetti codicologici e titologici dei papiri Bodmer con particolare riguardo ai codici copti», in: Agosti/Buzi/Camplani (2015) 47-59

Byron (2011): John Byron, Cain and Abel in Text and Tradition. Jewish and Christian Interpretations of the first Sibling Rivalry, Leiden-Boston

Camplani (2015): Alberto Camplani, «Per un profilo storico-religioso degli ambienti di produzione e fruizione dei Papiri Bodmer», in: Agosti/ Buzi/Camplani (2015) 98-135

Carlini (2002): Antonio Carlini, «Gli studi critici sul Pastore dopo la pubblicazione di PBOD 38 e la presenza delle Visioni di Erma nei testi poetici del Codex Visionum», in: Hurst (2002) 123-38

Crisci (2004): Edoardo Crisci, «l più antichi codici miscellanei greci. Materiali per una riflessione», in: Segno\&Testo 2, 109-144

Fournet (2015): Jean-Luc Fournet, «Anatomie d'une bibliothèque de l'Antiquité Tardive: l'inventaire, les faciès et la provenance de la Bibliothèque Bodmern, in: Agosti/Buzi/Camplani (2015) $8-24$

Gil/Torallas (2010): José Gil, Sofia Torallas, Hadrianus P. Monts.Roca III, Barcelona

Grypeou/Spurling (2013): E. Grypeou, H. Spurling, The Book of Genesis in Late Antiquity Encounters between Jewish and Christian Exegesis, Leiden-Boston

Hilhorst (2002): A. Hilhorst, "The Bodmer Poem on the Sacrifice of Abraham», in: Tigchelaar Noort (ed.), The Sacrifice of Isaac. The Aqedah (Genesis 22) and Its Interpretations, Leiden, 96-108

Hurst/Reverdin/Rudhardt (1984): André Hurst, Papyri Bodmer XXX-XXXVII. "Codex des Visions» Poèmes divers, édités avec une introduction générale, des traductions et des notes, München Hurst/Rudhardt (1999): André Hurst, Jean Rudhardt,

Hurst (2002): André Hurst (ed.), Le Codex des Visions, Genève.

Kasser/Cavallo/van Haelst (1991): Rodolphe Kasser, avec la collaboration de Guglielmo Cavallo et Jospeh Van Haelst, «Nouvelle description du Codex des Visions”, in: A. Carlini (ed.), Papyrus Bodmer XXXVIII. Erma. Il pastore (I-III visione), Cologny-Genève, 103-127

Kessels/van der Horst (1987): A.H.M. Kessels, P.W. Van Der Horst, «The Vision of Dorotheus (Pap. Bodmer 29)», in: Vigiliae Christianae 41, 313-359

Livrea (1986): Enrico Livrea, «Recensione a Hurst, Reverdin, Rudhardt», in: Gnomon 58, 687-711 (réimpr. dans Studia Hellenistica, Firenze 1991: 319-350)

Livrea (1994): Enrico Livrea, «Un poema inedito di Dorotheos: Ad Abramo», in: Zeitschrift für Papyrologie und Epigraphik 100, 175-187 (réimpr. dans Da Callimaco a Nonno. Dieci studi di poesia ellenistica, Firenze-Messina 1995, 107-127

Livrea (1996): Enrico Livrea, «LaVisione di Dorotheos come prodotto di consumo», in: Antonio Stramaglia (ed.), La letteratura di consumo nel mondo greco-latino, Cassino, 71-95

Livrea (2004): Enrico Livrea, «Dorothei Laudes] Domini Jesu (P. Bodmer XXXII)», in: Zeitschrift für Papyrologie und Epigraphik 147, 39-43

Livrea (2006 - 2008): Enrico Livrea, «Dorothei Carmen Ad Justos (= P. Bodmer XXXI)», in: Analecta Papyrologica 18-20, 27-43 
Orsini (2015): Pasquale Orsini, «l papiri Bodmer: scritture e libri», in: Agosti/Buzi/Camplani (2015) $60-78$

Miguélez Cavero (2012): Laura Miguélez Cavero, «Rhetoric for a Christian Community: The Poems of the Codex Visionum», in: Alberto J. Quiroga Puertas (ed.), Rhetoric and Literature in the Fourth Century A.D., Tübingen, 91-121

Nocchi Macedo (2103): Gabriel Nocchi Macedo, «Bilinguisme, digraphisme, multiculturalisme: une étude du Codex Miscellaneus de Montserrat», in: Marie-Hélène Marganne, Bruno Rochette (eds), Bilinguisme et digraphisme dans le monde gréco-romain: l'apport des papyrus latins, Liège, 139-167

Norelli (2002): Enrico Norelli, «Quelques conjectures sur le Poème au titre mutilé», in: André Hurst, Jean Rudhardt (éd.), Le Codex des Visions (Recherches et rencontres. Publications de la Faculté des ettres de Genève 18), Genève, 203-217.

Robinson (2011): James M. Robinson, The Story of the Bodmer Library. From the First Monastery's Library in Upper Egypt to Geneva and Dublin, Eugene

Roca-Puig (1999): Ramon Roca-Puig, Anafora de Barcelona i altres pregaries (Missa del segle IV), Barcelona

Sandnes (2009): Karl Olav Sandnes, The Challenge of Homer. School, Pagan Poets and Early Christianity, London

Sandnes (2011): Karl Olav Sandnes, The Gospel 'According to Homer and Virgil' Cento and Canon, Leiden-Boston

Torallas Tovar/Worp (2006): Sofia Torallas Tovar, Klaas A. Worp, To the Origins of Greek Stenography. P. Monts. Roca I, Barcelona

Verheyden (2011): Joseph Verheyden, «When Heaven Turns into Hell: The Vision of Dorotheus and the Strange World of Human Imagination», in: Walter Ameling (ed.), Topographie des Jenseits, Altertumswissenschaftliches Kolloquium 21, Stuttgart, 123-41. 



\section{Anna Lefteratou}

\section{Deux chemins d'apprentissage}

\section{Le didactisme dans les Centons homériques}

Quand Eudocie, fille d'un philosophe néoplatonicien puis épouse chrétienne de l'empereur Théodose II, se serait mise à transposer la Genèse en hexamètres homériques elle avait derrière elle une tradition aux multiples facettes souvent antagonistes. Le fait de chanter les origines de l'univers, dans le monde grec, remonte à Homère et Hésiode et sera illustré dans la poésie hellénistique ${ }^{1}$; le fait de chanter le dieu chrétien remonte en revanche à la Genèse, transmise par l'interprétation hellénisée et surtout platonicienne de Philon d'Alexandrie et de Josèphe ${ }^{2}$. Il existe par ailleurs dans la littérature des Pères une riche tradition exégétique mais aussi poétique $:^{3}$ en Occident, Proba $^{4}$ a déjà composé des centons de la Genèse à partir de versets virgiliens et l'Orient connaît Grégoire de Nazianze à qui il doit des poèmes didactiques en hexamètres sur les origines de l'univers largement inspirés de la Genèse, où l'on discerne des traces vait rappelant non seulement les Présocratiques mais aussi les Néoplatoniciens ${ }^{5}$. Il va sans dire que, parallèlement à ces intertextes, coexiste aussi une tradition de textes bibliques apocryphes ${ }^{6}$ ainsi qu'un corpus néoplatonicien substantiel qui fait d'Homère et d'Hésiode les deux théologiens par excellence ${ }^{7}$. Cependant, si l'on se concentre uniquement sur les centons, contrairement à Proba qui avait le choix d'écrire des centons virgiliens héroiques inspirés de l'Eneide, des didactiques inspirés des Géorgiques ou encore des pastoraux inspirés des Bucoliques ${ }^{8}$, Eudocie, elle, n'avait à sa disposition que des centons homériques, ce qui empêchait, à priori, les jeux inter-génériques. Nous ne saurions dire avec certitude si l'auteur de la rédaction que Rocco Schembra appelle la Prima (I HC), la seule rédaction où l'on trouve une version de la Genèse, est en effet attribuable à

1 Cf. Sur le bouclier Homérique voir Hardie (1985) ; sur la réception d'Hésiode voir Cf. Koning (2010); Hunter (2014).

2 Droge (1989), Grypeou and Spurling (2013).

3 Sur la littérature de l'hexamère voir Delumeau (1995), Evans (1968).

4 Voir Sandnes (2011), Schottenius-Cullhed (2016a).

5 Moreschini-Sykes (1997), Arc. 4.

6 Cf. La vie apocryphe d'Adam et Eve ou l'Apocalypse de Moise. Tischendorf (1886), Tromp (2005); cf. 4 Esdras 6.38-59, Gordley (2011) 223.

7 Van den Berg (2014) sur Hésiode chez Plotin et Agosti (2016) sur la réception Chrétienne d'Hésiode. Voir aussi les éléments didactiques chez Georges de Pisidie dans Whitby (2014). Sur Hésiode et Dorothée voir Gelzer 2002 : 14. Sur «didacticism» dans l'antiquité tardive voir Johnson (2006), Agosti (2012) 365-366 ; pour Greg. Naz. voir Simelidis (2009) 22-25. Pour la littérature chrétienne en occident voir Fuhrmann (1977), Kuhn-Treichel (2016) et Hadjittofi et Lefteratou (2020).

8 Voir Bažil (2009) 144, Schottenius-Cullhed (2016b) 12 ; 141, sur l'importance des Géorgiques pour la Genèse. 
Eudocie ou non ; je ferai néanmoins ici l'hypothèse que c'est bien le cas ${ }^{9}$. Cependant, sa persona poétique, alliant paideia classique et foi chrétienne, me paraît être un bon outil pour réfléchir au cadre interculturel de la première moitié du $\mathrm{V}^{\text {ème }}$ siècle ap. J.C.

En première lecture des $I H C$ le/la lecteur/ctrice pourrait s'étonner de l'existence de deux ekphraseis du Paradis : une première faite par le narrateur - le «je» du prologue - suivie d'une autre faite par Satan à Eve dans la scène de la tentation ${ }^{10}$. Les deux descriptions contiennent une énumération des arbres et des merveilles du Paradis. Mais pourquoi la Prima contient-elle deux ekphraseis paradisiaques ? S’agitil d'un cas d'amplificatio et de variatio virtuose suivant l'esthétique tardive ? Ou bien peut-être la seconde ekphrasis est-elle censée mettre en lumière la première de façon antithétique ? Cet article se focalisera sur les cinquante premiers vers des I HC et fera une analyse narratologique centrée sur l'aspect didactique de ces versets : le narrateur, le destinateur, l'intention et les moyens didactiques, notamment l'emploi de l'ekphrasis ${ }^{11}$. Je démontrerai ensuite pourquoi l'existence de deux ekphraseis est nécessaire aussi bien sur le plan exégétique des I Homerocentones que sur le plan poétique, étant les deux programmatiques du mode didactique visé par excellence.

\section{Le mode didactique dans l'antiquité tardive}

\section{Enseigner les origines : la paideia classique et la Genèse}

Bien qu'il n'y ait pas d'accord sur la définition de la poésie didactique, ni parmi les

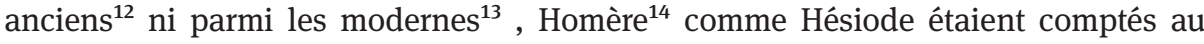
nombre des instructeurs des grecs et ce, sans tenir compte du genre de leurs œuvres $^{15}$. De l'autre côté, la poésie tardive montre une prédilection pour la moralisation et le didactisme ${ }^{16}$. Van den Berg (2014) démontre que, selon Plotin, les Travaux, qui

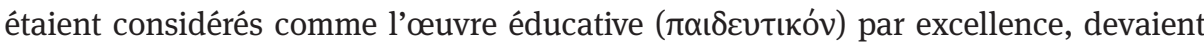
être lus comme une sorte de propédeutique aux messages sublimes dissimulés dans la Théogonie ${ }^{17}$. Il en va de même pour la réception d’Hésiode dans la poésie chré-

9 Hypothèse soutenue par Schembra (2007), cxxxvii Schembra (2006) Sur sa vie et oeuvre voir Van Deun (1993).

10 I HC 8-32 et 42-57

11 Le bilan dans Miguélez Cavero (2008) 282-308.

12 Cf. Hunter (2014) 550.

13 Études comme celles de Effe (1977) ou de Vollk (2002) sont très rigoureuses et ne peuvent pas être appliquées au corpus de la poésie didactique antique. C'est pourquoi j'adopterai ici le terme plus flexible mais aussi plus inclusif suggéré par Fowler (2002) 205.

14 Verdenius (1970).

15 Pour un bilan voir Koning (2010) 57-61.

16 Vian (1980) 336.

17 Van den Berg (2014) 388 sur Procl. in Op. 1.1-18 (Marzillo (n. 3)). 
tienne. Agosti (2016) illustre l'importance de la Théogonie pour les poètes du Codex des Visions qui ont perçu en Hésiode un visionnaire. Dans ce milieu culturel, la poésie cosmogonique a une place particulière. Mais ce ne sont pas seulement Homère et Hésiode qui ont revendiqué une place dans les descriptions du début. Les auteurs chrétiens connaissent aussi un fragment, souvent attribué à Sophocle, qui réutilise des versets homériques pour décrire la création du monde d'un seul dieu qui n'a pas besoin de statues ou des sacrifices superficiels ${ }^{18}$. Pourtant, l'exemple le plus célèbre dans la littérature grecque est le Bouclier d'Achille dans le chant 18 de l'Iliade (v. 478-608), qui a inspiré toute la poésie cosmogonique ${ }^{19}$. La réception de ce passage montre que, dans la poésie mythologique comme dans la poésie philosophique ou chrétienne le Bouclier s'accommodait aussi bien des relectures épiques que didactiques ${ }^{20}$.

Pour les chrétiens, le récit de la création originelle est sans aucun doute celui de la Genèse qui, dès ses débuts, était le sujet de débats brûlants entre philosophes grecs et juifs hellénisés à Alexandrie. Dans ces débats, certains essayaient d'attribuer la priorité de Moïse, la dette d'Homère ou du Timée de Platon à la Genèse, d'autres essayaient de montrer le contraire ${ }^{21}$. Quand le christianisme est devenu la religion officielle de l'Empire il existait déjà une tradition de comparaison et d'exégèse influente, bien qu'au $\mathrm{V}^{\mathrm{e}}$ siècle, le climat n'était plus aussi propice au discours polémique ou apologétique ${ }^{22}$. Mais la Genèse était également utilisée par de fameux prêcheurs chrétiens, dans un milieu ou prêcher est l'acte didactique par excellence ${ }^{23}$. En grec, la littérature de l'hexaemeron compte trois œuvres en prose : le commentaire d'Origène In Genesim, Homeliae in hexaemeron de Basile de Césarée suivis du De hominis opificio et de l'Apologia in hexaemeron de Grégoire de Nysse ${ }^{24}$. Parmi les deux frères, Grégoire donne une tournure philosophique et scientifique à son approche, et c'est chez Basile que l'on trouve la majorité des allusions poétiques ${ }^{25}$.

18 TGF frag. 618 (Snell). Dans Clem. Alex. Strom. 5.14.113, Euseb. Praep. Evang. XIII.13.140.

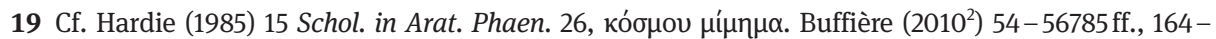
167, en tant qu'allégorie stoïcienne ; ibid. 203-207, sur les astronomes anciens. Le bouclier en tant que cosmogonie se trouve déjà dans Crates de Mallus (II ${ }^{\mathrm{e}}$ s. av. J-C.), Mette (1936). Cf. aussi la Cosmogonie de Strasbourg, Gigli Piccardi (1990). Sur la réception simultanée du bouclier et de la Théogonie chez Ovide Met. 1.2, voir Wheeler (1995) et van Noorden (2015) 213-215.

20 Sur Quint. Cf. Maciver (2012) 59-61 ; Vian (1990) 261-262 sur Dion. 25.398-401, et Arat. Phaen. 26-29 ; Sur le bouclier de Dionysos en tant qu'allégorie chrétienne voir Spanoudakis (2014). Cf. aussi les descriptions cosmiques tardives de Jean de Gaza et Paul le Silentiaire aussi inspirées du bouclier, Friedländer (1912) 7.

21 Evans (1968) sur Philon et Josèphe. Ces débats étaient surtout centrés autour de l'interprétation du Timée de Platon et non pas uniquement d'Homère et d'Hésiode. Köckert (2009).

22 Agosti (2009).

23 Sur l'effet de la rhétorique et surtout de la Deuxième Sophistique chez les Pères voir Kaldellis (2007) 160-165 et Elm (2012). Voir aussi les chapitres pertinents dans Johnson (2006). Pour la performance chez Eudocie voir Agosti (2012b) 203.

24 De Marco (2014).

25 Rist (1985) 205, surtout des poètes didactiques, e. g. Oppien, Arate. 
Quant à Gégoire de Nazianze il utilise l'œuvre de Basile pour sa réécriture poétique de la Genèse dans Arcana $4^{26}$ poème théologique et philosophique à priori.

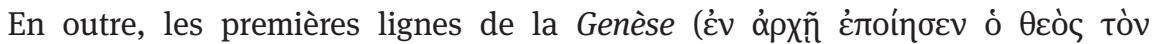

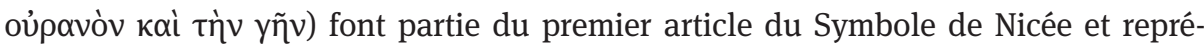
sentent une profession de foi ${ }^{27}$. Donc les poèmes du Papyrus Bodmer commencent avec la Création, en faisant allusion à la fois à la Genèse et au Credo ${ }^{28}$, et, par exemple, rien n'empêchait de le faire sous le couvert homérique comme dans l'Adresse à Abraham $^{29}$. Dans le cadre didactique du prêche, l'ekphrasis, un procédé de la rhétorique virtuose ${ }^{30}$ capable de convoquer une image devant les yeux et de convaincre en stimulant l'imagination et l'émotion, joue un rôle décisif dans le dialogue entre texte et image, puis texte et icône. Dans l'Antiquité tardive, puis à l'époque byzantine, les images ekphrastiques contribuent non seulement à une esthétique poétique visuelle mais aussi à l'instruction de la vraie foi ${ }^{31}$. Lorsqu'Eudocie se met alors à réécrire la Genèse en centons, elle a derrière elle deux courants didactiques différents : une tradition cosmologique classicisante et une exégétique de l'hexaéméron en prose et en hexamètres ${ }^{32}$.

\section{Les deux ekphraseis du Paradis dans I HC : deux modes d'apprentissage}

\subsection{Le maître du prologue}

\section{L'énonciateur/trice et son audience}

Une exploration du mode didactique doit commencer avec le portrait du maître/ enseignant. Pourtant, aux antipodes du prologue didactique du centon de Proba où la poétesse se présente comme un vates chrétien qui améliora Maron pour son «élève» Arcadius $^{33}$, les $I H C$ se caractérisent par une brusque entrée en matière et

26 Moreschini-Sykes (1997) 143.

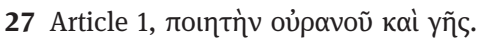

28 Robbins (2012) 8.

29 Agosti (2011b) 289.

30 Webb (2009).

31 Cf. Macrides-Magdalino (1988) 52 sur le symbolisme mystique de l'ekphrasis du temple à Tyr chez Eusèbe HE 10.4, sur l'ekphrasis à l'époque Byzantine James - Webb (1991), Agosti (2004-2005) Pour image et didactisme voir Vergados-Strauss Clay (forthoming).

32 Pour le caractère didactique de toute poésie de l'hexaemeron voir Hardie (2016) 188.

33 Cf. Juvenc. ELQ Praef. 25-28, fait appel aux eaux de Jourdain ; Proba recourt au Saint Esprit, CV 10 «ora resolve spiritus»; Schottenius-Cullhed (2016a) 119-120;130-135, Green (2006) 22, Sandnes (2011) 54. Pour Proba en tant que prophète et apôtre voir Dijkstra (2016) 114. 
restent assez vagues sur l'identité de l'énonciateur ${ }^{34}$. Cet auto-effacement ${ }^{35}$, caractéristique de l'épopée héroïque et non de la poésie censé didactique, est-il pour autant suffisant pour remettre en cause la simplement didactique du début du poème ? Ou s'agit-il d'une résurgence homérique, une formule épique qui ouvre des discours directs ${ }^{36} \mathrm{Ou}$ devons-nous voir dans le narrateur un autre type d'instructeur ? La Pour repondre à ses questions il faut une lecture attentive de la première ékphrasis qui se développe ainsi :

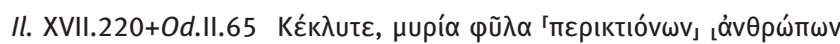

Od. VIII.222

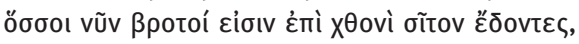

Od. XIII.240

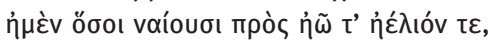

Od. XIII.241

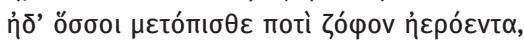

Il. VII.68

Il. V.128

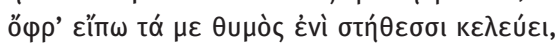

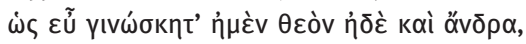

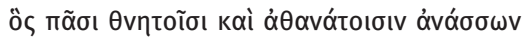

II. XVIII.483

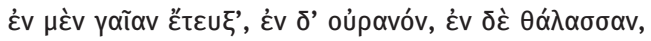

II. XVIII.484

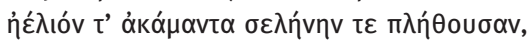

II. XVIII. 485

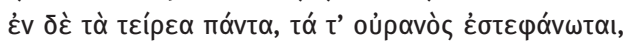
II. XVIII.486

II. XVIII. 487

II. XVIII.488

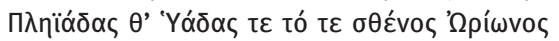

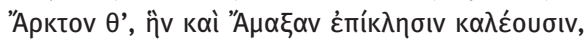

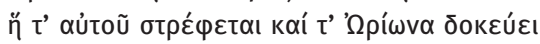

Od. XII.331

Od. V.67

Od. XII.96

Od. XII.97

II. XXIII.260

Od. XI.611

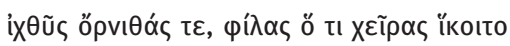

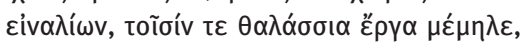

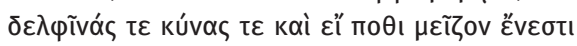

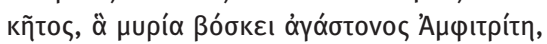

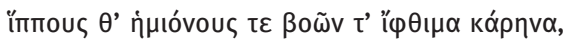

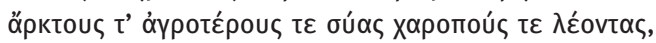

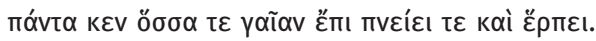

II. XIV.347

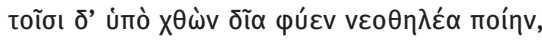

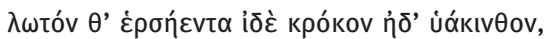

II. XIV.348

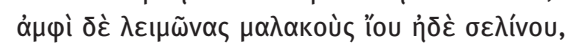

Od. $\mathrm{V} .72$

Od. IV. 604

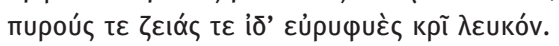

Od. IV.458

Od. VII.115

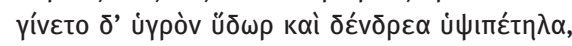

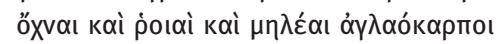

Od. VII.116

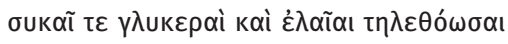

34 Je ne prends pas en compte l'apologia de Vat. suppl. gr. 388, et AP 1.119 puisque nous ne savons pas avec certitude quelle édition des HC elle introduisait. Contra see Usher (1997) et Sandnes (2011) $186-188$.

35 Sur le «narratorial self effacement» voir de Jong (1987), Morisson (2007) 45-46. Contreraiment sur l'«involved narrating» chez Eudocie voir Kuhn-Treichel (2017). Ici je vise à trouver un juste milieu entre narrateur actif et latent.

36 Cf. Hom. Il. VII.67 ; VIII.5 ; Od. VII.186 ; VIII.26 ; XVII.468, passim, et non seulement chez Homère mais voir aussi Hes. Ehoie Frag. 75 (M-W) : La formule est utilisée ainsi à d'autres occasions (Cf. I HC I

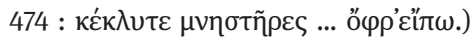


Od. V.64

Il. XX.9

Od. V.70

Od. V.71

Il. XVI.389

Il. XXIII. $107+536$

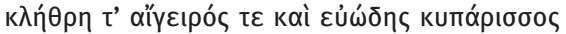

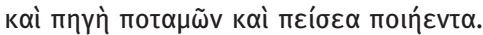

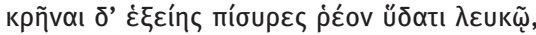

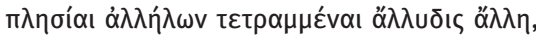

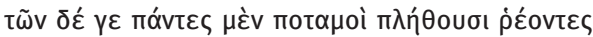

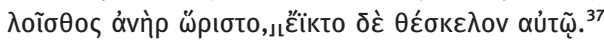

Malgré sa discrétion, l'engagement personnel du «je» du prologue n'est pas inexistant $^{38}$. Toutefois, bien que chez Homère la localisation et le sens du thymos ne soient pas concrets ${ }^{39}$, cela n'est pas le cas dans les I HC. Rocco Schembra montre avec pertinence que, dans le contexte chrétien, le thymos se réfère à l'Esprit Saint et l'illumination/inspiration poétique que celui-ci donne : seule un cœur purifié peut inviter l'esprit en soi $^{40}$. Mais plus intéressant, le texte que nous possédons commence d'une manière propre au sermon et à la déclamation homilétique, genres didactique et épidictique par excellence ${ }^{41}$. Selon Rocco Schembra (2006) 80-81, la phrase

37 «Ecoutez, tribus innombrables des humains d'alentour tant ceux qui habitent du côté de l'aurore et du soleil, que ceux qui regardent, sur le bord opposé, le couchant ténébreux, pour que je dise tout ce que mon cœur au sein m'exhorte à dire, afin que vous puissiez exactement discerner le Dieu de l'Homme, celui qui est de tous les mortels et les immortels le souverain. Il (Dieu) créa la terre ici, les cieux par-là, la mer, et le soleil infatigable et la lune dans sa plénitude et toutes les étoiles qui couronnent les cieux, la nuit. Les Pléiades et les Hyades et le fort Orion et l'Ourse, qu'on appelle aussi le Chariot et qui tourne autour de son axe et regarde Orion, et les poissons, les oiseaux, et tout ce que chassent avec leurs mains les braves pêcheurs, qui s'occupent avec les travaux maritimes. Les dauphins, et les requins, et les plus grandes mysticètes, qu'Amphitrite aux bruyants gémissements fait paître par millions, et les chevaux, les ânes, et les bœufs aux solides crânes, et les ourses et les sangliers sauvages, et les lions au regard étincelant, et tout ce qui sur la terre, respire et chemine. Et en dessous de celles-ci, il a fait pousser la belle herbe tendre, et le lotus rosé, les crocus et les hyacinthes, et autour des pâtures moelleuses avec du céleri, du lys, du blé, du sarrasin et les épis de blé. L'eau est devenue douce, les arbres grands, ainsi que les poiriers, les grenadiers, les pommiers avec leurs fruits savoureux, les figuiers doux et les oliviers en fleurs, les aulnes, les peupliers, et les chypres parfumés, et il y avait la source de rivières et des prairies verdoyantes. Et puis quatre sources à l'eau cristalline se faisaient face, d'où coulent tous les grands fleuves. Et à la fin l'homme fut créé, divin, à l'image de son créateur» Trad. A. Lefteratou.

38 Cf. aussi Kuhn-Treichel (2017) 67-68.

39 Chez Homère thymos est associé aux «organes psychiques» et pas nécessairement au cœur, voir Webster (1957) et Cairns (2014) ; mais dans la poésie épique tardive, le sens a commencé a changer surtout sous l'influence du stoïcisme, Cf. voir Maciver (2017) sur Quinte.

40 Schembra (2006) 69, 86, avec littérature. Le cas du thymos n'est pas unique. Pour la christianisation du rôle des Muses dans la poésie tardive voir Cf. Agosti (2002) 92-93 et Agosti (2015) 204. Kuhn Treichel (2017) n. 18 ne focalise pas sur l'aspect transcedent du thymos, mais y voit un « self-confident opening».

41 Usher (1998) 67-68 aussi remarque la tradition de la déclamation chez Usher (1998) 19, qui met l'acent sur la composition orale des I HC et l'opinion opposée de Schembra (2006) 82, «l'imperativo

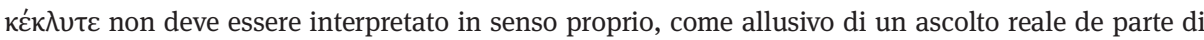
una comunità disposta davanti ad un poeta-rapsodo, bensì di un'auscultazione interiore, propria di un animo ben disposto a ricevere la verità di fede». Le contexte performatif de cette poésie est hors de 


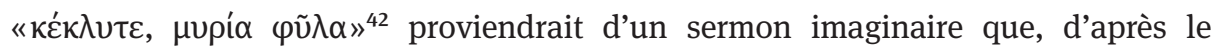
Protreptique de Clément, Jésus aurait tenu après avoir invité les Grecs et les barbares à écouter ses paroles ${ }^{43}$.

Cette phrase accentuerait la dimension œcuménique de son message qui ap-

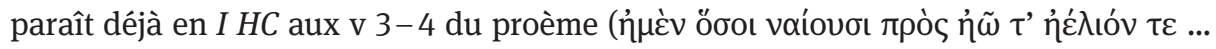

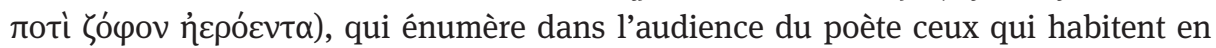
Orient et en Occident en faisant allusion aux habitants de l'est et de l'ouest de l'Empire Romain ${ }^{44}$. Au niveau lexical, ces centons sont empruntés à l'éloge d'Ithaque (une île renommée à l'est et à l'ouest) qu'Athéna, déguisée en jeune pâtre, fait à Ulysse $^{45}$. Dans la tradition philosophique, Ithaque était aussi la destination symbolique de l'âme ${ }^{46}$, ce qui aurait chargé ces centons d'un hypotexte platonicien : notre poème commence avec un retour symbolique de l'âme à sa destination idéale à côté, la confession du dieu unique (v. 6). Au niveau thématique ces versets encouragent une association avec le prologue de l'Odyssée où sont évoqués un peuple fameux, comme apparemment les habitants de l'empire, pour sa piétée ${ }^{47}$ - qui habite à l'est et à l'ouest : les Éthiopiens. L'association avec les Éthiopiens incite alors à une caractérisation supplémentaire du public comme pieux. Par ailleurs, l'insertion des paroles inspirées par l'épiphanie d'Athéna à Ulysse (vv. 2-4) souligne l'aspect de l'épiphanique, ou d'inspiration divine. Ainsi, le prologue met en scène non seulement le maître-prêcheur éclairé mais aussi son public dévot, en illustrant ainsi la situation didactique ${ }^{48}$, qui, étant donné le contexte du prêche, fait du premier un disciple et exégète et du second un catéchumène.

tout doute : Cf. Agosti (2006). Pour l'influence de la Deuxième Sophistique sur les Pères voir Kaldellis (2007) 160 - 165 et Elm (2012). Stewart-Sykes (2001) explique comment l'homélie chrétienne se développe à partir d'un genre prophétique dans un genre enseigné dans les écoles chrétiennes avec l'aide de la rhétorique. Sur l'influence de la rhétorique sur la poésie voir Cameron (2016). Le meilleur exemple de ce mélange est probablement Grégoire de Nazianze, Agosti (2006) 36, qui a composé ses œuvres en prose et en vers.

42 I HC $1 \sim$ Il. XVII.220 ; Od. II.65.

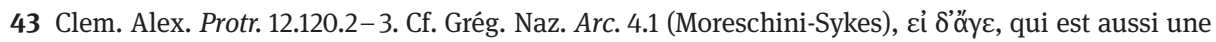
formule exhortative.

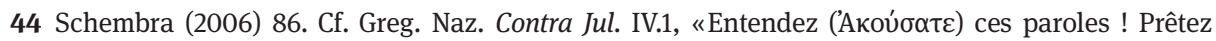

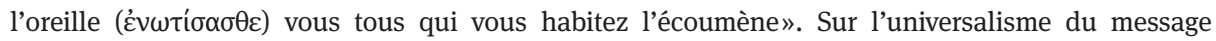
chrétien voir Bland Simmons (2015), Fowden (1993). Sur la topographie chrétienne, vraie et symbolique, voir Johnson (2016) esp.79-111; sur l'universalisme du message dionysiaque dans Nonn. Dion. voir Lefteratou (2016).

45 I HC 3-4 Od. XIII.240-241.

46 O’Meara (1982) 12-14, Ithaque comme lieu symbolique, comme l'archétype du voyage du retour de l'âme.

47 Hom. Od. I.24-25.

48 Un des critères majeurs de Vollk (2002) 40. 


\section{Intention didactique}

Les vers suivants du proème précisent explicitement le but du poème : v. 6 , $\dot{\omega} \varsigma$ عũ

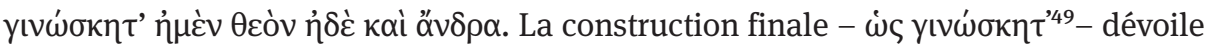
non seulement l'intention didactique de l'œuvre mais contient aussi une profession de foi : le public fera la connaissance du théanthrope ${ }^{50}$, de celui qui est à la fois dieu

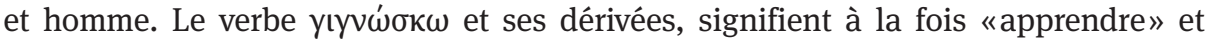
«connaître» et dans la poésie chrétienne de Nonnos ils commentent le voyage de l'ignorance à la croyance et la confession que le Christ est le dieu incarné ${ }^{51}$. Ces vers proviennent aussi d'une tirade d'Athéna, cette fois faite à Diomède pendant son aristeia : la déesse lui promet de l'aider à se battre et à distinguer les hommes des dieux en éloignant le brouillard que Zeus a jeté sur le champ de bataille. Ces vers ont été rendus célèbres dès l'Antiquité par l'adaptation qu'en a fait Platon $:^{52}$ distinguer entre le bien et le mal devient chez les Pères une métaphore de la distinction entre péché et piété ou une périphrase pour présenter le Christ en tant que le Fils incarné ${ }^{53}$.

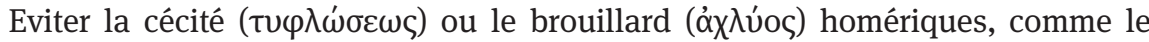
montre Gianfranco Agosti ${ }^{54}$, correspond, dans les milieux monastiques du $\mathrm{IV}^{\mathrm{e}}$ siècle, à la condamnation de la paideia païenne et du péché qu'elle induit. Le brouillard désigne alors l'obscurité mentale opposée à l'illumination divine, ou la métaphore du péché. A partir du $V^{\text {ème }}$ siècle cependant, il devient une expression technique renvoyant à la conversion et à la confession ${ }^{55}$. Il est caractéristique que, dans la Paraphrase de Nonnos, Jésus lorsqu'il enseigne, soit représenté comme sortant ses élèves de la brume pour les mener à la lumière, en faisant de son sermon un acte à la fois éclairant et instructif ${ }^{56}$. Dans ce milieu poétique et culturel, la présence d'Athéna comme avatar du poète-maître est significative dans les $I H C$ et importante non seulement au niveau métaphorique mais aussi parce qu'elle met l'accent sur l'association d'Eudocie avec la déesse de sa cité d'origine, Athènes. Athéna apparaît déjà comme éducatrice chez Hésiode ${ }^{57}$ mais c'est surtout dans la poésie didactique

49 I HC 6 Il. V.128, voir aussi, très bref, Kuhn-Treichel (2017) 68.

50 Schembra (2006) 87. Cf. Aussi Grég. Naz. Arc. 1.25-39 (Moreschini-Sykes), عís $\theta$ còs ... ò y’uiòs

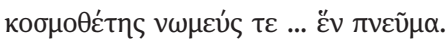

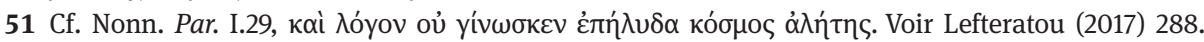

52 Cf. dans Pl. Alc. 150d, les vers évoquent la distinction entre bien et mal et sa reprise Cf. chez Luc. DMort 7, Max. Tyr. Diss. 8.5. Voir Bompaire (1958) esp.21-32, de Lacy (1974).

53 Cf. Clem. Alex. Protr. 1.113.1-2 (Mondésert), «Accepte le Christ, accepte de voir, accepte ta lumière,

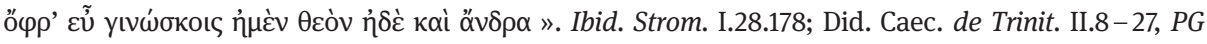
39.728, ou le brouillard est celui du paganisme. Pour le Platonisme des Pères voir Pépin (1976 (1958)), O’Meara (1982), et Rist (1985).

54 Agosti (2011a) notamment 37-43.

55 Agosti (2011a) 43.

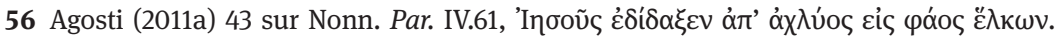

57 Athéna, dans son rôle didactique, enseigne à Pandore les rudiments des œuvres «féminins» dans

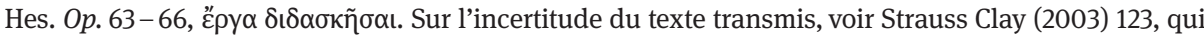


tardive $^{58}$ qu'elle devient l'incarnation de la sagesse et du savoir. Peut-être n'est-il donc pas étonnant qu'une femme, une Athénienne, interprète l'Athéna hésiodique à la lumière d'Iliade $\mathrm{V}$ et en fasse une incarnation de la poétesse didactique chrétienne ${ }^{59}$.

\section{Enseigner par l'image}

Si les $I H C$ ne suivent pas exactement la narration biblique ${ }^{60}$ il faut noter que les Homélies de Basile montrent déjà la liberté de l'exégète vis-à-vis du prototype. La Bible, dit Basile, ne fait qu'esquisser la poikilia de la création ${ }^{61}$. Mais avec le mot poikilia Basile commente et s'insère directement dans l'esthétique de l'antiquité tardive $^{62}$. Il n'est pas étonnant que, lui qui parlait devant une congrégation mixte, utilise des images pour éclairer son message : le Dieu de la Genèse est alors le

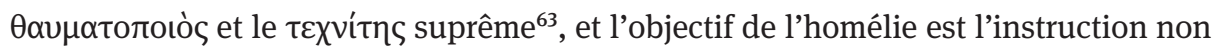
pas de l'intellect mais de l'âme ${ }^{64}$. Basile met l'accent sur le verbe $\pi$ ot $\tilde{\omega}$ de la Genèse,

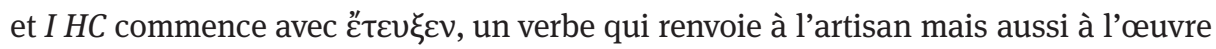
d'art au niveau métalittéraire ${ }^{65}$. Une ekphrasis illustre alors parfaitement la gloire de la création en la mettant devant les yeux.

La majorité des vers de la première ekphrasis, 5 sur un total de 35, appartiennent à la description du bouclier ${ }^{66}$, et un deuxième groupe à la description de la grotte de

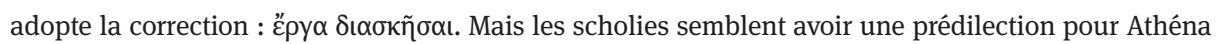

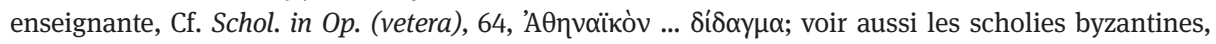

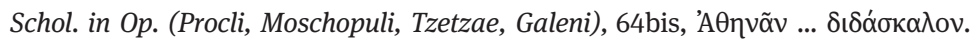

58 Mart. Cap. de Nupt. Deacy (2008) 141-145, surtout sur la poésie moralisante de la Renaissance. Sur Antioche et pas Athènes comme cité d'Eudocie voir Holum (1982); pour un aperçu du débat voir Van Deun (1993).

59 Cf. Ov. Met. VI.53ff., le concours entre Minerva et Arachnè, Innes $\left(1993^{2}\right) 254$.

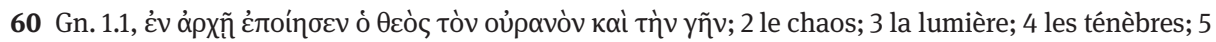
les cieux; 6-7 séparation de l'eau et des cieux; 8 la création du ciel; 910 la terre et la mer; $11-13$ les plantes; 14-15 les étoiles; 16-19 le soleil, la lune, le jour et le nuit; 20 les oiseaux; 21-23 les mysticètes et les poissons; 24 les animaux; 25 les reptiles; 26-27; l'homme.

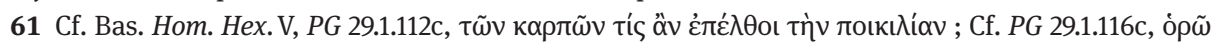

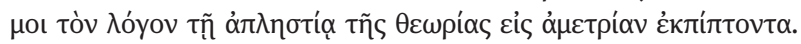

62 Cf. Roberts (1989), Fauth (1981), Agosti (1997), Miguélez Cavero (2008) 120-140, 375-380.

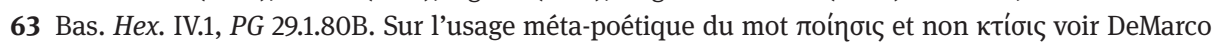
(2014) 341. Pour des métaphores artistiques et visuelles décrivant le divin voir Cf. Jensen (2005). Pour la puissance didactique des images voir Vergados Clay (à paraître).

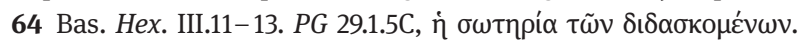

65 Voir Squire (2013), sur le «slippage of medium and recession».

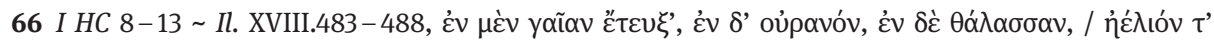

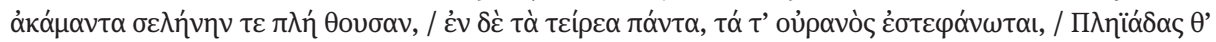

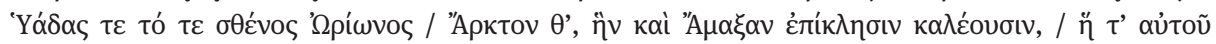

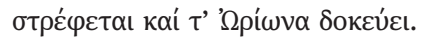


Calypso $^{67}$ et des jardins des Phéaciens ${ }^{68}$. Ces lignes n'étaient pas choisies au hazard; elles étaient importantes dans l'étude comparative d'Homère et de la Genèse. Clément cite le bouclier trois fois avec des variations des vers homériques choisis : avant Arate, dit-il à propos du bouclier, Homère a raconté une cosmogonie selon la Genèse de Moise ${ }^{69}$. On trouve la même idée chez Pseudo-Justin, pour qui la cosmogonie du bouclier est une dette du poète au prophète.

Ps.-Just. Cohort. 277 b-d : (J'évoque tout cela) pour démontrer que le poète a transformétransposé ( $\mu \varepsilon \tau \alpha \beta \alpha \lambda o ́ v \tau \alpha)$ dans sa poésie beaucoup de choses provenant de l'histoire divine des prophètes ; d'abord avec la narration des débuts dans la cosmogonie (кобнолой

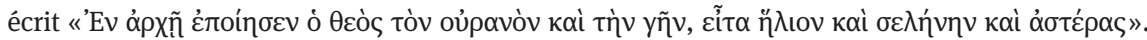
Ayant appris $(\mu \alpha \theta \dot{\omega} v)$ cela en Egypte ... (Homère) dans la scène du bouclier d'Achille a repré-

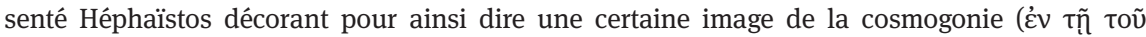

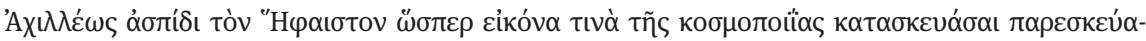

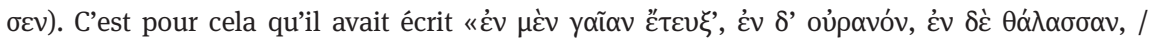

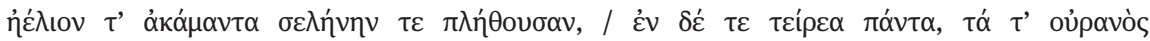

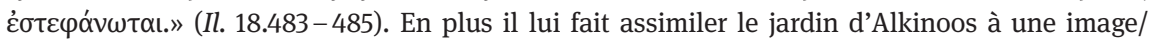

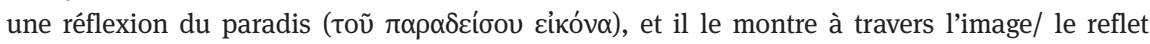

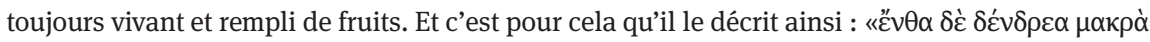

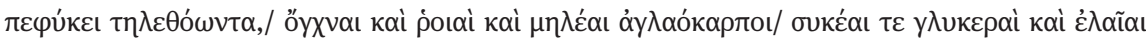

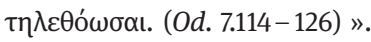

La citation de ce vers était alors attribuée à la diffusion de la paideia classicisante et de l'apologétique chrétienne. Il est intéressant de remarquer que la thématique de la Genèse chez Pseudo-Justin donne l'impression non seulement d'une dette mais aussi

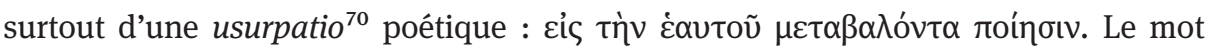
metabolè est un terminus technicus et désigne la méthode paraphrastique ${ }^{71}$. Dans notre texte, étonnement, ce n'est pas le poète chrétien qui adapte la poésie classique, mais Homère en tant que paraphraste de la Genèse. Aussi le procédé de l'ekphrasis est-il ici utilisé en deuxième degré : Homère représente Hephaistos créant une image (દíóvo) cosmogonique qui est en même temps le reflet du récit de la Genèse.

Pour ce qui est de la description des arbres du Paradis, il s'agit d'une liste qui s'appuie largement sur la description de la grotte de Calypso et des jardins des Phéaciens et qui donne l'impression d'un catalogue : parmi les arbres cités, on

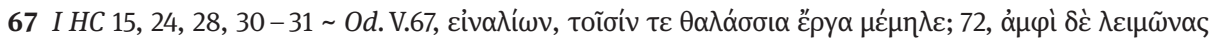

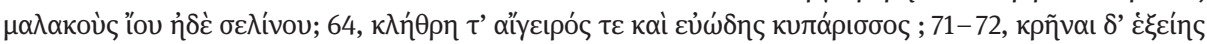

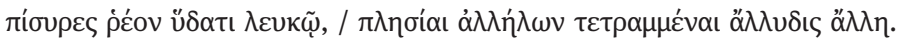

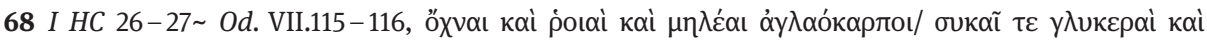

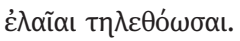

69 Cf. Clément cite Iliade XVIII trois fois : Paed. 3.12.99.3 seulement vers 483 et 485, et omet 484 ;

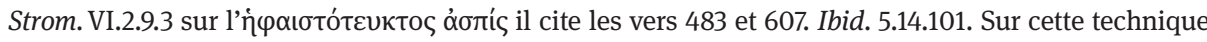
de citation sélective voir Adams (2016) p.18, qui les appelle des «summarizing composite citations». 70 Sur Usurpatio et Kontrastimitation comme techniques d'appropriation du matériel classique dans la poésie chrétienne voir Thraede (1962), Agosti (2011b), et Pollmann (2017).

71 Miguélez Cavero (2008) 314-316. Voir la contribution de Ricci dans ce volume. 
trouve des figuiers, des grenadiers, des oliviers, des pommiers, des cyprès. Les listes sont caractéristiques de la poésie didactique, notamment à partir de l'époque hellénistique ${ }^{72}$, mais il s'agit aussi d'un trait distinctif de l'exégétique homilétique. Par exemple, Basile commente souvent la manière dont il a été balayé par les myriades prodiges de la création et des créatures ${ }^{73}$. Par rapport au poids herméneutique des centons utilisés ici il faudrait souligner que ces lignes étaient également bien connues dans l'Antiquité. Julien par exemple loue Ulysse d'avoir fui les tentations de Calypso, de Nausicaa, de leurs royaumes et de leurs jardins impressionnants pour retourner auprès de sa femme fidèle ${ }^{74}$; et on a vu que pour Pseudo-Justin ces vers avaient également été utilisés dans des contextes apologétiques sans problème particulier. Il s'agit alors bien d'un cas d'usurpation de vers homériques dans des contextes chrétiens dans le but de faire d'Homère un proto-chrétien. On peut rappeler à ce propos ce que dit Lamberton : «Homer was ... a participant in the revelation lying behind Christianity ${ }^{75}$ ».

\subsection{Satan en tant que maître}

\section{L'énonciateur, son élève et son art de la persuasion}

Contrairement à l'énonciateur discret de la première ekphrasis, dans la deuxième Satan se présente comme un maître idéal qui aidera Eve à apprendre vite :

\begin{tabular}{|c|c|}
\hline Od. XI.146 & 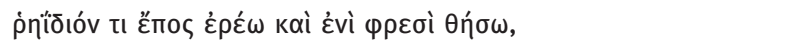 \\
\hline Il. X.324 & 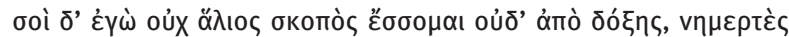 \\
\hline Od. XIX.296 & 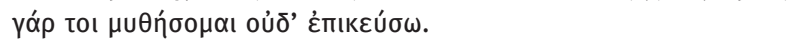 \\
\hline Od. IV.565 & 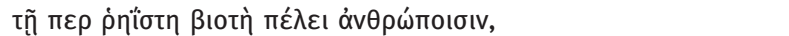 \\
\hline Od. IV.566 & 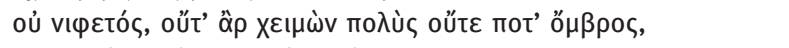 \\
\hline Od. IV.567 & 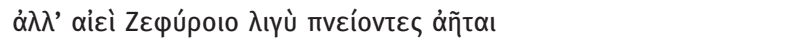 \\
\hline
\end{tabular}

72 On trouve des catalogues aussi bien chez Homère que chez Hésiode ; Kuhlmann (1973). Sur la forme du catalogue comme instrument didactique voir Overduin (2015) 30.

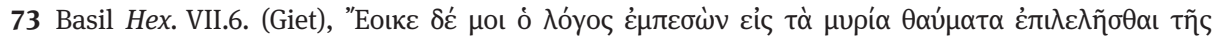

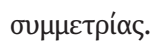

74 Jul. Encom. euseb. reg. 8 citant Od. V.70. Dans Stob. 1.1 .36 on trouve Od. VII.115 ; V.64, VII.116. Voir Lib. Prog. 12.9, ekphrasis d'un jardin, citant. Od. VII.116 et Od. VII.115.

75 Lamberton (1986) $79-80$.

76 «Mais je (Satan) te dirai quelque chose de facile et je te le mettrai en tête, je ne serai pas pour toi un instructeur qui trompe et je ne t'égarerai pas ! Je te dirai la vérité pure en ne te cachant rien. Là se trouve une vie de béatitude pour les mortels : il n'y a pas de neige, pas beaucoup de froid, et presque pas de pluie, mais toujours soufflent agréablement les brises du Zéphyr, en haletant des brises de toutes les sortes. Les mains ne plantent pas, ni ne labourent, mais tout pousse sans planter, sans labourer, sans moissonner. La pauvreté est absente de la cité et aucune autre maladie ne tourmente les malheureux mortels. Et on y trouve de beaux arbres éclatants, de doux figuiers, ses oliviers en fleurs, et bien d'autres encore» Trad. A. Lefteratou. 
II. XVIII.471

Od. IX.108

Od. 9.109

Od. XV.407

Od. XV.408

Od. VII.114

Od. VII.116

Il. IX.639

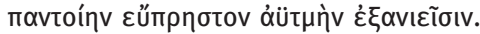

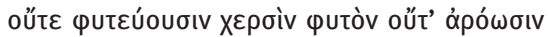

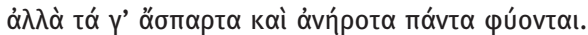

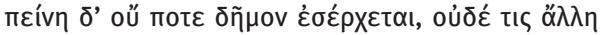

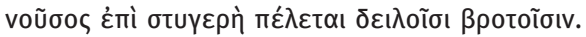

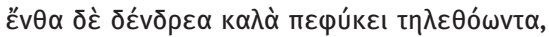

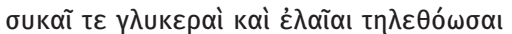

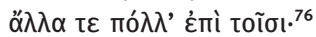

(50)

Au vers 44, Satan annonce à Eve qu'il va lui dire «quelque chose de facile» (’́nitosóv

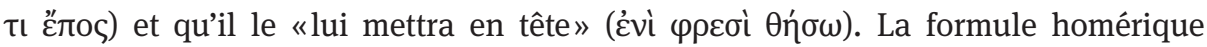
associée ici à Tirésias est reprise dans l'Hymne à Apollon où elle prend une couleur de révélation une fois mise dans la bouche du dieu ${ }^{77}$. Mais elle est aussi citée par

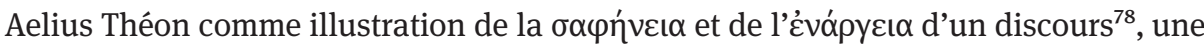
qualité appréciée par les exégètes chrétiens ${ }^{79}$. Sous l'apparence du devin Tirésias, Satan se présente alors comme un maître compétent tandis que le reste de l'hypotexte, lui, en fait un portait a contrario et alerte le/la lecteur/ctrice du danger imminent. Dans le détail, le vers appartenant à l'adresse que Tirésias réserve pour Ulysse dans la Nekyia transporte la conversation du Paradis aux Enfers. La récur-

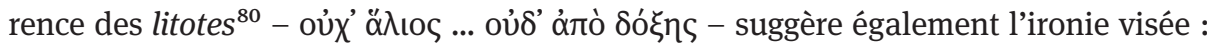
au vers 44, elle est attribuée à Dolon, une figure négative de l'Iliade dont le nom correspond à la tromperie ${ }^{81}$; le vers 46 introduit les récits mensongers qu'Ulysse raconte à Pénélope en tant que mendiant et révèle d'autant plus le climat de supercherie et de fraude ; enfin les vers 46-49 associent Satan à un autre devin, Protée, qui depuis Platon, incarne le sophiste trompeur ${ }^{82}$. Ainsi, Tirésias, Dolon, Ulysse et Protée deviennent des modèles négatifs que minent l'exhortation et la captatio benevolentiae de Satan ${ }^{83}$. En face d'un instructeur si habile, Eve est facilement trompée et persuadée ( $\pi \alpha \rho \varepsilon ́ \pi \varepsilon เ \sigma \varepsilon v)$ puisqu’il lui ait parlé d'une manière prétendument claire et convaincante ( $\delta\left\llcorner\varepsilon \pi \varepsilon \dot{\varepsilon} \varphi \alpha \delta \varepsilon \pi \alpha^{\prime} \nu \tau \alpha\right) .{ }^{84}$

Etant donnée la caractérisation infernale de Satan, je juge intéressant d'observer les intertextes homériques utilisés pour cette deuxième ekphrasis. La version que

77 HApoll 534, Richardson (2010) 150.

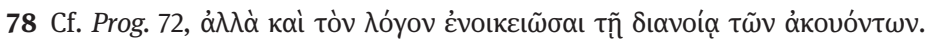

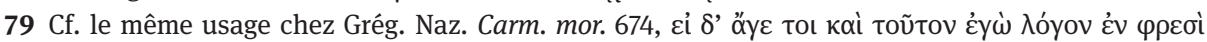
$\theta \eta ́ \sigma \omega$. Sur la clarté comme typique du style didactique de Lucrèce voir Kennedy (2014²) 17.

80 Lausberg (1990) 239.

81 Il. X.324.

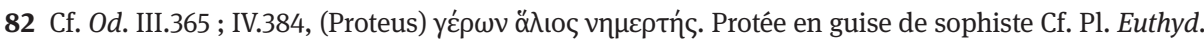
288b, Meno 80b, Polit. 219a-c; cf. Hld. Aeth. 2.24.4. Greg. Naz. Or. 4.62 attribue des qualités Protéenes, négatives à Julien, tandis que Lib. Or. 18.176, fait de Julien un modèle du sophiste Protéen positive.

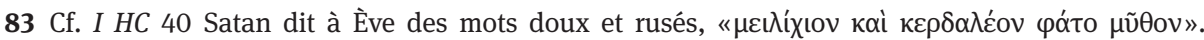
84 I HC 67. 
Satan propose à Eve, qui habite déjà au paradis, est, à travers la Kontrastimitation, ${ }^{85}$ une image d'un anti-Paradis ironiquement bouleversée : les associations malines sont soulignées par le contexte de la Nekyia et les lignes articulées par Protée proviennent de la description faite des Champs Elysées à Ménélas ${ }^{86}$. Les $I H C$, en ce qui concerne la relecture d'Homère, associent les deux passages catabatiques, celui de Ménélas et celui d'Ulysse ${ }^{87}$, mais surtout minent le caractère idyllique que la description de l'Elysium avait pour les lecteurs païens ${ }^{88}$ : en fait pour un public chrétien cette description contraste manifestement avec celle du Paradis biblique et rappelle d'ailleurs ce que la vie terrestre ne fut pas pour Adam et Eve selon la Genèse 3.14-19, à savoir une vie pleine de peine, de souffrance et de mort. Cette opposition entre l'ekphrasis idéalisée et le contenu de la Genèse est un cas formidable de Kontrastimitation.

\section{Enseigner par l'image}

Le choix de ces lignes dans l'ekphrasis de Satan n'est pas non plus à mettre sur le compte du hasard puisque ces vers ont été employés dans les débats judéo-chrétiens des premiers siècles de notre ère. Par exemple, dans le Contra Celsum, Origène mentionne combien les philosophes ont pu mésinterpréter la doctrine du Paradis quand ils la comparent avec l'Elysium païen, tandis que, dans la Bible, cet Elysium correspond à la Terre Promise. Il démontre son argument en citant les vers homériques utilisées pour Protée que l'on trouve aussi dans I HC 47-4989. Ce passage était alors un cas de Kontrastimitation entre le topos païen et l'exégèse chrétienne. Ironiquement, Satan décrit à Eve, qui habite déjà au Paradis, une image d'un antiparadis païen qui correspond non plus à la vie heureuse mais à une tromperie dangereuse, étant donnée la caractérisation catabatique de Satan en Tirésias et la localisation du dialogue aux «enfers» en IHC 40. Les vers 51-52 de I HC sont eux aussi issus d'un autre passage contesté : la description de l'île des Cyclopes comme pseudo-paradis. Ces lignes étaient connues des auteurs de la deuxième Sophistique ${ }^{90}$ comme indicatrices d'une vie de paresse aux marges de la société humaine et offrent un autre exemple de Kontrastimitation, puisqu'en Genèse 3.16 Dieu maudit Adam, le condamnant à manger le pain «à la sueur de [s]on visage ... jusqu'à ce qu['il] re-

85 Agosti (2011b) 288-289 «imitation contrastive par rapport à un contexte d'origine qui est renversé : la citation démontre ainsi la fausseté du modèle païen et la supériorité du christianisme»; cf. ibid 289 sur la P. Bodmer 31, Ad Just., où les allusions à la grotte de Calypso sont utilisées pour opposer celle du vrai Paradis chrétien.

86 Od. IV.565-567.

87 de Jong (2001) 109, 266-278.

88 Cf. Strab. Geogr. I.1.4 ; III.2.13.

89 Orig. Conta Cels. VII.28, citant Od. IV.563 et 565-7. Wilken (2003 (1984)) 101-102.

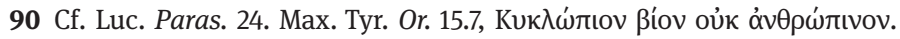


tourne dans la terre, d’où [il a] été pris ; car [il] es[t] poussière, et [il] retournera à la poussière». Par ailleurs, Satan laisse entendre à Eve que, dans cet anti-paradis, elle vivra un bonheur absolu en parfait accord avec son mari. Les vers qu'il utilise font partie des paroles qu'Ulysse adresse à Nausicaa, quand il lui souhaite de trouver une compréhension mutuelle avec son futur mari ${ }^{91}$. Les lignes étaient proverbiales à l'époque impériale - illustrant l'idéal conjugal ${ }^{92}$ - mais dans le contexte de la Genèse elles sont minées par le texte biblique, la malédiction que Dieu lance contre Eve, la condamnant à vivre dans la discorde familiale ${ }^{93}$.

Quant à la reproduction du lieu idéalisé, Satan utilise les vers dédiés à la description des jardins des Phéaciens, qu'on a vu dans la première ekphrasis aussi, pour faire une énumération des arbres du paradis, que comme déjè mentioné était un passage qui fait allusion à la tentation d'Ulysse. A la surprise du lecteur, alors que Satan vient de commencer à énumérer les arbres du paradis, il s'arrête et désigne

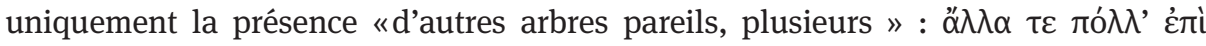
$\tau o$ ĩ ${ }^{94}$ Cette ligne a un rôle double : au niveau métalittéraire elle indique que, bien qu'il fût possible de faire une digression paradisiaque de plus, le poète s'abstiendra d'ajouter des répétitions et des listes inutiles, excluant ainsi une esthétique de $v a$ riatio vaine qui ne contribue pas à l'exégèse. D'un autre côté ce détail autoréflexif encourage le lecteur-public du poème à faire le lien entre les deux ekprhaseis et à voir en quoi Satan est une version négative $d u$ «je» conteur discret du prologue.

\section{Conclusion : la question de la persuasion et du libre arbitre}

Tandis que la première ekphrasis du Paradis est composée à partir de vers appartenant à la description du Bouclier d'Achille du chant XVIII de l'Iliade, la deuxième utilise des vers qui appartiennent aux discours polémiques des premiers siècles. Quand le Bouclier offre un parfait exemple d'Usurpatio, les Champs Elysées de l'Odyssée IV offrent, eux, un exemple de Kontrastimitation. La présence alors de deux ekphraseis dans la Prima n'est pas accidentelle - un simple cas d'amplificatio et de variatio - mais est au cœur de l'exégèse de la Genèse dans I HC. D'ailleurs cette prédilection pour le Bouclier peut aussi reposer sur une image chrétienne de cette arme puisque, dans le Nouveau Testament, le bouclier est l'arme du soldat de Christ, d'après Paul : ${ }^{95}$

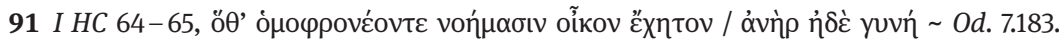

92 Cf. Dion. Halic. Ars rhet. 4.3 ; Plut. Amat. 770a et aussi dans Clem. Alex. Strom. IV.8.63.

93 Gn 3.15, "Je mettrai l'inimitié ( $\left.\varepsilon_{\chi} \theta \rho \alpha v \theta \eta \dot{ } \sigma \omega\right)$ entre toi et la femme, entre ta postérité et sa postérité».

94 I HC 57.

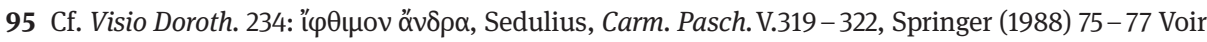
aussi Kuhn (2014) 75, 115. 
Eph. 6.10-12, «Revêtez-vous de toutes les armes de Dieu, afin de pouvoir tenir ferme contre les ruses du diable. Car nous n'avons pas à lutter contre la chair et le sang, mais contre les dominations, contre les autorités, contre les princes de ce monde de ténèbres, contre les esprits méchants dans les lieux célestes.»

Cet usage du bouclier en tant que cosmogonie christianisée agréée permet une comparaison entre les deux modes didactiques du poème. Les deux maîtres du prologue appartiennent alors non pas à deux genres différents mais ils exemplifient deux attitudes différentes face à l'instruction et à la persuasion. Contrairement au «je» conteur du prologue qui reste discret, Satan est un instructeur égocentrique, trompeur, qui revendique le rôle de maître auprès d'Eve bien que le chemin qu'il montre ne soit que périls et destruction. La discrétion $\mathrm{du}$ «je» du prologue, n'est pas seulement un écho de l'épopée homérique, mais éclaire probablement l'humilité de l'énonciateur, une qualité qui le distingue de l'éloquence virtuose de Satan. Les

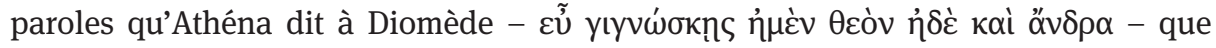
toute l'Antiquité - aussi bien païenne que chrétienne - a réutilisées et adaptées, sont d'autant plus importantes : le chrétien doit se montrer attentif et veiller à ne pas se laisser tromper par le brouillard du péché et du diable. Et ses paroles ont plus de poids quand elles sont articulées par une poétesse originaire de la cité d’Athéna, porte-parole de l'énonciatrice du proème.

Il y a alors dans cette interprétation une approche souple du sujet du libre arbitre qui a été tellement important pour les Pères ${ }^{96}$. En effet Eve apparaît comme une élève ingénue, qui se décide pour l'ö́nv $\lambda u y \rho \eta ́ v^{97}$ (la follie malheureuse), sans interroger suffisamment la leçon qui lui est délivrée. Etonnamment, ces lignes sont composées par une femme pour en défendre une autre car elles appartiennent à la critique de l'adultère d'Hélène avec Pâris que Pénélope fait à Ulysse : Hélène, dit Pénélope, n'aurait jamais fui avec Paris, si elle avait su comment se terminerait son idylle illégitime. Et comme la tradition ancienne a trouvé pour Hélène des circonstances atténuantes, où la peithô et l'éloquence de Pâris jouait un rôle majeur dans la scène de la séduction ${ }^{98}$, l'énonciatrice de la condamnation d'Eve trouve aussi des justifi-

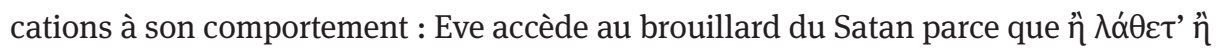

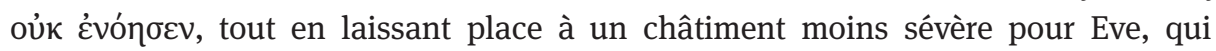
semble agir par ignorance et mécompréhension. Non seulement Satan comme maître était irrésistible mais son élève était d'autant naïve. Le lecteur doit alors attendre

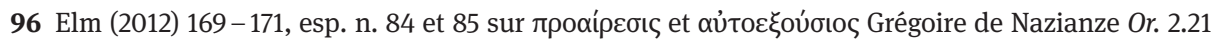
qui décrit le philosophe (chrétien), à l'instar du sage platonicien (Cf. Pl. Grg. 463a 465e), emmènera son public vers la vraie foi sans violence, en usant de persuasion - contrairement au tyran.

97 I HC 69-70 Od. 23.2234. And I HC Il. 9.537 (Oeneus oublie de sacrifier à Artémis).

98 Gorg. Enc. Hel. frag. 11 (D-K) 
jusqu'à la scène de l'Annonciation pour voir l'élève idéale, Marie, en face d'un autre messager et instructeur, cette fois sincère, Gabriel ${ }^{99}$.

Mais Eve n'était pas la seule ingénue: un passage caractéristique de l'Etymologicum Magnum fait exactement cette association entre, non plus dieux et mortels mais entre, dieux et sophistes -

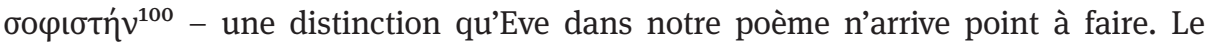
remède contre les sophistes selon l'Etymologicum Magnum est la philosophie, qui, dans le poème chrétien cède son rôle à la foi vraie. Le message est alors inversement proportionnel à la méthode d'instruction : plus le message est vrai et salutaire, plus la messagère est discrète et plus est libre l'élève incité à l'intégrer à son propre rythme. Par conséquent le premier énonciateur visionnaire du proème ne manque pas en habileté rhétorique mais atténue, délibérément la force persuasive de ses paroles, puisque son message didactique ne passe pas à travers l'instruction mais à travers l'assimilation empathique du public avec le maître visionnaire.

\section{Bibliographie}

Adams (2016): Sean Adams, «Greek education and composite citations of Homer», in: Sean Adams and Seth M. Ehorn, (eds.), Composite citations in antiquity: Jewish, Graeco-Roman, and early Christian uses, London, Oxford, New York, 17-34.

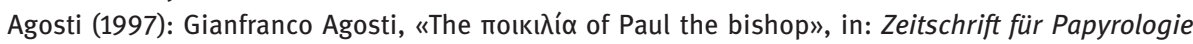
und Epigraphik, 116, 31-38.

Agosti (2002): Gianfranco Agosti, «l poemetti del Codice Bodmer et il loro ruolo nella storia della poesia tardoantica», in: André Hurst and Jean Rudhardt, (ed. eds.), Le codex des visions, Genève, $74-113$.

Agosti (2004-2005): Gianfranco Agosti, «Immagini e poesia nel la tarda antichità», in: Incontri triestini di filologia classica 4, 351-374.

Agosti (2006): Gianfranco Agosti, «La voce dei libri: dimensione performative dell'epica greca tardoantica», in: Eugenio Amato, (ed.), Approches de la Troisième Sophistique: hommages à Jacques Schamp, Bruxelles, 35-42.

Agosti (2009): Gianfranco Agosti, «Cristianizzazione della poesia greca e dialogo interculturale», in: Cristianesimo nella storia: richerche storiche, esegetiche, teologiche, 31, 311-335.

Agosti (2011a): Gianfranco Agosti, «Le brume di Omero. Sofronio dinanzi alla paideia classica», in: Lucio Cristante, (ed.), Il calamo della memoria: riuso di testi e mestiere letterario nella tarda antichità, IV, Trieste, 33-50.

Agosti (2011b): Gianfranco Agosti, «Usurper, imiter, communiquer: le dialogue interculturel in la poésie grecque chrétienne de l'Antiquité tardive», in: Nicole Belayche and Jean-Daniel Dubois, (eds.), L'oiseau et le poisson. Cohabitations religieuses dans les mondes grec et romain, Paris, 275-299.

99 I HC 71 contre la caractérisation de la prudente Vierge en I HC 259-263, la scène de l'Annon-

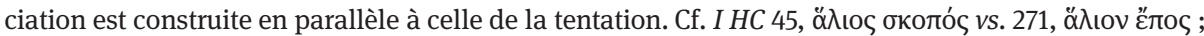

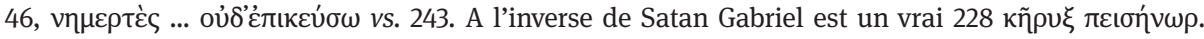

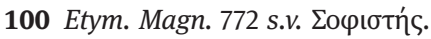


Agosti (2012a): Gianfranco Agosti, «Greek Poetry», in: Scott F. Johnson, (ed.), The Oxford Handbook of Late Antiquity, Oxford, 361-404.

Agosti (2012b): Gianfranco Agosti, «Versificare i riti pagani. Per uno studio del catalogo delle iniziazioni nel San Cipriano di Eudocia», in: /l calamo della memoria 5, 199-220.

Agosti (2015): Gianfranco Agosti, «Chanter les dieux dans la société chrétienne: les Hymnes de Proclus dans le contexte culturel et religieux de leur temps», in: Nicole Belayche and Vincianne Pirenne Delforge, (eds.), Fabriquer du divin. Constructions et ajustements de la représentation des dieux dans l'Antiquité, Liège, 183-212

Agosti (2016): Gianfranco Agosti, «Esiodo nella tarda antichità: prime prospezioni», in: Seminari Romani di cultura greca, 5, 179-246.

Bažil (2009): Martin Bažil, Centones christiani : métamorphoses d'une forme intertextuelle dans la poésie latine chrétienne de l'Antiquité tardive, Paris.

Bompaire (1958): Jacques Bompaire, Lucien écrivain. Imitation et création, Paris.

Buffière ( 20102): Felix Buffière, Les mythes d'Homère dans la pensée grecque, Paris.

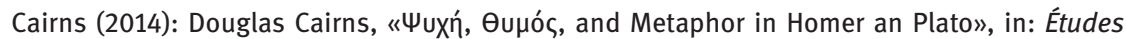
platoniciennes, 11, URL : http://etudesplatoniciennes.revues.org/566; DOI :

10.4000/etudesplatoniciennes.566

Cameron (2016): Alan Cameron, Wandering Poets and Other Essays on Late Greek Literature and Philosophy, Oxford.

de Jong (1987): Irene de Jong, Narrators and focalizers : the presentation of the story in the lliad, London.

de Jong (2001): Irene de Jong, A narratological commentary on the Odyssey, Cambridge.

de Lacy (1974): Philipp de Lacy, Plato and the intellectual life of the second century. Approaches to the Second Sophistic, Pennsylvania.

Deacy (2008): Susan Deacy, Athena, London, New York.

Delumeau (1995): Jean Delumeau, History of paradise: the Garden of Eden in myth and tradition, New York.

De Marco (2014): Tobyn C. De Marco, «The presentation and reception of Basilàs Homiliae in hexaemeron in Gregory's In hexaemeron», in: Zeitschrift für Antikes Christentum, 17, 2, $332-352$.

Dijkstra (2016): Roald Dijkstra, The Apostles in early Christian art and poetry, Leiden.

Droge (1989): Arthur J. Droge, Homer Or Moses? Early Christian interpretations of the History of Culture, Tübingen.

Effe (1977): Bernd Effe, Dichtung und Lehre: Untersuchungen zur Typologie des antiken Lehrgedicths, München.

Elm (2012): Suzanna Elm, Sons of Hellenism, Fathers of the Church: Emperor Julian, Gregory of Nazianzus, and the vision of Rome, Berkeley, LA.

Evans (1968): John Martin Evans, Paradise Lost and the Genesis tradition, Oxford.

Fauth (1981): Wolfgang Fauth, Eidos Poikilon. Zur Thematik der Metamorphose und zum Prinzip der Wandlung aus dem Gegensatz in den Dionysiaka des Nonnos von Panopolis (Hypomnemata 66), Göttingen.

Fowden (1993): Garth Fowden, Empire to commonwealth : consequences of monotheism in Late Antiquity, Princeton.

Fowler (2002): Don P. Fowler, «The didactic plot», in: Mathew Depew and Dirk Obbink, (eds.), Matrices of genre : authors, canons, and society, Cambridge, 205-219.

Friedländer (1912): Paul Friedländer, Johannes von Gaya et Paulus Silentiarius: Kunstbeschreibungen Justinianischer Zeit, Leipzig.

Fuhrmann (1977): Manfred Fuhrmann et Alain Cameron (eds.), Christianisme et formes littéraires de l'antiuité tardive en occident, Vandoeuvres Genève.

Gigli Piccardi (1990): Daria Gigli Piccardi, La Cosmogonia di Strasburgo, Firenze. 
Gordley (2011): Matthew Gordley, Teaching through song in Antiquity: didactic hymnody among Greeks, Romans, Jews, and Christians, Tübingen.

Green (2006): Roger Green, Latin Epics of the New Testament: Juvencus, Sedulius, Arator, Oxford. Grypeou - Spurling (2013): Emmanouela Grypeou et Helen Spurling, The Book of Genesis in late antiquity: encounters between Jewish and Christian exegesis, Leiden.

Hadjittofi et Lefteratou (2020): Fotini Hajittofi et Anna Lefteratou, (eds.), The genres of Christian poetry in Late Antiquity : between modulations and transpositions. Berlin.

Hardie (1985): Philip Hardie, «Imago mundi: cosmological and ideological aspects of the Shield of Achilles», in: Journal of Hellenic Studies, 105, 11-31.

Hardie (2016): Philip Hardie, «Reflections on Lucretius in Late Antiquity and early modern Biblical and scientific poetry: providence and the sublime», in: Jacques Lezra et Lizza Blake, (eds.), Lucretius and modernity: Epicurean encounters across time and disciplines, New York, $187-202$.

Holum (1987): Holum, Keenneth G. Theodosian empresses: women and imperial dominion in Late Antiquity. California LA.

Hunter (2014): Richard Hunter, Hesiodic voices. Studies in the ancient reception of Hesiod's Works and Days, Cambridge.

Innes (19932): Doreen C. Innes, «Augustan critics», in: George A. Kennedy, (ed.), The Cambridge history of literary criticism, vol. 1., Cambridge, 245-273.

James-Webb (1991): Liz James and Ruth Webb, «To understand ultimate things and enter secret places. Ekhrasis and art in Byzantium», in: Art History, 14, 1-17.

Jensen (2005): Robin Jensen, Face to face: portraits of the divine in early Christianity, Minneapolis. Johnson, (2006): Scott F. Johnson (ed.), Greek literature in Late Antiquity : Dynamism, didacticism, classicism, Hampshire.

Johnson (2016): Scott F. Johnson, Literary territories : geographical thinking in Late Antiquity, Oxford.

Kaldellis (2007): Anthony Kaldellis, Hellenism in Byzantium. The transformations of Greek identity and the reception of the classical tradition, Cambridge.

Kennedy (20142): E. J. Kennedy, Lucretius : De rerum natura, III, Cambridge.

Köckert (2009): Charlotte Köckert, Christliche Kosmologie und kaiserzeitliche Philosophie. Die Auslegung des Schöpfungsberichtes bei Origenes, Basilius und Gregor von Nyssa vor dem Hintergrund kaiserzeitlicher Timaeus Interpretation, Heidelberg.

Koning (2010): Hugo Koning, Hesiod : the other poet, Leiden.

Kühlmann (1973): Wilhelm Kühlmann, «Katalog und Erzählung. Studien zu Konstanz und Wandel einer literarischen Form in der Antiken Epik», PhD diss., Freiburg.

Kuhn (2014): Thomas Kuhn, Schweigen in Versen: Text, Übersetzung und Studien zu den Schweigegedichten Gregors von Nazianz, Berlin, New York.

Kuhn-Treichel (2016): Thomas Kuhn-Treichel, Die Alethia des Claudius Marius Victorius, Berlin, New York.

Kuhn-Treichel (2017): Thomas Kuhn-Treichel, «Involved narrating in Eudocia’s Homeric Centos», in: Medievalia et Humanistica, 43, 65-79.

Lamberton (1986): Robert Lamberton, Homer the theologian: neoplatonist allecorical reading and the growth of the epic tradition, Berkeley, LA.

Lausberg (1990): Heinrich Lausberg, Elemente der literarischen Rhetorik, Ismaning.

Lefteratou (2016): Anna Lefteratou, «Dionysus' catabasis to India : Christian echoes in Nonnus' Indiad», in: Ilinca Tanaseanu-Döbler, Anna Lefteratou, et. al. (eds.), Reading the way to the Netherworld. Education and the representation of the Beyond in later antiquity, Göttingen, $166-188$. 
Lefteratou (2017): Anna Lefteratou, «Late antique epiphanies : the Man Born Blind in Eudocia's Centos and Nonnus' Paraphrase», in: James Clauss, Ahuvia Kahane and Martine Cuypers, (eds.), The Gods in Greek Hexameter Poetry and Beyond, Leipzig, 274-293.

Maciver (2012): Calum A. Maciver, Quintus Smyrnaeus' Posthomerica: engaging Homer in late antiquity, Leiden.

Maciver (2017): Calum A. Maciver, «A Homeric afterlife in Quintus Smyrnaeus' Posthomerica?», in: Ilinca Tanaseanu-Döbler, Anna Lefteratou, et. al. (eds.), Reading the way to the Netherworld. Education and representations of the beyond in Later Antiquity, Göttingen.

Macrides and Magdalino (1988): Ruth Macrides and Paul Magdalino, "The architecture of ekphrasis: construction et context of Paul the Silentiary's poem on Hagia Sophia», in: BMGS, 12, 47-82.

Mette (1936): Hans Joachim Mette, Sphairopoiia : Untersuchungen zur Kosmologie des Krates von Pergamon, München.

Miguélez Cavero (2008): Laura Miguélez Cavero, Poems in context : Greek poetry in the Egyptian Thebaid 200-600 AD. Berlin, New York.

Moreschini-Sykes (1997): Claudio Moreschini, David A. Sykes et Leofranc Holford-Strevens, Poemata Arcana by St. Gregory of Nazianzus, Oxford.

Morisson (2007): Andrew D. Morisson, The narrator in Archaic Greek and Hellenistic poetry, Cambridge.

O'Meara (1982): Dominic J. O'Meara, Neoplatonism and Christian thought, New York.

Overduin (2015): Floris Overduin, Nicander of Colophon's Theriaca, Leiden.

Pépin (19762): Jean Pépin, Mythe et allégorie. Les origines grecques et les contestations judéo-crhétiens, Paris.

Pollmann (2017): Karla Pollmann, «Tradition and Innovation (orig. 2012)», in: Karla Pollmann, (ed.), The Baptized Muse : early Christian Poetry as cultural Authority, Oxford, 19-36.

Richardson (2010): Nicholas J. Richardson, Three Homeric Hymns: to Apollo, Hermes, and Aphrodite, Cambridge.

Rist (1985): John Rist, Platonism and Christian heritage, London.

Robbins (2012): Vernon K. Robbins, «Precreation Discource and the Nicene Creed Christianity finds its voice in the Roman Empire», in: Religion \& Theology, 18, 1-17.

Roberts (1989): Michael John Roberts, The jeweled Style: Poetry and Poetics in Late Antiquity, Ithaca.

Sandnes (2011): Karl Olav Sandnes, The Gospel according to Homer and Virgil : cento and canon, Leiden.

Schembra (2006): Rocco Schembra, La prima redazione dei centoni omerici: traduzione e commento, Alessandria.

Schembra (2007): Rocco Schembra, Homerocentones, CC SG 62, Turnhout.

Schottenius-Cullhed (2016a): Sigrid Schottenius-Cullhed, Proba the Prophet. The Christian Virgilian Cento of Faltonia Betitia Proba, Leiden.

Schottenius-Cullhed (2016b): Sigrid Schottenius-Cullhed, «Reading textual patchwork», dans : Henriette Harich-Schwarzbauer, (ed.), Weben und Gewebe in der Antike, Oxford.

Simelidis (2009): Christos Simelidis, Selected Poems of Gregory of Nazianzus: I.2.17; Il.1.10, 19.32. A critical edition with introduction and commentary (Hypomnemata 177), Göttingen.

Simmons (2015): Michael Bland Simmons, Universal Salvation in Late Antiquity, Oxford.

Spanoudakis (2014): Kostas Spanoudakis, «The shield of salvation: Dionysus' shield in Nonnus Dlonysiaca 25.380-527», in: Kostas Spanoudakis, (ed.), Nonnus of Panopolis in Context:

Poetry and Cultural Milieu in Late Antiquity, New York, 333-371.

Squire (2013): Michael Squire, «Ekphrasis at the forge and the forging of ekphrasis: The shield of Achilles in Graeco-Roman word and image», in: Word \& Image, 29, 2, 157-191. 
Stewart-Sykes (2001): Alistair Stewart-Sykes, From prophecy to preaching: a search for the origins of the Christian homily, Leiden.

Strauss Clay (2003): Jenny Strauss Clay, Hesiod's Cosmos, Cambridge.

Thraede (1962): Klaus Thraede, «Epos», Reallexikon für Antike und Christentum, 5, coll. 983-1042.

Tischendorf (1886): Constantin Tischendorf, Apocalypes Apocryphae Mosis, Esdrae, Pauli, Iohannis, Lipsia.

Tromp (2005): Johannes Tromp, The Life of Adam and Eve in Greek (Pseudepigrapha veteris testamentis graeca 6), Leiden.

Usher (1997): Mark Usher, «Prolegomenon to the Homeric Centos», in: American Journal of Philology, 118, 2, 305-321.

Usher (1998): Mark Usher, Homeric stitchings : the Homeric Centos of the Empress Eudocia, Lanham, MD.

Van den Berg (2014): Robert M. Van den Berg, «Proclus on Hesiod's Works and Days and didactic poetry», in: Classical Quarterly, 64, 383-397.

Van Deun (1993): Peter van Deun, 'The poetical writings of the Empress Eudocia: an evaluation', in: J. den Boeft and A. Hilhorst, Early Christian poetry: a collection of essays, 273-283, Leiden.

Van Noorden (2015): Helen van Noorden, Playing Hesiod: the Myth of the Races in classical Antiquity, Cambridge.

Verdenius (1970): Willem J. Verdenius, «Homer the educator of the Greeks», in: Mededelingen der Koninklijke Nederlandse Akademie van Wetenschappen, afd. Letterkunde. Nieuwe Reeks, 33, 5, 207-231.

Vergados-Strauss Clay (forthcoming): Athanasios Vergados et Jenny Strauss Clay, (eds.), Thinking in Images: Imagery in Greek and Roman Didactic Poetry, Leiden.

Vian (1980): Francis Vian, «L'épopée grecque», in: Actes du Xe congrès de l'Association Guillaume Budé, Paris 49-81.

Vian (1990): Francis Vian, Les Dionysiaques, Tome 9, Chants XXV - XXIX, Paris.

Volk (2002): Katharina Volk, The poetics of Latin Didactic : Lucretius, Vergil, Ovid, Manilius, Oxford.

Webb (2009): Ruth Webb, Ekphrasis, imagination and persuasion in ancient rhetorical theory and practice, Farnham.

Webster (1957): Thomas B. L. Webster, «Some Psychological Terms in Greek Tragedy», in: The Journal of Hellenic Studies, 77, 1, 149-154.

Wheeler (1995): Stephen Wheeler, «Imago mundi: another view of the creation in Ovid's Metamorphoses», in: American Journal of Philology, 116, 95-121.

Whitby (2014): Mary Whitby, «A learned spiritual ladder? Towards an interpretation of George of Pisidia's hexameter poem on human life», dans : Kostas Spanoudakis, (ed.), Nonnus in Context I, Berlin, 435-457.

Wilken (20032): Robert L. Wilken, The Christians as the Romans saw them, New Haven, London. 


\title{
Rachele Ricceri
}

\section{Two Metrical Rewritings of the Greek Psalms}

\author{
Pseudo-Apollinaris of Laodicea and Manuel Philes ${ }^{1}$
}

This paper aims to offer an insight into the reception of the Psalms, as poems, from the point of view of two Byzantine poetic rewritings of the biblical text. The first poem which is taken into account is an anonymous Metaphrasis Psalmorum in dactylic hexameters, dating to the $\mathrm{V}$ century, traditionally attributed to Apollinaris of Laodicea (IV century). The latter is a rewriting of the Psalms in political verses composed by Manuel Philes (XIII-XIV century). Both texts are underexplored and even partially unpublished. They were written at least 800 years apart but are both an attempt to adapt the Septuagint text to the cultural and literary taste of two different historical periods. A comparative reading of the two poems will shade some light on the Byzantine reception of the Greek Psalms and on the different motivations that led two poets to compose similar poems, resulting in different outcomes.

The starting point of this research is the observation that the Psalms were written in Hebrew as pieces of poetry. It has been calculated that roughly one third of the Hebrew Bible consists of poetry, ${ }^{2}$ being the books of Psalms, Proverbs, Song of Songs, Lamentations and Job the most prominent poetic biblical books. This poetic nature was not explicitly kept in the Greek translation, as the Septuagint text does not follow any recognizable metrical pattern. However, this poetic taste was still perceived by Christian readers, as for example is testified by Eusebius, who stated in the IV century that Psalm 118 was originally written in heroic metre, or hexameter:

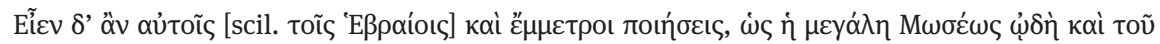

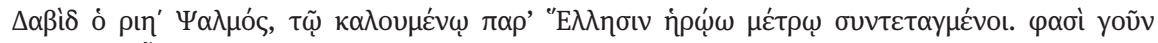

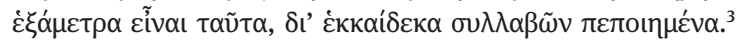

"There would also be found among them [the Hebrews] poems in meter, like the great Song of Moses and David's 118th Psalm, composed in what the Greeks call heroic meter. At least it is said that these are hexameters, consisting of sixteen syllables".

1 This contribution presents some preliminary results of a research which is being carried out within the framework of two research projects funded by the Flemish Research Foundation (FWO) and the Austrian Research Foundation (FWF): "The Legacy of the Psalms in Byzantine Poetry: Book Epigrams and Metrical Paraphrases”, supervisors: Kristoffel Demoen, Andreas Rhoby; “David, our Orpheus: Reception, Rewritings and Adaptations of the Psalms in Byzantine Poetry”, supervisors: Kristoffel Demoen, Reinhart Ceulemans. These projects aim to analyze how the poetic nature of the Psalms is reflected in various kinds of late antique and Byzantine poetry, especially metrical paratexts (book epigrams on the psalter) and metrical paraphrases.

2 Fokkelman (2001) 1.

3 Eusebius, Praep. Evang. XI.5.

https://doi.org/10.1515/9783110687224-016 
The composition of poetic paraphrases can be therefore explained as an attempt to fulfil this need of giving a new life to the biblical poetry. The analysis of the passages that will be proposed below aims at recognizing both the poetic features of the Greek Psalms and the strategies that the two paraphrasts put in use in order to enhance these characteristics by means of the chosen metre and language.

The present contribution falls into four parts. The first section has a methodological character and focuses on terminology as well. In the second part is presented an introduction to the two poems, which is followed in the third section by a selective comparison of the two works, in order to get to some conclusions on the literary and cultural meaning of these metaphraseis, namely in the fourth and last section of the paper.

\section{Methodology and terminology}

In late antique and medieval literature, the custom of rewriting several books of the Bible in metrical form was widespread to such an extent that is possible to identify a genre in itself, the so-called biblical epic. Metrical rewritings of biblical texts were produced both in Greek and in Latin. ${ }^{4}$ The most conspicuous examples (though not the only ones) of extant extensive biblical epos in Greek late antique literature are the Paraphrase of St. John's Gospel by Nonnus of Panopolis, the Homerocentones composed by the empress Eudocia and the Metaphrasis (which is by far the less studied among these three poems). ${ }^{5}$

The first step to introduce the comparative analysis proposed in this paper is a brief overview of the theoretical framework elaborated in scholarly literature to explain the trend of paraphrases in late antique and Byzantine culture, in order to figure out how this theory can relate to the two selected metrical rewritings.

The comprehensive study carried out by Michael Roberts remains pioneering to investigate the late antique paraphrases. In particular, he has inscribed the phenomenon of late antique literary rewritings in the broader concept of literary imitation, which can be furthermore articulated into abbreviation, transposition and amplification. ${ }^{6}$

In addition to the concept of imitation, the concept of appropriation is suitable to the study of paraphrases as well. Jeffrey Schnapp has applied this notion to the Latin

4 Besides the systematic study carried out by Roberts (1985), it is remarkable that Nazzaro (2006) 438- 439 has strongly pointed out that it is methodologically acceptable to speak of "Parafrasi biblica e agiografica” as a literary genre.

5 For a detailed overview of paraphrases belonging to late antique Greek literature, see Agosti (2001) passim.

6 Roberts (1985) 3. 
centos, ${ }^{7}$ and it can certainly be a valuable concept to read the late antique and Byzantine paraphrases as well. Paraphrases are in fact a form of appropriation of earlier texts, or even an extreme form of appropriation, by which the original texts are somehow replaced by a new one. The paraphrast imitates a source text, appropriates its content and focuses on how this content can be expressed in a more fruitful -or appealing- way to his readers.

This methodological introduction needs to be accompanied by a terminological discussion that relates to how these poems were labelled in their transmission, and especially to the difference between paraphrasis and metaphrasis. A reading of some relevant sources shows that the first definition of metaphrasis is to be found in the work of a ninth-century author, John of Sardis, who essentially proposed an equivalence between the two terms:

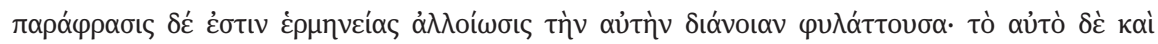

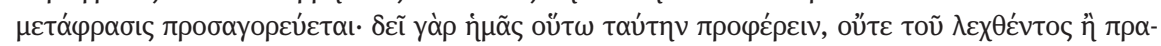

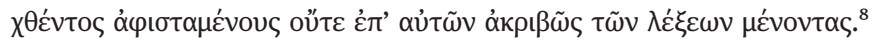

"Paraphrase is the alteration of expression preserving the same meaning; the same thing is also metaphrasis; for we must articulate the meaning in such a way, so that we neither depart from what was said or done, nor retain precisely the same words". ${ }^{9}$

A more articulated and complex explanation is expressed in a famous definition that many scholars quote as a standard reference, an interpolate passage by PseudoGeorge Choeroboscus (a ninth-century rhetor), who sets the difference between paraphrasis and metaphrasis in the number of words used by the compiler:

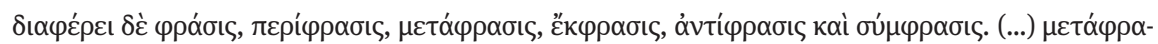

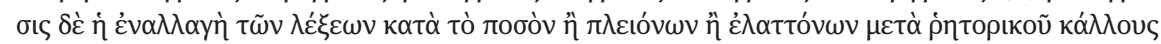

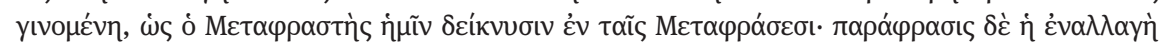

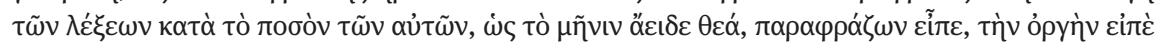
$\tilde{\omega}$ Moṽ $\alpha^{10}{ }^{10}$

"There is a distinction between phrasis, periphrasis, metaphrasis, ekphrasis, antiphrasis, and symphrasis. (...) metaphrasis is the alteration in diction in terms of quantity (using either more or fewer words) along with rhetorical beauty, as Metaphrastes shows us in his Metaphraseis; paraphrasis is alteration in diction but using the same number of words, such as in paraphrasing "Goddess, sing me the anger" someone said "Muse, tell me the rage"."11

7 Schnapp (1992) 100. He adopts the concept of détournement, as a process of "appropriating pre-existing artifacts and critically deflecting and historicizing their meanings without effacing them".

8 John of Sardis, Commentary on Aphthonios' Progymnasmata, 64.23-65.5.

9 Transl. Resh (2015) 757.

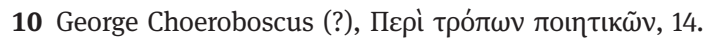

11 Transl. Resh (2015) 779. 
Juan Signes Codoñer has extensively studied the meaning of the words metaphrasis and paraphrasis in Byzantine sources ${ }^{12}$, coming to the interesting conclusion that, among many possible ways to perceive a rewriting, the shift to a new literary genre was mostly connected with metaphrasis rather than with paraphrasis.

The manuscript evidence, in addition, shows that Byzantine scribes used much more often the label metaphrasis than paraphrasis, so that the first word became in Byzantine literature a technical term to design rewritings of hagiographical texts. A metaphrastic process is normally connected, in the perceptions of Byzantines, with a stylistic improvement and higher linguistic choices. ${ }^{13}$ The manuscript tradition of the two poems that are the object of the present paper, in particular, confirms that the word metaphrasis is the designed term used by the scribes to indicate such rewritings. ${ }^{14}$

\section{Pseudo-Apollinaris of Laodicea and Manuel Philes: from Late Antiquity to Byzantium}

The first metaphrasis that we take into account, chronologically, is the anonymous one also known as the "Homeric Psalter" attributed by the manuscript tradition to Apollinaris of Laodicea. ${ }^{15}$ This poem totals more than 5300 hexameters and consists of a poetic translation of each of the Psalms, which are accompanied by one or more metrical titles. ${ }^{16}$ The metaphrasis is introduced by a prologue of 110 dactylic hexameters. ${ }^{17}$ This metrical preface is labelled as Protheoria and gives interesting information about the historical context in which the poem was possibly created as well as about the intellectual motivations that guided the paraphrast in the composition of the metaphrasis. ${ }^{18}$ The programmatic value of the Protheoria is particularly evident in a passage which testifies the poet's awareness of the poetic nature of the Psalms and justifies the composition of such a poem:

12 See Signes Codoñer (2014) 76-83.

13 See Demoen (2004) 172 and Resh (2015) 787.

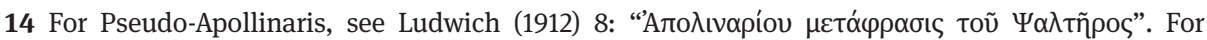
Philes, see Vaticanus graecus 952 (first half of the XV century), f. 34r: "Mavovì $\lambda$ тoṽ $\Phi \iota \lambda \tilde{\eta} \mu \varepsilon \tau \alpha \dot{\alpha} \varphi \rho \alpha \sigma ı \varsigma$

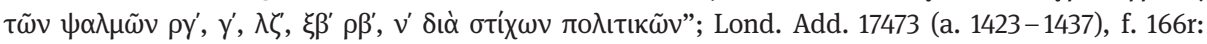

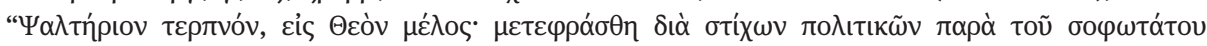

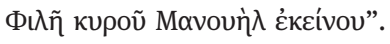

15 See Golega (1960) passim. The only complete available critical edition is the Teubner one by Ludwich (1912). Gonnelli (1987) published a commented edition of Ps 21. A new edition is currently in preparation by Andrew Faulkner.

16 See Gonnelli (1987) 127-128. On the paratextual material related to the Metaphrasis, see Ricceri (forthcoming).

17 Annotated translations of this prologue are to be found in Golega (1960) 25-43 and Ugenti (2005) $208-215$.

18 See Agosti (2001) 87-91 and Agosti (2009) 331. 


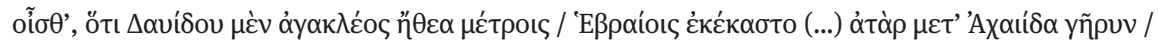

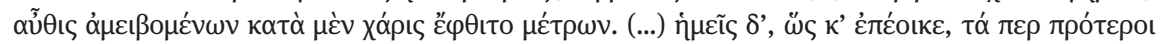

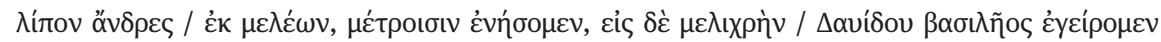

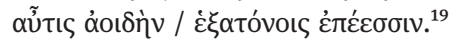

"You know, the glorious David's manners were adorned with Hebrew meters (...) but, once they were translated into Greek, the grace of meter was lost. (...) But, as it is convenient, we will put in verse the melodies that the men of former times left to us, and we reawaken again the sweet song of David the king in hexameters". ${ }^{20}$

After the flourishing of late antique poetic paraphrases, in middle and late Byzantine literature the trend of biblical paraphrases declined and, as a consequence, biblical epos was no longer as widespread as in Late Antiquity. However, a remarkable case of metrical metaphrasis of a biblical text in middle Byzantine literature is the Metaphrasis of the Odes in dodecasyllables written by John Geometres (dated to the second half of the $\mathrm{X}$ century). ${ }^{21}$ This poem shares a common manuscript tradition with the Pseudo-Apollinaris' Metaphrasis, as the Odes follow the Psalms in the actual biblical transmission. ${ }^{22}$ Possibly, John Geometres is also the author of a metrical rewriting of the Life of St. Panteleemon, which is one of the few examples of Byzantine metrical hagiography. ${ }^{23}$ Besides this Life written by Geometres, a number of metrical prefaces to hagiographical texts are preserved, and there is evidence that they were meant to be performed orally. ${ }^{24}$

While metrical paraphrases were not widespread, in middle and late Byzantine religious literature the rewriting of hagiographical texts was a common practice, starting from the most famous and productive rewriter, the tenth-century compilator Symeon Metaphrastes, who promoted a comprehensive rewriting of the menologion. ${ }^{25}$ In the massive corpus of hagiographical texts to be found in Byzantine literature, however, metrical works seem to be "a matter of individual and unsystematic efforts, which, as a result, convey an impression of fragmentation”. ${ }^{26}$

19 Pseuso-Apollinaris of Laodicea, Metaphrasis Psalmorum, Protheoria, 15-16, 18-19, 29 - 32.

20 Translation by the author.

21 John Geometres' paraphrase of the Odes has been edited by De Groote (2004) passim. It is also noteworthy that a paraphrase of this metaphrasis (written in dodecasyllables as well, also published by De Groote (2002-2003) passim) was composed at a later stage and is preserved in a sixteenth-century manuscript.

22 De Groote (2004) 378.

23 See Demoen (2004) passim.

24 See Antonopoulou (2010) passim.

25 For a systematic study of this important figure and relevant bibliography, see Høgel (2002) passim.

26 See Efthymiadis (2014) 172. Antonopoulou (2017) has recently published a poetic corpus attributed to Merkourios the Grammarian (to be dated to the early Palaeologan period), which includes two hagiographical poems that are in fact paraphrases of the respective standard texts by Symeon Metaphrastes, and represent therefore the result of an interesting process of double rewriting. 
The second metaphrasis that we examine is, therefore, quite exceptional in its time as a versified rewriting. It is attributed to one of the most prominent poets of the Palaeologan period, Manuel Philes. We do not know much of his life, besides some elements that we can infer from his own poems and this central literary figure has only recently begun to receive scholarly attention. ${ }^{27}$ He lived between the last quarter of the XIII century and the first half of the XIV century and served as a court poet. Under his name a conspicuous poetic corpus (about 30000 lines) is transmitted, whereas there is very little evidence of prose production written by him. ${ }^{28} \mathrm{He}$ was mostly active as a poet on commission and his works encompass several poetic genres, which include encomiastic poems, didactic poems, epigrams on various topics, religious poems, verse letters, as well as a number of metaphraseis. ${ }^{29}$ The vast majority of his poems are written either in dodecasyllable, which was by all means the most common metrical form for Byzantine epigrams, being the rest composed in political verse. ${ }^{30}$

The Metaphrasis of the Psalms by Manuel Philes is a long poem of more than 3600 lines. Its accessibility is still affected by the lack of a full edition, as the only editor of this metaphrasis, Stickler only provides the text of a relatively small group of Psalms and some 3000 lines are still unpublished..$^{31}$ The manuscript tradition of this rewriting is not ample, as the most extensive version of the text is transmitted only in the Vaticanus graecus 16, dating to the XIV century, whereas more limited selection of metaphrastic Psalms are preserved in six more manuscripts. ${ }^{32}$ Some of the Psalms are translated into political verse in two different versions, independent but both to be attributed to the same author. ${ }^{33}$

Unlike the Pseudo-Apollinaris' Metaphrasis, Philes' work is not accompanied by any programmatic prologue that gives a clue about the scope of the work. Philes was very likely to be willing to convert the biblical text into a poem which could indulge

27 A detailed description of his life and works is to be found in Stickler (1992) 10 - 36. Bazzani (2013) has recently drawn attention to the literary qualities and the intellectual meaning of Philes' compositions, which, as she remarks, still deserve a deeper investigation. See Rhoby (2019) 276-284 for a general overview of Philes'abundabt production.

28 The largest edition of Philes' poems is the one by Miller (1855-1857). On the Theoria, the only extant work in prose composed by Philes, see Stickler (1992) 27. I am grateful to Anna Gioffreda for drawing my attention to this work.

29 A list of manuscripts which transmit metaphraseis of liturgical texts under Philes' name is provided by Kotzabassi (1995) passim.

30 On the origin and features of this important Byzantine metrical scheme, see Jeffreys (1974) passim.

31 Ps. 3; 5; 32 (A-B); 37; 46 (A-B); 47 (A-B); 50; 62; 102; 103 (A-B). A new comprehensive edition of the Metaphrasis of the Psalms by Philes is foreseen in the context of a research project that is being carried out by Anna Gioffreda at the Austrian Academy of Sciences, Vienna (see supra, n. 1).

32 Provisional list drawn from Stickler (1992) 169 and from the Pinakes database (http://pinakes.irht. cnrs.fr/notices/oeuvre/11815/ last accessed 10/02/2020).

33 See Stickler (1992) 126. Philes adopts the same techniques of double composition also in his epigrammatic poetry (Stickler (1992) 127). 
the contemporary literary taste. It seems reasonable to suppose a didactic purpose for such a rewriting. In Byzantine poetry, moreover, the use of the political verse was strongly connected over the centuries with a didactic intention, as, for instance, is shown by the choice of Michael Psellos, who already in the XI century used the decapentasyllable for his didactic poems. ${ }^{34}$

\section{Features and adaptation techniques of the two paraphrases}

A comparative analysis of the two paraphrases can shed light on the appreciation of the Psalms in two different historical contexts. These two texts, whose investigation still lacks some philological work, share remarkable affinities, as they are both versified rewritings of the same literary source and they are both faithful to the original text (although, of course, we cannot have a clear view of the exact text the two authors used as their hypotext).

The chronological boundaries seem to play a little role, if two different paraphrases of the same texts were written in very different periods, given the immense popularity of the Psalms. However, some major dissimilarities cannot be overlooked.

First, the metre that is used by the two metaphrasts is different, the former using the dactylic hexameter, the latter versifying the Psalms in political verse. This obvious discrepancy is worth to be mentioned because it points to the cultural context which the two metaphraseis were produced and underlines a fundamental difference of scope of the two poems. The dactylic hexameter is a recognizable mark of the most refined late antique Christian poetry and it immediately recalls the classical tradition. Manuel Philes, conversely, did not attempt to classicize his metaphrasis. He used the decapentasyllable, which is one of the two typical Byzantine metres together with the dodecasyllable, and adapted the biblical text to the perception of his own time.

The most striking literary feature of the late antique metaphrasis is the pervasive use of Homeric language. Actually, this poem has often been criticized as only scarce traces of interpretation or originality might be found..$^{35}$ Although this severe judgement should be mitigated ${ }^{36}$. The, a modern reader can be disappointed indeed, but in the eye of a late antique paraphrast (and of his addressees) the adherence both to the biblical text and to the Homeric style was probably a sign of a successful

34 Significantly, Psellos' Poem 1 De inscriptionibus Psalmorum (Westerink (1992) 1-13) is also written in decapentasyllables, as well as the two pseudo-Psellian poems 53 Introductio in Psalmos (Westerink (1992) 302-327) and 54 Commentatius in Psalmos (Westerink (1992) 327-390).

35 See Gonnelli 1987 (54). On the ad verbum technique used by Pseudo-Apollinaris, see also Agosti/ Gonnelli (1995) 364 and Faulkner (2014) 205.

36 For an analysis of the aesthetic and exegetical merits of the Metaphrasis, see Faulkner (2019) 216 218. 
rewriting. The words of the Protheoria were fulfilled: the grace of the Hebrew poetry (v. 19: xópıs $\mu \varepsilon \tau^{\prime} \rho \omega \nu$ ) was restored thanks to the epic language and metre. Manuel Philes was generally less concerned with the update of the vocabulary: he often stuck to the biblical lexicon, so that we get the impression that his metaphrasis is even more literal than the late antique one.

When approaching metaphrastic texts, we should bear in mind that a metaphrasis is either an elaboration or a simplification of the hypotext ${ }^{37}$. The translational techniques of the two compilers can be investigated in the light of the triad connected to the literary theory of imitation, abbreviation, transposition and amplification. ${ }^{38}$ The first of the three concepts, namely abbreviation, is generally not relevant to the two metaphraseis, as the rewriters tended not to skip any biblical word. Both poets use the amplification as a mean to fit the chosen metre, although in different ways. Pseudo-Apollinaris introduced Homeric expressions (or, more generally, poetic words) in his verses, whereas Philes relied on the typically Byzantine habit to include glossae and comments in the text and used synonyms next to the biblical words, both to fill the metrical structure and to insert new words that point to an interpretative activity of the poet.

All in all, one can cautiously state that the late antique metaphrasis is closer to what Høgel, speaking of Symeon Metaphrastes and using Jakobson's terminology, calls an "intra-lingual translation", as the new text keeps the content of the source one but is completely reshaped. ${ }^{39}$ Manuel Philes, on the contrary, operated a metaphrastic process by means of systematic transpositions, as parts of the speech change their sequence for metrical reasons, as well as for exegetical purposes.

A close reading of a few brief passages taken from the Psalms, along with their two metrical rewritings, is helpful to detect some of the poetic strategies put in use by the two paraphrasts. Even if they chose a different style and used a partially different translational technique, they both perceived and appreciated the intrinsic poetic nature of the Psalms.

\footnotetext{
Ps. 32, 1-2

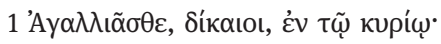

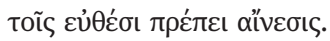

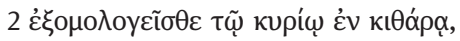

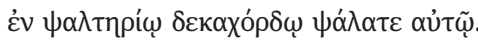

37 See Hinterberger (2014) 34.

38 See supra, 224-226.

39 See Høgel (2014) 182; Faulkner (2014) 196. 
"Rejoice in the Lord, O you righteous;

Praise befits the upright.

Acknowledge the Lord with a lyre;

With a harp of ten strings make music to him". ${ }^{40}$

Pseudo-Apollinaris, Ps. 32.1-4

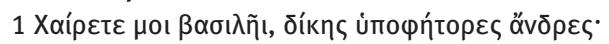

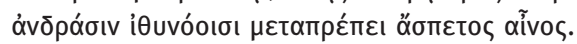

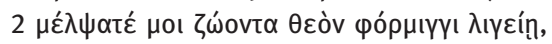

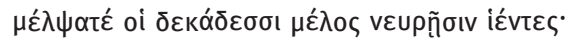

Manuel Philes, Ps. 32 version A.1-4

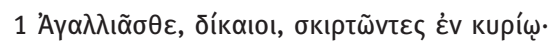

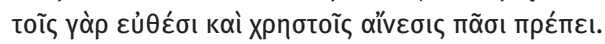

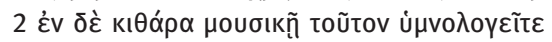

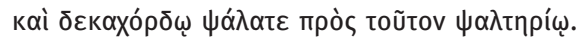

In this passage it is evident that both Pseudo-Apollinaris and Philes composed one line of poetry per each stichos of the Bible. Going deeper into each of the two versions, one may also notice that Pseudo-Apollinaris marked each verse with Homeric

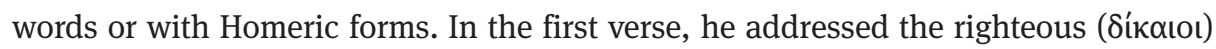

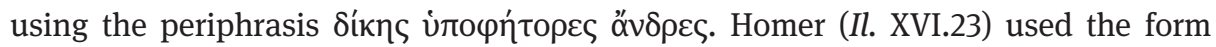

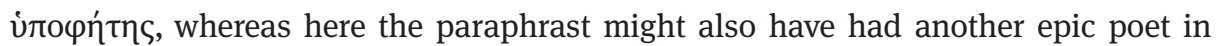
mind, Apollonius Rhodius, who at the beginning of his epic poem used the same

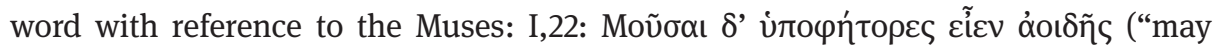

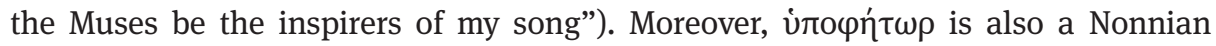

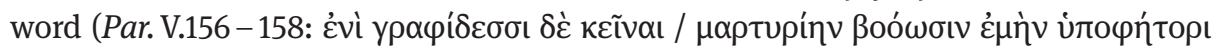

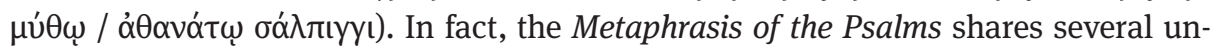
usual terms with Nonnus' works, and this argument has also been used as a proof that the Homeric Psalter must be dated to the V century. ${ }^{41}$ The compiler of the late antique Metaphrasis heavily drew from a Homer-inspired language, but he could also rely on a multifaceted poetic language that encompassed a variety of classical sources. ${ }^{42}$

The close of the following verse also has a clear Homeric inspiration: Il. IX.186

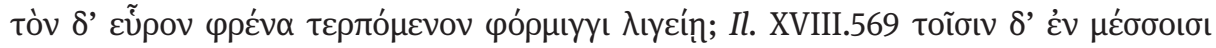

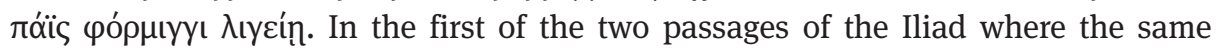
words occur, the expression "with a clear-toned lyre" refers to Achilles who is playing the lyre. Interestingly enough, the addressees are depicted as a new Achilles, or, in other words, there is a Christianization of the model. ${ }^{43}$

Reading Philes' adaptation of the same passage, one immediately notices that every line of poetry reproduces the words of the Septuagint (and the same holds generally true for the whole poem). The parallel reading of Philes' verses and their

40 Transl. Pietersma (2000) 562.

41 On the chronological relationship between Nonnus and the author of the Homeric Psalter, see De Stefani (2008) 5.

42 A survey of the poetic inspiration provided by Callimachus to our anonymous paraphrast is offered in Gonnelli (1988) passim.

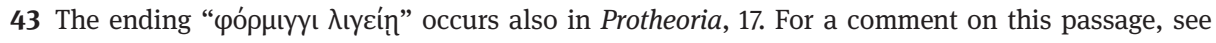
Ugenti (2007) 212. 
source text results in a nearly perfect coincidence, as for the vocabulary. In this passage, the political verse seems to be the main poetic mark of his paraphrase.

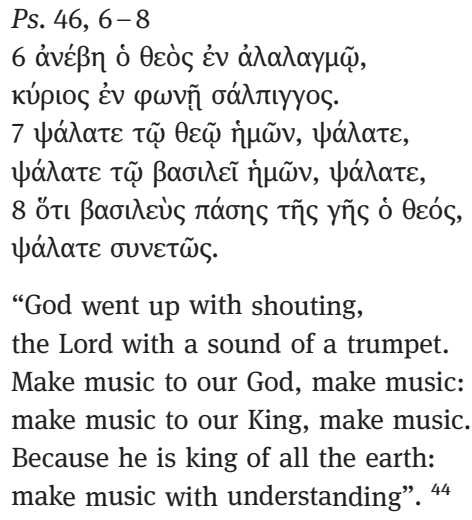

Pseudo-Apollinaris, Ps. 46.8-14

Manuel Philes, Ps. 46 version A.8-11

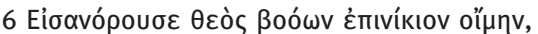

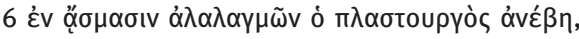

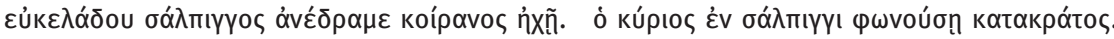

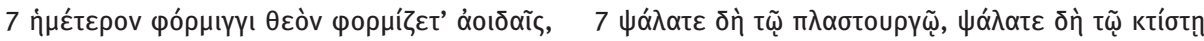

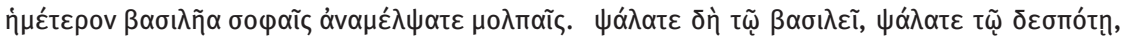

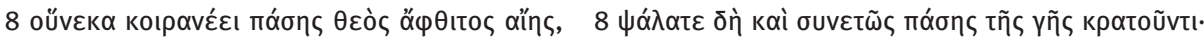

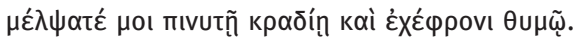

It is striking how in verse 7 of the Septuagint the beginning and the ending of the two

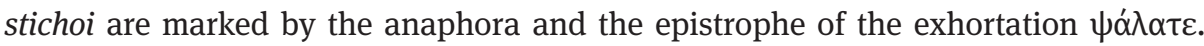
The two rewriters dealt with this poetic feature in a different way.

Pseudo-Apollinaris employed an unmistakable Homeric style. He substituted the

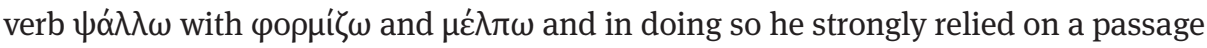
of the Odyssey:

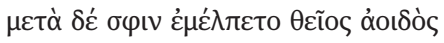

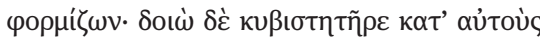

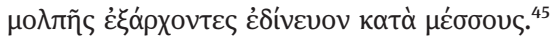

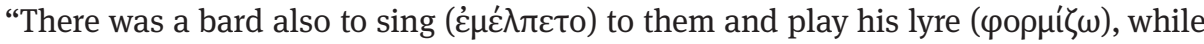

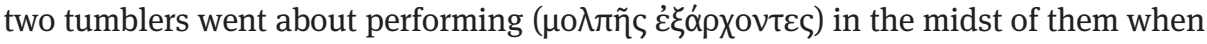
the man struck up with his tune". ${ }^{46}$

It is interesting to notice how the late antique metaphrast recognized the poetic character of the biblical pericope and kept it by using a different poetic model, which he drew from a non-Christian source.

44 Transl. Pietersma (2000) 570.

45 Hom. Od. IV.17-19.

46 Transl. S. Butler. 
Manuel Philes, as already pointed out, used also in this passage an ad verbum technique and was faithful to the structure of verse 7 of the Psalm. His rewriting of the passage recalls indeed the repetition of $\psi \alpha \dot{\alpha} \lambda \alpha \tau \varepsilon$ and each of the two political verses is articulated in two cola each, as the poet recurred to the synonymic ampli-

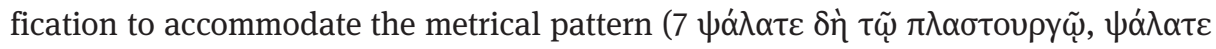

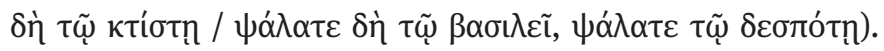

Ps. 102, 20-22

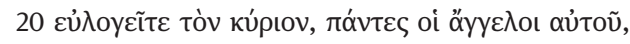

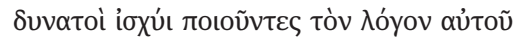

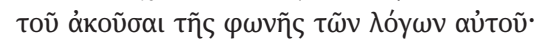

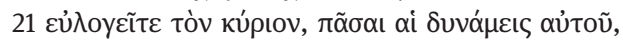

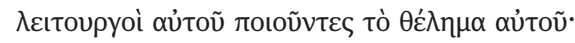

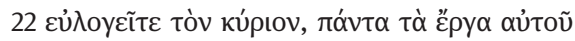

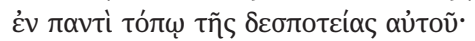

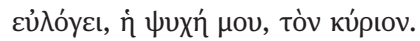

"Bless the Lord, O all you, his angels, powerful in strength doing his bidding, to obey the voice of his words.

Bless the Lord, $\mathrm{O}$ all his hosts, his ministers doing his will. Bless the Lord, all his works in every place of his dominion. Bless the Lord, O my soul". ${ }^{47}$

\section{Pseudo-Apollinaris, Ps. 102.38-44}

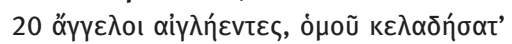

öv $\alpha \kappa \tau \alpha$,

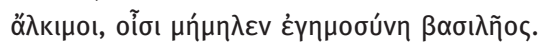

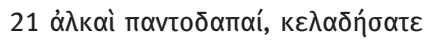

$\pi \alpha \mu \beta \alpha \sigma \iota \lambda \tilde{\eta} \alpha$,

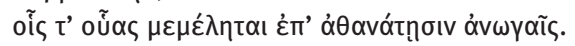

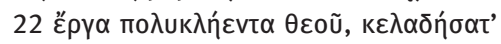

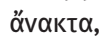

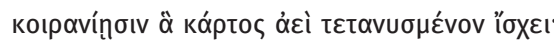

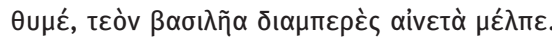

\author{
Manuel Philes, Ps. 102.36-43

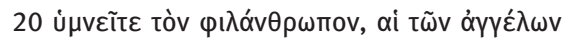

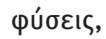

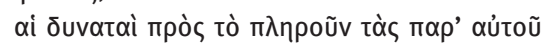

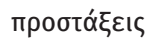

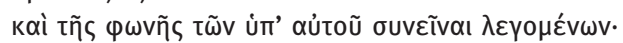

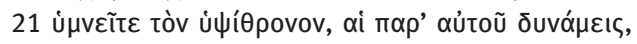

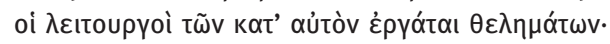

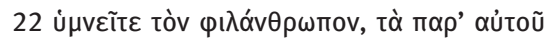

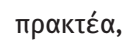

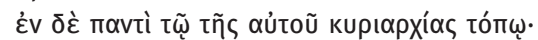

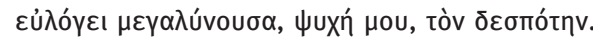

This passage is the conclusion of Psalm 102. Just as in the previous example, the text of the Septuagint has in these verses a harmonious and well-balanced structure,

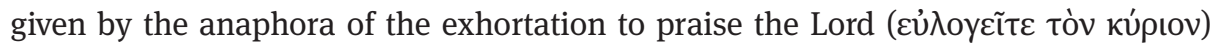
at the beginning of verse 20, 21 and 22 and by the reference to God by means of

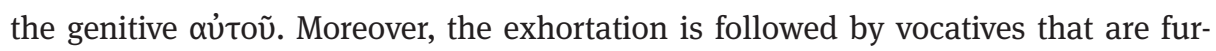
ther specified in the following stichoi.

47 Transl. Pietersma (2000) 598. 
Pseudo-Apollinaris inverted the order of the verbs and the vocatives, which open the verses in his version. Conversely, Manuel Philes kept the same order of a verb followed by a vocative. The repetitiveness of the $\alpha$ ư ov of the biblical text is here replaced by a series of hyperbatons in each line ${ }^{48}$.

In this case both the rewriters perceived the poetic nature of the model and challenged the source text achieving two different results, and giving life to an interesting form of creative appropriation of the biblical text.

\section{Conclusions}

The analysis of some of the literary features of the two metaphraseis of the Psalms has highlighted interesting similarities as well as some fundamental differences and has shed light on the reception of the Septuagint text in different periods. Both Pseudo-Apollinaris and Manuel Philes clearly aimed at providing their readers with a faithful rewriting of the biblical text. Their metaphraseis do not completely lack any exegetical intent but their texts are not primarily focused on interpretation and explanation of the Psalms. ${ }^{49}$

On the one hand, the hexametric metaphrasis conveys some typical elements of late antique Christian poetry. The rewriter felt that something (i.e. the poetic nature of the Psalms) was lost and he wanted to restore it. His work contributed to the establishment of a highbrow poetry with Christian content, which could benefit from the use of the Homeric metre and the Homeric language. The late antique metaphrasis possibly played a role in the process that led to the creation of a Christian literary tradition and was pursued by means of a twofold appropriation: of Homer (and in general of the pagan culture) and of the Bible.

On the other hand, Manuel Philes' Metaphrasis of the Psalms is situated in Late Byzantine literature and is grounded in a well-established, thousand-year old tradition of Christian poetry. Psalmody (that is the recitation of the Psalms) was part of the daily life of all Byzantines. Philes did not feel the need to radically alter the biblical vocabulary, but he was mainly concerned with the stylistic alteration of his source text in order to fit the chosen metrical pattern. It has been calculated that in the Palaeologan period around $80 \%$ of hagiographical texts were the fruit of a metaphrastic rewriting. ${ }^{50}$ Manuel Philes' metaphrastic effort tied in with this tenden-

48 The introduction of hyperbatons is a recurrent feature in metaphrastic rewritings (see Hinterberger (2014) 46)

49 It is certainly convenient to use the reference to exegesis with some caution and to remember what Faulkner has stated talking about Nonnus and the author of the Metaphrasis: "[they] interpret their source texts in ways that effectively refine the aesthetics and emphasis of their versions, whether or not theological exegesis is at play" (Faulkner (2014) 197).

50 See Talbot (1991) 16-17. 
cy and added a rather unusual tile to the variegated mosaic of Byzantine prose metaphrasis.

\section{Bibliography}

Agosti/Gonnelli (1995): Gianfranco Agosti and Fabrizio Gonnelli, "Materiali per la storia dell'esametro nei poeti cristiani greci", in: Marco Fantuzzi and Roberto Pretagostini (eds.), Struttura e storia dell'esametro greco. (Vol. 1), Rome, 289-434.

Agosti (2001): Gianfranco Agosti, “L'epica biblica nella tarda antichità greca. Autori e lettori nel IV e V secolo", in: Francesco Stella (ed.), La scrittura infinita. Bibbia e poesia età medioevale e umanistica, Firenze, 67-104.

Agosti (2009): Gianfranco Agosti, “Cristianizzazione della poesia greca e dialogo interculturale”, in: Cristianesimo nella storia 31, 313-335.

Antonopoulou (2010): Theodora Antonopoulou, "On the reception of homilies and hagiography in Byzantium. The recited metrical prefaces", in: Andreas Rhoby and Elisabeth Schiffer (eds.), Imitatio-Aemulatio-Variatio. Akten des internationalen wissenschaftlichen Symposions zur byzantinischen Sprache und Literatur, Vienna, 57-79.

Antonopoulou (2017): Theodora Antonopoulou, Mercurii Grammatici opera iambica (Corpus Christianorum, Series Graeca, 87), Turnhout.

Bazzani (2013): Marina Bazzani, “Livelli di stile e significato nella poesia di Manuele File”, in: Antonio Rigo, Andrea Babuin and Michele Trizio (eds.), Vie per Bisanzio: VII Congresso nazionale dell'Associazione italiana di studi bizantini, Venezia, 25-28 novembre 2009. (Vol. 1-2), Bari, 145-155.

De Groote (2002-2003): Marc De Groote, “The Paraphrasis of Joannes Geometres' Metaphrasis of the Odes", in: Greek, Roman and Byzantine Studies 43, 267-304.

De Groote (2004): Marc De Groote, “Joannes Geometres' Metaphrasis of the Odes: Critical Edition", in: Greek, Roman and Byzantine Studies 44, 375-410.

Demoen (2004): Kristoffel Demoen, “John Geometres’ lambic Life of Saint Panteleemon. Text, Genre and Metaphrastic Style”, in: Bart Jassens, Bram Roosen and Peter Van Deun (eds.), Philomathestatos. Studies in Greek and Byzantine Texts Presented to Jacques Noret for his Sixty-Fifth Birthday, Leuven-Paris-Dudley, 165-184.

De Stefani (2008): Claudio De Stefani, “La Parafrasi di Giovanni di Nonno e la Metafrasi dei Salmi dello Pseudo-Apollinare: un problema di cronologia”, in: Sergio Audano (ed.), Nonno e i suoi lettori, Alessandria, 1-16.

Efthymiadis (2014): Stephanos Efthymiadis, “Greek Byzantine Hagiography in Verse”, in: Stephanos Efthymiadis (ed.), The Ashgate Research Companion to Byzantine Hagiography. Volume II: Genres and Contexts, Farnham, 161-179.

Faulkner (2014): Andrew Faulkner, "Faith and Fidelity in Biblical Epic. The Metaphrasis Psalmorum, Nonnus, and the Theory of Translation", in: Konstantinos Spanoudakis (ed.), Nonnus of Panopolis in Context. Göttingen, 195-210.

Faulkner (2019): Andrew Faulkner, "Paraphrase and Metaphrase", in The Oxford Handbook of Early Christian Biblical Interpretation, Oxford, 210-220.

Fokkelman (2001): Jan P. Fokkelman, Reading Biblical Poetry. An Introductory Guide, Louisville. Golega (1960): Joseph Golega, Der homerische Psalter: Studien über die dem Apolinarios von Laodikeia zugeschriebene Psalmenparaphrase, Ettal.

Gonnelli (1987): Fabrizio Gonnelli, “Il Salterio esametrico. I-II”, in: Koinonia 13, 51-60; 127-151.

Gonnelli (1988): Fabrizio Gonnelli, “Parole 'callimachee’ nella parafrasi del Salterio”, in: Studi Italiani di Filologia Classica 81, 91-104. 
Hinterberger (2014): Martin Hinterberger, "Between Simplification and Elaboration: Byzantine Metaphraseis Compared", in Juan Signes Codoñer and Inmaculada Pérez Martín (eds.), Textual Transmission in Byzantium: between Textual Criticism and Quellenforschung, Turnhout, 33-60.

Høgel (2002): Christian Høgel, Symeon Metaphrastes. Rewriting and Canonization, Copenhagen. Høgel (2014): Christian Høgel, "Symeon Metaphrastes and the Metaphrastic movement", in: Stephanos Efthymiadis (ed.), The Ashgate Research Companion to Byzantine Hagiography. Volume II: Genres and Contexts, Farnham, 181-196.

Jeffreys (1974): Michael J. Jeffreys, "The Nature and Origins of the Political Verse", in: Dumbarton Oaks Papers 28, 141-195.

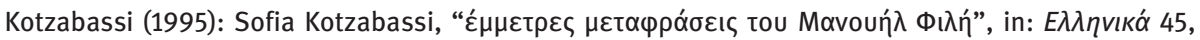
$359-362$.

Ludwich (1912): Arthur Ludwich (ed.), Apolinarii Metaphrasis Psalmorum, Leipzig.

Miller (1855-1857): Emanuel Miller, Manuelis Philae carmina, Paris.

Nazzaro (2006): Antonio Nazzaro, "Riscritture metriche di testi biblici e agiografici: in cerca del genere negato" in: Auctores Nostri 4, 397-439.

Pietersma (2000): Albert Pietersma, A New English Translation of the Septuagint: The Psalms, New York.

Resh (2015): Daria D. Resh, “Toward a Byzantine Definition of Metaphrasis”, in: Greek, Roman and Byzantine Studies 55, 754-787.

Rhoby (2019): Andreas Rhoby, "Poetry on Commission in Late Byzantium (13th-15th Century)", in Wolfram Hörandner, Andreas Rhoby and Nikolaos Zagklas, A Companion to Byzantine Poetry, Leiden-Boston, 264-304.

Ricceri (forthcoming): Rachele Ricceri "The Byzantine Reception of the Metaphrasis Psalmorum: Paratextuality and Visual Representation”, in: Reinhart Ceulemans and Barbara Crostini (eds.), Receptions of the Bible in Byzantium: Texts, Manuscripts, and their Readers, Uppsala.

Roberts (1985): Michael Roberts, Biblical Epic and Rhetorical Paraphrase in Late Antiquity, Liverpool.

Schnapp (1992): Jacques Schnapp, “Reading Lessons: Augustine, Proba and the Christian Détournement of Antiquity", in: Stanford Literature Review 9 (2), 99-123.

Signes Codoñer (2014): Juan Signes Codoñer, "Towards a Vocabulary for Rewriting in Byzantium", in Juan Signes Codoñer and Inmaculada Pérez Martín (eds.), Textual Transmission in Byzantium: between Textual Criticism and Quellenforschung, Turnhout, 61-90.

Stickler (1992): Günter Stickler, Manuel Philes und seine Psalmenmetaphrase, Wien.

Talbot (1991): Alice-Mary Talbot, "Old Wine in New Bottles: the Rewriting of Saints' Lives in the Palaeologon Period", in: Doula Mouriki and Slobodan Ćurčić (eds.), The Twilight of Byzantium: Aspects of Cultural and Religious History in the Late Byzantine Empire. Papers from the Colloquium Held at Princeton University 8-9 May 1989, Princeton, 15-26.

Ugenti (2005): Marco Ugenti, "La Protheoria della Metafrasi dei Salmi: traduzione e note di commento", in: Auctores Nostri 2, 205-218.

Ugenti (2007): Marco Ugenti, "Intertestualità classica e cristiana nella Protheoria della Metafrasi dei Salmi tràdita sotto il nome di Apollinare di Laodicea", in: Rudiae: ricerche sul mondo classico 19, 205-222.

Westerink (1992): Leendert G. Westerink (ed.), Michaelis Pselli. Poemata, Stuttgart-Leipzig. 
Jesús F. Polo

\section{Descent and Ascent in the 8th Hymn of Synesius of Cirene*}

\section{Introduction}

When the lyric poet Anacreon ( $6^{\text {th }}$ century BC) wrote a poem on the end of life, he had death and the journey to the place where the dead go in mind. This poem is reproduced below in text (1). Let us read it:

(1) Anacreon ${ }^{1}$

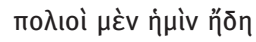

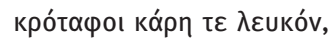

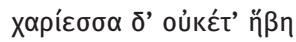

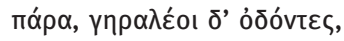

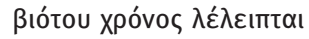

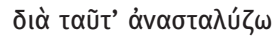

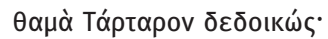

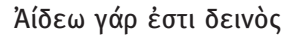

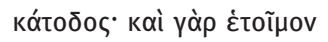

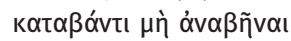

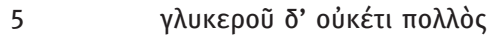

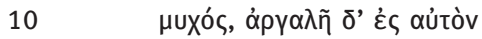

\author{
"My temples are ready grey; \\ and my head is white, \\ graceful youth is no more \\ with me, my theeth are old, \\ and no long span of sweet \\ life remains now. \\ And so I often weep \\ in fear of Tartarus: \\ for the recess of Hades is grim, \\ and the road \\ down to it grievous; and it is certain that he who \\ goes down not come up again
}

Many centuries later, Synesius of Cirene (370 - 413 AD) wrote his so-called $8^{\text {th }}$ Hymn, in which he presents a man who descends into the Tartarus and, after releasing the spirits of dead people, ascends out of there. ${ }^{2}$ The poem continues with the ascent, supposedly of that same man, to the upper places of kosmos. This man was the yóvoৎ $\pi \alpha \rho \theta \varepsilon ́ v o v$, the son of the Virgin, Jesus.

\footnotetext{
* This paper has been possible thanks to the financial aid delivered by the "Oficina de Investigación y Relaciones Internacionales" of the Universidad San Dámaso. I express my gratitude to Carmen Pulin, who helped me to make my English more understandable.

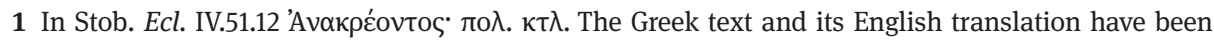
taken from the edition of Campbell (1988) 78-81, poem 395.

2 According to von Wilamowitz-Moellendorff (1907) 277-78 Synesius had quite probably read the poems of Anacreon. Garzya (1989) 793 points out certain influences of Anacreon 34, 1-3 (West) in Synes. Hymn. 9. Therefore, it is not impossible that Synesius had read Anacreon's poem presented in (1).
} 
Scriptural support for Jesus' visit to the place where dead people go can be found in the First Letter of Peter, (see texts (2) and (3) $)^{3}$.

(2)

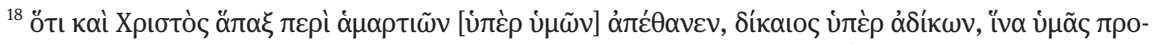

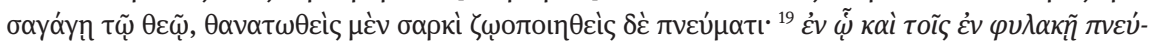

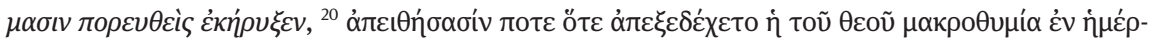

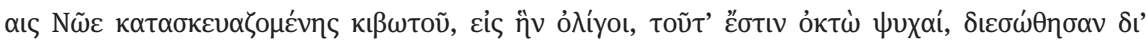

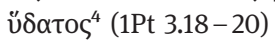

"18 Because Christ once went through pain for sins, the upright one taking the place of sinners, so that through him we might come back to God; being put to death in the flesh, but given life in the Spirit; ${ }^{19}$ By whom he went to the spirits in prison, preaching to those who, ${ }^{20}$ in the days of Noah, went against God's orders; but God in his mercy kept back the punishment, while Noah got ready the ark, in which a small number, that is to say eight persons, got salvation through water". ${ }^{5}$

(3)

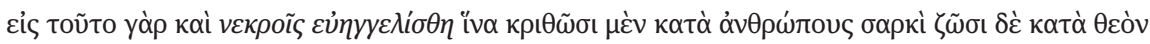
$\pi v \varepsilon \dot{\mu} \mu \alpha \tau \iota$ (1Pt 4.6)

"For this was the reason why the good news of Jesus was given even to the dead, so that they might be judged as men in the flesh but might be living before God in the spirit".

In text (2), Peter says that Jesus died in the flesh, was given life in the Spirit, and, in this Spirit, he went ( $\pi о \rho \varepsilon v \theta \varepsilon i ́)$ ) to the spirits in prison and preached to those who in ancient times were against God, whom Peter calls spirits ( $\pi v \varepsilon v \dot{\mu} \mu \sigma \iota v)$. The purpose of this journey and preaching is that men come back to God. In text (3), Peter talks about the preaching to the dead, who are called now veкрог̃ ${ }^{6}$

But the poem of Synesius is not a mere paraphrasis of Peter's texts. It is rather an original poem where the influence ${ }^{7}$ of Neoplatonism, Chaldean Oracles, apocryphal gospels, ${ }^{8}$ etc., can be found. This influence has already been studied, in particular regarding the ascent (vv. 31-71), by several scholars, such as, Theiler (1942), Smolak (1971), Gruber/Strohm (1991) 226-30, Seng (1996) 367-90 or Baldi (2011) 148-52. Therefore, I will not focus on these points, but try to show how Synesius had the pre-

3 Other references to Jesus' stay in the place of the dead after his own death: Mt 12.40, Hch. 2.24, (where the word $\theta$ avótov is substituted by o̊ $\delta$ ov in some traditions, cf. footnote 6 of Aland et al. 2000: 413), Hch. 2.31, Rm 10.7, Ef 4.8-10, etc. In the Gospel According to John there are also man references to the ascent and descent of Jesus, cf. Schneider (1987).

4 The Greek texts of the NT have been taken from Metzger/Wikgren (1968).

5 The English translations of the NT have been taken from Hooke (1982).

6 The interpretation of these texts and the beginnings of Jesus' descensus ad inferos has been briefly exposed in Grillmeier (1965) 86-89. Cf. also Colpe (1996) and Colpe et al. (1996).

7 Smolak (1971) 30 talks about a "kontaminatorisch Tecknik". This seems to be the case in this Hymn. 8 Like the Euangelium Nicodemi, cf. Garzya (1989) 789 and García Romero (1993) 93. 
vious Greek literary tradition in mind, where some mythological hero visits the place of the dead or Underworld. ${ }^{9}$ The most famous heroes to make such a journey are Odysseus, Heracles, Theseus, with Peirithous, and Orpheus, ${ }^{10}$ and their voyages are the subject of a good deal of Greek poetry and Mythography. ${ }^{11}$ Scholars have suggested in previous studies that, in this Hymn, Jesus may be understood as a new Heracles or a new Orpheus. ${ }^{12}$ Of all the possible parallels, I have chosen two heroes and two poems to compare with Synesius' $8^{\text {th }}$ Hymn: Odysseus in Odyssey 11 and Heracles in Bacchylides' $5^{\text {th }}$ victory-ode. I do not intend to be exhaustive on the subject. I will make only some remarks that may highlight the similarities and motifs of Jesus' journey to the place of the dead in the $8^{\text {th }}$ Hymn and the journeys of Odysseus and Heracles. ${ }^{13}$

This paper will be structured as follows: section 2 will present the $8^{\text {th }}$ Hymn in Ancient Greek with an English translation; its structure, meter and language. Section 3 will focus on the descent to Tartarus in Synesius' Hymn and compare it with the

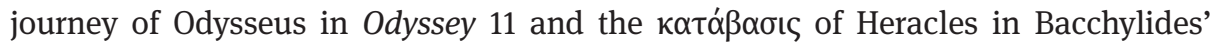
$5^{\text {th }}$ Victory-Ode. Finally, in section 4, I will summarize the main conclusions.

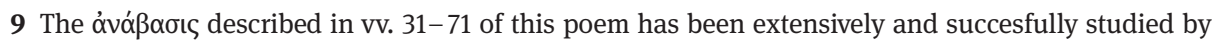
many scholars, for instance Terzaghi (1939) 266-69, Smolak (1971), Vollenweider (1985) 147-51, Seng (1996) 367-90, Baldi (2011) 148-52. Therefore, I will not focus on this part of the $8^{\text {th }}$ Hymn.

10 Cf. Ganschinietz (1919) 2398-2408, Graf/Brändle (1999), and Colpe/Habermehl (1996) 505-514. For a non-typical journey to Hades cf. Herrero (2011).

11 For Odysseus cf. Hom. Od. XI; for Heracles cf. Hom. Il. VIII.366-368, Od. XI.623-625, B. V.56-84, E. HF 23, 1227; D.S. IV.25.1, 26.1; Paus. II.31.2; 35.10; III.18.13; 25.5, V.26.7; IX.34.5; Str. VIII.5.1; Apollod. Bibliotheca. II.5.12, X. An. VI.2.2.; Palaeph. 39; for Theseus cf. Hes. fr. 280 M-W, Paus. IX.31.5, D.S. IV.63; Plut. Thes. 35; Apollod. Bibliotheca II.12; epit. 1.24; for Orpheus cf. E. Alc. 357, etc.

12 Cf. Terzaghi (1939) 262 and 264, Strohm (1965) 53, Lacombrade (1978) 21, Bregman (1982) 122, Vollenweider (1985) 147, Gruber/Strohm (1991) 225-226, Barkhuizen (1993) 270-71, Seng (1996) 373, Baldi (2011) 146.

13 According to Kayser (1956) 56: "Was ausserhalb eines literarischen Werkes in eigener Überlieferung lebt und nun auf seinen Inhalt gewirkt hat, heist Stoff. Der Stoff ist immer an bestimmte Figuren gebunden, ist vorgangsmässig und zeitlich und räumlich mehr oder weniger fixiert”. On the other hand Kayser (1956) 59 says that; “(Die Motive) stellen Einheiten dar, die in den verschiedenartisgten Zussamenhängen erschienen”; and: "Das Motiv ist eine sich wiederholende, typische und das heisst also menschlich bedeutungsvolle Situation" (Kayser (1956) 60). Alsina (1991) 496 calls them "pequeños rasgos comunes". Finally, "Die einzelnen konkreten Ausfüllungen in dem jeweiligen Motiv bezeichnet man als Zug” (Kayser (1956) 60). Therefore, in the theoretical framework proposed by Kayser, in these three poems we are in front of three "Stoffe": the journey to the underworld of Odysseus, of Heracles and the one of Jesus. They share some are "Motives", namely, the descent, the Fear, the Toil, the relation between the one who descends alive and corporeal and the incorporeal souls of the dead, the salvation. The differences in the development of the "Motive" are the "Züge". For the motifs of the $8^{\text {th }}$ Hymn (Fear, Salvation, etc.) cf. Barkhuizen (1993) and Smolak (1971) 9-26, especially for the "Himmelfahrt". 


\section{The 8th Hymn of Synesius of Cirene}

\subsection{Greek text and English translation of the 8th Hymn}

We will begin with the $8^{\text {th }}$ Hymn in its original Greek version and an English translation of it: ${ }^{14}$

(4) The 8th Hymn:

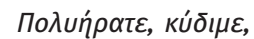

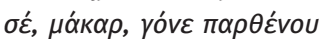

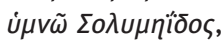

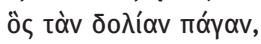

5

10

15

20

25

30
XӨóviov $\mu \varepsilon \gamma \alpha \dot{\lambda} \lambda \omega \mathrm{v}$ ö́ıı

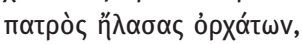

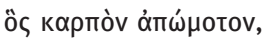

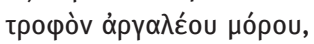

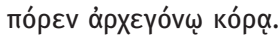

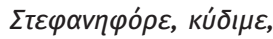

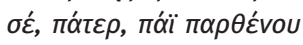

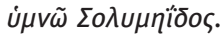

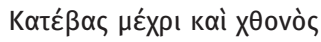

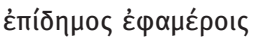

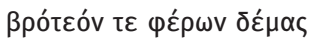

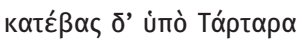

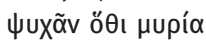

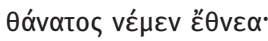

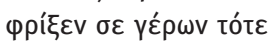

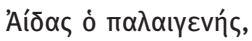

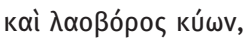
$<\star * \star>\dot{o} \beta \alpha \rho \cup \sigma \theta \varepsilon v \eta ́$, , $[\delta \eta \mu о \beta o ́ \rho o c] ~]^{15}$

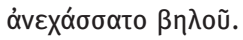

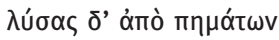

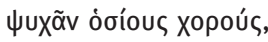

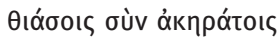

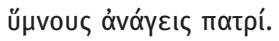

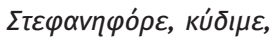

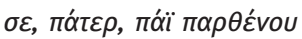

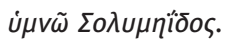

\author{
Most beloved august \\ Offspring of the Virgin of Solyma, \\ to Thee, Blessed One, I sing. \\ Thou hast expelled the serpent of the earth, \\ that fountain-head of treachery, \\ from the garden of the Father, \\ even the serpent who offered the abjured \\ fruit, nourisher of troublous destiny, \\ to the primal youth. \\ To Thee I sing, Illustrious \\ Father, that wearest the crown, \\ Son of the Virgin of Solyma. \\ Thou didst descend even to the earth, \\ sojourner of a day, \\ bearing a mortal body, \\ and didst go down beneath to Tartarus, \\ where death reigned over nations of souls in \\ thousands. \\ And then shuddered at Thee \\ the aged ancient Hades, \\ and his hound, \\ the devourer of man, \\ drew back from the threshold; \\ and Thou, delivering choirs of righteous \\ souls from their woes, \\ dost raise, with unpolluted bands, \\ hymns to the Father. \\ To Thee I sing, Illustrious \\ Father, that wearest the crown, \\ Son of the Virgin of Solyma. \\ The boundless races of demons
}

14 The Greek text of the $8^{\text {th }}$ Hymn has been taken from the edition of Dell'Era (1968) 147-53 and the English translation is the one of Fitzgerald (1930). This hymn forms a group with the $6^{\text {th }}$ and $7^{\text {th }}$ Hymns. According to Lacombrade (1978) 93 this hymn was written short time before or during his episcopate.

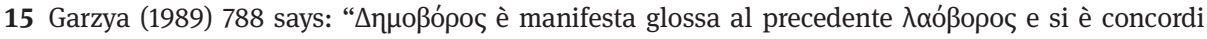
nell'espungerla". In the same sense cf. Lacombrade (1978) 95. 


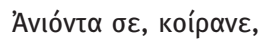

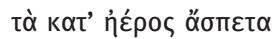

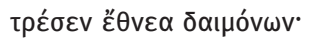

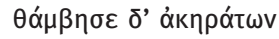

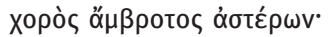

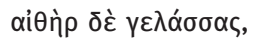

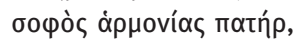

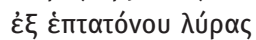

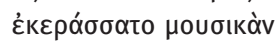

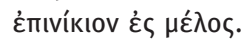

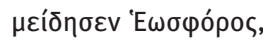

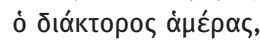

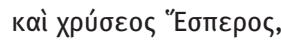

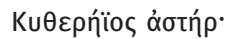

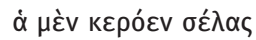
$\pi \lambda \eta ́ \sigma \alpha \sigma \alpha$ póou mupòs

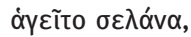

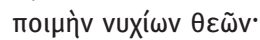

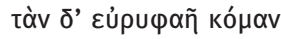

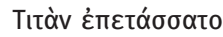

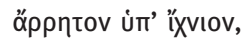

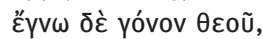
tòv ápıбтotéxvav vóov, iớiou mupòs ápxớv. ¿ù $\delta \dot{~} \tau \alpha \rho \sigma o ̀ v ~ \varepsilon ̇ \lambda \alpha ́ \alpha \sigma \alpha \varsigma$ kuavóvtuyos oủpavoũ

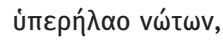

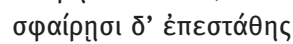

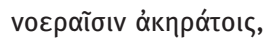

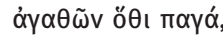

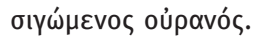

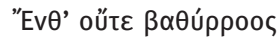

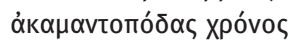

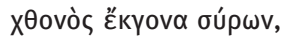

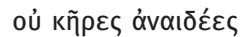

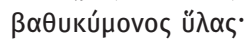

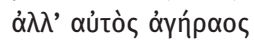

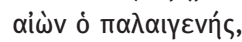

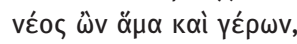

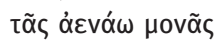

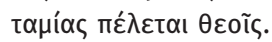

throughout the air trembled at Thy ascent, 0 King. The ambrosial choir of the stars immaculate was seized with awe; and ether laughing, wise father of harmony, blended upon the seven-stringed lyre a hymn of victory to Thy might.

The harbinger of dawn smiled, the messenger of day, and golden Hesperus, the star of Cythera. The moon filling with a stream of fire its horned light, led the way, the shepherd of the gods of night. Titan spread out his far-flaming hair under the ineffable track, and recognized the Offspring of God, Mind, the Artificer of all that is best, and the origin of his own flame.

But Thou, in winged flight, didst leap over the black of the azure sky, and didst take Thy place amongst the inviolate spheres of the Mind, wherein is the fountain of good things, the heaven that is kept secret, where there is neither deep-flowing time that draggeth with untiring foot the offspring of the earth, nor the shameless destinies of matter's billowy depths, but an age born of the distant past, though ageless itself, old and yet withal ever young, is to the gods the guardian of their eternal mansion. 


\subsection{Structure}

This Hymn seems to present a very clear structure. I will follow partially the proposal of Baldi (2011) 115-16.

(5) Structure of the 8th Hymn, cf. Baldi (2011) 115-16:

\begin{tabular}{|c|c|c|}
\hline vv. $1-3$ & Addresse (Refrain) & \\
\hline vv. 4-9 & Banishment of the serpent from Paradise & \\
\hline vv. $10-12$ & Refrain & \\
\hline vv. $13-27$ & $\begin{array}{l}\text { vv. } 13-15 \text { Reference to incarnation } \\
\text { vv. } 16-27 \text { Descent into hells and liberation of souls } \\
\text { Refrain }\end{array}$ & \\
\hline vv. $31-71$ & vv. 31-54 Ascent through the sensible cosmos: & 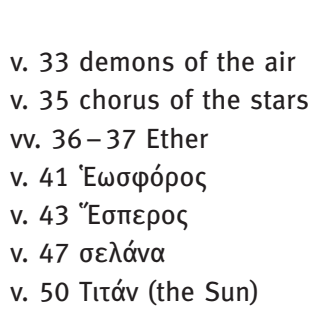 \\
\hline & vv. 55-71 Entrance in heaven that is kept secret & \\
\hline
\end{tabular}

The Hymn begins with an invocation to the addressee (1-9), ${ }^{16}$ Jesus, who is identi-

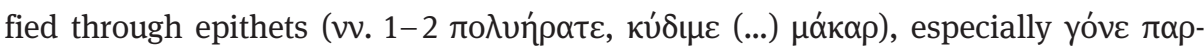

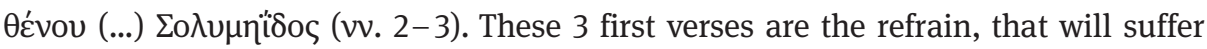
some modification in vv. 10-12 and 28-30. After this first version of the refrain, Synesius mentions the expulsion of the serpent from Paradise, labor of the yóvoৎ $\pi \alpha \rho-$

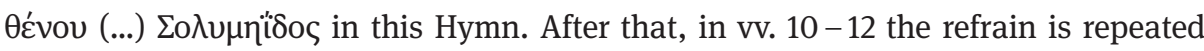

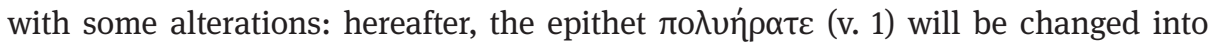

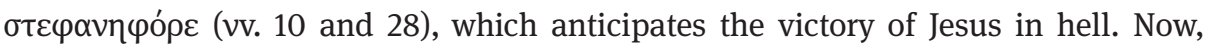
Jesus is not called $\mu \alpha \dot{\alpha} \alpha \rho$ (v. 2), but $\pi \alpha \dot{\tau \varepsilon \rho ~(v . ~ 11) . ~}{ }^{17}$ On the other hand, he is son, but he is not invoked as yóve (v. 2) but as rái (v. 11). Vv. 13-15 refer to the incarnation

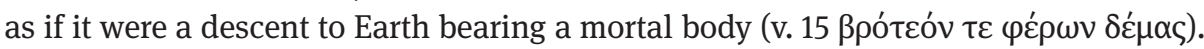
Vv.16-25 present the descensus ad inferos and the liberation of souls. The place into

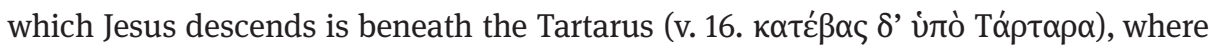
Death reigns over many nations of souls (vv. 17-18). Hades is frightened by the presence of Jesus, and Cerberus draws back (vv. 19-23). Then, Jesus releases the souls

16 The whole Hymn is in Du-Stil, which, according to Strohm (1965) 52, approaches the hymn to the sphere of the prayer, cf. also Norden (1913) 157-60.

17 Garzya (1989) 788 seems to interpret it so: "il poeta insiste sulla perfetta uguaglianza delle ipostasi”. 
from their woes (vv. 24-25). After this follows a brief transition (vv. 26-27) to the ascent: here the hymns raised by Jesus and the souls to the Father are mentioned. In vv. 28-30 we find again the same refrain of vv. 10-12 and, finally, in vv. 31-72 Jesus, or his voũ (v. 53 vóov), ascends through the spheres to the upmost part of the world, the heaven that is kept secret, and Synesius makes a rough description of this place. To sum up, in this poem there are two parts to be distinguished: first, the descent into the place of dead (including the banishment of the serpent from Paradise) (vv. 1-30) and secondly, the ascent to the upmost parts of the world (vv. 31-71).

Although certain authors, like Seng (1996) 376-77, have put some effort into highlighting the unity of both parts of the Hymn, Baldi (2011) 144-55 has demonstrated that we are actually in front of two poems that were put together sometime in the course of the manuscript tradition. His analysis reveals the thematic, stylistic and metrical differences of both parts and, mainly, the evidence offered by the codex Vat. Gr. 1390 , of the $13^{\text {th }}$ century, ${ }^{18}$ which clearly shows by the organization of the Greek text in the manuscript that the so-called $8^{\text {th }}$ Hymn of Synesius is formed, actually, by two Hymns: $8 \mathrm{a}$ (vv. 1-30) + 8b (31-71).

\subsection{Meter}

The meter of this Hymn has been interpreted in different ways: as a kind of telesillean ${ }^{19}$ or, even better, as an anapestic-iambic demeter. ${ }^{20}$ According to Seng (1996) $344-46$, its basic scheme in this Hymn is the one of (6) and (7): ${ }^{21}$

(6) $\underline{\mathrm{uu}}-\mathrm{uu}-\mathrm{ux}$

(7) $\underline{\mathrm{uu}}-\mathrm{uu}-\mathrm{x}$

\subsection{Language}

The language in this hymn is full of classical reminiscences, ${ }^{22}$ but it is also possible to recognize a slight doric flavor ${ }^{23}$ in it, as can be seen in (8) and in (9)

18 Cf. Pérez (1996) 346.

19 About this meter cf. Koster (1936) 183-85.

20 Cf. Terzaghi (1939) XXXII-XXXIII and, specially, Baldi (2011) 116-24, where the author summarizes all the proposals presented up to date.

21 Cf. also Gruber/Strohm (1991) 35. A brief study on the relation of this meter and the hymns of Synesios with the previous Christian poetry and the byzantine poetry is in Polo (2014) 123-24.

22 According to Baldi (2011) 146 Synesius uses in this Hymn "un linguaggio particolarmente intriso di reminiscenze classiche”. 


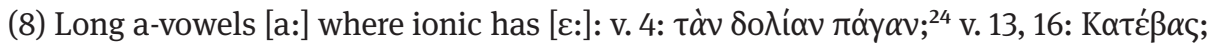

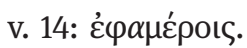

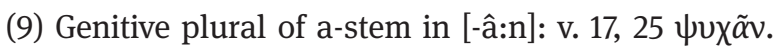

It is also possible to find features of the epic language, as it is usual in the Greek poetic tradition, ${ }^{25}$ topic on which I will focus in the next section.

\section{The descent into Tartarus}

As I mentioned in the first section, it is my aim to highlight some elements in the $8^{\text {th }}$ Hymn of Synesius that can be related to previous depictions in Greek poetry of heroic journeys to the place of the dead.

Therefore, in this section I will focus on some language usages in the $8^{\text {th }}$ Hymn that remind of the language of epic poetry, where heroes were the main characters.

Then I will summarize the features of the journeys to the place of the dead that can be found in the poem of Anacreon, in order to contrast them with the journeys of heroes in Odyssey 11 and Bacchylides' Ode. I will finish this section comparing the features of Odysseus' and Heracles' journeys with those of Jesus' descent.

\subsection{Epic language: ${ }^{26}$}

As is well known, the language of the Homeric Epic influenced the Greek poetry that came after Iliad and Odyssey, ${ }^{27}$ and the language of the $8^{\text {th }}$ Hymn is no exception, because it is possible to find in it, at least, the Homeric features presented in (10) to (14).

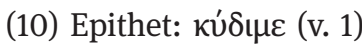

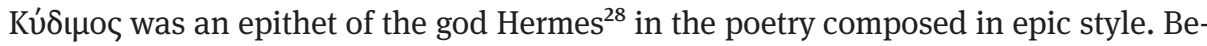
sides, one of the responsibilities of this god was to accompany men in their journeys,

23 Cf. von Wilamowitz-Moellendorff (1907) 277. About the dorian dialect in literary texts cf. Horrocks (2010) 53-54 and Colvin (2007) 44-47.

24 This word presents the same phonetics in Aeolic.

25 Cf. Horrocks (2010) 49.

26 Cf. Chantraine (1948)

27 Cf. Adrados (1999) 88 and, specially, Horrocks (2010) 44-59.

28 Cf. h.Merc. 46, Hes. Th. 938. 
like Priamus when he visits Achilles in Iliad. ${ }^{29}$ Another duty of Hermes was to accom-

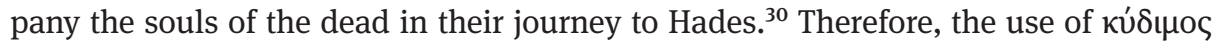
for Jesus in this very first verse could suggest the idea of the journey to the place of the dead, preparing the catabatic flavor of the first part of the hymn.

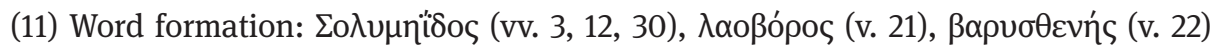

Synesius invents an adjective that is applied to the mother of Jesus, $\Sigma o \lambda u \mu \eta \hat{i} \delta$ os. It is

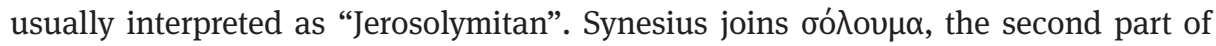

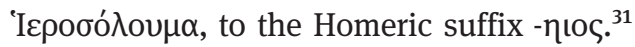

The compound $\lambda \alpha$ oßópos, a hapax with which Synesius ${ }^{32}$ designates Cerberus,

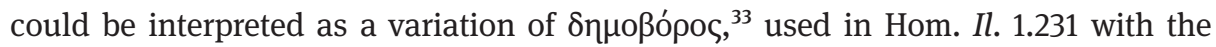
same meaning but used by Homer with regard to the hero Agamemnon.

Finally, as for $\beta \alpha \rho v \sigma \theta \varepsilon v \eta \dot{s}$, "das seltene Wort $\beta \alpha \rho v \sigma \theta \varepsilon v \eta ́ s$ in $h$. VIII 22, wohl auf den Kerberos bezogen, ist gebildet nach dem Muster zahlreicher Götterattribute auf

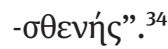

Therefore Synesius, with this word construction, evokes the epic language.

Other words yield a Homeric coloring as in (12):

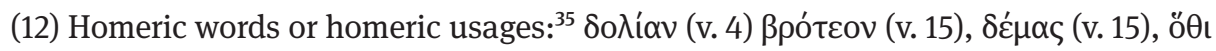

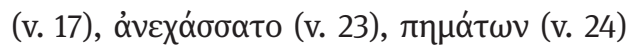

$\Delta o \lambda i ́ \alpha v(v .4)$ "treacherous". This adjective is used in Odyssey combined with substan-

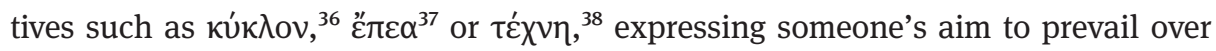
an enemy.

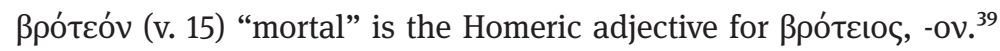

$\delta \varepsilon^{\prime} \mu \alpha \varsigma$ (v. 15) is used by Homer for designating the bodily frame. ${ }^{40}$ Synesius could have used $\sigma \tilde{\omega} \mu \alpha$ or $\sigma \alpha \dot{\rho} \xi \xi$ to refer to the corporeity of man, but he prefers a Homeric word.

29 Cf. Hom. Il. XXIV.334-347; 440-448; 457-467. Priamus' journey has been interpreted as short of

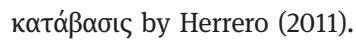

30 Cf. Hom. Od. 24.1-10.

31 Cf. Seng (1996) 216-127.

32 Cf. Seng (1996) 391.

33 Cf. Seng (1996) 304. For the difficulties of the verse $22 \mathrm{cf}$. Gruber/Strohm (1991) 226.

34 Seng (1996) $70-71$.

35 For the words of (12) and the references to the Homeric text cf. Liddell et al. (1996).

36 Cf. Hom. Od. IV.792, in a comparison, men in circle vs. a lon.

37 Cf. Hom. Od. IX.282, Odysseus vs. the Cyclops

38 Cf. Hom. Od. IV.455; 529, Proteus vs. Menelaus and his comrades.

39 Cf. Gruber/Strohm 1991: 225 for the metrical and textual difficulties of this verse.

40 Cf. Hom. Il. V.801; Od. VIII.116. 


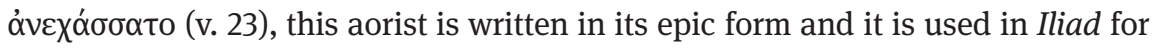
designating the withdrawal of some warrior. ${ }^{41}$

$\pi \eta \mu \alpha ́ \tau \omega \nu$ (v. 24) is also used in Iliad and Odyssey for expressing misery, calamity. ${ }^{42}$

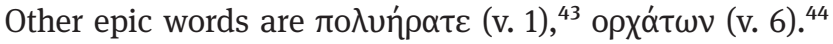

Further linguistic features of the Homeric language are the lack of augment in imperfect and aorist, ${ }^{45}$ as in (13), or the lack of contraction, ${ }^{46}$ as in (14).

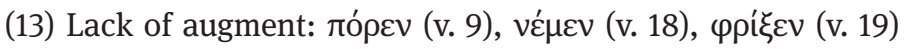

(14) Lack of contraction: $\varepsilon^{\prime} \theta v \varepsilon \alpha$ (v. 18)

In conclusion, the language used in the part of Jesus' $\kappa \alpha \tau \alpha \dot{\beta} \alpha \sigma \mathrm{s}$ in the $8^{\text {th }}$ Hymn contributes to create an epic atmosphere.

\subsection{Anacreon's descent into Tartarus}

As we already saw in text (1), it is possible to recognize in it some features of the journey to the place of the dead, summarized in (15):

(15) Features of Anacreon's view of the descent into Tartarus:

Status of the one who goes to Tartarus: dead

Name of the place of the dead: Tóp $\alpha \alpha \rho o v$ (v. 8), 'Aí $\delta \varepsilon \omega$ (v. 9)

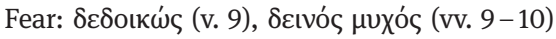

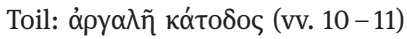

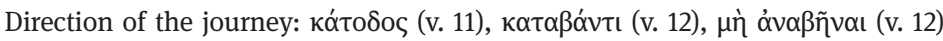

The features that are recognizable in Anacreon's Victory-Ode contrast with the features of the journey of the hero to the place of the dead, as it will be shown in the following sections.

41 Cf. Hom. Il. VII.264; XV.728; XVI.819; XVII.47.

42 Cf. Hom. Il. XI.347; XV.721; XVII.688; XXIV.547; Od. II.163; III.152; V.179; XIV.338.

43 Cf. Hom. Od. XV.126; Hes. Th. 404.

44 Cf. Hom. Od. VII.112.

45 Cf. Chantraine 1948: 481.

46 Cf. Chantraine 1948: 208. 


\subsection{Odysseus' journey in Hom. Od. XI}

In the $11^{\text {th }}$ book of Odyssey, ${ }^{47}$ Odysseus and his companions sail until the end of Oceanus, where the land of the Cimmerians is "wrapped in mist and cloud" (Hom. Od. 11.15), the sun does not shine and it is always night. He makes this journey in order to consult the dead Tiresias about the future. Circe ordered him to do so in Hom. Od. 10.487-540. I will highlight only the points that I found relevant for my purposes.

When Odysseus arrives to the land of the Cimmerians, he "dug a pit of a cubit's length (...) and around it poured a libation to all the dead" (Hom. Od. 11.25-26) (milk, honey, wine and water). After that, he sprinkled barley meal and entreated the dead, as can be seen in (16).

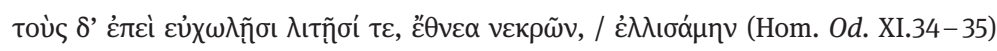

"But when with vows and prayers I had made supplication to the tribes of the dead". ${ }^{48}$

Immediately after, he sacrificed sheeps, and the souls ( $\psi v x \alpha i$ ) of the dead came out of the place of the dead, called Erebus, as in (17).

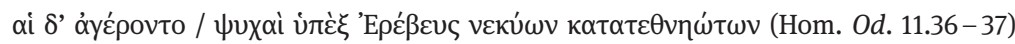

"Then there gathered from out of Erebus the spirits of those that are dead".

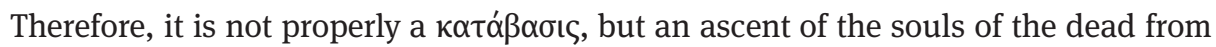
Erebus to the place where Odysseus dug a pit in the land of the Cimmerians. ${ }^{49}$ Properly said, it is a vékvı $\alpha$. The souls tried to drink the blood dropped at the sacrifice of sheeps. In this moment, Odysseus, fighting with his sword, struggles to drive the souls away from the blood, until Tiresias arrives. Let us read (18):

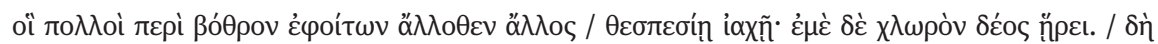

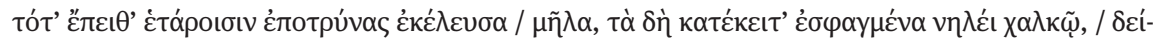

47 The structure of this $11^{\text {th }}$ book of Odyssey and the place of Odysseus journey in it has been well described by de Jong (2001) 271-312.

48 The Greek texts and English translations of Odyssey have been taken from the edition of Murray (1984).

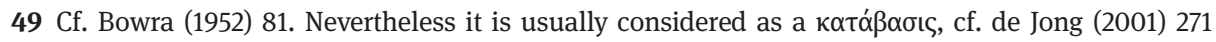
who calls it "Odysseus' descent into the Underworld". 


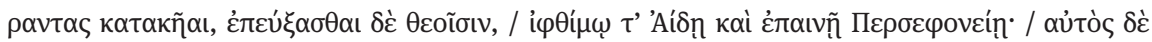

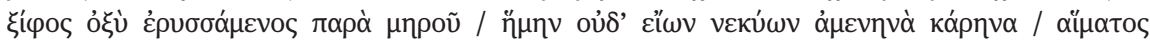

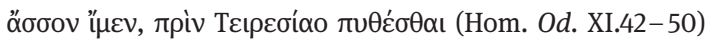

"These came thronging in crowds about the pit from every side, with a wondrous cry; a pale fear seized me. Then I called to my comrades and bade them flay and burn the sheep that lay there slain with the pitiless bronze, and to make prayer to the gods, to mighty Hades and dread Persephone. And I myself drew my sharp sword from beside my thigh and sat there, and would not suffer the powerless heads of the dead to draw near to the blood until I had enquired of Teiresias".

As we can see, the souls came in crowds, Odysseus is afraid, and two characters of the Underworld are mentioned: Hades and Persephone, the king of the Underworld and his wife. After that, he speaks with the spirits of the dead, like Elpenor, Tiresias or Anticlea. During the talk he holds with his mother, Odysseus paradoxically says:

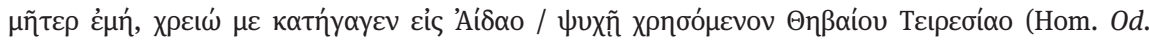
XI.164-165)

"My mother, necessity brought me down to the house of Hades, to seek soothsaying of the spirit of Theban Teiresias".

Odysseus uses the verb кatóy $\omega$ "bring down". Therefore, he understands in some

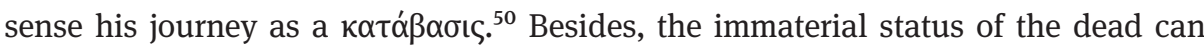
be seen in the text of (20):

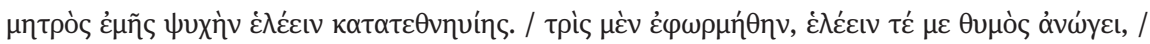

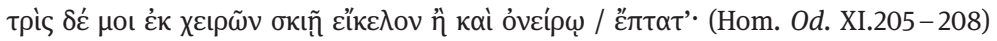

"I was fain to clasp the spirit of my dead mother. Thrice I sprang towards her, and my heart bade me clasp her, and thrice she flitted from my arms like a shadow or a dream".

Several verses after, when Odysseus speaks with Achilles, the latter uses the verb к $\alpha \dot{\rho} \rho \chi о \mu \alpha \iota$ in order to designate Odysseus' journey in (21). Therefore, Achilles

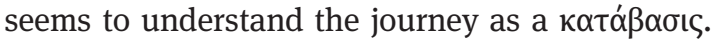

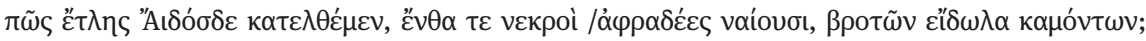
(Hom. Od. XI.475-476)

50 Heubeck/Hoekstra (1990) 75 talk about the hypothesis of "an older nekuomanteia (that) has been conflated with the poetic conception of a heroic katabasis". Cf. also Herrero (2011) 39, with further bibliography. 
"How didst thou dare to come down to Hades, where dwell the unheeding dead, the phantoms of men outworn?".

Finally, at the end of the $11^{\text {th }}$ book, Odysseus returns by going out of the place of the dead, embarking, and leaving the place with no explicit reference to an ascent. ${ }^{51}$

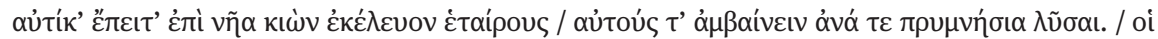

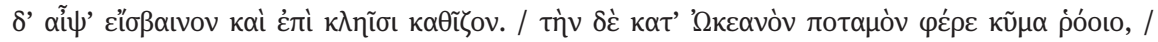

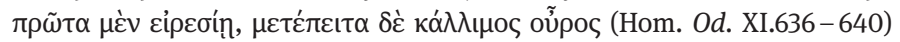

"Straightway then I went to the ship and bade my comrades themselves to embark, and to loose the stern cables. So they went on board quickly and sat down upon the benches. And the ship ware borne down the stream Oceanus by the swelling flood, first with our rowing, and afterwards the wind was fair".

To sum it up, in this $11^{\text {th }}$ book of Odyssey, the hero goes on a journey to the place of the dead. This journey is understood, in some sense, as a descent. The journey's end is called Erebus or Hades. The hero reaches this place alive, whereas the crowds of inhabitants are incorporeal $\psi v x \alpha$ í. Some inhabitants of this place are mentioned, like Hades and Persephone and many $\psi v x \alpha i$ of dead people are identified. In this place, Odysseus is afraid and must do efforts in order to achieve his objective. After that, he goes out of this place alive.

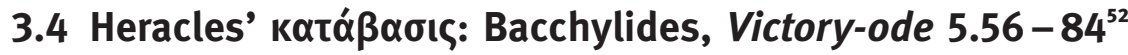

Only the verses $56-86$ are relevant for my purpose:

(23) Bacchylides, Victory-ode 5.56-84

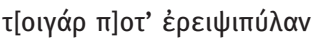

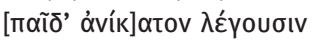

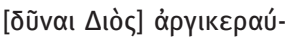

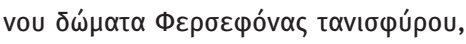

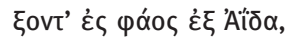 \\ viòv óm
}

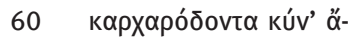

\author{
Once, the say, the gate-wrecking, \\ unconquerable $\operatorname{son}^{53}$ of thunder-flashing \\ Zeus went down to the house \\ of slender-ankled Persephone \\ to fetch up to the light from Hades \\ the jagged-toothed dog $^{54}$, \\ son of unapproachable Echidna.
}

\footnotetext{
51 The only reference to an ascent could be found when Odysseus and his comrades embark, because embarking entails an ascent. But it is not a convincing argument.

52 The Greek text and English translation have been taken from the edition of Campbell (1992) $142-45$.

53 Heracles.

54 Cerberus.
} 


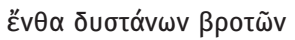

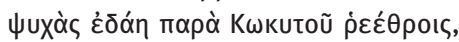

65

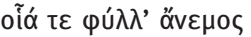

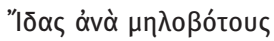

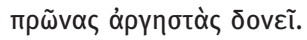

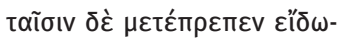

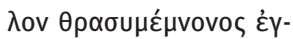

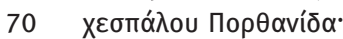

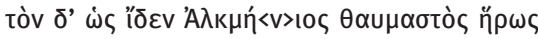

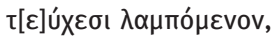

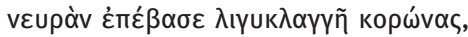

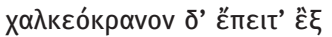

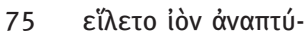

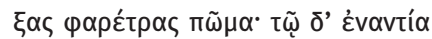

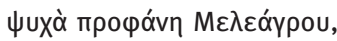

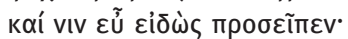

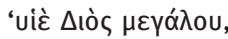

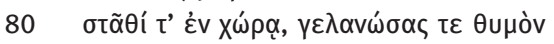

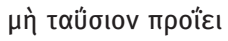

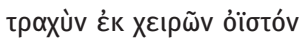

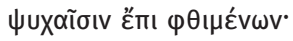

oü toเ ठह́o५.'
There he perceived the spirits

of wretched mortals by the waters

of Cocytus,

like the leaves buffered by the wind

over the bright sheep-grazed

headlands of Ida.

Among them stood out

the ghost of bold-hearted,

spear-brandishing Porthanides; ${ }^{55}$

and when the wonderful hero, Alcmena's

son, ${ }^{56}$

saw him shining in armour,

he put the clear-twanging string on his bow-

hook,

then opened the lid of his quiver

and took out a bronze-headed arrow.

But Meleager's spirit

confronted him, face to face,

and his full experience addressed him:

'Son of great Zeus,

stay where you are! Calm your heart,

and do not send a fierce arrow in vain

from your hands

against the spirits of the dead.

You have nothing to fear'.

In this part of the Victory-Ode, Bacchylides talks about the journey that Heracles, alive, made to the place of the dead. This journey is understood as a going down, if the reconstruction of $\delta \tilde{v} \boldsymbol{\alpha} \alpha$ in v. 58 is correct. The destination of the journey is called Hades (v. 61). The aim of his travelling there is to fetch up to the light to Cerberus (vv. 60-61). Actually, it is Heracles' last labor, according to Apollodorus. ${ }^{57}$ The characters of the place of the dead mentioned are Persephone (v. 59) and Cerberus,

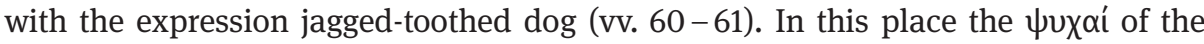
dead ( $\varphi \theta \mu \varepsilon^{\prime} \nu \omega \nu$ v. 83) dwell and can be identified, like that of Meleager (v. 70).

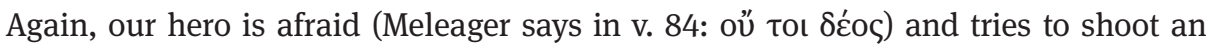

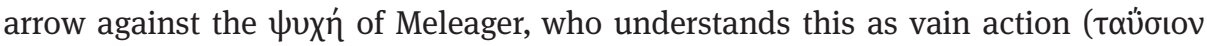
v. 81). In the rest of the ode, there is no explicit mention of the achieving of Heracles'

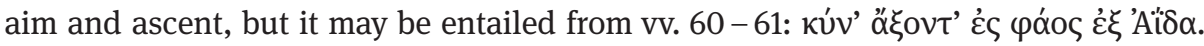

55 Meleager.

56 Heracles.

57 Cf. Apollod. Bibliotheca. 2.122. 


\subsection{Odysseus, Heracles and Jesus}

We may compare now these three poetic passages in order to verify if Jesus is presented somehow as a hero in a similar way to Odysseus or Heracles in their journey to the place of the dead. In (24) a table summarizes some heroic features and motifs that appear in the three poems.

(24) Odysseus (Hom. Od. 11), Heracles (B. 5) and Jesus (Synes. Hymn. 8):

\begin{tabular}{|c|c|c|c|}
\hline Feature /Hero & $\begin{array}{l}\text { Odysseus } \\
\text { (Hom. Od. 11) }\end{array}$ & $\begin{array}{l}\text { Heracles } \\
\text { (B. 5) }\end{array}$ & $\begin{array}{l}\text { Jesus } \\
\text { (Synes. Hymn. 8) }\end{array}$ \\
\hline $\begin{array}{l}\text { Direction of the } \\
\text { journey }\end{array}$ & 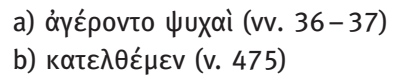 & ठũvaı (v. 58) & 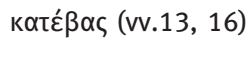 \\
\hline Name of the place & 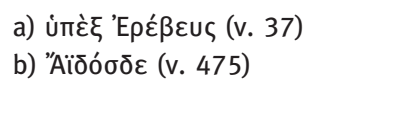 & 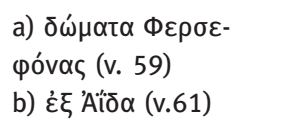 & 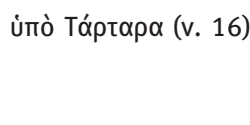 \\
\hline $\begin{array}{l}\text { Status of the one } \\
\text { who descends }\end{array}$ & 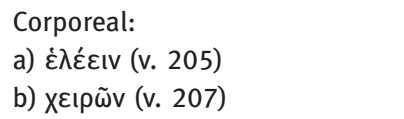 & $\begin{array}{l}\text { Corporeal: } \\
\text { عí̉̇to ìòv (v. 75) }\end{array}$ & 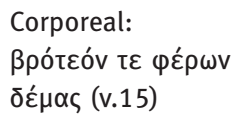 \\
\hline $\begin{array}{l}\text { Status of dead } \\
\text { people }\end{array}$ & 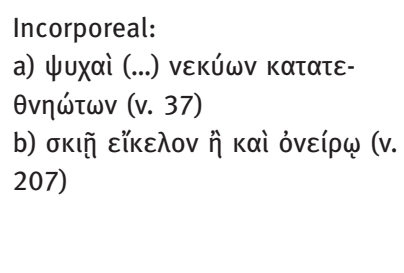 & 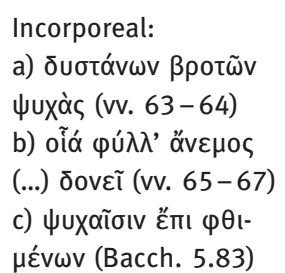 & $\begin{array}{l}\text { Incorporeal: } \\
\psi u x \alpha i ́\end{array}$ \\
\hline
\end{tabular}

\begin{tabular}{|c|c|c|}
\hline $\begin{array}{l}\text { Name of the group } \\
\text { of dead people }\end{array}$ & 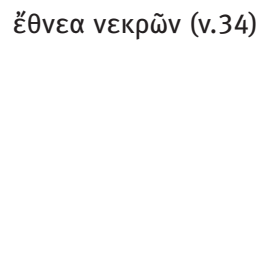 & 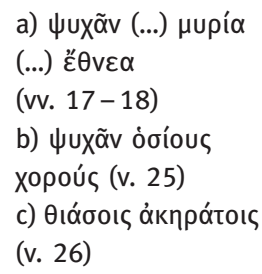 \\
\hline
\end{tabular}

\begin{tabular}{|c|c|c|c|}
\hline $\begin{array}{l}\text { Underworld charac- } \\
\text { ters }\end{array}$ & 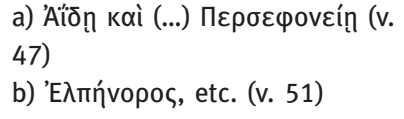 & 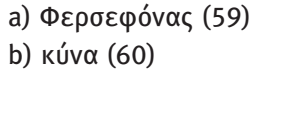 & 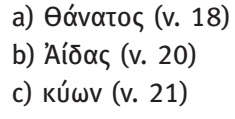 \\
\hline Fear & 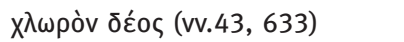 & 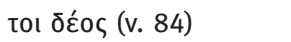 & фрі́દદv (v.19) \\
\hline Toil & 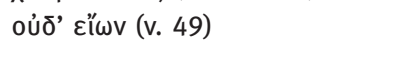 & 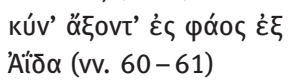 & $\begin{array}{l}\text { öpıv (...) ท̆ } \eta_{\alpha \sigma \alpha \alpha \varsigma} \\
\text { (vv. 5-6) }\end{array}$ \\
\hline
\end{tabular}


Continued

\begin{tabular}{|c|c|c|c|}
\hline Feature / Hero & $\begin{array}{l}\text { Odysseus } \\
\text { (Hom. Od. 11) }\end{array}$ & $\begin{array}{l}\text { Heracles } \\
\text { (B. 5) }\end{array}$ & $\begin{array}{l}\text { Jesus } \\
\text { (Synes. Hymn. 8) }\end{array}$ \\
\hline Victory-Success & $\begin{array}{l}\text { Speech of Teiresias (vv. } 100- \\
\text { 137) }\end{array}$ & 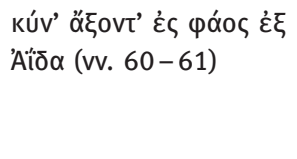 & 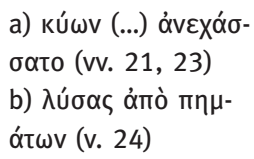 \\
\hline Ascent & 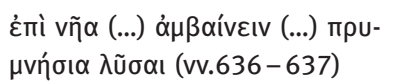 & 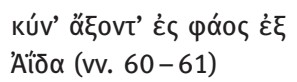 & 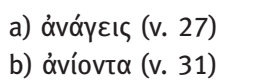 \\
\hline
\end{tabular}

Let us examine first the direction of the journey. It seems that in the three poems,

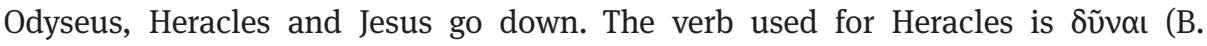

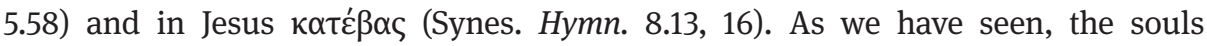

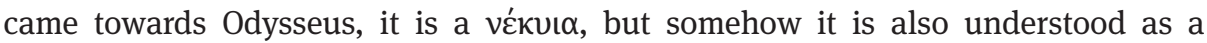

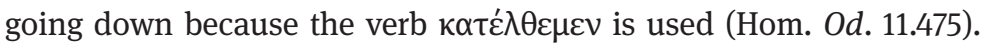

As for the destination of the going down, it receives different names:

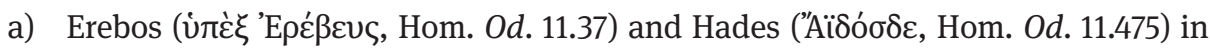
Odyssey

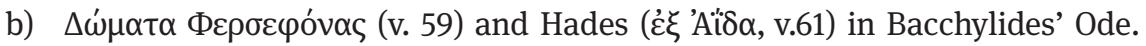

c) And, finally, "below Tartaros" (ن่⿰ò Tó $\rho \tau \alpha \rho \alpha)$ in Synes. Hymn. 8.16. The equivalence of Tartaros with Hades can be seen in Anacreon's poem of (1), although they are not necessarily the same place in the oldest Greek cosmology. Synesius could have used this denomination in order to emphasize the vertical descent of Jesus, since, according to Hes. Th. 119, it is in the innermost part or the earth, being the same distance from earth to heaven as from earth to Tartaros. ${ }^{58}$ Another reason for using this name is the fact that Tartaros was understood as the place where the condemned went after their criminal life, for example, in $\mathrm{Pl}$. Grg. 523a, Phd. 113e. Therefore, the descent of Jesus to Tartaros, not simply to Hades, could highlight his redeeming mission. ${ }^{59}$

Regarding the physical status of the one who descends, the hero is alive and corporeal.

a) In Odyssey, Odysseus tries to embrace with his arms the spirit of his mother, but that is impossible (Hom. Od. XI.205-207).

b) Heracles is corporeal and can grasp material objects like arrows, but the matter cannot touch the souls, it is a vain action (B. 5.81).

58 Cf. Hes. Th. 721-725, Apollod. Bibliotheca I.1.2.

59 In Greek mythology, Tartaros is also a place where to shut someone up, as it happened, for example, with Titans, cf. Hes. Th. $730-819$. 


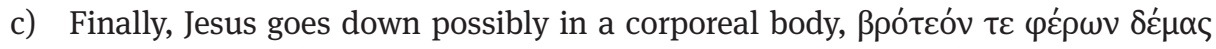
(Synes. Hymn. 8.15). ${ }^{60}$ Synesius does not specify if Jesus is alive or dead, since he

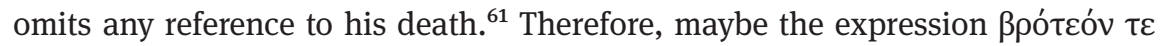

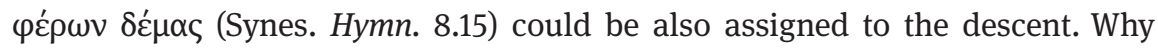
would he explicitly use this expression? If we see some actions performed by Odysseus (he tried to embrace his mother) or Heracles (he took an arrow) in the Underworld, one can realize that their actions entail corporeity. But in the $8^{\text {th }}$ Hymn of Synesius, this is not the case. Jesus' action in the Underworld, the releasing of the souls, is not described in physical terms. Therefore, the expres-

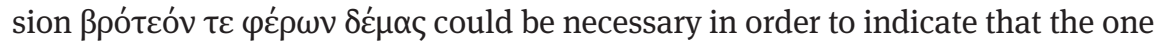

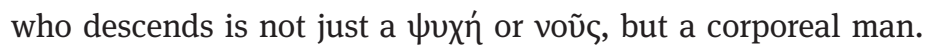

On the other hand, the inhabitants of this place are $\psi v x \alpha$ í in the three poems. Only in Odyssey and in the poem of Bacchylides it is said that they belong to dead people

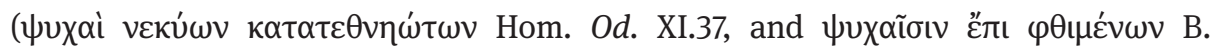
5.83). These souls are like shadows or dreams, in Odyssey (Hom. Od. XI.207) and, in a similar fashion, they are blowed like leaves (B. 5.65-67). In Synesius' $8^{\text {th }}$ Hymn, they are simply $\psi v x \alpha$ í.

Except in Bacchylides' Ode, the souls form groups. What Odysseus sees is desig-

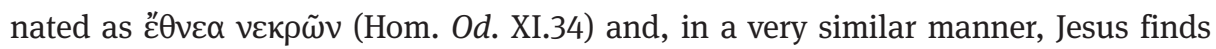
$\psi v \chi \tilde{\alpha} v(. ..) \mu v \rho i ́ \alpha$ (...) है $\varepsilon v \varepsilon \alpha$ (Synes. Hymn. 5.17-18), an expression that reminds the

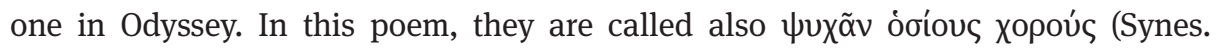

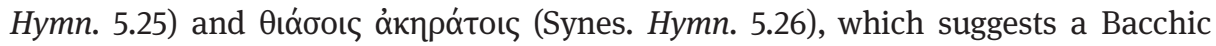
revel.

Regarding the characters of the Underworld in the three poems, some of them are mentioned:

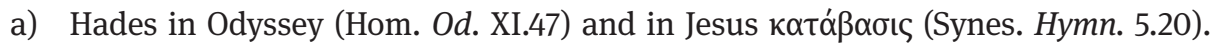

b) Persephone in Odyssey (Hom. Od. XI.47) and in Bacchylides' Ode (B. 5.49).

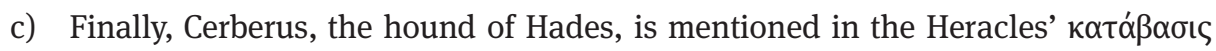

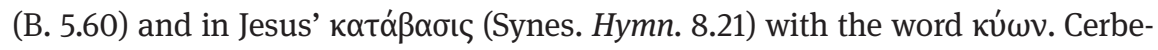

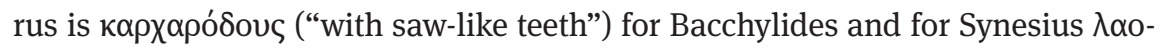
ßópos ("devourer of man”). In both cases, he is identified by his devouring ability.

d) Only Synesius mentions @ávatos (Synes. Hymn. 8.18) and relates it to souls

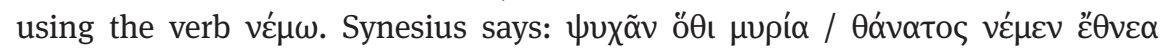

60 For the comprehension of incarnation in Synesius cf. Bregman (1982) 93-124.

61 About the relation of Jesus' dead and resurrection with descensus ad inferos and the moment it takes place cf. Müller (1998) 308 and especially Grillmeier (1965) 86, who commenting 1Pt 3.18-20,

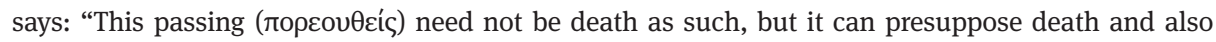
include the Resurrection and the Ascension. The one who descends to death and to Sheol (or who is already raised and now goes up to heaven) goes to a place where the spiritual powers or also the souls of men are lodged". 
(Synes. Hymn. 8.17-18). The verb vé $\mu \omega$ means "hold” or "reign” but also "drive to

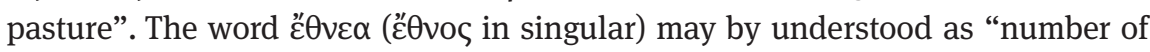
people living together", which is congruent with the translation "reign" of vé $\mu \omega$, but عै $\theta$ vo means also "flock". ${ }^{62}$ Therefore, Death reigns over the souls but at the same the same time Death is like a shepherd who leads the flocks to pasture. ${ }^{63}$

Concerning the motif of Fear, it is present in the three poems. ${ }^{64}$

a) In Odyssey and in the Bacchylides' Ode, the hero seems to fear ( $\chi \lambda \omega \rho$ òv $\delta$ ćos

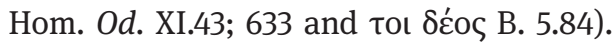

b) But in the case of Jesus, Synesius introduces a change, since it is not the hero who is afraid, but Hades who experiences Fear. Hades is the subject of the verb $\varphi \rho i ́ \xi \varepsilon v$, an aorist in its Homeric form that means "of the effect of fear, shudder". ${ }^{65}$ The object of this verb, $\sigma \varepsilon$, is Jesus. On the other hand, Cerberus, $\alpha \dot{v} \varepsilon \alpha \alpha \sigma-$

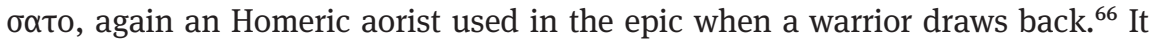
may be understood in this context that his withdrawal is a consequence of fear.

On another front, in the three poems the hero must do an effort:

a) Odysseus must avoid with his sword that wrong souls drink blood (Hom. Od. XI.49).

b) Heracles must fetch up Cerberus from Hades and lead it to the light (B. 5.60 - 61).

c) Synesius presents two actions performed by Jesus: the banishment of the serpent from Paradise (Synes. Hymn. 8.4-9) and the freeing of the souls in Hades from their woes (Synes. Hymn. 8.24). The first labor (in vv. 4-9) announces the achievement of Jesus' aim in the place of the dead: the release of souls.

As for the victory, we might atribute some sort of victory to the three heroes:

a) Odysseus achieves his goal: ${ }^{67}$ to speak with the soul of Tiresias (Hom. Od. XI.100 - 137).

b) It is supposed that Heracles successfully drives Cerberus out of Hades.

c) And, as it has been mentioned, Jesus releases the souls. In the case of Synesius, Jesus is presented as a victor o winner ${ }^{68}$ by the epithet $\sigma \tau \varepsilon \varphi \alpha v \eta \varphi$ ó Hymn. 8.10 and 28) that means "who wears a crown", prize of a victory in a com-

62 For all these meanings cf. Liddell et al. (1996).

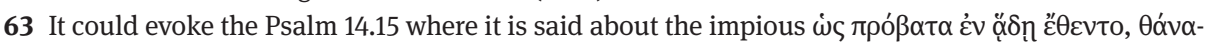

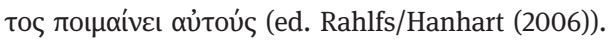

64 Vollenweider (1985) 147: "Furcht und Zittern sind überhaupt traditionelle Charakteristika der Hadesfahrt”.

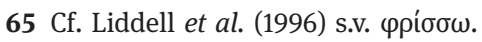

66 Terzaghi (1939) 264 relates these verses of the $8^{\text {th }}$ Hymn with Horatius 3.11 .15 and Verg. Georg. IV.481.

67 Cf. Graf/Brändle (1999) 327.

68 Cf. von Wilamowitz-Moellendorff (1907) 288. 
petition $^{69}$. In this sense, as Barkhuizen (1993) 265 says, this hymn "has been appropriately called a Christ-epinikion", ${ }^{70}$

Regarding the last feature, in the three poems the heroes return from the place of the Dead (Hom. Od. XI.636-637; B. 5.60 - 61). In the case of Synesius' Hymn, it is suggested that Jesus gets out of the place of the dead with the released souls elevating hymns to his Father (Synes. Hymn. 8.26-27). The verb óvóy $\omega$ (v. 27) suggests the ascent of the one who descended. The second part, which more than probably is anoth-

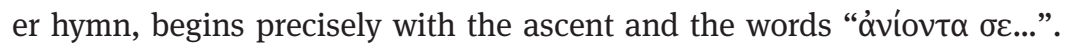

In the next section, I will draw conclusions from the comparison made in this section.

\section{Conclusions}

In the former sections I have tried to show how Synesius could have had in mind the journeys to the Underworld of some heroes of earlier Greek poetry.

In my opinion, the use of some linguistic features, idioms and expressions taken from the epic language, as we have seen in section 2, contributes to create a coloring that reminds the world and times of the heroes.

We should also consider that some features, motifs or literary elements employed by earlier poets when describing the journey to the Underworld of some heroe are also present in the $8^{\text {th }}$ Hymn; this, as well as the differences between them, has been explained in section 3 .

Therefore, considering his language and the aforementioned literary characteristics, Synesius could have had the intention of presenting Jesus as hero in his $8^{\text {th }}$ Hymn.

\section{Bibliography}

Adrados (1999): Francisco R. Adrados, Historia de la lengua griega, Madrid.

Aland et al. (2000): Kurt Aland, Matthew Black, Carlo M. Martini, Bruce M. Metzger, Allen

Wikgren, Barbara Aland and Johannes Karavidopoulos (eds.), The Greek New Testament, Stuttgart.

Alsina (1991): José Alsina, Teoría Literaria Griega, Madrid.

Baldi (2011): Idalgo Baldi, Gli Inni di Sinesio di Cirene, Vicende testuali di un corpus tardoantico, Berlin.

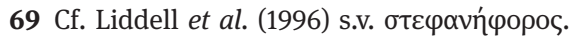

70 Barkhuizen (1993) 266-270 studies the two parts of the Hymn under the point of view of Jesus' victory. 
Barkhuizen (1993): J. H. Barkhuizen, "Synesius of Cyrene, Hymn 8: A Perspective on His Poetic Art", in: J. Boeft and A. Hilhorts (eds.), Early Christian Poetry. A Collection of Essays, Leiden New York - Köln, 263-71.

Bowra (1952): Cecil Maurice Bowra, Heroic Poetry, London.

Bregman (1982): Jay Bregman, Synesius of Cyrene. Philosopher - Bishop, Berkeley.

Campbell (1988): David A. Campbell, Greek Lyric II, Cambridge MA - London.

Campbell (1992): David A. Campbell, Greek Lyric IV Bacchylides, Corina, and Others, Cambridge MA - London.

Chantraine (1948): Pierre Chantraine, Grammaire Homérique. Tome I. Phonétique et Morphologie, Paris.

Colpe (1996): C. Colpe, “Jenseitsfahrt II”, in: Ernst Dassmann et al. (eds.), Reallexikon für Antike und Christentum 17, $466-89$.

Colpe et al. (1996): C. Colpe, E. Dassmann, J. Engemann and P. Habermehl, “Jenseitsfahrt I", in: Ernst Dassmann et al. (eds.), Reallexikon für Antike und Christentum 17, 407-66.

Colpe/Habermehl (1996): C. Colpe and P. Habermehl,"Jenseitsreise”, in: Ernst Dassmann et al. (eds.), Reallexikon für Antike und Christentum 17, 490-543.

Colvin (2007): Stephen Colvin, A Historical Greek Reader: Mycenaean to the Koiné, Oxford.

Dell'Era (1968): Antonio Dell'Era, Sinesio di Cirene: inni, Roma.

Fitzgerald (1930): Augustine Fitzgerald, The Essays and Hymns of Synesius of Cyrene: Including the Address to the Emperor Arcadius and the Political Speeches, London.

Ganschinietz (1919): Richard Ganschinietz, “Katabasis”, in: Paulys Realencyclopädie der classischen Altertumswissenschaft 10, 2359-2449.

García Romero (1993): Francisco Antonio García Romero, Sinesio de Cirene. Himnos, Tratados, Madrid.

Garzya (1989): Antonio Garzya, Opere Di Sinesio Di Cirene: Epistole, Operette, Inni, Torino.

Graf/Brädle (1999): Fritz Graf and Rudolf Brändle, "Katabasis”, in: Hubert Cancik and Helmut Schneider (eds.), Der neue Pauly 6, 327-30.

Grillmeier (1965): Alois Grillmeier, Christ in Christian Tradition. From the Apostolic Age to Chalcedon (451), London.

Gruber/Strohm (1991): Joachim Gruber and Hans Strohm, Synesios von Kyrene, Hymnen, Heidelberg.

Herrero (2011): Miguel Herrero, “Priam's Catabasis: Traces of the Epic Journey to Hades in Iliad 24", in: Transactions of the American Philological Association 141, 37-68.

Heubeck/Hoekstra (1990): Alfred Heubeck and Arie Hoekstra, A Commentary on Homer's Odyssey Volume II Books IX-XVI, Oxford.

Hooke (1982): Samuel Henry Hooke, The Bible in Basic English, Cambridge.

Horrocks (2010): Geoffrey Horrocks, Greek: A History of the Language and Its Speakers, Oxford. de Jong (2001): Irene de Jong, A Narratological Commentary on the Odyssey, Cambridge.

Kayser (1956): Wolfgang Kayser, Das sprachliche Kunstwerk. Eine Einführung in die Literaturwissenschaft, Bern.

Koster (1936): W. J. W. Koster, Traité de Métrique Grecque: Suivi d'un Précis de Métrique Latine, Leyden.

Lacombrade (1978): Christian Lacombrade, Synésios de Cyrène. Hymnes, Paris.

Liddell et al. (1996): Henry George Liddell, Robert Scott, Henry Stuart Jones and Roderick McEnzie, A Greek-English Lexicon, Oxford.

Metzger/Wikgren (1968): Bruce Manning Metzger and Allen Paul Wikgren, The Greek New Testament, Stuttgart.

Müller (1998): Gerhard Ludwig Müller, Dogmática, Barcelona.

Murray (1984): Augustus Taber Murray, Homer. The Odyssey I, Cambridge MA - London. 
Norden (1913): Eduard Norden, Agnosthos Theos. Untersuchungen zur Formen-Geschichte religiöser Rede, Berlin.

Pérez (1996): Inmaculada Pérez, El Patriarca Gregorio de Chipre (ca. 1240-1290) y La Transmisión de Los Textos Clásicos En Bizancio, Madrid.

Polo (2014): Jesús Polo, “Tradición e Innovación En El Himno Sexto de Sinesio de Cirene”, in: Miguel Herrero (ed.): Genus Omne Deum, Madrid, 117-38.

Rahlfs/Hanhart (2006): Alfred Rahlfs and Robert Hanhart (eds.), Septuaginta, Stuttgart.

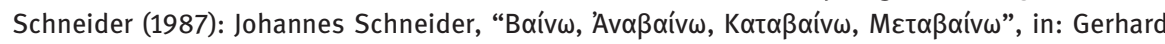
Kittel (ed.): Theological dictionary of the New Testament 1, Grand Rapids, 518-23.

Seng (1996): Helmuth Seng, Untersuchungen zum Vokabular und zur Metrik in den Hymnen des Synesios, Berlin.

Smolak (1971): Kurt Smolak “Zur Himmelfahrt Christi bei Synesios von Kyrene”, in: Jahrbuch der österreichischen Byzantinistik 20, 7-30.

Strohm (1965): Hans Strohm, “Zur Hymnendichtung des Synesios von Kyrene”, in: Hermes 93, 47-54.

Terzaghi (1939): Nicolaus Terzaghi, Synesii Cyrenensis Hymni, Roma.

Theiler (1942): Willy Theiler, “Die chaldäischen Orakel und die Hymnen des Synesios", in: Schriften der Königsberger gelehrten Gesellschaft 18, 1-41.

Vollenweider (1985): Samuel Vollenweider, Neuplatonische und christliche Theologie bei Synesios von Kyrene, Göttingen.

von Wilamowitz-Moellendorff (1907) Ulrich von Wilamowitz-Moellendorff, "Die Hymnen des Proklos und Synesios", Sitzungsberichte der königlich preussischen Akademie der Wissenschaften, 272-95. 



\title{
Gregory of Nazianzus' Hymn to Parthenie (II.1.2.1-214)
}

\author{
Christianizing Greek Theogonies
}

\section{Gregory as a poet}

Gregory of Nazianzus is the towering figure of Late Antique Christian literature, and form many he is the greatest Greek Christian poet of all times. Yet precisely the popularity, variety, and extension of his poetic work has been an unsurmountable obstacle for a reliable complete edition. The scarce critical editions of some specific poems are still a minor part of the more than 18.000 verses that are collected in Migne's Patrologia Graeca, which reproduces the unfinished and disorderly $18^{\text {th }}$ century edition of his works by Maurine monks. ${ }^{1}$ This is doubtless one main factor that contributes to the paradox that his poetry is less taken into account than it would doubtless merit in the studies that deal with theological Greek literature in Late Antiquity. Of course his discourses have more doctrinal consistence, as is to be expected from the systematic argumentations and terminological precision that are inherent to prose; but the poetic format allows often bolder formulations that can illuminate his theological conceptions without the doctrinal constrictions imposed by systematic discourse. Therefore, the project undertaken by this volume must necessarily take Gregory's poetry into account as a significant by-product of Christian poetic theology.

The variety of Gregory's poetic production makes it impossible to approach it from a single point of view. In his own account about the reasons for composing poetry, he offers four different motives: to exercise spiritual measure through the practice of linguistic measure imposed by poetic metre; to teach doctrines through persuasive language; to show that Christians are able to compose poetry of such literary quality as that composed by Greek pagans; and to get personal consolation in hard times. ${ }^{2}$ Leaving aside the first and last reasons, which deal with personal motives, the second and third ones are most relevant for the comprehension of the theological and Biblical contents in his verses. Poetry is both a didactic tool for teaching Christian doctrine and a key instrument in the cultural contest that pagans and Christians were maintaining around the right to claim possession of Greek paideia. As shown by his discourses against Julian's attempt in 362 to exclude Christians

1 The Maurine edition was lost during the French Revolution and was recovered by D. A. B. Caillau, whose edition (1840) is reproduced by Migne. The poems follow the numbering resulting from this edition. Translations from the poems are mine except otherwise indicated.

2 “On his own verses” (II.1.39.33-55). On this poem, cf. Milanovic-Barham (1997). 
from the teaching of the Greek classics, Gregory was fully conscious of the importance of that cultural struggle, and even years after the death of the Apostate Emperor, he was concerned with contributing to Christian Greek paideia through his poetic work. $^{3}$

The importance of his cultural achievement has been slowly recognized in the last decades, in which editions, translations, and commentaries of particular poems have been slowly emerging. Likewise, studies dealing with his classical sources have analysed Gregory's frequent use of Greek poets, specially Homer, and parallels with Archilochus, Sappho, or Callimachus in specific verses have been duly noted as a clear sign of his outstanding learning. The study of the literary genres that he takes as models to imitate, and at the same time, to innovate, is indeed a fruitful approach to his literary projects: his use of heroic epic, threnoi, oaths, lyric poetry, and even tragedy has been fruitfully researched by scholars. ${ }^{4}$ It is evident that the adoption of a specific stylistic or generic model has key influence in his way of presenting his poetry of Biblical content, which is our object of interest here. In this chapter, I will contribute to this flow of studies with the commentary of a poem dealing with creation, that is paradigmatic of his knowledge of classical Greek poetry and his firm will to renew it in order to adapt Greek forms and genres to Christian themes, needs, and tastes. In spite of their importance, the literary models he follows in this piece, from literary theory about hymns to Hesiod's Theogony, have not to my knowledge been explored before.

\section{Menander Rhetor on hymns}

Let us start by focusing the attention in the most important work of late antique literary theory that has been preserved, the treatise on hymns attributed to Menander Rhetor. Of course it is not my intention to prove that Gregory knew this work, which cannot be proved or even considered a likely probability. However, Menander's judgements are representative of the kind of teaching learnt in rhetorical schools like those frequented by Gregory when he was young (and also by some conspicuous pagan contemporaries of the so-called Third Sophistic). Therefore, as a student of

3 Julian, Epistle 36.423 A-C: "But I give them (scil. Christians) this choice; either not to teach what they do not think admirable, or, if they wish to teach, let them first really persuade their pupils that neither Homer nor Hesiod nor any of these writers whom they expound and have declared to be guilty of impiety, folly and error in regard to the gods, is such as they declare" (translation Wright). Gregory's Discourses 4 and 5 are entitled “Against Julian”. On the controversy, cf. Elm (2012).

4 Prudhomme (2006) in her thesis has thoroughly researched important literary aspects of Gregory’s poetic work underlining his reception of classical authors; Demoen (1996) collected his mythical exempla mostly taken from Homer and Hesiod; Moreschini and Sykes (1997) note the frequent parallels with epic poetry; cf. Kambylis (1982), Simelidis (2009), Hawkins (2014) 142-183, and Basso 2015 for his poetic relation to Archilochus and Callimachus; Cataudella (1927) and Koster (1964) for his use of Sappho; on his use of Euripides, cf. my own paper in Herrero de Jáuregui (2020). 
rhetorical schools, Gregory would have used, if not Menander, similar treatises on types of hymns and rules to compose them-which, as we shall see, he used creatively in his poetic works.

Now, Menander dedicates his first book on hymns to the gods, and he distinguishes, among other kinds that are not relevant for the present purpose (e.g. apopemptic, deprecatory), the following types of hymns: ${ }^{5}$

1) Cletic hymns ( $\kappa \lambda \eta \tau$ tкoí): "they are such as most of those to be found in Sappho, Anacreon, and the other lyric poets, containing invocations of many gods" (333.8-10); "the poet has a greater licence than the prose writer. The style appropriate to cletic hymns is that which moves with elegance and splendour. This is why the poets insert their additional passages. The appropriate figures are those of invocation" (335. 19-222).

2) Scientific hymns ( Empedocles, expounding the nature of Apollo or Zeus. Most of the hymns of Orpheus are of this kind" (333.12-15); “some scientific hymns are fully explanatory, others are abbreviated; it makes a great difference whether one is concisely reminding a reader who is assumed to know, or giving instruction to one who is completely ignorant... some are written enigmatically, others in an overt manner... the enigmatic variety demands brevity, and those which do not convey instruction are in any case more summary; the others admit ample developments... In these hymns there is no need of a prayer at all. Such hymns should be carefully preserved and not published to the multitude or the people, because they look too unconvincing and ridiculous to the masses. As to the style, it is quite acceptable for it to approach the heights of the dythiramb, for there is no more solemn theme than these on which a human tongue may give utterance" (337.6-29).

3) Mythical hymns ( $\mu$ $\theta$ เкoí): "they are those which contain myths and proceed by bare allegory: e.g. Apollo built the Wall, Apollo was a serf under Admetus, and the like" (333.15-18); "they must have no element of overt sicence... they are appropriate in a higher degree to the poet... style must be allowed less licence, retaining epideictic ornament but far removed from the manner of the dithyramb" (338.25-339.10).

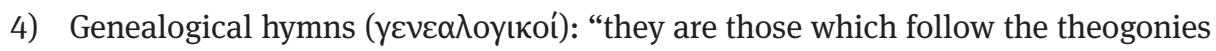
of the poets: e.g. when we say that Apollo is the child of Leto, and the Muses of Memory" (333.18-21). "If it is combined with other forms, this type welcomes length; it it is by itself, it is of use to poets, never to prose-writers... stylistic excellence in such composition resides in purity and freedom from wearisome excess; this may be achieved in poetry by moderation in the use of periphrases, and in prose by variety of cola" (340.8-20).

5 References to Menander's text and English translations are taken from Russell - Wilson (1981). 


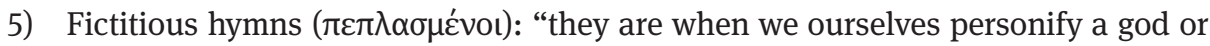
the births of gods or daemons, as when Simonides speaks of the daemon Tomorrow, and others of Hesitation, and so on" (333.21-24); "they cannot be constructed around the more celebrated of the gods, whose births and powers are well known, but rather, as a rule, around the obscurer gods and daemons... we should take care to invent hymns that are continuous and not unconnected... fictions should be elegant and pretty, not unpleasing...in all out fictions we must derive corroboration from true facts...fictitious hymns must be internally consistent and not introduce contradictory or conflicting statements... length and elaboration must also be carefully watched... this kind of hymn is very powerful and a sign of inventiveness" (341.1-20).

After having described the different kinds of hymns, Menander praises the highest possible composition that combines the different types: "I have said that some hymns are composed of a combination of all of these forms or most of them in like proportions. These are also the most complete laudations" (343.27-29).

Now Gregory's extense poetic production has a large number of compositions that clearly take into account the precepts of rhetoric such as those of Menander, while dwelling on purely Christian themes. Let us test this proposition with the analysis of a hymnic poem in which many of these types appear in isolation or in complex combinations.

\section{A Hymn to Virginity (I.2.1.1-214)}

The Dialogue of Virginity and Marriage is a lengthy poem in which each of the two personifications explain their own reasons from line 215 for several hundred lines. The dialogue from line 215 onwards has been commented in detail by Klaus Sundermann, who dates the poem around $370-372$. Since he discards the possibility that the first part springs from a different poem, this dating is of course also valid for the proem. ${ }^{6}$ Paradoxically, this proem (lines 1-214) has been neglected and it is seldom even mentioned. However, this section is central not only to introduce the allegorical characters of the dialogue, but also to understand Gregory's poetic agenda in this composition.

In effect, the poem is defined as a hymn, in a proem that follows the generic conventions of literary hexametric hymns. These are the first lines of the poem 1-14):

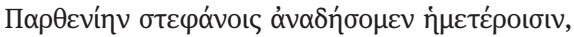

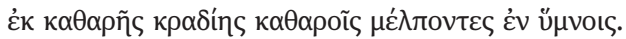
ToũTo yà

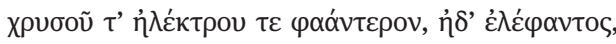

6 Sundermann (1991) 19-20. 


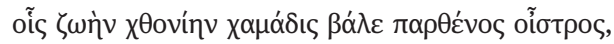

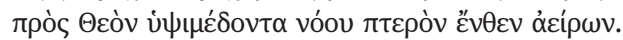

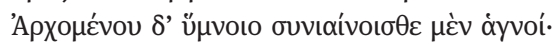

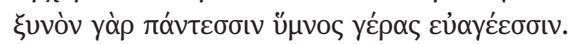

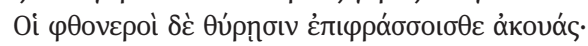

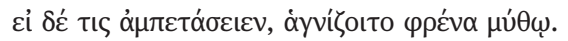

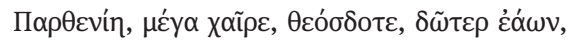

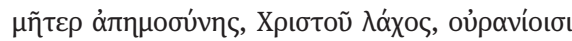

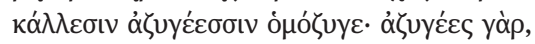

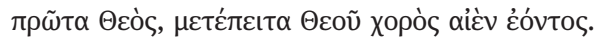

"We will bind Virginity with our crowns,

singing in pure hymns from a pure heart:

for this is the best gift of hospitality of our life,

shinier than gold and amber or ivory,

for those whom chaste impulse compelled to throw earthly life to the ground,

lifting from here the wing of the mind to God who rules from above.

Beginning the hymn, cheer up, you the pure:

for the hymn is a common privilege for all the pious;

and you, the invidious, close your ears with doors:

but if someone opens them, let him purify his mind with this account.

Virginity, I salute you, gift from God, deliverer of goods,

mother of goodness, possession of Christ, companion

of the heavenly beauties without spouse: for without spouse

is firstly God, and then the choir of eternal God”.

As in Homeric and Callimachean hymns, the first lines express the intention of starting a poem. They also refer explicitly to the tradition of initiatory poetry which is only adequate for the knowledgeable and pure, while the profane and impure may not listen and understand it. Purity is of course a fundamental requisite of cult that religious poets incorporated as a requisite of singing and listening to their poetry, like in Empedocles' invocation of the Muse. ${ }^{7}$ The profane are rejected from the audience of the poem, like in the imprecation canonized by Callimachus

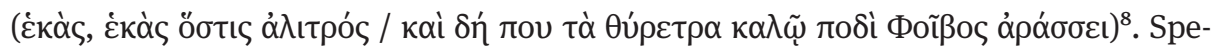
cifically, Gregory recuperates in this proem the Orphic image of closing the doors of the ears, a line functioning like a sphragis of Orphic poems (Orph. Fragm. 1 Bernabé:

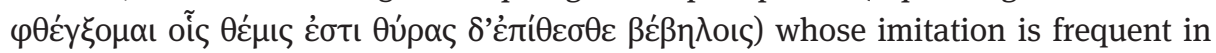
Greek literature9. Precisely Menander said (337.7) that “ scientific hymns ” should be presented as ainigmata so that only the chosen few may read them: Gregory's rhetoric of literary initiation is fully in accord with such prescription.

7 Emp. fr. 3 DK. Cf. Herrero de Jáuregui (2015) on these poetic images mimicking the proclamations of sanctuaries.

8 Call. Hymn. Apoll. 2.10. Cf. Verg. Aen. VI.258: procul, o procul este profani.

9 On the great fortune of Orph. Fragm. 1 in Greek literature, cf. Bernabé (1996). That Gregory was familiar with Orphic poetry can be ascertained: Herrero de Jáuregui (2007), (2010, 173-177, 213). 
The proem is followed by the invocation to the addressee, Parthenie (Viriginity),

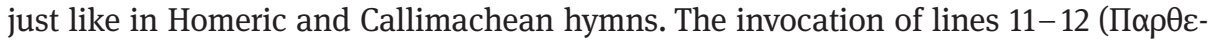

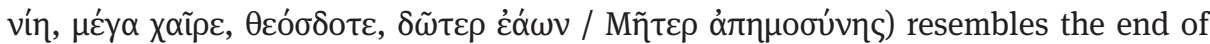
Callimachus' Hymn to Zeus too closely to be mere formulaic coincidence (91-92:

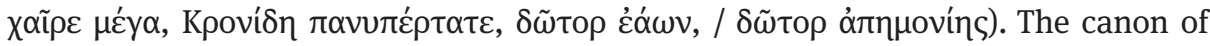
the cletic hymn could hardly be followed more strictly.

The following thirty lines, 20 - 55, dedicated to praise the Trinity and the angels, offer clear echoes of the "scientific hymns", to use Menandrean labels. It is a dense description, full of allusions, that appeals to those that are already familiar with the Trinitarian doctrine, which is adapted to the topic of chastity, in order to show that in the filiation of the Son there is no marital relation involved. Some prominent features of this section can be said to be typical of scientific hymns, whose formulations are only understood by the expert and initiated into the secret, in this case, the Trinitar-

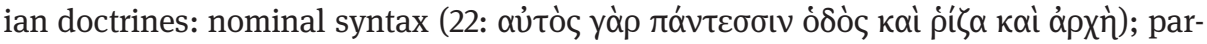

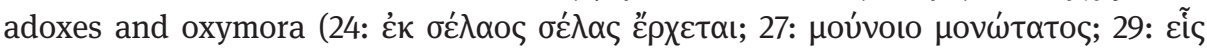

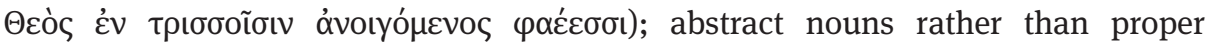

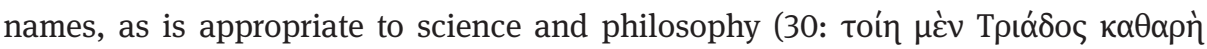

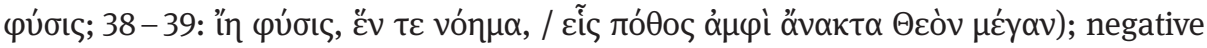
theology rather than mythical accounts (34-45); and neologisms that express doctrinal discoveries or intuitions, like the hapax legomenon oió

Parallels for these features are numerous in earlier Greek poetry, from Xenophanes and Parmenides among ancient poets to the theological lethanies of the Or-

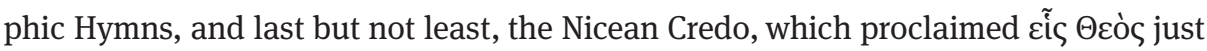
like so many henotheistic hymns from Hellenistic and Imperial times ${ }^{10}$. In fact, line 24, cited above, makes explicit echo to the formulation of the Nicean Credo, "light from light”, changing the regular phos for the epic term selas.

The most interesting part for our puroposes is the following section in which Gregory imitates and rivals Hesiod's Theogony. Gregory announces the revelation of “God's mysteries" as the necessary background for presenting Virginity's origin -for telling genealogy and birth is a most traditional way of hymning a divine being. This revelation, however, does not follow slavishly a given pattern: the two

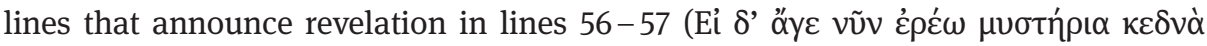

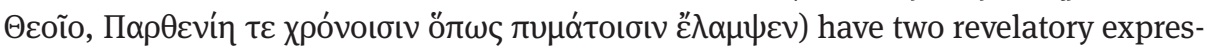

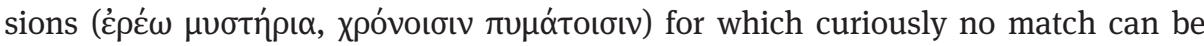
found in earlier philosophical or religious poetry. Imitation is not slavish or mechanic, but creative. And then his cosmogonic account starts (58-59):

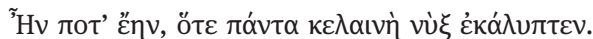

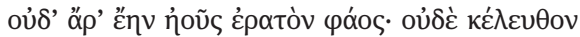

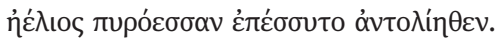

60

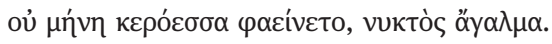

10 The classic monography on these expressions is Petersen (1926). 


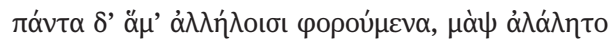

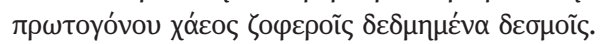

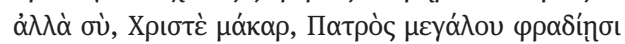

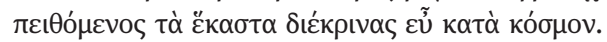

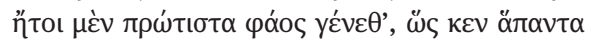

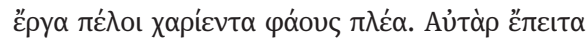

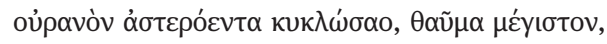

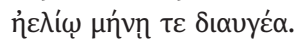

"There was a point in time when dark night covered everything:

For the amiable light of dawn was not, neither the sun pushed from the Orient his fiery path.

The moon, delight of the night, did not appear with its horns, and all things were carried together with each other, wandering vainly, submitted to the dark links of first-born Chaos.

But you, blessed Christ, obeying the desings of the great Father, discerned each thing well in order.

In effect, first of all light came to be, so that all works were made beautiful, full of light. But then, you formed into a circle the starry heaven, the greatest marvel, and shiny with the sun and the moon".

The first lines that describe the initial chaos do not allude Hesiod explicitly. There are some parallels with other poets, like Homer, Theognis, Pindar, Bion, or the Orphic Hymns, but none of them is particularly significant ${ }^{11}$. What these parallel expressions attest is a lively theogonic koiné, which would be particularly useful in the "mythical hymns" dealing with origins. It is in lines 62-78 that tell the creation of cosmos according to the account of the Book of Genesis when the reference to Hesiod becomes explicit.

Line 66 is clearly fashioned from line 116 of the Theogony, in which the Muses

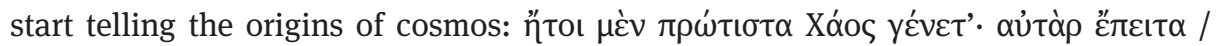

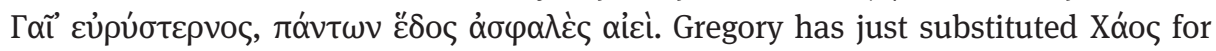

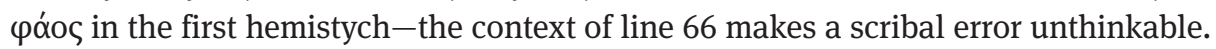
The huge differences between both poems and both cosmogonic accounts are stressed precisely by the explicit citation of Theog. 116. Furthermore, the fact that

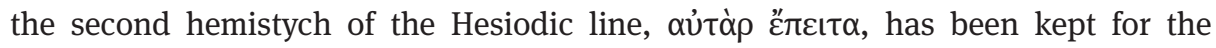
next line (67), in order to introduce a phrase about the creating role of light is signif-

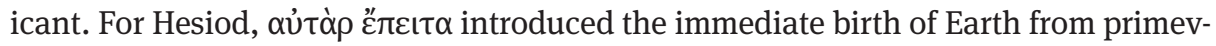
al Chaos. Heaven will be born from Earth at a later stage. Instead, in the Bible Heav-

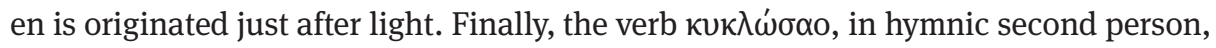
recalls that God's creating role excludes completely the theogonic metaphor of divine reproduction.

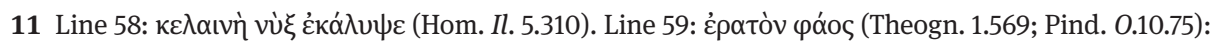
Line 62: vvктòৎ ö $\gamma \alpha \lambda \mu \alpha$ (Bion fr. 11.2 / Orph. Hymn. 9.9 / PMG 4.2786). 
This section, after more than a dozen lines paraphrasing the Genesis, closes up with an image of the entire cosmos as formed by the addition of sea, earth, and heav-

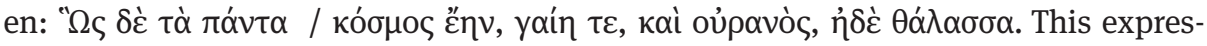
sion of cosmological completeness is markedly Hesiodic (Theog. 427, 487, in exactly the same order). Likewise, the final line of the section (78) contributes with a still

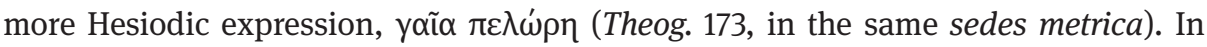
his poetic account of creation, Gregory proposes an alternative to Hesiod grounded on the Biblical model but using the Hesiodic model as point of reference.

The acceptance of the Hesiodic pattern, however, poses a serious theological problem. Gregory speaks (line 63) of a primordial obscurity, which he calls night and chaos, and this darkness becomes ordered and shaped through God's creative power. This chaos opposed to the current cosmos seems to spring from a Stoic reading of Hesiod rather than from the original meaning of the Theogony, but this is not too strange in the $4^{\text {th }}$ century ${ }^{12}$. However, this obscure and disorderly chaos is in any case, however it may be conceptualized, previous to póos, the primordial light through which creation begins. Is Gregory admitting, therefore, the pre-existence of matter? As it is well known, the pre-existent matter is a classical problem of ancient cosmology, both pagan and Christian, and Gregory himself defends in one of his dogmatic poems, On the Universe, the creation ex nihilo, i.e. that matter was also created by God ${ }^{13}$. This fundamental difference of Christian cosmology from Hesiod and his Stoicisant interpreters is marked in two ways.

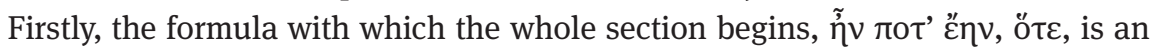
extremely rare analeptic expression, found only twice in Greek literature ${ }^{14}$. Gregory uses it only once more, in a poem On the soul, precisely before a section taken, as we shall see, from this poem. Sykes' commentary on this line says that this expression marks the recognition of a punctual moment of creation, the origin of time itself ${ }^{15}$. This may well be the case also here, since it would imply that the dark chaos was itself created by God before he started ordering it, and therefore it also had a beginning. This interpretation could seem slightly imposed by the need of

12 Gregory's notion of a dark chaos seems rather a huge disorder than a first separation, as it is in Hesiod. This conception, influenced by Stoic cosmogony, is already apparent in the beginning of Ovid's Metamorphoses (1.4: rudis indigestaque moles) and has been predominant up to our times: chaos would oppose cosmos as the order that is the telos of cosmogonic evolution.

13 Cf. Moreschini - Sykes (1997) 16-21; 143-173.

14 Apart from Gregory, the only example comes from 2nd cent. Rhetorician Alexander Numenius, who offers the following sentence, possibly Demosthenic, as example of analepsis (De figuris

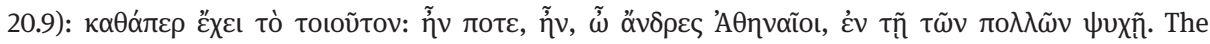
only further example comes from the Byzantine monk John Geometre in the 10th century (Or. I.3.23). 15 Poemata arcana 7.55 ( 451 A), cited below. Cf. Sykes 1997, 237: "the first four words recapitulate the point of Arc. 4 (scil. The poem "On the universe"): the world was not always in existence, but was created at a precise point in time. The words recall what Arius said about the Son (Symb. Nic. 325, anath. 1; Opitz 3.52.2; M 20.1540c), surely intentionally. It is right to talk in this way about the origin of the physical universe, just as it is wrong to use this language of the Son". 
ideological consistence rather than linguistics, since neither the imperfect tense nor

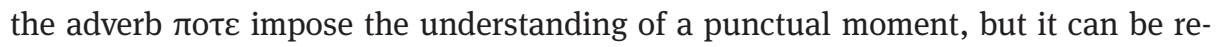
inforced by the purposeful similarity with the famous expression by Arius to express the creation of the Son: ก̃ ory's expression "there was, moment, when ..." emphasizes the positive meaning of the verb "to be" implying existence, but the inevitable resonance to Arius' formulation in the ears of the 4th century audience must have association to the beginning of such existence, and therefore, the lack of absolute eternity of that which has beginning-only God never began ${ }^{16}$.

Secondly, the creation of primordial darkness is also implied by the epithet $\pi \rho \omega$ toyóvoৎ that Gregory uses to qualify chaos in line 63. This might seem contradictory

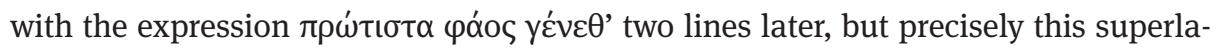
tive may be understood as an act of superior creation for light, while chaos would be a mere fabrication: $\pi \rho \omega ́ \tau \iota \sigma \tau \alpha$ would imply qualitative priority, rather than chronological. In fact, Protogonos is, in the aforementioned Greek theogonic koine, the name of the first-born god, Phanes in the Orphic theogonies, for instance (cf. Orphic Hymn 5 to Protogonos). By calling chaos $\pi \rho \omega \tau$ toyóvos, Gregory is definitely denying the eternity of matter.

Lines 79-138 continue the cosmogonic narrative using a different poetic register. This section seems to aim at what Menander calls "genealogical hymns", in which mythical narratives are combined with other hymnic forms. In fact, the tale of the creation of angels (lines 81-99) is exactly identical to that of the poem "On the soul" ${ }^{\prime 1}$. Since the internal chronology of Gregory's poems is very difficult to establish, can we ascertain which of the two poems is earlier? The two lines that introduce this section in the poem we are commenting describe God's pleasure in his creation

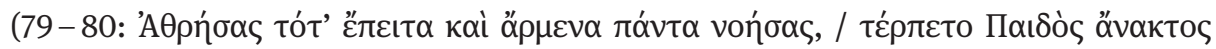

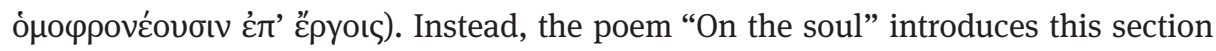
with these lines (53-60, PG 451a-452a):

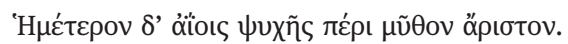

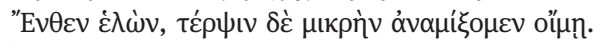

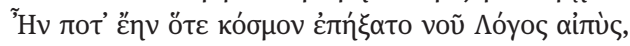

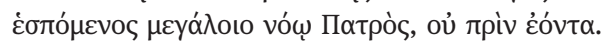

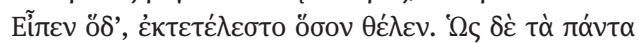

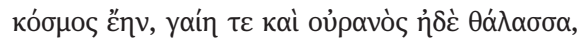

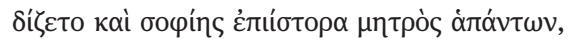

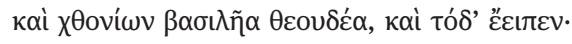

"Now I want you, picking up at this point, to hear my excellent account of the soul, and I shall mix a little enjoyment with my poem.

There was a point in time when the lofty Word of Mind,
}

16 I thank Filip Doroszewski for this suggestion, which is concomitant with Sykes' commentary on the poem "On the soul" (cf. previous line).

17 Sykes (1997) in his commentary to Arc. $7.59-77$ also points to a close parallel in Or. 38.11. 
following the intention of the mighty Father, framed the structure of the world which before did not exist.

He spoke, and his whole will was accomplished. When everything, earth, heaven and sea, cohered to form the world,

he sought a being to be acquainted with wisdom, mother of all that is,

to be also a godlike ruler of earthly affairs, speaking these words" (translation Sykes).

Like the poem on Virginity, also he poem "On the soul” talks about pleasure (terpsis), but it is that of the readers, when they hear the Christian account on the soul-a clearly secondary sense in comparison to God's pleasure upon seeing his creation (Gn. 1,12) versified by Gregory in lines $79-80$ of the poem on Parthenie quoted

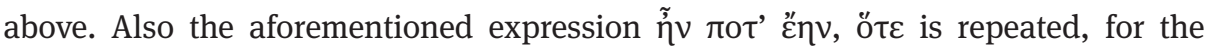
only time in Gregory's poetic corpus. So the account in the poem "On the soul" seems clearly a summarized version of this section of the poem on Virginity, which would be composed earlier.

From line 139 to line 171, the tale of Christ's incarnation and the deliverance from original sin combines the registers of the scientific and the mythical hymns, following Menandrean terminology typical features of both like the descriptive nominal syntax and the narrative speed coexist. For instance, lines 149-155 which describe the incarnation are characteristic of this mythical-doctrinal account:

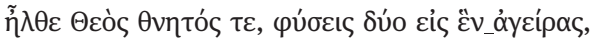

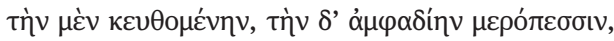

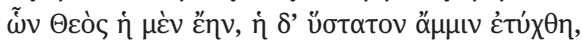

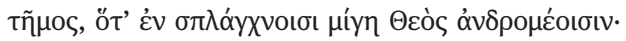

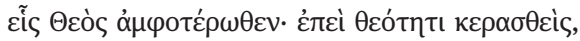

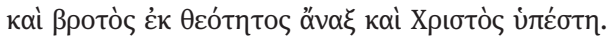

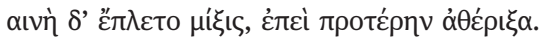
"He came as God and as mortal, uniting two natures in one, the former hidden, the latter apparent to men, the former was God, the latter was formed ultimately for us, in the time when God was mixed in human entrails: one God from both: for mixed with divinity, and mortal from divinity, came up as lord and Christ.
There was a new mixture, for the first one was despised".

After a lengthy account on the incarnation, Gregory goes back to the initial cletic hymn, with a brief praise of God (171-182) that announces through the annular structure implied in the return to invocation the imminent closing of this introductory section. A relevant structural parallel is the Homeric Hymn to Apollo (177-181), which makes the transition between the Delphic and the Delian parts with a brief cletic hymn in which the invocation $\tilde{\omega}$ ơv $\alpha$ (174) also appears-probably not by chance this expression is prominent in Gregory's invocation followed by a not less typical

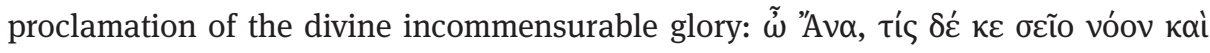

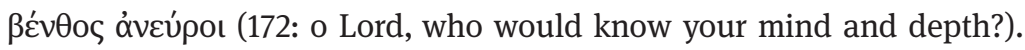


Finally, Gregory gets into the true subject-matter of the poem in a last section (182-214) which subtly introduces Virginity, Parthenie, the true divinity honoured in this hymn. Through correlative structures men... de..., hote... pote..., Gregory connects the account of the redemption by Christ with the contrapositions world /

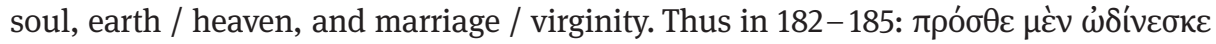

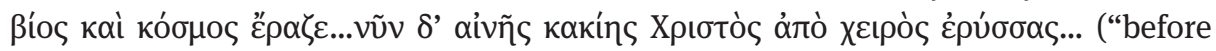
life and earthly world were suffering with childbirth pains... but now Christ taking them by the hand, liberates men from terrible disgrace"). Then in 187-188: кعivo

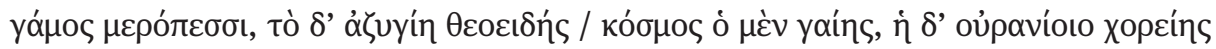
("marriage brings this to men, divine virginity that other thing; the former is ornate of the earth, the latter of the heavenly chorus"). Parthenie had been hidden during the

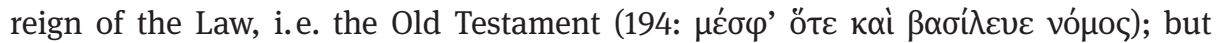

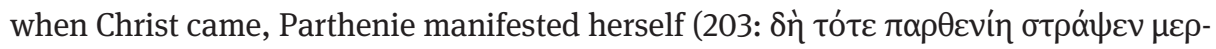

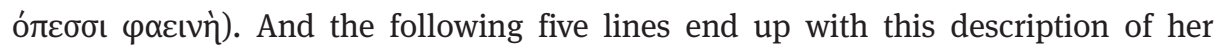
above-worldly place through perfectly symmetrical parallelisms (204-208):

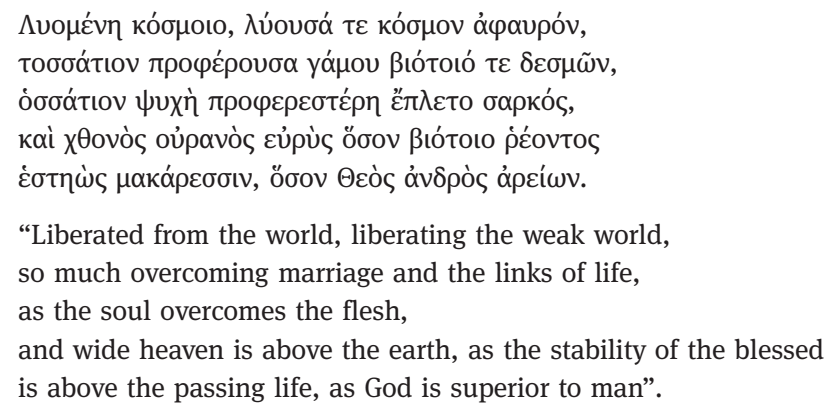

After this presentation, the dialogue between Parthenie and Gamos that constitutes the body of the poem will flow naturally. As Menander said, the true difficulty of fictitious hymns (peplasmenoi) is achieving consistence and continuity. Gregory's poetic effort to achieve them through this complex introduction is remarkable. Through the hymnic proem he has created the rhetorical plausibility of the subsequent dialogue. And just as the Homeric Hymns could function as proems to the larger epic poems, but they were independent compositions in themselves, this proem can also function as an independent hymn to Parthenie which shows Gregory's mastery in composing hexametric hymns.

\section{Conclusions}

If we go back to his self-confessed reasons to compose poetry, we may suppose that when composing this hymn, Gregory took personal delight, but he also achieved his other external goals: presenting Christian doctrine in a pleasurable way, and putting Christian literature at the height of pagan equivalents. The poem that has been com- 
mented, this hymnic proem to Parthenie, adapts the Christian accounts on creation to the canons of Greek traditional poetry, particularly theogonies: Orphic theogonies and Hesiod are the closest models which Gregory imitated and sometimes explicitly alluded to show precisely his doctrinal divergences. This effort is particularly original, since only Theophilus in his Autolycus had endeavoured to use Greek theogonical language to convey Christian Trinitarian doctrines: Theophilus' attempt was, however, in prose, and had little continuity ${ }^{18}$. In this poem, Gregory attempted to Christianize a genre that was particularly resistant to adapt, since Homer and Hesiod's accounts on the origin of the gods were the obvious rival that pagans, the last of them Julian, had opposed to the Christian Bible, and their polytheistic contents were full of images of sexual generation of the cosmos. After Gregory, Christian hexametric versions of the Bible would flow. His success in such difficult achievement showed that Christian poetry was already wholly worthy of Greek paideia.

\section{Bibliography}

Basso (2015): Sebastiano Basso "Per un approccio drammaturgico alle citazioni callimachee in Gregorio di Nazianzo", in: Atene e Roma 9.1, 1-24.

Bernabé (1996): Alberto Bernabé, 'La fórmula órfica "cerrad las puertas, profanos". Del profano religioso al profano en la materia', in: Ilu. Revista de ciencias de las religiones 1, pp. 13-37.

Cataudella (1927): Quintino Cataudella, "Derivazioni da Saffo in Gregorio Nazianzeno", in: Bolletino di Filologia Classica 33, 282-284.

Curry (1988): Carl Curry, "The Theogony of Theophilus," Vigiliae Christianae 42, 318-326.

Demoen (1996): Kristoffel Demoen, Pagan and Biblical Exempla in Gregory Nazianzen. A Study in Rhetoric and Hermeneutics, Turnhout.

Elm (2012): Susanna Elm, Sons of Hellenism, Fathers of the Church: Emperor Julian, Gregory of Nazianzus, and the Vision of Rome, Berkeley.

Hawkins (2014): Tom Hawkins. lambic Poetics in the Roman Empire. Cambridge.

Herrero de Jáuregui (2007): “¿A quién dirige Gregorio de Nazianzo su crítica de la reencarnación (De anima 22-52)?”, in: Adamantius 13, 231-247.

Herrero de Jáuregui (2010): Miguel Herrero de Jáuregui, Orphism and Christianity in Late Antiquity, Berlin-New York.

Herrero de Jáuregui (2013): Miguel Herrero de Jáuregui, “La filiación en las teogonías griegas según la apologética cristiana”, in: Patricio de Navascués et al. (eds.) Filiación V, Madrid, $111-126$.

Herrero de Jáuregui (2015): Miguel Herrero de Jáuregui, “The Construction of Inner Religious Space in Wandering Religion of Classical Greece”, in Numen: International Review for the History of Religions 62, 667-697.

Herrero de Jáuregui (2020): Miguel Herrero de Jáuregui, “Euripides in the Poems of Gregory of Nazianzus”, in: M. Schramm (ed.), Euripides-Rezeption in Kaiserzeit und Spätantike, Berlin-Boston.

Kambylis (1982): Athanasios Kambylis, “Gregor von Nazianz und Kallimachos”, in: Hermes 110, $120-122$.

18 Curry (1988), Herrero de Jáuregui (2013). 
Koster (1964): Willem J. W. Koster, "Sappho apud Gregorium Nazianzenum”, in: Mnemosyne 17, 374.

Milovanovic-Barham (1997): Celica Milovanovic-Barham, "Gregory of Nazianzus: Ars Poetica (In suos versus: Carmen 2.1.39)", in: Journal of Early Christian Studies 5.4, 497-510.

McGuckin (2006): John Anthony McGuckin, “Gregory: the Rhetorician as a Poet” in: Jostein Børtnes and Tomas Hägg (Hgg.), Gregory of Nazianzus: Images and Reflections, Copenhagen $193-212$.

Moreschini / Sykes (1997): Claudio Moreschini / David A. Sykes, St. Gregory of Nazianzus, Poemata Arcana, Oxford.

Peterson (1926): Erik Peterson, Heis Theos. Epigraphische, formgeschichtliche und religionsgeschichtliche Untersuchungen zur antiken "Ein-Gott" Akklamation, Göttingen.

Prudhomme (2006): Juliette Prudhomme, L'oeuvre poétique de Grégoire de Nazianze, Lyon (thèse de doctorat).

Russell - Wilson (1981): Donald Andrew Russell / Nigel Guy Wilson, Menander Rhetor, Oxford.

Simelidis (2009): Christos Simelidis, Selected Poems of Gregory of Nazianzus: I.2.17; Il.1.10, 19, 32: A Critical Edition with Introduction and Commentary, Göttingen.

Sundermann (1991): Karl Sundermann, Gregor von Nazianz: Der Rangstreit zwischen Ehe und Jungfräulichkeit: (Carmen 1,2,1,215-732), Paderborn. 

Juliette Prudhomme

\section{Les personnages bibliques, héros d'une épopée grecque chrétienne dans la poésie de Grégoire de Nazianze}

Dans le corpus poétique de Grégoire de Nazianze, l'influence de la poésie épique au niveau formel est bien visible : Grégoire écrit de nombreux poèmes en hexamètres dactyliques et il emploie les formes morphologiques et lexicales archaïques issues $\mathrm{du}$ corpus homérique. Les poèmes écrits en distiques élégiaques sont eux aussi fortement influencés par la langue homérique ou post-homérique. ${ }^{1}$ Cet usage correspond bien à l'époque à laquelle Grégoire écrit puisque c'est une forme poétique en vogue au IV ${ }^{\mathrm{e}}$ siècle. Citons pour exemple l'oeuvre des deux Apollinaire de Laodicée, le père et le fils, qui se sont essayés à plusieurs formes poétiques dont l'épopée. Grégoire connaît ces œuvres, qu'il juge hérétiques, et affirme dans une lettre qu'il souhaite que ses propres œuvres poétiques se substituent à celle des Apollinaire. $^{2}$

Pourtant, comme la majorité des chrétiens, Grégoire rejette les sujets de la poésie épique traditionnelle puisqu'il dit dans un des deux poèmes qui constituent son art poétique :

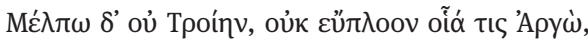

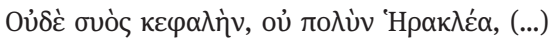

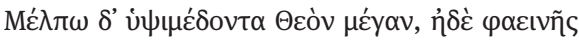

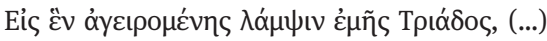

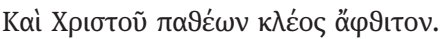

«Je ne chante pas Troie, ni comme un autre Argô à la belle navigation, ni la tête de sanglier ni le puissant Héraclès (...). Je chante le grand Dieu au trône sublime ainsi que la splendeur de ma Trinité brillante, réunie dans une unité, (...) et la gloire impérissable des souffrances du Christ». ${ }^{3}$

Tout en rejetant les sujets épiques, Grégoire affirme ici sa volonté d'écrire des vers épiques et chrétiens. Quelle est donc la place des personnages bibliques dans cette épopée chrétienne ? Si les personnages bibliques servent très souvent d'exempla, comme le montrent très bien les travaux de K. Demoen, peu de longs passages ou de poèmes sont entièrement consacrés à un personnage biblique précis. ${ }^{4}$ Ces pièces existent toutefois : il s'agit essentiellement des poèmes qualifiés de «bibliques», qui évoquent les textes scripturaires et les résument. Ils concernent très majoritairement

1 Ces poèmes se distinguent formellement assez peu des poèmes en hexamètres dactyliques. Voir Prudhomme (2006) 99-103 (http://www.theses.fr/2006LYO20054).

2 Grégoire de Nazianze, Lettre 101, 71, p. 68-69, Paris, 1974 (SC 208).

3 II.1.34, v. 71-72; 77-78; 83 (PG 37, 1307-1309). Traduction personnelle.

4 Demoen (1996).

https://doi.org/10.1515/9783110687224-019 
Jésus et les miracles qu'il a accomplis : le premier est en distiques élégiaques et les trois suivants sont en hexamètres dactyliques. ${ }^{5}$ Un autre poème présente des parallèles intéressants et porte sur les miracles d'Elie et Elisée : il est écrit en trimètres iambiques et va nous permettre d'élargir notre propos aux personnages de l'Ancien Testament. $^{6}$

Ces poèmes courts, peut-être destinés à être appris par cœur par des catéchumènes, ont-ils un intérêt sur le plan littéraire ? L'emploi de la forme et de la langue homérique est-il uniquement formel ou Grégoire cherche-t-il à donner un souffle épique aux héros bibliques ? Pour répondre à ces questions, nous allons procéder à une analyse précise des poèmes cités et des extraits d'autres poèmes qui nous ont paru significatifs.

\section{Des personnages bibliques évoqués dans une langue épique}

Chez Grégoire, les pièces à contenu biblique sont, en grande majorité, composées en hexamètres dactyliques et distiques élégiaques, le poète employant une métrique et une langue relativement élaborées, étrangères au matériau biblique lui-même.

\section{A Les liens avec le modèle scripturaire}

Grégoire dispose pour les poèmes étudiés de modèles bien déterminés et sa fidélité au texte scripturaire est grande. Ainsi, dans le poème Les Miracles du Christ selon Matthieu, Grégoire conserve l'ordre dans lequel sont rapportés les miracles dans chaque évangile. Ce premier poème, qui reprend l'Évangile de Matthieu, est un peu plus long, en raison de l'abondance des miracles qui y sont rapportés. Les deux poèmes écrits selon les Évangiles de Luc et de Marc sont plus courts : ils ont un nombre de vers à peu près semblable et comportent de très nombreux points communs. ${ }^{7}$ En revanche, le poème qui reprend l'Évangile de Jean est nettement plus court et ne fait que onze vers, ce qui est conforme au matériau biblique d'origine.

5 Quatre pièces sont intitulées Sur les miracles du Christ et portent sur les miracles rapportés dans le Nouveau Testament, composées, pour trois d'entre elles, en hexamètres dactyliques, et pour l'une en

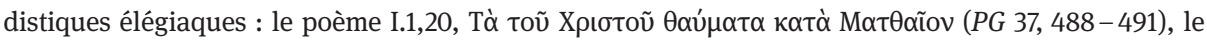

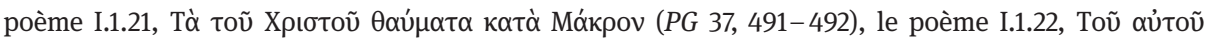

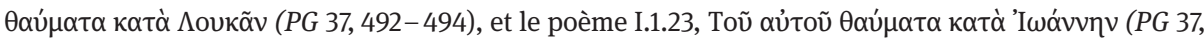
492-494).

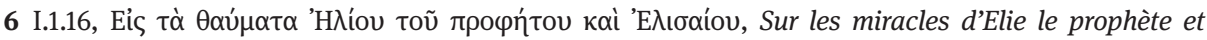
d'Elisée (PG 37, 477-479).

7 Une seule confusion apparaît à la fin du poème 21, où il est question des aveugles et des boiteux, épisode que Grégoire rattache à l'Evangile de Marc alors qu'il apparaît dans celui de Matthieu. 
L'étude du lexique montre aussi une certaine dépendance des vers de Grégoire à l'égard du texte scripturaire. Dans le poème Les Miracles du Christ selon Matthieu, plusieurs termes scripturaires sont conservés, même si Grégoire change parfois légèrement leur forme ou leur fonction. ${ }^{8}$

Dans quelques cas, on constate que Grégoire utilise un terme qui est attesté dans le texte scripturaire, mais qui apparaît dans un autre passage que celui qu'il est en train de paraphraser. Ce phénomène est perceptible dans les Miracles du Christ selon

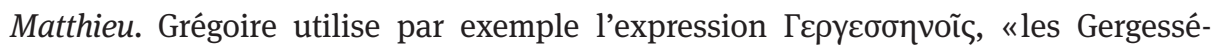
niens» (20, v. 7), terme attesté dans l'Évangile de Luc et non dans celui de Matthieu. Les démons sont souvent désignés par le terme $\Delta \alpha \dot{\prime} \mu \omega v(20$, v. 7, v. $12 ; 21$, v. 3 ; 22, v. 3 et v. 13) qui n’apparaît pas dans les passages paraphrasés mais qui est bien attesté dans le Nouveau Testament (Mt 8.31; Ap 16.14). Il est possible que Grégoire préfère ce terme en raison de sa présence dans le lexique épique. Le terme $\delta \alpha \mu$ ovíov (20, v. 14) est lui aussi emprunté à un verset relatif à un autre épisode que celui paraphrasé (Mt 9.33).

\section{B Le recours à la langue épique profane}

Même si Grégoire s'éloigne peu des Evangiles dans l'exposé des miracles, il recourt à un lexique qui est spécifiquement poétique et qui n'est pas attesté dans les passages bibliques correspondants. Dès une première lecture, le lecteur perçoit une différence entre la langue des poèmes en distiques élégiaques et hexamètres dactyliques d'un côté, et celle du poème en trimètres iambiques de l'autre. Dans les pièces en distiques élégiaques et hexamètres dactyliques, Grégoire utilise des désinences épiques

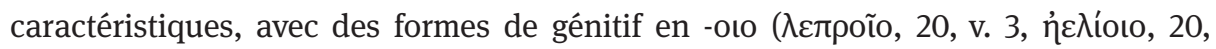

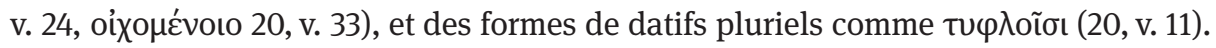
Grégoire utilise plusieurs fois des formes ioniennes comme voṽ $\sigma o v(20, v .3), v \tilde{n} \alpha$ (20, v. 17), vпoũ (20, v. 34). Plusieurs termes sont absents de l'Ancien Testament mais attestés en poésie épique : ainsi, le poète substitue ici au terme $\pi \varepsilon v \theta \varepsilon \rho \alpha ́$ (Mt 8.4) qui désigne la belle-mère dans les Evangiles, le mot homérique غ̇кupá (20, v. 5). ${ }^{9}$

De manière plus intéressante, il apparaît que Grégoire passe du lexique biblique à celui de la poésie profane, sans difficulté apparente. Ainsi, pour évoquer la guérison de la main sèche, le poète utilise deux fois l'adjectif łnpós qui est dans les Évangiles, tandis que dans le troisième poème, il emploie un adjectif homérique

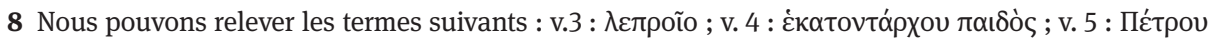

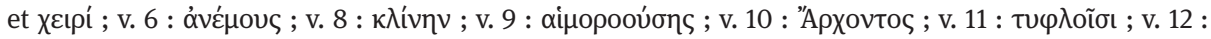

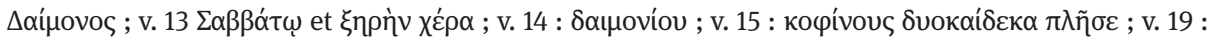

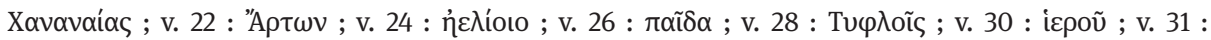

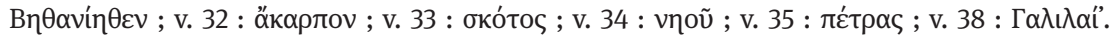

9 Il. XXII.451; XXIV.770.
} 


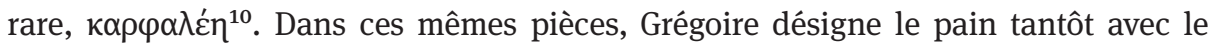
terme des Évangiles, åpтoৎ (21, v. 8 et v. 22), tantôt avec un terme homérique

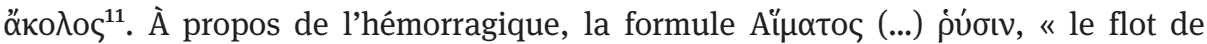

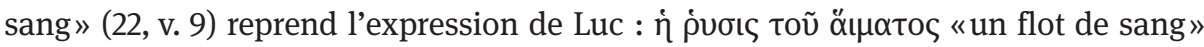
(Lc 8.44), en changeant l'ordre des mots, alors que l'expression $\alpha i \mu \alpha \tau o ́ \varepsilon \sigma \sigma \alpha v ~(. .$.

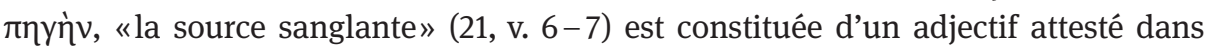
l'Iliade et chez Sophocle ${ }^{12}$.

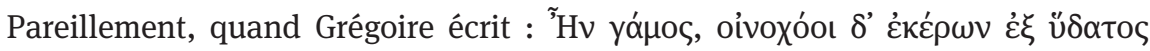
oĩvov, "Il y avait un mariage : les échansons mélangeaient le vin, à partir de l'eau»

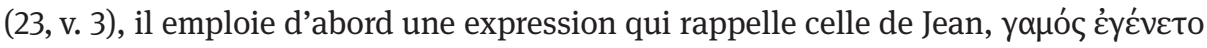
(Jn 2.1), mais change la forme verbale pour former un dactyle. Grégoire substitue ensuite au terme scripturaire $\delta$ ı́́kovoı, «les servants» (Jn 2.5) le terme homérique oivoxóou, «les échansons» et emploie une expression verbale typiquement homéri-

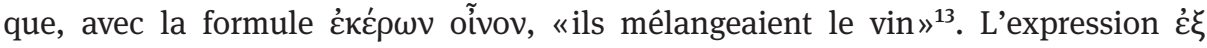

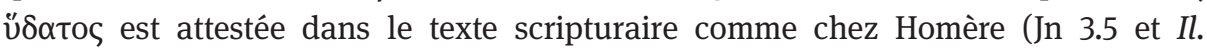
XXII.152) et le terme final, oívov, est placé en fin d'hexamètre, comme chez Homère.

L'examen de ces quelques exemples montre que, si la langue de Grégoire est composée d'éléments hétérogènes, le poète cherche souvent à employer une langue qui a une allure poétique, à varier le vocabulaire, tout en restant proche du texte scripturaire. Il est surtout révélateur de voir que le poète passe avec aisance, dans un même vers, d'une formulation qui nous semble plutôt proche du texte scripturaire à une expression d'allure plus poétique.

\section{Du personnage biblique au héros épique}

Une analyse axée sur les procédés stylistiques fait apparaître que Grégoire ne donne pas seulement un coloris poétique à ses vers mais cherche à mettre en valeur les personnages bibliques en reprenant des caractéristiques propres au genre épique.

\section{A La stylisation de la matière biblique}

Dans les exemples étudiés, il apparaît clairement que Grégoire procède non par amplification, comme de nombreux poètes latins auteurs de paraphrases bibliques, mais par omission. Les poèmes étudiés sont relativement courts, et si le poète reprend quelques éléments clés et caractéristiques, il en omet un plus grand nombre. Ces omissions sont rendues impératives par la brièveté du poème, brièveté qui vise

10 Od. V.369 et Il. XIII.409.

11 I.1.20.16 ; I.1.21.11; I.1.22.10. Voir Od, VII.222.

12 Il. V.82 ; Soph. Ant. 529 ; Anth. Pal. VI.154.

13 Od. XXIV.364 
sans doute à faciliter le travail de mémorisation. Cette brièveté est parfois extrême et conduit Grégoire à adopter très souvent un style concis, voire elliptique. Ainsi, quand

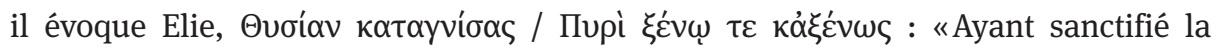
victime par un feu étrange(r) et de manière étrange» (16, v. 7-8), il faut sans doute

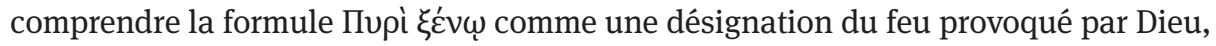
tandis que l'adverbe $\kappa a ̉ \xi \xi \varepsilon v \omega \varsigma$ renvoie à l'ordre donné par le prophète de jeter de l'eau sur le feu (3 reg 18, $30-40$ ).

Dans le poème Les Miracles du Christ selon Matthieu, les omissions sont pareillement très visibles : Grégoire récapitule en effet, dans cette pièce, des éléments épars de l'Evangile de Matthieu et les rassemble sous une forme versifiée et plus condensée. Tous les passages de dialogue disparaissent et seule l'action miraculeuse est rapportée. Souvent, les éléments relatifs au cadre spatio-temporel sont omis, sauf quand ils sont particulièrement significatifs pour l'identification du miracle (v. 7, 13, $28,31,38)$. Ce recours à la concision permet au poète de focaliser l'attention sur la figure évoquée : Jésus ou les prophètes.

\section{$B$ Le héros en action}

Un des éléments stylistiques récurrent qui permet de mettre le héros en valeur est le choix de formes verbales actives, qui n'apparaissent pas dans les passages bibliques paraphrasés. Ce phénomène est bien visible dans les épisodes de guérison, puisque Grégoire recourt à des formes verbales actives ou moyennes, alors que, dans les textes scripturaires, ce sont des formes passives qui sont employées. Grégoire écrit

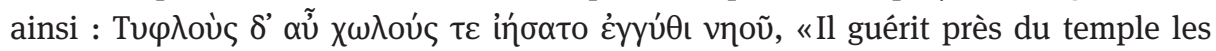
aveugles et les boiteux» (21, v. 17), alors que dans l'Evangile de Matthieu, le verbe est

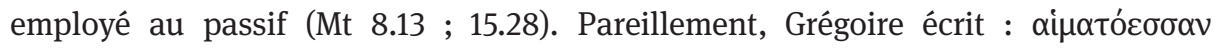

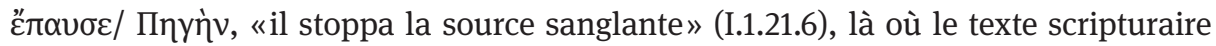

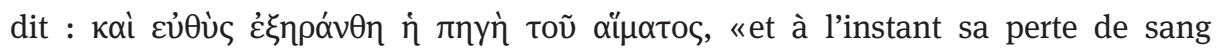
s’arrêta» (Mc 5.29). L'épisode de la fille de Jaïre est évoqué dans deux des poèmes.

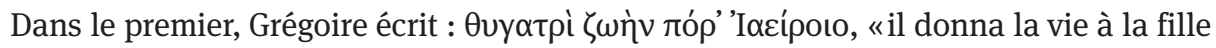

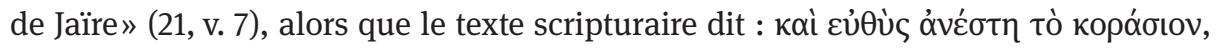
«et aussitôt la fillette se leva» (Mc 5.42). Dans le deuxième poème, la formule :

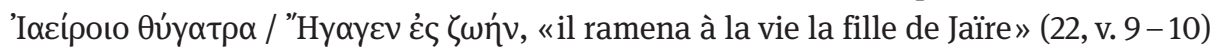

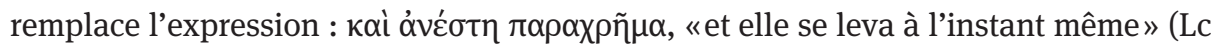
8.55). Si certains verbes sont conservés, Grégoire préfère aux tournures passives des tournures actives, mettant ainsi en valeur la figure du Christ agissant, alors que dans le texte biblique, c'est souvent la personne guérie qui est en position de sujet. Ce procédé permet à Grégoire de changer le point de vue de la narration pour souligner le rôle salvateur du Christ.

Le même procédé apparaît pour les prophètes Elie et Elisée. Ainsi, chez Grégoire, Elie est le maître de la pluie (16, v. 6-7), alors que dans l'Ancien Testament, Elie observe et annonce le retour de la pluie, mais ne la provoque pas réellement. $\mathrm{Pa}$ - 


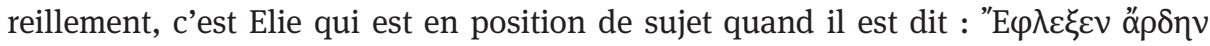

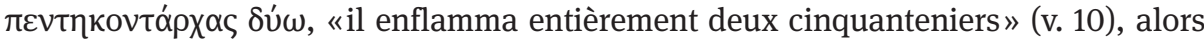

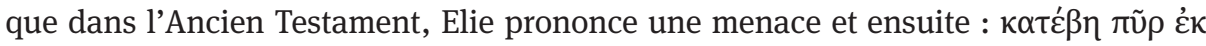

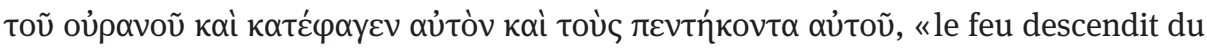
ciel et le dévora, ainsi que ses cinquante hommes» (4 Rg 1.12). C’est Elisée qui de-

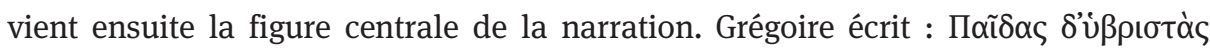

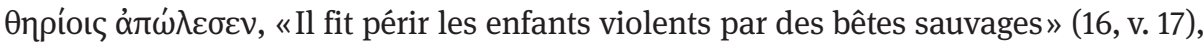

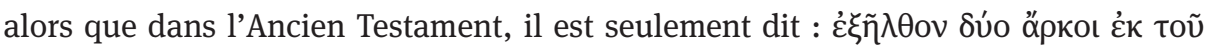

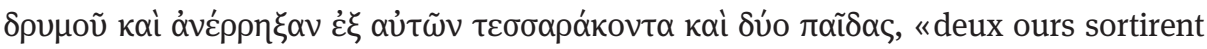
de la forêt et dépecèrent quarante-deux de ces enfants» (4 Rg 2.24). Grégoire focalise donc ici aussi l'attention non plus sur les victimes mais sur la figure prophétique concernée, présentée comme agissante et placée au premier plan.

\section{Le recours aux images poétiques frappantes}

Une autre caractéristique de la réécriture des miracles est le choix par Grégoire d'un lexique plus expressif, qui permet lui aussi de mettre en valeur la figure de Jésus.

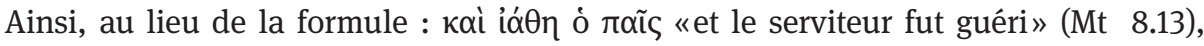

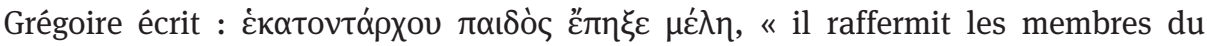
serviteur du centurion» (20, v. 4). La formule $\mu \varepsilon^{\prime} \lambda \eta \eta \dot{\eta} \gamma v v \mu$, «raffermir les membres»,

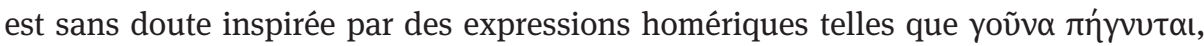
«les genoux se raidissent ${ }^{14}$. Toutefois, alors que, dans ces expressions, le verbe $\pi n ́ y v u \mu$ est employé au passif et évoque la peur qui raidit certains membres, Grégoire l'emploie ici à l'actif et dans un sens positif, afin de bien souligner que l'initiative salvatrice revient au Christ. Dans ce cas, Grégoire joue donc sur un écart de sens avec le modèle littéraire profane, pour souligner la puissance miraculeuse du Christ.

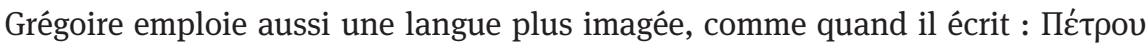

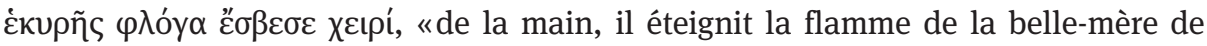
Pierre» (20, v. 5). Le poète réemploie ici une expression prosaïque, déjà appliquée à un phénomène miraculeux, dans un sens métaphorique. ${ }^{15} \mathrm{Il}$ met en outre en valeur le caractère apaisant du geste du Christ, alors que, dans l'Evangile, il est simplement

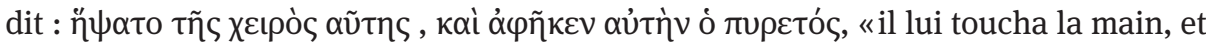
la fièvre la quitta» (Mt 8.15). C'est encore une formule plus imagée qui est employée,

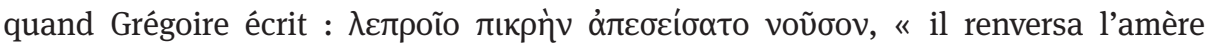

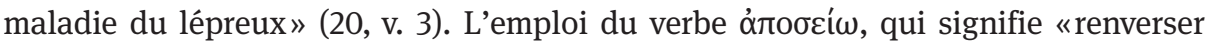
par une secousse», donne au vers l'allure d'un combat en personnifiant la maladie 
comme un ennemi qu'il faut abattre. ${ }^{16}$ Si des emplois métaphoriques sont attestés chez Aristophane avec ce verbe, son usage avec le thème de la maladie semble une innovation de Grégoire.

L'emploi récurrent de la métaphore du lien permet pareillement de mettre en valeur la figure du Christ. Cette métaphore est attestée dans certains passages évangéliques. ${ }^{17}$ Grégoire en a toutefois un usage particulièrement abondant et fait

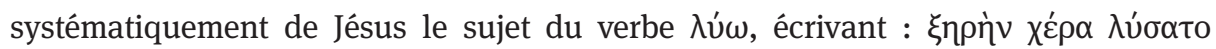
$\delta \varepsilon \sigma \mu \tilde{\omega} \nu$, «il délia une main sèche de ses liens » (20, v. 13), ou encore $\delta \varepsilon \sigma \mu o ̀ v ~ \varepsilon ้ \lambda v \sigma \varepsilon$ /

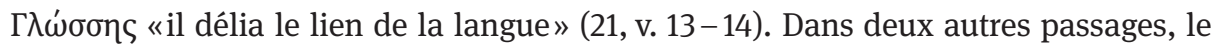

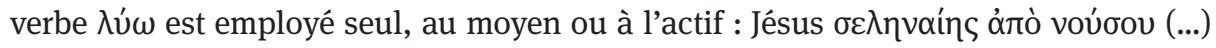

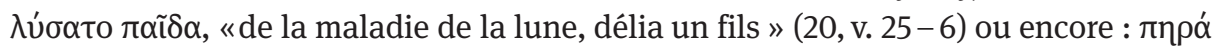

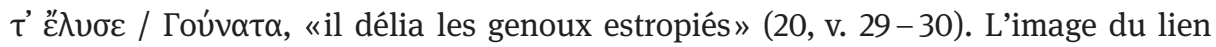
apparaît aussi pour souligner la force du Christ capable de dompter les éléments,

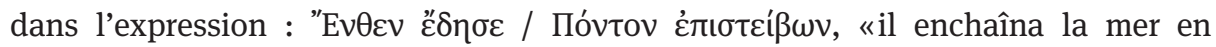
marchant dessus» $(21$, v. 8$)$, scène dans laquelle Jésus est présenté dans sa supériorité par rapport aux forces du mal, incarnées par la mer.

La personnification des éléments opposés permet aussi de faire du Christ un

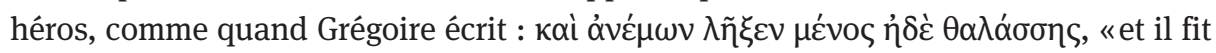

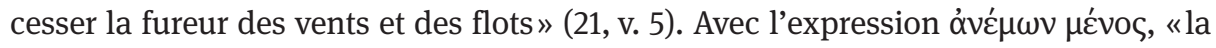
fureur des vents", Grégoire personnifie les forces cosmiques et il crée un tableau

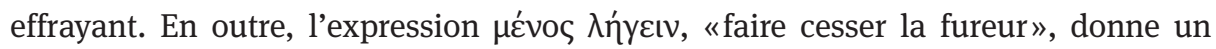
coloris épique à l'expression puisque c'est un emprunt à Homère, pour parler de la colère d'Idoménée qui veut massacrer les Troyens. ${ }^{18}$

Grégoire recourt donc à plusieurs procédés littéraires caractéristiques de l'épopée pour parler de Jésus et des prophètes Elie et Elisée : il met ainsi en valeur ces figures bibliques qui deviennent des héros puissants et salvateurs, évoqués dans de courtes vignettes stylisées.

\section{Une épopée chrétienne}

Dans son projet poétique cité en introduction, Grégoire dit qu’il veut chanter «le grand Dieu» (II.1.34.77) et non plus les sujets épiques habituels, ou encore «la gloire impérissable des souffrances du Christ» (II.1.34.83), formule dans laquelle il emploie

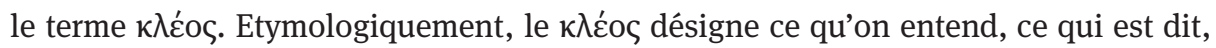
et par la suite signifie la gloire, gloire que la poésie homérique a pour but de chanter. ${ }^{19}$ Grégoire reprend donc la fonction traditionnelle de l'aède mais remplace les héros païens traditionnels par Jésus ou les figures bibliques. Nous avons vu

16 On trouve un emploi poétique de ce verbe chez Theog. Eleg. I.348.

17 Lc 13.16 et Mc 7.35

$18 \mathrm{Il}$. XIII.424.

19 Nagy (1991) 16-17. 
jusqu'à présent qu'une place importante était accordée à la figure de Jésus : nous allons maintenant analyser comment se fait ce travail de substitution en cherchant des parallèles plus précis entre les figures bibliques et les héros épiques traditionnels.

\section{A Jésus comme substitut des héros épiques traditionnels}

Si Grégoire favorise des formulations qui soulignent la puissance du Christ, il n'hésite pas non plus à reprendre des formules qui renvoient non seulement à un contexte militaire mais qui, en plus, désignent l'action d'un héros ou même d'un dieu de l'épopée.

Dans les poèmes portant sur les miracles, pour évoquer le Christ qui «chasse

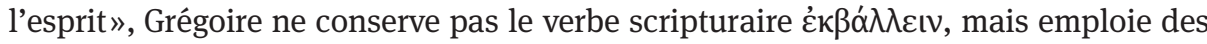

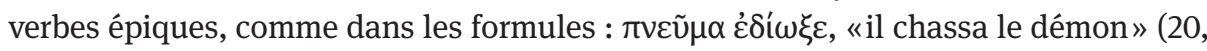

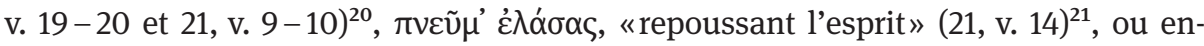

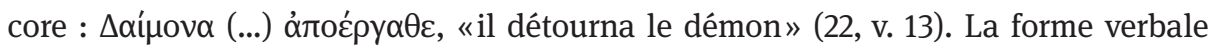

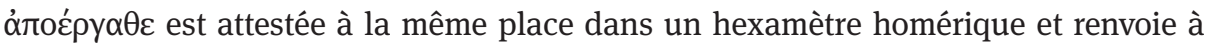
un contexte guerrier dans lequel intervient un dieu : il est en effet question d'un combat entre Achille et Agénor, au cours duquel Apollon, choisissant d'intervenir :

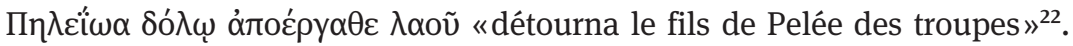

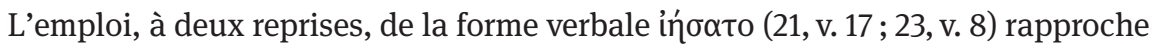
quant à elle le Christ de Péon, le médecin des dieux dans l'Iliade, à propos duquel la

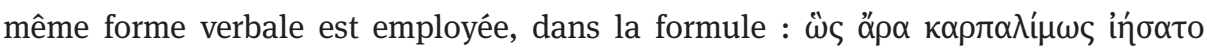

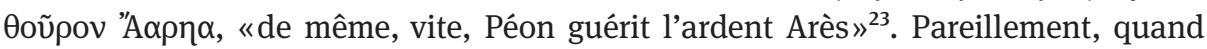
Grégoire dit que Jésus : $\varepsilon \xi \xi \sigma \alpha ́ \alpha \omega \sigma \varepsilon \mu \alpha \theta \eta \tau \alpha$ c,, «sauva ses disciples» (23, v. 7), il reprend une forme verbale homérique, employée à propos de Poséidon qui, poursuivant Ajax : $\varepsilon \xi \xi \sigma \alpha ́ \alpha \omega \sigma \varepsilon \theta \alpha \lambda \alpha ́ \sigma \sigma \eta \varsigma$ « le sauva des flots» ou à propos d'Aphrodite qui, pro-

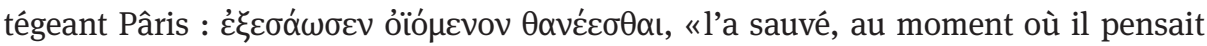
périr ${ }^{24}$. On voit donc que Grégoire évoque Jésus dans les mêmes termes que l'aède évoquait les dieux païens de l'épopée.

Un deuxième parallèle nous semble intéressant. Dans les pièces étudiées, Grégoire choisit un sujet très spécifique, le miracle, qui n'est pas seulement biblique, mais appartient aussi à la littérature grecque profane, et même, à certaines formes

20 Le verbe appartient au vocabulaire guerrier épique, mais n’est pas employé à l'aoriste chez les autres poètes épiques.

21 Voir Il. XVI.87 et XXI.217.

22 Il. XXI.599.

23 Il. V.904.

24 Od. IV.501 ; Il. IV.12. 
poétiques. ${ }^{25}$ Certains hymnes homériques laissent ainsi une grande part aux récits à caractère miraculeux, en particulier l'Hymne homérique aux Dioscures, dans lequel les divinités domptent les vents et la tempête, motif repris dans une idylle de Théocrite. ${ }^{26}$ Les pièces les plus proches auxquelles nous pouvons comparer celles de Grégoire appartiennent à l'Anthologie de Planude et énumèrent les travaux prodigieux d'Héraclès. Le mot «miracle» n'y est pas employé, mais les structures de ces pièces sont semblables à celles des poèmes de Grégoire. Nous citons les premiers vers du poème 92 qui est en hexamètres dactyliques et comporte des adverbes numériques :

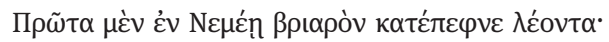

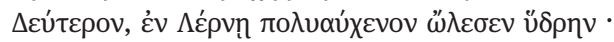

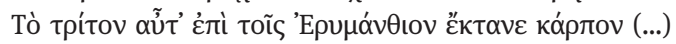

«Premièrement, il massacra le puissant lion à Némée.

Deuxièmement, à Lerne il exécuta l'hydre aux cous sans nombre.

Troisièmement, il tua le sanglier qui hantait l'Erymanthe (...) $»^{27}$.

Si l'on compare cette énumération avec celle du poème 20 , on peut rapprocher le

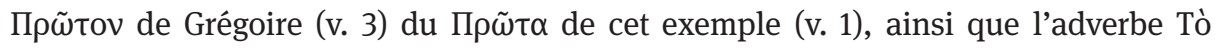
$\tau$ ¡́ítov placé dans les deux poèmes en début d'hexamètre (20, v. 5). Il est possible que Grégoire ait eu connaissance de ce genre de poèmes, consacrés à Héraclès ou à une autre divinité ayant accompli des hauts faits. Cette proximité entre les épigrammes consacrées aux travaux d'Héraclès et les poèmes de Grégoire apparaît aussi au niveau lexical ou thématique. Dans les deux types de poèmes apparaissent, au nombre

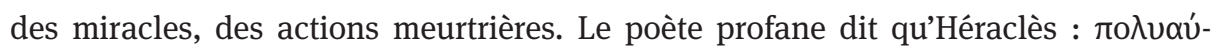

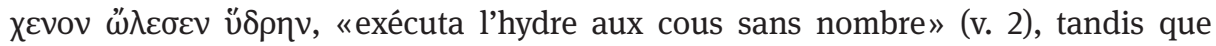

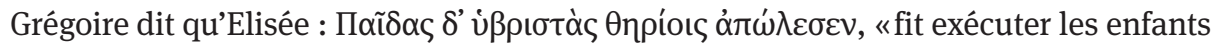
violents par des bêtes sauvages» (16, v. 17). D’autres ressemblances lexicales montrent qu'un terme qui désigne, dans les épigrammes profanes, un travail herculéen, remarquable par la force déployée, est repris par Grégoire pour parler d'une action

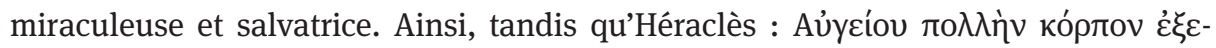

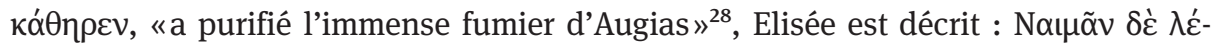

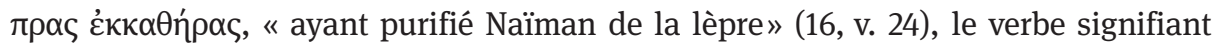
que Naïman est sauvé. Pareillement, le verbe «chasser», qui est employé pour parler

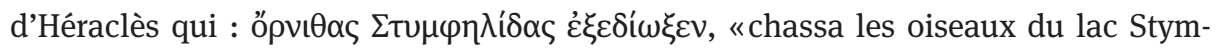

25 Voir à cet égard Cotter (1999), qui est constitué d'un répertoire de textes de l'Antiquité profane et de textes scripturaires. Pour la plupart des miracles présents dans les poèmes cités, elle propose des parallèles. Elle consacre plusieurs chapitres aux miracles concernant la guérison, l'expulsion des démons, le contrôle du vent et de la mer, et le changement de l'eau en vin.

26 Hymne homérique aux Dioscures, v. 12-17 et Theocr. Id. 22, v. 8-22.

27 Anthologie de Planude 92, v. 1-3, Paris, C.U.F., 1980 (trad. R. Aubreton, F. Buffière, p. 114-115).

28 Anthologie de Planude, 92, v. 7. 


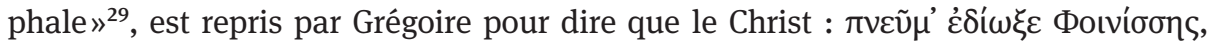
«chassa l'esprit de la femme de Phénicie» (21, v.9), action qui permet là encore une libération et une guérison humaine.

\section{B La christianisation des personnages vétéro-testamentaires}

Un autre procédé d'écriture témoigne de la volonté de Grégoire de créer un héroïsme chrétien : il s'agit de la christianisation des miracles accomplis par les prophètes Elie et Elisée. Pour les prophètes comme pour Jésus, Grégoire emploie le terme $\theta \alpha u ́ \mu \alpha \tau \alpha$ et procède ensuite par énumération. Les formulations choisies pour les prophètes renforcent encore le parallèle entre les miracles.

Ainsi, la reformulation de l'épisode dans lequel Elie redonne vie au fils de la veuve (16, v. 5-6) est particulièrement significative. Grégoire écrit dans son poème :

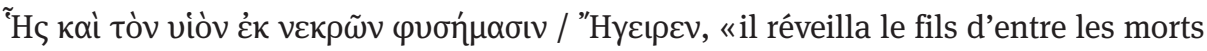
par son souffle» (16, v. 5-6). Avec le terme $\varphi v \sigma n ́ \mu \alpha \sigma ı$, Grégoire conserve l'idée

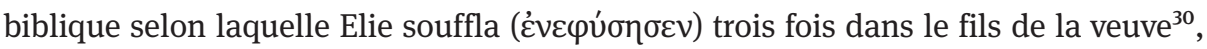

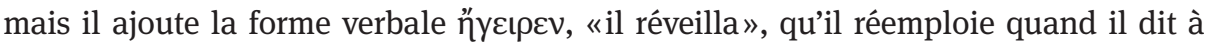

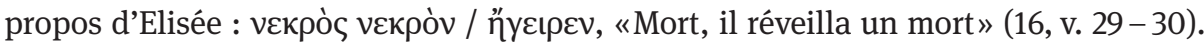

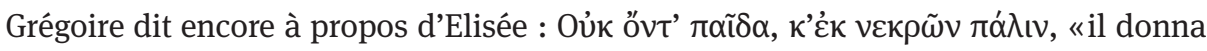
un fils, qui n'existait pas, (le ramenant) ensuite d'entre les morts» (16, v. 21), quand il

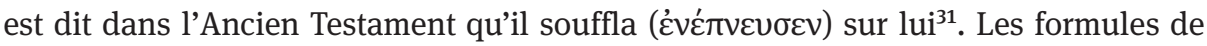
Grégoire rappellent les expressions habituellement employées par les chrétiens pour parler de la résurrection, comme lorsque les évangélistes écrivent à propos de Jean-

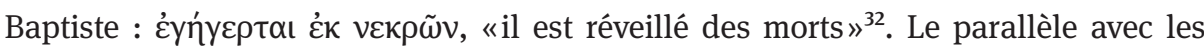
événements néo-testamentaires est renforcé par l'emploi du même type d'expression dans les poèmes rapportant les miracles de Jésus, puisque Grégoire écrit à propos du

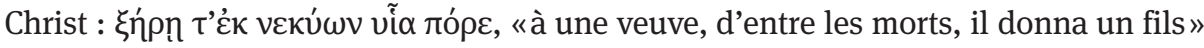
(22, v. 6). Grégoire suggère donc que les prophètes bibliques possèdent une force qui préfigure la résurrection, à la suite d'autres Pères grecs. ${ }^{33}$

Ces quelques exemples montrent bien la volonté de Grégoire de présenter à ses lecteurs des héros chrétiens, substituts aux dieux païens évoqués dans l'épopée, dans un mouvement de surenchère qui en fait des héros exceptionnels.

29 Anthologie de Planude, 92, v. 5.

$301 \operatorname{Rg} 17.21$.

$312 \operatorname{Rg} 4.35$.

32 Mc 6.14, à propos de Jean-Baptiste.

33 Irénée de Lyon évoque ainsi trois épisodes de la vie d'Elie dans leur rapport avec le salut chrétien : le jeûne, la théophanie de l'Horeb, mise en lien avec la Transfiguration, et l'enlèvement sur le char, qui préfigure la résurrection des Justes. Voir Iren. AH III.22.2 ; IV.20.9 -11; V.5.1 ; 21.2. Origène voit dans la traversée du Jourdain par Elie une figure du baptême, (Origène, Sur l'Evangile de Jean VI.238 -51), comme, plus tard, Basile de Césarée (Basile de Césarée, Sur le baptême I.2.5.21). 


\section{Grégoire, un héros de l’épopée chrétienne}

Deux autres extraits, qui s'éloignent des exemples étudiés jusqu'à présent, ont retenu notre attention et permettent de mettre en lumière un procédé caractéristique et original de l'écriture poétique de Grégoire. Les personnages bibliques que Grégoire y évoque - Moïse, Phinéès et Job - lui servent en effet de figures d'identification et lui permettent de se mettre en scène, lui le poète, comme le nouveau héros de son épopée chrétienne.

\section{A Grégoire combattant de la parole, nouveau Moïse et Phinéès}

Dans un poème dans lequel Grégoire exprime ses inquiétudes à voir la Trinité remise en cause, il dresse le portrait de l'homme qui pourrait sauver la situation. Bien que Grégoire ne présente pas ce portrait comme le sien, il est très probable qu'il parle de lui. Il écrit :

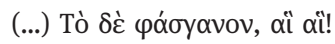

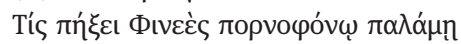

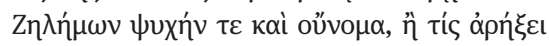

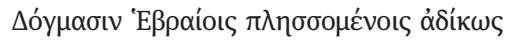

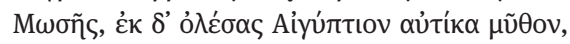

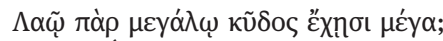

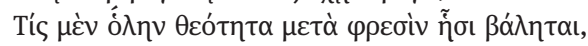

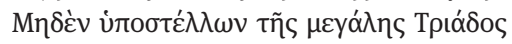

'Hغ̀ vó

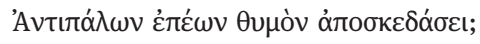

«L'épée ! Hélas! Hélas! Quel est le Phinéès qui la plantera d’une main pourfendeuse de la fornication, plein de zèle pour l'âme et le nom, ou quel est le Moïse qui défendra les enseignements des Hébreux criminellement frappés, et qui, ayant ainsi aussitôt anéanti la fable égyptienne, recueillera une grande gloire auprès de ce grand peuple ? Qui concevra dans son esprit la divinité tout entière, sans rien soustraire à la grande Trinité, ou qui, grâce à un esprit subtil et des paroles vigoureuses, repoussera la colère des déclarations ennemies ? $»^{34}$

Grégoire fait ici référence à deux figures vétéro-testamentaires, qui servent déjà de modèle aux chrétiens avant lui. ${ }^{35}$ Phinéès est un prêtre qui tue un israélite pour le punir de forniquer avec une étrangère, adepte du culte de Baal-Péor. Il les transperce en plein ventre, geste par lequel il fait cesser le fléau qui s'abattait sur le peuple (Nb 25.7-8). Ce personnage est évoqué dans des formules à caractère épique : il est armé

34 II.1.15.21-30.

35 Le statut de modèle de Phinéès apparaît en 1 M 2, 54. Voir également Philon d'Alexandrie, De vita Mosis I, 301 et Grégoire de Nysse pour qui le geste de Moïse est une image du combat de la vraie religion contre le paganisme, Vie de Moïse II.13. 


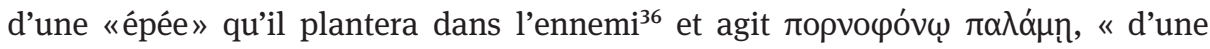
main pourfendeuse de la fornication», expression formée à partir d'un adjectif inventé par Grégoire pour souligner la dimension meurtrière du combat. Avec Moïse, dont le nom est mis en valeur en début de vers, Grégoire se réfère à l'épisode dans lequel celui-ci tue un égyptien qui s'est attaqué à un hébreu (Ex 2, 11-2), acte héroïque que Grégoire interprète selon les codes de l'épopée puisqu'il précise que

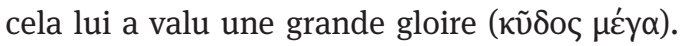

Ces deux modèles, Grégoire les choisit pour évoquer un combat d'un autre ordre : celui qu'il peut livrer grâce à ses paroles. La question posée par le poète au vers

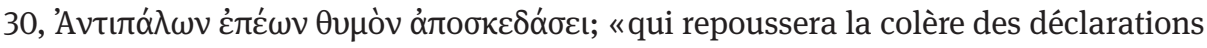
ennemies ?», concerne un combat dogmatique, mais rappelle, formellement, des combats physiques, puisque le verbe est employé habituellement pour parler des soldats. ${ }^{37}$ Les paroles du défenseur de la Trinité sont quasiment personnifiées avec le

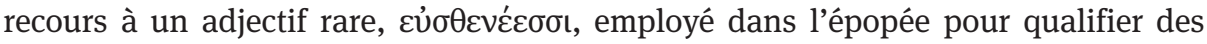

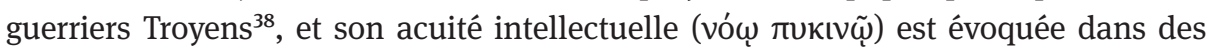
termes employés par Homère pour parler de l'intelligence divine ${ }^{39}$. Pour peindre le portrait du poète justicier, Grégoire utilise donc des figures scripturaires emblématiques du combat contre le mal et l'impiété : il y voit des modèles pour son propre combat et devient ainsi lui-aussi un héros épique au service de la Trinité

\section{B La gloire paradoxale : «je suis un nouveau Job»}

Une autre figure biblique à laquelle Grégoire s’identifie est celle de Job, personnage grâce auquel il réinterprète le motif épique de la gloire, déjà présent dans le passage précédent. Si Grégoire dit vouloir chanter la gloire du Christ, il se met aussi lui-même en scène comme un sujet poétique, digne d'être chanté car accablé de maux. Il introduit donc une nouvelle idée : celle de la gloire paradoxale. Dans ce poème, Grégoire déclare :

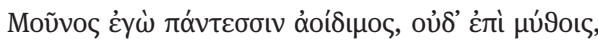

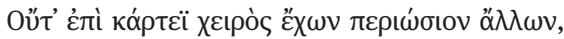

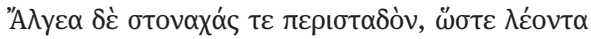

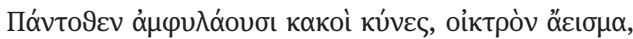

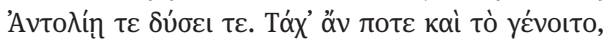

"H

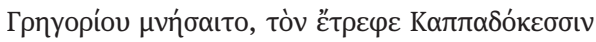

36 Le terme $\varphi$ óoyavov est employé par Sophocle pour parler de Déjanire dont le flanc est transpercé

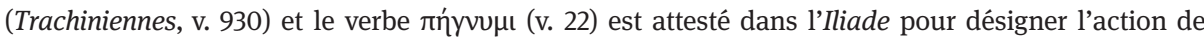
planter une pique : Il. XXII.283

37 Voir par exemple Démosthène, Sur la couronne, v. 289.

38 Quintus de Smyrne, Suite d'Homère I, v. 232. Voir aussi Suite d'Homère IV, v. 44 et v. 293.

39 Il. XV.461. 


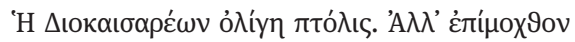

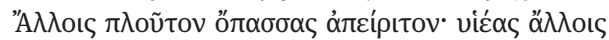

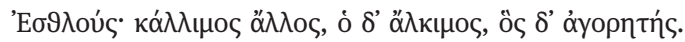

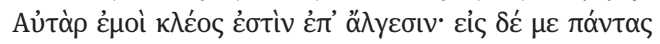

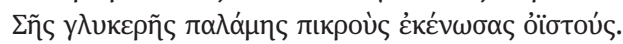

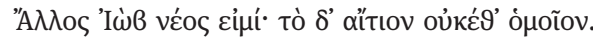

«Moi seul je suis digne d'être chanté par tous, non parce que je dépasse les autres par mes paroles ou par la force de mon bras, mais parce que je suis entouré de souffrances et de gémissements, comme un lion qu'environnent de toutes parts en aboyant des chiens méchants, misérable objet de chansons du Levant au Couchant. Il pourrait bien se faire qu'un homme (...) fasse mémoire de Grégoire qu'a nourri en Cappadoce la petite cité de Diocésarée. Mais à certains, tu as accordé l'infinie richesse laborieuse, à d'autres de nobles fils ; celui-ci est beau, celui-là est vaillant et cet autre bon orateur. Mais moi, ma réputation repose sur mes souffrances. Sur moi, tu as vidé toutes les flèches amères de ta douce main. Je suis un autre Job, mais la cause n'est plus la même $»^{40}$.

À l'image de son modèle, Grégoire se décrit comme un lion environné de méchants (Jb 10.16), ou comme une cible sur laquelle Dieu envoie ses flèches (Jb 16.12). Le paradoxe vient de ce que contrairement à Job, ses souffrances extrêmes ne lui apportent pas la gloire, mais font seulement de lui un motif de chansons. Pour ex-

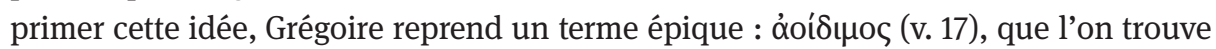
dans l'Iliade ${ }^{41}$, et qui signifie à l'origine, selon J. P. Vernant, «devenir digne d'un chant qui raconte, dans une geste sans cesse reprise et répétée, un destin admiré de tous». ${ }^{42}$

Grégoire insiste sur le caractère paradoxal de sa gloire, et l'oppose aux conceptions épiques en inversant un certain nombre de motifs. Ainsi, il évoque l'étendue géographique de sa gloire qui correspond, en négatif, à celle des héros de l'épopée. ${ }^{43}$ La formule employée par Grégoire, «du Levant au Couchant» (v. 21), placée en début de vers, rappelle des épigrammes écrites en l'honneur d'un grand personnage devenu célèbre à travers le monde. ${ }^{44}$ Grégoire reprend ici une manière de s'exprimer qui souligne habituellement l'ampleur de la gloire des empereurs, pour évoquer sa propre gloire, dont la grandeur repose sur des attributs opposés.

Pareillement, quand Grégoire énumère plusieurs types de personnages glorieux, il établit une liste qui reprend le procédé rhétorique du priamel, présent dans l'Iliade. ${ }^{45}$ Le poète chrétien compare en effet sa situation à celles qui, traditionnellement, sont synonymes de gloire : la richesse, l'abondante descendance, l'éloquence,

40 II.1.19.17-22; 25-31 (PG 37,1271-1273)

41 Il. VI.357-358.

42 Vernant (1989) 93.

43 Od. I.344.

44 Voir l'épigramme consacrée à Constantin dans Anthologie de Planude 369, v. 1-3 et l'épigramme 64, consacrée à Néron.

45 Voir par exemple Il. XIII.726-735. 
la beauté, le courage et l'éloquence (v. 27-28). A l'opposé de cette gloire, Grégoire définit la sienne propre, qui repose «sur les souffrances» (v. 29).

L'effet de surenchère dans les souffrances apparaît aussi dans la sphragis du poème (v. 25-26). Grégoire semble ici imiter la signature de Nicandre qui écrivait :

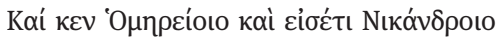

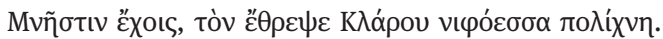

«Et, du poète homérique, tu pourras à jamais garder le souvenir, de Nicandre qu'éleva la blanche bourgade de Claros ${ }^{46}$.

S’il s'exprime comme le poète homérique, Grégoire ne définit toutefois pas sa ville d'origine de manière méliorative, mais en soulignant sa petitesse, avec l'adjectif óAíyn qui rappelle la dimension paradoxale de la gloire revendiquée.

En conclusion, l'analyse attentive de ces poèmes bibliques montre bien que ces pièces, en apparence courtes et banales, ont fait l'objet d'un travail d'écriture élaboré et présentent à ce titre un intérêt sur le plan littéraire. Elles constituent un bon exemple de la manière dont Grégoire entrelace deux traditions et réussit à créer une impression d'homogénéité et de cohérence. C'est sans doute parce que le poète favorise les motifs présents à la fois dans la Bible et la poésie épique et aussi parce qu'il procède par allusion discrète et savante. Par ailleurs, Grégoire essaie de marquer l'esprit du lecteur en mettant en scène de manière aussi frappante que possible les figures bibliques. Il reprend un lexique militaire adapté à son propos et des procédés épiques propres à renforcer l'expression, comme l'amplification, la surenchère, ou la stylisation. La figure centrale est celle de Jésus et c'est celle qui est la plus mise en valeur. Si peu de vers sont consacrés aux figures vétéro-testamentaires, ces personnages jouent toutefois un rôle important puisqu'ils servent de modèles héroïques à Grégoire et que c'est par leur intermédiaire que le poète se met en scène comme un héros épique au service de la Trinité. C'est sans aucun doute cet aspect qui fait l'originalité de la poésie de Grégoire : le poète met en effet en scène un «je» pas seulement épique mais aussi lyrique, devenant un anti-héros appelé à une gloire paradoxale et chantant ses propres malheurs.

\section{Bibliographie}

Demoen (1996): Kristofell Demoen, Pagan and biblical exempla in Gregory Nazianzen: a study in rhetoric and hermeneutics, Turnhout.

Cotter (1999): Wendy Cotter, Miracles in greco-roman Antiquity, Londres.

Nagy (1991): Gregory Nagy, The Best of the Acheans: Concepts of the Hero in Archaic Greek poetry, Baltimore.

46 Nicandre, Thériaques, v. 957-958, Paris, C.U.F., 2002 (trad. J.-M. Jacques, p. 75). 
Prudhomme (2006): Juliette Prudhomme, «L'oeuvre poétique de Grégoire de Nazianze: héritage et renouveau littéraires», 2006, thèse en ligne, p. 99-103 (http://www.theses.fr/ 2006LYO20054).

Vernant (1989): Jean Pierre Vernant, L'individu, la mort, l'amour, Paris. 



\section{Grave Matters: Love, Death, Resurrection, and Reception in the De laudibus Domini}

\section{Introduction}

This article is part of a larger project on love, death, burial, and resurrection. It is the point of departure for a longer and more elaborate story that will be presented elsewhere in a fuller, different form. ${ }^{2}$ There the discussion will focus not on philology, but on reception and cultural history. But it starts with a poem. And these Strasbourg conference-proceedings are the perfect venue in which to argue philological and literary-historical matters.

\section{De laudibus}

The De laudibus domini is a 148-verse-long hexameter poem that is known (by those who know it) as the first description of a post-Biblical miracle from the ancient world ${ }^{3}$ or the earliest reasonably securely datable (post-316/17) Christian poem in Latin. ${ }^{4}$ Jacques Fontaine-described it as "ce singulier pot-pourri poétique." 5 Brandes split it into the miracle (1-35), the laudes (36-142: Christ the Creator and Christ the Redeemer), and concluding prayer (143-148). I would characterize it as a highly personal and regional, slightly schizophrenic, aretalogy that is above all concerned with Resurrection, both being resurrected and resurrecting. For a long time, it gets dis-

\footnotetext{
1 We don't, thank goodness, work in a vacuum. Key points in the argument depend on the material realia of funerary culture. I am extremely grateful, first, to Barbara Borg for helping me get started with Roman double burial: bis dat qui cito dat! Patrick Périn, Paul Van Ossel, and Bailey Young shared expertise about the situation under the ground in Gaul. Roger Tomin and Ekkehard Weber gave me epigraphic instruction. Renate Pillinger shared her photos of early Christian material. Victoria Zimmerl-Panagl of the CSEL and David Morris of the Classics Collections of the University of Illinois Library generously provided scans of harder-to-find scholarship. Kurt Smolak corrected the German of a (different) oral version of this paper with his characteristic care and exquisite Sprachgefühl. My warm gratitude to all, and to the patronus operis, Michele Cutino, for the chance to take part in his wonderful conference in Strasbourg!

2 A preliminary version of the latter was delivered as "Liebe, Tod und Auferstehung im Weltbild der Spätantike," as part of the Maimonides Lectures, $7^{\text {th }}$ Symposium. "Verkörperung des Geistes: Die Auferstehung des Leibes" OeAW, 28 June 2018. See now also Shanzer (2019).

3 Fontaine (1981) 101, which is not quite accurate. See below p. 292, and Shanzer (2019) 722-23 for Tertullian.

4 For its early fortuna in literary histories, see Brandes (1887) 18.

5 Fontaine (1981) 101. Earlier see Brandes (1887) 16.
}

https://doi.org/10.1515/9783110687224-020 
tracted with the Son and with Creation. But it reins itself in and returns by its end to eschatology and triage at Interim and End Time. In one strange passage, where it is not strictly biblical (vv. 130 -143), it describes the Harrowing of Hell. ${ }^{6}$ And it contains a rare testimonium for exorcism of the ghost-possessed. ${ }^{7}$ In its later sections it can sound quite like a biblical epic. As with the blind men's elephant- it depends on which bit of it one has got in one's hand.

\title{
Grave affairs: "When one of us dies, I want to be buried in one grave ... "
}

My concern is the charming miracle with which the author began. The English poet Andrew Marvell famously urged his coy mistress to make love to him, for, said he, "The grave's a fine and private place, but none, I think, do there embrace ... ."8 But some were depicted embracing there in Antiquity as in the magnificent sarcophaguses of Ramtha Visnai and Thanchvil Tarnai from the Ponte Rotto Necropolis in Vulci now in the Boston Museum of Fine Arts. ${ }^{9}$ Etruscan society was prepared to depict man and wife reclining on a dining couch for two, as in the terracotta monument from the Banditaccia Necropolis in the Villa Giulia in Rome. But not every couple was lucky enough to die at the same moment. Leonard Mosley relates the following of Lord Curzon:

\begin{abstract}
"When the service was over. his body was put aboard the train and taken north to his beloved Kedleston. There, in the beautiful little Memorial Chapel which he had built, he was laid beside his beloved first wife, Mary, underneath the marble figure of the adoring Angel. And though the last years of his life had not been exactly filled with mirth, he did, in death, have his one little joke. Some months after his interment, Grace visited his tomb to leave some flowers. The electric light failed and she fumbled around among the shelves on which lay the remains of the Curzon ancestors. Her fingers encountered, on one of them, a slip of paper. When the lights went on again, she read it: 'Reserved for the Second Lady Curzon,' it said, in Curzon's handwriting."10
\end{abstract}

6 Bardy (1933) 46 and 50 is quite right about his curious relationship to the Bible. Ibid., 50. for an intriguing comparison to Arnobius.

7 This has to be the import of De Laud.137-39, where souls of the biaothanatoi acquire other bodies and cry out at Jesus' name and retreat from them. For the unusualness of the concept, see Shanzer (2017) $280-83$.

8 Andrew Marvell, "To his Coy Mistress." vv. 31-32.

9 Haynes (2000) 287-291 who says (291) that they are elsewhere unparalleled except at Chiusi, fig. 240. These are graves of the Tetnie family. Brelich (1937), 18 mentions the extreme polarities in Etruscan sepulchral imagery.

10 Mosley (1960) 269. 
And Roman epitaphic practice helpfully left open the possibility of planning for a Hereafter with a partner of one's choice. ${ }^{11}$ Ancient double burials of men and women have been excavated, such as the $5^{\text {th }}$ C. CE "Lovers of Modena." 12 So far archaeology (for the moment).

\section{The Miracle in De laudibus}

The De laudibus' initial miracle involves a similar situation but with a special twist. A loving married pair each hoped to predecease the other, but the woman died first. ${ }^{13}$ The bereft widower caused a large tomb to be excavated to accommodate both his wife and eventually himself, for in life they had slept in one bed. And when he died, the woman's corpse, though bound tight in grave-bandages, was caught stretching out her left hand to her husband with a gesture of living love. ${ }^{14}$

The text of this narrative is not sound: there are clear syntactic (and other) problems. And since in two cases I will be suggesting transposition, I will briefly annotate certain lines, noting either major problems (bold typeface), and observations, topics, or modality (smaller typeface) between square brackets. I am hoping that the desired logical sequence may thereby become clearer.

De Laudibus $7-35^{15}$

Nam qua stagnanti praelabitur agmine ripas

Tardus Arar, pigrumque diu vix explicat amnem

qua fraterna Remo progignitur Aedua pubes

coniugium memini summa pietate fideque:

lex divina tamen meritum cumulabat amoris

et votum ambobus socium praecedere morte

maerorique pio curam mandare sepulcri.

Sed prior uxorem decreti pagina legit.

Tunc desolatus largo iubet ore cavari,

post mortem fiant quae membris hospita saxa:

11 Sandys (1919) 61-62 on the uses of "V" and " $\theta$." Also Cagnat (1914) 292-293. The joke (which I have from Roger Tomlin) is one of "Beachcomber's" who in the "By the Way" column in the Daily Express once advertised an ocean cruise (a competition prize?) that included 'free burial at sea with partner of one's choice.' Pietri (1981) 577 says that bisomus and biscandens (IUR NS 8159 v. J. 393) are the terms for a grave for two people. The former is a hapax in Theodora's inscription in ICUR I. 317 (Supplement 1703): Theodora quae vixit annos XXI m. VII d. XXIII in pace est bisomu. 12 http://www.dailymail.co.uk/news/article-2057415/Together-forever-lovers-holding-hands-1-500years discovered-Rome-grave.html

13 De laudibus $10-14$.

14 For this as an authentically Gallic superstition, see Opelt (1978) 163 who cites Plin. NH XXVIII.25: Alius saliva post aurem digito relata sollicitudinem animi propitiat. pollices, cum faveamus, premere etiam proverbio iubemur. In adorando dextram ad osculum referimus totumque corpus circumagimus, quod in laevum fecisse Galliae religiosius credunt. fulgetras popsymis adorare consensus gentium est. 15 Text of Salzano (2000) 33-34 with some adjustments of capitalization. 


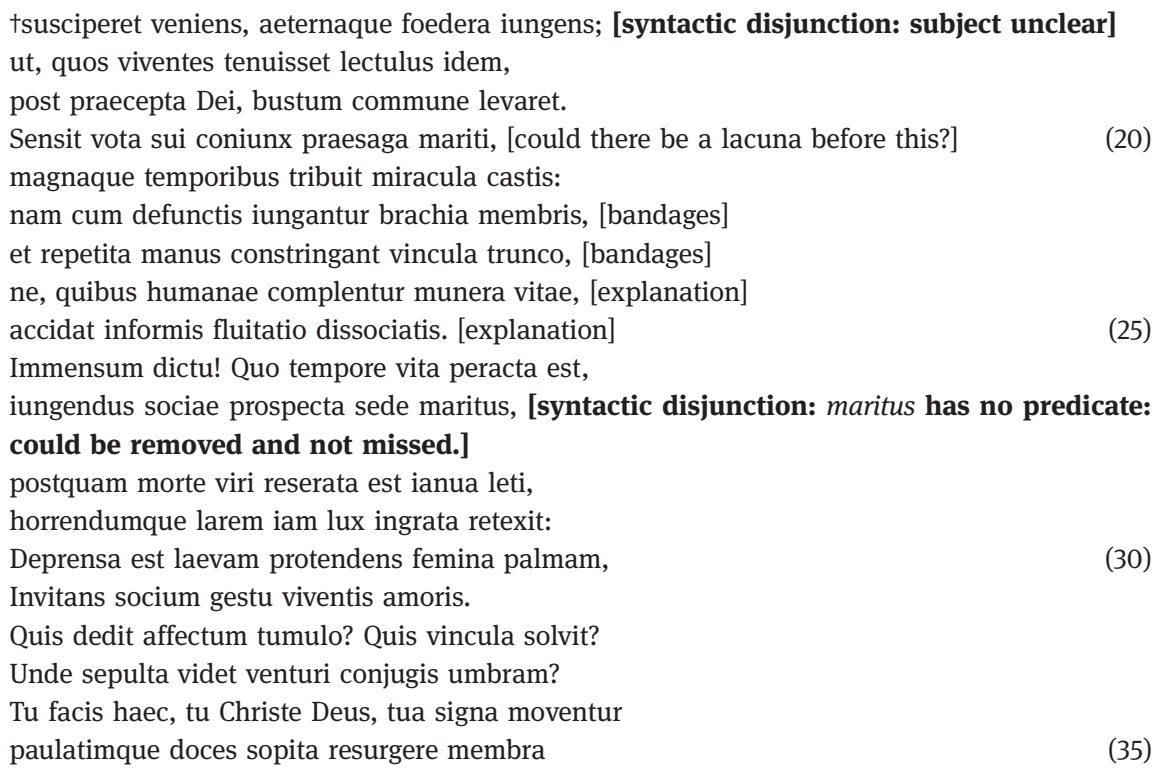

I have noted the two main problems: verse 17, which I am inclined to obelize and delete, and verse 27, which I suspect is out of place and may belong above, after line 19, with a conjectured lacuna in its environment. This would yield the following second version of the text, where I have relegated some of the problems to the footnotes to make it easier to read. The precise solutions to these textual problems do not, however, in any way affect the argument that follows.

\section{De Laudibus 7-35}

Nam qua stagnanti praelabitur agmine ripas

Tardus Arar, pigrumque diu vix explicat amnem

qua fraterna Remo progignitur Aedua pubes

coniugium memini summa pietate fideque.

Lex divina tamen meritum cumulabat amoris

et votum ambobus socium praecedere morte

maerorique pio curam mandare sepulcri.

Sed prior uxorem decreti pagina legit.

Tunc desolatus largo iubet ore cavari,

post mortem fiant quae membris hospita saxa, ${ }^{16}$

ut, quos viventes tenuisset lectulus idem,

post praecepta Dei, bustum commune levaret.

<iungendus sociae prospecta sede maritus>

16 I have deleted tsusciperet veniens, aeternaque foedera iungens for the moment. A possible logical subject would be the dead woman, in which case it would be necessary to emend veniens to venientem. But there still remains the problem of the subordination, for there isn't an obvious way to add it after levaret in verse 19. 
$<\ldots>^{17}$

Sensit vota sui coniunx praesaga mariti,

magnaque temporibus tribuit miracula castis:

nam, cum defunctis iungantur brachia membris,

et repetita manus constringant vincula trunco,

ne, quibus humanae complentur munera vitae,

accidat informis fluitatio dissociatis-

Immensum dictu-quo tempore vita peracta est, ${ }^{18}$

postquam morte viri reserata est ianua leti,

horrendumque larem iam lux ingrata retexit-

deprensa est laevam protendens femina palmam,

invitans socium gestu viventis amoris!

Quis dedit affectum tumulo? Quis vincula solvit?

Unde sepulta videt venturi conjugis umbram?

$\mathrm{Tu}$ facis haec, tu Christe Deus, tua signa moventur

paulatimque doces sopita resurgere membra ${ }^{19}$

The passage could then be translated thus:

"For where the sluggish procession of the Saône glides by its banks and barely unfolds its lazy course, where the youth of Aeduans, brothers to Remus, is produced, I remember a marriage characterized by the greatest love and fidelity. Their Christian faith however crowned the merit of their love, and each prayed to predecease his/her spouse and to entrust arrangements for his/her tomb to her/his loving care. But the page of fate chose the woman first. The griefstricken [husband] then ordered a rock-tomb to be excavated with a wide entrance to host [their] limbs after death, so that those whom one and the same marital bed had held when alive, after the commands of the Lord, ${ }^{20}$ a shared grave should gently cover. The wife had a presentiment of her husband's longing commitment and contributed a great miracle to these times of chastity: for, although the arms of the dead are joined to their limbs, and multiple bonds bind the hands tightly to the trunk, lest a repulsive dissolution befall those whose task in life was fulfilled once [their limbs] have fallen apart ${ }^{21}$-astounding to relate!-when, [the course of] his life was over, after upon the demise of the husband, the door of death had been opened, and the now unwelcome daylight had disclosed the fearsome abode, the woman was caught stretching out her left hand, inviting her husband with a gesture of living love! Who granted feeling to [the one in the] tomb? Who undid the bonds? From where did the buried woman see her husband's shadow coming? You accomplish these things, you Christ, God, your signs are set in motion and you gradually ${ }^{22}$ teach that limbs that sleep rise.” (Trans. DRS)

17 I am conjecturing a lacuna here.

18 I have likewise deleted Iungendus sociae prospecta sede maritus. Its content suggests to me that it might belong above after 19 with a lacuna inserted.

19 Text of Salzano (2000) 33-34 with some adjustments of capitalization.

20 This presumably refers to the Lord's commands about monogamous marriage, e.g. Gn 2.24, Mt 19.5 .

21 I.e. been disunited.

22 Paulatim, if construed with consurgere, could mean that there will be various interim resurrections before the General Resurrection at End Time. But it might also be construed with docere: "you teach us gradually," implying an ongoing divine revelation (cf. Montanism). 


\section{Models: Classical}

In order to understand this miracle, we need to concentrate on sources and models. Classical source material includes Vergil. ${ }^{23}$ And there is plenty of fuzzy matching for themes such as one grave, chastity of the survivor, praying to die simultaneously. ${ }^{24}$ In a broader cultural context I would emphasize a somewhat different discourse from the one with which it has been associated: namely das Unheimliche, and the reception of the zombie, revenant, vampire, lamia etc. But that is in another venue ${ }^{25}$.

\section{Models: Christian}

My concern here is with the Christian intertextualities, which oddly enough, have been ignored. ${ }^{26}$ There is an obvious and (oddly) unexploited relationship between this passage and Tertullian's De Anima 51.6-8, which I shall discuss elsewhere. Here I am more interested in John's Gospel, ${ }^{27}$ as mediated, I shall argue, by Juvencus.

\section{Juvencus}

I am not going to discuss the relative chronology of the two poets here. ${ }^{28}$ Van der Weijden thought Juvencus used the De laudibus. ${ }^{29}$ Salzano seems to have eliminated Juvencus from consideration altogether. ${ }^{30}$ Warburg doesn't discuss him. ${ }^{31}$ Green is agnostic. ${ }^{32}$ To me, however, it is clear that De laudibus is dependent on Juvencus, and that the model for the miracle is not Christ's resurrection, ${ }^{33}$ but Lazarus' in John $11 .{ }^{34}$

23 See Salzano (2000) $180-86$.

24 Schierl (2008) discusses a range of parallel classical Gemeingut that is not actually meant to be source-material, but is thematically relevant: one grave, chastity of the survivor, praying to die simultaneously. I would add to the mix various Liebestode from Valerius Maximus IV.6, especially IV.6.3 the grave of the two lovers, Plautius and Orestilla.

25 See Shanzer (2019).

26 Though secondary sources do note that the author knew about Lazarus' resurrection in De Laudibus 118-119. E.g. Bardy (1933) 44.

27 Pace Salzano (2000) 93 who cites Jesus' rock tomb at Mt 27.60.

28 Those who are bothered by the fact that the De Laudibus, which plausibly antedates the violent deaths of Crispus and Fausta, quotes Juvencus, who refers to Constantine's achievement of peace, which should postdate his victory over Licinius could (for example) imagine that the envoi to Juvencus was a later addition.

29 Van der Weijden (1967) 195. At 36-38 he does not cite relevant material from Juvencus IV.

30 Salzano (2000) 171: no entry at all in the Index locorum. Id.. 21. dates the Laudes before Juvencus and sees any similarities between them as due to their common use of Vergil. Warburg (2011) 24 sees the De Laudibus as earlier.

31 Warburg (2011) From what I have been able to find without access to a hardcopy.

32 Green (2006) 12.

33 Juvencus IV.747: Nuntius et saxum tumuli de limine volvit; 759: nulla istic iaceant fuerant quae condita membra. 
Although John features two extended resurrection narratives, Lazarus' and Jesus', only Lazarus' occurs under our eyes, and is relevant. Juvencus paraphrased John in verse, and the author of the De laudibus adapted him somewhat creatively. The latter deliberately muted his dependence on these texts by not naming names at Laud. 115-119 where he alluded to the resurrection of Lazarus.

\section{Staub in De Laudibus}

\section{Rock tombs}

The immortal Richard Moritz Meyer noted in his "Kriterien der Aneignung” that, "das Übertragene ist innerhalb des Zusammenhangs nicht so organisch wie das dort Gewachsene." ${ }^{35}$ "Staub, sagt der englische Spruch, ist ein Ding am unrechten Ort." ${ }^{36}$ So let us now consider some remaining Staub bestrewing our poem! One must start with the tomb itself. Gallic aristocrats were buried in sarcophagi, not in rock tombs. But De laudibus describes the excavation of a rock tomb: ${ }^{37}$ Laud. 15-16 largo iubet ore cavari, / post mortem fiant quae membris hospita saxa. ${ }^{38}$ If we look at Juvencus, we find numerous repeated allusions to Lazarus' tomb, its impenetrability, and its material: sepulchrum / Rupe sub excisa; lapidis quod pondere clausum / saxumque inmane reuulsis / Obicibus patuit / conplens caua saxa clamore. Cava saxa is not biblical. This Gallic rock-tomb is artefactual biblical Staub, whose linguistic clothing (cava saxa) comes from Juvencus. Lazarus' tomb was a renowned pilgrimage-site in Late Antiquity, ${ }^{39}$ and our author may have liked the idea of a virtual link to the Holy Land. ${ }^{40}$

\section{Liquefying Limbs and "Wrapped burial"}

The gruesome realia of the grave could include measures against the corpse's dissolution, such as mummification, embalming, and bandages. Also shrouds. And smells. Let us begin with bandages.

34 Neither of the two book-length commentaries on the poem has picked up on this.

35 Meyer (1906) 376. The article is an interesting theoretical discussion that ranges over comparative mythology, linguistics, history, textual criticism, literary imitations, and behavioral scripts.

36 Ibid. 377.

37 Pace Opelt (1978) 161 who insists that it has to be a sarcophagus. Van der Weijden (1967) 69 seems exclusively interested in archaeology; Salzano (2000) 93 says it could be either.

38 Joh 11.38 venit ad monumentum erat autem spelunca et lapis superpositus erat ei;

39 Spanoudakis (2014) 53-56 for the Lazarium.

40 If this is a legend from Autun, it is intriguing that the eventual dedication of the Cathedral of Autun was not to Nazarius, but to Lazarus, where it is now the $12^{\text {th }} \mathrm{C}$. Romanesque Cathédrale St-Lazare. For the career of Lazarus' head in Autun, see Cabrol (1929) $2037 \mathrm{ff}$. 


\section{From Smell to Bandages}

John is terse about olfactory matters: 11.39 iam fetet: quadriduanus enim est, said Martha. ${ }^{41}$ Here Juvencus amplified:

'Quattuor en luces totidemque ex ordine noctes

Praetereunt, quo membra solo conposta quiescunt.

Crediderim, corpus motu fugiente caloris

Fetorem miserum liquefactis reddere membris. ${ }^{42}$

"Look, four days and as many nights in succession have gone by during which his limbs have lain sleeping in the ground. I would imagine that, as its vivifying heat flees, his body is emitting a terrible stench from its liquefying limbs.”

The phrase "liquefying limbs," explains the smell. The De Laudibus feels it has to explain the need for grave-bandages to guard against informis fluitatio, "repulsive dissolution of limbs that are falling apart." 43 The emphasis on liquid decomposition is not biblical and, I suspect, is a significant addition that comes from Juvencus.

Whether a feature is organic or transferred matters. By the early $4^{\text {th }} \mathrm{C}$. images of the Raising of Lazarus in Early Christian art show him as a mummy in an aedicula ("Mumientypus"). ${ }^{44}$ But it is incorrect to assume that there is no biblical precedent for the bound corpse. ${ }^{45}$ The grave-bandages (institae) are an important canonical detail from Lazarus' resurrection, for his corpse was tightly bound: John 11.44 et statim prodiit qui fuerat mortuus, ligatus pedes et manus institis et facies illius sudario erat ligata.

The Gallic lady's arms too are bandaged tightly to her trunk. ${ }^{46}$ De laudibus $22 \mathrm{ff} .$, I suggest, respond directly to Lazarus' grave-bindings, rendered by Juvencus IV.394-96 as conexis manibus pedibusque and et totum gracilis conectit fascia corpus. Here again we have Meyer's Staub, a detail that is a literary artifact, not an historical one. Archaeologist colleagues have assured me that there is no evidence for "wrapped" burial or "bandelettes" in the West: a shroud ("linceul") is quite a different matter. ${ }^{47}$ Again, this Johannine detail has travelled West via Juvencus to manifest itself as

41 It seems to me that her remark could be read either as a warning apology (It'll smell.") or a disincentive ("It's too late.") for going ahead. I thus don't entirely agree with Deproost (2000) 140 on how Martha dilutes the "brutalité expressive" of the Gospel into "une diagnostique clinique." Marchetti (2013) 81 thinks, as do some patristic exegetes, that John is emphasizing the miracle here.

42 Juvenc. IV.376-79.

43 De laudibus 25 accidat informis fluitatio dissociatis.

44 Darmstaedter (1955) 9-11 and Albertson (1995) 124-125.

45 As does Albertson (1995) 123 who sees here only “strips on only his hands and feet.” Albertson seems to be mis-visualising John's description.

46 Not actually “a conventional part of funerary practice” (as says Rees [2010] 72).

47 Here I have benefitted from the generous expertise of Patrick Périn, Paul Van Ossel, and Bailey Young. 
an anomalous "wrapped" burial in a rock tomb in the Saône valley. How though do we know that it came via Juvencus? He alone features the added concern about dissolution combined with the grave-bandages.

\section{Accessing More Exegesis}

There is a comparative dearth of extant exegetic material about Lazarus in the West, some of which will be discussed below. But, fortunately, we have some access to the lower quarters of this iceberg by going over to the Eastern Empire to compare Nonnos of Panopolis' Paraphrase of the Gospel of John with Spanoudakis' fine commentary. Juvencus shows clear signs of contact with exegetic undercurrents, now attested only in Greek (which is not to say that he read them in Greek). A few examples:

\section{“Dead Man Walking:" Exegetic Reception of the Resurrection of Lazarus}

Haec cum dixisset voce magna clamavit, “Lazare, veni foras!” 44 Et statim prodiit qui fuerat mortuus ligatus pedes et manus institis et facies illius sudario erat ligata. Dicit Iesus eis, "Solvite eum et sinite abire!” (Joh. 11.43-44)

John thematizes Lazarus' "wrapped" mummy-like burial, and Jesus subsequently gives a command to release him. ${ }^{48}$ The Latin word used for his locomotion is the colorless prodiit. So, one may well ask, how did he walk? They wondered about this too back then and saw it as part of the miracle. It is just possible to discern such intent in Juvencus IV.394: Nec mora conexis manibus pedibusque repente/ Procedit tumulo, if one "spins" the ablative absolute concessively to bring the point out. Ambrose's funeral oration for his brother Satyrus contains one explicit highly rhetorical reflection on the problem from the Western Empire:

78. Audivit ergo defunctus, et exivit foras de monumento, ligatus pedes et manus institis, et facies eius orario colligata erat. Conpraehende, si potes, quemadmodum clausis oculis iter carpat, vinctis pedibus gradum dirigat, inseparabili gressu, separabili progressu. Manebant vincula nec tenebant, tegebantur oculi, sed videbant. Videbat denique, qui resurgebat, qui ambulabat, qui deserebat sepulcrum. Virtute enim divinae praeceptionis operante natura suum non requirebat officium et tamquam in excessu posita non iam suo ordini, sed divino nutui serviebat. Rumpebantur prius mortis quam sepulturae vincula, agebatur prius, quam parabatur incessus. 79. Si miraris haec, disce, qui imperaverit, ut mirari desinas: Iesus Christus, dei virtus, via, lux, resurrectio mortuorum.

48 Joh. 11.44 Solvite eum et sinite abire! And he is invariably depicted that way, see all the images in Cabrol (1929) 2009-2035. 
"And so the dead man heard and emerged from the monument, bound hand and foot with grave bandages. And his face was wrapped in a napkin. Grasp, if you can, how he takes to the road with closed eyes, how he directs his steps although his feet are bound with steps that were not separable, but with progress that is. His bonds remained, but did not hold him; his eyes were covered, yet he saw. The one who was rising again, the one who was walking, the one who was abandoning his tomb could finally see. As the power of the divine command acted, nature did not pursue her normal course of duty, and, as if placed at the limit of its existence, complied not with her normal orders but with the divine command. The bonds of death were broken before those of the grave. His gait was set in motion before it was ready. If you marvel at this, see who gave the command so that you cease to be astonished: Jesus Christ, the power of God, the way, the light, the resurrection of the dead."

On the Eastern side there is a spectacularly creepy passage in Nonnos' Gospel-Paraphrase:

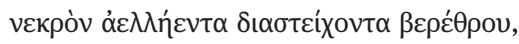

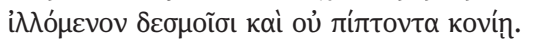

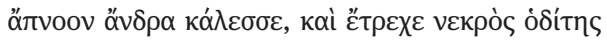

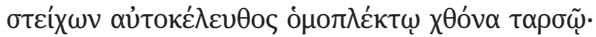

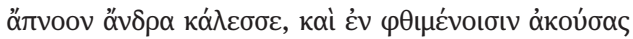

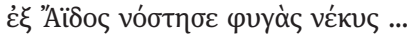

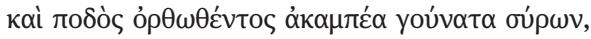

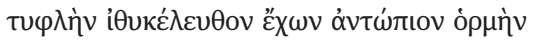

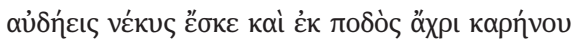

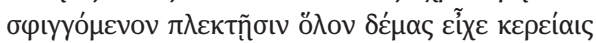

"a wind-swift corpse, walking out of the pit, bound in chains/bonds, but not falling in the dust ... he called an unbreathing man, and the dead traveler came running. Moving of his own accord on the ground with his ankles bound one to another. He called an unbreathing man, and the runaway corpse heard him among the dead and returned from Hades. ... With upright foot, dragging his unbending knees, and maintaining a blind, eyes-front, straight path, he was a speaking corpse and, from foot to head, his whole body was bound with coils of [swaddling-]bands" ${ }^{49}$ (trans. DRS)

The problem of the corpse's locomotion is simply there in John. It may well be problematized in Juvencus. It is discussed explicitly as a miracle in Ambrose. It is dramatized two different ways, walking (creepy) and running (all the way back from Hades), in Nonnos. Peter Chrysologus solves the problem by having Tartarus return Lazarus, bound hand and foot. ${ }^{50}$ In the De Laudibus, however, where the heroine plays the whole scene on her back, the problem is displaced to her arms, and we hear how she can stretch out a hand, bound tightly though she was. "To prevent dissolution" falls into the category of "too much information." The Gallic lady is "bouncing off” Lazarus, but Lazarus as depicted in Juvencus.

49 Other translations in Spanoudakis (2014) and into verse Prost (2003).

50 Sermo 65: Tunc Tartarus, ligatis manibus et pedibus, Lazarum retulit ad superna. 


\title{
Getting one's Soul Back
}

\author{
Let us now turn to Juvencus IV.392-93
}

\section{'Lazare, sopitis redeuntem suscipe membris}

En animam tuque ipse foras te prome sepulchro.

This passage reverses the usual formula for commending the soul of the departed to God: suscipe animam servi tui illius et illius. The separation of the winged soul is mentioned at Juvencus IV.369-70 quo condita nuper / Membra forent animae uolucris spoliata calore. Why is Jesus depicted as giving Lazarus back his soul ${ }^{51}$ It seems to be not just a gratuitous literary "point," but an allusion to an exegetic comparison between the re-ensoulment of Lazarus and God's ensoulment of the protoplast at Cre-

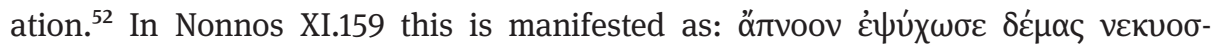
бóos n̉xú. ${ }^{53}$

One might conjecture that the form of Jesus' thaumaturgy in Juvencus, giving back his soul to Lazarus with a bold gesture-en!- may have had some connection with what we see in the De Laudibus. There the lady is mysteriously re-ensouled to welcome back her partner. We are all familiar with the erotic discourse about the soul (as well as the runaway soul) (54 $^{4}$ and with endearments such as zoe and psyche. ${ }^{55}$ The diminutive lectulus and the naughty word deprensa, which is used of those caught in flagrante delicto, license associations with the amatory sphere. ${ }^{56}$ Our anonymous poet had some urbanitas! ${ }^{57}$ In Juvencus Jesus is the visible and audible thaumaturge ${ }^{58}$ within the story; in Gaul he acts post mortem and invisibly but is invoked by the rhetorical questions of De Laud. $32 \mathrm{ff}$. This swift magical action is quite different from Sedulius who has the soul creeping back into its former marrow. ${ }^{59}$

51 Chromatius of Aquileia, Sermo $27.106 \mathrm{ff}$. is primarily concerned with the location of Lazarus' soul, and how Jesus is able instantaneously to reunite it with Lazarus' body using his voice. This same interest in the location of the souls of those resurrected can be seen in Petrus Chrysologus, Sermo 63. The daughter of Jairus and the son of the widow of Nain both lingered near their bodies. Lazarus was in Tartarus.

52 Hinted at by Prudentius in his Apotheosis 763-66, for which see Marchetti (2013) 87.

53 Spanoudakis (2014) 275-278.

54 Shanzer (2017) 282, n. 37.

55 Juvenal 6.194-95.

56 See for being caught "in fragrant delight," Hor. Sat. I.2.131: cruribus haec metuat, doti deprensa, egomet $m i$ and 134: deprendi miserum est.

57 Jacques Fontaine imagined the author as the owner of a latifundium, someone with connections at court, a "grand homme de province." See Fontaine (1981) 101-02. Contrast Brandes (1887) 25. who saw an Aeduan rhetor from Autun.

58 For depictions of Jesus with the thaumaturgic wand, see Albertson (1995) 124 and 128. Also Tsamakda, (2009). For the pagan Lebensrute, see Waele (1927) 184-93.

59 CP IV.287: lex perit atque animam proprias repente medullas. Van der Laan (1993) 146 cleverly compares Lucan. $C$ VI.753: et nova desuetis subrepens vita medullis. I would add that the parallel supports 


\section{Is Lazarus good to stink with?}

These are stories about interim resurrections and interim resurrection bodies. ${ }^{60}$ How were Christians to imagine them? They use the (neutral) story of Lazarus to think with. Take smell. In John it is factual and has a narrative dialogic function. ${ }^{61}$ In Juvencus likewise, but it is amplified to specify liquid putrefaction. ${ }^{62}$ It is quite properly omitted in the semi-erotic context of the De Laudibus. And then sublimated into the odor of embalming spices alone in Prudentius' Lazarus narrative in the Apotheosis, ${ }^{63}$ a text well worth comparing, for its metapoetic re-conjuring or re-evocation of Lazarus from his tomb onto the page. ${ }^{64}$
Prudentius, Apotheosis
ante fores tumuli, quas saxa inmania duro
obice damnarant scopulis substructa cauatis,
stat dominus nomenque ciet frigentis amici.
$\mathrm{Nec}$ mora funereus reuolutis rupibus horror
euomit exequias gradiente cadauere uiuas.
Soluite iam laetae redolentia uincla, sorores!
solus odor sparsi spiramen aromatis efflat, nec de corporeo nidorem sordida tabo
aura refert. Oculos sanie stillante solutos
pristinus in speculum decor excitat et putrefactas
tincta rubore genas paulatim purpura uestit.
Quis potuit fluidis animam suffundere membris?
nimirum qui membra dedit, qui fictilis uluae
perflauit uenam madidam, cui tabida glaeba
traxit sanguineos infecto umore colores.

Later on, in Severus of Malaga, the evil smell will be used as proof (had there been skeptics) that Lazarus really had been a corpse. ${ }^{65}$

It is by now a famous cliché that Christians developed a different relationship with the grave and grave matters from that of their pagan confrères. ${ }^{66}$ Issues of con-

the lectio difficilior. Some medieval readers preferred a swift re-entry, for which see the variant repetente listed on p. 111 of Huemer's edition.

60 See above, p. 293, n. 22 on paulatim.

61 See above, p. 296, n. 41.

62 Which may implicitly, though not explicitly, set up and emphasize the wonder of the eventual resurrection.

63 Prudentius leaves it unclear whether Lazarus in fact doesn't smell or whether the smell was miraculously gone by the time Mary and Martha undid his grave-bandages. Wright (2003) 443 concludes that (in the end) there was no smell.

64 Apoth. 741 titubanti voce contrasts with Jesus loud call in Joh 11.43.

65 See Cutino (2016-2017) 205 and 209 and Bischoff (1994) 78. In Petrus Chrysologus, Sermo 63. Lazarus who is four days dead and decomposing goes a step beyond Jesus himself, who was post triduum adhuc recentem.

66 Brown (1981) 6-12. Also Markus (1993) 146-148. 
tamination, proximity, dismemberment, handling, and also horror and disgust needed to be rethought. Some of the features of De laudibus can, as we have seen, be used to observe and track developing Christian attitudes towards the grave and the borders between life and death.

\section{Did they or didn't they?}

I will end with a question that hasn't really been asked in quite this form, namely: What sort of marriage was this? In Late Antiquity there is some evidence ${ }^{67}$ for the promotion of "mariage blanc," 68 marriage that was sexless right from the start, as preached, for example, in the Acts of Thomas 11-13. ${ }^{69}$ There were also what started as normal marriages, but morphed into continent ones, for example at the ordination of a spouse. Both seem to be reactive mechanisms, not outright goals, for remaining a virgin by refusing to marry may have been an option for only a minute and ascetically ambitious minority. ${ }^{70}$ One could see in the De laudibus simply the faithful marriage of a (textbook epigraphic) univira, or one might wonder, as we shall see, whether the author intended a mariage blanc. Did they or didn't they <have sex >?

\section{Love in the grave's reception and transformation}

By the later $6^{\text {th }} \mathrm{C}$. we find more-than-thrice-told ${ }^{71}$ tales of animated corpses and married continence: first in Autun ascribed to Rheticius in Gregory of Tours GC 74. Rheticius lived in a chaste marriage with his wife, whose dying wish was to lie in the same grave. Rheticius was later elected bishop. When he died, his bier initially could not initially be moved, and he came back to life to fulfill his promise to his wife. Her bones gathered together into a heap, presumably to make space for him. There is a second version of this story told of a layman, Hilarius of Dijon, in GC 41, where

\footnotetext{
67 It proves rather hard to find unified treatments of the subject even in books dedicated to relevant topics, such as Brown (1988), Clark (1994), or Cooper (1996), who at 114 says "It was not uncommon ... for a married women to let it be known publicly ... that she was withholding conjugal rights from her husband," but cites Ecdicia from Augustine, Ep. 262 alone. Old, but as always very helpful is Leclercq (1932) 1881-1888. covering a number of diverse phenomena, which Leclercq prefaces by (rightly) stating that "spiritual marriage" is to some extent a scholarly dream (or wish-fulfillment) that is not necessarily supported by its alleged proof-texts.

68 Josephsehe, weiße Ehe, Jungfernehe, white marriage.

69 See Hennecke - Schneemelcher (1974), vol. 2, 448 - 449. David Hunter kindly brought this passage to my attention. It is surprising both for its hostility to children and fertility and for its delivery (by Jesus impersonating Thomas).

70 Heiresses would have been under special pressure. See Brown (1988) 343-345.

71 Gregory had nothing against his own "réécriture." See Heinzelmann (2003) 22.
} 
the marriage is a normal one, and the dead man embraced his wife's corpse when she joined him in his supersized Parian marble sarcophagus.

More interesting, and indeed, risque is the related story of a lay-pair in the Auvergne in Gregory of Tours', DLH 1.47: Iniuriosus and his wife, the two chaste lovers of Clermont. On his wedding night Iniuriosus was persuaded by his wife to live in a continent marriage. She died first. When he committed her for burial saying that he was commending her to the Lord in the same condition as he had received her, she memorably awoke to respond: “Quid loqueris, quod non interrogaris?” (In modern English-“Too much information!") The story appears in a shorter form without names in GC 31, where both subsequently embraced the religious life. The mildly risqué joke was improved: the resuscitated wife told her husband with a smile, "Sile, sile, vir dei!" and not to let people know nostrum secretum, namely that they hadn't had sex. And the tombs, now more respectably two, even if moved apart, reunite into a double resting place, even if not quite a letto matrimoniale.

There has been disagreement right from the outset about whether the De Laudibus is actually about Rheticius of Autun. The Histoire Littéraire de la France said yes, Brandes disagreed. ${ }^{72}$ I will limit myself to a few minor points. If the De Laudibus had been about Rheticius, why ever not say so? In addition, the poem's action is not specifically located in Autun, but in the region of the Saône. Autun is ca. 28 miles west of Chalon-sur-Saöne. Furthermore I am somewhat troubled by the fact that I can't locate even a prose text that specifically associates Augustodunum with the Arar. ${ }^{73}$ But any Märchenforscher knows that the resemblances between these four stories are not fortuitous: they override variable "tweakings" such as lay/clerical status, who died first, corpse addresses the bereaved spouse/corpse embraces corpse, one sarcophagus/twin sarcophagi. ${ }^{74}$ The De laudibus cannot be Gregory's source for GC 74, etc. and they must share a lost source other than Tertullian's De Anima 51.6-8.

Tertullian's Ad Uxorem 1.6.2 alludes to couples who voluntarily forgave one another the marital debt and lived like eunuchs for the kingdom of heaven. ${ }^{75}$ But it, like the Acts of Thomas, is an outlier. It is first in the later $4^{\text {th }} \mathrm{C}$. that Jerome worked himself into a lather about subintroductae and whether one tectulum implied one

72 Brandes (1887)19-20. seems excessively skeptical about the Maurists' identification. There are too many parallels for them to be coincidental, starting with the Aeduan location. We see the oscillation between names and no names in Gregory's DLH and GC, why not here in De laudibus? Brandes doesn't consider the possibility that the borrowing may have gone in the other direction, from the De laudibus Domini or its ancestor to the ancestor of the tale about Rheticius.

73 And only Jerome, Vir. Ill. 82 of Rheticius associates Autun with the Aedui. Rees (2010) 73 identified the Aedui with the people of Autun.

74 Heinzelmann (2003) 54-59 discusses the stories as réécriture and details their similarities and differences in tabular form. Strangely, he says nothing about GC 41 and 74, which certainly belong to the same complex.

75 Quot item, qui consensu pari inter se matrimonii debitum tollunt, voluntarii spadones pro cupiditate regni caelestis? Abstinence within marriage is an argument for abstinence in widowhood. 
lectulum. ${ }^{76}$ It was he who famously staged the continent "marriage" between Malchus the Monk and his fellow-slave, a married woman in VMAlchi 6-7: "Habeto me ergo coniugem pudicitiae!” said she. The Younger Melania's marriage took a continent turn after she produced two children who died in infancy. ${ }^{77}$ And the battle about married bishops and episcopae was still being waged in the later $6^{\text {th }} \mathrm{C} .^{78}$ Therefore, to the best of my knowledge, marital continence is almost entirely a controversy from the later $4^{\text {th }} \mathrm{C}$. through the later $6^{\text {th }} \mathrm{C} .{ }^{79}$ For that reason, I am inclined to read $D e$ laudibus as about a normal marriage, where the two were both bedfellows and sexual partners. The phrase temporibus castis (De Laud. 21) may have been over-read, quite possibly in antiquity, and helped enable the back-reading of continence issues from the later $4^{\text {th }}$ to $6^{\text {th }}$ centuries into the Constantinian period. ${ }^{80}$

\section{Epigraphica}

I began with the Roman practice of joint burial, and will close with a few epigraphic documents as documentary comparanda to our literary texts. A curious Latin inscription on a sarcophagus from the Basilica at Salona can be dated securely to $378 \mathrm{CE}{ }^{81}$

$\mathrm{Fl}$ (avius) Terentius $\mathrm{Fl}$ (aviae) Taiasiae ob meritis et fideiitatem / totiusque sanctitatem arcam posui coniugi / carissimae et sibi quam a parentibus ipsius suscepi / annos XVIII qi aeque inlibatae mecum vixit annos XXXII / tradita sepulturae die Nonarum Septembres DD NN/ Valente VI et Vaientiniano iterum AUGG CONSS / si quis vero supir duo coriora nosira aliut / corpus voluerit ordinare dabit fisci viribus / argenti pondo quindecim. ${ }^{82}$

The text has been edited thus in Salona IV: ${ }^{83}$

$\mathrm{Fl}$ (avius) Terentius $\mathrm{Fl}$ (aviae) $\mathrm{Ta}<\mathrm{l}>$ asiae ob meritis et fide $<\mathrm{l}>\mathbf{i t a t}<\mathrm{e}>\mathrm{m} /$ totiusque sanctitatem arcam posui coniugi / carissimae et sibi quam a parentibus ipsius suscepi / annos XVIII q<u>aeque inlibatae mecum vixit annos XXXII / tradita sepulturae die Nonarum Septembres d(ominis)

76 As Jerome put it in the Ep. 117.9: separentur domus uestrae diuidaturque conuiuium, ne maledici homines sub uno tectulo uos manentes lectulum quoque criminentur habere communem. On the Greek side, there was Chrysostom, for whom see Clark (1994) 99-100.

77 VMel. Gr. 6-8; VMel. Lat. 1.7-8; See Melania 2 in Jones (1971) vol. 1593.

78 Ambrosiaster believed that post-marital celibacy for clergy was practicable. See Brown (1988) 378. For problems in Gregory, see Shanzer (2002).

79 Its practice is known from figures such as Paulinus of Nola and Therasia or in the Younger Melania and Pinianus on whom, see Brown (1988) 409-410.

80 For similar concerns, see Grubbs (1994) 408.

81 See Diehl (1925) vol. 1 155-56, No. 821; Inscriptions chrétiennes de la Gaule antérieures au VIIIe siècle, 2 vols., vol. 2 (Paris: L'Imprimerie Impériale) For an image of the actual object, see Friederike Harl and Ortolf Harl, 24470 Sarkophag der Flavia Talasia; available from http://lupa.at/24470.

82 The engraver slipped up multiple times by using I for $\mathrm{L}$, in one case I for a $\mathrm{P}$, and an I for an $\mathrm{E}$ (venial).

83 Marin (2010) 407. 
$\mathrm{n}$ (ostris) / Valente VI et Va<l> entiniano iterum Aug(ustis) cons(ulibus) / si quis vero sup $<\mathrm{e}>\mathrm{r}$ duo cor $<\mathrm{p}>$ ora nos $<\mathrm{t}>$ ra aliut / corpus voluerit ordinare dabit fisci viribus / argenti pondo quindecim.

It was written for/by one Flavius Terentius for his deceased spouse Flavia Talasia. Terentius marred Talasia when she was 18 and she lived with him illibatae for 32 years. But does illibatae represent a very rare adverb, meaning "impeccably," (as it was taken by the $T L L),{ }^{84}$ or does it mean literally "untouched," indicating that the pair were in a continent marriage ${ }^{85}$ The first alternative seems less strange and certainly syntactically easier. The interpretatio facilior (as it were) would be the solution taken by the French editors to delete the $i$ and supply a $u$ giving quaeque inlibatae (= inlibate) "who lived irreproachably with me." They may be right, but it might also be possible to read $q<u>i$ aeque and to see illibatae as an aural Perseverationsfehler from aeque-and hence to be corrected to/read as aeque illibata. "as untouched as previously (sc. when with her parents)." 86 In that case the stone could indeed commemorate a continent marriage.

I, Flavius Terentius, set out this casket for Flavia Talasia, dearest wife and for myself, ${ }^{87}$ for her good deeds, faithfulness, and the virtue of her her whole life.$^{88}$ I received her from her parents when she was 18 and she lived equally untouched with me for 32 years. She was laid to rest on the Nones of September when the Augustus Valens was consul for the sixth time and Valentinian for the second. If anyone should wish to lay out a third body on top of our two, he will pay [for the benefit of] the fisc ${ }^{89} 15$-weight ${ }^{90}$ of silver.

There are examples of conciliar prohibitions against adding corpses to existing graves. ${ }^{91}$ This inscription for a double burial prohibits any eventual threesomes with an unrealistically hefty fine.

84 The adverb illibate ("impeccably") is very rare. TLL 7.1.369.38 gives only 3 examples, one of which is this passage. Inculpatim in CIL 3.14524 may likewise be an inscriptional hapax or extremely rare. 85 As suggested by Leclercq (1932) 1964

86 Qui for quae is a VL development that will eventually be generalized in French.

87 Terentius wrote sibi through confusing first-person and third person formulae.

88 The French team do not print it, but rightly note that a word like vitae must have fallen out before sanctitatem. Marin (2010) 408.

89 Fisci viribus is a standard phrase from the CTheod. (also in Cassiodorus' Variae), roughly equivalent to "zugunsten," or "for the benefit of."

90 For pondum (a by-form for pondus, ponderis. See TLL 10.1.2614.25 legitur inde a Lege Sil. per totam fere latinitatem ... ex acc. *pondum: it. pondo.

91 Mâcon A (585) can. 17: Comperimus multos necdum marcidata mortuorum membra sepulchra reserare et mortuos suos superimponere vel aliorum, quod nefas est, mortuis suis relegiosa loca usurpare, sine voluntate scilicet domini sepulchrorum. Ideoque statuemus, ut nullus deinceps hoc peragat. Quod si factum fuerit, secundum legum auctoritatem superimposita corpora de eisdem tumulis reiactentur. Also the Diocesan Synod of Auxerre (561/605) can.15: non licet mortuum super mortuum mitti. 
Terentius and Talasia were thought not to stand entirely alone. ICLV 1727 commemorates a woman que vixit inlibata cum birginio suo annis $V,{ }^{92}$ which Leclercq took as referring to a continent marriage. ${ }^{93}$ But on the other hand, there is also CIL 3.13529 for Ursa who died in childbed. Her husband describes them as convirginios, a rare word" ${ }^{94}$ that must in this context mean "pair who were married as virgins," not "continent spouses." 95 The Clauss-Slaby epigraphic database now makes it possible to see that married men were regularly addressed as virginii by their wives in cases when the marriage produced offspring. ${ }^{96}$ But perhaps the word inlibata carries the weight and the marriage was indeed a continent one? The few other epigraphic examples of inlibata do not help resolve the question. ${ }^{97}$

There is thus, as one might expect, virtually no Late Antique documentary evidence that attests such continent arrangements as recounted in Gregory's DLH 1.47 and GC 31. The Passio S. Caeciliae 3-5, where the heroine informs her husband Valerianus that her lover, an angel, guards her chastity, reveals its extravagant and quite literary secret. ${ }^{98}$ Just as the irrepressible Wilhelm Kroll reproached Allia Potestas' otherwise exemplary partner Allius for the epigraphic publication of the secrets of his bedroom, ${ }^{99}$ so too was the dead Gallic lady leery about the betrayal of their secretum. That glimpse of naughtiness in De laudibus' deprehensa (De laudibus 30) could be compared to the "migrated" versions of the duo amantes of Clermont: "No need to advertise that we didn't have sex!" They were caught not doing it.

92 Diehl, Inscriptiones latinae christianae veteres, 336, No. 1727 from a sarcophagus found in the catacombs of Calixtus.

93 Leclercq (1932) 1963.

94 TLL 4.879.31-33 compares Hector Pais, Corpus Inscriptionum Latinarum: Supplementa Italica. Fasciculus 1. Additamenta ad Vol. V. Galliae Cisalpinae (Romae: Salviucci, 1884), 43. No. 344 sunbirgino, an inscription for the grave of Exsuperantia (25 years old) who lived 3 years and nine months with her sunbirgino. There is an image in Brusin (1993) 1067, no. 3038.

95 So likewise Blaise s.v. virginius.

$96 \mathrm{http} / / / \mathrm{db} . e d c s . e u /$ epigr/epibeleg.php?s_sprache=de I note 152 hits for virginio.

97 In the (very corrupt) CIL 10.5409 et inlibata erga me / superfuit (which the CIL and Roger Tomlin think must stand for semper fuit), the word seems unlikely to have sexual connotations, since the issue is curial duties. TLL 7.1.369.27-28 says "uncorrupted." I would prefer "unshaken" or "constant." In $A E$ 1982, No. 705, p. 183, since the honorand is a young mother, exempli inli/batae casti(ta)tis must mean "example of irreproachable chastity."

98 Delehaye (1936) 196-197. Amittis florem ... iuventutis almost sounds as if Valerianus were sexually threatened by the angel! In Chapter 8 they are mystically married by it.

99 Kroll (1914) 277: "Dazu kommt der Mangel nicht bloß an poetischem, sondern auch an menschlichem Takt, der ihn Dinge hat ausplaudern lassen, die das Geheimnis seines Schlafgemaches hätten bleiben sollen und ihn zu einem Kandaules redivivus stempeln.” 


\section{Bibliography}

Albertson (1995): Fred C. Albertson, "An Isiac Model for the Raising of Lazarus in Early Christian Art", in: Jahrbuch für Antike und Christentum 38, 123-132.

Bardy (1933): Gustave Bardy, "Les Laudes Domini. Poème autunois du commencement du IVe siècle”, in: Mémoires de l'Académie des sciences, arts et belles-lettres de Dijon, 36-51.

Bischoff (1994): Bernard Bischoff et alii, Severi Episcopi <Malacitani (?)> in Evangelia Libri XII: das Trierer Fragment der Bücher VIII-X, Abhandlungen der Bayerischen Akademie der Wissenschaften, Philosophisch-Historische Klasse, München, Verlag der Bayerischen Akademie der Wissenschaften.

Brandes (1887): Wilhem Brandes, “Über das frühchristliche Gedicht 'Laudes Domini:' Nebst einem Excurse: Die Zerstörung von Autun unter Claudius II.” Wissenschaftliche Beilage zu dem Programm des Herzoglichen Gymnasium Martino-Catharineum in Braunschweig, Braunschweig, Johann Heinrich Meyer.

Brelich (1937): Angelo Brelich, Aspetti della morte nelle iscrizioni sepolcrali dell'impero romano, Dissertationes Pannonicae ex Instituto Numismatico et Archaeologico Universitatis de Petro Pazmany Nominatae Budapestinensis Provenientes, Budapest, Magyar Nemzeti Múzeum.

Brown (1981): Peter R.L. Brown, The Cult of the Saints: Its Rise and Function in Latin Christianity. Chicago.

Brown (1988): Peter R.L. Brown, “The Body and Society: Men, Women, and Sexual Renunciation" in: Early Christianity, Lectures on the History of Religions, New York, Columbia University Press.

Brusin (1993): Johannes Baptista Brusin, Inscriptiones Aquileiae. Pars tertia. Udine.

Cabrol (1929): Fernand Cabrol, "Lazare", in: Dictionnaire d' Archéologie Chrétienne et de Liturgie, edited by F. Cabrol and H. Leclercq, 2010-2088. Paris, Letouzy et Ané.

Cagnat (1914): René Cagnat, Cours d'épigraphie latine. 4th revised and expanded ed., Paris: Fontemoing et cie., 1914.

Clark (1994): Gillian Clark, Women in Late Antiquity: Pagan and Christian Lifestyles, Oxford, Clarendon Press, 1994.

Cooper (1996): Kate Cooper, The Virgin and the Bride: Idealized Womanhood in Late Antiquity, Cambridge Mass., Harvard University Press.

Cutino (2016 - 2017): Michele Cutino, "L'accomplissement de la paraphrase néotestamentaire en Occident: les In evangelia libri de Severus de Malaga.", in: Poésie et Bible aux IVe-VIe s. Actes de la session scientifique de l'Assemblée générale de l'Association "Textes pour l'Histoire de l'Antiquité Tardive" Paris, École Nationale des Chartes, 8 octobre 2016, edited by Michele Cutino, 189-213.

Darmstaedter (1955): Richard Darmstaedter, Die Auferweckung des Lazarus in der altchristlichen und byzantinischen Kunst, Bern, Arnaud.

Delehaye (1936): Hippolyte Delehaye, Étude sur le légendier romain, les saints de novembre et de décembre, Subsidia Hagiographica, Bruxelles.

Deproost (2000): Paul Augustin Deproost, “"'La résurrection de Lazare dans le poème évangélique de Juvencus (IV, 306-402)", in: Revue Belge de Philologie et d' Histoire 78, 129-145.

Diehl (1925): Ernst Diehl, Inscriptiones latinae christianae veteres. 3 vols., Berlin, Weidmann.

Fontaine, J. Naissance de la poésie dans l'occident chrétien: esquisse d'une histoire de la poésie latine chrétienne du IIle au Vle siècle. Paris: Études augustiniennes, 1981.

Green (2006): Roger Green, Latin Epics of the New Testament: Juvencus, Sedulius, Arator. Oxford New York: Oxford University Press.

Grubbs (1994): Judith E. Grubbs, “'Pagan' and 'Christian’ Marriage: The State of the Question”, in: JECS 2, 361-412. 
Haynes (2000): Sybille Haynes, Etruscan Civilization: A Cultural History, J. Paul Getty Museum, 2000.

Heinzelmann (2003): Martin Heinzelmann, “La réécriture hagiographique dans l’oeuvre de Grégore de Tours", in: La réécriture hagiographique dans l'Occident médiéval: Transformations formelles et idéologiques, edited by Monique Goullet and Martin Heinzelmann, 15-50, Stuttgart.

Hennecke - Schneemelcher (1974): Edgard Hennecke and Wilhem Schneemelcher. New Testament Apocrypha. Vol. II Writings relating to the Apostles, Apocalypses and related subjects, 2 vols., Philadelphia, Westminster Press.

Jones (1971): Arthur H.M. Jones, J.R. Martindale, and J. Morris. The Prosopography of the Later Roman Empire. Vol. 1: A.D. 260-395. 3 vols., Cambridge, CUP.

Kroll (1914): Wilhem Kroll, “Die Grabschrift der Allia Potestas", in: Philologus 73, 274-288.

Le Blant (1856), Edmond Le Blant, Inscriptions chrétiennes de la Gaule antérieures au VIIle siècle. 2 vols., Paris, L'Imprimerie Impériale.

Leclercq (1932): Henri Leclercq, “Mariage”, in: Dictionnaire de l'archéologie chrétienne et de liturgie, edited by F. Cabrol and H. Leclercq, Paris, Letouzey et Ané, 1843-1892.

Marchetti (2013): Marta Marchetti, “'Lazzaro, vieni fuori!’. La resurrezione di Lazzaro nella poesia cristiana." In: Dulce Melos II. Akten des 5. internationalen Symposiums: lateinische und griechische Dichtung in Spätantike, Mittelalter und Neuzeit. Wien, 25.-27. November 2010, edited by Victoria Zimmerl-Panagl, Pisa, Edizioni E.T.S., 79-105.

Marin (2010): Emilio Marin- Nancy Gauthier and Françoise Prévot, Salona IV. Inscriptions de Salone chrétienne IVe-VII siècles, Collection de l'École française de Rome. Rome / Split: École française de Rome / Musé archéologique de Split.

Markus (1993): Robert Markus, The End of Ancient Christianity. Cambridge: CUP.

Meyer (1906): Richard M. Meyer, "Kriterien der Aneignung." Neue Jahrbücher für das klassische Altertum 17, 349-389.

Mosley (1960): Leonard Mosley, Curzon: the End of an Epoch, London.

Opelt (1978): Ilona Opelt, “Das Carmen de laudibus Domini als Zeugnis des Christentums bei den Galliern." in: Romanobarbarica: Contributi allo studio dei rapporti culturali tra mondo latino e mondo barbarico 3, 159-66.

Pais (1884): Hector Pais Corpus Inscriptionum Latinarum: Supplementa Italica. Fasciculus 1. Additamenta ad Vol. V. Galliae Cisalpinae, Romae, Salviucci.

Prost (2003): Mark Anthony Prost, Nonnos of Panopolis: The Paraphrase of the Gospel of John, Ventura.

Rees (2010): Roger Rees, “The rhetoric and poetics of praise in the 'Laudes Domini', in: Quaderni Urbinati di cultura classica 95, 71-84.

Salzano (2000), Aniello Salzano Laudes Domini: Introduzione, testo, traduzione e commento, Quaderni del Dipartimento di Scienze dell'Antichità / Università degli Studi di Salerno Napoli: Arte Tipografica.

Sandys (1919): John Edwin Sandys, Latin Epigraphy: An Introduction to the Study of Latin Inscriptions. Cambridge: Cambridge University Press.

Schierl (2008), Petra Schierl, “Die motive 'ewige Liebe' und 'göttliche Belohnung' in der Wundererzählung der Laudes Domini”, in: Motivi e forme della poesia cristiana antica tra Scrittura e Tradizione classica, XXXVI Incontro di studiosi dell'antichità cristiana, Roma, 3-5 maggio 2007, 861-871.

Shanzer (2002): Danuta R. Shanzer, “History, Romance, Love, and Sex in Gregory of Tours' Decem Libri Historiarum", in: The World of Gregory of Tours, edited by Kathleen Mitchell and I. N. Wood, 395-418. Leiden, Boston, \& Köln: Brill, 2002.

Shanzer (2017): Danuta R. Shanzer, “Evodius' Strange Encounters with the Dead: Questions and Answers in Augustine, Epp. 158-159", in: Scrinium Augustini. The World of Augustine's 
Letters, edited by Przemislaw Nehring, M. Stróżyński and R. Toczko, Turnhout, Brepols, $273-304$.

Shanzer (2019): Danuta Shanzer,"Resurrections before the Resurrection in the Imaginaire of Late Antiquity." in: The Biblical Annals 9, no. 4 (2019): 711-738."

Spanoudakis (2014): Kostantinos Spanoudakis, Paraphrasis of the Gospel of John XI, Oxford.

Tsamakda (2009): Vasiliki Tsamakda, “Eine ungewöhnliche Darstellung der Heilung des Paralytikers in der Domitilla-Katakombe: Zur Verwendung des Wunderstabes in der frühchristlichen Kunst”, in: MiChA 15, 25-46.

Van der Laan (1993): Paul W.A.T. Van der Laan, "Imititation créative dans le Carmen Paschale de Sédulius"." In Early Christian Poetry. A Collection of Essays, edited by Jan Den Boeft and A. Hilhorst, Leiden / New York, Brill, 134-166.

Van der Weijden (1967): Pieter Van der Weijden, Laudes Domini: Tekst, vertaling en commentaar, Amsterdam-Paris.

Waele (1927): Ferdinand Joseph M. de Waele, The Magic Staff or Rod in Græco-Italian Antiquity, Gent, Drukkerij Erasmus.

Warburg (2011): Ines Warburg, Laudes Domini. Loas del Señor. Introducción, texto, traducción y notas, Buenos Aires.

Wright (2003): Nicholas T. Wright, The Resurrection of the Son of God, Minneapolis, Fortress Press. 


\section{Gabriella Aragione, Agnès Molinier Arbo Un diner sur l'herbe}

\section{Proba et le pouvoir évocateur de la poésie}

Le poème connu sous le titre de Cento Probae est un centon virgilien de contenu biblique ${ }^{1}$. Composé de 694 vers, il se divise en deux parties : après un exorde général (1-28), la première partie, du vers 56 au vers 332, contient un nombre très restreint d'épisodes vétérotestamentaires (la création du monde et du premier couple, la transgression d'Adam et Ėve, le meurtre d'Abel par Caïn et le Déluge). La seconde partie, qui va du vers 346 au vers 688, porte sur un nombre plus important, mais tout aussi circonscrit, d'épisodes tirés du Nouveau Testament. Chacune de ces deux parties est précédée d'une préface $(29$ - 55 ; 333-345) ; six vers conclusifs clôturent l'œuvre.

On identifie généralement l'auteur avec Faltonia Betitia Proba, une femme de la haute aristocratie romaine, épouse de Clodius Celsinus Adelphius, préfet de la Ville en 351. Cette grande dame aurait vécu entre 320 et 370 environ ${ }^{2}$. Le Centon aurait alors été écrit dans les années 350-370 et représenterait le plus ancien centon virgilien chrétien connu à ce jour. Mais on ne peut exclure que l'auteur soit en fait sa petite-fille Anicia Faltonia Proba, qui vécut au tournant des $\mathrm{IV}^{\mathrm{e}}$ et $\mathrm{v}^{\mathrm{e}}$ siècles ${ }^{3}$. À notre sens, le problème reste ouvert ${ }^{4}$.

Quoiqu'il en soit, le Cento Probae est un poème savamment construit : la disposition soignée des épisodes, la maîtrise de la technique du centon et l'intelligence de la composition ne sont que quelques-uns des traits qui caractérisent cette œuvre. Il importe en effet de souligner aussi l'originalité et la sensibilité artistique de son auteur : Proba est une poétesse d'une remarquable finesse qui, à partir des vers de l'auteur dont elle s'inspire, au sens profond du terme, compose des tableaux d'une extraordinaire efficacité plastique et au fort pouvoir évocateur.

Mais Proba se distingue également par une grande liberté face au texte biblique. On peut presque parler d'une véritable hardiesse, d'une audace, qui donne une couleur absolument surprenante à sa réécriture de l'histoire biblique. Nous citons, à titre d'exemple, sa représentation de la relation intime qui unit Adam et Ève dans le

1 Sur l'œuvre, nous renvoyons aux sommes suivantes : Clark/Hatch (1981); Bažil (2009) ; Sineri (2011) ; Schottenius Cullhed (2015).

2 Pour la chronologie de Faltonia Betitia Proba, voir Sineri (2011) 20-26.

3 Cette attribution a été proposée par Shanzer (1986) 232-248; Shanzer (1994) 75-96.

4 Pour une discussion à propos de l'identité de la poétesse, cf. Matthews (1992) 282-291; Kyriakidis (1994) 185-200 ; Green (1995) 551-563 ; Green (1997) 548-549 ; Laurence (2002) 131-163 ; Barnes (2006) 249-256 ; Green (2008) 264-276 ; Corsaro (2008) 631-642 ; Schottenius Cullhed (2014) 199222 ; Schottenius Cullhed (2015) 114-120. Nous nous proposons d'approfondir la question de l'auteur dans l'introduction à notre traduction française du Centon, qui sera publiée prochainement dans la collection «Sources chrétiennes». 
jardin d'Eden, qui n'a aucune correspondance ni dans le texte biblique ni dans l'exégèse courante de son temps ${ }^{5}$; ou encore, l'importance qu'elle donne à l'épisode du fratricide, dont la gravité n'est nullement inférieure à celle de la faute originelle ; enfin, les événements de la Passion : Jésus ne subit aucun procès, mais, saisi par une foule furieuse et violente, est ligoté à un chêne dont la populace acharnée a coupé les branches ; et, pour finir, le passage dont nous proposons ici l'analyse et qui, à notre connaissance, n’a jamais fait l'objet d'une étude particulière, à savoir la dernière Cène, que, peut-être inspirées par l'audace de notre poétesse, nous avons rebaptisée : le «dîner sur l'herbe».

\title{
1 La dernière Cène dans le Centon
}

La dernière Cène est racontée par Proba aux vers 580-599. Suivant l'ordre des péricopes de l'évangile selon Matthieu, Proba présente sans solution de continuité les trois épisodes, dont elle fait une synthèse personnelle, de l'entrée de Jésus à Jérusalem (562-565), de l'expulsion des marchands du Temple (566-579) et du dernier repas du Seigneur avec ses disciples (580-599). C'est en ces termes que la poétesse évoque la Cène :

\begin{abstract}
[Puis le soir venu, Jésus et ses disciples] raniment leurs forces en mangeant, allongés çà et là sur l'herbe / Ils chargent les tables de mets et y posent des coupes. / Après que l'on eut fait une première pause dans le banquet et éloigné les tables, / Lui-même au milieu des Premiers institue les cérémonies en l'honneur de son père, / les yeux levés au ciel. Alors les langues ont fait silence, / il offre de ses mains les grains et la douce eau des sources, et remplit de vin pur une patère, les instruit dans les rites sacrés / [y] mêle des prières et parle ainsi : / «Écoutez, mes nobles compagnons, dit-il, et apprenez vos espérances. / Personne d'entre vous ne s'en ira sans avoir reçu un don de ma part, / et selon les promesses du Père, vos présents - déclara-t-il - vous demeurent / acquis, mes enfants, et personne ne change l'ordre de la victoire. / Et dès que la lumière sera demain rendue à la terre / un seul se dressera contre moi et pour la perte des miens, / tandis que notre corps s'offre en médiateur pour la paix. / Déjà le jour est proche, si je ne m'abuse. Chassez vos soucis : / C'est à moi de me charger de ce labeur et mon sentiment ne me trompe pas! / Une seule vie sera donnée pour le rachat d'un grand nombre». Après avoir prononcé ces paroles, / Il se tut et répandit à travers ses membres un repos tardif ${ }^{6}$.
\end{abstract}

5 Voir entre autres Badini (2008) 604-606 ; Curran (2012) 335-336 ; Schottenius Cullhed (2015) 146 150 ; Schottenius Cullhed (2016) 104.

6580 -599 : Deuexo interea propior fit Vesper Olympo. / Tum uictu reuocant uires fusique per herbam / Et dapibus mensas onerant et pocula ponunt. / Postquam prima quies epulis mensaeque remotae, /ipse inter primos genitori instaurat honores, / suspiciens caelum. tum facta silentia linguis. / Dat manibus fruges dulcesque a fontibus undas / impleuitque mero pateram ritusque sacrorum / edocet immiscetque preces ac talia fatur : / "Audite, o proceres, » ait "et spes discite uestras. / Nemo ex hoc numero mihi non donatus abibit, / promissisque patris uestra», inquit, «munera uobis / certa manent, pueri, et palmam mouet ordine nemo. / Et lux cum primum terris se crastina reddet, / unus erit tantum in me exitiumque meorum, / dum paci medium se offert de corpore nostro. / Iamque dies, nisi fallor, adest. secludite curas. / Mecum erit iste labor, nec me sententia fallit : / unum pro multis dabitur 
Comme le montre le tableau ci-dessus, les divergences par rapport au texte biblique sont nombreuses :

\begin{tabular}{|c|c|c|c|}
\hline Centon 580-599 & Matthieu 26.20-46 & Marc $14.17-42$ & Luc $22.14-46$ \\
\hline \multirow[t]{2}{*}{$\begin{array}{l}580-582 \text { : le soir venu, } \\
\text { repas, fusi per herbam, de } \\
\text { Jésus et les Douze }\end{array}$} & $\begin{array}{l}20 \text { : Le soir venu, } \\
\text { Jésus est à table avec } \\
\text { les Douze }\end{array}$ & $\begin{array}{l}17: \text { Le soir venu, } \\
\text { Jésus arrive avec les } \\
\text { Douze }\end{array}$ & $\begin{array}{l}14 \text { : Jésus et les apô- } \\
\text { tres se mettent à } \\
\text { table }\end{array}$ \\
\hline & $\begin{array}{l}21-25 \text { : pendant le } \\
\text { repas, il annonce la } \\
\text { trahison d'un des } \\
\text { Douze }\end{array}$ & $\begin{array}{l}18-21 \text { : pendant le } \\
\text { repas, il annonce la } \\
\text { trahison d'un des } \\
\text { Douze }\end{array}$ & \\
\hline $\begin{array}{l}583-588 \text { : première pause, } \\
\text { Jésus distribue le pain, } \\
\text { l'eau et le vin, et } \\
\text { enseigne les rites sacrés }\end{array}$ & $\begin{array}{l}26-29 \text { : pendant le } \\
\text { repas, Jésus distribue } \\
\text { le pain et le vin. } \\
\text { Paroles d'institution }\end{array}$ & $\begin{array}{l}22-25 \text { : pendant le } \\
\text { repas, Jésus distribue } \\
\text { le pain et le vin. } \\
\text { Paroles d'institution }\end{array}$ & $\begin{array}{l}15-20 \text { : pendant le } \\
\text { repas, Jésus distribue } \\
\text { le pain et le vin. } \\
\text { Paroles d'institution }\end{array}$ \\
\hline \multirow[t]{2}{*}{$\begin{array}{l}589-598 \text { : promesse de } \\
\text { Jésus aux Douze, annonce } \\
\text { de la trahison de l'un d'en- } \\
\text { tre eux et annonce de sa } \\
\text { propre mort }\end{array}$} & & & $\begin{array}{l}21-25 \text { : Annonce de } \\
\text { la trahison de l'un } \\
\text { des Douze. } \\
24-38 \text { : Avertisse- } \\
\text { ment et promesse } \\
\text { aux Douze }\end{array}$ \\
\hline & $\begin{array}{l}30-35 \text { Au mont des } \\
\text { Oliviers, Jésus annon- } \\
\text { ce le reniement de } \\
\text { Pierre }\end{array}$ & $\begin{array}{l}26-31 \text { Au mont des } \\
\text { Oliviers, Jésus annon- } \\
\text { ce le reniement de } \\
\text { Pierre }\end{array}$ & $\begin{array}{l}\text { 39-46 Au mont des } \\
\text { Oliviers, Jésus prie. } \\
\text { Les disciples s'en- } \\
\text { dorment }\end{array}$ \\
\hline $\begin{array}{l}599 \text { : Jésus et les disciples } \\
\text { s'endorment }\end{array}$ & $\begin{array}{l}\text { 36-46 Au Gethséma- } \\
\text { né, les disciples s’en- } \\
\text { dorment, Jésus passe } \\
\text { la nuit en prière }\end{array}$ & $\begin{array}{l}32 \text { - } 42 \text { Au Gethséma- } \\
\text { né, les disciples s'en- } \\
\text { dorment, Jésus passe } \\
\text { la nuit en prière }\end{array}$ & \\
\hline \multicolumn{4}{|l|}{ Suite du récit } \\
\hline
\end{tabular}

Dans le Centon, la Cène ne se déroule pas dans une salle, mais à l'extérieur, dans un cadre champêtre. Le repas a une structure composite, dont le déroulement ne correspond pas à celui des évangiles : on a d'abord un banquet, puis, pendant une pause, l'«institution» des rites (la Cène proprement dite). On écoute alors le discours de Jésus sur l'accomplissement des promesses et sur l'annonce de la trahison de Judas et de sa propre mort. Au terme de l'épisode, Jésus s'endort, alors que dans les évangiles il passe la nuit en prière au Gethsémané.

caput." Haec ita fatus / conticuit seramque dedit per membra quietem. L'édition utilisée est celle de Fassina/Lucarini (2015). La traduction est faite par nos soins. 
Notre analyse se focalisera sur le détail à notre sens le plus surprenant, à savoir le lieu où se déroule la Cène (fusi per herbam). Les rares explications avancées à ce jour ne nous satisfont que de manière partielle. Nous citons à titre d'exemple celle qui suggère un rapprochement avec l'épisode évangélique de la multiplication des pains d'après Mt 14.19 ; Mc 6.39 et Jn 6.10, où, avant d'accomplir le miracle, Jésus ordonne à la foule de s'asseoir sur l'herbe. Suivant cette interprétation, Proba aurait voulu établir une correspondance entre le pain distribué à l'assistance et le pain donné aux disciples lors de la Cène ${ }^{7}$.

Cette interprétation n'apparaît guère convaincante. On pourrait avec plus de vraisemblance supposer que la centoniste ait voulu situer l'épisode dans le jardin de Gethsémané, qui, dans les évangiles, est l'endroit où Jésus passe la nuit avant d'être livré et où le lendemain il est arrêté. Proba aurait ainsi voulu garantir une unité de lieu à tous les événements qui précèdent la Passion. Il arrive en effet fréquemment qu'elle fonde deux ou trois épisodes bibliques en un seul : par exemple, aux vers 531-561, Proba réécrit comme un épisode unique le récit de Jésus qui marche sur les eaux (Mt 14.22-33; Mc 6.45-52; Jn 6.16-21), celui de la tempête apaisée (Mt 8,23-27; Mc 4.35-41; Lc 8.22-25) et celui de la pêche miraculeuse (Lc 5.1-11 ; Jn $21.1-8)^{8}$.

Néanmoins, cette unité de lieu n'explique pas les raisons de son choix par Proba. Comme l'a bien montré Reinhart Herzog, la clé de lecture des centons virgiliens est fournie par ce qu'il appelle le «triangle herméneutique» : pour appréhender le sens profond du centon, affirme-t-il, il faut faire interagir la Bible, Virgile et la foi chrétienne de la centoniste ${ }^{9}$. C'est à partir de ce postulat que nous allons en premier lieu tenter de mettre en évidence et d'étudier le courant de sens qui passe entre l'hypotexte virgilien et l'hypertexte, à savoir le Centon.

\section{L'intertextualité avec Virgile}

Quels vers Proba sélectionne-t-elle dans l'épisode de la dernière Cène et comment choisit-elle de les agencer ? On remarque d'abord que la poétesse respecte grosso modo les règles canoniques du centon, telles du moins qu'elles sont énoncées par Ausone $^{10}$ : à l'exception du vers 588, qui est un assemblage de trois segments, les vers sont composés soit de deux demi-vers soit d'un vers entier. Il arrive également qu'un segment d'un vers et demi soit repris dans l'ordre. Proba se permet encore, toujours selon les règles admises, d'altérer légèrement certains mots de son modèle

7 Badini/Rizzi (2011) 196-197.

8 Voir Bažil (2009) 170-176.

9 Herzog (1975).

10 Cento nuptialis, adressé à Assius Paulus Cf. par exemple Moretti (2008) 317-347. 
pour les adapter à leur nouvel environnement sémantique ${ }^{11}$. Elle se livre ainsi à un exercice de déconstruction/reconstruction méthodique de l'œuvre de Virgile : elle n'hésite d'ailleurs pas à disloquer des vers ou des demi-vers voisins dans l'hypotexte ou à renverser leur ordre. Cela lui permet de conférer à certaines expressions une résonnance nouvelle ${ }^{12}$.

Examinons à présent le contexte d'origine des vers et des segments de vers cités : on note que, loin d'exploiter l'ensemble du corpus virgilien, elle puise essentiellement ses matériaux dans l'Énéide, et surtout dans les chants I et V : on se souvient que le premier chant raconte le débarquement en Afrique des Troyens rescapés d'une tempête et l'accueil amical qui leur est réservé par la reine Didon. Le chant $\mathrm{V}$ décrit quant à lui l'étape effectuée par les Troyens en Sicile après leur départ d'Afrique et les jeux organisés par Énée en l'honneur du premier anniversaire de la mort de son père. Il s'achève sur la promesse solennelle faite par Neptune à Vénus qu'un seul Troyen mourrait pour permettre aux autres d'effectuer sans encombre la traversée jusqu'en Italie. Sur les dix-neuf vers que compte notre passage, sept sont entièrement ou en partie issus du chant I dont cinq du banquet offert par Didon à ses nouveaux hôtes (697-756), neuf du chant V (six des Jeux, et notamment de la course à pied $(286-361)$ et trois du sacrifice de Palinure : $(779-871)^{13}$.

Une grande partie du récit de la Cène dans le Centon a donc été composée à partir de vers et de segments de vers issus de trois noyaux virgiliens bien précis qui s'enchaînent et s'entrelacent pour former un écheveau de plus en plus complexe. Ces choix sont parfois aisément explicables, quand l'hypertexte présente avec l'hypotexte des analogies manifestes de contenu. On pense notamment au dernier passage du livre V : Palinure, seul sacrifié pour permettre à l'ensemble des Troyens de parvenir en Italie où ils pourront commencer une nouvelle vie, pouvait suggérer le sacrifice du Christ pour le salut de l'humanité.

Les motivations de Proba sont en revanche moins immédiatement discernables en ce qui concerne les deux autres passages de l'Énéide, pourtant les plus cités. Prenons le premier noyau virgilien, issu du livre I : les segments empruntés au banquet de Didon confèrent une unité remarquable aux vers 581-587 du Centon. Et pourtant, ce repas, pris à l'intérieur du Palais et caractérisé par une profusion de mets servis dans de la vaisselle précieuse, était sans conteste plus luxueux que le

11 Au vers 582, Proba a par exemple légèrement modifié Aen. I.706 : qui dapibus est devenu dans l'hypertexte et dapibus. Le premier hémistiche du vers 586 (dat manibus fruges) résulte quant à lui de la contamination de deux segments empruntés à des contextes différents de l'Énéide : XII.173 (dant fruges manibus) + I.701 (dant manibus famuli).

12 Les premiers hémistiches des vers 594 et 598 du Centon proviennent par exemple des vers 814 et $815 \mathrm{du}$ chant XV de l'Énéide, où est évoquée la mort prochaine de Palinure.

13 Aen. I : C. 581 = A. I.24 ; C. 582 = A. I.706 ; C. $583=$ A. I.723 ; C. $585=$ A. I.730 ; C. 586 (premier hémistiche) $=A$. I.701; C. 587 (premier hémistiche) $=A . \mathrm{I} .729 ; C .596$ (second hémistiche) = A. I.562 ; Aen., V : C. 584 (deuxième hémistiche) =A.V. $94 ; C .587$ (troisième segment) =A.V 79 ou $552 ; C .590=$ A.V. $305 ;$ C. 591 (deuxième hémistiche) =A.V.348;C. $592=$ A. V.349;C. 596 (premier hémistiche) $=A$. V.49 ; C. $591=$ A. V.863 ; C. $594=$ A. V.814 ; C. $598=$ A. V.815. 
dîner sur l'herbe décrit par Proba. Il est d'ailleurs à l'origine de certains détails $a$ priori incongrus de la description de la poétesse. Pire encore, le vers commémorant la consécration du pain et du vin est composé de segments de vers appartenant au même contexte : un fervent chrétien ennemi du paganisme ne pouvait que sursauter en se rendant compte que la patera que Jésus emplit de vin pur dans le Centon est celle dont se sert Didon pour offrir une libation à Jupiter $(C .587=A \text {. I.729 })^{14}$.

\section{Le banquet}

Pourquoi Proba, qui aurait pu faire appel à d'autre passages de l'Énéide pour sa description ${ }^{15}$, a-t-elle délibérément choisi de déconstruire ce banquet pour construire sa sainte Cène ? La réponse doit certainement être recherchée dans l'intertextualité. L'hypertexte entretient en effet peut-être avec l'hypotexte des liens plus profonds et essentiels que ce que l'on pourrait croire au premier abord ${ }^{16}$. Le public de Proba, qui avait comme elle dès l'enfance appris par cœur l'ensemble du corpus virgilien, gardait bien présent à l'esprit le contexte d'origine de chaque citation : aucun vers ou segment de vers, même le plus passe-partout, n'acquérait une sorte de nouvelle virginité une fois transposé dans le texte d'accueil - et cela était particulièrement vrai pour les vers les plus réussis. Il est même probable que la connaissance du milieu d'origine des vers et de leur signification première était primordiale à la saisie de la signification du centon : l'hypertexte ne faisait pleinement sens qu'en relation avec l'hypotexte, qui comblait éventuellement les blancs, faisait ressortir certains aspects plutôt que d'autres et, surtout, s'il avait participé à la construction d'autres parties du Centon, pouvait les faire entrer en résonnance.

C'est à partir de cette hypothèse que nous souhaitons proposer une clef de lecture de notre surprenant dîner sur l'herbe. Dans le contexte virgilien d'origine, le personnage de Didon est fondamental : c'est la grande ordonnatrice du banquet qui va signer sa perte future, puisqu'elle tombe amoureuse d'Énée. Et c'est là qu'apparaît pour la qualifier la formule particulièrement réussie d'infelix, pesti deuota futura ${ }^{17}$. Or cet aspect du personnage de Didon au banquet a été exploité par Proba, avec d'autres détails de la même scène, dans un des premiers épisodes développés dans le Centon, celui de la Chute : l'expression virgilienne définit Ėve sur le point de commettre l'irrémédiable. La poétesse, dans sa réécriture du récit de la Chute, met en scène un luxurieux banquet entre Ėve et le Serpent au pied de l'arbre défendu,

14 On pense ici avant tout aux critiques formulées par Jérôme dans sa Lettre 53.7 (adressée à Paulin de Nole) à l'égard de la pratique contemporaine, en vogue jusque chez les chrétiens, du centon virgilien.

15 Les repas sur l'herbe improvisés par les héros troyens sont nombreux dans l'Énéide : cf. par exemple chez Évandre au livre VIII (175-183), etc.

16 Sur ce point, lire entre autres les réflexions de Hinds (2014) 171-197.

17 Cf. I.712. 
banquet qui va signer la perte de la première femme et celle de l'humanité toute entière (195-205) :

«C'est moi qui vous guiderai ; si je suis sûr de ta volonté, / nous dressons des lits de table et nous nous régalons de riches mets. /Ainsi parle-t-il [le serpent], et plus vite que ses paroles, en un geste interdit par la loi, / ils placent sous les mets du bois jadis vénérable, / apprêtent un repas et souillent tout de leur contact. / Elle surtout, la malheureuse, vouée qu'elle est à la ruine future, / admirant des frondaisons nouvelles et des fruits qui n'étaient pas à elle, / cause d'un si grand mal, elle les goûta du bout des lèvres. / Perpétrant un sacrilège plus grand, se livrant à une plus grande folie, / au malheureux mari, hélas ! l'épouse offre un fruit cueilli à un arbre qui ne lui appartenait pas / et émut son cœur d'une subite douceur ${ }^{18}$ ».

On repère des correspondances structurelles et textuelles entre le banquet de Didon et le fatal banquet du Jardin d'Éden, qui se déroule lui aussi en plusieurs étapes :

\begin{tabular}{ll}
\hline Centon & Virgile \\
\hline $\begin{array}{ll}\text { 1. Préparatifs des dapes, epulae et tori du } \\
\text { banquet luxurieux et corrupteur (195-199) }\end{array}$ & $\begin{array}{l}\text { Préparatifs des dapes et mensae du banquet de } \\
\text { Didon ; les Troyens prennent place sur les tori } \\
(\text { I.696-711) }\end{array}$ \\
\hline
\end{tabular}

2. Ève, incapable de résister à l'attrait des fruits 2 . première partie du banquet, au cours duquel défendus, les touche de ses lèvres $(200-202)$ Didon succombe à la séduction d’Énée (1.712722) ; pendant la pause, elle offre une libation que, la première, elle touche de ses lèvres $1.723-$ 737 : v. 737 : summo tenus attigit ore)

3. Ève associe Adam à son crime (203-205)

3. Didon passe la coupe à tous les autres participants du banquet $(737-756)$

Comme dans le cas de notre dîner sur l'herbe, les vers 696-756 du livre I de l'Énéide constituent un des fils dont est tissé le banquet du Jardin d'Éden. L'hypotexte virgilien à la fois participe dans une mesure plus ou moins grande dans l'un et l'autre cas à la création de ces deux scènes de repas et permet d'établir des correspondances internes entre elles :

\begin{tabular}{lll}
\hline Centon (Jardin d’Éden) & Virgile (banquet de Didon) &
\end{tabular} Centon (dîner sur l'herbe)

1. Préparatifs des dapes, epulae 1. Préparatifs des dapes et mensae

1. Préparatifs du dîner sur et tori du banquet luxurieux et du banquet de Didon; les Troyens l'herbe $(582-583)$ corrupteur (195-199) prennent place sur les tori (I.696711)

18 Dux ego uester ero : tua si mihi certa uoluntas, / extruimusque toros dapibusque epulamur opimis " / Sic ait, et dicto citius, quod lege tenetur, / subiciunt epulis olim uenerabile lignum / instituuntque dapes contactuque omnia foedant. / Praecipue infelix pesti deuota futurae /mirataque nouas frondes et non sua poma, / causa mali tanti, summo tenus attigit ore. / Maius adorta nefas, maioremque orsa furorem, / Heu misero coniux aliena ex arbore germen / obicit atque animum subita dulcedine mouit. 
suite

\begin{tabular}{lll}
\hline Centon (Jardin d'Éden) & Virgile (banquet de Didon) & Centon (dîner sur l'herbe) \\
\hline 2. Ève touche les fruits défendus & \multicolumn{1}{l}{ 2. Pendant la pause, Didon offre une } & 2. Pendant une pause du \\
de ses lèvres $(200-202)$ & $\begin{array}{l}\text { libation que, la première, elle touche } \\
\text { de ses lèvres (l.722-737) }\end{array}$ & banquet, Jésus institue \\
& l'eucharistie (584-587) \\
\hline
\end{tabular}

Le banquet de Didon n'a pas constitué pour Proba un simple réservoir de vers susceptibles de l'aider à concevoir deux scènes de banquets. Pour reprendre notre image initiale de l'écheveau et du tissage, l'épisode virgilien dans son ensemble a fourni des fils et même un patron sur lequel Proba a tissé deux scènes en miroir qu'elle souhaitait certainement mettre en relation à travers l'épisode virgilien. Le choix de décrire la Cène comme un banquet et de la placer au milieu d'un cadre champêtre s'explique alors à la lumière du repas primordial dans le jardin d'Éden : la dernière Cène est conçue dans le Centon jusqu'à un certain point comme une réplique $\mathrm{du} / \mathrm{au}$ fatal festin d'Ėve, et l'inverse est sans doute aussi vrai, en un complexe jeu d'échos et de renvois de sens orchestré au moyen de l'hypotexte virgilien.

\section{L'institution des rites}

On peut appliquer les mêmes principes d'analyse, fondés sur la recherche de l'intertextualité immédiate ou plus lointaine, au deuxième noyau virgilien qui a, pour sa part, participé dans des proportions relativement importantes aux promesses faites par Jésus à la suite du dîner sur l'herbe. On se souvient qu'il provient du livre V de l'Énéide, racontant les cérémonies et les Jeux (notamment la course à pied) organisés par Énée sur le tombeau d'Anchise ${ }^{19}$. La première occurrence se situe au vers 584 de notre passage, où Jésus genitori instaurat honores, à l'instar d'Énée au vers $94 \mathrm{du}$ chant V. Or ce dernier accomplit son geste dans des circonstances bien particulières: il vient d'assister à l'apparition miraculeuse d'un énorme serpent sorti du tombeau de son père pour aller goûter les offrandes. Voici la description qui occupe les dix vers précédents de l'Énéide (V.84-93) :

\footnotetext{
Dixerat haec, adytis cum lubricus anguis ab imis

Septem ingens gyros, septena uolumina traxit,

Amplexus placide tumulum lapsusque per aras,

Caerulae cui terga notae maculosus et auro

Squamam incendebat fulgor, ceu nubibus arcus

Mille iacit uarios aduerso sole colores.

Obstipuit uisu Aeneas. Ille agmine longo
}

19 Voir supra, p. 313 n. 13 Ces jeux sont encore exploités par Proba dans sa description de la tempête : cf. La Fico Guzz (2013) 60-74. 
Tandem inter pateras et leuia pocula serpens

Libauitque dapes rursusque innoxius imo

Successit tumulo et depasta altaria linquit ${ }^{20}$.

Selon le procédé déjà repéré, la citation du vers 94 sert de signal destiné à orienter l'esprit du lecteur vers son contexte immédiat qui, à son tour, le renvoie à un passage précédent du Centon, la Chute dont le Serpent avait été avec Ève l'artisan. Car l'anguis aux sept anneaux du Chant $\mathrm{V}$ de l'Énéide ressemble étrangement au serpent du Paradis :

ecce inimicus atrox | immensis orbibus anguis

septem ingens gyros, septena volumina versans ${ }^{21}$.

On a vu que le Tentateur participe pleinement au repas criminel d'Ève dans le Centon. De la même manière, le serpent du chant $\mathrm{V}$ de l'Énéide (inscrit, grâce à l'intertextualité, en filigrane aussi bien du banquet d'Ève que de la Cène chez Proba), touche aux mets et aux libations offerts par Énée sur le tombeau d'Anchise. Mais, cette fois-ci, la signification du geste répété n'est plus négative, mais positive. La réitération de la scène n'est plus symbole de chute, mais de rédemption : le serpent de l'Énéide est d'heureux augure car il se comporte de manière pacifique (placide) et est inoffensif (innoxius), à la différence de celui du Jardin, cui tristia bella/ iraeque insidiaeque et crimina noxia cordi ${ }^{22}$.

La guerre et son cortège de maux apparaissent à Proba - qui affirme d'ailleurs que c'était le sujet principal d'une œuvre qu'elle aurait composée avant le Cen$\operatorname{ton}^{23}$ - comme une des conséquences principales de la Chute ${ }^{24}$. Or une forme de lutte bien particulière est présente dans la première partie du chant $\mathrm{V}$ de l'Énéide $:$ le héros organise des Jeux en l'honneur de son père Anchise, et notamment une course à pied (286-361). C'est en direction de cette dernière que les vers 290-292 du Centon, correspondant aux vers 305, 348 et 349 du chant V, dirige l'attention du lecteur en sollicitant sa mémoire. Il s'agit en effet d'une course mémorable par son

20 «Il achevait quand, du fond du sanctuaire, un serpent tira, ondoyant sept replis prodigieux, sept anneaux, enlaçant paisiblement la tombe, se coulant entre les autels. Des tâches sombres marquaient son dos, un éclat chatyant embrasait d'or ses écailles ; tel dans les nuées de l'arc-en-ciel, face au soleil, jette mille couleurs changeantes. À cette vue, Énée fut frappée de stupeur. Lui, enfin, en une longue progression se glissant au milieu des patères et des coupes polies, goûta aux mets sacrés, rentra pacifiquement dans le fond du tombeau, abandonna les autels où il s'était nourri» (trad. G. Perret, Paris, CUF, 1981).

21 C., 173-174 : «voici l'ennemi cruel, un serpent aux immenses anneaux, énorme par ses sept replis, faisant onduler ses sept volutes». Sur la représentation du serpent tentateur d’Ève, cf. Bažil (2009) 183-185 ; Schottenius Cullhed (2015) 150-152.

22 C. 177-178 : «lui qui ne se plaît qu'aux funestes guerres aux colères, aux embûches et aux crimes meurtriers».

23 Cf. C. $1,8$.

24 Cf. par exemple C. 319-332. 
issue : Énée, qui décide d'attribuer des prix magnifiques non seulement aux trois vainqueurs mais aussi à leurs deux concurrents malheureux, l'un pour le consoler de sa malchance, l'autre pour récompenser son sens de l'amitié, instaure un ordre où il n’y a plus aucun perdant. La signification de cette riche intertextualité est claire : le sacrifice à venir du Christ annule la punition décrétée par le Père à la suite de la transgression d'Adam et Ėve et instaure un nouvel ordre sans vainqueurs ni vaincus, où les derniers deviennent les égaux des premiers, en un retour à la béatitude primordiale, à l'âge d'or du Jardin d'Éden.

\section{Quelques mots de conclusion}

L'analyse des centons est une entreprise sans doute fascinante, mais aussi d'une extrême complexité. Au cours des dernières décennies, on s'est beaucoup intéressé à la question de l'intertextualité et à la valeur euristique des résonances qu'elle éveille ${ }^{25}$. La clé d'accès au sens profond du poème de Proba est en fait donnée par le jeu d'allusions, d'un côté, entre le Centon et son hypotexte virgilien, et, de l'autre côté, entre les différentes parties du Centon lui-même ${ }^{26}$. L'interprétation proposée dans les lignes précédentes se fonde sur l'une des nombreuses possibilités de décryptage du Centon, à savoir que le second niveau de lecture d'un hypertexte A (dans ce cas, l'épisode de la Cène) peut être atteint grâce au jeu d'allusions sous-jacent entre son hypotexte (dans ce cas, le banquet de Didon) et un hypertexte B (dans ce cas, l'épisode du banquet au jardin d'Eden). L'interrelation ainsi établie entre les deux hypertextes A et B, par le biais d'un hypotexte commun, véhicule, nous semblet-il, la perspective théologique de Proba.

En d'autres termes, d'après notre interprétation, la poétesse établit des correspondances entre deux moments capitaux de l'histoire biblique : la transgression et la rédemption. Pour permettre la saisie de ces correspondances, elle situe en connaissance de cause ces deux événements dans un jardin. Mais il y a plus. Le choix du jardin n'est assurément pas anodin, puisque pour un chrétien cultivé du Iv siècle, qui partage les mêmes goûts littéraires et esthétiques que Proba, ce lieu symbolise l'Âge d'or. Il s'agit d'un thème cher à notre centoniste. Il traverse tout le Centon, qui est pour ainsi dire marqué par ce que Mircea Eliade appelait la «nostalgie des origines», c'est-à-dire de la condition paradisiaque perdue ${ }^{27}$.

En effet, d'autres détails dans notre passage semblent évoquer l'idée d'un retour à l'état des origines, voire au moment qui précède l'apparition de celle que Proba considère comme la cause de la faute : le vers qui clôt l'épisode de la Cène, où Jésus conticuit seramque dedit per membra quietem (599), rappelle de près celui qui se

25 La bibliographie sur les centons virgiliens est de plus en plus importante. Cf. surtout Consolino (1983) ; Polara (1990) ; McGill (2005) ; Bažil (2009).

26 Cf., entre autres, Herzog (1975) 5-51 ; Corsaro (2007) 25-46 ; Mazzucco (2008) ; Curran (2012).

27 Cf. Clark/Hatch (1981). 
réfère à Adam exactement avant la création d'Eve (124 : Haut mora continuo placidam per membra quietem).

$\mathrm{Au}$ terme de notre analyse, nous rejoignons entièrement l'avis de Herzog, selon lequel Proba ne s'adonne pas à un simple jeu littéraire, mais compose une poésie au second degré ; une poésie qui véhicule des contenus doctrinaux et spirituels précis. Nous l'avons constaté : rien, dans le Centon, n'est laissé au hasard : ni du côté de l'hypotexte biblique (choix des épisodes, lacunes et/ou amplifications), ni du côté de l'hypotexte virgilien (choix des vers et demi-vers, modifications qu'elle y apporte, leur combinaison). Dans son œuvre (qui est à la fois hypertexte et métatexte), Proba ne paraphrase pas la Bible, mais met en vers son interprétation de l'histoire du salut ainsi que du message chrétien. Par le biais de Virgile, elle est en ligne avec le sentiment esthétique de ses destinataires et peut ainsi exprimer sa foi de la manière la plus persuasive possible.

L'Énéide comme le Centon de Proba méritent donc à plusieurs égards d'être qualifiés d'«œuvres ouvertes» : l'Énéide, pour la beauté de son message et la richesse de ses vers, générateurs d'une variété si infinie de signifiés que les chrétiens ont pu en faire un réceptacle de l'histoire sainte et du message divin. Quant au Centon, il requiert pour prendre toute sa signification une participation active du lecteur, qui doit être capable d'identifier la provenance des vers cités pour maintenir sans cesse un contact indispensable entre l'hypertexte et l'hypotexte. Ainsi s'établit entre les œuvres un courant de sens multiple, se prêtant à une interprétation qui reste elle-même ouverte.

\section{Bibliographie}

Badini (2008): Antonia Badini, «I progenitori nella poesia biblica di Proba (Centone, vv. 115-277)», in: Motivi e forme della poesia cristiana antica tra Scrittura e tradizione classica, XXXVI Incontro di studiosi dell'antichità cristiana, Roma, 3-5 maggio 2007, Roma, 601-609.

Barnes (2006): Timothy D. Barnes, «An urban prefect and his wife», in: Classical Quarterly 56, 1, $249-256$.

Bažil (2009): Martin Bažil, Centones Christiani. Métamorphoses d'une forme intertexuelle dans la poésie latine chrétienne de l'Antiquité tardive, Paris.

Clark/Hatch (1981): Elisabeth A. Clark et Diane F. Hatch, The Golden Bough, the Oaken Cross. The Virgilian Cento of Faltonia Betitia Proba, Atlanta (Ga.).

Consolino (1983): Franca Ela Consolino, «Da Osidio Geta ad Ausonio e Proba. Le molte possibilità del centone», in: Atene e Roma 28, 133-151.

Corsaro (2007): Francesco Corsaro, «Scene e personaggi del cento Vergilianus di Proba nella loro arrière-pensée allusiva», in: Orpheus 28, 25-46.

Corsaro (2008): Francesco Corsaro, «ll Cento Vergilianus di Proba», in: Motivi e forme della poesia cristiana antica tra Scrittura e tradizione classica, XXXVI Incontro di studiosi dell'antichità cristiana, Roma, 3-5 maggio 2007, Roma, 631-642.

Curran (2012): John Curran, «Virgilizing Christianity in Late Antique Rome», in: Lucy Grig et Gavin Kelly (éds.), Two Romes. Rome and Constantinople in Late Antiquity, Oxford, 325-344. 
Fassina/Lucarini (2015): Alessia Fassina et Carlo M. Lucarini (éds.), Faltonia Betitia Proba, Cento Vergilianus, Berlin-Boston (Mass.).

Green (1995): Green Roger P. H., «Proba's Cento : Its Date, Purpose and Reception», in: Classical Quaterly 45, 2, 551-563.

Green (1997): Roger P. H., «Proba’s Introduction to her Cento», in: Classical Quaterly, 47, 2, $548-559$.

Green (2008): Roger P. H. Green, «Which Proba Wrote the Cento ?», in: Classical Quaterly, 58, 1, $264-276$.

Herzog (1975): Reinhart Herzog, Die Bibelepik der lateinischen Spätantike. Formgeschichte einer erbaulichen Gattung, München.

Hinds (2014): Stephen Hinds, "The Self-Conscious Cento», in: Marco Formisano, Therese Fuhrer (éds.), Decadence : Decline and Fall or Other Antiquity ?, Heidelberg, 171-197.

Kyriakidis (1994): Stratis Kyriakidis, « Proba, Faltonia Betitia», in: Kleos 1, 185-200.

La Fico Guzz (2013): Maria Luisa La Fico Guzz, « La tempestad en el Cento Probae (vv. 531-561) y los juegos en honor a Anquises en el libro V de la Eneida : vínculos intertextuales», in: Maia $65,1,60-74$.

Laurence (2002): Patrick Laurence, «Proba, Juliana et Démétrias : le christianisme des femmes de la gens Anicia dans la première moitié du cinquième siècle», in: Revue d'Études Augustiniennes 48, 1, 131-163.

Matthews (1992): John Matthews, «The Poetess Proba and Fourth-Century Rome : Questions of Interpretation », in Michel Christol / Ségolène Demougin / Yvette Duval [et al.], Institutions, société et vie politique dans l'empire romain au IV siècle ap. J.-C., Actes de la table ronde autour de l'œuvre d'André Chastagnol (Paris, 20-21 janvier 1989), Paris - Roma, 277-304.

Mazzucco (2008): Clementina Mazzucco, «Per una lettura unitaria del Centone di Proba», in: Motivi e forme della poesia cristiana antica tra Scrittura e tradizione classica, XXXVI Incontro di studiosi dell'antichità cristiana, Roma, 3-5 maggio 2007, Roma, 611-629.

McGill (2005): Scott McGill, Virgil Recomposed. The Mythological and Secular Centos in Antiquity, New York.

Moretti (2008): Paola Francesca Moretti, «Proba e il Cento nuptialis di Ausonio», in: Paola Francesca Moretti et al. (éds.), Debita dona : studi in onore di Isabella Gualandri, Napoli, 317-347.

Polara (1990): Giovanni Polara, «I centoni», in: Guglielmo Cavallo / Paolo Fedeli / Andrea Giadina (éds.), Lo spazio letterario di Roma antica, III, La ricezione del testo, Roma, 245-275.

Schottenius Cullhed (2014): Sigrid Schottenius Cullhed, «Proba and Jerome», in: Marco Formisano, Therese Fuhrer (éds.), Decadence : Decline and Fall or Other Antiquity ?, Heidelberg, 199-222.

Schottenius Cullhed (2015): Sigrid Schottenius Cullhad, Proba the Prophet : the Christian Virgilian Cento of Faltonia Betitia Proba, Leiden-Boston (Mass.).

Schottenius Cullhed (2016): Sigrid Schottenius Cullhed, «Patterning Past and Future : Virgil in Proba's Biblical Cento», in: Scott McGill Joseph Pucci (éds.), Classics Renewed. Reception and Innovation in the Latin Poetry of Late Antiquity, Heidelberg, 25-45.

Shanzer (1986): Danuta Shanzer, "The Anonymous Carmen Contra Paganos and the Date and Identity of the Centonist Proba», in: Revue d'Études Augustiniennes 32, 232-248.

Shanzer (1994): Danuta Shanzer, «The Date and Identity of the Centonist Proba», Recherches Augustiniennes 27, 75-96.

Sineri (2011): Valentina Sineri (éd.), /l centone di Proba, Roma. 


\title{
Biblical hypotexts in Prudentius' Contra Symmachum
}

\author{
Case study of C. Symm. II.95-96*
}

Prudentius' Contra Symmachum is a poem set against the literary backdrop of the dispute between the prefect of the city of Rome and Ambrosius, bishop of Milan, over the removal of the altar dedicated to the goddess Victory. In 384, Symmachus addressed for the third time a relatio -on this occasion to young emperor Valentinian III- in order to, among other issues, restore the ara Victoriae to its former place in the Roman curia after its removal by Constantius II in 357. To this, Ambrose reacted also by addressing two epistles to Valentinian (Epistulae 17 and 18). In the latter he specifically rebukes the main points in Symmachus' relatio; thereby, the prefect's intentions were once again thwarted.

As for Prudentius' answer in Contra Symmachum, there is growing consensus among scholars against the hypothesis of the poem having been prompted by a new intent on Symmachus' part (in Honorio regnante) of restoring pagan privileges, lost in 402 when Alaric's vandals had already set foot on Italian soil. Among the academics who share the opinion that the conflict involving Symmachus was by then already a matter of the past, some consider that Prudentius addressed the issue once more because he did not find the answer provided by Ambrose convincing enough. ${ }^{1}$ Others, on their part, think that Prudentius refutes Symmachus as some sort of indirect reaction against certain pagans who, at the time - like Claudian -, interpreted Stilicho's victory against Alaric in the Battle of Pollentia (402) as a victory of pagan Rome, still protected by the gods. ${ }^{2}$ From this perspective, Contra Symmachum would not be a pertinent answer to an already old conflict, but the literary result of a highly charged spiritual environment that had wrought a fragile peace for the Empire, and even more so for Italy. ${ }^{3}$

Therefore, the pagan exaltation of Victory would exceed the occasional dispute to expose, as Lavarenne points out, "l'idéologie triomphaliste de l'Empire théodosien et une certaine philosophie chrétienne de l'histoire qui, s’inspirant de la pensée d'Eusèbe de Césarée, annonce, avant la synthèse augustinienne de la Cité de Dieu, la conception d'un Bossuet sur l'histoire universelle". ${ }^{4}$

\footnotetext{
* English translation of Carmen Pulín Ferrer.

1 Fernández Vallina (1989) 249.

2 Claud. Get. 571-573 (Hall, Teubner): Romanum reparate decus molemque labantis| imperii fulcite umeris: hic omnia campus| uindicat, haec mundo pacem uictoria sancit.|

3 Garuti (1996) 24.

4 Lavarenne (1992) 95.
} 
Besides, Danuta Shanzer, who has studied the composition process of Contra Symmachum, concludes that its first part was written mainly during Theodosius' rule, in 394, whereas the complete work -rewritten, amplified and unified- was not issued until 402-403. These data allow us to maintain that Prudentius' Contra Symmachum is a literary work on an old issue (the apologetic debate) that was published on a new historical occasion (the instability caused by Alaric). ${ }^{5}$

The writing, ultimately addressed to young emperor Honorius, consists of two books: the first of them is a refutation of pagan polytheism, followed by an eulogy of Theodosius' religious policy, which put an end to paganism and reduced its stubborn followers, represented by Symmachus, to a minority. ${ }^{6}$ The second and longer one refutes each and every argument provided by Symmachus in his Relatio tertia (Rel. 3). Its main point is that the cause of Rome's military success is not the goddess Victory, but an effort on the part of its soldiers, assisted by the one true God. ${ }^{7}$ Six arguments by Symmachus are then addressed and refuted one by one: a) the pagan religious tradition is set in opposition to the new faith, which is seen as a positive evolution; ${ }^{8}$ b) Rome's destiny is permanence, sustained by Christ; ${ }^{9}$ c) the prosperity and the unification of many peoples attained by Rome were not caused by the gods, but meant as a preparation for the coming of Christ; ${ }^{10} \mathrm{~d}$ ) Rome is no longer a white-haired city, claiming for its lost freedom; it has been rejuvenated under the Christian empire and God's protection, and the victory at Pollentia undeniably proves it; ${ }^{11}$ e) as for the religious tolerance claimed by Symmachus, who argues that there are many paths leading to the knowledge of the mystery of God, Prudentius answers that against the path of idolatry, which leads to hell, only the path of God's truth, revealed by the Christian faith, is valid; ${ }^{12}$ f) Rome's famines do not come as a revenge of the gods after the Vestals had their allowance withdrawn; besides, their virginity is not praiseworthy, because it is only temporary, and these women do also show their harshness at gladiatorial combats, an entertainment which Prudentius suggests to suppress for good. ${ }^{13}$

Overall, the second book of Contra Symmachum runs parallel to Ambrosius' answer in his Epistula 18 to the pagan nobleman; this latter writing does also follow the order of the argumentation in the Relatio tertia by Symmachus. Nevertheless, it is clear that the work of Prudentius is more extensively developed when compared to the basic arguments provided by Ambrose. One of them is the answer to the religious

5 Shanzer (1989) 458-462.

6 The outline of contents suggested below follows Lavarenne (1992) 91-93.

7 C. Symm. 5-66 (Cunningham, CCSL 126) and Rel. 3.3 (Zelzer, CSEL 82.3).

8 C. Symm. 91-369 and Rel. 3.3-4.

9 C. Symm. $370-487$ and Rel. 3.8.

10 C. Symm. 488-640 and Rel. 3.8-9.

11 C. Symm. 641-772 and Rel. 3.9-10.

12 C. Symm. 773-909 and Rel. 3.10.

13 C. Symm. $910-1132$ and Rel. 3.11-17. 
relativism proposed by Symmachus. ${ }^{14}$ It should be noted that the pagan, an excellent orator, argued that there are many ways, many religious perspectives, to disclose the mystery which transcends man. His argument for justifying his relativism is that if every man can enjoy the goods of creation, then also every man can find the mysterious truth of what transcends mankind, even by following different paths (Rel. 3.10):

Eadem spectamus astra, commune caelum est, idem nos mundus inuoluit; quid interest qua quisque prudentia uerum requirat? Uno itinere non potest perueniri ad tam grande secretum. Sed haec otiosorum disputatio est; nunc preces, non certamina offerimus.

Ambrosius' answer (Epistula 18.8), built on elements typical of the genus epidicticum, based on a rhetorical swaying between praise and vituperation, directly opposes the faith of Symmachus to that of the Milanese bishop, and displays contrasting concepts against the former and in support of the latter: ignorance - knowledge; conjecture - certainty; religiousness against revelation. ${ }^{15}$ At the end of the paragraph, Ambrosius draws a distinction between pagan religion and the theodicy practiced by philosophers, and uses them for arguing that even they have laughed at polytheism and the worship of the gods:

Uno, inquit, itinere non potest perueniri ad tam grande secretum. Quod uos ignoratis id nos dei uoce cognouimus, et quod uos suspicionibus quaeritis nos ex ipsa sapientia dei et ueritate compertum habemus. [...] Denique etiam ipsi philosophi uestri ista riserunt.

In short, Ambrose succinctly answers discrediting Symmachus' relativist religiosity against the revealed certainty of the fides catholica.

As for Prudentius, he creates a fictitious Symmachus in Contra Symmachum, and discusses with him using arguments taken from the Relatio 3, written by the prefect in 384, as already said. This composition device enlivens the discussion. More specifically, Prudentius' answer to the argument used by Symmachus in his Relatio 3.10 appears in three different places. The fact that he addresses the issue thrice reveals that the main question of Symmachus' Relatio 3.10, where he defends the existence of many ways to meet the mystery transcending mankind, is for Prudentius one of the main points to be refuted in his poem. ${ }^{16}$ My analysis will be focused on the first of them.

The first refutation appears at the beginning of the second book. Prudentius answers to his fictional Symmachus, who, making Rome speak in his support, ends his allegation as follows:

14 Ambrosius states that there is only one true religion and one path leading to the mystery of God, against a religious pluralism covering a relativistic position. (Moreno [2002]).

15 Ambrosius' rhetorical pattern does certainly remind of Lactantius' Inst. VII.8.3: nos igitur certioribus signis eligere possumus ueritatem, qui eam non ancipiti suspicione colligimus, sed diuina traditione cognouimus.

16 C. Symm. II.85-90; 773-774; 843-846 
Vno omnes sub sole siti uegetamur eodem
aëre; communis cunctis uiuentibus aura;
sed qui sit qualisque Deus, diuersa secuti
quaerimus, atque uiis longe distantibus unum
imus ad occultum: suus est mos cuique genti,
per quod iter properans eat ad tam grande profundum. ${ }^{17}$

It must be noted that in the Relatio 3 the historical Symmachus does not question the nature (in singular) of God; this seems quite logical, as his perspective on the transcendental mystery is a polytheistic one. But Prudentius' fictitious Symmachus does actually put the question through Rome itself: qui sit qualisque Deus. ${ }^{18}$ Nevertheless, this issue does not appear as such among several interests displayed by Symmachus in his Relatio 3. The pagan text offers -but for the use of the singular mens divina ${ }^{19}$ all sort of polytheistic references: fatales genii, dei patrii, numina. However, Prudentius transforms the thesis sustained by the real Symmachus -the defense of religious relativism on the issue of the truth about the mystery transcending man- to address quite a different question, the possibility of knowing the mystery of the sole god by different paths provided by reason:

His tam magnificis tantaque fluentibus arte respondit uel sola fides doctissima primum pandere uestibulum uerae ad penetralia sectae. Nam cum diuinis agimus de rebus, et illum qui uel principio caruit uel fine carebit quique chao anterior fuerit mundumque crearit coniectare animo contendimus, exigua est uis humani ingenii tantoque angusta labori.

Quippe minor natura aciem si intendere temptet acrius ac penetrare dei secreta supremi, quis dubitet uicto fragilem lassescere uisu uimque fatigatae mentis sub pectore paruo turbari inualidisque hebetem subcumbere curis? sed facilis fidei uia prouocat omnipotentem credere, qui bona non tantum praesentia donat, sed uentura etiam longisque intermina saeclis promittit...20

17 C. Symm. II.85-90: "We all draw life from the same atmosphere under the same sun, all living beings share the same air; but we follow different paths when we inquire into the being and nature of God, and by ways far apart approach the same secret; every race has its own custom, and that is the line along which it must hasten to reach the great mystery" (Thomson (1953)).

18 C. Symm. II.87.

19 Rel. 3.8.

20 C. Symm. II.91-107: "To these fine words flowing with such art Faith has given the answer, for she before all has skill to open the first approach to the heart of the true belief. For when we are concerned with divine things and striving to reach a conception of Him who was without beginning and will be without end, who existed before the primeval darkness and created the world, the 
Manipulating Symmachus' ipsissima verba, Prudentius changes a debate where arguments defending monotheism against polytheism were expected, transforming it in a defense of the Christian faith, the only one that truly answers to the mystery of God. Prudentius justifies acting like this due to his own opponent, as Symmachus, in his Rel. 3.10, does not make a defense of polytheism, but of relativism as an option to disclose the transcendent mystery. To this proposal, based on the multiplicity of paths to seek God (C. Symm. II.87-88 diversa sequi, viae distantes), Prudentius answers that only faith teaches exclusively (sola fides doctissima) the secrets of the true doctrine (vera secta), which is also liberating (libera secta, C. Symm. II.486 ${ }^{21}$ ), for not only does it bestow present goods, but also everlasting ones in the future (bona praesentia; ventura et intermina, will he say later in C. Symm. II.105-106). The path of the faith received by Christians enables to meet easily (facilis fidei via) the mystery of God, which, by its same nature, exceeds human intents of disclosing it on its own (exigua est vis). He will later affirm that, being that mystery so grand, its knowledge via the Christian faith makes reasonable the truthfulness of what faith allows us to know about the truth on God and His promises. ${ }^{22}$

But most interesting for our investigation is that, in these verses, Prudentius not only defends the way of revelation (fides) against the many paths supported by Symmachus, as Ambrosius had already done in his epistle (384), but also answers the quaestio principalis of "his" Symmachus: the one which specifies the content of the grande secreto formula in the writing by the real Symmachus, implicitly raising the issue of the true nature of God: qui sit qualisque deus (C. Symm. II.87). Prudentius answers to this question right at the beginning of his confutation: the god about whom "his" Symmachus asks is both eternal and creator (C. Symm. II.95-96).

Prudentius is linking here two aspects highlighting both God's might -displayed in the visible creation (mundus) - and His greatness, which can comprehend and overcome time. This greatness is described in a twofold formula, in order to express that God surpasses time boundaries, as in time there is a before and an after. But he also adds a peculiar point by alluding to chaos, something that not only connects God's greatness to His creative powers but could also be hinting at a biblical back-

\footnotetext{
force of the human mind is too petty and limited for so great a task. If the lesser nature seek to strain its gaze too keenly and to penetrate the mystery of the most high God, who would question that its vision is beaten, its frail power flags, the working of the tired intellect is thrown out in the little mind and is dulled and fails under its feeble efforts? But the easy way of faith calls to believe that the Almighty is He who not only grants us blessings for the present time but promises blessings to come, that will last without end through the long ages, so that I shall not wholly pass away into empty nothingness and perish after a brief enjoyment of the light" (Thomson (1953)).

21 It is really symptomatic how Prudentius takes up here every issue in Symmachus' argumentation and turns them into an exhortation to conversion: Huc ades omne hominum genus, huc concurrite et urbes!| lux inmensa uocat, factorem noscite uestrum!| libera secta patet. (C. Symm. II.484-486).

22 C. Symm. II.120 -124: Hac ratione fides sapienter conicit, immo| non dubitat uerum esse deum qui quod sumus et quod| uiuimus inlaesum semper fore, si mereamur,| nos sperare iubet. Cf. Evenepoel (1991) 322-324.
} 
drop for this couple of verses, as we intend to prove in this paper. The expressions employed by Prudentius in his definition of God -beginning and end (principio caruit uel fine carebit); the allusion to chaos (chao anterior fuerit); the creation of the world (mundumque crearit) - will act as guidelines in our study.

We will start with the details provided by the leading scholars that have addressed Contra Symmachum. To the question of a possible biblical base underlying C. Symm. II.95-96 there is no positive answer to find when consulting the most relevant critical editions, both old ${ }^{23}$ and more recent $\left(20^{\text {th }}\right.$ century) ${ }^{24}$ Searching the annotated translations ${ }^{25}$ and partial commentaries ${ }^{26}$ does shed a more promising light, as will be shown.

In the first place, the idea of human intelligence being able by itself to comprehend God's mystery could have a rather vague biblical basis on Proverbs 25:27 and Ecclesiasticus 3.22 for C. Symm. II.97-98. ${ }^{27}$ By quoting Wisdom 9:16 we could be treading on more solid ground, as there are coincidences to be found both in theme and vocabulary ${ }^{28}$. The second notion, ex nihilo creation in two stages -creation of chaos and later creation of cosmos (C. Symm. II.96)- would find an imprecise coincidence in Genesis 1.1- $2^{29}$. In this verse by Prudentius, the use of the word chaos could also be referencing the Greek version of Wisdom $11.17 .^{30}$ The third idea, divinity being previous (and therefore eternal) to creation, and also its foundation, has a plausible biblical basis in Colossians 1.17, as noted by Brown (2003). ${ }^{31}$ We must also point out that this scholar does not justify proposing a quote attributed to Christ as scriptural reference for a text which apparently makes reference to an eternal, creator God, who could be seemingly identified with the Father in Christian theology. Nevertheless, his answer could be based on Prudentius' vague mention of a diuinae

23 Langen (1497), Arévalo (1789), Orbarius (1845), Dressel (1860).

24 Bergman (1926), Cunningham (1966) and the 1983' revision, Lavarenne (1992).

25 Lanfranchi (1898), Thomson (1953), Guillén (1959), Rivero (1997), Ortega and Rodríguez (1981), Brown (2003).

26 Middeldorpf (1823), Pascual (1976), Brown (2003), Tränkle (2008).

27 For exigua est uis humani ingenii (C. Symm. II.97-98), Lanfranchi (1898) and Guillén (1959) find reference in Prov 25.27 (Sabatier, Vetus Italica: Sicut qui mel multum comedit, non est ei bonum: sic qui scrutator maiestatis, opprimetur a gloria). On his part, Guillén (1959): Eccl 3.22 (Vetus Latina, Beuron edition: quae praecepit tibi Deus illa cogita semper et in pluribus operibus eius ne fueris curiosus). 28 Lanfranchi (1898) and Guillén (1959) connect C. Symm. II.97-98 to Sap 9.16 (Vetus Latina, Beuron edition: difficile aestimamus quae in terra sunt et quae in prospectu sunt inuenimus cum labore; quae in caelis sunt autem quis inuestigabit?). It is reasonable to think that labore, in caelis, inuestigabit can justify the scriptural substratum of C. Symm. II.94 and, in particular, of C. Symm. II.97-98.

29 Cf. Vetus Latina, Beuron edition: In principio fecit Deus caelum et terram. Terra autem erat inuisibilis et inconposita (textual variant: informis). This reference is given by Pascual (1976).

30 Cf. Middeldorpf (1823), Pascual (1976) give for C. Symm. II.96 the scriptural hypotext Sap 11.17 (Vetus Latina, Beuron edition: omnipotens manus tua quae creavit orbem terrarum ex materia invisa). The formula materia invisa has a textual variant, informi materia; which corresponds literally with the

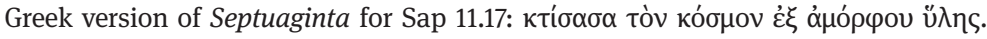

31 Cf. Col 1.17 in Sabatier, Vetus Latina: et ipse est ante omnes, et omnia in ipso constant. 
res, ${ }^{32}$ although this is by no means justification enough. Also, the notion of creation in Colossians 1.17 does not have Christ as a subject, and, if literally taken, is of no use in order to justify mundum crearit, an expression which shares the same subject with the remaining verbs in C. Symm. II.95-96. On our side, leaning also on the vague semantics of diuina res, we consider that the idea of divinity being prior to creation (and, therefore, eternal) could also find echo in Proverbs 8.22-29, ${ }^{33}$ but neither does this quote allude to the Father, but to Wisdom, usually identified in Christian tradition with the Son. Moreover, in these verses of Proverbs creative action does not appear, albeit being present in C. Symm. II.96.

We will try to overcome these difficulties by looking at other loci in Prudentius' poetry and in other non-prudentian testimonies. There are two passages by Prudentius which present some formal coincidences with C. Symm. II.95-96. The first one is in Contra Symmachum I.325-327; there, against those who dare to consider the Sun a god, the author presents the true God as He who is greater than matter and has no end, fine caret:

ille deus uerus quo non est grandior ulla materies, qui fine caret, qui praesidet omni naturae, qui cuncta simul concludit et inplet.

In Cathemerinon 4.7-9 we can also find an invocation describing God Sabaoth, everlasting spirit, devoid of beginning and end (expers principii, carensque fine), and creator of the world (rerum conditor):

Hic est quem sabaoth deum uocamus;

expers principii carensque fine,

rerum conditor et repertor orbis,

Along with these testimonies we do find two further passages also displaying formal parallelisms, but now the one depicted as eternal is not God, but the Word. The first of these passages, excerpted from Apotheosis 264-267, is put in a context thematically close to C. Symm. II, the present object of our study. There it is claimed that, by following the path of reason (cum uentum [...] ad normam rationis et $\operatorname{artis}^{34}$ ), human nature is able to recognize a mighty supreme being. ${ }^{35}$ But it is difficult for the human mind to go further, to disclose the hidden secrets of God's mystery before

32 C. Symm. II.94.

33 Cf. Prov 8.22-25 in Sabatier, Vetus Latina: Dominus condidit me initium [textual variant: in initio] uiarum suarum in opera sua. Ante saeculum fundauit me: in principio antequam terram faceret et antequam abyssos constitueret, priusquam procederent fontes aquarum, antequam montes conlocarentur, ante omnes colles genuit me...

34 Apoth. 207.

35 Apoth. 212-214: Non recipit natura hominis (modo quadrupes ille/ non sit et erecto spectet caelestia uultu)| non recipit neget ut regimen pollere supremum.| 
the beginning of the world..$^{36}$ Only transmitted faith ${ }^{37}$ allows mankind to know how the Father begot the beginningless Word. It is this transmitted faith what enables us to overcome the handicap of facing the mystery of God by sole reason; the main issue in this mystery is the trinitary intradivine life or, more specifically, the relationship between Father and Son, between God and His Word:

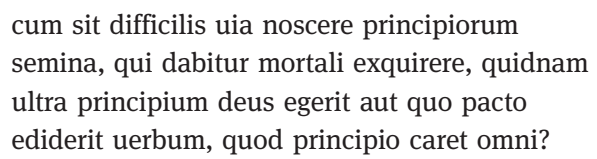

In this excerpt we can find the notion of the strenuous search of God (difficilis, exquirere); that of existence before time, now referred to the generation of the Word (ultra principium egerit aut ediderit), and, thirdly, the idea of timelessness (principio caret omni), also applied to the Word in an expression identical to that in C. Symm. II.95.

The second testimony, taken from Cathemerinon 12.37-40, contains quite significant parallels with our passage: the idea of searching -which, in this case, has vision (cernere) as a consequence- and the notion of eternity, also based on two temporal limits: endlessness (nesciat finem pati) and, on the other hand, existence before heaven and chaos (antiquius caelo et chao). This is the one text among those by Prudentius which offers the closest parallel to the formula chao anterior fuerit in the distich object of this study. Those verses refer to the Christ, sidus aeternum, king of the Gentiles, beheld as Sun of Justice by the stargazing Magi. This king, states Prudentius, is older than heaven and chaos, he is also eternal (interminum; aeternum manet $^{38}$ ) and not subjected to the limits imposed by time.

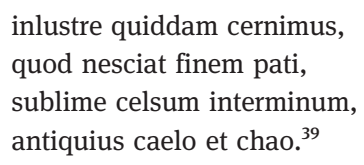

Ante chaos existence of the Verb is connected in another passage by Prudentius to His generation $a b$ aeterno in the bosom of the Father with the expression ante chaos genitus (Hamart. 44). The idea of being prior to chaos could also be alluding to the concept in Hesiod's Theogony, where chaos is the origin of cosmos and of the subsequent genealogies of gods. ${ }^{40}$ It is also possible that Prudentius had in

36 Apoth. 259-263.

37 Cf. traditur in Apoth. 268.

38 Cath. 12.17.

39 Cath. 12.37-40.

40 Hesiod. Theog. 115. Kayser (1881), 313, shows that the shapeless, chaotic mass, the Hebrew thohu wa bohu in Genesis 1:2, is sometimes associated by Christians to cosmological descriptions they read 
mind Lactantius' critic to the first theologian of paganism, when he affirms that Hesiod did not take the trouble to search for the origin of chaos in the truth of a creator god. ${ }^{41}$ Anyway, Prudentius also expresses the ab aeterno generation of the Word with equivalent formulas, like de natus ante mundi exordium, which appears in other verses of Cathemerinon. ${ }^{42}$

Out of Prudentius' writings, a passage by Arnobius the Younger in his theological dispute with Serapion (mid-fifth century) allows us to see that every descriptive element on divinity in C. Symm. II.95-96 -being prior to time; no beginning; endlessness; creation of the world- does appear in the description of Christ's divine nature:

Verbum quod erat antequam mundus esset, uerbum quod non est a principio, sed in ipso principio semper fuit, uerbum quod caret initio, sed est ipsum initium, uerbum quod non subiacet tempori uel atomo uel momento uel puncto, sed est omnium creator. ${ }^{43}$

To sum it up, in view of the above prudentian parallels, we can see that the expressions used by our author in C. Symm. II.95-96 refer to a divine entity whose eternity is described in formulae evoking the deus verus of C. Symm. I.325-327 and the Deus Sabaoth of Cath. 4.7-9, but they do find more connections with iuncturae uerborum in other writings (Apoth. 264-267; Cath. 12.37-40) related to the Word or Christ. These formulae do also appear in Christological writings, like the one by Arnobius in his Conflictus.

Besides, both loci prudentiani (in Cathamerinon) linked by academics to Proverbs 8.22-29 identify Wisdom -or Christ- developing its creative task without leaving the bosom or power of the Father. None of these references show lexical similarities with our writing, but they make clear that Prudentius associated the eternity of divine Wisdom to the creation of the world. In 11.17-32 the one who is called Sophia when in the heart of the Father leaves His bosom to, now as Verbum prolatum, undertake the creation of heaven, light and time governing the Earth's orb, all with God's own might, "for the Word is God" (nam Verbum Deus), an expression also evoked in John 1.1:

ex ore quamlibet patris sis ortus et uerbo editus, tamen paterno in pectore sofia callebas prius.

in pagan poetry. There is, for instance, Ovidius' Metam. 1.5-7: Ante mare et terras et [...] caelum unus erat toto naturae uultus in orbe, quem dixere Chaos, rudis indigestaque moles; Lactantius definition in Inst. 1.5.8 seems to be inspired in Ovidius: Caos est rudis inordinataeque materiae confusa congeries. 41 Lact. Inst. 1.5.8-10.

42 Cath. 9.10-12 [Christus] Corde natus ex parentis ante mundi exordium,| alfa et $\omega$ cognominatus, ipse fons et clausula| omnium quae sunt fuerunt quaeque post futura sunt.

43 Arnob. Confl. 2.21 (Daur, CCSL 25 A, 43-173). 


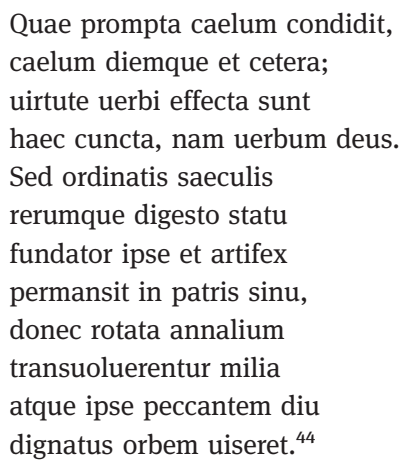

In the second passage, related to Proverbs 8.22-29, Christ -entitled omniparens, father of all things created- wields His power in the bosom of the Father before stars, earths and seas came into being (Cath. 3.1-5):

O Crucifer bone, lucisator, omniparens, pie, uerbigena, edite corpore uirgineo, sed prius in genitore potens, astra, solum, mare quam fierent. ${ }^{45}$

Even though scholars are not pointing to any reference for Colossians 1.17 in Prudentius' poetry -but the one by Brown, as already mentioned-, there are other non-prudentian writings where we can find the formulae used by our author in the verses under our scrutiny. These include, but are not limited to, the case of Faustinus the Luciferian, who identifies Christ -described by Paul as ipse est ante omnes- with the Wisdom that intervenes in creation (Psalm 103) in order to affirm the eternity of the pre-existing Christ; He, being prior to creation, is its beginning and also its creator:

Ergo ipse semper est, per quem et in quo omnia facta sunt. Sed et hymnidicus cantans ait: omnia in sapientia fecisti (Ps 103.24 LXX). Non tamen ipsam dixit factam esse sapientiam, quia et apostolus, cum dicit: et ipse est ante omnes (Col 1.17), factum negauit. Si enim eum qui non erat, factum credi uoluisset, ita posuisset: 'et ipse factus est ante omnes'; at cum dicit: 'et ipse est ante omnes', omnibus dedit initium, quorum anterior, immo et factor est; ipse uero sine initio est, qui ante omnes non factus sed esse memoratur. ${ }^{46}$

44 For Cath. 11.17, cf. Cunningham (1966): Prov 8.22; Guillén (1959): Prov 8.22; Io 1:1-2; for Cath. 11.21, cf. Cunningham (1966): Prov 8.27-30; Guillén (1959): Prov 8.27ss.; Io 1.1-3; for Cath. 11.23, cf. Guillén (1959): Io 1.1; for Cath. 11.28, cf. Guillén (1959): Io 1:18.

45 For Cath. 3.5, cf. Cunningham (1966), Rivero (1997): Prov 8.22-30. A novel interpretation of the value of crucifer, lucisator y uerbigena can be read in the article by Patricio de Navascués in this same volume.

46 Faust. Lucif. De fide contra Arianos 5.20 (Simonetti, CCSL 69, 295-353). 
This text by Faustinus shows that Colossians 1.17 is included in the scriptural arguments used for defending the consubstantiality of the Son with the Father, His generation before time, and His active presence in creation. It also allows us to justify considering Colossians 1.17 as an hypotext for our verses via formal parallels (sine initio; anterior) with C. Symm. II.95-96.

As already shown above, the loci prudentiani where Proverbs 8:22-29 appears as an hypotext associate the idea of creation to that of the eternity of the Wisdom or Word of God. Aside from Prudentius' poetry, we can also find other writings where expressions similar to those in C. Symm. II.95-96 are used, and they have as biblical basis Colossians 1.17; they also put in relation the eternity of the pre-existing Christ with His creative activity.

Last, in another non-prudentian writing, we will find again the key ideas of $C$. Symm. II.95-96, now sustained -among others- by quotations of Col 1.17 and Prov 8.22-29. In an anti-Arian context, in order to prove that the Son is of the same nature than the Father (de patris substantia), Gregory of Elvira provides a list of characteristics of the Word, as His eternity (nihil enim sine initio nisi solus deus), ${ }^{47}$ from which His being the firstborn of all creation derives (Col 1.15); an eternity inextricably shared with the Father, ${ }^{48}$ because He comes from His bosom; ${ }^{49}$ being eternal, He is true God. ${ }^{50}$ Gregory also explains that the Son is named Wisdom because of His being sapientia patris, sapientia dei, sapientia ineffabilis; in order to sustain this claim, he relies on Proverbs $8.22 .{ }^{51}$ As for the attributes of eternal Wisdom in this biblical passage, Gregory points out that initium should be understood as an operating, creative movement (initium motus operis alicuius ostendit), and deducts that both the strength and might of God's Wisdom are known through the effect of His works (de effectu operum suorum uirtus eius et potentia nosceretur), so that man can recognize the creator through the creatures (conditorem de conditis). ${ }^{52}$ Gre-

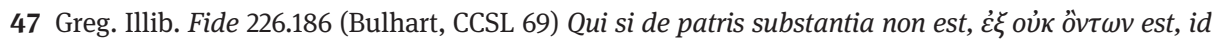
est ex nullis extantibus, ut idem arius tradidit; sublato enim eo, quod pater est, undecumque fuerit filius, necesse est, ut et initium ex nihilo et ortum ex tempore habeat; nihil enim sine initio nisi solus deus. 48 Greg. Illib. Fide 226.220 (Bulhart, CCSL 69) Ac proinde cuius origo principium non habet, sempiternus cum patre credendus est, quia nec pater potest umquam sine filio nominari nec filius sine patre uocari; ac per hoc semper filius, quia semper pater.

49 Greg. Illib. Fide 226.209 (Bulhart, CCSL 69) Igitur quod in principio erat, semper fuisse credendum est, sed nec aliunde esse, quam ex eo qui principium non habet, id est, de corde patris, quia eructauit, inquit, cor meum uerbum bonum.

50 Greg. Illib. Fide 227.227 (Bulhart, CCSL 69) Quod deus est, semper est, ne si semper non fuerit, uerus deus esse non possit, sicuti et in sophiae nomine, quia secundum apostolum ipse est sapientia patris, ego, inquit, ex ore altissimi prodiui.

51 Greg. Illib. Fide 227.234 (Bulhart, CCSL 69) Haec est illa sapientia ineffabilis, quae initium uiarum dei apud salomonem uel condita uel genita uel creata describitur; quam tamen sic conditam dicit, ut semper eam cum deo fuisse ostendat.

52 Greg. Illib. Fide 227.247 (Bulhart, CCSL 69) Creata est ergo sapientia, immo genita, non sibi, quae semper erat, sed his, quae ab ea fieri oportebat, ut quia quanta et qualis esset sciri non poterat, de ef- 
gory ends with a profession of faith in Wisdom, author and creator of the universe, who is the Son of God, by whom and in whom everything exists; this upholds Gregory on the basis of Colossians $1.16-17^{53}$ This passage by Gregory of Elvira shows that Col 1.17 and Prov 8.22-29 can both co-exist as scriptural substrate for the distich C. Symm. II.95-96, where divine eternity - expressed by the absence of beginning and end -, priority to formless matter, and creation of the world are the characteristics defining the nature of the God revealed by faith.

Nevertheless, an unanswered question remains. Even though diuinae res ${ }^{54}$ sets the context for those characteristics present in C. Symm. II.95-96, the link with deus verus in C. Symm. I.325-327 does not make clear whether Prudentius is alluding in both cases to God Father; something which becomes more likely when considering Cathamerinon 4.7-9, a passage where the same notions on divinity than those in $C$. Symm II.95-96 are undoubtedly addressed to Deus Sabaoth.

Therefore, we intend to consider the plausibility of the existence of two biblical hypotexts on the Son (be it as Wisdom of the Father, Word of God or pre-existing Christ) for this passage, where Prudentius describes the nature of God in the context of a dialogue against a fervent pagan like Symmachus. The answer to this question will be preceded by the solution to another issue: is it possible to admit, against an insufficient knowledge of God by man's sole strengths -the one proposed by Symmachus-, the description of God's nature as revealed by faith applying characteristics not entirely unsuitable for the Father, but more related to the Son, Wisdom of God, begotten before time and creator of cosmos? In other words, is there an explanation for Prudentius speaking of the deus verus to the pagan Symmachus, showing him the nature of the pre-existent Word, creator of everything by will of the Father without leaving His bosom? This is, why Prudentius, against Symmachus' pagan polytheism, does not provide arguments defending an unspecific monotheism, but reasons from the specific perspective of the sola fides christiana?

It could be argued that the aforementioned questions are pointless, because, in fact, Prudentius is answering from an undefined monotheistic point of view; against Symmachus' polytheism, he provides a generic perspective on a supreme, eternal god, maker of the cosmos and even ex nihilo creator of formless matter (chaos), out of which he models the beauty of the visible universe. Our text would perfectly fit the deus verus in C. Symm. I.325-327; besides, formal coincidences with Apoth. 264-267 and Cath. 12.37-40 (related to the Word) could be explained assuming

fectu operum suorum uirtus eius et potentia nosceretur, ut dum conditorem de conditis aestimamus, tunc magis timeremus, cum facta miramur.

53 Greg. Illib. Fide 228.262 (Bulhart, CCSL 69) Haec est, inquam, illa sapientia dei, quae dicit: ego ex ore altissimi prodiui, uniuersitatis conditrix et effectrix, id est filius dei, per quem omnia et in quo omnia, quia ut apostolus dixit: in ipso constituta sunt uniuersa in caelis et in terra, uisibilia et inuisibilia, siue throni siue dominationes siue uirtutes siue principatus siue potestates: omnia per ipsum et in ipso condita sunt et ipse est ante omnia et omnia in ipso constant.

54 Cf. C. Symm. II.94. 
that Prudentius was presenting the true doctrine in a vague way. From this perspective, it would be much the same for our author writing about the Father in Contra Symmachum using lexical materials also employed by him in other poems designing the $a b$ aeterno begotten Word, or about the pre-existing Son who later would be incarnated in History.

But there is another plausible explanation. In order to lay its basis, we must turn to other writings of the second-generation Christian apologetics, those of Lactantius. In his masterpiece, Diuinae Institutiones, against the premises of polytheism he opposes the truth of God as comprised in the theology of creation. As aforementioned, he states that the chaos mentioned by Hesiod is the pre-existing matter created by the God to whose might everything is subjected (deus fecit cuius potestati subiacent omnia) ${ }^{55}$ But before beginning with creation he made a spirit like Himself, endowed with the same virtues as God the Father, who resorted to Him as a counselor and author in the scheduling, arrangement and execution of everything. ${ }^{56}$ Therefore, for Lactantius the first step in the theology of creation starts with the generation of the Word, the holy and incorruptible spirit named Son.${ }^{57}$ His existence had been commented even by Hermes Trismegistus and the Sybils, ${ }^{58}$ but is expressed in words of Solomon in Proverbs 8:22-29. This spirit intervenes actively in the creation of the world. ${ }^{59} \mathrm{He}$ is very mighty, very dear to God, and not only is He born before the universe, but also ordered it with His intelligence and made it with His might. ${ }^{60}$

55 Lactant. Inst. I.5.8: potuit Hesiodus, qui deorum generationem unius libri opere conplexus est: sed tamen nihil dedit non a deo conditore sumens exordium, sed a chao, quod est rudis inordinataeque materiae confusa congeries, cum explanare ante debuerit chaos ipsum unde quando quomodo esse aut constare coepisset; Inst. II.8.8: nec audiendi sunt poetae, qui aiunt chaos in principio fuisse, id est confusionem rerum atque elementorum, postea uero deum diremisse omnem illam congeriem singulisque rebus ex confuso aceruo separatis in ordinem que discriptis instruxisse mundum pariter et ornasse. The idea for my demonstration is inspired by Garuti's intuitions (1996) 169.

56 Lactant. Inst. II.8.3: cum esset deus ad excogitandum prouidentissimus, ad faciendum sollertissimus, antequam ordiretur hoc opus mundi, quoniam pleni et consummati boni fons in ipso erat, sicut est semper, ut ab eo bonum tamquam riuus oreretur longe que proflueret, produxit similem sui spiritum, qui esset uirtutibus patris dei praeditus; Inst. II.8.7: exorsus igitur deus fabricam mundi illum primum et maximum filium praefecit operi uniuerso eoque simul et consiliatore usus est et artifice in excogitandis ordinandis perficiendisque rebus, quoniam is et prouidentia et ratione et potestate perfectus est; de quo nunc parcius, quod alio loco et uirtus eius et nomen et ratio enarranda nobis erit.

57 Lactant. Inst. IV.6.1 Deus igitur machinator constitutorque rerum, sicut in secundo libro diximus, antequam praeclarum hoc opus mundi adoriretur, sanctum et incorruptibilem spiritum genuit, quem filium nuncuparet.

58 Lactant. Inst. IV.6.3.

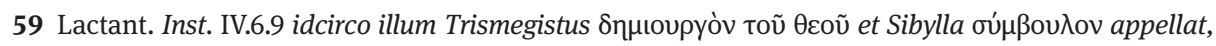
quod tanta sapientia et uirtute sit instructus a deo patre, ut consilio eius et manibus uteretur in fabricatione mundi.

60 Lactant. Inst. IV.7.1: iste tam potens, tam deo carus [...] cuius prima natiuitas non modo antecesserit mundum, uerum etiam prudentia disposuerit, uirtute construxerit. 
The theology of creation found in the apologetical writings represented by Lactantius enables us to discover that the nature of an eternal god creator is explained by the inspired or revealed news rendered by Scripture in Proverbs 8.22-29. When unspecifically alluding God in such contexts, this apologetical tradition implicitly takes into account the $a b$ aeterno generation of the Word, visible Wisdom endowed with creative power by the invisible Father. These passages by Lactantius show that the procedure of presenting notions specific to the Christian deus uerus, revealed by faith, is -even in the context of a dialogue with polytheistic paganism- a discursive device which could also have been employed by Prudentius in his disputation with Symmachus. ${ }^{61}$ Generically alluding the deus verus in C. Symm. I.325-327, as well as stating His eternal, creative nature in C. Symm. II.95-96 cannot be explained, not so much due to a lack of dogmatic specificity in a poetical context, but rather because there is a conscious lexical unspecificity overlaying the specificity of the sola fides, according to which there is no question of an eternal, creator God out of the implicit reality of the Son of the Father, the ab aeterno begotten Word, who, without leaving the bosom of the Father, participates in the creation of the world, as shown by the presence of Proverbs 8.22-29 in the poetry of Prudentius.

\section{Bibliography}

Arévalo (1789): F. Arevalus, M. Aureli Clementis Prudenti, v. c., Carmina. Tomus secundus, Romae. Bergman (1926): Io. Bergman, Aurelii Prudentii Clementis Carmina, Vindobonae - Lipsiae.

Brown (2003): M.P. Brown, Prudentius' Contra Symmachum, Book II. Introduction, Translation and Commentary, Newcastle.

Cunningham (1966): M.P. Cunningham, Aurelii Prudentii Clementis Carmina, Turnholti

Cunningham (1983): M.P. Cunningham, Aureli Prudenci Clement. Contra Simmac. Text revisat per

Maurice P. Cunningham, Barcelona.

Dressel (1860): A. Dressel, Aurelii Prudentii Clementis quae exstant Carmina, Lipsiae.

Evenepoel (1981): W. Evenepoel, “Prudentius: ratio and fides", in: L'antiquité classique 50, $318-327$.

Fernández Vallina (1989): E. Fernández Vallina, “¿Vino nuevo en odres viejos? Expresión de un conflicto a principios del siglo V", in: Helmantica 40, 245-254.

Garuti (1996): G. Garuti, Prudentius. Contra Symmachum, L'Aquila - Roma.

Guillén (1959): J. Guillén, Aurelio Prudencio. Obras completas, Madrid.

Kayser (1881): J. Kayser, Beiträge zur Geschichte und Erklärung der ältesten Kirchenhymnen, Paderborn.

Lanfranchi (1898): V. Lanfranchius, Aurelii Prudentii Clementis Opera. Volumen II, Augustae Taurinorum.

61 It is possible that Prudentius took his argumentative outline from Lactantius. We may think so not only on account of these passages of Inst. IV, but also -among other things- because of the allusion to the theology of the temple inscribed in the defense of true worship in Inst. VI (Inst. VI.25.3; 15). Prudentius resorts to the doctrine of inhabitation of the human soul by God against Symmachus' claims, in order to disprove the need of material temples for worshipping God: templum mentis amo, non marmoris (C. Symm. II.249). 
Langen (1497): R. von Langen, Opera Aurelii Clementis Prudentii, Deventer.

Lavarenne (1992): M. Lavarenne, Prudence. Tome III. Psychomachie. Contre Symmaque, Paris.

Middeldorpf (1823): H. Middeldorpf, Commentatio de Prudentio et theologia Prudentiana,

Vratislaviae.

Moreno (2002): J.L. Moreno Martínez, “Aurelio Prudencio y el debate sobre el altar de la Victoria”, in: Kalakorikos 7, 79-102.

Orbarius (1845): Th. Orbarius, Aurelii Prudentii Clementis. Carmina, Tubingae.

Ortega and Rodríguez (1981): A. Ortega, A. Rodríguez, Obras completas de Aurelio Prudencio, Madrid.

Pascual (1976): J. Pascual, Antropología de Aurelio Prudencio, Roma.

Rivero (1997): L. Rivero, Prudencio. Obras II, Madrid.

Shanzer (1989): D. Shanzer, “The Date and Composition of Prudentius's Contra orationem Symmachi libri”, in: Rivista di Filologia e di Istruzione Classica 117, 442-462.

Thomson (1953): H.J. Thomson, Prudentius II, London - Cambridge, Massachusetts.

Tränkle (2008): H. Tränkle, Prudentius. Contra Symmachum - Gegen Symmachus, Turnhout. 

Patricio De Navascués

\title{
O crucifer bone lucisator (Prudence, cath. 3.1)
}

\author{
Doctrine ancienne en termes nouveaux
}

\section{Sur le Cathemerinon}

Sur le style et la pensée de Prudence, un grand nombre de pages ont été écrites au cours de ces dernières décennies. Les questions les plus diversifiées, de grande envergure et incidence, ont été suscitées concernant l'œuvre de Prudence: je pense aux problèmes textuels qu'en présente la tradition manuscrite, aux questions littéraires touchant la métrique -plus d'une fois- toute originelle, à la chronologie et signification exacte de sa Préface, à la considération de son œuvre intégrale en tant qu'un seul poème, etcetera. Une bonne exposition sur les principales opinions soutenues par les specialistes jusqu'en 1993 a été donné par A. A. R. Bastiaensen dans le volume Early Christian Poetry. ${ }^{1}$ Après cette date, les chercheurs n'ont pas manqué de produire de nouvelles éditions, traductions, articles, etcetera. À titre illustratif, nous pourrions souligner les trois volumes Prudentiana, confectionnés par un expert de Prudence, de grande renommée, le professeur, déjà émérite à l'Université de Münster, Christian Gnilka. ${ }^{2}$

Les poèmes de Prudence ont provoqué dans la recherche moderne, des réactions contrastées. Aujourd'hui ils continuent à le faire. Toutefois, il y a certains points qui méritent l'assentiment de presque tous les spécialistes de Prudence. En tenant compte, ou mieux en considérant les paroles mêmes de Bastiaensen, la poésie de Prudence présente 'a strong internal unity', et de façon toute particulière, il s'agit d'une cohérence au niveau de la pensée théologique même, et mieux encore, d'une cohérence plus forte qui en fait une unité d'inspiration: Prudentius peut par conséquent, être considéré comme un écrivain, qui est fortement et hautement convaincu que la foi chrétienne est vraie et digne d'être honorée au moyen de la poésie.

Ce que je propose ici n'est qu'une approche beaucoup plus modeste. Ce n'est pas une réflexion générale sur un aspect particulier de l'œuvre du poète Calagurritanus. Par contre, je me suis concentré sur un verset de son Cathemerinon, je dirais plutôt, sur un seul mot. En effet, au cours de mes recherches sur Prudence, je me suis pris d'enthousiasme pour le début d'un de ses deux hymnes dédiés au repas. Il s'agit du Hymnus ante cibum, le troisième du Cathemerinon.

Le passage examiné appartient donc à cette collection d'hymnes appelée $\mathrm{Ca}$ themerinon, dans laquelle le poète hispanique a essayé de fournir une méditation

1 Cf. Bastiaensen (1993) 101-134.

2 Cf. Gnilka (2000. 2001. 2003). 
rythmée pour chaque moment de la journée (c'est d'ailleurs pour ça qu'il s'appelle quotidienne, cathemerinon) et de l'année. Il n'est pas inutile de rappeler que l'œuvre du Cathemerinon comprend douze hymnes, disposés en six paires en forme de chiasme. Ce qui nous donne donc la répartition suivante: ${ }^{3}$

\begin{tabular}{ll}
\hline Jour & Année \\
\hline I-II: Matin & XI-XII Noël et Epiphanie \\
\hline III-IV: Repas & IX-X: Pâque \\
\hline V-VI: Soir & VII-VIII: Carême \\
\hline
\end{tabular}

\section{Sur l'hymne ante cibum}

Notre verset appartient alors aux couples centraux, qui sont consacrés à la nourriture. Pour le cycle du jour, deux hymnes (troisième et quatrième) avant et après le repas; pour le cycle de l'année, deux hymnes (neuvième et dixième) autour de la Pâque. Ce n'est pas un lien superficiel. Par contre, chez un auteur comme Prudence, cela nous montre la perspective avec laquelle nous devrions lire l'hymne avant le repas: avec une perspective christologique, et même plus, pascale.

L'hymne en question a été commenté plusieurs fois. Il s'agit d'un hymne de quarante-et-une strophes pentastiques, deux cent cinq versets, composé pour être chanté avant le repas, afin d'aider les hommes à manger en découvrant le goût de Dieu (fercula nostra deum sapiant, cath. 3.16), la grâce du Christ dans les coupes et sur les plats (cf. cath. 3.16 ; 11-15) et par ailleurs pour que nos occupations sérieuses, nos récréations, nos paroles, nos jeux, en un mot nos personnes et nos actions (cath. 3,16-20) soient conduits par la Sainte Trinité (cf. cath. 3.20). La perspective, à mon avis, est très haute. Prudence projette sur le modeste thème du repas, une lumière, qui met en relief plusieurs aspects implicites (christologiques, anthropologiques, sotériologiques) dans l'acte de se nourrir.

Le mètre utilisé c'est le trimètre dactylique hipercatalectique, ou autrement dit, le tetramètre dactylique catalectique in syllabam (- U U - U U - U U x), exactement comme il l'a fait pour le troisième hymne du Peristephanon, dédié à Sainte Eulalie et en symétrie avec le dixième hymne sur la Pâque, qui présente des strophes dimètre anapestique catalectique (la symétrie émerge en considérant l'anapeste comme un dactyle inverti). ${ }^{4}$ En outre, en contraste avec les deux premiers hymnes qui consti-

3 Cf. Fontaine (1981) 184: "Au centre de chacune des deux moitiés, une attention particulière est accordée à la spiritualité des repas et des jeûnes. Autour de ces deux centres, se répondent en chiasme: dans le jour, le passage de la lumière à la nuit, et dans l'année, celui (inverse) de la mort à la résurrection».

4 Cf. Bergman (1921) 55-67. 
tuent le Cathemerinon, qui ont été faits en strophes strictement ambrosiennes, dimètres ïambiques, le mètre choisi ici par Prudence se place dans un niveau plus haut et, pour cette occasion, il dénonce l'influence d'Ausone. ${ }^{5}$

Si nous pensons au public auquel notre auteur s'est adressé, nous pouvons conclure, en empruntant les paroles à J. Fontaine, que «ce n'est pas le public mondain des recitationes romaines... pas davantage l'assemblée liturgique, pour laquelle écrivaient d'abord les évêques hymnodes... La communauté, rassemblée ou dispersée, pour laquelle Prudence a écrit ses poèmes, mène un style de vie comparable, dans ses aspects matériels et moraux, à celui de ces autres propriétaires terriens qu'ont été Sulpice en Aquitaine, Paulin en Campanie, ou l'ancien préfet Dardanus dans sa 'Théopolis' des Basses-Alpes. Le lyrisme de Prudence semble d'abord destiné à cette catégorie d'aristocrates lettrés, retirés sur leurs terres pour y mener une vie d'ascétisme monastique». ${ }^{6}$

Avant de mettre un point final à cette petite introduction, il faudra encore mentionner qu'ont été publiés heureusement au cours de ces dernières années, deux commentaires sur notre poème. L'un d'entre eux, le plus récent, a été écrit par le professeur émérite Gerard O’Daly en 2012;'7 l'autre c'est une œuvre de Maria Becker (c'est-à-dire, dans la tradition de Christian Gnilka), professeure à la Wilhelm Winter Universität, en Münster, publié il y a déjà un peu plus de dix ans, en 2006. Dans ce cas, l'œuvre concerne exclusivement le troisième hymne. ${ }^{8}$

En ce qui concerne la structure de l'Hymnus ante cibum, Maria Becker a réfuté la thèse de Jean Louis Charlet, ${ }^{9}$ selon laquelle, nous sommes en face d'une structure composée de cinq parties, qui renferme au centre - en imitant le rôle central joué par les exempla utilisés par Horace et Pindare- le récit biblique, le récit d'Adam et Eve au paradis, en en soulignant l'importance. Par contre, Maria Becker ${ }^{10}$ a défendu une structure à quatre parties, de type binaire, qui semble être acceptée aussi par Gerard O'Daly, ${ }^{11}$ et divise en deux la thématique principale de cet hymne: d'une part, la louange envers les dons de la Création; d'autre part, le récit de l'histoire de l'homme, en mettant en évidence Adam, Ėve, le péché, le nouvel Adam (Christ), né de la vierge Marie. Récement, dans sa thèse defendue à l'Université de Toronto, Cillian Conor O’Hogan soutiens que le text biblique de la Genèse (sur la création et le péché) se trouve dés le début de l'hymne en lui offrent d'une structure. ${ }^{12}$

5 Cf. Charlet (1980) 96-98.

6 Fontaine (1981) 181.

7 Cf. O’Daly (2012).

8 Cf. Becker (2006).

9 Cf. Charlet (1982) 61-72.

10 Cf. Becker (2006) 23-28.

11 Cf. O’Daly (2012) 96-97.

12 Cf. O’Hogan (2012) 126-130. 


\section{Sur cath. 3.1-5}

Du point de vue textuel, il n'y a pas de problème en ce qui concerne les cinq premiers versets de l'hymne ante cibum. Voici le début, la première strophe, de grande classe:

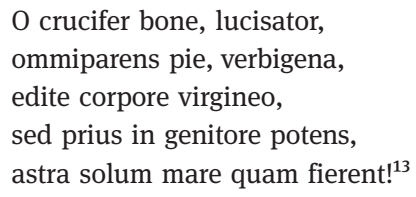

Ce début constitue un bon exemple pour illustrer l'un des traits distinctifs de Prudence, c'est-à-dire, sa capacité pour l'innovation lexicale. En l'espace de deux versets nous avons trouvé déjà jusqu'à trois mots forgés par lui: crucifer, lucisator, verbigena. Selon Becker, ${ }^{14}$ Prudence a essayé d'éviter, contrairement à l'usage qu'en fait Horace, la substitution du mètre dactylique par le mètre spondéen, en cherchant ainsi le principe de l'isosyllabismus, déjà trouvé dans la poésie ambrosienne. Cela a provoqué aussi un haut style avec beaucoup de mots (souvent néologismes) comprenant quatre ou cinq syllabes. Il y en a beaucoup tout au long du poème, mais seulement ici, dans les deux premiers versets, nous en avons trouvé trois: lucisator, omniparens, verbigena.

Il ne fait aucun doute que ce commencement nous offre la base christologique du poème entier. Le début avec l'interjection 'o' et cette accumulation aussi grande de mots inhabituels utilisés comme invocations toutes orientées vers le Christ, n’a pas d'équivalents dans les autres débuts que nous trouvons dans les hymnes du Cathemerinon. Nous sommes en présence de ce qu'on appelle «le mélange des genres dans la poésie de Prudence», plus précisément ici, nous constatons la présence de noms caractéristiques du style épique (lucisator, omniparens, verbigena) à l'intérieur d'un poème lyrique. ${ }^{15}$

Nous pouvons aussi remarquer la structure parallèle constatable entre les deux premiers versets: ils se répartissent en deux cola: le premier colon dans les deux versets avec six syllabes ( $O$ crucifer bone et omniparens pie); le deuxième, avec quatre

13 Cf. Lavarenne (1955) 12. Et voici la traduction offerte par l'édition française de M. Lavarenne en Prudence (1955) 12: «O porte-croix plein de bonté, créateur de la lumière, saint producteur de toutes choses, engendré par le Verbe et né du corps d'une vierge, mais déjà puissant dans le Père avant que ne fussent faits les astres, le sol et la mer!»; voici la version anglaise de O’Daly (2012) 83: «O kind cross-carrier, light-sower, / caring All-father, Word-born, / brought forth from a virgin's body, / but powerful in the Father / before stars, earth, sea were made». Et voici l'allemande de Becker (2006) 31: O guter Kreuzträger, Lichtbringer, / gütiger Allvater, durch das Wort Geborener, / dem Körper der Jungfrau entsprossen, / aber zuvor schon im Vater mächtig, / bevor Sterne, Erde und Meer geschaffen wurden!

14 Cf. Becker (2006) 22.

15 Cf. Fontaine (1975) 763; Lühken (2002) 203-207. 
syllabes (lucisator et verbigena). ${ }^{16}$ Par ailleurs, il a été aussi mis en évidence la gradatio où Prudence a disposé les quatre appellatifs du Christ: crucifer, lucisator, omniparens, verbigena, en passant des substantifs aux participes. ${ }^{17}$

Mais si nous considérons maintenant plutôt la signification de cette grande ouverture, qu'observons-nous?

On pourrait dire que la dénomination de crucifer doit être mise en rapport, à la manière de chiasme, avec verbigena, parce que tous les deux correspondent au Christ en tant que Sauveur: crucifer nous renvoie au mystère de la Rédemption et à la Pâque; verbigena, à son tour, au mystère de l'Incarnation. En tout cas, nous restons dans l'œuvre du salut. D'autre part, nous remarquons que lucisator et omniparens, qui nous indiquent l'œuvre de la Création, louent le Christ en tant que Créateur. C'est la thèse de Becker. ${ }^{18}$

À son tour, le premier mot, crucifer, 'celui qui porte la croix', nous offre, dès le début, le motif de la croix et correspond à la fin de l'hymne suivant dédié aussi au repas et qui s'appelle hymnus post cibum. Là, en effet, on fait une référence aux chrétiens qui doivent porter la croix (cf. cath. 4.102). La croix embrasse l'acte de nutrition. C'est la référence pour se nourrir. On peut donc affirmer que, dans l'intention de Prudence, existe la volonté de faire -grâce à la croix- un lien entre la louange envers Dieu et l'exigence étique concernant la nutrition. ${ }^{19}$ De plus ici, en ouvrant solennellement le poème, avec cette invocation, on satisfait à la fonction d'identifier sans ambigüité le Dieu, que le poète -ou les hommes- prient.

En outre, à la fin du verset, nous nous retrouvons en face d'un autre néologisme de Prudence: lucisator, ${ }^{20}$ c'est-à-dire, 'semeur de la lumière'. Je pense qu'il faut maintenir dans les versions modernes la traduction 'semeur', sans vouloir obtenir une autre traduction un peu plus figurée, comme 'créateur de la lumière' ou 'Lichtbringer'. En effet, l'image des semis, de la plantation, est capital dans le contexte d'un hymne dédié précisément à l'acte de la nutrition fait à partir des fruits de la terre.

Avec ce mot, Prudence, d'une part, baptise la tradition païenne habituée à s'adresser à Sator, c'est-à-dire à Jupiter; et d'autre part, il se sert de l'image de la lumière, si riche de significations pour un chrétien (et pour Prudence même): ${ }^{21}$ la lumière de la Création, la lumière de la grâce baptismale, la lumière de la gloire céleste, etcetera.

16 Cf. Becker (2006) 49.

17 Cf. Becker (2006) 49.

18 Cf. Becker (2006) 49.

19 Cf. Becker (2006) 50.

20 Dans l'ensemble de l'oeuvre de Prudentius, on peut trouver cent trente quatre mots avec le suffix -tor, dont il y a huit, qui sont néologismes: emancipator, infusor, lancinator, lucisator, perdomitor, traiector, uerberator, unicultor, cf. Mariner Bigorra (1959) 199-236.

21 Cf. Gosserez (2001). 
Enfin, le petit bone qui suit crucifer fait pendant aussi au pie, qui accompagne omniparens, dans le deuxième verset, et, selon Becker, tous deux (bone et pie) soulignent l'aspect sotériologique propter nos.

Apparemment tout semble être clair. Mais O’Daly indique justement que cette référence à la croix -Crucifer- ne trouve aucune mention explicite dans le reste du poème ante cibum. Par ailleurs, ce que Becker a proposé pour le comprendre, en faisant un chiasme avec verbigena ne s'avère pas conclusif sur ce point.

À mon avis, afin de mieux comprendre cette image du Christ portant la croix, crucifer, un peu énigmatique, tant du point de vue littéraire (un neologism qui, en outre, est presque un hapax) que théologique, il faut se rappeler de la tradition chrétienne ancienne, antérieure à Prudence, forgée par la mentalité des chrétiens prenicéens, qui étaient capables de découvrir la présence de la croix derrière une multitude d'éléments. Là, je pense notamment à l'image de la charrue, du soc, de l'aratrum.

\section{Crux - aratrum}

La réflexion sur la croix, aux premiers siècles du christianisme, déborde très souvent le cadre historique qui se limite à la crucifixion du Nazaréen au point d'en faire une clé capable de contenir l'histoire entière du salut, racontée dès le début dans le livre de la Genèse jusqu'à son exposé final dans l'Apocalypse de Jean. En effet, cette tradition, qui a peut-être été développée à partir d'un verset du prophète Esaïe 2,3, selon lequel, dans les temps messianiques, les épées se changeront en charrues, c'est-à-dire, qu'il n'y aura plus aucune guerre, et que par contre, les hommes se consacreront à la culture de la terre. C'est déjà Justin, qui a mis en rapport la charrue, le soc, avec la croix, mais nous allons nous appesantir sur Irénée de Lyon, qui nous a laissé de très intéressantes lignes à propos de l'équivalence entre la croix et l'aratrum. Voici le texte d'Irénée ( $a d v$. haer. IV, 34, 4):

Hic autem est Dominus noster, et in hoc est sermo verus, quoniam ipse est qui aratrum fecit et falcem intulit, hoc est hominis primam seminationem quae fuit secundum Adam plasmatio, et in novissimis temporibus per Verbum collectam fructificationem.

«Or, c'est notre Seigneur et »en lui se vérifie la parole« (Jn 4.37), car c'est lui qui a fait la charrue et qui a apporté la faucille, ce qui signifie, d'une part, le premier ensemencement de l'homme que fut son modelage en Adam et, d'autre part, la récolte du fruit faite par l'entremise du Verbe dans les derniers temps ${ }^{22}$

22 Cf. Rousseau (1965) 858-859. 
La parole vérifiée (cf. in hoc est sermo verus) c'est celle qui dit: l'un sème, l'autre moissonne (Jn 4.37). ${ }^{23}$ Pour les gnostiques valentiniens, ce lieu biblique fournit la base pour distinguer entre la seminatio réalisée par le Démiurge psychique (l'un sème) et la collecta, la moisson de l'homme menée par le Sauveur pneumatique (l'autre moissonne) en parfaite correspondance avec la division entre l'Ancien Testament (régime d'ignorance sous le gouvernement de Yahvé, le Dieu inferieur) et le Nouveau Testament (régime de connaissance pour les gnostiques, sous la providence du Dieu supérieur).

Afin de mieux contraster cela, Irénée de Lyon mettra un accent particulier sur l'identité entre le Semeur (Christ en tant que Demiurge) et le Moissonneur (Christ en tant que Sauveur). ${ }^{24}$

La suite du texte d'Irénée se présente comme suit ( $a d v$. haer. IV.34.4):

\begin{abstract}
Et propter hoc quod initium fini conjungebat, et utrorumque Dominus exsistens, in fine quidem aratrum ostendit, lignum copulatum ferro, et sic ejus expurgavit terram, quoniam firmum Verbum adunitum carni et habitu tali confixus emundavit silvestrem terram; initio autem falcem figurabat per Abel, significans justi generis hominum collectionem: Vide enim, inquit, quomodo justus perit, et nemo intuetur, et viri justi tolluntur, et nemo excipit corde (Is 57.1). Haec autem in Abel quidem praemeditabantur, in prophetis vero praeconabantur, in Domino autem perficiebantur, et in nobis autem idipsum, consequent corpore suum caput.

«Et c'est pourquoi, comme il unissait le commencement à la fin, étant le Seigneur de l'un et de l'autre, d'une part, à la fin il montra la charrue, c'est-à-dire le bois uni au fer et nettoyant ainsi la terre; car le Verbe solide, en étant uni à la chair et en étant fixé à elle de cette manière, a nettoyé la terre embroussaillée; d'autre part, dès le commencement, il préfigurait la faucille par Abel, signifiant par là la récolte de la race juste des hommes. 'Car vois, est-il-dit (Is 57.1), comment le juste a péri, et nul ne le remarque, comment les hommes justes sont supprimés, et nul ne le saisit en son coeur'. Cela était inauguré en Abel, puis proclamé par les prophètes, puis accompli dans le Seigneur, et il en va encore de même pour nous, le corps suivant sa tête. $»^{25}$
\end{abstract}

Dans l'Ancient Testament prophétique, le Seigneur fit la charrue, autant qu'il fit l'homme, Adam, destiné à son tour à semer le fils de Dieu dans la création. Dans le Nouveau Testament -apostolique- le Seigner a montré la charrue, en tant qu'il a été crucifié, en produisant ainsi comme conséquence la purification de la terre embroussaillée par le péché d'Adam et l'ensemencement définitif, afin que tous les hommes deviennent fils de Dieu. Dans la croix se trouvent réunis le bois, c'est-à-dire la faiblesse de la nature humaine, et le fer, c'est-à-dire, la nature divine, lumineuse, du Fils de Dieu. «Le Verbe incarné et cloué sur la croix purifia cette terre inutile et

23 Le text grec dit: દ̉v yò $\theta \varepsilon \rho i \zeta \omega v$.

24 Cf. Orbe (2012) 1146: «Un seul et le même, le Sauveur, a fait la charrue, outil d'ensemencement, pour semer avec Adam le genre humain dans le monde; il a aussi introduit la faucille, outil de moisson, pour récolter dans les derniers temps le genre humain et le rassembler dans les greniers du Père».

25 Cf. Rousseau (1965) 858-861. 
inféconde pour son Seigneur en la rendant utile et féconde». ${ }^{26}$ Ainsi le Seigneur, dans les derniers temps, montra l'aratrum, en tant que porteur de la croix, outil d'ensemencement et purification (au début avec Adam et dans les derniers temps grâce au mystère de la croix). ${ }^{27}$

Nous pouvons donc constater comment l'image de la charrue avec le soc, contemplée dans une perspective christologique, est capable de suggérer l'histoire entière du salut.

Le lien entre Christ et l'aratrum appartenait à l'univers d'idées que relayaient les chrétiens. Une preuve en est l'apparition d'aratrum, en tant que titre christologique, à l'intérieur d'une liste de noms du Christ dans les Actes de Pierre avec Simone 20 et dans les Actes de Jean 109.

Mais nous pouvons nous rapprocher davantage de Prudence, en rappelant un morceau du Sermo 38 de saint Maxime de Turin, De cruce et resurrectione Domini, oú nous pouvons lire (Sermo 38. 2. 3. 4):

\footnotetext{
Grande ergo crucis est sacramentum... Sed et bonus agricola cum parat terrae solum vertere et vitae alimenta perquirere, nonnisi per signum crucis id facere conatur. Dum enim aratro dentalem subicit adfigit aures stevam inserit, figuram crucis imitatur; conpositio enim ipsa similitudo quaedam est dominicae passionis... Nam ex quo homo dominus Iesus, qui ipsam crucem gestabat, sepultus in terra est, veluti disrupta ab eo et exarata terra omnes quos retinebat mortuos germinavit. ${ }^{28}$

«Donc il est grand le mystère de la croix... Et aussi le bon paysan, lorsqu'il se prépare pour retourner le terrain et chercher la nourriture pour la vie, il ne le fait autrement sinon au travers du signe de la croix. En effet, lorsqu'il met le dental sous la charrue, fixe les (aureilles) et insère le manche, imite la figure de la croix. En effet, la composition même présente une certaine ressemblance à la passion du Seigneur... En effet, à partir du moment où l'homme Jésus, le Seigneur, qui portait la croix même, fut enseveli dans la terre, comme brisée et labourée par Lui, il fit germer tous ceux que [la terre] retenait morts».
}

Nous retrouvons à nouveau le symbole de l'aratrum, avec lequel le bonus agricola travaille la terre. Dans la transposition au contenu chrétien, alors le bonus agricola est devenu Jésus, qui ipsam crucem -la charrue- gestabat, et qui, par sa mort et sépulture, devint capable de travailler la terre, c'est-à-dire, l'homme, qui était mort, pour lui redonner la vie. Le motif agricole de la charrue est devenu très spontanément pascal.

Maintenant aussi pouvons-nous nous intéresser, du point de vue géographique, à la patrie de Prudence et découvrir dans un sermon, cette fois-ci, appartenant à Grégoire d'Elvire, les paroles suivantes, cf. Hom. VI.19:

26 Cf. Orbe (2012) 1148.

27 Cf. Orbe (1994) 571-579; Doignon (1955) 535-544.

28 Cf. Mutzenbecher (1962) 149-150. 
Quem ideo taurum propheticus spiritus appelavit, eo quod primum aratrum crucis suae patibulo ipse portaverit, unde dura gentium pectora subacta necessario semini, id est Sancto Spiritui praeparaverit... ${ }^{29}$

"C'est pour ça que l'esprit prophétique l'appela bœuf, parce que Lui-même porta à l'échafaud la charrue de sa croix, d'où, une fois labourés les cœurs des Gentils qui étaient endurcis, prépara pour eux convenablement la semence, c'est-à-dire, l'Esprit Saint.»

\section{Vers une conclusion}

Dans les textes que l'on vient de citer (Irénée, Maxime, Grégoire) nous avons pu vérifier la facilité avec laquelle les premiers chrétiens mettaient en rapport la charrue avec la croix. En outre, nous avons trouvé chez Maxime et Grégoire l'image du Christ en portant de l'aratrum de sa croix. Et encore plus, chez Maxime nous avons trouvé à côté d'agricola, l'adjectif bonus, c'èst-à-dire le même que Prudence a mis à côté pour crucifer: o crucifer bone. En ce qui concerne la littérature païenne, nous connaissons le topos du bonus agricola, construi déjà à partir de Caton. ${ }^{30}$ Ce que nous remarquons chez Maxime et, à mon avis, aussi chez Prudence, concernant le topos du bon paysan, c'est le passage du module païen au module chrétien à travers l'équivalence crux=aratrum, où apparaît le Christ comme le bonus agricola.

Par ailleurs, point n'est besoin de vous rappeler l'importance de Virgile chez Prudence. Du reste, notre aratrum apparaît mystérieusement au début même des Georgiques, lorsque Virgile invoque le uncique puer monstrator aratri (G. I.19). À propos de ce lieu virgilien Servius, commentateur de Virgile, qui a vécu à l'époque de Prudence, a dit: bene autem tacuit de nomine et generaliter ait 'puer'. ${ }^{31}$ Cet enfant..., était-il pour Prudence le Christ? Et peu après, Virgile cite à nouveau le soc et la charrue parmi les outils avec lesquels le paysan travaille. Elle occupe la première place (cf. G. I.160 -162: dicendum est quae sint duris agrestibus arma, / quis sine nec potuere seri nec surgere messes: / vomis et inflexi primum grave robur aratri).

Dans cette perspective, si notre hypothèse est admise, le point de départ christologique de l'hymnus ante cibum acquiert de nouveaux profils. O crucifer bone lucisator... autant dire o bon porteur de la charrue mystique, o bone agricola, afin de rappeler, non seulement la fonction de Christ Sauveur, mais déjà aussi, au début de la Création, la fonction de Christ, qui prépare la terre d'Adam et qui prépare, en tant que Verbe Créateur, en général, la terre, qui donne des fruits pour les hommes.

$O$ crucifer a probablement des résonances cosmiques, liées au theologoumenon de la croix cosmique, si spontanée pour les chrétiens des premiers siècles, et c'est pour ça que ce début est capable de susciter avec un seul mot plusieurs connota-

29 Cf. Pascual Torró (1997) 166.

30 Cf. Stone (1998) 103-113.

31 Servii, Comm. in Verg. Georg. I, 19. 
tions: le travail du Verbe qui prépare la terre, qui doit soutenir les hommes; le travail du Verbe, au début de l'histoire, sur la terre, qui est l'homme, pour y ensemencer la lumière de l'esprit; le travail du Verbe, mais maintenant déjà incarné, pour purifier la terre de toute iniquité -c'est-à-dire-, pour purifier la chair des hommes, devenue sauvage à partir du péché, devenue morte, afin de semer en elle, la puissance lumineuse de l'Esprit vivifiant.

Il y a donc deux types de plantations: l'ensemencement de la terre qui donne les fruits (pour manger, je rappelle que nous nous trouvons dans l'Hymnus ante cibum) et l'ensemencement de l'homme appelé à devenir fils de Dieu. Tous les deux ont commencé, grâce au Christ, dès le début de la Création. Il y a un seul Semeur et il y a, en somme, un unique récepteur des deux semences, qui est le corps humain, la chair. Elle -la chair- reçoit soit les fruits de la terre, soit la lumière de l'Esprit. En fait, il n'y a qu'un unique but poursuivi par le Semeur: le corps virginal né de la Vierge, le vrai fruit de la création, que nous pouvons lire dans la troisième ligne de notre strophe: edite corpore virgineo. Si nous apprenons à manger et à boire, selon la volonté du bon Semeur, Prudence semble dire que nous aurons la même espérance qui fut réservée au corps virginal: Spes eadem mea membra manet (cath. 3, 201) et toute la création convergera finalement vers l'objectif principal: la gloire lumineuse de la chair des hommes nourries par la Création labourée avec la charrue et ressuscités par le Verb au moyen de la croix.

Le rythme initial devient vraiment intense: $O$ crucifer bone, qui avec son soc prépare la terre de la Création et la chair d'Adam, et qui peu après retourne le terrain et l'homme; lucisator, qui sème la lumière (l'esprit saint) pour les féconder au debut de la Création qua deus et dans la Pâque à travers son esprit qua deus et homo deificatus; omniparens pie, qui fait naître toutes choses au debut et dans la Pâque; verbigena edite corpore virgineo, qui par le Verbe est né de la Vierge...

\section{Bibliographie}

Bastiaensen (1993): Antoon A. R. Bastiaensen, «Prudentius in recent literary criticism», in: Jan den Boeft and Anton Hilhorst (eds.), Early Christian Poetry, Leiden, 101-134.

Becker (2006): Maria Becker, Kommentar zum Tischgebet des Prudentius (cath. 3), Heidelberg. Bergman (1921): Johan Bergman, Aurelius Prudentius Clemens, der grösste christliche Dichter des Altertums, Dorpat.

Charlet (1980): Jean-Louis Charlet, L'influence d'Ausone sur la poésie de Prudence, Paris. Charlet (1982): Jean-Louis Charlet, La création poétique dans le Cathemerinon de Prudence, Paris. Doignon (1955): Jean Doignon, «La salut par le fer et le bois. Notes de philologie et d'éxègese sur Adversus Haereses IV, 34, 4», in: Recherches de Science Religieuse 43, 535-544.

Fontaine (1975): Jacques Fontaine, "Le mélange des genres dans la poésie de Prudence», in: Forma Futuri. Studi in onore di M. Pellegrino, Torino, 755-777.

Fontaine (1981): Jacques Fontaine, Naissance de la poésie dans l'Occident chrétien. Esquisse d'une histoire de la poésie latine chrétienne du Ille au Vle siècle, Paris.

Gnilka (2000. 2001. 2003): Christian Gnilka, Prudentiana I. Crítica. II. Exegetica. III. Supplementum, München/Leipzig. 
Gosserez (2001): Laurence Gosserez, Poésie de lumière. Une lecture de Prudence, Louvain. Lavarenne (1955): Maurice Lavarenne (ed.), Prudence Tome I. Cathemerino Liber (Livre d'heres), Paris.

Lühken (2002): Maria Lühken, Christianorum Maro et Flaccus. Zur Virgil- und Horazrezeption des Prudentius, Göttingen.

Mariner Bigorra (1959): Sebastián Mariner Bigorra, «El latín de la península: léxico», in: Enciclopedia Lingüística Hispánica I, CSIC, Madrid, 199-236.

Mutzenbecher (1962): Almut Mutzenbecher (ed.), Maximi episcopi Taurinensis Collectio sermonum antiqua, Turnholti.

O’Daly (2012): Gerald O’Daly, Days linked by song. Prudentius' Cathemerinon, Oxford.

O'Hogan (2012): Cillian Conor O'Hogan, Geography and Space in the Poetry of Prudentius, diss. University of Toronto.

Orbe (1994): Antonio Orbe, Estudios sobre la teología cristiana primitiva, Madrid.

Orbe (2012): Antonio Orbe, Introduction à la théologie des II et III siècles, vol. II, Paris.

Pascual Torró (1997): Joaquín Pascual Torró (ed.), Gregorio de Elvira. Tratados sobre los libros de las Santas Escrituras, Madrid.

Rousseau (1965): Adelin Rousseau (ed.), Irénée de Lyon. Contre les hérésies. Livre IV, Paris.

Stone (1998): David L. Stone, «Culture and Investment in the rural Landscape. The Nort African bonus agricola», in: Antiquités Africaines 34, 103-113. 



\title{
Alice Leflaëc \\ Figures bibliques et idéal familial de la consécration à Dieu
}

\author{
Le protreptique de l'Ad Cytherium (Carm. 24) de Paulin de Nole
}

Aux alentours de 400, ${ }^{1}$ Paulin de Nole, alors retiré depuis quelques années dans son monastère de Nole auprès du tombeau de saint Félix, compose l'Ad Cytherium - le Carmen 24 dans l'édition de von Hartel. ${ }^{2}$ Cette longue lettre en vers iambiques est adressée à un ami lettré et chrétien. Elle relate, dans une première partie, le voyage mouvementé qu'a fait le courrier Martinianus pour se rendre à Nole apporter à Paulin une lettre de Cythérius. La seconde partie du poème, qui nous occupera ici, traite du choix qu'a fait Cythérius de consacrer son fils à la prêtrise. ${ }^{3}$ Le poète, prenant cette décision très au sérieux, adresse à Cythérius et à son fils une série d'exhortations pour que le jeune garçon, alors auprès de Sulpice Sévère, remplisse au mieux sa future charge ecclésiastique. Paulin offre ainsi un "protreptique à la consécration »" et à l'aide de toute une série de figures vétérotestamentaires, il semble dessiner le portrait idéal de l'homme consacré à Dieu au début du $\mathrm{V}^{\mathrm{e}}$ siècle. Si cette figure apparaît en lien étroit avec la vie sacerdotale, nous pouvons remarquer que les exemples bibliques choisis font intervenir des familles entières et donnent ainsi une dimension familiale au thème de la consécration. Paulin semble parler de deux types de consécration en même temps : celle du fils, qui prend la forme d'une vie sacerdotale, et celle, plus générale, qui concerne tout chrétien y compris les parents et qui est en relation avec la pratique de l'ascèse. Par «consécration", nous entendons le fait de se donner à Dieu, ce qui est en lien étroit avec la sanctification, le fait de

1 Fabre (1948) 117-122.

2 Nous utilisons principalement le texte et la classification de la nouvelle édition du Corpus Christianorum : Dolveck (2015). Toutefois, nous nous réfèrerons aussi, entre parenthèses, à la classification de l'édition du CSEL : Hartel (1894). Pour les traductions, voir Ruggiero (1996) et Walsh (1975). Toutes les traductions de Paulin de Nole présentées dans cet article sont personnelles.

3 Sur la structure et l'unité de ce poème, voir Walsh (1976). L'auteur montre le rôle que jouent les exemples bibliques dans l'unité entre les deux parties du poème.

4 Nous ne partageons pas l'avis de G. Guttilla qui considère le Carmen 24 comme une lettre de félicitations adressée à Cythérius qui, avec l'accord de sa femme, a consacré son fils à la vie monastique, et non comme un protreptique adressé à Cythérius ou à son fils (voir Guttilla (1995) 29-30). J. Rougé définit aussi ce poème comme une lettre de félicitation, mais il ne traite pas du tout la seconde partie du poème (voir Rougé (1987) 93). Si le ton de Paulin est, certes, plutôt laudatif et que le poète ne semble pas remettre en cause le salut de Cythérius, il nous semble que les exhortations finales du poème, le souci de Paulin que le fils de Cythérius soit formé au mieux et le thème de la consécration à Dieu invitent à lire la seconde partie de cette composition comme un protreptique adressé à l'ensemble de la famille. Il s'agit, cependant, non pas d'un protreptique à la conversion, mais d'un protreptique «à la consécration». 
rechercher au cours de sa vie la sainteté. ${ }^{5}$ Ce sont les formes de la consécration dans ce poème et les rapports qu'elles entretiennent que nous étudierons, en particulier la manière dont ce protreptique versifié à la consécration est mis en œuvre et le rôle qu'y joue la Bible.

\section{Piété paternelle et consécration de l'enfant}

La seconde partie de l'Ad Cytherium prend, selon l'expression de Serafino Prete, la forme d'une "poetica institutio cleri ${ }^{6}$ », i.e. de l'instruction d'un futur clerc sous une forme poétique. Mais si l'accent est mis sur le comportement que doit adopter le fils de Cythérius, le rôle du père n'est pas pour autant laissé de côté. Au contraire, Paulin de Nole insiste, dans ce poème, sur le rapport entre la piété paternelle et la démarche du fils.

\subsection{Consacrer son enfant à Dieu, un acte de piété et d’obéissance}

L'union de Cythérius et sa femme et d'Anne, la mère du prophète Samuel, dans une même communauté (consortium), nous indique, dans les vers 525-526, que ce sont les parents qui ont décidé de consacrer leur fils à une charge ecclésiastique :

Vobis et Annae sternitur consortium Infantis exemplo sacri :

Samuel et iste creuit in templo Dei, Nunc agnus et pastor dehinc.

\begin{abstract}
Cette communauté s'étend à vous et à Anne par l'exemple de la consécration de votre enfant. Votre Samuel aussi a grandi dans le temple de Dieu, maintenant agneau, il sera bientôt berger.
\end{abstract}

Vers $525-528$

Si ce rapprochement avec Anne est justifié par la ressemblance des situations entre les deux familles, à tel point que Paulin peut parler du fils de Cythérius en employant l'expression Samuel et iste (v. 527), il permet de souligner la foi de Cythérius et de sa femme puisqu'ils sont associés à l'acte de piété d'Anne qui, pour manifester sa reconnaissance à Dieu qui lui avait accordé un enfant malgré sa stérilité, avait décidé de lui consacrer son enfant ( $c f .1$ Sam 1.27-28).

L'identification de Cythérius à Abraham, un peu auparavant dans le poème, fait aussi de la consécration du fils de Cythérius à la vie ecclésiastique un acte d'obéissance de la part de Cythérius :

5 Paulin lui-même n'emploie pas le terme dans ce poème, mais il utilise le verbe consecrare dans l'Epist. 23.10 adressée en 400 à Sulpice Sévère pour évoquer une consécration à Dieu par l'ascèse. Sur les rapports étroits entre le Cyth. et l'Epist. 23, voir Fabre (1948) 119-122.

6 Prete (1964) 82 n. 95. 
Namque ut fideli te patri componeret

500

A te poposcit filium,

In semine Isaac semen ascribens tuum, Ipsumque ut Isaac expetens

Quem tu Abramiae caritatis aemulus

Viuam dedisti uictimam,

505

Deoque tradens iam peremisti tibi

$v t$ saluum haberes firmius.
En effet, pour t'associer au père de la foi, il a réclamé de toi un fils, inscrivant ta descendance dans sa descendance, Isaac, et la désirant elle-même comme Isaac. Et toi, rivalisant d'amour avec Abraham, tu l'as offert comme victime vivante (505) et en le livrant à Dieu, tu l'as fait mourir à toi maintenant pour le garder plus sûrement sauf.

Vers $499-506$

Comme le souligne Guiseppe Guttilla, ce rapprochement avec Abraham est une habitude artistique qui a une finalité laudative implicite. ${ }^{7}$ Il est, en effet, fort positif d'être, selon l'expression du vers 503, l'Abramiae caritatis aemulus. Or, en Gn 22.1-19, c'est par obéissance à Dieu qu'Abraham accepte d'offrir Isaac en sacrifice. En dressant un parallèle avec ce patriarche, Paulin insiste donc sur l'obéissance à Dieu dont a fait preuve Cythérius. Si les parents ont décidé de consacrer leur enfant à Dieu, l'initiative du geste est d'abord divine : «a te poposcit filium» peut-on lire au vers 500.

Le rapport entre l'obéissance et la consécration à Dieu est ici souligné par une réminiscence néotestamentaire : l'allusion à Abraham se double, au vers 504, d'une réminiscence de Rom 12.1 avec l'expression uiua uictima. ${ }^{8}$ Or, il s'agit d'un passage où l'apôtre Paul exhorte clairement ses lecteurs à la consécration. Cythérius fait preuve d'obéissance et de confiance en Dieu lorsqu'il consacre son fils. Il n'hésite pas à offrir son fils en sacrifice par amour à la fois pour Dieu, comme la comparaison avec Abraham le suggère, et pour son fils, puisque, confiant en Dieu, il est convaincu que c'est par ce sacrifice qu'il pourra garder son fils saluus (v. 506). ${ }^{9}$

\subsection{Un fils qui prolonge et accomplit la piété de ses parents}

Cette consécration du fils de Cythérius à la vie sacerdotale n'apparaît, toutefois, pas seulement comme une manifestation de la piété et de l’obéissance de Cythérius. Paulin semble aller plus loin et faire de la consécration du fils le prolongement et l'accom-

7 Guttilla (1995) 18.

8 Paulin superpose aussi cet épisode vétérotestamentaire et cette réminiscence de l'épître aux Romains dans le Nat. 9.616 (Carm. 27), dans un passage où il aspire à être pleinement consacré à Dieu. 9 Nous retrouvons cette idée dans l'Epist. 29.9 adressée en 400 à Sulpice Sévère. Paulin, alors qu'il retrace les grandes lignes de la vie de Mélanie l'Ancienne, évoque le choix qu'elle a fait de se séparer de son fils, convaincue que c'est parce qu'il serait loin d'elle et confié à Dieu qu'elle pourrait le retenir plus solidement.

Malgré la différence de situations - le fils de Cythérius est consacré à la vie sacerdotale, contrairement à celui de Mélanie -, Paulin prend les mêmes exemples parentaux, Anne et Abraham, pour évoquer le geste de Cythérius et celui de Mélanie l’Ancienne. 
plissement de la piété de ses parents. Là encore, ce sont des réminiscences bibliques et l'identification avec des figures vétérotestamentaires qui soulignent cette idée.

Ainsi, le fils de Cythérius se présente comme le signe certain de l'espérance en la vie éternelle de son père. ${ }^{10}$ Après avoir brièvement évoqué l'au-delà (v. 491-494), notre poète s'écrie :

Insigne tantae iam spei certum tibi Magno coruscat pignore!

Plantata Domino in atriis Hierusales Tui propago germinis.
Un signe assuré d'une si haute espérance brille déjà pour toi dans ton précieux enfant ! C'est sur les parvis de Jérusalem qu'a été planté, pour le Seigneur, le rejeton de ta semence.

Vers $495-498$

Or, dans les vers suivants (v. 499-506), Paulin associe le fils de Cythérius à Isaac pour justifier ce propos. ${ }^{11}$ En Genèse, Dieu promet à Abraham qu'il deviendra le père d'une foule de nations (Gn 17.4) et la naissance d'Isaac marque la réalisation de cette promesse. De même, le fils de Cythérius apparaît comme le signe du salut et de la bénédiction de son père.

Ce sont les réminiscences psalmiques des vers 518 à $520^{12}$ qui explicitent le plus cette idée :

Audistis et uos quod beatis dicitur

Vous aussi, vous avez entendu ce qui est dit "Potens erit semen tuum», aux hommes bénis : "Ta descendance sera Habes et illud: "Ventris a fructu tui puissante». Tu connais aussi ceci : (520) «Je In sedibus ponam meis»; placerai dans mes demeures ce qui vient du Qui sermo Dauid, quamlibet Christum sonet, fruit de ton ventre». Or, ces paroles de David, In Christo et illis concinit tout en annonçant le Christ, évoquent aussi Qui christiani corporis collegio In sede ponentur Dei. ceux qui vivent dans le Christ et qui, formant la communauté du corps des chrétiens, seront placés dans la demeure de Dieu.

Vers $517-524$

Si la tradition ${ }^{13}$ lit généralement dans le Psaume 131.11 une annonce du Christ, Paulin, tout en se faisant l'écho de cette lecture au vers 521, offre un élargissement de la compréhension de ce verset. Il concerne aussi les chrétiens qui, selon l'interprétation de notre poète, sont appelés à exercer des fonctions d'autorité à la suite du Christ. Ce passage nous invite alors à voir en Cythérius un homme béni, l'un des beati du vers 517, et à considérer la charge ecclésiastique de son fils comme un accomplissement de cette prophétie.

Cette idée d'un accomplissement de la piété des parents par la vie sacerdotale des enfants est à nouveau exprimée, en quelque sorte, par Paulin à la fin de l'Épi-

10 Cf. Cels. 611-612 (Carm. 31) où Paulin voit dans son défunt fils un espoir de salut, symbolisé par la thématique de la lumière.

11 L'emploi de l'adverbe nam au vers 499 souligne la valeur justificative de l'exemple d'Isaac.

12 Le vers 518 est une réminiscence du Ps 111.2 et les vers 519-520 du Ps 131.11.

13 Cf. notamment Tert., Adv. Marc. III.20 ; Ambr., Epist. 74.22 et in psalm. 1.8. 
thalame (le Carmen 25), un poème composé entre 400 et 404 pour le mariage du futur évêque Julien d'Éclane et de Titia. Le poète exhorte, en effet, les jeunes mariés à pratiquer la chasteté dans le mariage ou, s'ils décident d'unir leurs corps, à donner le jour à un sacerdotale genus (Epith. 237). ${ }^{14}$

Paulin de Nole semble donc lier assez étroitement sa conception de la consécration à la vie sacerdotale et en développer une vision familiale. La continuité généalogique se manifeste, en effet, aussi sur le plan de la foi, les enfants prolongeant la piété de leurs parents. Cela participe, bien sûr, à l'éloge des parents et de leur foi, puisque, comme le fait remarquer Paulin, à propos du fils de Cythérius, seules les racines d'un bon arbre sont fécondes. ${ }^{15}$

\section{Institutio cleri et nouvelle figure de sainteté}

Si la charge ecclésiastique d'un fils constitue l'accomplissement de la piété des parents, l'importance des exhortations adressées à Cythérius et à son fils pour que ce dernier devienne un bon homme d'Église n'en est que plus évidente. Or, pour conforter ses exhortations, Paulin convoque divers exempla vétérotestamentaires qui font émerger, en ce début de $\mathrm{V}^{\mathrm{e}}$ siècle, une nouvelle figure de sainteté.

\subsection{Des exempla vétérotestamentaires au service d'un idéal ascétique de prêtrise}

Notre poète recourt, en effet, à toute une série de figures vétérotestamentaires ${ }^{16}$ pour indiquer au fils de Cythérius le comportement à adopter pour remplir au mieux sa charge. Comme l'a fait remarquer Guttilla, Paulin s'est efforcé de «vivifier d'un point de vue formel l'aridité doctrinale du propos». ${ }^{17}$ Il nous offre, en effet, une composition très soignée où les exempla bibliques s'insèrent dans un portrait du fils de Cythérius et correspondent à diverses étapes de sa vie. Ainsi, Samuel est évoqué pour l'enfance avec la mention de l'éphod tissé par sa mère, Samson pour la jeunesse et les différents apprentissages qu'on y fait et Joseph apparaît à la fin, ses responsabilités administratives en Égypte étant mises en parallèle avec les fonctions sacerdotales qu'aura le fils de Cythérius à l'issue de sa formation. Ce choix de composition révèle l'approche pastorale de Paulin : cherchant à être au plus près des réalités de ses destinataires pour mieux les instruire, il insère, pour ainsi dire, la Bible dans la

14 Epith. 236-237 (Carm. 25) «... quod si corpore congruerint / Casta sacerdotale genus uentura propago.»

15 V. 889-890 «Benedicta prolis sanctae radix ut bonae / Rami feraces arboris».

16 Voir Gnilka (1972) 223-244 sur l'usage par les Pères de l'Église de listes d'exemples bibliques de jeunes gens sages et vertueux.

17 Guttilla (1995) 21. 
vie du fils de Cythérius. S’adressant à des lettrés, ${ }^{18}$ il offre également une composition poétique fort travaillée, ${ }^{19}$ à même de susciter leur intérêt. Il est bien plus plaisant, et dès lors bien plus marquant, de lire un portrait où sont mis en regard âges de la vie humaine et scènes bibliques plutôt qu'une longue liste de préceptes. Ces efforts formels adoucissent aussi le caractère strict des exhortations, car c'est un idéal ascétique de prêtrise qui se dessine dans ce protreptique.

La consécration du fils de Cythérius par ses parents à la vie sacerdotale l'apparente directement aux naziréens de la Bible, ces personnes consacrées à Dieu par un vœu dans le judaïsme. Il n'est donc pas étonnant que Paulin recoure aux exemples de célèbres naziréens de l'Ancien Testament, ici Samuel et Samson, pour mettre en évidence les vertus que le fils de Cythérius doit pratiquer.

Samson, qui n’a pas toujours mené une vie consacrée à Dieu, est loin d'apparaître comme une figure idéale dans la Bible. Pourtant, Paulin lui accorde une large place dans son protreptique (v. 541-588, cf. annexe 1). ${ }^{20}$ Il évoque, en effet, trois épisodes relatés dans le livre des Juges : le lion tué par Samson et dans la carcasse duquel il a trouvé du miel (Jg 14.5-10), le rapport de Samson avec les femmes et avec Dalila en particulier (Jg 14-16) et la mort de Samson et la destruction du temple des Philistins (Jg 16.21-30). Bien conscient de l'ambiguïté de cet exemple, Paulin, qui n’hésite pas à intervenir directement notamment au moyen des verbes nolo (v. 557 et 585) et uolo (v. 581), souligne clairement les enseignements que le fils de Cythérius doit tirer de cet exemple. Ainsi, ce dernier est invité à imiter dans sa vie de prière la puissance dont a fait preuve Samson pour tuer le lion. Mais il doit absolument se garder de la lex carnea (v. 549) qui peut mener à de grands désastres, comme le cas de Samson, qui s'est laissé séduire par des femmes étrangères, l'illustre bien. Ainsi, la succession des substantifs captiuitas, infirmitas et caecitas aux vers 559-560 avec l'enjambement, l'isosyllabisme et les homéotéleutes souligne la chute inéluctable de cet homme. Avec cet exemple, Paulin met en évidence l'opposition topique entre les séductions terrestres et les joies célestes. L'évocation de la mort du naziréen souligne, à nouveau, l'importance de s'opposer au monde. De même que Samson est mort et que sa mort a eu des conséquences positives pour le peuple d'Israël - la destruction du temple des Philistins -, le fils de Cythérius est exhorté à mourir au monde et aux séductions de la chair. ${ }^{21}$ Là encore, le travail poétique met en valeur la

18 Le choix de la forme poétique et non de la prose invite à penser que cette lettre était destinée à une diffusion plus large que Cythérius et sa famille.

19 Le milieu aristocratique possède à cette époque un goût pour le style ciselé, pour le maniérisme. Voir Roberts (1989) 118-121.

20 Samson est à nouveau évoqué dans les vers 605-638. À partir d'une référence discrète au meurtre par Samson de mille Philistins au moyen d'une mâchoire d'âne (Jg 15.15-16) et de la réputation de l'âne comme animal paresseux ( $c f$. Apul., Met.VI.31 et VII.21 et Ambr., Hex.VI.3.11), le poète exhorte le fils de Cythérius à faire preuve de courage, à tuer toute paresse en lui et à vaincre ainsi la chair et ses séductions.

21 Paulin de Nole offre également une méditation sur l'épisode de Samson dans l'Epist. 23. Si son interprétation ne diffère guère de celle du Cyth., Paulin fait, cependant, de la mort de Samson une 
recommandation : dans les vers 582-583 («Sic morte mortem, ut permanens / In carne carnem uincat et uiuat Deo»), les polyptotes morte / mortem et carne / carnem, eux-mêmes accentués par la juxtaposition des termes, mettent en évidence le caractère oxymorique et difficile à réaliser de l'exhortation. Or, ce thème d'une séparation radicale avec le monde et ses attraits est ascétique et se trouve à maintes reprises dans la poésie de Paulin. ${ }^{22}$

L'idée d'une lutte contre la chair est aussi illustrée par l'exemple de Joseph, ${ }^{23}$ où le poète insiste sur la chasteté et la maîtrise de soi dont a fait preuve le patriarche au cours de sa vie :

Sit et hic probatus corporis custos sui, $V t$ claustra teneat carceris ;

Si uitia carnis strinxerit Christi metu, Quasi uinculatis praeerit, Aliisque mundi carceri inclusis adhuc Et alligatis saeculo, Vt liber ipse iamque commissus sibi, Magister et custos erit.

\begin{abstract}
Que notre enfant aussi soit éprouvé comme gardien de son corps (750) afin qu'il garde les portes de la prison. $\mathrm{Si}$, par la crainte du Christ, il arrache les vices de la chair, il sera comme à la tête de ceux qui sont enchaînés; et pour les autres, encore enfermés dans la prison du monde et attachés au siècle, (755) parce qu'il sera lui-même libre et désormais confié à luimême, il sera un maître et un gardien.
\end{abstract}

Vers $749-756$

Le fils de Cythérius est invité à être éprouvé, de la même manière, comme gardien de son corps afin de prouver sa capacité à se maîtriser et ainsi à conduire les fidèles. ${ }^{24}$

C'est dans le traitement de l'exemple de Joseph que se trouve résumé le principe directeur de cette institutio cleri : «Caeli uitam in terris age» (v. 804). Le futur prêtre doit vivre les yeux tournés vers le ciel. Nous conservons ici la leçon uitam de von Hartel, contrairement à Dolveck qui édite uiam. ${ }^{25}$ Cette leçon invite à voir dans ce vers une réminiscence d'une expression de la Vita Pauli de Jérôme, «cum [...]beatus Paulus uitam coelestem ageret in terris» (7.22.10). Paulin ferait donc allusion à un texte qui fait l'éloge de la vie ascétique et même érémitique.

Dans les vers 515-516, la réminiscence du Psaume 70, 6 associe le fils de Cythérius à une autre figure vétérotestamentaire, le roi David.

préfiguration de celle du Christ (Epist. 23.13). L'exégèse allégorique pratiquée par Paulin est rare. $C f$. Ambr., Epist. 62.8-34 (éd. maur. 19) où Ambroise se sert de l'interprétation littérale de l'histoire de Samson pour montrer qu'il faut se garder des mariages avec les étrangers.

22 Cf. notamment, Nat. 13.428-459 (Carm. 21) et Cels. 447-578 (Carm. 31).

23 Le poète n'évoque pas seulement les naziréens de l'Ancien Testament. Le fils de Cythérius est aussi associé à Isaac, à Joseph et à David.

24 Cf. Ambr., Epist. e. c. 14.7 (éd. maur. 63). Augustin souligne aussi l'importance pour l'orateur de conformer sa vie à ses paroles s'il veut se faire écouter avec docilité (Doct. chr. 4.27.59-60).

25 W. von Hartel indique que uiam est une leçon du ms B (Codex Bruxellensis 10615-10729), F. Dolveck ne donne rien dans son apparat à ce sujet, mais il indique que la traditio textus pour ce passage sont les mss $S, J, B$. Il explique également dans son introduction (Dolveck (2015) 124) que $B$ est le résultat d'une contamination et qu'il est assimilé au groupe que forment avec lui les mss $S, J, O$ et $V$. 
Et nunc in aula paruulus ludit Dei Et ore lactanti canit : "De uentre matris et die prima mihi Tu, Christe, protector meus !»
Et à présent, le petit enfant joue dans la cour de Dieu et, de sa bouche nourrie par le lait, chante : «Dès le ventre de ma mère et dès mon premier jour, toi, ô Christ, tu es mon protecteur !».

Vers $513-516$

La louange de Dieu au moyen des psaumes apparaît donc comme une forme de consécration à Dieu. Avec cette réminiscence, Paulin décrit le fils de Cythérius comme chantant les Psaumes depuis sa plus tendre enfance. Or, comme le précise Guttilla, ${ }^{26}$ ce chant des psaumes dès l'enfance est un motif topique que l'on trouve chez Jérôme ${ }^{27}$ et en l'utilisant, notre poète s'inscrit dans la tradition littéraire du protreptique à la sanctification.

L'Ad Cytherium est composé à une époque où se développe, notamment avec la Vita Martini de Sulpice Sévère, le modèle du moine-évêque. ${ }^{28} \mathrm{Il}$ s'agit à la fois d'un texte bien connu de Paulin et d'un modèle qu'il approuve - lui-même, moine, deviendra évêque vers 410 . Or, il semblerait qu'avec notre poème, Paulin, en recourant à diverses figures vétérotestamentaires, participe à l'élaboration et à la diffusion de ce modèle en lui donnant des assises bibliques.

En lisant cette liste d'exemples bibliques, le lecteur peut, néanmoins, se poser une question : pourquoi, alors qu'il insiste, dans les vers 829-830 notamment, sur l'importance de connaître toute la Bible, ${ }^{29}$ Paulin n'évoque-t-il que des figures vétérotestamentaires, laissant de côté, par exemple, le personnage de Jean-Baptiste dont la manière de vivre correspond pourtant à son propos?

\subsection{Une nouvelle étape dans la manière de vivre la consécration}

S'il n'est pas simple de répondre à cette question, le survol de quelques étapes de ce protreptique met en avant l'importance d'une opposition forte entre la vie selon la chair et celle selon l'esprit. Pour cela, Paulin opère une spiritualisation des actions des figures de l'Ancien Testament pour les chrétiens de son époque. Ainsi, le fils de

26 Guttilla (1995) 19 n. 61.

27 Jer., Epist. 107.4 adressée à Laeta pour l'instruction de sa fille Paula : «Adhuc tenera lingua psalmis dulcibus imbuatur».

28 Grand ami de Sulpice Sévère, Paulin de Nole a fortement contribué à la diffusion de la Vita Martini en Italie et en Illyrie (cf. Sulp. Sev. Dial. 3.17). Sur les rapports entre les deux hommes et leur correspondance, voir Desmulliez et al. (2016).

29 Voir Cyth. 827-830 :

In carne uiuens, uita carnis exsulet

In lege mentis ambulans,

Totamque regni crediti terram sibi

Peragret in Libris sacris. 
Cythérius est exhorté à imiter la puissance de Samson par ses prières et non en partant à la chasse au lion...

Précisément, Paulin explique ce principe de lecture de l'Ancien Testament dans les vers $639-642$ :

Sed quae ante sanctis in figuram gesta sunt Nobis in actum scripta sunt, $V t$ quod parentes gestitarunt corpore Nos actitemus spiritu.
Mais ce que les saints ont accompli auparavant en figure a été écrit pour nous en acte, de sorte que ce que nos parents ont d'ordinaire accompli dans leur corps, nous ayons l'habitude de le faire, nous, en esprit.

En s'appuyant sur une réminiscence de 1 Cor 10.11, le poète oppose deux époques, celle des patriarches et la sienne, auxquelles sont associées deux manières d'accomplir les mêmes actions : les patriarches les font corpore, les chrétiens spiritu. Ce déplacement est le fruit de l'œuvre de salut du Christ, explique Paulin dans les vers suivants. $^{30}$

Mais le poète ne se contente pas d'énoncer ce principe exégétique. Dans son usage des différentes figures vétérotestamentaires, il le met en application. ${ }^{31}$ Par exemple, à la lecture littérale du récit de la vie de Samson s'ajoute une interprétation allégorique dont Paulin donne la clé de lecture au v. 549 : «Allophyla mulier est mihi lex carnea». La femme étrangère du livre des Juges représente, en fait, une entité bien plus grande et dangereuse, la loi de la chair symbole du péché.

Peut-être Paulin se concentre-t-il sur les figures vétérotestamentaires dans une optique exégétique et pastorale : il se soucie de la bonne compréhension de l'Ancien Testament du fils de Cythérius, parce que ce dernier devra enseigner les fidèles. ${ }^{32}$

Mais nous pensons surtout que la manière dont notre poète traite les différentes figures vétérotestamentaires insiste sur une spiritualisation de la lutte entre le bien et le mal qui vient renforcer le portrait de l'homme consacré dessiné par Paulin. En ce début de $\mathrm{V}^{\mathrm{e}}$ siècle, cet homme n'est plus forcément persécuté, voire destiné au martyre. Le combat pour la consécration à Dieu n'en est pas, pour autant, terminé, mais il prend une nouvelle forme. Ainsi, au vers 753, l'image de la prison du monde se substitue à celle matérielle de Joseph. ${ }^{33}$ Il s'agit, pour le fils de Cythérius, d'une lutte entre la chair et l'esprit, entre les séductions terrestres et les bénédictions célestes. Là encore, Paulin participe à la diffusion du modèle ascétique en lui donnant des fondements bibliques et en montrant que la consécration à Dieu ne

30 Voir les vers 643-668 où l'influence paulinienne est manifeste, en particulier par des réminiscences des deux épîtres aux Corinthiens.

31 Cf. Nat. 9 (Carm. 27), où Paulin accorde également une grande importance à l'exégèse allégorique de plusieurs passages scripturaires, notamment de l'histoire de Ruth (v. 529-541).

32 Dans les vers 669-688, Paulin, en insistant sur le rôle de chacun des Testaments, exhorte le fils de Cythérius à se nourrir des Écritures pour se préserver des dogmes nuisibles.

33 "Aliisque mundi carceri inclusis adhuc». 
revêt pas toujours les mêmes formes d'une époque à l'autre. Après le temps du martyre vient celui de la consécration à Dieu par l'ascèse.

Le recours aux exempla vétérotestamentaires permet donc de définir un idéal chrétien de la consécration pour un futur prêtre au début du $\mathrm{V}^{\mathrm{e}}$ siècle, un idéal marqué par les tendances ascétiques qui se développent à cette époque. ${ }^{34}$ Mais la lecture de l'Ad Cytherium montre que ce n'est pas seulement à la consécration du fils de Cythérius que s’intéresse Paulin. Il nous présente, en effet, une véritable économie familiale de la consécration.

\section{Une économie familiale de la consécration}

\subsection{Une aide réciproque}

En recourant non seulement à des figures particulières de l'Ancien Testament, mais aussi à des familles vétérotestamentaires, le poète met en évidence le rôle des parents dans la consécration de leur enfant. ${ }^{35}$ Cependant Paulin, au moyen de l'exemple de Joseph, développe également l'idée d'un rôle du fils dans la consécration de ses parents.

Vt ille quondam prouidentia Dei

Distractus in seruum puer

Ad arua frugum missus est ut et patrem

Praeiret et fratres suos,

Qui mox, per orbem consecutura fame,

Patris altor et fratrum foret.

Sic iste forsit in sacram panis domum

Vos antecessit filius

$V t$ et parentes pascat et fratres suos

In istius mundi fame,

Vbi terra, tribulos parere nobis largior,

Eget bonorum frugibus.

\begin{abstract}
Comme autrefois, le fameux enfant, par la providence divine, fut vendu comme esclave et envoyé vers les champs de céréales, pour précéder à la fois son père et ses frères, (705) lui qui bientôt, lors de l'arrivée imminente d'une famine sur la terre, serait celui qui allait nourrir son père et ses frères, de même, votre fils vous a peut-être devancés dans la demeure sacrée du Pain pour nourrir ses parents et ses frères (710) durant la famine de ce monde, là où la terre est plus prodigue à nous susciter des ronces et a besoin des moissons des hommes de bien.
\end{abstract}

Vers $701-712$

34 Ambroise, dans l'Epist. e. c. 14.66 (éd. maur. 63) datée de 396, souligne la nécessité d'avoir un évêque qui mêle sévérité monastique et discipline ecclésiastique pour l'Église de Verceil.

35 Paulin de Nole ne compare pas seulement Cythérius à Abraham. Il associe également son épouse à Anne, la mère de Samuel qui tisse un éphod pour son fils. La mère participe ainsi à la consécration de son fils en prenant, matériellement, soin de lui. Les vers 530-532 invitent aussi à une interprétation allégorique du vêtement. Faut-il en conclure que l'éphod que la mère de Cythérius doit coudre pour son fils correspond, en fait, à l'instruction religieuse qu'elle doit lui dispenser ? Les vers 689 à 696 soulignent, en tout cas, le rôle que joue l'épouse de Cythérius auprès de son mari ainsi que dans la croissance spirituelle de ses enfants. "In castitate liberos enutriens / Vitam nouellantes Deo» (v. 695-696). 
Dans ces vers, Paulin effectue un parallèle entre Joseph, qui a précédé sa famille en Égypte afin de la sauver d'une famine, et le fils de Cythérius, qui a devancé ses parents dans la sacra panis domus (v. 707) afin de peut-être les nourrir spirituellement au milieu l'istius mundi fames (v. 710). Selon une étymologie courante, ${ }^{36}$ l'expression sacra panis domus désigne Bethléem, haut-lieu d'ascétisme. Mais l'évocation de la famine du monde montre que Paulin donne aussi un sens métaphorique à l'expression sacra panis domus et qu'elle désigne également la cité de Dieu. Dans le contexte de l'instutio cleri, il faut peut-être aussi y voir une allusion à l'Église et l'Eucharistie que distribuera le fils de Cythérius une fois ordonné prêtre. Avec cette périphrase, le poète est à l'œuvre et souligne la double localisation du fils de Cythérius, sa position terrestre, dans l'Église, reflétant pour ainsi dire une réalité céleste. Par sa vie sacerdotale, le fils de Cythérius précède donc ses parents dans la demeure de Dieu. Il est, comme l'écrit Paulin au vers 880, leur salutis praeuius et peut ainsi agir pour leur bien en les nourrissant spirituellement parce que lui-même est nourri par Dieu. ${ }^{37}$

Paulin joue sans doute ici avec le thème du puer senex, ${ }^{38}$ de l'enfant jeune par les années mais âgé par sa sagesse. En effet, l'enfant est pour ses parents un magister paruulus (v. 894). Plus généralement, ce rôle du fils pour les parents relève de l'intercession et rappelle celle que les défunts qui ont atteint un haut degré de sainteté, qu'ils soient morts en martyrs ou non, exercent en faveur des vivants encore en proie aux luttes terrestres. Rappelons que c'est par ses prières que le fils de Cythérius est appelé à imiter la puissance de Samson. Paulin développe cette idée d'intercession dans le De obitu Celsi (le Carmen 31) : il invite en effet deux défunts qui partagent le même nom de Celsus, son propre fils et le fils des amis auxquels il adresse sa consolation, à prier pour le salut de leurs parents encore vivants. Préservés du mal du monde par leur mort précoce, ces enfants se trouvent dans le séjour de Dieu et peuvent prier avec efficacité pour la rémission des péchés de leurs parents. ${ }^{39}$

La différence, dans l'Ad Cytherium, réside dans le fait que c'est encore vivant que le fils de Cythérius pourra agir pour le bien spirituel de ses parents. Avec ce développement sur le rôle du fils de Cythérius et le recours à l'exemple de Joseph, Paulin

36 Voir Ambr., Iac. II.7 ; Epist. 18.9 ; 19.2 et Jer., in Ier. VI.19 et in Mich. II.5.

37 Voir vers 891-893 :

Deo dedistis nutriendum filium,

Et ille sic uobis alit

Vti uicissim nutriat canos puer.

Ce rôle du fils vis-à-vis d'un père déjà chrétien peut surprendre, mais le poète semble suggérer l'idée que le salut et la sanctification sont un trava il quotidien.

38 Voir Curtius (1956) 122-125 et Gnilka (1972), en particulier 135-147 sur le rapport entre cet idéal et le mouvement ascétique.

39 Voir Cels. 591-628 (Carm. 31), en particulier les vers 617-618 :

Innocuisque pares meritis peccata parentum,

Infantes, castis uincite suffragiis ! 
montre donc que l'efficacité «spirituelle» et plus précisément celle de l'intercession concerne, non pas les seuls martyrs ou les défunts particulièrement saints, mais plus généralement les hommes véritablement consacrés à Dieu, et donc en premier lieu ceux qui remplissent une charge ecclésiastique.

\subsection{Un renversement des rôles}

Dans notre extrait, c'est même un véritable renversement des rôles qui s'opère, le fils de Cythérius étant, au vers 896, factus parens parentibus. Paulin insiste beaucoup sur cette idée de renversement en insérant, au milieu de l'exemple de Joseph, une longue comparaison avec le comportement des aigles, où l'on peut observer une alimentation des parents par les jeunes aigles. ${ }^{40}$ Un tel développement sur le thème du renversement des rôles et des bienfaits spirituels peut surprendre, et le poète luimême parle d'un pietatis admirabile mysterium (v. 895). Mais il montre que la dimension familiale de la consécration n'est pas à sens unique : si les parents agissent pour la consécration de leur enfant, ce dernier, parce qu'il est devenu un modèle de sainteté, peut à son tour agir pour leur bien et les aider à parvenir, eux aussi, dans la demeure éternelle de Dieu. Cette vision familiale de la consécration est liée à l'idéal de l'ascète en charge de fonctions ecclésiales, mais elle le dépasse aussi puisque la consécration de tous est recherchée. Et de fait, le poème se termine sur des exhortations ascétiques adressées directement à Cythérius et sa femme, telles que se débarrasser du poids des possessions et de la souillure du péché pour être prêts à rencontrer Dieu.

Dans l'Ad Cytherium, une composition fort travaillée adressée à des lettrés, Paulin de Nole recourt à toute une série de figures vétérotestamentaires pour illustrer le comportement que doit adopter un futur prêtre. Il montre ainsi toute la valeur normative qu'il accorde à la Bible. Mais cette dernière est aussi utilisée dans le contexte du christianisme du début $d u V^{e}$ siècle où se diffuse de plus en plus la figure du moine-évêque. Avec l'institutio cleri présente dans la seconde partie de ce poème, Paulin donne des assises bibliques au personnage du prêtre ascète et fait de lui une figure idéale de consécration. Toutefois, avec les différents personnages vétérotestamentaires qu'il évoque, Paulin souligne, et c'est peut-être là l'aspect le plus singulier de notre passage, le caractère familial de la consécration : si les parents agissent pour le bien de leur enfant en le consacrant à Dieu, le fils accomplit pleinement la piété de ses parents et même, grâce au rôle qu'il acquiert, peut œuvrer pour leur salut afin qu'ils atteignent eux aussi le Royaume de Dieu. Or, c'est par la

40 Il s'agit des vers 851-884. Le poète lui-même insiste sur la valeur exemplaire des oiseaux qui parlent spontanément des «regni caelitis mysteria» (v. 873). 
consécration à Dieu qu'il est possible de l'atteindre. Si le fait de se donner à Dieu ne revêt pas forcément la forme d'une charge ecclésiastique, il suppose, néanmoins, un rejet des valeurs terrestres et un engagement radical pour le Christ. En somme, sur le chemin de la sanctification, c'est à l'ascèse qu'invite notre poète.

\section{Annexe : Vers 541-588 L'exemple de Samson}

Et, ut ille Samson ui capillorum potens, Virtute crinitus sacra

Sternat leonem strangulatum fortibus

Orationum bracchiis,

545 Dulcemque fructum nobilis uictoriae

Decerpat ore mortui.

Sed ab hoc triumpho caueat exemplo uiri

Aliena adire foedera ;

Allophyla mulier est mihi lex carnea

550 Blandis dolosa retibus :

Si lege mentis ista sit lex fortior,

In iura peccati trahet,

Malesuada uerbis fraudis arte dulcibus

Animum uirilem effeminat,

555 Excaecat oculos mentis et radit caput, Spolians et exarmans fidem.

Hac parte Samson nolo sit noster puer,

Ne misceatur copulae,

Quam consequatur protinus captiuitas

560 Infirmitas et caecitas,

Licet ille fortis postea receperit

Robur recretis crinibus,

Manuque ductus de mola ad ludibrium

Hostilis exsultantiae,

565 In caecitate corporis mente intuens

Vocarit ultorem Deum ;

Et, restituto mox capillis robore,

Prostrauit hostilem domum,

Cuius columnas fortior saxis manus

570 Vt clausit amplexu graui, Collapsa fulcris tecta subductis humo

Cecidere in ipsum ; sed tamen

Et morte <in> ipsa praepotens heros Dei

Hostes ruinae miscuit

Et gloriosa morte pensauit sibi

575 Vitae subactae dedecus :

Qui seruus hoste gloriante uixerat

Hoste obruto uictor cadit,

Et plura moriens interemit milia,

Quam uiuus interfecerat.

580

Imitetur istam filius noster uolo
Et comme le fameux Samson, dont la force des cheveux le rendait puissant, doté à son tour d'une puissance sacrée dans ses cheveux, qu'il terrasse le lion étranglé par les bras vigoureux de ses prières (545) et qu'il recueille le doux fruit d'une noble victoire dans la bouche d'un mort. Mais à partir de l'exemple de ce triomphe, qu'il se garde de conclure des alliances avec des étrangères. La femme d'un autre peuple est, pour moi, la loi de la chair, (550) qui piège dans ses rets séduisants. Si cette loi est plus forte que celle de l'esprit, elle l'entraînera dans les pouvoirs du péché ; persuadant le mal avec de douces paroles selon l'art de la tromperie, elle effémine l'esprit viril, (555) elle aveugle les yeux de l'esprit et rase la tête en dépouillant et désarmant la foi. Je refuse que notre cher enfant soit un Samson à cet égard, de peur qu'il s'engage dans une union que suivront aussitôt la captivité, (560) l'infirmité et la cécité, bien que cet homme vigoureux ait recouvré, par la suite, sa puissance, lorsque ses cheveux repoussèrent, et que, conduit par une main depuis son moulin pour être la risée de ses ennemis en liesse, (565) voyant par son esprit malgré sa cécité physique, il ait appelé la vengeance de Dieu. Et comme sa force lui fut bientôt rendue par ses cheveux, il renversa la demeure ennemie ; et, quand sa main, plus forte que les rochers, (570) enferma les colonnes dans une étreinte violente, les montants s'arrachèrent du sol, les toits s'écroulèrent et tombèrent sur lui ; et, cependant, le héros de Dieu, puissant même dans sa mort, mêla ses ennemis à sa chute (575) et il compensa par sa mort glorieuse le déshonneur d'une vie d'assujettissement. Lui qui avait vécu comme esclave sous un ennemi qui se glorifiait tomba victorieux en écrasant l'ennemi et, en mourant, il fit périr plus de milliers (580) qu'il en avait tué durant sa vie. Je veux que notre cher fils 
Sic morte mortem, ut permanens In carne carnem uincat et uiuat Deo, Peccata carnis opprimens ; Sed nolo carnis gaudiis ut noxiae 585 Dolis subactus feminae Addicat animum, et praeda fiat hostium, Virtute nudus gratiae. imite cette mort par sa mort, pour qu'en demeurant dans la chair, il puisse vaincre la chair et vivre pour Dieu en écrasant les péchés de la chair. (585) Mais je refuse qu'il voue son esprit aux plaisirs de la chair, comme soumis aux ruses d'une femme nuisible, puis qu'il devienne la proie des ennemis, dépouillé de la puissance de la grâce.

\section{Bibliographie}

Curtius (1956): Ernst Robert Curtius, La Littérature européenne et le Moyen Âge latin (transl. Jean Bréjoux), Paris.

Desmulliez et al. (2016): Janine Desmulliez, Cédric Vanhems and Jean-Marc Vercruysse, Paulin de Nole Correspondance avec Sulpice Sévère, Paris.

Dolveck (2015): Franz Dolveck, Paulini Nolani Carmina, Turnhout.

Fabre (1948): Pierre Fabre, Essai sur la chronologie de l'œuvre de Saint Paulin de Nole, Strasbourg.

Gnilka (1972): Christian Gnilka, Aetas spiritalis. Die Überwindung der natürlichen Altersstufen als Ideal frühchristlichen Lebens, Bonn.

Guttilla (1995): Guiseppe Guttilla, «ll carme 24 di Paolino di Nola e la sua novitas», in: Koinonia, $19,1,5-31$.

Hartel (1894): Wilhelm von Hartel, Sancti Pontii Meropii Paulini Nolani Carmina, Vienne.

Prete (1964): Serafino Prete, Paolino di Nola e l'umanesimo cristiano : saggio sopra il suo epistolario, Bologna.

Roberts (1989): Michael Roberts, The Jeweled Style. Poetry and Poetics in Late Antiquity, Ithaca London.

Rougé (1987): Jean Rougé, «Un drame maritime à la fin du Ve siècle : le voyage de Martinien de Narbonne à Nole (Paulin, poème 24)», in: Jean-Marie Pailler (ed.), Mélanges offerts à monsieur Michel Labrousse, Toulouse, 93-103.

Ruggiero (1996): Andrea Ruggiero, Paolino di Nola. I carmi. Testo latino con introduzione, traduzione italiana, note e indici, Napoli Roma.

Walsh (1975): Patrick Gerard Walsh, The poems of St. Paulinus of Nola, New-York.

Walsh (1976): Patrick Gerard Walsh, «Paulinus Nolanus, Carmen 24», in: Joseph O’Meara and Bernd Naumann (eds.), Latin script and letters A.D. 400-900. Festschrift presented to Ludwig Bieler on the occasion of his 70th birthday, Leiden, 37-43. 


\section{Poétique des listes apostoliques}

\section{Les premières énumérations d'apôtres dans la poésie latine chrétienne $\left(\mathrm{V}^{\mathrm{e}}-\mathrm{VI} \mathrm{e}^{\mathrm{e}}\right.$ siècle)}

L'histoire du christianisme, observait récemment Els Rose en introduction à un article sur le recueil des Virtutes apostolorum, fait apparaître deux grandes façons de faire référence aux apôtres : comme collège ou comme autorités individuelles ${ }^{1}$. Cette distinction essentielle joue un rôle structurant dans une récente étude consacrée aux apôtres dans la poésie et l'art chrétiens anciens : son auteur, Roald Dijkstra ${ }^{2}$, subdivise régulièrement ses chapitres en sous-parties intitulées «Apostles as a Group» et «Individual Apostles». Il y a toutefois eu également, tout au long de l'histoire chrétienne, une façon, certes moins usuelle, de se référer aux apôtres qui tient en quelque sorte le milieu entre ces deux pôles, collégial et individuel : on peut aussi se référer au groupe des Apôtres en les nommant individuellement. C'est ce que faisaient déjà les auteurs des évangiles synoptiques lorsqu'ils donnaient la liste des Douze (Mt 10.2-4 ; Mc 3.14-19; Lc 6.13-16 ; Ac 1.13), mais, au fil des siècles, ce type de référence a bien sûr trouvé bien d'autres expressions dans la littérature - on peut justement penser aux Virtutes apostolorum, qui rassemblent douze vies ou martyrs individuels - et dans l'iconographie-songer à la mosaïque de la coupole du Baptistère des Orthodoxes de Ravenne, qui figure les douze Apôtres autour d'un médaillon représentant le baptême du Christ. C'est l'appropriation par la poésie latine chrétienne de ce type de référence qui sera l'objet de cette contribution ${ }^{3}$. Je me concentrerai par conséquent sur les $\mathrm{V}^{\mathrm{e}}$ et $\mathrm{VI}^{\mathrm{e}}$ siècle, c'est-à-dire une période allant de l'apparition la première énumération versifiée des Douze aux derniers feux de la poésie d'inspiration antique dans Gaule mérovingienne, en particulier avec Venance Fortunat, qu'on qualifie à juste titre de «dernier poète de l'Antiquité» ${ }^{4}$. Je prendrai en compte à la fois son traitement littéraire et le rapport entre les poèmes étudiés et leurs sources.

Du point de vue littéraire, il importe de souligner d'emblée que la reprise poétique des énumérations d'apôtres par la poésie chrétienne ne fait que prolonger une longue tradition poétique, déjà présente dans la poésie grecque archaïque. En effet, depuis ses origines - on pense évidemment au Catalogue des Vaisseaux de l'Iliade

1 Rose (2013a) 57.

2 Dijkstra (2016).

3 La poésie latine pourrait fournir passablement d'exemples d'énumérations de quelques apôtres, mais je me concentrerai sur les énumérations ou catalogues qui à la fois montrent un intérêt pour les apôtres dans leur ensemble et indiquent leurs noms ou en tout cas un nombre significatif de ceux-ci. 4 En raison des incertitudes qui pèsent sur leur date, je ne prendrai pas en compte le petit poème $\mathrm{BHL}^{\mathrm{n}} 654 \mathrm{k}$ (Versus memoriales), bien qu'il soit envisageable qu'il appartienne encore au VI $\mathrm{e}^{\mathrm{e}}$ siècle ; je me contenterai de l'évoquer rapidement dans la conclusion. 
(II.484-780) -, listes et catalogues ont servi de matière à la poésie hellénique et, bien évidemment, il en est allé de même pour la poésie latine. La simple énumération acquerra ses lettres de noblesses avec Ovide, qu'on a pu présenter comme l'inventeur de cette forme particulière, illustrée à merveille par la longue liste d'arbres qui se mettent à couvrir une colline jusque-là nue, où Orphée joue de la lyre (Métamorphoses X.86-105) ${ }^{5}$. La poésie tardive et chrétienne tardive hérite de ce goût pour les énumérations, listes et les catalogues et assume pleinement cet héritage ${ }^{6}$. $A$ priori, donc, la liste des apôtres, figures fondatrices de l'Église, aurait pu constituer une matière poétique de choix. Néanmoins, la poésie chrétienne paraît avoir été réticente à l'intégrer : les poètes grecs n'ont montré qu'un intérêt très limité ${ }^{7}$, tandis qu'en Occident le développement sera assez lent. En la matière, la poésie latine délaissera la forme de l'énumération simple ${ }^{8}$, préférant celle de listes complexes, catalogiques, qui relient un nom à un type d'information (champ de mission, lieu de sépulture), comme le font les listes d'apôtre en prose.

La recherche des sources où les poètes puisent leurs données sur les apôtres m'amènera évidemment à étudier les rapports entre leurs compositions et les opuscules en prose que l'on désigne couramment comme listes d'apôtres. Étant donné que ces textes sont peu connus, il est sans doute utile de terminer cette introduction en les présentant très brièvement : ces petits textes, qui existent pratiquement dans toutes les langues utilisées par la chrétienté antique et médiévale, rassemblent de brèves notices sur les Douze et, le cas échéant, d'autres personnages apostoliques ou subapostoliques (Paul, Marc, Luc, certains collaborateurs de Paul, les soixante-dix disciples [cf. Lc 10.1], etc.) ${ }^{9}$. Ce genre d'opuscules a dû naître dans le courant du IV $\mathrm{I}^{\mathrm{e}}$ siècle dans le christianisme de langue grecque - comme le suggère sa diffusion rapide aussi bien en Orient qu'en Occident -, puisqu'il semble être totalement inconnu à Eusèbe $^{10}$; comme nous le verrons, le premier témoignage assuré de son existence est précisément un poème chrétien, le Natalicium 11 de Paulin de Nole, qui date de 405 environ. Le genre doit avoir connu un développement assez

5 Voir Williams (1978) 215.

6 Voir Roberts (1989) 59-61

7 Le seul poème grec contenant une énumération des apôtres qui soit certainement antérieur à la fin $\mathrm{du} \mathrm{VI}^{\mathrm{e}}$ siècle est un très bref poème de Grégoire de Nazianze (Carmina theologica I.1.19). Pour la période byzantine, il faut signaler le poème enregistré par la BHG sous le numéro 156e (on se reportera désormais à l'édition de L. G. Westerink, Michaelis Pselli poemata [Bibliotheca scriptorum Graecorum et Romanorum Teubneriana], Stutgardiae, In aedibus B. G. Teubneri, 1992, Inde Petrum et Paulum Romana461-463).

8 Celle qu'avait choisie Grégoire de Nazianze (voir n. 7).

9 Sur les listes d'apôtres, voir notamment : Dolbeau (2012), en part. VI ; Guignard (2015b); Vinogradov (2001) 121-124. Le recueil le plus complet reste l'édition, hélas très médiocre, de Schermann (1907).

10 Eusèbe n'est encore capable de donner sur les apôtres que des informations partielles ; avec lui, les données commencent seulement à être regroupées (voir Historia ecclesiastica III, 1), mais on reste loin de listes systématiques. Sur l'origine des listes d'apôtres, voir Dolbeau (2012) 178-179. 
rapide, car plusieurs listes sont datables avec un haut degré de certitude ou au moins de probabilité entre le $\mathrm{IV}^{\mathrm{e}}$ et le $\mathrm{VI}^{\mathrm{e}}$ siècle, aussi bien en latin qu'en grec.

\section{Le peu d'attrait de la poésie biblique pour l'énumération des apôtres}

Avant de s'intéresser aux énumérations que nous fournissent un certain nombre de poèmes, il convient de remarquer l'absence des noms des apôtres dans les paraphrases des évangiles ou des Actes des apôtres qui nous sont parvenues : ni Juvencus $^{11}$, ni, plus tard, Sedulius ou Arator n'ont inclus une telle liste dans leurs poèmes. Il n’y a que Sévère (de Malaga ?) à qui l'on peut laisser le bénéfice du doute, vu la conservation fragmentaire de ses De euangeliis libri XII. Pour Nonnos, le problème ne se posait pas, puisque Jean ne contient aucune liste complète des disciples de Jésus ${ }^{12}$. Quant aux centons, une telle énumération aurait évidemment été incompatible avec les lois du genre.

L'auteur de l'Hymnum de Christo (aussi désigné par son incipit : Hymnum dicat turba fratrum), en tétramètres trochaïques, qui pourrait être Hilaire de Poitiers, quoique cette paternité soit très discuté $e^{13}$, ne se soucie pas non plus de mettre en vers les noms des apôtres. Il se contente d'une référence collective à leur vocation : Duodecim uiros probauit, per quos uita discitur (v. 30). Il en nomme un seul, Judas, dont la mention sert de transition entre l'évocation des miracles de Jésus et celle de sa Passion :

Ex quis unus inuenitur, Christi Iudas traditor;

instruuntur missi ab Anna proditoris osculo (v. 31-32).

Il semble donc que l'énumération des noms des Douze, qui, en tout aux yeux de certains poètes, pouvaient présenter l'inconvénient d'être pour une bonne part des noms juifs et donc parfaitement étrangers à la tradition culturelle de la poésie grecque ou latine ${ }^{14}$, n'ait pas été, en règle générale, considérée comme une matière poétique suffisamment intéressante dans la poésie d'inspiration biblique.

11 Sur l'omission de cette liste par Juvencus, voir Dijkstra (2016) 87. Il remarque notamment : «Presumably Juvencus had omitted the names, because he wanted to avoid alienating effects in his work: he often omitted Jewish names ...». Sur la volonté de Juvencus de «déjudaïser» sa paraphrase en omettant les noms hébreux, voir aussi, par exemple, Charlet (1985) 633.

12 On trouve toutefois une liste partielle en Parphrase de Jean 21.3-8 (cf. Jn 21.2).

13 Voir les références données par Dijkstra (2016) 119 n. 206.

14 Nous pensons en particulier à l'attitude de Juvencus (voir n. 11). 


\section{Paulin de Nole}

C'est donc plutôt avec avec Paulin de Nole ${ }^{15}$ que l'enquête doit commencer. Car c'est dans son œuvre que l'on rencontre, pour la première fois dans poésie latine, une exploitation poétique d'une énumération d'apôtres. Énumération certes incomplète, car Paulin semble s'être refusé à proposer un catalogue complet ou systématique un tel catalogue n'apparaîtra que plus d'un siècle et demi plus tard, sous la plume de Venance Fortunat.

La première partie du Natalicium 11 (carmen 19 Hartel $^{16}$ ) célèbre le don qu'a fait dieux aux régions du monde en y plaçant les tombeaux des martyrs (v. 14-19) ${ }^{17}$ :

Omnis enim, quacumque manet mandatus in ora,

Martyr stella loci simul et medicina colentum est;

Namque, tenebrosum ueteri caligine mundum

Languentesque animas miseratus in orbe, Creator

Sic sacra disposuit terris monumenta piorum,

Sparsit ut astrorum nocturno lumina caelo.

Ce principe général une fois posé, Paulin va citer des exemples concrets en commençant par les apôtres (v. 54 ss.). Il passera ensuite à Cyprien (v. 141) et à d'autres martyrs d'Afrique et quelques autres martyrs d'Occident, avant d'en revenir à Nole et à Félix (v. 165), déjà évoqués au début du poème. Les apôtres occupent donc une part significative dans le catalogue des saints et martyrs de cette partie du poème.

Les apôtres et les villes et contrées abritant leurs tombeaux sont mentionnés dans deux petits ensembles de longueur inégale : trois vers sont d'abord consacrés à Pierre et Paul enterrés à Rome (v. 54-56) ; après une brève transition (v. 76-77), six vers et demi sont ensuite consacrés à neuf autres apôtres ou compagnons d'apôtres ${ }^{18}$ enterrés dans diverses cités et régions orientales (v. 78-84).

15 Pour une présentation des travaux sur Paulin publiés au cours des dernières décennies, voir Evenepoel (2016) 399-414. Sur le Natalicium XI, voir en particulier Cutino (2005) 69-79 ; Luongo (2006) 380 - 386 et 388-393. Je n’ai malheureusement pas eu accès à Luongo (2002-2006) 167-191. 16 À l'édition de W. von Hartel (Sancti Pontii Meropii Paulini Nolani carmina [Corpus scriptorum ecclesiasticorum Latinorum 30], Vindobonae, F. Tempsky, 1894), il faut préférer désormais celle de F. Dolveck, Paulini Nolani Carmina (Corpus Christianorum. Series Latina 21), Turnhout, Brepols, 2015. 17 Pour un rapide aperçu du rapport entre les martyrs et les lieux qui abritent leurs tombeaux dans la poésie latine de l'époque de Paulin, voir Fux (2003) 52-60 ; pour Paulin, on pourra consulter notamment Cattaneo (2001), 266-276.

18 Les compagnons d'Apôtres (Tite, Luc, Marc) sont regroupés à la fin (v. 83-84), ce qui suggère un statut inférieur à celui des Apôtres proprement dit, mais le fait même qu'ils soient unis à ceux-ci dans une même énumération suggère qu'ils jouissent aux yeux de Paulin d'un statut quasi-apostolique, ce que confirme le fait que, comme le remarque Dijkstra (2016) 256-257, la formule apostolicis ... corporibus des v. 335-336 s’applique manifestement à Timothée, Luc et André. 
Inde Petrum et Paulum Romana fixit in urbe,

Principibus quoniam medicis caput orbis egebat,

Multis insanum uitiis caecumque tenebris. [...]

Sic Deus et reliquis tribuens pia munera terris

Sparsit ubique loci magnas sua membra per urbes ;

Sic dedit Andream Patris Ephesoque Iohannem,

Vt simul Europam atque Asiam curaret in illis

Discuteretque graues per lumina tanta tenebras;

Parthia Matthaeum conplectitur, India Thomam,

Lebbaeum Libyes, Phryges accepere Philippum,

Creta Titum sumpsit, medicum Boeotia Lucan;

Marcus, Alexandria, tibi datus ...

Entre ces deux ensembles, une vingtaine de vers célèbre la victoire de la foi à Rome où le christianisme l'emporte désormais sur les anciens cultes païens (v. 57-75). Le second groupe de vers consacrés aux tombeaux des apôtres sera suivi d'un développement similaire, mais plus long, concernant les régions orientales (surtout l'Égypte et le monde grec ; v. 84-116), qui fait une place importante aux régions mentionnées en lien avec les apôtres aux v. 78 à $84^{19}$.

Divers thèmes et métaphores relient ces parties entre elles et avec le reste du poème. Paulin développe d'une part deux métaphores complémentaires : celle de la maladie, des soins et des médecins (les saints) et celle aveuglement et des ténèbres auxquels s'opposent l'illumination ou la guérison de la cécité. Très prégnante dans l'ensemble du poème, celle de la médecine apparaît à trois endroits clés : dans le premier ensemble de vers (principibus ... medicis, v. 55), au début du deuxième ensemble (curaret, v. 79, à propos d'André et Jean) et à la fin du même ensemble (Luc qualifié de médecin, v. $83^{20}$ ) ; elle contribue ainsi à l'unité de la section apostolique. Celle de la lumière et des ténèbres joue un rôle semblable : Paulin fait d'André et de Jean des lumières dissipant les ténèbres (discuteretque graues per lumina tanta tenebras, v. 80), ce qui fait écho aux ténèbres de la cécité évoquées dans le premier ensemble (v. 56), même si Paulin est soucieux de varier l'image. Les mêmes remarques valent également pour un autre thème, connexe, qui occupe lui aussi une place importante dans le poème : celui de la défaite et de la fuite des démons. Occupant les deux développements qui font suite à chacun des groupes de vers consacré aux apôtres, il marque à la fois à l'unité de la section et sa division en deux ensembles inégaux. Ces trois thèmes et métaphores sont étroitement liés entre eux, puisque, comme l'a relevé Michele Cutino, aussi bien les ténèbres que la maladie représentent

19 Sur la polémique antipaïenne dans cette partie du poème, voir Guttilla (2006) 355-377.

20 Paulin ne fait évidemment qu'exploiter une donnée néotestamentaire (Col 4.14), mais il semble jouer sur le double sens possible de la formule medicum Boetia Lucan [sumpsit] (v. 83). Dans le contexte, on comprend naturellement : «la Béotie a pris Luc le médecin», mais on pourrait aussi entendre «la Béotie a pris Luc pour médecin». 
l'erreur polythéiste et que Paulin, suivant en cela un topos apologétique, voit dans celle-ci l'œuvre du démon ${ }^{21}$.

La structure d'ensemble peut donc se résumer ainsi :
v. $54-56$
Pierre et Paul
v. $57-75$
défaite des cultes païens et des démons à Rome
v. $76-84$
neuf autres apôtres et compagnons d'apôtres
v. $84-140$
défaite des cultes païens et des démons en Égypte et dans le monde grec

Cette bipartition révèle la dualité fondamentale selon laquelle Paulin structure le passage : d'un côté Rome, caput orbis (v. 55), qui abrite les deux apôtres les plus prestigieux, Pierre et $\mathrm{Paul}^{22}$; de l'autre des villes ou contrées qui représentent le reste du monde (reliquis ... terris, v. 76) et se voient répartir d'autres apôtres ou personnages subapostoliques ${ }^{23}$. Cette dualité est accentuée par le fait que les deux développements sur la défaite des cultes païens construisent, au moyen d'évocations spécifiques, des univers religieux différents, typiquement romain pour le premier, gréco-oriental pour le second.

Paulin met ainsi en œuvre une dualité fondamentale entre Rome et le reste $\mathrm{du}$ monde, qui joue un rôle structurel majeur en ce qu'elle commande l'organisation de tout le passage. Elle oriente ainsi vers une lecture à la fois hiérarchique (caput orbis dotée de deux apôtres majeurs - autres villes abritant un seul apôtre ou compagnon d'apôtre) et géographique (Occident - Orient). Le lecteur est d'autant plus clairement invité à suivre ce second axe de lecture que les deux premières villes mentionnées lorsque le poète reprend l'énumération des apôtres après le développement des v. 57-75, à savoir Patras (André) et Éphèse (Jean), symbolisent explicitement l'Europe et l'Asie.

De fait, l'organisation géographique des noms n'est pas fortuite, mais dessine un parcours déterminé : après Rome, l'énumération des apôtres se dirige vers la partie orientale de l'Empire (Patras, Éphèse), puis, toujours vers l'Orient, franchit les limites de l'Empire (Parthie) pour atteindre ce qui était en quelque sorte l'ExtrêmeOrient (Inde). Il s'agit sans doute pour Paulin de montrer l'accomplissement de la

21 Voir Cutino (2005) 70. Concernant la métaphore médicale, Dijkstra (2016) 266 remarque que l'assimilation des apôtres à des médecins est une nouveauté dans la poésie latine.

22 Paulin avait déjà souligné dans d'autres poèmes le prestige que conférait à Rome la présence de leurs tombeaux ; voir Natal. 2 (= carm. 13 Hartel), v. 26-30 ; 3 (= carm. 14 Hartel), 65s (et cf. v. 85-88). Sur les liens entre les deux apôtres et Rome chez Paulin, voir Piras (2001) 277-283.

23 En fait, le principe posé aux v. 75-76 a sans doute une validité qui dépasse les seuls apôtres et s'applique également aux martyrs mentionnés à partir du v. 141. De ce point de vue, on pourrait considérer que Paulin opposerait d'une part Rome avec Pierre et Paul et d'autre part les reliquae terrae, d'abord avec le reste des apôtres, puis avec les martyrs. Il n'en reste pas moins que la section bipartite qui concerne les apôtres a sa cohérence propre, ce qui invite à faire passer la ligne de démarcation principale entre le dyptique qui concerne les apôtres (et leurs compagnons) et ce qui concerne les martyrs. 
parole par laquelle Jésus annonce à ses apôtres qu'ils seront ses témoins «jusqu'aux extrémités de la terre» (Ac 1.8). Le mouvement s’inverse alors : on revient vers l'Ouest, mais en passant par un troisième continent, l'Afrique (Libyens), pour ensuite rester dans des contrées qui évoquent le passé mythique et classique de la Grèce (Phrygie, Crète, Béotie). Enfin, le parcours, dans la section apostolique ${ }^{24}$, s'achève dans une ville qui, notamment de par son rayonnement culturel et son importance ecclésiastique en tant que siège d'un patriarcat, fait figure de pendant oriental à Rome : Alexandrie. Si, dans ce rôle, Alexandrie est préférée à Constantinople, c'est sans doute, en tout cas en partie, parce qu'en tant que ville à la fois grecque et égyptienne elle facilite la transition avec les vers qui, en décrivant la fin des cultes païens, vont évoquer la Grèce classique et l'Égypte. Néanmoins, l'absence de la Nouvelle Rome, qui aurait constitué une rivale plus sérieuse à l'Ancienne, ne paraît pas fortuite. En effet, la suite du poème montrera que Paulin est tout à fait conscient qu'elle abrite désormais des reliques apostoliques, importantes qui plus est (André et Timothée), mais son omission dans cette liste pourrait être destinée à en souligner le fait que Constantinople s'est invitée tardivement, et seulement par le biais de translations, dans le club fermé des villes abritant des tombeaux d'apôtres ${ }^{25}$.

Revenons à l'autre axe de lecture, l'axe hiérarchique : la structure bipartie du texte sert aussi à souligner l'importance de Pierre et de Paul en les séparant des autres. Cette analyse s'appuie non seulement sur la dignité particulière de Rome, caput orbis, mais aussi sur la qualification de principes medici (v. 55) accordée aux deux apôtres qu'elle abrite. La hiérarchie dicte aussi en bonne partie l'ordre des autres apôtres :

- le second bloc commence par deux autres apôtres de premier plan, André et Jean, qui font toujours partie de la première tétrade dans les listes des disciples de Jésus que donnent les évangiles. Leur dignité est soulignée par le fait qu’ils se voient attribuer trois vers, soit autant que Pierre et Paul ;

24 L'aspect géographique aura aussi son importance lorsque Paulin en viendra aux saints et martyrs postérieurs (v. 141 et suiv.), sans doute de façon complémentaire : d'Alexandrie, on passe à Carthage (toujours sur le continent Africain, mais dans sa partie occidentale) et, d'une manière générale, comme le souligne Cutino (2005) 75, «il movimento di evangelizzazione culmina infine nei santi dell'area più occidentale».

25 Voir v. 329-342. Paulin voit dans la translation des deux saints un projet divin et souligne que Constantinople tend ainsi à s'égaler à Rome (Constantinopolis, magnae caput aemula Romae, v. 338) ou presque, car il ne manque pas de souligner qu'André et Timothée (ne) sont (que) le frère de Pierre et le disciple de Paul. Il faut rappeler d'autre part que, de ce point de vue, Nole n'a apparemment rien à envier à la Nouvelle Rome, grâce aux reliques apostoliques qu'abrite la Basilica Nova (le Natal. 9 [carm. 27], 400 - 448 mentionne André, Thomas et Luc, ainsi que Jean-Baptiste et divers martyrs ; la position privilégiée de Nole en tant qu'elle abrite la tombe de Félix est aussi soulignée dans le Natal. 2 [carm. 13], 20-26, qui lui décerne même le second rang après Rome). C'est à juste titre que Cutino (2005) 79 fait remarquer que la section du Natalicium 11 consacrée aux corps des apôtres et autres saints «illustra i presupposti ideologici cui si era attenuta la costruzione della Basilica Nova, al cui interno sotto l'altare trovano posto le reliquie degli apostoli e il frammento della croce portato da Gerusalemme da Melania». 
- $\quad$ suivent quatre autres représentants des Douze : Matthieu, Thomas, Lébbée et Philippe. C'est sans doute sa dignité d'évangéliste qui vaut à Matthieu d'être cité avant Philippe (qui occupe systématiquement la cinquième place dans les listes néotestamentaires) et Thomas (qui vient toutefois après Matthieu en Mc 3, 18 et dans la plupart des manuscrits de Lc 6.15). On notera une omission importante, celle Jacques, frère de Jean ;

- les derniers nommés, Tite, Luc et Marc, ne sont plus des apôtres de plein droit, mais des compagnons d'apôtres. La mention des deux derniers permet que tous les évangélistes figurent dans la liste ${ }^{26}$.

Cet aspect hiérarchique jette un éclairage complémentaire sur le choix d'Alexandrie et de Marc pour clore l'énumération : la différence entre Rome, gratifiée de deux apôtres, et Alexandrie, qui reçoit seulement Marc, rehausse implicitement le prestige de la première en la plaçant plus non seulement que les autres villes, mais même qu'un autre siège patriarcal.

Ce parallèle structurant entre deux centres culturels et religieux est l'une des explications du nombre impair des personnages retenus, puisque, pour finir avec une ville qui fasse pendant à Rome, Paulin devait impérativement terminer avec une seule ville (et un seul apôtre, Rome étant la seule à pouvoir en revendiquer deux). Cette imparité est cependant plus qu'une nécessité d'organisation : le fait de citer onze personnages, et non douze, pour égaler au moins symboliquement le nombre des apôtres ${ }^{27}$, souligne le caractère incomplet, anthologique, de l'énumération. Il montre que Paulin n'entend nullement donner une liste exhaustive, comme le suggère d'ailleurs le sic qui ouvre le second groupe de vers (v. 78) : il fait apparaître les apôtres cités comme de simples illustrations de la répartition des tombeaux des saints dans le monde. Paulin s'est contenté d'un choix subtil, qui permet de concilier ordonnancement hiérarchique et géographique. J'ajoute que l'agencement même de l'énumération en souligne le caractère impair et donc incomplet : jusqu'à Marc, les apôtres et leurs compagnons sont toujours groupés deux à deux, avec un seul verbe pour exprimer leur lien avec leur lieu de sépulture. Paulin veille à varier son énumération en employant des verbes différents ${ }^{28}$ et diversifiant les références géographiques : adjectif (Romana, v. 54), noms de ville (Patras, Éphèse), nom de contrées (Parthie, Inde), noms de peuples (Libyens, Phrygiens), noms de régions (Crète,

26 L'association des apôtres et des évangélistes dans le poème est peut-être à rapprocher de leur association dans la mosaïque qui décorait l'abside de la Basilica Nova, récemment construite (400 403). Elle représentait en effet la Trinité, les apôtres et les évangélistes ; voir Trout (1999) 151.

27 Un peu plus d'un siècle plus tard, les douze noms inscrits sur le mausolée de Théodoric à Ravenne (texte chez Bovini (1977) 83) donnent un exemple d'une liste de douze noms qui intègre Paul, les évangélistes Marc et Luc et omet par conséquent trois des Douze (Barthélemy, Jacques fils d'Alphée, Thaddée-Lebbée ou Jude).

28 Pierre et Paul : fixit (v. 54) ; André et Jean : dedit (v. 78) ; Matthieu et Thomas : complectitur (v. 81); Lébbée et Philipppe : accepere (v. 82) ; Tite et Luc : sumpsit (v. 83). 
Béotie). Au terme de l'énumération, la référence à Marc joue sur des reprises (nouveau nom de ville, premier et unique réemploi d'un verbe ${ }^{29}$ ), mais aussi et surtout sur des ruptures : le passage à une formulation passive avec apostrophe à la ville (Marcus, Alexandria, tibi datus, v. 84), qui tranche nettement avec les constructions employées jusque-là ${ }^{30}$, et surtout, variatio ultime, la mention isolée d'un nom, qui rompt avec le rythme de deux noms par vers auquel Paulin avait habitué l'auditeur. Ces analogies et différences accentuent l'effet de clôture (aussi bien par rapport à l'ensemble de l'énumération, depuis Pierre et Paul, que par rapport à sa seconde partie, depuis André et Jean), mais elles soulignent aussi l'isolement de Marc et, par là, l'incomplétude de la liste.

En montrant que la liste constituée par Paulin est délibérément incomplète anthologique, pourrait-on dire -, l'analyse littéraire du passage amène un résultat important du point de vue de la Quellenforschung : si le poète n'indique pas les lieux de sépulture de l'ensemble des apôtres, ce n'est pas nécessairement qu'il serait dans l'incapacité de fournir une liste complète, faute d'information sur certains d'entre eux ; il semble s'agir d'un choix délibéré, qui sélectionne des données en fonction d'un dessein complexe et précis.

D’une manière générale, la poésie de Paulin ne manifeste que peu d'intérêt pour les figures apostoliques secondaires ${ }^{31}$, si bien que ce passage fait figure d'exception dans son œuvre. Ces vers sont les seuls dans lesquels Paulin mentionne certains des Douze. Si l'on remarque que l'ensemble des données qu'ils fournissent portent tous sur un seul et même point, à savoir la localisation du tombeau des Apôtres, cette exception n'est pas à expliquer par une connaissance superficielle des traditions apocryphes concernant certaines figures apostoliques ${ }^{32}$, mais bien par l'usage d'une liste d'apôtres, plus précisément d'une liste indiquant leurs lieux de sépulture. Cette hypothèse est confirmée par les convergences remarquables que l'on constate entre

29 Datus (v. 84) renvoie à dedit, employé au début de la seconde partie de l'énumération (v. 78) pour André et Jean.

30 Tous les autres noms étaient à l'accusatif, le sujet étant soit Dieu qui attribue des apôtres à une ville (Pierre et Paul, v. 54 ; André et Jean, v. 78), soit une région qui les prend ou reçoit (les six noms mentionnés aux v. 81-83).

31 Dijkstra remarque que, vu l'ampleur de l'œuvre de Paulin, on s'attendrait à ce que les Apôtres soient nommés plus souvent qu'ils ne le sont. De fait, l'intérêt du poète s'avère sélectif : il mentionne surtout les principaux, notamment Pierre et Paul, une partie des occurrences étant liées à leur production littéraire (Paul) ou à la présence de leurs reliques à Nole (André et Thomas). Certains ne sont cités que dans notre poème (Matthieu, Philippe, [Thaddée-]Lébbée), tandis que cinq d'entre eux ne sont même jamais mentionnés dans ses écrits (les deux Jacques, Barthélemy, Simon et Matthias), sans compter Judas (mentionné uniquement dans des lettres) ; voir Dijkstra 2016, p. 243s. On peut ajouter que, dans son œuvre poétique, Marc (v. 84), Tite (v. 83) et Timothée (v. 337.341-342) n'apparaissent que dans notre poème (Marc et Timothée étant mentionnés respectivement une et trois fois dans les lettres de Paulin, l'un en tant qu'évangéliste et l'autre en lien avec les épîtres qui lui sont adressées), tandis que Luc ne se retrouve que dans le Natal. 9 (= carm. 27 Hartel, v. 424s.). Dans ces conditions, la mention de Lébbée, de Philippe ou encore de Tite dans le Natal. 11 est remarquable. 32 Voir Dijkstra (2016) p. 266. 
les données reproduites par Paulin et celles que fournissent diverses listes anciennes apparentées entre elles, qui sont conservées en grec, en latin et en syriaque ${ }^{33}$. Je ne m'étendrai pas sur ce point ici, mais il faut relever l'apport mutuel entre ces listes et le poème : celles-là nous donnent à voir à quoi ressemblait la source de Paulin, tandis que celui-ci atteste que l'ancêtre commun de ces listes existait déjà en 405 .

Prose particulièrement sèche, les listes d'apôtres représentent à première vue la plus improbable des sources pour un poète. En y puisant son inspiration pour ce passage, Paulin pose un geste qui aura des répercussions importantes dans la tradition poétique postérieure de l'Occident. Il fait entrer la forme de la liste d'apôtres dans le domaine de la poésie chrétienne. Il le fait toutefois selon des modalités particulières : il ne l'y introduit pas sous la forme d'une simple simple énumération des noms des apôtres - qui n'a jamais «pris» dans la tradition poétique tardoantique -, mais en tant que liste «à double entrée» qui relie un apôtre et un type précis d'information ${ }^{34}$. Paulin n'aura certes pas d'imitateur immédiat, mais, comme je le montrerai, lorsque Venance Fortunat reprend et systématise ce type de liste et confirme pour les siècles à venir son droit de cité en poésie, il paraît se souvenir de ces vers de Paulin.

\section{Venance Fortunat}

L'œuvre de Venance Fortunat ${ }^{35}$ témoigne d'un intérêt inégalé pour les énumérations d'apôtres, puisqu'elle en compte deux ou trois, selon qu'on considère ou non l'In laudem sanctae Mariae comme étant, ou non, une œuvre authentique. La question n'est sans doute pas définitivement tranchée, mais, étant donné que l'hypothèse d'un imitateur paraît plus probable ${ }^{36}$, je traiterai ce poème à part. Quant aux deux

33 Je reviendrai sur ce thème dans un autre travail. Qu'il suffise ici de renvoyer à la liste syriaque éditée par Sims-Williams (1994) et à la liste latine dite Doopa (éd. Dolbeau (2012), II) dont une des sources semble proche de celle de la liste syriaque ; il faudrait ajouter une liste grecque inédite dont la BHG classe certains témoins sous BHG 156c (à tort, selon moi).

34 Cette appropriation poétique pourrait avoir été favorisée par l'association opérée par Prudence entre des martyrs et leur lieu de sépulture dans l'hymne 4 du Peristephanon (v. 15-52), si ce poème s'avérait être antérieur à celui de Paulin (sur cette question, voir Trout (1999) 102 et n. 133).

35 Sur Venance Fortunat, voir en particulier Roberts (2009).

36 Pour F. Leo, le caractère apocryphe de cette pièce était évident en raison du style et de la métrique (MGH. Auct. ant. 4, 1, p. XXIV). Son authenticité a cependant été défendue par Blomgren (1934) (non uidi). Dans son édition, Reydellet (2004) 165 n. 1 fait valoir la présence de ces vers parmi les œuvres authentiques de Fortunat dans plusieurs manuscrits ainsi que les rapprochements avec VIII.3, qu'il interprète comme un signe d'authenticité. La proximité en matière de christologie avec la lettre de remerciement à l'empereur Justin pour l'envoi des reliques de la Sainte-Croix l'amène à suggérer qu'«il pourrait s'agir ... d'une composition datant des débuts de Fortunat au moment de l'arrivée de la relique à Sainte-Croix (App. 2)». En revanche, dans un récent article où il se livre à une analyse attentive des particularités métriques, Ceccarelli (2015) 102, incline en faveur de l'attribution à un imitateur de Fortunat, sans toutefois prétendre formuler des conclusions définitives : «L'ipotesi che 
poèmes d'authenticité indiscutable, V.2 et VIII.3, bien qu'ils soient sont plus ou moins contemporains ${ }^{37}$, ils traitent le thème apostolique de façon différente.

\title{
Le Carmen V.2
}

Le Carmen V.2, rédigé au nom de Radegonde et des moniales de la Sainte-Croix de Poitiers, est adressé à Martin de Braga, évêque de Galice, ce qui nous place avant la mort de celui-ci, survenue en $580^{38}$. Les premiers mots, lumen apostolicum - une image qui n'est pas sans évoquer le Natalicium 11 de Paulin - introduisent le thème du ministère et de la prédication apostolique. Suit une énumération de sept saints six apôtres, puis Martin de Tours -, pour mieux célébrer cet autre Martin :

\author{
Lumen apostolicum cum spargeret una Triades \\ exciperetque nouum mundus honore diem \\ ut tenebras animae lux sementiua fugaret \\ et claram hauriret mens oculata fidem, \\ redditur auulsis spinis urbs Romula princeps, \\ principis egregii uomere culta Petri. \\ Paulus ad Illyricos Scythicas penetrando pruinas \\ dogmate feruenti frigora soluit humi; \\ Mattheus Aethiopos adtemperat ore uapores \\ uiuaque in exusto flumina fundit agro. \\ Bellica Persidis ${ }^{39}$ Thomae subiecta uigori \\ fortior efficitur uicta tiara Deo. \\ Lurida perspicuo datur India Bartholomeo ${ }^{40}$. \\ Andreae monitis extat Achaia seges. \\ Ne morer adcelerans, Martini Gallia prisci \\ excellente fide luminis arma capit. \\ Martino seruata nouo, Gallicia, plaude:
}

\footnotetext{
mi sembra spiegare meglio la situazione è quella di un imitatore sufficientemente abile per avvicinarsi alla tecnica di Venanzio, ma non abbastanza abile (o non abbastanza interessato) per non staccarsene in alcuni tratti caratterizzanti».

37 Voir Reydellet (1998) 14 n. 21.

38 Voir Labande-Mailfert (1986) 47.

39 Persidis est volontiers considéré comme un nominatif (voir à ce propos Nisard (1887) 145 n. 1 sur V.2), opinion qui peut s'appuyer sur un parallèle dans le De excidio Thoringiae (bellica Persidis seu te Byzantion optat, v. 95) ; on rappellera d'ailleurs que, si Fortunat n'emploie jamais Persis ni Persia, il invente en VIII.149, un nominatif plus étrange encore : Persida. Néanmoins, dans ces vers, j'inclinerais à rattacher bellica à tiara en faisant de Persidis un génitif.

40 L'adjectif luridus paraît désigner ici une couleur foncée (cf. TLL VII, 2 [1978], p. 1861, 1. 12-16). Quant à perspicuo, Reydellet (1998) 14 n. 22, y voit une allusion à la «transparence d'âme» dont témoigne Jn 1, 47, tandis que Spoth le prend au sens de «insignis, clarus» (TLL X, 1, p. 1746, 1. 55.73s.). Faudrait-il ici prendre l'adjectif au sens actif (cf. TLL X, 1, p. 1749, 1. 27-44), l'idée étant que Barthélemy sera capable de jeter sur les Indiens un regard (spirituel) que la couleur foncée de leur peau ne saurait arrêter?
} 
sortis apostolicae uir tuus iste fuit.

qui uirtute Petrum praebet tibi, dogmate Paulum,

hinc Iacobi tribuens, inde Iohannis opem (v. 1-20).

Alors que le jeu sur l'homonymie (v. 17) fait du destinataire l'égal de saint Martin, le lien établi avec les apôtres rehausse encore son prestige et ce, doublement. D’une part, ses qualités sont comparées à celles de quatre apôtres éminents : Pierre, Paul, Jacques (le Majeur) et Jean (v. 19-20). D'autre part, Fortunat met en œuvre un procédé particulièrement intéressant dans la perspective de cette étude : il insère en quelque sorte Martin de Galice, élevé au rang d'apôtre (v. 18.44 $4^{41}$ ), dans une répartition géographique des apôtres.

Je reviendrai plus tard sur le problème des sources de Fortunat et je me concentrerai pour l'instant sur l'organisation de la matière. Il apparaît très vite que les six apôtres retenus le sont surtout en fonction d'une logique géographique. À tout seigneur, tout honneur : Fortunat commence par Pierre, associé à Rome. Il ne pouvait en aller autrement et la qualification de princeps accordée à la fois à la ville et à son apôtre, effet encore accentué par le choc des deux formes de l'adjectif (urbs Romula princeps || principis ... Petri, v. 5-6), le souligne fortement. Comme lorsque Paulin énumère les apôtres et comme dans un certain nombre de listes en prose, en vertu du lien étroit existant entre les deux apôtres, Paul vient immédiatement après Pierre. Néanmoins, Fortunat ne fait pas référence à Paul en lien avec Rome, mais lui assigne une tout autre fonction dans sa géographie apostolique : il évoque sa mission à destination de l'Illyrie en le faisant passer par «les frimas de la Scythie». La référence à l'Illyrie évoque la limite atteinte par Paul dans sa mission selon $\mathrm{Rm} 15.19$ (... ita ut ab Hierusalem per circuitum usque in Illyricum repleuerim evangelium Christi) ; elle peut aussi se trouver dans la section consacrée à Paul dans les Virtutes apostolorum $^{42}$, qui, comme on le verra, ont servi de source à Fortunat. Plus surprenante (et sans équivalent dans de cette source) est l'allusion à la Scythie, contrée plus ordinairement associée à André ${ }^{43}$ : à ma connaissance, aucun texte n'y envoie saint Paul. De quelque manière qu'il faille expliquer ou interpréter cette donnée ${ }^{44}$, le but de l'opération est évident : présenter Paul (v. 7s.) comme l'apôtre des régions froides du Nord pour en faire le pendant de Matthieu (v. 9s.), qui évangélise les régions chaudes du Sud, symbolisées par l'Éthiopie. Avec les deux apôtres suivants,

41 Les v. 17-18 sont répétés à l'identique aux v. 43-44.

42 Ch. 7 (Fabricius, Codex apocryphus, $1719^{2}$, pars 2, p. 452).

43 Voir en particulier Eusèbe, Histoire ecclésiastique III.1.1 ; la Scythie fait aussi partie des régions évangélisées par André dans de nombreuses listes d'apôtres, à commencer par l'Anonyme I (voir Guignard (2015a) 187 ; Schermann (1907) passim).

44 Peut-être faut-il interpréter les Scythicae pruinae de façon métaphorique, le poète voulant alors suggérer qu'en se rendant jusqu'en Illyrie l'Apôtre serait entré dans les frimas septentrionaux. Néanmoins, dans un texte où les références géographiques n'ont d'ordinaire rien de métaphorique, il n'est pas évident que telle ait été son intention. Je serai amené plus loin à explorer une autre piste : une confusion avec une indication relative à André (voir p. 381). 
le regard se tourne vers l'Est, d'abord avec la Perse (Thomas, v. 11s.), puis l'Inde (Barthélemy, v. 13), qui représente l'Extrême-Orient. Après le Nord, le Sud et l'Est, le lecteur attendrait l'Ouest, mais Fortunat insère André (v. $14^{45}$ ), probablement pour faire pendant à son frère Pierre, qui avaient ouvert l'énumération ; sans doute s'agitil d'incarner, en face de Rome, le pôle grec de la chrétienté, symbolisé par l'Achaïe. Cette escale inattendue à Patras amorce néanmoins le mouvement vers l'Occident avec un dernier apôtre, mais c'est avec d'autres saints qu'il s'achèvera, en deux étapes progressives, de façon tout à fait parallèle à ce qu'on a constaté pour le mouvement vers l'Orient (Perse, puis Inde) : la Gaule apparaît d'abord, associée à Martin de Tours (v. 15s.), puis la Galice, où s'exerce l'apostolat du «nouveau Martin» (v. 17s.). De la sorte, Fortunat relie habilement son pays d'adoption et celui de son destinataire, tandis que le passage par Martin de Tours comme apôtre de la Gaule s'avère indispensable pour situer l'apostolat de son homonyme dans le prolongement de celui des Apôtres.

Le passage des Apôtres à Martin de Tours s'accompagne de la formule ne morer adcelerans. Elle a manifestement pour fonction de justifier le passage à ce saint «moderne» en omettant la façon dont la lumière de l'Évangile s'est répandue entre l'âge apostolique et celui-ci. Cependant, plus qu'à l'histoire générale de l'évangélisation du monde, les références apostoliques de tout le passage (dès le lumen apostolicum du v. 1) suggèrent que Fortunat pense à la mission des autres apôtres. Il est donc vraisemblable que, comme Paulin, Fortunat s'inspire dans ces vers du fonctionnement d'une liste d'apôtres. Le caractère très partiel de l'énumération - six apôtres, correspondant symboliquement à la moitié du collège apostolique ${ }^{46}$ - est manifestement lié à la géographie symbolique mise en œuvre : seuls un apôtre pour le Nord, un pour le Sud et deux pour l'Orient (pour faire pendant aux deux Martins) étaient absolument nécessaires à Fortunat, qui toutefois ne pouvait guère omettre Pierre et a ajouté André par souci de symétrie. Comme Paulin avant lui, Fortunat exploite le potentiel poétique des listes d'apôtres, mais sans se sentir tenu à produire une énumération complète. Cependant, alors que son prédécesseurs s’intéressait aux tombeaux des apôtres, ces vers de Fortunat reflètent un autre intérêt des listes en prose : les champs de mission.

\footnotetext{
45 Je comprends le v. 14 différemment que ne l’a fait Reydellet («L’Achaïe devient le champ des prédications d'André») : «Grâce aux prédications d'André, l'Achaïe devient un champ ensemencé (ou : une moisson)» (cf. l'expression euangelicam segetem satam caelesti semine employée par Pierre Chrysologue à propos de la parabole du Bon Grain et de l'Ivraie [Sermon 96, 1. 61, éd. Olivar, CCSL $24 \mathrm{~A}])$.

46 Symboliquement seulement, car l'adjonction de Paul suppose un total de treize apôtres.
} 


\section{Le Carmen VIII.3 (De uirginitate) ${ }^{47}$}

Composé à l'occasion de la consécration d'Agnès de Poitiers comme abbesse de la Sainte-Croix (peu avant 576) ${ }^{48}$, le De uirginitate (Carm. VIII.3) constitue un «épithalame mystique ${ }^{49}$ », qui reprend en le christianisant le thème du cortège divin ${ }^{50}$. Dans la partie initiale du poème (v. 1-46), qui décrit le cortège céleste célébrant le Créateur, le groupe des apôtres apparaît entre les saints de l'Ancien Testament et les martyrs, qui précèdent la Vierge Marie et des vierges. À ce stade, cependant, concernant les trois premiers groupes (v. 11-24), l'évocation se limite à quelques représentants éminents : Abraham et Moïse, Pierre et Étienne, respectivement.

Ce n'est que plus loin, après avoir célébré l'union particulière du Christ et des vierges (v. 97-128), que Fortunat reprendra de façon plus détaillée le thème apostolique en mentionnant douze apôtres, ainsi que Marc et Luc. Le chœur des «dignitaires du ciel» (siderei proceres, v. 129) convoqués aux noces du Roi comprend, outre les anges, les vingt-quatre anciens-prophètes (bis duodena senum ... uatum ${ }^{51}$; Fortunat semble amalgamer les seniores d'Ap 4, 4 et les prophètes de l'Ancien Testament ${ }^{52}$ ), Élie et Hénoch sur leurs chars, la Vierge Marie, Paul et Pierre, étroitement associés, André et sept autres apôtres Marc, Luc, Cyprien, et d'autres martyrs, presque tous d'Europe occidentale (v. 129-186). Parmi ce chœur des saints, les apôtres et les martyrs sont systématiquement associés à un lieu, qui est celui de leur sépulture, bien que cela reste souvent implicite. Cette association s'exprime selon deux modalités différentes : soit le saint vient de l'endroit en question (c'est le cas de Paul et Pierre, v. 138-140, ou de Victor, v. 155, etc.) ; soit, le plus souvent, la ville envoie le saint (c'est le cas de tous les autres apôtres, de Cyprien, v. 153, etc.) ${ }^{53}$.

47 La partie du poème qui concerne les apôtres (v. 137-152) s'est vu attribuer une entrée dans le Novum supplementum de la BHL (654ke), d'après Schermann (1907) 215s. Cette entrée ne se justifie guère, si ce n'est peut-être parce que ce passage a circulé sous forme d'extrait, en tout cas dans le Montepesulanus 39 (XII siècle), mais avec un incipit différent de celui qu'indique le Novum supplementum. Si je comprends bien les indications données par l'apparat de Schermann, l'extrait, pourvu d'une brève indication sur son auteur et sa provenance, commence en fait avec les v. 129s. et saute ensuite au v. 137. Ce texte présente une variante intéressante : le v. 144 par lequel Fortunat expédiait le sort des deux Jacques a été remplacé par trois vers qui reflètent, pour Jacques le Majeur, la tradition qui l'associe à la Galice (Alphaei Iacobum Ierusalem tribuit || Quam repetunt populi Iacobum natum Zebedaei || Galiciae tellus mittit ad astra poli). Cette adaptation peut difficilement être antérieure au IX ${ }^{\mathrm{e}}$ siècle (sur la légende espagnole, voir Starowieyski (1996) 198-201 ; Burnet (2014) 331-338). 48 Voir Reydellet (1998) 129 n. 10. Sur Agnès, fille spirituelle de Radegonde, voir par ex. Joye (2008). 49 Selon l'expression de Campanale (1980) 75-128, article que je n'ai malheureusement pas pu consulter.

50 Voir Guérard (2011) 10-15.

51 Cf. Carmen X.7.16.

52 Ce rapprochement a peut-être été facilité par des exégèses assimilant les vingt-quatre vieillards aux livres de l'Ancien Testament ; cf. Victorin de Pettau, Commentaire de l'Apocalypse 4.4.

53 Roberts (2009) 173s., observe : «There is an ambiguity ... whether the primary actors are the saints of the personified cities. A wedding celebration in heaven fades into or is combined with a ceremony 
Cette scène a été rapprochée du cortège des provinces dans le Panégyrique de Majorien (Carm. 5.40 - 53) de Sidoine Apollinaire et, surtout, de l'Hymne en l'honneur des dix-huit saints martyrs de Saragosse (Peristephanon 4) de Prudence, où l'on trouvait un procédé de personnification des cités qui envoient les martyrs qu'elles abritent très proche de celui que Fortunat met en œuvre ${ }^{54}$. Cette observation plaide fortement en faveur d'une imitation de cet hymne dans le Carmen VIII, 3 et ce dernier rapprochement peut en outre s'appuyer sur le fait que l'énumération des martyrs commence par Cyprien aussi bien chez Fortunat (v. 153) que chez Prudence (v. 17). Il me semble toutefois qu'à côté du poème de ce dernier, Fortunat se souvient du Natalicium 11 de Paulin, où l'énumération des martyrs commence également par l'évêque de Carthage (v. 123). En témoignent à la fois des analogies structurelles que quelques coïncidences dans l'expression. Certes, l'énumération de Fortunat est plus compacte que celle de Paulin, dont les divers ensembles sont, comme je l'ai noté, entrecoupés par de longs développements, mais on retrouve une séquence commençant par Pierre et Paul, étroitement associés, suivis par André et Jean, d'autres apôtres et évangélistes (Marc et Luc, quoique dans l'ordre inverse), des martyrs, dont l'énumération commence par Cyprien ${ }^{55}$ et comprend aussi Vincent (de Saragosse) ${ }^{56}$ et Martin de Tours ${ }^{57}$. La présence de Marc et Luc mérite d'être relevée, car ils ne figurent pas dans la source à laquelle Fortunat emprunte ses localisations apostoliques (les Virtutes apostolorum, comme on le verra), mais sont mentionnés par Paulin. À ces analogies structurelles s'ajoutent quelques similitudes dans la formulation. Le terme proceres (v. 129) était certes passablement banalisés8 mais n'en est pas moins un des termes clés du poème de Paulin (cf. v. 10), où il apparaît, comme chez Fortunat, au début de l'énumération des saints (v. 51), mais il faut signaler qu'il apparaît aussi dans le poème de Prudence (v. 191). Bien que cela n'ait rien d'original, je relève que Rome est qualifiée de caput orbis par Fortunat (v. 140) aussi bien que par Paulin (v. 55). Enfin, plus significatif paraissent les échos entre les vers où Paulin affirme que Dieu a donné André à Patras et Jean à Éphèse

Vt simul Europam atque Asiam curaret in illis

Discuteretque graues per lumina tanta tenebras (v. 79s.)

of consensus in the court of the heavenly king, with each city presenting its most precious possession with which it is most closely identified, its saint.»

54 Voir Roberts (2009) 174 ; Guérard (2011) 13-15. Roberts (2009) 174s. estime que ces représentations poétiques ont peut-être été influencées par des représentations de scènes similaires dans l'art tardo-antique.

55 Le rapport entre Paulin et Prudence sur ce point n'est sans doute pas fortuit, mais la question du rapport entre leurs poèmes respectifs dépasserait le cadre de cette recherche.

56 Vicentius exstat Hiberis (Paulin, v. 153) ; Vincenti Hispana surgit ab arce decus (Fortunat, v. 154)

57 Gallia Martinum (sumpsit) (Paulin, v. 154) ; Martinum Gallia mittit (Fortunat, v. 163)

58 Sur l'appropriation de ce terme par les poètes latins chrétiens (notamment Paulin), voir Doignon (1961) 152-156. 
et ce vers que Fortunat place à la suite de l'énumération des martyrs :

Europae atque Asiae quis lumina tanta recurrat? (v. 173).

Fortunat fait ainsi écho à une métaphore que Paulin utilise de façon récurrente dans son poème. L'énumération des apôtres et des saints du Carmen VIII.3 semble donc s'inspirer de deux modèles : d'une part, l'hymne de Prudence, dont il reprend en particulier l'image des villes qui présentent leurs martyrs (alors que chez Paulin l'idée est exactement inverse : les martyrs sont des dons que Dieu fait aux villes qui abritent leurs tombeaux) ; d'autre part, le poème de Paulin, dont il imite en particulier la structure.

Comme dans le poème V.2, Fortunat développe la poétique de l'énumération des apôtres, en lien, cette fois, avec leurs lieux d'ensevelissement. Il la déploie en suivant un schéma géographique qui va globalement de Rome (Pierre et Paul) vers l'Orient romain (André, Jean, Philippe), puis des contrées plus lointaines (Thomas, Barthélemy, Matthieu, Simon et Jude), mais qui n’a pas l'aspect contraignant de celui de V.2. Le poète est donc libre de donner une énumération complète des Douze, auxquels il ajoute en outre les deux évangélistes qui ne sont pas de leur nombre. C’est, en tout cas à notre connaissance, une première dans la poésie latine.

\section{Les sources des données de Fortunat concernant les champs de mission et les tombeaux des apôtres}

Il reste à revenir sur la question des sources de Fortunat. L'attention de la critique s'est surtout concentrée jusqu'ici sur VIII.3. On a depuis longtemps relevé l'accord des données de ce poème avec celles des Virtutes apostolorum (qui furent longtemps connues comme "Collection du Pseudo-Abdias» et le restent parfois ${ }^{59}$ et qui sont parfois désignées comme Actes latins des apôtres) : accord substantiel en ce qui concerne l'ordre des apôtres, complet en ce qui concerne les données géographiques $^{60}$ :

59 Sur cet ensemble (passablement mouvant) de passions, voir en particulier les travaux de Rose (2012) 11-45 ; Rose (2013a) 57-96 ; Rose (2013b) 227-268 ; voir également Alibert (2005) 735-864. 60 Dans le tableau ci-dessous, je suis l'ordre du poème VIII, 3 et j'indique par des numéros les sections des Virututes dans la colonne qui leur est consacrée (indications fondées sur Rose (2013a) 60 ; la réalité des manuscrits est cependant plus complexe, cf. Rose (2012) notamment 32). Quant au Carmen V.2, les apôtres y apparaissent dans l'ordre suivant : (1) Pierre, (2) Paul, (3) Matthieu, (4) Thomas, (5) Barthélemy, (6) André ; je ne prends pas en compte Jacques et Jean, qui apparaissent un peu plus loin (v. 20), dans un autre contexte. 


\begin{tabular}{|c|c|c|c|}
\hline & Carm. V.2 (mission) & Carm. VIII.3 (tomb.) & Virtutes apostolorum \\
\hline Paulus & $\begin{array}{l}\text { ad Illyricos Scythicas penetrando } \\
\text { pruinas }\end{array}$ & \multirow{2}{*}{$\begin{array}{l}\text { Romana ... } \\
\text { - ab arce }\end{array}$} & [1] Rome \\
\hline Petrus & urbs Romula & & [2] Rome \\
\hline Andreas & Achaia & Achaia & [3] Patras \\
\hline Iohannes & & Ephesus & [5] Éphèse \\
\hline \multirow{2}{*}{ [les deux] Jacobi } & & \multirow{2}{*}{ terra beata } & [4] Jérusalem \\
\hline & & & [6] Jérusalem \\
\hline Philippus & & Hierapolis & [7] Hiérapolis \\
\hline Thomas & Persidis $^{61}$ & Edessa & [8] Inde (m.) / Édesse (s.) \\
\hline Bartholomaeus & India & India & [9] Troisième Inde \\
\hline Mattheus & Aethiopos & Naddauer & $\begin{array}{l}\text { [10] Naddaver } \\
\text { (Éthiopie) }\end{array}$ \\
\hline Simon & & Persida $^{62}$ & \multirow{2}{*}{$\begin{array}{l}{[11-12] \text { Suanir }} \\
\text { (Perse) }\end{array}$} \\
\hline ludas & & - & \\
\hline Marcus & & Aegyptus & \\
\hline Lucas & & pas de lieu indiqué & \\
\hline
\end{tabular}

Concernant Marc et Luc, il est intéressant de relever que des passions de ces deux évangélistes circulent souvent aux marges des Virtutes $^{63}$, si bien que Fortunat pourrait s'inspirer à leur propos d'un recueil qui incluait leurs passions ou peut-être seulement celle de Marc. Le poème de Paulin est une autre source possible concernant Marc et Luc. Il faut cependant observer que le lien entre Marc et l'Égypte est une donnée des plus répandues et que Fortunat ne donne pas d'indication géographique à propos de Luc, si bien que leur mention ne dépend pas forcément d'une source précise.

Quoiqu'il en soit, la convergence entre Fortunat et les Virtutes est impressionnante. Lipsius, suivi par Duchesne, en concluait avec assurance que le poète avait connu et utilisé cette collection ${ }^{64}$. De fait, l'étendue de l'accord ne laisse guère de doutes sur le fait que Fortunat s'est servi la série de vies et passions qui constituent les Virtutes apostolorum, ce qui implique qu'elles circulaient déjà en Gaule à la fin du

\footnotetext{
61 Voir n. 39.

62 Voir n. 39.

63 Voir Rose (2013a) 60.

64 Voir Lipsius (1883-1890), I, 165-167 ; Duchesne (1895) 73.
} 
$\mathrm{VI}^{\mathrm{e}}$ siècle. Malgré la prudence d'Els Rose ${ }^{65}$, cela paraît d'autant moins douteux que Fortunat rejoint les Virtutes sur des points précis et des traditions rares, voire uniques : association de Simon et de Jude, Barthélemy en Inde, Matthieu dans la ville éthiopienne de Naddaver ${ }^{66}$ (donnée qui n'apparaît dans aucune autre source susceptible de remonter à l'époque de Fortunat). Ces accords, soulignés par Lipsius, ne sont pas contestés par E. Rose, qui admet que les Virtutes sont la seule source connue correspondant en tout au poème de Fortunat. Elle fait néanmoins valoir qu'il est également possible que le poète utilise une source inconnue comparable au Breviarium apostolorum ou à la Notitia des locis sanctorum apostolorum, dont elle est proche ${ }^{67}$. Ce n'est pas exclu, mais, à moins d'admettre un singulier hasard, il faut supposer qu'une telle liste dépendrait des Virtutes ${ }^{68}$. À mes yeux une hypothèse plus économique pour expliquer la récurrence dans deux poèmes des mêmes données serait que Fortunat ait fait pour son usage personnel un relevé des indications géographiques que les Virtutes fournissent pour chaque apôtre.

De fait, le Carmen V.2 reflète pour l'essentiel les mêmes données que VIII, 3, au moins au sens où la ville indiquée dans ce dernier poème appartient à la contrée indiquée dans le premier, comme on le constate dans le cas de Naddaver. Il faut aussi tenir compte de la différence de point de vue entre ces deux poèmes : l'un s'intéresse aux champs de mission des apôtres, l'autre les relie aux villes qui abritent leurs tombeaux ; le cas de Paul illustre bien cette différence.

Les Virtutes doivent donc avoir ici aussi servi de source ${ }^{69}$, mais le Carmen V.2 s'en écarte sur un point : il envoie Thomas en Perse et non en Inde, comme le font les Virtutes (qui réservent la Perse à Simon et Jude). La raison de cette infidélité est évidente : dans cette collection, l'Inde sert de cadre à la mission de deux apôtres. Or la poésie aime la variété. Fortunat a choisi d'assigner l'Inde à Barthélemy, si bien qu'il fallait trouver à Thomas une autre destination.

Il n'aura sans doute pas inventé cette donnée, car, bien qu'il n'existe pas, à ma connaissance, d'autre texte latin qui associe Thomas à la Perse, il en est qui l'associent aux pays des Parthes. Or la Perse de Fortunat pourrait bien n'être qu'une transposition poétique de la Parthie. La plupart des sources occidentales transmet-

65 «It is ... not certain that Venantius would not have been able to write this poem without knowledge of the narrative Virtutes apostolorum. In all cases but one, we find the same combination of apostle and missionary area elsewhere» (Rose (2013) 62). C'est exact, mais cela n'ôte rien au fait que Fortunat et les Virtutes partagent une combinaison particulière de ces données, qu'on ne retrouve nulle part ailleurs.

66 Sur les tentatives (infructueuses) de localisation de cette ville, voir Burnet (2014) 574 .

67 Rose (2013a) 63.

68 À supposer qu'une telle liste ait circulé, il serait évidemment invraisemblable qu'on ait composé les Virtutes d'après ses données ; la dépendance inverse s’impose.

69 Dans le cas de Paul, la mention de l'Illyrie pourrait être directement reprise au Nouveau Testament (Rm 15.19), mais les Virtutes apostolorum (Paul, chap. 7) restent une source possible. 
tent la tradition indienne en ce qui concerne l'activité de Thomas ${ }^{70}$. À vrai dire, les textes latins dont le poète aurait pu tirer sa localisation alternative ne sont pas légion. J'en vois quatre : l'Histoire ecclésiastique de Rufin (III.1 ; X.9), la traduction des Reconnaissances par le même Rufin (IX.29.2), Eucher de Lyon, qui reproduit les données de l'Histoire ecclésiastique (Instructiones ad Salonium I, Act. apost., 3), ou le Breviarium apostolorum. Cette dernière source est difficile à dater, mais elle pourrait fort bien être antérieure à Fortunat ${ }^{71}$. Bien qu'il soit impossible de se prononcer de façon définitive, c'est cette hypothèse que je privilégie, pour deux raisons. D'une part, contrairement aux deux autres, elle évoque les Parthes et les Mèdes à propos d'André, juxtaposition qui expliquerait au mieux la substitution de la Perse à la Parthie, puisque les Perses sont communément associés aux Mèdes. D’autre part, elle a l'avantage supplémentaire de fournir une explication possible à l'étrange mention des frimas scythes à propos de Paul. En effet, dans le Breviarium, la notice qui lui est consacrée est immédiatement suivie par celle d'André. Or cet apôtre, affirme-t-elle, praedicavit Scythiam et Achaiam. Il n'est pas exclu que ce soit une lecture inattentive de ce texte ait amené Fortunat à rapporter à Paul une donnée qui concernait en réalité l'apôtre suivant.

Si cette hypothèse s'avérait exacte, elle imposerait de placer le Breviarium au plus tard dans le troisième quart du $\mathrm{VI}^{\mathrm{e}}$ siècle. Et en ce qui concerne Fortunat, elle aurait l'intérêt de donner consistance à l'impression qu'il connaît le genre de listes d'apôtres, aussi bien sous l'angle des champs missionnaires que des lieux de sépulture - deux domaines que couvre justement le Breviarium. En effet, comme le remarque fort justement E. Rose, le contenu du Carmen VIII, 3 - et j'ajouterais pour ma part celui du Carmen V.2 - paraît supposer une certaine familiarité avec les Virtutes apostolorum, tandis que leur forme fait davantage écho aux listes d'apôtres $^{72}$.

\section{Pseudo-Venance Fortunat (?), In laudem sanctae Mariae}

Le long poème In laudem sanctae Mariae est, comme je l'ai signalé, d'authenticité contestée et semble représenter l'œuvre d'un imitateur ${ }^{73}$. Les v. 267-296 développent

\footnotetext{
70 La tradition parthe est la plus ancienne, mais elle sera supplantée par les traditions qui associent Thomas à Édesse (tombeau) et à l'Inde (champ missionnaire, souvent avec translation ultérieure à Édesse) ; sur les diverses traditions relatives à cet apôtre, voir Burnet (2014) 496-514.

71 Sur la date du Breviarium (BHL 652), voir Guignard (2019) 265 (avec davantage de références).

72 Rose (2013a) 63.

73 Voir n. 36.
} 
le thème du cortège céleste d'une façon qui rappelle le Carmen VIII.3. Les saints se rassemblent pour faire l'éloge de la Vierge Reine, qui trône aux côtés de son Fils ${ }^{74}$ :

Occurrunt proceres et gloria magna Iohannis, noscens ante Deum quam pareretur homo;

fratribus adscitis Paulo reliquisque beatis ductor apostolicus, fulgida palma Petrus.

$[\ldots]$

Hinc patriarcharum numero sociante prophetae conueniunt celso munera ferre throno,

martyrii hinc inde cohors redimita coronis, principe cum Stefano ciuica turba poli,

primitiae florum, Bethlemitica passio lactans, quae meruit nascens uiuere morte magis,

Italiae mundique caput quos Roma retentat, urbs uel Alexandri aut Antiochenus ager,

quos Hierosolymis aut quos Byzantion oris, quos Patras Ephesus Naddauer arce tenet, quos Oriens, Occasus habet, quos Africa et Arctos quosque sepultat humus, cingit et Oceanus.

Natio gens populus regiones agmina reges undique currentes ad noua dona patris, Aethiopes Thraces Arabes Daca Indus Alanus, Aurora et Vesper, Persa, Britannus adest, intrantes in regna dei pietate redempti, gaudia uisuri regis in arce poli,

quos recipit sacra porta Petri, quos ianua Pauli; postis ad Andreae limen Achaia petit.

Mattheus Aethiopes, Ephesenos ualua Iohannis, et quem quisquis amat hunc sua porta rogat.

Comme dans le Carmen VIII.3 (siderei proceres, v. 129), le poète nous fait assister à la procession des proceres (v. 267). Ces dignitaires sont, comme dans ce poème, les saints des deux testaments et les martyrs : Jean le Baptiste (v. 267), les Patriarches et les Prophètes (v. 275), les martyrs, à commencer par Étienne et les Saints Innocents (v. 277-280) et les apôtres. Cependant, contrairement à ce qu'on constatait dans le poème VIII, 3, quand bien même les martyrs chrétiens font partie du cortège, seuls des saints bibliques sont explicitement nommés ${ }^{75}$. Et sur les sept saints désignés par leur nom - Jean (le Baptiste, v. 267), Paul (v. 269 et 293), Pierre (v. 270 et 293), Étienne (v. 278), André (v. 294), Matthieu et Jean (v. 295) - cinq sont des apôtres. Les références aux apôtres se concentrent au début et à la fin du passage : au début, Pierre et

74 La royauté de la Vierge est développée aux v. 259-266 ; les éloges de la vierge occuperont les v. 315-346. Pour un commentaire de ces vers, voir Blomgren (1934) 286-294.

75 Ce n'est sans doute pas un hasard non plus que presque tous les saints désignés nominalement (concrètement tous ceux qui sont nommés ci-après, à l'exception de Matthieu) fassent partie de ceux qui occupent une place importante en Gaule au VI siècle ; cf. Beaujard (2000) 254. 
Paul ; à la fin, ces mêmes apôtres avec André, Matthieu et Jean. Cependant, la présence des apôtres parcourt de façon sous-jacente une bonne partie du passage et ce sont eux qui retiennent surtout l'attention du poète, bien plus que les autres saints.

Le thème apostolique est développé successivement de deux façons. D’abord, de façon entièrement implicite, dans la dernière partie de l'énumération des martyrs. En effet, formellement, les v. 281-286 continuent cette énumération et peuvent s'interpréter comme désignant l'ensemble de ceux qui sont ensevelis à Rome ${ }^{76}$, Alexandrie, Antioche, etc., interprétation que conforte le caractère général des v. 284 et, surtout, 285. Néanmoins, les lieux mentionnés - qui sont d'ailleurs au nombre de douze - sont presque tous susceptibles d'être reliés à tel ou tel apôtre et, en sens inverse, seul un apôtre ne peut être relié à aucun d'eux (Philippe) ${ }^{77}$. Les exemples les plus clairs sont Patras, connue comme lieu de sépulture d'André, Éphèse, comme abritant le tombeau de Jean, et, plus encore, Naddaver, toponyme qui n'est, semble-til, attesté que par la Passion de Matthieu des Virtutes apostolorum, qui y situe le tombeau de l'apôtre ${ }^{78}$. Une certaine similitude entre le v. 285 , qui fait référence aux quatre points cardinaux, et la géographie apostolique du poème V, 2 fait envisager qu'Africa (qui, dans ce contexte, pourrait avoir une portée assez générale) évoque la région où est enseveli Lebbée selon la tradition reproduite par Paulin (Lebbaeum Libyes [accepit], Natalicium 11.82). Cependant, étant donné que l'auteur s'appuie sur la Passion de Matthieu, il paraît probable qu'il suive aussi la Passion de Simon et Jude, qui est étroitement apparentée à celle de Matthieu ${ }^{79}$, comme le fait Fortunat dans le poème VIII.3, qui situe leur tombeau en Perse. Or Jude (de Jacques) est l'homologue lucanien de Thaddée-Lébbée. Autrement dit, si l'auteur suit la tradition attestée par les Virtutes apostolorum (en tout cas pour ces deux passions), il inclut sans doute Jude parmi ceux dont les tombeaux sont en Orient et ne s'occupe pas de Thaddée-Lebbée, qui ferait double emploi. Aussi est-il plus vraisemblable de lire dans Africa une référence visant particulièrement Cyprien, en écho à ce qu'on lit dans le poème VIII,.3 : Africa Cyprianum dat (v. 153). D’autant que l'Occident et le Nord (Arctos), contrairement aux onze autres régions mentionnées, n'ont aucun apôtre à fournir ${ }^{80}$. Il faut aussi relever que les cinq premières villes citées (Rome,

76 La formule Italiae mundique caput (v. 218) évoque évidemment le caput orbis du Carmen VIII.2.140.

77 Sur les raisons de cette omission, voir n. 83.

78 Cf. Lipsius (1883-1890), I, 167.

79 Voir Alibert (2005) 813 et 841.

80 Dans le poème V, 2, on l'a vu, Fortunat reliait tant bien que mal la prédication de Paul aux régions septentrionales, mais il est ici question de sépulture; même problème concernant la prédication de Philippe en Gaule (cf. Versus memoriales, v. 6 ; voir p. 386) Quant à l'Occident, la légende relative à la présence du tombeau de Jacques le Majeur en Galice n'était pas encore née. La seule échappatoire serait de supposer qu'en faisant référence à l'Occident et au Nord l'auteur penserait aux reliques apostoliques qui pouvaient se trouver dans ces régions, en particulier en Gaule, où, dès la fin du IV siècle, étaient présentes des reliques d'André, de Thomas et de Luc (Victrice de Rouen, De laude 
Alexandrie, Antioche, Jérusalem et Byzance) correspondent aux cinq patriarcats et que la volonté d'y faire référence prime sans doute ici sur la géographie apostolique. Rome ne fait évidemment aucune difficulté, Jérusalem peut revendiquer les deux Jacques (la terra beata qui les abrite selon le poème VIII.3.144 est sans doute la terre d'Israël) ou au moins l'un d'eux ${ }^{81}$, et, à défaut d'apôtre, Alexandrie a Marc. Le cas de Byzance peut se régler en prenant en compte les dépouilles apostoliques ou subapostoliques qui y ont été transférées (André, Luc et Timothée). Celui d'Antioche est plus compliqué, mais il ne serait pas impossible de lui attribuer Luc ; c'est en tout cas ce que fait une liste transmise par le Codex Fuldensis ${ }^{82}$.

Somme toute, il serait certainement excessif de faire une lecture uniquement apostolique des indications géographiques des v. 281-286, mais le fait est que les lieux nommés correspondent pour la plupart à des traditions relatives aux tombeaux des apôtres. Les deux premières colonnes du schéma ci-dessous résument les associations évidentes ou très probables (en gras) et les associations possibles ou éventuelles ; la troisième indique les équivalences (=) avec les données du Carmen VIII.3 :

\begin{tabular}{lll}
\hline Lieu & Apôtres (et martyrs) & Carmen VIII.3 \\
\hline Rome & Pierre et Paul & $=$ Aegyptus \\
\hline Alexandrie & Marc & [pas de lieu pour Luc] \\
\hline Antioche & Luc ? & $=$ terra beata \\
\hline Jérusalem & (les deux ?) Jacques & $=$ Achaïe \\
\hline Byzance & André (après transfert), Luc et Timothée (idem) $?$ \\
\hline Patras & autres martyrs ? & $=$ \\
\hline Éphèse & Jean (et Timothée [avant transfert] ?) & $=$ \\
\hline Naddaver & Matthieu & $(=)$ \\
\hline Orient & Barthélemy, Thomas, Jude et Simon & + Philippe à Hiérapolis \\
\hline Occident & autres martyrs ? & Cyprien (plutôt que Lebbée) ? \\
\hline Afrique & autres martyrs ? & \\
\hline Nord & & \\
\hline
\end{tabular}

sanctorum 6), et où, dans la seconde moitié du VI ${ }^{\mathrm{e}}$ siècle, Grégoire de Tours atteste la diffusion de reliques d'André (voir Denoël (2004) 56).

81 La plupart des listes d'apôtres anciennes assignent au moins l'un des deux Jacques à Jérusalem ; voir par ex. les trois listes mentionnées à la n. 33, ainsi que la Notita regionum (BHL 650), la liste du Codex Fuldensis (BHG 651) ou encore l’Anonyme I (voir Guignard 2015a).

82 BHL 651 ; le texte se lit par exemple dans Ranke (1868). Aucun texte de Fortunat ne nous indique où il situait le tombeau de Luc. 
La comparaison avec le Carmen VIII.3 révèle que les indications sont pour une bonne part identiques ou en tout cas compatibles, la ville indiquée par l'In laudem sanctae Mariae correspondant à la province mentionnée par le poème VIII.3. La seule différence significative résulte dans l'omission de Philippe - qui pourrait être un résultat mécanique de la volonté d'inclure les cinq patriarcats et les quatre points cardinaux sans dépasser le nombre de douze lieux ${ }^{83}$. Ce passage de l'In laudem s'appuie donc soit sur le poème VIII, $3^{84}$ soit sur les mêmes sources que lui. Il ne constitue cependant pas une simple reprise des mêmes données : d'une part, la mention de Byzance suggère que le poète relie André à la fois à cette ville et à Patras, en tenant compte du transfert de ses reliques et, peut-être, de celles de Luc et de Timothée ; d'autre part, d'autres martyrs sont manifestement pris en compte, en tout cas de façon collective, le seul que l'on puisse identifier précisément avec un haut degré de vraisemblance étant Cyprien.

Après ce premier traitement presque cryptique, le thème apostolique trouve une nouvelle expression dans la section suivante (v. 289-296), sous un autre angle : celui des régions ou peuples évangélisés. Comme l'explique Marc Reydellet, chaque nation a son protecteur apostolique qui l'accueille à une porte du ciel ${ }^{85}$. La présence des apôtres est encore implicite dans l'énumération éthnico-géographique des v. 289s., mais elle se fait explicite lorsque le poète met en scène quelques-uns d'entre eux et leur rattache des peuples ou des provinces (v. 293-296) ${ }^{86}$.

\begin{tabular}{ll}
\hline Apôtre & Peuple \\
\hline Pierre & - \\
\hline Paul & - \\
\hline André & Achaïe \\
\hline Matthieu & Éthiopiens \\
\hline Jean & Éphésiens \\
\hline
\end{tabular}

83 L'auteur devait donc inclure cinq villes ou régions (Alexandrie et Antioche, l'Occident, l'Afrique et le Nord) qui ne correspondent, semble-t-il, à aucun apôtre, tandis que Byzance et Patras se rapportent toutes deux à un même apôtre, André. Le fait que Rome et Jérusalem comptent pour deux apôtres chacune et l'Orient pour quatre compensent à hauteur de cinq apôtres au lieu des six qui auraient été nécessaires pour que la liste des Douze soit complète. Dans ces conditions, l'omission de l'un d'eux était inévitable.

84 Telle était l'opinion Blomgren (1934) 94, qui évoque une imitation de VIII.3 et peut-être aussi de V.2.

85 Reydellet (2004) 177 n. 168.

86 On remarquera que Pierre et Paul ne se voient pas assigner de peuple en particulier (les deux quos qui introduisent les relatives qui les mentionnent [v. 293] se rapportent en général aux nations nommées précédemment) ; ils apparaissent ainsi, contrairement aux autres, comme des apôtres œcuméniques. 
Le v. 296 implique que le principe s'étend aux apôtres omis : et quem quisquis amat hunc sua porta rogat. Cette indication signifie-t-elle que les peuples qui viennent d'être énumérés sont susceptibles d'être reliés à un apôtre ? Le fait que l'énumération des peuples aux v. 289s. commence par les Éthiopiens, reliés ensuite à Matthieu (v. 295), semble le suggérer, mais le poète n’a pas fourni d'autre clé. De fait, contrairement à la liste précédente, qui laissait facilement deviner des associations entre lieux, la liste de huit peuples ne s'y prête guère. Outre les Éthiopiens, seules deux relations se laissent facilement établir à la lumière du Carmen VIII.3 et des Virtutes Apostolorum : les Indiens sont à relier à Barthélemy ou (si le poète s'inspire des Virtutes sans la médiation du Carmen VIII.3) à Thomas ; la Perse, à Simon et Jude. La Thrace pourrait éventuellement être le champ de mission d'Andrée ${ }^{87}$. Quant aux quatre autres peuples (Arabes, Daces, Alains, Bretons), ils n’ont guère de liens avec les traditions apostoliques ${ }^{88}$. Le poète s'appuie-t-il sur une liste de champs de mission inconnue par ailleurs ? Le caractère plus ou moins exotique des peuples nommés suggère plutôt qu'il a tenu à insister sur l'extension de la mission apostolique en montrant qu'elle avait atteint des peuples barbares et lointains, jusqu'aux extrémités du monde connu (Éthiopiens, Indiens, Bretons ; cf. Ac 1.8). En effet, bien que les listes d'apôtres contiennent parfois des noms de peuples passablement exotiques dans telle ou telle notice, ils ne sont mis en relation qu'avec un ou deux apôtres (en particulier Thomas), tandis que le contexte invite ici à les relier plus largement à la prédication des Apôtres.

Il semble donc que, contrairement à ce qui passait pour les lieux de sépulture, le poète, tout en se souvenant du Carmen VIII.3 ou des Virtutes, n'a pas en tête une liste précise des champs de mission. Il est néanmoins probable qu'il ait une certaine connaissance de ce type de listes, puisqu'il sous-entend que différents peuples entrent par les portes de l'apôtre qui leur a annoncé l'Évangile.

Ainsi, bien que l'auteur de l'In laudem sanctae Mariae ne donne aucune liste systématique, les v. 267-296 mettent en œuvre une poétique qui joue sur deux types d'associations géographiques qu'indiquent les listes d'apôtres : champs de mission et lieux de sépulture. On rejoint la conclusion déjà atteinte à propos de Fortunat : ces deux types de liste lui sont sans doute familiers. Ce qui, dans l'hypothèse où celui-ci, n'est pas l'auteur du poème, suggère qu'il provient du même milieu.

\section{Conclusion}

$\mathrm{Au}$ terme de ce parcours, il faut d'abord souligner la rareté des énumérations (plus ou moins) complètes des membres du collège apostolique dans la poésie chrétienne

87 Cf. Grégoire de Tours, Liber de miraculis Andreae apostoli 9.

88 Le lien établi entre la Bretagne et les apôtres Matthias et Simon le Zélote par la liste grecque transmise sous le nom de Dorothée de Tyr (Schermann (1907) 156, 14 ; 157, 3), qui remonte au VIII siècle (voir Dolbeau (2012) 176s.), est tardif et isolé. 
antique. Alors que les poètes grecs ne semblent guère y avoir vu de potentiel littéraire, les Latins seront un peu plus sensibles à la poétique des listes d'apôtres. Toutefois, le recours que fera Paulin de Nole, au début du V $\mathrm{V}^{\mathrm{e}}$ siècle, à une énumération d'ampleur significative, mais (volontairement) incomplète, restera longtemps isolé. En effet, il ne trouvera un successeur que plus d'un siècle et demi plus tard en la personne de Venance Fortunat, qui donnera la première liste poétique complète dans son poème VIII.3. C'est, semble-t-il, avec lui que ce procédé s'inscrira véritablement dans la poésie chrétienne d'Occident, comme en témoignent à la fois son propre corpus (Carmen V.2 et l'In laudem sanctae Mariae, qui pourrait bien être l'œuvre d'un imitateur).

Aussi modeste soit le phénomène étudié dans ces pages, il est intéressant d'examiner cette évolution à la lumière du développement parallèle des listes et vies d'apôtres en prose. En effet, la simple énumération de noms que constituent les listes d'apôtres évangéliques n'a pas inspiré les poètes antiques ${ }^{89}$, et il semble qu'il ait fallu attendre l'existence de listes qu'on pourrait dire «à double entrée», c'est-àdire de listes reliant un apôtre et (au moins) un type donné d'information (champ de mission, lieu de mort et/ou de sépulture), pour que les poètes trouvent là une matière intéressante. En effet, Paulin, qui est le premier à l'inclure dans ses vers, a tiré ses informations d'une liste des lieux de sépulture des apôtres. Il est d'ailleurs, à notre connaissance, le plus ancien témoin d'une liste d'apôtres, genre qui était alors relativement nouveau. Fortunat s'inspirera pour sa part d'un type un peu différent de matériaux apostoliques, puisque les Virtutes apostolorum sont un ensemble de vies ou de passions des apôtres ; mais celles ne font somme toute que reproduire à l'échelle d'une collection le principe des listes. En outre, il connaît très vraisemblablement au moins une liste d'apôtres, peut-être le Breviarium apostolorum. Quelle que soit exactement sa source, la récurrence d'énumérations des apôtres ou de certains d'entre eux en lien avec leurs lieux de mission ou de sépulture - deux thèmes couverts par les listes - suggère que Fortunat et, s'il est différent, l'auteur du In laudem sanctae Mariae, avaient une certaine connaissance du genre.

Ce rapport a priori improbable entre listes d'apôtres et inspiration poétique aboutir à la production d'un type nouveau de poèmes, qui sont entièrement consacrés aux champs de mission ou aux tombeaux des apôtres et qui, à ce titre, représentent le pendant exact des listes d'apôtres en prose. Le premier exemple pourrait en être un bref poème sur les régions évangélisées par les apôtres auquel Schermann a donné le titre de Versus memoriales $\left(\mathrm{BHL}^{\mathrm{n}} 654 \mathrm{k}\right)^{90}$, si tant est que, comme on l'a proposé, cette pièce ne soit pas antérieure à la fin du $\mathrm{VI}^{\mathrm{e}}$ siècle $^{91}$ :

Romanis Petrus, Andreas sanctus Achiuis,

Iacobus Hispanis, Asiae dat iura Iohannes.

89 À l'exception de Grégoire de Nazianze ; voir n. 7.

90 Voir mon étude et mon édition : Guignard (2019).

91 Quicherat (1840-1841) 147. 
Aethiopes Matthaeus adit, loca Parthica Thomas.

Nilicolas Symon, Hebraeos Matthia cogit.

Alter habet Solymam Iacobus, Iuda Mesopotamos.

Bartholomeus Indos, Gallos tum porro Philippus.

Paulus adit gentes totus quas continet orbis.

En tout état de cause, ces quelques vers sont un excellent exemple d'une veine poétique que les poètes médiévaux, qu'ils s'expriment en latin ou dans des langues vernaculaires, continueront à exploiter ${ }^{92}$.

\section{Bibliographie}

Alibert (2005): Dominique Alibert - Gisèle Besson - Michèle Brossard-Dandré - Simon C.

Mimouni, «Actes latins des apôtres», in: P. Geoltrain - J.-D. Kaestli (éd.), Écrits apocryphes chrétiens, vol. 2 (Bibliothèque de la Pléiade 516), Paris, Gallimard, 735-864.

Beaujard (2000): Brigitte Beaujard, Le Culte des saints en Gaule. Les premiers temps. D’Hilaire de Poitiers à la fin du Vle siècle, Paris, Cerf.

Blomgren (1934): S. Blomgren, Studia fortunatiana, 2 (Uppsala Universitets årsskrift, 1934, 2), Uppsala, Almqvist \& Wiksell.

Bovini (1977): Giuseppe Bovini, Il Mausoleo di Teodorico, Ravenna.

Campanale (1980): Maria I. Campanale, «ll De Virginitate di Venanzio Fortunato (carm. 8,3 Leo): un epitalamio mistico», in: Invigilata Lucernis 2, 75-128.

Cattaneo (2001): Enrico Cattaneo, «La Devozione ai santi nei carmi di san Paolino di Nola», in: La Civiltà Cattolica 3615, 266-276.

Ceccarelli (2015): Lucio Ceccarelli, «Note sul Carmen in Laudem Sanctae Mariae attribuito a Venanzio Fortunato: metro e autenticità», in: Vichiana. Rassegna di studi filologici e storici 52/1, 87-102

Charlet (1985): Jean Louis Charlet, «L'inspiration et la forme bibliques dans la poésie latine chrétienne du $\mathrm{II}^{\mathrm{e}}$ au $\mathrm{VI} \mathrm{e}^{\mathrm{e}}$ siècle», in: J. Fontaine - Ch. Pietri (dir.), Le monde latin antique et la Bible (Bible de tous les temps 2), Paris, Beauchesne, 613-643.

Cutino (2005): Michele Cutino, «L'epopea taumaturgica di S. Felice nei Carmi 26 e 19 di Paolino di Nola», in: Auctores nostri 2, 47-80.

Dijkstra (2016): Roald Dijkstra, The Apostles in Early Christian Art and Poetry, Leiden (Supplements to Vigiliae Christianae 134).

Doignon (1961): Jean Doignon, «'Procer', titre donné à Saint Martin dans une inscription gallo-romaine de Vienne», in: N.N. (éd.), Saint Martin et son temps. Mémorial du XVle

92 Voir BHL 654 ; BHL $^{\mathrm{s}}$ 654a, 654b, 654f ; BHL $^{\mathrm{n}} 654 \mathrm{~g}, 654 \mathrm{~h}$; on peut ajouter en tout cas l'hymne $O$ Dei verbum (éd. J. Castro Sánchez, Hymnodia hispanica [Corpus Christianorum. Series latina 167], Turnhout, Brepols, 2010, p. 479-484). Dans le domaine vernaculaire, il n'existe à ma connaissance aucun catalogue de textes. Je ne suis en mesure de citer que les textes suivants : en vieil irlandais, un poème auquel son éditeur a donné le titre d'Abstammung der zwölf Apostel (Meyer (1912) 107 ; inc. Petor co treib Iuda áin) ; en vieil anglais, Cynewulf (IX siècle ?), The Fates of the Apostles ; en vieil allemand, la strophe V de la Chanson d'Annon, évêque de Cologne (†1075) ; en vieil islandais, Petrs saga postola, ch. 85 (Unger 1874). Je ne serais pas surpris qu'une recherche systématique en fasse émerger un nombre bien plus considérable. 
centenaire des débuts du monachisme en Gaule, 361-1961 (Studia Anselmiana 46), Romae, Orbis catholicus, 151-158.

Dolbeau (2012): François Dolbeau, Prophètes, apôtres et disciples dans les traditions chrétiennes d'Occident (Subsidia Hagiographica 92), Bruxelles : Société des Bollandistes.

Duchesne (1895): Louis Duchesne, "Les anciens recueils de légendes apostoliques », in: N.N. (éd.), Compte rendu du troisième Congrès scientifique international des catholiques tenu à Bruxelles du 3 au 8 septembre 1894, Bruxelles, Société belge de librairie, vol. 5, 67-79.

Guttilla (2006): Giuseppe Guttilla, «Il De errore profanarum religionum di Firmico Materno nel Carm. 19 di Paolo di Nola», in: Revue des études augustiniennes et patristiques 52/2, $355-377$.

Evenepoel (2016): Willy Evenepoel, Studies in the Christian Latin Poetry of Late Antiquity

(Spicilegium sacrum Lovaniense. Études et documents 53), Leuven, Peeters, 399-414.

Fux (2003): P.-Y. Fux, «Les patries des martyrs : doctrines et métaphores chez quatre poètes de l'Antiquité tardive», in: Connaissance des Pères de l'Église 92, 52-60.

Guignard (2015a): Christophe Guignard, «La tradition grecque de la liste d'apôtres »Anonyme l« (BHG 153c), avec un appendice sur la liste BHG 152n», in: Apocrypha 26, 171-209.

Guignard (2015b): Christophe Ch. Guignard, «Greek Lists of the Apostles: New Findings and Open Questions», in: Zeitschrift für Antikes Christentum - Journal of Ancient Christianity 20/3 (2016), p. 469-495.

Guignard (2019): Christophe Guignard, «Un bref poème latin sur les champs de mission des apôtres (»Versus memoriales«, BHLn 654k)», in: Revue bénédictine 129, 254-266.

Joye (2008): Sylvie Joye, «Agnès (après 500-vers 587)», in: Dictionnaire des femmes de l'Ancien Régime, [Paris], Société internationale pour l'étude des femmes de l'Ancien Régime (SIEFAR).

Labande-Mailfert (1986): Yvonne Labande-Mailfert, "Les débuts de Sainte-Croix», in: E.-R. Labande (dir.), Histoire de l'Abbaye Sainte-Croix de Poitiers (Mémoires de la Société des antiquaires de l'Ouest, $4^{\mathrm{e}}$ sér., 19), Poitiers, Société des antiquaires de l'Ouest.

Lipsius (1883-1890): Richard Adelbert Lipsius, Die apokryphen Apostelgeschichten und Apostellegenden. Ein Beitrag zur altchristlichen Literaturgeschichte, 3 vol. et 1 vol. suppl., Braunschweig, C. A. Schwetschke.

Luongo (2002 - 2006): Gennaro Luongo, «La Geografia della Santità nel Carme XIX di Paolino di Nola», in: Impegno e Dialogo 15, 167-191.

Luongo (2006): Gennaro Luongo, «Martyr stella loci (Paul. Nol., carm. 19, 15)», in: Auctores nostri 4, 373-396,

Meyer (1912): Kuno Meyer, «Mitteilungen aus irischen Handschriften »:, in: Zeitschrift für celtische Philologie 8, 108-112.

Nisard (1887): Charles Nisard, Venance Fortunat. Poésies mêlées, Paris, Firmin-Didot.

Piras (2001): Antonio Piras, «Roma Petro Pauloque potens: Roma e gli apostoli negli scritti di Paolino di Nola», in: N.N. (éd.), Pietro e Paolo. Il loro rapporto con Roma nelle testimonianze antiche. XXIX Incontro di studiosi dell'Antichità cristiana, Roma, 4-6 maggio 2000 (Studia Ephemeridis Augustinianum 74), Roma, Institutum Patristicum Augustinianum, 2001, $277-283$.

Quicherat (1840-1841): Jean Quicherat, «Fragments inédits de littérature latine», in: Bibliothèque de l'École des Chartes 2, 115-147.

Ranke (1868): Ernestus Ranke, Codex Fuldensis. Novum Testamentum Latine interprete Hieronymo ex manuscripto Victoris Capuani, Marburgi, N.G. Elwerti.

Reydellet (1998): Marc Reydellet, Venance Fortunat. Poèmes, t. 2 : Livres V - VIII [Collection des universités de France. Série latine 374], Paris, Les Belles Lettres.

Reydellet (2004): Marc Reydellet, Venance Fortunat. Poèmes, t. 3 : Livres IX - XI. Appendice - In laudem sanctae Mariae [Collection des universités de France. Série latine 374], Paris, Les Belles Lettres. 
Roberts (1989): Michael Roberts, The Jeweled Style: Poetry and Poetics in Late Antiquity, Ithaca.

Roberts (2009): Michael Roberts, The Humblest Sparrow, The Poetry of Venantius Fortunatus, Ann Arbor : University of Michigan Press.

Rose (2012): Els Rose, «Virtutes Apostolorum: Editorial Problems and Principles», in: Apocrypha 23, 11- 45 .

Rose (2013a): Els Rose, «Virtutes apostolorum: Origin, Aim and Use», in: Traditio 68, 57-96. Rose (2013b): Els Rose, «Abdias scriptor vitarum sanctorum apostolorum? The "Collection of Pseudo-Abdias « reconsidered», Revue d'histoire des textes n.s. 8, 227-268.

Williams (1978): Gordon Williams, Change and Decline. Roman Literature in the Early Empire (Sather Classical Lectures 45), Berkeley, University of California Press.

Schermann (1907): Theodor Schermann, Prophetarum vitae fabulosae, indices apostolorum discipulorumque Domini, Dorotheo, Epiphanio, Hippolyto aliisque vindicata (Bibliotheca scriptorum Graecorum et Romanorum Teubneriana), Lipsiae, B. G. Teubner).

Starowieyski (1996): Marek Starowieyski, «La légende de saint Jacques le Majeur», in: Apocrypha 7, $193-203$.

Trout (1999): Denis E. Trout, Paulinus of Nola. Life, Letters, and Poems, Berkeley, University of California Press.

Unger (1874): Carl R. Unger, Postola Sögur. Legendariske fortälliger om apostlernes liv, Christiania, B.M. Bentzen.

Vinogradov (2001): Andrey Vinogradov, «Апостольские списки [Listes d’apôtres]», in: Православная энциклопедия [Encyclopédie orthodoxe], t. 3, 121-124. 
Part III: The Versification of the Bible in the Latin West in the Middle Age 



\section{La réception en Afrique, au $\mathrm{VI}^{\mathrm{e}}$ siècle, du motif apocalyptique de la fin du monde à travers le poème de Verecundus de Junca et l'anonyme «À Flavius Felix»}

Un intérêt africain pour les fins dernières semble bien attesté dans la poésie latine au $\mathrm{VI}^{\mathrm{e}}$ siècle : en laissant de côté tels Versus de principio mundi uel de die iudicii et resurrectione carnis que nous ne possédons plus, mais que le catalogue de la bibliothèque de Lorsch attribuait, au milieu du IX ${ }^{\mathrm{e}}$ siècle, à un Cresconius en qui $\mathrm{H}$. Hofmann veut reconnaître Flavius Cresconius Corippus ${ }^{1}$, ce motif est au cœur du Poème sur la pénitence de Verecundus de Junca et des vers anonymes À Flavius Felix sur la résurrection des morts et le jugement du Seigneur que bien des indices rattachent à l'Afrique, plutôt qu'à la Gaule où ont voulu l'ancrer M. Dando et M. De Gaetano².

On a d'ailleurs pu supposer que ces deux textes avaient le même auteur, Verecundus $^{3}$, mais la tradition manuscrite qui domine au Moyen-Âge transmet le De resurrectione avec le corpus cyprianique, tandis que le catalogue de Lorsch et l'édition de Fabricius attribuent à Tertullien ce texte par ailleurs utilisé par Aldhelm et dans la liturgie ${ }^{4}$. Quant au poème de Verecundus, il nous est parvenu, pour l'essentiel, à travers un manuscrit madrilène des $\mathrm{IX}^{\mathrm{e}}-\mathrm{X}^{\mathrm{e}}$ siècles, originaire d'Oviedo, qui contient aussi des œuvres d'Eugène de Tolède, de Dracontius, de Corippe et de Juvencus, donc une sélection composite de poésie chrétienne, et un autre de Douai, de la fin du XII ${ }^{\mathrm{e}}$ siècle, originaire d'Anchin, qui pour sa part l'attribue à Isidore et le fait figurer entre le Peristephanon de Prudence et une Exhortatio penitendi ${ }^{5}$. En présence de titres différents selon les manuscrits (Versi/-us penitentie ; De satisfactione penitentie), la dernière éditrice du poème, M. G. Bianco, a choisi d'intituler le texte Carmen de paenitentia.

Les deux compositions ici considérées, qui n'ont pas suscité un grand intérêt chez J. Fontaine dans sa Naissance de la poésie dans l'Occident chrétien ${ }^{6}$, ne relèvent pas de la paraphrase biblique, quoique l'on s'en rapproche avec les vers 123-141 de Verecundus, inspirés d'un passage du livre de Jérémie et de deux autres de celui de $\mathrm{Job}^{7}$; mais elles proposent l'une et l'autre une méditation poétique, de tonalité plutôt

1 Voir Hofmann (2015) 99-100, avec bibliographie.

2 Voir Dando (1965) et De Gaetano (2013).

3 Voir Ciccolini (2008) 167.

4 Voir Ciccolini (2008) 167-169.

5 Voir Bianco (1984) 36-52.

6 Voir Fontaine (1981) 273 et 276-277.

7 Voir Bianco (1984) 127-129. 
pénitentielle chez Verecundus et protreptique pour le De resurrectione, qui se fonde sur la littérature biblique, apocryphe non moins que canonique - en sus de la lecture des poètes et de l'expérience du malheur, chez nos deux auteurs, en des temps difficiles. On s'intéressera ici à leur évocation de la fin du monde, qui procède d'une eschatologie à la fois "apocalyptique» et "pénitentielle», pour reprendre les catégories de S. Prete ${ }^{8}$. Mais il ne saurait être question pour le présent exposé d'entrer dans les multiples débats sur la littérature "apocalyptique»" ${ }^{9}$; on rappellera simplement :

- que l'Apocalypse johannique est loin d'être la seule à influencer la littérature chrétienne, comme le montrent notamment les Apocalypses de Pierre et de Paul, aux $\mathrm{II}^{\mathrm{e}}$ et $\mathrm{III}^{\mathrm{e}}$ siècles, qui contribuent à la mise en place de toute une imagerie infernale, bien plus haute en couleurs que celle des Evangiles (à peu près limitée à la présence de feu et de vers) ;

- que l'Apocalypse de Jean a fait l'objet, de la part des Pères latins depuis Victorin de Poetovio, de nombre de commentaires, qu'ont bien étudiés J. Haussleiter et R. Gryson $^{10}$ (dont, en Afrique, celui de saint Augustin qui, au livre XX.14 sq de La Cité de Dieu, considère que la catastrophe cosmique interviendra, de façon concrète et non symbolique, sous forme de conflagration, après le Jugement dernier ; et, au VI ${ }^{\mathrm{e}}$ siècle, celui de Primasius d'Hadrumète, en cinq livres, sur la base d'un texte biblique proche de celui de Cyprien ${ }^{11}$, et dont le contenu décalque parfois littéralement Augustin) ; l'on songera aussi aux réflexions de S. Prete sur les quatre formes que prend l'eschatologie chez les écrivains chrétiens de la latinité tardive : ascétique, apocalyptique, pénitentielle et théologique ${ }^{12}$, mais il faut se rappeler que les poètes ne sont pas d'abord des théologiens, quoiqu'un Prudence ou un Prosper puisse aborder des questions relevant proprement du dogme ;

- $\quad$ que le motif de la catastrophe cosmique, dans la littérature apocalyptique, ou dans les Oracles sibyllins, s'insère parmi plusieurs autres (signes avant-coureurs ; venue du Christ ; règne millénaire ; résurrection des morts ; Jugement dernier) ; mais il y est central, au point que communément, «apocalypse» signifie «fin du monde» - même si c'est dans la perspective gratifiante d'un salut final ${ }^{13}$;

- $\quad$ enfin, que ce motif a fait l'objet en 2002, pour la poésie latine du $\mathrm{III}^{\mathrm{e}}$ au VI siècle, d'un riche mémoire inédit de DEA soutenu par M. Cerati à l'université Paris-Sorbonne, sous la direction de J.-Cl. Fredouille ; le rôle fondateur de l'Africain Commodien y est très justement souligné ${ }^{14}$, de même que l'éloigne-

8 Voir Prete (1966).

9 Voir par exemple Kappler (1987) 15-45 ; Collins (1998) ; Christe (1999).

10 Voir Haussleiter (1891) ; Gryson (1997).

11 Voir Gryson (1997) 327-331.

12 Voir Prete (1966).

13 Voir Cohn (2000), qui souligne ici, peut-être trop fortement, le rôle du zoroastrisme.

14 Voir Cerati (2002) 15-24. 
ment croissant de la perspective d'une conflagration imminente, et le «recyclage» des motifs de la catastrophe cosmique en images de décor infernal. Cette belle enquête a stimulé plusieurs des présentes réflexions.

Faute de pouvoir établir avec certitude une chronologie relative des textes ici retenus, la plupart des arguments en la matière pouvant se retourner, on commencera par s'intéresser au poème de Verecundus, évêque de Junca (ou Iunci), en Byzacène, relégué sous Justinien à Chalcédoine pour son opposition à Constantinople dans la querelle des Trois-Chapitres et mort là-bas en $552^{15}$. Son éditrice, M. G. Bianco, en a minutieusement étudié l'insertion dans la poésie contemporaine en Afrique, entre autres dans ses rapports avec les vers anonymes à Flavius Felix qui ont été parfois attribués à Verecundus ${ }^{16}$, puis dans la littérature pénitentielle, au sens moral et non «sacramentel» du terme, dont on aurait ici la première attestation en poésie latine ${ }^{17}$, pour examiner enfin la relation de ce texte avec les commentaires de Verecundus sur les cantiques de l'Ancien Testament, où ne manquent pas non plus les protestations de componction $^{18}$.

Dans les 141 premiers hexamètres de ce poème, qui en compte 212, l'auteur s’invite lui-même à la pénitence, non sans penser d'emblée à la géhenne (v.16) et au Juge (v. 55), en implorant du Seigneur avec insistance le pardon de ses péchés. Puis, après un regret d'être né, s'ouvre au vers 142 un vaste développement apocalyptique, introduit par la terrifiante vision de la venue avec ses anges d'un Dieu vindicatif (Ecce uenit Dominus...), dont la portée semble d'abord générale. À une annonce de l'imminence du jugement et des peines nourrie de réminiscences scripturaires colligées avec soin dans l'apparat et le commentaire de M. G. Bianco (v. 142-151) - et caractérisée par un goût tardif pour l'accumulation verbale (v. 149-150) que l'on retrouve dans le poème anonyme à Flavius Felix (v. 246-247, mais avec une matrice virgilienne) - fait suite un long tableau de catastrophe cosmique (v. 152-188); puis le poète se voit personnellement confronté à son juge (Ecce ego... : v. 189-206), pour finir par déplorer que ces soucis lui ôtent le sommeil - non sans quelque préciosité néo-alexandrine dans la formulation (v. 207-212). Le tableau qu'offre Verecundus des peines infernales et de la conflagration universelle n'est pas sans rapport avec ses commentaires déjà mentionnés sur les cantiques vétéro-testamentaires, notamment au sujet du feu ${ }^{19}$, mais aussi avec la poésie de Commodien (Carm. apol., v. 9951044) et de Prudence (Ham., v. 824-838). La catastrophe cosmique embrase la terre et la mer (qui disparaît, comme dans l'Apocalypse de Jean $(21,1)$ commentée par Primasius d'Hadrumète ${ }^{20}$ ), avec un parallélisme parfait et des correspondances

\footnotetext{
15 Voir Bianco (1984) 7-16.

16 Voir Bianco (1984) 16-26.

17 Voir Bianco (1984) 26-30.

18 Voir Bianco (1984) 31-36 ; Magazzù (1983)

19 Voir Bianco (1984) 131 ; Magazzù (1990).

20 Voir Bianco (1984) 134.
} 
terme à terme (v. 154-156;157-159) ; puis l'air s’y ajoute, et «tout devient fournaise» (v. 162). La description de ce qui brûle se précise alors : les montagnes, qui fondent en un adynaton qui remonte au Ps 96.5, mais aussi à Commodien (Instr. I.45.7) ; les êtres vivants ; les constructions humaines, figures de vanité (non sans d'efficaces procédés oratoires comme l'allitération : v. 167, torridus increpitans calidis carbonibus aer, ou le polyptote : v. 171, fulgora fulgoribus). La foudre donne des couleurs rouges et blanches à la fois à ce tableau apocalyptique (v. 171-174: rubicunda / candescunt), qui font songer au ciel de la mosaïque d'abside de l'église romaine des SaintsCosme-et-Damien. Pour finir revient l'image des montagnes qui fondent comme cire, avec la plus «ignée» d'entre elles, cet Etna cher aux poètes (v. 175-178), jusqu'à ce que le feu consume, subsume et résume tout : Omnia tunc unum faciunt elementa caminum. / Mundus erit rogus ipse sibi mundusque cadauer (v. 179-180), en une hyperbole qui évoque le Carmen de Sodoma (v. 128 : tota rogus regio est) ou le Commonitorium d'Orientius (v. 2, 184 : uno fumauit Gallia tota rogo). Cette vision grandiose de destruction de l'univers par la flamme n'est évidemment pas sans rappeler l'Africain Commodien, seul poète avant Verecundus à mentionner à ce propos la disparition de la mer et la fonte des montagnes ; mais elle s'élargit ici en une méditation moralisatrice sur l'incapacité de l'homme à se détourner du péché, malgré la certitude que le Seigneur viendra comme l'éclair qui brille de l'orient à l'occident (cf. Mt 24, 27), avec un dernier renvoi au parallèle biblique de Sodome et Gomorrhe (v. 181-188 ; cf. Gen 19, 24-25). Et surtout, elle est encadrée de deux autres visions introduites par le présentatif ecce, l'une, impersonnelle, du Jugement universel (v. 141-151), l'autre, personnelle, du Jugement particulier (v. 189-206), qui sont pareillement associées à l'enfer, comme le montre la reprise quasi littérale au vers $199 \mathrm{du}$ vers 148 (Illic / mox ibi fletus erit stridorque in dentibus ingens), qui reproduit des images liées à ce lieu chez Marc et chez Luc $^{21}$. Cette vision, précisonsle, est plutôt sobre, par rapport à celle d'un Prudence, et renvoie à des tourments plutôt moraux que physiques (v. 151 : animae) : c'est que la violence inhérente à l'enfer est ici comme reportée sur la catastrophe cosmique, avec, à son propos, la mention d'éléments, tels la fournaise et le soufre, que Jean affectait à l'enfer (Ap 19, $20 ; 20,10,14$ et $15 ; 21,8)$; les réflexions morales qui concluent ce tableau apocalyptique permettent la même remarque ${ }^{22}$, et amènent progressivement le lecteur au Jugement particulier par quelques rappels subtils du Jugement universel des vers 142-151 ; quant aux vers conclusifs, les flammes éternelles s'y muent en brûlure spirituelle, dans une tonalité élégiaque qui amplifie une omniprésente culpabilité. Du feu de la géhenne au feu du remords, Verecundus fait le choix de l'intimité, et il reporte sur la catastrophe cosmique les ressources poétiques d'un enfer coruscant, tel que l'avaient élaboré maintes apocalypses apocryphes ${ }^{23}$, puis la littérature

21 Voir Bianco (1984) 132.

22 Voir Cerati (2002) 60-61.

23 Voir entre autres Himmelfarb (1983), Amat (1985) 381-390. 
chrétienne. L'héritage théologique, bien que l'évêque Verecundus ne soit pas étranger à ce domaine, paraît plus limité : si M. G. Bianco ${ }^{24}$ a pu mettre les vers 201206 en rapport avec la tripartition augustinienne des péchés in corde, in facto et in consuetudine, la componction que veut exprimer et susciter notre poète tient plus à des images qu'à des raisonnements ; le songe de Jérôme jugé pour cicéronianisme (Ep. 22.30) a pu également inspirer Verecundus.

Le poème anonyme Ad Flauium Felicem de resurrectione mortuorum et de iudicio Domini, pour reprendre ici le titre cumulatif que lui a donné, sur la base des différents manuscrits qui le transmettent, J. H. Waszink dans son édition de référence ${ }^{25}$, compte 406 hexamètres, dont la langue et la métrique ont pu faire penser à une datation très tardive ; mais s'il est impossible, et non nécessaire ici, de le placer avec certitude avant ou après les vers de Verecundus, une composition au $\mathrm{VI}^{\mathrm{e}}$ siècle est fort probable : de fait, de multiples parallèles ont pu y être relevés avec le Carmen de paenitentia ${ }^{26}$, bien au delà de l'attaque commune Quis mihi ${ }^{27}$ et d'une tonalité moralisatrice pareillement présente dans des textes que leur didactisme rapproche du sermon $^{28}$. C'est d'ailleurs autour de la notion de protreptique que L. Martin, dans un tout récent mémoire inédit, structure le plan qu'elle procure de l'Ad Flauium Feli$\mathrm{cem}^{29}$, avec quelques différences par rapport à celui de J. H. Waszink ${ }^{30}$. - Les vers qui nous intéresseront ici figurent dans la cinquième et avant-dernière partie de ce plan, qui précède le souhait conclusif de conversion spirituelle. Après une présentation du poème vient en effet un appel à la prière, puis une invitation de l'homme à connaître sa nature, la création impliquant, en l'espèce, la résurrection ; le Jugement de Dieu convoque alors les justes au paradis, puis les méchants en enfer. Comme le note L. Martin $^{31}$, cette cinquième partie (v. 269-372) «est construite de façon cyclique : elle commence et finit sur l'affirmation que tout est là pour avertir l'homme de ne pas mal se comporter - la nature est une preuve de la bonté divine (v. 269-291) et les prophètes, au nombre desquels on compte en quelque sorte le poète, ont annoncé les événements à venir (v. 356-372). Au centre figurent une description de l'enfer qui attend les mauvais (v. 292-332) et le second » guide pratique non exhaustif « des actes coupables à éviter (v. 332-356)». - Une première évocation du Jugement divin, juste avant le tableau de la résurrection des corps, pouvait se prêter à une vision apocalyptique ; mais cette virtualité n'est pas exploitée, et ce qui est dit alors des

24 Voir Bianco (1984) 142.

25 Voir Waszink (1937). Une édition plus récente (Escola (2007)) a suscité bien des réserves (voir Martin (2017) 2, n. 10).

26 Voir Bianco (1984) 22-23.

27 Voir Bianco (1984) 82.

28 Voir Fontaine (1981) 271.

29 Voir Martin (2017) 51-53.

30 Voir Waszink (1937) 36-37.

31 Voir Martin (2017) 52-53. 
anges, igneus his uigor est (v. 146), rappelle plutôt les Champs-Elysées virgiliens (Aen. VI.730 : igneus est ollis uigor) que les enfers judéo-chrétiens. En revanche, l'hypotypose infernale des vers 292-332 ne manque pas de couleur ni de puissance ; nous la lirons ici, sur la base du texte de J. H. Waszink, dans la traduction de L. $\operatorname{Martin}^{32}$, retouchée au besoin :

«Vous, cependant, vous avez dit qu'il n'existait pas, ce Seigneur du ciel et de la terre ; vous avez préféré massacrer cruellement les justes, et les hérauts de Dieu, la plupart d'entre vous les avez bien souvent mis en fuite. (295) La vérité a toujours été ancrée en vous à titre de crime. Et c'est pourquoi vous récolterez le fruit que vous avez semé, impies! Voici que vous découvrez le jour dont vous avez l'habitude de vous moquer. Vous irez dans les profondes ténèbres du feu et $d u$ soufre, en brûlant, pour endurer par vos douleurs un courroux cruel. (300) Le Seigneur ordonne que ces hommes-là se retirent pour une punition éternelle, qu'ils aillent au brasier toujours sans fin de la géhenne, que leur masse soit accablée à travers les étangs ardents. Il ordonne que les éléments se changent en flammes menaçantes, et que tout le feu du ciel descende des nuages.

(305) Alors, le Tartare avide fait jaillir des feux impétueux, les mers éructeront des flammes orageuses, la terre tout entière mêle les vivants aux cendres chaudes, l'air enflammé brandira des sillons (lumineux ${ }^{33}$ ) pris de colère, et la terre sera armée de toute sorte de torches : (310) dans une charge digne du Tartare, les incendies gronderont contre le monde. Les réprouvés sont précipités, boutés dans la fournaise ; d'un côté ils fuient, de l'autre ils sont emportés à nouveau par une course énergique. La cruelle colère de la flamme fait obstacle aux fugitifs et, dès lors, ils comprennent quel est le châtiment qui fait suite à leur crime. (315) Et désormais, l'étendue de la terre n'est plus possédée par aucun habitant et, sous sa limite profonde, elle est comprimée par les rivages les plus avancés de la mer, là où le soleil borne ses rayons après avoir parcouru l'Olympe, et où les astres après leur lever se dissimulent, une fois traversé l'univers. L'air s'embrase, une fois la lumière cachée dans les ténèbres épaisses ; (320) les eaux stagnantes les plus reculées s'enflamment en ruisseaux isolés. La nature de ce lieu est ignée ; les châtiments y sont assignés ; le fond d'un marais chauffé à blanc fait tonner les brasiers de l'enfer ; le châtiment est exécuté par d'horribles fournaises, et le fleuve agité en un tourbillon ravisseur, (325) et qui s'élance pour vous torturer en un maelström impétueux, bouillonne de flammes. Le sable torride se mélange complètement à la boue. Ici sera envoyée la foule captive et gémissante des méchants, et la troupe de la nation criminelle destinée à y être (horreur !) brûlée. Là, il y aura une grande lamentation, que les pleurs mêleront de cris, (330) et des grincements enragés ; de là, le hurlement de ceux qui souffrent s'élèvera de la flamme, au loin, et un profond gémissement, qui est aussi celui du feu ardent, s'élève vers les brises sonores. «

Dans cet ample développement relatif aux fins dernières, qui mêle au futur un présent de «re-présentation», la catastrophe cosmique n'apparaît pas en tant que telle, comme le note avec grande pertinence $\mathrm{M}$. Cerati ${ }^{34}$; mais on passe directement de l'arrivée de Dieu au bonheur des justes et aux tourments des coupables, impies et persécuteurs, sous une forme par ailleurs, cette fois, bien plus matérielle que spirituelle. Or un transfert s'opère en ce passage. Les vers 298-302 renvoient en effet

32 Voir Martin (2017) 109-113.

33 Cet emploi étonnant de sulci semble évoquer les sillons lumineux qui, dans le ciel, avec soufre et fumée, accompagnent la ruine de Troie (Verg. Aen. II.697-698).

34 Voir Cerati (2002) 65. 
explicitement à l'enfer judéo-chrétien : feu et ténèbres, soufre et douleur, colère et châtiment, géhenne et flammes, tout cela pour l'éternité, ne laissent pas le moindre doute à ce sujet. Mais avec les vers 303-304, les «éléments», le «ciel» et les "nuées» ${ }^{35}$ relèvent en revanche de la catastrophe cosmique, et si les vers 305 puis 310 mentionnent le «Tartare», en un langage néo-classique, les composantes de cet enfer parachèvent un tableau de ce type, avec la présence de la mer, de la terre et de l'air (v. 306-308), un élargissement à l'orbis (v. 309) et au mundus (v. 310 et 318), la convocation du soleil et des astres (v. 317-318), et des mots comme procellosas, fauillis, uibrabit ou incendia (des flammes animées qui font penser au sapiens ignis de l'ekpyrose stoïcienne ${ }^{36}$ ) - tandis qu'aux vers 312-313, les coupables, au lieu d'être clairement situés dans les lieux infernaux que leur assignaient les vers 298-299, «sont vus dans l'attitude que Commodien, presque dans les mêmes termes, décrivait dans le Carmen apologeticum au moment de la conflagration universelle, fuyant dans tous les sens, sans qu'il leur soit possible d'échapper à la flamme de la colère divine ${ }^{37}$. Ce glissement ne semble d'ailleurs pas échapper à notre poète, puisqu'à partir du vers 321, le lecteur est ramené par une topothésie épique (du type Est locus) à une isotopie proprement infernale, où, au souvenir virgilien des vers $325-326^{38}$, s'ajoute bientôt, aux vers 329-330, une référence évangélique aux «pleurs et grincements de dents» (Mt 8, 12 et 24, 51) - le "marais» du vers 322 pouvant, lui, renvoyer aussi bien à l'Enéide $(6,438)$ qu'à l'Apocalypse $(19,20 ; 20,10,14$ et $15 ; 21$, $8)^{39}$. En même temps, donc, que la catastrophe cosmique disparaît du poème comme étape eschatologique, la fin des temps semblant au fil des siècles moins urgente que la conversion du cœur, l'essentiel de son imagerie, et particulièrement le feu, donne ses couleurs à l'enfer, dont la doctrine et l'iconographie sont encore loin d'être alors fixées $^{40}$; Primasius d'Hadrumète écrit d'ailleurs, en commentant l'Apocalypse de Jean à peu près à l'époque de nos textes, au sujet de l'étang de feu et de soufre d'Ap 21.8 : Haec uel uitia criminum uel flagella poenarum non exponenda sunt ut intellegantur, sed cogitanda potius quomodo per Dei gratiam deuitentur ${ }^{41}$. Les relevés de M. Cerati montrent ainsi que, pour l'ensemble des poèmes tardifs qu'elle étudie, c'est dans l'Ad Flauium Felicem que le vocabulaire du feu est le plus présent dans la représentation de l'enfer, par cumul des motifs de la catastrophe cosmique et des peines infernales ; mais on n’y trouve pas, à rebours, mention des «vers » de Mt 9.44,

$35 \mathrm{Au}$ vers 304, la clausule nubibus ignem rappelle le jet de la foudre par Pallas contre les Argiens, en Verg. Aen. I.42.

36 Voir, par exemple, Min. Felix 35,3.

37 Cerati (2002) 66. Cf. Commod. Carm. apol., 1010, 1016, 1021.

38 Voir Verg. Aen. VI.296-297 : Turbidus hic caeno uastaque uoragine gurges / aestuat atque omnem Cocyto eructat harenam ; et, sur l'influence de Virgile dans l'évocation des enfers chrétiens, Courcelle (1955).

39 Sur les divers intertextes du passage ici examiné, voir Martin (2017) 70-75; voir aussi la peinture «mêlée» des enfers chez Arnobe (Adu. Nat. 2,14 et 30).

40 Voir Gauthier (1987) 5, citée dans Martin (2017) 68.

41 In Apoc. 5, 21 (p. 287 CCSL XCII, 1985). 
46 et 48. Notons aussi que c'est Dieu, de même qu'il déclenche la fin du monde, qui châtie les damnés aux enfers - et non le diable ou les démons, comme dans telles apocalypses apocryphes ${ }^{42}$. Cela rapproche notre poète de Commodien, avec bon nombre d'autres indices ${ }^{43}$, mais tout millénarisme a ici disparu. Enfin, L. Martin a scrupuleusement examiné les contrepoints que forment, dans l'Ad Flauium Felicem, un paradis ancré dans l'être et un enfer emporté par le mouvement, à travers de multiples échos internes entre ces deux évocations opposées : je ne puis cependant que renvoyer ici, faute de temps, à ses minutieuses et fructueuses «microlectures ${ }^{44}$.

On soulignera, pour conclure cet exposé, les intéressants échanges qui s’établissent entre catastrophe cosmique et peines infernales dans ces poèmes africains, en relevant l'originalité de Verecundus qui, dans le cadre d'une expression qui se veut plus personnelle que celle de l'anonyme, passe d'une vision infernale à la destruction universelle, et du feu de l'enfer à la brûlure du remords ${ }^{45}$. On observera également qu'au sein de la grande diversité possible des éléments du tableau (feu généralisé, ébranlement du monde, signes célestes... ${ }^{46}$ ), c'est le feu qui prédomine. Faut-il alors parler, avec J. Fontaine, d'une «obsession africaine de l'embrasement universel $»^{47}$, en la mettant en rapport avec l'âpre climat d'une terre ardente, ou simplement relever la présence prioritaire de ce motif dans la littérature apocalyptique ? Ainsi le feu est-il également presque la seule composante de la très brève évocation de la destruction de Sodome, dans le petit poème pseudo-cyprianéen consacré à cette dernière (v. 100 -106).

Par ailleurs, il ne nous semble pas que les textes ici examinés manifestent des rapports évidents avec l'exégèse patristique. C'est ainsi que les subtils arguments de M. De Gaetano pour rattacher l'Ad Flauium Felicem à un «cercle aquitain» pour des raisons théologiques ont fait l'objet, de la part de L. Martin, d'une lecture critique qui emporte l'adhésion ${ }^{48}$. Il ne suffit pas qu'un poète rencontre la théologie, sauf si c'est sur des questions très particulières et avec des rapprochements irréfragables, pour qu'il devienne un théologien ipso facto : en général, l'euidentia prime sur la ratiocination, en poésie. - En revanche, la question des rapports avec les poètes antérieurs qui ont traité de la catastrophe cosmique (Commodien, mais aussi Prudence et Avitus, ou Orientius et Prosper, chez qui l'examen de conscience adopte une finalité

42 Voir Martin (2017) 67-70.

43 Voir les notes de Waszink (1937) 100-105, qui proposent aussi plusieurs rapprochements intéressants avec un autre poème pseudo-cyprianéen, le De Sodoma, et bien sûr avec les apocalypses apocryphes et les Oracles sibyllins.

44 Voir Martin (2017) 75-82.

45 Voir Cerati (2002) 63 et 88.

46 Voir Cerati (2002) 68-88.

47 Fontaine (1981) 277.

48 Voir Martin (2017) 18-30. 
protreptique $^{49}$ ) se prêterait à des recherches prometteuses, qui élargiraient les pistes frayées par M. Cerati, et pourraient descendre vers le Moyen-Âge. La présente esquisse, très imparfaite encore, entend donc tout au plus attirer l'attention sur deux textes peu connus en France, et toute suggestion visant à l'améliorer sera reçue avec gratitude.

\section{Bibliographie}

Amat (1985) : Jacqueline Amat, Songes et visions. L'au-delà dans la littérature latine tardive, Paris.

Bianco (1984) : Verecundi luncensis Carmen de Paenitentia. Introduzione, testo critico, traduzione e commento a cura di Maria Grazia Bianco, Napoli.

Cerati (2002) : Marie Cerati, La représentation littéraire de la catastrophe cosmique à la fin des temps chez les poètes latins entre le III et le VI siècle (Mémoire de DEA, Université Paris-Sorbonne, inédit), Paris.

Christe (1999) : Yves Christe, Jugements derniers, Paris.

Ciccolini (2008) : Laetitia Ciccolini, L'héritage littéraire de Cyprien de Carthage à travers les écrits pseudépigraphiques (Thèse de Doctorat, Université Paris-Sorbonne, inédite), Paris.

Cohn (2000) : Norman Cohn, Cosmos, chaos et le monde qui vient, Paris.

Collins (1998) : John J. Collins (ed.), The Encyclopedia of Apocalypticism. I, The Origins of Apocalypticism in Judaism and Christianity, New York.

Courcelle (1955) : Pierre Courcelle, "Les Pères de l'Eglise devant les enfers virgiliens», in : Archives d'histoire doctrinale et littéraire du Moyen Age 22, 5-74.

Cutino (2006) : Michele Cutino, "Continuità e innovazione nella poesia latina cristiana del V secolo : il protrettico in versi», in : Auctores nostri 4, 341-380.

Dando (1965) : Marcel Dando, «Alcimus Avitus (c. 450 - c. 518) as the author of the De resurrectione mortuorum, De Pascha (De Cruce), De Sodoma and De Iona, formerly attributed to Tertullian and Cyprian», in : Classica et mediaevalia 26, 258-275.

De Gaetano (2013) : Myriam De Gaetano, Carmen ad Flavium Felicem de resurrectione mortuorum et de iudicio Domini. Introduzione con saggio di commento e traduzione (Corso di Dottorato di Ricerca), Macerata.

Escolà (2007) : Pseudo-Cebrià. Poemes. Introduccio, edicio critica, traduccio i notes de Josep Maria Escolà, Barcelona.

Fontaine (1981) : Jacques Fontaine, Naissance de la poésie dans l'Occident chrétien, Paris.

Gauthier (1987) : Nancy Gauthier, «Les images de l'au-delà durant l'Antiquité chrétienne», in : Revue d'Etudes augustiniennes 33, 3-22.

Gryson (1997) : Roger Gryson, «Les commentaires patristiques latins de l'Apocalypse», in : Revue théologique de Louvain 28-3, 305-337.

Haussleiter (1891) : Johannes Haussleiter, Die lateinische Apokalypse der alten afrikanischen Kirche, Erlangen - Leipzig.

Himmelfarb (1983) : Martha Himmelfarb, Tours of Hell. An Apocalyptic Form in Jewish and Christian Literature, Philadelphia.

Hofmann (2015) : Heinz Hofmann, «Flavius Cresconius Corippus : Textbestand und Überlieferung», in : Benjamin Goldlust (ed.), Corippe. Un poète latin entre deux mondes, Lyon, 87-122.

Kappler (1987) : Claude Kappler (ed.), Apocalypses et voyages dans l'au-delà, Paris.

49 Voir Fontaine (1981) 229-243 ; Cutino (2006). 
Magazzù (1983) : Cesare Magazzù, Tecnica esegetica nei Commentarii super cantica di Verecondo di lunca, Messina.

Magazzù (1990) : Cesare Magazzù, "L'ignis purgatorius in Verecondo di lunca ovvero

l'interpretazione di Deuteronomio 32, 22 da Origene agli esegeti medievali», in : Studi tardoantichi 9, 337-346.

Martin (2017) : Lucie Martin, Traduction et introduction du Carmen ad Flavium Felicem de resurrectione mortuorum et de iudicio Domini (Mémoire de Master 1, Université Paris-Sorbonne, inédit), Paris.

Prete (1966) : Serafino Prete, Escatologia e parenesi negli scrittori cristiani latini, Bologna.

Waszink (1937) : Carmen ad Flavium Felicem de resurrectione mortuorum et de iudicio Domini recensuit prolegomenis commentario indicibus instruxit Jan Hendrik Waszink, Bonn. 


\section{La doctrine dans les hymnes de la liturgie wisigothique}

\section{Entre tradition patristique et réécriture biblique}

La liturgie hispanique, qui conserva sa spécificité jusqu'à sa suppression par Rome en 1089, comprend un corpus d'hymnes propres particulièrement important - 210 dans l'édition de référence de J. Castro Sánchez ${ }^{1}$. Il s'agit de pièces de mètre et de mesure variés, pour la plupart rythmiques et recherchant la rime ${ }^{2}$. Ces hymnes relevant de la liturgie des heures sont divisés, depuis $\mathrm{Cl}$. Blume ${ }^{3}$, en cinq groupes d'importance inégale : 1 . Propre du temps (1-43); Commun du temps (44-80); Propre des Saints (81-179) ; Commun des Saints (180-186) ; Occasions diverses (187-210). On connaît le nom de plusieurs hymnographes dont Maxime et Jean, évêques de Saragosse, Isidore de Séville, Eugène de Tolède ou encore Quiricus de Barcelone aux $\mathrm{VI}^{\mathrm{e}}$ et $\mathrm{VII}^{\mathrm{e}}$ siècles. Cependant, presque tous ces poèmes nous sont parvenus de manière anonyme, dans des manuscrits très tardifs où ils sont mêlés à des hymnes empruntés à d'autres liturgies, d'où les sérieuses difficultés que pose parfois leur datation.

Le corpus est évidemment trop vaste et trop hétérogène pour être considéré dans son ensemble ici. Notre attention ira, en accord avec nos thèmes de recherche actuels et la grande fortune que connut ce genre à l'époque wisigothique, aux quelque cinquante hymnes qui furent, de manière certaine ou probable, composés entre la conversion des Wisigoths (589) et l'invasion arabe $(711)^{4}$. Au cours de cette période, la création liturgique fut en effet particulièrement florissante en Hispanie, même si la

1 Castro Sánchez (2010), qui remplace désormais Blume (1897). Tous les textes seront cités d'après cette édition, et accompagnés d'une traduction personnelle. De fait, ces hymnes n'ont été traduits qu'en castellan par Arana Tarazona (2016) d'après l'édition de Blume, et en espagnol par Castro Sánchez / García Ruiz (2014) d'après l'édition de Castro Sánchez (avec des annotations sommaires). La traduction française donnée par Guéranger (1841) de l'hymne Gaudete flores martirum est très libre. - Parmi les contributions récentes sur l'hymnodie hispanique en général prenant en considération les hymnes de la période wisigothique, on renverra, outre les références précitées, à Szövérffy (1998) ; Valcárcel Martínez (2005) ; Arocena-Solano (2012) ; sur les hymnes du temporal antérieurs à l'invasion musulmane, De Almeida Matos (1977).

2 Cf. Almeida Matos (1984) qui se fonde, entre autres, sur l'hymne Auctor luminis étudié infra. - Les dates de composition avancées par l'auteur sur la base de ses analyses métriques sont désormais dépassées.

3 Blume (1897). Cette typologie est commentée par Castro Sánchez / García Ruiz (2014) 17-19.

4 À l'exemple de Rovalo (1966) 244, nous les qualifions de «wisigothiques» par opposition aux hymnes antérieures de l'époque «hispano-romaine» et, celles, postérieures, de l'époque mozarabe. L'utilisation du terme «mozarabe» au sens large est très discutée, cf. Castro Sánchez / García Ruiz (2014) 16 avec bibl. n. 6. 


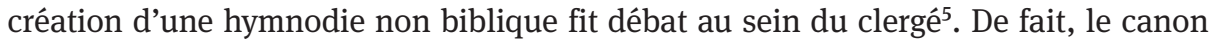
$13 \mathrm{du} \mathrm{IV} \mathrm{V}^{\mathrm{e}}$ Concile de Tolède en 633, inspiré et présidé par Isidore de Séville, laisse entrevoir l'attitude d'un clergé hostile aux hymnes composés en dehors des Écritures, alors que la composition d'hymnes postcanoniques était en plein essor :

[...] il est de notoriété publique que quelques hymnes ont été composés par le zèle des hommes pour la louange de Dieu, mais aussi pour les triomphes des Apôtres et des martyrs, tels ceux qu'ont produits les très bienheureux docteurs Hilaire et Ambroise - et pourtant certains les réprouvent nommément pour la raison qu'ils ne procèdent pas des saintes Écritures canoniques ou de la tradition des Apôtres - ; qu'ils rejettent donc aussi ce fameux hymne, composé par des hommes, que nous chantons chaque jour dans les offices publics et privés, à la fin de tous les Psaumes [...] et toute la suite que composèrent des docteurs de l'Église $[. . .]^{6}$

Sans entrer dans le détail des arguments scripturaires et patristiques invoqués par Isidore pour justifier l'hymnodie «humaine ${ }^{7}$, on notera, à la fin du canon, l'allusion aux compositions actuelles qui devaient, à l'exemple des hymnes d'Hilaire et d'Ambroise affirmant et défendant la foi de Nicée, être «les instruments efficaces d'une pédagogie de la foi ${ }^{8}$ ».

La manière dont Isidore inscrit de la sorte l'hymnodie de son époque dans la continuité des laudes des grands évêques $\mathrm{du} \mathrm{IV}^{\mathrm{e}}$ siècle pose la question de la place de la doctrine dans ces poèmes d'un autre temps. De fait, le contexte politico-religieux n'était plus le même qu'au $\mathrm{IV}^{\mathrm{e}}$ siècle, où l'essentiel de la foi était sans cesse menacé par des hérésies diverses : même si un sentiment d'insécurité a pu persister un temps, surtout dans le clergé, tout le peuple wisigoth s'était solennellement converti au catholicisme lors du III $^{\mathrm{e}}$ Concile de Tolède en 589 . Quelle forme prend, dès lors, la doctrine dans ces hymnes, a fortiori dans les hymnes du temporal et ceux pour des occasions variées?

S’il n'était plus nécessaire de barrer la route à l'hérésie arienne, on verra qu'une partie de l'hymnodie ecclésiale continuait, comme chez les grands évêques hymnographes, d'être le support d'une foi authentique, et a abouti à des hymnes d'une élaboration doctrinale remarquable, conformément à la liturgie de l'époque. On verra cependant qu'en fait de doctrine, le contenu de plusieurs hymnes se limite singulièrement à une mise en vers plus ou moins littérale de la Bible, dont on examinera les modalités caractéristiques.

5 Voir, sur ce débat, Fontaine (1999).

6 Trad. Fontaine (1999) 387.

7 Ils sont au centre de Fontaine (1999), qui emploie l'expression citée à la p. 391.

8 Fontaine (1999) 394. 


\section{L'élaboration doctrinale dans les hymnes de facture ambrosienne}

Plusieurs hymnes de l'ancienne liturgie hispanique répondent à l'exigence proprement doctrinale qui présida, selon Isidore, à la création des hymnes postcanoniques. Comme chez Ambroise ${ }^{9}$, ce contenu doctrinal est particulièrement élaboré dans les hymnes du temporal, dont les festivités, de l'Incarnation à la Passion, de la Résurrection à la Pentecôte, étaient propices à la célébration du mystère du Christ et de sa mission.

Les exemples les plus intéressants sont significativement constitués par des hymnes de facture ambrosienne, i.e. des hymnes composés de quatrains de dimètres iambiques, même s'il s'agit, comme on l'a rappelé, d'hymnes rythmiques et non quantitatifs, qui recherchent suivant une évolution médiévale la rime ; les strophes sont souvent au nombre du huit, mais pas forcément ${ }^{10}$. En raison des limites qui nous sont imparties, notre étude se limitera à un hymne dédié à la célébration de l'Adventus (« venue, avènement»), en référence à la période avant Noël pendant laquelle les fidèles se préparent à célébrer l'arrivée du Christ : d'après ses premiers mots, Gaudete, flores martirum ${ }^{11}$. L'examen de son contenu doctrinal sera l'occasion d'une confrontation avec la manière d'Ambroise, en particulier du point de vue du choix des sources et, plus largement, des traditions suivies en son temps par le Milanais. On verra ainsi que, si ces hymnes hispaniques trouvent, comme les hymnes ambrosiens, leur point de départ dans la Bible, l'invention lyrique suit une voie différente, en phase avec les orientations liturgiques de l'époque.

Comme l'attestent les titres transmis par la tradition manuscrite ${ }^{12}$, l'hymne Gaudete, flores martirum vise à célébrer le début de l'Avent, le 17 novembre, dont la date coïncide, dans le calendrier liturgique hispanique, avec l'anniversaire des saints Aciscle et Victoire, martyrisés à Cordoue en $303^{13}$. Vraisemblablement chanté lors des matines $^{14}$, il prend la forme d'un chant de réjouissance ${ }^{15}$ :

9 Voir, sur les hymnes d'Ambroise, Fontaine (1992).

10 Il s'agit d'un assouplissement fréquent qu'on trouve, dès la fin de l'Antiquité, dans des liturgies variées. En dépit de ses variations, le nombre de strophes reste toutefois limité aux $\mathrm{vI}^{\mathrm{e}}$-vII ${ }^{\mathrm{e}} \mathrm{s}$., avec une prédominance des poèmes de six ou huit strophes, cf. Valcárcel Martínez (2005) 146.

11 Il s'agit de l'hymn. 1 dans l'édition de J. Castro Sánchez.

12 Castro Sánchez (2010) retient l'intitulé In adventu Domini. In festo sancti Aciscli et sociorum. 13 Voir, sur cette conjonction du temporal et du sanctoral dès l'époque wisigothique, Rovalo (1966); en général sur la célébration de l'Avent dans l'ancienne liturgie hispanique, Ferro Calvo (1972). Suivant l'une des tendances étudiées par Rovalo (1966), les saints célébrés le 17 novembre sont évoqués de manière très générale (aucun d'eux n'est nommément cité), à égalité avec le thème de l'Avent. Cette conjonction étroite du temporal et du sanctoral se retrouve dans l'Officium Inquoante Adventu Domini du Misticus Toledano 35.4 pour lequel fut sans doute composé cet hymne au viI ${ }^{\mathrm{e}}$ s., cf. Rovalo (1966), 260-261 et 291. - Voir en général, sur cette relation étroite entre temporal / sanctoral (avec un enrichissement mutuel) qu'on observe à partir du début du viI ${ }^{\mathrm{e}}$ s., Janeras (1954). 
1

5

10

15

20

25
Gaudete flores martirum, salbete, plebes gentium, visum per astra mittite, sperate signum glorie.

Voces prophetarum sonant, venire Ihesum nuntiant, redemtionis previa, qua nos redemit gratia.

Hinc mane nostrum promicat et corda leta exestuant, cum vox fidelis personat prenuntiatrix glorie.

Tante salutis gaudium ! Quod est redemtum seculum, exceptionis inclitum abhinc ciamus canticum !

Adventus hic primus fuit, punire quo non seculum venit, sed ulcus tergere, salbando quod perierat.

At nunc secundus premonet adesse Xristum ianuis, sanctis coronas reddere celique regna pandere.

Eterna lux promittitur, sidusque salbans promitur; iam nos iubar prefulgidum ad ius uocet celestium.
Réjouissez-vous, fleurs des martyrs, salut, peuples des nations, portez votre regard vers les astres, espérez le signe de la gloire.

Les voix des prophètes résonnent, annoncent la venue de Jésus, prélude de la rédemption, de la grâce par laquelle il nous a rachetés.

Aussi, notre matin étincelle, et nos cœurs bouillonnent de joie, quand la voix de la Foi résonne, pré-annonciatrice de la gloire.

Joie d'un si grand salut !

Puisque le siècle a été racheté, élevons donc, pour l'accueillir, un cantique solennel!

Ce fut sa première venue, quand il vint non pour punir le siècle, mais pour effacer sa blessure, en sauvant ce qui était perdu.

Mais à présent la seconde prévient que le Christ se tient à la porte, qu'il rend aux Saints leur couronne et ouvre le royaume des cieux.

La lumière éternelle nous est promise, et l'astre salvateur apparaît ; déjà son éclat resplendissant nous appelle à la justice céleste.

14 Cf. le titre notamment donné par le manuscrit M (Madrid, Biblioteca Nacional 10001, $\mathrm{IX}^{\mathrm{e}}-\mathrm{XI}^{\mathrm{e}} \mathrm{s}$.), que semble corroborer mane au v. 9 : Ymnus de adventu domini et sanctorum festivitate ter mixtus qui in matutinum dicendus est quando adventus domini incipitur. L'office in matutinum correspondait manifestement à nos laudes même si, dans certains cas, il semble avoir inclus nos matines, cf. Fernández Alonso (1955), 338-339.

15 En accord avec les trois objets de la célébration présentés comme tels dans le titre du ms. M (l'Avent, les martyrs et le matin, cf. l'expression ter mixtus dans le titre cit. n. 14), sont ainsi évoqués, dans l'ordre du texte, la symbolique psalmique attachée à ce moment de la journée (mane... corda leta, v. 9-10, cf. Ps 29, 6), la joie liée à la naissance du Christ (gaudium, v. 13) et le bonheur céleste promis aux martyrs (beato cetui, v. 36). Deux des injonctions qui ponctuent le texte invitent par ailleurs expressément à la réjouissance et, partant, au chant de louange : gaudete (v. 1), gaudium (v. 13) et abhinc ciamus canticum (v. 16), où l'adverbe abhinc explicite la relation de cause à effet entre le gaudium du v. 13 et le canticum du v. 16. 
Te, Xriste, solum querimus videre sicut es Deus, ut leta nos hec visio evellat omni tartaro,

Quo dum redemtor veneris cum candidato martyrum globo, adunes celibi nos tunc beato cetui.

Deo patri sit gloria eiusque soli filio cum spiritu paraclito et nunc et in perpetuum.
Nous voulons seulement, ô Christ, te voir comme tu es, Dieu, afin que cette heureuse vision nous arrache entièrement au tartare,

pour que le jour où tu viendras, rédempteur, avec la foule blanche des martyrs, tu nous adjoignes à cette sainte assemblée bienheureuse.

Gloire à Dieu le Père et à son Fils unique, avec l'Esprit Paraclet, maintenant et pour toujours.

La venue du Christ est présentée de manière très abstraite, ainsi qu'en témoigne l'absence de toute référence narrative ou descriptive à l'incarnation ou à la nativité par exemple. Elle est évoquée à travers un dense réseau d'images lumineuses qui se prêtent, d'une part, à une lecture référentielle, à travers l'allusion à la lumière du matin au v. 9 (mane... promicat, où nostrum invite toutefois d'emblée à dépasser ce premier niveau et à interpréter mane comme une image du Christ ${ }^{16}$ ) ; d'autre part, surtout à une interprétation symbolique, suivant l'orientation suggérée au v. 4 par l'expression signum glorie annonçant les prophéties vétérotestamentaires évoquées dans la $\S 2$. De fait, cette lumière est celle de toute théophanie ; elle est aussi, dans la continuité du khabod hébraïque, une manifestation de la gloire divine et, en référence à Jn 8, 12, une figure du Christ-lumière ainsi qu'une préfiguration de la lumière éternelle.

Cette représentation imagée concourt à la dimension contemplative de l'hymne. L'assemblée en prière, comprise dans la première personne du pluriel, est invitée dès l'injonction du v. 3, en écho à Is 40.26 et 51.6, à tourner ses yeux vers le ciel ; la prière de demande des v. 29 sqq., qui émane directement des orants, lui fait écho à la fin de l'hymne (Te, Xriste, solum querimus / videre sicut es Deus...). L'expression Te... videre sicut es Deus, qui permet d'assimiler le Christ au Père, est notable par sa charge doctrinale ${ }^{17}$. Par-delà l'égalité des deux personnes, cette contemplation est cependant surtout l'occasion d'une méditation sur le sens de l'adventus Domini, dans la perspective non seulement de la venue de Jésus, mais aussi de la parousie du Christ.

Comme cela ressort nettement de la division, la célébration de la première venue du Fils de Dieu est en effet étroitement liée à l'attente de sa seconde venue à la fin

16 Castro Sánchez / García Ruiz (2014), 102d.

17 Elle est cependant moindre que dans l'hymn. 3 Xristi caterba clamitet composé à la même époque pour le premier dimanche de l'Avent où la même idée est exprimée en des termes d'une densité théologique remarquable (mais caractéristique de la liturgie hispanique, cf. infra), cf. les v. 13-16 A matre natus tempore, / sed sempiternus a patre / duabus in substantiis / persona sola est numinis. 
des temps. Dès la strophe introductive, le signum glorie du (v. 4) se réfère de manière ambivalente à l'un et l'autre de ces adventus, avant que, dans un parfait équilibre des masses, un groupe de quatre strophes soit consacré à l'adventus... primus (v. 17, cf. $\S 2-5$ ), puis au secundus (v. 21, cf. § 6-9).

Le premier mouvement est centré sur la rédemption préparée par la venue de Jésus (redemtionis previa, v. 7). Cette dernière est signifiée en des termes d'origine néotestamentaire, comme gratia et redemptio ${ }^{18}$ ou le participe redemtum (seculum) qui évoque plusieurs occurrences bibliques du verbe simple ou composé $\mathrm{e}^{19}$. On notera également, dans les v. 18-20, l'écho à Jn 12.47 et la citation quasi littérale de Mt 18.11 :

v. $18-20$ :

punire quo non seculum venit, sed ulcus tergere, salbando quod perierat.
Jn 12.47 non enim veni ut iudicem mundum sed ut salvificem mundum

Mt 18.11 venit enim Filius hominis salvare quod perierat (cf. Lc 19, 10)

Dans le second mouvement dominent, de manière significative, les visions empruntées à l'Apocalypse. Celles de la $\S 6$ donnent à voir l'accueil réservé aux saints par le Christ (avec, en référence à 2 Tm 4.8, l'octroi de la couronne) :

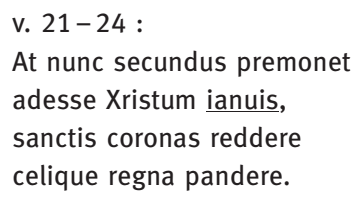

Ap 3.20 ecce sto ad ostium et pulso si quis audierit vocem meam et aperuerit ianuam... Ap 19.11 et vidi caelum apertum...

La $\S 7$ s'organise autour de deux images lumineuses. Celle de la lumière éternelle est commune à l'évangile de Jean $(8,12 ; 12,46)$ et à l'Apocalypse $(21.23-24 ; 22.5)$; quant à celle de l'astre salvateur, elle évoque l'étoile du matin d'Apocalypse 2.28 et 22.16. Elles préparent la prière de demande des $\S 8-9$ où les orants répondent à l'appel du iubar prefulgidum du v. 27 en priant le Christ de jouir à leur tour de cette vision bienheureuse lors de son avènement, au centre de la $\S 9$, fondée sur l'amalgame de plusieurs images empruntées à l’Apocalypse :

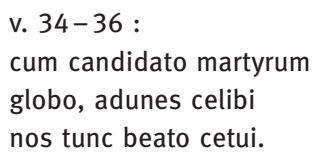

Ap 7.9 vidi turbam magnam... amicti stolas albas
et palmae in minibus eorum Ap 20.4 et vidi... et animas decollatorum propter testimonium lesu et propter verbum Dei Ap 21.3 ... ecce tabernaculum Dei cum hominibus et habitabit cum eis et ipsi populus eius erunt et ipse

Deus cum eis erit eorum Deus

18 Cf. p. ex. Rm 3.23-24 (omnes enim peccaverunt ... justificati gratis per gratiam ipsius per redemptionem quae est in Christo Iesu).

19 Cf. 1 Co 6.20 ; 7.23 ; 1 P 1.18. L'expression est redemtum seculum a joui d'une grande fortune dans l'hymnodie, cf. infra n. 33. 
Cette évocation de la venue du Christ rédempteur entouré de la troupe blanche des martyrs permet, en écho à l'invocation liminaire des flores martirum, de rattacher la célébration du début de l'Avent à celle des saints fêtés le même jour dans le calendrier liturgique hispanique. Il est fort probable que la volonté de chanter conjointement la venue du Christ et les martyrs mis à l'honneur le premier jour de l'Avent ait déterminé le choix de la structure, avec la mise en parallèle du primus et du secundus adventus. Ce dernier trouve toutefois son origine dans une double tradition digne d'intérêt pour notre propos, car elle est caractéristique des hymnes doctrinaux de l'ancienne liturgie hispanique.

Inusité par ailleurs dans le genre poétique ${ }^{20}$, le concept de primus et secundus adventus connut en effet une grande fortune chez les Pères latins ${ }^{21}$, à partir desquels il fut vraisemblablement intégré, dès l'époque wisigothique, aux textes de l'office. Bien que les livres liturgiques hispaniques soient tous relativement tardifs ${ }^{22}$, l'Oracional visigotico édité par J. Vives atteste en effet l'utilisation de cette expression d'origine patristique dans les prières employées lors de l'office de Adventu Domini ${ }^{23}$; il n'est que de songer à cette benedictio prononcée lors des vêpres du $5^{\mathrm{e}}$ samedi où l'évocation de la venue du Christ apparaît, comme dans l'hymne Gaudete, flores martirum, une source de joie :

Christus Dei filius, quem venturum in proximo sustinetis, proximitate sui adventus emundet corda vestra a cunctis mundanae vitae inlecebris. Ipsum quoque quem iudicem venturum metuitis, liberatorem indulgentissimum sentiatis. Quo omnes, qui hic primi adventus sui gaudia devote inquolitis, secundi adventus sui premia capiatis. ${ }^{24}$

Ce type d'emprunts est habituel dans les textes de l'ancienne liturgie hispanique, qui porte l'empreinte marquée des Pères ${ }^{25}$; les hymnes ne font pas exception.

Comme en témoigne la densité des références relevées par J. Castro Sánchez dans son apparat critique, les expressions d'origine patristique sont nombreuses dans

20 En dehors justement de l'hymne wisigothique Xristi caterba clamitet évoqué dans la n. 17 (cf. le v. 29 où l'adjectif secundus se réfère, en écho au v. 28, à l'adventus... secundus).

21 Pour nous limiter au témoignage très proche, d'un point de vue spatio-temporel, d'Isidore, cf. fid. I.61.2 sqq.

22 Cf. le recensement de Díaz y Díaz (1965b) 109-164 («Los textos de la antigua liturgia hispanica Fuentes para su estudio »), d'où ressort la rareté des sources liturgiques de l'époque wisigothique. 23 Voir, sur cette utilisation, Vives (1946) XV ; sur sa datation, que Vives situe à la fin du vil ${ }^{\mathrm{e}} \mathrm{s}$. ou au début du viII ${ }^{\mathrm{e}}$ s., en tout cas avant 711, Vives (1946) XXXII-XXXIv.

24 Vives (1946), Oratio 35, cf. 0.3 .45 ; le motif de la joie revient également de manière récurrente, cf. par exemple les Orationes 30, 36, 44, 53, etc. L'expression se retrouve dans les livres liturgiques postérieurs édités par Férotin (1912), cf. entre autres ce passage de la messe du $3^{\text {e }}$ dimanche de l'Avent : Quosque prospicis adventum olim mystice peracte Incarnationis tue nunc promtissima devotione suscipere, hos facito in secundum iudicii tui adventum ad te exsultantibus animis pervenire, atque in amenitate paradisi iucundaluros induce (c. 15-16).

25 Cf. sur cette influence plus marquée dans la liturgie hispanique que dans les autres liturgies antiques, Díaz y Díaz (1965b), 59-62. 
l'hymne Gaudete, flores martirum. Il peut s'agir d'expressions relativement communes chez les Pères, comme l'expression voces prophetarum (v. 5) dont on trouve plusieurs attestations en référence aux prophéties annonçant la venue de Jésus ${ }^{26}$; d'autres sont moins usuelles, à l'exemple du tour plebes gentium qui trouve probablement sa source dans l'interprétation allégorique du Cantique des Cantiques de Grégoire d'Elvire ${ }^{27}$.

L'influence de la tradition liturgique n'est pas moins nette, même si elle est difficile à évaluer en raison de la rareté des témoins wisigothiques ; on peut en juger grâce aux exemples suivants - tous personnels - empruntés à l'Oracional visigotico édité par J. Vives ${ }^{28}$ ou, en raison de leur résonance liturgique caractéristique, peutêtre déjà wisigothique, à des manuscrits postérieurs édités par M. Férotin ${ }^{29}$ :

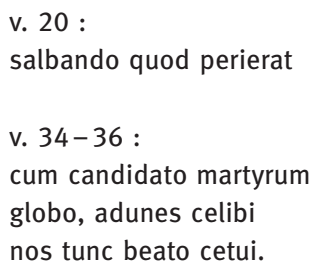

Oratio 9 Ex Syon Deus veniens, ab impietatibus vestris eripiat vos. [...] Tales etiam vos redimendo statuat, quales iudicando non puniat.

Oratio 63 Christe Dei filius, cum quo sanctorum milia ad iudicium venient, sanctorum vos cetibus coronandos adsociet, cf. Oratio 127 ... sanctorum mereamur et congregationi et cetibus interesse.

Ferotin c. 490 Et que iam suo sunt candidate martyrio Ferotin c. 576 iste himnus, Domine, Martirum tuorum candidatus laudat exercitus

Ferotin c. 875 et secunde mortis calcata severitate sanctorum cetui mereamur obtinere societatem.

Les emplois liturgiques de caelebs (celibi, v. 35) dans le sens de "céleste, saint»" tendent dans le même sens. Cette double filiation, qui concourt, sur fond de réminiscences bibliques, à l'élaboration doctrinale du poème, charge sans jamais entraver l'harmonie de son mouvement, l'expression lyrique d'une inspiration pleinement religieuse, là où les hymnes d'Ambroise portent l'empreinte de la tradition poétique profane, en particulier virgilienne ${ }^{31}$. Rares sont en effet, dans l'hymnodie hispanique, les réminiscences poétiques et, le cas échéant, elles se limitent aux

26 Cf. p. ex. Arnobe In Psalm. 31 Mundus [...] clamavit semper per voces prophetarum, ut veniret qui salvaret eum ; 118.81-176 Sciunt enim et intellegunt voces prophetarum, in quibus verba tua pollicentur nostri redemptoris adventum ; Grégoire le Grand, Moral. 30.10.36 ... hoc idem tempus incarnationis domini ante prophetarum voces cognitum non fuit...

27 Cf. en particulier ce passage du livre II, où l'on trouve une attestation remarquable de cette expression très rare par ailleurs : plebes gentium ante adventum Christi sub iugo et potestate diaboli subditas esse dicebat (CPL 547, 1. 190).

28 Cf. en outre le parallèle qu'on peut faire entre les vers de l'hymne 3 cités dans la n. 16 et le début de l'Oratio 10 Christe Dei filius, qui a patre sine tempore natus, per virginem in tempore nasciturus... 29 Férotin (1912).

30 Cf. Castro Sánchez (2010) 735 et Castro Sánchez / García Ruiz (2014) 102 (h).

31 Cf. Fontaine (1992) 26 ; en général, sur les modèles poétiques classiques des hymnes d'Ambroise, Fontaine (1974/75). 
suggestions de la tradition hymnique chrétienne. Outre la reprise de la structure métrique caractéristique des hymnes ambrosiens, l'hymne Gaudete, flores martirum ne compte ainsi que deux emprunts manifestes à l'œuvre poétique de Prudence qui jouit, à la fois en raison de sa spiritualité infuse et de son origine espagnole, d'une grande fortune dans la liturgie hispanique ${ }^{32}$ :
v. 1 Gaudete, flores martirum
v. 12 prenuntiatrix glorie
Prudence, Cath. 12.125 Salvete flores martyrum
Prudence, Perist. 2.30 praenuntiatrix gloriae

L'unique autre parallèle poétique concerne un autre hymne hispanique ${ }^{33}$. Mais outre la délicate question de la filiation qui relie ces textes, il s'agit alors d'un cas particulier d'imitation «interne», peu ou prou semblable à celui qui rattache ces hymnes aux autres textes liturgiques, dans un réseau d'une densité remarquable.

\section{Les réécritures de la Bible : modalités et enjeux}

Nombreux sont, à côté de ces hymnes doctrinaux, les pièces qui empruntent tout ou partie de leur matière aux Écritures. Il s'agit, pour les raisons qu'on a vues précédemment, principalement d'hymnes du temporal ; mais la célébration isolée de certaines heures, en particulier le chant du coq, et celle de plusieurs saints bibliques (comme Jean-Baptiste ou Étienne) étaient propices à la reprise de péricopes bibliques, souvent très fidèles à la lettre du texte ${ }^{34}$. Pour mesurer les enjeux de la réécriture, notre attention ira à deux pièces qui illustrent chacune un traitement différent du texte biblique, le premier narratif, le second exégétique ${ }^{35}$.

\section{a) Les paraphrases narratives}

Selon un usage largement répandu dans l'hymnodie hispanique, en particulier dans les pièces du sanctoral, plusieurs de ces hymnes d'inspiration biblique prennent une forme narrative suivant la division tripartite invocatio - narratio - peroratio (avec

32 Voir à ce sujet Urlacher-Becht (2012).

33 Cf. hymn. 1.14 quod est redemtum seculum et 83.11 a quo redemtum seculum.

34 La part de la paraphrase biblique est très importante dans les hymnes suivants, dont la datation est particulièrement problématique dès lors qu'ils ne sont conservés que dans les hymnaires d'éditions imprimées : hymn. 27 (Carême) ; 25.30 et 41 (Pentecôte - avec la focalisation sur le chant du coq dans l'hymn. 30) ; 81 (Purification de la Vierge Marie) ; 132 (Saints Innocents) ; 134-135 (Jean Baptiste) ; 171 (Saint Étienne). Sur ce procédé qui serait caractéristique de l'ancienne hymnodie hispanique, cf. Messenger (1946) 160-161. L'hymn. 30, qui fait partie de la même série que l'hymn. 25 évoqué infra, fait partie des pièces caractéristiques de l'époque wisigothique étudiées par Valcárcel Martínez (2005).

35 Voir, sur cette distinction entre paraphrases narratives et exégétiques, Charlet (1985) 631 sqq. 
doxologie) ${ }^{36}$. Leurs auteurs anonymes s'inscrivent dans le sillage de poètes illustres dont les amples pièces avaient été intégrées, parfois de manière fragmentaire, à la liturgie hispanique : on pense notamment aux hymnes du Cathemerinon, tous construits autour d'une paraphrase biblique et dont la diversité métrique a probablement influencé celle des pièces qui nous occupent ; d'autre part, à l'hymne alphabétique de Sédulius relatant la vie du Christ de sa naissance à l'Ascension. ${ }^{37}$ Comme ce dernier, la plupart de ces poèmes consistent de prime abord en une simple réécriture lyrique d'une ou de plusieurs péricopes bibliques, où la multiplication des citations quasi littérales semble fortement limiter la part de la création poétique. L'étude détaillée de l'hymne Auctor luminis, filius virginis ${ }^{38}$ montrera cependant qu'il n'en est rien.

Cet hymne, composé pour l'office des vêpres du deuxième dimanche du Carême, est constitué de 8 strophes saphiques ${ }^{39}$. Par son fond et sa forme, il s'apparente à une simple mise en vers du texte évangélique du jour : Jean 9 qui relate la guérison miraculeuse d'un aveugle né ${ }^{40}$.

1 Auctor luminis, filius virginis paterque matris filiusque patris, qui ceco sedenti stipite ${ }^{41}$ petenti lumen dedisti.

5 Sedensque cecus tenebris oppressus, quem voluerat sic nasceret cecus, in quem virtus sua omnibus credentis comprobaretur.

Gaudetque cecus lumine recepto, 10 quem visitabit medicus exelsus a patre dilectus, ut ablueretur mundi delictum.
Auteur de la lumière, fils d'une vierge, Père de ta mère et Fils du Père, qui à l'aveugle assis, mendiant de l'argent, as donné la lumière.

Assis, l'aveugle était oppressé par les ténèbres, Dieu avait voulu qu'il naquît aveugle, afin qu'en lui tous les croyants reconnaissent son pouvoir.

Et l'aveugle se réjouit d'avoir reçu la lumière, lui qu'a visité le médecin suprême, choisi par le Père pour enlever le péché du monde.

36 Cf. Díaz y Díaz (1980) 68-70.

37 Voir, sur la «création poétique» dans le Cathemerinon, Charlet (1982) et, sur la réception de Prudence dans la liturgie hispanique, Urlacher-Becht (2012) 77-79. Tout comme de nombreux hymnes anonymes, plusieurs pièces de poètes connus furent intégrées à la liturgie hispanique, cf. dernièrement dans Castro Sánchez / García Ruiz (2014) 21, la liste invariablement reprise d'une édition à l'autre (avec toutefois des erreurs, les hymnes d'Ennode de Pavie n'ayant jamais été chantés en Hispanie, cf. Urlacher-Becht 2014269 n. 14).

38 Hymn. 25 dans l'édition de Castro Sánchez.

39 Voir, sur cette structure métrique particulièrement goûtée aux $\mathrm{VII}^{\mathrm{e}}-\mathrm{VIII}^{\mathrm{e}}$ s., Valcárcel Martínez (2005), 150, avec une analyse sommaire de l'hymn. 25 dans les p. 150 sqq. Ce dernier est daté du viI ${ }^{\mathrm{e}}$ s. par Castro Sánchez / García Ruiz (2014) 172.

40 Le texte de tous les offices du $2^{\mathrm{e}}$ dimanche du Carême est conservé en intégralité dans le Liber misticus de Cuaresma y Pascua (Cod. Toledo, Bibl. Capit. 35.5) édité par Janini (1980) 11-19: la lecture de Jn 9.1-38 Ad missam est spécifiée à la p. 17 ; sur ce type de livre liturgique, cf. Pinell (1954). 41 stipite = stipem, cf. Castro Sánchez (2010) 739. 
Plebs Ebreorum zelumque dixerunt: "parentes eius veniant»; perquisierunt: «qui cecus est natus, cuius virtute est inluminatus?».

Parentes autem Ebreorum fatent: «ex utero matris cecus fuit natus, etatem habet, ipsum interrogate, dicat veritatem ».

Confidet cecus qui fuerat factus: «ad me accessit prophetaque magnus, cuius virtute oculo et corde sum inluminatus.

25 Fecitque lutum de sancto sputo, tegmen oculorum linuit, a luto iussit labari Siloe piscina, me clarificavit».

Gloria patri, trino sempiterno, 30 gloria Xristo spirituque sancto, predicet trinum pie voce nomen omne per evum.
La foule des Hébreux dit avec jalousie : «Que ses parents viennent »; ils les interrogèrent :

«Lui qui est né aveugle, par le pouvoir de qui a-t-il reçu la lumière ?»

Mais ses parents, des Hébreux, déclarèrent : «Il est né aveugle du ventre de sa mère ; il est assez grand, interrogez-le lui-même, qu'il dise la vérité.»

Celui qui était né aveugle confessa : «Un grand prophète s'est approché de moi : par son pouvoir, mes yeux et mon cœur furent illuminés.»

De sa sainte salive, il fit de la boue, l'appliqua au voile de mes yeux, et m'ordonna de laver la boue à la piscine de siloé ; ainsi il m'éclaira.»

Gloire au Père, à la Trinité éternelle, gloire au Christ et à l'Esprit Saint ; que d'une voix pieuse le nom ${ }^{42}$ trine soit célébré à tout jamais.

La narration occupe la plus grande partie du poème (§ 2 à 7 vs une seule strophe pour l'invocation liminaire et la doxologie finale). Comme en témoignent les nombreux emprunts textuels relevés dans le tableau suivant, elle s’inscrit dans la continuité directe du récit de Jn 9.

v. 3 qui ceco sedenti stipite petenti

6 quem voluerat sic nasceret cecus, in quem virtus sua omnibus credentis comprobaretur.

13 Plebs Ebreorum zelumque dixerunt: "parentes eius veniant»; perquisierunt: «qui cecus est natus, cuius virtute est inluminatus?».

17 Parentes autem Ebreorum fatent: "ex utero matris cecus fuit natus,
Jn 9.8 mendicus erat... nonne hic est qui sedebat et mendicabat

Jn 9.1 hominem caecum a nativitate (cf. In 9, 19-20)

Jn 9.3 ... ut manifestetur opera Dei in illo

In 9.18-19 non crediderunt ergo ludaei de illo quia caecus fuisset et vidisset donec vocaverunt parentes eius qui viderat et interrogaverunt eos dicentes hic est filius vester quem vos dicitis quia caecus natus est quomodo ergo nunc videt

In 9.20 responderunt eis parentes eius et dixerunt... quia caecus natus est

42 Par nomen, il faut entendre "personne», cf. Castro Sánchez / García Ruiz (2014) 183 (e). 
etatem habet, ipsum interrogate, dicat veritatem».

22

«ad me accessit prophetaque magnus

25 Fecitque lutum de sancto sputo, tegmen oculorum linuit, a luto iussit labari Siloe piscina, me clarificavit».
In 9.21 ipsum interrogate aetatem habet ipse de se loquatur (cf. Jn 9.23)

Jn 9.17 quia propheta est

In 9.6 haec cum dixisset expuit in terram et fecit lutum ex sputo et linuit lutum super oculos eius et dixit ei vade lava in natatoria Siloae quod interpretatur Missus abiit ergo et lavit et venit videns (cf. $9.11 ; 15$ )

De fait, les variantes observées, à l'instar de Siloe piscina (v. 27) vs Jn 9.6 in natatoria Siloae, sont manifestement dues à des considérations métriques. L'élaboration narrative n'est pas nulle pour autant. On observe une réduction substantielle de l'hypotexte, qui passe notamment par la suppression des redites dues aux interrogatoires répétés et la réduction à l'essentiel du cheminement conduisant l'ex-aveugle vers la foi ; elle tient aussi à la réorganisation de certains éléments (comme le fait de présenter d'emblée l'aveugle comme un mendiant : v. 3, cf. Jn 9.8), qui permet au récit de gagner en précision et en fluidité. Mais la narration n'est pas seulement condensée : elle fait l'objet d'une dramatisation à travers l'utilisation répétée du discours direct qui rend la scène à la fois plus vivante et plus aisée à se représenter ${ }^{43}$. Par-delà la question de la représentation, le resserrement opéré permet aussi et surtout de valoriser divers éléments suggérant une interprétation allégorique qui approfondit celle qui est donnée dans Jn 9.35-4144.

À la fin du récit, l'aveugle présente en effet sa guérison miraculeuse comme le résultat d'une intervention divine qui lui a permis de reconnaître le fils de Dieu et, ce faisant, d'accéder à une vision spirituelle de la foi ; il devient ainsi l'allégorie d'une humanité aveuglée par ses péchés, à laquelle le Christ, lumière du monde, est venu «ouvrir les yeux». Cette lecture est clairement suggérée aux v. 7-8 où nous comprenons, en relation avec l'idée de preuve (comprobaretur), que tous sont portés à croire grâce à l'exemple de manifestation de la puissance (virtus) de Dieu au centre du récit. L'idée de virtus est répétée à deux reprises dans la suite du texte, en relation avec la forme verbale inluminatus est dont on trouve, dans la tradition patristique, plusieurs occurrences pour signifier, au sens propre, la vue recouvrée, au sens figuré, l'illumination de la foi ${ }^{45}$. De fait, l'auteur de l'hymne joue constamment sur ces deux niveaux de signification, les juifs s'interrogeant, aux v. 14-15, sur les circonstances

43 Cet aspect de la réécriture a été noté par Valcárcel Martínez (2005) 152.

44 Non repris dans l'hymne, alors que la lecture de Jn 9 s'arrêtait au verset 38.

45 Parmi les nombreuses occurrences de l'expression caecum ou caecos illuminare, cf. notamment Augustin, serm. 136C (REAug 24, p. 89, 1. 15), en référence à Jn $9:$ : [...] huius dominici quo illuminatus est caecus [...]. Le verbe illuminare, non attesté dans la Bible, est également usuel, sous l'influence des Pères, dans la tradition liturgique, cf. dès l'époque wisigothique cette benedictio prononcée lors du Carême : Christus Dei filius labores vestros propitiatus aspiciat, et cordis vestri tenebras inluminando submoveat (Oratio 536, ed. Vives 1946). 
de la guérison miraculeuse, tandis que l'ex-aveugle reconnaît, aux v. 23-24, avoir accédé non seulement à la vue, mais aussi à la vision spirituelle de la foi (oculo et corde). Par-delà cette exégèse traditionnelle, induite par le texte de Jean, le traitement de la dichotomie ténèbres/lumière répond cependant aussi aux exigences de la célébration liturgique. Comme on l'a dit, cet hymne fut composé pour les vêpres du $2^{\mathrm{e}}$ dimanche du Carême. Or on sait, depuis Ambroise, la place du jeu de l'ombre et de la lumière dans les hymnes des heures, en lien avec la symbolique johannique du Christ «lumière». Quant au Carême, il prépare à la fête pascale, traditionnellement présentée comme «un jour plus lumineux que les autres [...] ; un jour qui ne connaîtra pas de déclin ${ }^{46}$. La symbolique lumineuse est donc particulièrement bienvenue dans ce contexte, auquel se réfère l'allusion (absente en tant que telle de Jn 9) à la Rédemption aux v. 10-11 (ut ablueretur / mundi delictum).

L'hymne n'est donc pas dénué de toute portée doctrinale et prend même, dans les v. 1-2 et dans la strophe finale, un tour théologique qui inscrit le récit dans un cadre orthodoxe. La doxologie finale n'est guère originale. Un grand nombre des hymnes hispaniques s'achèvent, conformément au modèle ambrosien, par une doxologie trinitaire détachée de l'hymne et, de fait, souvent commune à plusieurs pièces ${ }^{47}$. L'invocation liminaire est, en revanche, étroitement liée à l'objet de la narration ${ }^{48}$. L'un des enjeux du récit de Jn 9 concerne en effet l'identité de Jésus, que les juifs refusent de reconnaître comme le fils de Dieu, tandis que la connaissance de l'ex-aveugle gagne, au fil du récit, en profondeur : d'abord un anonyme, Jésus devient pour lui un prophète (cf. propheta, v. 22), un homme de Dieu, et finalement le Fils de Dieu qu'il confesse dans la foi. Or la série de périphrases liminaires, qui jouent des paradoxes inhérents au dogme de l'incarnation, plongent d'emblée les orants dans le mystère de leur relation intime avec Dieu, tout en rendant le Christ, absent du récit, présent à leur conscience ${ }^{49}$. L'enjeu de l'hymne dépasse donc largement le récit : par-delà le développement du thème de la foi, le discernement de la nature divine du Christ est affirmé avec force par des orants appelés à se réjouir, comme l'aveugle dans la §5, de la venue de celui qui les lavera, par son sacrifice, du péché. Le lyrisme de la composition, fondé, par-delà le mètre, le rythme et la rime, sur les jeux de reprises et de variations, concourt grandement à cette ouverture des perspectives, et nous aide à saisir la portée

46 Cf. les références patristiques indiquées par H. Savon dans Fontaine (1992) 418-419 ; plus particulièrement sur l'importance du thème de la lumière lors de la célébration de Pâques dans l'ancienne liturgie hispanique, Fernández Alonso (1955) 361-362.

47 Cf. Castro Sánchez / García Ruiz (2014) 52-53.

$48 \mathrm{Cf}$. outre les éléments relevés dans la suite, l'introduction en filigrane du thème de la lumière à travers l'expression auctor luminis (v. 1).

49 L'expression paterque matris, qui présente de manière paradoxale le Christ comme le père de sa mère, apparaît dans l'Antiquité tardive, cf. l'étude de Mayer (1927) 66-72. Elle est attestée sous cette forme dans le symbole du $\mathrm{xI}^{\mathrm{e}}$ Concile de Tolède (675) où l'affirmation des deux naissances miraculeuses du Christ débouche sur la conclusion suivante : qui tamen secundum Deus est, creavit Mariam ; secundum quod homo, creatus est a Maria : ipse et Pater Matris, et Filius (§ 48, éd. Madoz 1938). 
spirituelle de cet hymne qui s’apparente, de prime abord, à une simple réécriture de l'Évangile du jour. On ajoutera que cette variation lyrique faisait d'autant moins «double emploi» avec le texte scripturaire qu'elle n'était pas destinée au même office. L'évangile de Jean était en effet lu lors de la «messe ${ }^{50}$, tandis que l'hymne était chanté lors des vêpres : cette distribution accrédite la thèse de deux utilisations complémentaires, orientée, pour la première, vers la catéchèse, pour la seconde, vers la contemplation et la célébration. Les hymnes narratifs se rapprochent en cela des hymnes doctrinaux ainsi que des hymnes exégétiques que nous considérerons in fine.

\section{b) Les paraphrases exégétiques}

Il existe, à côté des paraphrases narratives où divers éléments du récit recèlent les clés d'une interprétation allégorique, un second type de modalité de réécriture biblique où, suivant une tendance caractéristique de la poésie biblique tardive, la paraphrase proprement dite est suivie d'un développement exégétique donnant explicitement ses clés d'interprétation ${ }^{51}$. Les exemples les plus intéressants sont constitués par des hymnes pour des occasions variées, étrangers à la typologie ambrosienne, dont la liturgie hispanique recèle un nombre élevé reflétant sa richesse. De fait, dans ces hymnes composés pour des circonstances fort diverses, les références bibliques sont nombreuses, et sont parfois l'occasion de véritables réécritures dans des contextes moins attendus, sans équivalent dans les autres liturgies ${ }^{52}$. Notre attention ira, là encore, à un exemple emblématique de l'hymnodie wisigothique qui n'a guère retenu l'attention jusque-là : l'hymne Verus redemtor, Xriste, lumen luminis ${ }^{53}$.

Cet hymne, constitué de dix strophes de cinq trimètres iambiques rythmiques, était chanté lors de la consécration épiscopale, sur laquelle il constitue une source unique dans la liturgie hispanique ${ }^{54}$. Il fait pendant à l'hymne 191 composé pour l'office du matin, tandis que l'hymne 190 était utilisé ad vesperas. Son intérêt tient, après une strophe introductive d'une densité théologique remarquable, à l'ample réécriture proposée, dans les $\S 2$ à 5 , du passage de l'Exode consacré aux vêtements sacrés du premier grand prêtre, Aaron ; elle est suivie, dans les $\S 6-7$, d'une subtile exégèse d'Ex 28 qui débouche, dans les $\S 8-9$, sur la célébration de l'institution par le Christ des évêques à la tête de l’Église.

50 Cf. sur le sens controversé du titre «Missa», Pinell (1954) et Ramos (1964) 89-101; sur la «La misa del domingo », Fernández Alonso (1955) 328-330.

51 Voir, sur ce type de paraphrase, Charlet (1985) 641.

52 Cf. notamment, outre l'hymn. 191 étudié infra, la densité des hypotextes vétérotestamentaires dans l'hymn. 195 O verum regimen chanté lors du départ de l'armée du roi.

53 Il s'agit de l'hymn. 190. L'hymne daterait, d'après Díaz y Díaz (1986) 445-448, de la fin du règne de Chindaswinthe († 653).

54 La formule utilisée durant le cérémonial de la consécration des évêques n'est conservée dans aucun des nombreux manuscrits mozarabes, cf. Férotin (1904) 60-62. 
Verus redemtor, Xriste, lumen luminis, imago patris, splendor invisibilis, de patre natus antecedens tempora, ex matre vero prodiens in tempore, promissionis fedus inplens devite.

Tu es sacerdos, tu sacerdotes creas, tu principatum sortis huius floride Aaron dedisti, consecrator inclite, perfusione sacrosancti unguinis et veste sancta vultum eius preparans.

Sublime cuius in caput premittitur nitens olivum, mitra, auri lamina; stola decoris, vestimento poderis ambitur idem, quem sacratum nuntiat

15 inpressa vesti et colorum dignitas:

Coccus, iacinctus, torta bissus, purpura cuius dicati preferentes gloriam; vestis sacrate ora tintinnabulis erant corusca rite dependentibus, ut templum intrans audiretur pontifex.

Distincta gemmis pulcritudo pectoris affigebatur sub figuris optimis, zmaracdus illic, sardius, topatius, onicinus, carbunculus, ligurius, 25 saffirus, iaspis et nitens crisolitus.

Berillus inde seu acates fulgidi cum ametisto ordinis sui loco distinctionis iure illic positi dabant future gratie signaculum, 30 quo hec figure nuntiarent te Deum.

Huius dicate sacramentum ${ }^{55}$ gratie temtum per umbras transiendo seculi pervenit ad te, liberator obtime,
Vrai rédempteur, Christ, lumière de la lumière, image du Père, splendeur invisible, né du Père avant les temps, mais entré par sa mère dans le temps, accomplissant dûment le pacte promis.

Tu es prêtre, tu crées les prêtres ; la primauté de ce sort florissant, tu l'as donnée à Aaron, illustre consécrateur, en répandant le Saint Onguent et en préparant son visage par des vêtements sacrés.

En haut de sa tête sont appliquées l'huile brillante, la mitre, les lames d'or ; une étole d'apparat, une longue tunique le couvrent également, lui dont le sacre est annoncé

par la dignité des couleurs ornant ses vêtements :

écarlate, jacinthe, lin tordu et pourpre qui manifestaient la gloire de celui qui est consacré ; les clochettes suspendues rituellement aux pans du vêtement sacerdotal les rendaient étincelants, afin qu'on entendît le pontife entrer dans le temple.

Son pectoral se signalait par la beauté des pierres

qui y étaient fixées sous les meilleures figures : émeraude, sardoine, topaze, onyx, escarboucle, rubellite, saphir, jaspe et chrysolithe éclatante.

Puis, béryl et agates scintillantes, placés là avec l'améthyste au rang qui est le leur en guise de distinction, marquaient le signe de la grâce future, puisque ces figures t'annonçaient, Dieu.

Le mystère de la grâce de celui qui était ainsi consacré, retenu parmi les ombres du siècle en le traver-

55 Sur cet emploi de sacramentum dans le sens de mysterium, cf. Castro Sánchez / García Ruiz (2014) 509 (k). 
ut, que figure precinebant mistice, completa in te veritas ostenderet.

Hinc finis ipse legis ad iustitiam mundi reatum proximans detergere, oblatus ipse tu, oblator, consecrans in patris aram conlocatam victimam, hoc sacramento suscitans ecclesiam,

Caput cui factus et ducator previus duces in illam presulesque conlocans, quorum regatur instruenda legibus, ut erudita gratia pontificum vitare possit damna seva mortium.

Hinc te corona, Xriste, fratrum postulat, successionis clara huius gratia descendat in his, quos futuros preligis uni columbe preferendos principes, sant,

est parvenu à toi, libérateur par excellence, afin que la vérité, annoncée symboliquement par les figures, apparût accomplie en toi.

Puis toi-même, fin de la loi en vue de la justice, t’apprêtant à laver les fautes du monde, consacrant par ton propre sacrifice, sacrificateur, la victime placée sur l'autel du Père, tu as fait naître par ce mystère l’Église.

Tu as mis à sa tête un dignitaire montrant la voie, qui établit en elle les prélats comme guides; leurs lois la forment et la régissent afin qu'instruite par la grâce des pontifes, elle puisse éviter les cruels dommages de la mort.

Aussi, cette assemblée de frères te demande, Christ, que la grâce éclatante de cette succession descende sur ceux que tu as déjà choisis de présenter comme futurs chefs à l'unique colombe, qui leur confère la gloire de l'apostolat.

Suivant l'expression veste sancta du v. 10, la paraphrase des v. 6 à 30 est dédiée aux vêtements d'Aaron, sur la base d'Exode 28. Il s'agit, comme dans l'hymne 25, d'une réécriture très proche de la lettre du texte biblique, fondée sur de nombreux emprunts textuels qui sont ajustés aux exigences du mètre ${ }^{56}$. Elle s'accompagne là encore d'une nette réduction de l'hypotexte biblique qui passe, notamment, par la suppression des répétitions et la focalisation sur certains aspects, comme les insignes de la tête dans la §3 dédiée aux ornements vestimentaires d'Aaron. On notera par ailleurs l'effort d'organisation de la description, à travers des effets d'annonce et une distribution strophique éclairant sa progression ; on peut en juger grâce au tableau suivant, qui met en regard le texte des $\S 3$ à 6 avec les passages correspondants d'Ex 28 :

§ 3 Liste des vêtements Sublime cuius in caput premittitur (annoncée par vesta nitens olivum, mitra, auri lamina; sancta v. 10, cf. Ex 28.2) stola decoris, vestimento poderis ambitur idem, quem sacratum nuntiat inpressa uesti et colorum dignitas:
Ex 28.4 haec autem erunt vestimenta quae facient rationale et superumerale tunicam et lineam strictam cidarim et balteum facient

56 Cf. en part. la réorganisation des pierres énumérées dans les §5-6 dont rend compte la comparaison ci-dessous. 
§ 4 Liste des couleurs Coccus, iacinctus, torta bissus, purpura (annoncée par le dernier cuius dicati preferentes gloriam; vers de la §3) vestis sacrate ora tintinnabulis erant corusca rite dependentibus, ut templum intrans audiretur pontifex.
§ 5 et début de la $\S 6$ Liste des pierres incrustées sur le pectoral (pectoris, v. 21)
Distincta gemmis pulcritudo pectoris

affigebatur sub figuris optimis, zmaracdus illic, sardius, topatius, onicinus, carbunculus, ligurius, saffirus, iaspis et nitens crisolitus. Berillus inde seu acates fulgidi cum ametisto ordinis sui loco... vestimenta sancta Aaron fratri tuo et filiis eius ut sacerdotio fungantur mihi

Ex 28.5 accipientque aurum et hyacinthum et purpuram coccumque bis tinctum et byssum Ex 28.2 vestem sanctam ... in gloriam Ex 28.34-35 ita ut tintinabulum sit aureum... ut audiatur sonitus quando ingreditur et egreditur sanctuarium...

Ex 28.17-20 ponesque in eo quattuor ordines lapidum in primo versu erit lapis sardius et topazius et zmaragdus in secundo carbunculus sapphyrus et iaspis in tertio ligyrius achates et amethistus in quarto chrysolitus onychinus et berillus inclusi auro erunt per ordines $\underline{\text { suos }}$

Dans la continuité du texte biblique, cette description est en elle-même hautement symbolique. Plusieurs expressions suggèrent en effet, sur la base d'un symbolisme qui reste implicite, que les couleurs et les pierreries ornant les vêtements d'Aaron représentent sa sainteté (veste sancta vultum eius preparans v. 10 ; sacratum nuntiat v. 15, cf. sub figuris optimis v. 22) ${ }^{57}$. Mais surtout, ces ornements se prêtent, dans les $\S 6$ à 8, sur la base de l'Épitre aux Hébreux (chap. 7 à 10), à une lecture typologique explicitement présentée comme telle. Sa progression et sa place dans l'économie du poème sont remarquables. Conformément au procédé d'annonce observé dans la paraphrase d'Ex 28, les v. 29-30 introduisent les thèmes des §7-8 en évoquant le temps de la Grâce (future gratie signaculum, cf. v. 31) et la divinité du Christ (te deum où l'utilisation de la $2^{\mathrm{e}}$ personne permet de renouer avec l'orientation eucologique

57 Dans l'exégèse traditionnelle d'Ex 28, les Pères, à partir d'Origène, rapportent en effet les quatre étoffes dont sont constitués les vêtements d'Aaron aux quatre éléments dont se compose le monde ; quant aux douze pierres de perfection ornant son rational, elles sont identifiées aux bonnes actions produites par l'âme rationnelle, cf. sur son développement par Grégoire le Grand dans la Règle pastorale 2, 2-4, Judic (1985) 460-463. 
des $\S 1-2$ qui caractérise les $\S 7$ à 10). Puis, la $\S 7$ développe d'un point de vue théorique, en se référant clairement à la méthode typologique (ut, que figure precinebant mistice, / completa in te veritas ostenderet, v. 34-35), l'idée que la figure sacerdotale d'Aaron annonce le Christ, véritable grand prêtre ${ }^{58}$. L'office du Christ, différent de celui des autres grands prêtres, est, dès lors, au centre de la $\S 8$ où le poète reprend les thèmes principaux d'He 7-10 : le Christ, par son sacrifice unique destiné à enlever les péchés de la multitude ${ }^{59}$, a définitivement aboli l'ancien culte et scellé une nouvelle alliance fondée non plus sur la loi, mais sur la grâce. L'affirmation, au v. 40, que l'Église résulte de ce mystère prépare la figure des évêques et des prêtres qu'ils sacrent au centre de la $\S 9$, où ces derniers apparaissent, en tant que guides de l'Église (v. 42), garants de la nouvelle loi (v. 43) et dépositaires de la doctrina (v. 44), à même de sauver leurs ouailles de la mort par la foi en Christ (v. 45). On notera le rôle actif prêté dès la $\S 9$ au Christ dans l'établissement des évêques à la tête de l'Église, avant que la foule de leurs frères ne l'implore, dans la §10, de faire descendre la grâce de l'Esprit sur ses successeurs apostoliques. La boucle est ainsi bouclée avec la § 2 où, dans le prolongement des considérations théologiques de la § 1 sur l'antériorité du Christ au temps par son Père, le Christ était d'emblée présenté, dans son éternité, comme le créateur de tous les sacerdotes depuis Aaron. Parallèlement, l'allusion finale à l'Esprit octroyé par le Christ permet de faire le lien avec le rite de l'ordination, dont l'hymne reprend manifestement, sur un mode lyrique, plusieurs éléments traditionnels.

D'une longue tradition patristique ${ }^{60}$, la typologie sacerdotale des vêtements d'Aaron est en effet au centre des plus anciens rituels d'ordination épiscopale occidentaux. Depuis le sacramentaire Léonien, la prière d'ordination compare l'évêque à Aaron et ses fils aux prêtres, en insistant, comme le suggère l'hymne, sur la transposition qu'a opérée le Nouveau Testament : les rites et les ornements extérieurs, au centre de l'hymne, signifiaient les réalités spirituelles du nouveau sacerdoce (en particulier la pureté des mœurs et des actes) ${ }^{61}$. Même si le texte du rituel épiscopal hispanique est perdu, il est fort vraisemblable que cette typologie y figurait et que le poète anonyme y ait trouvé l'idée d'une paraphrase exégétique d'Exode 28. Les divergences mêmes qu'on observe avec l'interprétation traditionnelle trouvent de toute évidence leur source dans la pratique liturgique. De fait, tout en donnant à

58 Voir, sur cette typologie, Lécuyer (1983) 261-262. On la trouve, à l'époque wisigothique, chez Isidore, De officiis ecclesiasticis II.5.

59 Cf. He 9.15 et 28.

60 Cf. supra n. 57.

61 Cf. ce passage du «Sacramentaire léonien»sur la Consecratio episcoporum (XXVIII) : ... illius namque sacerdotii anterioris habitus nostrae mentis ornatus est et pontificalem gloriam non iam nobis honor commendat vestium sed splendor animorum quia et illa quae tunc carnalibus blandiebantur obtutibus ea potius quae in ipsis erant intellegenda poscebant. [...] hanc quaesumus Dne gratiam largiaris ut quidquid illa velamina in fulgore auri in nitore gemmarum in multimodi operis varietate signabant hoc in horum moribus actibusque clarescat. 
Aaron la place exemplaire qu'il avait dans la tradition liturgique, l'hymne propose une lecture différente de l'interprétation morale traditionnelle faisant, à la lumière de l'Épître aux Hébreux, d'Aaron le modèle non de l'évêque, mais du Christ, véritable sacerdos. Or cette typologie permet, en accord avec un autre motif central des rituels de l'ordination épiscopale, de souligner le rôle essentiel joué par le Christ dans la consécration $^{62}$, tout en lui donnant une place conforme à celle qui est la sienne dans la tradition hymnique, tournée, depuis Hilaire et Ambroise, vers la célébration de son mystère. On notera à cet égard que son invocation se prête, dans la $\S 1$, à des affirmations plus théologiques que dans les hymnes considérés jusque-là : l'image de la «lumière de la lumière» au v. 1 et l'affirmation de l'antériorité du Christ au temps au v. 3 font directement écho au credo de Nicée, dans l'esprit de l'hymne Ante saecula qui manens d'Hilaire dont s'est probablement souvenu l'Anonyme en composant son poème. Mais l'accent théologique que prend à maintes reprises la liturgie hispanique a également dû jouer, d'autant plus que des parallèles précis sont possibles $^{63}$.

Les hymnes de la fin de l'époque wisigothique continuent donc de faire une large place à la doctrine, à des fins désormais purement catéchétiques : les uns traitent, dans la continuité des hymnes d'Ambroise, des grands thèmes christologiques ; les autres empruntent leur inspiration directement à la Bible, alors au centre de la vie religieuse et spirituelle. En dépit de leurs orientations divergentes, tous sont fortement redevables à l'enseignement des Pères, dont ils reprennent non seulement les leçons, mais aussi maintes expressions caractéristiques. Ils s'avèrent ainsi en consonance étroite avec la liturgie de l'époque, qui se signale par son empreinte patristique et théologique. Cette adéquation se vérifie dans le choix des thèmes et des motifs traités, en résonance avec les textes liturgiques du jour, qu'ils reprennent sur le mode de la célébration. Ces hymnes présentent de la sorte un accent nouveau, loin du lyrisme empreint de classicisme d'Ambroise et de la tradition poétique tout court, sinon hymnique. On notera cependant que la part importante de ces sources prosaïques ne nuit guère à leur valeur esthétique, loin s'en faut. La part importante de la doctrine dans ces poèmes, et le choix fait ici d'aborder ces textes sous l'angle doctrinal ne sauraient en effet occulter la charge poétique de ces hymnes, qui facilitait largement l'assimilation de la doctrina. Outre la part importante des images, ces hymnes jouent à maintes reprises des répétitions, des parallélismes et des énumérations, qui concourent à leur musicalité et chargent leur langue simple d'une grâce délicate ; quant à leur écriture rythmée et rimée, elles donnent à leur poésie une intensité nouvelle, plus accessible au peuple, que ces laudes visaient à édifier tout en rendant hommage à Dieu.

62 Cf. Lécuyer (1985) 225-324 («À l'origine de l'ordination : le Christ»).

63 Cf. en particulier les affinités des v. 3-4 avec le passage liturgique cité n. 28. 


\section{Bibliographie}

Arana Tarazona (2016) : Himnos de la liturgia mozárabe. Versión castellana de los himnos de la liturgia mozárabe. Realizada desde la edición de Blume, Clemens, Hymnodia Gotica. Die Mozarabischen Hymnen des alt-spanischen Ritus, obra inédita facilitada a La Ermita en febrero de 2016 (URL : http://www.hispanomozarabe.es/oficio/ofi-himnos.htm\#inicio)

Arocena-Solano (2012): Félix María Arocena-Solano, «El Himnario del Oficio hispano», in Scripta Theologica 44.1, 9-44.

Blume (1897): Clemens Blume (ed.), Hymnodia Gothica. Die Mozarabischen Hymnen des alt-spanischen Ritus, Leipzig (reprint 1961) (AH 27).

Castro Sánchez (2010): José Castro Sánchez (ed.), Hymnodia hispanica, Turnhout (CCSL 167).

Castro Sánchez / García Ruiz (2014): José Castro Sánchez (ed.) / Emilio García Ruiz (trad.), Himnodia hispánica: Introduccion, traduccion, indices y notas, Turnhout (CCT 19).

Charlet (1985): Jean-Louis Charlet, «L'inspiration et la forme bibliques dans la poésie chrétienne $\mathrm{du} \mathrm{II}^{\mathrm{e}}$ au $\mathrm{VI}^{\mathrm{e}}$ siècle», in: Jacques Fontaine / Charles Pietri (dir.), Le monde latin antique et la Bible, Paris, 613-643.

De Almeida Matos (1977): Alibo De Almeida Matos, Hinos do Temporal Hispánico Até à Invasâo Muçulmana: estudo histórico-crítico, Coimbra.

De Almeida Matos (1984): Alibo De Almeida Matos, «Hinario hispânico do Temporal. Hinos mais recentes», in: Revista da Universidade de Aveiro 1, 107-118.

Díaz y Díaz (1965): Manuel C. Díaz y Díaz, «El latin de la liturgia hispanica», in: Juan Francisco Rivera Recio (ed.), Estudios sobre la liturgia mozarabe, Toledo, 55-87.

Díaz y Díaz (1980): Manuel C. Díaz y Díaz, "Literary Aspects of the Visigothic Liturgy», in: Edward James (ed.), Visigothic Spain: New Approaches, Oxford, 61-76.

Díaz y Díaz (1986): Manuel C. Díaz y Díaz, «Noticias históricas en dos himnos litúrgicos visigodos», in: Antigüedad y Cristianismo III. Los visigodos, historia y civilización, Actas [21-25 Oct. 1985], Murcia, 443-456.

Fernández Alonso (1955): Justo Fernández Alonso, La Cura pastoral en la España romanovisigoda, Roma.

Férotin (1912): Marius Férotin, Le Liber mozarabicus sacramentorum et les manuscrits mozarabes, Paris.

Ferro Calvo (1972): Mauricio Ferro Calvo, La celebración de la venida del Señor en el oficio hispánico: estudio histórico doctrinal de los formularios del oficio para el ciclo natalicio en las dos tradiciones del rito hispánico, Madrid.

Fontaine (1974/5): Jacques Fontaine, «L'apport de la tradition poétique romaine à la formation de l'hymnodie latine chrétienne ", in: Revue des Études latines 52, 318-355.

Fontaine (1992): Jacques Fontaine (ed.), Ambroise de Milan, Hymnes, texte établi, traduit et annoté sous la direction de Jacques Fontaine, Paris.

Fontaine (1999): Jacques Fontaine, «Un débat sur les Hymnes en 633 lors du $4^{\text {ème }}$ Concile de Tolède», in: Helmántica 50, 383-402.

Gallego Moya (2002): Elena Gallego Moya (éd.), Los himnos de la Hymnodia Hispanica-Estudio preliminar, traduccion, notas y comentarios, Alicante.

Guéranger (1841): Prosper Guéranger, L'année liturgique. L'Avent liturgique, Mans.

Janeras (1954): Vicente Janeras, «Combinación de los oficios temporal y festivo en la liturgia hispana», in: Archivos leoneses 8, 196-225.

Janini (1980): José Janini (ed.), Liber misticus de Cuaresma y Pascua (Cod. Toledo, Bibl. Capit. 35.5), Toledo. 
Judic (1985): Bruno Judic, «La Bible miroir des pasteurs dans la Règle Pastorale de Grégoire le Grand», in: Jacques Fontaine / Charles Pietri (dir.), Le monde latin antique et la Bible, Paris, 455-478.

Lecuyer (1983): Joseph Lecuyer, Le sacrement de l'ordination, Paris.

Lopetegui Semperena (2005): Guadalupe Lopetegui Semperena, «Poesía latina hispana: lírica religiosa», in: Vitalino Valcárcel Martínez / Carlos Pérez González (eds.), Poesía Medieval (Historia literaria y transmisión de textos), Burgos, 135-180.

Madoz (1938) : José Madoz, Le symbole du Xle Concile de Tolède: ses sources, sa date, sa valeur, Louvain.

Mayer (1927): Anton L. Mayer, «Mater et filia», in: Jahrbuch fur Liturgiewissenschaft, 60-82.

Messenger (1946): Ruth E. Messenger, «Mozarabic Hymns in Relation to Contemporary Culture in Spain», in: Traditio 4, 149-177.

Pinell (1954): Jorge M. Pinell, «Las Missae, grupos de cantos y oraciones», in: Archivos Leoneses 8, 145-185.

Pinell (1955): Jorge M. Pinell, «El Liber Horarum y el Misticus entre los libros de la antigua liturgia hispana», in: Hispania Sacra 8, 85-109.

Pinell (1957): Jorge M. Pinell, «El Oficio hispano-visigotico», in: Hispania Sacra 10, 1-43.

Pinell (1965): Jorge M. Pinell, «Los textos de la antigua liturgia hispánica. Fuentes para su estudio», in: Juan Francisco Rivera Recio (ed.), Estudios sobre la liturgia mozarabe, Toledo, $109-164$.

Ramos Sánchez (1964): Manuel Ramos Sánchez, Oratio admonitionis. Contribución al estudio de la antigua misa española, Granada.

Rovalo (1966): Pedro Rovalo, «Temporal y santoral en el adviento visigodo, su relación a través del Oficio», in: Hispania Sacra 19, 243-321.

Szövérffy (1998): Josef Szövérffy, Iberian Hymnody. Survey and problems, Leiden.

Urlacher-Becht (2012): Céline Urlacher-Becht, «Les recueils hymniques du poète latin Prudence. Des livres poétiques destinés à être goûtés par un lecteur aux chants liturgiques», in: Greta Komur-Thilloy / Anne Réach-Ngô (ed.), L'écrit à l'épreuve des médias du Moyen Âge à l'ère électronique, 75-91.

Urlacher-Becht (2014): Céline Urlacher-Becht, Ennode de Pavie, chantre officiel de l'Église de Milan, Paris.

Vives (1946): José Vives (ed.), Oracional visigótico. Edición crítica por José Vives ; estudio paleográfico de los códices por Jerónimo Claveras, Barcelona. 



\section{Pascale Bourgain}

\section{La dramatisation de l'histoire biblique dans la poésie carolingienne}

Quand on parle de poésie biblique carolingienne, on ne peut partir évidemment que du superbe livre de Francesco Stella, et de ses autres travaux. ${ }^{1}$ Ajouter quelque chose à ce monument tiendrait de l'exploit. Pourtant, ayant récemment travaillé sur le même sujet aux alentours du XII ${ }^{\mathrm{e}}$ siècle, et ayant exploré, dans le cadre de l'entreprise menée par Fr. Stella sur les rythmes, ${ }^{2}$ les manuscrits carolingiens, j'ai été tentée de passer quelques temps dans l'intimité de ces textes. La manière dont les copistes réagissent face aux discours directs m'avait spécialement intéressée, à propos notamment des Versus de Lazaro de Paulin d'Aquilée, ${ }^{3}$ que Christiane Cosme a prévu de vous présenter, ce qui montre bien que c'est un des sommets de la poésie de l'époque. C'est ce qui m'a poussée à m'engager sur ce thème incommode, plutôt pour le plaisir que dans l'espoir d'ajouter un arbrisseau à la forêt.

Thème incommode et sûrement mal formulé. Que veut dire en effet la dramatisation ? Le propre de la poésie est de magnifier et de concentrer le sens. On peut attendre un accent mis sur la célébration de choses ou de situations, et parler alors de lyricisation, ou d'accent mis sur les faits, transmis par une narration, et parler d'épicisation, les deux catégories n'étant pas étanches. Dans le cas de la Bible, la prose de la Vulgate véhicule déjà une qualité poétique interne. En découle une poésie de célébration, méditation, prière, prenant pour matériau les livres sapientiaux et le Cantique ; ou une poésie plus narrative, prenant appui sur les livres historiques, et y ajoutant la forme épique la plus propre, pour les auditeurs et lecteurs, à faire percevoir la grandeur et l'importance des faits narrés.

A première vue, ce serait cette direction, celle de la paraphrase de textes narratifs, qui serait plus propre à la dramatisation. Mais de fait c'est l'ensemble de la Bible, qui est le grand code historique du salut de l'homme, où s'inscrit le drame, drame général de l'humanité et personnel de chaque être humain. Or, par l'intégration des éclaircissements exégétiques, la présence permanente de ce caractère dramatique affleure dans presque toutes les réalisations poétiques, sauf dans ce qu'on peut appeler 'paraphrase pure'. On n’oublie pas, en célébrant les épisodes bibliques, que leur aboutissement est toujours le même : le salut du genre humain, sa libération des incertitudes de sa condition mortelle et du péché. Ainsi l'horizon du

1 Stella (1993) ; Stella (1995); Stella (2001); Stella (2010).

2 Poesia (2000) ; Poetry (2003) ; Corpus (2007).

3 Voir Bourgain (2016) 149-181, notamment pl. 22 et 26. Paulin pratique les enjambements, ce qui est rare en poésie rythmique, et a beaucoup de discours directs avec des changements rapides de locuteur : cette souplesse prend les copistes au dépourvu. 
salut, «en qui trouve sens tout effort intellectuel» ${ }^{4}$ est quelque chose de dramatique parce qu'il implique profondément tant la communauté humaine que chaque âme, donc collectivement et individuellement (ce qui implique en gros deux sens allégoriques, l'anagogie et la tropologie). L'angoisse existentielle de l'attente du jugement, donc l'eschatologie, irrigue la poésie pénitentielle, abondamment représentée, avec la lamentation récurrente «malheureux, que ferai-je au jour du jugement ?». Dans nos textes, même s'ils ont un point de départ narratif, le salut ou le jugement apparaît presque toujours à la fin du poème, ou en filigrane sous la présentation, ou dans les refrains, dont la répétition exacerbe l'angoisse. C'est le jugement futur qui oriente et donne son sens au début du poème. Ceci est spécialement sensible dans les poèmes rythmiques, qui sont généralement antérieurs aux réélaborations plus sereines de la renovatio carolingienne. ${ }^{5}$

Quelques exemples parmi des rythmes alphabétiques, dont on ne peut donc pas croire qu'ils sont incomplets ; les rubriques font généralement référence au début du poème plus qu'à sont sujet véritable :

- Un rythme 'De adventu Domini', refrain Venite et gaudete nato Christo Domino va jusqu'aux noces de Cana, puis passe à la Résurrection et à la descente aux Enfers. ${ }^{6}$ La mention de l'Incarnation, premier Avent, semble bien avoir appelé l'idée du second Avent. Aussi l'insistance sur le retour du Christ pour le jugement est-elle un thème récurrent.

- $\quad$ Le rythme 8, 'De nativitate Christi', Alta prolis sanctissime, saute du choix des apôtres à l'ensevelissement par Joseph d'Arimathie et à la Résurrection, la dernière strophe (Zelum <tunc Gestas> perdidit) étant pour le mauvais larron. ${ }^{7}$ Même la jeunesse du Christ, ses 'Enfances' dirait-on en français, ne se comprend que dans l'optique de sa Passion. La prédication du Christ et ses miracles ne reçoivent pas la même attention.

4 Stella (1993) 48. La plupart des pièces qui seront citées sont accessibles dans les Poetae latini aevi carolini (PLAC) des Monumenta Germaniae historica. Ceux qui ont conservé une notation musicale sont réédités dans Corpus (2007).

5 PLAC IV, r. 13, 17, 23, 54.

6 A superna celi parte, PLAC IV 477-480, r. 7. Autre poème centré uniquement sur l'Avent : Qui de morte estis redempti, in Corpus p. 353. Celui-ci est tragique par son sujet, mais remarquablement mesuré et compact dans sa forme. (Il reprend le Dies irae dies illa de Sophonie 1, 15). Autres manifestations de cette centralité du thème eschatologique dans les poèmes rythmiques : Adorate omnes gentes ... Refrain Grandis pavor in mundo erit / quando deus iratus venit, PLAC VI 227, et une autre addition du même manuscrit Paris lat. 242, ibid. 230, Audite vobis omnes / quod erit a iudicio. La très grande fréquence des poèmes pénitentiels va dans le même sens ; la crainte du jugement y est parfois explicite, comme en PLAC IV 489, r. 12, 'De commendatione uniuscuiusque animae', str. 5 : Ecce in illa die iudicii / qualis ego ero miser / qui tanta peccata feci ! ; r. 14, p. 495, 'Versus de contemptu mundi', str. 11 : Luge modo, dum tempus est, / ne gemas in iudicio, et str. 19-20 ; r. 18, p. 510, 'De accusatione facinoris', str. 15, 2 : Miser ego quid faciam in die iudicii, etc.

7 Ce qui suppose une trace de l'évangile de Nicodème qui cite leurs noms, comme la str. 18 sur l'ouverture des enfers et l'évasion d'Adam. PLAC IV 480. 
- Les rythmes 13 et 17 insistent sur le Jugement. Le second et plus ancien, Apparebit repentina, titré 'De die judicii', utilise beaucoup les prophètes et les évangiles, avec des adaptations facilitées par la forme rythmique. ${ }^{8}$ Le premier, non alphabétique, Apparebit ante summum, s'intitule 'De Enoch et Haeliae', mais c'est une suite de prophéties prises autant dans les épîtres et les évangiles que dans les prophètes ou l'Apocalypse, avec pour refrain Imminente die judicii, puis In pavendo die judicii.

- L'un des plus répandus de ces rythmes, Gratuletur omnis caro, ${ }^{9}$ intitulé 'De nativitate Domini', commence bien à la Nativité, (deux strophes), continue avec le baptême (deux strophes), les miracles (deux strophes), la Passion (deux strophes), puis (str. 9-13) s'étend longuement sur la descente aux Enfers (qui figure dans le Credo, probablement d'après la même élaboration que ce qui préside à la rédaction de l'Évangile de Nicodème, mais pas dans les Évangiles) pour annoncer le Jugement. La présence dominante du jugement, individuel ou particulier, dans les poèmes rythmiques qui nous sont parvenus, est en soi un élément de dramatisation.

C'est sans doute pour cela aussi qu'une grande partie de ces textes, les plus anciens semble-t-il, et surtout les textes rythmiques où la forme strophique appelle à morceler les épisodes, sont assez indifférents à la succession dans le temps des épisodes bibliques. Le récit, notamment dans les résumés et autres microformes, selon l'expression de F. Stella, peut être tout à fait dans le désordre, car l'intérêt est de toute façon actuel. Ce sont des vignettes, qui toutes préfigurent l'Incarnation ou l'accompagnent, leur succession a moins d'importance que leur unique direction qui pointe vers la Résurrection. Le rythme Ama puer castitatem $^{10}$ est une méditation qui n'est absolument pas portée par le déroulement historique : sont évoqués dans l'ordre Jugement, incarnation, miracles, jugement, baptême, création, multiplication des pains, bâton de Moïse, miracle de la femme hémorroïde, Noé, jugement des Juifs, Pierre marchant sur les eaux... Il est imité par le r. $n^{\circ}$ 41, dans l'ordre : Annonciation, multiplication des pains, incarnation, appel aux apôtres après la Résurrection, Hérode et fuite en Egypte. Et cela arrive aussi dans des rythmes qui ne sont pas alphabétiques, ce qui fait qu'on ne peut pas incriminer le désordre alphabétique pour cette indifférence à la chronologie ; ainsi le rythme Alpha et omega ${ }^{11}$, 'De nominibus sanctorum', est un résumé biblique sous forme de portraits, avec une suite Jésus, Adam, Abel, Enoch, Noé, etc. Il s’agit de signification, pas de récit, et l'histoire ne se comprend que transmutée en son aspect de vérité éternellement prédestinée.

\footnotetext{
8 PLAC IV 491 et 507.

9 PLAC II $252 \mathrm{n}^{\circ} 13$; Corpus (2007) 251.

10 PLAC IV 573-575, n XLVIII.

$11 \mathrm{~N}^{\circ}$ 52, PLAC IV 630.
} 
Si l'on passe aux grands auteurs carolingiens, Florus de Lyon concentre toujours son propos sur le but de l'Incarnation qui est le salut. ${ }^{12}$ Il insiste très peu sur les éléments émotifs, ne joue jamais avec un pathétique facile, ne s'apitoie pas sur les souffrances de la Passion : il suit une veine très intellectuelle, qui fait penser, beaucoup plus tard, à Maître Eckart et à sa mystique toute cérébrale. Lorsque Florus paraphrase Daniel et les trois enfants dans la fournaise, ${ }^{13}$ c'est l'hymne qui l'intéresse, la position douloureuse des chanteurs n'est mentionnée qu'en passant. Il existe aussi toute une veine, de paraphrase pure, ou de paraphrase qui insiste plus sur le dogme que sur le pathétique, qui ne conserve de la valeur dramatique de la Bible qu'un profond sentiment d'appartenance et d'actualité du message. Toute la partie de résumés didactiques, les tituli, une grande partie des hymnes, qui sont célébration essentiellement, ainsi que les œuvres d'auteurs sereins comme Alcuin ${ }^{14}$ ou Florus, se passent fort bien de toute dramatisation extérieure à la conscience de cet enjeu du salut. Vivant sub gratia, après l'Incarnation, ils ont conscience de vivre dans la lumière de la grâce, qui a rendu le salut possible, et les épisodes de l'histoire biblique ne font que leur redire la même histoire prévue depuis toujours. Ils la méditent et la magnifient, mais les auteurs les plus conscients, comme Théodulfe d'Orléans à propos du bonheur des méchants chez Jérémie ou Job, ${ }^{15}$ n'éprouvent pas le besoin d'ajouter de l'emphase ou du pathos à leur reformulation poétique.

Mais le drame, dans nos esprits, a aussi d'autres connotations, plus techniques. Il représente un mode de représentation pathétique, fondé sur des procédés visant à susciter l'émotion, avec une dose de théâtralité : interjections, apostrophes, dialogues, discours directs. Ce sont ces marques, qui font partie de l'arsenal rhétorique, dont il nous faut évaluer l'emploi. ${ }^{16}$

Parce que c'est le but de la rhétorique, ses procédés les plus naturellement employés amènent à rendre l'expression pathétique et proche, à y impliquer l'auditeur. La répétition, quasi litanique et lancinante, fait la force des pièces à refrain, généralement rythmiques. Elles rapprochent ces pièces du genre de la prière, avec répons de l'assistance, ce qui est une des possibilités d'emploi du refrain (et ces refrains sont effectivement souvent une imploration, comme dans Ad te Deus ${ }^{17}$ ). Parmi les différents procédés d'emphase, Francesco Stella a insisté sur les apostrophes, ${ }^{18}$ les interpellations : ce sont des moyens de rapprocher une narration de l'auditeur, par l'utilisation des premières et secondes personnes, en dynamisant le récit.

12 Stella (1993) 212-220, et Stella (1995) 36.

13 PLAC II 374 ; Stella (1993) 247.

14 Voir $\mathrm{n}^{\circ}$ 69, PLAC I 288.

15 PLAC I 463.

16 Je ne ferai pas de différence entre les formes concentrées ou au contraire développées de la paraphrase, la typologie de Francesco Stella ayant parfaitement balisé le terrain.

17 PLAC IV 602.

18 Stella (1993) 203. 
L'influence du genre de la prière et l'habitude de s'adresser à la divinité facilitent l'emploi de la deuxième personne, même à propos d'épisodes bibliques, avec en contrepartie soit le 'nous' collectif des hymnes et des prières, soit, beaucoup plus rarement, le 'je' psalmique et sa valeur universelle, qui peut prendre un ton personnel en passant au registre moral, ${ }^{19}$ notamment dans les poèmes pénitenciels. Les appels à Dieu et au Christ qui commentent et ponctuent le récit biblique, les exclamations admiratives ou suppliantes viennent tout naturellement. ${ }^{20}$ Gottschalk d'Orbais, le plus grand poète de l'intériorité, pratique le genre de la prière où l'impératif, adressé à Dieu, se fait lancinant. Dans le superbe $O$ mi custos, ${ }^{21}$ il s'assimile d'abord au fils prodigue, Ego, pater, ille tuus prodigus sum filius (str. 29-36), avant de parler de ce dévoyé à la troisième personne, en l'appelant son frère (str. 37-45) et en implorant de Dieu la même miséricorde que pour lui, mouvement qui montre bien l'assimilation aux misères du fils prodigue, alternant avec la distanciation envers la figure biblique qui a reçu le pardon que lui-même implore encore. Puis Gottschalk passe à Lazare (str. 48-57), en implorant, second Lazare, d'être sauvé comme lui, avec une insistance dans l'objurgation qui réitère, dramatiquement, le moment du miracle : Clama, clama, Iesu Christe, voce magna, domine:/ "Prodi foras, tumulate, veni foras, Lazare, / Exi, exi, ac procede iam mortis de carcere». L'unique impératif de la Bible est multiplié par cinq, enchassé dans la longue série des impératifs de la prière, tentative frénétique de relier le plus étroitement possible le 'je' de l'orant à l'interlocuteur silencieux dont il vocifère la réponse qu'il sollicite. Les deux séries d'impératifs se croisent. La souffrance de Gottschalk s’identifie à la déréliction de Lazare. Il ne s'agit plus ici de paraphrase, mais d'appropriation.

Mais l'apostrophe à l'ennemi, au méchant, qui est l'inverse de la prière, l'exécration au lieu de la louange, est plus original. On le voit mis en œuvre à l'encontre de Judas, assez rarement, mais surtout à l'encontre d'Hérode dans différentes pièces célébrant les saints Innocents, avec toutes les nuances de l'indignation à la compassion. C'est un des lieux privilégiés de l'impératif narratif : on encourage le personnage négatif, par antiphrase. L'impératif, qui sert de supplication vis-à-vis de la divinité, se fait à l'inverse ironique : on encourage l'action perverse parce qu'elle sera sans effet ou aura des effets contraires, en un mouvement emprunté à Prudence, qui le met dans la bouche d'Eulalie : Age Ergo age, tortor, adure, seca ${ }^{22}$.

19 Ibid., p. 232.

20 Les prières liturgiques reposent parfois sur le procédé de transformation d'un texte biblique en imploration par le replacement d'un indicatif par un impératif, ce qui réactualise en demandant pour le présent une intervention divine semblable à celles du passé. Voir Colette et Iversen (2014) 78. 21 Corpus (2007) 315-334.

22 PLAC II 246, str. 7 de Carmina psallere voce lyra, Raban Maur dub. Sauf le cinquième vers, presque toute la strophe est empruntée à Prudence, Cathemerinon 3.91-94. La strophe précédente est également reprise des v. 86-89, seul le cinquième vers étant différent. L'auteur a ainsi calqué trois strophes de Sedulius, puis deux de Prudence ; le défi d'Eulalie à l'empereur Maximien se transforme avec peu de retouches en défi à Hérode. Je remercie F.E. Consolino d'avoir attiré mon attention sur cet emprunt, non identifié par l'éditeur Karl Strecker. 
A côté des impératifs, les interrogations sont une autre façon de dynamiser le propos. Les questions peuvent être un moyen de structuration. Ainsi dans le $D e$ laude Dei alphabétique, Ante saecula et tempora, sont énumérés des miracles bibliques, sur le schéma : Qui a fait cela ? Réponse par le refrain : Benedictus dominus / Christus Dei filius ${ }^{23}$. Le poème joue à fond de l'insistance du refrain, du schéma question-réponse, pour une mise en série (non historique, comme on l'a déjà fait remarquer, puisque par exemple l'expulsion d'Adam du Paradis, str. 21, vient après la lamentation de Rachel sur les Innocents, et la résurrection du fils de la veuve, str. 14, juste après l'arche de Noé). La force du poème ne vient pas de l'insistance sur des détails pathétiques, mais de la convergence dans la direction, tendue vers le salut des hommes par le Christ. Le procédé, question et réponse unique, par accumulation, prend une force non pathétique, mais dramatique par l'intensité du sujet et la force du refrain.

La Bible comporte beaucoup de discours directs. Les paroles du Christ en particulier sont souvent reprises et paraphrasées, même dans les pièces qui ne pratiquent pas généralement ce procédé. Ainsi dans le récit 'De resurrectione Christi', Venit tristis ad Pilatum ${ }^{24}$, qui n'insiste pas sur le pathétique et n'interpelle pas l'auditeur, seules les paroles du Christ sont paraphrasées : Ego sum, nolite flere, carnem meam cernite ... Ego vos, sicut me pater, mitto sicut miserat ... et à Thomas : Mitte manum, tange latus, sis fidelis, Didime : / Felix erit qui viderit et credere potuit (str. 10, 17, 22). Le discours direct y est à peu près le seul procédé dramatisant.

Le discours direct est le plus souvent justifié par le modèle biblique. Mais l'embellissement poétique permet de développer son usage. Ainsi le Pseudo-Paulin, sur Noël, Gloriam deo in excelsis hodie, ${ }^{25}$ présente beaucoup plus de discours directs que dans Matthieu et Luc (str. 15, 23, 25, les deux dernières dans la bouche d'Hérode qui va être violemment pris à partie). Cette pièce, riche par ailleurs de tous les procédés d'interpellations ( $5+1$ str., $26-30$ et 36 , à Hérode, 4 strophes aux Innocents, 38-41) représente parfaitement l'immédiateté dramatique de Paulin d'après Stella, son 'style sentimental'. ${ }^{26}$ En ce sens Paulin est plus proche des rythmes du VIII $^{\text {e }}$ siècle qui lui sont quasi contemporains que de l'intellectualité d'un Florus.

Parfois les paroles sont transformées, généralement dans le sens d'une appropriation de la situation biblique au poète ou à l'auditeur, ainsi les paroles du bon larron dans Surrexit Christus :

23 PLAC IV 524-526.

24 PLAC IV 531.

25 PLAC I 144.

26 Stella (1993) 359 ; Corpus (2007) 206. 
Memora, domine, me peccatorem hominem, qui non sum dignus ego tecum loquere, sed propter meam tantam neglegentiam precor te, Iesus, dona indulgentiam. ${ }^{27}$

Paroles qui pourraient servir à n'importe quel pécheur, et ne reflètent guère les paroles du larron de Lc 23.42 (elles ont peut-être été rapportées, la strophe ayant un vers de trop). On a ici une identification au personnage biblique, comme chez Gottschalk, mais beaucoup moins forte.

Le choix de privilégier tel ou tel locuteur est aussi significatif. Homo quidam erat dives, sur la parabole du mauvais riche et du pauvre Lazare, ${ }^{28}$ Lc $16.23-31$, passe au discours indirect les discours du riche, mais transpose en discours direct les deux réponses d'Abraham le patriarche, qui expriment directement la pensée du Christ.

L'histoire de Joseph, fort dramatique en soi, était spécialement riche en discours, qui ont orienté les réélaborations. Ainsi Audite mirabilia, titré 'De Joseph"29, a six strophes de discours directs. Sur le même thème narratif, Paulin d'Aquilée, Tertio in flore, 'De Jacob et Joseph', ${ }^{30}$ présente d'autres discours directs que la Bible. S'il simplifie les épisodes de l'indignation des frères au récit des rêves de Joseph en ne gardant que les rêves eux-mêmes, et saute les discours directs d'envoi de Joseph par Jacob et une partie des conciliabules entre les frères, en gommant en particulier le rôle de Ruben, il ajoute quatre strophes de lamentation de Jacob (str. 15-18). Puis, sautant l'épisode de la femme de Putiphar, il simplifie également les discours en ne conservant que les rêves et leur interprétation. Dans tous les échanges de la reconnaissance de Joseph et de ses frères, qu'il est obligé d'abréger, il ne garde que les plus émouvants et les plus forts, faisant montre d'un goût raffiné. Le passage ajouté est un planctus : c'est justement vers cette époque que naît le genre. Abélard fera de même, bien plus tard, un Planctus Iacob super filios suos, et les lamentations de Jacob seront abondamment exploitées au XII ${ }^{\mathrm{e}}$ siècle, avec toutes les ressources du pathos. Les poèmes pénitentiels, d'ailleurs, sont l'équivalent de planctus à la première personne : ils ouvrent la voie à la poétique de la plainte. Il est d'ailleurs probable que tous les discours directs, d'abord adaptés de la Bible, puis développés, que l'on rencontre à cette époque, et qui ajoutent à la vivacité des récits bibliques, sont une étape qui accompagne la formation des tropes dialogués aux origines des représentations sacrées.

27 PLAC II 254, str. 6.

28 Dans la version la plus complète, version A, Corpus (2007) 276-278. Plus exactement, il transforme en un vers entier, Filium eum nuncupavit, quod esse debuerat, le vocatif Fili de sa source, ce qui est un début de glose, avant de passer au discours direct ; les autres versions sont plus proches du verset 16, 25. Voir Björkvall - Haug (2003), qui éditent également les deux versions.

29 PLAC IV 640-643, str. 7, 13, 14, 19, 25-26.

30 PLAC IV 462-71; Corpus (2007) 397, commenté par Stella ibid. 347-356. 
Plusieurs discours directs aboutissent aux dialogues. Le dialogue entre Jésus et Judas $^{31}$ en est un parfait exemple, avec ses refrains alternés $O$ Juda, traditor meus et Heu me peccatorem, qui tradidi salvatorem, où les reproches de l'un et la repentance désespérée de l'autre sont conclus par une apostrophe à l'auditoire et à Judas, Et tu, crudeles Iuda, permanes in ardura, bien que l'éditeur Peter Stotz doute de la pertinence de cette dernière apostrophe peut-être plus tardive. Ce dialogue est entièrement tragique. De même que les échanges entre le Christ et les âmes qu'il juge du chapitre 25 de Mathieu sont reprises dans le très ancien poème Apparebit repentina, avec les réponses étonnées des bénis et des damnés : Quando, Christe, pauperem te vidimus ? / Te, rex magne, vel egentem miserati juvimus ? $^{32}$

Le dialogue est l'essentiel également dans des poèmes inspirés non de la Bible mais des apocryphes, lesquels ne sont pas tellement présents dans les poésies bibliques à nous parvenues, mais qui y sont représentés par un superbe résumé du ch. 20 de l'Evangile de Nicodème. Il s'agit de 'De contentione zabuli cum inferno', incipit Audiat celum atque terra, du début du VIII ${ }^{\mathrm{e}}$ siècle. ${ }^{33}$ Il est sous forme de dialogue, comme sa source. Il a pour refrain un appel direct aux auditeurs, Videte principem mortis/ religatum in tormentis, ce qui fait appel à leur imagination visuelle, et en fait des spectateurs. L'Enfer tremble après l'évasion de Lazare, alors que Satan encore sûr de lui croit avoir réduit Jésus et l'avoir envoyé à l'Enfer. Mais celui-ci sait que Satan va devoir combattre Jésus et sera vaincu : Fortis timor me concutit, dixit Infer pavidus : Es cum illo pugnaturus et ab ipso religandus (str. 6). L'apocryphe est prêt à être mis en scènes à la fois hiératiques et déclamatoires, comme le seront plus tard les jeux du théâtre sacré. Mais le poème, entièrement ombreux, avec la sombre jubilation du refrain, 'Voyez le prince de la mort ligoté dans les tourments', a une force dramatique encore plus grande. La mise en forme poétique conserve le dialogue, mais l'épure, néglige les effets dramatiques extérieurs comme les prisonniers qui s'agitent, la voix qui exige que les portes s'ouvrent, les témoignages des différents patriarches. Le poème est concentré sur la terreur croissante des tyrans vaincus, leur déconfiture. Il esquisse tout juste la lâcheté servile de l'Enfer qui, dans l'apocryphe, est tout prêt à se faire le geôlier de Satan puisque le Christ a vaincu. La tension dramatique est perçue entièrement par l'appréhension croissante des forces du mal. Le texte en prose savourait toutes les circonstances de la victoire sur la mort, dans tous les détails, avant et après l'affrontement entre les deux puissances mauvaises. Le poème ne reprend que le désarroi des vaincus, il exalte donc cette victoire en négatif, du point de vue de la défaite.

Indépendamment de leur promesse typologique, ce sont les épisodes les plus pathétiques qui reçoivent le plus souvent une valorisation poétique. Nous avons déjà rencontré à plusieurs reprises l'histoire de Joseph, mais Esther (IV.588) et Judith,

31 Ed. Peter Stotz (2000).

32 PLAC IV 507, r. 17. Str. 11.

33 PLAC IV 636, n LXXXIII. 
illustrant toutes deux un danger mortel écarté dans des circonstances dramatiques grâce à la mort d'un ennemi, sont également présentes, et plus rarement les Macchabées. ${ }^{34}$ Pour le Nouveau Testament, les thèmes favorisés parlent également de mort et de résurrection : d'abord Lazare, objet de pièces séparées, mais aussi les Saints Innocents qui figurent dans presque toutes les pièces sur la Nativité. ${ }^{35}$ L'épisode des Innocents est compris comme un chant de victoire, car non seulement Hérode n'a pas réussi à faire échouer le plan de Dieu et la survie du Christ enfant annonce sa victoire finale, mais encore les enfants morts ont gagné la palme du martyre. La souffrance des mères est à peine citée, à cause du passage de Mathieu, mais on ne s'y arrête guère. Dans son infatuation et sa cruauté, Hérode, traité de renard et de loup par le Ps.-Paulin d'Aquilée, ${ }^{36}$ est le véritable protagoniste de l'épisode ; lié en enfer comme Satan, il apparaît comme une incarnation du Mal. Le drame des enfants suscite une indignation plus forte encore que la compassion, ou plutôt celle-ci ne s'exprime que par l'indignation. ${ }^{37}$ Ce n'est qu'un peu plus tard que le deuil des mères rejoindra le courant des lamentations féminines, à peine perceptible chez Notker de Saint-Gall (Quid tu, virgo mater) ${ }^{38}$, qui se développera dans les jeux liturgiques. ${ }^{39}$ En effet le drame de la bible est à cette époque théologique et peu sentimental (seule la souffrance des sœurs de Lazare entrouvre la possibilité d'attendrissement, chez Paulin).

On peut noter la relative absence des thèmes issus des apocryphes sur l'enfance du Sauveur (Proto-évangile de Jacques, Infantia Salvatoris ou Ps.-Mathieu). Florus, dans ses Gesta Christi, écrits pour une école, fait des allusions aux épisodes de l'enfance, mais de façon assez lointaine et détachée. Ces textes étaient pourtant connus puisqu'on y a des allusions chez certains Pères ou dans les Joca monacho-

34 Chez Walahfrid Strabon, voir Vélez Latorre (2005). Il montre que le combat des Machabées est interprété comme une lutte du Christ contre le mal et le démon.

35 Ainsi PLAC IV 478, r. Nº 7, str. 10 - Ibid. 481, Nº 8, str. 5 - PLAC IV 521 ; 524- 526, str. 20 - Micon de Saint-Riquier, PLAC III 299-300. - Versus Hartmanni de natale Innocentum ad processionem, de Saint-Gall, PLAC IV.1 318. - PLAC IV 351, n IV, chanson à boire pour chaque fête, ms. Reg. lat. 321, de Saint-Julien de Brioude fin $\mathrm{IX}^{\mathrm{e}} \mathrm{s}$.

36 PLAC I 144, n 11 , str. 26-31.

37 Vulpes Herodes, cur cauda dissimulas / predam captare, qui beluino gutture / sanguinem sitis, agni carnes esuris, / lupe crudelis, str. 26 de PLAC I 144, dubia de Paulin, Gloriam Deo in excelsis ; le poème multiplie les imprécations et les adjurations à propos des Innocents, str. 34-41; de même avec une ironie mordante (str. 6, Dux bone, arbiter egregius) Raban, PLAC II 246, voir Stella (1993) 246 et anthologie $\mathrm{n}^{\circ}$ 49. Notker, In Natale Innocentum, PL 131, col.1007-1008, ne parle même pas des mères et insiste surtout sur la sainteté et le pouvoir d'intercession des Saints Innocents. Quant à Micon de Saint-Riquier, PLAC III 299-300, v. 63-72, son indignation rhétorique est dépourvue de la moindre émotion, et sa muse demande ensuite à boire pour sa peine. Mais Micon insiste sur sa propre superficialité : il prétend écrire pour qu'on ne puisse lui reprocher d'être oisif. D’autres poèmes de Saint-Gall (PLAC IV, 318 ; 481) ou d'ailleurs (PLAC IV 524-526, str. 20) sont assez convenus.

38 Stella (1995) 232-234.

39 Voir Colette - Iversen (2014) 271-288, et, pour le rapprochement avec les lamentations féminines mises en musique dans les manuscrits de poètes classiques, Ziolkowski (2007) 195-196. 
rum, et que l'âne et le bœuf apocryphes apparaissent dans les plus anciennes miniatures de la Nativité. Mais ils ne sont pas encore actifs dans la poésie occidentale, et leurs potentialités dramatiques n'intéressent guère. Un rythme sur l'Annonciation, qui va en fait jusqu'au baptême de Jésus et finit avec Zachée (car il est alphabétique), n'en fait pas usage, ${ }^{40}$ non plus que les pièces sur la nativité, ${ }^{41}$ ou à la louange de la Vierge. ${ }^{42}$ Le fait que le Christ se soit fait homme n'entraîne pas à l'époque d'attendrissement, du moins de la part des clercs. Il n'y a pas encore de lamentations de la Vierge, à peine la mention de Siméon lui promettant un glaive dans le cœur, ni de Marie Madeleine. Cette époque s'intéresse peu à l'humanité du Christ sinon au plan dogmatique et théologique, et s'en tient résolument aux textes canoniques. Le seul apocryphe qui a vraiment inspiré les poètes, c'est l'Evangile de Nicodème, à cause de sa tension eschatologique ; on retrouve son influence, même discrète, dans presque tous les poèmes sur la Résurrection ou le Jugement, où Satan grince des dents et les âmes des justes montent au ciel.

La seule conclusion de ce rapide coup d'œil sera une comparaison avec les poèmes analogues de la fin $\mathrm{XI}^{\mathrm{e}}-\mathrm{XII}^{\mathrm{e}}$ siècle, qui ne me permettra que quelques généralités, discutables comme toutes les généralités.

Il me semble que l'accent passe avec le temps de l'eschatologie à la tropologie, avec toutes les nuances à apporter. On rencontre à l'époque carolingienne moins souvent d'épisodes tirés de paraboles : le fils prodigue par exemple apparaît très peu comme source d'inspiration, sauf chez Gottschalk dans $O$ mi custos, alors qu'il est très présent $\mathrm{au} \mathrm{XII}$ e siècle. Le bon Samaritain est absent. Mais sont favorisés les épisodes ayant une valeur eschatologique évidente, comme la parabole du riche et du pauvre Lazare.

Le thème des Innocents nous fait toucher du doigt les caractères propres de l'émotivité de l'époque. Le VIII ${ }^{\text {e }}$ siècle, assimilant dans la punition Hérode à Satan et Judas, est nettement plus vindicatif que les époques postérieures, à partir de Notker le Bègue, où Hérode s'efface ${ }^{43}$; chez Hildegarde au XII' siècle, il n'est plus promis qu'au sommeil de la mort, tandis que la compassion pour les enfants morts prend le dessus.

40 PLAC IV 474.

41 PLAC IV 477, r. 7 A superna caeli parte.

42 PLAC IV 515 Aurora dicta, où toutefois dans la str. 10 Kasta turture voce, vero sermone / se profitentem virum non cognoscere, l'allusion à la tourterelle ne vient pas seulement de Lc 1.34.

43 Notker de Saint-Gall, PL $131 \mathrm{n}^{\circ}$ 6, ne parle que de la rémunération céleste des Innocents, et Hérode qui sert de repoussoir (Herodis ut non fiat socius quisquis) semble très lointain. Dans cette séquence l'accent est sur le présent des orants, sur leur crainte et leur espérance, plus que sur le drame passé. Abélard dans l'Hymnarius paraclitensis est encore dans le droit fil de la tradition qui met en parallèle la tristesse de la mort et la gloire de la récompense, mais, avec une antienne tout aussi liturgique, Hildegarde de Bingen, avec le refrain Sed nubes super eundem sanguinem plangunt, semble intégrer une dimension pathétique de la déploration qui marque une sensibilité nouvelle (éd. Barth-Ritscher-Schmidt, Salzburg 1969, p. 262). 
L'expression de la méthode exégétique me semble un peu moins souvent qu'au $\mathrm{XI}^{\mathrm{e}}-\mathrm{XII}^{\mathrm{e}}$ s. constitutive ; elle reste souvent implicite, sauf chez Paulin où elle est juxtaposée, après le récit, ${ }^{44}$ ou intériorisée, chez Walahfrid, ${ }^{45}$ alors que certains poèmes d'Hildebert sont uniquement fondés sur l'exégèse.

La fascination devant le réservoir de méditation de la Bible est toujours le même, ainsi que le besoin de l'actualiser, donc de l'intérioriser par la rumination poétique. Il me semble que l'insistance est plus à l'eschatologie à la fin de l'époque mérovingienne, notamment dans les rythmes, et plus à la tropologie à l'époque tardive, où ce qui semble l'essentiel, ce sont les mœurs et la foi, dans le présent des fidèles. Sur le plan de la dramatisation, l'arsenal est toujours le même : interpellations aux protagonistes, commentaires, exclamations. Avec le temps, les moyens rhétoriques de plus en plus rodés permettent une surenchère dans la grandiloquence, qu'on pourrait illustrer en plaçant à côté du poème de Paulin d'Aquilée sur Joseph et Jacob, cité plus haut, le même thème traité par Pierre Riga dans son Floridus aspectus : le planctus de Jacob y est un feu d'artifice de 36 vers anaphoriques et baroques, pleins d'apostrophes, d'allitérations et de figures. Le classicisme mesuré de Paulin prend en comparaison toute sa valeur.

\section{Bibliographie}

Björkvall - Haug (2003): Gunilla Björkvall et Andreas Haug , «Rhytmischer Vers : performative Aspekte seiner form zu MGH Poetae IV, 2 n. 35 und n. 88», in: Poetry, 119-148.

Bourgain (2016): Pascale Bourgain, «Mise en texte et ponctuation des rythmes lyriques latins», in: Ponctuer l'œuvre médiévale. Des signes au sens, Etudes réunies par Valérie Fasseur et Cécile Rochelois, Genève (Publications romanes et françaises, 267), 149-181.

Colette - Iversen (2014): Marie-Noël Colette et Gunilla Iversen, La parole chantée, invention poétique et musicale dans le haut Moyen Âge occidental, Turnhout.

Corpus (2007): Corpus rythmorum musicum saec. IV-IX, directed by Francesco Stella I. Songs in non-liturgical sources, I, Lyrics, Firenze (Millennio medievale 72, Testi 18).

PLAC: Poetae latini aevi carolini, Monumenta Germaniae historica

Poesia (2000): Poesia dell'alto Medioevo europeo : Manoscritti, lingua e musica dei ritmi latini. Atti delle euroconferenze per il Corpus dei ritmi latini (IV-IX sec.), Arezzo 1998 e Ravello 1999, a cura di Francesco Stella, Firenze, SISMEL/Ed. del Galluzzo.

Poetry (2003): Poetry of the early medieval Europe : manuscripts, language and music of the rythmical Latin texts, III Euroconference for ... the Corpus of latin rythmical texts 4th-9th Century, a cura di E. D’Angelo e Fr. Stella, Firenze (Millennio medievale 39).

Stella (1993): Francesco Stella, La poesia carolingia latina a tema biblico, Spoleto (Biblioteca di Medioevo latino, 9)

44 La riche terminologie de Paulin d'Aquilée, comportant des expressions qui lui sont propres, a été étudiée par Stella (1993) 343 ; 364. Mais il faut remarquer que la partie exégétique très fournie de Fuit Domini dilectus (p. ex. str. 43) a été négligée par la plus grande partie de la tradition manuscrite, et qu'il n'est pas même sûr qu'elle nous soit parvenue complète (Stella, dans Corpus (2007) 206) : elle est détachable, et non pas intégrée dans le récit.

45 Voir Velez Latorre (2005). 
Stella (1995): La poesia carolingia. Testo latino a fronte, a cura di Fr. Stella, Firenze.

Stella (2001): Francesco Stella, Poesia e teologia. I. L'Occidente latino tra IV e VIII secolo, Milano. Stella (2010) : Francesco Stella, Poesia e teologia. II. Il dibattito carolingio, Milano.

Stotz (2000): Peter Stotz, «Judas Iscarioth als Büsser : zu einer wiedergewonneren rhythmischen Wechselrede zwischen Christus und seinem Verräter», in Poesia (2000), 298-312.

Vélez Latorre (2005): José Manuel Vélez Latorre, «La paràfrasis bìblica en cuatro textos de Walafrido Estrabon », in: Poesía latina medieval (siglos V-XV). Actas del IV Congreso del «Internationales Mittellateinerkomitee', Santiago de Compostela, 2002, ed. Manuel C. Diaz y Diaz \& José M. Diaz de Bustamante, Firenze, 351-356.

Ziolkowski (2007): Jan M. Ziolkowski, Nota bene : Reading Classics and Writing Melodies in the Early Middle Ages, Turnhout (Publications of the Journal of Medieval Latin, 7). 


\section{François Ploton-Nicollet}

\section{Entre satire de l’Église et parodie biblique}

\section{L’Apocalypse de Golias}

L'Apocalypse de Golias ${ }^{1}$ est un long poème de 440 vers, dont le succès au Moyen Âge semble avoir été inversement proportionnel à l'intérêt qu'il a suscité chez les critiques contemporains. Si l'on évalue l'impact d'une œuvre au nombre manuscrits qui nous en sont conservés, comme permet maintenant de le faire la base FAMA $^{2}$ de l'IRHT, grâce au zèle de Pascale Bourgain et de son équipe, on est incontestablement face à une œuvre à succès, transmise par 69 manuscrits, datables en majorité des $\mathrm{XIII}^{\mathrm{e}}$ et $\mathrm{XIV}^{\mathrm{e}}$ siècles, et principalement copiés en Angleterre, dans une moindre mesure en France. Mais c'est incontestablement en Angleterre qu'elle a connu le succès le plus massif et le plus durable, puisque, comme l'a montré le dernier éditeur, Strecker, ${ }^{3}$ elle y a été copiée jusqu'au XviI ${ }^{\mathrm{e}}$ siècle, et plusieurs fois traduite en langue vernaculaire.

Il s'inscrit dans la grande tradition de la poésie lyrique latine du xII ${ }^{\mathrm{e}}$ siècle, tant par sa dimension satirique $\mathrm{e}^{4}$ que par sa forme : le poème est composé en strophes de quatre vers rythmiques réguliers, richement rimés, comptant douze syllabes, césurés 6/6, chaque hémistiche comportant un accent principal sur l'antépénultième syllabe.

C'est l'œuvre d'un poète virtuose, dont l'identité nous échappe et qui s'efface derrière le pseudonyme de Golias, figure par ailleurs bien connue dans la littérature goliardique, ${ }^{5}$ où on le qualifie généralement d'évêque, et dont il faudrait encore définir ici le statut : s'agissant de littérature apocalyptique, est-il censé être l'auteur du texte, le visionnaire, ou l'un et l'autre à la fois ? La rédaction du poème à la première personne ne répond que partiellement à la question. La virtuosité du texte fait qu'on l'a attribué parfois à Gauthier Map, à Primat, à Gautier de Châtillon, voire à Alain de Lille, ${ }^{6}$ toutes attributions séduisantes, mais reposant chacune sur des in-

1 Le texte est disponible dans deux éditions : Wright (1841) et Strecker (1928). Nous le citons dans celle de Strecker. Les traductions proposées sont toujours personnelles.

2 Institut de recherche et d'histoire des textes (IRHT-CNRS), Notice de Apocalypsis Goliae, dans Pascale Bourgain, Francesco Siri, Dominique Stutzmann, FAMA : Euvres latines médiévales à succès, 2017 (permalink : http://fama.irht.cnrs.fr/oeuvre/267502). Consultation du 08/07/2018.

3 Strecker (1928) 3.

4 Mann (1980).

5 Rigg (1977) ; Walsh (1983) ; Mantello/Rigg (1996) 564 ; voir aussi, dernièrement, les réflexions de Bridges (2012) 249-251.

6 L'attribution à Primat s'appuie sur le témoignage, à la fois peu fiable et peu clair de Salimbene, au XIII ${ }^{\mathrm{e}}$ s. (Cronica, 117, 27, éd. G. Scalia, Turnhout, CCCM, 125, 1998, 121 : De Primate trutanno et de versibus suis et rithmis. Nota quod Primas Aurelianensis fuit. Fuit his temporibus Primas canonicus Coloniensis... Cujus Appocalipsim, quam fecerat, vidi et alia scripta plura). L'attribution à Gauthier Map, reprise par Wright (1841), sur l'opinion de Matthias Flacius Illyricus, au Xvi s. (Varia doctorum piorumque virorum de corrupto Ecclesiae statu poemata, Bâle, 1557, sig. i 3r). Mais il a été noté par la 
dices ténus plutôt que sur des preuves, ce qui nous semble conduire à un constat de non liquet.

Pour être complet, il faudrait ajouter que le texte circule tantôt de manière isolée, tantôt accompagné d'autres poèmes, plus courts, appartenant à la même veine lyrique et satirique, mais répondant à une métrique différente et, si l'on en croit le style, sortis de mains différentes, quoique attribués par les suscriptions au même Golias - qui n'est donc qu'une persona poétique ${ }^{7}$ - ou à l'un de ses disciples. Il s'agit de la Métamorphose de Golias, de la satire De grisis monachis, du De sacerdotibus et du De conjuge non ducenda, corpus dont l'unité est assurée par la récurrence de quelques thèmes : une violente satire des moines, des attaques en règle contre le pire d'entre eux, Bernard de Clairvaux, une admiration inconditionnelle pour Abélard et, dans une moindre mesure, pour les maîtres séculiers de l'école de Chartres, enfin une prise de position vigoureuse en faveur du célibat des clercs. ${ }^{8}$

S'ils ne remontent pas à la même main, ${ }^{9}$ tous ces textes nous semblent être l'œuvre d'un cercle, probablement composé d'étudiants et de maîtres, peut-être artiens, en tout cas familiers de la culture scolaire. On peut les dater sans grand risque de la seconde moitié du XII ${ }^{\mathrm{e}}$ siècle. Quant au lieu de composition, on peut hésiter entre l'Angleterre et le Nord de la France. Dans le cas de l'Apocalypse de Golias, la prédominance des manuscrits anglais dans la transmission n'est pas un indice très fiable, car il n'est pas rare de voir des œuvres latine d'origine française connaître une grande fortune outre-Manche. Beaucoup dépend en fait de la lecture que l'on fait à la $\S 17$, lorsque le visionnaire reçoit l'ordre d'écrire à sept Églises comme saint Jean avait reçu l'ordre d'écrire aux sept Églises d'Asie :

Set visa scripserat ille misteria
septem Ecclesiis que sunt in Asia.
Tu scribes eadem, forma set alia,
septem Ecclesiis que sunt in Anglia. ${ }^{10}$

La tradition manuscrite se répartit alors entre la leçon septem Ecclesiis que sunt in Anglia et septem Ecclesiis que sunt in Neustria, ${ }^{11}$ cas qui semble difficile à trancher en l'état actuel des travaux sur la transmission du texte.

Plutôt qu'à ces quaestiones vexatae, nous souhaiterions consacrer la présente contribution à deux problèmes qui nous semblent plus en accord avec la thématique

critique que le texte circule parfois sous le nom et souvent parmi les œuvres d'Alain de Lille ou d'un Gauthier qui pourrait être aussi bien Gauthier Map que Gauthier de Châtillon (Strecker (1928) 7-8). De manière générale, sur ces questions d'attribution, voir au premier chef Rigg (1977) 81-87.

7 Raby (1934) II 215 parle de literary phantom.

8 Pour une présentation d'ensemble de ces textes, voir Raby (1934) II 219-227.

9 Comme l'a bien montré Raby (1934) II 222.

10 Sa vision mystique, il l'avait, lui, écrite, aux sept Églises qui sont en Asie. Toi, tu écriras la même chose, mais sous une autre forme, aux sept Églises qui sont en Angleterre.

11 Strecker (1928) 8-10 ; Raby (1934) II 215. 
de ce volume : celui de la structure du texte et celui de l'intertextualité biblique, deux questions qui ne sont d'ailleurs pas tout à fait sans lien et dont l'examen permettra d'atténuer un double reproche que l'on a fait parfois à ce poème, à savoir, d'une part, d'être dépourvu d'unité, d'autre part, d'être un simple pastiche où l'Apocalypse serait parodiée dans sa forme sans que sa mise en œuvre soit au service d'une véritable esthétique. $^{12}$

Il est vrai que la structure peut sembler hétérogène de prime abord. Le poème se présente ainsi :

- I. § 1-13 : Scène d'ouverture: il est midi, par une chaude journée de printemps; le narrateur se réfugie à l'ombre d'un arbre. Pythagore lui apparaît, le corps couvert d'inscriptions et portant sur les différentes parties de son corps le signe des sept arts libéraux. Il s'offre comme guide et conduit le narrateur in terram alteram (§ 8). Là se trouve une foule au milieu de laquelle apparaissent Priscien, Aristote, Cicéron, Ptolémée, Boèce, Euclide et Pythagore, puis les poètes (Lucain, Virgile, Ovide, Perse, Stace, Térence), ainsi qu'Hippocrate.

- II. §14-104 : Subitement, un ange s’approche et lui dit : Suspice! Oculos aperi / et vide, cito que oportet fieri (§ 14). Cette référence à peine voilée à l'Apocalypse biblique $^{13}$ fait entrer dans la seconde partie du texte, qui constitue le cœur du poème, lequel est une parodie directe de l'Apocalypse johannique, dans une finalité clairement satirique. Le visionnaire est emporté «en esprit» dans les airs. ${ }^{14}$ L'ange lui dit alors de ne pas bouger et lui indique qu'il verra ce qu'a vu saint Jean, ${ }^{15}$ lui intimant l'ordre d'écrire aux sept Églises d'Angleterre (ou de Neustrie, selon la leçon adoptée) comme son prédécesseur avait écrit aux sept Églises d'Asie. ${ }^{16}$ Apparaissent alors sept chandeliers et sept étoiles (cf. Apc 1.12 sqq.), puis l'ange apporte un livre fermé par sept sceaux, ${ }^{17}$ et l'ouverture successive de chacun d'entre eux révèle les turpitudes de l'Église, en suivant un

12 À seul titre d'exemple, voici les mots très durs de Hauréau (1880) 291-292, cité par Newman (1967) 113 : «Cette longue satire n'est pas, au point de vie littéraire, vraiment digne de remarque. Il y a sans doute quelques traits d'esprit ; mais il n'est pas du tout certain qu'ils soient originaux. Ce qui appartient plus sûrement à l'auteur, ce sont les défauts de son œuvre. Elle est d'abord très mal composée ; la première partie ne tient au reste par aucun lien. Il ne suffit pas de donner à une pièce le titre d'Apocalypse pour avoir le droit d'y mêler toutes sortes de choses incohérentes.»

13 L'injonction est une récriture de Apc 1.19: Scribe ergo quae vidisti, et quae sunt et quae debent fieri post haec. Nous citons la Bible en suivant le texte de la Vulgate sixto-clémentine.

$14 \S 15$ : et fui postea statim in spiritu / tractus per ethera. On relèvera la phraséologie apocalyptique ; cf. Apc 1.10 : fui in spiritu dominica die ; 4.2 : et statim fui in spiritu ; 17.3 : et abstulit me in spiritu in desertum ; 21.10 : et sustulit me in spiritu in montem magnum.

$15 \S 16$ : Siste et videbis que Johannes viderat («Tiens-toi là : tu verras ce qu’avait vu saint Jean»). $16 \S 17$ : Set visa scripserat ille misteria / septem Ecclesiis que sunt in Asia. / Tu scribes eadem, forma set alia, / septem Ecclesiis que sunt in Anglia. Cf. Apc 1.4 : Johannes septem Ecclesiis que sunt in Asia. $17 \S 21$ : post hec apposuit cum septem titulis / signatum codicem septem signaculis («Il apporta ensuite, contenant sept chapitres, un livre qui était scellé avec sept sceaux»). Cf. Apc 5.1 : et vidi... librum sriptum intus et foris, signatum sigillis septem. 
ordre hiérarchique décroissant. Il serait trop long de détailler les différents tableaux - tous très vivants et très caustiques - à quoi cette révélation donne lieu, mais qu'il nous soit permis d'en livrer un aperçu à travers deux exemples empruntés l'un au début, l'autre à la fin du passage. Ils rendront en effet justice à la virtuosité dont fait montre l'auteur, d'une part dans le remaniement de l'hypotexte biblique, d'autre part dans le déchaînement de sa verve satirique.

Le premier sceau provoque l'apparition de quatre Vivants (un lion, un veau, un aigle, un homme) en tous points semblables à ceux que décrit saint Jean au quatrième chapitre de l'Apocalypse, c'est-à-dire pourvus d'ailes, couverts d'yeux et sans cesse en mouvement :

Primi capituli quedam potencia

signum aperuit, et animalia

perspexi quatuor, que redit varia

forme diversitas, gestus equalia.

Est primum animal leoni simile, secundum vitulo, tercium aquile, et quartum homini, quodque volatile repletum oculis, rotis volubile. ${ }^{18}$

La lecture du livre au sept sceaux révèle au visionnaire que ces quatre vivants représentent le pape, l'évêque, l'archidiacre et le doyen. L'assimilation du pape au lion est l'occasion d'un quadruple jeu de mots d'une grande habileté (§ 26) :

Est leo pontifex summus qui devorat, qui libras siciens libros inpignorat, marcam respiciens Marcum dedecorat, in summis navigans in nummis ancorat. ${ }^{19}$

$18 \S 23-24$ : «Et du premier chapitre une Puissance ouvrit le sceau, alors je vis clairement m’apparaître quatre êtres que distingue leur aspect varié, mais agissant de même. Le premier de ces êtres ressemble à un lion, le second à un veau, le troisième à un aigle, le quatrième à un homme, et chacun est ailé, a le corps couvert d'yeux et bouge sur des roues.» Cf. Apc 4.6-8 : et in medio sedis, et in circuitu sedis quatuor animalia plena oculis ante et retro. Et animal primum simile leoni, et secundum animal simile vitulo, et tertium animal habens faciem quasi hominis, et quartum animal simile aquilae volanti. Et quatuor animalia, singula eorum habebant alas senas : et in circuitu, et intus plena sunt oculis : et requiem non habebant die ac nocte.

19 «Le lion est le grand pontife, qui dévore, qui dans sa soif de livres hypothèque ses Livres, par respect pour les marcs déshonore saint Marc, et sur la mer des sommes s'amarre dans les sous.» La virtuosité de cette strophe n'avait pas échappé à Th. Wright, qui connaissait si bien cette œuvre, et qui lui a réservé une place dans History of Caricature and Grotesque : voir Wright (1875) 167. 
Le procédé est difficile à restituer en français ; il repose sur l'ambiguïté de la forme leo, qui peut s'admettre comme nom commun («lion») ou comme nom propre (Léon, fréquemment choisit comme nom pontifical ${ }^{20}$ ). Ce jeu de mots permet le glissement vers une lecture allégorique et enclenche une série de paronomases opposant ce que le pape devrait aimer (les livres, et probablement les Livres sacrés ; saint Marc, en tant qu'évangéliste ; les sommes, c'est-à-dire les ouvrages universitaires) et ce qu'il aime en réalité (les livres d'or ; les marcs d'or ou d'argent ; ${ }^{21}$ les espèces monétaires), en une critique acerbe et brillante - mais topique - de la rapacité fiscale du Saint-Siège.

À la fin de la vision, et donc à l'opposé symétrique de ce portrait peu flatteur du souverain pontife, l'ouverture du septième sceau donne à voir un tableau de l'ivrognerie et de la goinfrerie des moines (§ 84-102), que l'auteur considère donc comme la lie de l'Église, si l'on en croit l'ordre hiérarchique décroissant adopté jusque-là. En tout cas, il raille leur vêtement sordide, qui ne les empêche pas d'avoir du goût pour les arts de Vénus. ${ }^{22}$ Le passage est moins savant que le précédent, et il fait nettement moins appel à l'intertextualité biblique, ${ }^{23}$ ce qui doit peut-être s'interpréter comme une volonté de souligner par là-même l'inculture des moines. En revanche la verve du poète, son goût pour l'hyperbole, son art du jeu de mots ne se démentent pas, jusque dans les dernières strophes de la section :

Est nullum monacho maius demonium, nichil avarius, nil magis varium ;

cui, si quid datur, est possessor omnium, si quicquam petitur, nil habet proprium.

Si prandet, convenit ut loqui nesciat, ne lingua dencium opus impediat ; si bibit, expedit ut sedens hauriat, ne pes sub pondere ventris deficiat. ${ }^{24}$

20 Cela dit, aucun pape n’ayant porté le nom de Léon entre Léon IX (mort en 1054) et Léon X (élu en 1513), il faut renoncer à y voir une allusion à un pontife précis : ce sont la fonction et l'institution qui sont ici visées, comme souvent dans la veine satirique du Moyen Âge, d'ailleurs.

21 Le jeu de mots sur Marcus / marca se retrouve, avec la même intention satirique dans le célèbre Evangelium secundum marcas argenti (dont une version est conservée dans les Carmina Burana, $\mathrm{n}^{\circ} 44$ Bernt).

$22 \S 88$ : Set cum sit habitus illorum turpior, / in ipsis habitat Venus securior («Mais malgré leur habit ignoble s'il en est, c'est en eux que Vénus a son plus sûr repaire»).

23 Tout au plus quelques réminiscences psalmiques et néo-testamentaires, si l'on en croit l'apparat de Strecker (1928) 32-36.

$24 \S 100-101$ : «Il n'est aucun démon plus terrible qu'un moine, rien qui soit plus avide, rien de plus inconstant : quand on lui fait un don, tout lui est dû de droit ; quand on le sollicite, il ne possède rien. S'il déjeune il convient qu'il ne sache parler, pour ne pas de sa langue gêner l'œuvre des dents ; s'il boit il est de mise qu'il ingurgite assis, de peur que son pied cède sous le poids de son ventre.» 
Ici, l'hyperbole confine à la mauvaise foi, parfaitement assumée, quand le poète explique les différentes prescriptions de la règle monastique par une volonté de mieux jouir des plaisirs matériels. Si on l'en croit, en effet, le vœu de pauvreté n'a d'autre but que de se faire entretenir par autrui sans jamais rien donner en retour ; l'obligation de manger en silence - effectivement contraire à l'urbanité séculière - se justifie par la nécessité de manger plus à son aise ; et la coutume monastique de boire assis serait un moyen de se prémunir contre les effets d'une ivresse volontairement recherchée.

Après cette vision, l'ange en inscrit la teneur dans le cerveau du visionnaire pour qu'il en conserve le souvenir.

- $\quad$ III. § 105-110 : Sans transition, le narrateur est alors ravi au troisième ciel, où de grands mystères lui sont révélés (§ 105) :

His gestis deferor in summa nubium celumque raptus sum usque ad tercium, ubi mirabile vidi misterium et ineffabile cuique mortalium. ${ }^{25}$

Mais de ce qu'il a vu, il n'a rien retenu, car, pris de faim, il s'est vu offrir du pain de pavot et de l'eau du Léthé. Ce repas lui fait alors tout oublier (§107-108) :

Que postquam noveram, statim esurii michique proceres magni consilii panem papaveris proponunt, alii Lethei laticem propinant fluvii.

Cumque papaveram panem papaveris labrisque laticem infundi miseris, statim oblitus sum divini muneris. ${ }^{26}$

Il tombe alors du ciel (§ 109) et n’a plus qu’à regretter amèrement l'effet qu'a eu sur lui ce repas fait de pain de pavot et arrosé d'eau du Léthé (§110).

25 « Après cela je suis porté en haut des nues, et je fus élevé jusqu'au troisième ciel ; là je vis un mystère digne d'admiration, et impossible à dire pour quelque homme que ce soit.»

26 «Quand j'eus appris cela, j'eus faim subitement ; alors par les seigneurs du souverain conseil, je me vois proposer du pain de pavot, d'autres m'offrent à boire une onde puisée dans le Léthé. Et dès que j'eus goûté à ce pain de pavot et fait couler cette onde entre mes pauvres lèvres, j'oubliai sur le champ cette faveur divine.» On notera en passant l'inspiration virgilienne que constitue l'apparition concomitante du motif du pavot et de celui du Léthé. Cf. Verg. Georg. I.78 : Urunt Lethaeo perfusa papavera somno (mention didactique: la culture du pavot, imprégné du sommeil du Léthé, épuise les sols). Cela montre que l'hypotexte biblique n'est pas le seul à l'œuvre dans le poème. 
De prime abord, on est donc face à un poème à la structure décousue, pastichant l'Apocalypse uniquement dans sa partie centrale, muni d'une introduction sans lien véritable avec le corps du poème et pourvu d'un appendice où le poète botte en touche, mettant fin au principe apocalyptique de révélation - et par là-même au poème - au motif qu'il a tout oublié.

Mais, en fait, dans un article lumineux de 1962, la seule personne qui se soit véritablement intéressée à la structure de ce texte, Francis X. Newman, ${ }^{27}$ parvint à montrer qu'il y avait bien un effort de composition, unissant intimement les trois révélations qui constituent les trois parties de l'œuvre, autour de la théorie de la vision telle qu'elle est développée chez saint Augustin au dernier livre du De Genesi ad litteram. ${ }^{28}$ L'évêque d'Hippone distingue en effet la visio corporalis, c'est-à-dire physique, qui permet de voir des objets réels, la visio spiritalis, qui correspond à la faculté d'imagination et permet de se représenter mentalement des objets qui ne sont pas présents, sous forme d'imagines ou de similitudines, enfin la visio intellectualis, qui permet de percevoir ce qui n'a pas de corps (Dieu, les concepts, etc.). ${ }^{29}$

Cette théorie a de fortes chances d'avoir été connue de l'auteur de l'Apocalypse de Golias, car on la retrouve exposée chez nombre de ses contemporains : Honorius d'Autun, Hugues de Saint-Victor, Alain de Lille, Guillaume de Saint-Thierry, Jean de Salisbury, par exemple. ${ }^{30}$ Et Newman relève même dans l'Apocalypse de Golias un indice de la connaissance directe ou indirecte du principe augustinien des trois visions. Au livre XII du De Genesi ad litteram, Augustin utilise, comme pierre de touche de sa théorie la péricope paulinienne du ravissement au troisième ciel (2 Cor 12.2-4), où l'Apôtre écrit qu'un homme de sa connaissance a été, quatorze ans auparavant, «ravi jusqu'au troisième ciel», avant d'ajouter «jusqu'au paradis, où il entendit des paroles ineffables, qu'il n'est pas permis à un homme de répéter ». ${ }^{31} \mathrm{Et}$ Augustin de se demander, d'une part si le «troisième ciel» est, sous la plume de saint Paul, synonyme ou non du paradis, d'autre part, puisqu'il y a trois ciels, ce que peuvent représenter les deux autres. À cela, l'évêque d'Hippone répond que les trois ciels correspondent aux trois modalités de la «vision» humaine : le premier est celui

27 Newman (1962) 115-120.

28 Aug. Gen. litt. XII.3-34 (éd. Zycha, CSEL, 1894).

29 Voir par exemple Gen. litt. XII.11 : Tria igitur ista genera visorum, corporale, spiritale, intellectuale, singillatim consideranda sunt. Augustin prend ensuite l'exemple de ce qui se passe quand un lecteur lit dans l'Évangile le précepte «Tu aimeras ton prochain comme toi-même» : la vision corporelle donne à voir des lettres ; la vision spirituelle, permet d'imaginer le prochain ; la vision intellectuelle permet d'appréhender l'amour qu'on porte au prochain (Cum enim legitur diliges proximum tuum tamquam te ipsum, corporaliter litterae videntur, spiritaliter proximus cogitatur, intellectualiter dilectio conspicitur).

30 Pour les références précises, voir Newman (1962) 115 et 117.

31 2Cor 12.2-4: Scio hominem in Christo ante annos quatuordecim, sive in corpore nescio, sive extra corpus nescio, Deus scit, raptum hujusmodi usque ad tertium caelum. Et scio hujusmodi hominem sive in corpore, sive extra corpus nescio, Deus scit, quoniam raptus est in paradisum; et audivit arcana verba, quae non licet homini loqui. 
de la vision corporelle, le second, celui de la vision spirituelle, le troisième, celui de la vision intellectuelle. ${ }^{32}$

Newman a eu parfaitement raison d'insister sur le fait que la péricope paulinienne a une importance capitale pour l'herméneutique de l'Apocalypse de Golias. De fait, elle est à l'origine de la $\S 105$ du poème satirique, où le narrateur explique d'une part qu'il a été ravi au troisième ciel, ${ }^{33}$ mais encore qu'il y a eu connaissance de mystères ineffables à l'homme. ${ }^{34}$ Mais ce passage précis de la seconde Épître aux Corinthiens trouve un autre écho dans l'Apocalypse de Golias, au début du poème, lorsque Pythagore apparaît au narrateur (§ 2-3) :

Astantis video formam Pithagore :

Deus scit, nescio, utrum in corpore.

Ipsam Pithagore formam inspicio

inscriptam arcium scemate vario.

An extra corpus sit hec revelacio

utrum in corpore, deus scit, nescio. ${ }^{35}$

Le visionnaire précise alors par deux fois qu'il ne sait si Pythagore lui apparaît «corporellement» - autrement dit s'il est physiquement présent, selon les modalités de la vision corporelle - ou s'il lui apparaît extra-corporellement, c'est-à-dire si cette apparition est le produit de son imagination - ou peut-être d'un songe - donc de la vision spirituelle. Et cette itération rappelle celle que faisait saint Paul, dans la seconde Épître aux Corinthiens, lorsqu'il se demandait si son ami avait été enlevé au troisième ciel corporellement ou extra-corporellement (2 Cor 12.2 et 3 : sive in corpore nescio, sive extra corpus nescio, Deus scit). Plus discrets, certes, que l'inspiration johannique, mais savamment placés au tout début du poème (§ 2-3) et à l'extrême fin (§105), ces deux échos pauliniens très nets indiquent qu'il s'agit là d'un hypotexte d'importance majeure pour l'interprétation du poème dans son ensemble.

$\mathrm{Au}$ terme de sa démonstration, Newman s'appuie sur l'interprétation augustinienne de 2 Cor 12 , pour proposer une lecture très convaincante du poème et de sa structure, appuyée sur la théorie augustinienne des trois "visions ». ${ }^{36}$ La première

32 Aug., Gen. litt. XII.34 : si ergo caelum primum recte accipimus hoc omne corporeum generali nomine quidquid est super aquas et terram, secundum autem in similitudine corporali quod spiritu cernitur, sicut illud, unde animalibus plenus in extasi Petro discus ille submissus est, tertium uero quod mente conspicitur ita secreta et remota et omnino abrepta a sensibus carnis atque mundata.

33 Apoc. Gol., §105, 2 : celumque raptus sum usque ad tercium ; cf. 2Cor 12, 2 : raptum hujusmodi usque ad tertium caelum.

34 Apoc. Gol., § 105, 4 : et ineffabile cuique mortalium ; cf. 2Cor 12, 4 : et audivit arcana verba, quae non licet homini loqui.

35 «Je vois auprès de moi Pythagore apparaître : Dieu sait, mais je ne sais s'il était là en corps. Cette apparition de Pythagore, je vois qu'elle est marquée des signes spécifiques des Arts. Cette révélation fut-elle corporelle ou extra-corporelle ? Dieu le sait, je l'ignore.»

36 Newman (1962) 119-122. 
partie correspondrait à la "vision corporelle», en ce qu'elle est centrée sur les arts libéraux, qui permettent d'appréhender le monde. ${ }^{37}$ La seconde partie, appuyée sur l'hypotexte apocalyptique, représenterait la «vision spirituelle», au sens où elle ne donne pas à voir directement la réalité, mais repose sur une perception allégorique. ${ }^{38}$ Et Newman en tire une interprétation globalement convaincante de la fin de l'œuvre : le visionnaire a eu faim, et cette faiblesse du corps l'a empêché de tirer les enseignements de sa "vision intellectuelle», puisqu'il s'est endormi et a tout oublié. ${ }^{39}$ La conclusion de Newman impose donc de voir dans l'œuvre une structure fermement articulée autour de la théorie augustinienne de la vision.

Nous voudrions, à notre tour, poser ici la question de la structure du poème, mais en d'autres termes : l'unité de l'œuvre est-elle assurée aussi par l'intertextualité biblique?

On a souvent pensé que l'Apocalypse johannique avait servi de modèle à la partie centrale du poème (§14-104), et non aux deux autres. ${ }^{40}$ Il est vrai que la prégnance du motif du livre aux sept sceaux dans la partie centrale invitait à une telle remarque, mais, pour y être plus discret, l'hypotexte johannique n'est toutefois pas complètement absent de l'introduction et de la conclusion.

On peut au moins relever, dans l'introduction, l'inscription que le visionnaire découvre sur le corps de Pythagore et par laquelle le philosophe s'offre pour guide (§ 7 : inscriptum reperi fusco caractere : / "Dux ego previus et tu me sequere ! ${ }^{41}$ ). Elle évoque la manière dont l'Ange propose au visionnaire de l'accompagner. ${ }^{42}$ Plus saisissant encore, les auteurs classiques portent leur nom inscrit sur le front :

Per frontes singulas traducens lumina,

vidi quorumlibet inscripta nomina. ${ }^{43}$

37 Newman (1962) 119 : Priscien représente la grammaire, Aristote la dialectique, Cicéron la rhétorique, Ptolémée l'astronomie, Boèce l'arithmétique, Euclide la géométrie, Pythagore la musique. Puis les poètes classiques représentent la variété des différents genres poétiques, et Hippocrate est l'allégorie de l'art pratique qu'est la médecine.

38 Newman (1962) 120-121: «Golias' second vision is a pseudo-Apocalypse. But the correspondance extends beyond the parallel of subject matter. Spiritual vision, in Augustine's scheme, is knowledge by means of images, that is, by means of shapes which have corporeal form, but lack corporeal substance. It is just such figurative insight that Golias is promised in his second vision.»

39 Newman (1962) 122 : «Neither Paul nor Golias can report on his vision of the third heaven, Paul because he utterly overcame the senses, Golias because the senses overcame him.»

40 Raby (1934) 216, à propos de la §14 : «An angel comes on the scene to introduce the true Apocalypse». Voir aussi, quoique avec plus de prudence, Newman (1962), 114 : «This last phrase [= § $14:$ Suspice ! Oculos aperi / et vide, cito que oportet fieri] is quoted from Apoc. 1, 10 and marks the beginning of the direct Apocalyptic parody of the work».

41 «Je repérai inscrit en sombres caractères : »Marchant devant, je suis ton guide, et toi, suis-moi !«» 42 Apc 17.1: et venit unus de septem angelis [...] et locutus est mecum dicens : "Veni, ostendam tibi damnationem meretricis magnae.»

$43 \S 9$ : «Promenant mon regard sur le front de chacun, j'y découvris leurs noms qui s'y trouvaient inscrits.» 
Or le motif du signe porté sur le front est récurrent dans l'Apocalypse johannique, où les élus portent le nom de Dieu inscrit sur le front ${ }^{44}$ et refusent de se faire imprimer celui de la Bête. ${ }^{45}$ Surtout, la grande prostituée porte sur son front l'inscription : «Babylone la Grande, la mère des prostituées et des abominations de la terre». ${ }^{46}$ Plutôt qu'à un seul, c'est probablement à l'ensemble de ces hypotextes bibliques que l'auteur de l'Apocalypse de Golias fait référence : les classiques se rapprochent des élus par leur nombre ; ${ }^{47}$ mais ils sont comparables à la Grande Babylone en ce qu'ils portent sur le front leur propre nom.

Dans la conclusion, il est vrai que les échos de l'Apocalypse johannique sont plus discrets, ${ }^{48}$ mais un détail permettra peut-être d'en repérer la présence tout en donnant peut-être une clef de lecture de l'ensemble du texte. Newman a bien relevé que le motif apocalyptique du livre apparaissait deux fois dans le poème, tout d'abord dans l'introduction (§ 3), où le corps de Pythagore, porteur d'inscriptions, est un livre «corporel», dans les deux sens du terme - au sens propre parce qu'il s'agit du corps du philosophe, au figuré en vertu de la typologie augustinienne de la vision (autrement dit un livre à lire) $)^{49}$ - puis dans la partie centrale du poème, où le livre aux sept sceaux est un livre spirituel.

Ce que Newman n'a pas vu, c'est qu'on aurait attendu une troisième occurrence du motif du livre, sous le rapport de la «vision intellectuelle». Apparemment, dans l'appendice que constituent les $\S 103-110$, il n'est pas fait allusion au moindre livre, mais l'étrange repas fait de pain de pavot et d'eau du Léthé évoque le symbole apocalyptique de la manducation du petit livre. Au chapitre 10 de l'Apocalypse johannique, le visionnaire voit en effet apparaître un ange tenant à la main un petit livre ouvert. ${ }^{50}$ Puis une voix lui ordonne d'aller le prendre dans la main de l'ange ; celui-ci le lui remet en lui disant le manger et en lui annonçant qu'il serait amer à ses entrailles, mais doux comme le miel dans sa bouche, ce que l'expérience du visionnaire confirme. ${ }^{51}$ On comprend alors que ce livre est celui de la parole de Dieu,

44 Аpc $7.3-4 ; 14.1 ; 22.4$.

45 Apc 20.4.

46 Apc 17.5 : Et in fronte ejus nomen scriptum : Mysterium : Babylon magna, mater fornicationum et abominationum terrae.

$47 \S 9$, v. 1 : Dum miror dubius que sint hec agmina... («Comme je me demande quelles sont ces cohortes...»).

48 Strecker (1928), 36-37 n'en relève aucun dans son apparat.

49 Newman (1962) 120 : «Golias in fact »reads« Pythagoras, or, at least, the dark characters engraved in his corpus-codex.»

50 Apc 10.1-2 : Et vidi alium angelum fortem descendentem de caelo [...]. Et habebat in manu sua libellum apertum.

51 Apc 10.8-10 : Et audivi vocem de caelo iterum loquentem mecum, et dicentem : Vade, et accipe librum apertum de manu angeli stantis super mare, et super terram. Et abii ad angelum, dicens ei ut daret mihi librum. Et dixit mihi : Accipe librum, et devora illum : et faciet amaricari ventrem tuum, sed in ore tuo erit dulce tamquam mel. Et accepi librum de manu angeli, et devoravi illum; et erat in ore meo tamquam mel dulce, et cum devorassem eum, amaricatus est venter meus. 
douce à recevoir, mais amère à assumer car il faut la transmettre, et l'évangélisation suppose des efforts et des dangers. Et l'ange confirme cette interprétation : le visionnaire va maintenant devoir "prophétiser». ${ }^{52}$

Et cette péricope n'est pas sans lien avec les §107-108 de l'Apocalypse de Golias :

michique proceres magni consilii panem papaveris proponunt, alii Lethei laticem propinant fluvii.

Cumque papaveram panem papaveris

labrisque laticem infundi miseris, statim oblitus sum divini muneris.

Outre le motif commun de la manducation, qui attribue au pain de pavot un statut fonctionnel comparable à celui du petit livre apocalyptique, on peut noter un certain nombre de détails qui, communs aux deux textes, confirment que le poète avait probablement en tête le chapitre 10 de l'Apocalypse. D'une part, les deux objets symboliques sont remis solennellement au visionnaire par les mains des messagers divins que sont l'ange dans le texte johannique et les proceres magni consilii chez le pseudo-Golias. D'autre part, on relève, au plan stylistique, un goût commun dans les deux passages pour l'itération, notamment pour la répétition du terme désignant l'objet de la manducation (deux occurrences de l'expression panis papaveris et du substantif latex en deux strophes, dans l'Apocalypse de Golias ; quatre occurrences de la forme librum en trois versets dans l'Apocalypse johannique ${ }^{53}$ ).

En d'autres termes, le repas mentionné dans le poème se substitue au petit livre johannique moyennant une écriture allégorique qui est le principe même du genre apocalyptique. Ce qui change, en revanche, d'un texte à l'autre, c'est l'effet produit par le mets sur celui qui le mange. Le petit livre est, comme on l'a vu, doux en bouche et amer aux entrailles, tandis que le pavot et l'eau du Léthé semblent avoir été, pour visionnaire médiéval, l'objet d'une agréable digestion - au point que l'on peut légitimement se demander si l'oubli n'est pas la conséquence d'un sommeil post-prandial ! Probablement faut-il aussi leur attribuer une certaine amertume en bouche : on sait, d'une part, que le pavot donne un goût âcre aux préparations quand il y est mêlé en trop grande quantité - or il semble avoir été le seul ingrédient du pain offert au narrateur ! - et l'on peut, d'autre part, s'interroger à bon droit sur le sens de l'adjectif miser appliqué aux lèvres du visionnaire au v. 2 de la $\S 108$ (lab-

52 Apc 10.11 : Et dixit mihi : Oportet te iterum prophetare gentibus et populis et linguis et regibus multis.

53 Cf. Apc 10.8-10 : Et audivi vocem de caelo iterum loquentem mecum, et dicentem : Vade, et accipe librum apertum de manu angeli stantis super mare, et super terram. Et abii ad angelum, dicens ei ut daret mihi librum. Et dixit mihi : accipe librum, et devora illum [...]. Et accepi librum de manu angeli, et devoravi illum. 
risque laticem infundi miseris). Est-ce une hypallage, le poète déplorant par anticipation son sort et regrettant d'avoir commis une faute qui lui a valu de perdre la mémoire («je faisais couler cette onde entre mes pauvres lèvres» = je faisais malheureux que je suis ! - couler cette onde entre mes lèvres), comme pourrait le donner à penser une lectio facilior. Ou ses lèvres ne sont-elles pas malheureuses en elles-mêmes pour avoir dû endurer l'amertume de l'eau du Léthé ?

Quoi qu'il en soit, il y a bien un jeu de miroir inversé par rapport au chapitre 10 de l'Apocalypse, parce que le visionnaire johannique retient la parole de Dieu, tandis que le narrateur médiéval l'oublie pour sa part.

Quel message faut-il y voir ? Assurément, que le service de Dieu et la recherche des vérités célestes sont incompatibles avec les satisfaction des besoins du corps. Mais, face à cette alternative, que choisit le visionnaire ? On ne peut le juger tout à fait sincère dans la dernière strophe du poème, où il admet qu'il pourrait rapporter des mystères admirables s'il n'avait goûté au pavot :

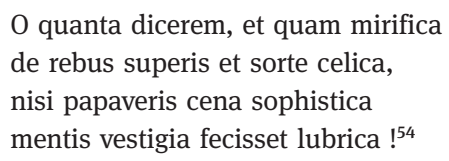

Ces regrets modérément professés semblent plus proches de la plaisanterie que de la componction : le narrateur semble au fond peu marri d'avoir assouvi sa faim et, comme souvent les personae de la lyrique latine $\mathrm{du} \mathrm{XII}^{\mathrm{e}} \mathrm{s}$., il tend moins à l'ascétisme qu'à la satisfaction des besoins du corps.

$\mathrm{Au}$ terme de cette étude, force est de donner raison à Newman, qui pensait que la cohérence de l'œuvre était assurée par un rapport ludique à la théorie traditionnelle de la vision. ${ }^{55}$ Mais nous serions tentés, pour notre part, de croire que l'organicité de l'œuvre est bien plus grande encore, garantie non seulement pas la présence de l'hypotexte johannique en trame de fond, mais encore par la délivrance d'un triple message où l'on retrouve trois des grands thèmes de la lyrique goliardique : le rapport au savoir dans l'introduction, à travers les arts libéraux et l'autorité des classiques ; le rapport au pouvoir et aux institutions dans la satire centrale ; et, au prix d'une pirouette finale, le rapport au corps, à travers un rituel de potatio, fût-il d'un genre nouveau.

Seul un thème cher aux Goliards est ici absent : il s'agit de l'amour, mais c'est à mettre sur le compte d'une des spécificités du corpus attribué au pseudo-Golias : la méfiance à l'égard des femmes et la promotion du célibat des clercs.

$54 \S 110$ : "Que je dirais de choses et combien étonnantes sur les choses d'en haut et le destin céleste, si ce dîner trompeur de pavot n'en avait rendu dans mon esprit les marques incertaines !» 55 Newman (1962) 122 : "As we now have it, the main interest of the poem still lies in the central vision, but by expanding the poem briefly at either end, the author has converted a mock Apocalypse into something more, a mocking of total vision» 


\section{Bibliographie}

Bridges (2012): Venetia Bridges, «'Goliardic poetry’ and the problem of historical perspective : medieval adaptations of Châtillon's quotation poems», in: Medium AEvum 81/2, 249-270.

Hauréau (1880): Jean Barthélemy Hauréau, «Notice sur un manuscrit de la reine Christine à la bibliothèque du Vatican», in: Notices et extraits de la Bibliothèque nationale 29/2, 231-362. Mann (1980): Jill Mann, «Satiric subject and satiric object in Goliardic literature», in: Mittellateinische Jahrbuch 15, 63-86.

Mantello/Rigg (1996): F.A.C. Mantello et A.G. Rigg, Medieval Latin: An Introduction and Bibliographical Guide, Washington D.C.

Newman (1967): Francis X. Newman, «The structure of vision in Apocalypsis Goliae», in: Mediaeval Studies 29, 113-123.

Raby (1934): F.J.E. Raby, A History of Secular Latin Poetry in the Middle Ages, Oxford. Rigg (1977): A.G. Rigg, «Golias and other pseudomyms», in: Studi medievali 18, 65-109. Strecker (1928): Die Apokalypse des Golias, éd. Karl Strecker, Romae, 1-7.

Walsh (1983): P.G. Walsh, «Golias and goliardic poetry», in: Medium AEvum 52, 1-9.

Wright (1841): The Latin Poems Commonly Attributed to Walter Mapes, éd. Thomas Wright, London.

Wright (1875): A History of Caricature and Grotesque in Literature and Art, London. 

Kurt Smolak

\section{Die Bibeldichtung Aurora des Petrus Riga (P.R.)}

\section{Beobachtungen zu Stil und Poetik*}

Die Werkreihe der christlichen Bibelparaphrasen begann im lateinsprachigen Kulturraum des Römischen Reiches im frühen vierten Jahrhundert unter Kaiser Konstantin mit den vier Büchern Evangelia des spanischen Presbyters Iuvencus, die den vier kanonischen Evangelien entsprechen sollten, obwohl der Autor hauptsächlich das Matthäusevangelium als Referenztext verwendete, weil dieses ja am ausführlichsten ,erzählt‘. Auf Iuvencus folgten in der ersten Hälfte des fünften Jahrhunderts die fünf Bücher des Carmen Paschale des italischen (?) Presbyters Sedulius, der den narrativen vier Evangelienbüchern ein weiteres, auf das AT verweisendes gewissermaßen als Vorbereitung des soteriologischen Geschehens des NT voranstellte. Beide spätantiken Werke zählten zu den meistgelesenen poetischen Texten der folgenden Jahrhunderte. Die Werkreihe setzte sich ungebrochen bis ins Spätmittelalter fort. ${ }^{1}$ Was vornehmlich als rhetorisch beeinflusste Paraphrase begonnen hatte, sollte allmählich diverse Formen von Exegese einschließen, ${ }^{2}$ besonders allegorische Interpretationen dieser Tendenz entspricht bereits der Titel, welcher der um 500 entstandenen, ebenfalls fünf Bücher umfassenden und auf ausgewählte Episoden konzentrierten Bibeldichtung des den Arianismus bekämpfenden Alcimus Avitus von Vienne traditionell gegeben wird: 'Geistliche Geschichte', De spiritalis historiae gestis. Eine noch weiter gehende Aktualisierung eines ausgewählten biblischen Narrativs liegt in der auf die historische Situation der gegen Rom vorrückenden Truppen Belisars im Gotenkrieg Justinians applizierte Versifizierung von Abschnitten der Apostelgeschichte durch den in Rom als Subdiakon wirkenden Arator vor: Die Dichtung wurde der Überlieferung

\footnotetext{
* Als Siglen der biblischen Bücher werden jene der deutschen Einheitsübersetzung verwendet: Die Bibel, Stuttgart 2016 1547-48. - Für Hilfe bei Erstellung der diesem Beitrag zu Grunde liegenden englischen Vortragsfassung danke ich Danuta Shanzer, Wien.

$1 \mathrm{Zu}$ den einzelne Dichtungen übergreifenden Standardwerken über die Gattung als solche, deren literaturwissenschaftliche Erforschung mit dem Lexikonartikel von Thraede (1962) 997-1042 (über christliche Epik) einsetzte, zählen nach wie vor die Monographien von Green (2006); Roberts (1985); Herzog (1975): Forschungsspektrum nicht abgeschlossen; Kartschoke (1975). Darüber hinaus sei im Allgemeinen hingewiesen auf Stella 2001, besonders zur Bibelepik Smolak (2001) 15-29 (mit geringfügigen Abweichungen bereits gedruckt in: Smolak [1999] 7-24); Spezialliteratur zu einzelnen Autoren beziehungsweise einzelnen Werken wird gegebenenfalls an den jeweiligen Stellen angeführt.

2 Ein auffälliges Beispiel für die massive Einwirkung der Exegese schon auf die spätantike Bibeldichtung stellt der umfangreiche litaneiartig-anaphorische Hymnus des Dracontius auf das Licht des ersten Schöpfungstages, laud. dei 1.119-128, dar, eine freie Entfaltung des Lobes des Lichts bei Ambr. hex. I.9.33.
} 
nach im Jahr 544 in der römischen Kirche S. Petri ad vincula öffentlich rezitiert. ${ }^{3}$ Das Verhältnis des Umfangs von Referat des biblischen Bezugstexts einerseits und Kommentaren beziehungsweise Interpretationen andererseits hatte im Lauf der Weiterentwicklung der Gattung ,Bibelepik‘ sosehr überhandgenommen, dass es angebracht ist, im Hochmittelalter, konkret in der zweiten Hälfte des zwölften Jahrhunderts, weniger von Bibel-Paraphrase zu sprechen als von paraphrasiertem Kommentar.

Für die eben vorgetragene Feststellung ist die gegen Ende des zwölften und zu Beginn des dreizehnten Jahrhunderts entstandene umfangreiche bibelbezogene Dichtung des Reimser Kanonikers Petrus Riga, gestorben 1209, mit dem allegorischen Titel Aurora das am besten geeignete Beispiel. ${ }^{4}$ In ihr werden folgende biblische Bücher behandelt: der Pentateuch, Josua, Richter, Ruth, Könige 1-4 (= Samuel 1-2, Könige 1-2), Tobias, Daniel, Judith, Hester, Makkabäer, die Evangelien als Diatessaron, Apostelgeschichte, Hiob, Hohelied. ${ }^{5}$ Das ergibt eine Gesamtzahl von über 15000 Versen, leoninischen Hexametern und, der epischen Gattung im Grunde fremd, hauptsächlich elegischen Distichen, wie sie etwa zeitgleich auch Matthäus von Vendôme in seinem Tobias ebenfalls im ausgehenden zwölften Jahrhundert für ein

3 Zu Avitus s. Arweiler (1998); zu Arator s. Schwind (1990).

4 Die Tendenz des Werkes zur Kommentarparaphrase betont bereits die ausgezeichnete Edition von Beichner (1965). Beichners Text liegt den folgenden Ausführungen zu Grunde. - Zur Biographie des Autors s. Beichner (1965) XII-XVI. - Über den metaphorischen Titel, der sich in eine bereits in der Antike einsetzende, im späteren Mittelalter zunehmend dichter werdende Reihe einfügt, äußert sich der Autor im Vorwort zu der ersten Teilausgabe des Werkes: Grundlage sei die - bereits biblische (Kol 2.17 Hebr 8.5; 10.1) und frühchristliche - Metapher von ,Schatten` und ,Licht‘ für das gegenseitige Verhältnis von AT und NT einerseits und das mühevolle, mit der Morgenröte beendete Ringen Jakobs mit dem Engel (Gen 32.26) als Metapher für die Anstrengung des Dichtens andererseits (Beichner [1965] 7-8). Dass durch den Begriff Aurora ein Hinweis auf stilistischen ,Glanz' unterschwellig angedeutet wird, darf vermutet werden.- Aus frühmittelalterlicher lateinischer Bibeldichtung (tituli zu einem geplanten Bilderzyklus im Dom zu Mainz) sei die exegetische Präsentation der gesamten Bibel durch Ekkehart IV., Versus ad picturas domus Domini Mogontinae 1-4;11-12;15- 24 (zu den Schöpfungstagen 1, 4, 6) genannt, dazu s. Smolak (2015) 84-89; Leithe-Jasper (2015) 373-391; zur Bibeldichtung des Spätmittelalters s. Dinkova-Bruun (2008a) 263-284 (über paraphrastische Methoden, vorgeführt am Beispiel der Behandlung der Geschichte des Ägyptischen Joseph) und die sehr knappe Übersicht von Schmidt (2001) 449-457; vgl. auch Donnini (1995) 221-270 (über Bibelparaphrasen in diversen poetischen Gattungen 222-232, unverständlicherweise wird P.R. nicht erwähnt).

5 In seinem Vorwort äußert sich P.R. - gemäß einem schon antiken Exordial- und Bescheidenheitstopos mit Bezugnahme auf eine Aufforderung durch Freunde und anfängliche Bedenken wegen mangelnder Fähigkeit - nur auf den Pentateuch und dessen Potential allegorischer Interpretation. Es ist daher auch hinsichtlich der Ausweitung des Materials anzunehmen, dass dieser Aspekt zusammen mit der jeweils zur Verfügung stehenden exegetischen Literatur ausschlaggebend war. Das in dem zur Erweiterung offenen, nicht abgeschlossenen Werk des P.R. erkennbare Bestreben, möglichst viele biblische Bücher, im Idealfall die gesamte Schrift, zu versifizieren - die Evangelienparaphrasen des Iuvencus und Sedulius zielen nicht darauf ab, sondern behandeln die vier parallelen Texte als eine Art Diatessaron -, entspricht einer Tendenz, die sich innerhalb der spätantiken Bibelepik nur in dem fragmentarisch vorliegenden Werk des so genannten Heptateuchdichters (,Cyprianus Gallus', ,Cyprianus poeta') erkennen lässt; zu ausgewählten Aspekten dieser Bibelparaphrase s. Petringa (2016); zu der komplexen Bibel als tituli Ekkeharts IV. s. Anm. 4. 
biblisches Sujet anwendete. ${ }^{6}$ Der Bruch mit dieser linearen Tradition exegetisch-didaktisch aufgeladener bibelbezogener Dichtung erfolgte erst mit den klassizistischen Bibelepen und -epyllien des Renaissance-Humanismus. ${ }^{7}$

Die Aurora des P.R. stellt nichtsdestoweniger eine Besonderheit und daher eine Herausforderung an die philologische Analyse dar: Sie liegt nämlich als ein work-inprogress vor. Denn der Verfasser hat selbst drei Versionen erarbeitet, in denen er den ursprünglichen Textbestand im Detail erweiterte und Versifizierungen ganzer biblischer Bücher hinzufügte - diesmal in Hexametern. Dazu kommen die so genannten Recapitulationes, lipogrammatische Kurzgedichte, in denen er alttestamentliche Typologien nach Isidor von Sevilla vorstellte. ${ }^{8}$ Zum originalen Text kamen schon um 1200 die umfangreichen Erweiterungen des Aegidius von Paris, der seinerseits zwei Arbeitsgänge dafür aufwendete. ${ }^{9}$ Die breite handschriftliche Überlieferung und die zahlreichen Vorworte und Begleitschreiben aus dem Mittelalter bezeugen den hohen Grad an Akzeptanz dieser komplexen Lehrdichtung. P.R. kam offenbar einem Bedürfnis seiner Zeit entgegen. ${ }^{10}$

Im Folgenden soll versucht werden, mittels close reading verschiedene Vorgehensweisen von P.R. bei der Präsentation der versifizierten Bibel mit versifiziertem Kommentar vorzustellen. Grundlage der Untersuchung ist die Ausgabe von Beichner (s. Anm. 4). ${ }^{11}$

Als Einleitung der Ausführungen im Einzelnen diene ein Beispiel für die Art, in der P.R. mit seinem biblischen Bezugstext sprachlich-stilistisch verfährt, Ev(angelium) $409-410^{12}$ :

6 Leoninische Hexameter gebrauchte bereits Ekkehart in dem in Anm. 4 erwähnten epigrammatischen Epos gemäß mittelalterlicher tituli-Tradition, und Matthaeus von Vendôme urteilt nahezu zeitgleich mit P.R. im Nachwort seines Bibelgedichtes Tobias, 2103-2132 (2105: Tobie tituli [!]), negativ über den epischen Gebrauch.

7 Als Beispiele klassizistischer Bibelepik der frühen Neuzeit seien genannt: Marcus Marulus (Marko Marulić), Davidias (abgeschlossen 1517); Marcus Hieronymus Vida, Christias (veröffentlicht 1535).

8 Die jeweiligen Bezugsstellen aus Isidor, Allegoriae quaedam Sacrae Scripturae: Ex Veteri Testamento (PL 83,99-116) sind bei Beichner (1965) [49]-[52] aufgelistet. - Die Entstehung der recapitulationes dürfte aus dem Bestreben des Dichters erwachsen sein, technisches Können durch die lipogrammatische Versifizierung eines Prosatextes mit besonders vielen biblischen Eigennamen zur Schau zu stellen.

9 Über Aegidius s. Beichner (1965) XXI-XXIV.

$10 \mathrm{Zu}$ der Überlieferung s. Beichner (1965) L-LV: Er spricht von ungefähr 250 Handschriften. Zu späteren Handschriftenfunden (UB Heidelberg, Biblioteca Apostolica Vaticana, Bibliothek des Benediktinerklosters Engelberg) s. https://de.wikipedia.org/wiki/Petrus_Riga (abgerufen 29.1.2019); zur enormen Wirkungsgeschichte s. Dinkova-Bruun (2006) 237-260.

11 Die hilfreichen Quellenangaben von Beichner (1965) [39]-[61], können und wollen nicht mehr leisten, als einige Anhaltspunkte für weitere Interpretationen zu bieten.

12 Das Beispiel wurde ausgewählt, weil Lamech neben anderen Gestalten in der ersten exemplarischen quellenkritischen Untersuchung zur Aurora erscheint, und zwar im Genesisteil: Oppermann (1926) 60 -62. Die Namensetymologie hat P.R. im Evangelienteil nachgetragen. 
In Lamech est humilis, penetrans ad Tartara Christus;

Hinc est illud: „Ero morsus, Auerne, tuus.“

„In der Person von Lamech ist er (Christus) der Niedrigkeit des Erdbodens verbunden als einer, der in den Tartarus eindringt. Darauf bezieht sich der folgende Satz: ,Ich werde dich beißen, Unterwelts-See!““

In der Versifizierung des Stammbaums Jesu im Lukasevangelium - dargeboten mit Allegoresen der Etymologien der einzelnen Namen nach Zacharias von Besançon (Zacharias Chrysopolitanus) - findet sich bei P.R. folgende Erklärung für den Lk 3.36 erwähnten hebräischen Namen Lamech: humilis, vom Dichter versehen mit dem erklärenden Zusatz penetrans ad Tartara - dazu im Folgenden mehr. An diese Ergänzung schließt P.R. eine biblische auctoritas an: Hinc est illud: Ero morsus, Averne, tuus. Ein Zusammenhang ist zunächst nicht erkennbar, trotz des ungezwungenen Umgangs mit einem Bibelzitat, Os 13.14: ero morsus tuus, inferne. P.R. brauchte bloß das biblische Wort für Unterwelt, inferne, durch den antikisierenden Eigenamen des kampanischen Avernersees, eines der Eingänge in das Reich Plutos, ${ }^{13} \mathrm{zu}$ ersetzen und zwei Wörter umzustellen. Die Änderung des Eigennamens war übrigens aus metrischen Gründen notwendig - und nicht zu vergessen: Averne und inferne sind einander im Klang ähnlich. Außerdem konnte P.R. dadurch seine Versiertheit in der lateinischen Synonymik zur Schau stellen, schon in der Antike ein literarisches Qualitätsmerkmal: So verwendet bereits Verg. Aen. X.377-378 drei Wörter für ,Meer`innerhalb zweier Verse. P.R. glänzt in diesem Sinn innerhalb von vier Versen mit drei Ausdrücken für ,Unterwelt‘: Tartara, Averne und, zwei Verse später bereits in der Erklärung des Namens Methusalem, inferno (Ev 412, hier chronologisch anschließend im Zusammenhang mit Christi Rückkehr aus der Unterwelt).

Doch zurück zur Etymologie des Namens Lamech. Der Zusammenhang zwischen der Deutung als humilis und dem Abstieg Christi in die Unterwelt kann dem Text nicht unmittelbar entnommen werden, es sei denn man reduziert das derivierte Adjektiv auf die eigentliche Bedeutung des Substantivs humus, ,Erd(boden)‘. Für das vom Autor intendierte theologische Verständnis muss man vielmehr mit der gängigen Exegese einer anderen Bibelstelle vertraut sein: Im Christushymnus von Phil 2.8 heißt es: (Christus) humiliavit semet ipsum, factus oboediens usque ad mortem, mortem autem crucis. Die Selbsterniedrigung Christi durch seinen Abstieg aus dem Jenseits und seinen Kreuzestod bis in die Unterwelt wird schon in der patristischen Exegese häufig mit dem Zitat aus Osea als der entsprechenden alttestamentlichen Prophetie verbunden, zwar unter Weglassung des Kolons factus oboediens usque ad mortem, aber unter Beibehaltung des vollständigen Satzes des Propheten, der da lautet: ero mors tua, o mors, ero morsus tuus, inferne, z. B. Ambrosius, explanatio psalmi 43.78. P.R.

13 Avernus (Averna,- orum) ist das in der lateinischen hexametrischen Dichtung der Antike und des Mittelalters bevorzugte klassizistische Wort für Unterwelt, als Vokativ in dem angeführten Bibelzitat ist es sonst nicht nachweisbar. 
zeigt also ein Streben nach brevitas, um die biblische auctoritas in einem einzigen Vers zu konzentrieren. Dieser Absicht kam die Assonanz der Anfangswörter der zwei Kola entgegen, mors bzw. morsus.

Zum Abschluss der Interpretation von Ev 409-410 noch zur sprachlichen Formulierung des erklärenden Zusatzes zur Etymologie des Namens Lamech, humilis, dem klassisch anmutenden Halbvers von 409, penetrans ad Tartara (Christus): Diese Formulierung war zur Zeit des Autors im Zusammenhang mit Christi descensus ad inferos zwar bereits formelhaft geworden, ${ }^{14}$ hinsichtlich ihres weiteren Kontexts steht sie aber ihrer ,klassischen` Ursprungsstelle auffälligerweise in einem zentralen Detail sehr nahe, und zwar in Form einer so genannten Kontrastimitation: Ovid, met. II.260 261. Die Verse berichten nämlich von der Todesfahrt Phaëthons, des Sohnes des Sonnengottes, im Wagen seines Vaters. Er ist gewissermaßen ein ,falscher Helios‘. Als er mit dem ungezügelten Gefährt der Erde zu nahe kommt, spaltet sich der Erdboden infolge der gewaltigen Hitze, durch die so entstandenen Risse dringt das Licht in die Unterwelt ein und versetzt deren König mitsamt seiner Gattin in Schrecken: Dissilit omne solum, penetratque in Tartara rimis / lumen et infernum terret cum coniuge regem. Die Schilderung der Höllenfahrt Christi in dem weit verbreiteten, ursprünglich wahrscheinlich auf Latein verfassen Zusatz zum apokryphen Nikodemusevangelium (Acta Pilati), der descensus ad inferos, ${ }^{15}$ weist deutliche Parallelen auf: Zunächst das vom Eindringen Christi, des „Königs der Herrlichkeit“ - rex gloriae, nach ps. 23.7.9 (der Vers wird in dem Apokryphon zitiert) und somit Gegenstück zu dem ovidischen „Unterweltskönig“, infernum regem - in ihren Bereich der Finsternis in Schrecken versetzte ,Herrscherpaar‘: Tod und Teufel - im Lateinischen als Mors und Diabolus tatsächlich ein ,heterosexuelle Verbindung. ${ }^{16}$ Dazu kommt die Komponente des unverhofften Sonnenlichtes. Denn Christus wurde seit patristischer Zeit auf Grundlage der Exegese von Mal 3.20 (= 4) als die ,wahre ${ }^{6}$ Sonne der Gerechtigkeit ${ }^{17}$ verstanden. Demzufolge ist mit seinem Auftreten in der Unterwelt nicht ein ,falsches ' Sonnenlicht erschienen (wie das des Phaëthon), sondern eben jenes, das zu Beginn der Liturgie der Osternacht, für gewöhnlich knapp vor Sonnenaufgang, schon damals mit dem dreimaligen Ruf lumen Christi herbeigerufen beziehungsweise begrüßt wurde. ${ }^{18}$ Vor die-

14 Aus der paganen römischen Literatur ist noch zu nennen Lucan. 693: penetratque in Tartara lingua (sc. der Hexe Erichtho), die Stelle hat außer dem Thema ,Unterwelt keinen Bezug zu dem Bibelepos; in der christlichen Dichtung erstmals bei Sedul. carm. pasch. V.428: Tartara post caelum penetrat, post Tartara caelum, von Christi Abstieg in die Unterwelt und seiner Himmelfahrt; stilistisch und kontextuell liegt kein Bezug zu der Aurora-Stelle vor, Gleiches gilt für die späteren sprachlich ähnlichen Belegstellen.

15 Dazu s. https://de.wikipedia.org/wiki/Nikodemusevangelium (abgerufen 20.2.2019) mit Literatur. 16 Evangelium Nicodemi (Descens. Christi), 20-23 (4-7).

17 Aus der Menge der Belegstellen für Christus als, wahre Sonne' seien die früheste in Prosa und die früheste in der Dichtung hervorgehoben: Cypr. domin. orat. 35: Christus sol verus est et dies verus; Ambr. hymn. 2.5: verusque sol illabere (Bitte an Christus im Morgenhymnus).

18 Zu lumen Christi s. Dölger (1936) 1-43. - In diesen Kontext gehört auch das Konzept von Christus als der ,Übersonne‘, der nach Prud. cath. 5.127-132 durch seinen Aufstieg aus der Unterwelt im Zuge der 
sem Hintergrund, der von Gebildeten jener Epoche unschwer assoziiert werden konnte, erweist sich die Anspielung auf den Ursprung der Phrase als kontrastierende Imitation nach dem Prinzip der Ecloga Theoduli: falscher (paganer) Mythos vs. (christliche) Wahrheit. ${ }^{19}$ Die zwei genannten Punkte, Furcht der Unterweltsherrscher und Eindringen des Sonnenlichtes, zählten und zählen bis heute zu den unabdingbaren Elementen der Auferstehungsbilder vom Typ der orthodoxen Anastasis-Darstellungen, in denen die gefesselten Figuren Satans und bisweilen auch des Hades furchtsam unter den Füßen Christi neben den aufgebrochenen Höllenpforten kauern. Dieser ist umgeben von einer strahlenden, mitunter mit Sternen als Kosmos gestalteten Mandorla, die ihn in ihrer Mitte als die ,wahre' Sonne erscheinen lässt. ${ }^{20}$

Nun ein zweites Beispiel für eine zwar mühelose, aber vom Bezugstext in lexikalischer Hinsicht stärker abweichende Paraphrasierung eines Bibeltextes: Es handelt sich um den universalen Missionsauftrag Jesu an die Apostel am Ende des Matthäusevangeliums, Mt 28,18-19 bei P.R. wiedergegeben in Ev 2889-2890 und 28932896:

Discipulos post alloquitur: „mihi cuncta potestas

Est data, terrigenas caelicolasque regens“

und

\footnotetext{
„Ergo precipio vobis, gentes ut in omnes

Eloquiis vestris hec mea verba pluant,

Ut baptizetur in nomine Patris et eius

Prolis et amborum Pneumatis omnis homo.“
}

Zum Vergleich der Evangelientext: data est mihi omnis potestas in caelo et in terra ... Euntes ergo docete omnes gentes baptizantes eos in nomine Patris et Filii et Spiritus Sancti. P.R. belässt auch hier Etliches vom Wortbestand des Matthäusevangeliums, z. B. data mihi, potestas, ergo, gentes, omnes, baptizetur, in nomine Patris, setzt aber häufiger Synonyma als in den zuvor analysierten Versen- cuncta für omnis und die auf konkrete Wesen bezogenen, poetischen Komposita terrigenas und caelicolas ${ }^{21}$ für die abstrakten Raumbegriffe in caelo et in terra, wobei terrigenas auf die seit Hieronymus

Osternacht den Tag zurückbringt, s. Smolak (1994) 32-33. Dass in der solaren Komponente des descensus ad inferos Einfluss von Mysterienkulten (Isis) vorliegt, ist nicht auszuschließen, vgl. Apul. met. 11.23 .

$19 \mathrm{Zu}$ Methode und Zielsetzung dieses bukolischen Gedichts s. Herren (2007) 190 - 230.

$20 \mathrm{Zu}$ den Anastasis-Darstellungen s. Loerke (2003) 26-36; ferner www.beyars.com/kunstlexikon/le xikon_4133.html (abgerufen 23.3.2019). - Besonders deutlich ist die solare Komponente Christi als Kosmokrator in der Unterwelt dargestellt in dem Anastasis-Fresko im Parekklesion der Chora-Kirche (Kariye Camii) in Konstantinopel / İstanbul aus 1320/21.

21 Ms Cambridge, Gonville and Caius College Library, 363.569 (CMA 1068) kehrt die Wortstellung entsprechend jener des Bibeltexts um: celicolas terrigenasque. 
gängige Etymologie von Adam, terrigena, verweist. ${ }^{22}$ Das über den Bezugstext überschießende, syntaktisch auffällige, da auf potestas und nicht auf den Sprecher bezogene Partizip regens in Ev 2890, in der Überlieferung denn auch durch rego ersetzt, ${ }^{23}$ soll auf das Königtum des auferstandenen und in den Himmel zurückgekehrten Christus anspielen, dem potestas „gegeben wurde“, data est. Die Verbalform des passiven Perfekts scheint der Dichter im Sinn des historischen, d. h. innerhalb der Zeit vollzogenen Aktes zu verstehen, nämlich der Inkarnation oder der Beglaubigung durch die in allen kanonischen Evangelien bezeugte Hallstimme des Vaters bei der Taufe Jesu im Jordan. Durch die Ausformulierung dieser Exegese in dem folgenden Distichon 2891-2892 verwahrt sich P.R. gegen die Annahme eines außerzeitlichen Zustandsperfekts, das eine Subordination des ,Empfängers‘, also des Sohnes, unter den ,Gebenden', also den Vater, im Sinn des Arianismus nahelegen würde. ${ }^{24}$

Die auf diese christologische Exegese folgende sprachliche Gestaltung des Missionierungsauftrags in 2893-2894 ist in die Metapher eines befruchtenden Regens gekleidet und für die Benetzung der Menschen mit den Worten Christi verwendet. Es handelt sich hier nicht um ein bloß poetisches Schmuckmittel, sondern die Metapher soll zunächst den unmittelbar folgenden Befehl Christi zur Taufe in der damals längst üblichen Form einer Infusionstaufe durch Stiftung einer Assoziation lexikalisch vorbereiten. Der ,Regen der Worte Christi‘, vermittelt durch die ,(kultivierten) Reden` der Apostel, meint also die der Taufe vorangehende Taufkatechese, die Petrus nach Apg 2.38 empfiehlt, und auf die er in dem pseudepigraphischen so genannten zweiten Petrusbrief, 2 Petr 1.5-11, Bezug zu nehmen scheint. ${ }^{25}$ Die apostolischen Katecheten werden in dieser ihrer Funktion als Weise gemäß einer Definition in Sir 39.9 (Zählung der Vulgata) und dadurch als Vollender des AT vorgeführt: Von dem auf Gotteser-

22 Tert., adv. Marc. II.12.3 als Attribut von animalia in Gegensatz zu aquigena; Hier nom. hebr. p. 73,1.23 Lagarde als alternative Übersetzung von Adam neben homo. - Der früheste Beleg für das Wort findet sich in einem unsicheren Fragment bei Lucil. 1377 Marx = D 35 Charpin (überliefert von Cic. div. 2.133) in der bekannten parodistischen Periphrase für die Schnecke; als poetisches Synonym für Menschen erstmals gebraucht von Lucr. 5.1114. Eine nur scheinbare Ausnahme stellt die Verwendung in einem nicht poetischen Text bei Flor. epit. 1.31.6, dar: Das Wort ist dort als die Übersetzung des griechischen

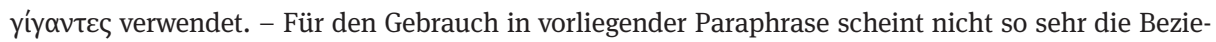
hung auf Adam als vielmehr der poetische Charakter und die Übereinstimmung mit celicolas in Umfang, Rhythmus und Vokalharmonie maßgeblich gewesen zu sein: Dem Begriff fehlt hier nämlich jegliche negative Konnotation, die er bei christlichen Autoren nicht selten hat.

23 Ms Oxford, Bodleian Library, Laud Misc. 576.

24 Hier der Text: Hoc de carne sua dicit, non de Deitate, / Qui Patri consors consimilisque manet. - Die vorgetragene Erklärung findet sich weder in der Historia Scholastica noch bei Zacharias von Besançon (Zacharias Chrysopolitanus), dessen Kommentar P.R. über weite Strecken folgt, scheint also von dem Dichter selbst entwickelt, s. Beichner (1965) II, [48], möglicherweise in Anlehnung an die Unterscheidung zwischen menschlicher und göttlicher Natur Christi im Zusammenhang mit der Aussage des Auferstehungsengels in Ev 2863-2864, dass der Auferstandene „nicht hier“ sei; die Quelle für diese auf die Zwei-Naturen-Christologie bezogene Exegese dieser Stelle findet sich bei Zacharias (PL 186,591C).

25 Vgl. Ruf (2011) 208. 
kenntnis ausgerichteten Weisen heißt es nämlich an der alttestamentlichen Stelle: tamquam imbres mittet eloquia sapientiae suae - als Signalwort fungiert eloquia, unterstützt durch das von P.R. mit dem synonymen pluat übernommene Bild des Regens. Sowohl der Weise im Sinne der Sirachstelle als auch die Apostel verkünden demnach in ihren Reden dieselbe Weisheit, nämlich die ihnen von Gott übermittelte: Die Sapientia (Dei) nimmt ja gemäß Weish 1.4 nur im Herzen des Rechtschaffenen Wohnung. Die Metapher des (befruchtenden) Regens für die Katechese leitet außerdem zur Assoziation zu einem anderen Metaphernkomplex über. Denn die Bereitschaft zur Taufe kann im Sinn des Sämannsgleichnisses von Mt 13.8 als reiche Feldfrucht der Annahme des Wortes Gottes gesehen werden. Reiche Ernte setzt aber genügend Bewässerung durch Regen voraus. Der Auftrag, diese Ernte einzubringen, ist wie an der biblischen Bezugsstelle in 2895-2896 als trinitarische Taufformel ausgesprochen: Ut baptizetur in nomine Patris et eius / Prolis et amborum Pneumatis omnis homo. Die trinitarische Taufformel bleibt durch den Ersatz von Filius durch proles auf poetischem Niveau. Dasselbe kann auch für das griechische Wort Pneumatis statt Spiritus gelten - auch an anderen Stellen der Aurora dienen Pneuma und Flatus entsprechend einer lexikalischen Tradition lateinischer christlicher Dichtung als Synonyme für den (Heiligen) Geist. ${ }^{26}$ Allerdings dürfte in dem Zusatz amborum auch eine leise polemische Anspielung auf die Ostkirche enthalten sein, die ja das Filioque des Chalzedonensischen Konzils nicht angenommen hat und daher vom westlichen Standpunkt aus nicht ,orthodox' im ursprünglichen Sinn des Wortes ist. Der Zusatz amborum geht also über die sprachliche Gestaltung des Referenztextes hinaus und enthält eine dogmatisch-theologische Dimension.

Im Folgenden sollen kurz weitere Beispiele formaler und / oder inhaltlicher Modifikationen des biblischen Berichts vorgeführt werden, die stärker als die bisher analysierten in diesen eingreifen und ihn somit verändern. Dabei ist stets zu bedenken, dass P.R. nicht eine bloße Bibelparaphrase bieten will wie die frühen patristischen Bibelepiker von sich behaupteten ${ }^{27}$ - obwohl auch sie ihre Bezugstexte ver-

26 Flatus wird in der patristischen Prosa häufig für das Wirken (,Wehen') des Heiligen Geistes gebraucht, in der Dichtung besonders von Iuvencus, bei dem der Begriff zum Synonym von spiritus erscheint: II.714; IV.97, bei P.R. vgl. Ev 17: Dona Sacri Flatus.

27 Besonders ,Cyprianus Gallus‘ (Heptateuchdichter) will nur paraphrasieren und enthält sich exegetischer Zusätze, trotzdem werden sachliche Änderungen allein durch das Metrum und die epische Sprache erzwungen, z. B. bereits im ersten Vers Gen 1-2: Principio dominus caelum terramque locavit: / namque erat informis fluctuque abscondita tellus (Gen 1.1: In principio creavit Deus caelum et terram. Terra autem erat inanis et vacua et tenebrae super faciem abyssi et spiritus dei ferebatur super aquas). Es wird nicht nur der erst im Elohistenbericht angewendete Machttitel dominus (deus) als Ersatz für Deus verwendet, sondern durch das Prädikat locavit sogar der Akt der creatio ex nihilo (unbewusst?) durch eine Trennungs- (Diakrisis-) Kosmogonie im antiken Sinn unter Weglassung der facies abyssi ersetzt, so dass die Aussage eher Ov. met. I.21-22 (hanc deus et melior litem natura diremit; / nam caelo terras et terris abscidit undas) nahesteht als jener der Bibel.- Methodisch grundlegend dazu Herzog (1975) 109123. Zum formalen Aspekt der sprachlichen Transposition bei dem Heptateuchdichter, ohne detaillierte Interpretationen s. Petringa (2016) 29-67; aber bereits Iuvencus, der anders als der Heptateuchdichter 
änderten. Er beabsichtigt vielmehr eine der aktuellen Exegese folgende Kommentierung der von ihm ausgewählten biblischen Bücher in ansprechender Form zu verfassen. Eine seiner Hauptquellen ist hierfür, wie Ende des zwölften Jahrhunderts nicht anders zu erwarten, die für den Pariser Studiengang verfasste Kirchengeschichte Historia scholastica des Petrus Comestor. ${ }^{28}$ Auf sie muss in vorliegender Studie mehrfach hingewiesen werden. Die drei folgenden Abschnitte sind alle dem ersten Schöpfungsbericht, Gen 1.1-2.3 (,Priesterbericht'), entnommen, einem der von der Patristik am ausführlichsten kommentieren biblischen Narrativen überhaupt. Trotz der durchgehenden Bezugnahme auf exegetische Referenztexte verfährt der Dichter in Gewichtung und Anordnung des Materials im Detail vergleichsweise frei. ${ }^{29}$

Erstes Beispiel: Erster Schöpfungstag (Gen 7-8 P.R. ${ }^{30}$ )

Principio celum terramque creasse refertur

Qui sine principio, qui sine fine manet.

Gleich die erste sprachliche Einheit, in principio beziehungsweise in der dichterischen, seit der Welterklärung durch Anchises bei Verg. Aen. 6.724 präpositionslosen Form principio, unterzieht P.R. einer christologischen Deutung, die freilich modernen hermeneutischen Kriterien nicht standhalten könnte. Doch vorab müssen zwei Be-

für seine Paraphrase ornamenta terrestria linguae (IV.805) zulässt, induziert raffiniert den Bibeltext überhöhende Exegese: Wenn er den Besuch der Frauen am Grab Jesu mit einem epischen Morgenanbruch einleitet, ersetzt er die biblischen Ausdrücke quae lucescit in primam sabbati (Mt 28.1), valde mane ... orto iam sole (Mk 16.2), valde diluculo (Lk 24.1), mane, cum adhuc tenebrae essent (Jh 20.1) in 4.743 durch sidera iam noctis venturo cedere soli / incipiunt, und weist unter Nutzung des exegetischen Potentials der diversen Lichtelemente aller vier Zeitangaben (von ,noch dunkel` bis ,nach Sonnenaufgang ${ }^{\star}$ ) mittels des Futurpartizips venturo, das in epischer Sprache für den Sonnenaufgang nicht üblich und etwa surgenti (Verg. Aen. XII.172: surgentem ... solem) metrisch gleichwertig ist, auf die unmittelbar bevorstehende Auferstehung Christi hin, welcher z.B. Chromat. in Matth. 54 A,1.68 und Ambr. epist. IX.68 als venturus sol iustitiae gemäß der christologischen Exegese von Mal $3.20=4.2$ : oriteur ... sol iustitiae bezeichnet wird - venturus wird ferner in Glaubenssymbolen für die zweite Parusie Christi verwendet. - Naturgemäß müssen überdies Bibelcentonen auf größtmögliche Nähe zum Referenztext verzichten: $\mathrm{Zu}$ den diesbezüglichen Problemen des Cento s. schon Herzog (1975), Smolak (2004a) 55-56.

$28 \mathrm{Zu}$ den Quellen der Aurora s. Beichner (1965) XLVII-L. Auf Petrus Comestor als wichtigste Informationsquelle hat erstmals Oppermann (1926) 55-73 hingewiesen.

29 Als Beispiel diene die insgesamt 36 Verse umfassende Präsentation des ersten Schöpfungstages: Das die Handlung des Sechstageberichts bestimmende ,Machtwort‘ Gottes, fiat, sc. lux (Gen 1.3), wird erst im Zusammenhang mit der ,Erhellung، der alttestamentlichen Schriften durch den von Jesus (29: veniente Iesu) gesandten Heiligen Geist angedeutet, der bis dahin nur „über den Wassern schwebte“ (Gen 1.2), offenbar ohne sie zu „befruchten“. Das ,Machtwort“ ist somit chronologisch von der Erstschöpfung getrennt, als Metapher syntaktisch in Form einer Partizipialkonstruktion (31: facta luce) marginalisiert und des Sprechcharakters beraubt. Die Stelle der Lichtschöpfung besetzte P.R. dagegen durch die Angabe der schon in der vorchristlichen Exegese in den Bibelbericht eingedrungenen Erschaffung der Himmelswesen (15-16).

30 Zur Vermeidung von Unklarheit bei Zitaten der Genesisparaphrase von dem paraphrasierten Bezugstext sind ersterer jeweils die Initialen P.R. beigefügt. 
merkungen über die Zusammenfassung aller geschaffenen himmlischen Wesen unter dem Begriff celum durch P.R. und deren Folgen gemacht werden: 1. Für diese Begriffserweiterung dient ein argumentum ex silentio als Beweis: Die zugleich mit dem Himmel erschaffene Erde sei am ersten Tag noch „wüst und leer“ gewesen, über den gleichzeitig geschaffenen Himmel werde das aber nicht ausgesagt. Daraus sei zu schließen, dass der Himmel bereits von den Engeln besiedelt gewesen sei (Gen 13-14 P.R.: non ita de celo scriptum legis ut sit inane, / quod replet angelicus, ditat et ornat honor). 2. P.R. interpretiert in principio nicht in temporalem, sondern in instrumentalem Sinn. ${ }^{31}$ Als instrumentale Präposition entspricht in dem weit verbreiteten instrumentalen griechischen '́v der Septuaginta. ${ }^{32}$ Somit ist (in) principio gleichbedeutend mit in Christo, „durch (den präexistenten) Christus“, das Wort Gottes, den Logos „vom Anfang“, gemäß dem Johannesprolog, Jh 1.1. Jesus bezeichnet sich übrigens Jh 8.25 selbst als principium. Diese von P.R. als bekannt vorausgesetzte Exegese führt beispielsweise Aug. gen. c. Manich. I.2.3 klar aus: Deum [in principio] fecisse caelum et terram, non in principio temporis, sed in Christo, cum verbum erat apud patrem, per quod terra et in quo facta sunt omnia. Dominus enim noster Iesus Christus, cum eum Iudaei interrogassent, quis esset, respondit: principium, quod et loquor vobis. P.R. selbst bekräftigt seine anfänglich wenig deutliche Interpretation von principium, indem er nur einige Verse später, Gen 21-22 P.R., ausdrücklich schreibt: Principium Iesus est, celum creat Auctor in isto,/ Per quem celestes efficit esse viros.

Da aber in Christus, kraft dessen der Schöpfer den Himmel hatte entstehen lassen, auch die Kirche ihren Ursprung hat, repräsentiert die noch leere Erde eben die erst zu erschaffende, aber vor der Zeit von Gott konzipierte Kirche (Gen 23 P.R.): Terra prius vacua notat ecclesiam sine fructu. Die Zweckbestimmung der Kirche, beziehungsweise die ihres Schöpfers Christus, sei es aber, „himmlische Männer“, celestes viros (Gen 22 P.R.), das bedeutet: heilige, einer himmlischen Existenz würdige Männer (!), hervorzubringen. Dieses Konzept macht den Eindruck einer Applikation der hocharchaischen Vorstellung der ,Heiligen Hochzeit‘ von Himmel und Erde als dem Ausgangspunkt allen Seins, in der europäischen Tradition durch den schon von Hesiod, theog. 45-46 bezeugten Mythos der Vereinigung von Uranos und Gaia belegt. Wohl in Hinblick auf die Vorstellung einer ,Vermählung“ verwendet der Dichter Gen 24 P.R. das Verb iungere: Donec Christus adest et sibi iungit eam (sc. ecclesiam), eben als con-iunx, seine „Gattin“, offenkundig eine Bezugnahme auf die weit verbreitete allegorische Exegese des Hoheliedes, der gemäß die Kirche die Braut Christi sei. ${ }^{33}$

31 An der zitierten Vergilstelle hat das präpostitionslose principio wohl unter dem Einfluss der didaktisch-deduzierenden Diktion des Lukrez nicht zeitliche, sondern enumerativ-argumentative Funktion, in biblisch-zeitlicher Funktion verwendet es ,Cyprianus Gallus‘ (Heptateuchdichter) Gen 1, s. Anm. 27.

$32 \mathrm{Zu}$ diesem Gebrauch von in s. Hofmann, Szantyr (1965) 126.

33 Z. B. Greg. M. in cant. 8.: dominus et ecclesia ... sponsus nominatur et sponsa, 10: sponsa ... ipsa perfecta ecclesia est; Bern. Clarav. serm. super cant. 14.7: sponsa ... ecclesia est, 25.9: sponsus ecclesiae Iesus Christus. - Die Vermählung von Christus und Ecclesia ist nach der Historia Scholastica (PL 
In Weiterführung der Allegorese der christianisierten ,Heiligen Hochzeit' handelt Gen 25 P.R. von der dieser Verbindung entstammenden Nachkommenschaft: huius (sc. Christi) in adventu datur ecclesie nova proles. Die Phrasierung des Verses lässt erkennen, dass der Dichter auf der im 12. Jahrhundert allgemein akzeptierten Deutung der vierten Ekloge Vergils auf die Ankunft Christi in seiner irdischen Geburt aufbaut, wie sie der Überlieferung nach Kaiser Konstantin vor den Konzilsvätern von Nizäa im Jahr 325 vorgetragen hat. ${ }^{34}$ In Abweichung von der Tradition der durchgehend christologischen Interpretation teilt P.R. den Vers Verg. ecl. 4,7: iam nova progenies caelo demittitur alto auf Christus als den vom Himmel kommenden Messias, huius in adventu, und das „,neue Geschlecht“ der zu errettenden Menschheit, nova proles, auf, das der bis dahin ,ertraglosen“, sine fructu, das bedeutet metaphorisch ,unfruchtbaren“ Erde entsprossen war - die allgemein geläufige Etymologie von Adam als „Erdensohn“, terrigena (s. Anm. 22), kommt dieser Metaphorik entgegen: der ,Neue (,letzte', ,endgültige') Adam‘, novissimus Adam, bei Paulus 1 Kor 15.45 Christus selbst, ist hier auf die Menschheit als ,Neue Adamsnachfahren', nova proles, übertragen.

Zweites Beispiel: Vierter Schöpfungstag (Gen 88-102 P.R.)

Sol et luna duo lumina magna micant;

Noctem sive diem distinguunt hec duo; fiunt

Nota per hec anni tempora, signa, dies.

Sol notat ecclesiam, synagogam luna figurat;

Vel sol esse potest lex nova; luna, vetus.

Nullum luna iubar sine solis lumine profert:

Nil prodesse potest lex vetus absque nova.

Vel sol doctores preclaros, luna minores

Signat, qui spargunt lumen in orbe suum.

Mox ut preficitur luci sol cereus orbis,

Et lune speculo nox radiata nitet,

Tamquam candelis non sic ardentibus, astris

Innumeris celi sphera nitere datur.

Astra notant iustos qui qualemcumque nitorem

Dant populis iuxta posse modumque suum.

In der Paraphrase des vierten Schöpfungstages fällt zunächst die allegorische Interpretation von Sonne und Mond als Kirche und Synagoge auf. Grundlage dafür ist die schon in der Antike bekannte Tatsache, dass der Mond sein Licht von der Sonne erhält. ${ }^{35}$ Diese Erkenntnis hatte bereits Ekkehart IV. in seinem epigrammatischen Bi-

198,1070B) auch in den Prophetien Adams (vgl. Anm. 44) enthalten, auf die sich P.R. in Gen 309-310 P.R. ohne konkrete Inhaltsangaben bezieht - oder sollte er mit fidem auf die eheliche Treue der Braut anspielen, die den ,rechten Glauben' bewahrt?

34 Der Abschnitt mit der Rede Konstantins Ad sanctorum coetum über die Sibyllinischen Orakel und Vergil, ecl. 4, als christliche Prophetien (Eus. HE 4.28, über Vergil XIX-XXI) gilt heute nicht mehr als authentisch und ist daher in neueren Ausgaben nicht enthalten; gesondert ediert von v. Heikel (1902).

35 Z. B. Lucr. V.705; Cic. nat. deor. II.119; rep. VI.17; Ambr. hex. IV.2.7. 
belepos verwertet, aber ohne Allegorese. ${ }^{36}$ Für P.R.s allegorische Deutung bietet die Abhängigkeit der Gültigkeit des dunklen, das heißt nur in ,Typen` das Heilsgeschehen verborgen andeutenden Alten Testaments von dem hellen, das heißt die Ereignisse in ihrer Erfüllung offenbarenden Neuen Testament, die Grundlage für die Allegorese der zwei ,großen Leuchten‘. Dieselben Qualitäten, nämlich dunkel und hell, werden übrigens in der zeitgleichen Stiftungsinschrift des so genannten Verduner Alters im Chorherrenstift Klosterneuburg bei Wien den zwei Testamenten zugewiesen, die ja de facto Synagoge und Kirche entsprechen. ${ }^{37}$ In einem weiteren Ansatz der Allegorese bezieht P.R. die unterschiedliche Helligkeit der Himmelskörper auf Personen mit unterschiedlich intensiver geistlicher und theologischer ,Strahlkraft', ,Kirchenlichter - die laut Bibelbericht zuletzt geschaffenen Sterne bezieht er auf ,Gerechte‘, das heißt heiligmäßige Personen, ungeachtet der Tatsache, dass es Mt 13.43 heißt, „die Gerechten“ - ohne Differenzierung - würden einst „im Himmelreich wie die Sonne strahlen“.

Lexikalisch bemerkenswert innerhalb der Paraphrase des vierten Schöpfungstages ist aber gerade die Metapher für die Sonne: cereus orbis (Gen 97 P.R.). Sie passt zwar in den umgebenden astralen Metaphernkomplex, ist aber dennoch ungewöhnlich und lexikalisch bemerkenswert, stiftet sie doch nahezu notwendigerweise bei den Lesern die Assoziation zur Osterkerze, für die cereus mit oder ohne das Attribut paschalis die terminologische Bezeichnung ist. ${ }^{38}$ Gemäß der Allegorese von P.R. wären demnach durch die Sonne die vier ,großen` westlichen Kirchenväter, doctores preclaros (Gen 95 P.R.), repräsentiert, durch den Mond die nachantiken, von den patres abhängigen Kirchenlehrer wie etwa Beda Venerabilis, minores (Gen 95 P.R.), zum Unterschied von den noch kleineren Leuchten, wohl Lokalheiligen mit begrenzter Strahlkraft, qualemcumque nitorem / dant populis (Gen 101-102 P.R.), welche von den „nicht so (stark) glühenden“ Sternen / Kerzen, candelis non sic ardentibus (Gen 99 P.R.), repräsentiert werden ${ }^{39}$ - candela bezeichnet, zum Unterschied von cereus, stets eine kleine, handliche Kerze. Am auffälligsten an der Behandlung des vierten Schöpfungstages ist aber, dass P.R. die naheliegende, seit frühesten Zeiten geläufige

36 Versus ad picturas 11-12: zu dem Werk s. Anm. 4 und Smolak (2015) 86-87.

37 Die Stifterinschrift von 1182 enthält folgende wertende Dunkel-Hell-Metaphern zu den zwei Testamenten (vgl. Anm. 4): umbre (3), obscura (5) über das AT, pura (6) über das NT. Der Text findet sich z.B. bei Buschhausen (1980) 13 mit (fehlerhafter) deutscher Übersetzung; Korrekturen dazu Buschhausen (1987) 265-309 (in Kooperation mit Smolak); als nova lex bezeichnet z. B. eine Inschrift auf dem so genannten Wiltener Kelch (Wien, Kunsthistorisches Museum, Inv. Nr. 8924) von 1160/70 das NT, s. Fillitz, Pippal (1987) 171-172; zum Ausdruck lex nova für die Ära des Evangeliums vgl. bereits Paul. Nol. epist. 32.5; carm. 22.155.

38 Zum Begriff cereus, wahrscheinlich für ,Osterkerze‘, vgl. Aug. civ. XV.22; vom Mittelalter an ist cereus (paschalis) jedenfalls terminus technicus für die Osterkerze.

39 Zur Metapher lumen ecclesiae, 'Kirchenlicht' für Theologen: Mar. Victorin. adv. Arrium 1 A 28 (von Konzilsvätern von Nizäa); Cassiod. in psalm. SL 97, psalm. 9.1.645 (Hilarius und Augustinus), in Mittelalter und Neuzeit häufig belegbar, im Deutschen mitunter noch in der Gegenwartssprache mit Negation versehen für intellektuell minder begabte Personen in Gebrauch. 
Interpretation der Sonne als Symbol Christi, nach der allegorischen Auslegung der Stelle Mal 3.20 (=4.3) der ,Sonne der Gerechtigkeit‘, nicht bietet. Vielmehr beschränkt er sich, wie bereits erwähnt, auf die Exegese der Beziehung zwischen AT und NT in Hinblick auf die Lehrautorität der Kirche. Der Grund dafür muss in den vorgestellten Adressaten des Werkes liegen, nämlich zölibatär lebenden Klerikern, für welche die Dichtung eine mit Genuss lesbare Belehrung sein soll. Dies geht aus den Versen Gen 163-166 P.R. hervor. ${ }^{40}$ Dort wird Gottes Befehl an die Ureltern, sich zu vermehren, von den Lesern ausdrücklich ferngehalten, indem die ,Vermehrung' in Allegorese zunächst allgemein auf menschliche Ethik (zweimal dicitur his) bezogen wird und an zweiter Stelle, wie aus dem Zusammenhang hervorgeht, im Besondern auf das Wirken einer eigens apostrophieren (tibi dictum) ausgewählten Gruppe von Lehrenden in der Kirche. Jeder Bezugnahme auf körperliche Fortpflanzung wird mit sprachlichen Mitteln unterbunden, möglicherweise auf Grund der von den Kirchenvätern, besonders von Augustinus vertretenen Auffassung einer ohne als Lust empfundenen, sondern dem Willen und dem Pflichtbewusstsein gegenüber dem Auftrag Gottes zur Fortpflanzung unterworfenen sexuellen Betätigung vor dem Sündenfall. ${ }^{41}$ Soweit die in sich geschlossene Allegorese des P.R. Das Fehlen einer In-Beziehung-Setzung von Sonne und Christus wurde aber schon auf der frühesten Rezeptionsstufe der Dichtung als Mangel empfunden: Der „letzte Korrektor“, ultimus corrector, in Wahrheit erweiternde Bearbeiter der Aurora, der eingangs erwähnte Aegidius von Paris, hat bereits in seinem ersten Revisionsdurchgang die Allegorese der Sonne auf Christus als eine weitere Erklärungsmöglichkeit nachgetragen. ${ }^{42}$

Als drittes und letztes Beispiel für die auf Exegese gegründete Behandlung des Priesterberichts des Sechstagewerkes Anmerkungen zum sechsten Tag, dem Tag der Menschenschöpfung. Die Darstellung der Erschaffung von Adam und Eva ist in der Aurora wie in der Bibel fragmentiert, und das noch deutlicher als in dem Bezugstext: Sie erscheint nämlich bei P.R. zunächst in der interpretierenden Paraphrase des Priesterberichts mit deutlicher sprachlicher Bezugnahme auf diesen (Gen 133-176 P.R.). Die narratio ist verbunden mit trinitarisch-theologschen und anthropologischen Fragen - ausgehend von dem Plural faciamus (hominem) von Gen 1.26, dem Problem des Ebenbildes Gottes im Menschen, der Herrschaft des Menschen über die Natur und endend mit der Frage nach der Abwesenheit des - im ersten Schöpfungsbericht bereits oder noch nicht - gestürzten Satan / Luzifer. Diese Frage bietet zugleich eine Überleitung zum zweiten, gemäß der biblischen Abfolge erst nach der Sabbatruhe Gottes

40 Hier die Verse Gen 163-166 P.R.: „Crescite,“ dicitur his, „et multum reddite fructum.“ / Pertinet ad mores ista loquela bonos. / Dicitur his: „Terram replete.“ Nota tibi dictum: / Plenus in ecclesia fructibus esto bonis. Die Interpunktion der Ausgabe von Beichner (1965), Semikolon nach dictum, ist irreführend. 41 Ausdrücklich auf den Zustand der Menschen im Paradies bezogen Aug. c. Iul. 4 (PL 44,757 A); vgl. Anm. 46.

42 Nach Vers 94 ergänzte Aegidius 1.1-6: Vel sol est Christus, et lux que sole relucet / Ecclesiam signat ecclesieve fidem. / Preficitur luci sol, cereus orbis: ab illo / Lux nitet, a Christo fit radiosa fides. / Vere sol Christus, sine quo nox occupat omnes, / nec recte fidei lucet in orbe dies. 
(Gen 177-188 P.R.) behandelten Schöpfungsbericht. Dieser enthält erwartungsgemäß die zweite Beschreibung der Erschaffung der protoplasti. Diese ist ihrerseits aufgeteilt in eine gesonderte narratio der Bildung von Adams Leib aus Lehm, entsprechend dem Elohistenbericht von Gen 2. Der Abschnitt endet mit der theologisch und anthropologisch relevanten Feststellung, dass die lebenserhaltende Seele, die der opifex ${ }^{43}$ Adam einhauchte, eine Neuschöpfung und keine Gottesspartikel war (Gen189-194 P.R.). Die dritte, gleichfalls auf dem Elohistenbericht (Gen 303-327 P.R.) beruhende Erzähleinheit behandelt die Erschaffung Evas aus der Rippe des schlafenden Adam. Dieser Schlaf Adams wird als Ekstase interpretiert, während derer er prophetische Visionen gehabt habe, die er später niederschrieb und veröffentlichte. Diese Legende ist ebenfalls der Historia scholastica zum Teil wörtlich, aber auf das Wesentliche gekürzt, entnommen (PL 198,1070 B). ${ }^{44}$ Abgeschlossen wird der Bericht über die Erschaffung Evas - entsprechend Isidors typologischer Erklärung in den Quaestiones in vetus testamentum (PL 83,217B) - mit einer Allegorie betreffend die Erschaffung der Kirche aus der Seitenwunde Christi bei seinem Tod am Kreuz, die ihm nach Jh 19.34 erst zugefügt wurde, als er bereits tot war - der Tod gilt ja bereits in der griechischen Mythologie als Bruder des Schlafes, d.h. als diesem wesensverwandt und daher mit ihm austauschbar. Dieser Umstand ist übrigens auch im ,Paradies' der Antike wirksam: Im Goldenen Zeitalter trat nach Hesiod, erg. 110-125, der tiefe Schlaf an die Stelle des Todes. Zurück zur Genesis: Der ,Neue (,letzte‘, ,endgültige‘) Adam‘, Christus (1 Kor 15.45), bringt durch seinen Tod die Kirche als ,neue (zweite, ,letzte‘, ,endgültige') Eva’ hervor, die den Sündenfall der ,ersten‘, während Adams Schlaf geformten, wieder rückgängig macht.

Als Abschluss einige Bemerkungen zu Darstellung der Jungfrau Maria in der Aurora. Es fällt auf, dass P.R. in keinem der drei Teile über die Erschaffung der Protoplasten näher auf deren Aussehen eingeht, obwohl es diesbezügliche Ansätze in der bibelepischen Tradition gab: Dracontius beschrieb die eben erschaffene Eva in ihrer nackten Schönheit und verglich sie sogar mit einer Meeresnymphe (laud. dei I.393-

43 Diese Übersetzung des „Handwerksgottes“, $\delta \eta \mu$ ıopyóc, aus Platons Timaios und „Ursprungs der besseren (d.h. aus dem Chaos heraus geordneten) Welt" erinnert an Ov. met. 1.79: ille opifex rerum, mundi melioris origo. Ovid verwendet das Wort wie P.R. auffälligerweise erst im Zusammenhang mit der Menschenschöpfung. Die im Haupttext erwähnte Definition der Menschenseele durch P. R. als einer Neuschöpfung ohne göttlichen Anteil dürfte als Verwahrung gegen die von Ovid an dem angeführten Abschnitt erwogene Möglichkeit der ,himmlisch-ätherischen` Herkunft des eben erschaffenen Menschen im Sinn der Stoiker (met. I.78: sive hunc [sc. hominem] divino semine [sc. deus] fecit ; I.80 - 81: sive recens tellus ... cognati retinebat semina caeli angebracht sein.

44 Gen 304 P.R.: non sompnus sed erat extasis ille sopor, vgl. hist. scholast.: immisit Deus soporem in Adam, non somnum, sed extasin; Gen 306 P.R.: et evigilans inde propheta fuit, vgl. hist. scholast.: et evigilans prophetavit; Gen 310 P.R.: inque suis libris hec reseravit, vgl. hist. scholast.: et libris suis postea indicavit. - Zur Tradition des Testaments Adams s. Knittel (2002); Adam gilt auch im Islam als der erste Prophet, s. https://de.wikipedia.org/wiki/Adam_im_Islam. 
397). ${ }^{45}$ P.R. dagegen erwähnt erst in der Einleitung zum Sündenfall kurz die schönen Leiber der Ureltern, ditabat singula membra decor (Gen 329 - 330 P.R.), ${ }^{46}$ aber eben die Schönheit der Körper, denen zwar noch jegliches sexuelle Verlangen fehlte, deren Liebreiz aber nach dem Genuss der verbotenen Frucht Ursache für Sexualität und deren negative Folgen für Leib und Seele war. Somit erscheint körperliche Schönheit von vornherein in negativem Licht. Dem von Eva verursachten Sündenfall setzt P.R. im Sinn des so genannten Protoevengliums, Gen 3.15, die verheißene Erlösung der Menschheit von ihrer Urschuld durch eine jungfräuliche Geburt entgegen - zur Hervorhebung dieses soteriologisch zentralen Satzes wendet er in beiden Versen das rhetorische Mittel der dreifachen Alliteration zweier Laute an: vipera vim perdit, sine vi pariente Puella / exclusit virus nescia Virgo viri (Gen. 361-362 P.R.), in Anlehnung an die auf Klangähnlichkeit von vipera und vis beziehungsweise von párere und dem Wortbestandteil -pera beruhende Etymologie des Wortes Viper, vipera, bei Isidor, orig. 12.4.10: vipera dicta quod vi pariat. ${ }^{47}$

Das in Gen 361 P.R. angeschnittene marianische Thema greift der Dichter erst einige Zeit später, in der zweiten Fassung der Aurora, mit einem vorbereitenden Abschnitt De pulcritudine Beate Virginis Marie auf (Ev 31-68), und zwar in Form einer Ekphrasis, die der Beschreibung der Schönheit des jugendlichen Absalom in Aurora, II Regum 41-72 nachgebildet ist, woraus sogar ganze Verse übernommen werden. ${ }^{48}$

45 Drac. laud. dei I.393-396: Constitit ante oculos nullo velamine tecta, / Corpore nuda simul niveo quasi nympha profundi. / Caesaries intonsa comis, gena pulchra rubore, / Omnia pulchra gerens, oculos, os, colla manusque. Dracontius evoziert die Ekphrasis der nackten Corinna nach Ov. am. I.5.17-22 durch das erste Hemistich von 1.393, wobei er Ovids Wortlaut: ut stetit ante oculos durch einen ähnlich lautenden, an drei anderen Stellen Ovids belegten (am. III.5,10, epist.15.162, 16.61: constitit ante oculos) ersetzte und den Vergleich mit der Meeresnymphe dem an zweiter Stelle angegebenen Ovidvers entnahm, worin eine Najade Subjekt ist. Durch die Bezugnahme auf Ovids Geliebte erhält Eva schon vor dem Sündenfall die Konnotation der erotischen Verführerin.

46 Den Ausdruck membra movere gebraucht mit Vorliebe Augustinus in seinen antipelagianischen Schriften als Euphemismus für sexuelle Betätigung (ausgehend von männlicher Aktivität), z. B. pecc. orig. (= grat. Christ. 2) 34.39; 36.41 (in Zusammenhang mit der Bedeckung der Genitalien nach dem Sündenfall); 35.40; nupt. et concup. I.24.27. Vgl. Anm. 41.

47 Den Hintergrund der Etymologie bietet ein erstmals bei Herodot, 3.109 berichtetes zoologisches Phänomen: Die Mutterschlange werde bei der Geburt ihrer Jungen von diesen ,gesprengt‘, die dadurch ihren Vater rächen, dem das weibliche Tier bei der oralen sexuellen Vereinigung den Kopf abgebissen habe. In der christlich-lateinischen patristischen Dichtung vgl. die indirekt Bezugnahme bei Marius Victor(ius). aleth. 1.505-507, dazu s. Smolak (1980) 181-188 mit weiteren Belegen aus der lateinischen patristischen Literatur.

48 Hier die Parallelstellen: zeigt Ähnlichkeit an, = Gleichheit: Ev $35 \sim$ II Regum 41 P.R.; 36 42; 38 43; 39 45; 40=46; 49= 51; 50=52; 51= 53; 52=54; 57=55; 58=56; 59=59; 60=60; 53=61; 54=62; 63=57; 64=58; 65=67; 66=68; 67=71; 68=72. - Einen Sonderfall stellen die Verse Ev und II Regum 66 P.R. dar (Beschreibung des natürlich schönen Gesichtes Marias): non hospes colit ( incolit) ora color, nec fuscus adulter (/ Inclita nature dona iuvare potest) (Absque pilis candor in colli colle diescit /) Nec niveum fuscat umbra pilosa decus (vom unbehaarten Nacken Absalos): Aus Gründen der Ausgewogenheit des Verses Ev 61 wäre die Rahmung zweier sinnverwandter Subjekt-Substantiva für Schminke durch je ein adjektivisch-attributiv gebrauchtes Substantiv (hospes, adulter: beide Begriffe bezeichnen in einer 
Diese Fortsetzung der im Genesisteil angelegten narrative Einheit beginnt schon im ersten Distichon von De pulcritudine mit Erwähnung der Aussendung Gabriels zu Maria (Ev 31-3249), wird mit Ev 33 durch die eigentliche Beschreibung und von Vers Ev 69 an durch eine bis Ev 134 reichende katalogartige Aufzählung der Verweise auf Maria in der gesamten Bibel, De commendatione Beate Marie Virginis in eloquiis scripturarum, unterbrochen und erst nach deren Ende mit der Einheit Ev 135-140 weitergeführt. Dass in Vers Ev 33 eine neue Einheit, eben die Ekphrasis, beginnt, markiert P.R. durch eine Apostrophierung seiner selbst: Hic, Petre, fige stilum; tam clare Virginis ortum, / virtutes, speciem carmine pinge novo (Ev 33-34): Er werde also unter Zuhilfenahme aller seiner sprachlichen Möglichkeiten hier ein „neues Lied“, carmine novo - in Anlehnung an den aus den Psalmen bekannten Terminus canticum novum, z.B. ps. 32.3 - vortragen, wobei sich die Neuheit auch auf den Umstand beziehen lässt, dass das Stück im Evangelienteil der Aurora erst in einem späteren Arbeitsgang dazugekommen ist. Die Aufforderung des Dichters an sich selbst betrifft ausschließlich die literarische Form, es gibt keine Allegoresen oder typologische Interpretationen in der Beschreibung der physischen Schönheit.

Die Ekphrasis folgt nach Angabe des Autors den entsprechenden Grundregeln: $\mathrm{Zu}$ behandeln seien ortus, virtutes, species (Ev 33-34). Als Schöpferin des materiellen Leibes Marias wird nicht Gott, sondern die im Mittelalter wie eine Göttin personifizierte Natura angegeben. ${ }^{50}$ Sie habe sich bei Maria so sehr verausgabt, dass es keine

Antiklimax ,Fremdheit') zu erwarten - der Gebrauch des Wortfeldes von adulter im Zusammenhang mit Damenkosmetik ist in der patristischen Literatur häufig belegt (z. B. Cypr. hab. virg. 14-15, laps. 6; Ambr. Cain et Ab. 1.4.14, 5.15; Aug. doctr. Christ. 4.21); als zweites Subjekt würde sich das metrisch taugliche fucus anbieten, an dessen Stelle unter dem Einfluss des Verbs fuscat aus der Ekphrasis Absaloms das Adjektiv fuscus getreten ist und adulter personifiziert erscheint: Der „dunkle Ehebrecher" muss sich auf die unter der Verwendung von Ruß hergestellte Lidschattencreme beziehen, die rötliche Gesichtsschminke verbirgt sich hinter dem unspezifischen color.

49 Ev 31-32: Post missus Gabriel in sexto mense (sc. nach der Empfängnis Johannes des Täufers), salutem / Affert angelicam, Virgo Maria, tibi. Durch das in der Dichtung häufig angewendete Stilmittel der namentlichen Apostrophierung einer Person oder Sache zwecks Fokussierung übernimmt P.R. gewissermaßen den Part des Verkündigungsengels: Das Distichon enthält eine Anspielung auf das Angelusgebet, die Selbstanrede in unmittelbarem Anschluss an die Apostrophierung Marias suggeriert dem Leser das Nahverhältnis eines Dialogs zwischen Dichter und seinem ,Gegenstand‘.

50 Die ,Göttin Natura‘ als Dienerin Gottes im Bereich der materiellen Weltschöpfung und -erhaltung wird seit Curtius (1948) 116-137 als handelnde Person im mittelalterlichen Weltbild, das letztlich auf hellenistischen Physis-Konzepten beruht, wahrgenommen. Dies wird besonders deutlich in der hochund spätmittelalterlichen Buchmalerei, welche die personifizierte Natura als kunstvolle Handwerkerin und Produzentin (vgl. Ev 133) noch nicht beseelter Kinderkörper mit Hammer, Amboss und gegebenenfalls anderen Schmiedewerkzeugen darstellt, s. Modersohn (2003) 86-92: Natura als Schöpferin und Künstlerin, dazu Abbildungen 2, 9-15. - In der Edition von Beichner (1965) ist natura in dem zu analysierenden Abschnitt allerdings durchwegs mit kleinem Anfangsbuchstaben geschrieben, das Wort sollte aber als Eigenname aufgefasst und daher mit großem Anfangsbuchstaben geschrieben werden: Denn an sämtlichen Stellen erscheint Natura aktiv beziehungsweise als Person: 35: Tanto compluit hanc (sc. Mariam) dives Natura decore (als Folge wundert sich Natura über ihre Verarmung); 39: s. Haupttext; 61: inclita Nature dona die von der Natur gegebene Schönheit könne kein ,Fremdling‘, 
zweite Frau dieser Art gab und sie selbst mittellos wurde. Diesen vom physischen Aspekt von Marias Einzigartigkeit ausgehenden Vorzug leitet P.R. in einen Lobpreis ihrer Tugend über, und zwar, wie zu erwarten, ihrer Jungfräulichkeit. Diesen Lobpreis handelt er durch einen Vergleich ihrer jungfräulichen Mutterschaft mit dem - im Mittelalter überwiegend als weiblich aufgefassten - Vogel Phönix ab, der ohne gleichen ist, wie sie, und sein Leben ebenfalls ohne Partner weitergibt. Die viel gerühmte, hier nicht ausgesprochene, aber selbstverständliche Schönheit des / der Phönix führt die narratio wieder zu der Fortsetzung der die leiblichen Vorzüge betreffenden Ekphrasis zurück, so dass das Lob der Partnerlosigkeit, für P.R. eine moralische Qualität, innerhalb dieser unorganisch wirkt. ${ }^{51}$ Denn die nun folgende Beschreibung ist gänzlich den Vorzügen von Marias äußerlicher Erscheinung gewidmet, so sehr, dass ihre ,Makellosigkeit‘ in Ev 39: unam nec maculam natura reliquit in ista, sich nicht auf die Jungfrau als immaculata in mariologischem Sinn bezieht, sondern auf ihren Leib: Die engste Parallele findet sich einmal mehr in Ovids Beschreibung der nackten Corinna, an deren Körper nicht der geringste Makel zu sehen war: in toto nusquam corpore menda fuit (am. I.5.18) - der Vers ist derselben erotische Elegie Ovids entnommen, die Dracontius für die Ekphrasis Evas herangezogen hatte. ${ }^{52}$ Was in der Aurora auf diese aus Ovid übernommene Feststellung folgt, ist eine kunstgemäße Beschreibung des weiblichen Körpers - im Fall der ,Neuen Eva' des bekleideten, selbstverständlich, was in gewissem Widerspruch zu der ovidischen Ankündigung des physischen Makellosigkeit steht. Die Ekphrasis Marias enthält typische Vergleiche, typische Details wie das harmonische Zusammenspiel von Rot und Weiß, die glatte Haut, das blonde Haar und die Überbietung indischen Elfenbeins durch Marias Zähne. Für modernes Empfinden befremdlich ist allein der Vergleich der Beine der ideal geformten Jungfrau mit Säulen in Ev 68: More columpnarum firmus uterque pedum. Der Vergleich ist wortwörtlich aus der Beschreibung Absalons übernommen, wo er die körperliche Tüchtigkeit des Jünglings charakterisiert, im Zusammenhang mit einer Frau muss er eher auf den geraden Wuchs und den aufrechten Gang abzielen.

Der bereits erwähnte, auf die Ekphrasis folgende Abschnitt über Marias Gegenwart in den Büchern der gesamten Bibel der Christen (Ev 69-134), beginnend mit der Arche Noah, wirkt zunächst wegen seines unerwarteten persönlichen Schlusses (Ev

61: hospes (color), und kein ,dunkler Ehebrecher', 61: (fuscus) adulter vermehren. Die Personifizierung der Kosmetik lässt Natura noch deutlicher als Person hervortreten.

51 Ev 35-38; der / die Phönix aufgrund seiner / ihrer sexuellen Indifferenz als marianisches Symbol findet sich z. B. bei Gauterus de Wymburnia (Winborne), hymnus Mariae, Str. 1.2-3: Que pudore meruisti / Dici fenix virginum. - Dass der Vogel in der Ekphrasis Marias bei P.R. in unvermutetem Kontext erscheint, erklärt sich aus der adaptierten Übertragung der Beschreibung der einzigartigen leiblichen Schönheit Absalos von II Regum 44 P.R.: (Pre cunctis pueris, quos ornat gratia forme) / Felix et phenix iste fit absque pare auf die moralische Schönheit Marias auf der Grundlage einer bereits vorhandenen Symbolik in Ev 38.

52 Es ist nicht anzunehmen, dass P.R. sich auf diesen Dichter aus dem Africa der Vandalenzeit bezog, dessen Werke er offensichtlich nicht kannte. Vielmehr zählte Ov. am. I.5 im Mittelalter zu den meistzitierten erotischen Texten und lag sogar in Sonderüberlieferung vor. 
129-134) nicht passend. In diesem drückt nämlich der Dichter seinen Wunsch aus, Marias Schönheit jetzt, nunc, zu schildern - obwohl er in Ev 33-68 bereits eine entsprechende Beschreibung geboten hatte, wenngleich erst in der überarbeiteten Version. Doch während er sich dort durch die Apostrophierung seiner selbst zu einem hohen Stil aufgefordert hatte (Ev 33-34), wünscht er an der späteren Stelle, dass die Jungfrau seinen unschönen Stil, deformem stilum (Ev 130) - die Worte stehen in deutlichem Gegensatz zu fige stilum in Ev 33 - kraft ihrer Schönheit ziere, wie er in einem ein wenig krampfhaft wirkenden Spiel mit der Wortfeld forma erbittet. Da die strahlende Schönheit von Marias Antlitz, die mit der Morgenröte in Wettstreit stehe (Ev 134), menschliches Maß überschreite und „gottgleich“, numinis instar ${ }^{53}$, sei (Ev 132), lasse sie die Gaben der ,Künstlerin Natura‘, artificis Nature (Ev 133), das bedeutet: Jene, die $\mathrm{zu}$ beschreiben er in der vorangehenden Ekphrasis (Ev 33-68) noch mit ,menschlicher Sprache fähig gewesen war, armselig erscheinen (Ev 129-134). ${ }^{54}$ Nunc in Ev 129 bezeichnet also die nunmehr gegenüber der vorangehenden Ekphrasis grundsätzlich veränderte Voraussetzung einer Beschreibung. Mit der Metapher der Morgenröte für Marias Antlitz in Ev 134 spielt P.R. offenkundig auf den Titel seines Werkes, Aurora, unter Anwendung des Endreimeffekts von (certans) aurore und or-is (hon-or) an - eine raffinierte, schon in dem eben zitierten Vers Ev 130 vorbereitete Variante der Topoi der Bescheidenheit beziehungsweise des helfenden Eingreifens eines ,übermenschlichen' Wesens in den formal-ästhetischen Akt dichterischen Schaffens. ${ }^{55}$ Vor allem aber rechtfertigt die Aussage der Verse Ev 129-134 das Fehlen einer detaillierten Beschreibung Marias an dieser Stelle. Betrachtet man den Abschnitt über Marias Präsenz in der Bibel (Ev 69-128) im Zusammenhang mit der ausführlichen Verkündigungsszene in Ev 135-140, Missus ad hanc Gabriel etc., einer Doublette der knappen von Ev 31-32, so zeigt sich, dass in Ev 135 ein Anschluss an diese glatt verliefe. Denn bereits Ev 128 lautet: Cuius (sc. Virginis) in exortu lux fuit orta reis, „(die Jungfrau), bei deren Aufgang - man beachte die astronomische Metapher des Aufgangs für Maria, die stella maris beziehungsweise den Morgenstern - das ,Licht“ (nämlich Christus als Sol iustitiae beziehungsweise als „Licht der Welt“, vgl. Jh 8.12, oder „Sonne der Gerechtigkeit“, Mal 3.20 [= 4.23]) - für die Sünder aufgegangen ist.“ Die Verkündigungsszene von 135 würde also sprachlich und inhaltlich bruchlos anschließen. Wenn der Dichter aber die Verse in der zweiten Fassung, in die er eine

$53 \mathrm{Zu}$ der Wortverbindung numinis instar vgl. Ov. am. III.11.47: Der Kontext ist ebenfalls Frauenschönheit: perque tuam faciem (vgl. oris bei P.R.), magni mihi numinis instar (dieser Halbvers wird in der nachklassischen Dichtung mehrmals zitiert), met. XIV.124: numinis instar eris semper mihi (in ähnlichem Kontext).

54 Ev 129-134: Nunc metra formare de forma Virginis opto; / Ornet deformem Virgo decora stilum. / Humanam speciem transcendit forma puelle; / Excedens hominem, numinis instar habet. / Pauperat artificis nature (Nature Smolak) dona, decori / Certans aurore, splendidus oris honor. Zum Konzept der sich bei der Schöpfung eines besonderen menschlichen Individuums verausgabenden Natura vgl. Alan., Anticlaud. 7.12 (den Hinweis danke ich Christine Ratkowitsch, Wien).

55 Vgl. in der christlichen Dichtung der Spätantike z. B. Paul. Nol. carm. 23.27-36. 
umfangreiche Ekphrasis der leiblichen Schönheit einbaute, trotzdem nicht tilgte, so konnte er seine Zurückweisung einer solchen an der späteren Stelle (Ev 129-134) immerhin noch zusätzlich damit rechtfertigen, dass er in den unmittelbar vorangehenden Versen Maria als die von der Sonne umhüllte und von zwölf Sternen bekränzte himmlische Frau der Apokalypse nach Off 12, präsentiert hatte (Ev 125-128), die sich infolge ihre übernatürlichen Wesens, wie bereits erwähnt, jeder natürlichen Beschreibung entziehe.

Die ergänzte Ekphrasis der physischen Schönheit in Ev 31-68 scheint dagegen dreifach motiviert zu sein. Erstens: P.R. konnte Maria als die Neue Eva präsentieren, in ihrer vollen natürlichen, für alle Zeiten unverdorbenen und nie korrumpierbaren Schönheit - die Schönheit der 'Mutter des Lebens' schien in der Exegese außer Frage zu stehen. Das Konzept einer ,umgedrehten Eva' in Analogie zu Christus als dem Neuen (zweiten) Adam (1 Kor 15.45) war für die lateinische Welt seit dem frühen Mittelalter allein in dem Gruß des Engels ausgesprochen: ave ist ja, anagraphisch gelesen, die Umkehrung von Eva, worauf P.R. schon Gen 323-324 in der Darstellung des Sündenfalls Bezug genommen hat. ${ }^{56}$ Der zweite Grund für die Einfügung der ersten Ekphrasis dürfte darin liegen, dass jede Beschreibung die Gelegenheit bietet, ein typisches Produkt rhetorischer Schulbildung mustergültig vorzuführen, hier technisch besonders reizvoll, da es galt, die Beschreibung einer männlichen Person auf eine weibliche umzulegen. Drittens: schließlich entsprach es vermutlich dem Wunsch des Dichters, in sein Werk ein zeitgenössisches poetisches Sujet einzuschließen, die lyrische Marienminne, die spiritualisierte Form der höfischen Minnedichtung. ${ }^{57}$ Eine mögliche Parallele zu diesem Streben von P.R. nach Selbstdarstellung als Künstler kann darin gesehen werden, dass er in die außerbiblische Geschichte des Schicksals des siechen Herodes nach dem Bethlehemitischen Kindermord und der Hinrichtung des Antipater in Ausarbeitung einer vergleichsweise knappen Angabe in der Historia Scholastica (PL 198,1546C-1548 A) ein kunstvolles Paar langer juristischer Reden und Gegenreden vor Kaiser Tiberius in Rom einbaute (Ev 479-778), ebenfalls Musterstücke der Schulrhetorik und vergleichbar mit den Reden von Ajas und Odysseus im Streit um die Waffen Achills, die auf der Grundlage von Ovid, met. XII.620XIII.382, ein mittelalterlicher Anonymus verfasste. ${ }^{58}$

Hier wäre die Stelle, einen Blick auf die gelehrten, mitunter gewagten und aus heutiger Sicht nicht immer sachlich zutreffenden Erweiterungen des Textes der Aurora durch Aegidius zu werfen, dessen Tätigkeit mehrfach bereits kurz erwähnt wurde. Dies würde aber den Rahmen vorliegender Untersuchung sprengen, deren Ziel es war, anhand der Analyse einiger weniger Abschnitte aus dem komplexen Werk der Aurora deutlich zu machen, welch umfangreiche philologisch-exegetische Arbeit an jenem

56 Gen 323-324 P.R.: Eva necem mundo dedit; hoc nomen retroverte, / Fiet ave, per quod fulsit in orbe salus.

57 Zu Marienminne vgl. Nemes (o.J.); Stanovská (2003) 117-130; Frings (1960) 20.

58 Herausgegeben von Schmidt (1964) 100 -132; zur stilkritischen Interpretation s. Smolak (2004b) 511- 524 . 
im Spätmittelalter so hoch geschätzten Verskommentar zu großen Teilen der Bibel zu leisten wäre. Das gilt auch und vielleicht noch mehr für die Rezeptionstexte, und zwar nicht bloß für die zweistufige Erweiterung durch Aegidius, sondern auch für die zahlreichen, in weit gestreuter Überlieferung erhaltenen kleineren Stücke. Mit der Erweiterung von deren Bestand ist zu rechnen, wie die diversen Funde durch die verdienstvolle, unermüdliche Forschungstätigkeit von Greti Dinkova-Bruun vermuten lassen. ${ }^{59}$ Die Aurora ist somit mutatis mutandis bis heute ein opus operantium, ein work-in-progress.

\section{Literaturverzeichnis}

\section{Edition}

Beichner (1965): Aurora. Petri Rigae Biblia Versificata. A Verse Commentary on the Bible, Part I, Part II, ed. Paul E. Beichner, C.S.C., Notre Dame (Indiana) 1965.

\section{Sekundärliteratur}

Arweiler (1988): Alexander Arweiler, Die Imitation antiker und spätantiker Literatur in der Dichtung ,De spiritalis historiae gestis' des Alcimus Avitus. Mit einem Kommentar zu Avit. carm. 4, 429-540 und 5, 526-703, Berlin.

Buschhausen (1987): Helmut Buschhausen, „Die Geschichte der Inschriften auf dem Verduner Altar des Nikolaus. Überlegungen zu einer Neudatierung“, in: Wiener Studien 100, 265-309.

Buschhausen (1980): Helmut Buschhausen, Der Verduner Altar, Wien.

Curtius (1948): Ernst Robert Curtius, Europäische Literatur und lateinisches Mittelalter, Bern.

Dinkova-Bruun (2016): Greti Dinkova-Bruun, „Verse Epigrams Added to Peter Riga's Aurora from Olomouc“, in: Sacris Erudiri 55, 391-418.

Dinkova-Bruun (2008a): Greti Dinkova-Bruun, „Rewriting Scripture: Latin Biblical Versification in the Later Middle Ages“, in: Viator 39,1, 263-284.

Dinkova-Bruun (2008b): Greti Dinkova-Bruun, „“Proverbia Salomonis“. An Anoymous Accretion to Peter Riga's „Aurora““”, in: Frank T. Coulson, Anna A. Grotaus (edd.), Classica et Benevantana (Studia in onore di Virginia Brown), Turnhout, 9-44.

Dinkova-Bruun (2007): Greti Dinkova-Bruun, „Additions to Peter Riga’s „Aurora“ in Paris. Bibliothèque Nationale de France, lat. 13050“, in: Medieval Studies 69, 1-57.

Dinkova-Bruun (2006): Greti Dinkova-Bruun, „Peter Rigả s Aurora and its Gloss from Salzburg, Stiftsbibliothek St. Peter, MS a VII.6“, in: G. B. Wieland, C. Ruff, R .G. Arthur (edd.), Insignis Sophiae Arcator. Medieval Latin Studies in Honour of Michael Herren on his $65^{\text {th }}$ Birthday, Turnhout, 237-260 (Publications of the Journal of Medieval Latin 6).

Dölger (1936): Franz Dölger, „Lumen Christi“, in: Antike und Christentum 5,1,1-43.

59 Dinkova-Bruun (2016), 391-418; Dinkova-Bruun (2008b) 9-44; Dinkova-Bruun (2007) 1-57; vgl. auch Anm. 10. 
Donnini (1995): Marco Donnini, „Versificazione: I testi“, in: Guglielmo Cavallo, Claudio Leonardi, Enrico Menestò (edd.), Lo spazio letterario del medioevo III: La ricezione del testo,1. Il Medioevo Latino, Rom.

Fillitz, Pippal (1987): Hermann Fillitz, Martina Pippal, Schatzkunst, Salzburg - Wien 1987.

Frings (1960): Theodor Frings, „Die Anfänge der europäischen Liebesdichtung im 11. und

12. Jahrhundert", in: Sitzungsberichte der Bayerischen Akademie der Wissenschaften 1960, Bd. 2, 1-23.

Green (2006): Roger P. H. Green, Latin Epics of the New Testament. Iuvencus, Sedulius, Arator, Oxford.

Heikel (1902): Ivar v. Heikel, Eusebius, Erster Band, Leipzig (Die griechischen christlichen Schriftsteller der ersten drei Jahrhunderte).

Herren (2007): Michael Herren, „Reflections on the Meaning of the Ecloga Theoduli: Where is the Authorial Voice?“, in: Vigiliae Christianae, Suppl. 87, 190-230.

Herzog (1975): Reinhart Herzog, Die Bibelepik der lateinischen Spätantike. Formgeschichte einer erbaulichen Gattung, Band 1, München.

Hofmann, Szantyr (1965): Johann Baptist Hofmann, Anton Szantyr, Lateinische Grammatik, zweiter Band, München (Handbuch der Altertumswissenschaft, 2. Abteilung, 2. Teil, 2. Band).

Kartschoke (1975): Dieter Kartschoke, Bibeldichtung. Zur Geschichte der epischen Bibelparaphrase von Juvencus bis Ottfried von Weißenburg, München.

Knittel (2002): Thomas Knittel, Das griechische 'Leben Adams und Evas', Tübingen.

Leithe-Jasper (2015): Helena Leithe-Jasper, „Versus ad domus domini Mogontine. Mehr als nur eine tituli-Sammlung?“, in: Nobert Kössinger, Elke Krotz, Stephan Müller (Hrsg.), Ekkehart IV von St. Gallen, Berlin - Boston, 373-391 (Lingua Historica Germanica 8).

Loerke (2003): Marc-Oliver Loerke, Höllenfahrt Christi und Anastasis. Ein Bildmotiv im Abendland und im christlichen Osten, Regensburg (Dissertation).

Modersohn (2003): Mechthild Modersohn, „Natura als Göttin - eine Personifikation zwischen Mythos und Aufklärung“, in: Peter Dilg (ed.), Natur im Mittelalter. Konzeptionen - Erfahrungen - Wirkungen. Akten des 9. Symposiums des Mediävistenverbandes, Marburg, 14.-17. März 2001, Berlin, 84-110.

Nemes (o.J.): Balázs J. Nemes, „minne - vrouwe - Maria. Interferenzen zwischen Marienlyrik und Liebeslyrik im Hoch- und Spätmittelalter“: https://www.academia.edu/19112799/minne_ vrouwe_Maria_Interferenzen-zwischen-Marienlyrik_und_Liebeslyrik (abgerufen 29.3.2019)

Oppermann (1926): Hans Oppermann, „Petrus Riga und Petrus Comestor“, in: Zeitschrift für Romanische Philologie 4,1, 55-73.

Petringa (2016): Maria Rosaria Petringa, Il poema dell'Heptateuchos, Catania.

Roberts (1985): Michael Roberts, Biblical Epic and Rhetorical Paraphrase in Late Antiquity, Liverpool.

Ruf (2011): Martin G. Ruf, Die heiligen Propheten, eure Apostel und ich. Metatextuelle Untersuchungen zum zweiten Petrusbrief, Tübingen 2011.

Schmidt (2001): Paul Gerhard Schmidt, „La Bibbia versificata: I testi mediolatini“, in: Francesco Stella (ed.), La scrittura infinita. Bibbia e poesia in età medievale e umanistica, Firenze, $449-457$.

Schmidt (1964): Paul Gerhard Schmidt, „'Causa Aiacis et Ulixis I-Il'. Zwei ovidianische Streitgedichte des Mittelalters", in: Mittellateinisches Jahrbuch 1, 100-132.

Schwind (1990): Johannes Schwind, Arator-Studien, Göttingen 1990.

Smolak (2015): Kurt Smolak, „The 'epigrammatic' Epic. Ekkehart's Versus ad picturas and the Poetic Tradition“, in: Symbolae Philologorum Posnaniensium XXV/2, 73-95.

Smolak (2004a): Kurt Smolak, „Maro mutatus in melius? Zum Phänomen des literarischen Zitierens in der christlich-lateinischen Spätantike“, in: Oswald Panagl, Ruth Wodak (Hrsg.), Text und 
Kontext. Theoriemodelle und methodische Verfahren im transdisziplinären Vergleich, Würzburg, 51-66.

Smolak (2004b): Kurt Smolak, „Semivir arma tulit. Zu den mittellateinischen 'Causae Aiacis et Ulixis'“, in: Paul Gerhard Schmidt, Andreas Bihrer, Elisabeth Stein (Hrsg.), Nova de veteribus. Mittel- und neulateinische Studien für P. G. Schmidt, München, Leipzig, 511-524.

Smolak (2001, 1999): Kurt Smolak, „Die Bibeldichtung als „Verfehlte Gattung“““, in: Francesco Stella (ed.), La scrittura infinita. Bibbia e poesia in età medievale e umanistica, Firenze 2001, 15-29 (mit geringfügigen Abweichungen bereits gedruckt in: Wiener Humanistische Blätter 41 [1999], 7-24).

Smolak (1994): Kurt Smolak, „Horazische Lyrik zwischen Ablehnung, Anverwandlung und Travestie. Ein Rezeptionsparadigma“, in: Janus 15, 26-38.

Smolak (1980): Kurt Smolak, „Die Geburtsschmerzen Evas bei Claudius Marius Victorius“, in: Grazer Beiträge 9, 181-188.

Stanovská (2003): Sylvie Stanovská, „“Es strahlt ein Licht aus der Wolke“. Zur Figur der Frau in der mittelalterlichen Literatur als Anlass von Begriffs-, Motiv- und Gattungsmischungen“, in: Sborník Prací Filosofické Fakulty Brněské Univerzity 8, 113-130.

Stella (2001): Francesco Stella (ed.), La scrittura infinita. Bibbia e poesia in età medievale e umanistica, Firenze.

Thraede (1962): Klaus Thraede, „Epos“, in: Reallexikon für Antike und Christentum 5, 983-1042. 
Francesco Stella

\title{
Théologie de la poésie entre Scolastique et Humanisme
}

\author{
Le statut de la poésie biblique ${ }^{1}$
}

\section{Exclusion de la poésie du système culturel du Moyen Âge}

Je vais partir d'une image (Fig. 1) dont je me sers souvent pour exemplifier l'attitude de la culture médiévale chrétienne envers le statut de la poésie : la miniature qui adorne la feuille 32r du célèbre manuscrit perdu de l'Hortus deliciarum ${ }^{2}$ d'Herrade, abbesse de Hohenbourg au XII ${ }^{\mathrm{e}}$ siècle, qui se trouvait justement ici à Strasbourg.

On y illustre les relations entre les arts et les disciplines dans le système culturel médiéval : au centre du cercle règne Sagesse, soit Philosophia, assise sur un trône sous lequel Socrate et Platon dialoguent, alors que sept niches, disposées en couronne autour du cercle, encadrent les sept arts libéraux. En dehors du cercle, en bas, apparaissent quatre figures de scribes, ou écrivains, caractérisées par un inspirateur négatif : un petit oiseau noir, représentant le démon, qui suggère dans leurs oreilles le contenu des écritures in fieri. La légende transversale nous explique qu'il s'agit des poetae, vel magi, spiritu immundo instincti («les poètes, ou magiciens, inspirés par un esprit immonde»). Et, entre l'un et l'autre de leurs sièges, des lettres spécifient : Isti immundis spiritibus, scribunt artem magicam et poetriam id est fabulosa commenta («ceux-ci, inspirés par les esprits immondes, écrivent des traités d'arts magiques et poétiques, c'est-à-dire des inventions fantastiques»). Les poètes sont donc des exécuteurs du malin, identifiés aux magiciens en tant que producteurs d'une réalité étrangère, d'une fiction de l'esprit humain, et, en qualité de magiciens, ils sont exclus du système culturel et bannis de ses marges ${ }^{3}$.

Une condamnation et des effets pareils sur le système des genres littéraires sont repérables dans la culture islamique, et arabe et persane, comme je l'ai écrit ailleurs (Stella 2003).

1 J'utilize ici des parties de mon essai italien Stella (2010) 251-328 et 350-357.

2 Chef-d'oeuvre d'Herrade de Landsberg, abbesse de Hohenbourg en Alsace au XII siècle. Texte et images dans l'édition de Gillen (1979) ; les symboles sont commentés dans Cames (1971) ; Nonn (2012); Mersch (2012); Joyner (2016).

3 Cfr. Gompe (1973) ; Verdier (1969) ; Pagani (1992) 151.

https://doi.org/10.1515/9783110687224-031 


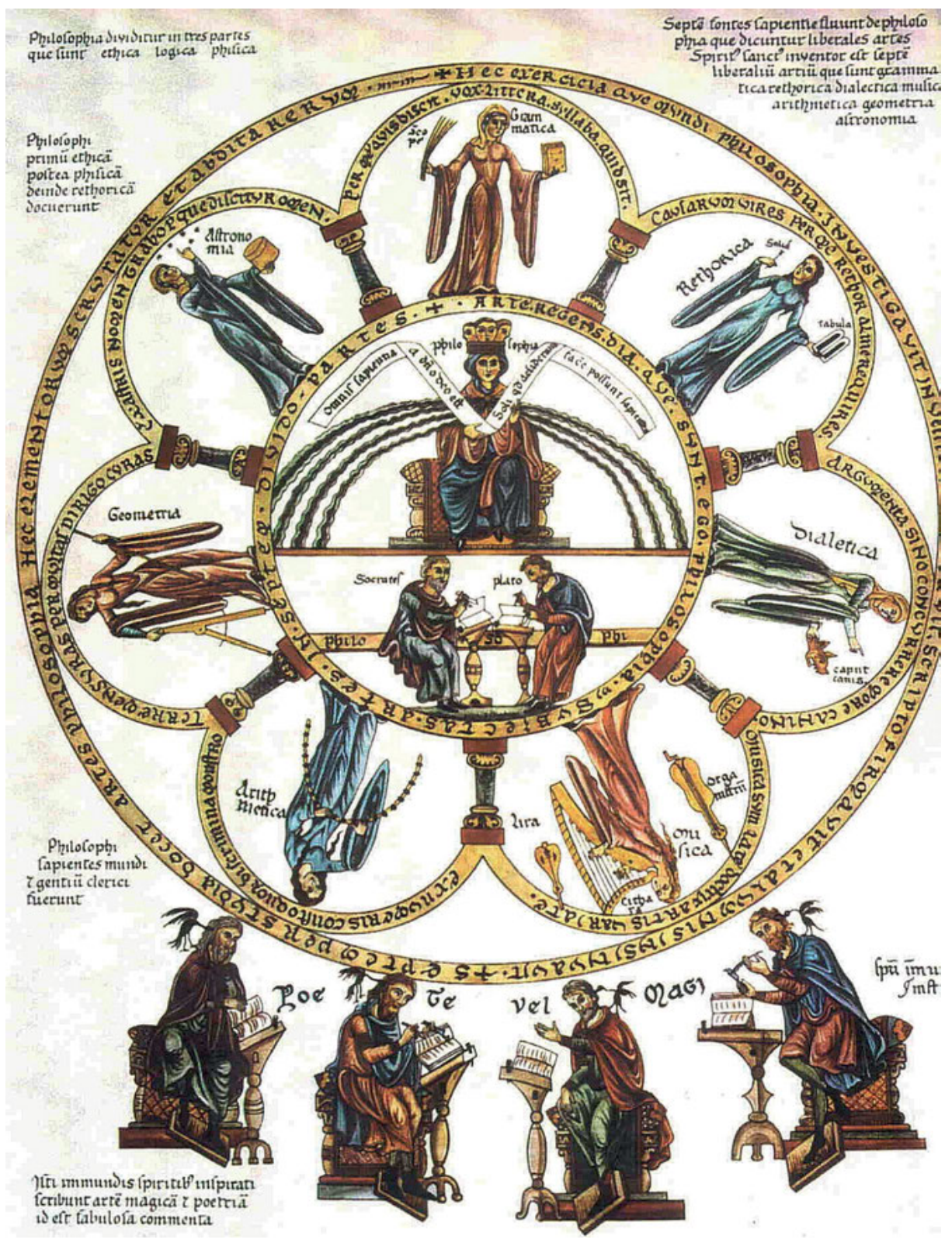

Fig. 1: $f$. 32r Hortus deliciarum d'Herrade de Landsberg (manuscrit perdu) 


\section{Les Summae scolastiques}

\section{Le Decretum Gratiani}

Juste avant que l'Hortus deliciarum soit composé (1140), le Decretum Gratiani ${ }^{4}$, qui recueillait et harmonisait la législation canoniste de l'Église dans un ouvrage qui a servi de texte de référence pendant des siècles, paraît codifier aux clercs l'interdiction de cultiver la poésie ${ }^{5}$. Il la tire d'Isidore ${ }^{6}$, où le titre est explicitement Quare prohibetur Christianus poetica figmenta legere, qui adresse la prohibition à tous les fidèles, alors que la Distinctio est entièrement destinée à la formation cléricale. Quelle en est la raison? "C'est que, à travers leurs attraits, les histoires excitent excessivement l'esprit à la stimulation des passions ; car non seulement elles célèbrent les démons, les encensant, mais elles reportent aussi volontiers leurs dictons ». Pourtant Gratien, dans sa réponse (pars V), réplique que, pour le prêtre, le pire des malheurs est l'ignorance, puisqu'elle remet la conduite d'une âme dans les mains d'autrui ; l'ignorance est donc à éviter autant que la peste. La conséquence non explicite est que finalement le danger dérivant d'un renoncement à la lecture de la poésie (terme qui désigne inévitablement la poésie classique) est plus grand que celui auquel expose la lecture de ses parties les plus lascives.

\section{Alexandre d'Halès (Hales, Hayles)}

$\mathrm{Au}$ XIII ${ }^{\mathrm{e}}$ siècle, le thème de la poésie devient l'objet de commentaires rapides dans les grandes synthèses théologiques des intellectuels appartenant aux ordres mendiants, destinées aux écoles de théologie des universités. Comme Curtius ${ }^{7}$ le rappelle déjà, la summa circulant sous le nom du franciscain anglais (de formation et enseignement parisiens) Alexandre d'Halès (Hales, 1183-1245) ${ }^{8}$ s'ouvre précisément sur la question «Si la théologie est une science», et, à l'article I du IV chapitre, se demande «an modus sacrae Scripturae sit artificialis vel scientialis ${ }^{9}$, c'est-à-dire "si le genre des Saintes Écritures est technique [rhétorique] ou scientifique», ce qui introduit ou confirme une distinction polaire entre des approches gnoséologiques

4 Avec ce titre est connue la Concordantia discordantium canonum rédigée par le moine Gratien. 5 Chap. 15 de la distinctio 37, fondé sur Isidore In libro Sententiarum III de summo bono 13. Cf. Meersseman (1958).

6 Sententiae, PL 83, 685 A; reprise par Ive de Chartres Decretum P.L. 161, 303C et Abélard Theologica christiana, PL 178, 1208 D.

7 Curtius (1992) 239-253 : sur les summae voir 248-250.

8 L'ouvrage a été écrit par lui et d'autres confrères (Jean de la Rochelle, Oddon de Rigaud et Guillaume Meliton).

9 Summa theologiae I.1, Quaracchi (1924) 7. 
habituellement superposées ou confondues ${ }^{10}$. L'objection (nécessairement présente dans le genre de la quaestio) déclare que le mode d'exposition de la Bible ne répond pas à des critères scientifiques ni à des critères techniques, car en fait theologicus modus est poeticus ${ }^{11}$. La responsio d'Alexandre, basée sur Augustin ${ }^{12}$, surmonte le problème en expliquant que les Écritures sont au-delà des séparations ars/science ou poésie/ars/science, et que, lorsqu'elles emploient des techniques poétiques, c'est à la fois pour suppléer l'insuffisance de la capacité humaine de compréhension et pour voiler leur sens à ceux qui ne sont pas dignes de le saisir. Pour soutenir sa thèse, il cite un passage de la Hiérarchie céleste ${ }^{13}$ de l' "heureux Denys», soit Denys pseudo-Aréopagite, où celui-ci avance que «la théologie s'est servie avec adresse de figures sacrées pour la compréhension de réalités non figurables» et qu'«il n'est pas possible que le rayon divin nous éclaire sans être voilé par la variété des couvertures anagogiques» : c'est pourquoi les Saintes Écritures font recours à de «belles représentations figurées de ce qui n’a pas de figure» («pulchre in sacra Scriptura procreatae sunt informium formae et figurae carentium figuris»). Les raisons qui justifient cet usage relèvent, d'un côté, de la nécessité de l'intellect humain, qui n'arrive pas à la pleine compréhension de la réalité divine, et, de l'autre, de l'opportunité de cacher aux méchants la dignité du Vrai. La Bible se distingue donc nettement de la poésie, mais aussi de la philosophie (mieux : des méthodes dialectiques de ses traités scientifiques) ; voilà pourquoi, même si parfois ses techniques d'expression coïncident avec celles d'une science ou d'un art, elles ne sont jamais assimilables à celles-ci.

\section{L’argument du Pseudo-Denys}

Denys, cité dans la Summa d'Alexandre, partageait le présupposé ${ }^{14}$ néo-platonicien sur l'impossibilité d'exprimer Dieu par toute forme d'expression du langage humain $^{15}$. La conséquence, au niveau pratique, est la nécessité de parler de Dieu par

10 Vincent de Beauvais, par exemple, soutenait que art, science et doctrine sont synonymes: Speculum doctrinale I.13: Idem est ars et scientia, doctrina quoque, disciplina et facultas. De façon analogue ils s'étaient exprimés Aristote Metaph. I.1 e II.468, Isidore Etym. I.1 (PL 82, 73) et Hugues de Saint-Victor Eruditio didascalica II.1 (PL 176, 751).

11 Omnis modus poeticus est inartificialis sive non scientialis, quia est modus historicus vel transumptus, qui quidem non competunt arti, sed theologicus modus est poeticus vel historialis vel parabolicus; ergo non est artificialis. Sur le rôle de la poésie dans l'éducation franciscaine cf. Roest (2004). 12 Trin. XIV.1, n. 3 (PL 42, 1037).

13 Comme on le sait, il s'agit d'une partie de la Hiérarchie céleste de Denis.

14 Il est connu en Occident par les traductions d'Ilduin, abbé de Saint-Denis à l'époque carolingienne (827), de Jean Scot Erigène (860 - 862), les plus important philosophe du haut moyen âge, et après de Jean Saracène (XII ${ }^{\mathrm{e}}$ s., la version connue par Thomas d'Aquin).

15 Pour ne donner qu'un example de cette théorie, on peut citer De praedestinatione de Jean Scot, dans lequel on affirme explicitement que: nihil digne de deo dicitur, omnia paene sive nominum sive 
images et par métaphores ${ }^{16}$, ainsi que le théorise, en latin, Jean Scot, au IX ${ }^{\mathrm{e}}$ siècle, justement dans son commentaire de Denys. Donc, Denys-Érigène établissent une analogie entre les procédés des Saintes Écritures et ceux de la composition poétique, en partant de leur nécessité partagée d'une narrativité figurée. Ainsi définissent-ils le pivot central de toutes les légitimations ultérieures de la vérité poétique comme instrument de connaissance non indigne de la culture chrétienne :

«De même que l'art poétique présente une doctrine morale ou naturelle à travers des histoires inventées et des similitudes allégoriques, dans le but de faire travailler l'esprit humain (en effet, ceci caractérise les poètes épiques, qui célèbrent les exploits et les conduites des héros à travers des symboles), ainsi la théologie, telle une poétesse [ou bien : telle une composition poétique ${ }^{17}$, adapte les Saintes Écritures à l'utilité de notre esprit, afin de le reconduire, par des fantaisies fictionnelles, à la connaissance parfaite des réalités intelligibles, comme d'un état d'enfance imparfaite jusqu'à une sorte de maturité intérieure».

Cette affirmation n'entraîne pas pour autant une justification, et moins encore un ennoblissement de l'activité poétique en tant que telle. Il est vrai que, dans ce même commentaire, l'Érigène développe un parcours de légitimation des arts basé sur l'interprétation du réel comme théophanie, où les œuvres d'art deviennent elles aussi manuductiones ad Deum, toutefois, parmi ces arts, il ne cite pas la poésie, et il ne rappelle que la musique et; l'art plastique.

De la même manière, lorsque, au XII ${ }^{\mathrm{e}}$ siècle, Anselme de Laon et Abélard développeront l'analyse rhétorique et stylistique de la Bible, dans la lignée des prémisses de Bède et des Carolingiens ${ }^{18}$, l'apologie de l'esthétique biblique ne produit pas le passage à une acceptation de la poésie en tant que art. Au contraire, dans sa Theologia Christiana, Abélard, bien qu'il soit l'auteur raffiné d'hymnes et de planctus bibliques, répète à ce sujet les anathèmes platoniques d'Isidore et Gratien contre les

verborum aliarumque orationis partium signa proprie de Deo dici non posse. Quomodo enim signa sensibilia, id est corporibus adhaerentia remotam illam omni corporeo naturam ad liquidum significare possent, quae vix purgatissima mente attingitur, omnem transcendens intellectum? Eis tamen utitur humane ratiocinationibus post peccatum primi hominis laboriosa egestas, ut quodammodo credatur et innuatur copiosa conditoris sublimitas (Cap. IX, PL 122, 390B).

16 Translative de Deo praedicari: chap. X, col. 394 A.

17 Super Ier. Cael. Sancti Dionysii, PL 122, col. 146 B-C: Quemadmodum ars poetica per fictas fabulas allegoricasque similitudines moralem doctrinam physicam componit ad humanorum animorum exercitationem (hoc enim proprium est heroicorum poetarum, qui virorum fortium facta et mores figurate laudant): ita theologia veluti quaedam poetria sanctam Scripturam fictis imaginationibus ad consultum nostri animi et reductionem a corporalibus sensibus exterioribus, veluti ex quadam imperfecta pueritia, in rerum intellegibilium perfectam cognitionem, tamquam in quadam interioris hominis grandaevitatem, conformatseu. «Poème» est la traduction de poetria choisie par De Bruyne (1998) I. 344. Sur ce passage voir Dronke (1977).

18 Lobrichon (1985) 167. Voir aussi Colnago (2009). 
poètes mensongers ${ }^{19}$. Seuls les adeptes de l'école de Chartres $^{20}$, à travers la théorie de l'integumentum ou involucrum, reconnaîtront avec Bernard la fonction introductoria des poètes par rapport à la philosophie, et accepteront, avec Alain de Lille et Guillaume de Conches, la nécessité d'un discours symbolique sur Dieu ${ }^{21}$, revendiquant en même temps une capacité de communication propre à la poésie ${ }^{22}$.

Bientôt, pourtant, cet argument analogique - avant qu'il ne soit vigoureusement repris par l'humanisme - s'affaiblit, même indépendamment de la réaction scolastique : devant la floraison de la poésie des troubadours, qui envahit les cours avec son prestige nouveau, Jean de Salisbury, bien qu'il se soit probablement formé à l'école de Chartres et qu'il défende, dans le Metalogicon (1159) ${ }^{23}$, l'utilité didactique de la Poésie, déqualifie l'ennoblissement qu'on revendique pour celle-ci en raison de ses affinités avec la polysémie biblique : selon lui, seules les Saintes Écritures peuvent soutenir le véritable sens allégorique. Les auteurs humains, soit qu'ils écrivent au sens propre qu'au sens figuré, doivent rester compréhensibles en soi. Il y a ici une consonance fondamentale, ante litteram, avec l'argument thomiste qui distinguera le langage figuré de l'allégorie in factis, laquelle n'est présente que dans la Bible et est inépuisable, du sensus parabolicus, lequel, au contraire, peut caractériser l'écriture humaine aussi, quoique toujours sous l'aspect du sensus litteralis, c'est-à-dire de l'intention de l'écrivain.

\section{Albert le Grand}

Dans la Summa theologiae, l'éminent dominicain Albert le Grand ${ }^{24}$ (1206-1280) reprend strictement l'argumentation d'Alexandre d'Halès ${ }^{25}$ et s'interroge de modo theologiae en questionnant justement l'idée que, étant donné la nature mystique et «cachée» de la communication (traditio) biblique, les Saintes Écritures n’emploient

19 Theologia Christiana, II livre, conclusion, PL 178, 1207 C (et alibi). Unde et a sanctis postmodum Patribus non incongrue liberalium artium studia, tanquam sacrae paginae admodum necessaria, plurimum commendantur, cum omnino poetica figmenta Christianis interdicantur, non solum quia falsitate referta sunt, et os quod mentitur occidit animam (Sap. I, 11), verum etiam, quia inanium fabularum cogitationibus ad desideria turpitudinum quae fingunt, alliciunt animum, atque a sacrae lectionis meditatione nos abducunt.

20 Les exemples cités par Chevalier (2000) sur la base de Pépin (1970) sont les Allegories d'Homer d'Eraclite, L'antre des nymphes de Porphyre et la Théologie platonique de Proclus.

21 Alain de Lille, Theologicae Regulae et Quoniam homines (ed. Glorieux 1953).

22 En poésie, à la suavitas du sens littéral et à l'instructio moralis se joint l'acutior allegorie subtilitas: Pagani (1995) spec. 155.

2342.32 ss.: il se limite toutefois à en confirmer la position subordonnée à la grammaire, pour en éviter l'autonomie et la conséquente exclusion du système des artes.

24 Poeticus modus infirmior est inter modos philosophiae (Curtius (1992) 249).

25 Dans la cinquième quaestio du Ie livre: I q. membrum 1, ed. Lyon 1651, vol. XVII p. 13², cité par Curtius (1992) 249. 
pas de mode scientifique ni artificiel car elles veulent s'adapter à la compréhension de tout le monde, et non seulement des compétents. Et, pour expliquer comment cela peut arriver, il recourt à l'exemple de la chauve-souris, qui ne perçoit la lumière que si elle est immergée dans le noir, en s'appuyant sur toute une série d'autorités (de Denys jusqu’à Augustin, Grégoire, Boèce) reprises d'Alexandre. En particulier, citant lui aussi la Hiérarchie Céleste, il en conclut que «traitant d'une lumière imperceptible, la théologie emploie au sens propre des expressions figuratives quasi poeticis, à travers ce que Denys ${ }^{26}$ définit materialis manuductio, soit guide matériel. Les autres sciences philosophiques se trompent lorsqu'elles emploient ce » code «, car elles obscurcissent leur énoncé.

\section{Thomas d'Aquin}

Pour Thomas d'Aquin ${ }^{27}$ aussi - dont on a pu explorer tous les passages de textes portant sur la poétique grâce à l'Index du père Busa - la poésie n'est pas en elle un objet théologique, mais plutôt un thème occasionnel, que la théologie rencontre lorsque l'on parle du statut des arts humains ou des critères de la communication sacrée. Mais l'argumentation, ainsi que le genre d'autorités qu'il invoque, sont sensiblement différents de celles des maîtres qui l'avaient précédé, et révèlent une organisation rationnelle, propre à lui, qui reprend des textes d'Augustin autres par rapport à ceux que l'on évoquait d'habitude dans ce débat, en réintroduisant des sujets oubliés, tel celui des poètes théologiens, selon l'organisation du discours établi dans les interrogations anciennes, aristotéliques et patristiques, et en reléguant la présence de Denys et de la théologie apophatique à une position marginale. Ainsi offre-t-il une analyse fine et aiguë du mécanisme sémiotique.

Nous ne nous arrêtons que sur deux morceaux, schématisant une situation $d u$ texte bien autrement complexe. Le premier se trouve dans le Commentaire aux Sentences de Pierre Lombard. Thomas le composa pendant la première période de son magistère à Paris, entre 1252 et 1257. Dans la quaestio unica du premier livre sur le rapport entre les arts et la théologie $\mathrm{e}^{28}$, le troisième argument soutient qu'il ne doit pas y avoir une seule méthode pour des sciences différentes. Notamment la poétique, quae minimum continet veritatis, maxime differt ab ista scientia, quae est verissima. Ergo, cum illa procedat per metaphoricas locutiones, modus huius scientiae non debet

26 Chap. 1.3 ( $P G$ 3, $121 \mathrm{~cd})$.

27 Curtius curieusement ne l'inclut pas dans son aperçu.

28 L'article cinquième en particulier pose le problème du critère (modus procedendi), en se demandant s'il soit artificialis, c'est-à-dire s'il corresponde aux procedure correctes de l'art (dialectique): si - comme on le dirait aujourd'huy - il soit scientifique. Ainsi l'intend aussi le commentaire à la version française de l'oeuvre, p. 40, en ajoutant que che «lorsque Thomas reprendra le sujet dans la Summa theologiae, il mettra la question dans ces termes: cette doctrine est soumise à l'argumentation. Ici il trait le même sujet en considerant surtout la méthode». 
esse talis : «[la poétique] qui contient le moins de vérité, est la plus éloignée de cette science $^{29}$, qui est la plus vraie. Donc, étant donné qu'elle procède par des expressions métaphoriques, le mode de cette science ne saurait être le même ${ }^{30}$.

C'est donc une double question qui émerge ici : d'un côté, la théorie sur le statut de la poésie, ici définie, en passant, comme discipline contenant le moins de vérité, selon les positions traditionnelles. De l'autre, la conclusion selon laquelle le mode expressif qui est propre à la poésie ne saurait être adopté dans l'argumentation théologique, ce qui paraît nier frontalement la tradition de Denys.

Selon Umberto Eco, l'assertion sur l'infima doctrina «ne doit pas être entendue comme un rabaissement de la poésie, ni comme une définition de l'acte poétique tenu, pour user de la terminologie du XVIII ${ }^{\mathrm{e}}$ siècle, pour une perceptio confusa. Il s'agit plutôt de reconnaître à la poésie son titre à figurer au rang des arts (et, donc, sa qualité de recta ratio factibilium), étant admis d'autre part que cette opération, ce facere, ce faire demeure inférieur par nature à la connaissance épurée que procurent la philosophie et la théologie. [...] En fait, à l'instar de tous les penseurs scolastiques, il n'éprouve aucun intérêt pour une théorie de la poésie : un sujet bon pour les spécialistes de rhétorique, lesquels professeraient à la faculté des Arts, et non à la faculté de Théologie» ${ }^{31}$. En fait, un peu plus loin, dans l'argument V, on réaffirme que chaque science a sa méthode, et, dans le $\mathrm{III}^{\mathrm{e}}$, on lit que ${ }^{32}$ «la poétique est la science de ce que la raison ne peut saisir par manque de vérité : il est donc inévitable que la raison soit conduite comme par similitudes ; le mode symbolique est donc commun à l'une et à l'autre, étant donné que ni l'une ni l'autre ne sont adéquates la raison». Cet argument, quoiqu'il soit avancé par nécessité du débat, paraît limiter l'enjeu du précédent, et ouvrir une porte à la justification de l'emploi du langage métaphorique, qui vise à suppléer un défaut de vérité - et donc de capacité d'expression rationnelle - des objets des deux sciences : les fictions poétiques et Dieu, justification sur laquelle se basera la défense humaniste de la poésie.

29 Trop faible la traduction française: «est très différente de cette science». Dans Ia q. 1 a. 8 on réaffirme que «procéder par similitudes diverses et rappresentations sensibles c'est propre de la poétique ».

30 Claudio Mésoniat observe que dans le système thomiste de classement des sciences la poétique est comprise entre les sciences pratiques, qui incluent les arts mécaniques, inférieures en dignité aux spéculatives, tandis qu'Aristote avait concédé à la poétique «uno statuto singolare, non riducibile a quello delle scienze speculative né a quello delle scienze pratiche». Dans l'oeuvre de Thomas un classement semblable de la poétique ne paraît pas exprimé de façon explicite, mais on le déduit de ce qu'on en dit dans les passages mentionnés plus haut: Mésoniat (1984) 16 n. 18. Autre bibliographie citée par lui Mariétan (1901) 177-179 et 192 ; Eco (1975) 1-7 et 202-204.

31 Eco (1987), 94-95, trad. fr. 1997127.

32 Poetica scientia est de his quae propter defectum veritatis non possunt a ratione capi: unde oportet quod quasi quibusdam similitudinibus ratio seducatur: tehologia autem est de his quae sunt supra rationem; et ideo modus symbolicus utrique communis est, cum neutra rationi proportionetur. 
Le texte ${ }^{33}$ de Thomas qui aura influé plus que d'autres sur le débat pré-humaniste $^{34}$, se trouve dans le commentaire à la Métaphysique, où, à propos des philosophes présocratiques, il signale que, chez les Grecs, certains poetae theologi furent célèbres, qui étaient appelés ainsi car de divinis carmina faciebant (ils composaient des poèmes sur les réalités divines «), et il en rappelle trois, Orphée, Musée et Linos, contemporains des Juges du peuple juif ${ }^{35}$. Ces poètes étudièrent quelques aspects de la nature à travers quibusdam aenigmatibus fabularum, soit travers des histoires allégoriques. ${ }^{36}$ Dans Metaphisica 1000a9, Aristote cite Hésiode (auteur d'une cosmogonie) et » d'autres théologiens «, tandis que, dans d'autres passages ${ }^{37}$, il identifie les théologiens aux spécialistes de la nature, et les distingue des philosophes en raison de la nature scientifique de leur pensée. Pourtant, il ne cite pas les trois poètes mentionnés par Thomas (Orphée, Musée et Linos), qui les tire d'une autre source. Le texte d'Aristote, déjà cité par Lactance dans le $D e$ ira $D i^{38}$, qui était pourtant peu lu au Moyen-Âge, avait été employé par Augustin dans plusieurs morceaux de La Cité de

33 On renonce ici pour manque d'éspace à analyizer d'autres passages pertinents. Dans I.l.1 n. 6 il écrit poetae est inducere ad aliquod virtuosum per aliquam decentem repraesentationem, c'est-à-dire que «propre du poète c'est de conduire vers un objectif virtueux par une réprésentation esthétique», en n'excluant pas donc un rôle positif de la poésie au niveau pratique, tout en ayant nié un statut théorique.

34 La source aristotelique ici commentée sera la base soit de la critique du dominicain Giovannino da Mantova, soit des justifications humanistiques de la poésie.

3515 Ad cuius evidentiam sciendum est, quod apud Graecos primi famosi in scientia fuerunt quidam poetae theologi, sic dicti, quia de divinis carmina faciebant. Fuerunt autem tres, Orpheus, Museus et Linus, quorum Orpheus famosior fuit. Fuerunt autem tempore, quo iudices erant in populo Iudaeorum. Unde patet, quod diu fuerunt ante Thaletem, et multo magis ante Aristotelem qui fuit tempore Alexandri. Isti autem poetae quibusdam aenigmatibus fabularum aliquid de rerum natura tractaverunt. Dixerunt enim quod Oceanus, ubi est maxima aquarum aggregatio, et Thetis, quae dicitur dea aquarum, sunt parentes generationis: ex hoc sub fabulari similitudine dantes intelligere aquam esse generationis principium. Cfr. Super Meteora II.1 n. 3. [...] Circa primum duo facit: primo ponit opiniones antiquorum theologorum; secundo naturalium, ibi: qui autem sapientiores etc. Circa primum sciendum est quod ante tempora philosophorum, fuerunt quidam qui vocabantur poetae theologi, sicut Orpheus, Hesiodus et Homerus: quia sub tegumento quarundam fabularum, divina hominibus tradiderunt. De his ergo dicit quod posuerunt quod mare habeat fontes proprios ex quibus causatur. [... ]. Sententia Metaphysicae lib. III.11 n. 3.[...]. Tertio se excusat a diligentiori improbatione huius positionis, ibi, sed de fabulose etc. Circa primum considerandum est, quod apud Graecos, aut naturales philosophos, fuerunt quidam sapientiae studentes, qui deis se intromiserunt occultantes veritatem divinorum sub quodam tegmine fabularum, sicut Orpheus, Hesiodus et quidam alii: sicut etiam Plato occultavit veritatem philosophiae sub mathematicis, ut dicit Simplicius in commento praedicamentorum. Dicit ergo, quod sectatores Hesiodi, et omnes, qui dicebantur theologi, curaverunt persuadere solis sibi, et nos alios spreverunt; quia scilicet veritatem, quam intellexerunt, taliter tradiderunt, quod eis solum possit esse nota. [...]. 36 Parmi eux il y les premiers qui, «à l'époque archaïque, firent des dieux l'objet d'une réflexion» (hoi prótoi ... theologhésantes) en enseignant qu'Océan et Téthys avaient engendré le monde et que les dieux erraient dans le Styx: Arist. Metaph. 939b 29.

37 Curtius (1992) 243.

38 11.8. 
$D_{i e u^{39}}$ : en particulier, au chapitre $14 \mathrm{du}$ livre $\mathrm{XVIII}^{40}$, il rappelle que, à l'époque historique où vécurent les Juges du peuple hébraïque, existaient les poetae, qui etiam theologi dicerentur, quoniam de diis carmina faciebant. Mais il spécifie tout de suite que ces dieux étaient de grands hommes ou des éléments de la nature, et que, si parmi tant de faussetés ou vanités, ces poètes chantèrent quelque chose du Dieu unique et vrai : en le confondant parmi d'autres divinités fausses, ils ne lui furent pas avantageux, Orphée, Musée et Linos non plus, car eux-mêmes ne purent éviter l'indécence des fables mythologiques. La sévère condamnation est donc répétée et précisée dans ce passage, qui, de toute évidence, est la source originale, quoique non déclarée, de Thomas $^{41}$.

Les attestations relatives au rapport de la poésie et de la théologie à la Bible, dans les summae scolastiques, paraissent parfois exclure, parfois soutenir une continuité technique, et donc une possibilité de comparaison entre les deux "genres», sans pourtant exprimer une véritable condamnation de la poésie pareille à celles que lui réserve la théologie patristique et dialectique inspirée par Platon. Comme Curtius l'avait bien compris ${ }^{42}$, Thomas ne discute pas les raisons pour lesquelles la poétique est le dernier des arts, puisqu'il «[...] n’a aucune raison pour la discuter ou la réexaminer. La Scolastique ne s'intéresse pas d'ennoblir la poésie ; elle n'a produit ni

39 Dans le livre VI, dedié à la théologie payenne, le chapitre 5 trait des trois types de théologie exposés par Varron (mythique, naturelle et civile, où d'après Varron mythicon appellant quo maxime utuntur poetae) et le 6 de la théologie mythica, id est fabulosa, qu'Augustin critique en tant que matière de poétes, théâtre, spectacle, où est réprésentée la vie de divinités immorales. La théologie fabulosa est celle qui de diis nefanda figmenta hominum carminibus personat, c'est-à-dire 'fait resonner dans les poèmes abominables des inventions humaines sur les dieux'.

40 Per idem temporis intervallum exstiterunt poetae, qui etiam theologi dicerentur, quoniam de diis carmina faciebant, sed talibus diis, qui licet magni homines, tamen homines fuerunt aut mundi huius, quem verus Deus fecit, elementa sunt aut in principatibus et potestatibus pro voluntate Creatoris et suis meritis ordinati, et si quid de uno vero Deo inter multa vana et falsa cecinerint, colendo cum illo alios, qui dii non sunt, eisque exhibendo famulatum, qui uni tantum debetur Deo, non ei utique rite servierunt nec a fabuloso deorum suorum dedecore etiam ipsi se abstinere potuerunt Orpheus, Musaeus, Linus. Verum isti theologi deos coluerunt, non pro diis culti sunt; quamvis Orpheum nescio quomodo infernis sacris vel potius sacrilegiis praeficere soleat civitas impiorum.

41 L'unique autre auteur médiéval qui mentionne cette sequence est Philippe d'Harveng, perçant exégète et théorique de l'exégèse, dans De institutione clericorum III.45, PL 203 1019a: Et quia studium eorum fuit verbosa de diis carmina fabricari, theologi meruerunt generaliter nominari, gratum habentes tale sibi vocabulum assignari, in quo posset eorum quasi divinum officium designari. Quorum priores et antiquiores Orpheus, Linus, Musaeus fuisse referuntur, qui suis contemporaneis fama et scientia praeferuntur, quorum labore litterario, diis falsis laudes et carmina deferuntur, et hominibus erroneis documenta placita conferuntur. (1020 A) Eo autem tempore quo poetae in Graecia claruerunt et famae testimonio litteralis artem scientiae tenuerunt, in terra promissionis iam populus Israel versabatur, ibique a iudicibus, et, ut quidam aestimant a Debbora iudice regebatur.

42 Curtius (1992) 199 ; 249. Une discussion intéressante sur le placement des livres de poésie dans les bibliothèques scolaires est celle proposée par Franklin-Brown (2015). 
une poétique ni une théorie esthétique ${ }^{43}$. [...] La Scolastique, produite par la dialectique du XII ${ }^{\mathrm{e}}$ siècle, ne conserve pas l'opposition aux auctores, à la rhétorique et à la poésie ; elle ôte de l'aristotélisme la justification philosophique de la poésie». Pourtant, c'est bien l'argument augustinien et thomiste des poetae theologi qui soutiendra la légitimation de la poésie classique.

\section{Le passage de la Scolastique à la discussion humaniste}

Comme on le sait, la qualité du débat change radicalement à partir d'Albertino Mussato (1261-1329), notaire et dramaturge de Padoue, qui reprend les suggestions pseudo-denysiennes, élaborées par Jean Scot et par l'école de Chartres ${ }^{44}$, sur l'équivalence entre poésie et théologie, visant à attribuer à la poésie une position de primauté dans le système de la culture. Selon la lecture vulgarisée d'abord par Garin et Ronconi, puis par d'autres, cette approche aurait été contrecarrée par les penseurs thomistes, tandis qu'elle aurait été adoptée par l'Épître à Cangrande della Scala que l'on attribue à Dante, et, ultérieurement, par Pétrarque ${ }^{45}$, et Boccace $^{46}$; cela ouvre la voie à la sacralisation de la poésie qui, à partir de Coluccio Salutati ${ }^{47}$, mènera jusqu'à Scaliger ${ }^{48}$ et au-delà.

Mais, au cours des dernières années, Thomas Ricklin a accompli des progrès importants, bien que méconnus, dans le repérage de traités de logique modistes qui sont à la source de son approche, alors que Casadei et d'autres ont puissamment remis en cause la paternité de l'Épître. Les positions de ceux qui attribuent à Dante l'anticipation de la théorie du "poète théologien», en sortent donc affaiblies. En fait - comme j'ai déjà essayé de le démontrer ailleurs ${ }^{49}$-, que l'auteur soit ou non Dante, il reste que celui-ci applique à la Comédie, tout comme à l'un de ses chants du

43 C'est important de rappeler ici la note de bas de age de Curtius (1992) n. 23, sans la quelle non ne comprend pas sa position, qui s'oppose aux efforts (à nos jours, les exemples les plus célébres sont Eco (1956) et Biffi (2005)) d'individuer une esthétique dans la doctrine de la Scholastique: «Quando, nella filosofia scolastica, si parla di bellezza, si intende con ciò un attributo di Dio. La metafisica della bellezza (ad es. in Plotino) e la teoria dell'arte non hanno assolutamente nulla in comune. L'uomo »moderno« sopravvaluta smisuratamente l'arte perché ha perduto il senso della bellezza intelligibile, che invece possedevano il neoplatonismo e il Medioevo. Agostino (Conf. X.27.38) si rivolge a Dio: Sero te amavi, pulchritudo tam antiqua et tam nova, sero te amavi [Tardi giunsi ad amarti, o bellezza così antica e così nuova; tardi giunsi ad amarti]. È evidente che qui si tratta di una bellezza del tutto estranea all'estetica.»

44 Sur ça voir la syntèse de Lemoine (1998).

45 Fam. X.4.1: parum abest quin dicam theologiam esse poeticam de deo.

46 Genealogie deorum gentilium, libro XIV.

47 Il défend ces positions dans le De laboribus Hercolis.

48 Declamatio contra poetices calumniatores.

49 Stella (2010). 
Convivio, des méthodes de lecture réservées à la Bible, sans impliquer explicitement l'idée d'une fonction théologique de la poésie, mais se limitant à adopter des instruments d'interprétation devenus communs. De voir ce choix technique comme le témoignage d'une culture pré-humaniste est un malentendu qui révèle la tentation de forcer les textes du XIV $\mathrm{X}^{\mathrm{e}}$ siècle pour y lire à tout prix des anticipations de l'humanisme.

\section{Albertino Mussato et la conception du poète théologien}

Le pas décisif vers la sacralisation de la poésie sur la base de ses procédés expressifs sera accompli par Albertino Mussato et par Boccace, qui le reprend.

Le cœur de ce tournant ${ }^{50}$, qu'on peut suivre, depuis quelques années, dans l'édition de Chevalier, est la célèbre querelle qui s'alluma en 1315 entre Mussato et le frère dominicain Giovannino da Mantova, maître de grammaire (c'est-à-dire de lettres) au Studium de Padoue. Dans l'épitre IV, Mussato avance sa thèse générale de la sacralité de la poésie, s'appuyant sur deux arguments anciens et et eux aussi destinés à un long succès : celui de l'analogie narrative entre épisodes de la Bible et contes mythologiques, analogie qui attesterait le partage d'une base spirituelle et d'une inspiration divine communes, et celui de la nature poétique de la Bible, ou au moins de quelques-unes de ses parties (comme le Cantique de Moïse et l'Apocalypse). Giovannino lui répond dans un texte qui ne nous est jamais arrivé, mais que l'on peut reconstituer à partir de la réponse de Mussato (ép. 18, dans les éditions modernes). À leurs deux voix, s'ajoutent celle des declarationes qui, dans les manuscrits, accompagnent le texte poétique, et dont Chevalier attribue la rédaction à deux amis de Mussato, appartenant au même milieu pré-humaniste : Castellano di Bassano et Guizzardo di Bologna, commentateurs de l'Ecerinis ${ }^{51}$ dont les arguments Ricklin a démontré tres proches de la lettre à Cangrande. Nous allons analyser les plus significatifs des neuf arguments, et les plus utiles à encadrer le statut de la poésie biblique.

50 Chevalier (2000) XCIII ss. ; les informations ici données sont plus exactes et mises à jour que dans la bibliographie précedente. Voir aussi Greenfield (1981) ; Fitzgerald (2017) chap. 6 Albertino Mussato and Humanist Prophecy, 193-229. Sur l'esthétique de Mussato avant lui Vinay (1949) 113-159 et Dazzi (1964). Le MS. des épîtres poétiques est Venise, Archivio di Stato, ex Brera 277.

51 Les on a récemment involvés pour la coïncidence des expressions de leur commentaire avec des formules de l'Épitre à Cangrande : Chevalier (2000) XCIII. Il s'agit de deux commentateurs de l'Ecerinis, la tragédie avec la quelle Mussato reouvre la tradition du théâtre classique interrompue au Moyen Âge. Le texte de Castellano et Guizzardo a été publié seulement dans un imprimé du 1616, d'où Garin 1965 l'a traduit dans les pages 2-19. Voir Billanovich (1976) 73-74. B. Fiztgerald cite une ed. HR fasc. 7 p. 69 et Cecchini (1985) 95-119. 


\section{Contre-arguments 1 et 2 . La poésie n'est pas un art «divin» car elle ne parle pas de réalités divines}

Giovannino s'oppose à Mussato en rappelant les condamnations que la poésie avait subies de la part de la théologie catholique, depuis Jérôme et Grégoire le Grand, et il reprend le raisonnement de Thomas, qu'on reconnaît de la citation d'Orphée, Musée et Linos $^{52}$, en lui opposant la remarque que les textes poétiques païens, contrairement à la Genèse biblique, ne parlent pas du vrai Dieu, mais de phénomènes célestes (tels Océan et Téthys) ou d'hommes divinisés ${ }^{53}$.

\section{Argument 6. L’emploi biblique de la poésie en confirme la nature sacrée}

Dans Exode 15, Moïse prononce un chant de louanges et d'exultation pour la «victoire» sur les Égyptiens après la traversée de la Mer Rouge. Giovannino admet qu'il s'agit là de poésie ${ }^{54}$, mais, à son avis, ce rapprochement ne justifie pas la poésie en général. Il reconnaît aussi que quelques poètes bibliques exceptionnels, tels qu'Arator et Sedulius, ont versifié la Bible entière ${ }^{55}$, mais cet élément non plus ne permet pas de définir divine la poésie dans son ensemble, tandis que la Bible est entièrement divine. Ce problème, déjà abordé par Aristote à propos d'Empédocle, relève donc de catégories logiques, et non d'un préjugé culturel : «en effet, de même que la science naturelle ou n'importe quelle autre ne saurait être définie Logique, bien qu'elle emploie des procédés de démonstration typiques de la Logique, ainsi toute science qui est susceptible d'être versifiée ne peut pas pour autant être définie "poésie«, bien que la poésie présente ce même mode d'expression » ${ }^{56}$.

52 Voir ci-dessus p. 481-482. L'exemple sera repris par Coluccio Salutati De laboribus Herculis I.9, rr. 25-28 Ullmann: Fuerunt et post eos Museus, Orpheus et Linus, qui nedum carminibus deos colebant, sed ceperunt etiam de diis et ipsorum statu naturaque non medioctriter disputare. Unde et theologi dicti sunt. Chevalier (2000) CV n. 43 renvoie au célèbre passage d'Augustin, Civ. XVIII.14, mais, comme on l'a vu, les références préalables à Salutati sont plus nombreuses et complexes, et peuvent être déchiffrées par l'individuation exacte des textes.

53 C'est un argument de la critique anti-religieuse rationaliste, le soi-disant évémerisme, que la culture chrétienne avait déjà exprimé de façon organique avec Lactance : Institutiones Divinae I.11 et De ira Dei 11.

54 Mussato ep. IV.61-62.

55 Ceci n'est pas du tout exacte: Sedulius versifia l’Évangile, même s’il le fit précéder, dans les premier de ses quatre livres, par une synthése des événements bibliques antérieurs, et Arator se borna aux Actes des apôtres. Le passage de Giovannino, qui est de difficile obtention, dit: Dato etiam quod tota sacra theologia esset metrice tradita, sicut quidam excellentes viri, ut Arator et Sedulius, facere conati sunt, propter hoc tamen poetica non esset dicenda divina.

56 Sicut enim scientia naturalis vel quaelibet alia non potest dici logica, licet utantur modo demonstrandi quem tradidit logicus; sic etiam quaelibet scientia potest tradi metrice, non tamen propter hoc est dicenda poetica, licet talem modum scribendi poetica doceat (Garin 1958, de l'ed. Venezia 1636). 
Le commentaire attribué à Guizzardo et Castellano ${ }^{57}$ interprète cette argumentation en expliquant que, de même que les autres sciences se divisent en théorie et pratique, ainsi la poésie est soit une science théorique, lorsqu'elle compose des histoires à propos d'une vérité, comme Christ le faisait dans les paraboles, soit une science pratique, lorsqu'elle versifie des dictons ou des actions super alia significatione, comme le font Arator et Sedulius. Donc, la poésie serait divine sous son aspect théorique, alors qu'elle serait «technique» (artificialis) du moment où elle est pratique $^{58}$. Il s'agit d'une interprétation spécieuse et aiguë, car, si elle a l'air de décrire l'argument négatif de Giovannino, néanmoins elle l'emploie, en postulant l'équivalence théorique=divine qui en effet n'est pas démontré, pour «sauver » un élément de sacralité de la poésie ; ainsi cherche-t-elle une position de conciliation à laquelle sa source ne visait pas, et elle prouve l'existence d'un milieu intellectuel décidé à soutenir la légitimation de la poésie sans s'opposer à la Scolastique et sans en nier les raisons «scientifiques». L'observation du commentateur pouvait avoir des issues importantes parce qu'il identifie dans la poésie biblique un élément de médiation entre les deux positions : mais ce n'est pas là que se trouve la solution du problème, puisque le contenu de vérité de la poésie ne "transmet» pas sa vérité au code expressif, c'est-à-dire à la poésie. La prémisse implicite est que, de toute façon, lorsqu'elle s'occupe de la Bible, la poésie est divine. Cette prémisse a eu effectivement une grande fortune dans la pratique de la production poétique, mais moins de reconnaissance dans les textes de théorisation poétique que nous connaissons ${ }^{59}$.

\section{Argument 7. L’analogie expressive entre poésie et Bible (symbolisme)}

C'est le nœud de l'entière démonstration : Christ a lui-même communiqué à ses disciples sous forme d'énigmes obscures : nigmata discipulis dixit operta suis (7.38, concernant les paraboles) et les «sacres» poètes suscitent de l'admiration car un sens différent du littéral impose davantage d'attention. Sur cette base, Mussato défend la définition de poésie comme «deuxième philosophie» légitimée par les plus grandes autorités, telles Aristote et Platon, tout en soulignant que même la doctrine juridique, si chère à son interlocuteur, mentionne de temps en temps les vers d’Homère. La réplique de Giovannino s'appuie sur un argument thomiste très solide :

57 Voir ci-dessus, n. 78.

58 Quemadmodum aliae scientiae in practicam et theoricam dividuntur, sic et poetica scientia theorica est, cum quis super veritatem aliquam fabulam fingit, sicut faciebat Dominus noster Iesus Christus in Parabolis. Poetica vero practica est, quum quis quae dicta vel acta sunt super alia significatione in metro describit, ut illi Arator vel Sedulius. Secundum igitur theoricam poetica est divina, secundum autem practicam est ut aliae scientiae artificiales.

59 Par souci de concision, je me réfère à Stella (2001), 42-46 («Legittimità di un'estetica eteronoma»). La position de Mussato sur la poésie dans ses dernières années est étudiée par Fiacchini (2017). 
la ressemblance entre les modes d'expression de la un poésie et ceux des Saintes Écritures n'est qu'apparente. En effet, «la poésie emploie des métaphores pour représenter et plaire, alors que les Écritures divines le font pour voiler le rayon des Écritures mêmes et de la Vérité, qui peut ainsi être cherchée avec plus d'engagement par ceux qui en sont dignes, tout en restant cachée aux indignes. Les Écritures, en effet, sont couvertes pour ne pas s'avilir, et sont dévoilées pour nourrir les âmes ${ }^{60} »$ : la différence en termes de finalité et de substance que l'allégorie vise à souligner, répète, de façon concise, ce qu'exprimait Thomas ${ }^{61}$, et ignore tout à fait la spécificité des paraphrases poétiques de la Bible.

Mussato répond dans la lettre 18 (113 s.), en rappelant à son interlocuteur qu'il avait lui-même cité l'Apocalypse comme étant connotée d'un langage assimilable au langage de la poésie élevée ${ }^{62}$, et il l'invite à lire ce que les novi poete - les poètes bibliques, justement - avaient écrit sur la naissance du Christ ${ }^{63}$, en invoquant quelques vers de celui que, dans l'un des rares versets chrétiens de sa production ${ }^{64}$, il appelle Claudien et qui est, précisément, Claudius Claudianus, que Chevalier confond avec Claudien Mamert. La réplique de Mussato se base donc sur une méprise intentionnelle de l'argument de Giovannino ${ }^{65}$, mais elle saisit la puissance gagnante de la solution anti-classiciste : l'existence d'une poésie capable d'associer la vérité des contenus aux capacités prophétiques et métaphoriques du langage. Ce serait la poésie chrétienne, la poésie biblique, à avoir résolu l'aporie du peu de «contenu de vérité» de la poésie classique. Dans le sillage de Mussato et de ses commentateurs, à la fois Dominici, dans sa querelle contre Boccace-Salutati, et Boccace lui-même développeront cette solution, et ce dernier en tirera une projection de grande envergure, reconstituant un fil commun allant de Juvencus jusqu'à Alain de Lille, à Dante et au Pétrarque-Bucoliques, projection que l'humanisme et l'historiographie moderne ont effacée.

60 Ed. Garin 1958, chap. 10: [dici potest] quod poetica propter hoc videtur habere similitudinem cum dictis Scripturis, quia divina Scriptura metaphoris utitur, sicut poetica, ut patet maxime in Apocalypsi et in libris prophetarum. Sed differunt omnino. Nam poetica utitur metaphoris ad repraesentandum et delectandum, sed Divina Scriptura ad radium divinae Scripturae et veritatis circumvelandum, ut a dignis studiosius inquiratur et indignis occultetur; et ob hoc aperiuntur, ut pascant animam.

61 Vedi ci-dessus, p. $479-482$.

62 Sicut ais vere similatur Apocalis alto / eloquio vatum: restat fatearis ut ipsa / sit de fine boni summi concepta poesis.

63 Et posuere novi simul et cecinere poetae, v. 117.

64 Chevalier dans son commentaire le confonde avec Claudien Mamerte, en citant l'edition de la $P L$ (3, coll. 788-9), tandis qu'il s'agit de Claudien, Carmina minora 32.

65 Giovannino en effet citait la poéticité de l'Apocalipse en tant que partie de l'argumentation de l'interlocuteur; deuxièmement il niait de toute façon que ceci pouvait être un exemple d'analogie entre la Bible et la poésie ancienne, justement parce-que dans les deux typologies de texte l'image métaphorique prend deux rôles et deux poids différents. Á cet argument, l'argument thomiste, Mussato ne répond pas, entrainé par l'enthousiasme qui associait chaque forme d'écriture inspirée dans une légitimation commune. 


\section{Argument 9. Contenus crypto-chrétiens de la poésie.}

Le dernier des neuf arguments élaborés par Giovannino concerne ${ }^{66}$ le contenu chrétien de toute poésie. Mussato rappelait que Virgile avait prédit l'avènement du Christ (dans le célèbre puer de la quatrième des Bucoliques), et que ses vers ont été employés pour exprimer des contenus chrétiens dans les centones de Proba et d'autres auteurs de l'Antiquité tardive. Govannino insiste sur l'antériorité de Virgile qui, le Christ n'étant pas encore né, ne pouvait se dire chrétien, et il considère que la reprise de ses vers dans un contexte altéré est un coup de force, ce que Jérôme avait déjà soutenu. Pourtant Mussato et la declaratio anonyme inversent l'argument en rappelant que les prophètes Isaïe, Ézéchiel, Daniel et les autres parlent eux-aussi du Christ avant qu'il ne soit né, puis le Commentaire loue la capacité d'expression chrétienne de Proba, première auteur de Bibeldichtung en latin, dont Mussato avait accepté la condamnation de la part de Jérôme, mais dont le commentaire cite plusieurs vers pour avérer sa thèse ${ }^{67}$.

\section{Issues de la querelle}

Giovannino conclut en affirmant que les arguments de Mussato sont faibles et obscurs (dubia), et il paraît en prôner le développement d'une façon plus articulée et dans un langage convenable, soit dialectique ${ }^{68}$. En revanche, le commentaire qui clôt le texte explique que la réponse qu'a donnée, à son tour, le poète, une fois bien analysée, dissipe tout doute, mais que, puisque le langage poétique contraint à la synthèse, le lecteur cultivé devra en développer les arguments ${ }^{69}$. Le débat peut apparaître comme un dialogue entre deux approches incompatibles, mais ceci dérive surtout de la différence dans la méthode d'articulation des arguments. Frère Giovannino donne à la discussion une structure professionnelle établie selon les règles dialectique de la Scolastique, tandis que Mussato accumule des intuitions et des références qui ne relèvent que d'un nœud essentiel : l'analogie entre Bible et poésie en termes de procédés expressifs et de contenus sapientiels, une suggestion pleinement médiévale - et non seulement patristique, comme le disent quelques étu-

66 Nostra fides sancto tota est predicta Maroni: / Inclita Centone despice metra Probe.

67 Á ces-ci il ajoint une référence au poéte qui, avec le même esprit, adapta les vers de l'Hercules furens de Sénèque à Christ.

68 Sermo ad hoc conveniens: ici Garin traduit «quando se ne darà l'occasione», tandis que nous croyons que Giovannino se réfère au genre qui convient à la discussion théorique, qui ne peut pas être la poésie mais justement la quaestio.

69 Verum cum sententiae quae metrice insinuantur succinctae sint, sic exigente natura metrorum et poeticae facultatis, si prosaice dissererentur clarius elucescerent, despiciat igitur lector prudens et faciliter per metra correspondentia singulis quaestionibus convenientias discerneret artis poeticae ad veram theologiam, et dubia incunctanter absolvet. 
des -, mais déjà dépassée par la Scolastique. Albertino n'avait pas eu la formation pour pouvoir soutenir ce rapport sous l'aspect technique, mais l'emphatisation enthousiaste de l'approche analogique «dionysienne-eriugénienne» finira par s'imposer pendant l'Humanisme entier, et jusqu'au Romantisme, comme on a démontré dans les colloques sur Bible et poésie à Florence $1998^{70}$ : la poésie, grâce à son langage figuré, transmet des contenus de vérité les cachant sous des images apparemment étrangères, de même que la Bible et la théologie ne parlent de Dieu, entité par définition inexprimable, qu'à travers l'intermédiaire de effacer la virgule figures, allégories, négations, circonlocutions. Par ce retour, apparemment inconscient, au néoplatonisme, Mussato ainsi qu'un certain humanisme contrastent les positions plus «modernes» et «scientifiques» des thomistes, réagissant de façon «conservatrice» aux innovations de ces derniers. L'issue que la Bibeldichtung serait susceptible d'offrir, reste sur l'arrière-fond de la discussion, et n'apparaît que de temps en temps dans les réflexions des différents interlocuteurs, écrasée par le postulat selon lequel, lorsque l'on parle de poésie, l'on entend automatiquement la poésie profane. Sous cet aspect, l'humanisme vainc avant même que ne s'ouvre le conflit, par le simple fait que, à l'exception de quelque personnalités conciliantes tels les auteurs du commentaire, on ne visait pas à trouver un point de rencontre, mais plutôt à affirmer les ambitions d'une nouvelle classe intellectuelle - de genre 'bourgeois', notarial et politique - face à l'ordre établi scolastique et universitaire de genre clérical, et la querelle sur la poésie, qui pendant l'humanisme deviendra débat sur les programmes scolaires, n'est qu'un instrument de cet affrontement de pouvoir social et de la concurrence dans le marché de l'instruction publique.

Pourtant l'hétérogénèse des buts fera de cet instrument polémique l'une des pierres angulaires de la culture européenne de la fin de la Renaissance, puis du Romantisme, et seule une analyse affranchie d'aprioris historiographiques et fermement ancrée aux textes et aux manuscrits, pourra nous en raconter le développement, qui, avant Novalis et Blake ${ }^{71}$, atteindra ses sommets intellectuels dans le dialogue Boccace-Dominici et Salutati-Sanminiato, source directe de la Defence of Poesy di Philip Sidney (1595), des sommets destinés à rester incompréhensibles si on le arrache de l'arrière-plan médiéval que nous avons essayé de résumer.

70 En particulier Pagnini (1999) 39-51; voir aussi, qui naturellement se rattache aux travaux de N. Frye, y compris Frye (1969).

71 La question des rapports entre poésie et disciplines de la connaissance (en particulier la philosophie) se ramifie dans le deux veines platonique et «romantique», déjà dans Francis Bacon (1624, p. 85): Historia ad memoriam refertur, poesis ad phantasiam, philosophia ad rationem. Nietzsche considère la poésie une forme de philosophie, continuation de la pensée mythique. Shelley appelle les poètes, comme Mussato l'avait fait en utilisant l'expression altera philosophia pour la poésie, «philosophes de sublime puissance» (Valentino (2002) 214 n. 87). 


\section{Bibliographie}

\section{A. Sources}

par ordre alphabétique du nom de l'éditeur, sauf pour les gravures anciennes

Epistola fratris lohannini de Mantua ... Mussato poetae paduano invehens contra poeticam, Venetiis 1636.

S. Antonini, Summa Theologica, voll. 4, ex typographia Seminarii: apud Augustinum Carattonium, Veronae 1740.

Bossuat (1953): Alano di Lille, Anticlaudianus, éd. R. Bossuat, Paris, Vrin.

Cecchini (1985): E. Cecchini, Le epistole metriche del Mussato sulla poesia, in Tradizione classica e letteratura umanistica per Alessandro Perosa, a cura di R. Cardini, E. Garin, L. Cesarini Martinelli, G. Pascucci, vol. I, Roma, Bulzoni, 95-119 (con ed. delle lettere I, IV, VII e XVIII).

Chevalier (2000): Albertini Mussati Ecerinis. Epitres metriques sur la poésie, Songe, édition critique, traduction et présentation critique par J.-F. Chevalier, Paris, Les Belles Lettres.

Coulon (1908): Beati Iohannis Dominici Lucula noctis, éd. R. Coulon, Paris, Picard, online in www. archive.org.

Fredborg (1988): The Latin Rethorical Commentaries by Thierry of Chartres, ed. K.M. Fredborg, Pontifical Institute of Mediaeval Studies, Toronto.

Frugoni-Brugnoli (1996): Dante Alighieri, Epistole. Egloge. Questio de aqua et terra, a cura di A. Frugoni, G. Brugnoli et al., Milano, Ricciardi.

Gerson (1966): G. Gerson, Oeuvres complètes, vol. vii/1, L'oeuvre française, Paris Desclée \& C. Gillen (1979): O. Gillen, Herrad von Landsberg, Hortus Deliciarum, Neustadt, Pfalz Verlanganstalt. Glorieux (1953): P. Glorieux, La somme «Quoniam homines» d'Alain de Lille, Archives d'Histoire Doctrinale et Littéraire du Moyen Age 20, 113-364.

Hunt (1961): Iohannis Dominici Lucula noctis, ed. E. Hunt, Notre Dame (Ind.), Notre Dame University Press, 1940, 19602.

Megas (1967): A.Ch. Megas, 'O prooumanistikòs kúklos tes Pádouas (Lovato Lovati-Albertino Mussato) kài oi' tragwdies tou L.A. Seneca, Thessaloniki, 154-161.

Pignoria (1636): Albertini Mussati Historia Augusta Henrici VII Caesaris et alia quae extant opera, edd. L. Pignoria-F. Osio-N. Villani, Venetiis 1636.

\section{B. Études}

Biffi (1999): I. Biffi, La poesia e la grazia nella Commedia di Dante, Milano, Jaca Book.

Biffi (2005): I. Biffi, L'eucaristia in san Tommaso d'Aquino: teologia, mistica e poesia, Siena, Cantagalli 2005.

Billanovich (1976): Guido Billanovich, Storia della cultura veneta.

Cames (1971): Gérard Cames, Allégories et symboles dans l'Hortus deliciarum, Leiden, Brill.

Chenu (1957): Marie Dominique Chenu, La théologie come science au XIIle siècle, Paris (tr. it. La teologia nel XII secolo, Milano, Jaca Book, 1986).

Colnago (2009): Filippo Colnago, Poesia e teologia in Giovanni Scoto l'Eriugena, Roma, Herder Editrice e Libreria

Curtius (1949) = Ernst R. Curtius, «Theologische Poetik im italienischen Trecento», in: Zeitschrift für romanische Philologie 9, 1-15.

Curtius (1992): Ernst R. Curtius, Letteratura europea e medioevo latino, La Nuova Italia, Firenze, La Nuova Italia (ed. or. Francke, Bern 1948). 
Dazzi (1964): Manlio Torquato Dazzi, Il Mussato preumanista (1261-1329): l'ambiente e l'opera, Vicenza, Nei Pozza.

Dronke 1977 = Peter Dronke, «Theologia veluti quaedam poetria: quelqus observations sur la fonction des images poétiques chez Jean Scot», in: Jean Scot Erigène et l'histoire de la philosophie, Paris, Ed. du CNRS, 243-255.

Eco (1975): Umberto Eco, Sviluppo dell'estetica medievale, in Momenti e problemi di storia dell'estetica. 1. Dall'antichità classica al Barocco, Milano, Marzorati.

Eco (1987): Umberto Eco, Arte e bellezza nell'estetica medioevale, Milano, Bompiani.

Facchini (2017): Bianca Facchini, «Albertino Mussato: ultime riflessioni sulla poesia dans »Moribus antiquis sibi me fecere poetam «», in: Albertino Mussato nel VII centenario dell'incoronazione poetica (Padova 1315-2015) cur. R. Modonutti - E. Zucchi, 141-158.

Fitzgerald (2017): Brian Fitzgerald, Inspiration and Authorities in the Middle Ages. Prophets and their critics from Scholasticism to Humanism, Oxford, OUP.

Frye (1969): Northrop Frye, Anatomia della critica, trad. it. Torino.

Garin (1958): Eugenio Garin, Il pensiero pedagogico dell'umanesimo, Firenze, Sansoni.

Gompe (1973): L. Gompe, «Figmenta poetarum», in Literatur und Sprache im Europäischen Mittelalter. Festschrift für Karl Langosch, Darmstadt, Wissenschaftliche Buchgesellschaft, 53-62.

Greenfield (1981): Concetta Carestia Greenfield, Humanist and Scholastic Poetics, 1200-1500, Lewisburg-London-Toronto, Bucknell University Press.

Guthmüller (2013): Bodo Guthmüller, «Giovanni Dominici lettore della »Genealogia«. La polemica religiosa contro lo studio degli antichi poeti in Boccaccio e i suoi lettori. Una lunga ricezione», cur. G.M. Anselmi - G. Baffetti - C. Delcorno - C. S. Nobili, Bologna, Il Mulino, $263-78$.

Jeauneau (1957): Edouard Jeauneau, «L'usage de la notion d'integumentum à travers les gloses de Guillaume de Conches», in: Arch. d'hist. doctr. et litt. du Moyen Âge 32, 35-100.

Joyner (2016): Danielle B. Joyner, Painting the «Hortus deliciarum». Medieval Women, Wisdom, and Time, University Park, PA.

Kristeller (1961): Paul Oskar Kristeller, Renaissance Thought: The Classic, Scholastic, and Humanist Strain, New York, Harper Thorchbooks.

Kristeller (1967): Paul Oskar Kristeller, Le Thomisme et la pensée italienne de la Renaissance, Montréal-Paris, Institut d'études médiévales-Vrin.

Leclercq (1957): Jean Leclercq, L'amour des lettres et le désir de Dieu. Initiation aux auteurs monastiques du Moyen Âge, Paris, Cerf (tr. it. Cultura umanistica e desiderio di Dio: studio sulla letteratura monastica del Medio Evo, Firenze, Sansoni,1965).

Mariétan (1901): Joseph Mariétan, Le problème de la classification des sciences d'Aristote à St. Thomas, Paris, Alcan.

Marrone (1973): S.P. Marrone, «Domenico Silvestri's Defence of Poetry», in: Rinascimento 13, $115-132$.

Meersseman (1958): Giles G. Meersseman, «In libris gentilis non studeant». L'étude des classiques interdite aux clercs au Moyen Âge? «, in: Italia medioevale e umanistica 1, 1-13.

Mersch (2012): Katharina Ulrike Mersch, «Innovationen auf der Grundlage von Traditionen. Kanonikerreform, Selbstreflexivität und Konventsgeschichte im Miniaturenprogramm des Hohenburger »Hortus Deliciarium «», in: Innovation in Klöstern und Orden des Hohen Mittelalters. Aspekte und Pragmatik eines Begriffs cur. Mirko Breitenstein - Stefan Burkhardt - HYPERLINK «http://sip.mirabileweb.it/search-scholars/julia-d\%C3\% BCcker-scholars/1/172295»J. Dücker, Berlin, 225-246.

Mésoniat (1984): Claudio Mésoniat, Poetica Theologia. La Lucula noctis di Giovanni Dominici e le dispute letterarie tra '300 e '400, Roma, Edizioni di Storia e Letteratura. 
Michel (1994): Alain Michel, La Parole et la Beauté. Rhétorique et estéthique dans la tradition occidentale, Paris, Les Belles Lettres.

Minnis (1984): Alastair J. Minnis, Medieval Theories of Authorship: scholastic literary attitudes in the later Middle Ages, London, Scholar Press.

Mixson (2014): James D. Mixson, Giovanni Dominici's «Firefly» Reconsidered in Christianity and Culture in the Middle Ages. Essays to Honor John Van Engen cur. David C. Mengel - Lisa Wolverton, Notre Dame (IN), University of Notre Dame Press.

Nauert (1998): Charles G. Nauert, «Humanism as Method: Roots of Conflict with the Scholastics», in: The Sixteenth Century Journal 29, 427-438.

Nonn (2012): Ulrich Nonn, Mönche, Schreiber und Gelehrte. Bildung und Wissenschaft im Mittelalter, Darmstadt.

Pagani (1995): I. Pagani, La critica letteraria, in Lo spazio letterario del Medioevo, I. Il Medioevo Latino, 3. La circolazione del testo, Salerno Editrice, Roma, 113-162.

Pagnini (1999): M. Pagnini, La Bibbia e i romantici inglesi, in La Scritura infinita. Bibbia e poesia in età romantica e contemporanea (vol. I) a cura di F. Stella, Firenze, Olschki, 39-51.

Pépin (1970): Jean Pépin, Dante et la tradition de l'allégorie, Montréal-Paris, Institut d'études médiévales-Vrin.

Prati (1965): Pino da Prati, Giovanni Dominici e l'Umanesimo, Napoli, Istituto Editoriale del Mezzogiorno.

Roest (2004): Bert Roest, Franciscan Literature of Religious Instruction before the Council of Trent, Leiden.

Romano 2008 = M. Romano, Giovanni Dominici da Firenze: il catalogo delle opere, SISMEL, Firenze 2008.

Ronconi (1976): Giorgio Ronconi, Le origini delle dispute umanistiche sulla poesia (Mussato e Petrarca), Roma, Bulzoni.

Rummel (1995): Erika Rummel, The Humanist-Scholastic Debate in the Renaissance and Reformation, Cambridge (Ma), Harvard University Press.

Siti (1985): Walter Siti, «An American Gnosis. Appunti su critica e religione in margine all'opera di Harold Bloom», in: Rivista di Letteratura Italiana 3, 147-170

Smolak (2000): Kurt Smolak, Die Bibeldichtung als «verfehlte Gattung», in Stella (1999), 14-29.

Stella (1999): Francesco Stella (a cura di), La Scrittura infinita. Bibbia e poesia in età romantica e contemporanea, Firenze, Olschki.

Stella (2001): Francesco Stella, Ad supplementum sensus. Pluralità ermeneutica e incremento di senso nella poetica biblica dal Medioevo a Derrida. Le ragioni di un convegno, in La Scrittura infinita. Poesia e Bibbia in età medievale e umanistica, SISMEL, Firenze, 31-46.

Stella (2001): Francesco Stella, Poesia e teologia. Età patristica e altomedievale, Jaca Book, Milano 2001 (= Stella 2009).

Stella (2009): Francesco Stella, Poesia e teologia. L'Occidente latino tra IV e VIII secolo, in Fondamenti e inizi. IV-IX secolo (Figure del pensiero medievale. Storia della teologia e della filosofia dalla tarda antichità alle soglie dell'umanesimo) dir. I. Biffi e C. Marabelli, Roma-Milano, Città Nuova-Jaca Book, 471-563.

Stella (2010): Francesco Stella, Condanna e difesa della poesia dalla Scolastica all'Umanesimo, paru dans Figure del pensiero medievale VI «La via moderna». XIV e inizi del XV secolo, Milano, Jaca Book.

Treip (1994): Mindele Anne Treip, Allegorical Poetics and the Epic: the Renaissance Tradition to Paradise Lost, Lexington, The University Press of Kentucky.

Valentino (2002): Francesco Valentino, Poesia, fantasia, filosofia. La didattica della creatività nell'esperienza educativa, Armando Editore 2002,

Verdier (1969): Philippe Verdier, «L'iconographie des arts libéraux dans l'art du Moyen Age jusqu'à la fin du quinzième siècle», in: Arts libéraux et philosophie au moyen age. Actes du 
quatrième congrès international de philosophie médiévale. Université de Montréal, Montréal, Canada, 27 août-2 septembre 1967, Montréal-Paris, Institut d'études médiévales-Vrin, $305-355$.

Vinay (1949): Gustavo Vinay, Studi sul Mussato I Il Mussato e l'estetica medievale, Giornale Storico della Letteratura Italiana 126, 113-159.

Wels 2009 = Volkhard Wels, Der Begriff der Dichtung in der frühen Neuzeit, Berlin-Boston, De Gruyter. 



\section{Voice of the Muse, Word of the Church}

\section{The Parable of the Rich Man and Lazarus in Late Medieval Latin Poetry}

The earliest writers of Christian Latin poetry were not different from their pre-Christian forerunners in attending to both message and craft, seeking effectively to express truth, human and divine. Yet in several ways it was a new poetry. Emerging in the fourth century with new freedom, a new mission, and a new message, Christian poets wrote mainly to praise God, but their way of doing this was to put the new gospel wine into old Roman bottles for the educated elite, to provide memorable lessons in style and elegance for generations of students, and to engage in debates over doctrine in order to teach the truth of the faith as perceived. Christian poetry was born as liturgical hymns for use alongside the Psalms and as supplements to scriptural readings and sermons. As part of that function from the beginning, Christian poetry communicated biblical lessons and the theology underlying them. The first Christian Latin hymns by Hilary of Poitiers (c. 315-c. 368) champion Nicene orthodoxy. Hilary's first hymn, "Ante saecula qui manes”, includes doctrinally precise formulas like "ut genitor, quicquid inest sibi, ... totum in unigenam ediderit deum". ${ }^{1}$ Following Hilary, Ambrose (c. 340 - 397) composed hymns against his doctrinal rivals the Homoians. After Ambrose's death, his hymns for feast days continued to engage in controversies because Augustine of Hippo (354-386) and Celestinus I (d. 432) used them in their disputes with rival new theologies.

Besides hymns, narrative versifications were composed to present the Bible's stories and the Church's lessons vividly and elegantly, joining and rivaling the beloved ancient epics. Poems based on episodes from the Bible constitute a major instance of a cultural transformation and assimilation of classical literary and rhetorical form by Christian writers and teachers. ${ }^{2}$ Deliberate, conscious attention to poetics is always present, but the new poets, responding also to epic poetry's potential for signification and even direct commentary, made hermeneutics, exegesis, and theological interpretation a part of the compositions. The contribution that poetic form made to biblical narrative is that of the voice of the Muse in the expression of the word of God. If we seek a verb to describe the complex action, the writers may be said mainly to have paraphrased or amplified the biblical text, so long as those terms are understood to include both esthetics and ideas. When the fifth-century poet Sedulius, for example, amplifies the details of the water changing into wine at Cana by the verb

1 Dunkle (2016) 34.

2 For an overview of the concept of reception see Martindale (1993). The broader concept of transformation has been gaining a useful conceptual framework and vocabulary. See Böhme, Bergemann (eds.) (2011). 
rubescunt, readers may ask whether he embellished a narrative detail with an allusion to the sacramental fullness of water and wine as a figure of Christ's water and blood flowing from the cross. ${ }^{3}$

The richness of certain biblical versifications on many levels was also compatible with the progressive nature of medieval schooling, from rudimentary grammar to philology and rhetoric, a setting in which the schoolmaster explicated the features of the historical, literary, moral, or doctrinal meaning to address his students' needs. The value seen in Juvencus, Arator, Avitus, and Sedulius is evident from their dominance of the early medieval school curriculum, even over the Bible itself, as is often pointed out. ${ }^{4}$ What lessons were to be derived from the study of those biblical poems? Classical rhetorical paraphrase gave elegant form and diction to the scriptural narrative, but since the subject matter was the Scriptures, poets had an enormous added weight of presenting a sacred narrative in a faith community. Further, the guiding belief was that the Bible is univocal, presenting many facets of the one message of creation, fall, and redemption. While the accounts of creation and resurrection of Genesis and the Gospels were versified more often because of their centrality and dramatic content, most parts of the univocal Bible were versified, the Book of Revelation being the main exception. Some poets were more theologically competent than others. Avitus, for example, did not write an epic on Genesis and Exodus so much as depict the celestial cycle of sin, redemption, and sacramental renewal, focusing his narrative elements on events from the first two books of the Bible but cross-referencing them with Gospel texts. ${ }^{5}$ Typology or allegory connect the Testaments to one another and both to the Church's central teachings.

The Gospel parables communicate essential Christian teachings and are among the versifications of the Bible in all periods. Scholars have paid less attention to them than to the versifications of Genesis and the Gospel accounts of Christ's life likely because of the parable-poems' relative brevity and frequently obvious moral messages. That richer exegetical traditions, however, are included in poems treating the parables is what will be explored here through a case study of poems that have the parable of the rich man and Lazarus as their subject. The parable in Luke, likely already transformed from earlier sources with its events occurring both on earth and in the afterlife, was further transformed in its reception by Christian readers. The Gospel lection (Lk. 16.19-31) was read and preached every year on the second Sunday after Pentecost (First Sunday after Trinity), and it was abundantly commented on

3 Sedul., A solis ortus cardine 50; Bianco (1993) 56.

4 E.g., Lapidge (2006) 11-12.

5 Dinkova-Bruun (2007) 318-320, also dissatisfied with the division of early biblical poetry into three classes according to genre: full-scale epics (Avitus, SHG), carmina (De Sodoma), and secondary paraphrase (Dracontius, De Laudibus Dei), and into two classes according to source: Old Testament and New Testament works, instead proposes a division according to subject, as those addressing the Fall and those addressing the Redemption. While that classification is helpful, it is still important to remember the essential interconnection between those endpoints. 
in sermons and depicted frequently in art. The parable thus provides a well-stocked exegetical laboratory in which to examine the purpose and method of the versifications.

The story of the anonymous rich man who fails to show mercy to poor Lazarus, with each experiencing a reversal in the afterlife, presents a clear moral lesson on the relative value of material and spiritual goods and a warning to be charitable. The parable is also readily adaptable to rhetorical shaping, especially by antithesis, a pattern that is so prominent in Christian discourse. A homily by Augustine sustains the following rigid antithetical pattern, replete with rhetorical questions, over sixteen sentences:

Quid est illud? Quod oculus non vidit. Quid est hoc? Quod fidelis oculus non sitit. Quid est illud? Quod invenit Lazarus ulcerosus. Quid est hoc? Quod habuit dives inflatus. Quid est illud? Quod perire non potest. Quid est hoc? Quod teneri non potest ... . ${ }^{6}$

Patristic and medieval commentators also contrasted the rich man's neglectfulness with the empathy of the dogs who came to lick Lazarus's wounds, showing how responsibility and kindness do not need great material resources. Farther afield is the observation that while riches are dangerous, it is not riches themselves but personal vices that condemn the rich, vices that can all be traced back to the sin of pride. Jerome, for example, using a powerful anaphora, points out that the rich man was condemned for nothing else, not even the vice of greed, but rather for his pride: "Diues iste purpuratus et splendidus non accusatur quod auarus fuerit, non quia res alienas tulerit, non quia adulter fuerit, non quia aliquid mali fecerit: sola in illo condemnatur superbia". ${ }^{7}$ Commentators also went beyond ethics to explain theological implications. Ambrose teaches that the abyss teaches the impossibility of personal atonement after death: "Inter hunc igitur diuitem et pauperem chaos magnum est, quia post mortem nequeunt merita mutari".

Poets of the later Middle Ages inherited those exegetical traditions and communicated them to their readers, using fewer narrative verses and more commentary. Odo of Cluny's tenth-century Occupatio stands as a virtually unique example of a mainly narrative biblical epic. Newly composed commentaries in verse form competed with narrative epics in the school curriculum. ${ }^{9}$ The twelfth century's growing interest in philosophical method as systematized by Aristotle, and the development of philosophical-allegorical poems like the Cosmographia of Bernard Sylvestris (fl. 1130 -1150), further reduced explicit narrative versification of the Bible. ${ }^{10}$ The as-

6 Aug., Sermo 19.4, PL 38.136, CCSL 41.257. Among medieval writers this same moral emphasis can be found, for example, in Hugh of St. Victor PL 176.608D, and Hugh of Rouen, PL 192.1157B.

7 Jerome Hom. in Luc., de Laz. et divite CCSL 78.508.

8 Ambrose, In Luc. Exp., VIII.18 on Lk. 16.24.

9 Dinkova-Bruun (2007) 321.

10 Lapidge (2006) 28. 
cendancy of metaphysics by the systematic theologians from the twelfth and thirteenth centuries is seen further to have relegated poetry's role from the position of being a vehicle for expressing truth to a more primitive, inventive phase of rational thought, good at best for offering embellishment of truths arrived at philosophically, and at worst, a "devil's tool" to corrupt mankind. ${ }^{11}$ Thus, in harmony with this new emphasis, poets in the scholastic period wrote biblical poetry that shifted the balance away from narrative paraphrase to systematic lessons on Scripture in verse. ${ }^{12}$ In the actual poems, however, there survives a strong interrelationship between narrative and commentary, allusion and direct expression.

The Aurora of Petrus de Riga (1140 - 1209) typically represents the new emphasis of biblical poetry with its attention paid to overt commentary and exegesis. ${ }^{13}$ Some of Petrus's poems are not even based on the Bible itself but on prose biblical commentaries. His "Exodus", for example, is seen to be derived from commentary on Exodus by Bruno, Bishop of Segni (ca. 1045-1123). ${ }^{14}$ For all the shift in proportion, however, the practice of inserting explicit theological commentary in biblical poems was not a new phenomenon in the twelfth century. Avitus of Vienne at the dawn of the sixth century inserted the parable of the rich man and Lazarus into his Spiritual History at Book 3, "De sententia Dei", on the sentencing of Adam and Eve. He did this to teach by example, not the obvious moral lesson about greed and charity but the derivative theological lesson of the impossibility of repentance after death: "Namque obitum quemdam casu tum pertulit ipso, / Perdita ne precibus lacrymisve reduceret ullis". ${ }^{15}$ That analogy is all the more theologically poignant because, in light of Adam's continued bodily life, the death that is mentioned here is unmistakably meant as that of his soul, a spiritual death that would be signalled as the most permanent kind without the poet's insertion of other parables like the Good Shepherd and Lost Coin, and the typological narratives in Books 4 and 5 pointing to Baptism. Avitus's lesson is that just as the rich man had no recourse, so too Adam now be saved only by the Redeemer.

The later medieval poetry is also both direct in its commentary and allusive in its narrative paraphrase elements. What is different about the later verse commentaries on Scripture is the linear nature of their comments, following the order of events in the biblical text instead of focusing on a single exegetical line to illustrate a main lesson. This change of form corresponds to the express aims of the synthetic commentaries of the period with the goal of encapsulating theological doctrines. But both the earlier rhetorical epics that are richer in their narrative elements, and the

11 Greenfield (1981) 53.

12 Dinkova-Bruun (2007) 325.

13 The parable of the rich man and Lazarus is the subject of a rhythmical poem dating from the $9^{\text {th }} \mathrm{c}$. Mainly a close paraphrase of the biblical narrative, the poem also expands the narrative details and contains both direct and indirect exegesis. See Stella (1993) 330.

14 Lapidge (2006) 29; 32.

15 Avitus SHG III.313-314. 
later verse commentaries that are richer in explicit exegetical lessons utilize both direct commentary and poetic allusion.

In terms echoing St. Paul and Origen, Petrus Riga says that he wrote to instruct both the inexperienced and the learned: "Accedat igitur parvulus ad huius libri lectionem quia in eo invenitur lac parvulorum, accedat et perfectus quia in eo inveniet solidum cibum ... Accedat similiter ingeniosus vel studiosus, quia reperiet unde possit et debeat exercere ingenium suum". ${ }^{16}$ Natural to this effort, the Aurora includes many verses addressing the parables and their lessons in history, allegory, and mysticism at various levels of meaning. With the broad aim of commenting on the entire Bible, Petrus did not produce a comprehensive paraphrase but rather a commentary with condensed narrative, albeit one still capable of presenting exegesis through poetic allusion.

Petrus's treatment of the parable of the rich man and Lazarus is one of nine major parables included in his verses on the New Testament. It is in six elegiac couplets, the preferred meter for sententious poetry, wherein the poet immediately exploits the stark distinction of the two main characters. From the patristic era into the Middle Ages, commentators emphasized the naming of Lazarus but not the rich man. ${ }^{17}$ Petrus therefore took the weak homo quidam designation of the rich man in the Vulgate and weakened it further by removing it from the subject position to the oblique genitive case, making the subject rather the rich man's sumptuous feasts and radiant clothing:

Semper splendebant cuiusdam diuitis esce,

Et uestes eius purpura, bissus erant.

Lazarus, on the other hand, is the first word of the couplet describing him:

Lazarus esuriens mendicabat prece micam,

Sed non audiuit mica petita precem (2053-2056).

Just as the naming of Lazarus is a consistent exegetical motif, his name here occupies the first position. Petrus could rely on readers experienced with the sermon tradition to understand the deliberate change of syntax.

Then, even more starkly than the Gospel account, the third couplet bluntly emphasizes the equal death of the two characters (each one simply obit) followed immediately by a summary of their unequal aftermath: "Dives obit, rapit hunc infernus, traditur igni; / Pauper obit, fruitur pace, quiete, bonis” (2057-2058). Petrus chose to comment on the allegorical associations rather than the sufficiently clear moral import. Couplets four through six focus on the allegorical symbolism. And they do this

16 Petrus Riga Aurora, ed. Beichner (1965) vol. 15-6. All citations of the Aurora are from this edition. 17 The fact that Lazarus was named led some exegetes to argue that the story was not a parable at all but a historical account of a historical occurrence. 
both explicitly and also allusively. First, the rich man is to proud Judea as Lazarus is to the humble Gentiles: "Diues Iudeam signat, qui floruit olim. / Deliciis, opibus, unde superba fuit. / Gentes quas curat confessio signat egenus" (2059-2061). Examples of this explicit exegesis are abundantly preserved. ${ }^{18}$ The next line in this uninterrupted sentence explaining the symbolism of Lazarus as the Gentiles reads as a narrative paraphrase of Lc 16.21: "Cuius curabat uulnera lingua canum" (2062). In this context, however, the narrative reference to the dogs is surrounded by explicit commentary explaining the symbolism of the details. Immediately before this line Petrus interpreted poor Lazarus as the Gentiles, nourished by their confession of faith, and the final couplet relates the allegory of the rich man's five brothers as the five books of the Law: "Quinque notant fratres Iudeos legis habentes / quinque libros” (2063-2064). Within Petrus's emphasis on commentary, the reference to the dogs' therapeutic tongues functions allusively by representing the prelates of the Church, who bring to the people the word of God and cleansing of their spiritual sores, thus continuing the flow of symbolism. The comparison of preachers to dogs is well developed before, during, and after Petrus's time. In the patristic era Ambrose and Gregory I used the comparison. ${ }^{19}$ In the twelfth century a homily of Godfrey of Admont (d. 1165) contains the explicit exegesis of the dogs who came to lick Lazarus's sores as preachers: “Quicunque mendicus ille est, qui vere se mendicum, pauperem dico et egenum, cognoscit ... huic cupienti saturari, canes veniunt, ulcera lingunt, dum praedicatores sancti, canes significati, languentis animae vulneribus et lingua exhortationis, et lingua consolationis subveniunt". ${ }^{20}$ After Petrus, the same explicit analogy is preserved in a homily by the Catalan cleric Vincent Ferrer (1350-1419) in his sermon for the first Sunday after Trinity. ${ }^{21}$ The connection is also evident through the constructed etymology of the Domini-canes, the Order of Preachers.

Thus, the rich man and Lazarus symbolize the Pharisaic Jews and Gentiles, those rich and proud in the Law in the first case, and those aware of their need, hungry for divine knowledge, and patient in hope of rescue in the other. That exegesis is extended with a traditional interpretation of the five brothers whom the rich man wants belatedly to warn. They are five because they symbolize the Pentateuch. As with the naming of Lazarus, this motif is widely represented in commentaries from all periods. ${ }^{22}$ The Aurora is rightly understood as a verse commentary on the Bible, thus dif-

18 E. g., Greg., Hom. 40. Bede, In Luc. Exp. V.16.

19 Ambr. Hex. VI.4.23; Gregory I Exp. Cant. II.17 (PL 79.500B).

20 PL 174387 A-401B. The Glossa ordinaria, commenting on Lc 16.22, preserves a related interpretation, that of the dogs' tongues signifying the tongues of flatterers who perversely praise faults in us that we reprehend in ourselves ( $P L$ 114.316).

21 Sivera (ed.) Sermo 24 (1932), 1.269.

22 Augustine reflects on the reason for five brothers: "appellati enim sunt quinque, quia sub lege detinebantur quae per Moysen data est, qui libros quinque conscripsit”. Aug. Quaest. Ev. II.38. The interpretation is also preserved in the Catena aurea 16.6. And close to the time of the Aurora, 
fering from the more allusive commentaries of the biblical epics. But while allusiveness in narrative is subordinate to explicit didacticism, both types of commentary operate in the passage.

Despite the Aurora's great length, Giles of Paris (Aegidius Parisiensis, 1162-1224) produced between 1200 and 1208 two large redactions with supplements in his own skillfully crafted elegiac couplets. ${ }^{23}$ Giles wrote that he intended to reorder the entries, correct discrepancies, and add commentary on themes which Petrus treated insufficiently or omitted out of weariness or ignorance. ${ }^{24}$ In his second redaction he added the Evangelium Aegidii, within which he included interpolations and additions to Petrus's poem on the parable of the rich man and Lazarus. It is one of eight parables selected for expansion out of the nine that Petrus had versified. The added verses are over twice the length of Petrus's versification, twenty-six lines to twelve. He devoted all of them to expound on the theme of the rich man being without a name while Lazarus is both named and known by God. This motif is present in Petrus, but in Giles it takes center stage.

As mentioned, the naming and witholding of a name is present in the Gospel parable but is not emphasized, but from the patristic era on, commentators reflected on it. Augustine made this emphasis in a sermon on the parable: "Nominabatur dives ille ab hominibus, pauper tacebatur: contra Dominus pauperem nominavit, divitem

Bruno of Segni's Commentary on Luke speaks of this interpretive strain as allegory with an alternate interpretation of the five brothers: Haec autem si allegorice intelligantur, dives iste Judaicum populum significat. Solus enim Judaeorum populus legis, et prophetarum divitiis, et deliciis locupletatus, omnes alios despiciebat, nullisque, in cibis spiritualibus, quibus abundabat, communicare volebat. Hoc enim vitio, usque nunc laborat populus ille, et sic omnia celat, ac si revelando perdere debuisset. Qui purpura quidem in regibus, in sacerdotibus autem bysso induebatur. Cujus quinque fratres quinque populi partes intelliguntur. Reges scilicet, et sacerdotes, Scribae, et Pharisaei, et caetera populi multitudo. Mendicus vero, id est, Lazarus, qui adjutus interpretatur, quem Dominus adjuvit et a mortis periculo liberavit, gentilis populus est (Commentaria in Lucam pars secunda PL 165425 A). Rupert of Deutz is referenced also as including this typology: PL $170 \mathrm{n}$. 240. Within the general connection with Jews and Gentiles, Augustine locates the Gentiles in the dogs who lick Lazarus's (i.e., Christ's) wounds, while the rich man (Jews) ignore Lazarus. Thus Aug.: in divite intelligantur superbi Iudaeorum, ignorantes Dei iustitiam, et suam volentes constituere (Quaest. Ev. II.38; also cited in Aquinas, Catena aurea ch. 61, lect. 6). Also, Quorum in typum vulnerati Lazari clamor ad Deum pervenit, dum secundum nomen suum adjutus, Lazarus enim interpretatur adjutus, "ab angelis in sinu Abrahae portaretur, dives autem" per quem Judaicus designatur populus, scilicet copia legis in elatione abutens, "in inferno sepeliretur (Luc. XVI)" Nec discutere quis audeat, vel reprehendere profunda Dei judicia (Rupert of Deutz, Comm. Job. 168 1131B).

On the psychological level, an alternative strong tradition interprets the rich man's five brothers as the five senses. See Jerome In Laz. et Div. 86; Bede In Luc Ex. V.16; Catena 16.6. Glossa ordinaria. The Glossa ordinaria also includes the parallelism between the rich man and Lazarus and the Jews and Gentiles in its commentary under allegory.

23 Beichner (ed.) (1965) II.584. All citations of Giles are from this edition.

24 Beichner (ed.) I, xx-xxiv and Giles's own verse prologues, I.12-13. 
tacuit”. ${ }^{25}$ Other early examples are extant in Jerome, Gregory, and Bede. In the ninth century Rabanus Maurus (d. 856) composed a homily reflecting on the way the public will know rich men's names more readily than the names of poor men: Certe plus solent in populo nomina divitum, quam pauperum sciri. Quid est quod Dominus de paupertate et divite verbum faciens, nomen pauperis dicit, nomen divitis non dicit, nisi quod Deus humiles novit atque approbat et superbos ignorat”. ${ }^{26}$

In the twelfth century Bruno of Segni made it part of his commentary on Luke. ${ }^{27}$ The exegesis became part of the Catena aurea. ${ }^{28}$

Giles takes up the same line of argument: "Nam mundo celebres sunt per sua nomina dites; / pauper ubique latet sed neque nomen habet” (1995-1996). To that general premise he adds a rhetorical amplification:

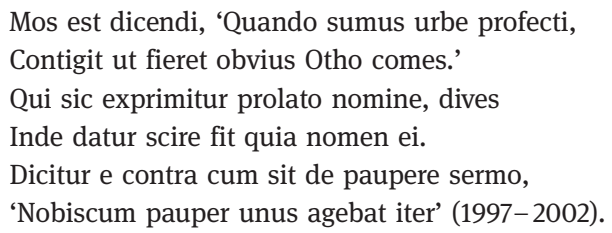

Then, to the amplified premise, Giles shows that the Gospel word shows the divine priorities, where the rich man is introduced, as he observes, absque ulla additione (2008 - 09), but Lazarus expresse (2010). Lastly, a moral invective against worldliness is tersely delivered by the contrast between the culmen mundi and aula Dei (20152016). Giles thus gives an amplification of Petrus's commentary through a focused exemplum featuring the difference between, as he had already written, "publica lex mundi" and "lex benigna Dei" (1994), and states that the Lord himself presented this parable contra dites (1991).

Composed of an example but no narrative, Giles's verse interpolation is to be described neither as a paraphrase nor a linear commentary but as a verse homily, or better, a collation, a type of reflection on a small select aspect of a scriptural text or liturgical reading that was popular in the medieval exegetical tradition. And while Giles displays rhetorical and poetic skill, he directs all amplifications to the

25 Aug. Sermo 41.4, CCSL 41.498. Cf. Jerome Hom. in Luc. de Lazaro et divite: Lazarus pauper, quoniam sanctus erat, nominatur: iste uero diues et superbus nec nomine quidem dignus habitus est. homo quidam erat diues. propterea dico quidam: quia quasi umbra praeteriit (CCSL 78). Cf. Gregory Mor. I.8; Bede In Luc. Exp. V.16 534C.

26 Rabanus, Hom. II.77 PL 110.294D.

27 Lazarus, qui jacebat ad januam ejus, ulceribus plenus, cupiens saturari de micis quae cadebant de mensa divitis; et nemo illi dabat. Sanctorum etenim nomina scripta sunt in coelis; malorum vero nomina non sunt scripta in libro vitae. Unde et hoc loco divitis nomen non dicitur; mendici vero dicitur. Hic Lazarus vocatur. Ille quomodo vocetur nescimus. Talibus enim dicturus est Dominus: 'Amen dico vobis, nescio vos.' Quid igitur mirum si illum nescimus, quem nescit ille qui omnia scit. Comm. in Luc., pars secunda PL 165 422CD.

28 Aquinas, Cat. Aur. 16.4. 
poem's didactic aims. Readers can appreciate the poetic skill in service to a lesson on the heavenly priorities discoverable in the language of the world and the language of Scripture. For this reason, it seems just to soften the harsh criticism of the editor Beichner, who suggested that it would be better, when reading the Aurora, to neglect the interpolations of Giles. To do so is to miss his distinct interplay between theology and poetry.

The parable of the rich man and Lazarus is also the subject of verses included in the biblical anthology from York Cathedral. ${ }^{29}$ This anonymous compendium dating from the thirteenth century contains both well-known and unique poetic entries, with selections ranging from Sedulius to Geoffrey of Vinsauf and beyond. The treatments of individual biblical episodes appear to be free-standing versifications, and the editor Greti Dinkova-Bruun describes the collection as "without sustained coherent structure", "uneven", and "miscellaneous", but the section that includes poems on the New Testament as "the most homogeneous part of the anthology", "the most original", intended to tell the story of salvation through its selections for other writers to draw inspiration and moral example. ${ }^{30}$ The poetry treating the parable of Lazarus and the rich man consists of poems numbered 48 to 55 in the collection, a series of couplets and longer stanzas of various meters totaling 22 lines. The verses are not attested to elsewhere and have not yet received detailed study. The editor notes only one verse as an echo from a poem by Hugh 'Primas' ${ }^{31}$ The interplay of poetic and exegetical elements in the lines, however, is noteworthy, especially when the verses are read alongside various individual parts of the biblical parable.

In the first couplet, the different worldly situation of the two protagonists is illumined by grammar and syntax: "Victus, uestis, opumque domi dum diues habundat, / Lazarus ante fores esurit, alget, eget” (48.1-2). The first line focuses on the possessions of a rich man, while the second line names Lazarus first before his hardships. The alliteration but more so the syntax of the lines helps to bring out this point: Not only is the rich man named after his possessions, those possessions are described in three nouns in the genitive case (one is tempted to say possessive): victus, uestis, opum, and the emphasis on the location in a house, domi. The only noun associated with Lazarus, by contrast, without possessions, is fores, those of the rich man where Lazarus sat suffering, described in three intransitive verbs.

The second couplet engages the reader directly with moral commentary: "Cerne ualere parum thesaurum diuiciarum", followed by a stark description of their afterdeath rewards that also reemphasizes the name of Lazarus and not the neutral diues here but the condemnatory auarus: Cum requies Lazarum teneat; cremet ignis auarum" (49.1-2). The third couplet engages in typology, reflecting on the relationship of suffering to virtue, which is presented not as an automatic or casual relationship.

29 Dinkova-Bruun (2002) 99-100.

30 Dinkova-Bruun (2002) 66.

31 Dinkova-Bruun (2002) 100, n. 102. 
Rather, patient endurance is what transforms suffering into virtue, as the poet explains by way of a typology connecting Lazarus and his Old Testament prototype, Job: "Lazarus meritis multus, Iob rarus habetur: / Infirmi multi, patiens uix inuenietur" (50.1-2). The typological link with Job is meant to teach that suffering becomes virtue through patient endurance, alluded to by the name Job, a motif that endured in the exegetical tradition. Long after Giles, preachers like Lawrence of Brindisi (1559-1619), for example, were still bringing out the typology and parallelism in homilies, as here, where Lawrence celebrates the virtue of both men in their suffering and poverty: Ostenditur in duobus hominibus his, quam nobilis sit natura humana cum virtute tantum, licet nullum aliud coniunctum habeat bonum, in Lazaro, in quo nonnisi patientia elucet, sicut in patientissimo Iob in sterquilinio; et quam vilis eadem sine virtute sit, licet omne aliud bonum possideat, in epulone. ${ }^{32}$

The fourth couplet exhorts the reader to recognize both that he himself is a Lazarus, which is to say, to understand that life entails suffering, and that he can also be a Job, who makes virtue from that suffering. That lesson is reinforced with a return in stanzas five and six to the reversal of the conditions of Lazarus and the rich man in life and after death. This final section reinforces the contrasting earthly and heavenly rewards through skillful and theologically relevant word-play, as on purpura and pauper and splendida cena and celi amena (54.1-2).

The general effect of all the couplets combined is to highlight the theme of reversal. The versification can be accurately described as a commentary in verse, like the Aurora of Petrus; but besides direct commentary, the verses offer lessons allusively, in the manner of the earlier biblical epics, inviting attentive readers to perceive the lessons in the word choice and selection of details.

In contrast to Petrus, the author of the Dyalogus de divite et Lazaro, preserved in a fourteenth-century manuscript from the Benedictine monastery at Oudenberg, Flanders, returned to the inventive and self-consciously rhetorical approach to biblical versification. The piece shows that the scholastic verse commentary did not eliminate rhetorical versifications of the Bible, as stylized, moralistic poetry regained favor toward the birth of the Renaissance. The Dyalogus represents a direct verbal exchange between the rich man and Lazarus in their respective afterlives. It comprises 107 lines: dactylic hexameters interspersed among the principal meter of trochaic septenarius, 'vagantenzeile', or the meter of the vagantes, vagabonds, in which the Carmina Burana and the works of the Archpoet are composed. The nineteenth-century editor of the Dyalogus, Johannes Bolte, argued that one cannot properly consider this verse dialogue between the rich man, bound for Hell, and Lazarus, already in heaven, as a dramatic paraphrase of the biblical account of the parable; for the poet confines himself to the rhetorical depiction of the contrasts between the life of luxury of the selfish bon vivant and his punishment in the beyond. Bolte, however, further suggested that the demands of the poetic form and the requirements of rhyth- 
mical verse compromised the poet's freedom of thought and clarity of expression. ${ }^{33}$ Bolte's standard of clear expression may have been scholastic commentaries like the Aurora. As has been our intention to show, however, readers familiar with exegetical traditions connected with the parable will find more substantial content in the Dyalogus than Bolte's assessment suggests.

The poem supplements the gospel narrative by building on a framework of rhetorical antithesis, a practice illustrated above in reference to Augustine's homily on the parable. Gregory Hays has noted the tendency in Christian discourse to frame biblical episodes by means of contrasts between two figures (Cain/Abel; Abraham/ Lot; Jacob/Esau; Mary/Martha): The figures allow instances of paired contrasts that "can be traced as a rhetorical device back to the Greek rhetorician Gorgias (c. 483-376 B.C.)". Hays adds, however, that "their frequency in preaching owes something to sheer rhetorical effectiveness, but it also reflects a deeper pattern inherent in Christian discourse". ${ }^{34}$ In the present study, interest is precisely in that deeper pattern which Hays mentions. Rhetorical contrast may provide the frame, but what the poet puts into the frame requires choices about substance, act, motivation, and meaning, through which poets reflect the values and lessons expressed in homilies, commentaries, and compendia like the Glossa ordinaria or the Catena aurea. Even the form of a dialogue in which the rich man is imagined speaking in defense of himself, amplifying his few words in the scriptural account, is a rhetorical framework that already appeared in the early Christian exegetical tradition to teach theological lessons. ${ }^{35}$

The dialogue begins dramatically as the first eight stanzas engage the three parties in a debate where both rivals give opening speeches to Abraham as judge. The rich man opens by bewailing his suffering in words not of repentance but anguish. Lazarus gives a caution about the rich man's falseness through words: "fallax fallere verbis te laborat" (6). The rich man repeats his expression of loss, and Lazarus names his lack of pity as the cause, "cum misereri / Nolueris miseri" $(9-10)$. Then, the rich man abandons his pretense and states his enduring disdain for Lazarus. He says heaven won't accept Lazarus because of his physical condition. Lazarus affirms that he will be accepted, while the rich man will be taken to Hell; but the rich man's initial disdain is coupled with envy. Assuming the role of a preacher, Lazarus explains that heaven rejects those of little faith, the rich, and the unjust, unless Christ saves them. This is the first of Lazarus's condemnations, which are all qualified by conditional statements that highlight the essential intervention of a savior and the wasted opportunity for prior forgiveness: "Iste locus modicos fidei, dites et iniquos / Non recipit nisi quos Christus sibi fecit amicos” (24-25).

Stanza 9 makes a major turn in the debate, where the rich man begins his own defense as a praise of wealth for the worldly honors that accompany it. Lazarus takes

33 Bolte (ed.) 261. All citations of the Dyalogus are from this edition.

34 Hays (2012) 224.

35 E.g., Pet.Chrys., Sermo 122, PL 52.533. Peter's sermon, like the poetic dialogue under study, focuses on the final scene, after the rich man sees Lazarus in the bosom of Abraham. 
a new turn as well in refuting the rich man directly, which he never does in the Gospel version. The rich man abandons all pretense of repentance but rather boasts to be elevated, magnificent, and happy. In stanza 11, the final line of his argument is descriptive of his disposition: "perque potentatum me glorior esse beatum" (34). Lazarus refutes that claim by inverting, mocking the same expression: "Iure potentatus numquam potes esse beatus" (35), again with the lost chance for forgiveness presented in a conditional clause: "sis ni purgatus totius labe reatus" (36).

The rebuke does not deter the rich man, who presses his defense of wealth and the instant gratification it brings; nor Lazarus, who observes that disproportionate wealth displeases God and introduces destruction:

\begin{tabular}{|c|c|}
\hline $\begin{array}{l}\text { Ultra modum cupere } \\
\text { Cum deus in opere }\end{array}$ & $\begin{array}{l}\text { census non est sensus, } \\
\text { tali sit offensus. }\end{array}$ \\
\hline $\begin{array}{l}\text { Dum res solent crescere, } \\
\text { Accensum generat magni }\end{array}$ & $\begin{array}{l}\text { crescit et accensus. } \\
\text { custodia census }(41-44) \text {. }\end{array}$ \\
\hline
\end{tabular}

This theme is familiar in the exegetical tradition regarding the parable of the rich fool of Luke's Gospel. Bede, for example, wrote: "Is qui sibi thesaurizat et non est in deum diues stultus est et in nocte rapiendus". ${ }^{36}$ Regarding the diction, the poem's editor has noted the dual significance of accensus, as both the fire of longing and as an allusion to hellfire. To be noticed also is the poet's echo of Juvenal's proverb, "miseria magni custodia census". ${ }^{37}$

In stanza 15 the rich man's self-incrimination worsens: he claims that he was content not to give food satis pleno ... egeno, "to a beggar who was already full enough" (46). Lazarus corrects him: "Querens de micis, me pulsas et maledicis" (48). Peter Chrysologus in the fifth century, amid four sermons on the parable, observed that the rich man, suffering more from Lazarus's reward than his own situation, continued to treat Lazarus with contempt: "Quod agit dives, non est novelli doloris, sed livoris antiqui, coelo magis incenditur quam gehenna ... Adhuc divitem malitia non deserit, quem iam possidet poena". ${ }^{38}$

The rich man then even tries to blame his servant for neglecting Lazarus:

$\begin{array}{lc}\text { Precepi multociens, } & \text { quod fragmentum detur, } \\ \text { Ut tu vel esuriens } & \text { quivis saturetur; } \\ \text { Sed non facit serviens } & \text { omne, quod iubetur. } \\ \text { Si fuit insipiens, dominum cur pena sequetur? (51-54) }\end{array}$

That strategy recalls the rich man in Jerome's sermon on this parable, where Jerome imagines words of defense the rich man might have used were it not for the fact that

36 Bede In Luc. Exp. IV.12.

37 Juv. Sat. 14.303.

38 Pet. Chrys., Sermo 122 (PL 52.543) 
Lazarus was plainly visible at his door: "Iacebat ad ianuam, ne diues diceret, non uidi, in angulo fuit, aspicere non potui, nemo mihi nuntiabat ... eo tempore quando te greges seruorum et clientum prosequebantur". 39

Subsequent exchanges are summarized as follows: Lazarus says he found the animals kinder than the rich man, but the rich man advances criticism of Lazarus's vile face, scabrous skin, raucous breathing, and asks why so vile a person, rejected on earth is received into heaven. He suggests he will infect the healthy ones there. The rhetorical diatribe shows his complete lack of progress during the dialogue. Lazarus comments that bodily health produces nothing unless it is joined by a pure mind. He does not deride physical grace but spiritual deficiency. He says that sickness that leads to salvation is more effective than well-being that kills a man. In further defense of wealth, the rich man quotes Horace, "Et genus et formam regina pecunia donat" (68), further confirming his failure to repent. ${ }^{40}$ The rich man remains out of touch with his present situation and thus cannot be repentant. Lazarus states that no one lacks beauty who is adorned by "alma fides", an epithet for the holy (Christian) faith, common to biblical poetry. ${ }^{41}$ The rich man boasts that he "plucked many flowers from the world" ("flores collegi de mundo"), and he equates himself with any rich and powerful patron or king ("par ego regi"), claiming that he did only what he willed to do. In a subtle shift of syntax, Lazarus counters that pride, wealth, and honors are the 'flowers of the world' ("mundi flores"), that "spoil the character" ("violant mores") and, in the end, bring pain. This echoes Augustine, "Mundi flores quomodo colligeres, qui a spinis non revocas manum?"42 Lazarus soon after completes the allusion: "Quasi spine / pungunt [diviciae] in fine" (83-84).

The rich man asks why he is condemned for riches, to which Lazarus replies "Quia nimis in eas ardes totus datus" (86). The line presents a suggestive syntax: Ardes can be read as the subordinate verb under quia: "because you burn for them beyond measure, having surrendered totally. Ardes can also be read as the main verb: "because you were totally given over to them beyond measure, you are burning now". As a poetic allusion, the syntax ambiguity symbolizes the close connection between greed and hellfire. And then Lazarus quotes from the late antique Distichs, traditionally attributed to the Elder Cato: "Despice divicias, si vis animo esse beatus!” (89)..$^{43}$

39 Jerome Hom. in Luc., de Laz. et divite (CCSL 78.507-516).

40 Hor.,Ep. I.6.37.

41 Cf. Pruden., Psycho., Arator De Actu Apost. 714, Ven. Fort., Carm. X.14.2, Pauli. of Nola, Carm. 14.80; 19.200; Ennod., 128.8, Anthol. Lat. 80(91aR). Also in epigraphy: See TLL Epigraphicae Vol. 1, 252 col. 2 s.v. almus.

42 Aug. Sermo 38.8.11. The context in Aug. 38 is that the material world, even in its troubled condition, is loved; Aug. asks 'what if it were peaceful?, to which he refutes the questioner: How would you cling to something beautiful, who so embrace what is foul.

43 Cato Dist. 4.1. 
The closing four stanzas return to the rich man's now desperate but still hedging language of repentance. The rich man presents any sin on his part, however, only as a possibility through a series of conditional sentences and indirect questions: "Quidquid mali fecerim, penitet et fleo. / Culpam si gemuerim, remittatur reo; / Volo, si peccaverim, reformari deo" (90-92). The last sentence of the stanza summarizes the rich man's case: "Penitet et facto torqueor ipse meo. (93).

Finally, in a reiteration of the doctrinal lesson we heard from Ambrose and Avitus at the beginning of our discussion, Lazarus reminds the rich man of the futility of repentance after death, and so through him the poet exhorts the audience to repent now.

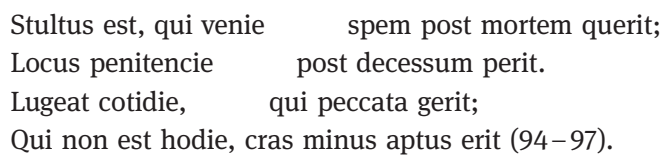

An allusion to the great abyss between them leads to the final stanza, an appeal by the rich man to God and Abraham, just as he did in the first stanza. The rich man pronounces his own death and guilt, and his own typological similarity to the Pharisees, who, not in the literal world of the parable but according to its theological significance, were to deny Christ. It is a commentary, made allusively, but a commentary nonetheless.

The final stanza displays the poet's craft, with all four lines in matched rhyme and parallel syntax:

\footnotetext{
Ha quid agam! morior miser ego reus!

Non est dolor gravior, quam sit dolor meus.

In inferno crucior tamquam pharizeus.

Parce mihi, senior, tu mihi parce, deus! (104-107).
}

We have examined four versifications based on the parable of the rich man and Lazarus composed during the later Middle Ages. The poet Petrus wrote a verse commentary in the Scholastic manner, which Giles supplemented with a verse homily or collation using rhetorical amplification. The anonymous York poet wrote couplets on the theme of reversal, and the anonymous poet of the Dyalogus wrote a rhetorical exercise with theological commentary. Those pieces provide a valuable case study of a much larger collection of poems devoted to the gospel parables, which still constitute a group of works not thoroughly examined by scholars. The intentional variations of genre and diction in the four works notwithstanding, the versifiers of the Gospel parable produced works that are a skillful and theologically astute blend of overt commentary and subtle allusion, elements that offer the patient reader a dynamic interplay between tradition and innovation, theology and poetry. 


\section{Bibliography}

\section{Primary Sources}

Beichner (ed.) (1965): Petrus Riga, Aurora: Petri Rigae Biblia versificata; a verse commentary on the Bible, 2 vols., Notre Dame, Ind.

Bolte (ed.) (1891): Johannes Bolte, "Dyalogus de Divite et Lazaro" in: Zeitschrift für deutsches Altertum und deutsche Literatur 35, 257-262.

Dinkova-Bruun (2002): Greti Dinkova-Bruun, "Medieval Latin Poetic Anthologies (VII): The Biblical Anthology from York Minster Library (Ms. XVI Q 14)”, in: Medieval Studies 64, 61-109.

Lawrence of Brindisi (1928-1956): S. Laurentii a Brundusio, Opera omnia, vol. 8, dominicalia, Padua.

Sivera (ed.) (1932): Vincent Ferrer, Sermons a cura de Josep Sanchis Sivera, 2 vols., Barcelona.

\section{Secondary Sources}

Bianco (1993): Maria Grazia Bianco, “A proposito di aquae rubescunt hydriae”, in: Augustinianum $33,49-56$.

Böhme, Bergemann (2011). Hartmut Böhme, Lutz Bergemann, et al. (eds.), Transformation. Ein Konzept zur Erforschung kulturellen Wandels, Munich.

Dinkova-Bruun (2007): Greti Dinkova-Bruun, "Biblical Versifications from Late Antiquity to the Middle of the Thirteenth Century: History or Allegory?", in: Poetry and Exegesis in Premodern Latin Christianity: The Encounter between Classical and Christian Strategies of Interpretation, ed. Willemien Otten and Karla Pollmann, Leiden.

Dunkle (2016): Brian P. Dunkle, Enchantment and Creed in the Hymns of Ambrose of Milan, Oxford, UK.

Greenfield (1981): Concetta Carestia Greenfield, Humanist and Scholastic Poetics 1250 To 1500, Lewisburg, Pa.

Hays (2012): Gregory Hays, “Prose Style”, in: Oxford Handbook of Medieval Latin Literature, Ralph Hexter, David Townsend eds. Oxford, UK, 218-235.

Lapidge (2006): Michael Lapidge, "Versifying the Bible in the Middle Ages", in: The Text in the Community: Essays on Medieval Works, Manuscripts, Authors, and Readers, Notre Dame, Ind. Martindale (1993): Charles Martindale, Redeeming the Text: Latin Poetry and the Hermeneutics of Reception, Cambridge, UK.

Stella (1993): Francesco Stella, La poesia carolingia latina a tema biblico. Spoleto. 



\section{Post vestigia gregum}

\section{La poétique de l'image dans le commentaire Super Cantica Canticorum de Jean Gerson (1429)}

Dernier ouvrage de Jean Gerson laissé inachevé à sa mort en 1429, le commentaire Super Cantica canticorum se présente comme un double testament, théologique et poétique. L'épithalame y est traité comme un dialogue entre l'âme et Dieu qui fait valoir un «amour de fruition, extatique, anagogique et séraphique, consistant en une perception expérimentale de l'union de l'âme avec Dieu, son objet suprême et sa fin ${ }^{1}$. On a pu y voir un "traité de l'amour de Dieu» ${ }^{2}$ structuré en dix chants ou sympsalmata, à leur tour divisés en «considérations» ou «propriétés», qui couronne la grande entreprise de théorisation gersonienne en matière de théologie mystique ${ }^{3}$.

Je présenterai dans un premier temps la méthode et le modus tractandi suivis par Gerson dans son commentaire, afin de préciser sa place dans la tradition exégétique. Je poserai en particulier la question du lien entre les styles «rhétorique» et «scolastique» distingués dans le prohemium, et du rapport complexe à l'image métaphorique qui en découle. Dans un second temps, j'illustrerai la démarche gersonienne en présentant un extrait de la deuxième partie de l'œuvre, dont je proposerai une analyse littéraire. Le passage, correspondant au deuxième sympsalma et glosant Cant. 1.6-10, forme une unité tant du point de vue de l'idée que de celui de son traitement poétique, marquée par le procédé de l'inclusio (le texte s'ouvre et se referme par le même syntagme, emprunté au verset 6a). J'étudierai comment le concept émerge de l'image (en l'occurrence, une scène pastorale) en s'appuyant sur une vision du sensible dont le traitement se situe aux antipodes de l'ornemental, puis j'examinerai le collage métaphorique avec le motif épique du char de Pharaon, en prêtant une particulière attention à la manière dont le montage creuse l'image et approfondit dans le même temps l'idée théologique sous-jacente.

C'est donc une écriture personnelle, attentive à l'expressivité du poème biblique sans sacrifier aux facilités de l'ornatio rhétorique, une écriture scolastique exploitant le sens figuré du texte mais refusant de se plier à un décryptage allégorique systématique, que je me propose de faire paraître en la rapportant à ses modèles exégétiques et à sa principale source d'inspiration, l'Itinerarium mentis in Deum de Bonaventure.

1 «Amor fruitivus et extaticus vel anagogicus et seraphicus, quia consistit in experimentali perceptione conjunctionis animae cum supremo objecto suo et fine Deo». Je cite le Tractatus super Cantica Canticorum (désormais TCC) d'après Glorieux (1971) 576.

2 Vial (2006) 22.

3 Pour un aperçu du projet gersonien dans son ensemble, tel que le présent commentaire le met en œuvre, voir les pages de Combes (1964) 650-668. 


\section{Novo modo scribere : Gerson dans la tradition exégétique du Cantique des Cantiques}

«Tout est dit et l'on vient trop tard...». C'est sur un constat apparemment désabusé, annonçant la formule de La Bruyère, que s'ouvre le commentaire du Cantique de Gerson. Il n'y a pas là de quoi s'étonner, s’agissant du livre biblique le plus commenté au Moyen Âge, à la «fortune aussi exubérante et encombrante ${ }^{4}$. On comprend les réticences de Gerson à répondre favorablement à la requête qui lui avait été adressée :

\footnotetext{
Verum post tot a summis ingeniis dictata super eisdem Canticis quid aut quale posset addere paupercula nullius vel tepidae devotionis meae, diu satis in dubio fuit animus. Tandem confisus in auxilio precum vestrarum decrevi novum aliquid aut saltem novo modo scribere sub praemisso themate : Amo te. ${ }^{5}$

«Mais quant au type de contribution que pourraient apporter les pauvres ressources de ma faible dévotion - celles de quiconque d'ailleurs - à tant de commentaires composés par les plus grands esprits sur ce Cantique, j'en suis resté longtemps dubitatif. Enfin, m'en remettant à vos prières, je résolus d'écrire quelque chose de nouveau - ou du moins de l'écrire d'une manière nouvelle - sur le thème déjà mentionné : «Je t’aime».
}

La posture est topique. Mais derrière l'humilité affectée du prologue et son pendant obligé, la valorisation implicite des destinataires (les Pères Chartreux qui lui ont commandé le traité), on décèle l'ambition de l'écrivain qui entend, moins par la nouveauté de sa lecture que par ses choix formels et stylistiques, se faire une place dans la tradition exégétique où se sont illustrés avant lui Origène et Grégoire le Grand, Aymond d'Auxerre et Rupert de Deutz, Bernard de Claivaux et Guillaume de Saint-Thierry.

Parmi les critères permettant de situer Gerson dans la longue lignée des commentateurs du Cantique, on retiendra trois éléments. Premièrement, le choix du thema : l'amo te de l'Evangile de Jean (Jn 21.16) où la triple question du Christ à Pierre s'attire trois fois la même réponse («tu sais bien, Seigneur, que je t’aime»). Ce thème ouvre la voie à une réflexion sur l'amour de Dieu dans ses modalités d'énonciation, en tant qu'il essaie de se dire. Or le mot dit tout (amo se lit comme un acrostiche joignant l'alpha et l'oméga - AMO - à la fois principium, medium, finis ${ }^{6}$ ) et pas assez à la fois. Comment extraire alors le sens du signe ? Comment déployer le signifiant en énoncé afin de le mettre en forme d'un point de vue théologique ? Telle est le soubassement de l'enquête gersonienne. L'originalité de Gerson tient en second lieu à sa méthode d'exposition : l'œuvre est divisée en dix chants ou sym-

4 Ricoeur (1998) 411.

5 TCC, 565.

6 «In hac dictione Amo significatur principium, medium et finis secundum tres ejus litteras» (TCC, 593). 
psalmata auxquels correspondent d'une part la structure littéraire du Cantique en dix dialogues ou dragmata, de l'autre les dix cordes du psaltérion de David. Cette divisio textus est probablement empruntée à la Cantuariensis Glossa super Cantica, à moins qu'elle ne soit directement issue de la Glossa tripartita, important commentaire franciscain composé au tournant des XIII ${ }^{e}$ et XIV ${ }^{\mathrm{e}}$ siècles ${ }^{7}$. À chacun de ces dix ensembles correspondent dix «considérations» ou "propriétés» résumées chacune par un distique mnémotechnique. On obtient un total de cinquante unités, assimilables au nombre de jour séparant Pâques de la Pentecôte et aux langues de feu du Saint-Esprit. Telle est la lingua amoris, unifiée et plurielle. Troisième et dernier critère, celui de l'interprétation : Gerson choisit d'orienter son commentaire vers le sens anagogique de l'épithalame ; il y sera donc question du chant d'amour entre l'âme et Dieu, interprété selon les principes de la théologie mystique dionysienne, plus précisément du Pseudo-Denys tel que le transmettent Thomas Gallus et Bonaventure, deux influences qui se combinent aussi dans la Glossa tripartita.

Mais c'est dans la mise en œuvre formelle de son projet de lecture, et dans la poétique qui le sous-tend, qu'il faut chercher la singularité remarquable de Gerson :

Placuit igitur, duce Spiritu Sancto, verarum ope precum coarctare sermonem et aptare principaliter ad sensum anagogicum de amore sponsae. Quod ut sincerius fiat et absque involucris similitudinum, expediens esse censui conditiones vel effectus et signa vel proprietates hujus amoris sub quinquaginta considerationibus, quasi totidem scintillis aut linguis igneis annotare. Verumtamen ne videamur a littera nimis exorbitare, studuimus istas amoris proprietates ab involucris et fumis litterae quadam exagitativa depuratione in emicationem deducere. Hic enim modus tractandi proximior est scholastico quam rhetorico stylo, quali hactenus utique studuimus, permixtione quadam facta ; quam accomode vel utiliter judicet lector, sed benignus. ${ }^{8}$

«C'est pourquoi, guidé par l'Esprit-Saint et avec l'aide d'authentiques prières, il m’a paru bon de resserrer mon discours et de l'adapter principalement au sens anagogique concernant l'amour de l'épouse. Et afin de mener à bien mon projet de manière plus franche, en écartant les voiles de l'analogie, il m'a paru utile de relever les conditions ou les effets, les signes ou les propriétés de cet amour, et de les ordonner en cinquante considérations qui sont comme autant d'étincelles ou de langues de feu. Mais de peur de paraître m'écarter trop loin de la lettre, je me suis attaché à extraire ces propriétés de l'amour de l'enveloppe fumeuse de la lettre, en la soumettant à une intense purification, afin de les faire briller. En effet, cette manière de procéder est plus proche du style scolastique que du style rhétorique tel que je l'ai privilégié jusqu'ici, non sans pratiquer un certain mélange. Au lecteur de juger de la pertinence et de l'utilité de la chose, mais qu'il le fasse avec bienveillance».

Deux éléments retiennent ici l'attention, à commencer par les verbes coarctare et aptare, qui signalent un effort de disposition et de synthèse typique de l'exégèse scolaire, illustré sur le plan formel par les distiques élégiaques accompagnant chaque sympsalma et, sur le plan de l'idée, par la lecture anagogique qui est privilégiée. À cela s'ajoute le motif du voile (involucrum) et de la fumée, qui invite à

7 Cf. Schepers (2000) 85-139.

8 TCC, 577. 
considérer le mode d'agencement du discours (un ensemble de "propriétés» ordonnées en «considérations») comme un instrument de purification et de "clarification» (in emicationem deducere) du langage poétique du Cantique ${ }^{9}$. Il ne s'agit pas de reléguer la lettre du poème au second plan, mais de la rationaliser en mettant en évidence la manière dont le sens émerge de l'image. Tel est le style «scolastique» mis en œuvre ici par Gerson, dans une rupture revendiquée avec le modus tractandi pratiqué auparavant. Rupture plus «rhétorique» - tel est le paradoxe apparent - que réelle (permixtione quadam facta) ? On peut y voir une habile manière d'attirer l'attention du lecteur sur le caractère innovant de la démarche, tout en sollicitant son indulgence.

Gerson ne s'en tient pas là. La question du statut et du traitement des «similitudes» est abordée plus loin, en lien avec la catégorie de lecteurs à laquelle est destiné le commentaire :

Quaererent enim confestim nonnulli nec ab exspectatione sua confundi putabunt : edissere nobis, si expositor es plenarius, quid osculum, quid os, quis osculans, quis osculatus, qualis osculatio ? Dic quae sunt oris duo labia, in osculante simul et osculato. Sed nec terminus hic erit inquisitionis ; fiet processus ad omnes symbolicas significationes quas textus Canticorum decurrit universus : de uberibus, de unguentis, de cellariis, de tabernaculis Cedar, de pellibus Salomonis et ceteris in hunc modum. Sed jam praetacta est nostri super his causa silentii : plus itaque suscepimus umbras et fumos excutere quam discutere. Sane distinctiones et magistrales sermones, homeliae praeterea sanctorum copiosissime pro incipientibus et proficientibus haec docuerunt. Sed nunc perfectis, quamvis imperfectus, debitor sum qui pro consuetudine exercitatos habent sensus. ${ }^{10}$

«Certains n'hésiteraient pas à demander, en croyant ne pouvoir être déçus dans leur attente : «Expose-nous, si tu es un commentateur plus exhaustif que les autres, ce que représentent le baiser, la bouche, l'être qui embrasse et celui qui est embrassée ${ }^{11}$, et ce que signifie l'acte même d'embrasser. Dis-nous ce que sont les deux lèvres de cette bouche, chez celui qui donne le baiser et chez celui qui le reçoit.» Mais il n'y aurait pas de fin à cette enquête et il faudrait en passer par toutes les significations symboliques que compte l'ensemble du texte du Cantique, en commentant de cette manière les seins, les parfums, les celliers, les tentes de Qédar, les peaux des tentes de Salomon etc. Nous avons déjà exposé les raisons de notre silence sur ce point ; c'est pourquoi nous avons pris le parti de dissiper plutôt que de disséquer les ombres et les fumées. Nul doute que les distinctions et les sermons des maîtres, ainsi que les homélies des saints n'aient enseigné avec un luxe de précisions ces interprétations qu'ils destinaient aux débutants et aux plus avancés. Mais pour l'heure, c'est aux parfaits que, tout en étant moi-même imparfait, je suis redevable, eux qui ont leurs facultés aiguisées par la pratique».

9 À noter que la métaphore de l'involucrum est surtout utilisée, depuis la Cosmographie de Bernard Silvestre, pour justifier la fréquentation des lettres païennes, dans une démarche où la poésie, assimilée à une forme d'expression contestable, est valorisée seulement en tant que promesse de vérité. Cf. Iribarren (2011).

10 TCC, 581.

11 On note l'emploi du masculin appliqué aux deux sexes (quis osculans, quis osculatus, et plus loin in osculanto simul et osculato) comme si le genre grammatical participait de l'unification et de la spiritualisation de l'un et de l'autre. Je remercie Arnaud Aizier pour cette remarque et pour sa relecture de ma traduction. 
Les lecteurs familiers du décryptage des «similitudes» systématiquement pratiqué dans les compilations allégoriques du Cantique (on songe au recueil de distinctiones du cistercien Thomas de Perseigne, très diffusé au Moyen Âge ${ }^{12}$ ) s'attendraient à ce que Gerson reprenne à son compte cette technique. Mais il refuse de se livrer à ce qu'il assimile à un vain tour de force (nec terminus hic erit inquisitionis). Son partipris est autre : il se situe moins dans la continuité avec les devanciers qu'à côté, dans une poétique qui révèle ou restaure la vérité de l'image en lui ôtant sans l'altérer le superflu, autrement dit en dissipant (excutere) ce qui la ternit et la dissimule, par opposition à l'image «disséquée» (discutere) et brisée dans la glose allégorique qui analyse le texte terme à terme et se contente de substituer un sens à un autre. La singularité du propos tient à ses destinataires. Loin de se situer dans une démarche pastorale, visant à instruire et à édifier des lecteurs novices ou encore médiocrement aguerris, Gerson s'engage dans un échange avec des "parfaits», autrement dit des contemplatifs déjà formés à ce type de lecture. C'est donc moins un commentaire qu'un «exercice» du texte (exercitium intrinsecum ${ }^{13}$ ) qui leur est ici proposé.

\section{De l'image "évidée» au paysage de l'âme}

Venons-en au passage qui nous intéresse. Situé dans le deuxième sympsalma de la deuxième partie, il correspond aux versets 6 à 10 du chapitre 1 du Cantique :

\footnotetext{
${ }^{6}$ Indica mihi, quem diligit anima mea, ubi pascas, ubi cubes in meridie, ne vagari incipiam post greges sodalium tuorum. ${ }^{7} \mathrm{Si}$ ignoras te, o pulcherrima inter mulieres, egredere et abi post vestigia gregum et pasce hedos tuos juxta tabernacula pastorum. ${ }^{8}$ Equitatui meo in curribus Pharaonis adsimilavi te, amica mea. ${ }^{9}$ Pulchrae sunt genae tuae sicut turturis, collum tuum sicut monilia. ${ }^{10}$ Murenulas aureas faciemus tibi vermiculatas argento. ${ }^{14}$

« ${ }^{6}$ Montre-moi, toi qu'aime mon âme, où tu fais paître, où tu fais reposer à midi, de peur que je ne m'égare en suivant les troupeaux de tes compagnons. ${ }^{7} \mathrm{Si}$ tu ne te connais pas, toi, la plus belle des femmes, sors, suis les traces des troupeaux et fais paître tes boucs près des tentes des bergers. ${ }^{8} \mathrm{~A}$ mes chevaux attelés aux chars de Pharaon je t’ai comparée, mon amie. ${ }^{9}$ Tes joues sont belles comme des tourterelles, ton cou comme des chaînes précieuses. ${ }^{10}$ Nous te ferons des colliers d'or, incrustés de torsades d'argent».
}

À ces six versets correspondent quatre des cinq «propriétés» du deuxième distique élégiaque :

(1) Oppugnatur amor || (2) desiderat alta tenere

(3) Esse vagus refugit || (4) doctus (5) equesque Dei est. ${ }^{15}$

12 PL 206, 17-862. Cf. Bell (2013).

13 TCC, 576

14 On donne le texte dans la version de la Vulgate Sixto-Clémentine.

15 TCC, 577. 
(1) L'amour est combattu ; (2) il cherche à gagner les hauteurs ;

(3) Il répugne à l'errance ; (4) il est savant ; (5) c'est le cheval de Dieu.

On laissera ici de côté la première propriété, qui découle de la précédente et constitue un élément de transition entre le premier et le deuxième sympsalma, et on s'attachera dans un premier temps aux propriétés 2 et 3, qui forment une unité exégético-poétique et dont on présentera successivement les deux composantes, l'une centrée sur l'image du berger-poète, l'autre sur celle du soleil au zénith :

\begin{abstract}
Secunda proprietas. Amor, igitur, desiderat alta tenere. - Indica mihi, inquit sponsa, quem diligit anima mea, ubi pascas, ubi cubes in meridie [Cant. 1.6]. Attendat pietas quemadmodum cito nomen regis, quod est excellentiae et dignitatis, deflexit sensim in nomen pastoris : ubi pascas, inquit. Scimus attribui pastoribus amatoria carmina ubi simplicitas libera et campestris sine dolo versatur, ubi nec arrogantia dominatur. Et quoniam ex hac proprietate pendent non modicum praecedentes et sequentes, consideremus quid sibi velit amor, quid desiderat alta tenere, et tam alta ut notitiam de sponso suo Deo meridianam audeat postulare. ${ }^{16}$

«Deuxième propriété. L'amour cherche à gagner les hauteurs. «Montre-moi, dit l'épouse, toi qu'aime mon âme, où tu fais paître, ou tu fais reposer à midi». Que la piété prête attention à la rapidité avec laquelle le nom de roi, qui exprime l'excellence et la dignité, s'efface devant celui de berger : «où tu fais paître», dit-elle. On prête aux bergers, comme on sait, des chants d'amour caractérisés par leur style simple, fluide et plat, dénué d'artifice et où l'arrogance ne règne pas en maître. Dans la mesure où de cette propriété dépendent en grande partie les précédentes et les suivantes, nous examinerons ce que désire l'amour pour lui-même et quelles sont ces hauteurs auxquelles il aspire, si élevées qu'il ose prétendre à la connaissance de midi au sujet de Dieu son époux».
\end{abstract}

L'attention de Gerson se porte d'abord sur le signifiant. L'enjeu est de montrer qu'il s'agit d'un passage seuil, d'un pivot dans l'interprétation (ex hac proprietate pendent non modicum praecedentes et sequentes) qui se construit à partir de deux images ou figures, celle du berger-poète et celle du soleil de midi.

Voyons d'abord l'image du berger-poète. Le verbe pascas signale un changement référentiel : on glisse sans crier gare d'une image à une autre, de la figure du roi à celle du pâtre. La rupture est camouflée par le texte biblique, qui n'emploie pas le mot pastor, trait dont Gerson signale la subtilité (cito, sensim) : loin d'y voir un collage créant un effet de disparate, il l'interprète comme un détournement doublé d'un abaissement (deflectere). Il signale ainsi une orientation nouvelle donnée au discours qui substitue à l'image royale une image pastorale (les bergers au repos qui chantent l'amour, amatoria carmina) dans laquelle on reconnaît le modèle virgilien des Bucoliques. Ce transfert affectant le dispositif énonciatif s'accompagne d'un changement de registre : on passe d'un style élevé à un sermo humilis (simplicitas libera et campestris) ce qui crée une tension entre l'humilité de la figure du berger et le caractère sublime du «lieu» auquel aspire l'épouse (desiderat alta tenere, et tam 
alta ut...audeat postulare). Gerson ne reconstitue pas les détails de la scène, qui reste relativement abstraite, mais en convoquant les bergers-poètes et en insistant sur l'ethos de leur chant (sine dolo, ubi nec arrogantia versatur), il ramène le texte à un horizon esthétique qui «(é)vide» la représentation de ses détails sensibles jugés pourtant signifiants par les devanciers (c'est le cas des sèmes de nourriture et de repos $^{17}$ ) pour n'en garder qu'un «vestige» sonore.

Le deuxième élément qui retient l'attention de Gerson est le syntagme in meridie. Il s'intègre à l'image précédente par ses connotations : le soleil de midi nous renvoie au moment le plus chaud de la journée, propice au loisir et au chant (on suit le fil de la première Bucolique). Jouant sur la polysémie de la particule ubi, Gerson interprète la question initiale de l'épouse comme portant moins sur le lieu que sur le temps. Il en résulte une temporalité mise en espace, dans laquelle l'image est creusée jusqu'à l'échelle du paysage. Pris au sens spatial (vertical) et considéré dans sa dimension géographique, alta tenere peut s'entendre comme référant aux hauts plateaux (les hauteurs du Golan ?) plus frais à cause de l'altitude, par contraste avec le style campestris ou "plat» référant à la plaine. Au sens temporel, le midi est aussi le moment où le soleil est à son plus haut point dans le ciel, par opposition au matin et au soir.

La distinctio didactique qui suit procède de ce déploiement du sens littéral :

Constat ex doctrina pietatis hausta in sapientiae cellariis quadruplicem in genere esse notitiam amoris divini : meridianam de se et apud se, ubi est qui est ens purum super se reflexum ; meridianam secundo notitiam dicimus de Deo, sed extra se in creatura beata ; tertio matutinam in ipso de creaturis ; quarto vespertinam in proprio genere videndo creaturas per speculum et in aenigmate maxime pro statu viae, vel in speculo et fortassis in aenigmate quodam vestigiorum etiam in patria.

«Il est évident, d'après la doctrine de la piété tirée des celliers de la sagesse, qu'il y a quatre sortes de connaissance de l'amour divin : celle de midi concerne l'amour dans son essence et en lui-même, là où réside celui qui est, l'être pur réfléchi au-dessus de lui-même ; la deuxième sorte de connaissance est aussi de midi et s'applique à Dieu appréhendé hors de lui-même, dans la créature bienheureuse ; la troisième correspond au matin et concerne la connaissance des créatures en Dieu ; la quatrième est celle du soir et consiste à voir les créatures dans leur genre propre à travers un miroir et en énigme particulièrement durant le cours de cette vie, et même dans la patrie, dans le miroir voire dans l'énigme de leurs vestiges».

Le sens spirituel concerne ici la noétique et repose sur des catégories que Gerson emprunte à Bonaventure (Itinerarium mentis in Deum, I.3) qui lui-même les tient d'Augustin (De Genesi ad litteram IV.12) :

17 Voir par exemple l'image du pâturage chez Apponius (Commentaire sur le Cantique des Cantiques II.7-13, De Vregille - Neyrand (1997) 238-253), le lexique de l'innutrition chez saint Bernard (Sermons sur le Cantique, XXXI.10 Verdeyen - Fassetta (1998) 447) dans une interprétation christologique et eucharistique, celle du bon pasteur qui donne sa vie (sa chair) pour nourrir ses brebis, et le développement sur le banquet céleste dans le commentaire vercellien «Deiformis anime gemitus» (cf. Barbet/Ruello (2005) 124-129). 
Haec est igitur via trium dierum in solitudine ; haec est triplex illuminatio unius diei, et prima est sicut vespera, secunda sicut mane, tertia sicut meridies ; haec respicit triplicem rerum existentiam, scilicet in materia, in intelligentia et in arte aeterna [...] haec etiam respicit triplicem substantiam in Christo, qui est scala nostra, scilicet corporalem, spiritualem et divinam.

«Voilà bien la marche de trois jours dans le désert et la triple illumination d'une même journée : la première semblable au soir, la seconde au matin, la troisième au midi. Cette illumination correspond à la triple existence des choses : dans la matière, dans l'esprit et dans l'exemplaire divin [...]. Elle correspond aussi dans le Christ, notre échelle, à sa triple substance : corps, âme et divinité. ${ }^{18}$ »

La source augustinienne s'appliquant à la connaissance angélique ${ }^{19}$, qui n'est pas convoquée ici, on prendra l'Itinerarium pour l'hypotexte le plus probable. Chez Bonaventure, en effet, la connaissance de l'amour de Dieu est déclinée en trois étapes ou degrés, correspondant aux trois moments de la journée, dans une double démarche per / in (chaque degré se dédouble) qui part du sensible, de la créature en tant que vestigium entis, pour s'élever vers le divin (ens purum) en passant par l'âme imago Dei. Gerson laisse de côté l'interprétation christologique de Bonaventure et dédouble le deuxième élément (notitia meridiana) qu'il déplace en première position pour des raisons de mise en valeur rhétorique (c'est l'objet de la quête et de la démonstration) et poétique (ne pas rompre le fil qui relie le sens spirituel à la lettre). Il insiste sur l'intensité du désir d'unité (Vult amor sponsae soli intendere quem ex toto corde non diviso, non disperso diligit) exprimé par le caractère hyperbolique de l'image, ou plutôt - le soleil au zénith n'est pas en soi une hyperbole - l'image ne devient telle que par l'idée qui la sous-tend et l'oriente, à savoir l'aspiration à une forme de connaissance transcendante qui s'énonce et s'actualise en termes affectifs, dans le désir d'union avec l'Un exprimé par l'épouse (Gerson combine ici Origène et Grégoire $^{20}$ ).

D’où la troisième propriété qui, commentant la suite du verset, oppose à ce mouvement vertical, exclusivement orienté vers l'époux divin, les atermoiements d'un désir «divagant», incapable de se fixer sur son objet :

18 Saint Bonaventure, Itinéraire de l'esprit vers Dieu (Duméry (1994) 28-29).

19 Augustin associe la connaissance du matin aux «raisons éternelles» vues par les anges dans le Verbe de Dieu, celle du soir à ces mêmes raisons appréhendées dans les créatures. La distinction est reprise et discutée par Thomas d'Aquin dans sa Somme théologique, $\mathrm{I}^{\mathrm{a}} .58 .6-7$.

20 Il reprend la radicalité intellectuelle d'Origène : «Je ne cherche point d'autres moments, quand tu fais paître le soir, le matin ou au coucher du soleil. Je cherche ce temps-là, quand, dans la splendeur du jour (florente die), tu te trouves en pleine lumière dans l'éclat de ta majesté.» (Homélies sur le Cantique des Cantiques, Rousseau (2007) 97) Il rejoint aussi la dimension affective mise en valeur par Grégoire le Grand : «À midi, le soleil est le plus ardent (sol ferventior est). Quiconque vit d'une foi ardente, vit de l'amour ardent du désir.» (Commentaire sur le Cantique des Cantiques, 41, Bélanger (1984) 131) 
Quidquid enim divisionem ab unitate separantem recipit aut nutrit, horret et amor tamquam unice dilecto contrarium. Propterea sodales hoc loco et greges, similiter et tabernacula pastorum intelligimus in partem uni ovili, uni gregi, uni pastori contrariam accipi.

«Tout ce qui participe de la division séparant de l'unité et qui l'entretient, l'amour l'a en horreur comme étant contraire au seul bien aimé. C'est pourquoi on interprète ici les compagnons et les troupeaux, et semblablement les tentes des bergers, comme désignant des choses contraires à l'unicité de l'étable, du troupeau et du berger».

Loin d'expliquer l'image en en commentant les détails un à un (greges, sodales, tabernacula), Gerson la réduit à une seule idée, l'antithèse unition / dispersion. C'est qu'il lit le Cantique non comme un réservoir de métaphores signifiantes que le poète enfilerait comme des perles et qu'il appartiendrait au commentateur d'élucider tour à tour, mais comme un discours poétique dont le caractère expressif repose sur une combinaison d'images, ainsi que sur des figures alliant connotation et intensification qui lui confèrent sa profondeur sémantique.

\section{Le collage métaphorique}

Les propriétés suivantes $\left(\mathrm{n}^{\circ} 4-5\right)$ rassemblent en deux paragraphes d'inégale longueur les versets 1, 7-10 du Cantique. Elles correspondent d'abord à un changement de locuteur : c'est désormais l'époux qui a la parole. Ce changement n'intervient pas au hasard et participe d'une intention pédagogique :

Doctus est amor sponsae ut altera denotat amoris proprietas et hoc sciens sponsus. Sed ne superbiat sponsa, immo cognoscat qualiter et unde acceperit donum istud, dicit in altera proprietate : si ignoras te, etc. [Cant. 1, 7]..$^{21}$

«L'amour de l'épouse est savant, quand il fait connaître une autre propriété de l'amour, ce qui n'échappe pas à l'époux. Mais de peur que l'épouse n'en conçoive de l'orgueil, et afin qu'elle sache comment et d'où lui vient ce don, il déclare dans une autre propriété : «Si tu ne te connais pas, etc.».

L'enchaînement des répliques, dans le «drame» minutieusement orchestré qu'est le Cantique, relève d'une stratégie de dévoilement du sens qui tient compte des «caractères» et de leur interaction. Là encore, Gerson considère le poème biblique non seulement dans son axe paradigmatique, selon le principe des correspondances analogiques, mais aussi dans son axe syntagmatique, en vertu de quoi il commente le discours tant dans son déroulement syntaxique que dans sa dynamique énonciative ou «dramatique».

De ce point de vue, c'est la prévenance de l'époux à l'égard de l'épouse qui lui fait rajouter ce qui suit ( $5^{\mathrm{e}}$ propriété) :

21 TCC, p. 591. 


\begin{abstract}
Amor est eques Dei, qui vehit scilicet et vehitur. Equitatui meo, etc. [Cant. 1, 8]. Blandiens ergo sponsus neque cum austeritate indignabundus abjiciens : si ignoras te, ait, o pulcherrima mulierum, «si» pro «non» intelligens, egredere et abi, hoc est egredieris et abibis vagabunda post vestigia gregum in dispersione hac illacque discorditer errantium, et illic pasces haedos sensuum tuorum qui ponendi sunt a sinistris sub varietate pastorum fictorum et tabernacula [Cant. 1,7] sibi multiplicantium in falsitate et vanitate. Quod nec feceris aut factura sis, equitatui meo in curribus Pharaoni assimilavi te, amica mea, quia gratiam contemplationis quae te de curribus Pharaonis eripiat, quae persecutrices curas perdere te volentes perdat, largitus sum. ${ }^{22}$

«L'amour est le cheval de Dieu, qui transporte et qui est transporté. «À mes chevaux, etc.» dit l'époux d'une voix douce ; il ajoute posément, d'un ton dénué de sévéritée ${ }^{3}:$ «Si tu ne te connais pas, toi, la plus belle des femmes» (l'hypothèse équivaut à une assertion négative), «sors et suis», c'est-à-dire tu sortiras et suivras en vagabondant «les traces des troupeaux» qui se dispersent et errent en tous sens dans la confusion, et là «tu feras paître les boucs» de tes sens qu'il faut placer à gauche et qui sont sous l'autorité des bergers hypocrites multipliant leurs tentes dans le mensonge et la vanité. Pour t'éviter d'agir ainsi ou de devenir telle, «à mes chevaux attelés aux chars de Pharaon je t'ai comparée, mon amie», car je t'ai accordé la grâce de la contemplation pour t'arracher aux chars de Pharaon et anéantir les soucis qui te harcèlent et veulent ta perte».
\end{abstract}

On assiste en apparence à une nouvelle rupture de registre, avec l'introduction d'une image discordante, celle du cheval attelé au char de combat. Au pastoral succèderait l'épique ; on retournerait au style noble et à la figure royale qui précédaient notre extrait. Or Gerson annule l'écart entre les registres en collant les deux images et en les articulant l'une à l'autre ; il les commente l'une par l'autre, en ce qu'elles s'ajustent comme les deux facettes, opposées mais complémentaires, d'un même raisonnement.

L'enjeu est d'abord dégagé par l'énoncé de la propriété : la relative qui vehit scilicet et vehitur renvoie aux motiones amoris d'Origène, à ces mouvements du désir que le texte met en scène et figure - on rejoint le «nuptial» de Ricœur ${ }^{24}$ - mettant ainsi en valeur la réciprocité ou la réversibilité de la dynamique qui porte la relation. Ces mouvements du désir sont de deux natures opposées. Dans leurs manifestations négatives, ils signifient l'errance et la dispersion ; ce sens est pris en charge par l'image pastorale, dont les connotations sont alors inversées (in dispersione hac illacque discorditer errantium, pastorum fictorum, in falsitate et vanitate) : les bergers sont assimilés au sensible en tant qu'il trompe l'âme et l'égare (vagabunda). Pris comme force positive, les motiones amoris sont assimilés à l'idée d'une course libre et orientée ; ils sont donc du côté de l'image équestre (v. 8) qui se dédouble à son tour en deux facettes antagonistes (le cheval de Salomon vs le char de Pharaon). L'analogie est "prophylactique» (Quod nec feceris aut factura sis, equitatui meo in curribus Pharaoni assimilavi te) en ce qu'elle met en évidence l'intention qui préside

22 Ibid.

23 Réminiscence d'Apponius (blanda commonitione docetur). Op. cit., II.14.255.

24 Op. cit. (note 4). 
au montage des images : il s'agit de prévenir le danger auquel s'expose l'épouse dans l'ardeur de son désir.

L'élément qui articule les deux aspects et introduit le sens spirituel est le syntagme gratiam contemplationis : c'est le «don» de l'époux d'où l'épouse tire sa connaissance (notitia) ; c'est donc aussi le principe moteur de la dynamique «nuptiale». L'exégèse n'est pas neuve. La nouveauté tient ici à son traitement, autrement dit à la manière dont l'idée s'intègre à l'image. La contemplation est associée au domaine céleste et aérien ; elle connote, on l'a vu avec le motif du soleil au zénith, l'élévation ou la hauteur (alta). Saisie du point de vue subjectif, en tant que mouvement qui porte le sujet vers son objet sublime, elle est aussi assimilée à un envol ou à un vol ${ }^{25}$. La connotation est exploitée chez Platon, dans le Banquet 28-29 avec la définition de l'amour comme mouvement d'élévation du sensible vers l'intelligible que donne Diotime, et dans le Phèdre 25 et 34 avec la description de la nature de l'âme, force composée d'un cocher menant un attelage ailé et contrasté : le cheval de droite est de bonne race et obéissant, tandis que celui de gauche est mauvais et rétif. L'image de l'âme-char est connue de la tradition médiévale ${ }^{26}$; elle est employée, en lien avec Cant. 6, 11 (motif du char d'Aminadab) pour figurer l'envol de l'âme vers les réalités supérieures dans le De Isaac d'Ambroise, qui la tient d'Origène ${ }^{27}$. En assimilant l'attelage du Cantique à celui du Phèdre, Gerson figure de manière spatiale et dynamique, par une trajectoire verticale, la polarisation prise en charge par le motif solaire dans la scène pastorale (v. 6-7).

La dynamique tient aussi à la dimension antagoniste de l'image, empruntée elle aussi à Platon : si le bon cheval de l'âme - son désir amoureux - emporte le char vers les hauteurs, le mauvais cheval - celui de gauche, qui représente les passions désordonnées - est responsable de sa chute dans la sensualité de la matière et de son éparpillement dans la «pluralité» des objets qui s'offrent à elle, par opposition à l'unicité de l'époux divin. Rapportée à l'image déjà en place (les bergers et leurs troupeaux sous le soleil de midi), la représentation s'élargit et s'enrichit de l'apport du mythe. Ce faisant, elle subit un autre dédoublement : d'un côté, on visualise l'élévation ascendante de l'âme vers le soleil divin, sous la conduite du cocher (la Grâce) que celui-ci lui a donné ; de l'autre, c'est la chute de l'âme dévoyée par son ou ses chevaux de gauche, assimilés aux boucs de l’Évangile (haedos sensuum tuorum

25 Sur l'importance de cette métaphore chez Gerson, voir Fabre (2013).

26 On la retrouve en particulier chez Martianus Capella (De nuptiis, I) et dans l'œuvre d'Alain de Lille, en particulier dans la description du char construit par les sept Arts et conduit par Raison, qui tient les rênes des chevaux des cinq sens, dans l'Anticlaudianus II.325 à IV.241 (Bossuat 1955) et dans le Sermo de sphaera intelligibili. Cf. D’Alverny (1965) 302.

27 Chez Ambroise (De Isaac vel anima, 8.65, Schenkl - Moreschini, 1982, 106-109), c'est le Christ qui conduit le char, constitué de 2 x 4 chevaux ; les bons chevaux correspondent aux quatre vertus cardinales, les quatre mauvais aux passiones corporis (colère, concupiscence, crainte et injustice). Cf. Courcelle (1975) 599 et Cutino (2016) 13-26. À noter que Gerson consacre quelques lignes au motif du char d'Aminadab au début du Sympsalma IX, mais il ne dit rien des chevaux et se contente de gloser les roues du char, qui représentent les quatre Évangiles (cf. TCC, 628). 
qui ponendi sunt a sinistris $)^{28}$. La dégradation est plaisante et expressive ; elle n'empêche pas de reconnaître le mythe de Phaéton, le mauvais aurige qui, perdant le contrôle du char du Soleil son père, effectue une course erratique au cours de laquelle il manque d'embraser la terre, avant d'être foudroyé par Hélios. Notons que le mythe se retrouve aussi chez Platon, dans le Timée (22d) bien connu au Moyen Âge par le commentaire de Chalcidius.

Le collage intègre ainsi une image dans une autre. Le char grotesque de Pharaon, constitué des bergers et de leurs sinistres troupeaux, a pour pendant l'attelage de la contemplation mené par la Grâce : c'est elle qui maintient le désir unifié de l'âme dans sa «rectitude» et lui permet de tendre vers son but, le soleil divin au zénith. Les éléments mythiques recomposés et redistribués restent certes sous-jacents, mais la vision sensible qui affleure et s'accompagne de l'intériorisation des référents est très expressive. Reste une difficulté, consistant à raccorder à ce qui précède l'évocation des bijoux aux verset 9 et 10 :

\begin{abstract}
Dedi praeterea ut essent pulchrae genae tuae sicut turturis, in honestate conversationis, et collum tuum, quod mihi te conjungit, sit sicut monilia [Cant. 1, 9]. Nos quoque murenulas aureas, quae sunt sententias pietatis aureae, faciemus tibi vermiculatas argento [Cant. 1, 10] eloquentiae, quoniam eloquia mea eloquia casta sunt sicut argentum igne examinatum, probatum terrae, purgatum septuplum. ${ }^{29}$

«'ai aussi fait en sorte que tes joues soient belles comme des tourterelles, par la noblesse de ta vie, et que ton cou qui t'unit à moi soit telle une chaîne précieuse. Quant à nous, ce sont des «colliers d'or», c'est-à-dire des paroles pleines d'une piété resplendissante, que «nous te ferons», des paroles «incrustées des torsades d'argent» de l'éloquence, car mes paroles sont pures, tel l'argent éprouvé au feu, passé au creuset et purifié sept fois».
\end{abstract}

Nouvel effet de disparate ? Plutôt une surimposition d'images, celle de l'attelage et celle du corps de l'épouse. On sait que les chars et les chevaux d'apparat étaient ornés ; quant aux bijoux de l'aimée, ils participent de sa grâce. Gerson les rattache $\mathrm{au}$ «don» qui lui est fait, autrement dit aux effets de la Grâce (l'ultime théorisation de la théologie mystique chez Gerson est une doctrine de la Grâce). Mais le motif ornemental s'entend aussi au plan métapoétique, dans la lettre du commentaire dont l'ambition est d'être l'analogon de son objet, l'amour spirituel. Dire l'amor fruitivus de l'épouse suppose ainsi un discours passé au creuset de l'éloquence (sicut argentum igne examinatum, probatum terrae, purgatum septuplum), un discours "décanté» et intériorisé, ajusté doctrinalement (sententias pietatis aureae) et poétiquement, autrement dit fidèle à la poétique du Cantique telle que Gerson la comprend et la restitue, comme une poétique des "vestiges».

Reste alors, par un effet de mimétique discursive, à clore ce point du commentaire sur lui-même en revenant au point de départ (la petitio de l'épouse en Cant. 
1,6) par la figure typique de la poésie biblique ${ }^{30}$ qu'est l'inclusio, tout en ouvrant le texte sur ce qui suit et, aussi bien, sur ce qui n’a pu être dit :

Sint haec interim pro concordia et sympsalmata secundo contexta absque praejudicio sententiarum quas esse multiplices alias non me latet. Fiat recursus ad petitionem et desiderium sponsae ex amoris fiducia sponso loquentis : amo te. Indica mihi per amorem tuum quo amas me, ubi pascas, ubi cubes in meridie.

«Qu'on prenne dans l'intervalle les considérations suivantes comme visant à rehausser l'harmonie de ce deuxième chant, sans préjuger des explications qui, je ne l'ignore pas, se trouvent ailleurs en grand nombre. Revenons à la demande et au désir de l'épouse qui, mue par la confiance que lui inspire l'amour, dit à l'époux «je t'aime» et «montre-moi» par l'amour dont tu m’aimes «où tu fais paître, où tu fais reposer à midi.»

\section{Conclusion : une poétique des vestigia imaginis}

Si les vestigia gregum du Cantique s'apparentent pour Gerson aux vestigia imaginis de la mystique bonaventurienne, ce sont aussi les «vestiges» de l'image-«similitude» telle qu'elle prolifère dans la lettre et sert ordinairement d'assise au décryptage systématique des compilations allégoriques médiévales. Gerson prend le contrepied de cette démarche en dépouillant l'image de ses détails jugés secondaires et ornementaux, qu'il ne glose pas, pour la «réduire» et n'en garder que la part la plus pure, en la restaurant dans sa vérité. Faut-il y voir un refus ou une mise à distance de la rhétorique ? Gerson met en œuvre, de son propre aveu, un modus tractandi qui s'appuie sur les «règles scolastiques de la théologie et de la philosophie» (scholasticis theologiae et philosophiae regulis ${ }^{31}$ ) et s'écarte du «style rhétorique» qu'il a jusque là privilégié. Ce n'est pas pour autant un rejet de la rhétorique, dont il s'est efforcé de promouvoir le bon usage à l'université, mais un changement de méthode induit par une nouvelle intentio. En entreprenant de ramener le Cantique à une «intelligence commune» qui est celle du «mystère» que les «parfaits» seuls peuvent comprendre, intérioriser et "pratiquer» tel un exercice spirituel (exercitium intrinsecum), Gerson renonce à une visée homilétique et édifiante destinée au plus grand nombre. C'est dans ce dernier cadre que la rhétorique classique par son usage des figures et des ornements (expolitio) vient à l'appui de la démonstration en s'adressant aux affects in declamationibus et exhortationibus moralibus sine fine ${ }^{32}$. En cela aussi Gerson se démarque de l'horizon homilétique qui est le fait de nombreux commentaires, tant monastiques que scolaires ; il s'écarte aussi de la perspective pastorale qui était celle du De duplici logica. Dans cet opus ultimum qu'est le traité

30 Cf. Alter (2003).

31 TCC, p. 579.

32 Ibid., p. 576. 
sur le Cantique, la rhétorique n'est certes pas évacuée, mais en changeant d'objet et de visée, elle a changé de nature.

\section{Bibliographie}

Alter (2003): Robert Alter, L'art de la poésie biblique, trad. fr. par Ch. Leroy et J.-P. Sonnet, Bruxelles, Editions Lessius, 2003.

Barbet/Ruello (2005): Un commentaire vercellien du Cantique des Cantiques «Deiformis anime gemitus», Jeanne Barbet (éd.) et Francis Ruello (trad.), Turnhout, Brepos, 2005.

Bélanger (1984): Grégoire le Grand, Commentaire sur le Cantique des Cantiques, trad. R. Bélanger, Paris, Cerf: «Sources chrétiennes, 314», 1984.

Bell (2013): David N. Bell, « Le Commentaire du Cantique des Cantiques de Thomas de Perseigne revisité ॥, in: Annales de Bretagne et des Pays de l'Ouest [En ligne], t. 120/3 (2013), mis en ligne le 30 septembre 2015, consulté le 08 janvier 2017

Bossuat (1955): Alain de Lille, Anticlaudianus, Robert Bossuat (éd.), Paris, Vrin, 1955.

Combes (1964): André Combes, La théologie mystique de Gerson. Profil de son évolution, Rome etc, Desclée \& Cie, 1964, t. II.

Courcelle (1975): Pierre Courcelle, "Connais-toi toi-même» de Socrate à saint Bernard, Paris, Etudes augustiniennes, 1975, t. III.

Cutino (2016): «Ambroise de Milan et l'exégèse vétérotestamentaire d’Origène: questions méthodologiques à partir d'un cas exemplaire», in: Transmission et réception des Pères grecs dans l'Occident, de l'Antiquité tradive à la Renaissance. Entre philologie, herméneutique et théologie, Emanuela Prinzivalli, François Vinel et Michele Cutino avec la collaboration d'Isabelle Perée (éds.), Paris, Institut d'Etudes Augustiniennes, 2016, p. 13-26

D’Alverny (1965): Alain de Lille, Textes inédits, Marie-Thérèse d’Alverny (éd.), Paris, Vrin, 1965.

De Vregille - Neyrand (1997): Apponius, Commentaire sur le Cantique des Cantiques, t. I, (livres I-III), édition et traduction par Bernard de Vregille et Louis Neyrand, Paris, Cerf: «Sources chrétiennes, 420 », 1997.

Duméry (1994): Saint Bonaventure, Itinéraire de l'esprit vers Dieu, texte de Quaracchi, traduction par Henry Duméry, Paris, Vrin, 1994.

Fabre (2013): Isabelle Fabre, «La plume et l'envol: une analyse stylistique de la Méditation sur l'Ascension de Jean Gerson», in: Revue de l'Histoire des Religions, numéro spécial "Sermo mysticus», Cédric Giraud et François Trémolières (dir.), t. 230, 4/2013, p. 509-544.

Glorieux (1971): Palémon Glorieux (éd.), Jean Gerson, Euvres complètes, Paris, Desclée \& Cie, 1971, t. VIII, $\mathrm{n}^{\circ} 422$ (Super Cantica Canticorum).

Iribarren (2011): Isabel Iribarren, "Le théologien: poète de la doctrine. Quelques considérations autour de la Josephina de Jean Gerson », in: Revue des sciences religieuses [En ligne], 85/3 (2011), mis en ligne le 12 mars 2015, consulté le 01 octobre 2016

Ricoeur (1998): Paul Ricoeur et André LaCocque, Penser la Bible, Paris, Seuil, 1998.

Rousseau (2007): Origène, Homélies sur le Cantique des Cantiques, trad. Olivier Rousseau, Paris, Cerf: «Sources chrétiennes, 37bis», 2007.

Schenkl - Moreschini (1982): Ambroise, De Isaac vel anima, Carolus Schenkl (éd.), Claudio Moreschini (trad.), Milan/Rome, Bibliotheca Ambrosiana/Città Nuova Editrice: «Sancti Ambrosii Episcopi Mediolanensis Opera, 3», 1982.

Schepers (2000): Kees Schepers, «The Genesis of Glossa Tripartita super Cantica», in: Revue d'histoire des textes, 29 (1999), 2000, p. 85-139.

Vial (2006): Marc Vial, Jean Gerson théoricien de la théologie mystique, Paris, Vrin, 2006. 


\section{Bible, poésie et doctrine dans la Josephina de Jean Gerson}

Connu surtout comme théoricien de la théologie mystique et par son action réformatrice en tant que Chancelier de l'Université de Paris au début du XVe siècle, Jean Gerson nous a aussi légué une œuvre poétique latine d'envergure ${ }^{1}$. Loin d'être un exercice marginal, celle-ci, comme le fait remarquer G. Matteo Roccati, «trouve sa place dans la logique de l'ensemble de sa production et elle en partage thèmes et préoccupations ${ }^{2}$.» C'est le cas notamment de la Josephina, poème épique de près de 3000 hexamètres, composé entre 1414 et $1417^{3}$, pour l'essentiel au concile de Constance. À travers le récit de l'histoire de la Sainte Famille depuis l'Annonciation jusqu'à la mort de Joseph, Gerson entend promouvoir le culte du mariage virginal des saints époux comme exemple de l'union du Christ et de l'Église dans un contexte de trouble politique et ecclésial ${ }^{4}$.

La Josephina puise une bonne partie de son contenu dans les Évangiles, l'Ancien Testament, et, indirectement, dans les apocryphes ${ }^{5}$. Elle comporte aussi de nombreuses réminiscences classiques. À cet égard, le choix de forme métrique n'est pas anodin. Traditionnellement réservé à l'épopée antique, l'hexamètre dactylique connaît un nouvel essor au tournant du $\mathrm{Xv}^{\mathrm{e}}$ siècle grâce à l'Africa de Pétrarque. L'affinité entre les deux épopées ne relève pas d'un simple aspect formel. Tout comme l'Africa, la Josephina comporte une dimension de fierté nationale, où l'auteur entend s'ériger en poète de la res gallica ${ }^{6}$. Il ne s'agit pas ici de célébrer les exploits guerriers d'un Scipion ou d'un Enée en vue de faire reconnaître la suprématie romaine, mais de chanter la primauté intellectuelle de Paris injustement décriée par Pétrarque.

Mais malgré toutes ses affinités avec la production littéraire des italiens de la période $^{7}$, la Josephina ne pointe vers aucune source précise qui pourrait nous guider

1 Voir Roccati (1980) ; Roccati (2001) ; Glorieux (1962). Ici, les références à l'édition critique de la Josephina et à sa traduction française renvoient toutes à Iribarren- Roccati (2018).

2 Roccati (2001) 5. Voir aussi Hobbins (2009) 92-101.

3 Au sujet de la datation du poème, voir Roccati (2001) 15-24; Lieberman (1955) 289-333, surtout 323-326 ; Combes (1964) 290-297; Glorieux (1962) 15.

4 Pour l'histoire du culte de saint Joseph, l'ouvrage de référence reste Seitz (1908) ; voir aussi Dordoni (1996) 321-342.

5 Au sujet de l'utilisation des apocryphes dans la Josephina, je me permets de renvoyer le lecteur à Iribarren (2018).

6 On retrouve les mêmes idées dans le traité inachevé contre Juan de Monzón, où le jeune Gerson, alors bachelier à Paris, déplore que la France, pourtant si riche en hommes sages, manque toujours d'historiens et de poètes pour les célébrer. Voir Ouy (1962) 433-492, en part. p. 447-450; voir aussi Fabre (2006) 111-125.

7 À d'autres occasions, Gerson exprime aussi la volonté de s'exercer dans des genres nouveaux, comme les mètres utilisés par Boèce. Voir à ce sujet Burrows (1991). 
vers un modèle éventuel ${ }^{8}$. Pour décrire son poème, Gerson utilise des termes d'origines variées. Dans le Prologue (v. 92), il emploie l'antique camena ; ailleurs, il emprunte des termes de la tradition classique, comme carmen (Prol., v. 71, 83 et 99 ; dist. I, v. 272, 371 ; dist. II, v. 728 ; dist. III, v. 1007) ou oda (dist. I, v. 274) ; il recourt aussi au registre de la poésie liturgique comme le verbe psallere et ses dérivés (dist. I, v. 274 ou dist. IV, v. 982). Dans la composition du poème, l'auteur agence soigneusement divers types de registres : les passages narratifs alternent avec des descriptions, des dialogues «dramatisés» et des réflexions théologiques. On y trouve également des exercices plus traditionnels de la paraphrase biblique des passages les plus connus des évangiles : le Magnificat (v. 1595-1620), le Benedictus (v. 1735-1753), le Nunc dimittis (v. 2369-2374).

Trois aspects de l'épopée, sur lesquels on s’attardera tour à tour, font ressortir la conception gersonienne du rapport entre Bible, poésie et développement doctrinal : d'abord, son organisation formelle en distinctiones ; deuxièmement, la notion d'«estimation pieuse» qui gouverne la composition ; enfin, les présupposés herméneutiques de l'affaire Jean Petit sur le tyrannicide.

\section{Organisation formelle du poème}

Certains aspects de l'organisation formelle du texte se conforment à un genre bien défini. Il est constitué d'un Exordium, d'un résumé (Titulus brevius) et de douze distinctiones, dont la douzième s'achève par une Oratio finale. À l'instar de l'Énéide, le modèle du genre, Gerson veut manifestement se conformer à la répartition classique en douze chants, même si, à la manière scolastique, il utilise le terme de distinctio pour les désigner. Ce choix est significatif et mérite un commentaire?

Évocatrices de la culture d'école, les distinctiones renvoient tout d'abord à une technique bien attestée depuis le $\mathrm{XII}^{\mathrm{e}}$ siècle chez les exégètes, et adoptée massivement par les prédicateurs dès le $\mathrm{XIII}^{\mathrm{e}}$ siècle. Dans sa définition la plus générale, la distinctio consiste dans le déploiement des diverses significations figurées ou symboliques d'un terme ou d'un passage biblique, souvent tempérées par le recours à des exempla. À la fin du XII ${ }^{\mathrm{e}}$ siècle, on assiste à la rédaction des premiers recueils de distinctiones, sortes de classements ordonnés alphabétiquement des sens multiples des mots bibliques ${ }^{10}$. Gerson hérite de cette tradition et la met à profit dans la Josephina. Selon le chancelier, les distinctiones désignent une forme d'organisation

8 Voir Roccati (1982) 278-285.

9 Pour une typologie des formes de l'exégèse médiévale, voir Dahan (1999) 121-159.

10 Leur utilité comme instruments de travail dans le cadre de la prédication est bien attestée. Pour des études générales sur les distinctiones bibliques et leur impact sur la prédication, voir Rouse (1974) 27-37 ; Bataillon (1982) 213-226 ; Bataillon (1993) 280 - 289 ; Weijers (1991) 120-126 ; Dahan (1999) 131-135; 134-138 et 145-151 ; Hasenohr (1978) 46-96 et 183-206 ; Wilmart (1940) 307-346 ; Landgraf (1973) 57-58. Chenu (1964) 129-135, surtout 130-131. 
du discours dont la vertu formelle doit servir l'affect : «de façon succincte elles [les distinctiones] éclairent l'intellect et sans trop de peine charment l'affect ; c'est ainsi que la parole vive et efficace de Dieu pénètre doucement, à la manière d'une conversation, par moyen de parties ordonnées (per particulas ordinatim) ${ }^{11}{ }^{\prime}$. Davantage que le caractère succinct de la distinctio, ce qui doit retenir notre attention dans le passage cité est l'adverbe ordinatim : les distinctions permettent la présentation ordonnée d'un savoir doctrinal, visant en l'occurrence la progression vers l'union à Dieu par une voie affective. Elles forment un tout organique, permettant de passer par étapes des parties les plus élémentaires d'un verset biblique à la construction d'un discours plus complexe où ressort la diversité de ses sens spirituels. La distinction est ainsi le support d'une mise en ordre du savoir employée emblématiquement dans les sommes et commentaires des Sentences scolastiques ${ }^{12}$, et qui dans la Josephina est fondé sur un itinéraire spirituel et non chronologique. En effet, à l'instar de l'ordo artificialis de l'Enéide, la trame narrative de la Josephina ne respecte pas l'ordre chronologique des cycles de l'Enfance, qui débutent d'ordinaire avec l'Annonciation, mais choisit de commencer par la fuite en Égypte. Le choix opéré par Gerson fait non seulement ressortir l'aspect dramatique de la vie du protagoniste ${ }^{13}$, mais favorise une lecture anagogique qui met en exergue l'ascension mystique de l'âme, thème qui sous-tend le récit. En effet, comme l'a montré Isabelle Fabre, le lien fonctionnel entre poésie et mystique constitue la base de la réhabilitation théologique de l'inspiration poétique chez Gerson ${ }^{14}$. Dans ce but, il mobilise les topoi traditionnels : le contraste entre les Muses de la poésie profane et le Christ comme source d'inspiration de la poésie chrétienne (Prologue) ${ }^{15}$; le recours aux modèles bibliques extraits des commentaires des Psaumes, notamment la figure de David «le

11 Gerson, Gratia tibi, lettre à Michel Bartine, moine de la Grande Chartreuse, Lyon, 9 juin 1426, éd. P. Glorieux, Euvres complètes, vol. II.276 [désormais éd. Glorieux, vol. et p.] : sermones magistrales vel determinationes in materiis particularibus qui fiunt succinte per distinctiones, valde illuminant intellectum et sine labore gravi demulcent etiam affectum, cum inspicitur sermo Dei vivus et efficax dum ad modum colloquentis eidem se infundit suaviter per particulas ordinatim.

12 Dans la scolastique, le terme ordinatio désigne le plus souvent le principe qui guide la mise en ordre d'une matière donnée, dans une logique de subordination des savoirs aux Écritures. Voir par exemple Hugues de Saint-Victor, De sacramentis, Prol., c. 6 (PL 176), col. 185 : omnes artes naturales divinae scientiae famulantur, et inferior sapientiae recte ordinata ad superiorem conducit ; Bonaventure, Collationes in Haexaemeron, XIX.6, dans Opera omnia V, Quaracchi, 421 ; Vincent de Beauvais, Libellus totius operis apologeticus, Prologue au Speculum maius, c. 2, in : S. Lusignan (éd.) (1979), Préface au "Speculum majus» de Vincent de Beauvais : réfraction et diffraction, Montréal-Paris, 117. À ce sujet, voir Parkes (1976) 115-141.

13 Voir Roccati (2001) 11. Sur l'ordo artificialis dans la poésie médiévale, voir Zink (2003) 95-97, surtout 97 n. 1.

14 Voir Fabre (2011) 79-107. Voir aussi Witt (1977) 538-563.

15 Gerson, Prebe fidem, in : Fabre (2005) 458, v. 51-54 et 457, v. 17-24 ; Gerson, De laudibus elegie spiritualis (Quisquis amas), in : Fabre (2005) 455, v. 5-8; Gerson, De laude musice (Musica divini), in : Fabre (2005) 449-450, v. 43-44; Gerson, Tractatus de canticis, in : Fabre (2005) 151 et 322 . À ce sujet, voir aussi Zink (2003) 110-111. 
berger citharède ${ }^{16}$; enfin, l'emphase sur la dimension morale et pédagogique de la poésie ${ }^{17}$.

Comme le veut la pratique universitaire de la distinctio biblique, la démarche de Gerson réserve toute sa place aux techniques de communication de la doctrine, que les artes praedicandi des siècles antérieurs avaient résumée dans la trilogie auctoritates - rationes - exempla ${ }^{18}$. L'application de ces pratiques dans la Josephina nous fait comprendre que les rationes tiennent moins ici d'une dialectique universitaire appliquée aux concepts ${ }^{19}$ que de l'exercice d'amplification rhétorique décrite par Cicéron dans le De Inventione ${ }^{20}$ et dans la Rhetorica ad Herennium, textes qui ont connu une large diffusion dans les écoles depuis au moins le $\mathrm{xI}^{\mathrm{e}}$ siècle ${ }^{21}$. La Rhetorica ad Herennium emploie le terme de argumentum à cet égard comme un type de narration mitoyenne entre la historia, qui relate les choses réellement survenues, et la fabula, qui porte sur l'invraisemblable : l'argumentum porte sur les «choses qui auraient pu arriver» mais qui ne sont pas réellement arrivées. Ce genre de récit cherche le veri similis, selon ce qui est «habituel, attendu et naturel ${ }^{22}$.

\section{«Estimation pieuse» et amplificatio biblique}

Un passage de la troisième distinctio de la Josephina se prononoce sur le statut épistémologique de l'amplificatio biblique pratiquée par le poète :

notre méditation... n’affirme rien de façon téméraire

sur ce qui nous est inconnu, mais recourt modérément

aux conjectures par moyen d'un raisonnement topique.

À partir de ce qui est écrit, l'esprit, par un effort pieux,

16 Gerson, De laudibus elegie spiritualis (Quisquis amas), in : Fabre (2005) 455, v. $11-14$; Gerson, De laude musice (Musica divini), in : Fabre (2005) 448, v. 11-14.

17 Gerson, De laude musice (Musica divini), in : Fabre (2005) 450-451, v. $45-84$; Gerson, De laudibus elegie spiritualis (Quisquis amas), in : Fabre (2005) 455, v. 15-24. À ce sujet, voir Di Stefano (1971) 26-27.

18 Parmi la vaste littérature à ce sujet, voir Charland (1936) ; Bériou (1998); D’Avray (1985) ; Longère (1983) ; Briscoe -Jaye (1992).

19 Voir par exemple Alexandre de Halès, Summa theologiae, Tractatus introductorius, q. 1, a. 1, c. 4, ad 2 : ... modus definitivus debet esse, divisivus, collectivus, et talis modus debet esse in humanis scientiis, quia apprehensio veritatis secundum humanam rationem explicatur per divisiones, definitiones, et ratiocinationes.

20 Cicéron, De Inventione, I, 34, 57.

21 Pour la réception médiévale de ces oeuvres et la tradition des commentaires, voir Ward (2006) 3-75; Ward (1995).

22 Rhetorica ad Herennium, I.8, éd. T.E. Page et alii (1964), Cambridge, Mass., The Loeb Classical Library, 22-24:Id quod in negotionum expositione positum est tres habet partes : fabulam, historiam, argumentum. Fabula est quae neque veras neque veri similes continet res, ut eae sunt quae tragoediis traditae sunt. Historia est gesta res, sed ab aetatis nostrae memoria remota. Argumentum est ficta res quae tamen fieri potuit, velut argumenta comoediarum... (je souligne). 
est capable d'inférer ce qui n'est pas mis par écrit.

C'est ainsi qu'une foi certaine révèle ce qui est incertain,

quels ont été les faits ou ce qui aurait pu arriver ${ }^{23}$ (je souligne).

La conception de la poésie comme un récit fondé sur ce qui aurait pu arriver plutôt que sur des choses réellement survenues provient de la Poétique d'Aristote. À ce titre, le philosophe considère la poésie comme «plus philosophique et d'un caractère plus élevé que l'histoire ; car la poésie raconte plutôt le général, l'histoire le particulier. Le général, c'est-à-dire que telle ou telle sorte d'homme dira ou fera telles ou telles choses vraisemblablement ou nécessairement ${ }^{24}$ ». Le qualificatif de "philosophique» pour caractériser le procédé poétique renvoie à un principe aristotélicien contenu dans les Topiques ${ }^{25}$ : «si deux énoncés contradictoires ne peuvent être simultanément vrais, ils peuvent toutefois être simultanément probables». Philosophie et poétique convergent ainsi dans le terrain du raisonnement topique : de même que la philosophie se sert de prémisses probables et d'une argumentation basée sur les lieux (topoi) tout en prétendant être probante, de même la poésie aspire à une certaine forme d'universalité par moyen d'un raisonnement probable ou topique. Les deux démarches emploient des modalités d'argumentation qui se veulent crédibles et convaincantes, mais qui échappent aux exigences de la déduction formelle.

Autour des mêmes années, en 1416, Gerson traite plus systématiquement de cette question dans la Declaratio compendiosa quae veritates sint de necessitate salutis credendae. Ce traité se trouve à la base de la légitimation de la poésie comme moyen d'expression de la vérité doctrinale, en même temps qu'il établit les fondements épistémologiques de l'élaboration poétique. Dans une classification normative du discours doctrinal, la Declaratio établit six degrés (gradus) de vérité selon un ordre décroissant d'adhésion ${ }^{26}$. Les trois premiers correspondent à la doctrine orthodoxe telle qu'elle est explicitement contenue dans les Écritures ou transmise par la tradition apostolique. Ces vérités, directement révélées par Dieu, constituent les articles de la foi, nécessaires au salut. Les trois degrés suivants découlent logiquement des premiers, et ne détiennent qu'une valeur probable. Parmi ceux-ci, le plus bas degré correspond aux vérités qui servent à «édifier la charité ou la dévotion du cœur

23 Josephina, dist. III, v. 855-860 : Nil super ignotis igitur meditatio nostra/Affirmet temere, sola suffecerit uti/Coniecturarum thopica ratione modeste./Ex scriptis inferre potest non scripta pio mens/ Cum studio, sic certa fides incerta revelat/Qualia sunt acta vel que fieri potuere. Voir aussi les vers programmatiques à la fin du Prologue, v. 92-94 : ...favete/Nostraque sit, facite pietas accepta Camene,/Ancillans fidei, nulli preiudica vero,/Multa probabiliter suadens, temeraria nusquam,/Apta peregrinum cor sursum attollere celis. Voir aussi Gerson, sermon Jacob autem genuit, éd. Glorieux, $5.345-346$.

24 Poétique, c. 9, 1451a36-10. Au sujet de la vraisemblance poétique chez Aristote, voir Poétique, 1447a18-1448a27, 1448b4-23.

25 Aristote, Topica I, c. 10 et VIII, c. 11 ; voir aussi Auctoritates Aristotelis 36.121, éd. J. Hamesse (1974), Les "Auctoritates Aristotelis» : Un florilège médiéval, Louvain, 331 et 124.

26 Gerson, Declaratio compendiosa, éd. Glorieux, 6.181-189. 
pieux», plutôt qu'elles n'instruisent l'intellect. Ces vérités pieuses, l'Église autorise à croire $^{27}$. Elles résultent d'un jugement «estimatif» ou "croyance pieuse» (existimatio vel pia credulitas) qui échappe à la logique binaire du vrai et du faux, dans la mesure où elle relève du probable. En d'autres termes, une croyance pieuse est vraie si elle n'est pas entièrement improbable. Quant à la définition de' "estimation pieuse» comme forme de «raisonnement topique ou moral», elle s'inscrit dans la tradition des commentateurs de l'œuvre aristotélicienne qui élaborent une conception élargie du raisonnement logique pour inclure une stratégie de persuasion. Dans ce contexte, l'aestimatio dénote une forme de raisonnement à visée pratique ou morale, distinct et inférieur, du point de vue épistémique, du raisonnement démonstratif propre aux sciences spéculatives ${ }^{28}$.

La Josephina présente de nombreux exemples de ce genre d'agencement du récit biblique. Dans sa reconstruction de l'épisode de la fuite en Égypte, Gerson imagine qu'en y arrivant, Joseph aurait voulu dissimuler prudemment l'identité de son épouse. Il s'inspire ici d'un passage de la Genèse, qui attribue ce comportement à Abraham lors de son séjour en Égypte ${ }^{29}$. Un autre exemple est fourni par l'épisode des Rois mages, où l'absence de Joseph dans le récit évangélique est à la fois expliquée et comblée par une comparaison avec l'épisode de l'annonce aux bergers, où Joseph figure bel et bien aux côtés de la Vierge et l'enfant ${ }^{30}$.

27 Gerson, Declaratio compendiosa, éd. Glorieux, 6.184-185 : in sexto gradu... collocantur veritates illae quae tantummodo faciunt ad nutriendam vel fovendam devotionis religiosam pietatem, quae scilicet magis inducuntur ad inflammandum affectum quam ad instruendum intellectum, ubi pietas devota magis inspicitur quam veritas certa, ubi hoc unum reprobatur si adesset assertionis temeritas priusquam elucidaretur alio modo vel rationem certam ipsa veritas... Cadit existimatio vel pia credulitas non super veritate vel falsitate sed tantummodo super probabilitate vel apparentia... de talibus eligibilius est pie dubitare quam temere definire.

28 Voir aussi Quaestio in poetriam (XIII ${ }^{\mathrm{e}}$ siècle) anonyme, in : Dahan (1980) 171-247, surtout 216, où la notion de aestimatio est utilisée pour désigner l'assentiment qui correspond au champ de l'imaginaire poétique. À ce sujet, voir Marmo (1990) 145-198 ; voir aussi l'article plus récent de Robert (2012) 27-45.

29 Cf. Gn 12.11-13; Josephina, d. II, v. 411-424 : Vir prior alloquitur sponsam : «Cognosco decora/Quod sis, o domina; gens ista libidine fervens/Fedis urgetur stimulis; si sciverit uxor/Quod mea sis, mihi quid nisi mors, o Virgo, paratur/Atque pudicicie tibi discrimen, Pharaonis/Ducet ad aspectum mox te manus improba servi./Sors indigna nimis, nos o tibi quid faciemus,/Blande puer, fugimus neu te unum perdat Herodes;/Deserimus dulcesque lares, carosque propinquos./Ecce quod irruimus in tanta pericula soli/ Ignoti atque inopes, lingue ignari. Deus alme,/Nobis quid facere voluisti? Queso, Maria,/Filia dic mea sis, hoc etas credere verum/Suadebit, reliquum auxilio committo superno".

30 Cf. Mt 2.11 et Lc 2.16 ; Josephina, d. IX, v. 2278-2287: Invenisse Joseph pastores littera tradit,/Mentio nulla fit hic; sed qualiter huius honoris,/Huius mysterii mansisse putabitur exsors/Presertim reges quia non cessere repente/De (reditu) vetito, nam sompnis visio facta est./Quid? Quod muneribus erat aptus suscipiendis/Atque recondendis, an sola relicta videtur/Mater cum puero, quando vaga fama per urbem/Insonuit totam reges venisse potentes/In dromedariis cum pulchro et divite cultu. 


\section{Tyrannicide et herméneutique biblique}

D'autres lieux de la Josephina permettent d'illustrer, pour finir, les enjeux politiques des présupposés herméneutiques de Gerson. En guise d'épilogue à l'épisode du massacre des Innocents traité dans la dixième distinctio, le poète affirme que s'il est juste de tuer des tyrans sanguinaires, cela incombe seulement Dieu ou ses ministres (ministris) $^{31}$. L'allusion à l'actualité politique ne saurait pas nous échapper. Rappelons que le 23 novembre 1407, Louis d'Orléans, frère du roi Charles VI, est assassiné sur l'ordre de Jean sans Peur, duc de Bourgogne, son rival pour la régence. En mars de l'année suivante, Jean Petit, avocat à la solde de Jean sans Peur, prononce à Paris l'apologie du meurtre de Louis d'Orléans, connue comme la Justification du duc de Bourgogne. Le duc est ensuite acquitté, alors que la guerre civile ne tardera pas à éclater. Gerson réagit à maintes reprises contre la doctrine de Jean Petit à maintes reprises entre 1408 et $1413^{32}$. Après une première condamnation, éphémère, de la Justification du duc de Bourgogne en 1414, l'affaire Jean Petit occupa Gerson - en vain - pendant une bonne partie de son séjour à Constance.

Dans sa justification du tyrannicide, l'avocat de la cause bourguignonne soulève la question de l'interprétation du texte biblique, notamment le sixième commandement du Décalogue, «Tu ne tueras point». La Justification soutient que lorsqu'un sujet du roi porte atteinte ou complote contre sa personne, il est licite de le faire tuer comme un tyran traître et infidèle ${ }^{33}$. Jean Petit prétend ainsi que l'homicide compte comme «tyrannicide licite» lorsqu'il s'agit de protéger le roi d'un vassal qui complote sa destruction - c'est-à-dire, d'un vassal qui s'auto-condamne comme «tyran» selon la définition de Petit ${ }^{34}$.

Cherchant à dissoudre le conflit entre la thèse du tyrannicide et les lois $d u$ Décalogue, les défenseurs de Jean Petit à Constance prônaient une distinction herméneutique au sein du sens littéral entre une grammaire «basse», dont il fallait se méfier car subjective et trop attachée à la lettre, et une grammaire «haute», qui correspond à l'intention objective de l'auteur, le Saint-Esprit ${ }^{35}$. Gerson trouvait que ce

\footnotetext{
31 Josephina, dist. X, v. 2504-2507 : Cuilibet est ; si fas sevos jugulare tirannos/Cur sceleratus, cur truculentus vivit Herodes ?/Sed non fas; tibi vindictam, Deus alme, reservas./Solis quos statuis est exercenda ministris.

32 Voir par exemple Gerson, Veniat pax, éd. Glorieux, 7.2.1100 -1123 ; Id., Rex in sempiternum vive !, éd. Glorieux, 7.2.1005-1030.

33 Jean Petit, Justificatio ducis Burgundiae, tertia veritas, in : E. Du Pin (éd.), Ioannis Gersonii Doctoris Theologi et Cancellarii Parisiensis Opera Omnia, vol. 5, Anvers, 1706, col. 15-42, ici col. 27. 34 Jean Petit, Justificatio Ducis Burgundiae, col. 24.

35 Jean Petit, Justificatio ducis Burgundiae, col. 28-30 : in omni lege sunt duo. Primum, est sententia textualis. Aliud, est finis propter quem facta fuit lex, quem finem, conditores legis intendebant principaliter. Et quando accidit quod sententia textualis est contraria fini, debet epikë̈are lex ad intentionem finis, et non ad sensum litteralem. À ce sujet, on consultera Froehlich (1977) 20-48; Coville (1932).
} 
dédoublement du sens littéral était indésirable, car il pouvait semer la confusion et affaiblir l'autorité et du texte biblique et des arguments théologiques qui en dérivent. Selon le chancelier, il n'y a qu'un sensus litteralis, critère ultime d'interprétation biblique, qui résulte de l'intention de l'auteur des Écritures et que seule l'Église est en mesure de circonscrire contre l'arbitraire individuel ${ }^{36}$. Gerson s'inspire ici des règles herméneutiques du De doctrina christiana d'Augustin, en particulier la distinction entre la lettre du texte (la signification sémantique), et l'intention de l'auteur cachée derrière les mots dont il se sert (la signification dianoétique). Selon Augustin, l'interprète qui assujettit son regard à la lettre fait une lecture selon la chair (carnalis, corporalis), contrairement à l'ordre naturel qui prescrit la subordination du corps à l'esprit. Celui-ci se sert des réalités matérielles pour les dépasser vers une signification supérieure ${ }^{37}$.

Toujours est-il que, suivant un trait caractéristique de l'exégèse tardo-mediéva$1 \mathrm{e}^{38}$, Gerson développe une distinction entre la lettre et le sens littéral de la Bible, articulée en termes d'une opposition entre le sensus litteralis, l'intention de l'auteur, et le sensus logicalis, le sens grammatical du texte. Il importait donc d'élucider cet éclatement apparent du sens littéral sans conforter les principes herméneutiques de Jean Petit, en particulier son instrumentalisation de II Cor. 3, 6 : littera enim occidit, pour relativiser la normativité de la sixième loi du Décalogue, «Tu ne tueras point» ${ }^{39}$. C'est la notion buridanienne d'une «double logique ${ }^{40}$ qui permettra à Gerson de sortir de l'écueil : la lettre biblique n'est pas soumise aux critères de la logique spéculative, mais suit plutôt les règles de la rhétorique, plus adaptée au langage figuré des Écritures et sensible au contexte dans l'explication de la signification des mots. Car «l’Écriture sacrée dans sa qualité de science morale et historique (histo-

36 Gerson, De sensu litterali sacrae Scripturae, éd. Glorieux, 3.335 : Tertia [propositio] : sensus Scripturae litteralis iudicandus est prout Ecclesia, Spiritu sancto inspirata et gubernata, determinavit et non ad cuiuslibet arbitrium et interpretationem.

37 Augustin, De doctrina christiana I.36.41 ; III.10.15 ; Id., De Gen. ad litt., I.2.5 ; Id., De util. cred. 3.5. À ce sujet, Eden (1990) 45-63.

38 Voir Froehlich (1977) 46-47.

39 L'adage Semper tenere litteralem sensum in sacra scriptura est occidere animam suam est une paraphrase du caveat qu'Augustin énonce dans le De doctrina christiana, III.5.9. Pour l'emploi du verset paulinien par Jean Petit, voir Justificatio ducis Burgundiae, col. 29-30 ; voir aussi Chartularium Universitatis Parisiensis, IV, 278, n. 2011, Octava assercio ; Gerson, Errores circa praeceptum : Non occides, éd. Glorieux, 10.273-274 ; Id., Réponse à la consultation des maîtres (Constance, 4 décembre 1415), éd. Glorieux, 10.233. Au sujet des diverses interprétations du passage paulinien, voir Froehlich (1977), 28-29 ; Dahan (2009) 237-262, surtout 258-260.

40 Voir Jean Buridan, Questiones in rhetoricam Aristotelis, I.2 ; Id., Quaestiones super decem libros Ethicorum, Paris, 1513 (réimpr. Frankfurt a.M., 1968), f. 2a-b. Buridan s'inspire d'Aristote, Ethique à Niomaque, I, ch. 1, 1094b 11. Voir aussi Gerson, lettre Jucundum est aux Messieurs de Navarre (1400), éd. Glorieux, 2.32 ; Id., De duplici logica, éd. Glorieux, 3.57-63. Sur l'origine buridanienne de la conception de la rhétorique comme une logique propre aux «sciences morales», voir Kaluza (1994) 197-258, en part. $233-238$. 
rialis, narrative) possède sa propre logique, qu'on appelle la rhétorique ${ }^{41} »$. La rhétorique est donc pour ainsi dire la façon dont Dieu nous parle dans la Bible, qu'il faut distinguer de la surface grammaticale du texte. Elle suit ses propres critères d'interprétation, qui relèvent davantage de l'intellect pratique ou affectif que de l'intellect spéculatif. Dans cette optique, le sens littéral induit en erreur seulement lorsqu'il est l'objet d'une interprétation suivant des critères de vérité issus de la logique spéculative. En tant que science morale, l'Écriture condescend à l'usage commun de la langue et se sert de figures et de tropes afin d'attiser l'affect des auditeurs.

Comme le signale à juste titre Zach Flanagin ${ }^{42}$, la distinction entre la lettre (gouvernée par la logique spéculative) et le sens littéral (obéissant aux règles de la rhétorique) introduite par Gerson vise moins à établir un double référent historique qu'à promouvoir l'idée selon laquelle la Bible est un texte mystique qui cèle une vérité spirituelle. À ce sujet, Gerson récupère et adapte une vieille tradition victori$\mathrm{ne}^{43}$, selon laquelle la surface grammaticale du texte biblique sert de porte d'entrée à une réalité supérieure ${ }^{44}$. S'il conçoit la Bible comme un texte mystique dont la lecture entend nous ramener à Dieu, cette signification supérieure du texte biblique, contrairement aux victorins, ne correspond pas au sens spirituel. On l'a vu, l'herméneutique biblique de Gerson nuance la distinction entre l'esprit et la lettre pour accueillir deux niveaux de littera : le scriptum et l'intention de l'auteur. La signification supérieure du texte biblique est donc plutôt considérée comme faisant partie du sens littéral de la Bible. Afin d'articuler cette double signification du sens littéral, Gerson recourt à la distinction psychologique des facultés de l'âme entre volonté et intellect. Ainsi, l'Esprit peut communiquer par moyen de la signification première des mots (termini) dans le but d'éveiller l'affect et de susciter l'action. Il nous parle ainsi lorsqu'il s'agit du contenu moral ou historique des Écritures. Ici, la signification première de la lettre suffit pour nous transmettre l'intention de l'auteur. À un second niveau, la signification littérale entend stimuler notre intellect vers des réalités supérieures. Tout comme le premier se sert des mots pour inciter l'affect, ce second niveau utilise des choses (res) qui représentent à leur tour d'autres réalités. Il s'agit ici du sens littéral, par opposition au sens grammatical de la lettre. C'est seulement à ce deuxième niveau «intellectif» que l'on peut dire à juste titre que «la lettre tue» ${ }^{45}$.

41 Gerson, De sensu litterali s. Script., prop. 2, éd. Glorieux, 3.334 : Sensus litteralis sacrae Scripturae accipiendus non est secundum vim logicae seu dialecticae, sed potius iuxta locutiones in rhetoricis sermonibus usitatas, et iuxta topos et figuratas locutiones quas communis usus committit, cum consideratione circumstantiarum litterae ex praecedentibus et posterius appositis. Habet enim Scriptura sacra, sicut et moralis et historialis scientia, suam logicam propriam, quam rhetoricam appellamus. 42 Flanagin (2006) 133-177, surtout p. 154-159.

43 Voir Hugues de Saint-Victor, Didascalicon, c. 3, éd. Buttimer, Washington, 1939, 116.

44 Hugues de Saint-Victor, De scripturis et scriptoribus sacris, 14 (PL 175), col. 20 - 21.

45 Gerson, Réponse à la consultation des maîtres, éd. Glorieux, 10.239-240 ; Id., De examinatione doctrinarum, éd. Glorieux, 9.463 : Unde generaliter in parabolicis locutionibus sensus litteralis est, non qui per verba, sed per res et facta designatur, ut de lignis constituentibus sibi regem [Jg. 9.8], etc. 
Et qu'une considération des circonstances de la lettre et des figures rhétoriques peut s'avérer féconde pour l'intellect qui cherche une connaissance spirituelle. La Josephina combine à son tour ces deux niveaux de signification littérale : l'histoire de Joseph et Marie doit être lue dans un sens à la fois littéralement prescriptif (leurs mœurs et leur piété sont à imiter), et comme conduisant à une réalité supérieure (leur mariage virginal symbolise l'union mystique de l'âme à Dieu).

\section{Conclusion}

Les considérations herméneutiques de Gerson reflètent la limite très floue entre sens littéral et sens spirituel qui caractérise l'exégèse Moyen Âge tardif, dans la mesure où la pluralité des sens spirituels semble être absorbée par le «vrai» sens littéral, désigné par l'intention de l'auteur divin ${ }^{46}$. La chose se complique davantage avec les enjeux propres au schisme. Car Gerson admet un troisième niveau interprétatif, celui de la tradition extratextuelle transmise par la succession apostolique, incluant les écrits des Pères et des docteurs de l’Église. Lorsque le chancelier fait référence à la «tradition» comme norme interprétative, c'est surtout pour souligner l'importance de se tenir à un certain stylus theologicus, dans le sens de la manière courante de parler (usus loquendi) des docteurs et des anciens interprètes des Écritures ${ }^{47}$. Ici, le clivage herméneutique entre la lettre et l'esprit obtient en termes de «sens théologique littéral» (sensus theologicus litteralis), par opposition au «sens logique» grammatical (sensus logicalis). Selon Gerson, le sens théologique littéral est le vrai sens de la Bible, qui correspond à l'interprétation transmise par l'Église depuis ses origines apostoliques et à travers certaines révélations ${ }^{48}$. Dans cette optique, la Josephina serait un exemple emblématique de la mise en application des principes herméneutiques de Gerson : un récit gouverné par une interprétation «théologique littérale» des implicites bibliques, là où le théologien-poète limite son intervention à une explicitation doctrinale, guidée par la rhétorique, de ce qu'il estime être l'intention de l'auteur divin.

46 À ce sujet, voir Froehlich (1977), 45 - 46, qui souligne l'importance donnée au sens littéral comme un trait saillant de l'exégèse de la fin du Moyen Âge ; voir aussi Smalley (1952) 69 ; Dahan (2009) 237262 ; Dahan (2014) 115-142, surtout 128-129.

47 Gerson, Réponse à la consultation des maîtres, éd. Glorieux, 10.241. À ce sujet, voir Burrows (1991) 88-125 ; Iribarren (2017) 183-221.

48 Voir Gerson, De sensu litterali Sacrae Scripturae, sexta prop., éd. Glorieux, 3.335 ; Id., Declaratio compendiosa, 6.182 ; Id., De necessaria communione laicorum sub utraque specie, regula 9, éd. Glorieux, 10.58 . 


\section{Bibliographie}

Bataillon (1982): Louis J. Bataillon, «Intermédiaires entre les traités de morale pratique et les sermons: les distinctiones bibliques alphabétiques», in: Les genres littéraires dans les sources théologiques et philosophiques médiévales, Louvain, 213-226.

Bataillon (1993): Louis J. Bataillon, La prédication au XIIIe siècle en France et en Italie, Aldershot.

Bériou (1998): Nicole Bériou, L'avènement des maîtres de la parole. La prédication à Paris au XIII' siècle, 2 vols, Paris.

Briscoe - Jaye (1992): Marianne G. Briscoe et Barbara H. Jaye, Artes praedicandi and Artes orandi, Turnhout.

Burrows (1991): Mark Burrows, Jean Gerson and De Consolatione Theologiae (1418). The Consolation of a Biblical and Reforming Theology for a Disordered Age, Tübingen.

Charland (1936): Thomas-Marie Charland, Artes Praedicandi. Contribution à l'histoire de la rhétorique au Moyen Âge, Paris-Ottawa.

Chenu (1964): Marie-Dominique Chenu, "La décadence de l'allégorisation. Un témoin: Garnier de Rochefort (v. 1200)», in: L'homme devant Dieu. Mélanges offerts au P. Henri de Lubac, t. II, Paris.

Combes (1964): André Combes, La théologie mystique de Gerson. Profil de son évolution, 2, Rome.

Coville (1932): Alfred Coville, Jean Petit: La question du tyrannicide au commencement $d u X V^{e}$ siècle, Paris.

Dahan (1980): Gilbert Dahan (éd.), «Notes et textes sur la Poétique au Moyen Âge», in: Archives d'histoire doctrinale et littéraire du Moyen Âge, 47, p. 171-247.

Dahan (1999): Gilbert Dahan, L'Exégèse chrétienne de la Bible en Occident médiéval, XII ${ }^{e}$-XIV siècle, Paris.

Dahan (2009): Gilbert Dahan, «Le sens littéral dans l'exégèse chrétienne de la Bible au Moyen Âge», in: 0.-Th. Venard (dir.), Le sens littéral des Écritures, Paris, 237-262.

Dahan (2014): Gilbert Dahan, «Herméneutique et procédures de l'exégèse monastique ", in: G. Dahan et A. Noblesse-Rocher (dir.), L'exégèse monastique au Moyen Âge (Xle-XIV siècle), Paris, 115-142.

D'Avray (1985): David D'Avray, The Preaching of the Friars. Sermons diffused from Paris before 1300. Oxford.

Di Stefano (1971): G. Di Stefano, «II Trecento », in: C. Pellegrini (dir.), Il Boccaccio nella cultura francese, Atti del Convegno di studi "L'opera del Boccaccio nella cultura francese ", Certaldo 2-6 settembre 1968, Florence, 1- 47.

Dordoni (1996): Annarosa Dordoni, «Per la storia della devozione a san Giuseppe: indicazioni di metodo e linee di ricerca», in: Annali di Scienze Religiose 1, 321-342.

Du Pin (1706): Ellies Du Pin (éd.), Ioannis Gersonii Doctoris Theologi et Cancellarii Parisiensis Opera Omnia, Anvers.

Eden (1990): Kathy Eden, «The Rhetorical Tradition and Augustinian Hermeneutics in De doctrina Christiana», in: Rhetorica, 8/1, 45-63.

Fabre (2006): F. Fabre, «Pétrarque poète chrétien ? La critique de l'Africa par Jean Gerson», in: E. Duperray (dir.), La postérité répond à Pétrarque. Sept siècles de fortune pétrarquienne en France., Paris, 111-125.

Fabre (2005): Isabelle Fabre (éd.), La doctrine du chant du cœur de Jean Gerson. Édition critique, traduction et commentaire du "Tractatus de canticis » et du "Canticordum au pèlerin », Genève.

Fabre (2011): Isabelle Fabre, «Un hault chant de unisson en souveraine silence: étapes et contours de l'ascension mystique dans le Canticordum au Pelerin de Jean Gerson (1363-1429)», in: S. 
Triaire et P. Victorin (dir.), Deviser, diviser. Pratiques du découpage et poétiques du chapitre de l'Antiquité à nos jours, Montpellier, 79-107.

Flanagin (2006): Zach Flanagin, «Making sense of it all: Gerson's biblical theology», in: Brian P. McGuire (dir.), A Companion to Jean Gerson, Leiden-Boston, 133-177.

Froehlich (1977): Karlfield Froehlich, «»Always to Keep the Literal Sense in Holy Scripture Means to Kill One's Soul«: The State of Biblical Hermeneutics at the Beginning of the Fifteenth Century ", in: Earl Miner (dir.), Literary Uses of Typology, from the Late Middle Ages to the Present, Princeton, $20-48$.

Glorieux (1962-1973): Palémon Glorieux (éd.), Jean Gerson. Oeuvres complètes, Paris-Tournai. Hamesse (1974): Jaqueline Hamesse (éd.), Les «Auctoritates Aristotelis»: Un florilège médiéval, Louvain.

Hasenohr (1978): Geneviève Hasenohr, «Un recueil de distinctiones bilingue au début du XIV $s$ », in: Romania 99, 46-96 et 183-206.

Hobbins (2009): Daniel Hobbins, Authorship and Publicity before Print. Jean Gerson and the Transformation of Late Medieval Learning, Pennsylvania.

Iribarren (2017a): Isabel Iribarren, «Réception et fonctions des récits apocryphes dans la Josephina de Jean Gerson», in: Apocrypha 28, p. 187-229.

Iribarren (2017b): Isabel Iribarren, «Question de style. Langage et méthode comme enjeux rhétoriques dans l'œuvre de Gerson», in: U. Zahnd (dir.), Langage et méthode. Réflexions historiques et historiographiques sur la pensée médiévale, Freiburg-Bg, 183-221.

Iribarren -Roccati (2019): Isabel Iribarren (trad., introd., notes et commentaire) et G. Matteo Roccati (édition critique), Josephina. L'épopée de saint Joseph, Paris.

Kaluza (1994): Zenon Kaluza, «Les sciences et leurs langages. Note sur le statut du 29 décembre 1340 et le prétendu statut perdu contre Ockham », in: L. Bianchi (dir.), Filosofia e teologia nel trecento, Louvain-la-Neuve, 1994, 197-258.

Landgraf (1973): Artur M. Landgraf, Introduction à l'histoire de la littérature théologique de la scolastique naissante, éd. française de A.-M. Landry, Montréal-Paris.

Lieberman (1955): Max Lierberman, «Chronologie gersonienne. IV: Gerson poète», in: Romania 76, $289-333$.

Longère (1983): Jean Longère, La prédication médiévale. Paris.

Marmo (1990): Costantino Marmo, "Suspicio, a Key Word to the Significance of Aristotle's Rhetoric in XIIIth Century Scholasticism », in: Cahiers de l'Institut du moyen âge grec et latin 60, 145-198.

Ouy (1962): Gilbert Ouy, « La plus ancienne œuvre retrouvée de Jean Gerson: le brouillon inachevé d’un traité contre Juan de Monzón (1389-1390)», in: Romania 83, 433-492.

Parkes (1976): Malcom B. Parkes, «The Influence of the Concepts of Ordinatio and Compilatio on the Delopment of the Book», in: J. J. G. Alexander et M. T. Gibson (dir.), Medieval Learning and Literature, Essays presented to Richard William Hunt, Oxford, 115-141.

Robert (2012): Aurelien Robert, "L'idée de logique morale aux XIII et XIV siècles», in: I. Costa, A. Robert et N. Bouloux (dir.), Philosophies morales. L'éthique à la croisée des savoirs (XIIle-XIVe siècles), Médiévales 63, 27-45.

Roccati (1980): G. Matteo Roccati (éd.), J. Gerson, Oeuvre poétique latine, thèse de troisième cycle, Paris, EHESS.

Roccati (1982): G. Matteo Roccati, «Gerson e il problema dell'espressione poetica: note su alcuni temi e immagini ricorrenti nelle poesie latine», in: Studi francesi 77, 278-285.

Roccati (2001): G. Matteo Roccati (éd.), Jean Gerson. Josephina, Paris, LAMOP (CD-ROM).

Rouse (1974): Richard H. et Marie A. Rouse, "Biblical Distinctions in the XIIlth century», in: Archives d'histoire doctrinale et littéraire du Moyen Âge 41, 27-37.

Seitz (1908): Joseph Seitz, Die Verehrung des hl. Joseph in ihrer geschichtlichen Entwicklung bis zum Konzil von Trient dargestellt, Freiburg. 
Smalley (1952): Beryl Smalley, The Bible in the Middle Ages, Oxford.

Ward (1995): John O. Ward, Ciceronian Rhetoric in Treatise, Scholia and Commentary, Turnhout. Ward (2006): John O. Ward, «The Medieval and Early Renaissance Study of Cicero's De inventione and the Rhetorica ad Herennium. Commentaries and Contexts", in: V. Cox et J. O. Ward (dir.), The Rhetoric of Cicero in Its Medieval and Renaissance Commentary, Leiden, 3-75.

Weijers (1991): Olga Weijers, Dictionnaires et répertoires au Moyen Âge. Une étude de vocabulaire, Turnhout.

Wilmart (1940): André Wilmart, «Un répertoire d’exégèse composé en Angleterre vers le début du XIII ${ }^{\text {e }}$ siècle», in: Mémorial Lagrange, Paris, 307-346.

Witt (1977): Ronald Witt, "Coluccio Salutati and the Conception of the Poeta Theologus in the Fourteenth Century», in: Renaissance Quarterly 30, 538-563.

Zink (2003): Michel Zink, Poésie et conversion au Moyen Âge, Paris. 



\title{
Abstracts
}

\section{Part I: The Greek-Latin Biblical Epic in Late Antiquity}

\author{
M. Roberts (Middletown), Narrative and Exegesis in Sedulius' Carmen paschale
}

In an important monograph from 2011 David Deerberg distinguishes Sedulius' poetic practice from that of his predecessor Juvencus: while the amplifications of the earlier poet operate at the horizontal level of the narrative, and are largely extrapolations on the biblical text, Sedulius introduces elements, "vertical” in Deerberg's terminology, primarily exegetical in nature, that disrupt the narrative continuity. In my paper I propose a different, complementary approach to Sedulius' text, laying the emphasis on the distinction between narrator and instructor. Building on a passage from Cicero's De oratore on historical narrative (2.15.62-63), I argue that exegesis is consistent with, and even necessary to, narrative. In my analysis of some passages from the Carmen paschale $(2.94-96,4.222-25,4.255-57,5.70-72,5.77-78,5.165-69,5.177-81)$ I show that Sedulius' introduction of exegetical detail regularly conforms to Cicero's understanding of the historical narrative, which is expected to discuss causes, purposes, and motives for actions and events and the reasons for their outcomes. The Opus paschale provides a useful point of comparison in that it adopts the role of instructor rather than narrator, and with it characteristic lexical and syntactic markers, more often than the Carmen. Non-narrative exegesis is rare in the body of the Carmen outside the passage on the Lord's Prayer, though there are certainly cases where the roles of narrator and teacher are hard to distinguish (e.g., 2.168-71).

\section{Cutino (Strasbourg), Fictions poétiques et vérités bibliques dans les paraphrases vétéro et néotestamentaires en vers. Questions méthodologiques}

In this article we show how the theme of pagan literary on which we notice the most important programmatic affirmations about the legitimacy of inserting poetic fictions into the paraphrases of Ancient and New Testament, is the humanity's prehistory, like the initial condition and the decadence or subsequent progress. It is a theme that necessarily intersects the biblical narrative of man's loss of the Edenic condition because of original sin with that of the progressive degradation of humanity, and for this reason it is inserted by some poets into the biblical truth. Indeed, the poets find in this theme, so to speak, a "neutral" space to legitimately use the fictions of classical literature as examples of this dimension of fall and decadence, and to discuss the great questions of the history of humanity, those of progress or corruption of humanity, as Victorius most probably does in relation to the didactic, even scholastic destination of his Alethia, or to transmit theological considerations through understandable forms to a cultivated audience, uncomfortable with biblical exegesis, as the author of Laus lohannis does.

These elements pose the fascinating problem of the context in which these compositions fit. It is interesting, in this regard, to note that the Alethia and the Laus were transmitted to us by the same manuscript, the Parisinus Latinus 7558 of the Carolingian period, alongside other compositions, such as the correspondence in verse between Ausone and Paulin of Nole, the poem that Paulin of Nole still addressed to Jovius inviting him to no longer dedicate himself to profane poetry, but to devote himself to a true Christian poetry, and a small poem called Epigramma Paulini: these are compositions all interested in the relationship between literature and in general clas- 
sical culture and Christian novelty, which testifies to a learned - and ideologically oriented choice on the part of the one who made this collection, a choice that deserves to be carefully studied.

\section{Nicole Hecquet-Noti (Genève), L’auteur et son public. Les différentes lectures de l'épopée biblique selon Avit de Vienne}

In the two prologues of his poem De spiritalis historiae gestis, Avitus of Vienne defines, as the target audience of his epic, his peers, the Christian literati of the Gallo-Roman aristocracy. He also specifies that his poem serves a double purpose: to transmit Christian teaching and to display its author's rhetorical mastery of the epic genre. He thus proceeds by inserting moral exegetical comments into the various sections of his epic narrative, as has already been well appreciated. Our study focuses on the epic narrative itself to show how these two goals are constantly pursued. In the 5 books of the poem, we find two remarkable "mirror descriptions": the description of the Garden of Eden (1.188-298) and that of the Flood (4.425-540). These ekphraseis should be understood as a rhetorical amplification of the corresponding passages of Genesis (2,8-15 and 7,17-24); they also take as a model the epic descriptions of the locus amoenus and the storm. In the depiction of the Garden of Eden, Avitus firstly continues the tradition of the descriptions of exotic mirabilia, by the evocation of the Phoenix - a passage that combines allusions to Ovid (Met. 15,392-407) and Statius (Silv. 3,2) -, and then he dialogues with the poetics of Claudian (Carm.min. 33-39) and the Anthologia Latina (519-530), in shaping a short comparison between the beauty of the heavenly spring and crystal. At the same time, this description, like that of the flood, maps the new geography of the Christian world. It conveys a vision of the world that corresponds to the one we know from the cosmographies of this period, especially the Topographia Christiana (4.7) of Cosmas Indicopleustes and the Latin Expositio totius mundi et gentium.

\section{S. Labarre (Le Mans), La réécriture des récits bibliques de guérison chez les poètes latins du $\mathrm{IV}^{\mathrm{e}}$ au $\mathrm{Vi}^{\mathrm{e}}$ siècle}

Latin Christian poetry of the IV-VI centuries draws largely its inspiration from the Bible. The miracles of healing effected by Christ or the Apostles have given rise to various rewritings, in order to defend the faith, to train the believers, or to make known the main orientations of the exegetical discourse. We have identified the different genres that produced them: biblical epics (Juvencus, Sedulius, Dracontius, Arator), didactic or apologetic poetry (Prudentius, Commodianus), hymns or epigrams (Prudentius, Rusticus Helpidius). But while poets sometimes introduce a form of theological commentary, they hardly take part in theologians' debates. They most often practice an allegorical exegesis and their main intention is to prove that the power of Christ is more than human. They use the expressive resources of poetry to make this divine nature visible, whether by epic dramatization, hymnic stylization, or conciseness of tituli (e. g. Miracula Christi). 


\section{Furbetta (Roma), Avit de Vienne et Dracontius en rapport. 'Chanter' et 'expliquer' la Bible entre formation scolaire et création poétique}

In this paper we will try to present some reflections on the De spiritalis historiae gestis composed by Avitus of Vienne and on De laudibus Dei written by Dracontius, in order to analyze the poetic treatment of the same passages of the biblical narrative starting from the rhetorical strategies and processes, that the two poets set up in the structuring of narrative tableaux. Through the study of the loci similes and a deep analysis of Alc.Av. carm. 1.24-29 and carm. 3.213-278 (these verses in particular compared with Drac. laud. 3.49-80) we will try to question the possibility of a 'relationship' between the two poems.

\section{Br. Bureau (Lyon), L'autorité apostolique à travers les discours de l'Historia Apostolica d'Arator}

In his Historia Apostolica, Arator intends to give a commented poetic version of the Acts, but, for a modern reader, the poem is more a rewriting of the biblical text than an actual commentary. In this paper, we will discuss the way of rewriting the speeches of the two main characters Peter and Paul. Arator considerably changes the content of the speeches in order to 1-give an epic tone to the words of the apostles, 2-get rid of every detail that is not suitable for his purpose, 3-insert elements that could be of major interest for his 6th century Roman audience. Through quotations from the letters of Peter and Paul and insertions of elements coming from the Patristic tradition, the poet rebuild "his" apostles according to what he considers as the most important part of the apostolic message for his own time.

\section{F.E. Consolino (L'Aquila), Severus (of Malaga?) and narrative construction. The healing of Bartimaeus (VIII.119-153)}

This enquiry focuses on the way Severus constructs his account of a miracle that appears in two of the Synoptic Gospels, and that is also treated by Sedulius, namely the healing of the blind man Bartimaeus (8.119-153-see the commentary on this section in Bischoff 1994, 82-86- , which is described in the Gospels of Mark (10.46-52) and Luke (18.35-43), and by Sedulius in carm. Pasch. 4, 210-221. This comparison between Severus and Sedulius is supplemented with a brief analysis of the same authors' accounts (Severus 9, 163-186 and Sedulius 4.251-270) of the part strictly related to the miraculous healing of the man born blind recounted in $\mathrm{Jn} 9$. These two comparisons with Sedulius's treatments of the same episodes throw Severus's scarce propensity for reshaping the Gospel narrative for the purposes of theological or exegetic interpretation into sharp relief. All the same, in the course of his verse, Severus does not exempt himself entirely from providing explanations that he clearly believes will interest his readers. Paradoxically, the very admission of few exegetic excursus, on the part of Severus, reluctant as he is to stray too far in his poem from the letter of the Gospels, helps us to appreciate how, with Sedulius, exegesis had become a distinctive and inescapable trait of the Bibelepik. 


\section{R. Lestrade (Strasbourg), Usage des sources poétiques classiques et perspectives " théologiques » dans l'Heptateuchos de Cyprien le Gaulois ( $V^{\mathrm{e}} \mathbf{s}$.)}

The study, through a range of examples, of the reception of classical poetic sources in the Old Testament paraphrase known as the Heptateuchos shows a delicate craftsmanship which can be analyzed, as far as textual strategies are concerned, into four categories: epic amplification, moral characterization, pathetic emphasis, and mythical-epic analogies. Within a Christian reading of the Law, this layer of neoclassical ornamentation implies and enhances attitudes that draw from both psychological and theological motives: a divine and cosmic anthropomorphism, a valuation of the phenomenal world, and a valuation of pity. Last, a comparison is hinted between the Heptateuch Poet's stance toward biblical hermeneutics and Varro's 'three theologies' theory as attacked by Augustine in book 6 of the The City of God.

\section{De Gianni (Wuppertal), Four Variations on the Theme. "The Withered Fig Tree" (Mc 11.12-14; 20-25; Mt 21.18-22) in Juvencus, Sedulius, Avitus of Vienne and Severus of Malaga(?)}

This paper proposes a comparative analysis of the hexametrical rewritings of the evangelical account of Jesus cursing the fig tree (Matthew 21.18-22; Mark 11.12-14; 20-25) by Juvencus, Sedulius, Avitus of Vienne and Severus of Malaga (?). The comparison between the four pieces allows us to evaluate the different narrative strategies adopted by these authors, as well as the paraphrastic techinques and their "consonances" with previous classical poetry. The gap between the literal paraphrase by Juvencus, who rewrote the biblical text with few changes, and the work by Severus of Malaga (?), who was attentive to the exegetical and theological implications present in the hypotext, suggests reflections on the evolution of the literary genre of the poetic rewriting of the Bible. The different approaches to the biblical text by these authors reflect their cultural backgrounds and the instances of their audience. If the purpose of Juvencus is to spread the gospel in an acceptable poetic form, then the succeeding poets are motivated by exegetical intents, understandable in light of the theological and doctrinal debate, which is progressively growing in the Latin West.

\section{F. Doroszewski (Warsaw), Dieu rejeté, Dieu triomphant. Réception des Bacchantes d'Euripide dans la Paraphrase de l'évangile de Saint Jean de Nonnos de Panopolis}

The Bacchae of Euripides exercised an enormous impact on ancient literature. Christian literature was no exception, especially in the Alexandrian milieu where Philo had already introduced the Dionysian motifs into biblical exegesis. It was there that, starting at least with Clement of Alexandria, the Bacchae was reinterpreted to express Christian beliefs. The Paraphrase of Saint John's Gospel written by Nonnus of Panopolis, a poet influenced by the Alexandrian intellectual circles, follows this exegetical tradition. Nonnus was well familiar with the Bacchae which is confirmed by the three books of Pentheid comprised of Dionysiaca 44-46, his other epic, as well as by numerous references to the play in the Paraphrase. The present paper demonstrates how the narrative of the Bacchae serves Nonnus as an important intertext in paraphrasing the episodes of the Mar- 
riage of Cana (Book 2), of the Feast of Tabernacles (Book 7), and of Jesus' meeting with Martha and Mary in Bethania (Book 11). More specifically, the paper focuses on the symbolic role played by wine, the motif of sadness turning into ecstatic joy, and the opposition between the true and false wisdom.

\section{A. Rotondo (Catania), Salut et prophéties messianiques dans le septième chant de la Paraphrase de Nonnos de Panopolis}

In the seventh chapter of the Paraphrase of St. John's Gospel, Nonnus of Panopolis deals with the theme of disbelief through the controversy between Christ and the group of Jews/Pharisees about the interpretation of the messianic promises in the Scriptures and about Christ's messianity. The cause of the dispute, according to Nonnus, is the anger, aroused by envy, of Jews. Therefore, the poet represents the opposition through emotions (for example, anger). He uses emotions as markers to polarize non-believers and believers. All his exegetic work is founded on such polarization. Nonnus interprets Jn 7 emphasizing the dichometis, 'discord', as an outcome of the human ignorance in the face of divine wisdom. The Scriptures constantly reveal divine wisdom, but arrogance prevents human beings from recognizing it. The ground for challenge is the Book/Law with its prophecies about the Messianic advent.

\section{S. Costanza (Messina), Voices, Hearing and Acoustic Epipahny in Nonnus' Paraphrase of St. John's Gospel}

In his Paraphrase of St John's Gospel, Nonnus of Panopolis focuses on the appearance of the Lord as a perennial theophany, which also deals with acoustic signs revealing his divine presence. In the Graeco-Roman world, the spoken word corresponds to a fatal voice as kledon. According to a longdating tradition, Nonnus' epiphany reports remark auditory signs of Christ revelation as Messiah, whose word is defined as Life-giving, as in 10.133 or releasing grief, as in 5.37. Miracles of Jesus are also enacted through his consoling Word. The voice of John, the true witness, is also prophetic. Under a key theological perspective, the Word of Christ shows God's nearness. Finally, Nonnus gives emphasis on auditory revelation as a privileged way to gain access to the divine. At this respect, he follows Greek epic tradition as well as mystical, gnostic or orphic, poetry.

\section{Part II: Biblical Poetry and Theological Aims in other Poetic Genres between Late Antiquity and the Middle Ages}

\section{G. Agosti (Roma), La poésie biblique grecque en Egypte au IV' siècle. Enjeux littéraires et théologiques}

The paper deals with the early phase of Biblical poetry in the Greek East. The new Christian poems preserved in a papyrus codex from the so-called Bodmer Library (a group of papyri coming from the area of the city of Panopolis, Upper Egypt), has dramatically shown that in Egypt verse 
paraphrases of Biblical books were composed already in the middle of the fourth century. Their author had already attempted to give their answer to the challenge represented by a Christian poetry in classical language and metres. Before the few Biblical poems by Gregory of Nazianzus and the brief season of the fifth century Biblical epic (Nonnos, Eudocia, the Ps-Apollinaris), The Bodmer poet(s) show to be aware of the literary and theological issues involved by the paraphrastic genre. It is questionable whether this is a creative innovation or the author(s) have been inspired by previous examples. The study of the environment where these poems have been composed (where Latin texts are known) could suggest that the author(s) were aware of the Latin experiments. On the other hand, an analysis of Christian metric inscriptions from the first half of the 4th century points out that some aspects of 'biblical poetry' (namely the juxtaposition of Classical and Biblical expressions) were more common than admitted.

\section{Lefteratou (Heidelberg), Deux chemins d'apprentissage. Le didactisme dans les Centon s homériques}

This article explores the didactic character of lines 1-70 of the first edition of the Homeric Centos. The didactic and ekphrastic potential of the story of the Genesis is treated in a twofold way: by the external narrator, who addresses the reader, and by the embedded one, Satan, who addresses Eve. These two narrators offer a contrasting, albeit similar stylistically, description of paradise and of paradisal bliss, though their didactic intentions differ diametrically. The discreet narrator of the introit presents him/herself as a preacher responsible for revealing, but not for forcefully convincing his/her audience. Contrarily, Satan is depicted as the pushy sophist par excellence and his addressee, Eve, as an easy target. This disparity of didactic means and ends invites the reader/audience to ponder on the question of free will when it comes to the revelation of the Christian message.

\section{R. Ricceri (Ghent), Two Metrical Rewritings of the Greek Psalms. Pseudo Apollinaris of Laodicea and Manuel Philes}

This paper aims to provide a preliminary insight into the reception of the Psalms from the point of view of two Greek paraphrases. The first text I take into account is the so-called Metaphrasis Psalmorum, written in dactylic hexametres and dating to the fifth century. This text is anonymous, although traditionally attributed to Apollinaris of Laodicea (IV century). The latter is a rewriting of the Psalms in political verses (decapentasyllables) carried out by a well-known Byzantine poet, Manuel Philes (XIII-XIV century). A comparative analysis of the above-mentioned paraphrases can shed light on the appreciation of the Psalms in two different historical contexts. These two texts, whose investigation still lacks some philological work, share remarkable affinities, as they are both versified rewritings of the same literary source and they are both faithful to the original text. However, some major dissimilarities cannot be overlooked. On the one hand, the hexametric metaphrasis conveys some typical elements of late antique Christian poetry. It contributes to the establishment of a highbrow poetry with Christian content, which can benefit from the use of the Homeric metre and the Homeric language. On the other hand, Manuel Philes' Metaphrasis of the Psalms is situated in Later Byzantium and is grounded in a well-established, thousand-year old tradition of Christian poetry. Moreover, it is connected with the characteristic Byzantine taste for 
(prose) rewritings. The texts resulting from the process of rewriting are profoundly influenced by the cultural role that they perform in their own historical context. The author of the Homeric Psalter strives to reshape the Psalms by means of an unmistakably epic language. Conversely, Manuel Philes is more cautious when dealing with the biblical text. He adopts the political verse as the main poetic mark of his paraphrase and slightly alters the source text, following the path of Byzantine rhetoricians and hagiographers.

\section{Jesús F. Polo (Madrid), Descent and Ascent in the VIIIth Hymn of Synesius of Cirene}

The aim of this paper is to study the $8^{\text {th }}$ Hymn of Synesius of Cyrene. As it is well known, this hymn deals with Jesus' incarnation, descent into Tartarus and ascent to Heaven. Neoplatonism and Chaldean Oracles shape the background of the Hymn. But in its first part, the descent, it is possible to recognize some typical features of the heroic journey to the place of the dead. It is my intention to focus on Jesus journey to Tartarus comparing it with Odysseus journey in Hom. Od. 11 and with the one of Heracles in Bacchylides Victory-ode 5, in order to show how the previous Greek literary tradition could have influenced the first part of this Hymn.

\section{Herrero de Jáuregui (Madrid), Gregory of Nazianzus' Hymn to Parthenie (II.1.2.1-214). Christianizing Greek Theogonies}

Gregory of Nazianzus took classical literary genres as models to imitate, and at the same time, to innovate: in the long proem of his Hymn to Parthenie Gregory clearly follows rhetorical theory about hymns, combining different hymnic types in a single poem; also, since the poem deals with Christian account of creation, he explicitly takes Hesiod's Theogony as model to be surpassed. As in the rest of his poetic work, he manages to raise Christian poetry to the height of classical Greek models, and to explain Christian doctrines in a pleasant and elegant form.

\section{J. Prudhomme (Strasbourg), Les personnages bibliques, héros d'une épopée chrétienne dans la poésie de Grégoire de Nazianze}

The influence of the traditional epic on Gregory of Nazianzus' poetry is formally undeniable but Gregory's heroes are of a new kind, since they are biblical characters, whom he wants to turn into the heroes of a new, Christian epic.

These figures are at the centre of Gregory's biblical works, which resemble the paraphrase genre. How does the encounter between the traditional epic language and the biblical material take place? The analysis of some poems (I.1.16; I.1.20-23) testifies to the flexibility with which Gregory mixes the biblical heritage with the epic language, so that we can speak of "formal syncretism". However, the rewriting is not only ornamental: through the use of stylization, through the choice of active verbal formulas, striking images or personifications, Gregory focuses attention on biblical figures who become heroes performing exceptional feats and successfully fighting against the forces of evil. The Christian dimension of the new heroes is greatly enhanced, so that 
the figure of Jesus replaces the ancient pagan heroes, and the prophets become heralds of Christ. Finally, the poet Gregory himself is affected by this process of epic heroism: in his autobiographical poems (II.1.15; II.1.19), Gregory uses Old Testament figures as models to stage himself as a Christian hero, whose glory consists in defending the Trinity and enduring adversity.

\section{Shanzer (Wien), Grave Matters: Love, Death, Resurrection, and Reception in the De Laudibus Domini}

This paper is best read as a diptych with D.R. Shanzer, "Resurrections before the Resurrection in the Imaginaire of Late Antiquity" forthcoming in The Biblical Annals (Lublin). The point of departure for both articles is the Anonymous Carmen de laudibus Domini's description of a sentimental miracle (situated in Gaul in the territory of the Aedui): the corpse of a dead wife woke up temporarily to welcome her loving husband's body (De Laudibus 7-35). Here it is demonstrated how anomalous details of the description of the burial (rock tomb, wrapped burial) suggest intertextuality with the Lazarus narrative in the Gospel of John mediated through Juvencus (with implications for the date of the Carmen de laudibus). The deceased woman's problematized ability to move her arms echoes an exegetic discussion about Lazarus' locomotion, despite his bound feet. This is to be found in texts such as Ambrose's funeral oration for Satyrus, in Nonnos' Gospel Paraphrase, and Sermon 65 of Petrus Chrysologus. The discourse of being re-ensouled is also explored, from the philosophical to the erotic. Poets (Prudentius and Severus of Malaga) reacted differently to Lazarus' resurrection and the problem (for example) of his possible stench and how to soft-pedal or transform it into poetry. The paper then turns to the nature of the Gallic couple's marriage (white or not?) and the reception of the base Legende behind Gregory of Tours. The relationship between the Carmen de Laudibus, Tertullian's De Anima 51.6-8, is explored with the conclusion that Gregory didn't work from De Laudibus, but from a (now lost) Vorlage or Vorlagen. The paper ends with some attempt to contextualize the double burial and marital continence in epigraphy (with very limited success), but showing that one word (deprehensa Carmen de laudibus 30) teasingly alludes to what does or doesn't go on in the double grave as letto matrimoniale of a Christian couple.

\section{G. Aragione (Strasbourg) - A. Arbo (Strasbourg), Un diner sur l'herbe. Proba et le pouvoir évocateur de la poésie}

The description of the Last Supper proposed by the Christian poet Proba in her Virgilian Cento (v.580 -599) deviates in many respects from the text of the Gospels. This article attempts to show that the reasons for such deviations must be sought above all in the stream of meaning that passes between the hypotext (the Aeneid), and the hypertext (the Cento). Proba did not compose her description with verses borrowed from the entire Virgilian corpus, but privileged specific nuclei of the Aeneid, already used for a previous biblical episode: the fall of Adam and Eve. The Last Supper in Proba's poem appears thus, thanks to the hypotext, as a replica of the story of the transgressive meal of Eve and the serpent in the Garden of Eden and the symbol of Redemption after the Fall. 


\section{Crespo Losada (Madrid), Biblical hypotexts in Prudentius' Contra Symmachum. Case study of C. Symm. II.95-96}

The theology of creation found in the apologetical writings represented by Lactantius enables us to discover that the nature of an eternal god creator is explained by the inspired or revealed news rendered by Scripture in Proverbs 8.22-29. Several passages by Lactantius (Institutiones divinae) show that the procedure of presenting notions specific to the Christian deus verus, revealed by faith, is -even in the context of a dialogue with polytheistic paganism- a discursive device which could also have been employed by Prudentius in his disputation with Symmachus. Generically alluding the deus verus in C. Symm. 1.325-327, as well as stating His eternal, creative nature in $C$. Symm. 2.95-96 can be explained because there is a conscious lexical unspecificity overlaying the specificity of the sola fides, according to which there is no question of an eternal, creator God out of the implicit reality of the Son of the Father, the $a b$ aeterno begotten Word, who, without leaving the bosom of the Father, participates in the creation of the world, as shown by the presence of Proverbs 8.22-29 in the poetry of Prudentius.

\section{P. De Navascués (Madrid), $O$ crucifer bone lucisator (Prudence, cath. 3.1). Doctrine ancienne en termes nouveaux}

The Hymnus ante cibum (Prudentius, Cath. 3), with a refined metric pattern -as used by Ausoniusand containing differents neologisms, was addressed to Prudentius' elite group of Christians. The beginning of the first stanza $-O$ crucifer bone lucisator- leads to the most important issue to us all: the Christological meaning of food. As noted in prior authors (Irenaeus, apocryphal litterature, Maximus, Gregorius Illiberitanus) to Prudentius, Crucifer, the one who bears the cross, should be understood in light of the traditional equivalence: cross-plaugh (crux-aratrum). According to this, since the very beginning of History, Christ, crucifer and lucisator, shows up, as the one and the same sower (sator), who bears the plaugh (crux), nourishing the mankind with food from the land and the Light of the Spirit. Thereby Cato's bonus agricola has become Prudentius' crucifer bonus.

\section{A. Leflaëc (Strasbourg), Figures bibliques et idéal familial de la consécration à Dieu. Le protreptique de l'Ad Cytherium (Carm. 24) de Paulin de Nole}

Around 400 Paulinus of Nola writes a long versified letter (Carmen 24) to his friend Cytherius who has chosen the priestly life for his son. The poet sends him a series of exhortations in order to prepare Cytherius' son as well as possible for the priesthood. Using different characters of the Old Testament, he paints a well-made portrait of the future clergyman which recalls the ideal of the monk-bishop becoming important at this time. Through the Nazirites Samuel and Samson and the figure of Joseph, Paulinus underlines the importance of struggling against the flesh and its seductions. The poet's allegorical interpretation of some Old Testament events invites Cytherius' son to spiritually imitate the deeds of his Biblical predecessors and emphasises that, at a time when persecutions have passed, the future priest's hardships are especially in his mind. The chosen examples also involve complete families and thus give a familial dimension to the theme of consecration to God. Paulinus uses the figures of Abraham and Hannah to underline the faith and the obedience to God of Cytherius and his wife and to show how their piety can be achieved through the priestly life of their son. Inversely, the poet explains that the son, because of his religious 
function, can likewise spiritually help his parents. Like Joseph, who arrived in Egypt ahead of his family in order to preserve them against famine, Cytherius' son arrives in God's house ahead of his parents in order to feed them spiritually and help them to live in a way consecrated to God. They are in fact invited at the end of the poem to give themselves wholly to God, not through the priesthood, but through an ascetic life.

\section{Ch. Guignard (Strasbourg), Poétique des listes apostoliques. Les premières énumérations d'apôtres dans la poésie latine chrétienne ( $\mathrm{V}^{\mathrm{e}}-\mathrm{Vl}^{\mathrm{e}}$ siècle)}

Lists are a well-known literary form in Ancient Poetry, both Greek and Latin. For the Christian poets, the New Testament lists of the apostles (Mt 10.2-4 and parallels) were a potential subject matter for poetic enumerations, but these lists do not seem to have exercised much fascination on them. In particular, no such catalogue is known form the Biblical epic. Indeed, in the Latin poetry of the $4^{\text {th }}$ and $5^{\text {th }}$ centuries, only Paulinus of Nola exploited the literary potential of an enumeration of the apostles, though in a (deliberately) incomplete form (Carmen 19.54-56 and $78-84$ ). However, it is only with Venantius Fortunatus that the catalogue of the apostles really finds its way in the Western Christian poetry, as a number of Latin and vernacular examples will attest in the Middle Ages.

\section{Part III: The Versification of the Bible in the Latin West in the Middle Age}

\section{V.Zarini (Paris), La réception en Afrique, au $\mathrm{VI}^{\mathrm{e}}$ siècle, du motif apocalyptique de la fin du monde à travers le poème de Verecundus et l'anonyme « À Flavius Felix »}

In 6th centry Africa, two poems provide substantial eschatological tableaux: the Carmen de paenitentia of Verecundus of Junca and the anonymous verses Ad Flauium Felicem de resurrectione mortuorum et de iudicio Domini - it is neither possible nor, in this case, necessary to determine which poem was written first. This article seeks to set out the respective portions, in each tableau, devoted to the representation of cosmic catastrophe, and to that of the punishments of hell, along with the possible interchanges between these two representations, distinct in themselves. While classical and biblical references naturally underpin the poets' imagination, within the framework of a call to conversion, the influence of Commodian and the preference for euidentia seem to play a greater role, for these poets, than the Latin exegetical tradition on the Johannine Apocalypse. 


\section{Urlacher-Becht (Mulhouse), La doctrine dans les hymnes de la liturgie wisigothique. Entre tradition patristique et réécriture biblique}

As it can be seen from Canon 13 of the Fourth Council of Toledo (633), the creation of a non-Biblical hymnody was debated in Hispania in the first half of the seventh century. The argument developed in this context by Isidore of Seville to justify the "human" hymnody is based in particular on the idea that the current compositions, following the example of the hymns of Hilaire and Ambrose affirming and defending the Nicene faith, should be an "effective instrument of a pedagogy of the faith". The way in which Isidore thus inscribed the hymnody of his time in the continuity of the lauds of the great bishops of the fourth century raises the question of the place of doctrine in these poems composed at a time where the heretical threat had largely lost its relevance.

If it was no longer necessary to block the way to Arian heresy, we will see that part of the ecclesial hymnody continued, as it was the case by the great hymnographic bishops, to be the support of an authentic faith, and resulted in hymns of a remarkable doctrinal elaboration, largely due to the teaching of the Church Fathers. On many occasions, however, in terms of doctrine, the content of several hymns is limited in whole or in part to a versification of the Bible, the modalities and issues of which will be examined. We will thus measure the vitality of this hymnographic creation, which was able to renew the Ambrosian model by exploring other modes of doctrinal expression, in phase with the liturgy of the time.

\section{P. Bourgain (Paris), La dramatisation de l'histoire biblique dans la poésie carolingienne}

The Bible is a huge reserve of poetical meditation. Salvation dramatically concerns the whole mankind and everybody's soul, engaging two exegetic significations, anagogy and tropology. Thence the final judgement appears at the end of a majority of poems written during merovingian (with anguish) and carolingian (more serenely) times. Merovingian rythms neglect chronology in favour of eschatologic signification. Carolingian poems are more dogmatic than pathetic, insisting on the actuality of the message of salvation. Penitential poems develop a poetic of complaint. Theatrical pathos appears in rhetorical devices : iterations, interpellations, implorations, favouring interrogations and imperative verbs, thus appropriating the pathos of biblical figures, or execrating the bad ones. Biblical direct speech is paraphrased and extended (it is the origin of dialogic tropes, forerunners of medieval theater). Joseph, Esther, Judith, Lazarus and the Holy Innocents are favorite themes, but their treatment is more theological than sentimental (even Christ's infancy does not generate much emotion, in spite of apocryphal Gospels ; Nicodem's Gospel is the one influential apocryph). Eschatology is the essential point, while tropology and compassion will afterwards become more important.

\section{F. Ploton-Nicollet (Paris), Entre satire de l’Église et parodie biblique. l’Apocalypse de Golias}

The Apocalypsis Goliae is a long anonymous Latin poem of about 400 lines dating to the twelfth century. It is mainly known as a satire of the ecclesiastical institution parodying the Biblical Apocalypse of John. It apparently consists of three independent parts: an introduction (§ 1-13), in which the visionary sees many ancient authors, and specially Pythagoras, whose body is covered 
with inscriptions; the main part of the poem (§14-104), directly inspired by the Apocalypse of John, in which an angel brings a book sealed with seven seals and, opening them, shows the poet many allegorical scenes aimed at the clergy's depravity; finally, a short conclusion ( $§ 105-$ 110 ), in which the poet is caught away to the third heaven, where he sees various mysteries, but remembers nothing because, being hungry and thirsty, he is offered poppy bread and water from the river Lethe, which cause him to fall back to earth. The only attempt to look further by studying the poem's structure was made by Francis Newman (1967), who argued that the three parts fit the Augustinian theory of vision as exposed in De Genesi ad litteram (12, 3-34): Augustine actually defines three kinds of vision: corporeal, which enables to see real things, spiritual, which enables to imagine things that are not present, and intellectual, which enables to conceive invisible things (such as God or concepts). Also according to Newman, the ancient authors, embodying the artes liberales, correspond to corporeal vision, because their knowledge enables to apprehend the world; the allegorical vision, similar to a dream, corresponds to spiritual vision, and the final revelation, which the visionary cannot remember, corresponds to intellectual vision. Newman's hermeneutic explanation of the poem proves very effective. In the same way, the present author wishes to highlight the importance of another structuring detail of the poem, which is the - distinctly apocalyptic - motif of the book: in the first part, Pythagoras' body, covered with inscriptions, is a corporeal (in both senses) book to be read; the book with seven seals is a spiritual (i.e. allegorical) book. Lastly, in the third part, if we refer to the Augustinian theory of vision, we should expect an "intellectual" book; if we refer to the Apocalypse of John, we should expect a book to be eaten (like the "little book" that the visionary eats in Apc. 10). This could be represented by the poppy bread and water. But, whereas John ate the "little book" and kept the word of God, our poet is unable to remember anything thereafter, which signifies that high intellectual activity and bodily care are incompatible concerns.

\section{K. Smolak (Wien), Die Bibeldichtung Aurora des Petrus Riga (P.R.). Beobachtungen zu Stil und Poetik}

The late antique genre of Biblical epic, exemplified by Juvencus, Sedulius, and Alcimus Avitus, developed out of metrical paraphrase and was subject to continual innovation and elaboration. In the later High Middle Ages, the genre had reached a point at which the exegetical presentation of biblical passages, selected primarily for poetic reinterpretation based on their exegetical usefulness, had prevailed. This predominance is not only apparent in a quantitative sense, but also because certain interpretations were occasionally implied or even assumed to be familiar to the reader.

One consequence of this fact was that new literary and stylistic means of expression came into use via the reworking of popular exegetical literature. These means of expression conformed to contemporary aesthetics, but they often explicitly engaged the tradition of classical poetry, including that of Vergil and Ovid, in various ways. The "Aurora," aptly christened with an allegorical title, provides an excellent example of this phenomenon in literary and intellectual history. The "Aurora" is a work of biblical poetry covering most of the Old and New Testaments, written by Peter Riga; it represents an incomplete 'work in progress,' already enlarged by the roughly contemporary Aegidius of Paris. In light of the perspective detailed above, selected passages have been analyzed and documented in their close - and more remote - literary and exegetical contexts: Ev(angelium) 409 f.; 2889 f., 2893-96; Gen(esis) 7-8; 88-102; 133-176; Ev 31-68, 129134. In the latter passages, the description of the beauty of the human physique is treated as an 
object of the poet's personal reflection: thus representing an application of traditional rhetorical education to biblical figures, including Mary.

\section{F. Stella (Siena), Théologie de la poésie entre Scolastique et Humanisme. Le statut de la poésie biblique}

After the condemnation expressed by Isidore, codified in the Decretum Gratiani and generally accepted in the twelfth century, poetry is object of different treatments, based rather on the procedures of the dialectic, in the summae of the thirteenth century of the mendicant orders: Alexandre d'Hales, Albert the Great, Thomas of Aquino, who judges poetry as the infima doctrina (...) quae minimum continet veritatis. This presentation extracts and analyzes in short the cultural positions and motivations, highlighting the presence of a trend that goes back to Dionysius pseudo-Areopagite and supports a close analogy between poetry and theology, and an Agostinian current, which on the contrary exalt the contrast. Albertinus Mussatus, more than Dante, forces the interpretation of these arguments for a defense of poetry in the humanistic sense, laying the foundations for Petrarch's and Boccaccio's rehearsals until Philip Sidney and later. In this discussion, the status of biblical poetry (from luvencus to Pierre Riga), which at the theoretical level could solve the problem of truth content, emerges occasionally as a marginal phenomenon, which will not become a true cultural lineage, yet without much success, only with Boccaccio.

\section{D.J. Nodes (Waco), Voice of the Muse, Word of the Church. The Parable of the Rich Man and Lazarus in Late Medieval Latin Poetry}

Four verse treatments of the parable of the rich man and Lazarus from the Gospel of Luke (Lk 16.19-31) offer case studies of the interaction between poetry and theology, overt commentary and allusion, doctrinal fidelity and literary innovation in Christian biblical poetry. Peter Riga (1140-1209) wrote a verse commentary in the manner of scholastic exegesis. Giles of Paris (1162-1224) supplemented Peter's work through a verse homily or, better, a verse collation. An anonymous poet whose work is included in a thirteenth-century anthology from York Cathedral composed allusive couplets on the theme of reversal. The anonymous poet of the Dyalogus de divite et Lazaro (fourteenth century) prepared dramatic encounter among the rich man, Lazarus, and Abraham in the form of a rhetorical exercise. The distinct and intentional variations of genre and diction in these four examples notwithstanding, all achieve a rich blend of overt commentary and oblique reference, elements offering the patient reader a dynamic interplay between tradition and innovation, theology and poetics. Medieval Latin poems devoted to the various gospel parables, of which these four are representative, constitute a group of texts containing much to be discovered. 


\section{Fabre (Montpellier), Post vestigia gregum. La poétique de l'image dans le commentaire Super Cantica Canticorum de Jean Gerson (1429)}

The last and uncompleted work by Jean Gerson (1363-1429), the commentary on the Song of Songs stands as a treatise on God's love that allows for a twofold reading, both theological and poetical. Gerson lays it out in fifty "considerations» or "proprieties» accounting for the sponsa's "fruitul love», which goes into ten sympsalmata or musical sections of sorts, each coming along with a elegiac distic suming up its content and mood. Such a specific layout paves the way for a speculative reading enhancing the poem's anagogical interpretation. It also stems from a so-called "scholastic» stance which deliberately turns its back on common «rhetorical» style and its systematic probing into every single metaphor to aim at a deeper and more synthetic view on the Song of Songs' imagery. To what extent can Gerson's opus ultimum afford for a literary writing avoiding the ornatio's flourishes while unfolding a rich poetry of its own ? This paper will address this question based on a stylistic analysis of a delineated section of sympsalma 2 commenting on Song 1, 6-10 and relying on Bonaventure's Itinerarium mentis in Deum.

\section{Iribarren (Strasbourg), Bible, poésie et doctrine dans la Josephina de Jean Gerson}

Based on an analysis of certain passages of the Josephina, an epic poem composed by Jean Gerson at the council of Constance between 1414 and 1417, this article aims at examining three aspects of Gerson's conception of the relation between Bible, poetry and doctrinal development. The first one emerges from the formal structure of the poem, organized in twelve distinctiones as opposed to the classical cantos; the second aspect concerns the Aristotelian notion of aestimatio that governs the composition and serves as basis of Gerson's ars poetica; finally, the third aspect focuses on the gersonian conception of sensus litteralis in biblical exegesis within the context of the controversy triggered by Jean Petit's justification of tyrannicide. 


\section{Index of Ancient and Medieval Authors ${ }^{1}$}

Aeg. Paris.

Evang.

$1995-1996 \quad 502$

1997-2002 502

Alb. Muss.

Fam.

$X .4 .1483$

Ep.

IV.61-62 $485 f$.

Alc. Avit.

Epist. ad Apollin.

$13 f ., 27$

Epist. 25bis.

368

Prol.

SHG 28

\section{SHG}

1.24-29 59

I.211-217 31

I.218-224 58

I.223-227 59

$1.238-246 \quad 34$

I. $251-253 \quad 35$

1.29033

I.293-294 33

I.297-298 33

II.31-32 140

II.154 68

III.12-15 133

III. $213-27860 \mathrm{f}$.

III.334-341 70 $\begin{array}{lc}\text { IV. } 386-387 & 68 \\ \text { IV. } 516-521 & 33\end{array}$

Virgin.

417-440 146

$421 \quad 133$

$422 \quad 133$

$423 \quad 135$

$425 \quad 138$

$426 \quad 140$

$427 \quad 140$

$430-440 \quad 140$

$430 \quad 140$

431140 bis

433140

434140 bis

438140

$440 \quad 140$

Alex. Hal.

Summa theol.

I.1 475, 476

Ambr.

Exc. Sat.

II.78-79 297

Helia

3.423

lacob

I.1.4 133

in Luc.

V.107 64

VIII.18 65

1 Only explicit quotations of texts are taken into consideration; the numbers correspond to the pages, they are in Italic if the quote is in the notes. 
Nab.

$\begin{array}{lc}1.1 & 64 \\ 1.3 & 65 \\ 2.4 & 65 \\ 5.26 & 65\end{array}$

parad.

$15.7 \quad 221$

Anth. Lat.

I, $524 \quad 36$

\section{Apocalypsis Goliae}

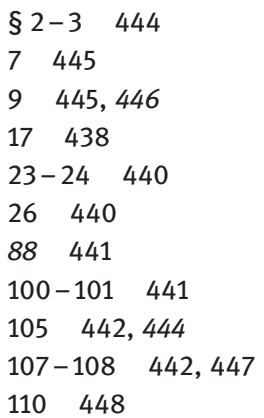

\section{Arator}

ad Vigil.

15-16 81

$19-20 \quad 13$

act.

$1.69-83 \quad 77$

I.83-84 76

I. $261-262 \quad 47$

I.297-301 84

$1.634-64284$

I.797 47

I.796-797 48

II. $40-4277$

II.43-44 77

II. $216-21878$

II. $262-273 \quad 85$

II.274 86

II.532 93

II.831-832 80

II.839-844 81
II.871-879 82

II.890-891 75

II.1233-1245 78

Vig.

$17-22 \quad 75$

Aug.

civ.

VI.6 124

XVIII.14 482

coll. Don.

III.2.51 123

conf.

X.27.38 483

gen. c. Manich.

460

gen. ad litt.

XII.11 443

XII.34 444

in psalm.

30.2.14. 85

serm.

2.74

$19.4 \quad 497$

$41.4 \quad 502$

$97.14 \quad 133$

122.1141

$296.9 \quad 82$

Avien.

Arat.

292-294 20

338-342 22 
Bacch.

Od.

5.56-84 $249 \mathrm{f}$.

Bruno de Segni

Comm. in Luc. p. II

PL 165.422CD 502

PL 165.425 A 501

De Cain, P. Bodm.

33.17-19 196

Call.

Hymn. Apoll.

$2.10 \quad 263$

Carm. de ressur.

292-332 398

Cic.

de orat.

II.15.62-63 3

part.

9.324

Clem. Al.

Protr.

$12.120 .2 \quad 155$

Strom.

I.28.178 176

IV.25.162 153

Col. Salut.

Lab. Herc.

I.9.25-28 485

\section{Commod.}

instr.

II.10.9-11 136

\section{Const. apost.}

V.7.12 50

\section{Cyr. Al.}

In Io.

IV.5 163f., 166, 167

De Abel. verbis, P. Bodm.

35.15-18 197

De Abraham, P. Bodm.

30.1-3 195

20-21 195

De iustis, P. Bodmer

31.111-119 193

Drac.

Laud.

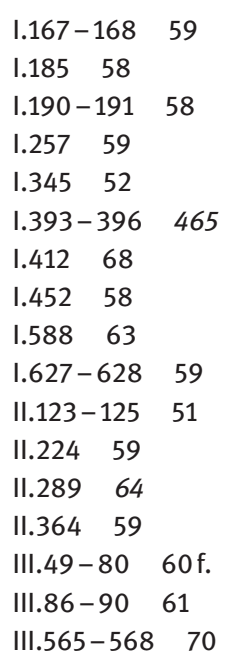

Satisf.

1564 
Eleg. in Maecen.

$1.23-24 \quad 20$

Eur.

Bacc.

$\begin{array}{lc}274-285 & 151 \\ 311-313 & 157 \\ 343-346 & 157 \\ 471-472 & 153 \\ 479-480 & 157 \\ 482-484 & 157 \\ 489-490 & 157 \\ 655-656 & 157 \\ 773-774 & 152\end{array}$

Euseb.

Praep. Evang.

XI.5 223

Euseb. Emes.

Serm.

11.2136

Faustin.

Fid.

$5.20 \quad 330$

Greg. Illib.

Fid.

$\begin{array}{cc}226.186 & 331 \\ 226.209 & 331 \\ 226.220 & 331 \\ 227.227 & 331 \\ 226.234 & 331 \\ 226.247 & 331 \\ 228.262 & 332\end{array}$

Hom.

VI.19 345
Greg. Naz.

Poem.

I.1.16.5-6 282

I.1.16.10 278

I.1.16.17 278

I.1.16.21 282

I.1.16.29-30 282

I.1.20.3 278

I.1.20.4 278

I.1.20.5 278

I.1.20.13 279

I.1.20.19-20 280

I.1.20.25-26 279

I.1.20.29-30 279

I.1.21.5 279

I.1.21.6 277

I.1.21.7 277

I.1.21.9-10 280

I.1.21.13-14 $279 \mathrm{f}$.

I.1.21.17 280

I.1.22.20 282

I.1.22.9-10 277

I.1.22.13 280

I.1.23.7 280

I.1.23.8 280

I.1.34.77 279

I.1.34.83 279

II.1.2.1-14 $262 \mathrm{f}$.

II.1.2.58-69 $264 \mathrm{f}$.

II.1.2.149-155 268

II.1.2.204-208 269

II.1.15.21-30 283

II.1.19.17-22 284

II.1.19.25-31 285

II.1.34.71-72 273

II.1.34.77-78 273

II.1.34.83 273

\section{Heptateuchos}

gen.

$1-2 \quad 458$

$15-16 \quad 115$

$20 \quad 116$

$50-51 \quad 108$

$66 \quad 106$

$81 \quad 121$

120-121 120

$140 \quad 119$ 
147116

154119

$162-163119$

$188-190 \quad 113$

$197-198 \quad 112$

243-248 110

290116

290-292 110

293-294 116

306-307 116

$316-317 \quad 107$

324120

326107

361-362 123

365120

463-466 121

592112

593117

596108

$597 \quad 117$

620117

745-746 108

884110

903117

904109

935109

1081-1083 112

1141-1142 115

1147-1149 117

1172-1174 113

$1200 \quad 114$

1236-1237 113

1240-1241 118

1255-1257 118

1312109

$1400 \quad 110$

1418-1419 109

1433-1437 123

los.

$49 \quad 116$

Hier.

Epist.

107.4356 in Matth.

III.21.6 134

III.21.18 132, 133

III.21.19 134

vir. ill. $84 \quad 42$

Hilar. (?)

hymn. de Christo

$31-32 \quad 365$

Hilar.

Matth.

VIII.8 47

Himn. Hisp. 1 Castro Sánchez

1411

1-40 406f.

12411

$18-20 \quad 408$

$20 \quad 410$

21-24 408

$29-30 \quad 407$

$34-36 \quad 408,410$

25 Castro Sánchez

1-32 $412 \mathrm{f}$.

3413

6-8 413

$13-16 \quad 413$

$17-20 \quad 413 \mathrm{f}$.

$22 \quad 414$

25-28 414

190 Castro Sánchez

$1-50 \quad 417 \mathrm{f}$.

10419

$10-15 \quad 418$

$15 \quad 419$

$16-20 \quad 419$

21-27 419

$22 \quad 419$

3419

$34-35 \quad 420$ 
Hom.

II.

I.68-70 109

XVIII.483-484 195

Od.

IV.17-19 232

XI.34-35 247

XI.36-37 247

XI.42-50 248

XI.164-165 248

XI.205-208 248

XI.475-476 248

XI.636-640 249

Hor.

Ars

9-10 14

151-152 15

Serm.

I.2.131 299

I.2.134 299

Hugo de Sanct. Vict.

Sacr.

Prol. 6527

Ioh. Gers.

Decl. comp.

6.184-185 G. $\quad 530$

Gratia tibi

276 G. 528

Josephina

II.411-424 530

III.855-860 528f.

IX.2278-2287 530

X.2504-2507 530
Sens. litt. Sacr. Script.

3.354 G. $\quad 533$

3.355 G. $\quad 532$

Super Cant. Cant.

565 G. $\quad 512$

576 G. $\quad 511,515$

577 G. $\quad 513,515 f$.

579 G. $\quad 523$

$581 \mathrm{G} . \quad 514$

590 G. $\quad 516$

$591 \mathrm{G} . \quad 519$ f., 522

Ioh. Parv.

lust. Ducis Burg.

$28-30 \quad 531$

Ioh. Scott.

Praed.

$9476 \mathrm{f}$.

Trans. de deo praed.

$10 \quad 477$

Sup. Ier.Cael. Sancti Dionysii

PL 122.146B-C 477

Iren.

Adv. Haer.

IV.34.4 342, 344

Isid.

In los.

VII.1 95

Itin. Anton. Plac. Rec. A

$17 \quad 142$ 
Iuv.

Sat.

$1.27-29 \quad 63$

1.7964

1.8564

$1.147-14963$

$6.268-271 \quad 114$

$6.284-285114$

14.10-14 113

$14.18-20 \quad 113$

$14.303-304 \quad 65$

\section{luvenc.}

Praef.

$15-18 \quad 13$

1942

Evang.

I.323-325 18

I.344 135

$1.631-63319$

1.653135

II.89-94 51

II.115-117 132

II.119 92

II.24293

II.753 135

III.653-674 145

III.662-663 136

III.663 137

III.671 138

IV.369-370 299

IV.376-379 296

IV.392-393 299

IV.394-395 297

IV.394-396 296

IV.400 138

IV.630-631 142

Lact.

Inst.

I.5.8-10 329, 333

II.8.3 333

IV.6.1 333

IV.6.9 333

IV.7.1 333

\section{Laudes Domini}

7-35 291-293

15-16 295

$25 \quad 296$

112-115 46

Lucan.

VI.753 299

Lucr.

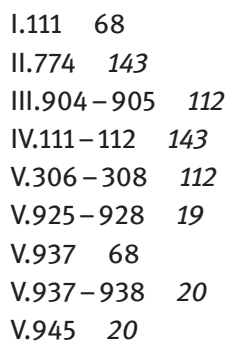

Man. Phil.

Ps. 32 versio $A$.

1-4 231

Ps. 34 versio $A$.

$8-11 \quad 232$

Ps. 102

36-43 233

Mar. Vict.

Aleth.

II.1-5 14

II.195-198 16

\section{Max Taur.}

Serm.

38.2.3.4 344

Nican.

Ther.

957-958 286 


\section{Nonn.}

Dion.

VII.82-88 152

VII.94-96 152

XVII.373 180

Par.

I.129-130 180

I.135 180

II.12-20 153

II. $35-38 \quad 154$

II. 39154

V.110 180

VI.4 181

VI.122-123 170

VII.7-8 161

VII.8-9 162

VII.13-15 162

VII.19 162

VII.20 162

VII.21 162

VII.22 163

VII.24-25 163

VII.26 163

VII.27-28 163

VII.30 $163 \mathrm{f}$.

VII.31 161

VII.37 161

VII.138 164

VII.41-45 155

VII.46-49 164

VII.53 165

VII.55-57 166

VII.65 166

VII.67-68 166

VII.119 166

VII.166 166

VII.64-68 155

VII.72-73 167

VII.79-80 165

VII.85 167

VII.89 167

VII.90 167

VII.103 168

VII.104 169

VII.114 165

VII.117-119 168

VII.12 165

VII.128 169
VII.138-139 169

VII.139 169

VII.143-145 169

VII.143-147 170

VII.154-155 168

VII.171 165

VII.172-182 156

VII.17 156

VII.181-182 168

VII.18 170

VII.190-193 170

X.133 178

XI.89 182

XI.96-102 155

XI.155-170 298

XI.159 299

XI.185-206 158

XIII.30 179

XIII.85-89 181

XIII.158-160 182

XVIII.95-96 179

Opt. Porph.

carm.

$16.23-25 \quad 80$

\section{Orat. Wisig. Vives}

9410

35409

$63 \quad 410$

$127 \quad 410$

$536 \quad 414$

\section{Ferotin}
c. 15-16 409
c. $490 \quad 410$
c. $576 \quad 410$
c. $875 \quad 410$

Orig.

in lesu Nave hom.

$6.4 \quad 95$

7.195 
Ov.

am.

III.8.33-34 19

III.11.47 468

ars

III.723 108

fast.

I.185 134

IV.747-755 121

met.

I. $21-22 \quad 458$

I.71 464

I.128-130 22

III.725-727 118

VII.502 92

VIII.674 134

XI.1-2 138

XI.339-341 116

XIV.124 468

XIV.338-340 138

trist.

I.1.35 92

Paul. Nol.(?)

carm. 6(= Laus Iohannis)

229-254 17

$229 \quad 18$

$247 \quad 23$

$252 \quad 23$

Paul. Nol.

carm. 19 (= Nat. 11)

14-19 366

$54-56 \quad 367$

$76-84 \quad 367$

carm. 20 (=Nat. 12)

$28-32 \quad 15$ carm. 24 (ad Cyth.)

\begin{tabular}{|c|c|}
\hline $495-498$ & 352 \\
\hline $499-506$ & 351 \\
\hline $513-516$ & 356 \\
\hline $517-524$ & 352 \\
\hline $525-528$ & 350 \\
\hline $541-588$ & $361 \mathrm{f}$. \\
\hline $639-642$ & 357 \\
\hline $695-696$ & 358 \\
\hline $701-712$ & 358 \\
\hline $707 \quad 359$ & \\
\hline $710 \quad 359$ & \\
\hline $749-756$ & 355 \\
\hline $\begin{array}{ll}753 \quad 357\end{array}$ & \\
\hline $827-830$ & 356 \\
\hline $889-890$ & 353 \\
\hline $891-893$ & 359 \\
\hline $895 \quad 360$ & \\
\hline 896360 & \\
\hline carm. 25 & $=$ Epith. Iul.) \\
\hline $236-237$ & 353 \\
\hline carm. 31 (= & = obit. Cels.) \\
\hline $465 \quad 68$ & \\
\hline $470-472$ & 67 \\
\hline $473-474$ & 68 \\
\hline $488 \quad 68$ & \\
\hline $495-498$ & 68 \\
\hline $617-618$ & 359 \\
\hline
\end{tabular}

Paul. Petr.

Mart.

$\begin{array}{ll}\text { I. } 232-234 & 81 \\ \text { II. } 141-148 & 19\end{array}$

Pers.

$3.86-87 \quad 112$

Petr. Abael.

Theol. Christ.

PL 178.1207C 478 
Petr. Crys.

Sermo

$65 \quad 298$

Petr. Riga

Aurora

$2053-2056 \quad 499$

Evang.

$33-34 \quad 466$

61465

$129-134 \quad 468$

409-410 454

2889-2890 456

2893-2896 456

2895-2896 456

Gen.

$7-8 \quad 459$

21-22 460

99462

163-166 463

$304 \quad 464$

306464

$310 \quad 464$

323-324 469

361-362 465

Phipp. Harv.

Inst. cler.

III.45 482

Poetae lat. aev. Carol.

II 254.21-24 431

Proba

Cento

173-174 317

177-178 317

195-205 315

276-277 22

290-293 22
299-302 22

580-599 310

Prud.

apoth.

$207 \quad 327$

212-214 327

264-267 328

$672-674 \quad 46$

$752-766 \quad 300$

938-939 68

cath.

3.1-5 330, 340

4.7-9 327

9.10-12 329

$9.31-3352$

$9.40-4253$

$9.6952,53$

11.17-32 329f.

$12.37-40 \quad 328$

12.125411

c. Symm.

I. $325-327 \quad 327$

II.85-90 324

II. $87 \quad 324$

II. $87-88 \quad 325$

II.91-107 324

II.120-124 325

Ditt.

$183 \quad 54$

ham.

27919

$282-284 \quad 19$

395-397 140

76364

$942-94368$

Perist.

$2.30 \quad 411$

psych.

$629-630 \quad 140$ 
Ps.-Apol.

Met. psalm.

Protheoria 15-16 227

18-19 227

29-32 227

Ps. 32.1-4 231

Ps. 46.8-14 232

Ps. 102.38-44 233

\section{Ps.-Cypr.}

resurr.

$300 \quad 68$

\section{Quint.}

Inst.

VI.2.32 52

\section{Raban.}

Hom.

II.77 502

Rhet. Her.

I.9.16 4

Rupert. Tuit.

Comm. Job

168.1131B 501

Sall.

Cat.

$5.8 \quad 22$

Sedul.

Carm. Pasch.

1.1268

I.17-18 13

$1.23 \quad 13$

I.26 8,13

$1.30-35 \quad 47$

$1.99-100 \quad 70$

1.3609
II.94. 7

II.97 10

II.168-171 10

III.33-39 48

III.148-151 49

III. $273 \quad 47$

IV.42-56 145

IV.49 135

IV.210-221 $95 \mathrm{f}$.

IV.213-215 $95 \mathrm{f}$.

IV. $222-225 \quad 6$

IV. 251-270 $98 \mathrm{f}$.

IV. $255-2567,99$

IV.263-264 10, 99

IV.287 299

V.71 7

V.77-78 7

V.166-167 7

V.168-169 7

V.180-181 7

V.420 9

Epist.

$1.12 .4-5 \quad 8$

Op. Pasch.

II.4 9, 10

II.7 10

II.13 10

II.1410

III.14 10

IV.5 138

V.8 10

V.10 9

V.17 10

V.22 10

V.37 8

Ser.

med.

$974 \quad 134$

Serv.

ad Aen.

I, $159 \quad 37$ 
ad ecl.

Synes.

1.34130

Hymn.

Severus

8.1-71 241f.

in Evang.

Theophylact.

VIII.108 94

VIII.119-136 90

VIII.137-138 90

VIII.137-153 90

VIII.145-146 92

VIII.149-151 93

IX.81-93 100

IX.93 129

IX.93-140 $146 \mathrm{f}$.

IX.9694, 131

IX.104 138

IX.106 94

IX.107 141

IX.119 141

IX.137 143

IX.137-149 101

IX.138-139 143

IX.140 143

IX.163-180 97f

IX.163 98

IX.164 98

IX.251 93

Sidon.

Enarr. in evang.

Marc. $232 \quad 127$

Thomas Aq.

Comm. sent. Petr. Lomb.

I.1.1.3 $479-480$

I.1.1.6 481

I.1.1.15 481

Super meteora

II.1.3. 481

Sent. Metaph. I

II.11.3 481

Ven. Fort.

Carm.

V.2.1-20 $373 \mathrm{f}$.

VIII.3.79-80 377

VIII.3.173 377

Carm.

$11.126 \quad 135$

Ven. Fort. (?)

in laud. sanctae Mariae

Stat.

$267-270 \quad 382$

275-296 382

Th.

V.445-446 132

X.674 135

Verg.

Aen.

Sulp. Sev.

I.216 110

1.30494

Mart.

I.305 117

10.819

I.503-504 120

I.701 313

1.706313

II. $252-254 \quad 120$

II.634 108 
II.730 94

III.205-206 107

IV.453-454 118

V.40-41 109

V.84-93 $316 \mathrm{f}$.

V.615-616 110

VI.255 108

VI.258 263

VI.536-537 108

VII.68-70 107

VII.254 117

VII.539 119

VII.808-811 116

VIII.8-9 115

VIII.69-71 78

VIII.84 110

VIII.90 109

VIII.324-327 22

IX.144 106

IX.393 117

XII.172 459

XII.359-361 120

XII.664 119

XII.689-692 119

XII.173 313 ecl.

1.51-52 117

$4.7 \quad 461$

$5.38-39 \quad 120$

georg.

I.19 345

1.78442

II. $458-460 \quad 18$

III.242-244 110

IV.478-479 116

IV.39 109

Versus memoriales (BHL 654k)

$387 \mathrm{f}$.

Vincent. Bell.

Spec. Doctr.

1.13476

Vigil.

Epist. ad Auxanium

381 



\section{Index of Biblical Texts ${ }^{1}$}

Ac

1.15. 77

$1.16-17 \quad 76$

4.8-12 $83-84$

$8.20-23 \quad 84$

$13.16 \quad 76,77$

15.7-11 85

$17.24 \quad 195$

Apc

$3.20 \quad 408$

7.9408

10.1-2 446

$10.8-10 \quad 446,447$

$10.11 \quad 447$

$17.1 \quad 445$

$17.5 \quad 446$

19.11408

$20.4 \quad 408$

$21.3 \quad 408$

$21.8 \quad 399$

Col

$1.17 \quad 326$

1 Cor

$7.34 \quad 140$

2 Cor

$12.2 \quad 444$

$12.2-4 \quad 443$

$12.3 \quad 444$

$12.4 \quad 444$

Eccl.

$3.22 \quad 326$
Ex

$28.2 \quad 419$

$28.4 \quad 418-419$

$28.5 \quad 419$

28.17-20 419

28.34-35 419

Gn

1.1458

1.1-2 326

4.116

$4.10 \quad 196$

$\mathrm{Hbr}$

$11.14 \quad 196$

Jn

1.1-3 137

$2.11 \quad 46$

\begin{tabular}{ll}
$7.3 \quad 162$ \\
\hline .5
\end{tabular}

$\begin{array}{ll}7.5 & 162\end{array}$

\begin{tabular}{ll}
$7.6 \quad 163$ \\
\hline
\end{tabular}

$\begin{array}{ll}7.18 & 166\end{array}$

$\begin{array}{ll}7.23 & 167\end{array}$

$\begin{array}{ll}7.27 & 168\end{array}$

$7.34 \quad 169$

7.37-38 169

$7.42 \quad 168$

$8.12 \quad 176$

$9.32 \quad 199$

$10.21 \quad 164$

11.43-44 297

$11.44 \quad 296,297$

$12.47 \quad 408$

Lc
$7.16 \quad 137$
$8.55 \quad 277$
13.6-9 139
$18.35-43 \quad 102$

1 Only explicit quotations of texts are taken into consideration; the numbers correspond to the pages, they are in Italic if the quote is in the notes 


\begin{tabular}{|c|c|c|}
\hline $18.37-38$ & 91,91 & Prv \\
\hline $18.38-39$ & 96 & $8.22-25 \quad 327$ \\
\hline $22.14-46$ & 311 & $25.27 \quad 326$ \\
\hline 24.1459 & & \\
\hline Mc & & Ps \\
\hline 1.617 & & $32.1-2 \quad 230$ \\
\hline $\begin{array}{ll}1.0 & 17 \\
5.9 & 277\end{array}$ & & $101.4-5196$ \\
\hline $5.42 \quad 277$ & & $102.7 \quad 233$ \\
\hline $6.14 \quad 282$ & & $102.20-22 \quad 233$ \\
\hline 10.4691 & & \\
\hline $10.46-52$ & 102 & $1 \mathrm{Pt}$ \\
\hline $10.47 \quad 91$ & & $3.18-20 \quad 238$ \\
\hline $10.50 \quad 92$ & & $4.6 \quad 238$ \\
\hline $11.12-24$ & 144 & \\
\hline $14.17-42$ & 311 & Sap \\
\hline 16.2459 & & $9.16 \quad 326$ \\
\hline Mt & & $11.17 \quad 326$ \\
\hline $3.4 \quad 17$ & & II reg \\
\hline $3.10 \quad 139$ & & $5.7 \quad 130$ \\
\hline $8.13 \quad 278$ & & $66 \quad 465$ \\
\hline $\begin{array}{l}8.14-15 \\
8.15 \quad 278\end{array}$ & 48 & \\
\hline $9.8 \quad 137$ & & III reg \\
\hline 18.11408 & & $2.10 \quad 130$ \\
\hline $21.17 \quad 130$ & & \\
\hline $21.17-22$ & 144 & IV reg \\
\hline $25.33 \quad 521$ & -522 & \\
\hline $26.20-46$ & 311 & $2.24 \quad 278$ \\
\hline $28.1 \quad 459$ & & \\
\hline $28.18-19$ & 456 & $\mathbf{R m}$ \\
\hline $\mathrm{Ph}$. & & $3.23-24 \quad 408$ \\
\hline $3.20-21$ & 84 & $1 \mathrm{Tm}$ \\
\hline & & $6.17-19 \quad 82$ \\
\hline
\end{tabular}

